



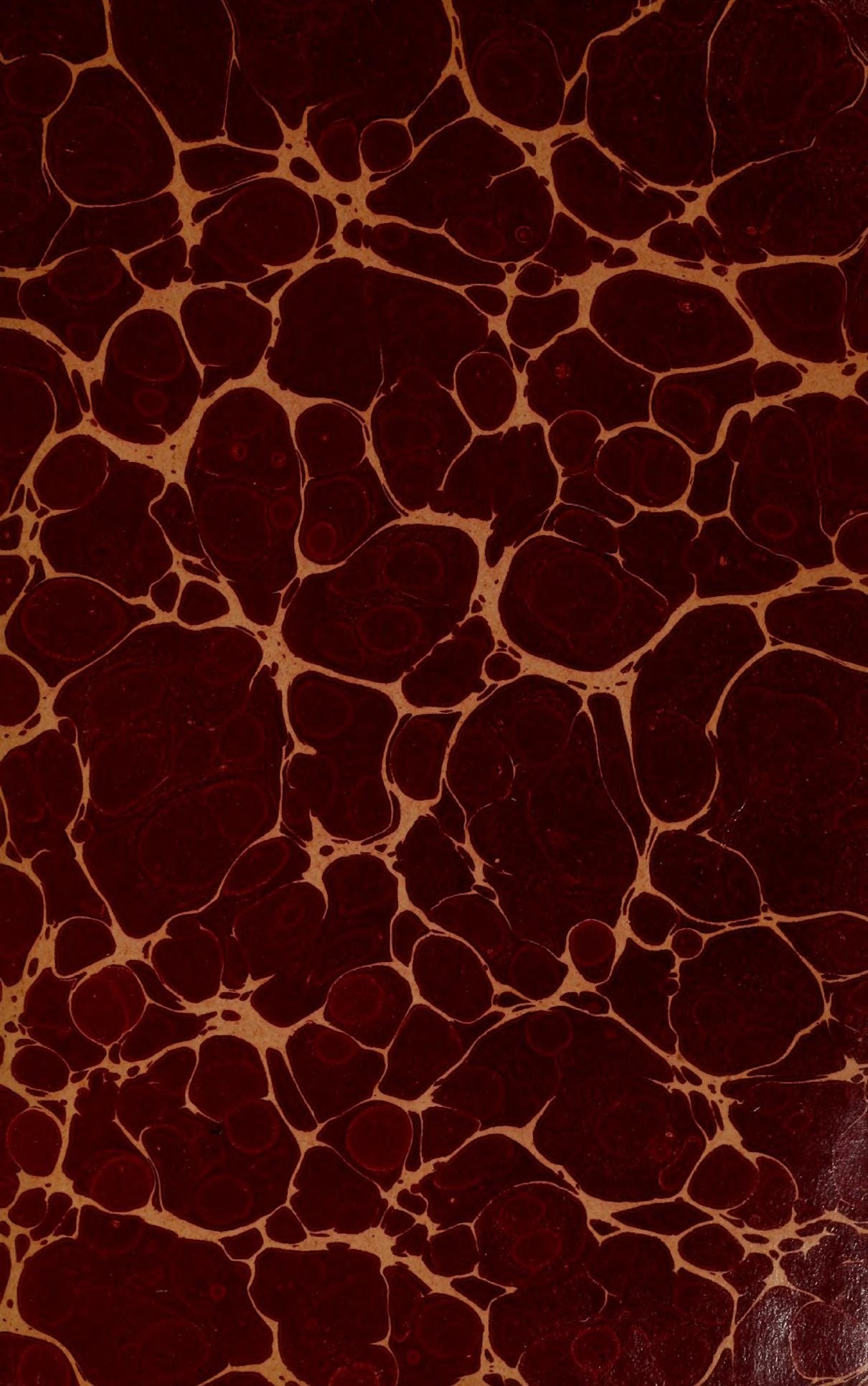







$$
\frac{68}{791}
$$



, 9

\section{THE HORSE AND OTHER LIVE STOCK.}

Werfi

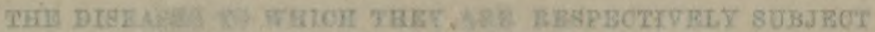

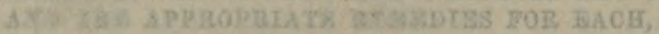

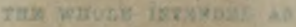

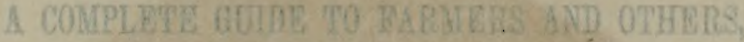

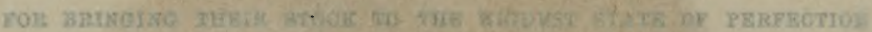

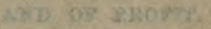

BY ROBERT JE NNTNGS, V. S.

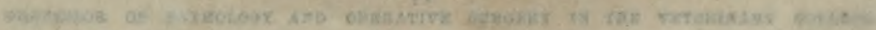

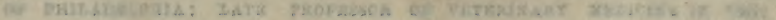

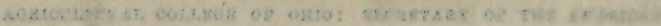

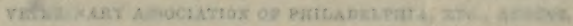

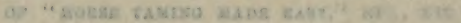

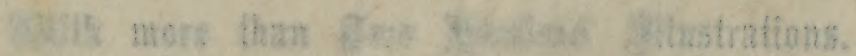

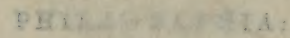

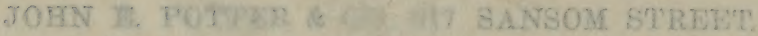

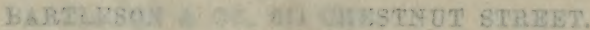


Oours Jung. 


\section{THE HORSE AND OTHER LIVE STOCK.}

WITH

THE DISEASES TO WHICH THET ARE RESPECTIVELY SUBJECT AND THE APPROPRIATE REMEDIES FOR EACH,

TOGETHER WITH

THEIR HISTORY AND VARIETIES : THEIR CROSSING AND BREEDING, AND THE BEST METHODS FOR THEIR FEEDING AND GENERAL MANAGEMENT.

THE WHOLE INTENDED $\triangle S$

A COMPLETE GUIDE TO FARIERS AND OTHERS,

FOR BRINGING THEIR STOCK TO THE HIGHEST STATE OF PERFECTION AND OF PROFIT.

BY ROBERT JENNINGS, V.S. PROPESSOR OF PATHOLOGY AND OPERATIVE SURGERY IN THE VETERINARY COLLEGH

OF PHILAdELPhIA: LATE PROFEssOR OF VETERINART MEDICINE IN THE AGRICULTURAI, COLLEGE OF OHIO: SECRETART OF THE AMERICAI VETERINARY ASSOCIATION OF PHILADELPHIA, ETC., AUTHOB OF "gORSE TAMING HADE EAST," ETC., BTC.

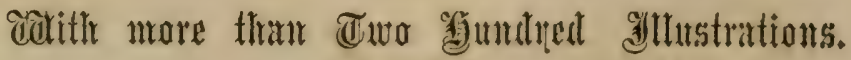

PHILA D ELPHIA:

JOHN E. POTTER \& CO,, 617 SANSOM S'TREFT. BARTLESON \& CO., 011 CHESTNUT STREET. 


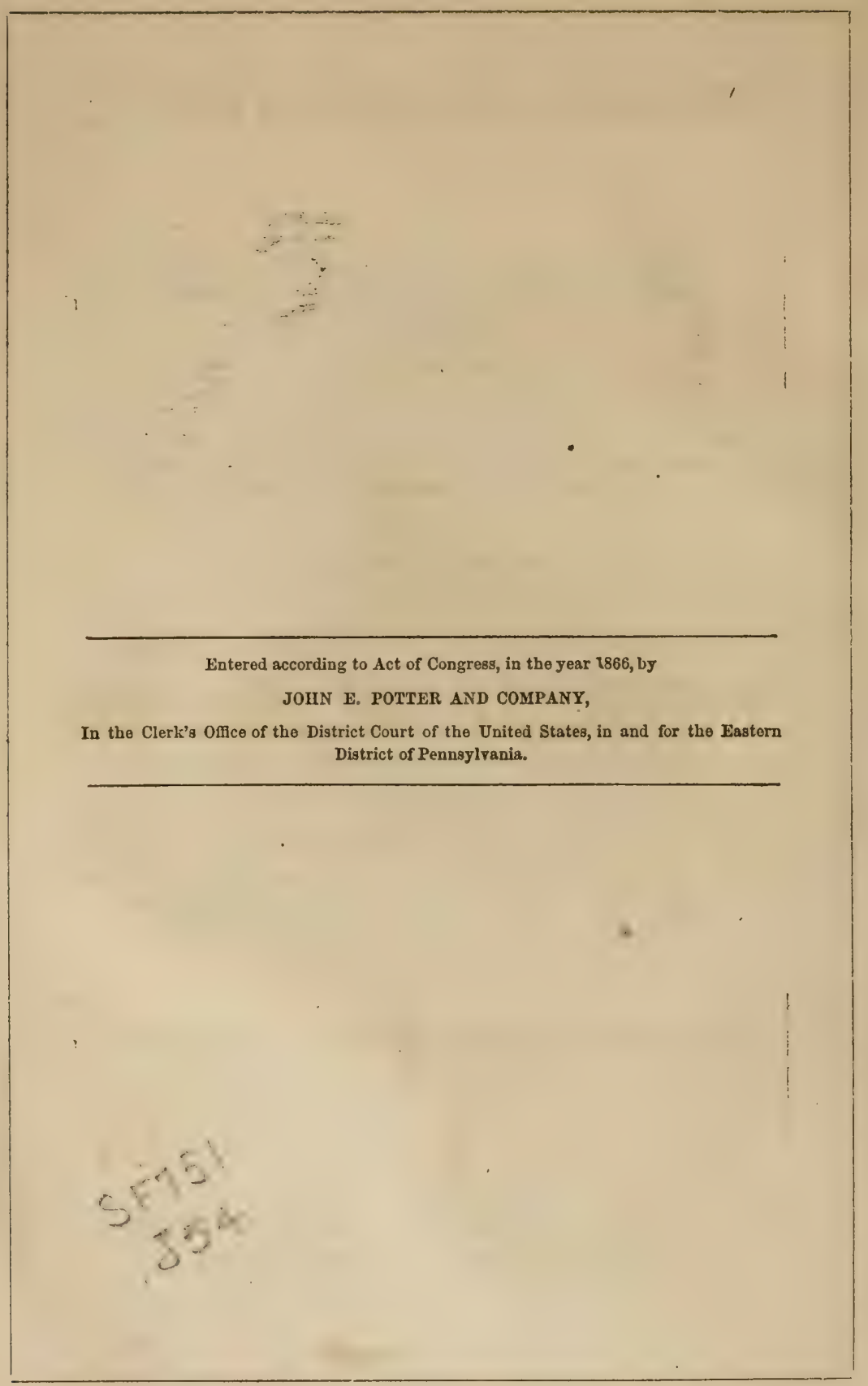


THE

HORSE AND HIS DISEASES. 



\section{PREFACE.}

Turs volume is offered to the consideration of the public, not without a knowledge on the part of the author that many excellent works upon the horse have already appeared. It has occurred to him, however, that each of these various works is devoted rather to the consideration of solie particular topic of interest in connection with this generous animal, than to a generai treatment of the various subjects which appropriately claim notice in a work intended for the ordinary reader.

There are comparatively few in our country who are not, at some period or other, brought into contact with the horse, either as nwwers, hirers,-or in some other capacity. The great majority cannot avail themselves of the numerous treatises already extant, which touch upon this animal, without gathering about themselves a library so large as seriously to trench upon their pecuniary counfort. Besides, so far as the ailments of the horse are concerned, much progress has been made in their treatment within the last few years. Old theories have been exploded, and, as the anthor believes, an era of a more humane and jurlicious medical treatment is damning upon us. A marked improvement is discernible in the class of practitioners who essay the veterinary art ; a greater amount of intelligence characterizes their action, and, as a consequence, the occupation of the veterinary surgeon is fast rising in popular estimation.

To these cheering indications of a better day for the horse and his owner, the author claims not to be indifferent. If an experi. ence of fifteen years, diligently devoted to an investigation of the 
habits, peculiarities, wants, and weaknesses of the horse, has not been utterly fruitless in results, he flatters himself that he can at least contribute his mite in furtherance of a better understanding of an animal, which can never be too well understood by any one who would gain the greatest possible advantage from such a ser vant.

With such riews the author has prepared the present work. Its pages are believed to contain a complete, candid, and truthful exposition of all the points which it is incumbent upon the horseowner to comprehend. Standard authorities upon the subject have been freely cousulted, and the suggestions therein contained have been adopted, when corroborated by the author's own experience or observation. Reference has been made to the following among others:-Percival, Blain, Morton, Clark, Finley Dunn, Youatt, Coleman, and Spooner, on the Horse ; Herbert's Horse of America, and Hints to Horsekeepers; Stewart's Stable Economy; The Fariner's Encyclopedia; and the Morgan Horse by Linsley.

The remedies recommended have all stood the test of actual trial, and are known to have proved efficacious in previous cases. As the nuthor has no special hobby to ride, he has in this department of the subject given such modes of treatment only as he personally has superintended in actual practice, no matter from what source they may have been suggested. The very many illustrations throughont the volume it is believed will materially enhance its interest and value.

With the hope that the work may meet the approval of the large class for whom it was specially prepared, and with the consciousness that no effort to that end has been omitted by the author, he connidently leaves it in their hands, to be dealt with as to them shall seem most meet and proper. 


\section{CONTENTS.}

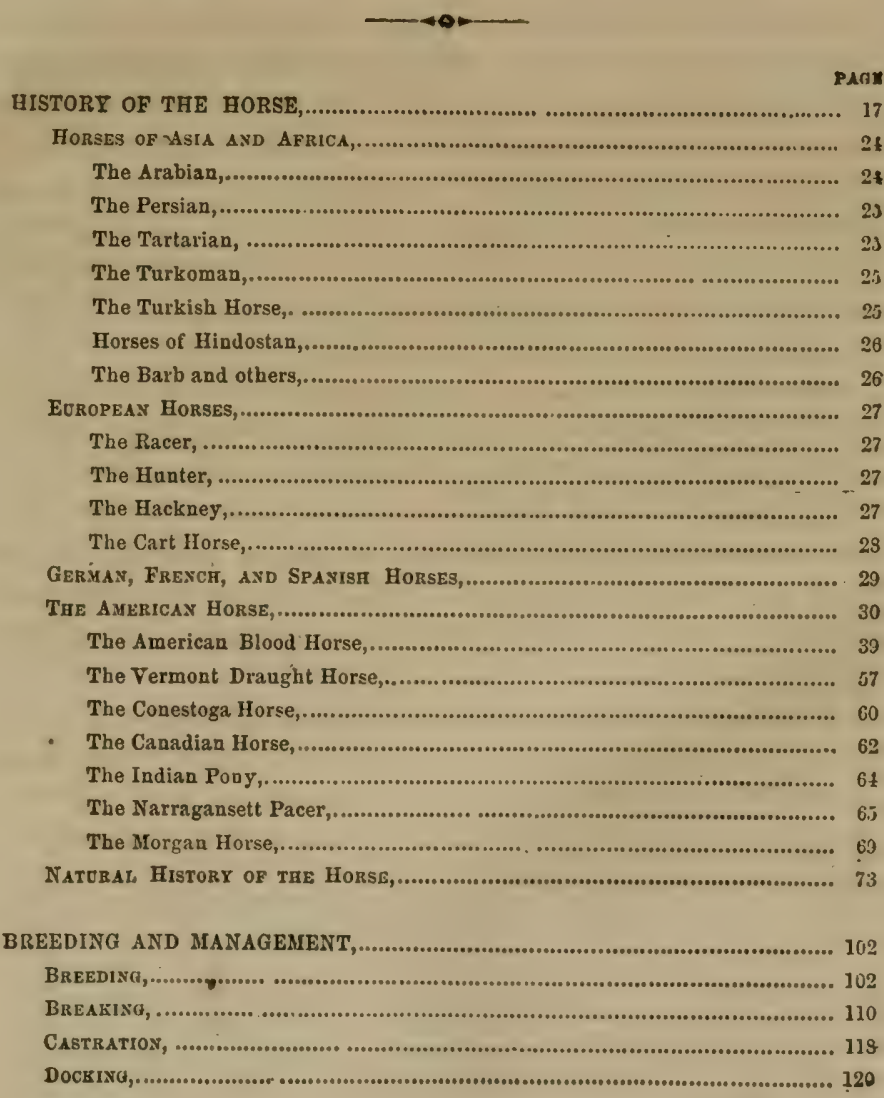


BREEDING AND MANAGEMENT-CONTINEED. PAGE

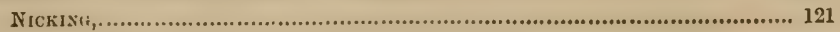

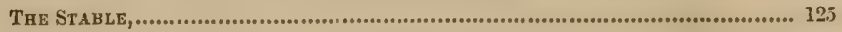

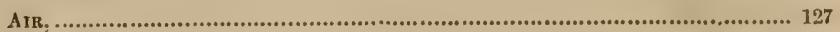

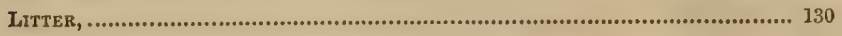

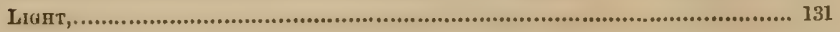

GroomING, ............................................................................. 133

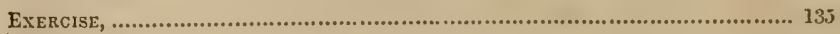

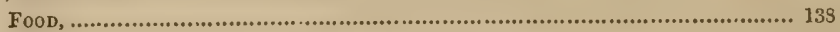

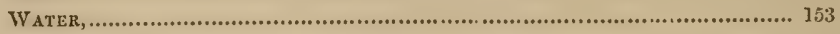

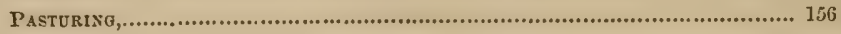

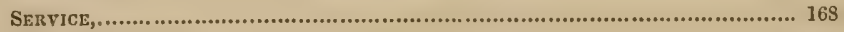

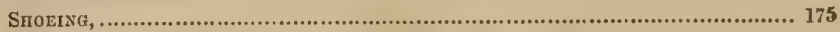

ADMINISTERING MIEDICINE, .......................................................... 193

VICES OF THE HORSE, ........................................................ 198

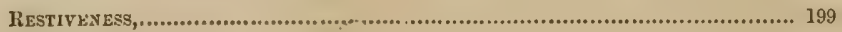

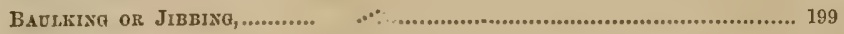

Bitixg, ........................

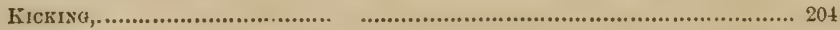

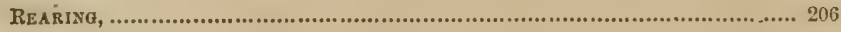

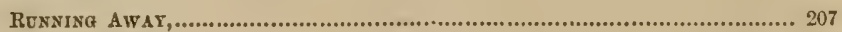

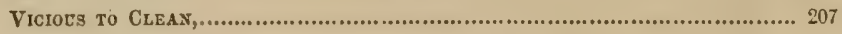

Viciods To SHOE, ........................................................... $20 \mathrm{~B}$

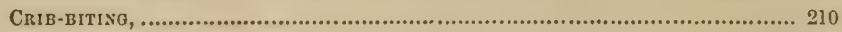

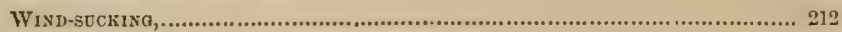

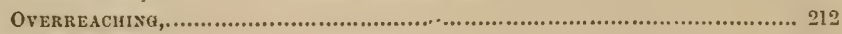

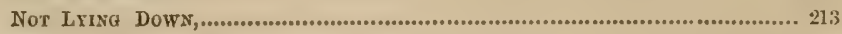

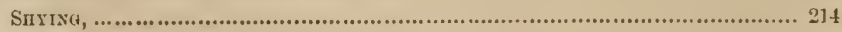

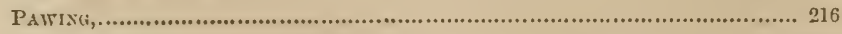

RoLl1:i,

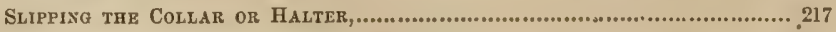

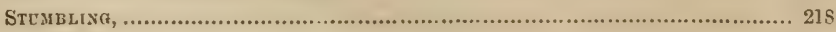

UNSTEADINESS WHILE BEING MIOUNTED, ......................................... 219

DISEASES, AND THEIR REMEDIES, ........................................ 220

DISEASES OF THE MOUTH, ....................................................... 22]

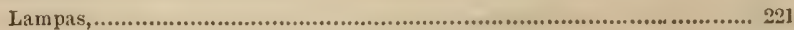

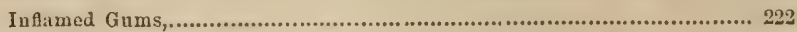

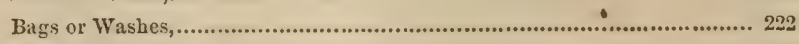

Ulcers in the Mouth, ............................................................ 222

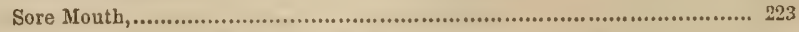

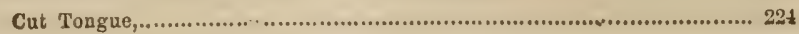


DISEASES, AND THEIR REMEDIES-CoNTINUED.

Uneveu Teeth, ............................................................... 22!

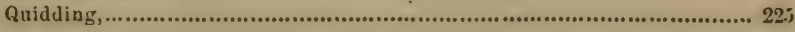

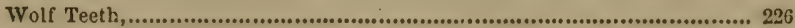

Caries of the Teeth, .............................................................. 227

Extracting Teeth,................................................................... 230

DISEASES OF THE RESPIRATORY ORGANS,............................................ 231

Inflammation, ................................................................. 23!

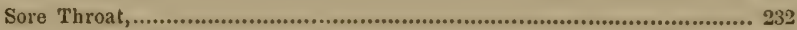

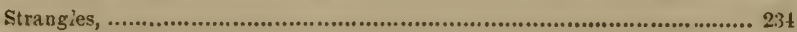

Chronic Cough, ..................................................................... 235

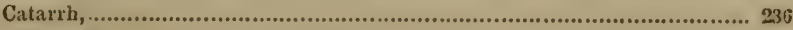

Distemper,...................................................................... 237

Influenza, ................................................................. 237

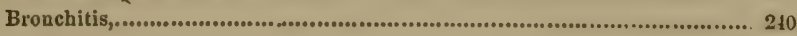

Nasal Gleet, ................................................................... 241

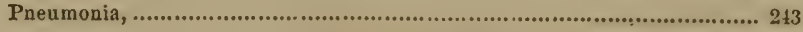

Plett:isy, ................................................................... 245

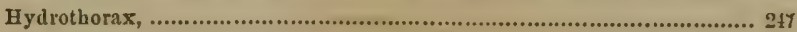

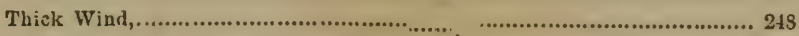

Roaring and Whistling,....................................................... 219

Broken Wind, ........................5n................................................ 249

DISEASES OF THE STOMLACH AND INTESTINES, .......................................... 251

Infla mmation of the Stomach, ................................................. 251

Inflammation of the Bowels, ................................................ 252

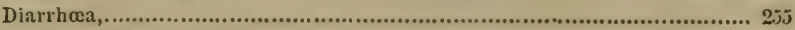

Inordinate Appetite, ................................................................ 256

Palsy of the Stomach, ......................................................... 2.57

Rupture of the Stomach, ..................................................... 2;S

Calculus, or Stony Concretions, ................................................ 2.59

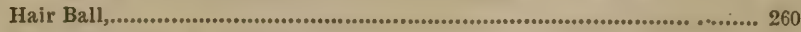

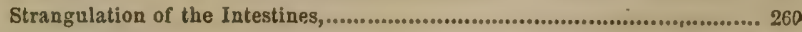

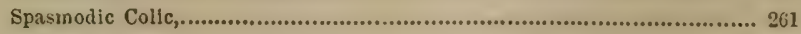

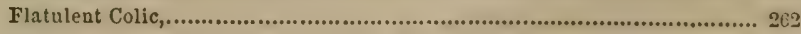

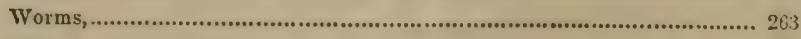

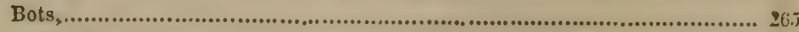

DISEASES OF THE LiVER, ............................................................ $26 S$

Inflammation of the Liver, .................................................. 269

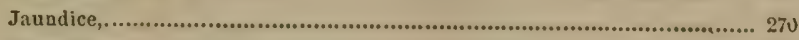

Hepatirrhaca, .................................................................. 271

Decayed Structure of the Liver,................................................ 272

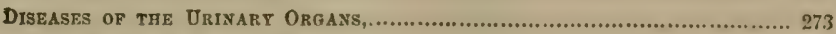

Inflammation of the Bladder, ............................................. 273 
DISEASES, AND THEIR REMEDIES-CONTINUED.

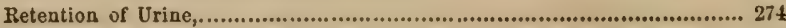

Profuse Staling,..................................................................... 275

Bloody Urine, .......................................................................... 276

Stones in the Kidneys, ..................................................... 277

Stones in the Bladder, ............................................................. $27 \mathrm{~S}$

DISEASES OF THE FEET AND LEGS, ................................................ 279

Contraction of the Hoof, ........................................................ 279

Corns, .................................................................................. 250

Quitter,........................................................................ 2S

Thrush, ................................................................................ 282

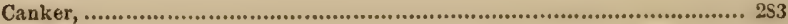

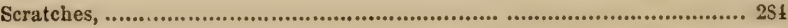

Grease Heels, .................................................................... $28 t$

Water Farcy,......................................................................... 2S6

Weed, ................................................................................ 297

Cracked Hoof, .................................................................... 287

Sole Bruise and Gravel,........................................................ 2SS

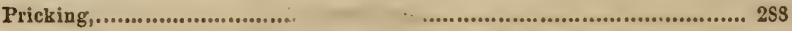

False Quarter, ................... [............................................ 289

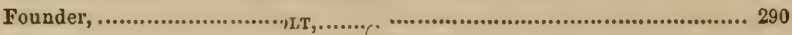

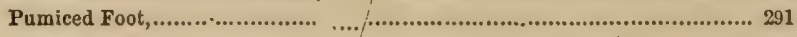

Corinitis, .......................................................................... 291

Navicularthritis, ....................................................................... 292

Ossiflcation of the Lateral Cartilages, ............................................... 293

Wind Galls, .................................................................................... 294

Sprung or Broken Knees,........................................................ 294

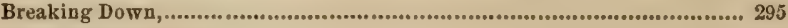

Strains of the Knees,......................................................... 295

Strain of the Hip Joint,............ ................................................. 296

Shoulder Strain, .................................................................. 296

Open Joints, ................................................................... 297

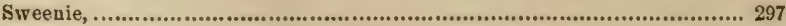

Ostitis, ................................................................................... 298

Capulet and Capped Hock,............................................................. 299

Caries of the Boues, ................................................................ 299

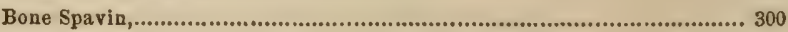

Ring Bone, ........................................................................ 303

Splint, ............................................................................. 303

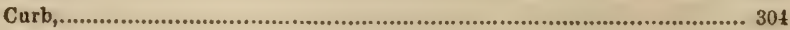

String Halt, ............................................................................... 305

Blood Spavin, Bog Spavin, and Thoroughpin ................................... 305

Fractures,. m................................................................................. 300 
DISEASES AND THEIR REIEDIES-CONTINEED. PATE

DISEASES OF THE HEART, ........................................................... 307

Pericarditis, .............................................................. 308

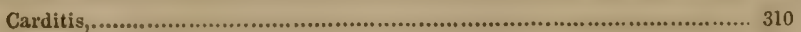

Endrocarditis, ................................................................ 310

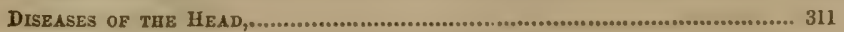

Osteo-Sarcoma, ................................................................... 311

Inflammation of the Brain,.................................................... 312

Megrims, ......................................................................... 313

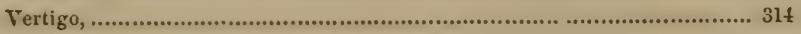

Epilepsy, ......................................................................... 314

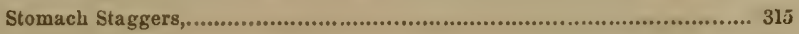

DISEASES OF THE EYE, .......................................................... 317

Amaurosis, ...................................................................... 317

Inflammatiou of the Membrana Nictitans,..................................... 318

Simple Ophthalmia, ............................................................ 319

Specific Ophthalmia, ....................................................... 320

Cataract, ........................................................................ 321

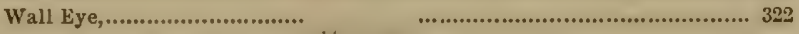

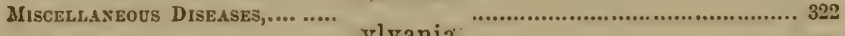

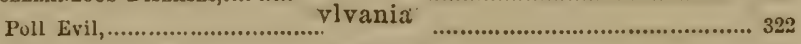

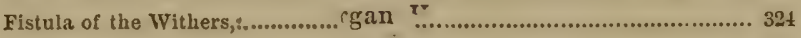

Melanotic Tumors, .................... r......................................... $32 t$

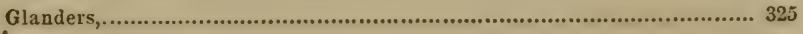

Farcy, ........................................................................ 327

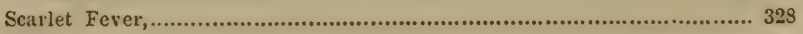

Drange, ........................................................................ 329

Surfeit, ...................................................................... 331

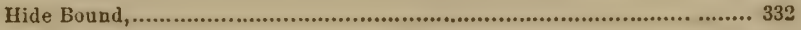

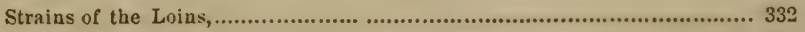

Palsy, ........................................................................... 333

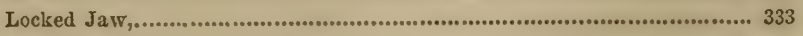

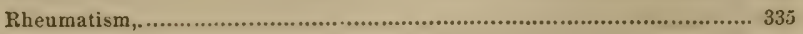

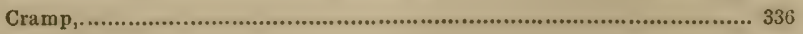

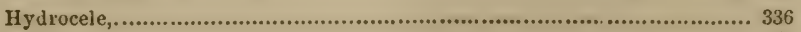

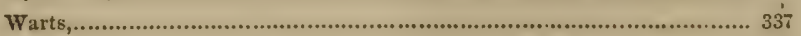

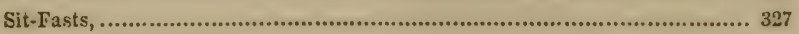

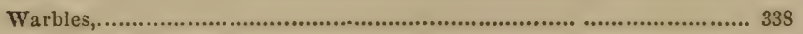

Saddle or Harness Galls, ......................................................... 338

Mrallanders and Sellenders, ..................................................... 338

Ulceration of the Udder, ........................................................... 339

Inflamed Veins, ................................................................... 339

SURGICAL CASES, .................................................................................... 239 
DISEASES AND THEIR REMEDIES-CONTINUED.

Bleeding,

Neurotomy or Nerving, ........................................................ 342

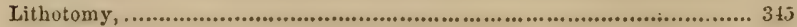

Trephining, ................................................................. 345

Tenotomy,

Couching, .......................................................................... 346

Tapping the Chest, .......................................................... 346

Periosteotomy, ................................................................. 347

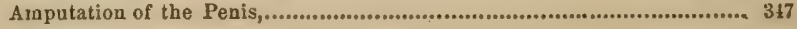

Esophagotomy, .......................................................... 348

Hernia, ................................................................... 349

losveling, ........................................................................... 350

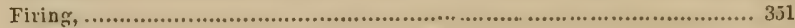

Tracheotomy, ,................................................................ 352

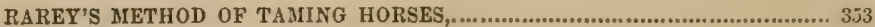

How to Call a Colt from Pasture, ......................................... 356

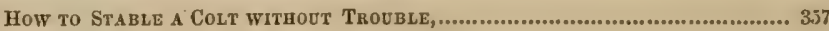

APPROACHING A COLT, .................................................................. 362

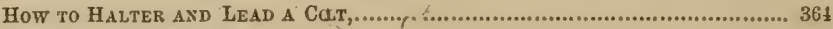

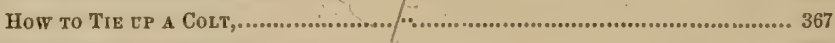

How TO TAME A HORSE, .................................................... 368

How to MAKE A HoRse Lie Down, ........................................ 36 ?

TO ACcUSTOM A. HoRSE TO STRANGE SOUNDS AND SIGIITS, ............................ 370

To Accustom a Horse to a Drum,............................................... 371

To Teach a Horse to bear an Umbrella, ........................................... 372

To Fire off a Horse's Back, ........................................................ 372

How te ACCUSTOM A HoRSE TO A BiT, ........................................... 372

The PROPER WAT Tro BIT A COLT, ........................................................ 373

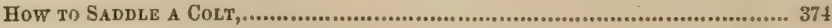

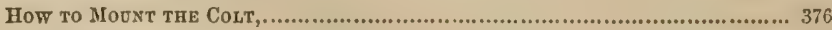

How TO RIDE A COLT, ............................................................ 378

HOW TO BREAK A HORSE TO HARNESS, ............................................... 379

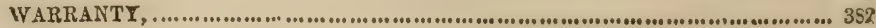




\section{ILLUSTRATIONS.}

PAGR

The Arab and his Steed,......................................... It

The Shetland Pony.-An English Sporting Scene,.............. 21

The Stallion, .................................................... 28

American Farm Scene,............................................. 30

The Canadian,................................................ 35

Black Hawk, -An American Racer,............................. 43

American Plantation Scene,...................................... 47

The Vermont Draught-Horse,..................................... 58

A Conestoga. - The Great Pennsylvania Draught-Horse, ....... 60

Ethan Allen,-A Fast-trotting Morgan Horse,.................... 69

Skeleton of the Horse, as covered by the Muscles,............... 73

Names applied to the various External Parts of the Horse,..... 80

Eight Days' Teeth,............................................. 88

T'hree or Four Months' Teeth,.................................... 88

Teeth at Twelve Months,.......................................... 90

A Grinder sawed across, ........................................ 90

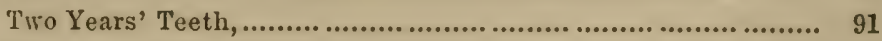

Three Years' Teeth,.............................................. 92

Four Years' Teeth,................................................. 94

Five Years' Teeth,................................................ 95

Six Years' Teeth,................................................... 96

Seven Years' Teeth, ............................................... 97

Eight or Nine Years' Teeth,.......................................... 98

Mare and Foal,.................................................. 102

The Arab Stallion, Jupiter,...................................... 105

Breaking, ....................................................... 110

The Agriculturist's Method,...................................... 117 


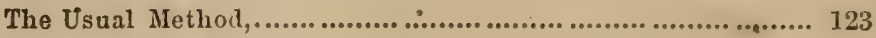

The French Method,............................................... 124

Customary Forms of Stalls, .................................... 126

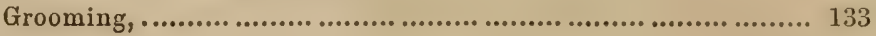

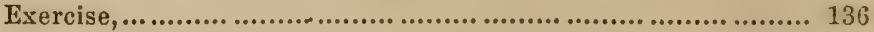

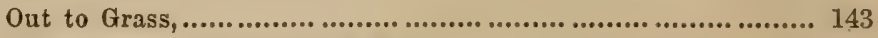

The American Racer, Black Maria,............... ........... 147

Pasturing, ..................................................... 157

Service,................................................................. 169

Ground Surface of the Hoof,.................................... 175

The Hoof of the Horse,........................................ 176

A Section of the Foot,............................................ 177

The Position of the Shoe,....................................... 187

The Proper Form of a Shoe, ....................................... 192

Running Away, ................................................. 198

Particularly Dangerous, ........................................... 204

MLuzzle for a Crib-Biter, ......................................... 210

Disagreeable and Dangerous, ..................................... 214

The Sick Horse,..................................................... 220

The Blooded Mare Fashion, and Foal,.......................... 227

The Saddle-Horse, ................................................. 232

Quiet Enjoyment, ............................................. 237

The Trotting-Horse, Lexington,.................................. 244

The Attack and Defense,......................................... 250

Omar Pasha, the Turkish Chieftain, .......................... 256

Sir Archy, the Godolphin of America,......................... 262

Common Gad-Fly or Bot,....................................... 265

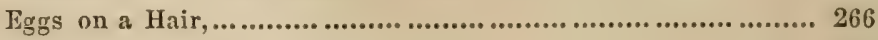

Eggs Magnified,................................................. 266

Caterpillar, full size,............................................. 267

Caterpillar or Larvæ, adhering to the Lining of the Stomach,... 267

The Red Gad-Fly, .................................................. 268

Caterpillar of the Red Gad-Fly,................................... 268

Virginia Mill-Boys on a Race,...................................... 273

The Fast-Trotting stallion, Geo. M. Patchen,.................. 279 
The Children's Pet, ...................................................... 285

The Famous Trotting-Mare, Flora Temple,.......................... 292

The Equestrienne, ...................................................... 298

The High-Bred Pacing Mare, Pocahontas, ............................ 302

The end of Pericarditis, ................................................ 309

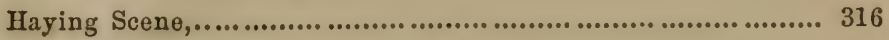

The Trotting Stallion, American Eclipse, ........................... 323

The Three Friends, ...................................................... 330

Byron's Mazeppa, ...................................................... 335

Lady Suffolk, .......................................................... 341

Good for Heavy Drafts, ................................................. 349

The Horse Tamed, ....................................................... 353

Bridle with a wooden Gag-bit for conquering vicious Horses,... 358

Strap for the Right Fore-leg, .......................................... 360

Strap for the Off Fore-leg, ............................................. 362

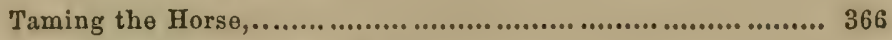

Teaching the Horse to lie down, ....................................... 370

Struggles of the Vioious Horse against lying down,.............. 373

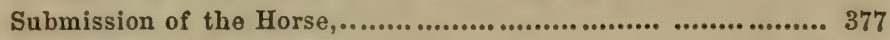

Breaking the Horse to Harmess, ........................................ 380 



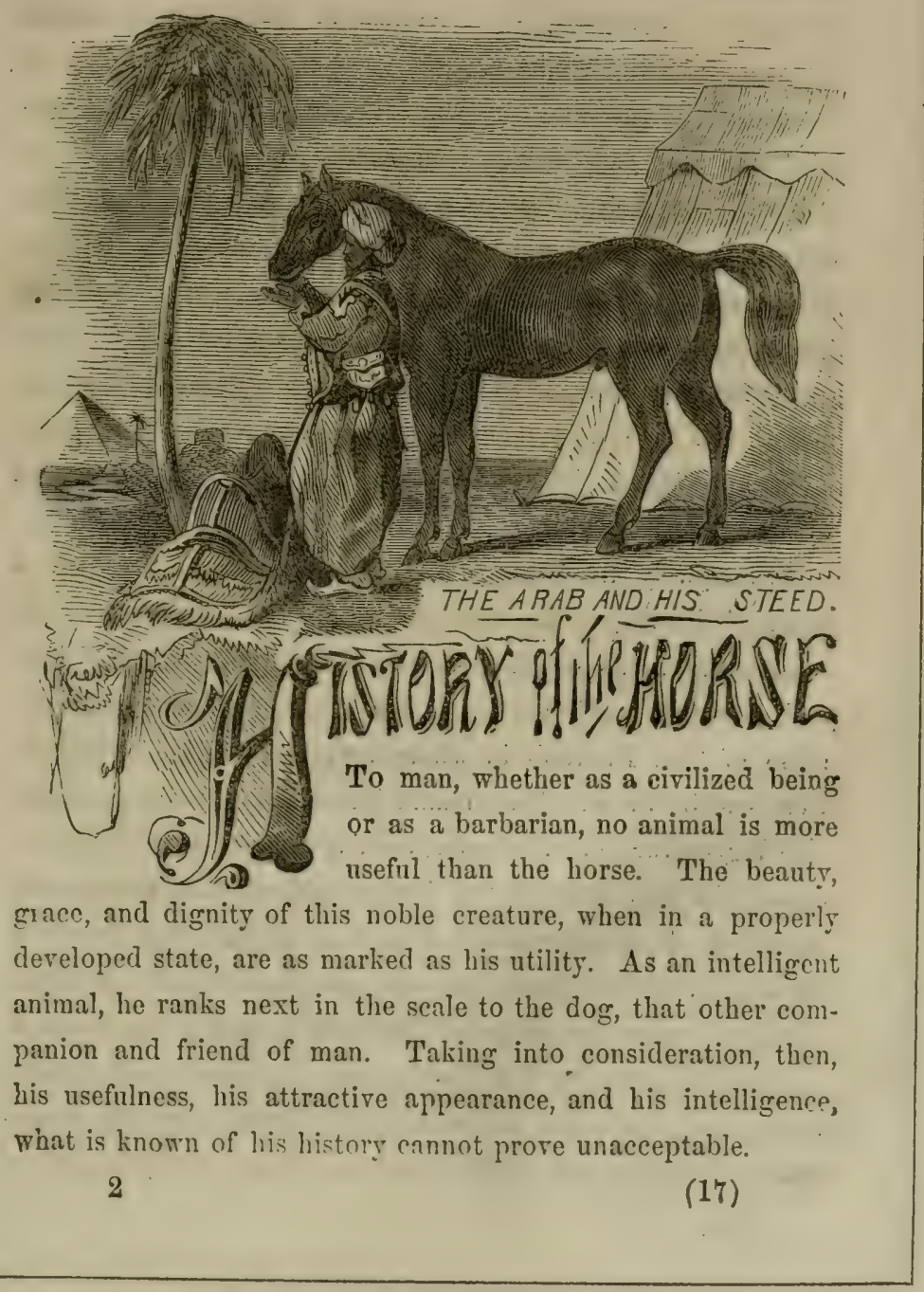


In order to ascertain the special land which can claim the proud honor of being the parent country, the birth-place of this noble animal, recourse must be had primarily to the pages of Scripture, as being the most ancient and best authenticated of all existing histories. By reference to those pages, we find that, although the ass was in early use among the children of Israel, the horse was unknown to them until after the com. mencement of their dwelling in Egypt; and strong evidence exists for the belief that he was not brought into subjection, even in that country, until after their arrival. Clear it is, at all events, that Arabia, which many have supposed to be the native home of the horse, did not possess him until within a comparatively recent period; while his introduction into Greece, and thence into those countries of Europe and Asia in which he is now found, either wild or domesticated, may be traced with much certainty to an Egyptian source.

Although in the history of Abraham frequent mention is made of the ass, of the camel, of flocks and herds, sheep and oxen, there is no allusion to the horse; nor, indeed, do we find any such until we reach the time of Joseph. In the reign of that $\mathrm{Pharaoh}$ in whose service Joseph was, wagons were sent by the king's command into Canaan, to bring thence into Egypt Jacob and his sons, their wives and their little ones, during the prevalence of the famine against which Joseph had provided. It is not recorded that those wagons were drawn by horses; but the inference that such was the fact is by no means irrational, when we remember that it was during the continuance of this famine that horses are first mentioned, having beer taken by Joseph in exchange for bread from the Egyptıan cultivators and cattle-breeders; that on the death of 
Jacob, his funeral was attended hy "both chariots and horsemen;" and lastly, that we know from the writings of Honer, and from the ancient sculptures of Persepolis and Ninereb, that the horse was used for purposes of draught for some time previous to his being ridden.

From this time, the horse appears to hare been speedily adopted for use in battle. At the Exodus, some fifteen bundred sears before the Clristian era, the pursuing army contained "six hundred chosen chariots, and all the chariots of Egspt," together with all the horsemen. And when the Israelites returned into Canaan, we find that the horse had already been naturalized in that country, since the Canaanites "went out to fight against Israel with horses and chariots very many."

From these considerations, and from the fact that, so late as six hundred years after this date, Arabia had still no horses, it is by no means an improbable conclusion that the shepherd kings of Egypt, whose origin is unknown, introduced the horse into Lower Egypt; and that, after this period, that country became the principal herding district of this animal, whence he was gradually introduced into Arabia and the adjoining Asiatic countries. From the same stock is doubtless derived the entire race in all the southeastern parts of Europe. As Egypt is not, in any respect, a farorable country for horsebreeding, still less for his original existence in a state of nature, the source whence he was first introduced into that country is in some degree enveloped in uncertainty; though the better opinion, based upon muclr indirect testimony, is that he wás an original native of the soil of Africa, which alone was 
the parent country of the Zebra and the Quagga-in some sort his kin.

It is questionable whether the horse is still to be found in a state of nature in Arabia; although it is asserted that they exist thinly scattered in the deserts, and that they are hunted by the Bedouins for their flesh, and also for the purpose of improving their inferior breeds by a different lind of blood. In central Africa, however, whence the horse is supposed to have been first introduced into Egypt, and thence into Arabia, Europe, and the East, wild horses still roam untamed far to the southward of the great desert of Sahara, where they were seen by Mungo Park in large droves.

At the period of the first Roman invasion, the horse was domesticated in Britain, and in such numbers, that a large portion of the forces which resisted the invaders were charioteers and cavalry.

In Europe, however, with but few exceptions, the horse, for purposes of warfare, was slowly, and not till the lapse of ages, brought into use: even the Spartans, the Athenians, and the Thebans, when at the height of their military renown, having but inferior and scanty cavalry services.

In the oldest sculptures probably in existence,-those removed by Layard from the ruins of Nineveh, and illustrative of almost every phase of regal and military life,- the horse is uniformly represented as a remarkably high-crested, largeheaded, heary-shouldered animal : rather long-bodied; powerfully limbed; his neck clothed with volumes of shaggy mane, often plaited into regular and fanciful braids; and his tail coarse and abundant, frequently ormamented similarly to his own mane and to the beard and hair of his driver-an ani- 
mal, indeed, as unlike as possible to the low-statured, delicatelimbed, small-headed Arabs and barbs of modern days, with their basin-faces, large full eyes, and long, thin manes, from which the blood-horse of our times has derived his peculiar excellence. The same remarks may, in the main, be made as

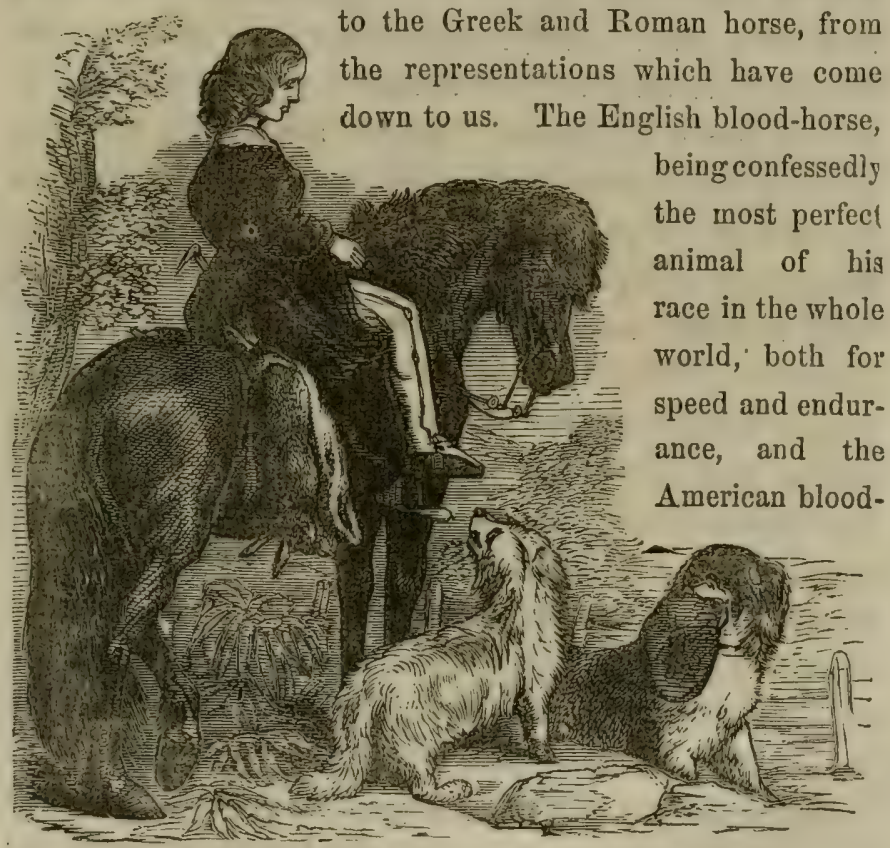

THE EHETLAND PONX.-AN ENGLISH SPORTING ICENE.

horse directly tracing withont mixture to English, and through the English to Oriental parentage, some account of the former variety may be of interest to the reader.

It has already been remarked that large numbers of horses were found in Britain at the first Roman invasion. It is to be added, that Cæsar thought them so raluable that he carried 
many of them to Rome: and the British horses were, for a considerable period afterward, in great demand in various parts of the Roman Empire. After the evacuation of England by the Romans and its conquest by the Saxons, considerable attention was prid to the English breed of horses; and after the reign of Alfred, running horses were imported from Germany, this being the first intimation given us in history of Junning horses in England. English horses, after this, were so highly prized upon the Continent, that, in order to preserve the monopoly of the breed, in A.D. 930 a law was passed, prohibiting the exportation of the animal. In Athelstan's reign many Spanish horses were imported; and William the Conqueror introduced many fine animals from Normanảy, Flanders, and Spain,-circumstances which show the strong desire, even at that early period, to improve the English breed. In the reign of Henry $I$. is the first account of the importation of the Arab horse into the country, at which time it is evident that the English had become sensible of the value and breed of their horse: and in the twelfth century a race-course had been established in London,-Damely, Smithfield,-at once horse-market and race-course.

King John imported Flemish horses for the improvement of the breed for agricultural purposes; and in his reign is found the origin of the draught-horse now in general use in that country. Edward II. and Edward III. imported horses for the improvement of the stock, the latter introducing fifty Spanish horses. In the reign of Ifenry VII., the exportation of stallions was prohibited; but that of mares was allowed, when more than two years old, and under the value of six shillings and eight pence. In the reign of Henry VIII., many very 
arbitrary statutes were passed for the improvement of the horse; and it was during the same period that an annual race was run at Chester. In the reign of Elizabeth, the number and breed appear to have degenerated; for it is stated that she could collect but three thousand horse throughout her realm to resist the invasion of $\mathrm{D}$ on Philip.

With the accession of James $I$. to the throne, a great improvement was systematically wrought in the English breed; and from this period a constant and progressive attention was paid to the matter of breeding. This monarch purchased an Arabian horse at the then extraordinary price of five hundred pounds; but he proving deficient in speed, Arabians for a time fell into disrepute. Race meetings were then beld at various places (Newmarket, among others) throughout the kingdom, the races being mostly matches against time, or trials of speed or bottom for absurdly long and cruel distances.

Although Cromwell, during his Protectorate, was obliged to forbid racing, yet he was an ardent lorer of the horse, an earnest patron of all pertaining to horsemauship, and to his strenuous exertions the present superior condition of the English blood-horse is in no small degree owing.

Before proceeding to the history of the American borsewhich is our main concern in the present branch of this work-a concise summary of the different varieties of this useful quadruped cannot fail to interest. We commence with the horse of Asia. 


\section{HORSES OF ASIA AND AFRICA.}

\section{THE ARABIAN.}

In this country the horse, even in its wild state, (in which condition, as before remarised, it is rarely found,) is possessed of a beautiful symmetry of form, and a disposition of the greatest gentleness and generosity. His size is small, averaging in height generally between thirteen and fourteen hands, (the hand being reckoned at about four inches of our measure); color a dappled grey, though sometimes a dark brown; mane and tail short and black. The only mode of capturing him is by snares carefully concealed in the sand, as his exceeding swiftness prevents all possibility of taking him by the chase. The fondness of the Arab for his steed is well known, having long since passed into a proverb. The horse of the poorest wanderer of the desert shares with his master and his family every attention and caress which the strongest attachment can prompt. Mares are always preferred by the Arab to horses, as they endure fatigue and the hurdships iucident to a desert life much more patiently, and they can be kept together in greater numbers without the risk of quarrels and mutual in. juries. Great attention is paid to the coat of the animal. He i: carefully washed each moruing and evening, or after a long ride; is fed only during the night, receiving throughout the day nothing but one or two drinks of water.

The head of the pure Arab is light, well made, wide between the nostrils, forehead broad, muzzle short and fine, nostrils expanded and trausparent, eyes prominent and sparkling, ears small; ueck somewhat short; shoulders high and well 
thrown back; withers high and arched; legs fine, flat, and small-boned, and the body somewhat light.

\section{THE PERSIAN.}

- This horse is slightly taller than the Arab : is full of bone, and very fust. The Persian feeds his horse as does the Arab, the food given being coarse and scant. Hay is utterly unknown for the purpose, barley and chopped straw being generally substituted. Although this rariety is in most respects less esteemed than the Arab, it is in some points its superior.

\section{THE TARTARIAN.}

Like the Persian, this variety is swift; but the horses are heary-headed, low-shouldered, and altogether rery awkwardly put together. The Tartars eat the flesh of their horses and use the milk of their mares, from which they also make excellent cheese.

\section{THE TURKOMAN.}

This is a variety of the Tartar, but superior to it; bringing, even in Persia, frequently from five hundred to a thousand dollars. Its average height is some fifteen hands, and in general appearance it bears a strong resemblance to a well-bred $\mathrm{En}$ glish carriage-horse. Though possessed of considerable speed, it is not enduring. This variety is often foisted upon the ignorant as the pure Arabian.

\section{THE TURKISH HORSE.}

This horse is a cross between the Persian and the Arabian, and is of slender build, carrying his head high, lively and fiery, and possessing a gentle and affectionate disposition. The tail of the horse is regarded in Turkey and Persia as a 
badge of dignity, princes measuring their rank by the number of tails they carry; those of the highest rank being allowed three.

\section{HORSES OF HINDOSTAN.}

In India, the horse, owing to the peculiar climate of the country, is invariably found to degenerate, unless great attention be paid to breeding. The principal breeds are the Tazee, the Takan, the Folaree, the Cutch, and the Dattywarr.

Passing from the Asiatic lorses to the African, it is to be remarked that Egypt bas long since lost its character as a breeding country, its horses being justly deemed much inferior to those of Persia, Barbary, or Arabia.

\section{THE BARB, AND OTERRS.}

This variety-the principal of the African race-is taller than the Arabian, and is remarkable for the height and fullness of its shoulders, drooping of the haunches, and roundness of the barrel.

The Bornou race, in the central parts of Africa, is described as possessing the qualities of the Arabian with the beauty of the Barb; as being fine in shoulder and of general elegance of form. The Nubian horses are stated by travelers to be even superior to the Arabian. Dongola has a noticeable breed, of large size, their chief peculiarities being extreme shortness of body, length of ueck, height of crest, and a beautiful forehand. 
EUROPEAN HORSES.

THE RACER.

As the varieties of the horse in Great Britain are the most noticeable of any in Europe, we append a brief description of the principal breeds at present in use.

The Racer, which excels, in beauty, speed, and endurance, that of all other nations, was gradually formed by the introduction of the best blood of Spain, Barbary, Turkey, and A rabia, and bears a strong family likeness to each. The characteristics of this breed are a high and lofty head, bright and fearless eye, small ear, expanded nostril ; arched neck, curved on the upper surface, with no curve underneath; the neck gracefully set on ; the shoulder lengthened, oblique, and lying well back; the quarters ample and muscular; the fore-legs straight and fine, but with sufficient bone; the hinder legs well bent, and the pasterns long and springy.

\section{THE HUNTER.}

The best horses of this breed stand fifteen or sixteen hands high : head small; neck thin, especially beneath the crest, firm and arched; and jaws wide; lofty forebead; shoulders as extensive and oblique as that of the racer, and somewhat thicker; broad chest; muscular arm; leg shorter than that of the racer; body also more short and compact; loins broad; quarters long; thighs muscular; hocks well bent, and under the horse.

THE HACKNEY.

This horse is still more compact than the hunter, with more 
substance in proportion to his height; forchead light and high; head small, and placed taperingly upon the neck; shoulders deep and spacious, lying well back; back straight, loins strong; fillets wide, and, withers well raised. Too higk breeding is considered objectionable in this species, as being ill adapted for ordinary riding upon the road.

\section{THE CART HORSE.}

The principal varieties of this class, are the Cleveland, the Clydesdale, the Northamptonshire, the Suffolk Punch, and the

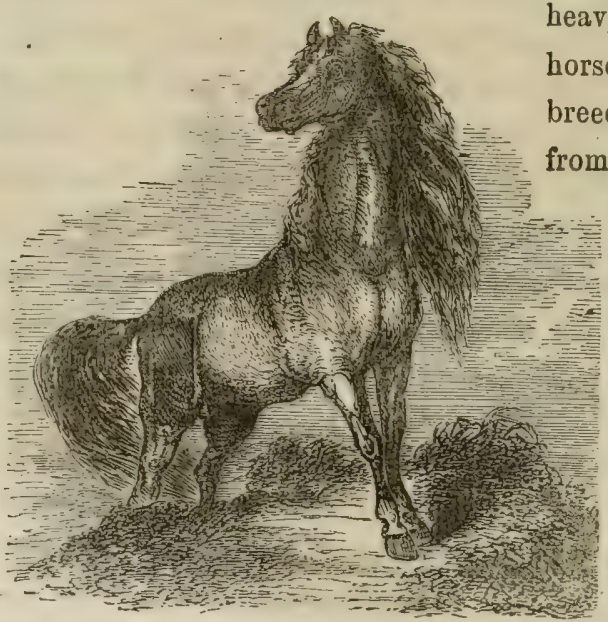

THE GTALLION. heavy black or dray horse. The Clydesdale breed obtains its name rom being bred chiefly in the valley of the Clyde. They are strong and hardy, have a small head, are longer necked than the Suffolk, with deeper legs and lighter bodies. The Suffolk Punch originated by crossing the Suffolk cart mare with the Norman stallion. Its color is yellowish or sorrel; large head, wide between the ears, muzzle rather coarse, back long and straight, sides flat, fore-end low, shoulders thrown much forward, high at the hips, round legs, short pasterns, deep-bellied, and full barrel. The modern-bred cart horse of England, originated 
fiom a cross with the Yorkshire half-bred stallion, and is of much lighter form, and stands much higher. This horse is hardy and useful, kindly, and a good feeder. The heavy black horse is chiefly bred in Lincolnshine ant the Midlaud sounties.

\section{GERMAN, FRENCH, AND SPANISH HORSES.}

The horses of Germany, with the exception of the Hungarian, are generally large, heary, and slow. The Prussian, German, and the rreater part of the French cavalry, are procured from Holstein. They are of a dark glossy bay color, with small heads, large nostrils, and full dark eyes, being beautiful, active, and strong.

The horses of Sweden and Finland are small, but beantiful, and remarkable for their speed and spirit; those of Finland being not more than twelve hands high, yet trotting along with ease at the rate of twelve miles an hour.

The Iceland horse is either of Norwegian or Scottish clescent. They are very small, strong, and swift. Thousands of them live upon the mountains of that barren country, never entering a stable, but taught by instinct or habit to scrape away the snow, or break the ice, in quest of their meagre food.

The Flemish and Dutch horses are large, and strongly and beautifully formed. The best blood of draught horses is Dwing, in a great degree, to crosses with these.

The best French borses are bred in Limousin and Normandy; the prorinces of Aurergne and Poitou producing ponys and galloways, which are excellent sadule-horses and Lunters.

The Spanish horse of other days, as the Andalusian charger 
and the Spanish jennets, exists but in history or romance. The modern Spanish horse resembles the Yorkshire half-bred, with flatter legs and better feet, but a far inferior figure.

The Italian horses, particularly the Neapolitan, were once in high repute; but, owing mainly to intermixtures of European, rather than Eastern blood, they have sadly degenerated.

\section{THE A MERICAN HORSE.}

At a very remote period in the history of America, the horse began to be imported from Europe by the earliest settlers; it

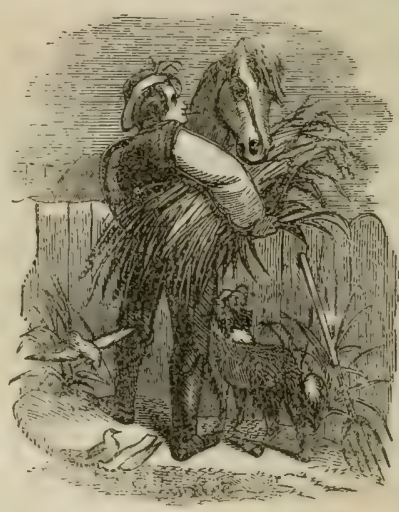

AMERICAN FARM SCENE.

being conceded that, although the horse had, at some former time, existed on this continent, as is proved by his fossil remains, which bave been found in abundance in various parts of the country, he had become extinct previous to its colonization by the white nations.

It is generally believed that. the horses which are found in a wild state on the pampas or ylains of South America, and the prairies of North America, as far east as to the Mississippi River, are the descendants of the parents set loose by the Spaniards at the abandonment of Buenos Ayres. This opinion, however, is combated by some, on the ground that this date is too recent to account 
for the rast numerical increase, and the great hordes of these animals now existing in a state of nature; and they are inclinerd to ascribe their origin to animals escaped, or voluntarily set at liberty, in the earlier expeditions and wars of the Spanish invaders, the caralry of that uation consisting entirely of perfect horses or mares.

An opportunity for such an origin must undoubtedly have been furnished in the bloody wars of Mexico and Peru; since upon the issue of many battles, which were disastrous to the Spaniards, the war-horses, their riders being slain, could hare recorered their freedom and propagated their species rapidly in the wide, luxuriant, and well-watered plains, where the abundance of food, the genial climate, and the absence of beasts of prey capalle of successfully contending with so powerful an animal as the horse, would favor their rapid increase.

We know, moreorer, that De Soto had a large force of cavalry in that expedition in which he discovered the Mississippi, and found a grave in its bosom; and when his warriors reiurned bome in barques which they built on the banks of the "Father of waters," there can be little doubt that their chargers mast have been abandoned, since their slender vessels, luilt by inexperienced hands for the sole purpose of saring their own lires, must have been incapable of containing their steeds.

The first horses imported to America for the purpose of creating a stock, were brought by Culumbus, in 1493 , in bis second royage to the islands. The first landed in the United States, were introduced into Florida in 1527 , by Cabeca de $\checkmark$ aca, forty-two in number; but these all perished cr were 
killed. The next importation was that of De Soto, before mentioned; to which is doubtless to be attributed the origin of the wild horses of Texas and the prairies, a race strongly marked to this day by the characteristics of Spanish blood.

In 1604, L'Escarbot, a French lawyer, brought horses and other domestic animals into Acadia ; and in 1608, the French, then engaged in colonizing Canada, introduced horses into that country, where the present race, though somewbat degenerated in size, owing probably to the inclemency of the climate, still "shows the blood, sufficiently distinct, of the Norman and Breton breeds.

In 1609, the English ships landing at Jamestorn, in Virginia, brought; besides swine, sheep, and cattle, six mares and a horse; and in 1657 , the importance of increasing the stock of this raluable animal was so fully recognized, that an act was passed, prohibiting its exportation from the province.

In 1629, horses and mares were brought into the plantations of Massachusetts Bay, by one Francis Higginson, formerly of Leicestershire, England, from which county many of the animals were imported. New York first received its horses in 1625, imported from Holland by the Dutch West India Company, probably of the Flanders breed, though few traces of that breed yet exist, unless they are to be found in the Conestoga horse of Pennsylvania, which shows some affinity to it, either directly or through the English dray-horse, which latter is believed to be originally of Flemish origin.

In 1750 , the French of Illinois procured considerable numbers of French horses; and since that time, as the science of agriculture has improved and advanced, pure animals of many distinct breeds bave been constantly imported into this country, 
Which have created in different sections and districts distinct families, easily recognized,-as the horses of Massachnsetts and Vermont, admirable for their qualities as draft-horses, powerful, active, and capable of quick as well as heavy work; the Conestogas, excellent for ponderous, slow efforts, in teaming and the like; and the active, wiry horses of the West, well sdapted for riding, and being in most general use for American cavalry purposes.

It is evident, then, that the original stock of the unimproved American horse- is the result of a mixture of brecds; the French, the Spanish, the Flemish, and the English horses haring all sent their representatives to some one portion at least, of the United States and British Provinces, and probably still prevailing to a considerable degree in some locations, though nowhere wholly unmixed-while, in others, they have become so thoroughly mixed and amalgamated, that their identity can no longer be discovered.

In New York, for example, the early importations of thorough blood, and the constant support of horse-racing, appear to have so changed the original Dutch or Flemish stock, that the characteristic of her horses is that of the English race, with a decided admixture of good blood. In Massachusetts, Vermont, and the Eastern States generally, the Cleveland bay, and a cross between that and the English dray-horse blood, with some small admixture of thorough blood, predominate. In Pennsylvania, the most distinct breed appears to be of Flemish and English dray-horse origin. In Maryland, Virginia, and South Carolina, English thorough blood prevails to a great extent; so much so as to render the inferior class of working horses undersized. In Louisiana, and many of the 
Western States, French and Spanish blood partly prevail, though with a mixture of English blood. It may, in short, be generally assumed that, with the exception of the thoroughbreds, there is scarcely any breed in any part of America wholly pure and unmixed; and that there are very few animals anywhere, which have not some mixture, greater or less, of the hot blood of the East, transmitted through the Englisb race-horse.

Indeed, with the exception of the Conestoga horse, there is, in the United States, no purely-bred draft or cart-horse, nor any breed which is kept entirely for labor in the field or on the road, withont a view to being used at times for quicker work, and for purposes of pleasure or travel. Every horse, for the most part, bred in America, is intended to be, in some sense, used upon the road; and it is but asserting a weli-known fact, when we say, that for docility, temper, soundness of constitution, endurance of fatigue, hardiness, sure-footedness, and speed, the American roadster is not to be excelled, if equaled, by any horse in the entire world not purely thorough-bred.

Of roadsters, two or three families have obtained, in different localities, decided reputations for different peculiar qualities : such as the Narkagansett pacers, the families known as the Morgan and Black Hawk, the Canadian, and generally what may be called trotters. No one of these, however, with the single cxception of the Narragansetts, appears to have any real claim to be deemed a distinctive family, or to be regarded as capable of transmitting its qualities in line of hereditary descent, by breeding within itself, without further crosses with higher and hotter blood.

Of the Narragansetts, but little can be said with certainty; 
for there is reason to beliere that, as a distinct variety, with natural powers of pacing, they are extinct; and their origin is, in some degree, uncertain. The other families clearly owe their merits to a remote infusion of thorough-blood, perhaps amounting to one-fourth, or one-third part, some three or four generations back.

The original Canadians were, doubtless, of pure Norman and Breton descent; but, since the Canadas

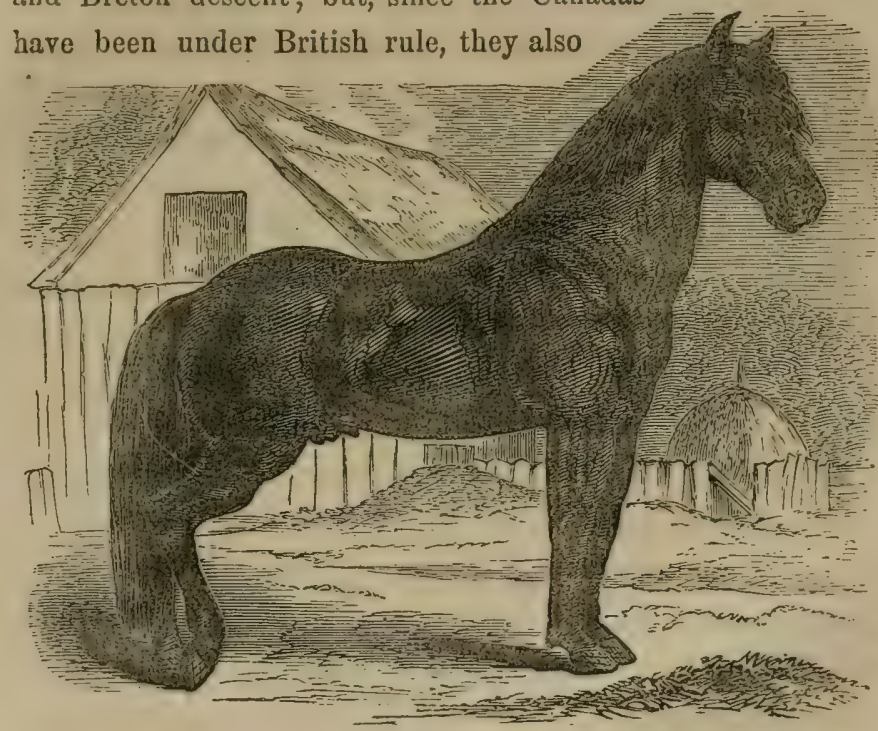

TEE CANADIAN.

have been largely mixed with, and much improved by, the introduction of a pure blood; so that the animals which in late years pass here under the name of Canadians, such as Moscow, Lady Moscow, and many others of that name, are Canadians only in name, differing from other American roadsters simply in the fact that they have, for the most part, only two crosses 
of the Norman and pure English blood, while the ordinars road-horse of the United States is perhaps a combination of several distinct Euglish families, with French, Spanish, and Flemish crosses, besides an infusion of thorougli-blood.

Of trotters, there is certainly no distinctire breed or family, or mode of breeding. 'The power, the style, the action, the mode of going, are the points regarded; and it is most probable, that the speed and the endurance, both of weight and distance, depend, more or less, on the greater or inferior degree of blood in the animal.

Indeed, the wonderful superiority of the American roadster is attributable to the great popularity of trotting in this country, to the great excellence of the trotting-trainers, drivers, and riders, arising from that popularity, and to the employment of all the very best half and three-quarter-part bred horses in the land for trotting purposes, none being turned from that use for the hunting-field or park-riding.

The general American horse, as compared with the English horse, is inferior in height of the forehand, in the loftiness and thinness of the withers, and in the setting-on and carriage of the neck and crest; while he is superior in the generil development of his quarters, in the let-down of his hams, and in his height behind; and further remarkable for his formation, approaching what is often seen in the Irish horse, and krown as the goose-rump. Even the American racer stands very much higher behind and lower before than his English fellow.

Another point in which the American horse of all conditions differs extremely and most advantageously from the European animal, is his greater sure-footedness and freedom from the dangerous vice of stumbling. Any one can satisfactorily con- 
vince himself of this, by comparing the knees of hack-horses let for hire, either in the cities or rural villages of the United States, with those of similar English localities. In this country, a broken knee is one of the very rarest blemishes encountered in a horse; while of horses let for hire in England, with the exception of those let by a few crack livery-keepers in London, in the Universities, and in one or two other of the most important towns in hunting neighborhoods, a majority are decidedly broken-kneed.

The exemption of the horse, on this side of the Atlantic, from this fault, is ascribable: first, to the fact, that both the pasture-lands and the roads here are far rougher, more broken in surface, and more interrupted by stones, stumps, and other obstacles, than in the longer cultirated and more finished countries of Europe, which teaches young horses to bend their knees, and throw their legs more freely while playing with the dams in the field; and also to lift and set down their feet with . much greater caution even on our great thoroughfares; secondly, to the higher blood and breed of riding-horses in England, which are often cantering thorough breds, liable to be unsafe travelers on the road; and lastly, to the well-known circumstance, that most of the hired horses are roadsters-these are worn-out or broken-down animals of a higher caste, which are deemed, by reason of their disqualification for a higher 'position, fit for a secondary one, although suited to none, and dangerous in any.

To this admirable quality of the American horse, must be added his extreme good temper and docility, in which he undeniably excels any other horse in the world. From the first childhood of the animal until he is fully put to work, he ro- 
quires and receives little or no breaking, unless he show qualities which promise such speed or endurance as to render it advisable to train him as a trotter. Eren when this is done, it is for the purpose of developing his powers, getting him to exert himself to the utmost, and teaching him how to move to the best adrantage; and not to render him submissive, easy of management, or gentle to be handled. There is scarcely ever any difficulty in saddling, in harnessing, in backing, or in in. ducing him to go. He may be awkward at first, uncouth, shy, and timid; but he is never, one may almost say, violent, spas. modic in his actions, and fierce.

It is true that horses are treated, for the most part, with superior judgment and greater humanity in the United States; that the whip is little used, and the spur almost unknown; still the whole of this remarliable difference in temper, on the part of the American horse, camnot be attributed to the difference of treatment.

As he begins, moreover, he continues to the end. One rarely encounters a kicker, a runaway, an inveterate shyer or balker, and hardly ever a furious animal, not to be approached, save at the risk of limb or life, in an American horse of any class or condition.

Probably this fact may, in some respects, be attributed to the less high strain of blood in the American roadster, and still more to the hardier and less stimulating mode of treatment to which he is subjected. The heating treatment to which the English horse is subjected, unquestionably deprives him, in some degree, of the power of enduring long-protracted exertion, privation, hardship, and the inclemency of the weather; and the pampering, high feeding, excessive grooming, and 
general maintenance of horses in an unnatural and excited state of spirits has, assuredly, an injurious effect upon the general temper of the animal; though not, perhaps, so greatly as to account for all the difference to which allusion has just been made.

Haring premised thus much, in general terms, of the history and peculiarities of the general American horse, we will next take up the leading varieties which obtain in this country, commencing with

\section{THE AMERICAN BLOOD-HORSE.}

Unlike the human race of the United States, unlike the ordinary working horse, unlike the cattle and most of the domestic animals of North America-which cannot be traced or said to belong to any single distinct breed or family, having originated from the combination and amalgamation of many bloods and stocks, derived from many different countries-the blood-horse, or racer, of America stands alone, unquestionably of pure English thorough-blood.

What that English thorough-blood is, it is only necessary here to say that, although it is not possible, in every instance, to trace the great progenitors of the Euglish and American turf, directly on both sides, to Desert blood; and although it can scarcely be doubted that, in the very commencement of turf-breeding, there must hare been some mixture of the best old English blood, probably, in great part, Spanish by descent, with the true Arab or Barb race; jet the impure admixture is so exceedingly remote, not within fourteen or fifteen generations-since which the smallest taint has been carefully excluded-that the present race-horse of England or North 
America, cannot possess above one sixteen-thousandth part of any other blood than that of the Desert.

Nor can it be doubted, that the modern thorough-bred is far superior to the present horse of the East in his qualities

- and powers, as he is in size, bone, strength, and ability to carry weight. It is to this very superiority of our thoroughbred, which has been proved wherever it has encountered the Oriental horse, that it must be ascribed, that no late cross of Arab blood has, in the slightest degree, improved the Euro. pean or American racer.

It seems now to be a conceded point, that to improve any blood, the sire must be the superior animal; and, since by care, cultivation, superior food, and better management, our descendant of Desert blood has been developed into an animal superior to his progenitors, mares of the improved race can gain nothing by being crossed with the original stock; although it is yet to be seen, whether' something might not be effected by the importation of Oriental mares, and breeding them judiciously to modern thorough-bred stallions.

It has been already stated, that the first systematic attempts at improving the blood of the English horse began in the reign of King James I., was continued in that of Charles I. and during the Commonwealth, and adranced with renewed spirit on the restoration of the Stuarts. In the reign of Queen Anne, the last of that house who occupied the English throne, the English thorough-bred horse may be regarded as fairly estab. lished; the Darley Arabian, sire of Flying Childers, Curwen's Barb, and Lord Carlisle's Turk, sire of the Bald Gallowny, being imported in her reign. Sixteen years after her death, and three years before the settlement of Georgia, the youngest 
of the original American colonies, twenty-one foreign, and fifty native stallions, some of them the most celebrated horses which the world has ever seen, were in service as stock-getters in the United Kingdom; and from some of those are descended all our racers of the present day.

i It was precisely during this period that the Amcrican colonies were planted; and, as might be anticipated, English horses of pure blood were introduced at a very early date. Indeed, in those sections where the settlement was mainly effected by men attached to the Cavalier party, race-horses were kept and trained, race-courses were established, and a well-authenticated stock of thorough-bred animals, tracing to the most celebrated. English sires, many of which were imported in the early part of the eighteenth century, was in existence for some time before the outbreak of the old French war.

In the Eastern States, whose settlers were mainly attached to the Puritan party, and therefore opposed in an especial manner to horse-racing, very few horses of thorough blood were imported.

In Virginia and Maryland, as the head-quarters of the Caraliers, it is probable that racing commenced simultaneously, or nearly so; it being an attribute of the principal towns of Maryland some years prior to Braddock's defeat in 1753. In the latter State, indeed, it appears for some time to have been considered a part of the duty of the Governor to lieep a racing stud; since no less than five successive governors were all determined turfmen and supporters of the American racing interest.

As our Revolutionary War interrupted the peaceful progress of the country and the arocations of our country gentlemen at 
so early a period in the history of the American Turf, the difficulty of ascertaining how far records or registries hare been preserved, or were lept from the first, has been materially onhanced. Yet, on the whole, it may be regarded as remarkable rather that so many pedigrees can be unequivocally followed out, than that a few should be obscure and untraceable farther than to an imported mare. Indeed, it must be granted as a fact which cannot be questioned or doubted, fully established both by their own performances and by the unfailing transmission of their hereditary qualities, that our American horses are as certainly thorough-bred as are any of those English champions, whose blood no one ever dreams of disputing, which go back, like that of Eclipse himself, or many others of equal renown, to an unknown dam or sire.

From Virginia and Maryland, the racing spirit extended rapidly into the Carolinas, where it has nerer to this day flagged. The oldest race-courses in this country, which are yet kept up for purposes of sport, are the Newmarket course, near Petersburg, Virginia; and the Washington course, near Charleston, South Carolina. At Alexandria, 1). C., there was a race-course early in the last century, and the courses in the neighborhood of Richmoud have been in existence above seventy years.

It was not until about the commencement of the present century, that what may be called race-courses proper were established in New York; the first club for the promotion of the breed of horses by means of racing dating from 1804; although long previously the improvement of the breed of horses had created much interest in that State, celebrated stock-getters having been imported as early as 1764 and 1765 .

Into Pennsylvania, a State which has never particularly dis- 
tinguished itself in the racing turf, were brought at an early date two horses, Gray Northumberland (also called Irish Gray), and Old England; to these must be given the credit of running one of the oldest great American time-races on record, as long ago as 1767 , against two other horses, Selim and Granby.

Although the use of the horse for merely racing purposes does not at present obtain to as great an extent with us as in England-a circumstance which can be readily accounted for

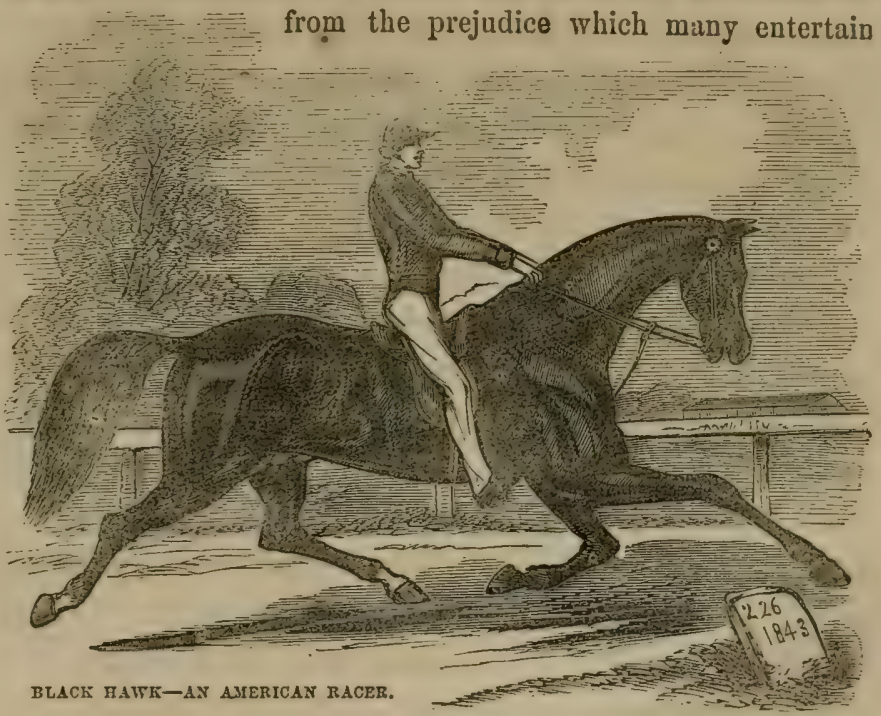

against such a use, owing to the objectionable accompaniments which are too often found in connection with it-still it should not be forgotten, that the advantage to be derived from the thorough-bred horse depends upon far more than his applicability to the turf and his fitness for racing purposes. Tere it otherwise, it would scarcely be worth. while to devote the space 
to the cousideration of this topic which has, by common con. sent, been deemed indispensable.

The truth is, that the race-course was not, in the beginning, so much as thought of as a scene for the display of the high qualities of this animal; much less was racing considered by our ancestors as an end for which they imported the Eastern horse into Europe. It was for the improvement of the native stock of horses in the various European Kingdoms, by giving to them speced and endurance,-in which respects no other breed can compare with them,- that the Asiatic and North-African horse was so eagerly sought by the monarchs, especially of England, during the seventeenth, and the early part of the eighteenth century.

The race-course was at first employed solely as a method of testing the prevalence or superiority, in certain animals or breeds of animals, of these qualities of speed and endurance, which can by no other known method be so completely, so accurately, and so fairly tested. Soon after the introduction of the thorough-bred horse, this process of testing his qualities grew into a farorite sport with all classes of persons in England. After the multiplication of race-courses throughout the king. dom and the establishment of racing as a national institution, the objects of the possessors and breeders of race-horses underwent a change : what had been a means originally, becoming eventually, more or less, the end. Horses, in a high form and of the most favorite and purest strains of blood, were eagerly sought and commanded large prices, for the purposes of sport and honorable competition, as was the case in the Olympic Games of ancient Greece.

At a yet later date, a second change of olject has taken 
place ; and, with but few exceptions, the thorough-bred horse is now kept. both in England and this country, for the paramount purpose of money-making, either by the actual winning of his prizes, or by his service in the stud, after his raciug career is ended.

Still, although the animals employed may be generally liept merely for the gratification of eupidity and the excitement of the contest, and though racing and race-courses may be subject to abuses by far too many, yet such means are, ercn now, as they were intended to be from the first, the best and only mode of really improving the general stock of any country. As the points of the tharough-bred horse are precisely those which constitute the perfection of a blood-horse in a high form as a stallion for improving the breed of animals, and for getting the best horses from any possible class of mares, for all possible uses, unless for the rery slowest and most ponderous draught, the description of those points which are most generally accepted as accurate is subjoined.

Purity of blood is an indispensable requisite for the thoroughbred horse. By the term "blood," it is not intended to be understood that there is any real difference between the blood of the thorough-bred horse and that of the half-bred animal, as no one could discriminate between the two by any known process. The term is here used in the same seuse as "breed," and by purity of blood is meant purity in the breeding of the individual animal under consideration; that is to say, that the horse which is entirely bred from any one source is pure, or free from any mixture with others, and may be a pure Suffolk Punch, or a pure Clydesdale, or a pure thorough-bred horse. All these terms are, however, comparative, since there is no such animai 
as a perfectly purely-bred horse of any brecd, whether cart-horse, hack, or race-horse; all have been produced from an admixture with other breeds, and though now kept as pure as possible, yet they were originally compounded of varying elements. As, however, the thorough.bred horse as he is called, has long been bred for racing purposes, and selections have been made with that view alone, it is reasonable to suppose that this breed is the best for that purpose, and that a stain of any other is a deviation from the classical stream into one more muddy, and therefore impure. Indeed, in actual practice this is found to be the case; for in every instance it has resulted that the horse bred with the slightest deviation from the sources indicated by the stud-book, is unable to compete in lasting power with those which are entirely of that breed. Hence it is established as a rule, that for racing purposes every horse must be thorough-bred; that is, bred of a sire and dam, whose names are found in the -stud-book.

The external form of the blood-horse is of great importance; it being true, other things being equal, that the horse will be the best runner which is formed in the mould most like that of the greatest number of good race-horses. Still, it is admitted on the turf, that high breeding is of more consequence than external shape, and that, of two horses, one perfect in shape but of an inferior strain of blood, and the other of the most winning blood, but in shape not so well formed, the latter will be the most likely to give satisfaction on the race-course. Hence originates the proverb, "an ounce of blood is worth a pound of bone." Yet, in spite of all this recognized superiority of blood, it is indisputable that for the highest degree of success there must be not only high purity of blood, and that 
of the most winning strains, but there must also be a frame of the most useful character, if not always of the most elegant form. Many of our very best horses have been plain and eren coarse-looking; but, in spite of their plainness, all their points were good and useful, and the deficiency was in mere elegance, not in real utility.

The height of the race-horse raries from fifteen hands to sixteen and a half hands, or even serenteen hands; but the general height of our best horses, is about fifteen hands and three inches. Fêw first-class performers have exceeded the height of sixteen hands and one inch. The average, above giren, may be fairly laid down as the best height for the race-horse; though it cannot be denied, that for some small and confined courses, a smaller horse, of little more than fifteen hands high, has a better chance, as being more capable of turning round the constantly recurring angles or bends.

The head and neck should be characterized by lightness, which is essential for this department. Whatever is unneces-

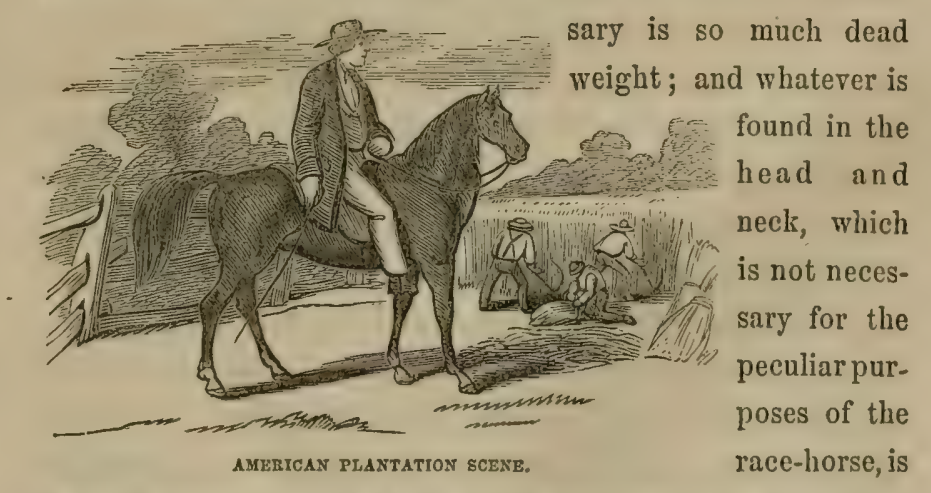

so much weight thrown away, which must still be carried by the horse. The head, we may say in detail, should be lean 
about the jaw, yet with a full development of forehead, which should be convex and wide, so as to contain within the skull a good volume of brain. If this fullness exist, all the rest of the head may be as fine as possible; the jaws being reduced to a fine muzzle, with a slight hollowing out in front, but with a width between the two sides of the laver jaw where it joins the neck, so as to allow plenty of room for the top of the windpipe when the neck is bent. The ears should be pricked and fine, but not too short; eyes full and spirited; nostrils large, and capable of being well dilated when at full speed, which is easily tested by the gallop, after which they ought to stand out firmly, and so as to show the internal lining fully. The neck should be muscular, and yet light; the windpipe loose and separate from the neck,- that is, not too tightly bound down by the membrane of the neck. The crest should be thin and wiry, not thick and loaded, as is often seen in coarse stallions, or even in some mares.

Between the two extremes of the ewe-neck and its opposite, there are many degrees, but for racing purposes the former is preferable of the two, to the latter; for few horses can go well with their necks bent so as to draw the chin to the bosom; yet here, as in other cases, the happy medium between the two extremes is the most desirable.

The body, or middle-piece, should be moderately long, and not too much confined between the last rib and the hip bone. So long as the last or back-ribs are deep, it is not of so much importance that they should be closely connected to the hipbone, for such a shape shortens the stride; and though it enables the horse to carry a great weight, yet it prevents him from attaining a high rate of speed. The back itself should 
be muscular, and the hips so wide as to allow of a good development of the muscular department. The withers may rise gently, but not too high, with that thin, razor-like elevation which many people call a good shoulder, but which really has nothing to do with that part, and is oniy an annoyance to the saddler, in preventing its being pinched by the saddle. The chest itself should be well developed, but not too wide and deep; no horse can go a good distance without a fair "bellows-room;" but, supposing the beast to be sound and of good quality, the amount of lungs will suffice which may be contained in a medium-sized chest, and all above that is wasted, and is extra weight. Many of our best-winded horses have had mediumsized chests, and some of the very worst have been furnished with room enough for a blacksmith's bellows to play in. If the heart only does its duty well, the lungs can always furnish sufficient air ; and we know that when frequently renewed, and with sufficient power, the blood is aerated as fast as it is propelled, and the chief difficulty lies in this power of propulsion, which resides in the heart alone. If the chest be too wide, it materially affects the action of the fore-leg's, and, therefore, in erery point of view, theoretically and practically, there is a happy medium between the too great contraction in this department, and the heary, wide, lumbering chests, sometimes seen eren in the thorough-bred race-horse, especially when reared upon rich succulent herbage, more fitted for the bullock than for the Eastern horse. In the formation of the hips, the essential point is length and breadth of bone for muscular attachment, and it matters little whether the croup droops a little, or is pretty straight and level, so that there is a good length from the hips to the haunch-bone the line between which 
two points may be either nearly horizontal, or forming a considerable angle with the ground; but still in both cases it should be a long line, and the longer it is the more muscular substance is attached to it, and the greater lererage will the muscles have.

The fore-quarter, consisting of the shoulder, upper and lower arm and leg and foot, should be well set on to the chest; and the shoulder-blade should lie obliquely on the side of that part, with a full development of muscle to move it, and thrust it well forward in the gallop. Obliquity is of the greatest importance, acting as a spring in taking off the shock of the gallop or leap, and also giving a longer attachment to the muscles, and in addition enabling them to act with more leverage upon the arm and leg. As the shoulder-blade does not reach the top of the withers, and as the bones forming that part have nothing to do with the shoulder itself, many high-withered horses have bad and weak shoulders, and some very upright ones; whilst, on the other hand, many low-withered horses have very oblique and powerful shoulders, and such as to give great facility and pliability to the fore extremity. The shoulder should be rery muscular, without being over-done or loaded, and so formed as to play freely in the action of the horse. The point of the shoulder which is the joint corresponding to the human shoulder, should be free from raggedness, but not too flat; a certain degree of development of the bony part is desirable, but more than this leads to defects, and impedes the action of this important part. The upper arm, between this joint and the elbow, should be long, and well clothed with muscles; the elbow set on quite straight, and not tied in to the chest; the lower arm muscular and long; linees broad and strong, with the bony projection 
behind well developed; legs flat, and showing a suspensory liga. ment large and free; pasterns long enough, without being weak; and the feet sound, and neither too large nor too small, and unattended with any degree of contraction, which is the bane of the thororgh-bred horse.

The hind-quarter is the chief agent in propulsion, and is therefore of the utmost consequence in attaining a high speed. It is often asserted that the oblique shoulder is the grand requisite in this object, and that it is the part upon which speed mainly depends, and in which it may be said to reside. This is, to some extent, true, because there can be no doubt that with a loaded shoulder high speed is impracticable; for, however powerfully the body may be propelled, yet when the fore-quarter touches the ground it does not bound off again as smartly as it ought to do, and the pace is consequently slow. The elastic shoulder, on the contrary, receives the resistance of the earth, but reacts upon it, and loses very little of the power given, by the strike of the hind-quarter, which, nevertheless, must be strong and quick, or else there is nothing for the shoulder to receive and transmit. For the full action of the hind-quarters, two things are necessary, viz: first, length and rolume of muscle; and, secondly, length of leverage, upon which that muscle may act. Hence, all the bones comprising the hind-quarter should be long, but the comparative length must vary a good deal, in order that the parts upon which the muscles lie may be long, rather than those connected with the tendons, which are mere ropes, and have no propelling power residing in them, but only transmit that which they derive from the muscles themselres. Thus, the hips should be long and wide, and the two upper divisions of the limb-viz., the stifle and 
lower thigh-should be long, strong, and fully developed. By this formation, the stifle-joint is brought well forward, and there is a considerable angle between these two divisions. The hock should be long and strong, free from gum or spavin, and the point long, and so set on as to be free from weakness at the situation of curb. In examining the hind-quarter, to judge of its muscular development, the horse should not be looked at sideways, but his tail should be raised, and it should be ascertained that the muscles of the two limbs meet together below the anus, which should in fact be well supported by them, and not left loose, and, as it were, in a deep and flaceid hollow. The outline of the outer part of the thigh should be full, and in ordinary horses the muscles should swell out beyond the level of the point of the hip. This fullness, however, is not often seen to such an extent in the thorough-bred horse, until he has arrived at mature age, and is taken out of training. The bones below the hock should be flat and free from adhesions: the ligaments and tendons fully developed, and standing out free from the bones; and the joints well formed and wide, yet without any diseased enlargement; the pasterns should be moderately long, and oblique; the bones of good size; and, lastly, the feet should correspond to those already alluded to in the anterior extremity.

These points, taken as a whole, should be in proportion to one another-that is to say, the formation of the horse should" be "true." He should not have long, well-dereloped hindquarters, with an upright, weak, or confined fore-quarter. Nor will the reverse of this answer the purpose; for, however wellformed the shoulder may be, the horse will not go well unless he, has a similar formation in the propeller. It is of great impor- 
tance, therefore, that the thorough-bred horse should have all his various points in true relative development, and, that there should not be the hind-quarter of a long, racing-like horse, with the thick, confined shoulder which would suit a stride less reaching in its nature.

The color of the thorough-bred horse is now generally bay, brown, or chestnut, one or the otler of which will occur in ninetynine cases out of a huudred; gray not being common, though it sometimes appears. Black, also, occasionally makes its appearance $_{\iota}$ but not more frequently than gray. Roans, duns, sorrels, etc., are now quite exploded, and the above five colors may be said to complete the list of colors seen in the race-horse. Sometimes these colors are mixed with a good deal of white, in the shape of blazes on the face, or white legs and feet; or even both may occur, and the horse may have little more than his body of a brown, bay, or chestuut. Most people, however, prefer the self-color, with as little white as possible; and nothing but the great success of a horse's stock would induce breeders to resort to him, if they were largely endowed with white. Gray hairs mixed in the coat, are rather approved than otherwise; but they do not amount to a roan, in which the gray hairs equal, or even more than that, the other colors mixed with them.

The texture of the coat and skin is a great proof of high. breeding, and, in the absence of the pedigree, would be highly regarded; but when that is satisfactory, it is of no use descending to the examination of an inferior proof; and, therefore, except as a sign of health, the skin is seldom considered. In all thorough-bred horses, however, it is thinner, and the hair more silky than in common breeds; and the veins are more apparent 
under the skin, partly from its thinness, but also from their extra size and number of branches. This network of veins is of importance in allowing the circulation to be carried on during high exertions, when, if the blood could not accumulate in them, it would often choke the deep vessels of the heart and lungs; but, by collecting on the surface, great relief is afforded, and the horse is able to maintain such a high and longcontinued speed, as would be impracticable without their help. Hence these points are not useful as a mere mark of breed, but as essential to the very purpose for which that breed was established.

The mane and tail should be silky, and not curly, though a slight wave is often seen. A decided curl is almost universally a mark of degradation, and shows a stain in the pedigree as clearly as any sign can do. Here, however, as in other cases, the clear tracing of that all-powerful proof of breeding, will upset all reasoning founded upon inferior data. The setting on of the tail is often regarded as of great importance, but it is chiefly with reference to appearances; for the horse is not dependent for action or power upon this appendage. Nor is strength of dock of any value as a sign, and many rery stout horses have been known with flaccid and loosely pendant tails.

It is well known that certain horses can run half a mile at high speed, but no more; others, a mile; others, again, a mile, and a half, or two miles; whilst another class, now less common than formerly, require a distance of three or four miles to develop their powers, as compared with ordinary horses. These peculiarities are generally hereditary, though not always so; but still, when the blood is known, it may generally be surmised, that the individual will, or will not, stay a distance. When the 
cross in question is stout on one side, and flashy on the other, it is not easy to guess to which the young scion may lean; but in those cases where a horse is bred from sire or dam, both of stout blood, or the reverse, the experienced hand may, in almost all cases, decide beforehand upon the qualities of the son or daughter, as far as staying qualities are concerned. Again, there are some horses of strong, compact frames, with short backs and strong quarters; who may be expected to climb a hill without difficulty, especially if of stout blood; and, again, there are others of lathy frames, with long but weak points, and a great deal of daylight under them, who mas win over the flat for a mile, or a mile and a quarter, but can never climb a hill, or get beyond the above distance over a flat. All these points should be carefully studied by the breeder in getting together his breeding stock, and by the owner in deciding how he will enter his young produce in the race.

In passing from the consideration of the history of the American Race-Horse to the examination of other races and types of this animal in general use in our country, it must be borne in mind, as before remarked, that the thorough-bred horse of America is the only family of the horse on this continent of pure and unmixed blood.

In the United States, and British America, the process of absorption, or abolition of all the old special breeds, and of the amalgamation of all into one general race, which may fairly be termed specially "American," possessing a very large admixture of thorough blood, has gone on far more rapidly than in England-the rather that, with the one solitary exception of the Norman horse in Cauada, no special breeds have ever taken 
root as such, or been bred, or even attempted to be bred in their purity, in any part of America.

In Canada East, the Norman horse, imported by the early settlers, was bred for many generations entirely unmixed; and, as the general agricultural horse of that province, exists so yet, stunted somewhat in size by the cold climate, and the rough usage to which he has been subjected for centuries, but in no wise degenerated; for he possesses all the honesty, courage, endurance, hardihood, soundness of constitution, and characteristic excellence of feet and legs of his progenitor. Throughout both the provinces, he may be regarded as the basic of the general horse, improved as a working animal by crosses of English half-bred sires; and as a rondster, carriage-horse, a higher class riding or driving horse, by an infusion of English thorough blood.

All these latter types are admirable animals; and it is from the latter admixture that have sprung many of the most celebrated trotting horses, which, originally of Canadian descent, have found their way into the New England States and New York, and there won their laurels as American trotters. Still, it is not to be denied, that there are in different sections of the United States, different local breeds of horses, apparently peculiar, and now become nearly indigenous to those localities, and that those breeds differ not a little, as well in qualities as in form and general appearance. A good judge of horse-flesh, for instance, will find little difficulty in selecting the dranghthorse of Boston, that is to say, of Massachusetts and Vermont, from those of New York and New Jersey, or any of the three from the large Pennsylvania team-horses, or from the general stock of the Western States. 
The Vermont draught-horse, and the great Pennsylvania horse, known as the Conestoga horse, appear in some considerable degree to merit the title of distinct families; inasmuch as they seem to reproduce themselves continually, and to have done so from a remote period, comparatively speaking, within certain regions of country, which have for many years been furnishing them in considerable numbers to those markets, for which their qualities render them most desirable.

With the linited information at present accessible as to the origin and derivation of these various families, nothing more can be done in the present work than to describe the characteristic points of the breeds in question; and, by comparison with existing foreign races, to approach conjecturally the blood from which they are derived, and also the manner in which they have been originated, where they are now found.

\section{THE VERMONT DRAUGHT-HORSE.}

No person familiar with the streets of New York zan have failed to notice the magnificent animals, for the most part dark bays, with black legs, manes, and tails, but a few browns, and now and then, but rarely, a deep, rich, glossy chestrut, which draw the heary wagons of the express companies in that city. They are the veryo model of what draught-horses should be; combining immense power with great quickness, a very respectable turn of speed, fine show, and good action.

These animals have almost invariably lofty crests, thin withers, and well set-on heads; and, although they are emphatically draught-horses, they have none of that shagginess of mane, tail, and fetlocks, which indicates a descent from the black horse of Lincolnshire, and none of that peculiar curliness or waviness 
which marks the existence of Canadian or Norman blood for many generations, and which is discoverable in the manes and tails of very many of the Morgan horses.

The peculiar characteristics of these horses are, however, the shortness of their backs, the roundness of their barrels, and the closeness of their ribbing-up. One would say, that they are ponies, until he comes to stand beside them, when he is as-

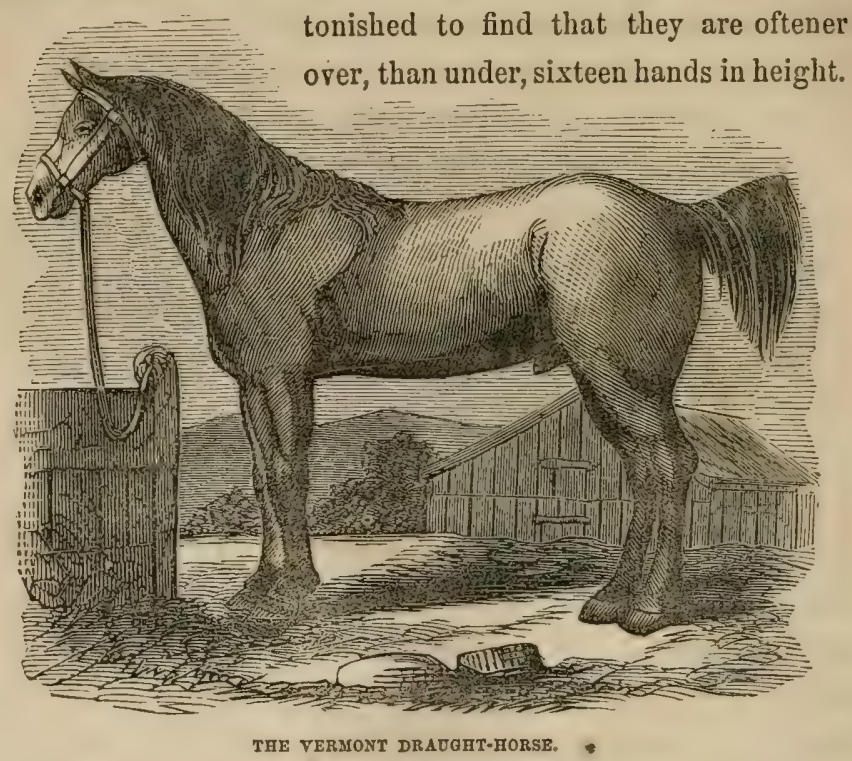

Nine out of ten of these horses are from Vermont; and not only are they the finest animals in all the United States, for tho quick dranght of heavy loads, but the mares of this stock are incomparably the likeliest, from which, by a well-chosen thorongh-bred sire, to raise the most magnificent carriage-horses in the world.

As to the source of this admirable stock of horses, it may be 
said, that the size, the action, the color, the comparative freedom from hair on the limbs, the straightness of the longer hairs of the mane and tail, and the quickness of movement, would at once lead one to suspect a large cross, perhaps the largest of any; on the original mixed country horse, of Clereland Bay. There are, however, some points in almost all of these horses, which must be referred to some other foreign cross than the Cleveland, not thorough bred, and certainly, as above remarked, not Norman or Canadian, of which these animals do not exhibit any characteristic. These points are, principally, the shortness of the back, the roundness of the barrel, the closeness of the ribbing-up, the general punchy or pony build of the animal, and its form and size, larger and more massively muscular than those of the Cleveland Bay, yet displaying fully as large, if not a larger, share of blood than belongs to that animal in its unmixed form.

The prevalent colors of this breed also appear to point to an origin different, in part, from that of the pure Cleveland Bays, which lean to the light or yellow bay variation, while these New Englanders tend as decidedly to the blood bay, if not to the brown bay, or pure brown. These latter are especially the dray-horse colors, and the points above specified are those, in a great measure, of the improved dray-horse. The cross of this blood in the present animal, if there be one, is doubtless very remote; and, whether it may have come from a single mixture of the dray stallion long since, or from some half-bred imported stallion, perhaps got by a three-part thorough bred and Clevelander from a dray mare, must, of course, be doubtful. One need have little hesitancy in asserting that the bay draught-horse of Vermont, has in its veins, principally 
Cleveland Bay blood, with some cross of thorough blood, one at least, directly or indirectly, of the inprored English drayhorse, and not impossibly a chance admixture of the Suffoll.

\section{THE CONESTOGA HORSE,}

In appearance this noble draught-horse approaches far more nearly to the improved light-class London dray-horse, and has little, if any, admixture of Cleveland Bay, and certainly none

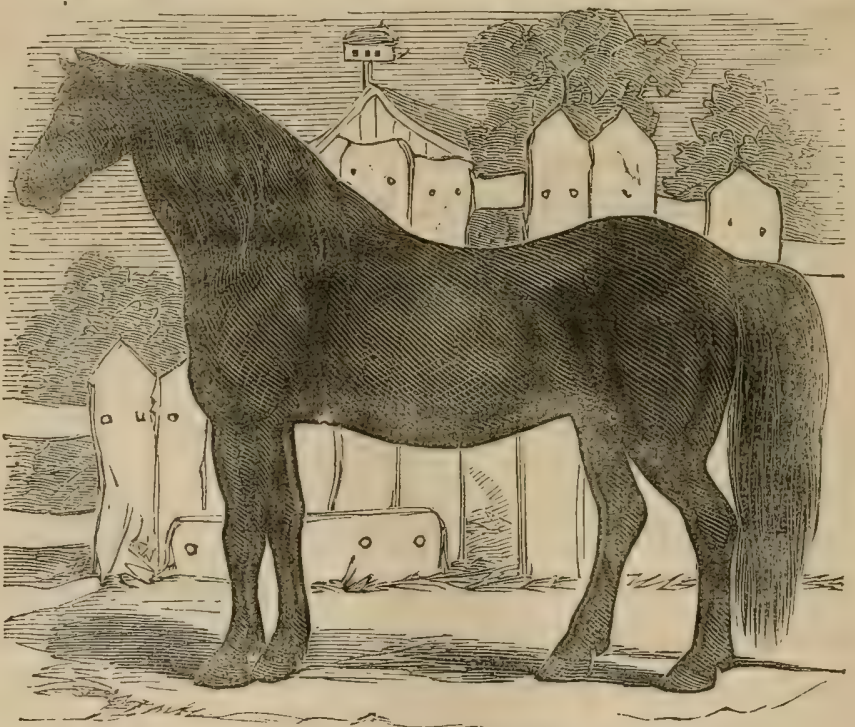

A CONESTOGA-THE GREAT PENNSTLVAXIA DRAUGHT-HORSE.

of thorough blood. $\mathrm{He}$ is a teamster, and a teamster only; fut a very noble, a very honest, and a moderately quick-working teamster. In size and power some of these great animals employed in draught upon the railroad track in Market street, Philadolphia, are little, if at all, inferior to the drayhorses of the best breweries and distilleries in London ; many 
of them coming fully up to the standard of seventeen or serenteen and a half hands in height.

In color, also, they follow the dray-horses; being more often blood-bays, brown, and dapple-grays than of any other shade. The bass and browns, moreover, are frequently dappled also in their quarters, which is decidedly a dray-horse characteristic and beauty; while it is, in some degree, a derogation to a borse pretending to much blood. This peculiarity is often obserrable also in the larger of the heary Vermont draught-horses, and is not unlinown in the light and speedy Morgan.

They hare the lofty crests, shaggy volumes of mane and tail, round buttocks, hairy fetlocks, and great round feet of the dray-horse; they are, howerer, longer in the back, finer in the shoulder, looser in.the loin, and perhaps, fatter in the side than their English antitypes. They do not run to the unwieldy superfluity of flesh, for which the dray-horse is unfortunately famous; they have a lighter and livelier carriage, a better step and action, and are, in all respects, better travelers, more active, generally useful, and superior animals.

They were for many years, before railroads took a part of the work off their broad and honest backs, the great carriers of produce and prorisions from the interior of Pennsylrania to the seaboard, or the market; and the vast white-topped-wagons, drawn by superb teams of the stately Conestogas, were a distinctire feature in the landscape of that great agricultural State. The lighter horses of this breed, were the general farmhorses of the country; and no one, who is familiar with the agricultural regions of that fine State, can fail to observe that the farm-horses generally, whether at the plough, or on the 
road, are of considerably more bulk and bone than those of New York, New Jersey, or the Western country.

Of the Conestoga horse, although it has long been known and distinguished by name as a separate family, nothing is positively authenticated, from the fact that such pedigrees have never been, in the least degree, attended to ; and, perhaps, no less from the different language spoken by the German farmers, anong whom this stock seems first to have obtained, and by whom principally it has been preserved. It would ap pear, however, most probable, taking into consideration the thrifty character, and apparently ample means of the early German settlers, their singular adherence to old customs and conservatism of old-country ideas, that they brought with them horses and cattle, such as Wouvermans, and Paul Potter painted; and introduced to the rich pastures of the Delaware and the Schuylkill, the same type of animals which had become famous in the similarly constituted lowlands of Flanders, Guelderland, and the United Provinces.

\section{THE CANADIAN HORSE.}

The Canadian is generally low-sized, rarely exceeding fifteer hands, and more often falling short of it. His characteristicz are a broad, open forehead; ears somewhat wide apart, and not unfrequently a basin face; the latter, perhaps, a trace of the far remote Spanish blood, said to exist in his veins; the origin of the improved Norman or Percheron stock, being, it is usually believed, a cross of the Spaniard, Barb by descent, with the old Norman war-horse.

His crest is lofty, and his demeanor proud and courageons. His breast is full and broad; his shoulder strong, though some- 
what straight, and a little inclined to be heary; his back broad, and his croup round, fleshy, and muscular. His ribs are not, however, so much arched, nor are they so well closed-up, as his general shape and build would lead one to expect. His legs and feet are admirable; the bone large and flat, and the sinews lig, and nerrous as steel-springs. His feet seem almost unconscious of disease. His fetlocks are shaggy; his mane roluminous and massive, not seldom, if untrained, falling on both sides of his neck; and his tail abundant; both having a peculiar crimpled wave, never seen in any horse which has not some strain of this blood.

He cannot be called a speedy horse in his pure state; but he is emphatically a quick one, an indefatigable, undaunted traveler, with the greatest endurance, day in and day out, allowing him to go his own pace-say from six to eight miles the hour-with a horse's load behind him, os an animal one can derice. He is extremely hardy, will thrive on any thing, or almost on nothing; is docile, though high-spirited, remarkably sure-footed on the worst ground, and has fine, high action, bending his knee roundly, and setting his foot squarely on the ground. As a farm-horse and ordinary farming roadster, there is no better or more honest animal; and, as one to cross with other breeds, whether upwards by the mares to thorough-bred stallions, or downwards by the stallions to common country mares of other breeds, he has hardly any equal.

From the upward cross, with the English or American thorough-bred on the sire's side, the Canadian has produced some of the fastest trotters and the best gentleman's road and saddlehorses in the country; and, on the other hand, the Canadian stallion, wherever he has been introduced, as he has been largely 
in the neighborhood of Skaneateles, and generally in the western part of the State of New York, is gaining more and more favor with the farmers, and is improving the style and stamina of the country stock. He is said, although small himself in stature, to have the unusual quality of breeding up in size with larger and loftier mares than himself, and to give the foals his own vigor, pluck, and iron constitution, with the frame and general aspect of their dams. This, it may be remarked in passing, appears to be a characteristic of the Barb blood above all others, and is a strong corroboration of the legend, which attributes to him an early Andalusian strain.

\section{THE INDIAN PONY.}

The various brecds of Indian ponies found in the West, generally appear to be the result of a cross between the Southern mustang, descended from the emancipated Spanish horses of the Southrest, and the smallest type of the Canadian, the proportions varying according to the localities in which they are found; those further to the South sharing more largely of the Spanish, and those to the North of the Normal blood.

These little animals, not exceeding thirteen hands in height, have, many of them, all the characteristics of the pure Canadians, and, except in size, are not to be distinguished from them. They have the same bold carriage, open countenance, abundant hair, almost resembling a lion's mane, the same general build, and, above all, the same iron feet and legs. They are merry goers, and over a hard and good road can spin along at nearly nine miles in the hour. They are distinguished for their wonderful sure-footedness, sagacity, and docility. They are driven without blinkers or bearing reins, 
and where, as is often the case, bridges seem doubtful, the bottom of miry fords suspicious of quagmires, or the road other. wise dangerous, they will put down their heads to examine, try the difficulty with their feet, and, when satisfied, will get through or over places which seem utterly impracticable.

Whence this peculiar pony breed of Canadians has arisen cannot with certainty be traced ; it seems, however, to be almost entirely peculiar to the Indian tribes, and, therefore, may have been produced by the dwarfing process, which will arise from hardship and privation, endured for generation after generation, particularly by the young animals and mares while heavy with foal. Most of these animals have no recent cross of the Spanish horse; althongh some ponies approaching nearly to the same type, show an evident cros of the Mustang; and many animals called Mustangs, have in them some unmistakable Canadian blood.

\section{THE NARRAGANSETT PACER.}

This beautiful animal, which, so far as can now be ascertained, has at present entirely ceased to exist, and concerning which the strangest legends and traditions are afloat, was, it may be asserted with comparative certainty, of Andalusian blood. The legends, to which allusion has been made, are two-fold; or, rather, there are two versions of the same legend; one saying, that the original stallion, whence the breed originated, was picked up at sea, swimming for his life, no one knew whence or thither, and, that he was so carried in by his salvors to the Providence Plantations; the other, evidently another form of the same story, stating that the same original progenitor was discovered running wild in the woods of Rhode Island. 
The question, however, thus far seems to be put at rest by the account of these animals, given in a note to the very curious work, "America Dissected," by the Rev. James McSparran. D.D., which is published as an appendix to the History of the Church of Narragansett, by Wilkins Updike. In this work, the Doctor twice mentions the pacing horse, which was evidently at that remote date, (1721-59,) an established breed in that province. "To remedy this," he says_- "this" being the great extent of the parishes in Virginia, of which he is at first spealing, and the distance which had to be traveled to church, - " as the whole province between the mountains, two hundred miles up, and the sea, is all a champaign and without stones, the gr have plenty of a small sort of horses, the best in the world, like the little Scotch Galloways; and 'tis no extraordinary journey to ride from sixty to seventy miles, or more, in a day. I have often, but upon large pacing horses, rode fifty, nay, sixty miles a day, even here in New England, where the roads are rough, stony, and uneven." Elsewhere he speaks more pointedly of the same breed. "The produce of this Colony," (Rhode Island,) "is principally butter and cheese, fat cattle, wool, and fine horses, which are exported to all parts of Englistr America. They are remarkable for fleetness and swift pacing, and I have seen some of them pace a mile in a little more than two minutes, and a good deal less than three."

If the worthy doctor of divinity was a good judge of pace, and had a good timing watch, it would seem that the wonderful me of our fleetest racers was equaled, if not outdone, upwards of a century ago ; at all events, he establishes, beyond a peradrenture, the existence of the family, and its unequaled powers both of speed and endurance. 
To the latter extract is attached a lengthy note, a portion of which we gire. "The breed of horses, called 'Narragansett Pacers,' once so celebrated for fleetness, endurance, and speed, Las become extinct. These horses were highly valued for the saddle, and transported the rider with great pleasantness and sureness of foot. The pure blood could not trot at all. Formerly, they had pace races. Little Neck Beach, in South Kingston, one mile in length, was the race-course. A silver tankard was the prize, and high bets were otherwise made on the sperd. Some of these prize tankards were remaining a few years ago. Traditions respecting the swiftness of these horses are almost incredible. Watson, in his 'Historical Tales of Olden Times,' says: 'In olden time, the horses most valued were pacers, now so odious deemed. To this end the breed was propagated with care. The Narragansett pacers were in such repute, that they were sent for, at much trouble and expense, by some who were choice in their selections.'"

The most natural reason assignable for the extinction of this breed, would seem to be somewhat as follows. Up to the beginning of the present century in this country,-much as it was half a century yet farther back in Englawd,- the roads were so bad, as to be, except in the finest weather, utterly impracticable for wheel-carriages; and that, except on the great turnpike-roads, and if the immediate vicinity of the larger towns, private pleasure-rehicles were almost unknown; all long jous. neys, with few exceptions, all excursions for pleasure or for ordinary business, and all visitings between friends and neighbors being performed by both sexes on the saddle. At that time there was, therefore, a demand, as an actual necessity, ror speedy, anch abore all, for easy and pleasant-going saddle-horses. 
Pacers, whenever they could be found, would most readily ansiver the desired end.

The expense of this was, of course, considerable, since the pacer could not be used for any other purpose; when, therefore, the roads improved, in proportion to the improvement of the country and the general increase of the population, wheelcarriages generally came into use, and the draught-horse took the place of the saddle-horse. It was soon found that a horse could not be kept even tolerably fit for the saddle, if he was allowed to work in the plough or draw the team, while the same labor in no wise detracted from the chaise or carriagehorse. The pacer, therefore, gave way to the trotter; and the riding-horse, from being an article of necessity, became exclusively one of luxury; to such a degree, that, until comparatirely a recent period, when ladies began again to take up riding, there have been rery few distinctively broken ridinghorses, and still fewer kept exclusively as such in the Northern States of America.

This, unquestionably, is the cause of the extinction of the pacer, although there have been pacing-horses in the eastern section of this country, professedly from Rhode Island, and called by names implying a Narragansett origin; and although it may well be that they were from that region, and possibly, in a remote degree, from that blood, yet they did not pace naturally because they were Narragansett Pacers, but were so called, because coming somewhere from that region of country, they paced by accident_as many chance horses do-or, in some instances, had been taught to pace.

Considering the rare qualities of this variety, and its ad. mirable adaptedness for many purposes of pleasure and conve- 
nience, it is a matter for real regret that the family has entirely disappeared, presumably without any prospect or hope of its resuscitation.

THE MORGAN HORSE.

Within a few years past the sporting world have become familiar with a class or type of horses coming from the State of Vermont, known as the Morgan horse; in behalf of which a claim has been made, that it is a distinct family, directly descended from a single horse, owned a little

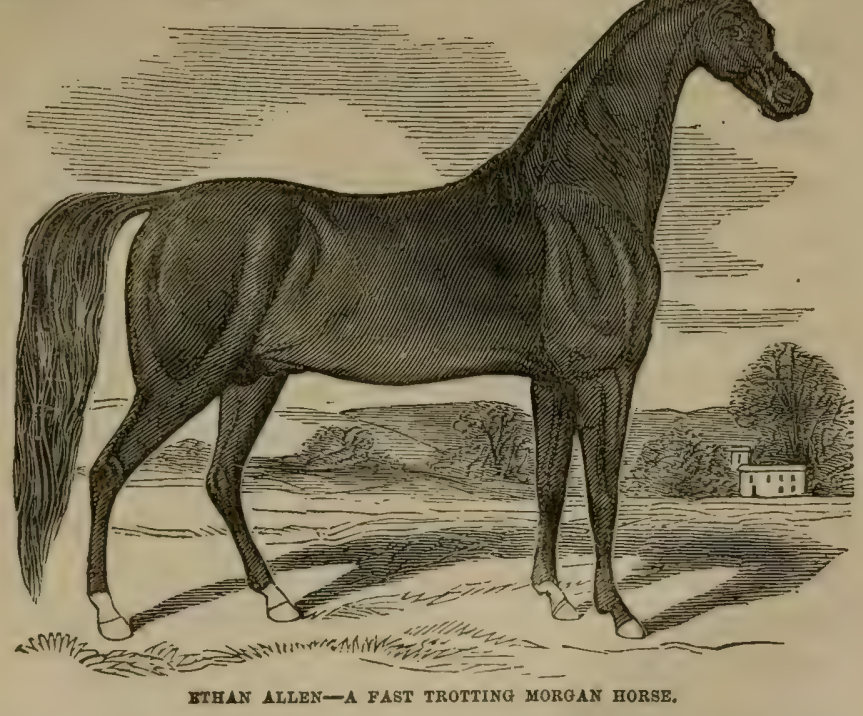

before and a little after the commencement of the present century, by Justin Morgan, of Randolph, in Vermont, from whom the name takes its rise.

Without choosing to go into an examination of the validity of this claim-relative to which question an amount of bickering, crimination and recrimiuation has sprung up, sufficient to 
furnish the stock in trade of all our stump orators for the next fifty Presidential campaigns-we content ourselves here with alluding to the strong points and excellencies of this particular rariety, (for such the most sturdy opponents to its rank as a distinct family freely admit that it possesses, referring the reader, who is curious in such matters, to the appropriate treatises for and against the claim, which hare been as voluminous as the most prolix of Presidential messages.

"The original, a 'Justin Morgan'"-we now quote from "Morgan Horses," by D. C. Linsley-" was about fourteen hands high, and weighed abont nine hundred and fifty pounds. His color was dark-bay, with black legs, mane, and tail. He had no white hairs upon him. His mane and tail were coarse and heary, but not so massive as has been sometimes described; the hair of both was straight, and not inclined to curl. IIis head was good, not extremely small, but lean and bony, the face straight, forehead broad, ears small and rery fine, but set rather wide apart. His eyes were medium size, very dark and prominent, and showed no white around the edge of the lid. His nostrils were very large, the muzzle small, and the lips close and firm. His back and legs were, perhaps, his most noticeable points. The former was very short; the shoulder-blades and thigh-bones being very long and oblique, and the loins exceedingly broad and muscular. His body was rather long, round and deep, close-ribbed up; chest deep and wide, with the breastbone projecting a good deal in front. His legs were short, close-jointed, thin, but very wide, hard and free from meat, with muscles that were remarkably large for a horse of his size; and this superabundance of muscle manifested itself at every step. His hair was short, and at almost all seasous short and glossy. 
He had a little long hair about the fetlocks, and for two or three inches above the fetlock, on the back-side of the legs; the rest of his limbs were entirely free from it. His feet were small, but well-shaped; and he was in erery respect perfectly sound and free from blemish. He was a very fast walker. In trotting, his gait was low and smooth, and his step short and nervous; he was not what in these days would be called fast, and we think it doubtful whether he could trot a mile much, if any, within four minntes, although it is claimed by many that he could trot in three.

"Although he raised his feet but little, he nerer stumbled. His proud, bold, and fearless style of movement, and his vigorous, untiring action bave, perhaps, never been surpassed. * * * * * * He was a fleet runner at short distances. Running short distances for small stakes, was very common in Vermont fifty jears ago. Eighty rods was very generally the length of the course which usually commenced at a tavern or grocery, and extended the distance agreed upon up or down the public road. In these races the horses were started from a scratch; that is, a mark was drawn across the road in the dirt, and the horses, ranged in a row upon it, went off at the dropping of a hat, or some other signal.

"It will be observed that the form of Justin Morgan was not such as, in our days, is thought best calculated to give the greatest speed for a short distance. Those who believe in longlegged racers will think his legs, body, and stride, were all too short, and to them it may, perhaps, seem surprising that he should be successful, as he invariably was, in such contests."

The qualities claimed for this stock are neat style, good trotting action, great honesty, great quickness and sprightliness 
of movement,-apart from extraordinary speed, which is not insisted upon as a characteristic of the breed, although some have possessed it-and considerable powers of endurance. There has been some conflict of opinion concerning the courage and endurance of the Morgans, and their ability to maintain a good stroke of speed, say ten miles an hour, for several hours in succession; but it is now well established that this exception has not been fairly taken, and that these horses lack neither courage nor ability to persevere, though not at a high rate of speed.

By fair deduction from the various conflicting accounts of the Morgans, as they now exist, it may be stated that they are a small, compact, active style of horse, showing the evidence of a strain of good blood. They rarely, if ever, exceed fifteen hands two inches, and it is probable that a hand lower, or from that up to fifteen, is nearer to their standard. They are not particularly closely ribbed up, and many of them incline to be sway-backed. Their hind-quarters are generally powerful, and their legs and feet good. There is an evident family resemblance in their foreheads, their neck and crests being so often, as to render the mark somewhat characteristic, lofty but erect, without much curvature, and the neck apt to be thick at the setting-on of the head, which, though good, is rarely blood-like. The manes and tails are almost invariably coarse, as well as heavy and abundant, and have very often a strong wave, or even curl, of the hair.

It is admitted by the most strenuous opponents of this horse as a distinct family, that the very best general stock for breeding for general work-namely, a high cross of the very hest thorough-bred on the sires side, with the very best general stock 
on the dam's-is to be found, so far as the Uuited States are coucerned, on the frontiers of Vermont, and that of the most approved quality.

Having given the history of the various types or families of the horse throughout the world, we next propose taking up

THE NATURAL HISTORY OF THE HORSE.

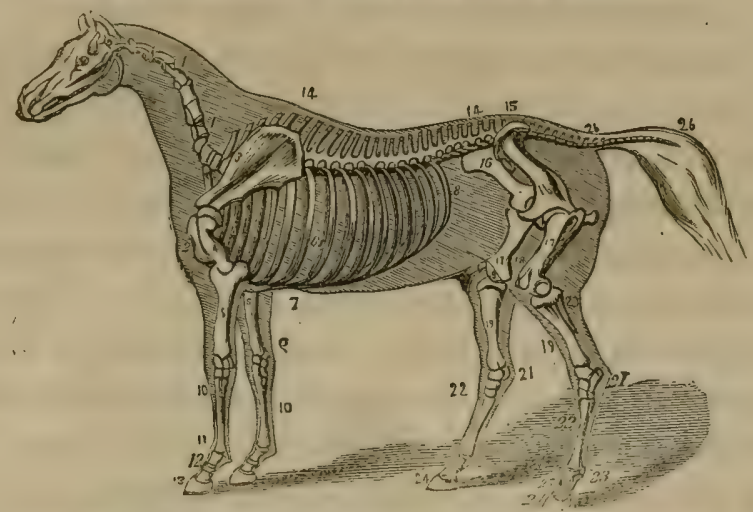

SKELETON OF THE HORSE AS COVERED BY THE MUSCLES.

1. 1. The seven cervical vertebra, or bones of the neck. 2. The sternum, or breastboye. 3. The scapula, or shoulder-blade. 4. The humerus, or bone of the arm. 5, 5. The radius, or bone of the fore-arm. 6. The ulna, or elbow. 7. The cartilages of the ribs. $8,8,8$. The costr, or ribs. 9. The carpus, or seven bones. 10, 10. The metacarpal, or shank-bones: the larger metacarpal, or cannon, or shank-bone, in frout; and the small metacarpal, or splint-bone, behind. 11. The upper pastern. 12. The lower pastern. 13. The coffin-bone. 1t to 14. The eighteen dorsal vertebræ, or bones of the spine. 15. The six lumbar vertebræ, or bones of the loins, 16, 16. The haunch, consisting of the llium, the ischium, and the pubis. 17, 17. The femar, or thigh-bone. 18, 18. The stifle-joint, with the patella, or knee-cap. 19, 19. The tibia, or proper leg-bone. 20. The fibula. 21, 21. The tarsus, or hock. 22. The metatarsal bones of the hind-leg. 23, 23. The pastern of the hind-feet, including the upper and larger bone, (fig. 23,) the lower pasteru, (fig. 25,) and the coflin-bone. (fig. 21.) 26, 26. The caudal vertebrx, or tail-bones.

Division. Vertebrata-possessing a back-bone.

CuAss. Mammalia-such as give suck.

OrDER: Pachydermata-thick-skinned. 
FAMILY. Solipeda-uncleft-footed.

Genus. Equus-the horse family.

With the horse are ranked all those quadrupeds, whose generic distinction is the undivided hoof-the equine genus.

Equus caballus, the horse.

Equus Hemionus, the dziggtai, Asiatic.

Equus Zebra, the zebra,

Equus Burchelli, South African.

Equus Quagga, the Quagga,

Equus Asinus, the ass.

0

The horse by far the noblest of the genus, is easily distin. guishable from the rest of the group. His varieties are exceed ingly numerous, and differ widely in physical appearance. The effects of climate and other agencies are displayed in his frame. It has been asserted, though not upon sufficient basis, that he arrives at the greatest perfection between the fifteenth and fiftyfifth degrees of northern latitude. The mare is found capable of generating her species as early as the second year of her existence; but it is detrimental to her form and the future energies of her offspring, thus prematurely to tax the productive powers of her frame. It would be far more profitable to delay this important function to the fourth or fifth year, when the outline of her form approximates more closely to that of the adult, and the vital energies of the animal economy become more confirmed. Mares, in common with the females of many other quadrupeds, are subject to a periodical appetency for the male, which in them is termed horsing. The natural season of its first occurrence is from the end of March to July, and so providential is this arrangement, that the foal will be produced at a time when nourishment is plentiful for its support. 
Common assertion fixes the period of gestation, or the timse intervening between conception and foaling, at eleven months; whether lunar or calendar, is not explained. This discrepancy will appear the more unsatisfactory, when it is recollected thas eleren calendar months want but two days of twelve luna months. By various investigations made in France, it has been established that the term of eleven calendar months was often exceeded by several weeks; and sometimes, though less frequently, parturition took place within that period. Some breeders entertain an opinion, that old brood-mares carry the foal considerably longer than young ones; but no satisfactory evidence is offered by them in support of this opinion.

The indications of approaching parturition are enlargement of the external parts of generation, and a gummy exudation from the orifice of the teats. Birth generally takes place within twenty-four hours after the appearance of the latter symptom; but the first acts as a warning, by preceding it for several days. It is but seldom that the mare requires manual assistance at the time of foaling, which generally takes place, without difficulty or danger in the night. The mare, unlike the generality of quadrupeds, foals standing. She rarely produces twins, and when double births do occur, the offspring almost invariably die.

As great facility of motion appears to have been designed by nature in the formation of the horse, many physical peculiarities contribute to insure that end. A bulky, pendulous udder, like that possessed by some of the ruminantia, would be incompatible with that quality. The mamma, therefore, is small, and furnished with only two teats, which supply a milk of a highly 
nutritious character, and possessing a larger quantity of saccha. rine matter than any other animal is known to possess.

The disproportionate length of the foal's legs, which is so strikingly apparent, when compared with those of the adult animal, is thought by some naturalists to be provided by prescient nature to enable the young animal to keep pace with its dam during flight from any menacing danger. Linnaeus attempted to ascertain the future height of the colt by admeasurement of its legs; but so much is found to depend upon the quantity and character of the nutriment with which it is provided during the period of its growth, that little reliance can be placed upon early experiments of this kind. The historian, the warrior, and the horseman, Xenophon, has long ago alluded to the same subject in his treatise upon horsemanship. "I now explain," said he, "how a man may run the least risk of being deceived, when conjecturing the future height of a horse. The young horse, which, when foaled, has the shankbone the longest, invariably turns out the largest. For, as time advances, the shank-bones of all quadrupeds increase but little; but that the rest of the body may be symmetrical, it increases in proportion."

Puberty commences in both sexes as early as the second year, but all the structures continue to be gradually dereloped until the end of the fifth year, by which time the changes in the teeth are perfected, and the muscles have acquired a growth and tone which give to the form the distinctives of adolescence. It is during the term which elapses between the period of adult age and that of confirmed virility, that a further progressive change takes place in the animal economy; the powers of the whole frame continue to acquire strength, and although there is no 
further increase in height, the parietes of the large cavities and the muscles of voluntary motion assume a finished and rotund appearance, and render the animal more capable of enduring continued privation and exertion; the vital endurance and resistance being greater than during the period of adolescence. The fire and expression of the head, the spirit, character, and disposition, become also more marked toward the termination of this epoch.

The natural period of the decay of the vital powers, senility, and mature death, may be conjectured to be about thirty years; but few horses, owing to our barbarous treatment, attain that term.

The walk, the trot, and the gallop are the usually well-known natural paces of the horse; lut the fact of some individuals contracting the pace called amble (which is neither racking or pacing), without previous tuition, has induced many writers to regard that also as a natural method of progression.

In England, and other northern countries, on the approach of mild weather, the horse, by a natural process, analogous to moulting in birds, divests himself of his winter's clothing of long hair, and produces one of a shorter and cooler texture; and again, before the recurrence of cold weather, reassumes his warm and lengthened coat to protect himself from the inclemency of the approaching season. The autumnal cliange is not by any means so general as that which takes place at the commencement of spring; in America, however, at least in the northern parts, this change is invariable. The hair is not so completely changed; only a portion of it is thrown off, and that which remains, with that which springs up, grows long, and is adapted to the temperature of the atmosphere. These alternate clauges 
are not so well marked in countries possessing an even temperature, nor even are they so plainly seen in horses lept in the warm atmosphere of a close stable all the year round. When the shedding of the coat commences, the bulbs of the old hair become pale, and by the side of each a small black globular body is formed, which is soon developed into the new hair. Thus the matrix of the new hair is not the old bulb, but it is based in another productive follicle. The long hair of the mane, tail, and fetlocks is not shed at definite periods with that of the body, but is replaced by a shorter and more uniform process. The hair of the mane and tail will, if protected, grow to an almost incredible length.

The property of changing the color of the hair with the season, possessed by many animals of the arctic region, adapting them to the temperature, is also manifested in the horse, though in a much less degree, for it may be seen that when constantly cxposed to the elements, the long winter-coat assumes a much lighter hue than that of its predecessor.

The horse in common with many other animals, is provided with a thin, sub-cuticular muscle, covering the shoulders, flanks, and sides, whose use is to corrugate the skin, shake off tlies, and dislodge other annoying substances.

The sense of smell is so delicately acute in the horse, that perhaps he is not exceeded in this function by any other animal. The nose is provided with a very extensive surface for the distribution of the olfactory nerve, by the curious foldings of the turbinated bones. It is principally by means of this faculty that he is enabled to distinguish the qualities of the plants upon which he feeds, and to reject such as are of a noxious or poison. ous description. "Nature," said Linnæus, "teaches the brute 
creation to distinguish, without a preceptor, the useful from the hurtful, while man is left to his own inquiries." On putting the finger into the nostrils, at the upper and outward parts, they pass into blind pouches of considerable dimensions. These curious cavities have nothing to do with smelling, because they are lined with a reflection of common integument, but they may possibly be of use in mechanically distending the external entrance of the nostrils, and thus materially facilitate respiration during violent exertion. They are also brought into use when the animal neighs $;$ and the Hungarian soldiery slit them up, to preclude the possibility of being prematurely discovered to the enemy by the exercise of this habit. It is worthy of remark, in this connection, that the preference of Arabs for the mare to the horse, for warlike purposes, is attributable to the fact that they do not neigh when they scent the vicinity of other horses, as stallions invariably do-the Arabs never attacking, save by surprise. Those nations which fight by open force lave no such preference, but mainly use the stallion. On the lower part of the nostril, toward the outer edge, may be seen the mouth of a small tube, which conveys the tears from the inner canthus, or corner of the eye. It opens on the skin just before it joins the lining membrane of the nose. This little cavity has often been mistaken, by unqualified persons, for an ulcer common in glanderous affections, and the poor animal has frequently fallen victim to the error.

Their eyes are large in proportion to those of some other quadrupeds, and the pupilar opening is of an oblate elliptic form, with its long axes parallel to the horizon, thus increasing the lateral field of vision. Round the edges of the pupil is a curious fringe of deep plum-colored eminences, supposed to be 
serviceable in absorbing the superabundant rays of light which may be transmitted to the eye. The horse's sight is excellent, and, although not regarded as a nocturnal animal, he can distinguish objects at night with great facility. There are but few horsemen, who hare not benefited by this power, when tha shades of night have fallen round them.

The ears are comparatively small, but the conch is endowed with extensive motion, so as to catch the sound coming from

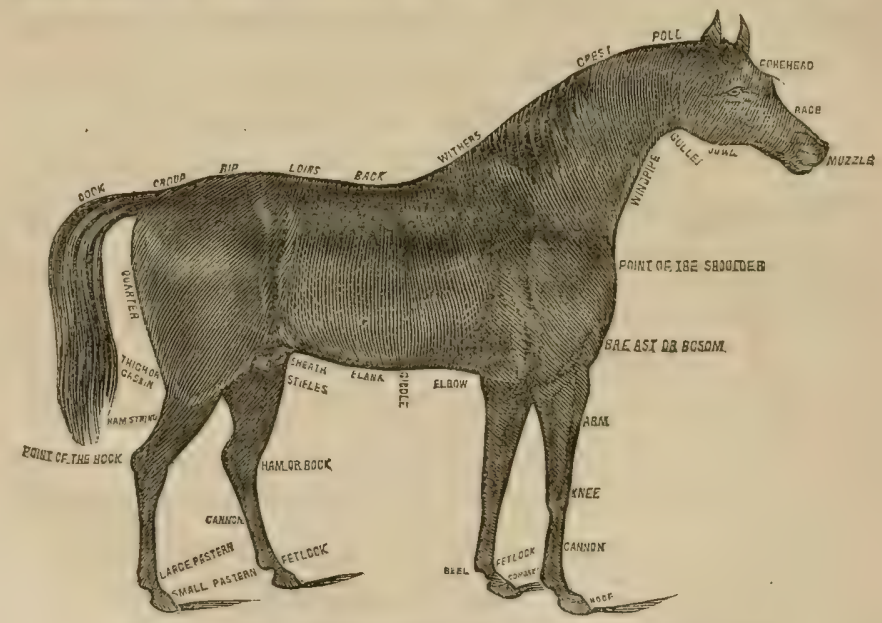

NAMES APPLIED TO THE VARTOUS EXTERNAL PARTS OF THE HORSE.

any quarter. Their hearing is quick, and although blindness is so distinctively prevalent among horses, deafness is exccedingly uncommon. During sleep, one ear is usually directed forward, and the other backward; when on a march at night, in company, it has been noticed "that those in the front direct their cars forward, those in the rear backward, and those in the centre turn them laterally, or across; the whole troop seeming thus to be actuated by one feeling, which watches the general 
safety." In contests of speed the ears are generally laid back" wards, so as to afford no opposition to the rapid progress of the animal. It must be evident, that if the concave surfaces of these organs be presented forward, they would gather the wind, and slightly impede progression. Another reason assigned for this deflection, is that the animal may aroid the inconrenience, if not pain, which the current of air, produced by his velocity, would inflict on that delicate organ.

The different rocal articulations to which the horse gives utterance, are collectively termed neighing; but some rariety of intonation may be discovered in the expression of its passions; as, for instance, the cry of joy or recognition differs in a marked manner from that of desire; and anger from playfulness. The females do not neigh so frequently, nor with so much force as the males. Castration is known to have a modulating effect upou the roice. It is supposed that neighing is produced by the ribration of two small triangular membranes found at the extremity of the glottis. In the ass and mule, this structure is wanting; but they are provided with a more singurar apparatus. Hollowed out of the thyroid cartilages is a small concarity, orer which is stretched a membrane, similar to the parchment on the head of a drum. Tihen air is forced behind this substance, a very considerable noise is produced, though from the absence of muscularity the vibrations are without modulation, and consequently dissonant.

The intellectual character of the horse is scarcely excelled by that of any other quadruped. His perceptions are remarkably clear, and his memory excellent. Attachment to those who tend him with kindness, forms a prominent trait in his cháracter. The feats which he is often taught to perform, erince a bigh 
intellectual capacity. Travelers in the desert assure us that horses possess the faculty of directing their course to the nearest water, when hard pressed for that necessary article.

Horses swim with the greatest facility, and the distances they have been known to perform in the water exceed our expectation. A horse that was wrecked off the coast of South America swam seven miles to land, thus saving his life.

There exist, some important differences in the animal conomy of the equine family and that of other herbivorous 'nimals, which, as the inferences from them are of some conse'fuonce, it is necessary briefly to notice. The horse naturally requires but little sleep, and even that it often takes standing. In a state of nature, when fodder is short, to support itself properly it is compelled to graze twenty hours out of the twenty-fix. Ruminating animals eat with greater rapidity, and lie down to chew the cud. The horse eats no faster than it digests. Digestion in the former is interrupted; in the latter, continuous. This explains why the horse has no gall-bladder, as it requires no reservoir for that necessary fluid; for, as fast as the bile is secreted by the liver it is carried to the intestines to perform its important action on the chymous mass. The stomach of the horse is also remarkably small and simple, differing widely from the capacious and complicated structures of the ruminantia; but the intestines are long, and the coecum capable of containing a large quantity of fluid, of which it is considered the receptacle. The mamma of the mare is by no means so pendulous and bulky as that of the cow. The horse's feet, from their compact, undivicied nature, are much less liable to injury during fleet exertion than those of the ox. All these circumstances tend to establish the individuality of the horse, 
and are so many proofs of admirable design for the purposes to which man has applied him; for, without these peculiarities, he would not be so valuable and superior, as a beast of continued and rapid motion, and would consequently occupy a very inferior station.

Linneus asserted that the male horse was without the rudimentary mamma in rariably found in the males of other animals; but this naturalist was mistaken, for they may be seen on each side of the sheath, and, although of no possible use, still their existence preserves the uniformity of nature's operations.

The horse and zebra possess horny callosities on the inside of the fore-legs, above the knees, and on the hocks of the hindlegs; the ass and the quagga have them only on the fore extremities.

In a state of nature, the horse is purely a herbirorous animal, but under the restraint which domestication imposes, his habits become changed, and grain and dry grasses form the principal articles of his diet. Domestication is known to uriginate many diseases totally unknown in a natural state, but it appears to have the effect of augmenting the muscular power of the animal far beyond its uncultivated state.

It may be remarked, in addition to what has been preriously said as to the limit of lifc allotted to the horse, that there is some difficulty in estimating the natural average length of his life, since many obstacles oppose an inquiry on a scale of sufficient magnitude to be satisfactory. The numerous evils entailed on him by the arduous labors and the $r$ stricted and unnatural habits of a domesticated state tend gr satly to abbreviate life. From these and other reasons. it cannot be much doubted that his age is greatly underrated. Horses are most erroneously termed 
aged on the obliteration of the mark from the lower incisor tecth, which occurs by the completion of the eighth year; and though it is far from being the natural term of age and debility, or eren of the decline of the vital energies, it too frequently happens, that by that time bodily infirmities have been prema. turely induced by over-exertion of their powers. Horses at twenty years of age, are often met with in cases where the least humanity has been bestowed on their management. Eclipse died at the age of twenty-five; Flying Childers, at twenty-six: Brom's mare Maggie reached more than twenty-nine years. Bucephalus, the cclebrated horse of Alexander of Macedon, lived till thirty. The natural age is probably between twentyfive and thirty. A faint and uncertain guide is found in the register of the ages of the most celebrated racing stallions, recollecting, however, that several of them were destroyed on becoming useless for the purposes of the turf. The united ages of ninety-three of these horses amounted to two thousand and five years; or rather more than twenty-one and a half years to each horse.

As a matter of ciril economy, it is important to judge correctly of the age of the horse. This is chiefly accomplished by observing the natural changes which cecur in his teeth, the periods at which they appear, are shed a.d replaced, and the alterations in their form and markings.

The teeth of most animals offer some criterion by which their age can be estimated with more or less accuracy. The teeth are nearly the sole indices of t $c$ age of the horse, ass, elephant, eamel, dog, and the polled varisties of the ox and sheep; while in other domesticated animals, as the elk, deer, goat, common 
$o x$ and sheep, the horns also present legible indications of the progress of time.

Reference to the teeth to ascertain the age of the horse is not by any means of recent origin. Xenophon, in his work on horsemanship, from which we have already quoted, alludes to it as an established custom used in the selection of cavalry for the Grecian armies; he properly advised the rejection of such horses as have lost the dental mark. The same facts are sub. sequently noticed by Varro, Columella, Vegetius, and other Roman writers.

The horse, when full-mouthed, possesses forty teeth-iwenty in each jaw. They are named from their use, position, and character. Those in the front of the mouth, whose office it is to gather food when grazing, are termed incisors, or, more pro. perly, nippers. They are twelve in number; six above, and six below. They do not orerlap each uther, as is the case in man, but meet in a broad tabular surface. From these teeth the age of the animal is principally decuced. For the sake of description, they are usually ranged in pairs, as they appear; and the first pair is called the central, the second the dividers, and the third the corner nippers. The tushes, or canines, come next; one above, and one below on each side. They are of a pointed form, and are convex on the outer sides, and slightly concave on the inner surface. They scarcely ever appear above the gums in mares, although their rudiments may be discovered on dissection, imbedded in the maxillary bones. They are consequently regarded as sexual distinctions. It is difficalt to assign their use ; their position precludes the possibility of their being used as weapons of offense or defense. They may be viewed as a link of uniformity so commonly 
traced in the animated world. The grinders, or molars, are twenty-four in number. They are teeth of great power. By them the food is crushed or ground into small particles, and prepared for the digestive action of the stomach. In order to fit them for this office, they possess additional interlayers of enamel, which prevent their too rapid wear.

In common with most animals, the horse is provided with two sets of teeth; those appearing first are known as the temporary, deciduous, or milk teeth, and are succeeded by the permanent set. On comparing the different magnitudes of the jaw-bones of the colt and the adult horse, the necessity of such a change is at once apparent. By it the teeth are adapted to the size of the maxillary bones. The teeth, from their peculiar character and mode of growth, do not admit of any material increase of dimension; and nature was therefore forced either to place the large permanent teeth in small and disproportionate jaw-bones, or to adapt the size of the teeth by displacement to the growth of the bones that contained them. The latter process is adopted, and constitutes one of those remarkable eridences of creative power, with which the living frame is replete.

Three substances enter into the structure of the teeth; first the enamel; secondly, the dental bone, or ivory; and thirdly, a cortical envelope, surrounding the fang. The enamel differs but little in chemical constitution from the bony body of the teeth; and that principally results from the absence of animal matter in it. It appears closely analogous to the univalve porcellaneous shells, and is the bardest and most indestructible substance of the body. The dental bone is distinctly tubular in structure; these tubuli taking a perpendicular direction, 
being exceedingly small, but capable of absorbing ink by capillary attraction. No such tubuli have been traced in the enamel. The teeth, both incisors and grinders, are being constantly worn away at the crown; but the loss is supplied by hlie gradual, continuous, and equivalent growth from the root. The horse's; teeth are sometimes, but not frequently, subject to disease. It is seldom that any of them are lost from age, as is the case with man, and most other animals.

It has been remarked, that the constitution of horses and men may be considered as in an equal degree of perfection and capability of exertion, or of debility and decay, according: as youth or age preponderates. Thus, the first five years of a horse may be considered as equivalent to the first twenty in man ; or thus, that a horse five years old may be comparatively considered as a man of twenty; a horse of ten years, as a man of forty ; a horse of fifteen, as a man of fifty ; a horse of twenty, as a man of sixty; of trenty-fire, as a man of serenty; of thirty, as a man of eiglity; of thirty-five, as a man of ninety. So far from this comparison being in favor of the horse, it may rather be regarded as too little. Horses of thirty-five years of age are as common as men of ninety, provided it be taken into account that there are twenty human subjects for every horse; and, unquestionably, a horse of forty-five is less rare than a man of one hundred and ten.

To this it may be added, that the early English racers appear to have been more addicted to longerity than those of modern days, and the American horse generally than the English; probably because, in the former case, the horse was not put to hard work until his powers were developed by an advance toward maturity. Two and three year old training 
was unknown until a recent date; and, in the latter case, in America horses are little used in harness, or for general work, until they have attained to five or six years.

We will next consider the first appearance and successive

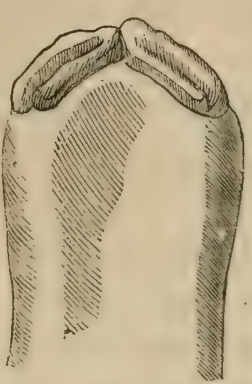
changes of the teeth, with the marks and their descriptions from commencement to maturity.

Seven or eight months before the foal is born, the germs or beginnings of the teeth are visible in the cavities of the jaws. At the time of birth, the first and second grinders have appeared, large, compared EIGHT DAFs' TEETH. with the size of the jaw, seemingly filling it. In the course of seven or eight days, the two centre nippers are seen as here represented.

In the course of the first month, the third grinder appears, above and below; and not long after, and generally before six weeks have expired, another incisor above and below will be seen on each side of the two first, which have

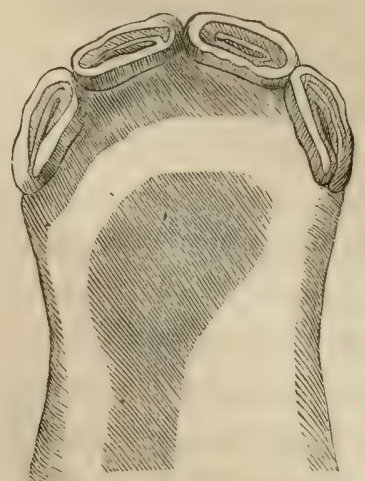

THREE OR FOUR MONTH' TEETH. now considerably grown, but not attained their perfect height. This cut will then represent the appearance of the mouth.

At two months, the centre nippers will have reached their natural level, and between the second and third month the second pair will have overtaken them. They will then begin to wear a little, and the outer edge, which was at first somewhat 
raised and sharp, is brought to a level with the inner edge, and so the mouth continues until some time between the sixth and ninth month, when another nipper begins to appear on each side of the first two, making six abore and below, and completing the colt's mouth; after which the only observable difference, until between the second and third year, is in the wear and tear of these teeth.

These teeth are covered with a polished and exceedingly hard enamel; indeed, it is so hard that it almost bids defiance to the action of a file. It spreads over that portion of the tooth which appears above the gum, and not only so, but as they are to be so much employed in nipping up the grass and gathering the animal's food-and in such enployment eren this hard substance must be gradually worn away-a portion of it, as it passes over the upper surface of the teeth, is bent inward, and sunk into the body of the teeth, and forms a little pit in them. The inside and bottom of this pit being blackened by the food, constitute the mark in them, by the gradual disappearance of which, in consequence of the wearing down of the teeth, we are enabled for several years to judge of the age of the animal.

The colt's nipping teeth are rounded in front, somewhat hollow toward the mouth, and presenting a cutting surface, with the outer edge rising in a slanting direction abore the inner edge. This, however, soon begins to wear down, until both surfaces are level, and the mark, which was originally long and narrow, becomes shorter, wider, and fainter. At six months, the four nippers are beginning to wear to a level.

The annexed cut will convey some idea of the appearance of the teeth at twelve months. The four middle teeth are 
almost level, and the corners are becoming so. The mark in the two middle teeth is wide and faint, in the next two teeth

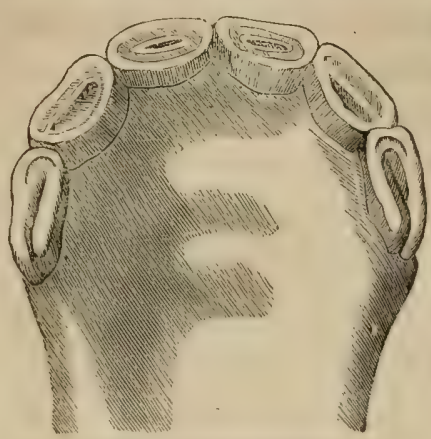

TEETH AT TWELVE MONTHS. it is longer, darker, and more narrow. In the corner teeth it is longest, darkest, and most narrow.

The back teeth, or grinders, will not guide us far in ascertaining the age of the animal, for we cannot easily inspect them; but there are some interesting particulars connected with them. The foal is born with two grinders in each jaw, above and below, or they appear within two or three days after birth. Before the expiration of the month they are succeeded by a third, more backward. The crowns of the grinders are entirely covered with enamel on the tops and sides, but attrition soon wears it away from the top, and there remains a compound surface of alternate layers of crusta petrosa, enamel, and ivory, which are employed in grinding down the hardest portions of the food. Nature has, therefore, made an additional

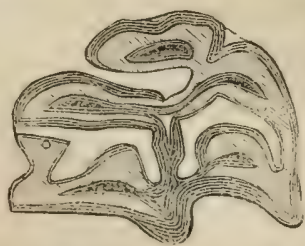
provision for their strength and endurance The annexed cut represents a grinder sawed across. The five dark spots represent bony matter; the parts covered with lines enamel, and the white A GrimDER SAWED ACross. spaces a strong bony cement uniting the other portions of the teeth.

At the completion of the first year a fourth grinder usually comes up, and the yearling has then, or soon afterwards, six 
nippers and four grinders above and below in each jaw, which, with the alteration in the nippers just described, will enable us to calculate the age of foal, subject to some variations, arising from the period of weaning and the nature of the food.

At the age of one year and a half, the mark in the central nippers will be much shorter and fainter; that in the two other pairs will have undergone an evident change, and all the nippers will be flat. At two years this will be more manifest. The accompanying cut deserves attention, as giving an accurate representation of the nippers in the lower jaw of a two-year-old colt.

About this period a fifth grinder will appear, and now

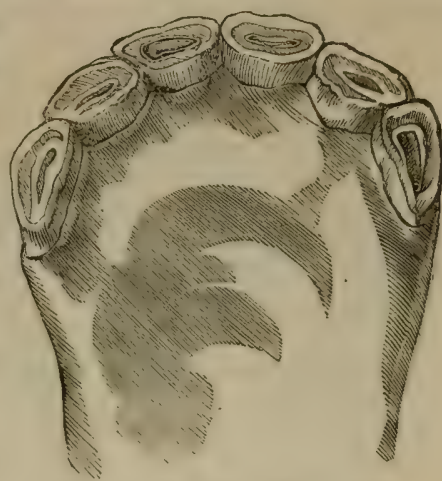

TWO YEARS TEETH.

likewise commences another process. The first teeth are adapted to the size and wants of the young animal. They are sufficiently large to occupy and fill the colt's jaws; but when these bones have expanded with the increasing growth of the animal, the teeth are separated too far from each other to be useful, and another and larger set is required. The second teeth then begin to push up from below, and the fangs of the first are absorbed, until the former approach the surface of the gum, when they drop out. Where the temporary teeth do not rise immediately under the milk teeth, but by their sides, the latter being pressed sideways are absorbed throughout their whole length. They grow narrow, are pushed out of place, and cause inconrenience to the gum, and sometimes to the 
cheek. They are then sometimes improperly called wolf's teeth, and should be extracted.

The teeth which first appeared are first renewed, and therefore the front or first grinders are changed at the age of two years. During the period between the falling out of the central milk teeth, and the coming up of the permanent ones, the colt; having a broken mouth, may find some difficulty in grazing. If

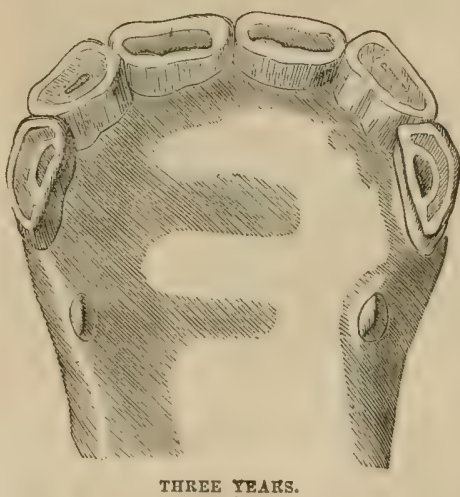
he should fall away considerably in condition, he should be fed with mashes and corn, or cut feed. The cut annexed represents a three-year-old mouth.

The central teeth are larger than the others, with two grooves in the entire convex surface, and the mark is long, narrow, deep, and

black. Not having yet attained their full growth, they are lower than the others. The mark in the next two nippers is nearly worn out, and it is wearing away in the corner nippers.

Is it possible to give this mouth to an early two-year-old?

The ages of all horses used to be reckoned from the first of May; but some are foaled even as early as January, and being actually four months over the two years, if they have been well nursed and fed, and are strong and large, they may, with the inexperienced, have an additional year put upon them. The central nippers are punched or drawn out, and the others appear three or four months earlier than they otherwise would. In the natural process they would only rise by long pressing upon the 
first teeth, and causing their absorption. But, opposition from the first set being removed, it is easy to imagine that their progress will be more rapid. Three or four months will be gained in the appearance of these teeth, and these three or four months will enable the breeder to term him a late colt of the preceding year. To him, however, who is accustomed to horses, the general form of the animal, the little development of the forehand, the continuance of the mark upon the next pair of nippers, its more erident existence in the corner ones, some enlargement or irregularity-about the gums from the riolence used in forcing out the teeth, the small growth of the first and fifth grinders, and the non-appearance of the sixth grinder, which, if it be not through the gum at three years old, is swelling under it, and preparing to get through-any or all of these circumstances, carefully attended to, will be a sufficient security against deception.

A horse at three years old ought to hare the sentral permanent nippers growing, the other two pairs wasting, six grinders in each jaw, above and below, the first and fifth level, the others and the sixth protruding. The sharp edge of new incisors, although it could not well be expressed in the cut, will be very evident when compared with the old teeth.

As the permanent nippers wear and continue to grow, a narrow portion of the cone-shaped tooth is exposed by the attrition, and they look as if they had been compressed, but it is not so. Not only will the mark be wearing out, but the rowns of the teeth will be sensibly smaller.

At three years and a half, or between that and four, the next pair of nippers will be changed, and the mouth at that time cannot be mistalien. The central nippers will have attained 
nearly their full growth. A vacuity will be left where the second stood, or they will begin to peep above the gum, and the corner ones will be diminished in breadth, worn down, and the mark becoming small and faint. At this period, likewise, the second pair of grinders will be shed. Previously to this may be the attempt of the dealer to give to his three-year-old an additional year; but the fraud will be detected by an ex. amination similar to that already described.

At four years, the central nippers will be fully developed; the sharp edge somewhat worn off, and the mark shorter, wider, and fainter. The next pair will be up, but they will be small,

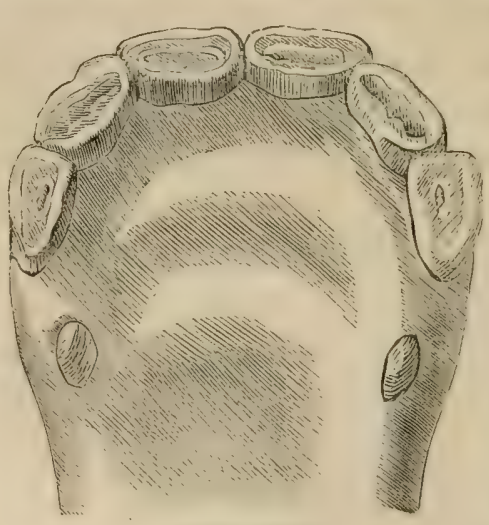

FOUR TEARS. with the mark deep and extending quite across them as in the annexed cut. The corner nippers will be larger than the inside ones, yet smaller than they were, and flat, and the mark nearly effaced. The sixth grinders will have risen to a level with the others, and the tushes will - begin to appear.

Now, more than at any other time, will the dealer be anxious to put an additional year upon the animal, for the difference between a four-year-old colt and a five-year-old horse, in strength, utility, and value, is very great; but the want of wear in the other nippers, the small size of the corner ones, the little growth of the tush, the smallness of the second grinder, the low forehand, the legginess of the colt, and the thickness and little 
depth of the mouth, will, to a man of common experience among horses, at once detect the cheat.

The tushes are four in number, two in each jaw, situated between the nippers and the grinders, much nearer to the former than the latter, and nearer in the lower jaw than in the upper, but this distance increases in both jaws with the age. In shape, the tush somewhat resembles a cone; it protrudes from the gum about half an inch, and is sharp-pointed and curved. The appearance of this tush in the horse may vary from four years to four years and six months. It can only be accelerated a few weeks by cutting the gum over it. At four years and a half, or between that and five, the last important change takes place in the mouth of the horse. The corner nippers are shed, and the permanent ones begin to appear. The central nippers are considerably worn, and the next pair are commencing to show marks of usage. The tush has now protruded, and is generally a full half inch in height; externally, it has a rounded promi-

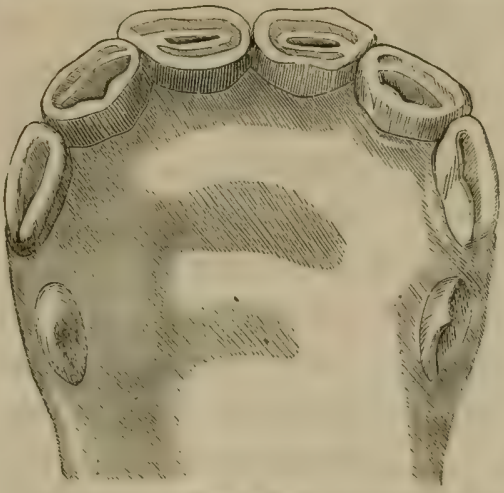

FIVE TEARS. nence, with a groove on cither side, and it is evidently hollowed within. The reader scarcely needs to be told that after the rising of the corner nipper, the animal changes its name. The colt becomes a horse, the filly a mare.

At five years, the horse's mouth is almost perfect, as represented in the annexed cut. The corner nippers are quite up, with the long, deep 
mark irregular in the inside, and the other nippers bearing evident tokens of increased wearing. The tush is much grown; the grooves have almost or quite disappeared, and the outer surface is regularly convex. It is still as concare within, and with the edge nearly as sharp, as it was six months before. The sixth molar is quite up, and the third molar is wanting. This last circumstance, if the general appearance of the animal, and particularly his forehand, and the wearing of the centre nippers, and the growth and shape of the tushes be likewise carefully attended to, will prevent deception, if a late fouryear-old is attempted to be substituted for a five-year-old. The nippers may be brought up a few months before their time, and the tushes a few weeks, but the grinder is with difficulty displaced. The last three grinders and the tushes are never shed.

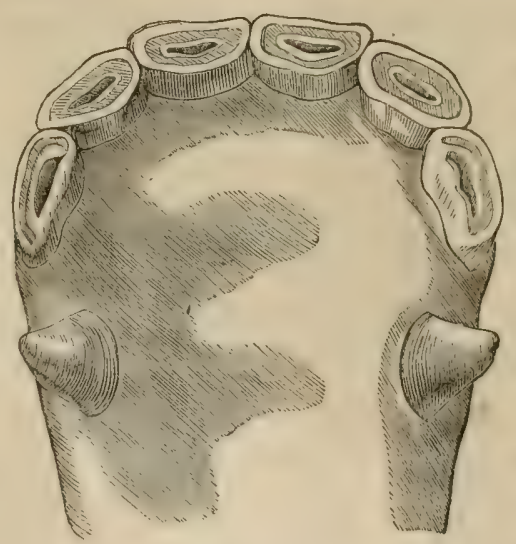

STX TEARS.

At six years, as in the annexed cut, the mark on the central nippers is worn out. There will still be a difference of color in the centre of the tooth: The cement filling up the hole, made by the dipping of the enamel, will present a browner hue than, the other parts of the tooth; and it will be evidently surrounded by an edge of enamel, and there will remain ever a little depression in the centre, and also a depression round the case of enamel; but the deep hole in the centre of 
the teeth, with the blackened surface which it presents, and the elerated edge of enamel, will have disappeared. Persons not much accustomed to horses have been puzzled here. They expected to find a plain surface of uniform color, and lnew not what conclusion to draw when there were both discoloration and irregularity.

In the next incisors, the mark is shorter, broader, and fainter, and in the corner teeth the edges of the enamel are more regular, and the surface is evidently worn. The tush has attained its full growth, being nearly or quite an inch long, convex outward, concare within, tending to a point, and the extremity somewhat curved. The third grinder is fairly up, and all the grinders are level.

The horse may now be snid to have a perfect mouth. All the tecth are produced, fully grown, and hare sustained no material injury. During these important changes of the teetb, the animal has suffered less than could be supposed possible.

At seren years, as in the accompanying cut, the mark, in the way in which it bas - been described, is worn out in the four central nippers, and is fast wearing away in the corner teeth; the tush is also beginning to be altered. It is rounded at the point, rounded at the edges, still

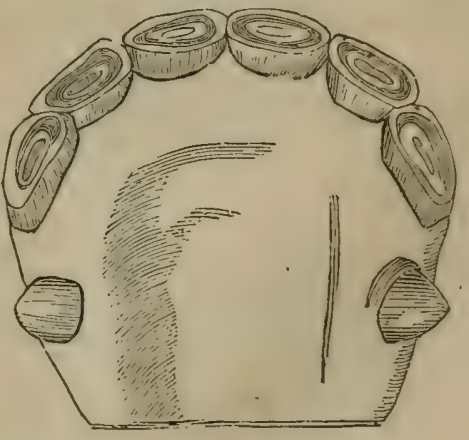

SEVEN TEARS. round without, and beginning to get round inside.

At eight years old, the tush is rounder in every way; the mark is gone from all the bottom nippers, and it may almost 
be said to be out of the mouth. There is nothing remaining in the bottom nippers that can clearly show the age of the Lorse, or justify the most experienced examiner in giving a positive opinion. This should be distinctly borne in mind, as it is a very common error in the United States, and one especially insisted on by dealers having old horses to sell, that the age can be positively ascertained even to ten, eleven, or twelve years, so that it can be predicated of a horse that he is so old, and no older. This is an absolute fallacy. It is easy, from many general signs, to see that a horse is above eight years old; but it is impossible to judge certainly how much older. The length and angularity of the nippers, the depth of the super-orbital cavities, and other points of information, may enable a good judge to guess comparatively, but never to speak surely.

Dishonest dealers have been said to resort to a method of prolonging the mark on the lower nippers. It is called Bishoping, from the name of the scoundrel who inrented it. The

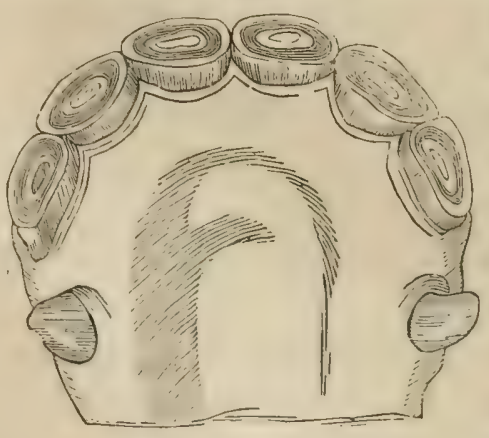

EIGHT OR NINE YEARS. horse of eight or nine years old-whose mouth is represented in the accompany. ing cut - is thrown, and with an engraver's tool a hole is dug in the now almost plain surface of the corner teeth, in shape resembling the mark yet left in those of a seven-yearold horse. The hole is then burned with a heated iron, and a permanent black stain is left. The next pair of nippers is 
sometimes slightly touched. An ignorant man would be very easily deceired by this trick; but the irregular appearance of the carity, the diffusion of the black stain around the tushes, the sharpened edges and concave inner surface of which can never be given again, the marks on the upper nippers, together with the general conformation of the horse, can never deceire the careful examiner.

Horsemen, after the animal is eight years old, are accustomed to look to the nippers in the upper jaw, and some conclusion has been drawn from the appearances which they present. It cannot be doubted that the mark remains in them for some years after it has been obliterated in the nippers of the lower jaw.

There are various opinions as to the intervals between the disappearance of the mark from the different cutting teeth of the upper jaw. Some have averaged it at two years, others at one. The latter opinion is more commonly adopted by those most conversant, and then the age is thus determined. At nine years, the mark will be worn from the middle nippers; from the next pair at ten; and from all the upper nippers at eleven. During these periods the tush is likewise undergoing a manifest change. It is blunter, shorter, and rounder. In what degree this takes place in the different periods, long and farorable opportunities can alone enable the horseman to decide.

The alteration in the form of the tushes is frequently uncertain. It will sometimes be blant at eight; and at others remain pointed at eighteen.

After eleven, and until the horse is very old, the age may be guessed at with some degree of confidence, from the shape 
of the upper surface or extremity of the nippers. At eight they are all oval, the length of the oval running across from tooth to tooth; but as the horse gets older, the tecth diminish in size-and this commencing in their width, and not in their thickness. They become a little apart from each other, and their surfaces become round instead of oval. At nine, the centre nippers are evidently so; at ten, the others begin to have their orals shortened. At eleven, the second pair of nippers is quite rounded; and at thirteen, the corner ones have also that appearance. At fourteen, the faces of the central nippers become somerhat triangular. At seventeen, they are all so. At nineteen, the angles begin to wear off, and the central teeth are again oval, but in a reversed direction, viz., from outward, inward; and at twenty-one, they all wear this form.

It would, of course, be folly to expect any thing like a certainty in an opinion of the exact age of an old horse, as drawn from the above indications. It is contended by some, though denied by others, that stabled horses have the marks sooner worn out than those that are at grass; and crib-biters still sooner. At nine or ten, the bars of the mouth become less prominent, and their regular diminution will designate increasing age. At eleven or twelve, the lower nippers change their original upright direction, and project forward horizontally, becoming of a yellow color.

The general indications of old age, independent of the teeth, are the deepening of the hollows over the eyes; gray hairs, and particularly orer the eyes, and about the muzzle; thinness and hanging down of the lips; sharpness of the withers, sinking of the back, lengthening of the quarters; and 
the disappearance of windgalls, spavins, and tumors of erery kind.

Horses kindly and not prematurely used, sometimes live to between thirty-five and forty-five years of age; and a well authenticated account is given of a barge horse that died in his sixty-second year.

Under this head of age, nothing beyond the cut of the complete aged mouth, with the accompanying description of it, would hare been here inserted, were it not for the prevalent opinion, inculcated by interested dealers in the United States, that the age of a horse, after eight or nine years, can be as certainly and as exactly predicated by mouth-mark, and his exact age guaranteed accordingly, as previously to that period.

Summing up all that need be offered on this particular point, we simply say, that if one chooses to buy a horse past mark of month, he must do so on his own judgment and at his own risk; for to credit any assertions, or to give car to any horsedealer's opinion on the subject, is sheer folly. 


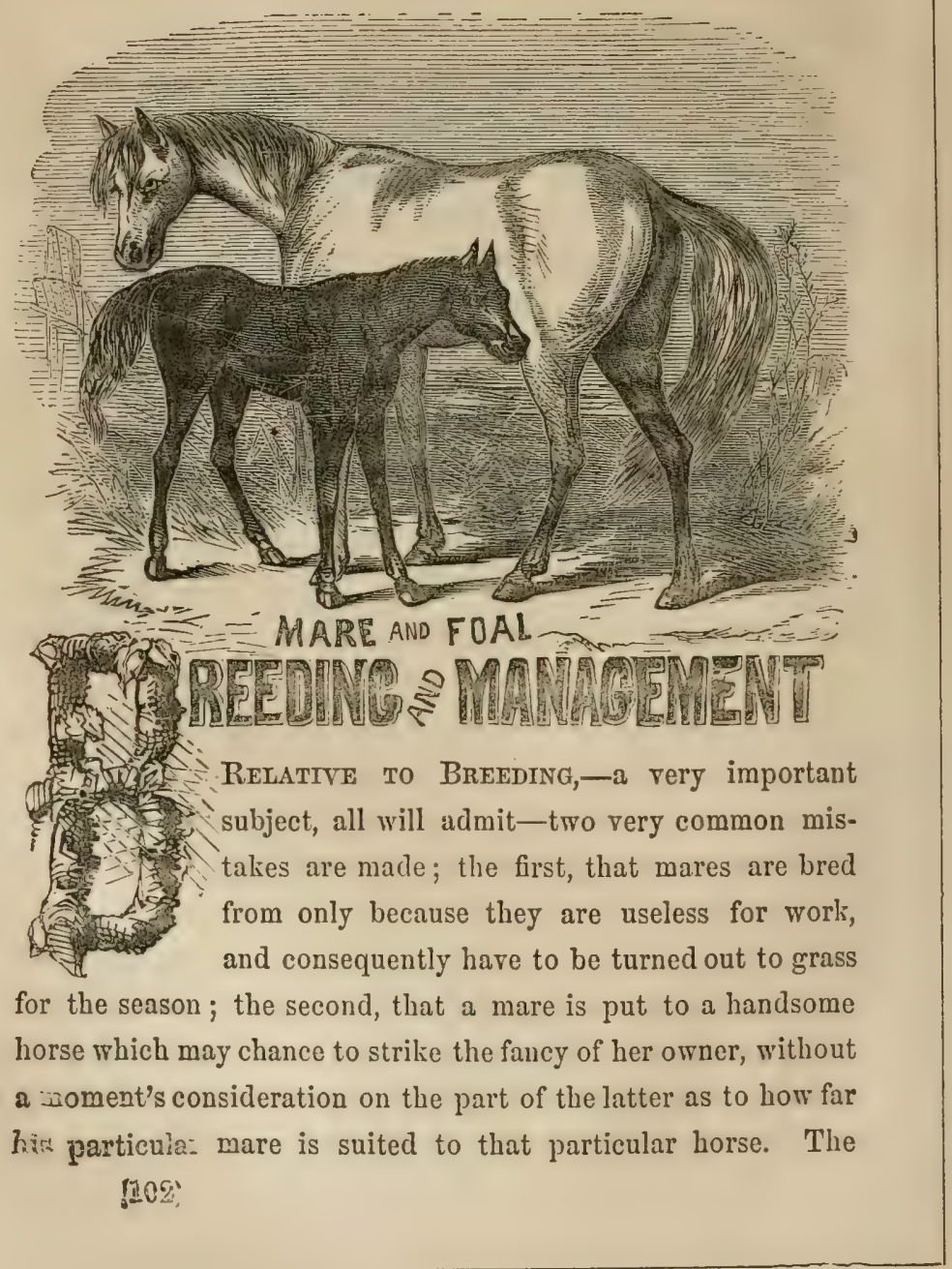


consequence of the first error is, that the infirmities of the mare are perpetuated in her unfortunate offspring, and thus become hereditary, to the no small disappointment of the breeder. In the second case mentioned, the result is an indescribable mongrel, possessing only a combination of bad qualities, without a single redeeming trait.

Now, no principle is better established in breeding than that "like will produce like;" in other words, that the offspring will inherit the general or mingled qualities of the parents. So true is this, that there is scarcely a disease affecting either of the parents that is not inherited by the foal, or, at least, to which he does not at times show a predisposition. The consequences of bad usage or hard work eren will descend to the progeny. Though the defects may not appear in the immediate offspring, they often do in the next, or some succeeding generation. Some knowledge is therefore indispensable of the parentage both of the sire and the dam.

Both parents should be selected with reference not only to their individual points of excellence, but also to the relative adaptation which the points of one present to the points of the other. Though both may be excellent in their way, one parent may have points of excellence which actually counteract or neutralize those of the other. None but sound parents, therefore, should be bred from; accidents, howerer, are not to be regarded as unsoundness; but if a defect exists in a mare which is intended for breeding, the breeder should be certain that such defect is a mere accident, and not a natural malformation. Both parents should also be as free from moral as from plyysical infirmity; from faults or vices of temper or disposition. Although a defect of one parent may sometimes be counteracted by a pre- 
ponderating excellence relative to that defect in the other, great care is necessary that both parents do not possess the same defect. If one would be perfectly certain in breeding, it is better to aroid even such mares as have suffered merely from accident; nol should the mare be put to the horse at too early an age, if one would avoid the hazard of obtaining an unreliable offspring.

The best form of a mare from which to breed, for any purpose, is a short-legged, lengthy animal, with a deep, roomy chest and carcass, wide and capacious hips, and a sound constitution. "Breed," of course, must be loolied for, according to the class of horses to which the mare belongs; a good, animated countenance, an upright, sprightly carriage; general structure of muscle, bone and sinew firm, dense, and compact. The head of the brood-mare is an important point to be regarded; a mare that has a heary head and a stupid countenance cannot breed a good foal, unless to a horse possessed of fire almost to madress-for her countenance indicates her disposition. The neck should be brought out of the top of the withers, and not of the bottom of the shoulders and chest; the shoulders should be well back, the blade-bone lying obliquely from the shoulder joint; the blade should also be long and wide, extending nearly to the top of the withers, but attached so closely and so well covered with muscle as not to present any undue prominence; the back of the shoulder should also be well furnished with muscle, appearing to the mounted rider of a wedge shape widening towards his knee; the fore-leg should be perpendicular, the toe and the point of the shoulder being in a right line; the foot should be round, even, and of a dark color; the heels should be open, but not low ; the brisket should be deep, especially in the case of a riding-horse, as otherwise a crupper will be ro- 
quired to keep the saddle in its proper place; the quarters should be long and oral on the top; the hips cannot be too broad in a brood-mare, though in a stallion too wide hips are objectionable; the hocks should be regarded, and the shank-bone and sinew, both before and behind, should be well developed, and dropped straight below the joint.

As to the shape of the stallion litile satisfactory can be said. It must depend upon that of the mare, and the kind of horse wished to be bred; but, if there is ono point absolutely essential,

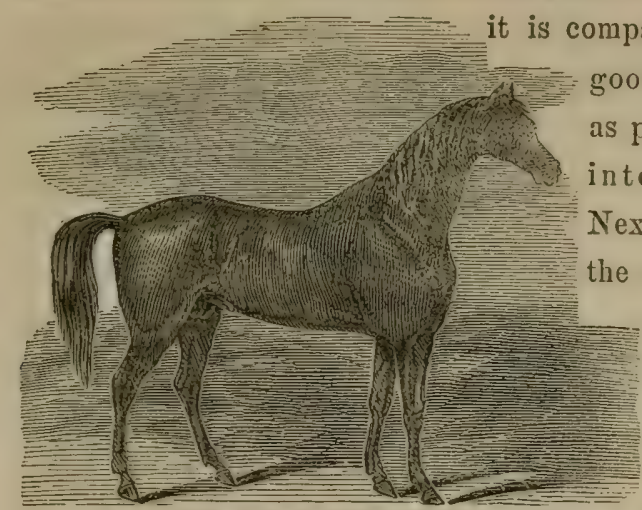

THE ARAB STALLION JUPITER.

goodness and strength as possible condensed into a smali space. Next to compactness, the inclination of the shoulder should be regarded. A. huge stallion, with upright shoulders, nerer got a capital hunter or hackney; from such nothing but a cart or dray horse can be obtained, and that, perhaps, spoiled by the opposite form of the mare. If, however, a merely slow draught-horse is desired, an upright shoulder is desirable, if not absolutely necessary.

The principal requirements in connection with breeding may. be concisely summed up as follows :-

First. There should be mutual adaptation in form and size, and indeed in all important characteristics, between the sire and the dam. 
Second. If the mare be defective in any particular, she should not be bred to a stallion having a similar, or even an opposite, fault; but one should rather be chosen perfect in that point.

Third. Exceedingly small mares should not be bred with enormously large horses; distortions will generally be the result. For a mare of sixteen hands, a horse of not less than fifteen hands should be selected; if she be too low or small, the horse may be an inch or two higher, but not of the tall or leggy kiud.

Fourth. As it is frequently the case, that without any known cause the blood of a certain kind of horses will not cross well with that of another, such instances when ascertained should be avoided.

Fifth. If the mare is of a good kind of horses, but one which has degenerated in size from "in-breeding," (that is, from continuous breeding into the same family and blood-with their own daughters and grand-daughters, in other words-for about two generations, ) the only remedy is, to breed to the purest stallion that can be found, but of a different lind from hers, unless some ten or more generations removed.

Sixth. After breeding for several generations from males and females of one kind, it is generally beneficial to change to another entirely different; otherwise degeneracy in size will be the general result.

The mare should not be put to horse under three years of age. Although some contend that, if lightly worked, she may be used for breeding until she is twenty, yet it is very doubtful whether breeding from any mare over twelve years old, at the very utmost, will prove satisfactory. If a large colt is desired, have a large mare; as her size has generally more to do with the matter than that of the stallion. The most favorable time 
for putting the mare to the horse is from March to the beginning of May; colts foaled in March are generally found to turn out hardier, and to stand better, than those foaled earlier.

From the time of covering to within a few days of the expected period of fonling, the cart-mare may be kept at moderate labor not only without injury, but with decided advantage. She should ther be released from work and kept near home under the frequent inspection of some careful person. When nearly half the time of pregnancy has elapsed, she should have a little better food, being allowed one or two feeds of grain in the day. As this is about the time when they are accustomed to slink their foals, or when abortion occurs, the owner's eye should be frequently upon her. Good feeding and moderate exercise are the best preventives of this mischance. As the mare that has once slunk her foal is liable to a repetition of this accident, she should never be suffered to be with other mares between the fourth and fifth months; for so great is the power of sympathy or imagination in the mare that if one suffers abortion, others in the same pasture will too often share the same fate. Farmers frequently suppose that such mishaps originate from some infection; and many wash and paint and tar their stables to prevent an infection that really lies in the imagination.

The period of pregnancy varies from forty-four to fifty-six weeks, but it is usually from forty-seven to fifty. If the mare, whether of pure or common breed, be cared for as suggested above, and be in good bealth while in foal, little danger will attend the act of giving birth to the young. Should there be, howerer, false presentation of the fœtus, or any difficulty in producing it, recourse should be had to a well-informed veterinary 
surgeon, rather than to run the risk of injuring the mare by violent attempts to relieve her.

After the mare has foaled, she should be turned into some well-sheltered pasture, with a shed or hovel into which she may run when she pleases. If she has foaled early and the grass is scanty, she should have a feed or two of oats or Indian corn daily; if the corn is given in a trough upon the ground, the foal will partake of it with her. Nothing is gained at this time by starving the mare and stinting the foal. When the new grass is plentiful, the quantity of grain may be gradually diminished. The proper care of young foals will repay a lundred-fold; this being, indeed, the most critical period of the animal's life, when attention or neglect produces the most noticeable and permanent results.

If convenient, the foal may be permitted to run for twelve months at the foot of the mare; but when mares are kept expressly for breeding purposes, many circumstances render this objectionable. Within about a month or six weeks from foaling the mare will be again in heat, and sbould be put to the horse; at the same time, also, if she is used for agricultural purposes, she may resume light work. At first, the foal should be shut up in the stable during working hours; but, as it acquires sufficient strength, it is better to allow it to follow its dam. The work will contribute to the health of the mother, and increase her flow of milk; and the foal, by accompanying her, will suck more frequently, thrive better; become tamed, and gradually familiarized with the objects among which it is afterward to live. While the mare is thus worked, she and the foal should be well fed; and two feeds of corn, at least, should be added to the green food which they get when turned out after their work, and at night. 
In five or six months, according to the growth of the foal, it may be weaned. For this purpose, it should either be housed, or turned into some pasture at a distance from the dam. The mare should be put to harder work and drier food. If her milk is troublesome, or she pines after her foal, a few purgatives (one or two urine-balls, or a physic ball) will be found useful. The foal should be fed well and biberally every morning and erening, bruised oats and bran being about the best kind of food which can be giren. The money so laid out upon the liberal nourishment of the colt, is well expended; yet, while he is well fed, he should not be rendered delicate by excess of care. Toward the end of summer the foal may be turned out to general pasture without fear of his again seeking his dam.

Should the foal be a male, and emasculation be desirable, it is better to perform the operation at the time of weaning, that the one trouble shall serve for both occasions. If, however, weaning take place in June or July, when che fly abounds, the operation should not be performed, as this insect by its attacks will cause restlessness and consequent inflammation, and thus retard recovery. Early spring, or an adranced period of autumn, is the best time. This operation should in no instance be performed by any other than a competent reterinary surgeon. One thing in this connection should be mentioned; when a horse is suffered to attain two-thirds of his growth before emasculation, an animal is obtained of form, power, and ralue far superior to that which has been operated upon when a foal. This much is deserving of remembrance; though we cannot omit heartily condemning the practice of emasculation at all. 


\section{BREAKING.}

No greater mistake can be made than the postponement of this part of the rearing of a horse. It should always commence as soon as the colt is weaned, or immediately after the effects of the emasculation have disappeared; it should

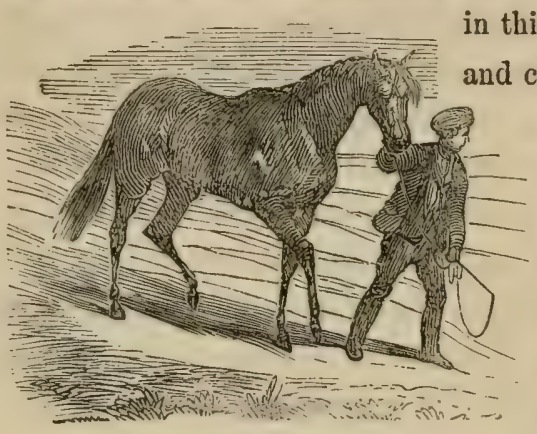

BREAKING.

in this manner be commenced and carried on gradually, with gentleness and kindness. The foal shonld be daily handled, partially dressed, accustomed to the halter when led about, and even tied up occasionally for an hour or so.

The tractability, good temper, and value of the horse depend much more upon this than most breeders consider. The person who feeds the colt should have the entire management of him at this period, and he should be a trustworthy person, possessed of a quiet, uniform temper and a kindly disposition. Many a horse is spoiled and rendered permanently untamable by early harshness or improper treatment; and many a horse that otherwise would hare proved a vicious, unmanageable brute, has been brought to be a docile, gentle, and affectionate servant by the judicious treatment of those to whose charge his management at this particular period was fortunately intrusted.

Such a treatment is sufficient for the first year; after the second winter, the operation of training should commence in 
good earnest. The colt should be bitted, a bit being selected which will not hurt his mouth, and much smaller than those in common use. The work of bitting may perhaps occupy three or four days; the colt being suffered to amuse himself with the bit; to play, and to champ it for an hour or so during a few successive days. When he has become accustomed to the bit, he may have two long ropes attached to it, slightly fastened to his sides by a loose girth over the back, and his feeder may thus drive him, as it were, around a field, pulling upon him as he proceeds. This will serve as a first lesson in drawing. If he is intended for a saddle-horse, a filled bag may be thrown across his back and there secured, and, after he has become used to this, a crotch may be fastened upon his back, its lower extremities grasping his sides, and thus preparing him for the legs of his rider.

Portions of the harness may next be pat upon him, reserving the blind winkers for the last; and a few days afterward he may go into the team. It is better that he should be one of three horses, having one before him, and the shaft-horse behind him. There should at first be the mere empty wagon; and the draught is best begun over the grass, where the colt will not be frightened by the noise of the wheels. Nothing should be done to him, except giving him an occasional pat or a kind word. The other horses will keep him moving and in his place; and after a short time, sometimes even during the first day, be will begin to pull with the rest. The load may then be gradu. ally increased.

If the horse is desired for purposes of riding as well as for exclusively agricultural uses, his first lesson may be given when he is in the team; his feeder, if possible, being the first one put 
upon him. He will be too much confined by the harness and by the other horses, to malie much resistance; and, in the greater number of instances, will quietly and at once submit Every thing, howerer, should proceed gradually and by successive steps, and, above all, no whip or harsh language should, under any circumstances, be allowed to be used. Although mildness is absolutely essential, it is none the less necessary that the colt should be taught implicit obedience to the will of his master. To accomplish this, neither whip, nor spur, nor loud shouting, nor hallooing is necessary; the successful horsebrcaker is required to possess but the three grand requisites of firmness, steadiness, and patience.

When the colt begins to understand bis business somewhat, the most difficult part of his work, backing, may be taught him; first, to back well without anything behind him, then with a light curb, and afterwards with some more heary load-the greatest possible care being always talien that his mouth be not seriously hurt. If the first lesson causes much soreness of the gums, he will not readily submit to the second. If he has been previously rendered tractable by lind usage, time and patience will accomplish every thing that is desired. Some persons are in the habit of blinding the colt when teaching him to back. This can only be necessary with a restire and obstinate one, and even then should be used only as a last resort.

In the whole process of breaking it should constantly be borne in mind, that scarcely any horses are naturally vicious. Cruel usage alone first provokes resistance. If that resistance is followed by greater severity, the stubbornness of the colt increases in proportion; open warfare ensues, in which the man seldom gains the alrantage, and the horse is frequently ren- 
dered utterly unfit for service. Correction may, indeed, be necessary for the purpose of enforcing implicit obedience, after the training has proceeded to a certain extent; but the early lessons should be imparted with kindness alone. Young colts are sometimes very perverse; and many days will occasionally pass, before they will suffer the bridle to be put on, or the saddle to be worn. It must not, however, be forgotten, that a single act of harshness will indefinitely increase this length of time; but that patience and kindness will always prevail. On some occasion, when the colt is in a better humor than usual, the bridle may be put on, or the saddle be worn; and, if this compliance, on his part is accompanied by kindness and soothing on the part of the breaker, and no inconvenience or pain be suffered by the animal, all resistance will be ended.

The same principles will apply to the breaking-in of the horse for the road. The handling and some portion of instruction should commence from the time of weaning; for upon this the future tractibility of the horse in a great measure depends. At two years and a half, or three years, the regular process of breaking-in should commence. If it is put off until the animal is four years old, his strength and obstinacy will be more diffcult to overcome. The plan usually adopted by the breaker cannot, perhaps, be much improved; except that there should be much more kindness and patience, and far less harshness and cruelty, than those persons are accustomed to cxhibit, and a great deal more attention to the form and natural action of the horse. A headstall is put on the colt, and a cavesson (or apparatus to confine and pinch the nose,) affixed to it with long reins. He is first accustomed to the rein, then led around a ring on soft ground, and at length mounted and taught his 
paces. Next to preserving the temper and docility of the horse, there is nothing of so much importance, as to teach him every pace and every part of his duty distinctly and thoroughly. Each should constitute a separate and sometimes long-continued lesson, taught by a man who will nerer allow his passion to overmaster his discretion.

After the cavesson has been attached to the headstall, and the long reins put on, the colt should be quietly led about by the breaker-a steady boy following behind, to keep him moving by occasional threatening with the whip, but never by an actual blow. When the animal follows readily and quietly, he may be taken to the ring and walked around, right and left, in a very small circle. Care should be taken to teach him this pace thoroughly, never allowing him to break into a trot. The boy with his whip may here again be necessary, but an actual blow should never be inflicted.

Becoming tolerably perfect in the walk, he should be quickened to a trot, and kept steadily at it; the whip and the boy, if needful, urging him on, and the cavesson restraining him. These lessons should be short, the pace being kept perfect and distinct in each, and docility and improvement rewarded with frequent caresses, and handfuls of corn. The length of the rein may now be gradually increased, and the pace quickened, and the time extended, until the animal becomes tractable in these his first lessons; toward the conclusion of which, crupper straps, or something similar, may be attached to the clothing. These, playing about the sides and flanks, accustom him to the flapping of the coat of the rider. The annoyance which they occasion will pass over in a day or two; for when the animal learns by experience that no harm comes from them, he will cease to regard them. 
Next comes the bitting. The bits should be large and smooth, and the reins buckled to a ring on each sile of the pad. There are many curious and expensive machines for this purpose, but the simple rein will be quite sufficient. It should at first be slack, and then very gradually tightened. This prepares for the more perfect manner in which the head will afterward be got in its proper position, when the colt is accustomed to the saddle. Occasionally the breaker should stand in front of the colt, and take hold of each side-rein near to the mouth, and press upon it, and thus begin to teach him to stop and to back on the pressure of the rein, rewarding every act of docility, and not being too eager to punish occasional carelessness or waywardness.

The colt may now be taken into the road or strect, that he may become gradually accustomed to the objects among which his services will be required. Here, from fear or playfulness, a considerabie degree of starting and shying may be cxhibited, of which as little notice as possible should be taken. The same or a similar object should be soon passed again, but at a greater distance. If the colt still shies, let the distance be still further increased, until he takes no notice of the object. Then he may be gradually brought nearer to it; and this may usually be accomplished without the slightest difficulty; whereas, had there been an attempt to force him close to it in the first instance, the remembrance of the contest would have been associater with erery appearance of the object, and the habit of shying would have been established.

Hitherto, with a cool and patient breaker, the whip may hare been shown, but will scarcely have been used; the colt should now, however, be accustomed to this necessary instrument of 
authority. Let the breaker walk by the side of the animal, throw his right arm over his back, holding the reins in his left, occasionally quickening his pace, and at the moment of doing this tapping the horse with the whip in his right hand, and at first very gently. The tap of the whip and the quickening of the pace will soon become associated in the animal's mind. If necessary, these reminders may gradually fall a little heavier, and the feeling of pain be the moniter of the necessity of increased exertion. The lessons of reining in and stopping, and backing on the pressure of the bit, may continue to be practised at the same time.

He may next be taught to bear the saddle. Some little caution will be necessary in first putting it on. The breaker should stand at the head of the colt, patting him and engaging his attention, while one assistant, on the off-side, gently places the saddle on the back of the animal; another on the nearest side slowly tightening the girths. If he submits quietly to this, as he generally will when the previous process of breaking-in has been properly conducted, the operation of mounting may be attempted on the following, or on the third day. The breaker will need two assistants in order to accomplish this. He will remain at the head of the colt, patting and making much of him. The rider will put his foot into the stirrup, and bear a little weight upon it, while the man on the opposite side presses equally on the other stirrup-leather; and according to the docility of the animal, he will gradually increase the weight, until he balances himself on the stirrup. If the colt is uneasy or fretful, he should be spoken kindly to and patted, or a mouthful of grain be given to him; but if he offers serious resistance, the lessons must terminate for that day. He may possibly be in a better humor on the morrow. 
When the rider has balanced himself for a minute or two, he may gently throw his leg orer, and quickly seat himself in the saddle. The breaker should then lead the animal around the ring, the rider meanwhile sitting perfectly still. After a fer minutes he should take the reins, and handle them as gently as possible, guiding the horse by the pressure of them; patting him frequently, and especially when he thinks of dismounting; and, after having dismounted, offering him a little grain, or green feed. The use of the rein in checking him, and of the pressure of the leg and the touch of the heel in quickening his pace, will soon be taught, and his education will be nearly completed.

The horse having thus far submitted himself to the breaker, these pattings and awards must be gradually diminished, and implicit obedience mildly but firmly enforced. Severity will isot often be necessary, in the great majority of cases it being

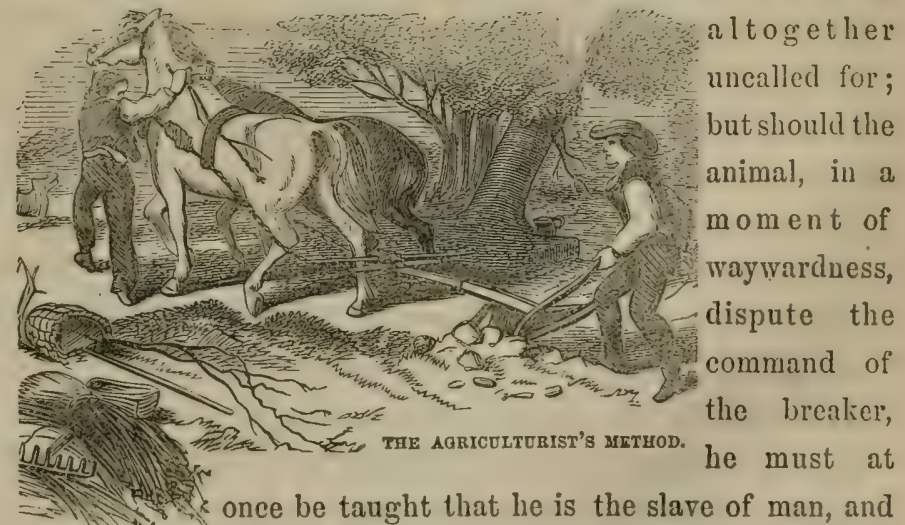
that we have the power, by other means than those of kindness, to bend him to our will. The education of the horse, in short, should be that of the child. Pleasure is, as much as possible, 
associated with the early lessons; but firmness, or, if need be, coercion, must establish the habit of obedience. Tyranny and cruelty will, more speedily even in the horse than in the child, prorolie the wish to disobey; and, on erery practicable occasion, the resistance to command. The restive and vicious horse is, in ninety-nine cases out of a hundred, made so by ill-usage, and not by nature. None but those who will take the trouble to make the experiment, are aware how absolute a command the due admixture of firmness and kinduess will soon give us over any herse.

\section{CASTRATION.}

The period at which this operation may be best performed depends, as has been previously remarked, much on the breed and form of the colt, and the purpose for which he is destined. For the common agricultural holse, the age of four or five months will be the most proper time, or, at least before he is weaned. Few horses are lost when cut at that age; though care should be taken that the weather is not too bad, nor the flies too numerous.

If the horse is designed either for the carriage or for heary draught, he should not be castrated until he is at least a year old; and, even then, the colt should be carefully examined. If he is thin and spare about the neck and shoulders, and low in the withers, he will materially improve by remaining uncut another six months; but if his fore quarters are fairly developed at twelve months, the operation should not be delayed, lest he grow gross and heary before, and, perhaps, has begun too decidedly to have a will of his own. No specific age, therefore, Ean be fixerl; but the operation should be performed rather late 
in the spring, or early in the autumn, when the air is temperate and particularly when the weather is dry.

No preparation is necessary for the sucking colt, but it may. be prudent to physic one of more advanced age. In the majority of cases, no after treatment will be necessary, except that the animal should be sheltered from intense heat, and more particularly from the wet. In temperate weather he will do much better running in the field than nursed in a close and hot stable. The moderate exercise which he will necessarily take in grazlng, will be preferable to entire inaction.

The old method of opening the scrotum, or testicle bag, on each side, and cutting off the testicles, preventing bleeding by a temporary compression of the vessel, while they are seared with a hot iron, must not, perhaps, be abandoned; but there is no necessity for that extra pain, when the spermatic cord (the blood-ressels and the nerve,) is compressed between two pieces of wood as tightly as in a vice, and there left until the following day, when it may be removed with a knife.

The practice of some farmers of cording, or twitching their colts at an early period exposes the animal to much unneces6ary pain, and is attended with no slight danger.

Another method of castration is by torsion. An incision is made. into the scrotum, and the vas deferens is exposed and divided. The artery is then seized by a pair of forceps contriver for the purpose, and twisted six or seven times round. It retricts without untwisting the coils, and bleeding ceases. The testicle is remored, and there is no sloughing or danger. The most painful part of the operation-the operation of the firing-iron, or the claws-is aroided, and the wound readily heals. It is to be remarked, in this connection, that the use 
of chloroform has been found very beneficial in performing the operation in the old way, both in removing all pain, and also preventing that severe struggling which often takes place, and which has sometimes been followed with very dangerous consequences. With the assistance of this agent, the operation has been safely performed in seven minutes, without any pain to the animal.

\section{DOCKING.}

This is an operation, whose only sanction is to be found in the requirements of a senseless fashion. "The conrenience of the rider," which is sometimes urged in its favor, is the veriest nonsense afloat. In truth, the operation is one of the most useless which the brain of man, fertile in romance and expedients as it is, ever derised; since, instead of adding to the beanty of the animal, as some assert, it but adds deformity. Not many years back, this attempted improvement upon nature became a perfect mania. In England, howerer, this cruel practice has been almost entirely discarded; and it is to be hoped that the operation in the United States also will speedily be frowned down.

The operation, as now performed by veterinary surgeons, was introduced some years ago by the American Veterinary Asso. ciation of Philadelphia. It consists in passing a narrow-bladed knife (a pricling knife will answer, ) between the coccygeal bones at the desired point, from above downwards, cutting outwards and backwards on each side so as to form two flaps, which are carefully lrouglat together orer the end of the tail and secured by the interrupted suture; thus giving protection to the stump of the tail, and making a much neater finish than by any other 
nethod which could be adopted. No styptic whatever is required, and there need be no fear of hemorrhage, as the union cenerally takes place by what surgeons call first intention. If, howerer, the flaps do not fit nicely, healing will not take place without suppuration. This fact should be borne in mind in performing the operation, as much time in healing may thus be saved.

By the old method that joint is searched for, which is nearest to the desired length of tail. The hair is then turned up, and tied round with tape for an inch or two abore this joint, and that lying immediately upon the joint is cut off. The horse is fettered with the side-line, and then the veterinary surgeon with his docking-machine, or the farmer with his carving-kuife and mallet, cuts through the tail at one stroke.

Some farmers dock their colts a few days after they are dropleded. This is a commendable custom on the score of humanity. No colt was ever lost by it; the growth of the hair, and the beauty of the tail not being at all impaired.

\section{NICKING.}

This barbarous operation was once sanctioned by fashion, and the breeder and the dealer are even now sometimes tempted to inflict the torture of it in order to obtain a ready sale for their colts. It is not, practiced to the extent that it used to be, nor is it attended by so many cireumstances of cruelty.

The operation is thus performed. The side-line is put on the horse, or some persons deem it more prudent to cast him, and that precaution may be recommended. The hair at the end of the tail is securely tied together, for the purpose of afterward attaching a weight to it. The operator then grasps 
the tail in his hand, and, lifting it up, feels for the centre of one of the bones-the prominences at the extremities guiding him-from two to four inches from the root of the tail, according to the size of the horse. He then with a sharp knife divides the muscles deeply from the edge of the tail on one side to the centre, and, continuing the incision across the bone of the tail, he makes it as deep on the other side. One continued incision, steadily yet rapidly made, will accomplish all this. If it is a blood-horse that is operated on, this will be sufficient. For a hunter, two incisions are usually made, the second being about two inches below the first, and likewise as nearly as possible in the centre of one of the bones.

On a hackney, a third incision is made; for fashion has decided that his tail shall be still more elevated and curved. Two incisions only are made in the tail of a mare, and the second not very deep.

When the second incision is made, some fibres of the muscles between the first and second will project into the wound, and must be removed by a pair of curved scissors. The same must be done with the projecting portions from between the second and third incisions. The wound should then be carefully examined, in order to ascertain that the muscles hare been equally divided on each side, otherwise the tail will be carried awry. This being done, pieces of tow must be introduced deeply into each incision, and confined, but not too tightly, by a bandage. A very profuse bleeding only will justify any tightness of bandage, and the ill consequences that have resulted from nicking are mainly attributable to the unnecessary force that is used in confining these pledgets of tow. Even if the bleeding, immediately after the operation, 
should have been rery great, the roller must be loosened in two or three hours, otherwise swelling and inflammation, and eren death, may possibly ensue. Twenty-four hours after the operation, the bandage must be quite removed; and then all that is necessary, so far as the healing of the incisions is concerned, is to keep them clean.

TLe wounds must remain open; and this can only be accomplished by forcibly keeping the tail curved back during two or three weeks. For this purpose, a cord, one or two feet in length, is affixed to the end of the hair, which terminates in an-

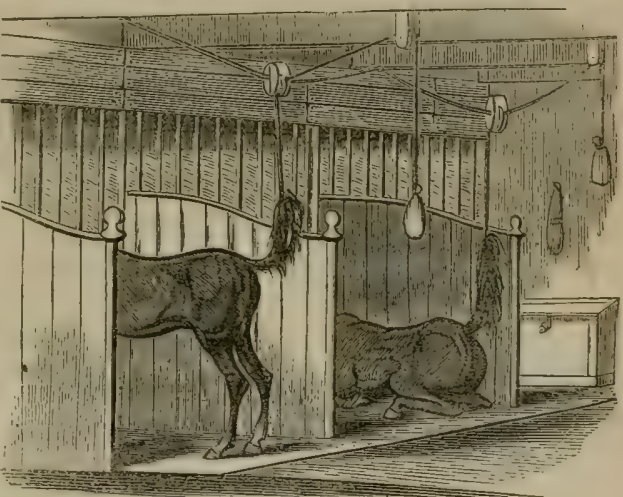

THE USUAL MLTHOD.

other divided cord, each division going over a pulley on each side of the back of the stall. A weight is hung at each extremity, sufficient to keep the incisions properly open, and regulated by the degree in which this is wished to be accom. plished. The animal will thus be retained in an uneasy position, although, after the first two or three days, probably not of acute pain. It is barbarous to increase this uneasiness or pain by affixing too great a weight to the cords; for it should be remembered that the proper elevated curre is given to the tail, not by the weight's keeping it in a certain position for a considerable time, but by the depth of the first incisions, and the degree in which the wounds are kept open. 
The dock should not, for the first three or four days, be brought higher than the back. Dangerous irritation and inflammation would probably otherwise be produced. It may, after that, be gradually raised to an elevation of forty-five degrees. The horse should be taken out of the pulleys, and gently exereised once or twice every day; but the pulleys cannot finally be dispensed with until a fortnight after the wounds hare healed, because the process of contraction, or the approach of the divided parts, goes on for some time after the skiu is perfect orer the incisions, and the tail would thus sink below the desired elevation. The French method is simpler and less barbarous than ours, allowing the horse to lie down or move about at his pleasure. Where this operation is to be performed, it might be adopted with advantage as shown in the. engraving nexed.

If the tail has

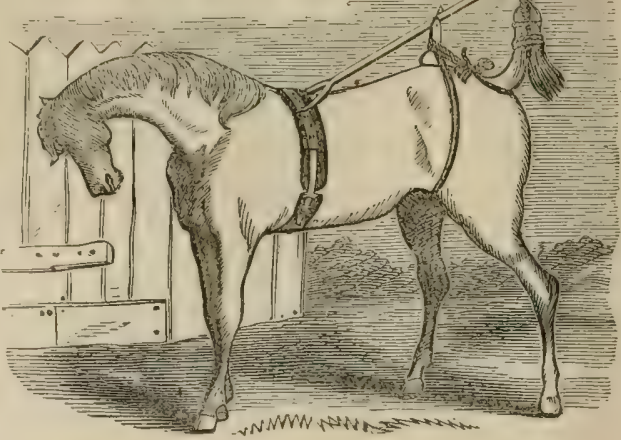
THE FRENCH METHOD.

not been unnecessarily extended by enormons weights, no bad consequences will usually follow ; but if considerable inflammation shonld ensue, the tail must be taken from the pulley, and carefully fomented with simple warm water, and a dose of physic given Locked-jaw has, in some rare instances, followed, under which tne horse generally perishes. The best means of cure in the early state of this disease, is to amputate 
the tail at the joint above the highest incision. In order to prevent the hair from coming off, it should be unplaited and combed out erery fourth or fifth day.

\section{THE STABLE.}

The most desirable thing in a stable is ventilation. A horse requires air equally with his master; and as the latter requires a chimney to his sleeping apartment, so does the former. This may be a mere outlet through the ceiling, or it may be formed as a dome or cupola. It should not, of course, be open at the top, or rain will get in, but roofed over, and have an opening at the sides. Besides this, there should be openings in the wall, near the ground, but not in the stalls. This will produce a thorough air, and may be so placed as not to expose the horses to the draught.

The stable should not be less than twelve feet high, from floor to cciling, and the floor should be well paved, slope slightly backward, and along the back of the stalls should run a gutter, about a foot wide and an inch or two deep. No stable should be less than eighteen feet deep, and each stall should be at least six feet clear; but if eight feet can be allowed, so much the better. Although some horses will agree when kept together in one stall, it is far preferable to allow each a stall to himself. The manger should be about sixteen inches deep, the same from front to back, more narrow at bottom than at top, and two fect in length. The rack is best when closed in front, the back part being an inclined plane of rood sloping gradually towart the front, and terminating about two feet down. This lind of rack effects a considerable saving in hay; for the reader scarcely needs to be reminded that in the common rack much 
of the hay given is dragged down and trampled in the litter. It also prevents the hay-seed from falling into the horse's eyes;

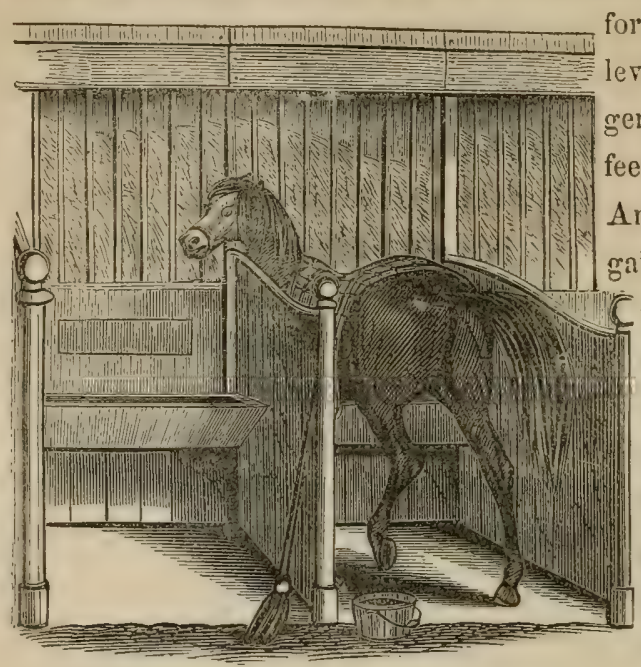

CDSTOMIART FORM OF STALLS. for the rack is on a lerel with the manger, and about three feetfrom the ground. Another advantage gained by this rack is the facility with which it can be filled, thus obriating all necessity for a.lofi over the stable, and, consequently, admitting of a greater height of ceiling above the horses, as well as of a superior ventilation.

The windows and the doors should be at opposite ends, as ventilation is thereby promoted; the doors should be divided transcersely, at the height of about four feet from the ground. The upper portion may thus be occasionally opened. Whitewash is a bad dressing for the interior of the stable, as it causes too great a glare of light; paint of a leaden color is best, and it can be washed from time to time with soap and water. There should be a bin, properly divided into partitions for oats, beans, and the like; and this is better at the back of the stable.

A few buckets of water dashed over the floor of the stable while the horses are at work, will keep all sweet. The litter 
should also be turned out to diry, and a little fresh straw spread for the horses to stale on. A shed placed beside the stable is a great advantage, on two accounts-it admits of the litter being dried, and the horse dressed there in wet and stormy weather.

A little powdered gypsum, strown upon the stable floor, will also act by absorbing the ammoniacal gas, and thus remoring its foul smell-a frequent predisposing cause of ophthalmia. If the ammonia, however, accumulates in any considerable quantity, the speediest and most efficacious remedy as a disinfectant is muriatic acid.

\section{AIR.}

The importance of thorough rentilation has been adrerted to under the preceding head, but a few words additional seem necessary.

A hot stable has in the minds of many been long connected with a glossy coat for the horse. The latter, it is thought, cannot be obtained without the former. To this it may be replied that in winter a thin, glossy coat is not desirable. Nature gives to every animal a warmer clothing when the cold weather approaches. The horse-the agricultural horse, especiallyacquires a thicker and a lengthened coat, in order to defend him from the surrounding cold. Man puts on additional and a warmer covering, and his comfort is increased and his health preserved by it. He who knows anything of the farmer's horse, or cares about his enjoyment, will not object to a cont a little longer, and a little roughened when the wintry wind blows bleak. The coat, however, does not need to be so long as to 
be unsightly; and warm clothing, even in a cool stable, will, with plenty of careful and faithful grooming, keep the hair sufficiently smooth and glossy to satisfy the most fastidious. The over-heated air of a close stable dispenses with the necessity of this grooming, and therefore the idle attendant unscrupulousiy sacrifices the health and safety of the horse.

If the stable is close, the air will not only be hot, but foul. The breathing of every animal contaminates it; and when, in the course of the night, with erery aperture stopped, it passes again and again through the lungs, the blood cannot undergo its proper and healthy change; digestion will not be so perfectly performed, and all the functions of life are injured. Let the orner of a valuable horse think of his passing twenty or twenty-two out of the twenty-four hours in this debilitating atmosphere. Nature does wonders in enabling every animal to accommodate itself to the situation in which it is placed, and the horse that lives in the stable-oven suffers less from it than would scarcely be deemed possible; but he does not, and cannot, possess the porrer and hardihood which he would acquire under other circumstances.

The air of the improperly closed and heated stable is still further contaminated by the urine and dung, which rapidly ferment there, and give out stimulating and unwholesome odors. When one first enters an ill-managed stable, and especially carly in the morning, he is annoyed, not only by the heat of the confined air, but by a pungent smell, resembling hartshorn; what surprise, then, need be excited at the inflammation of the eyes, and the chronic cough, and the disease of the lungs, by which the animal, which has been all night shut up in this vitiated atmosphere, is often attacked; or if glanders and farcy should occa- 
sionally break out in such stables? Chemical experiments have demonstrated that the urine of the horse contains in it an exceedingly large quantity of hartshorn; and not only so, but that, influenced by the heat of a crowded stable, and possibly by other decompositions which are going on at the same time, this ammoniacal vapor begins to be rapidly given out almost immediately after the urine is roided.

When disease begins to appear among the inhabitants of these ill-rentilated places, it is not wonderful that it should rapidly spread among them, and that the plague-spot should be, as it were, placed on the door of such a stable. When distemper appears in spring or autumn, it is in very many cases to be traced to such a pest-house. It is peculiarly fatal there. The loorses belonging to a small establishment, and rationaily treated, have it comparatively seldom, or, when they do, but lightly; but among the inmates of a crowded stable it is sure to display itself, and there it is most deadly. The experience of every veterinary surgeon, and of every large proprietor of horses, will corroborate this statement.

Every stable, then, should possess within itself a certain degree of rentilation. The cost of this would be trifling, and its saring in the preservation of valuable animals may be immense. The apertures need not be largse, and the whole, as before said, may be so contrived that no direct current of air shall fall on the horse.

A gentleman's stable should never be without a thermometer. 'The temperature should seldom exceed serenty degrees in the 6ummer, or sink below forty or fifty degrees in the winter. 


\section{IITTER.}

Having spoken of the vapor of hartshorn, which is so rapidly and plentifully giren out from the urine of a horse in a heated stable, the subject of litter comes naturally next in order. The first caution is, frequently to remove it. The early extrication of gas shows the rapid putrefaction of the urine; the consequence of which will be the rapid putrefaction of the litter which is moistened by it. Every thing hastening to decomposition should be carefully removed where life and health are to be preserved. The litter which has been much wet or at all softened by the urine, and is beginning to decay, should be swept away every morning; the greater part of the remainder may then be piled under the manger; a little being left to prevent the painful and injurious pressure of the feet on the hard parement during the day. The soiled and soaked portion of that which was left should bo removed at night. In the better lind of stables, however, the stalls should be completely emptied every morning.

No heap of fermenting dung should be suffered to remain during the day in the corner or in any part of the stable. With regard to this, the directions for removal should be peremptory.

The stable should be so contrived that the urine may quickly run off, and the offensive and injurious vapor from the decomposing fluid, and the litter will thus be materially lessened; but if this is effected by means of gutters and a descending floor, the descent must be barely sufficient to cause the fluid to escape, as, if the toes are kept higher than the heels, it will lead to lameness, and is also a frequent cause of contraction of the foot. 
Stalls of this lind certainly do best for mares; but for horses those are preferable, which have a grating in the centre, and a slight inclination in the floor on every side towards the middle. A short branch may communicate with a larger drain, by means of which the urine may be carried off to a reservoir outside the stable. Traps are now contrived, and may be procured at littlo expense, by means of which neither any offensive smell nor cur. rent of air can pass through the grating.

In stables with paved floors particularly, humanity and interest, as well as-the appearance of the stable, should induce the proprietor of the horse to place a moderate quantity of litter under him during the day.

\section{LIGHT.}

This neglected branch of stable-management is of $1 \pi$ more consequence than is generally imagined. The farmer's stable is frequently destitute of any glazed window, and has only a shutter, which is raised in warm weather, and closed when the weather becomes cold. When the horse is in the stable only during a few hours in the day, this is not of so much consequence, nor of so much, probably, with regard to horses of slow work; but to carriage-horses and roadsters, so far, at least, as the eyes are concerned, a dark stable is little less injurious than a foul and heated one. In order to illustrate this, reference may be made to the unpleasant feeling, and the utter impossibility - of seeing distinctly, when a man suddenly emerges from a dark place into the full glare of day. The sensation of mingled pain and giddiness is not speedily forgotten; and some minutes elapse before the cye can accustom itself to the increased light. If this were to happen erery day, or several times in a day, the 
sight would be irreparably injured, or possibly blindness would be the final result. We need not wonder, then, that the horse, taken from a dark stable into a blaze of light, feeling, probably, as we should do under similar circumstances, and unable for any time to see anything around him distinctly, should become a starter; or that the frequently repeated violent effect of sudden light slould induce inflammation of the eye so intense as to terminate in blindness. There is, indeed, no doubt that horses kept in dark stables are frequently notorious starter's, and that abominable habit has been properly traced to this cause.

If plenty of light be admitted, the walls of the stable, and especially that portion of them which is before the horse's head, must not be of too glaring a color. The color of the stable should depend on the quantity of light. Where much can be admitted, the walls should be of a gray hue. Where darkness would otherwise prevail, frequent painting may in some degree dissipate the gloom.

For another reason, it will be evident that the stable should not possess too glaring a light; it is the resting-place of the horse. The work of the farmer's horse, indeed, is principally confined to the day. The hours of exertion having passed, the animal returns to his stable to feed and to repose, and the latter is as necessary as the former, in order to prepare him for renewed work. Something like the dimness of twilight is requisite to induce the animal to compose himself to sleep. This half-light is more particularly adapted to horses of heavy work. In the quietness of a dimly-lighted stable, they obtain repose, and accumulate flesh and fat. 


\section{GROOMING.}

To the agriculturist it is not necessary to say much under this head, as custom, apparently without any ill effect, has allotted so little of the comb and brush for the farmer's horse. The animal that is worked all day, and turned out at night,

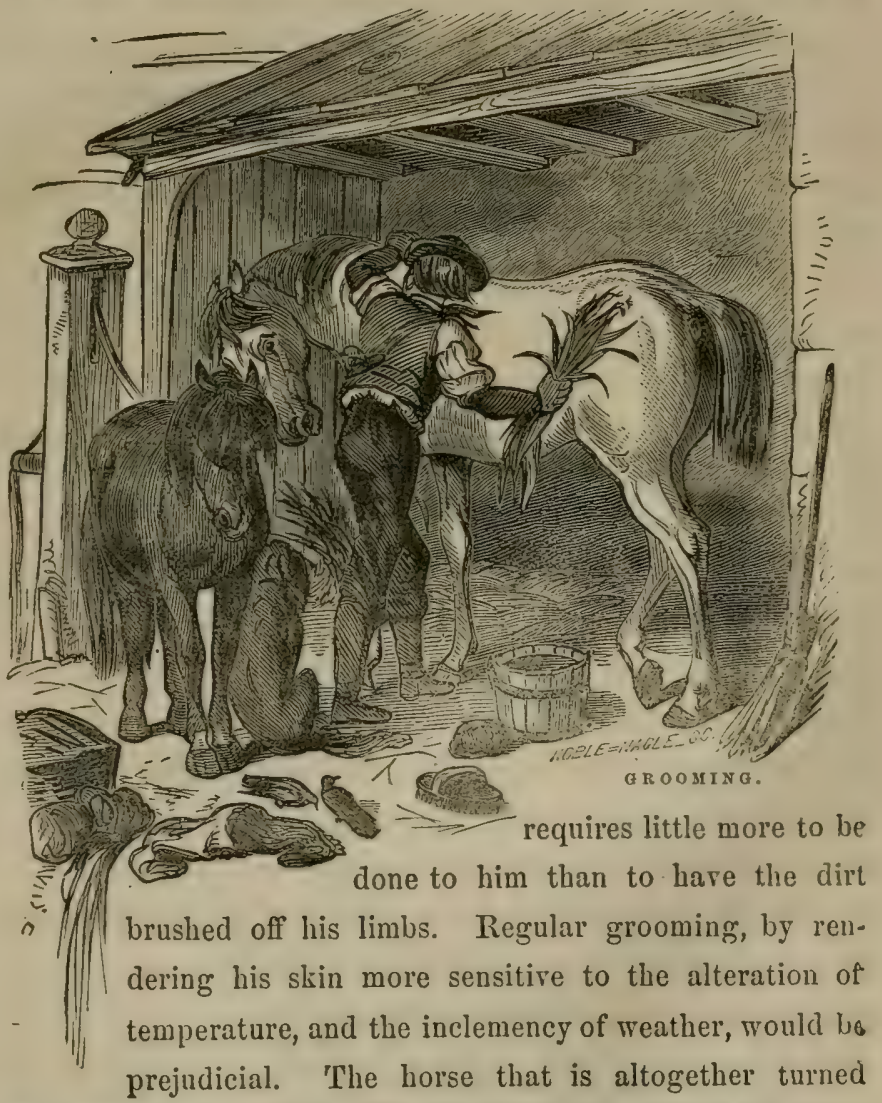
out, needs no groorning. The dandruff, or scurf, which accu- 
mulates at the roots of the hair, is a provision of nature to defend him from the wind and the cold.

It is to the stabled horse, highly fed, and little or irregularly worked, that grooming is of so much consequence. Good rubbing with the brush, or the curry-comb, opens the pores of the skin, causes the blood to circulate to the extremities of the body, produces free and bealthy perspiration, and stands in the stead of exercise. No horse will carry a fine coat without either unnatural heat, or dressing. They both effect the same purpose; they both increase the insensible perspiration; but the first does it at the expense of health and strength, while the second, at the same time that it produces a glow on the skin, and a determination of blood to it, rouses all the energies of the frame. It would be well if the proprietor of the horse were to insist-and to see that his orders are implicitly obeyed - that the fine coat, in which he and his groom so much delight, is produced by honest rubbing, and not by a heated stable and thick clothing, and, most of all, not by stimulating or injurious spices. The horse should be regularly dressed every day, in addition to the grooming that is necessary after work.

When the weather will permit the horse to be taken out, he should never be groomed in the stable, unless he is an animal of peculiar value, or placed for a time under peculiar circumstances. Without dwelling on the want of cleanliness, when the scurf and dust which are brushed from the horse lodge in his manger, experience teaches that, if the cold is not too great, the animal is braced and invigorated to a degree that cannot be attained in the stable, from being dressed in the open air. There is no necessity, however, for half the punish- 
ment which is often inflicted upon the horse in the act of dressing; and particularly on one whose skin is thin and sensitire. The curry-comb should always be applied lightly. With many horses, its use may be almost dispensed with; and even the brush does not need to be so hard, nor the points of the bristles so irregular as they often are. A soft brush, with a little more weight of the hand, will be equally effectual, and much more pleasant to the horse. A hair-cloth, while it will scldom irritate and tease, will be almost sufficient with horses that have a thin slin, and that have not been neglected. After all, it is no slight task to dress a horse as it ought to be done. It occupies no little time, and demands considerable patience, as well as dexterity. It will be readily ascertained whether a horse has been well dressed, by rubbing him with one of the fingers. A greasy stain will expose the idleness of the groom. When, however, the horse is changing his coat, both the curry-comb and the brush should be used as lightly as possible.

Whoever would be conrinced of the benefit of friction to the horse's skin, and to the horse generally, needs only to observe the effects produced by rubbing the legs of a tired horse well with the hands. While every enlargement subsides, and the painful stiffness disappears, and the legs attain their uatural warmth and become fine, the animal is evidently and rapidly reviving; he takes hold of his food with zest, and then quietly lies down to rest.

EXERCISE.

The remarks upon this branch, also, can have but a slight reference to the agricultural horse. His work is usually, regu- 
lar, and not exhausting. He is neither predisposed to disease by idleness, nor worn out by excessive exertion. He, like bis master, has enough to do to keep him in health, and not enough to distress or injure him; on the contrary, the regularity of his work prolongs life to an extent seldom witnessed in the stable of the gentleman. These remarks on exercise, then, must have a general bearing, or have principal reference to those persons who keep a horse for business or pleasure, but cannot afford to maintain a servant for the express purpose of looking after it. The first rule to be laid down is, that every horse should have daily exercise. The animal, that with the usual stable feeding stands idle for three or four days, as is the case in many establishments, must suffer. $\mathrm{He}$ is predisposed to fever, or to grease, or, most of all, to diseases of the foot; and if, after three or four days of inactivity, he is ridden far and fast, he is almost sure to lave inflammation of the lungs or of the feet.

Any horse, used for business or pleasure merely, suffers much

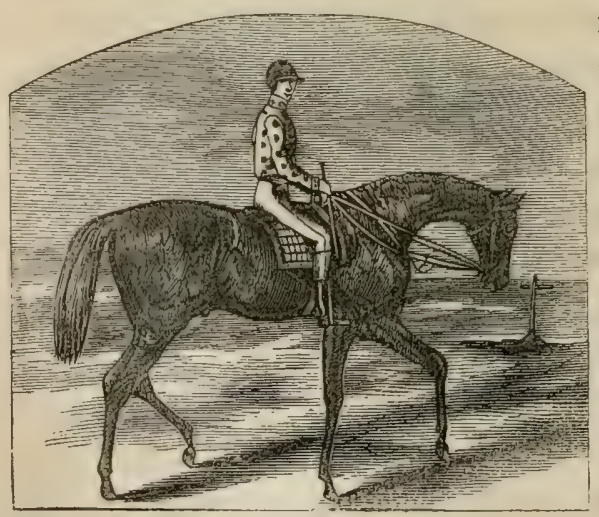
more from idleness than he does from work. A stable-fed horse should have two hours' exercise every day, if he is to be kept free from disease. Nothing of extraordinary, or even of ordinary, labor can be effected MEERCISE. on the road or in 
the field, without sufficient and regular exercise. It is this which alone can give energy to the system, and derelop the powers of any animal.

In training the race-horse, or the horse for hunting purposes, regular exercise is the most important of all considerations, however much it may be neglected in the usual management of the stable. The exercised horse will discharge his task, and sometimes a severe one, with ease and pleasure; while the idle and neglected one will be fatigued before half his labor is accomplished; and, if he is pushed a little too far, dangerous inflammation will ensue. How often, nevertheless, does it happen, that the horse which has stood inactive in the stable for three or four days, is ridden or driven thirty or forty miles in the course of a single day! The rest is often purposely given in order that he may be prepared for extra exertion-to lay in a stock of strength for the performance required of him-and then the owner is surprised and dissatisfied if the animal is fairly knocked up, or possibly becomes seriously ill. Nothing is so common and so preposterous, as for a person to buy a horse from a dealer's stable, where he has been idly fattened for sale for many a day, and immediately to give him a long run, and then to complain bitterly, and think that he has been imposed upon, if the animal is exhausted before the end, or is compelled to be led home suffering from violent inflammation. Regular and gradually increasing exercise would have made the same horse appear a treasure to his owner.

Exercise should be somewhat proportioned to the age of the horse. A young horse requires more than an old one. $\mathrm{Na}$ ture has given to young animals of every kind a disposition to 
activity; but the exercise must not be violent. Much depends upon the manner in which it is given. To preserve the temper, and to promote bealth, it should be moderate, at least at the beginning and at the termination. The rapid trot, or even the gallop, may be resorted to in the middle of the exercise,' but the horse should be brought in cool.

\section{FOOD.}

One half of the diseases of the horse owe their origin to over-feeding with hay. This applies more particularly to joung horses, and to such as are not put to severe work. They are ever placed before a full rack, and, like children gorged with bread and butter, they eat merely for amusement; until at length the stomach gradually becomes preternaturally distended, the appetite increases in a relative proportion, becomes sooner or later voracious, and finally merges into a mere craving-it being a matter of indifference what the food is, so that the stomach is filled with it. This depravity of appetite is always accompanied by more or less thirst. This naturally enough produces general debility of the entire digestive function, including stomach, bowels, liver, spleen, and pancreas; worms are produced in thousands, and symptoms present themselves of so many varied hues, that enumeration, far less classification, becomes utterly impossible.

A horse's appetite is not to be taken as the criterion by which to determine the quantity of hay which he is to be permitted to consume; for most horses will eat three or four times as much as they onght. Horses have been known to consume thirty pounds weight of hay between a day and a night; and ten pounds is the most that should have been given during 
that time. Upon eight pounds of hay daily, with a due allowance of oats, a horse can be kept in full work, in prime health and spirits. It is better to keep young horses at grass until qbont five years old, and to work them during that period. When kept in the stable and not worked they are apt to acquire many rery bad habits; and if the rack and manger be kept empty, with a view of preventing the over-loading of their stomachs, they will fall into a habit of playing with and mouthing them-a habit which finally degenerates into wind-sucking or crib-biting.

The system of manger-feeding is now becoming general ımong farmers. There are fer horses that do not habitually Faste a portion of their hay; and by some the greater part is Wulled down and trampled under foot, in order first to cull the stveetest and best locks, which could not be done while the hay was confined in the rack. A good feeder will afterward pick up much of that which was thrown down: but some of it must be soiled and rendered disgusting, and, in many cases, one-third of this division of their food is wasted. Some of the oats and beans are imperfectly chewed by all horses, and scarcely at all by hungry and greedy ones. The appearance of the dung will sufficiently establish this.

The observation of this induced the adoption of mangerfeeding, or of mixing a portion of cut feed with the grain and beans. By this means the animal is compelled to chew his - food; he cannot, to any great degree, waste the straw or hay; the cut feed is too hard and too sharp to be swallowed without sufficient mastication, and while he is forced to grind that down, the oats and the beans are also ground with it, and thus yield more nourishment; the stomach is more slowly filled, and there- 
fore acts better upon its contents, and is not so likely to be over.loaded; and the increased quantity of saliva thrown out in the protracted maceration of the food, softens it, and makes it more fit for digestion.

Cut feed may be composed of equal quantities of clover or of meadow hay; and wheaten, oaten, or barley straw, cut into pieces of a half or an inch in length, and mingled well together; the allowance of oats or beans is afterwards added, and mixed with the whole. Many farmers very properly bruise the oats or beans. The whole oat is apt to slip out of the feed and be lost; but when it is bruised, and especially if the feed is wet a little, it will not readily separate, or, should a portion of it escape the grinders, it will be partly prepared for digestion by the act of bruising. The prejudice against bruising the oats is utterly unfounded, so far as the farmer's horse, and the wagon horse, and every horse of slow dranght, are concerned. The quantity of straw in the feed will always counteract, any supposed purgative quality in bruised oats. Horses of quicker draught, uuless they are actually inclined to scour, will thrive better on bruised than on whole oats; for a greater quantity of nutriment will be extracted from the food, and it will always be easy to apportion the quantity of straw or beans to the effect of the mixture on the bowels of the horse. The principal alteration that should be made for the horse of harder and more rapid work, such as the post-horse and the stage-coach horse, is to increase the quantity of hay, and diminish that of straw. Two trusses of hay may be cut with one of straw.

Some gentlemen, in defiance of the prejudice and opposition of the coachman or groom, have introduced this mode of feed- 
ing into the stables of their horses, and with manifest advantage. There has been no loss of condition or power, and considerable saving of provender. This system is not however, calculated for the hunter, or the race-horse. Their food must lie in smaller bulk, in order that the action of the lungs may not be impeded by the distention of the stomach; yet many hunters have gone well over the field who have been manger-fed, the proportion of grain, however, being materially increased.

For the agricultural and cart-horse, eight pounds of oats, and two of beans should be added to every twenty pounds of cut feed. Thirty-four or thirty-six pounds of the mixture will be sufficient for any horse of moderate size, with fair, or even hard, work. The dray and wagon horse may require forty pounds. Hay in the rack at night is, in this case, supposed to be altogether omitted. The rack, however, may remain, as occasionally useful for the sick horse, or to contain green feed.

Horses are very fond of this provender. The great majority of them, after having become accustomed to it, will leare the best oats giren to them alone, for the sake of the mingled cut feed and grain. The farmer should be cautioned, however, not to set apart damaged hay for the manufacture of the cut feed. The horse may thus be induced to eat that which he would otherwise refuse, and if the nourishing property of the hay has been impaired, or it has acquired an injurious principle, the animal will either lose condition, or become diseased. Much more injury is done by eating damaged hay, or musty oats, than

- is generally imagined. There will be sufficient saving in the diminished cost of the provender by the introduction of the straw and the improved condition of the horse, without poisoning him with the refuse of the farm. For old horses, and for 
those with defective teeth, cut feed is peculiarly useful, and for them the grain should be broken down as well as the fodder.

While the mixture of the cut feed with the grain prevents it from being too rapidly devoured and a portion of it swallowed whole, and therefore the stomach is not too loaded with that oll which, as containing the most nutriment, its chief digestive power should be exerted; yet, on the whole, a great deal of time is gained by this mode of feeding, and more is left for rest. When a horse comes in wearied at the close of the day, it occupies, after he has eaten his grain, two or three hours to clear his rack. On the system of manger-feeding, the chaff being already cut into small pieces, and the beans and oats bruised, he is able fully to satisfy his appetite in an hour and a half. Two additional hours are therefore devoted to rest. This is a circumstance deserving of much consideration, even in the farmer's stable ; and of inmense consequence to the stage-coach proprietor, the livery-stable keeper, and the owner of every hardworked horse.

Manger food will be the usual support of the farmer's horse during the winter, and while at constant or occasional hard work; but from the middle of April to the end of July, he may be fed with this mixture in the day, and turned out at night, or he may remain out during every rest-day. A team in constant employ should not, however, be suffered to be out at night after the end of July.

The farmer should take care that the pasture is thick and good; and that the distance from the yard is not too great, or the fields too large, otherwise a very considerable portion of time will be occupied in catching the horse in the morning. He will likewise have to take into consideration the sale he 
would have for his hay, and the necessity of sweet and untrodden pasture for his cattle. On the

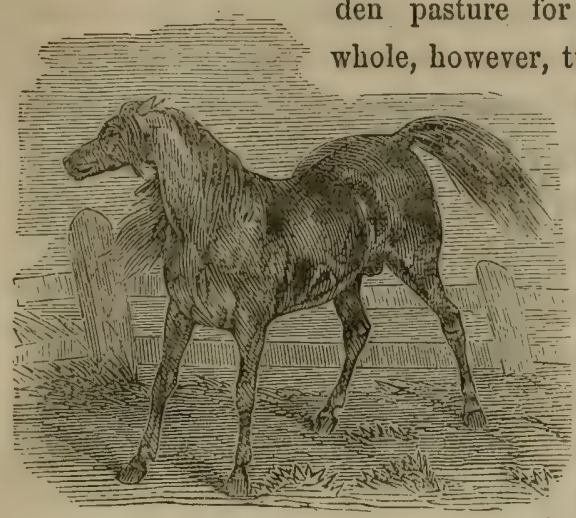

OUT TO GRASS.

w hen circumstances will admit of it, will be found to be more beneficial for the horse, and cheaper than soiling in the yard.

The horse of the inferior farmer is sometimes fed on hay or grass alone, and the animal, although he rarely gets a feed of grain, maintains himself in tolerable condition, and performs the work required of him; but hay and grass alone however good in quality, or in whatever quantity allowed, will not support a horse under hard work. Other substances, containing a large proportion of nutriment in a smaller compass, have been added; a brief enumeration of which follows, and an estimate is formed of their comparative value.

In almost every part of Great Britain and this country, OATS have been selected as that portion of the food which is to afford the principal nourishment. They contain from seven hundred and forty-three to seven hundred and fifty parts of the nutritire matter. They should be abont, or somewhat less than, a year old, heavy, dry, and sweet. New oats will weigh ten or fifteen per cent. more than old ones; but the difference consists principally in watery matter, which is gradually evaporated. New oats are not so readily ground down by the teeth as old 
ones. They form a more glutinous mass, difficult to digest, and, when eaten in considerable quantities; are apt to occasion colic, or even staggers. If they are to be used before they are from three to five months old, they would be materially improved by a little kiln-drying. There is no fear for the horses from simple drying, if the grain is good when put into the kiln. The old oat forms, when chewed, a smooth and uniform mass, which readily dissolves in the stomach, and yields the nourishment which it contains. Perhaps some chemical change may have been slowly effected in the old oat, disposing it to be more readily assimilated. Oats should be plump, bright in color, and free from unpleasant smell or taste. The musty smell of wet or damaged grain is produced by a fungus growing upon the seed, which has an injurious effect upon the urinary organs, and often on the intestines, producing profuse staling, inflammation of the kidneys, colic, and inflammation of the bowels.

This musty smell is remored by kiln-drying the oat; but care is here requisite that too great a degree of heat is not employed. It should be sufficient to destroy the fungus without injuring the life of the seed. A considerable improvement would be effected by cutting the unthrashed oat-straw into chaff, and the expense of thrashing would be saved. Oatstraw is better than that of barley, but does not contain so much nutriment as that of wheat.

When the horse is fed on hay and oats, the quantity of the oats must vary with his size and the work to be performed. In winter, four feeds, or from ten to fourteen pounds of oats in the day, will be a fair allowance for a horse of fifteen hands and one or two inches in height, and that has moderate work. 
In summer, half the quantity with green feed will be sufficient. Those which work on the farm have from ten to fourteen pounds, and the hunter from twelve to sixteen. There are no efficient and safe substitutes for good oats; but, on the contrary, it may be safely asserted, that they possess an invigorating property which is found in no other kind of food.

Oatmeal forms a poultice more stimulating than one composed of linseed-meal alone-or they may be mingled in different proportions, as circumstances require. In the form of gruel, it constitutes one of the most important articles of diet for the sick horse; not, indeed, to be forced upon him, but a pail containing it being slung in his box, of which he will soon begin to drink when water is denied. Gruel is generally either not boiled long enough, or a sufficient quantity of oatmeal is not used for it. The proportions should be, a pound of meal throm into a gallon of water, and kept constantly stirred until it boils, and five minutes afterwards.

White-water, made by stirring a pint of oatmeal in a pail of water, the chill being taken from it, is an excellent beverage for the thirsty and tired horse.

BARLEY is a common food of the horse in various parts of the continent, and, until the introduction of oats, seems to have constituted almost his only food. It is more nutritious than oats, containing nine hundred and twenty parts of nutritive matter in erery thousand. There seems, however to be something necessary besides a great proportion of nutritive matter, in order to render any substance wholesome, strengthening, or fattening; therefore it is, that with many horses that are hardly worked, and, indeed, with horses generally, barley does not agree so well as oats. They are occasionally subject to inflammatory complaints, and particularly to surfeit and mange. 
When barley is given, the quantity shonld not exceed a peck daily. It should always be bruised, and the chaff should consist of equal quantities of hay and barley-straw, and not cut too short. If the farmer has a quantity of spotted or unsalable barley that he wishes thus to get rid of, he must accustom his horses to it very gradually, or he will probably produce serious illness among them. For horses that are recovering from illness, barley, in the form of malt, is often serviceable, as tempting the appetite and recruiting the strength. It is best given in mashes -water, considerably below the boiling heat, being poured upon it, and the vessel or pail kept covered for half an hour.

Grain, fresh from the mash-tub, either alone or mixed with oats or chaff, or both, may be given occasionally to horses of slow draught; they would, however, afford very insufficient nourishment for horses of quicker or harder work.

Whent is more rarely given than barley. It contains nine hundred and fifty-five parts of nutritive matter. When farmers have a damaged or unmarketable sample of wheat, they sometimes give it to their horses, and, it being at first used in small quantities, they become accustomed to it, and thrive and work well; it should, however, always be bruised, and given in chaff. Wheat contains a greater portion of gluten, or sticky, adhesive matter, than any other kind of grain. It is difficult of digestion, and apt to cake and form obstructions in the bowels. This will more often be the case, if the horse is suffered to drink much water soon after feeding upon it.

Fermentation, colic, and death, are occasionally the consequence of eating any great quantity of wheat. A horse that is fed on it, should have very little hay. The proportion should not be more than one truss of hay to two of straw. Wheat or 
flour, boiled in water, to the thickness of starch, is given with good effect in over-purging, especially if combined with chalk and opium.

Bras, or the ground husk of the wheat, used to be frequently given to sick horses, on account of the supposed advantage derived from its relaxing the bowels. There is no doubt that it does operate gently on the intestinal canal, and assists in quickening the passage of its contents, when occasionally given; but it must not be a constant, or even frequent food. Bran or pollard often accumulates in the intestines, when given injudiciously, seriously impairing the digestive powers. Bran may, however, be useful as an occasional aperient in the form of a mash, but never should become a regular article of food.

BEANS afford a striking illustration of the principle, that the nourishing or strengthening effects of the different articles of food depend more upon some peculiar pro-
quantity of nutri-
tive matter. Beans
contain but from
ing they add materially to the vigor of the horse. There are many horses that will not stand hard work without beans being mingled with their food; and there are horses, whose tendency to purge it may be necessary to restrain by the astrin- 
gency of the bean. There are few travelers who are not aware of the difference in the spirit and continuance of the horse, whether he is allowed or denied beans during the continuance of the journey. They afford not merely a temporary stimulus, but they may be daily used without losing their power, or producing exhaustion. They are indispensable to the hard-worked coach-horse. Weakly horses could never get through their work without them; and old horses would otherwise often sink under the task imposed upon them. They should not be given whole, or split, but crushed. This will make a material difference in the quantity of nutriment which will be extracted. They are sometimes given to turf-hor'ses, but only as an occasional stimulant. Two pounds of beans may, with advantage, be mixed with the chaff of the agricultural horse, during the winter. In summer, the quantity of beans should be lessened, or they should be altogether discontinued. Beans are generally given whole. This is very absurd; for the young horse, whose teeth are strong, seldom requires them; while the old horse, to whom they are in a measure necessary, is scarcely able to masticate them, swallows many of them which he is unable to break, and drops much grain from his mouth in the ineffectual attempt to crush them. Beans should not be merely split, but crushed; as they will even then furnish sufficient employment for the grinders of the animal. Some persons use chaff with beans, instead of oats. This may possibly be allowed with hardly-worked horses; but, in general cases, beans without oats would be too binding and stimulating, and would produce costiveness, and probably megrims or staggers.

Beans should be at least a twelremonth old before they are given to the horse, and they should be carefully preserved from 
damp and mouldiness, which at least disgust the animal, if they do no other harm, and harbor an insect which destroys the inner part of the bean.

The straw of the bean is nutritive and wholesome, and is usually given to the horses. Its nutritive properties are suppposed to be little inferior to those of oats. The small and plump bean is generally the best.

Peas are occasionally given. They appear to be in a slight degree more nourishing than beans, and not so heating. They contain five hundred and seventy-four parts of nutritive matter. For horses of slow work they may be used; but the quantity of chaff should be increased, and a few oats added. They have not been found to answer with horses of quick draught. It is essential that they should be crushed; otherwise, on account of their globular form, they are apt to escape from the teeth, and many are swallowed whole. Exposed to warmth and moisture in the stomach, they swell considerably, and may painfully and injudiciously distend it. The peas that are given to horses should be sound, and at least a year old. In some sections, pea-meal is frequently used, not only as an excellent food for the horse, but as a remedy for diabetes.

LINSEED is sometimes given to sick horses-raw, ground, and boiled. It is supposed to be useful in cases of catarrh.

INDIAN CoRN in combination with roots, forms a valuable article of diet. Horses will eat the mess with an avidity of appetite calculated to excite surprise at first. The mess, to which a little salt should invariably be added, will keep them in fair average condition; and those which it is desirable to fatten may have a small quantity of oats, pea or bran meal added. 
HAY is most in perfection when it is about a year old. The horse, perhaps, would prefer it earlier, but it is then neither so wholesome nor so nutritive, and often has a purgative quality. When it is about a year old, it retains, or should retain, somewhat of its green color, its agreeable smell, and its pleasant taste. It has undergone the slow process of fermentation, by which the sugar which it contains is developed, and its nutritive quality is fully exercised. Old hay becomes dry and tasteless, and innutritive and unwholesome. After the grass is cut, and the hay stacked, a slight degree of fermentation takes place in it. This is necessary for the development of the saccharine principle; but it occasionally proceeds too far, and the hay becomes mow-burnt, in which state it is injurious, or even poisonous. The horse soon shows the effect which it has upon him. He has diabetes to a considerable degree; he becomes, hidebound; his strength is wasted; his thirst is excessive; and he is almost worthless.

Where the system of manger-feeding is not adopted, or where hay is still allowed at night, and chaff and grain in the day, there is no error into which the farmer is so apt to fall as to give an undue quantity, and that generally of the worst kind. The pernicious results of this practice have been already mentioned in the commencement of this bead, and the practice cannot be too strongly reprobated.

It is a good practice to sprinkle the hay with water in which salt has been dissolved. It is evidently more palatable to the animal who will leare the best unsalted hay for that of an inferior quality which has been moistened with brine; and there can be no doubt that the salting materially assists the process of digestion. The preferable way of salting hay is to sprinkle 
it over the different layers as it is put away, or as the stack is formed. From its attraction to water, it would combine with that excess of moisture which in wet seasons, is the cause of too rapid and violent fermentation, and of the hay becoming moistened, or of the stack catching fire, and it would become more incorporated with the hay. The only objection to its being thus used is, that the color of the hay is not so bright; but this will be of little consequence for home consumption.

Clover is useful for soiling the horse; and clover hay is preferable to meadow hay for chaff. It will sometimes tempt the sick horse, and may be given with advantage to those of slow and heavy work; but custom seems properly to have forbidden it to the roadster or those used for quick work.

The Stwedish Turnip is an article of food, the value of which, particularly for agricultural horses, has not been sufficiently appreciated. Although it is far from containing the amount of nutritive matter which many have supposed, that which it has seems to be capable of complete and easy digestion. It should be sliced with chopped straw, and without hay. It quickly fattens the horse, and produces a smooth glossy coat and a loose skin. It is a good plan to give it once a day, and that at night when the work is done.

The virtues of CARrots are not suffciently known, both as contributing to the strength and endurance of the sound horse, and to the rapid recovery of the sick one. To the healthy horse they should be given sliced in his chaff. Half a bushel will be a fair daily allowance. There is little provender, of which the horse is more fond. There is none better, nor, perhaps, so good. When first giren, it is slightly diuretic and laxative, but as the horse becomes accustomed to it, these effects 
cease to be produced. They also improve the state of the skin. They form a good substitute for grass, and an excellent alterative for horses out of condition. For sick and idle horses they render grain unnecessary. They are beneficial in all chronic diseases connected with breathing, and have a marked influence upon chronic cough and broken wind. They are serviceable in diseases of the skin, and in combination with oats they restore a worn horse much sooner than oats alone.

Potatoes have been given and with advantage in their raw state, sliced with chaff; but, where it has been convenient to boil or steam them, the benefit has been far more evident. Purging then has rarely ensued. Some have given boiled potatoes alone, and horses, instead of rejecting them, have soon preferred them even to oats; but it is better to mix them with the usual manger feed, in the proportion of one pound of potatoes to two and a half pounds of the other ingredients. The use of the potato must depend upon its cheapness, and the facility for boiling it. Those who have tried potatoes extensively in the feeding of horses, assert that an acre of potatoes goes as far as four acres of hay. A horse fed upon them should have his quantity of water materially curtailed. Half a dozen horses would soon repay the expense of a steaming boiler for potatoes in the saving of provender alone, without taking into account their improved condition and capability for work.

The times of feeding should be as equally divided as convenience will permit; and when it is likely that the horse will be kept longer than usual from home, the nose-bag should invariably be taken. The small stomach of the horse is emptied in a few hours; and if he is allowed to remain hungry much beyond his accustomed time, he will afterwards devour his food 
so voraciously as to distend the stomach and endanger an attack of the staggers.

When extra work is required from the animal, the system of management is often injudicious; for a double feed is put upon him, and as soon as he has swallowed it, he is started. It would be far better to give him a double feed on the previous evening, which would be digested before he is wanted, and then he might set out in the morning, after a very small portion of grain had been given to him, or, perhaps, only a little hay. One of the most successful methods of enabling a horse to get well through a long journey, is to give him only a little at a time while on the road, and at night to indulge him with a double feed of grain and a full allowance of beans.

\section{WATER.}

The watering of the horse is a very important but disregarded portion of his general management, especially by the farmer. He lets his horses loose morning and night, and they go to the nearest pond or brook and drink their fill, and no harm results; for they obtain that kind of water which nature designed them to have, in a manner prepared for them by some unknown influence of the atmosphere, as well as by the deposition of many saline admixtures.

The kind of water fitted for the horse has not been, as a general thing, sufficiently considered. The difference between what is termed hard and soft water, is a circumstance of general observation. The former contains certain saline principles, which decompose some bodies, as appears in the curdling of soap, and prevent the decomposition of others, as in the maling of tea, the boiling of regetables, and the process of brewing. 
It is natural to suppose that these different kinds of water would produce somewhat differing effects upon the animal frame: and such is the case. Hard water, freshly drawn from the well, will frequently roughen the coat of the horse unaccustomed to it, or cause griping pains, or materially lessen the animal's power of exertion. The racing and the hunting-groom are perfectly aware of this; and instinct or experience has made even the horse conscious of it, for he will never drink hard water if he has access to soft, and he will leave the most transparent and the purest water of the well for a river, although the stream may be turbid, and even for the muddiest pool. Some trainers, indeed, have so much fear of hard or strange water, that they carry with them to the different courses the water which the animal has been accustomed to drink, and that which they know agrees with it.

The temperature of the water is of far more consequence than its hardness. It will rarely harm if taken from the pond or the running stream; but its coldness, when recently drawn from the well, has often proved injurious; it has produced colic, spasms, and even death.

There is often considerable prejudice against the horse being fairly supplied with water. It is supposed to chill him, to injure his wind, or to incapacitate him for hard work. It certainly would do so, if, immediately after drinking bis fill, he were galloped hard; but not if he were suffered to quench his thirst more frequently when at rest in the stable. The horse that has free access to water, will not drink so much in the course of the day as another, who, in order to cool his parched mouth, swallows as fast as he can, and knows not when to stop. 
A horse may, with perfect safety, be far more liberally sup. plied with water than he generally is. An hour before his work commences, he should be permitted to drink a couple of quarts. A greater quantity might probably be objectionable. He will perform his task far more pleasantly and effectually than with a parched mouth and tormenting thirst. The prejudice both of the hunting and the training groom on this point is cruel, as well as injurious. The task or the journey being accomplished, and the horse haring had his head and neck dressed, his legs and feet washed, should have his water before his body is cleaned. When dressed, his grain may be offered to him, which he will readily take; but water should never be given immediately before or after the grain.

If the horse were watered three times a day, especially in summer, he wonld often be saved from the sad torture of thirst and from many a disease. Whoever has observed the eagerness with which the overworked horse, hot and tired, plunges his muzzle into the pail, and the difficulty of stopping him before he has drained the last drop, may form some idea of his previous suffering, and will not wonder at the violent spasms, inflammation, and sudden death, that often follow.

It is a judicious rule with travelers, that when a horse begins to refuse his food, he should be pushed no further that day. It may, horvever, be worth while to ascertain whether this does not proceed from thirst as much as from exhaustion; for in many instances his appetite and his spirits will return soon after he has partaken of the refreshing draught. 


\section{PASTURING.}

So far as mere health is concerned, grass is the most salubrious food which the horse can receive. When it is eaten where fit grows, the horse is said to be turned out, to be getting a run at grass, or to be at grass. When it is cut, and consumed in the stable, the horse is said to be soiled.

It is probable that grass eaten in the field produces quite the same effects as that eaten in the stable. But at pasture, there are several agents in operation to which the stabled horse is not necessarily exposed. The excreise which he must take; the position which his head must assume, in order that he may obtain food; the annoyance he suffers from flies; his exposure to the weather; the influence of the soil upon the feet and legs; and the quantity of food placed at his disposal; are the prinsipal points wherein pasturing differs from soiling.

The Exencise which he must take as he gathers his food, varies according to the herbage. When the ground is bare, the exercise may amount even to work, but to a sound horse it is never injurious; in cold weather it keeps him warm, or, at least, prevents him from becoming very cold. With a lame horse, the case is different. In some species of lameness, as in chronic diseases of the joints, the slow but constant exercise thus rendered necessary is highly beneficial; but the exertion demanded by a bare pasture is unfavorable to any sprain or lameness arising from disease in the ligaments and tendons. Lameness, when very great, no matter where seated, forbids pasturing, even though the grass be knee-high. The pain of standing, and moving on two or three legs, may be so great that the horse will be obliged to lie down before he has ob- 
taincu half a meal. It is for slight lameness only that horses should be turned out; and the pasture should be such as to afford sufficient nutriment, without giving the horse more exercise than is good for the disease.

The legs of fast-working horses often become turned, shapeless, tottering, bent at the knee, and

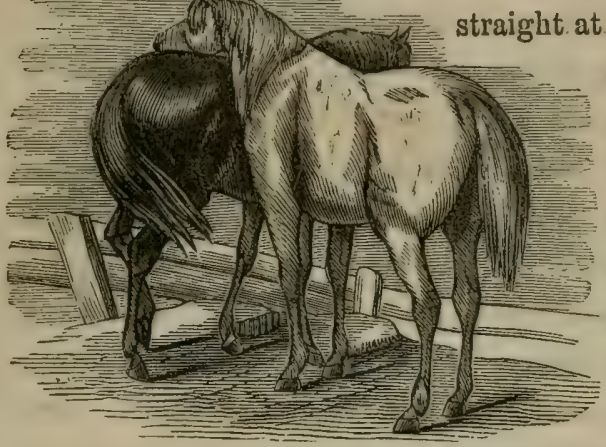

PASTURING. always improve at pasture, as, indeed, they do in the stable, or loose-box, when the horse is thrown out of work. Grazing exercise does not appear to be unfavorable to

their restoration; but when the knees are very much bent, the horse is unfit for turning out; he cannot graze; when his head is down, he is ready to fall upon his nose, and it costs him much effort to maintain his balance.

THE POSITION OF THE HEAD in the act of grazing is unfarorable to the return of blood from the brain, from the eyes, from all parts of the head. Horses that have had staggers, or bad eyes, those that have recently lost a jugular vein, and those that have any disease about the head-strangles, for instanceshould not be sent to pasture. The disease becomes worse. or. if gone, is apt to return. Even healthy horses are liable to attacks on the brain, when turned to grass, particularly when ine weather is hot, and the herbage abundant.

Horses that have been for more than a year in the stable, 
and especially those that have been reined up in harness, often experience considerable difficulty in grazing. The neck is rigid, and the muscles which support the head are short. It is often several weeks before an old coach-horse can graze with ease. Very old coach-horses that have short, stiff necks, should not be turned out when they can be kept in; if they must go, they should be watched, lest they die of want.

Exposure to the Weather. Wet, cold weather always produces emaciation and a long coat. If the horse is put out without preparation, he is apt to have an attack of inflamed lungs, or sore throat, or a common cold, with discharge from the nose, and may sicken and die. Many persons seem to think that no usage is too bad for the horse, if it do not immediately produce some fatal disease. Early in spring, or late in autumn, the animal is turned out of a warm, comfortable stable, and left to battle with the weather as he best can. He crouches to the side of a wall, shivering and neglected, as if he bad no friend in the world. In time, the horse becomes inured to the weather, if he does not sink under it, but sometimes he comes home with diseased lungs, and very often with a cough which never leaves him, and which produces broken wind.

Shelter, so easily provided-at the cost of a few rude boards even-is too much neglected in the pasture. A hovel, covered on three sides, the fourth open to the south, and just high enough to admit the horse, will answer the purnose. The bottom should be sloping, elevated, and quite dry. When litter can be afforded, it will tempt the horse out of the blast. There may be hay-racks and mangers, strong, though of rude construction. In summer, the horse can retire here during the heat of the day, and in the more inclement season he may thus avoid the wind and the storm. 
Exposure to hot weather is not so pernicious, although it always produces pain, if the horse be turned out in the middle of summer. For a while he is fevered all day and loses flesh ; but he soon recovers. The parts that are most apt to suffer are the brain and the eyes. Staggers, that is, an affection of the brain, is not common, and the eyes never suffer permanent mischief. They are inflamed by the flies, but the brain is injured, partly by tie heat, and partly by the pendent position of the head.

FLIES. The horse is persecuted by at least three kinds of flies. One, the common horse-fly, settles on his ears and different parts of his body, tickling and teazing him. Another is a large fly, termed the gad-fly; it is a blood-sucker, bites pretty smartly, and irritates some tender-skinned horses almost to madness, forcing them sometimes to rush into the water to escape their attacks. Another fly is a small insect, whose name is unknown, which lives in the blood, attacking those parts where the skin is thinnest, as the eyelids, inside and outside, the sheath, and the vagina. The eyelids especially always swell where this fly abounds, and the swelling is sometimes so great as to make the horse nearly blind, while the eye is red and weeping. The injury however, is not permanent.

The principal defense which the horse has against these puny, but tormenting enemies, is his tail. On some parts of his body he can remore them with his teeth and his feet; and that which cannot be done by these, is done by the tail. With us, however, in far too many instances the effective instrument which nature has furnished is removed, or materially impaired, before he has attained maturity; and, as if the pains of scrvitude were not sufficiently great and numerous, domestication is rendered still more intolerable by whim and caprice. 
Tre sorr. Much has been said about the influence of the soil upon the horse's feet and legs, and much exaggeration of assertion has been set afloat. Horses reared in soft, marshy pastures have large flat feet, low at the heels, and weak everywhere. On dry ground the boof is hard, strong, and small, the sole concave, and the heels high. But to impart any peculiar character to the hoof, or to produce any change upon it, a long and continuous residence upon the same lind of soil is necessary. A period of six months may produce some change; but it is so insignificant in general that it is not apparent.

The low temperature at which the feet and legs are kept in a moist pasture has probably some influence, though not very great, in abating inflammation in those parts. The legs become finer and free from tumors and gourdiness; but they would improve nearly or quite as soou, and as much, in a loose box.

When the pastures are hard and baked by the sun, unshod horses are apt to break away the crust, and they often come home with hardly horn enough to hold a nail. Feet that have never been shod suffer less; others should, as a general thing, be preserved by light shoes, especially on the fore feet; kicking horses, when shod behind, are rather dangerous among others.

It has been supposed that the act of grazing throws con siderable stress upon the tendons of the fore legs, and ultimately impairs them. This has been urged against grazing hunters; but so far as sound legs are concerned, there seems to be no foundation for the supposition, and it certainly has never been proved. 
Quantity of Food. In the stable, a horse's food can be apportioned to him as bis wants may require; but at pasture, he may get too much or too little. It is difficult to put the horse where he will obtain all the nourishment he needs, and no more. In a rich pasture, he may acquire an inconvenient lond of fat; in a poor one, he may be half starved. If he must go out, he may be taken in before he becomes too fat; or lie may be placed in a bad pasture, and fed up to the point required by a daily allowance of grain.

Thie of turning out. Horses are pastured at all times of the year. Some are out for lameness, some for bad health, and some, that they may be kept for less than the stable cost. The usual time of turning out is about the end of April, or the beginning of May. Then the grass is young, juicy, tender, and more laxative than at a later period. The spring grass is best for a horse in bad health, worn out by sickness, hard work, or bad food. The weather is mild, neither too hot nor too cold; when it is unsettled and backward, the delicate horse, and sometimes every one, should come in at night and on bleak days. Toward the end of summer, the grass is hard, dry, coarse, fit enough to afford uutriment, but not to renorate a shattered constitution. The days are hot, the nights cold and damp, and the flies strong and numerous. This is not the time for turning out a delicate or thin-slinned horse.

Many persons are accustomed to give the horse a dose or two of physic before sending him to grass. Unless the animal has tumid legs, or is afflicted with some ailment, this is entirely unnecessary, though it may do no harm. To preparo the horse for exposure to the weather, the clothing to which 
he has been accustomed is lightened, and then entirely removed, a week or two before turning him out. The temperature of the stable is gradually reduced, until it becomes as cool as the external air. These precautions are most necessary for horses that have been much in the stable, and particularly a warm stable. For eight or ten days previous to going out, the animal should not be groomed. The dust and perspiration which accumulate upon the hair, seem in some measure to protect the skin from rain and from flies. The feet should be dressed, and the grass shoes, or plates, applied a week before turning out. If they are injured by the nails, the injury will become apparent before much mischief is done; at grass it might not be noticed so soon. On the day of going out, the horse should be fed as usual. If he goes to grass when very hungry, he may eat too much. Indigestion will be the result, which may prove fatal. Weather permitting, night is usually chosen for the time of turning out, as the horse is not so apt to gallop about. Let loose in the day time, many are disposed to gallop till they lame themselves, and to try the fences.

In autumn, or early in spring, the stable preparation for grass is often insufficient. If the horse be tender, or the weather unsettled, he should be taken home every night, for perhaps the first week. For eight or ten days longer, it may be proper to house him on very wet or stormy nights. The stable given to him should always be cool, not so cold as the external air, but never so warm as if he were accustomed to it.

Confinement. Some horses are not easily confined at pasture. They break or leap the fences, and wander over the 
country, or proceed to the stable. The fore feet are some. times shackled in order to confine them; but these fetters, if worn for a long time, are apt to alter the horse's action, rendering it short, confined, irregular, at least for a time, till he regains the use of his shoulders. Sometimes the horse is tied by a rope to a stake driven in the ground. He then requires almost constant watching, for he must be often shifted as he eats down the grass, and he may get his legs entangled in the rope, thereby casting himself, and receiving serious injury, unless relief be immediate. Sometimes he is tied to a stake, which he can drag about the field. He soon finds that he can walk where he pleases, but he cannot run, and seldom attempts to leap. This, however, is also liable to throw the horse down, or to injure his legs by getting them entangled in the rope. To prevent the horse from leaping, a board is sometimes suspended round his neck, reaching to his knees, which it as apt to bruise. None of these clumsy and unsafe restraints should ever be employed, when it is possible to dispense with them. Few horses, mares in spring and stallions excepted, require them after the first two days. For horses that are turned out only an hour or two during the day, they are as much used to enable him to be easily caught when wanted, as to prevent him from wandering.

Attendance while out. Horses at grass should be visited at least once every day. If neglected for weeks, as often happens, one may be stolen, and conveyed out of the country before he is missed; the fences may be broken; the water may fail; the horses may be lamed, or attacked with sickness: one may roll into a ditch, and die there for want of assistance to extricate him; the shoes may be cast; the heels may crack; 
thrushes may form; sores may run into sinuses, or become full of maggots; the feet and legs may be injured by stubs, thorns, broken glass, or kicks; or the horses may quarrel, fight, and wound each other. That these and similar evils and accidents may be obviated, or soon repaired, the horses should be visited every morning by a trustworthy person who knows what is required of him.

The grain, hay-either or both-if any be given, should be furnished at regular intervals; when fed with grain, the horses ought to be watched till it is eaten, lest they rob each other, or some prowling thief appropriate the whole. Horses at grass require, and should have, no dressing, as it exposes the skin too much. The shoes may be removed, however, and the feet dressed every four or five weeks.

Treatuent after Grazing. When taken from grass to warm stables, and put upon rich, constipating food, horses frequently become diseased. Some catch cold, some suffer inflammation in the eyes, some take swelled legs, cracked heels, grease, thrushes, founders, surfeit, or a kind of mange. These are very common; and physic is often, and indeed generally, giren to prevent them. They are produced by a combination of circumstances; by sudden transition from gentle exercise and indolence or exciting work; from a temperate to stimulating diet; from a pure, cool, and moving atmosphere, to an air comparatipely corrupt, hot, and stagnant. These changes must be made, and are, to a certain extent, unavoidable; but it is not in all cases necessary that they should be made suddenly. It is the rapid transition from one thing to another and a different thing, that does all the mischief. If it were effected by slow degrees, the evils would be aroided, and 
there would be less need, or none at all, for those medicines which are given to prevent them.

During the first week, the temperature of the stable ought to be little different from that of the external air. Subsequently it may be raised, by slow degrees, till it is as warm as the work or other circumstances demand. The horse should not at first be clothed, and his first clothing should be light. Grooming may commence on the first day; but it is not good to expose the skin very quickly by a thorough dressing. The food should be laxative, consisting of bran-mashes, oats, and hay; but no beans, or very few. Walking-exercise, twice a day, is absolutely necessary for keeping the legs clean, and it assists materially in preventing plethora.

The time required for inuring a horse to stable treatment, depends upon several circumstances. If taken home in warm weather, the innovation, so far as the temperance and the purity of the air are concerned, may be completed in about two weeks. If the horse is not very lean, his skin may be well cleaned in the first week; and to clean it, he must have one or two gentle sweats, sufficient to detach and dissolve the dust, mud, and oily matter which adhere to the skin, and glue the hair together. All this, or as much of it as possible, must be scraped off while the horse is warm and perspiring. If it is allowed to get dry before scraping, he is just where he was. If the weather be cold, there need be no great hurry about cleaning him completely.

The propriety of giving physic after grazing has been often questioned. In the stable, its utility is generally acknowledged. In books it is sometimes condemned as pernicious, sometimes as useless. It may be safely said, however, that. 
there are many cases in which physic is very useful; but that as a general thing, it is given too indiscriminately, and before it is wanted.

To a lusty horse, one or two doses may be given for the purpose of reducing him, for removing superfluous fat and flesh. The physic may be strong, sufficiently so to produce copious purgation. It empties the bowels, takes up the carcass, and gives freedom to respiration; it promotes absorption, and expels the juices which embarrass exertion. Work, sweating and a spare diet of condensed food, will produce effects without the aid of pliysic. But purgation shortens the time of training, and it saves the legs. If the horse must be rapidly prepared for work, with as little hazard as possible to his legs, he must have physic. The first dose may be given on the day when he comes from grass; the others, if more than one be necessary, at intervals of eight or ten clear days.

A lean borse, fresh from grass, needs no physic till he has been stabled for several days, and perhaps not then. By the time he has acquired strength sufficient to stand training, his bowels are void of grass, and his belly small enough to allow freedom of respiration. At the end of a fortnight or three weeks, the lean horse ought to be decidedly lustier. If too much so, and acquiring flesh too rapidly, one dose of physic may be given, active enough to produce smart purgation, and prevent the evils which arise from plethora. If he is not taking on flesh so rapidly as he should, he may have two, perhaps three, mild doses of physic, just active enough to produce one or two watery or semi-fluid evacuations. If he eat a great deal without improving in condition, he is probably troubled with worms, and half a drachm of calomel may be 
added to each dose of physic. If he does not feed well, there is probably a torpid state of the digestive apparatus, produced by a bad or deficient diet. Iu such a case, mild physic is still proper, and, in addition, the horse may have a few tonic balls between the setting of one dose and the administration of another. Four drachms of gentian, two of ginger, and one of tartar emetic, made into a ball with honey, forms a very useful tonic. One of these may be given every day, or every second day, for a fortnight. If the horse does not improve under these, he requires the aid of a veterinary surgeon.

The MODE of GRAZING FARM-HORSES requires some notice. Other horses are sent to pasture, and with few exceptions, remain at it for days and weeks without interruption. Those employed in agriculture are pastured in three different ways. By one, the horse is constantly at grass, except during his hours of work; he is put out at night, is brought in the next morning, goes to work for two or three hours, and is then returned to pasture for about two hours; in the afternoon lie again goes to work, which may be concluded at five or six o'clock, and from that time till he is wanted on the next morning he is kept at grass. By another mode, the horse is turned out only at night. During the day he is soiled in his stable at his resting intervals. When work is over for the day, he is sent out till the next morning. By the third mode, which is generally allowed to be the best, the horse is turned to grass only once a week. He is pastured from the time his work is finished on Saturday night till it commences again on Monday morning.

If the horses have any thing like work, the first two modes are decidedly objectionable. There is much expenditure of 
labor in procuring the food, and there is great loss of time. It may cost the horse four or five hours good work to cut down the grass which he eats. A man supplied with a scythe will do the same work with far less labor in a few minutes. If there be nothing else for the horse to do, it is quite right to make him gather his own food. But, otherwise, it is absurd to make him exhaust his strength and time in doing that which a man can do so much more easily and quickly. Besides this expenditure of the horse's time and strength, the loss of manure, and the damage done to pasture by the feet, ought to be taken into consideration.

The third mode of grazing appears to be the least objectionable. The horses have no field labor on Sunday; if the pasture be good, the weather favorable, and the horses not fatigued, they are better at grass than in the house.

In some places the road-horses are sometimes put to grass on Sunday. This practice has nothing apparently to recommend it. The weekly work of these horses in general demands the rest which Sunday brings; and if they travel at a fast pace, as all coach-horses do now, they are apt to eat so much grass, and carry such a load in their bellies, that on Monday they are easily over-worked. The breathing is impeded, unless the horses purge, which few do. They often come from grass as haggard and dejected as if they had done twice their ordinary work the day before.

\section{SERVICE.}

A change of lodging, or of diet, is often a cause of disease. When a fresh horse is procured, it is well to know how he has been treated during the previous month; if he is a valuable 
animal, he will certainly be worth this inquiry. Horses that come from a dealer have probably been standing in a warm stable, well-clothed, well-groomed, highly fed, and seldom exercised. They have fine glossy coats, are lusty, and in high spirits; but their flesh is soft and flabby. They are unfit for fast work; they are easily heated by exertion, and when the least warm,

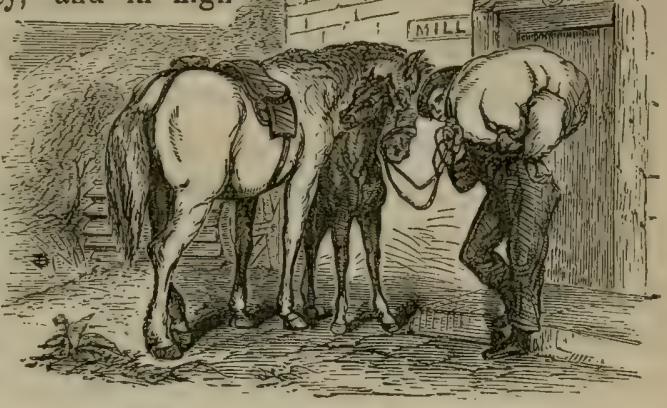

SERVICE. are rery apt to take cold. But, wherever the horse comes from, or whatever his condition may be, changes in reference to food, temperature, and work, must be effected by slow degrees. It is absurd and always pernicious to take a horse from the field, and put him in a warm stable, and on rich food all at once; it is no less erroneous to take him from a warm to a cold stable, or to demand exertion to which he has not been trained.

When the horse's history cannot be traced, both his work and his diet should at first be moderate. More of either than he has been accustomed to, will do more harm than less of either. It may, however, soon be ascertained by trying him whether he has been doing much work; if fit for work, he may be fed in proportion. The temperature of the stable had better be warmer than colder. If too warm, the horse will perspire; his coat will be wet in different places, especially in the morning 
when the stables are first opened. If it be too cold, his coat will be roughened, and become dim, and the horse will catch cold, evidence of which will be given by a cough.

The work of some horses exposes them much to the weather. Those employed in street-coaches, in the carriages of medical men, all those that have to stand in the weather, can never do so with safety until they have been seasoned. In the cold rainy season, many are destroyed, and many more endangered by injudicious exposure. Wet weather is the most pernicious; yet it is not the rain alone that does the mischief. If the horse is kept in motion, and afterwards perfectly and quickly dried, or is kept in motion till he is dry, he suffers no injury. His coat may be bleached till it is like a dead fur; but the horse does not catch cold. If he is allowed to stand at rest with his coat drenched in the rain, the surface of the body rapidly loses its heat, there being no stimulus to the formation of it; the blood circulates slowly, accumulates internally, and oppresses vital organs, especially the lungs; the legs become excessively cold and benumbed; the horse can hardly use them, and, when put in motion, he strikes one against the other. Exposure, when it deprives the body of heat in this way, is a fruitful source of inflamed lungs, of thoracic influenza, catarrb, and founder. When the skin is wet, or the air very cold, the horse should, if possible, be kept in motion, which will preserve him, however little he may have been accustomed to exposure.

Horses that have been kept in warm stables, and never out but in fair weather, are in most danger. If they cannot be kept in constant motion, they must be prepared before they are exposed. If they commence work in summer, or early in the autumn, they will be fully inured to the weather before the worst 
part of winter arrives. But if they commence in winter, they should be out for only one or two hours at a time; in good days they may be out longer, no one being able to give a precise rule as to the length of time appropriate, as it varies with the condition of the animal, the weather, and the work required. It should shorten with the wetness or coldness of the weather, and the tenderness of the animal. If he must run rapidly from one place to another, and wait perhaps half an hour at each, he is in more danger than if the pace were slower, and the time of waiting shorter; and if moved about constantly, or every ten minutes, he suffers less injury than if he was standing still. After a time he becomes inured to exposure, and may be safely trusted in the severest weather.

Repeated and continued application of cold to the surface of the body stimulates the skin to produce an extra supply of heat. The exposure of two or three days is not sufficient to rouse the skin to this effort. It is always throwing off a large quantity of heat; but it is several days, and with many horses several weeks, before the skin can assume activity sufficient to meet the demands of a cold or wet atmosphere. Ultimately, it becomes so vigorous that the application of cold, whether wet or dry, is almost instantly followed by an increased production of heat. To this, however, there are limits. By exposure, gradually increasing in length and frequency, the system may be able to maintain the temperature at a comfortable warmth for three or four successive hours, even when the horse is standing at rest in wet or cold. But he cannot endure this beyond a certain point. Exhaustion and emaciation succeed, in spite of all the food the horse can eat. The formation of so much heat consumes the nutriment that ought to produce vigor for work. 
Hence, working horses kept very much in very cold stables are lean and dull.

I: is chiefly the horses that have to stand in the weather, which require preparation for exposure. Bleeding, purging, and other means, which debilitate or emaciate, are never necessary in this process. Hunting, stage-coach, and cart-horses seldom require any preparation for exposure, as they are in motion from the time of leaving the stable till their return. They only require to be well and quickly dried when wet.

New horses are very liable to have the skin injured by the harness. The friction of the saddle, collar, or traces, pro. duces excoriation. In some horses this is altogether unavoid: able, especially when they are in poor condition. Their skin is tender, and a little chafing exposes the quick. In all horses it is some time before the skin thickens, and becomes sufficiently callous to carry the harness without injury. The time required to undergo this change varies materially, and cannot be much shortened by any means. Attention to the larness, however, will frecnnently prerent excoriation. After every journey, the neck should be closely examined. If there be any spot, however little abraded, hot and tender when pinched, that part of the collar which produced it should be cut out before the next journey. The guard, or safe; is a useful article to prevent galls of this kind. It is merely a thin slip of soft leather, covering the seat of the collar. It obviates friction, and prevents injurious pressure from any little protube ance or hardness in the stuffing of the collar. On the first or second journey a new horse often comes in with his neck some. what inflamed; it is hot, tender, and covered with pimples. In the stables it is said to be fired. A solution of common 
falt in water is commonly applied, and it serves to allay the inflammation; it should be applied whenever the collar is remored. Tumors, containing bloody water, frequently rise on the neck. They should be opened immediately, emptied, and liept opened for a few days. The piece must be taken out of the collar, and a safe used. On a billy road the lower part of the collar often galls the neck seriously, in spite of any alteration in the stuffing. A broad strap attached to the collar, and passing over the windpipe, is a good remedy. The strap should be two inches broad, and drawn tightly enough to keep the collar steady, and make it stand nearly upright. It should be adjusted before the head is put on the bearing 'reins, and should be worn till the neck is quite sound. A broad breast-band may also be substituted for the neck collar, till the neck and shoulders get well. A horse will pull nearly as well in this as in the collar and hames. When the traces, crupper, or pad, threaten or produce excoriation, they must be kept off by cushions placed behind, before, or at each side of the part injured.

The back requires nearly as much care as the neck. A new saddle is objectionable for a new horse, particularly when he has to travel far under a heavy rider. A tender back may be hardened by frequent use of the saddle and a light weight. The horse may stand saddled in the stable, and saddled when he groes to exercise. When the back is hot, and the skin dis. posed to rise in tumors, the saddle should remain on till the back becomes cool. Slacken the girths, raise the saddle for a moment, and then replace it. Its weight prevents tumors; excoriation and firing must be treated as on the neck. Always let the pommel of the saddle be dry before it is again 
used, and put it on half an hour before the horse is to bo mounted.

Horses, from whom extraordinary exertions are not demanded, and those that are never expected or required to do all that a horse is capable of doing, stand in little need of inurement to work, and it is seldom that any is intentionally given. When a saddle or draught-horse is purchased, he is often put to his work at once, without any preparation. He is treated as if he were as able for the work as it is possible to make him. So long as the work is slow and not very laborious, he may perform it well enough; but this system will not do for full work, whether fast or slow. If the horse has been idle for a month or two, he is weak. It matters little that he is plump and in good spirits. He may be able to draw a load of twenty or thirty hundred-weight with ease, and perhaps to draw it a considerable distance; but on the next day the is sore all over, stiff, feeble, dull, almost unable to carry his own weight. If the same work be exacted day after day, the horse loses flesh, and at last becomes unfit for any work. But if the werk be less severe at first, and graduarly increases from week to week, the horse at last acquires strength and endurance greater, perhaps, than he ever before possessed. $\mathrm{He}$ is then able to do with ease as much in a week as would have completely knocked him up at the beginning. For slow, moderate work, this is all the preparation which the borse needs. At first, let it be very gentle; and the weight he is to carry or draw, and the distance he is to travel, may be increased as he is found able to bear it. In preparing the horse for hunting, racing, or coaching, the treatment must be some. what different. 


\section{SHOEING.}

There is hardly any other class of mechanics who combine so much ignorance of the principles on which their art is founded, with so much conceit of their knowledge, as do ordinary horse-shoers; and it should be one of the first duties of the horse-owner to inform himself of the nature and structure of the horse's foot, the reason why shoeing is necessary at all, what parts of the foot it protects, what is the best form of shoe to effect the purpose, how it may be best fastened to the foot, and how often it should be removed.

To illustrate these important points, cuts are here introduced, showing the construction of the horse's foot.

Our first one shows the ground surface of the hoof prepared for receiving a shoe; and marks very distinctly the difference between the curvature of the outer and inner quarters.

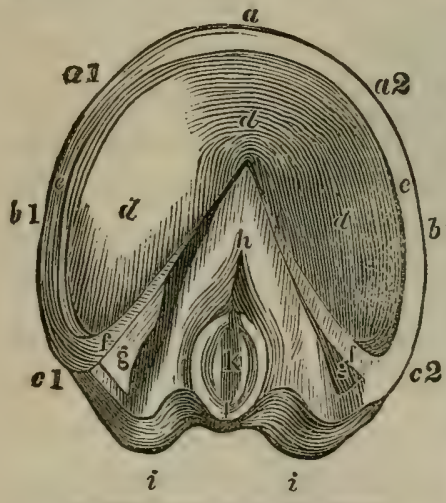

GROUXD SURPACE OF THE HOOF.

The hoof is divided into horny crust or wall, sole, and frog. The horny crust is secreted by the numerous blood. $b_{2}$ vessels of that soft protruding band which encircles the upper edge of the hoof, immediately beneath the termination of the hair ; and is divided into toe, quarters, heels, and bars. Its texture is insensible, but elas-

a. The toe-rasped away to receive the turned-up shoe, $a$ 1. The inner toe. $a 2$. The outer toe. $\delta 1$. The inner quarter. $b 2$. The outer quarter. $c 1$. The inner hoel. c 2. The outer heel. $d . d$. $d$. The sole. e. e. The crust or wall of the hoof. $f . f$. The bars. $g . g$. The commissures. $h . k$. $l$. The frog. $h$. The part immediately under the navicular joint. $k$. The oval cleft of the frog. $l$. The elevated boundary of the cleft. $\tau_{i} i$. The bulbs of the heels. 
tic throughout its whole extent; and, yielding to the weight of the horse, allows the horny sole to descend, whereby much inconvenient concussion of the internal parts of the foot is avoided. But if a large portion of the circumference of the foot is fettered by iron and nails, it is plain that that portion, at least, cannot expand as before; and the beautiful and efficient apparatus for effecting this necessary elasticity, being no longer allowed to act by reason of these restraints, becomes altered in structure; and the continued operation of the same causes, in the end, circumscribes the elasticity to those parts alone where no nails have been driven; giving rise to a train of consequences destructive to the soundness of the foot, and fatal to the usefulness of the horse.

The toe of the fore foot is the thickest and strongest portion of the hoof, and is in consequence less expansive than any other

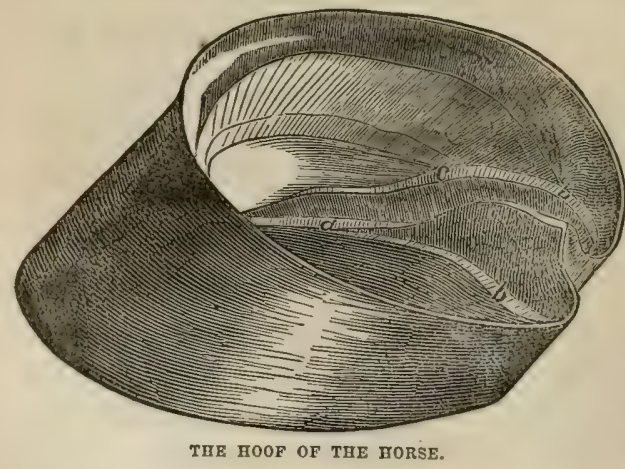
part, and there. fore better calculated to resist the effects of the nails and the shoe. The thickness of the horn" gradually diminishes to. ward the quarters and heels, particu-

Is a broad flat mass of horn, projecting upward into the middle of the elastic cush. 1on, and called "the frog stay." $b, b$. Are two horny projections rising into the cavity of the hoof formed by the commissures. $c$. $c$. Are portions of the same projections, and are situated just under the two ends of the navicnlar bone, and mark the point on either side where diminution in the natural elasticity of the fatty frog would be felt with the greatest severity by the navienlar joint ; for under the most favorable circumstances, the quantity of cushion between these points and the navicular joint cannot be very large; and hence tho importance of our doing all we can to preserve its elasticity as loug as possible. 
larly on the inner side of the foot, whereby the power of yielding and expanding to the weight of the horse is proportionably increased, clearly indicating that those parts cannot be nailed to an unyielding bar of iron, without a most mischievous interference with the natural functions of the foot. In the hind foot, greater thickness of horn will be found at the quarters and heels, than in the fore foot. This difference in the thickness of horn is beautifully adapted to the inequality of the weight which each has to sustain, the force with which it is applied, and the portions of the hoof upon which it falls.

The toe of the fore foot encounters the combined force and weight of the fore hand and body, and consequently in a state of nature is exposed to considerable wear and tear, and calls for greater strength and substance of horn than is needed by any portion of the hind foot, where the duty of supporting the hinder parts alone is distributed on the quarters and heels of both sides of the foot.

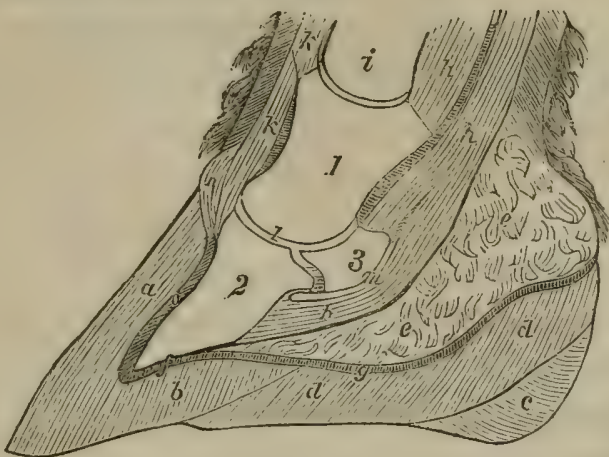

A SECTION OF THE FOOT:

The bars are continuations of the wall, reflected at the heel towards the centre of the foot, where they meet in a point, leaving a triangular space between them for the frog.

1. The coronet bone. 2. The coffin bone. 3. The navicular bone. $a$. The wall. $b$. The sole. $c$. The cleft of the frog. $d . d$. The frog. e. e. The fatty frog, or elastic cusbion. $f$. The sensitive sole. $g$. The sensitive frog. $h . h . h$. Tendons of the muscles which bend the foot. $i$. Part of the pastern bone. $\pi$. $k$. Tendons of the muscles which extend the foot. $l$. The coffin joint. $m$. The navicular joint. n. The coronary substauce. 0 . The sensible laminæ, or covering of the cofin bone. 
The whole inner surface of the horny crust, from the centre of the toe to the point where the bars meet, is everywhere lined with innumerable narrow, thin, and projecting horny plates, which extend in a slanting direction from the upper edge of the wall to the line of junction between it and the sole, and possess great elasticity. These projecting plates are the means of greatly extending the surface of attachment of the hoof to the coffin bone, which is likewise covered by a similar arrangement of projecting plates, but of a highly vascular and sensitire character; and these, dovetailing with the horny projections above named, constitute a union combining strength and elasticity in a wonderful degree.

The horny sole covers the whole interior surface of the foot excepting the frog. In a well-formed foot it presents an arched appearance, and possesses considerable elasticity, by virtue of which it ascends and descends, as the weight above is either suddenly removed from it, or forcibly applied to it. This descending property of the sole calls for one especial consideration in directing the form of the shoe; for, if the shoe be so formed that the horny sole rests upon it, it cannot descend lower; and the sensitive sole above, becoming squeezed between the edges of the coffin bone and the horn, produces inflammation, and perhaps abscess. The effect of this squeezing of the sensitire sole is most commonly witnessed at the angle of the inner heel, where the descending heel of the coffin bone, forcibly pressing the vascular sole upon the horny sole, contuses a small bloodressel, and produces what is called a corn, but which is, in fact, a bruise.

The horny frog occupies the greater part of the triangular space between the bars, and extends from the hindermost part 
of the foot to the centre of the sole, just orer the point where the bars meet, but is united to them only at their upper edge; the sides remain unattached and separate, and form the channel called the commissures.

If we carefully observe the form and size in the frog in the foot of a colt of from four to five years old, at its first shoeing, and then note the changes which it undergoes as the shoeings are repeated, we shall soon be convinced that a visible departure from a state of health and nature is taking place. At first it will be found large and full, with considerable elasticity; the cleft oval in form, open, and expanding, with a continuous, well-defined, and somewhat elevated boundary; the bulbs at the heels fully developed, plump, and rounded; and the whole mass occupying about one-sixth of the circumference of the foot. By degrees the fulness and elasticity will be observed to have diminished; the bulb at the heels will shrink, and lose their plumpness; the cleft will become narrower, its oval form disappear, the back part of its boundary give way, and it will dwindle into a narrow crack, extended back between the wasted, or perhaps obliterated, bulbs, presenting only the miserable remains of a frog, such as may be seen in the feet of most horses long accustomed to be shod.

The bones proper to the foot are three in number,- - viz., the coffin bone, the navicular bone, and part of the coronet bone; they are contained within the hoof, and combine to form the coffin joint; but the smallest of them, the navicular bone, is of far more importance as connected with the subject of shoeing, than either of the others; for upon the healthy condition of this bone, and the joint formed between it and the tendon, which passes under it to the coffin bone, and is called the navicular joint, mainly depends the usefulness of the horse to man. 
This small bone, which in a horse sixtecn hands ligh mea. sures only two and a quarter inches in its longest diameter, three-fourths of an inch at the widest part of its shorter diameter, and half an inch in thickness in the centre, its thickest part, has the upper and under surfaces and part of one of the sides overlaid with a thin coating of gristle, and corered by a delicate secreting membrane, very liable upon the slightest injury to become inflamed; it is so placed in the font as to be continually exposed to danger, being situated across the hoof, behind the coffin bone, and immediately under the coronet bone; whereby it is compelled to receive nearly the whole reight of the horse each time that the opposite foot is raised from the ground.

The coffin bone consists of a body and wings; and is fitted into the hoof, which it closely resembles in form. Its texture is particularly light and spongy, arising from the quantity of canals or tubes that traverse its substance in every direction, affording to numerous blood-vessels and nerves a safe passage to the sensitive and rascular parts surrounding it; while the unyielding nature of the bone effectually protects them from compression or injury, under every variety of morement of the horse.

In an unshod foot, the front and sides of the coffin bone are deeply furrowed and roughened, to secure the firmer attachment of the vascular membranous structure, by which the bone is clothed; but in the bone of a foot that has been frequently shod, the appearance is greatly changed, the furrows and roughness giving place to a comparatively smooth surface. This change is probably produced by the shoe limiting, if not destroying, the expansive power of that part of the horn to which it is nailed: whereby a change of structure in the membrane itself, as ${ }^{*}$ is as 
absorption of the attaching portions of the bone, is induced ; for it is an invariable law of the animal economy not to continue to unemployed structures the same measure of efficient reparation that is extended to parts constantly engaged in performing their allotted tasks. The shoe restricts or prevents expansion; while nature, as the secret influence is called, immediately sets to work to simplify the apparatus for producing the expansion, which art has thus rendered impracticable, and substitutes for it a new structure, less finely organized, but admirably suited to the altered condition of the parts.

The wings extend from the body of the bone directly backward, and support the lateral cartilage of the foot.

The sensitive sole, or, as it is sometimes called, the fleshy sole, is about the eighth of an inch thick, and is almost entirely made up of blood-ressels and nerves; it is one of the most vascular and sensitive parts of the body, and is attached to the lower edge of the sensitive corering of the coffin bone, to the bars, and point of the frog, and also with great firmness to the whole of the arched under-surface of the coffin bone.

The sensitive frog includes not only the part corresponding to the sensitive sole, but also the peculiar spongy elastic substance which intervenes between it and the navicular joint, and fills the space between the cartilages. The proper sensitive frog is thicker, and less finely organized, than the sensitive sole, possessing fewer blood-ressels and nerves.

It is a common, but very erroneous, opinion, that the shape of the perfect foot is circular, or very nearly so. This induces most smiths to endeavor to reduce the foot to that shape as soon as possible. There are very few things in nature so little varied as the form of the ground surface of horses' feet; for whether the 
hoof be high-heeled and upright, or low-heeled and flat, large or small, broad or narrow, the identical form of ground-surface is maintained in each, so long as it is left entirely to nature's guidance. The onter quarter, back to the heel, is curved considerably and abruptly outward, while the inner quarter is carried back in a gradual and easy curve. The advantage of this form is so obvious, that it is strange that any interference should ever be attempted with it. The enlarged outer quarter extends the base, and increases the hold of the foot upon the ground; while the straighter inner quarter lessens the risk of striking the foot against the opposite leg.

The inclination of the front of the horny crust of the foot, should be at an angle of about forty-five degrees. If the foot is much steeper than this, it is very liable to contract; while, if it is much more slanting, it constitutes what is called the "oyster shell" foot, in which there is an undue flatness of the sole, and a tendency to pumiced feet.

Before removing the old shoes, care should be taken to raise all the clinches of the nails to prevent injury to the crust, and to avoid giving pain to the horse; even after clinches are raised, if the shoes cannot be easily drawn off, those nails which seem to hold most firmly should be punched, or drawn out, that the shoe may be removed withont injury to the hoof, and without weakening the nail-hold for the new shoeing.

The shoe being removed, the edge of the crust should be well rasped to remove so much of the horn as would have been worn away by the contact with the ground, had it been unshod. In no case should the rasp be used on the surface of the hoof, except to make the necessary depressions for the 
clinches, after the new shoe has been put on, and to shape the hoof below the line of the clinches of the nails. The hoof, above this line, will inevitably be injured by such treatment, which is one of the most fruitful sources of brittleness of the horn, which often results in "sand-crack."

The operation of paring out the horse's foot is a matter requiring both skill and judgment, and is, moreover, a work of some labor, when properly performed. It will be found that the operator errs much oftener by removing too little than too much; at least it is so with the parts which ought to be removed, which are almost as hard and unyielding as flint, and in their most favorable state, require considerable exertion to cut through.

No general rule can be given applicable to the paring out of the feet of all horses, or even of the feet of the same horse at all times. It would be evidently unwise, for example, to pare the sole as thin in a lot, dry, season, when the roads are broken up, and strewed with loose stones, as would be proper in a moderately wet one, when the roads are well bound and even; for, in the case first named, the sole is in constant danger of being bruised by violent contact with loose stones, and therefore, needs a thicker layer of horn for its protection; while the latter case offers the most favorable surface that the greater part of our horses ever have to travel upon, advantage of which should be taken for a thorough paring out of the sole, in order that the internal parts of the foot may derive the full benefit accruing from an elastic and descending solf; a condition of things very essential to the due perrormance of their separate functions. To take another illustration: horn grows very freely, especially toward the toe in horses with 
upright feet and high heels; and such are always benefited by having the toe shortened, the heels lowered, and the sole well pared out; whereas in horses with flat feet and low heels, horn grows sparingly, and the toe of such feet being always weak, adrnits of very little shortening. Such heels being already too low, they should scarcely be touched with the rasp; and the sole presents such a small quantity of dead horn, that the knife should be used with great discretion.

The corners formed by the junction of the crust and bars should be well pared out, particularly on the inside; for this is the common seat of corn, and any accumulation of horn in this situation must increase the risk of bruising the sensitive sole between the inner part or heel of the coffin bone and the horny sole. Little, if anything, is gained by allowing the bars to project beyond the surface of the sole; the power of resisting contraction cannot possibly be increased by this arrangement, and the projecting rim is left exposed to the danger of being broken and bruised by contact with stones and other hard substances; and the method is further attended with the disadvantages of making the cleaning out of these corners a work of considerable ingenuity with so unwieldly an instrument as a common drawing-knife. It is much preferable to pare them down to a level with the sole, or very nearly so; avoiding, however, every approach to what is styled 'opening out the heels," a most reprehensible practice, which means cutting away the sides of the bars, so as to show an apparent increase of width between the heels, which may for the time deceive the eye, but is in reality a mere deception, purchased at the expense of impaired powers of resistance in the bars and ultimate contraction of the feet. It is palpable that the 
remoral of any portion from the sides of the bars must diminish their substance, and render them weaker, and consequently less able to resist contraction.

The frog should never be cut or pared, except in very rare cases of horses with unusually fast-growing frogs. The first stroke of the knife removes the thin horny covering altogether, and lays bare an under surface, totally unfitted, from its moist, soft texture, for exposure either to the hard ground or the action of the air $\boldsymbol{r}_{\hat{\gamma}}$ in consequence of which exposure it soon becomes dry and shrinks; then follow cracks, the edge of which turning outward forms rags; these rags are removed by the smith at the next slioeing, by which means another simi'ar surface is exposed, and another foundation laid for other rags; and this process continues until finally the protruding, plump, elastic cushion, interposed by nature between the navicular joint and the ground, and so essential to its preservation from injury, is converted by this senseless interference into the dry, shrunk, unyielding apology for a frog, to be seen in the foot of almost every horse that has been regnlarly shod for a fer years. The frog is provided within itself with two very efficient modes of throwing off any superfluous horn with which it may be troubled, and it is very unwise in man to interfere with them. The first and most common of these modes is the separation from the surface of the frog of small, bran-like scales, which becoming dry, fall off in a kind of whitish scurf, not unlike the dust that adheres to Turkey figs; the other, which is upon a large scale, and of rarer occurrence, is sometimes called "casting the frog." A thick layer of frog separates itself in a body, and shells off as deep as a common paring with a knife; but this very important 
difference is to be noted between the two operations-that nature never removes the horny covering until she has provided another horny covering beneath, so that although a large portion of the frog may have been removed, there still remains behind a perfect frog, smaller, it is true, but covered with horn, and in every way fitted to sustain exposure; while the knife, on the contrary, remores the horny covering, but is unable to substitute any other in its stead. The frog should, therefore, be left to itself; nature will remove the superfluous Lorn, and the rags do no harm, since, if they are unmolested, they will soon wholly disappear.

The shoe should possess these general features : first, it should be, for ordinary work, rather heary, in order that it may not be bent by contact with hard, uneven roads; second, it should be wide in the web, and of equal thickness and width from the toe to the heel, that it may as much as possible protect the sole, without altering the natural position of the foot; third, it should be well drawn in at the heels, that it may rest on the bars, and extend to the outer edge of the crust on the outside, and reach beyond the bar nearly to the frog, so that there may be no danger of its pressing on the "corn-place," or angles between the bar and the crust; anc fourth, it should in no part extend beyond the outer edgo of the crust, lest it strike against the opposite leg when the horse is traveling, or be stepped on by another horse, or be drawn off by a heavy soil.

Such a shoe, and its position on the foot, is shown in the cut opposite.

The shoe should be made as nearly of this form as the shape of the foot will allow; but it is always to be borne in 
mind, that the shoe is intended for the foot, and not the foot for the shoe, and that it is therefore peculiarly proper to make the shoe to fit the natural form of the foot, instead, as is too often the case, of paring, burning, and rasping the foot until it fits the shoe, which is made according to the smith's notion of what the form of the horse's foot should be. No amount of paring can bring the foot of a horse to an unnatural figure, and also leave it

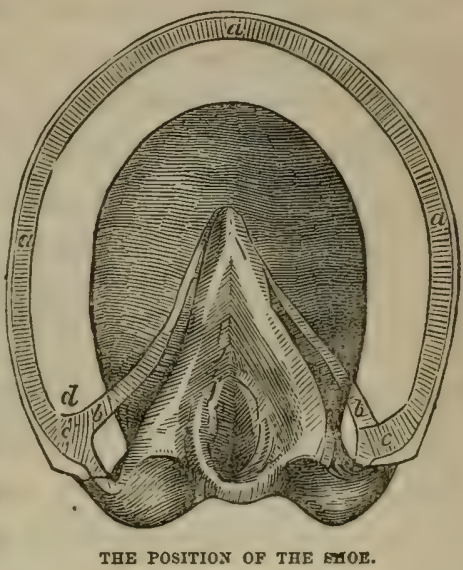
sound and safe for work and use.

This cut represents the foot with the shoe rendered transparent, showing what parts of the foot are protected and covered by bringing in the heels of the shoes. $a, a, a$, the crust, with the shoe closely fitted all around. $b, b$, the bars, protected by the slioe. $c, c$, the heels, supported by the shoe. $d$, the situation of corns protected from injury.

The truth really is, that the shape of the shoe cannot by possibility influence the shape of the foot; for the foot being elastic, it expands to the weight of the horse in precisely the same degree, whether it is resting upon the most open or the most contracted shoe. It is the situation of the nails, and not the shape of the shoe, that determines the form of the foot. If the nails be placed in the outside quarter and toe, leaving the heels and quarters on the inside, which are the most expansive portions, free, no shape which we can give to the shoe can of itself change the form of the foot. It must not, however, be inferred from this, that the shape of the shoe is therefore of no importance; quite the contrary being the case, 
as has been already shown. As the shape of the foot is in no degree changed by the form of shoe, that form should manifestly be adopted which produces the greatest number of advantages with the fewest disadrantages.

A small clip at the point of the toe is very desirable, as preventing displacement of the shoe backwards; it need not be driven up hard, as it is simply required as a check or stay. The shoe should be sufficiently long to fully support the angles at the heels, and not so short, as is too often the case, that a little wear imbeds the edge of it in the horn at these parts. The foot surface of the shoe should alrays have a good flat even space left all around for the crust to bear upon; for it must be remembered, that the crust sustains the whole weight of the horse, and should therefore have a perfectly eren bear. ing everywhere around the shoe. In this space the nail-holes should be punched; and not, as is too generally the case, partly in it, and partly in the seating. In what is technically called "back-holing the shoe," which means completing the openings of nail-holes on the foot surface, great care should be taken to give them an outward direction, so as to allow the points of the nails to be brought out low down in the crust. The remainder of the foot surface should be carefully seated out particularly around the elevated toe, where it might otherwise press inconveniently upon the sole, and the seating should be carried on fairly to the point where the crust and bars meet, in order that there may be no pressure in the seat of corns; the chance of pressure in this situation will be still further diminished by beveling off the inner edge of the heels with a rasp.

The ground surface should be perfectly flat, with a groove 
running round the outer edge, just under the plain surface, upon which the crust bears. The principal use of this groove is to receive the heads of the nails that secure the shoe, and prevent their bending or breaking off; it is further useful in increasing the hold of the shoe upon the ground, and should be carried back to the heels.

In fitting the shoe on the foot, it should never while red-hot be burned into its place, as this would so heat the sensitive sole as to produce a serious derangement of its parts; but it may with safety be touched lightly to the foot, that by a slight burning it may indicate those parts where the foot needs paring; incleed, it is necessary to pursue this course in orcler to make the shoe so exactly fit the foot that there will be no danger of its moving sufficiently to loosen the hold of the nails. The shoe should be made with steel in front, this being sloped backwards to a line running at right angles with the upper slope of the hoof. Old shoes being always worn to about this form, new ones should be so made, and the steel will prevent their being unduly worn.

The shoe having been so fitted that the foot exactly touches it in every part, the next step is to nail it fast to the hoof. Upon the number and situation of the nails which secure it depends the amount of disturbance that the natural functions of the foot are destined to sustain from the shoe. If the nails are numerous, and placed back in the quarters and beels, no form of shoe, however perfect, can sare the foot from contraction and navicular disease. If, on the contrary, they are few, and placed in the outside quarter and toe, leaving the inside quarter and heels free to expand, no form of shoe is so bad that it can, from defective form alone, produce contraction of the foot. 
Various experiments, which have been made for the purpose of ascertaining how few nails are absolutely necessary under ordinary circumstances for retaining a shoe securely in its place, have satisfactorily established that five nails are amply sufficient for the fore-shoes and seven for the hind. The nails should not be driven high up in the crust, but brought out as soon as possible; they should also be very lightly driven up before the clinchers are turued down, and not, as is generally the case, forced up with all the power which the smith can bring to bear upon them with his hammer. The clinches should not be rasped away too fine, but turned down broad and firm. The practice of rasping the whole surface of the hoof after the clinches have been turned down, should never be allowed; it destroys the covering provided by nature as a protection against the too rapid evaporation of the moisture of the hoof, and causes the horn to become dry and brittle.

The fear, very commonly entertained, that a shoe will be cast almost at every step, unless it is held to the foot by eight or nine nails driven high up into the crust, is utterly groundless, as both theory and practice concur in asserting. If the presence of a nail in the crust were a matter of no moment, and two or three more than are necessary were merely useless, no great reason would exist for condemning the common practice of using too many nails; but it is far otherwise;-the nails separate the fibres of the horn, which nerer by any chance become united again, but continue apart and unclosed, until by degrees they grow down with the rest of the hoof, and are finally, after repeated shoeings, remored by the knife.

If the clinches chance to rise, they must be at once replaced, as such rising imparts to the nails a freedom of motion which 
is certain to enlarge the size of the holes; and this mischief is often increased by the violent wrenching from side to side which the shoe undergoes in the process of removal by the smith. As these holes cannot possibly grow down and be removed under three shoeings, it will be found that even with seven nails the crust must always have twenty-one of these separations existing in it at the same time; and as they are often from various causes extended into each other, they necessarily keep it in a brittle, unhealthy state, and materially interfere with the security of the future nail-hold.

By the mode of fastening abore adrocated the struggle between the expansion of the foot and the resistance of the shoe is entirely overcome; the outer side of the foot, being the only part nailed to the shoe, carries the whole shoe with it at every expansion; while the inner side, being unattached, expands independently of it, whereby all strain upon the nails is avoided, and the foot is left, with respect to its power of expansion, as nearly as possible in a state of nature.

The position of the hind foot and the nature of its office render it less liable to injury than the fore foot, and consequently it less frequently lames. As, however, disease of the navicular bone of this foot is by no means impossible, care should be taken to guard against its contraction by interfering as little as possible with the expansive power of the foot; and this is best done by keeping the nails on the inside as far removed from the heel as convenient, placing four nails in the outer and three in the inner side of the shoe. The holes in the inner side should be punched closer together, and kept more towards the toe than those on the outside, which should be more spread out, as affording greater security of hold to 
the foot. The shoe should be carefully fitted to the hoof an round, particularly at the heels, which are too often left without any support whaterer; and the mischievous custom of turning down the outer heel only must be aroided, because it throws the weight entirely upon the inner quarter, which is the part least able to bear it, and causes much uncomfortable strain to the fetlock joint above. Calkins, even though they are turned down of perfectly erén length on each side, (which, however, is rarely done,) are objectionable appendages, and had better be dispensed with, except, perhaps, for very heavy draft, where their ends by entering the ground may prevent the foot from slipping backwards, and may thus enable the toe to obtain a firmer hold.

The form of shoe here referred to, and the position of the nail-holes are shown in the cut annexed.

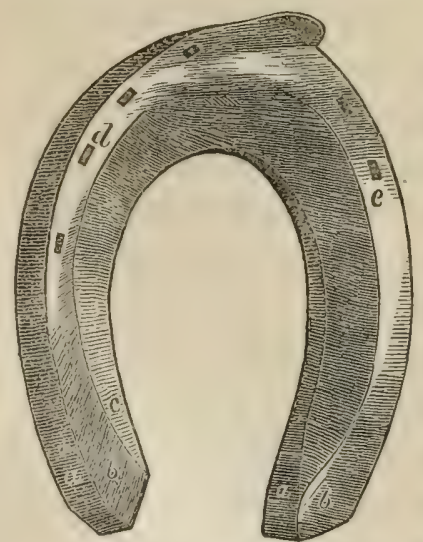

IIE PROPER FORM OF A SHOE.

Before leaving this subject it should be remarked, that contracted feet-that is, feet that have shrunken and become narrow at the heels, and of which the frog has become materially reduced in size,-are often, and doubtless most frequently, caused by inflammation arising from im-, proper shoeing. It is the custom of many smiths to "set the shoes well off at the heels;" and to

a. $x$ The heels of an even thickness with the rest of the shoe. b. b. Show the points ac which the heels of the hoof terminated. c. c. The seating carried back, so as to clear the angles at the heels, and leave the seat of corns free from pressure. $d$. The nail-holes placed in the flat surface which supports the crust, where they should always be. $e$. The hindermost nail of the inuer side at the inner toe, whereby the whole of the quarter aud heel are left free to expand. 
carry the seating or level of the upper side of the shoes so far back that the heels, instead of resting on a flat surface, as they would on a properly fitted shoe, rest on the slopes of the seating, which are in this respect simply two inclined planes, so placed that, at each step taken by the horse, his heels must be pressed together, until a greater or less contraction is mado manifest, but at too late a period to enable us to remedy the evil; for there is no means by which this contraction of the foot can be cured-although, when it exists only to a slight extent, the internal portions of the foot will sometimes accommodate thenselves to its new form. So far as disense is the result of bad shoeing, it can be obriated by so forming the shoe that it will afford a sufficient and perfectly secure and level support for the heels.

\section{ADMINISTERING MEDICINE.}

The most common form in which medicine is given to the horse is by means of the BALL, which is an oblong mass of rather soft consistence, yet tough enough to retain its shape, and wrapped up in thin paper for that purpose. The usual weight of the ball is from half an ounce to an ounce, but they may be given of a larger size, if they are made longer but not wider. Every person in charge of horses should know how to give a ball, which is managed either with or without a balling-iron, an' instrument seldom wanted, and which sometimes occasions considerable injury to the roof of the horse's mouth. Occasionally, a horse cannot be managed by any other means; but, generally speaking, these instruments only furnish an excuse for bad management. In giving a ball in the ordinary way, the horse's tongue is drawn out of his mouth on the off or right side, and 
held there firmly with the left hand grasping it as near the root as possible, but to a certain extent yielding to the movement of the horse's head, so as not absolutely to tear it out. While the tongue is thus held, the ball is placed between the fingers and thumb of the right hand, extended in a wedge-like or conical form, so as to pass as far down the swallow as possible; and the hand in this form, with the arm bared to the shoulder, is carried over the root of the tongue till it feels the impediment caused by the contraction of the swallow, when the finger's leave the ball there, and the hand is withdrawn quickly yet smoothly, while at the same moment the tongue is released, and the head is held up till the ball is seen to pass down the gullet on the left side of the neck, after which the head may be released. When the balling-iron is used, the oval ring of which it is composed is passed into the mouth, so as to keep it open, being first well guarded with tow or cloths wrapped around it; the handle is then held in the left hand, together with the halter, so as to steady the head, and yet to keep the horse from biting; and while thus held the hand can be freely carried over the tongue, and the ball be deposited in the pharynx. When a horse is very determined, it is sometimes necessary to keep the iron in the month by means of the check-pieces of an ordinary bridle buckled to the sides of the oval ring; but this expedient is seldom required if the halter is firmly grasped with the handle of the iron.

In the usual way the horse to be balled is turned around in his stall, which prevents his backing away from the person in charge; and if the latter is not tall enough, he may stand upon a sound stable-bucket, turned upside down. Balls should be recently made, as they soon spoil by keeping; not 
only losing their strength, but also becoming so hard as to be almost insoluble in the stomach, and frequently passing through the bowels nearly as they went into the mouth. When hard they are also liable to stick in the horse's gullet. If ammonia, or any other strong stimulant, is given in this way, the horse should not have his stomach quite empty, but should have a little gruel or water just previously; for if this is put off till afterward, the nauseous taste of the ball almost always prevents this drinking. When arsenic forms an ingredient of the ball, it should be given soon after a feed of corn; or a quart or two of gruel should be given instead, just before the ball.

The administration of a DRENCH is a much more troublesome affair than the giving of a ball; and in almost all cases more or less of the dose is wasted. Sometimes, however, a liquid medicine is to be preferred, as in colic or gripes, when the urgent nature of the symptoms demands a rapidly acting remedy, which a ball is not, as it requires time to dissolve; and, besides this, a ball cannot contain any of the spirituous cordials. The best instrument for giving a drench is the horn of the ox, cut obliquely, so as to form a spout. Bottles are sometimes used in an emergency, but their fragile nature always renders them dangerous. In giving a drench, the tongue is held in the same way as for the delivery of a ball, but the head must be more elevated; the drench is then carefully poured into the throat, after which the tongue is let go, but the head still kept up till it is all swallowed. Allowance should always be made for some waste in giving a drench.

In managing horses while in PHYSIC, the horse should in all cases, if possible, be prepared by bran mashes, given for 
two or three nights, so as to make the bowels rather loose than otherwise, and thus allow the dose to act withont undue forcing of the impacted freces backward. If physic is given without this softening process, the stomach and bowels pour out a large secretion of fluid, which is forced back upon the rectum, and met by a solid obstacle which it takes a long time to overcome, and during that interval the irritating purge is acting upon the lining membrane, and often produces excessive inflammation of it. Purging physic should generally be given in the middle of the day, after which the horse should remain in the stable, and have chilled water as often as he will drink it, with bran mashes. By the next morning he will be in a conclition to be walked out for an hour, which will set the bowels acting, if they have not already begun. It is usual to tie up the tail with a tape or string, so as to keep it clean. The horse should be warmly clothed, and if the physic does not act after an hour's walk, he may be gently trotted for a short distance, and then taken home; and if still obstinate, he may be exercised again in the afternoon. As soon as the physic operates pretty freely, the horse is to be taken into his stable, and not stirred out again, under any pretense whatever, for forty-eight hours after it has "set," or, in common language, stopped acting. When the purging has ceased, the mashes may be continued for twenty-four hours, with a little corn added to them, and a quantity of hay. The water, during the whole time, should be in small quantities, and chilled; and the clothing shonld be rather warmer than usual, taling great care to aroid draughts of cold air. Every horse requires at least a three-day's rest for a dose of physic, in order to aroid risk of mischief. 
The mode of giving a CLYSTER is now rendered simple enough, because a pump and tube are expressly made for the purpose ; and it is ouly necessary to pass the greased end of the tube carefully into the rectum, for about eight or nine inches, and then pump the liquid up until a sufficient quantity is given. From a gallon to six quarts is the average quantity, but in colic a much larger amount is required.

Lotions are applied by means of cloth bandages, if used to the legs; or by a piece of cloth tied over the parts, if to any other surface.

Fonentations are very serviceable to the horse in all recent external inflammations; and it is astonishing what may be done by a careful person, with warm water alone, and a goodsized sponge. Sometimes, by means of an elastic tube and stop-cock, warm water is conducted in a continuous stream over an inflamed part, as in severe wounds, etc., in which this plan is found wonderfully successful in allaying the irritation, which is so likely to occur in the nervous system of the horse. A ressel of warm water is placed above the level of the horse's back, and a small india-rubber tube leads from it to a sponge fixed above the parts, from which the water runs to the ground as fast as it is over-filled. This plan can be very easily carried out by any person of ordinary ingenuity. 


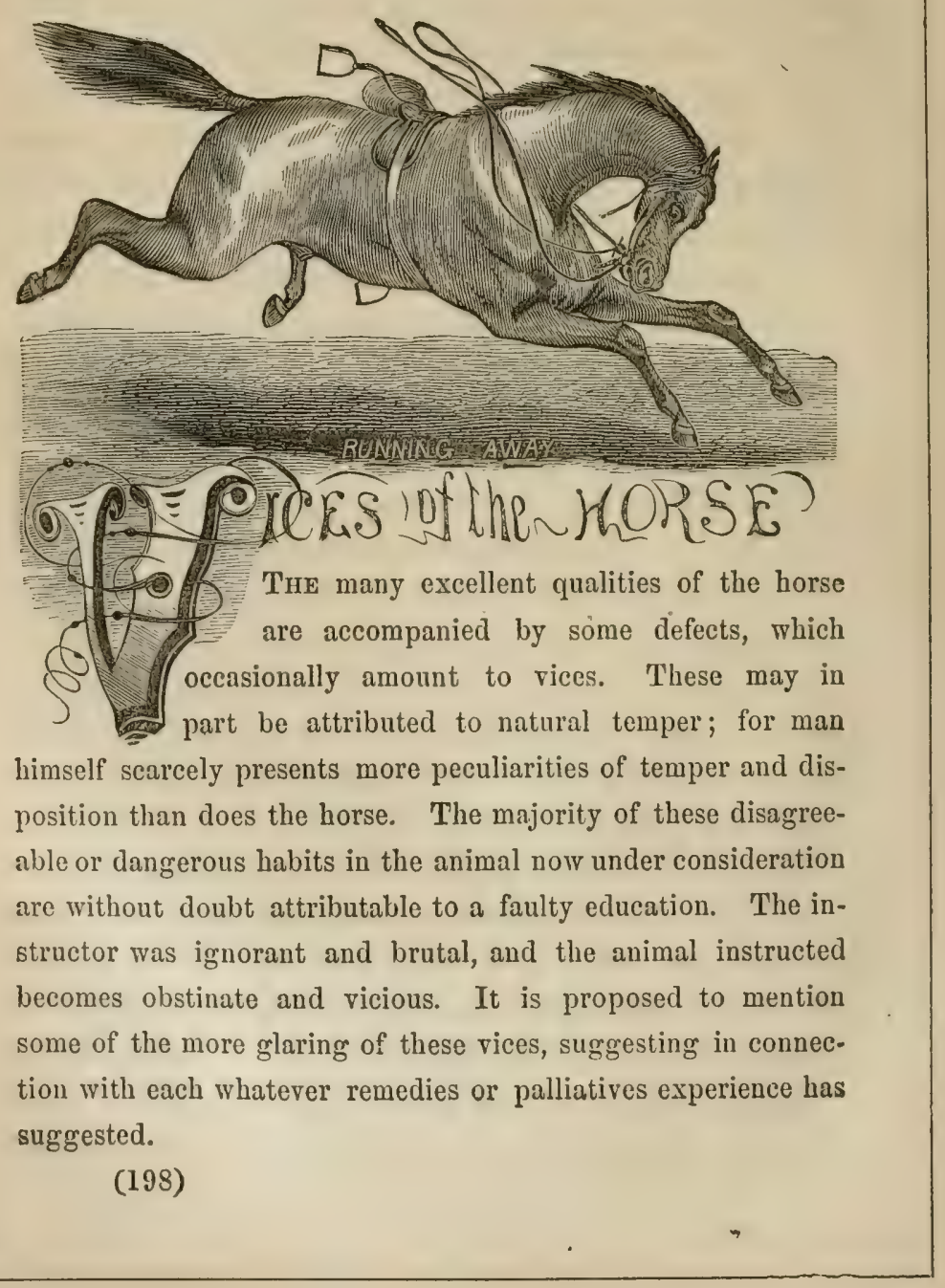




\section{RESTIVENESS.}

This stands in the front rank of all the vicious qualities of the horse, being at once the most annoying and the most dangerous of all. It is the direct and natural result of bad temper and worse education; and, like all other habits based upon nature and engrained by education, it is inveterate. Whether it derelop itself in the form of kicking, rearing, plunging, bolting, or in any way that threatens danger to the rider or horse, it rarely admits of a cure. The animal may, incleed, to a certain extent be subjugated by a determined rider; or he may have his favorites, or form his attachments, and with some particular person be comparatively or perfectly manageable; but others cannot long depend upon him, and even his master is not always sure of him.

\section{BAULKING OR JIBBING.}

This species of restiveness is one of the most provoling vices of the horse, and it can be successfully combated only by a man of the most imperturbable temper. The slightest sign of vexation only increases the evil, and makes the animal more and more troublesome each time that he refuses his work. Many a thickheaded, quick-tempered driver flies into a passion, and beats or otherwise abuses his horse, on the least symptom of baulking, until the animal becomes utterly worthless from a confirmation of the habit.

As a rule it may be stated, that horses baulk from nervousness, or unsteadiness of disposition; if not, indeed, from au over-anxiety to perform their work. Nervous, well-bred horses are more susceptible to the influences which induce baulking, 
than are colder blooded, more indolent ones. A high-mettled horse, when carelessly driven, will start suddenly against his collar, fail to start his load, draw back from the pain which the concussion causes, rush at it again, and again draw back, until it becomes impossible for his driver to steady him in his collar for a dead pull. If to all this be added a smart cut with the whip, and a fiercely spoken word,-with perhaps a blow over the nose, or a stone in the ear,-every fear or vicious feeling of the horse will be summoned into action, and the animal will become entirely unmanageable, requiring to be left for an hour or two in his position before he gets sufficiently calm to be induced to move. There may, occasionally, be a horse which cannot be made to draw steadily by the most careful treatment; but the cases are exceedingly rare in which gentle treatment and firmness-a patient persistence in mild, authoritative command, and judicious coaxing-would not either prevent the formation of the habit, or cure it when formed.

The prevention of baulky habits lies with the driver. If he jump upon his load, gather up his reins carelessly, flourish his whip, or call out wildly to his horse, he will be quite likely to start him forward with a jerk which will be of no avail to move a heavily laden wagon. The horse thus commences to baulk at a heary load, and after a certain amount of such treatment, will refuse to draw anything except under the most farorable circumstances. Let any person driving a strange horse, Fith a load that he is not perfectly sure he can start easily, proceed according to the following directions, and he may be certain that, if the animal be not already a "jibber," he will not make him so, and that if he is one he will have the best chance for getting him along without trouble: He should slowly ex- 
amine the harness and wagon (partly to accustom the horse to his presence,) gather up the reins gently, speaking to the horse to prevent his starting, get quietly into his seat, and then, if possible, get control of the horse's mouth before allowing him to move, so that when he does step off it may be only at a slow walk. If by a forward movement of the hands he can be made to press very gradually against the collar, and if the whole operation is performed in a cool and unexcited manner, there will be little difficulty in bringing him to a dead pull, from which he will recoil only if the load is a serious tax upon his strength.

If the first attempt fail, wait until your horse has become quiet, and until you have recovered from your own rexation, and then try again. It may be necessary to have the assistance of one or two persons, to start the wagon from behind; but they should not push it until the horse is fairly against the collar.

To cure the habit of baulking is not an easy matter, and it is possible only by the kindest treatment. If the horse show fear by his excited manner, or, by looking about him wildly, that he is expecting a blow, you may be sure that he has received hard usage under similar circumstances, and that he must be convinced by caresses and kind words that you will treat him gently. You must recollect that the horse cannot understand your language; and that, while he is confused, he will misin. terpret every sigu which you may make to him. He has an idea of your superior power; and, in his fear that you will exercise it, as bad drivers have done before, to his iujury, he will not at once feel confidence in your kind intentions. He must feel this confidence, whether it take an hour or all day to convey it to him, before you can do anything to cure him of 
his trick. If you have him harnessed to a light wagon on a smooth road where it will afford but little resistance, you ma! by repeated trials convince him that it is a simple, easy mattes to draw it; and you should continue to exercise him from daj to day with the same light load, and afterward increase it gradually, until you have trained him to a quiet manner of starting, or of going up a hill or elsewhere where he has been accustomed to baulk.

By the same gentle treatment you may start a horse or a team that have baulked under the driving of another person. Request the driver and all spectators to go to the side of the road, and then unfasten the check-reins, hang the reins where they will be easily accessible, but so that they may lie loosely upon the horses' backs, caress them, and allow them to look about and convince themselves that no harm is doing. When they have come properly quiet, go to their heads and stand directly in front of the worst jibber of the team, so that his nose may come against your breast if he start. Turn them gently to the right, without allowing them to tighten their traces, and after caressing them a little, draw them in the same way to the left. Presently turn them to the right, and as you do so, bring them slowly against their collars, and let them go.

Sometimes a horse not often accustomed to baulk, betrays a reluctance to move, or a determination not to move. In such cases, the cause, if practicable, should always be ascertained. He may be overtaxed, his withers may be wrung, or he may be insupportably galled or pained by the harness. Those accustomed to horses know what seemingly trivial circumstances occasionally produce this vice. A horse, whose shoulders are raw, or have frequently been so, will not start 
with a cold collar; but when the collar has acquired the warmth of the parts upon which it presses, he will go without reluctance. Some determined baulkers have been reformed by constantly wearing a false collar, or strip of cloth around the shoulders, so that the coldness of the usual collar should never be felt; and others have been cured by keeping the collar on night and day, for the animal is not able to lie down completely at full length, which the tired horse is always glad to do. When a horse baulks, not at starting, but while doing his work, it has sometimes been found useful to line the collar with cloth instead of leather; the perspiration is readily absorbed, the substance pressing upon the shoulder is softer, and it may be far more accurately eased off at a tender place.

\section{BITING.}

This is either the consequence of natural ferocity, or a habit scquired from the foolish and teasing play of grooms and stable-boys. When a horse is tickled and pinched by thoughtless and mischievous youths, he will at first pretend to bite his tormentors; by degrees he will proceed further, and actually bite them, and very soon after that he will then be the first to challenge to the combat, and without provocation will seize the first opportunity to grip the carcless teaser. At length, as the love of mischief is a propensity too easily acquired, this war, half playful and half in earnest, becomes habitual to him, and degenerates into absolute viciousness.

It is seldom that any thing can be done in the way of cure. Kindness will aggravate the evil, and no degree of severity will correct it. Biters have been punished until they have trembled in every joint, and were ready to drop, but this treatment 
scarcely ever cures them. The lash is forgotten in an hour, and the horse is as ready and determined to repeat the offense as before. He appears unable to resist the temptation, and in its worst form biting is a species of insanity.

Prevention, however, is in the power of every proprietor of horses. While he insists upon gentle and humane treatment, he should systematically forbid this horse-play.

\section{KIOKING.}

This, as a vice, is another consequence of the culpable habit of teasing the horse. That which is at first simply an indication of aunoyance at the pinching and tickling of the groom, and without any design to injure, gradually becomes the expression of anger, and the effort to do mischief. The horse, also, too soon recognizes the least appearance of timidity, and takes advantage of -the discovery.

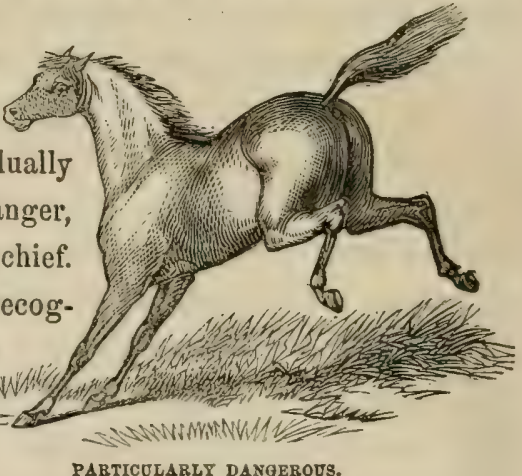
PABTICULARLY DANGEROUS.

Some horses acquire, from mere irritability and fidgetiness, a habit of kicking at the stall or the bail, and particularly at night. The neighboring horses are disturbed, and the kicker gets swelled hocks, or some more serious injury. This is a habit very difficult to correct, if it is allowed to become established. Mares are much more subject to it than horses.

Before the habit is inveterately established, a thorn-bush or a piece of furze fastened against the partition or post will some- 
times effect a cure. When the horse finds that he is pretty severely pricked, he will not long continue to punish himself In confirmed cases it may be necessary to have recourse to the log, but the legs are often not a little bruised by it. A rather long and heavy piece of wood attached to a chain has been buckled above the hock, so as to reach about half-way down the leg. When the horse attempts to kick violently, his leg will receive a severe blow; this, and the repetition of it, may after a time teach him to be quiet.

Kicking in harness is a much more serious vice. From the least annoyance about the rump or quarters, some horses will kick at a most violent rate, and destroy the bottom of the chaise, and endanger the limbs of the driver. Those that are fidgety in the stable are most inclined to do this. If the reins chance to get under the tail, the violence of the kicker will often be most outrageous; and while the animal presses down his tail so tightly that it is almost impossible to extricate the reins, he continues to plunge until he has demolished every thing behind him.

This is a vice standing foremost in point of danger, and one which no treatment will always conquer. It is altogether in vain to attempt coercion. If the shafts are very strong and without flaw, or.if they are plated with iron underneath, and a stout kicking-strap resorted to, which will barely allow the horse the proper use of his hind limbs in progression, but not permit him to raise them sufficiently for the purpose of kicking, he may be prevented from doing mischief. 


\section{REARING.}

This vice is not very common, at least in a dangerous form, and can generally be prevented by the use of the martingale.

In the case of saddle-horses, another good prevention is, when the horse is about to rise, to touch him with the spur on one side only; this will cause him to stop to lift the hind leg on that side, and if he persists in his attempt the spurs may be used vigorously, first on one side, and then on the other, but not so fast as to prevent the horse from raising his hind legs alternately, as he is spurred. The least touch of the curb-bit will cause some vicious and badly trained horses to rear, while those which have been thoroughly trained will rear slightly, to a great height, or not at all, as their rider may desire; but it is obrious that horses so delicately trained should not be ridden by unskillful persons, lest the awkwardness of the rider should cause unex= pected curveting.

The remedy of some breakers, that of pulling the horse backward on a soft piece of ground should be practiced by reckless and brutal fellows alone. Many horses have been injured in the spine, and others have broken their necks, by being thus suddenly pulled over; while even the fellow who fears no danger, is not always able to extricate himself from the falling horse. If rearing proceeds from vice, and is unprovoked by the bruising and laceration of the mouth, it fully partakes of the inveteracy which attends the other divisions of restiveness.

PULIING BACK ON THE HALTER.

This is a rice which has probably arisen from the horse haring, at some time, broken a weak halter in a fit of impa- 
tience. The only safe cure for it, and this is not always successful, is to tie the horse with a very strong halter, which it will be impossible for him to break; finding that his efforts are futile, he will, after a time, generally desist from pullingthough some incorrigible brutes will try every new halter as soon as they are fastened, and will break it if possible.

\section{RUNNING AWAY.}

Some headstrong horses will occasionally endeavor to bolt with the best rider; others, with their wonted sagacity, endeavor thus to dislodge only the timid or unskillful one. Some are hard to hold, or bolt only during the excitement of a trial of speed, or the like; others will run away, prompted by vicious propensity alone. There is no certain cure here. The only method which affords any probability of success is, to ride such a horse with a strong curb and sharp bit; to have him always firmly in hand; and if he will run away, and the place will adimit of it, to give him (sparing neither curb, whip, nor spur,) a great deal more running than he likes.

\section{VICIOUS TO CLEAN.}

It would scarcely be credited to what an extent this exists in some horses that are otherwise perfectly quiet; it is only at great hazard that they can be cleaned at all. The origin of this is probably some maltreatment. There is, however, a great difference in the sensitiveness of the skin in different horses. Some seem as if they could scarcely be made to feel the whip, while others cannot bear a fly to light upon them without an expression of annoyance. In young horses the skin is peculiarly delicate. If they have been curried with a 
broken comb, or hardly rubbed with an uneven brush, the recollection of the torture they have felt makes them impatient and even vicious during every succeeding operation of the kind. Many grooms, likewise, seem to delight in producing these exhibitions of uneasiness and vice, although, when they are carried a little too far, and at the hazard of the limbs of the groom, the animals that have been almost tortured into these manifestations of irritation, are brutally kicked and punished.

This, however is a vice that may be conquered. If the Lorse is dressed with a lighter hand, and wiped rather than brushed, and the places where the skin is most sensitive are aroided as much as thorough cleanliness will allow, he will gradually lose the recollection of former ill-treatment, and become tractable and quiet.

In those instances where the skin is so irritable that the horse really endures a great deal of misery every time he is cleaned besides requiring needlessly the expenditure of a great amount of muscular exertion, the remedy is very simple; instead of being curry-combed and wiped, the horse should be merely washed over with warm water on his coming in warm from a journey, then gently scraped and covered with a rug. The warmth of the body will very soon dry the skin.

\section{VICIOUS TO SHOE.}

The correction of this is more peculiarly the business of tho smith; yet the master should diligently concern himself with it, for it is more often the consequence of injudicious or bad usage, than of natural vice. The vice is certainly a bad one, and it very materially diminishes the value of the horse; for it 
is a habit which generally gets worse at each time of snoeing. It is not so much the kicking of the horse that is to be feared, but the animal will bear his whole weight on the foot requiring to be shod, so that the smith is unable to lift it up, or afterward to support it; beside which the animal will keep continually kicking or endeavoring to get the foot away, to the imminent danger of the limbs of the unfortunate operative. This deplorable and vicious habit is greatly increased, if not altogether produced, by rough usage at the early shocings, and it generally gets worse at each time of shoeing, so that the horse is often rendered at last completely worthless.

It may be expected that there will be some difficulty in shoeing a horse for the first ferv times, as it is an operation that gives him a little uneasiness. The man to whom he is most accustomed should go with him to the forge; and if another and steady horse is shod before him, he may be induced more readily to submit. It cannot be denied that, after the habit of resisting this necessary operation is formed, force may sometimes be required in order to reduce our rebellious servant to obedience; but there can be no manner of question that the large majority of horses vicious to shoe are rendered so by harsh usage, and by the pain of correction being added to the uneasiness of shoeing. It should be a rule in every forge, that no smith should be permitted to strike a horse, much less to twitch or gag him, without the master-farrier's order; and that a young horse should never be twitched or struck. There are ferw horses that may not gradually be rendered manageable for this purpose by mildness and firmness on the part of the operator; they will soon understand that no harm is meant, and they will not forget their usual habit of 
obedience; but if the remembrance of corporeal punishment is connected with shoeing, they will always be fidgety, and occasionally dangerous.

\section{CRIB-BITING.}

This is a very unpleasant habit, and a considerable defect, although not so serious as it is often represented. The horse lays hold of the manger with his teeth, violently extends his neck, and then, after some convulsive action of the throat, a slight grunting is heard, accompanied by a sucking or drawing in of air. It is not an effort at simple eructation, arising from indigestion; it is the inhalation of air. It is that which tales place with all kinds of diet, and when the stomach is empty as well as when it is full.

The effects of crib-bitins are plainly perceptible. The teeth are injured and worn away, and that, in an old horse, to a rery

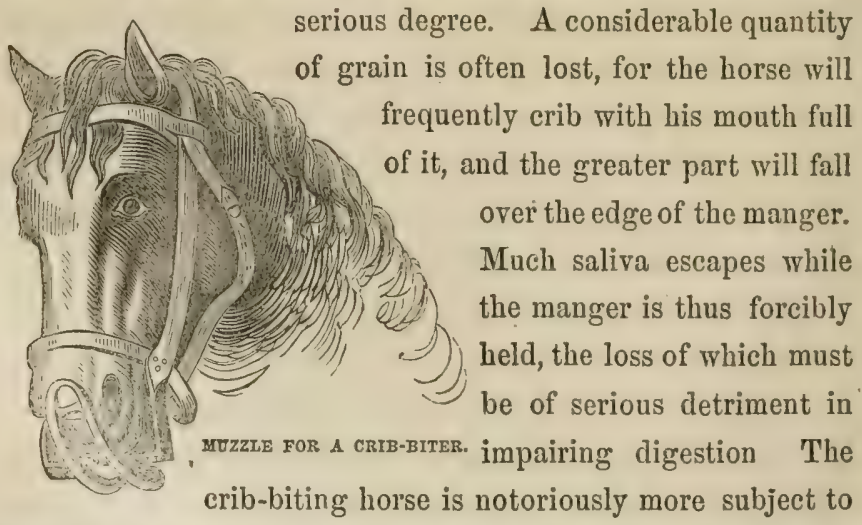
colic than other horses, and that of a kind difficult of treatment and peculiarly dangerous. Although many a crib-biter is stout and strong, and capable of all ordinary work, these horses do 
not generally carry as much flesh as others, and hare not their endurance; on these accounts, crib-biting has been, and very properly, decided by the highest authority to be unsoundness.

It is moreover one of those tricks which are exceedingly contagious. Every companion of a crib-biter in the same stable, is likely to acquire the habit, and it is the most inveterate of all habits. The edge of the manger will in vain be lined with iron, or with sheep-skin; or with sheep-skin covered with tar or aloes, or any other unpleasant substance. In spite of the annoyance which these may occasion, the horse will persist in his attack on the manger. A strap buckled tightly round the neck, by compressing the mindpipe, is the best means of prerenting the possibility of this trick; but the strap must be constantly worn, and its pressure is apt to produce a worse affection, viz., an irritation of the windpipe, which terminates in roaring.

Some have recommended turning out for five or six monthis; but this has never succeeded, except with a young horse, and then but rarely. The old crib-biter will employ the gate for the same purpose as the edge of his manger, and he will often gallop across a field for the mere purpose of having a bite at the rail. Medicine is altogether thrown away in such a case.

The only remedy is a muzzle, with bars across the bottom; sufficiently wide to enable the animal to pick up his corn and to pull his hay, but not to grasp the edge of his manger. If this is worn for a considerable period, the horse may be tired of attempting that which be cannot accomplish, and for a while forget the habit; but in a majority of cases the desire of crib-biting will return with the power of gratifying it.

The causes of crib-biting are various, and some of them be- 
yond the control of the owner of the horse. It is often the result of imitation; but it is more frequently the consequence of idleness. The high-fed and spirited horse must be in mischief, if he is not usefully employed. Sometimes, but not often, it is produced by partial starvation; and another occasional cause is the frequent custom of dressing the horse, even when the weather is not severe, in the stable,-thus enabling the animal to catch at the edge of the manger, or at that of the partition on each side, if he has been turned.

\section{WIND-SUCKING.}

This closely resembles crib-biting, and arises from the same causes; the same purpose is accomplished, and the same results follow. The horse stands with his back bent, his head drawn inward, his lips alternately slightly opened and then closed, and a noise is heard as if he were sucking. It appears quite probatble, judging from the same comparative want of condition and the flatulence noted in connection with the last habit, that either some portion of wind enters the stomach, or there is an injurious loss of saliva.

This vice diminishes the value of the animal nearly as much as crib-biting; it is equally as contagious and inveterate. The only remedies-and they will seldom avail-are tying the head 11p, except when the horse is feeding, or putting on a muzzle with sharp spikes toward the neck, which will prick him whenever he attempts to rein his head in for the purpose of windsucking.

\section{OVERREACHING.}

This unpleasant noise known also by the name of "clicking," is occasioned by the toe of the hind foot, or the inner edge of 
the inside of its shoe, striking upon the heel of the coronet of the fore foot. The preventive treatment is the beveling, or rounding off, of the inside rim or edge of the hind shoe. The cure is, the cutting away of the loose parts, the application of Friar's balsam, and protection from the dirt.

Some horses, particularly young ones, overreach so as to strike the toes of the hind shoes against the fore ones, which is termed "clinking." Keeping up the head of the horse does something to prevent this; but the smith may do more by shortening the toe of the bind shoes and having the web broad. When they are too long, they are apt to be torn off; when too narrow, the hind foot may bruise the sole of the fore one, or may be locked fast between the branches of the fore shoe.

\section{NOT LYING DOWN.}

It occasionally happens that a horse will seldom or never lie down in the stable. He sometimes continues in apparent good bealth, and feeds and works well ; but generally his legs swell, and he becomes fatigued sooner than another horse. If it is impossible to let him loose in the stable, or to put him into a spare box, nothing can be done to obviate the difficulty. No means, gentle or cruel, will force him to lie down. The secret is, that he is tied up, and either has never dared to lie down through fear of the confinement of the halter, or he has been cast in the night and severely injured. If he can be suffered to range the stable, or have a comfortable box in which he may be loose, he will usually lie down the first night. Some few horses, however, will lie down in a stable,-and not in a loose box. A fresh, well-made bed will generally tempt the tired horse to refresh hiniself with sleep. 
It may be observed in this connection, that the basis of sup. port afforded by the four extremities is so considerable in tho horse, that he is able to sleep in a standing position, and some horses have even been known to preserve their health, strength, and condition, although they were never known to lie down. At the same time, it is undeniable, that an animal that will quickly lie down and take his rest, as a general rule, preserves his condition, and is better fitted for exertion.

\section{SHYING.}

This most dangerous habit is sometimes the effect of fear, and sometimes is a downright vicious propensity; and there are

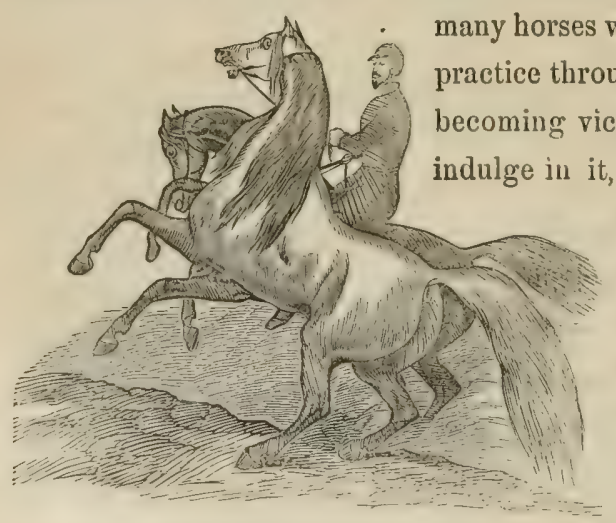

DISAGREEABLE AND DANGEROUS.

sheer mismanagement. The young colt is almost always more or less shy, especially if he is brought at once from the retired fields in which

he was reared to the streets of a busy town.

There are, however, numberless varietids of shyers, some being dreadfully alarmed by one kind of olject, w wich to another is not at all formidable. When a horse finds that he gains his olject by turning around, he will often repeat the turning without cause, pretending to be alarmed, and looking out for ex- 
cuses for it. This is not at all uncommon, and with timid riders leads to a discontinuance of the ride, by which the horse gains his end for the time, and repeats the trick upon the first occasion. In genuine shying from fear, the eyes are generally more or less defective; but sometimes this is not the cause, which is founded upon a general irritability of the nerrous system. Thus, there are many that never shy at meeting wagons, or other similar objects, but which almost drop with fear on a small bird flying out of a hedge, or any other startling sound. These are also worse, because they give no notice, whereas the ordinary shyer almost always shows by his ears that he is prepared to turn.

For shyers the only remedy is, to take as little notice as possible, to make light of the occurrence, speak encouragingly, jet rather severely, and to get them by the object in one way or another. If needful, the aid of the spur and whip may be called in, but not as a punishment. If the horse can be urged to go by the object at which he is shying without the whip or spur, so much the better; but if not, he must be compelled to do so by their use. Wherever fear is the cause of shying, punishment only adds to that fear; but where vice has supplanted fear, severity should be used to correct it.

As a general rule, the whip need never be used, unless the horse turns absolutely round, and not then unless there is reason to suspect that he is pretending fear. If he will only go by the object, even with "a wide berth," as the sailors say, he may be suffered to go on his way unpunished; and nothingois so bad as the absurd severity which some horsemen exercise after the horse has conquered his reluctance, and passed the object. At this time he should be praised and petted, with all the en- 
couragement which can be given; and on no account should he be taught to make those rushes which are so commonly seen on the road, from the improper use of whip and spur. If punishment is necessary at all, it must be used beforehand; but it often happens that the rider cannot spare his whip-hand until the shying is over; and then, in his passion, he does not reflect that the time has passed for its employment.

Shying on coming out of the stable is a habit that can rarely or never be cured. It proceeds from the remembrance of some ill-usage or hurt which the animal has received in the act of proceeding from the stable, such as striking his head against a low door-way, or entangling the harness.

When the cure, however, is early attempted, it may be so far overcome that it will be unattended with danger or difficulty. The horse should be bridled when led out or in. He should be held short and tight by the head, that he may feel that he has not liberty to make a leap, and this of itself is often sufficient to restrain him. Punishment, or a threat of it, will be highly improper. It is only timid or high-spirited horses that acquire the habit, and rough usage invariably increases their agitation and terror.

\section{PAWING.}

Some hot and irritable horses are restless even in the stable, and paw frequently and violently. Their litter is destroyed, the floor of the stable broken up, the shoes worn out, the feet bruised, and the legs sometimes sprained. If this habit does not exist to any great extent, yet the stable never looks well. Shackles are the only remedy, with a chain sufficiently long to enable the horse to shift his posture, or move in his stall; but 
these must be taken off at night, otherwise the animal will seldom lie down. Unless, however, the horse possesses peculiar value, it will be better to dispose of him at once, than to submit to the danger and inconvenience that he may occasion.

\section{ROLLING.}

This is a very pleasant and perfectly safe amusement for a horse at grass, but cannot be indulged in the stable without the chance of his being dangerously entangled with the collar, rein, or halter, and being cast. Yet, although the horse is cast, and bruised, and half strangled, he will roll again on the following night and continue to do so as long as he lives. The only remedy is not a very pleasant one for the horse, nor always quite safe; yet recourse must be had to it, if the habit of rolling is inveterate. The horse should be tied with length enough of halter to lie down, but not to allow of his head resting upon the ground; because, in order to roll over, a horse is obliged to place his head quite down upon the ground.

\section{SLIPPING THE COLLAR OR HALTER.}

This is a trick in which many horses are so well accomplished, that scarcely a night passes without their getting loose. It is a very serious habit, for it enables the horse sometimes to gorge himself with food to the imminent danger of producing staggers; or it exposes him, as he wanders about, to be kicked and injured by the other horses, while his restlessness will often keep the whole team awake. If the web of the halter, being first accurately fitted to his neck, is suffered to slip only one way. or a strap is attached to the halter and buckled round the neck, but not sufficiently tight to be of serious inconvenience, the power of slipping the collar will be taken away. 


\section{STUMBLING.}

That person must either be a skillful practitioner, or a mere pretender, who engages to remedy this habit. If it arise from a heavy forehand, and the fore legs, being too much under the horse, no one can alter the natural frame of the animal; if it proceeds from tenderness of foot, grogginess, or old lameness, these ailments are seldom cured. Also, if it is to be traced to habitual carelessness and idleness, no whipping will rouse the drone. A known stumbler should never be ridden or driven by any one who values his safety or his life. A tight hand or a strong bracing-rein are precautions that should not be neglected, although they are generally of little avail; for the in- veterate stumbler will rarely be able to save himself, and this tight rein may sooner and further precipitate the rider. If after stumbling the horse suddenly starts forward, and endeavors to break into a short trot or canter, the rider may be assured that others before him have fruitlessly endeavored to remedy the nuisance.

If the stumbler has the foot kept as short, and the toe pared as close as safety will permit, and the shoe is rounded at the toe, or has that shape given to it which it naturally acquires in a fortnight from the peculiar action of such a horse, the animal may not stumble quite so much; or if the disease which produced the habit can be alleviated, some trifling good may be done; but in almost every case the stumbler should be got rid of, or put to slow and heary work. If the latter alternative is adopted, he may stumble as much as he pleases, for the weight of the load and the motion of the other horses will keep him upon his legs. 


\section{UNSTFADINESS WHILE BEING MOUNTED.}

When this merely amounts to eagerness to start-very unpleasant, indeed, at times, for many a rider has been thrown from his seat before he was fairly fixed in it-it may be remedied by an active and good horseman. It oftentimes happens that while the elderly, inactive, and fearful man is engaged in making more than one ineffectual attempt to rault into the saddle, the horse is-dancing about to his annoyance and danger; but no sooner is the animal transferred to the management of a younger and more agile rider, than he becomes perfectly subdued. Severity will here, more decidedly than in any other case, do harm. The rider should be fearless; he should carelessly and confidentially approach the horse, mount at the first effort, and then restrain him for a while; patting him, and not allowing him to proceed until he becomes perfectly quiet. Horses of this kind should not be too highly fed, and should have sufficient daily exercise.

When the difficulty of mounting arises, not from eagerness to start, but from unwillingness to be ridden, the sooner that horse is disposed of the better. He may be conquered by a skillful and determined horseman; but even he will not succeed without frequent and dangerous contests that will mar all the pleasures of the ride. 


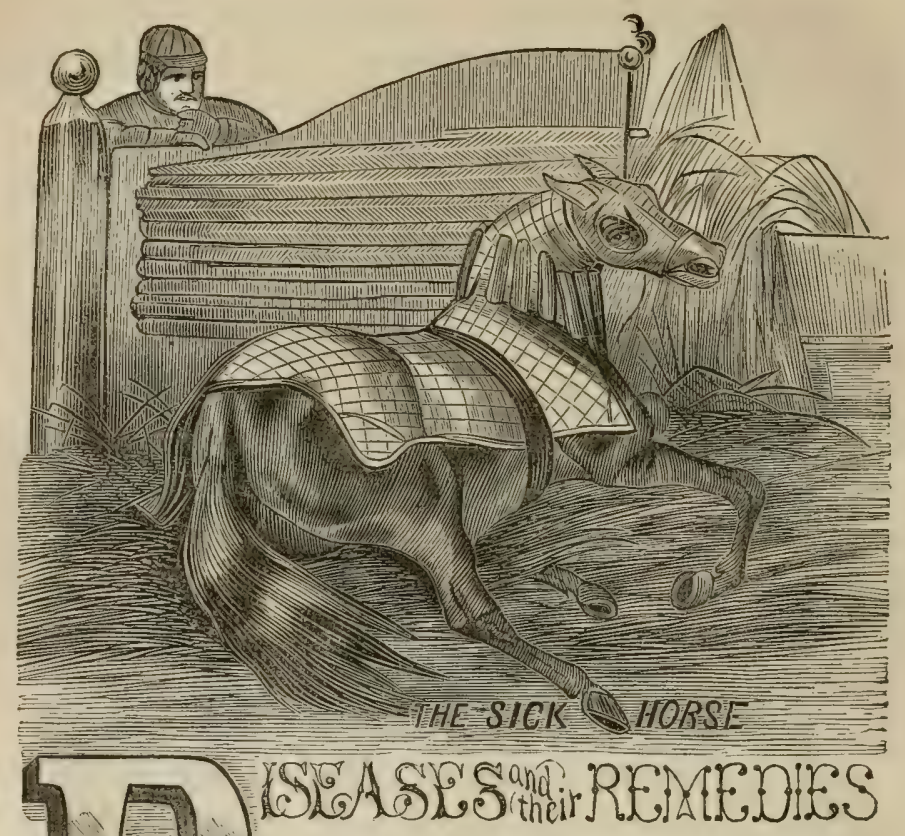

UNDER this head it is proposed to treat of the various diseases which horse-flesh is heir to, together with their symptoms, and to offer such remedies as personal experience, or the authority of other's in whom implicit confidence may be placed, suggests as the most efficacious. For convenience of discussion, these diseases are arranged in the present work under the heads of diseases of the mouth; of the respiratory organs; of the stomach and intestines; of the limbs; of the urinary organs; of the feet and legs; of the heart; of the head; and (220) 
LAMPAS.

of the eye;-placing under the head of miscellaneous such as do not appropriately fall under either of the foregoing diseases.

\section{DISEASES OF THE MOUTH.}

\section{IAMPAS.}

This term is used to designate a fullness or swelling of the bars or roof of the mouth, caused by the cutting of the teeth. Lampas will be found in all colts, although in many the slight inconvenience occasioned by it attracts little or no attention. In others, however, the great tenderness of the parts affected causes the animal to refuse his food, in consequence of which he is by many compelled to submit to an operation equally cruel and unnecessary-that is, no less than burning out the bars of the mouth with a red-hot iron, thereby destroying the functions of the part, and leaving the mouth sore for some time afterward. This mode of treatment has been practised for years, and is even at the present day almost the only one in vogue, although it is of no practical benefit whatever, but, on the contrary, is often very injurious. In the case of the child similarly affected, the humane practitioner seldom does more than to lance the gums. This, certainly, is a more rational mode of operating, and the author's experience convinces him that if the parts inflamed in the case of the horse be simply lanced, the swelling will soon subside, and the horse partake of his food as usual. A common pocket-knife will answer the purpose quite well; and after the lancing the 
mouth should be washed with a solution of the tincture of myrrh, two ounces to a pint of water, or a solution of alum in water. This should be repeated twice a day for three or four days, during which time give bran mashes or flax-seed gruel, and, if procurable, a small quantity of new grass. No hay, corn, or oats, should be given for a week; at the expiration of which period the teeth will be in a condition to masticate such food.

\section{INFIAMED GUMS.}

Occasionally the gums of very young horses, when cutting their teeth, become exceedingly tender, sore, and swollen. As this is principally confined to the yearling, it is generally overlooked by the owner. The treatment in such cases is to cut the gum through to the tooth immediately under it with a lancet or common pocket-linife. The gum being thus broken, the tooth comes through with little pain.

\section{BAGS OR WASHES.}

These are soft, puffy strellings of the membrane of the mouth, lining the lips, just within the corners of the mouth. This disease is generally caused by the bearing rein being too tight. They are cured by cutting off a portion of the swelling with a pair of scissors or a knife; after which the parts should be dressed with a little salt, or powdered alum. This generally proves successful.

\section{ULCERS IN THE MOUTH.}

Horses, during the process of breaking, are frequently hurt : by the pressure of the bit upon the under jaw a little in front of 
the first molar tooth; in consequence of which the periosteum, or thin fibrous membrane corering the bone, often becomes involved in the inflammation, the bone itself not always escaping injury, a neglect of which occasionally causes the bone of the jaw to become carious or decayed; sinuses, or pipe-like openings, are sometimes formed, which becoming filled with masticated food, become fetid and often occasion troublesome sores. Grooms on discovering this sore, generally attribute it to what is commonly called squirrel grass, or wild barley. If the sore is confined to the gum alone, it should be washed frequently, and dressed with a little tincture of myrrh; but when the bone is affected, it must be examined carefully with a probe, and if found rough, or presenting small openings, the bone must be exposed, and all the diseased parts removed, after which the tincture of myrrh should be used for a dressing. Such operations should be performed by a qualified veterinary surgeon, if one is to be had; otherwise more injury may be done by the bungling operator than would be occasioned by the disease. If such services cannot be procured, caustic silver, or lunar caustic, should be applied to the diseased bone. If the caustic is not readily obtainable, the red-hot iron will answer the purpose as well, or even better. Butter of antimony, placed on a little cotton or tow, and packed in the sore, is an excellent application, as it hastens a separation or exfoliation of tho diseased bone, thus enabling the parts soon to heal.

\section{SORE MOUTE.}

This is often caused by the bit's cutting or bruising the lips at the angles of the mouth. In carelessly balling horses, also, the under part of the tongue sometimes becomes injured, which 
- frequently escapres notice until the animal refuses his food, and the tongue becomes tender and swollen. In such cases, wash tho mouth clean, and sprinkle a teaspoonful of table salt on the sore; the tincture of myrrh occasionally applied will hasten the cure.

\section{CUT TONGUE.}

The tongue sometimes becomes bruised from the sudden jerking of the lines in the hands of a careless or obstinate driver, or it may happen from tight reining; that portion of the tongue upon which the bit rests becoming bruised and ulcerated, and the frequent use of the bit keeping up the irritation, until the tongue, in some cases, becomes almost separated by ulceration before it is discovered. Alum water, saltpetre, and tincture of myrrh are the proper dressings.

\section{UNEVEN TEETH.}

The molar teeth frequently become very uneven upon their faces or grinding surfaces, in consequence of the crusta petrosa wearing away too rapidly and often leaving deep cavities in the teeth, which become filled with food and soon prove a great source of annoyance by interfering with proper mastication. This occurs more particularly in old horses. The upper molar teeth being well protected on the outer surface with enamel, wear less rapidly than the lower ones which are protected upon the inner side. In consequence of this the upper teeth often become very sharp upon the outside, and when the reins are drawn up the cheeks are forced upon these sharp edges and become sore and often lacerated, while the lower ones becoming starn on the inside edges, lacerate the tongue in a similar 
QUIDDING.

manner. The horse from this cause often refuses his food, since mastication causes him severe pain. He soon begins to lose . flesh, the digestive organs become deranged, the skin becomes tight, and the animal is perhaps doctored for bots, worms, and the like.

In all these cases the tooth-rasp becomes necessary, which is an instrument made concave, or hollow, upon one side, and convex, or rounding, on the other, with a long handle attached. 'The rasp is upon the hollow side, the round side and the edges being perfectly smooth so as not to wound the cheeks or tongue when used. With this instrument the sharp corners of the teeth are easily taken off, and the horse is enabled to feed again in the proper manner. If the teeth are in this condition, no medicine is of any avail; all the condition powders in the world will not benefit in the slightest degree; the tooth-ras\}) is the only remedy that will prove serviceable.

\section{QUIDDING.}

This disease, if disease it may be called, is generally caused by the irregular wear of the teeth already mentioned; or it may arise from caries of the teeth, or from a diseased state of the muscles of deglutition. "I have seen," says White, "at the kemnel the jaw of a horse which died literally from starvatiou in consequence of a disease of the grinding teeth, which appeared to have been brought on by feeding on coarse woody hay, containing the stocks of thistles, docks, \&c. This animal was what dealers term a quidder, for the muscles of deglutition were at least so affected that he was incapable of swallowing; and after fruitless attempts to chew his food it was thrown out : $x$ to the manger in a ball or quid, and a great deal of imper- 
fectly chewed hay had been forced into the cavities formed at the roots of some of the grinding teeth." The tooth-rasp , sometimes proves a perfect cure in such cases.

\section{WOLF TEETH.}

Very erroneous opinions are entertained by horsemen, and even by veterinary surgeons, in reference to these teeth, and various theories have from time to time been set afloat regarding them, arising, for the most part, from a want of proper investigation.

These teeth are natural to all horses, and make their appearance between the first and fifth year. They are not supernumerary teeth, as has been stated by some writers, but are natural teeth found in all colts. The germs of these teeth will be found in the foal at birth, and developed in the jaw of the yearling ready to make their way through the gums. In an examination of at least one hundred heads of colts that have died under eighteen months of age, the author has found in every instance either natural wolf teeth, or the germs from which they are developed. It is a mistaken idea, that these teeth exert any influence over the eyes. Nature never placed them in their position for the purpose of injury. In cases where the eye is supposed to be affected by them, it is simply necessary to treat the eye for inflammation, and allow the teeth to remain. As a general rule they do not remain in the jaw long after being cut; having performed their function, whatever it may be, they fall out and are therefore seldom found. Their removal can do no harm but it is an entirely unnecessary operation. 


\section{CARIES OF THE TEETH}

The teeth of horses, as has already been stated, are made up of three substances, the enamel, the bone, and the crusta petrosa; and in consequence of their pecter,

THE BLOODED MARE FASHION AND FOAL. and the inability of the animal to inform us of his sufferings, this disease frequently becomes much more serious than in man. Its operation, besides, is quite different upon the teeth of horses from what it is upon the human teeth. In the human subject caries is found, in a large majority of cases, making its appearance as a dark spot between the teeth, on one side of the crown, gradually working inwards, destroying the bone in its progress, and leaving the enamel a mere shell upon the outside of the tooth, while the roots generally remain in a comparatively sound condition during the progress of decay. In the horse, however, caries is a very different thing, as far as its effects are concerned. It makes its appearance upon some one or more of the indentations or depressions upon the face of the tooth, attacking the crusta petrosa, (a substance not found in the human tooth,) and extending from the face through the entire length of the tooth, splitting it up into several thin plates, in consequence of which abscesses often form at the roots of such teeth, which, being prevented from dis 
charging into the mouth by the food that fills up the cavity, generally find an opening into the nose, discharging their fetid matter through that channel. The animal while in this condition is often treated for catarrh; commonly called distemper. The discharge still continuing, and becoming more and more fetid, the animal is at last supposed to be in a glandered condition and killed.

The first case of this kind which came under the author's notice occurred in the year 1853. Having occasion to visit the yard where dead animals are boiled, the peculiar appearance of one horse lying upon the ground attracted his attention. Upon inquiry he learned that he had been killed as a glandered horse; but failing to recognize any such marlis as might be expected in that disease, he made a very careful examination of the head and 'found the real cause of trouble to be, not glanders, but a carious tooth, of which but three small ribbon-like fragments remained. This horse was but seven years old. An abscess had formed at the root of the tooth, discharging itself into the nostril, whence it was cjected. Another horse, with similar symptoms, pronounced glandered by two eminent reterinary surgeons, was destroyed at the same place in the year 1859 . The author's examination disclosed the fact, that the first two molar teeth were almost entirely destroyed by caries, and that a large abscess had formed at their roots, which extended into and completely closed up one nostril, causing an immense tumor on the right side of the head.

The difficulty of examining the molar teeth of the horse, together with the silence of veterinary author's on this important subject, are the only assignable reasons for the little information given us relative to a disease of such common occurrence. 
Indeed, the author has frequently been called upon to treat horses laboring under this disease, without a suspicion ever being entertained of its true nature.

A case of this lind came under his notice in the winter of 1858, while on a visit to Jackson, Michigan. He was called to see a bay mare kept for livery purposes, having a discharge from the right side of the face some two inches below the eye, which had existed for about two years. The discharge was of so fetid a character that the animal was rendered unfit for use, and she was consequently turned upon the common to die or get well, as the chances might be, all known modes of treatment having been previously adopted without any beneficial results. He discovered, upon examination, a carious tooth, which was removed, and in a short time the animal became well. During the winter of 1859 , a brown mare, belonging to a gentleman in Germantown, Pennsylvania, was sent to the Clinic of the Phi. ladelphia Veterinary College, having been pronounced glandered by a veterinary surgeon and ordered to be killed. Upon ex. amination a large abscess was discovered opening into the nose; together with two carious teeth-the first and second molars of the right side. The mare was cast, and ten pieces of carious teeth removed; the cavity was then well cleaned out, and tow saturated with tincture of myrrh filled in, removing and cleaning erery day. Some four weeks subsequently, the animal was sold for one hundred and fifty dollars, sound as a bell ; though previously to this operation she could not have been sold at any price. Many similar cases could be mentioned, but the foregoing will serve to show the necessity of making a thorough examination of an animal before pronouncing sentence of death upon it. 
Acidity of the fluids of the mouth is generally-and, as the author believes, correctly-assigned as the cause of caries of the teeth. The symptoms are fetid discharges from the nose, obstructed respiration, improper mastication of the food, passing the oats or corn whole, quidaing, drowsiness, loss of flesh, staring coat, hide-bound, tossing to and fro of the head, stopping short on the road, starting suddenly, and at times becoming almost frantic. All these symptoms, however, must not be expected to be found in the same case, as different horses are differently affected by the disease. One is drowsy, feeds daintily it times, and again ravenously; another is at times wild, so as to be almost unmanageable. Many of these symptoms occur in wther diseases besides those of the teeth; but their presence suggests the necassity for an examination of the mouth, and particularly of the molar teeth, which may be done by passing the hand along the upper molar teeth inside of the cheek, thus enabling the examiner to detect the presence of caries without difficulty.

\section{EXTRACTING TEETH.}

When a carious tooth, or one so unequally worn as to cause mischief, is discovered, its removal is necessary to the restoration of the animal's health. In order to accomplish this, the horse must be cast, and the age of the animal considered, in order to make choice of proper instruments. If he is young, say from four to six years, an instrument made similar to the key used by surgeon dentists, is the best adapted; if he is old, a pair of forceps of large size, made in the same manner as the tooth-forceps of dentists, will answer, as the roots of the teeth in old horses are comparatively short, and therefore may be sasily extracted. 


\section{DISEASES OF THE RESPIRATORY ORGANS}

\section{INFLAMMATION,}

The diseases of the respiratory organs and air passages are generally of an inflammatory type. In order to fully understand the various diseases to which these important organs are subject, a few remarks regarding the nature of inflammation, its progress, \&c., mày not be out of place in a work like the present.

Inflammation, then, is a state of altered nutrition, an increased vascularity and sensibility of the parts involved, together with a tendency to change of structure. The symptoms are swelling, pain, heat, and redness where the parts are not covered with hair. The redness is in consequence of a redundancy of blood in the inflamed part, which distends the small capillaries with red particles of blood. When the inflammation is acute, the parts present a bright red or crimson hue; when it is chronic, they are of a dark or purplish red color. As the various terms employed by authors to indicate the various degrees are uninteresting to the general reader, no attempt at detail is here made.

The sensation of pain is mainly due to a stretching of the nerves by the distended blood-vessels. It differs in its character and intensity according to the parts involved, varying from a burning, throbbing, sharp, and lacerating pain to a mere sense of heat, soreness, and a dull sensation of pain. The heat in inflammation is supposed to arise from an increased quantity of blood in the inflamed part. The swelling in the early stage is due to the increased quantity of blood, and 
afterward to the effusion which takes place in all loose tissnes. By inflammation all the various structures of the animal economy may be so altered as to interfere with the performance of their natural functions; in some cases by a permanent thickening of the parts, and in others by adhesion and the like.

By the aid of auscultation, that is, the application of the ear to the parts to be examined, the slightest change in the normal and healthy condition of the respiratory organs may be detected, and the various parts involved in inflammatory action may be pointed out with a considerable degree of certainty. With thus much of introduction we proceed to the consideration of the various diseases naturally falling under ouj present division.

\section{SORE THROAT.}

Sore throat is a common attendant upon catarrhal affections. When it is confined to that portion of the throat at

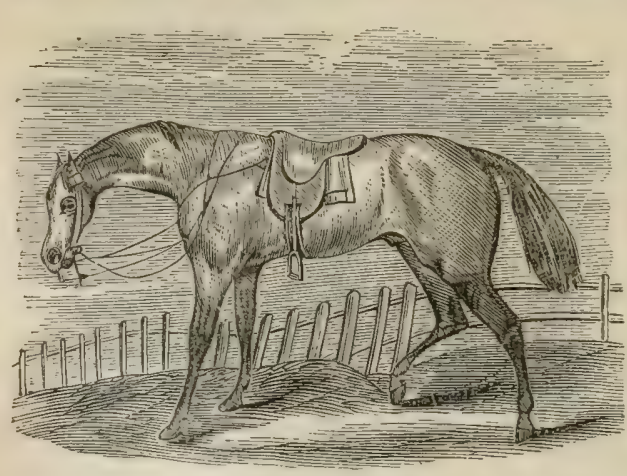

TEE SADDLE HORSE.

the root of the tongue, which is known to medica! men as the larynx, it is called laryng. itis; and this part is the commox. seat of this dis. ease, from whicl. it extends dowr. the trachea, $\mathrm{O}$ windpipe, to the lungs. As leng as the thront remains rem: sore, it is a pretty good evidence that the lungs nia not, arferter 
This disease may exist either in an acute, sub-acute, or chronic form. When acute, its management is simple and usually successful; but if it is neglected in this early stage, it not unfrequently proves troublesome, and in some cases leaves the animal permanently unsound, terminating in wheezing, whistling, roaring, or broken-windedness.

The symptoms of sore throat are easily detected by the ordinary observer. According to the intensity of the disease there is an accumulation of saliva in the mouth, clear, thick, and stringy, more particularly when the tongue is swollen; a stiffness of the head, the horse coughing upon the slightest pressure on the larynx; difficulty in swallowing, more particularly hard grain or hay, and a consequent refusal of food altogether; a short, hard eough; more or less copious discharges from the nose, as the disease adrances; an accelerated pulse, frequently rising to ninety or one hundred pulsations in a minute; mouth hot, with considerable ferer accompanying.

For treatment, apply strong mustard, mixed with water to the thickness of cream, to the throat, rub it well in, and repeat as often as may be necessary; or poultice the part with flaxseed meal for several days, and sprinkle on the tongue a teaspoonful of common table salt three or four times a day, which in ordinary cases is all the treatment which will be necessary for the acute type of the disease.

The attention of the veterinary surgeon is more frequently called to chronic forms of this disease, in which, though no swelling of the parts is usually perceptible, a pressure upon the larynx at once excites a hard cough. In this stage of the disease much relief will be obtained by the application of a blister, prepared as follows - Pulverized cantharides (Spanish 
flies) half an ounce; of lard, one and a half ounces; mixed well, and as thin as may be desired with spirits of turpentine. This must be well rubbed in, and after it has acted thoroughly, dress with sweet oil or lard.

\section{STRANGLES.}

This is but another form or stage of laryngitis. The throat becomes enormously swollen, the swelling extending under the jars and up to the very ears, threatening suffocation; then respiration becomes much disturbed; the flanks heave violently, and the breathing can be heard at a considerable distance; the animal begins to sweat from his frequently convulsive efforts to breathe, and, if not speedily relieved, dies a most violent death.

Life may be saved by the veterinary surgeon at this crisis by the operation of bronchotomy, that is, by opening the windpipe, and inserting a tube through which the animal may breathe instead of through the nose. This operation affords instant relief, and gives an opportunity to apply remedies to the diseased throat, which in a few days usually effect a cure, when the tube may be removed. The author has never lost a case where he has resorted to this operation.

The early treatment of this disease is to poultice the throat well with flaxseed meal, commonly called cake-meal or oil-cake, using salt upon the tongue as before. Mustard plasters are also very effective, and steaming the nostrils frequently affords relief. As soon as the swelling permits, it should be lanced; and when it has once discharged freely, the animal may be considered out of danger, provided proper care be taken to guard against a relapse. A seton applied between the jaws 
often relieves; but these cases are safer in the hands of a competent surgeon. Under no circumstances of this disease should the animal be bled.

Malignant or putrid sore throat, is fortunately but little known in the United States, the author not being aware of its existence in any portion. Cases presenting somewhat similar symptoms have been found upon examination to differ in a marked degree from those which accompany this form of disease as they are laid down in the works of foreign authors. A detailed description of this type of the disease is therefore deemed unnecessary in the present treatise.

\section{CHRONIC COUGH.}

This arises from various causes, and is present in a number of diseases. It is often symptomatic of some affection of the lungs and air passages; and it sometimes exists apparently as an independent affection, the animal thriving well, and retaining unimpaired his appetite and spirits.

If it arises from irritation of the larynx, or upper part of the throat, a few applications of mustard will be beneficial; if from worms in the stomach or intestines, treat as directed under the head of "Worms." If it exists without any apparent connection, or as the termination of disease previously existing, give every night in a bran mash one of these pow. ders : of sulphate of copper (blue vitriol), digitalis (fox-glove), pulverized squills, nitre; and camphor, each one ounce; to be made into ten powders. Green food, as carrots, potatoes, turnips, or parsnips, should be given when procurable. 


\section{CATARRH.}

This disease, commonly called a cold, is confined in ordinary cases to the lining membrane of the rose and neighboring parts; but in severe cases the inflammation sometimes extends down the air passages to the lungs, frequently resulting fatally. In the spring of the year this disease frequently appears in an epizootic form, when the symptoms are more alarming aud the termination more generally fatal.

If the inflammation is confined to the nostrils, the membrane lining those cavities is reddened, a thin watery or mucous discharge from the nostrils takes place, accompanied with frequent sneezing; if the larynx is involved, there are cough, swellings underneath the jaws, etc.

Some authors recommend bleeding in this affection; but such an abuse of the lancet can do no good, and is often productive of much harm. If the symptoms are slight, one of the following powders given night and morning will be all that is required: of saltpetre two ounces; of pulverized Jamaica ginger one ounce; mixed, and divided into eight powders. If there is swelling under the jaws, poultice the throat with flasseed meal; if much discharge from the nostrils, steam them well with boiling water poured upon bran. If the inflammation exhibits any tendency to extend down the windpipe, apply a blister all along: the neck over the windpipe from the throat to the breast, giving one of the following balls night and morning; of nitrate of potassa and pulverized gentian root, each one ounce; Jamaica ginger and caraway seeds, each half an ounce; mix with molasses and divide into six balls. If the discharge from the nose continues, the animal losing flesh, and the appetite being 
impaired, give one of the following powders in the feed night and morning : sulphate of copper one ounce; pulverized gentian root one and a half ounces; pulverized ginger six drachms; mix and divide into eight powders. Good wholesome food only should be given.

\section{DISTEMPER.}

All catarrhal affections are classed by horse-owners under the common head of distemper. Common catarrh, epizootic or epidemic catarrh, Iaryngitis, bronchitis, and all other diseases accompanied by nasal discharges, are regarded by horsemen generally as one and the same disease.

\section{INFIUENZA.}

For several years past a disease has been more or less prevalent in various sections of the United States, known to the

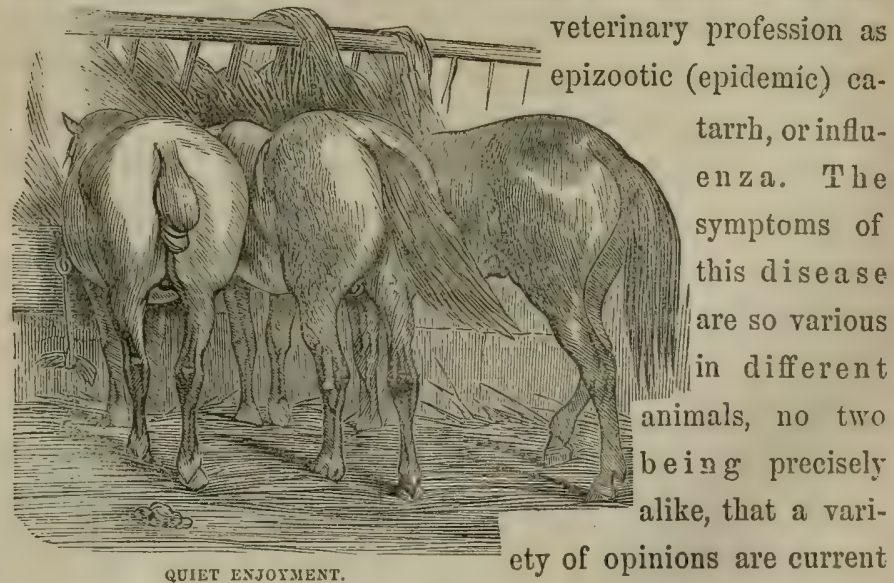
concerning it and its nature, and, as a consequence, various other diseases are often confounded with it. 
In the year 1855 , this disease made its appearance in the stables of one of the largest omnibus proprietors in Philadelpha, and some nine horses died in about two weeks. These were supposed to have been foundered, and were treated for that disease. A careful examination, however, by a competent practitioner revealed the true nature of the disease, and under proper treatment the balance of the stock was saved. Shortly after the demand for veterinary surgeons was very great, and while they saved forty-eight out of every fifty cases, the farrier lost almost every case he attempted to treat, principally from his too common practice of bleeding and purging; thus reducing the system so low that nature became exhausted.

This disease is called by horsemen pink-eye distemper, and is by many regarded incurable, though the author knows of no disease that more readily yields to proper treatment, and in his own practice he has been eminently successful in accomplishing a cure. It commences with slight watery or thin mucous discharges from the nostrils; matter collecting in the inner corner of the eyes; eye-lid on the inner side of a very slight or yellow. ish red color; pulse feeble, with occasional paralysis of the hind extremities; sore throat; excessive debility; membrane of the nose much reddened; hard cough; heart sometimes violently agitated; flanks heaving; and feet sometimes hot; thus producing all the symptoms of founder.

For treatment, never bleed, as in nine cases out of ten, the animal dies. If inflammation runs high, as it sometimes does, use for several days the following : of tartar emetic and nitrate of potash, each two drachms, made into a ball with molasses and given at night. Give also in a pail of water one ounce of spirits of nitre twice a day; or, if more convenient, two drachms 
of the extract of belladonna (nightshade) dissolved in the water. When the inflammation is reduced, give one of the following balls night and morning : of pulverized gentian root and nitrate of potassa, cach an ounce; pulrerized Jamaica ginger, half an ounce; ground fenugreek seeds six drachms; mix with molasses, and divide into eight balls. In pure cases of debility (this being one of the serious symptoms of the disease), or in the early stages, previous to extensive inflammation being established, one of the following should be given twice a day :-sulphate of iron (green vitriol) two ounces; pulverized ginger one ounce; pulverized gentian root two ounces; mix with molasses, and divide into eight balls. In cases where the lungs are affected, give the following ball twice a day : of tartar emetic and pulverized digitalis (foxglove) each one scruple ; nitrate of potash three drachms; mix with molasses. Linseed tea, or oat-meal gruel should be given frequently. No hay should be given, unless the bowels are in good condition. If the liver is affertedwhich may be known by the yellow tinge of the mucous membrane, dung small and hard, horse lying on his side, and occasionally looking at his side as if in pain, with occasional fits of uneasiness-the following may be given, but must not be repeated; of Barbadoes aloes three drachms, calomel and pulrerized digitalis each half a drachm; make into a ball with molasses. In all these cases where there is soreness or swelling of the throat, the parts should be freely blistered; and the sides also, if the lungs are involved. This mode of treatment has proved - verg successful in the author's practice. 


\section{BRONCHITIS.}

The larynx (upper part of the windpipe), the trachea (windpipe), and the bronchial tubes (branches from the trachea into the lungs for the passage of air), are lined by one continuous membrane, called the mucous membrane, which sceretes a thin mucous substance that always keeps the parts soft and moist. When this membrane becomes inflamed, the disease is named according to its location. If it is confined to the larynx (as has been before observed), it is termed laryngitis; if to the windpipe, trachitis; and if to the bronchial tubes, bronchitis. The trachea and bronchia are rarely diseased separately, the inflammation generally extending from one to the other. We shall therefore treat of bronchitis as embracing trachitis likewise. Even this disease rarely exists unmixed with others, in consequences of which it is often overlooked, or confounded with other diseases of a pulmonary character.

Bronchitis is generally preceded by a shivering fit; mouth hot, with more or less saliva; discharge from the nose; cough ; sore throat; fever; short breathing; loss of appetite; acclerated pulse; and membrane of nose and eyelids reddened.

In treating this disease it is much safer to call in the veterinary surgeon, in consequence of the difficulty which the ordinary observer will experience in distinguishing it from other pulmonary diseases, and from the fact that the treatment varies with the changes that take place in the progress of the disease. It is not necessarily fatal; yet the most trifling neglect or mistake in trentment may make it so. The average loss, if proper treatment is pursued, is not more than five per cent. Resort should never be had to bleeding in any form which the 
disease may assume, although such treatment has been recom. mended by the highest authorities.

If much fever is present, give the following ball: of nitre two drachms; pulverized digitalis and tartar emetic each half a drachm; solution of gum arabic sufficient to make the ball This may be repeated if the desired effect is not produced in twelve hours. Apply to the throat, sides, and along the spine, strong mustard mixed with water to the consistence of cream, which may be repeated as often as necessary. The fly blister is also recommended; but the author prefers mustard, as being so much quicker in its action. After the inflammation has subsided, give one of the following powders twice a day: of pulverized gentian root and nitre, each one ounce; pulverized Jamaica ginger, half an ounce; caraway seeds six drachms. This course of treatment is perfectly safe in the hands of any horseman, though it will not reach all stages of the disease; nor can any general directions be given better calculated to warrant a successful issue in these cases.

\section{NASAL GIJEET.}

"Nasal gleet is the name here given to those discharges from the nose, which are commonly preceded by some inflammatory or catarrhal attack of the air passages, in particular those of the head; though there occur examples of their appearing without any such detectible precursors, originating, indeed, without any visible or apparent cause whatever; in most cases they are apt to continue long after all signs of inflammation have died away. Gleet is more likely to supervene after a chronic, than after an acute, attack of catarrh, and to show itself in an 
adult or aged horse rather than in the young subject. Some. times the discharge comes from one nostril alone; more usually from both. Sometimes the submaxillary glands (glands under the jaws), remain tumefied, and sometimes they are not. 'The Schneiderian membrane (membrane of the nose) discolored by inflammatory action, has become pallid and leaden-hued, but is free from all pustular or ulcerative indications. The discharged matter varies in quantity and quality in different individuals, and even in the same horse at different stages of this disease. The ordinary gleet consists of a matter more mucous than purulent, remarkable for its whiteness, about the thickness of cream, and in some cases is smooth and uniform, in others clotty or lumpy; in other cases it is yellow, and appears to contain in its composition more pus than mucus. At one time it will collect about the nostrils, and become ejected in flakes or masses in pretty regular succession; at another time there is a good deal of irregularity in this respect, the running from the nose ceasing altogether for a while, as though the animal were cured, and then returning with double or treble force. Sometimes fetor is an offensive accompaniment of the discharge; at other times no fetor is perceptible. The health does not suffer in the least; on the contrary, it is one of the indications of this disease, that the horse eats and drinks, and has his spirits, as well as though he were quite free from complaint.

Formerly, these cases were considered to be evidences of glanders, and were called chronic glanders; many a horse having been destroyed under this mistaken impression. That a case of the kind might not turn to glanders, is, perhaps, more than can be asserted with certainty; but that, so long as 
it continues gleet, it is not glanders, I am fully persuaded; and to show that it is not, I have been in more than one instance successful in bringing the case to a favorable issue." [Percival's Hippopathology.]

The treatment recommended by veterinary writers has not been found successful in the author's practice; nor, indeed, do they themselves appear to have encountered any better fortune. That which has proved efficacious has, in all cases, been strictly tonic. Give the following powder night and morning for a month : of sulphate of copper (blue vitriol), half a drachm; pulverized gentian root, two drachms; pulverized ginger, one drachm; mix for one dose: or, give night and morning, mixed in the feed, half-drachm doses of powdered nux vomica (commonly called Quaker button). There is no danger in giving this preparation to a horse, provided he does not have water for some time afterward, say half an hour ; and it very rarely fails.

\section{PNEUMONIA.}

By pneumonia, or inflammation of the lungs, is meant either a highly congested or an inflammatory condition of the lungs, arising from various causes, as high feeding, blanketing, close or badly ventilated stables, violent or extraordinary exercise, or sudden changes from heat to cold. Cold applied to the external surface of a heated animal drives the blood from the skin to the internal organs, often causing congestion of the lungs. Pulmonary diseases are more prevalent in the spring and fall, particularly if the weather be cold and damp.

This disease is generally ushered in by a shivering fit; the horse is sometimes attacked very suddenly; he refuses his food; 
the respiration becomes disturbed, sometimes suddenly, at other times more slowly; legs, ears, and muzzle cold; cough sometimes present; staring coat; membrane of nose reddened or leadened-hued; the animal hangs his head in or under the manger, stands with his feet wide apart, remaining in one position with no inclination to move. The pulse varies very much; it is sometimes full and quick, at other times weak and scarcely perceptible.

In these cases auscultation is found of the greatest advantage in enabling one to detect to a certainty the true condi. tion of the parts affected. If the attack is sudden, coming on after any violent exercise, and the pulse is quick, weak, and scarcely perceptible; by the THE RUNNING HORSE LEXINGTON. application of the ear to the animal's side the case is decided, in the absence of all sounds, to be one of congestive pneumonia. In all these cases the less medicine which is used the better; they require the free use of the lancet, which must be promptly applied, or the animal dies. Blood must be taken until the animal begins to show symptoms of weakness; after which place him in a cool box with \& pail of water, but nothing else, before him, the fresh air being all the medicine required. He will either speedily recover, or inflammation of the lungs will ensuc. A second bleeding, notwithstanding the inflammatory action, is positively 
injurious. As the disease assumes an inflammatory character, the breathing becomes more disturbed, the mouth hot, flanis heaving, and the nostrils expand and contract violently. Blisters must now be applied to the sides and breast, and those which will act quickly. The author prefers the following : of pulverized cantharides half an ounce; lard one ounce; croton oil twenty drops; linseed oil suffieient to make it liquid. Divide the following into five parts, and give one part internally every two hours: liquor ammonia acetatis twelve ounces; extract of belladonna one ounce; water one pint. If there is no improvement in twelve hours, give one scruple of white hellebore with three drachms of nitre every four hours until its action is manifest. This remedy, however, is a dangerous one in the hands of any but the qualified practitioner. Instead of it, the tincture of aconite may be usedindeed, it is one of the very best remedies. Take of tincture of aconite half an ounce to an ounce of water; give twenty drops on the tongue every three hours. Active purgatives should not be given; injections, however, are very useful. The horse should be kept on a low diet for a few days, as bran mashes, carrots, or green food; but no hay should be allowed, and a pail of water should be kept before him. This is regarded by the author in all inflammatory diseases as one of our best medicines.

\section{PLEURISY.}

By pleurisy is meant an inflammation of the pleura, or membrane covering the lungs and internal walls of the chest, without the lungs being involved in the inflammation; when, however, they partake of its inflammatory action, it is styled pleuro- 
pneumonia. The former disease rarely exists in a pure form ; and as in a work like the present it is unnecessary to consider the delicately drawn distinctions between the two types, both will be treated as if they constituted in reality but one disease.

Pleurisy may exist in an acute or chronic form. The attack may be sudden, or gradual, the animal manifesting indisposition several days previous. A hard drive, over-exertion, exposure to cold, washing in cold water when warm, a fall, fracture of a rib, a punctured wound, \&c., are all causes of pleurisy.

The horse manifests uneasiness; there is a violent heaving of the flanks, a looking round at his sides, with an anxious expression of the face; pulse quick and wiry; body, mouth, and breath hot; sweating in different parts of the body; a high state of nervous irritation, the animal pawing, lying down but rising immediately; a pressure against the side causes pain. A peculiar symptom is observable in this disease; the right fore-leg differs in temperature from the left, and such is the case with the hind ones; if the right fore-leg is warm, the left hind one will also be warm, and the others cold.

Experience proves that blood-letting in this disease is only opening the vein to let life escape; for if by this means we succeed in relieving the inflammatory action, the loss of blood so prostrates the system that the animal from pure debility becomes the victim of hydrothorax, or dropsy of the chest, living a miserable life for several weeks, perhaps months, to die at last from the accumulation of fluid in the chest. Bleeding, therefore, is uncalled for, and in fact is positively injurious. The early application of blisters to the sides is very important; and for this purpose the same preparation will be found serviceable as has 
been recommended in the case of inflammation of the lungs. The application of blankets saturated with hot water and kept round the body for several hours is very beneficial. Give one of the following powders on the tongue every hour :-of calomel one drachm; lactucarium (the juice of the common garden lettuce) two drachms; divide into three powders. In two hours after giving the last powder, give the following drench : liquor ammonia acetatis four ounces; sulphuric ether one ounce; tincture of aconite ten drops ; water one pint. If no improvement takes place within six hours, give half a drachm of the extract of belladonna in a pail of water every three hours; continue this until the pupils of the eye dilate, or a favorable change otherwise takes place. If the pulse is weak, give two ounces of nitrous ether; one ounce tincture of opium; and half a pint of tepid water; but do not repeat the dose. The animal must be kept upon a low diet; no hay or corn should be given; carrots and green food may be used sparingly; give water frequently; injections of soap and water are necessary from the first attack. After the animal becomes convalescent, strong tonics must be given, as the case may even then terminate in dropsy of the chest. Nux vomica should be given in halfdrachm doses in the feed at night; or half-drachm doses of the iodide of potassa dissolved in a pail of water may be given three times a dar.

\section{HYDROTHORAX.}

Dropsy of the chest, or hydrothorax, is usually the termination of pleurisy in cases where bleeding or long-continued sedative medication has been practised. The fluid contained within the chest, if following an acute attack of pleurisy, is a beauti- 
fully clear, bright yellow fluid. In sub-acute cases there is considerable lymph floating in it, thus rendering it turbid. The quantity varies in different cases, from a quart or two to several gallons.

In this disease the animal stands with legs straddling; the breathing is short and quick, and as the water accumulates the respiration becomes more labored; pulse small and quick ; staggering gait; breast, belly, and sheath swelled, leaving after pressure the impression of the fingers; if the ear is applied to the side, no sounds are heard.

No course of treatment can be suggested which would be likely to succeed in the hands of the amateur; this disease far too often proving fatal in the most skillful hands.

\section{THICK WIND.}

This disease differs in its action and effects from broken wind or heaves, though they are frequently confounded. It is characterized by a quickened respiration, in consequence of the obstruction existing in the air passages as the termination of inflammatory action. The capacity of the lungs is often very considerably diminished; the air-cells become filled up or obliterated; and the bronchial tubes become thickened; so that the same amount of atmospheric air cannot be admitted, thus giving rise to the quick, blowing action witnessed in this disease. "It is astonishing," says Mr. Spooner, "what great alteration of the structure of the lungs may exist, and the horse be still able to perform his accustomed work. I remember a horse that for some months worked in a fast coach, doing a stage of twelve miles daily in about an hour and a quarter. He was seized with inflammation of the lungs, and died in about sixteen hours. 
On examining the body after death, it appeared that one half of the lungs for a long time past must have been perfectly useless, for the purposes of respiration, being so completely hepatized as to be heavier than water."

But little can be done in the way of treatment for a thick. winded horse. It is important to keep the bowels regular; and by feeding with good sweet provender some relief is usually afforded.

\section{ROARING AND WHISTLING.}

There are different stages of the same disease, arising from a thickening of the windpipe, or of the membranes of the larynx, rendering the passages smaller at the diseased parts. These diseases are generally the termination of neglected bronchitis, laryngitis, and all diseases of a pulmonary or catarrhal cha, racter; ulceration of the glottis (a portion of the larynx) is also a cause of roaring.

If these diseases are caused by tight reining, the bearing rein should be left off; if they arise from other causes, there is but little prospect of benefiting the animal, except in cases where the thickened parts are in an inflammatory condition, when relief will be afforded by the application of mustard plasters or fly blisters to the parts affected.

\section{BROKEN WIND.}

The cause of broken wind, or heares, has never been satisfactorily ascertained; some writers attributing it to functional derangement of the digestive organs, others to rupture of the air-cells of the lungs, while yet a third class to a spasmodic action of the diaphragm, a muscle dividing the chest from the 
abdomen. In this disease there is a short dry cough, which is characteristic, and familiar to all practised ears.

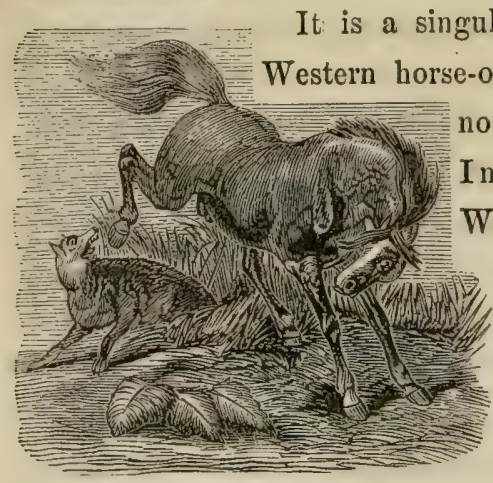

TEE $\triangle T T A C K$ AND DEEFENE. no existence on the prairies of Indiana, Illinois, and other Western States; and brokenwinded horses that have been taken to those sections soon get well, and remain so.

The symptoms of this disease are, a peculiar, doublebellows motion of the flanks; respiration quicker than natural; a short peculiar cough ; and frequent passing of wind.

In its treatment the digestive organs should be kept in as healthy a condition as possible. The throat should be examined; and if by merely rubbing the sides of the throat a cough is excited, the chances for a cure are favorable; but if the windpipe requires a squeeze in order to produce the cough, there is little use in attempting a cure. Use upon the throat three times a week for five or six weeks the following salve well rubbed in : iodine ointment two ounces; blue (mercurial) ointment one ounce; mix well together, and make thin with oil. Give internally every night one of the following powders: of sulphate of copper and pulverized ginger, each one ounce; pulverized gentian root two ounces; divide into sixteen powders.

The benefits of this course of treatment have been very marked in the author's practice. In all cases no hay should be allowed, but wheat or oat straw will be found of great advantage. 


\section{DISEASES OF THE STOMACH AND INTESTINES.}

\section{INFLAMMATION OF THE STOMACH.}

Inflammation of the stomach, or gastritis, is usually the result of swallowing poisons, or powerful stimulants. Mr. James Clark relates a case of death occurring from inflammation of the stomach in a horse in consequence of being drenched with a pint of vinegar; and another case where death was caused by giving a drench which contained half an ounce of spirits of hartshorn. A correspondent writing to the Turf Register in 1855 , recommends the use of nux vomica, to destroy worms; to which the editor appends the following remarks:- "We must caution those not acquainted with the deleterious properties of nux vomica against giving that drug in large doses. Three nuts ol buttons weigh eighty grains, and we have recorded evidence that sixty grains of the powder have killed a horse in a short time. Hoffman mentions that two doses, of fifteen grains each, proved fatal to the patient." The cause of these fatal terminations was doubtless some morbid condition of the stomacb at the time the medicine was given. "I have known," says White, "a horse quickly destroyed by being drencher with a quart of beer in which one or two ounces of tobaceo had been infused, and have seen other horses take much larger doses without any ill effects." The author has known cases where bots were supposed to have given rise to inflammation of the stomach.

The symptoms from poisoning are extreme distress and restlessness, with a perfect loathing of all food; the animal breaks out in cold sweats, lies down but rises quickly, and becomes 
quickly prostrated in strength; the pulse is quick and oppressed; purging may, or may not, exist.

The treatment will depend upon the cause of the attack, and should in all cases be intrusted to the hands of a competent practitioner, if one can be obtained. Where poison is suspected, it is better to gire plenty of gruel, linseed tea, starch water, chalk water, with a couple of ounces of tincture of opium. The lancet should not be used, as the animal is already in a debilitated condition, which bleeding would only increase, thereby preventing the possibility of a speedy recorery.

\section{INFLAMMATION OF THE BOWELS.}

Enteritis, or inflammation of the bowels, called by farriers red colic, admits of three divisions : enteritis, or inflammation of the muscular coat of the intestines ; peritonitis, or inflammation of the outer coat of the intestines and the membrane lining the cavity of the abdomen ; and dysentery, or inflammation of the inner or mucous coat of the intestines.

The muscular and peritoneal coats are those usually inrolred in inflammation of the bowels; but the muscular is more frequently involved than the peritoneal coat. The causes of this disease are washing when warm, or swimming in a rirer, drinking cold water when in a heated condition, orer exertion, costiveness, dry food such as hay with little water, worms, calcareous concretions, and metastasis.

The disease is sometimes preceded by a shirering fit; there is loss of appetite; hot skin; continued restlessness; mouth hot and dry; membranes of nose and eyes rery much reddened; pawing; the animal lies down and gets up frequently, kicks at his belly, looks frequently at his sides; no cessation of pain ; pulse hard, 
small, and wiry, often beating one hundred times or more a minute; respiration quickened; bowels constipated ; dung small, hard, and dry ; extremities cold; and the urine highly colored and passed with difficulty. As the disease progresses, the intensity of the symptoms very much increases. The animal is now covered with perspiration, which is succeeded by a chilly state; the pulse becomes quicker; the belly begins to swell; the entire system becomes prostrated, and the animal dies, frequently in the most violent manner.

These cases require prompt and active treatment, for the disease runs its course very rapidly, often terminating in the course of ten or twelve hours. If the costiveness yields early, the pulse becomes less frequent, soft, and full ; the extremities regain a moderate temperature, attended with remission of pain, and the case will be likely to have a favorable termination. It is important that this disease should be distinguished from an attack of colic, since the symptoms of one very much resemble those of the other; the pulse, however, is the surest guide in distinguishing these diseases. The ordinary mode of treating colic would be highly injurious in the treatment of inflammation of the bowels.

In this disease copious bleedings are necessary. A large opening should be made in the jugular vein, and from six to eight quarts of blood taken, the quantity varying with the size and condition of the animal; the hardened dung should be removed by back-raking, after which tobacco-smoke injections are of great service; where these are not convenient, injections of soap and water may be used, or, what is better, an injection of two gallons of water with six ounces of tincture of arnica. One pint of linseed oil may now be given; and if the 
case be a very severe one, and likely to terminate in death unless relief be afforded, ten drops of croton oil may be added to the drench; but this last preparation should not be given except in very desperate cases, as of life or death. Aloes should not be given uuless combined with opium; and even then this treatment is not advisable.

Blankets well saturated with hot water should be applied to the abdomen, and kept up for two or three hours ; the legs should be well rubbed with cayenne pepper or strong mustard, and bandaged with strips of flannel; if there is no improvement in the course of four or five hours, give one drachm of chloroform in one pint of linseed oil, which may, if necessary, be followed in two hours by the following ball, mixed - with molasses : one drachm of pulverized opium; half a drachm of calomel; and two drachms of linseed meal. The injections should be continued throughout; give linseed tea to drink, instead of water; soft mashes and new grass, if obtainable, may be given sparingly, but no hay, until the bowels are opened. The animal should not be worked for some days after recovery, as this disease is apt to return if he is put to work or exposed too soon. An attack of this character does not necessarily render the animal less useful or valuable after his restoration to health.

Peritonitis differs but little from enteritis. The horse is more affected with pain; the pawing, rolling, and kicking at the belly are most violent; the eye is wild in appearance; tenderness is evinced on pressing the abdomen; the pulse is full and throbbing; the dung is small and hard, and corered with a slimy substance. The same course of treatment should be pursued as is recommended for enteritis. 
Dysentery (molten grease, or inflammation of the intestines), is often confounded with diarrhœa. It is sometimes accom. panied with purging, but this is by no means an invariable symptom. The most common causes are irritation, translation or obstructed perspiration, and the administration of improper $\therefore$ purging medicines, causing undue irritation, which terminates in inflammation. The animal usually evinces but little pain; the pulse is quick and small; there is sometimes purging, with great prostration of strength.

The belly should be well rubbed with the following wash: half a pound of strong mustard; four ounces of spirits of ammonia; and one pint of water. The following drink may be given every three hours until some improvement is observed, when it should be discontinued at once: of prepared chalk and tincture of ginger each one ounce; powdered opium one drachm; tincture of catechu half an ounce; tincture of red pepper two drachms; and one pint of water. Throw up injections of two ounces of laudanum in half a pint of water, frequently, and give thin gruel to drink. No blood should be taken under any circumstances.

\section{DIARRHCEA.}

This disease often arises in the absence of any inflammatory action upon the mucous surface of the intestines; and hence the distinction cannot be made by the ordinaly observer between it and dysentery, if purging should be present. In order to obviate this difficulty we recommend only such remedies as are calculated to answer either case, without the possibility of doing injury by the administration of medicines 
The causes of diarrhœa are over-exertion, exposure to cold, drinking freely of pump or spring water, and over doses of physic.

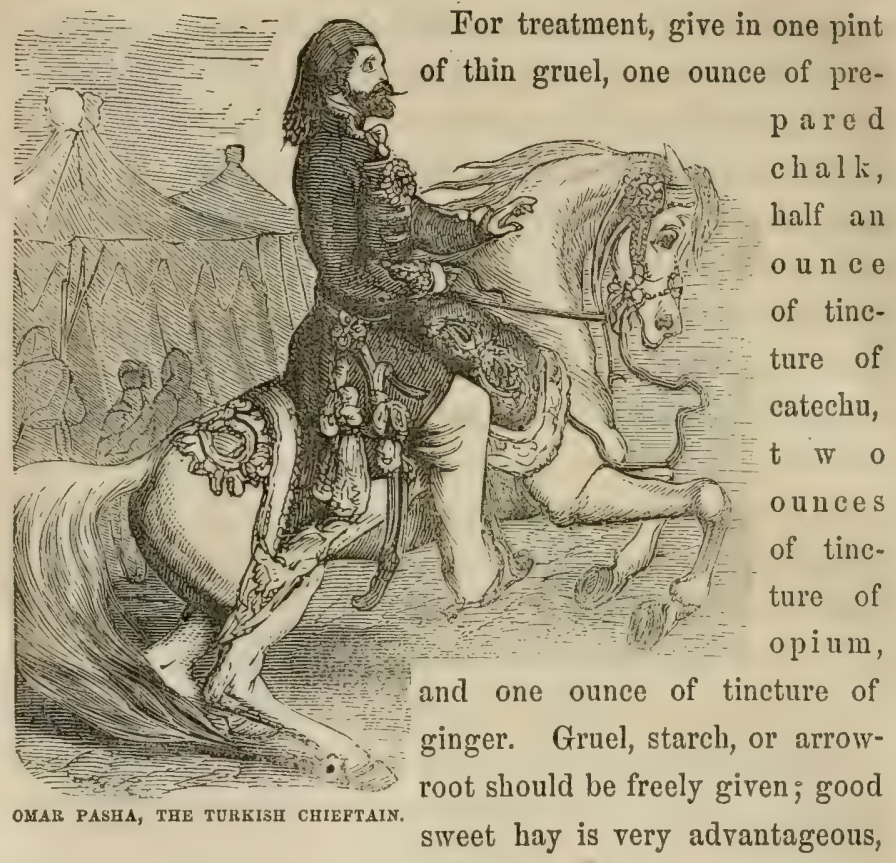

but no grass or bran mashes should be allowed.

\section{INORDINATE APPETITE.}

Loss of appetite is soon observed aud complained of by the, horse-owner, and in too many instances gives occasion for inproper medication. Some horses are particularly choice in the selection of their food, refusing that which is poor, or daintily and languidly picking it over. Horses sometimes eat slowly and daintily in consequence of weakness of the diges- 
tive organs; in such cases a handful of camomile flowers occasionally mixed in the food will be of great beriefit. Boiled potatoes and the like will also be found beneficial in such cases.

The disease (for it is no less) of a voracious or depraved nppetite arises from a morbid condition of the digestive organs, and is generally regarded by horsemen as a rery desirable feature. The owner is greatly surprised, under such circumstances, that his animal does not thrive. A distinction must be made between a healthy and a morbid appetite. The former is indicated by the animal being ready for his food as soon as he comes in from work, and eating his allowance, if good sweet prevender, with evident relish; but the latter is indicated by a constant craving for food and water, without regard to the quality of either, the animal oftentimes in addition to his usual allowance eating up the litter from under him, which is frequently in a very filthy condition. He is almost constantly craving water, and will drink even from a stagnant pool. We find him tucked up in the flanks, or carrying a big belly; his dung is often soft, slimy, and fetid; he stales largely, and his urine is often very foul; he is dull, lazy, and stupid, performing his work languidly or unwillingly. Such horses are more than any others subject to the disease next mentioned.

\section{PALSY OF THE - STOMACH.}

In this disease, arising from a voracious appetite, the stomach becomes overloaded with food, and distended beyond its natural capacity. This is seldom observed until the symptoms are so plainly marked as not to be mistaken, developing 
in many instances the disease known as stomach staggers, which has been already mentioned. There are rarely any symptoms of acute pain; the pulse remaining in nearly its natural condition; respiration is but slightly disturbed; there is great heaviness of the head; the horse stands with the fore feet well under him, and appears to be weak in the knees; the membranes of the mouth and eyes present a yellow or orange appearance, indicating the liver as involved in the disease; the urine is highly colored; and in some casess there is paralysis of the eye, and often of the extremities.

The treatment required is much the same as in stomach staggers; in fact, this disease is the origin of the last named. Attention should be directed in the first place to opening the bowels, which requires a strong cathartic, made in the following manner: of Barbadoes aloes one ounce; of pulverized gentian root two drachms; pulverized ginger one drachm; mix with molasses. Give no food for at least forty-eight hours; a little water may be occasionally given. In twelve hours after the ball, give one scruple of calomel on the tongue, which may be repeated at intervals of twelve hours for two or three days.

\section{RUPTURE OF THE STOMACH.}

Rupture of the stomach or diaphragm is caused hy the stomach and bowels being distended with food far beyond their natural capacity, or by an accumulation of gas in the stomach, as in flatulent colic. The diaphragm, or midriff, is often ruptured in cases of flatulence, as is the case also with the intestines. As nothing in the way of treatment can be offered in these cases, all speculation upon them is superfluous. 
CALCULUS, OR STONY CONCRETIONS.

Calculous deposits are not unfrequently found in the stomach, intestines, bladder, kidneys, liver, brain, and in the glands, more particularly in the salivary glands; often giving rise to much difficulty, particularly when situated in the brain, salivary glands, or bladder.

Stones in the stomach and intestines of the horse are quite common. The author has seen several weighing from one to three or four pounds; and Mr. Spooner mentions one in his possession weighing little less than six pounds. There were found by the author in the stomach of a horse which died of colic, one hundred and fifty-one barrel nails, two buttons, and three small calculi. This horse belonged to a baker, and had been fed with the scrapings of the shop. The nails presented a very singular appearance, many of them being entirely covered with calculous deposits, and others covered with the same deposits on the beads and points, presenting a body with two heads.

The presence of these foreign bodies in the stomach and intestines occasions frequent attacks of colic, and sometimes produces inflammation of the bowels. Miller's horses are supposed to be most subject to these accumulations. These abdominal calculi generally have a metallic nucleus, are composed of the triple phosphates, and are generally round and smooth. When first taken from the intestines, they are of a brown or greenish color, but they soon become white. When a horse is subject to frequent attacks of colic, not occasioned by feeding upon corn, these accumulations may reasonably be suspected to be the cause. 


\section{HAIR BALL.}

Hair balls are occasionally found in the stomach and intestines of a horse, generally accumulating around a metallic nucleus. There are several in the possession of the author where a piece of iron is the nucleus, and one where a piece of coal afforded the same basis. These balls occasion the same disorders, preceded by the same symptoms, and followed by the same results as the calculus. The animal may recover from a number of attacks of colic, and die at last from the same cause.

\section{STRANGULATION OF THE INTESTINES.}

On examining horses after death from an attack of colic, the small intestines are occasionally found tangled in a knot so as to cause a complete obstruction in the passages. This gires rise to colic pains, terminating in inflammation of the bowels and death. The small intestines being but loosely attached by the peritoneum, their outer covering, have free play in all directions, whence the tendency arises to these accidents; for the author believes them to spring from accidental rather than natural causes. There may be a simple twisting, or the intestine may be firmly tied into a knot.

There is another species, called intro-susception, or intra-susception, which is a slipping of one portion of the intestines into, or inside of, another portion, thus completely blocking up the passage. There are no symptoms by which either of these conditions may be known; and such cases are therefore treated as cases of ordinary colic, or of inflammation of the borrels, as the case may be. Where, however, such a condition of the parts exists, all treatment will be useless. 


\section{SPASMODIC COLIC.}

This disease, called by farriers gripes, cramp, fret, \&c., is a cramp or spasm of the muscular structure of the intestines, most generally of the small ones. The most common causes are the application of cold water to the surface of the body, drinking cold water when in a heated condition, costiveness, stones in the intestines, hair ball, strictures of the intestines, unwholesome food, \&c.

The premonitory symptoms are sudden in their nature. The animal is first observed pawing violently, showing evident symptoms of great distress, shifting his position almost constantly, and manifesting a desire to lie down. In a few minutes these symptoms disappear, and the animal is again easy. But the same uneasiness again returns, increasing in severity until the animal cannot be kept upon his feet; the pulse is full, but scarcely altered from the normal standard. As the disease advances, the symptoms become more severe, the animal at times throwing himself with great force upon the ground as though he were shot, looking anxiously at his sides, sometimes snapping at them with his teeth, and striking his belly with his hind feet. The symptoms vary but little from those of inflammation of the bowels, the condition of the pulse and the remission of pain being the distinguishing features. The extremities are of a natural temperature; there are frequent but ineffectual efforts to stale, and a cold sweat beders the body.

In this disease it is necessary to back-rake, and throw up the fundament injections of castile soap and water. Give internally two ounces of nitrous ether, one ounce of tincture of opium, and half a pint of water mixed, which may be repeated in twenty 
minutes with the addition of one ounce of tincture of aloes. Rub the belly well with mustard and water; if in half an hour there is no improvement, and no symptoms of inflammation are present, give of lactucarium half an ounce, of Jamaica ginger half an ounce, and one pint of the best rum or gin ; shake well together, and give one-third with twice the quantity of water every hour until relief is obtained.

\section{FLATULENT COLIC}

This is an accumulation of gas in the stomach and intestines, occurring more often in the spring and fall than at any otber season. Horses fed on corn are most subject to these attacks, in consequence of this kind of food fermenting readily in the stomach, more particularly when green. If the accumulation of gas thereby occasioned is not arrested, it soon swells the stomach and intes. tines to such an extent as to cause the diaphragm, or walls of the stomach to give way, and the death of the animal ensues. The author has known cases to terminate in death in less than half an hour from the observation of the first symptoms, so rapid is the course of this disease. The symptoms are the same in spasmodic colic, with the exception of the swelling of the abdomen. The same medicines are to be used, with the addition of from one to two drachms of chloride of lime in each dose, 
according to the urgency of the symptoms. This, if given in time, will generally prove efficacious. Tincture of hartshorn and spirits of turpentine are recommended by some veterinary authors, and are excellent remedies; but as much injury has been caused by their use by inexperienced persons, the author would not advise their use since the animal may be killed by an improper administration of them.

\section{WORMS.}

Four kinds of worms are found in the horse, viz : the lumbrici, which very much resemble the common earth-worm in form; ascarides, so called from their supposed resemblance to a thread; tænia, or tape-worm, of which variety but little is known, as it is very rare; and, lastly, the persecuted bots, considered by farmers and horsemen the greatest of pests and the most dangerous of all the species.

The lumbrici are most generally found in the small intestines, where they sometimes do much mischief by their irritating effects. The author was recently shown a very remarkable specimen of these worms by his friend, W. W. Fraley, V. S. This specimen was some two yards long, consisting of a portion of the small intestines so completely filled with these worms as apparently to render it almost impossible for anything to pass through it, the worms having accumulated in thousands. These worms are from eight to ten inches in length, round and perfectly white. There appear to be two varieties of the lumbrici. The other variety is similar in form and length, but has numerous brown transverse lines, at about equal distances from each other, along its entire length.

The ascarides are found in the large intestines, and are white 
worms from one to three inches in length. It is a somewhar singular fact, that although these worms are usually found in the large intestines, their origin, apparently, is in the stomach of the horse. On opening horses after death, tumors are often found in the stomach, which upon being cut open will be found to contain either a thick whitish matter, or kuots of small worms, from half an inch to an inch in length, of precisely the same appearance as that of the ascarides, and believed by the author to be identical with them.

The symptoms of worms are a rough, harsh, staring coat; irregular or depraved appetite; a whitish, or yellowish white, shining substance sometimes observable about the fundament, accompanied by a disposition on the part of the animal to rub the tail; breath occasionally hot and fetid; and in some cases a dry, short cough. The animal becomes poor in flesh and spirits.

Various modes of treatment have been adopted with but little benefit. The remedies which have become most popular are tartar emetic, calomel, turpentine, an infusion of Indian pink, arsenic, green vitriol, \&c. That which has usually been found most successful in the author's practice is to give one of the following powders for three successive nights; of calomel three drachms; of tartar emetic one drachm; mix and divide into three powders. Twenty-four hours after, give the following purgative ball: of Barbadoes aloes six drachms; pulverized ginger two drachms; and pulverized gentian root one drachm. Oil of turpentine in doses of two ounces has been very highly recommended by some authors; but this the author regards as a dangerous remedy, from its tendency to produce inflammation 
BOTS.

of the stomach or bowels. Too many horses have been killed by its destructive agency to render its use advisable.

\section{BOTs.}

These are the larvæ of the gad-fly. During the summer months, when the horse is at grass, the parent fly is seen busily engaged in depositing its eggs upon the hairs of the animal in such places as are easily reached by his mouth. This seems to be an instinctive feature in this insect. The legs, shoulders, and body are the parts selected for this purpose. The gad-fly is

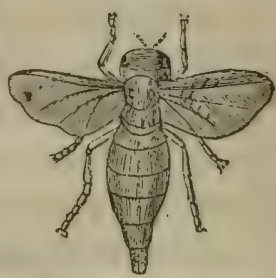
seen hovering in an upright position when COsısos OAD-FLT OR вот. about to deposit her egg; she then darts upon the horse, fixing the egg to the hairs by means of a glutinous substance; she again prepares another, which is deposited in like manner, until many hundreds are observed covering the hairs of the animal. The rapidity with which these eggs are prepared and deposited is astonishing. They are taken into the mouth by the animal biting or licking himself or his mate, and are hatched upon the tongue, or taken into the stomach and there hatched. If the eggs are recently produced, they pass into the stomach before they are hatched; but if they remain for a considerable time upon the hairs, they are hatched by the warmth of the tongue, and they pass into the stomach, where they are developed. This fact may be easily and satisfactorily proven by taking the newly deposited egg in the hand, and then applyiug a warm fluid; when it will be observed that the egg is softened or dissolved, but does not produce the bot; whereas, if the egg be 
BоTs.

old, it will hatch in the hand. The investigations of Mr. Bracy Clark, V. S., have thrown much additional light upon the natural history of these parasites.

The dread entertained of this species of worms by farmers and horsemen arises from the fact that so many useless books have been published, purporting to be guides to the farmer and horseman, many of which attribute the death of a majority of horses to ravages of the bot, and give as symptoms of their presence those which characterize inflammation of the bowels, kidneys, bladder, and the like. To this circumstance is to be attributed the vast distruction of life by drenching and physicking the animal for bots. Now, a rational view of the subject leads us but to one conclusion, viz., that Eas on the stomach of the horse is the natural habitaA Hair. tion of the bot, and that it cannot be, or is not, Matixified. developed anywhere else. This being the case, it is reasonable to suppose that inasmuch as the animal apparently suffers no inconvenience from their presence in his stomach, they were intended to serve some good purpose, rather than to do mischief. Indeed, without going to the extreme of asserting, as does Mr. Clarke, that bots are "always harmless," it may be safely asserted as the unanimous opinion of veterinary surgeons (farriers are not included), the world orer, that they are comparatively harmless, and that when they do become injurious, it is almost always preceded by some morbid condition of the digestive organs. This may either arise from disease, or from enormous accumulations of bots, which are sometimes so great as to completely block up the pyloric orifice, or opening from the stomach into the intestines. 
There are no symptoms by which the existence of bots is indicated, except it be in the spring, when they pass from the horse by the fundament, assuming again the form of a chrysa. Iis to re-produce the parent fly. As has already been stated, the symptoms of other diseases, as inflam mation of the bowels, \&c., are often assigned as indicat. ping the presence of bots, but although bots may someWhe times give rise to these conditions, it is worse than folly to jump at the probable cause in such cases and cATERPIILAR, say that it is a case of bots because a horse looks at FCLL EIzE. his sides and the like. When such an instance is encountered, no matter whether it arise from bots or not, the animal must be treated for the inflammation which is present. If we succeed in controlling it, and restoring the stomach to healthy action, the bots are no longer troublesome; but if, on the contrary, we commence arenching the animal for bots, the chances are that we shall kill him. Morbid conditions of the

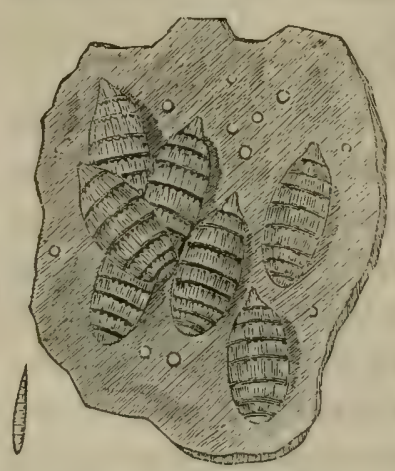

CATERPILLAR OR IARVE ADHERING TO THE LINING OF THE STOMACH. stomach will sometimes so incommode these little creatures as to cause them to escape from their un. pleasant situation, which is commonly effected by perforating the walls of the stomach and allowing the fluids to escape into the abdomen, in which case no medical agent will save the animal's life. Fortunately, however, these cases but rarely occur. The author has met with but a solitary case in an experience of ten years where death could be attributed to the action of bots.

We lnow, moreorer, from frequent experiments that the 
horse bot is more tenacious of life than even the cat, which is

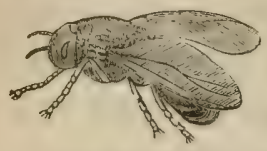
popularly endowed with nine lives. The live bot has been immersed in spirits of turpentine, alcohol, nitric and muriatic acid, and THI RED GAD-FLY. many other equally powerful fluids, and yet he still adhered to life with marvelous tenacity. If, then, it

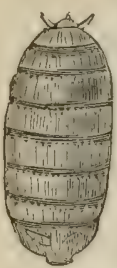
were possible to detect the presence of bots by any marked symptoms, the attempt to remove them would certainly be hazardous to the life of the animal. The author has known cases of flatulent colic to be treated for bots, when, upon opening the stomach after the death which inevitably ensued, not a solitary bot was caterpillar of to be found. It will be borne in mind that in large cities, where horses are not indulged in a run at grass it is no unusual occurrence to find their stomachs entirely free from bots.

\section{DISEASES OF THE LIVER.}

Diseases of the liver are of very common occurrence in the horse, although the singularity of the internal structure of that animal renders it less liable to jaundice than the human being. The horse possesses no gall-bladder ; instead of such a reservoir it has simply a gall-duct, called the hepatic duct, which enters that portion of the intestines called. the duodenum about six inches from the stomach, so that the gall is emptied into the bowels as fast as it is secreted. Various opinions bave been expressed touching this singular arrangement in the liver of the horse, any examination of which would be out of place in the present work. We proceed therefore to the mention of such diseases as come apparently under the above head. 


\section{INFLAMMATION OF THE IIVER.}

Hepatitis, or inflammation of the liver, does not generally exist as a primary affection, though it is frequently found as a sympathetic one, being not uncommonly connected with epidemics, or epizootic diseases, particularly in that which is known to horsemen as pink-cye distemper.

The most common cause of this disease is a fullness of blood, or a plethoric condition of the system, in consequence of which too much blood is sent to the liver; want of exercise, and too

- high feeding, particularly with corn, are also causes of inflammation of this important organ.

The symptoms of this disease are more obscure than those of any other part, and the difficulty is materially enhanced by the inability of the animal to assist us with his tongue. Still, by close observation we can trace the symptoms with such a degree of accuracy as to render our treatment almost a certainty. The mouth and breath are hot; the extremities cold; the membrane lining the eyelids highly injected, presenting an orange-red appearance; the pulse rises from seventy to one hundred or more a minute, and is soft and full; the appetite lost; the animal looks wistfully and deploringly at his sides; lies down, but gets up again directly; the respiration at times is perfectly tranquil, at other times slightly disturbed, and at others again very much disturbed, and distressing to the animal-so that, in fact, the amateur cannot be governed by this symptom,-there is usually much tenderness of the right side; and the dung small, hard, and generally dark-colored.

In the acute stage the animal is generally in a state of plethora, in consequence of which a small quantity of blood 
may be taken to good advantage; but in the absence of plethora he must not be bled; a blister may be applied to the sides, or the application of creosote will be found serviceable. Injections of castile soap and water should be used occasionally until the bowels are opened. Give every four hours one of the following balls : of Barbadoes aloes six drachms; calomel three drachms; mix with molasses, and divide into twelve parts. Keep the body warm, and bandage the legs with flannel; turn into a loose box stall, where the atmosphere is pure. When convalescent, give one of the following balls night and morning: of sulphate of iron two ounces; pulverized gentian root one and a half onnces; pulverized Jamaica ginger one ounce; and pulverized anise seed one ounce: mix with molasses, and divide into sixteen parts.

\section{JAUNDICE.}

This disease depends upon an obstruction of the biliary excretions, causing a yellow discoloration of the mucous membrane, fat, ligaments, and other tissues of the body; it will oftener be found in connection with other diseases than distinct and independent of them, although it does occasionally exist in a pure or unmixed form, the symptoms of which are not at first observed by the horseman on account of their obscurity.

The lining membranes of the eyelids and lips are of a yellow or orange color, extending even to the white of the eye; the dung pale, small, and bally; bowels generally constipated; appetite lost or languid; the animal hangs his head, is t!ill and mopy, and becomes very poor in flesh. 
In the treatment of this disease the principal reliance is upon calomel; two drachms of which made into a bolus with flaxseed meal and molasses should be given, followed in twenty-four hours by a purging ball. The animal should have modcrate exercise daily; his body should be kept warm; and if there be pain in the right side, apply a blister; if necessary, the calomel may be repeated in scruple doses once a week.

\section{HEPATIRRHGE.}

This is a rupture of the peritoneal coat of the liver, and hemorrhage from it. It occurs most generally in aged horses, and is always preceded by structural derangement, or disorganization which, from the obscurity of the symptoms escapes notice until it is too late for medical aid. The animal generally does his work as usual until within a few hours of his death, keeping in full condition, and presenting to the eye of bis owner no appearance of disease. The symptoms are so gradual in their development as to escape observation until the peritoneum, or covering of the liver, gives way, or becomes ruptured, from the great distension of the liver, when the blood flows freely into the abdominal cavity, giving rise to the most alarming symptoms, and the horse often dies within an hour after he is first discovered to be ill.

The symptoms which are noticeable are suddenly developed. and generally appear immediately after eating or drinking. The animal will sometimes fall suddenly, and die in a few minutes, without having shown any previous indispoșition; at other times the respiration becomes hurried, the belly begins to swell, the pulse becomes gradually diminished and very feeble, partial or general sweating takes place, the animal 
walks with a tottering gait, the membranes lining the eyelids, lips, and nose, become blanched, indicating internal hemorrhage, there is a vacant stare in the eye, with great prostration of strength, which soon terminates in death. Upon opening the abdomen, it is found filled with dark venous blood in a fluid state, and the liver is several times its natural size, and exceedingly tender. Where it is possible to detect the existence of the disease in its incipient stages, calomel would be the appropriate remedy, as it is as justly entitled to rank as a specific for the diseases of the liver of. the horse, as it is for those of his master-man.

\section{DECAYED STRUCTURE OF THE LIVER.}

This also is a disease of common occurrence, though like the other diseases of this organ, the symptoms, from their obscurity, are not well understood by the veterinary practitioner, but little attention having as yet been paid to its investigation.

The first symptoms noticed are loss of appetite; surfeit; the being hide-bound; rough, staring coat; food passing undigested; stools of a clay color; prostration of strength; readiness to sweat; pulse quick but feeble; respiration hurried; sometimes violent purging, after which the animal usually dies.

Caution is necessary in the treatment of this variety of diseased liver. Bleeding must not be resorted to upon any consideration. In the absence of purging, give one of the following balls every other day: of calomel half an ounce; Barbadoes aloes one ounce; resin three ounces; mix with molasses, 
and divide into six balls. Upon the intermediate days give of sulphate of potash one and a half ounces; carbonate of potash one ounce; pulverized Jamaica ginger half an ounce; linseed meal two ounces: mix with molasses, and divide into six balls.

\section{DISEASES OF THE URINARY ORGANS.}

\section{INFLAMMATION OF THE BLADDER.}

Inflammation of the bladder, or cystitis, is a disease of comparatively rare occurrence in the horse, and generally is found in connection with other diseases. It is commonly supposed to occur more frequently in mares; although the author's experience has not confirmed this supposition.

The symptoms are continual cmission of urine in small quantities; the moment it snters the bladder it is again expelled, but voided with much straining; pulse accelerated; pawing; the animal looks imploringly at his flanks; and upon passing

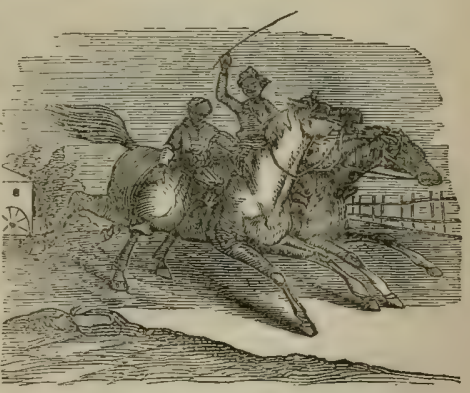
the hand into the rectum, the bladder will be found contracted, and hard as a ball, being also hot and tender.

For treatment, back-rake the animal in the first place, and then throw up injections of water, adding to every gallon three ounces of tincture of opium. Give internally one and a half. 
pints of linseed oil, to which may be advantageously added one drachm of chloroform. Bathe the loins with the following mixture : of strong mustard, a quarter of a pound; water, half a pint; hartshorn, two ounces : mix thoroughly together, , and rub it well in. Give half a drachm of lactucarium three 'times a day; or, if more convenient, the extract of belladonna may be substituted. Give plenty of flaxseed tea ; if the animal refuses to drink it, drench him with it. No hay must be given until twenty-four hours after he becomes convalescent. This is one of the most daugerous diseases to which the horse is subject.

\section{RETENTION OF URINF.}

This disease, technically known as spasm of the neck of the bladder, is found more frequently as an attendant upon other diseases than as an independent affection. It frequently occurs in colics as an accompanying symptom, thus misleading the ordinary observer in his judgment of the disorder.

The most common symptom is frequent but unsuccessful efforts to stale. This, however, must not be depended upon too strongly; as it will sometimes be observed in horses that are comparatively sound in these organs, particularly in those that have been well cared for. In such cases this temporary retention of urine arises from a dislike on the part of the animal of splattering his legs in voiding his water; hence he will often retain it in the bladder, though painful to him, until the litter is placed under him, when he at once stretches himself, and the urine flows freely and copiously. This fact has given rise to a superstitious notion among horsemen, that there is some peculiar virtue in the straw to cause this sudden. 
cure; as a consequence, we frequently hear the remark, "Put some straw under him-that will cure him," etc.

If, however, retention of urine arises from disease, the straw possesses no magic charm to afford relief. In such instances the animal manifests but little pain, and rarely lies down. On passing the hand up the rectum or fundament, the bladder, which is easily felt, will be found very much distended with urine.

The services of a regular veterinary practitioner will be required in the treatment of this disease, as the bladder must be at once evacuated, which can in most cases be accomplished by means of an instrument called the catheter, which is not commonly found in the hands of any but the qualified surgeon. This desired evacuation can in some instances be produced by careful manipulation. Back-raking is very necessary in these cases, and injections of soap and water should be freely used. Unless the bladder is speedily emptied, it swells and bursts, causing a fatal termiuation. Fomentations of hot water to the abdomen, and pressure of the hand upon the bladder will be of assistance in enabling the animal to voic the urine.

\section{PROFUSE STALING.}

This disorder, called also diabetes, is of frequent occurrence in the horse, and is attended with debility, impaired appetite, and sometimes loss of flesh. The causes are the improper use of nitre, saltpetre, and other powerful diuretics, as also un wholesome food, and the like.

The treatment is simple and effective; a great variety of medicinal substances being used in its abatement-as catechu. 
oak bark, gum kino, opium, chalk, etc. Either of these in moderate doses will.usually check the copious flow of urine. Either of the following will be found sufficient : wva ursi (bear's whortleberry), powdered, two ounces; oak bark pulverized, four ounces; catechu pulverized, one ounce; opium pulverized, two drachms : mix either with molasses or honey, and divide into six balls, giving one every day. Or, the following may be used with equal advantage : opium pulverized, half an ounce; sulphate of iron, one ounce; gentian root pulverized, one ounce: mix with molasses, and divide into six balls-one to be given every day.

\section{BLOODY URINE.}

This disease, known also as hematura, frequently arises from strains across the loins, violent exercise, unwholesome food, calculous concretions in the kidneys, etc. It is not attended by symptoms of general derangement; the appetite is not usually impaired, nor is any marked degree of fever present. The color of the urine first calls attention, in roiding which the animal appears to strain slightly.

If the bowels are at all costive, injections should at once be thrown up the rectum; linseed tea should be given as a drink; mustard applications to the loins. Give internally one of the following once a day: of sugar of lead, one ounce; linseed meal, two ounces; mix with molasses or honey, and divide into eight pills; follow this for ten or twelve days, with one drachm of sulphuric acid in a pail of water to drink. Catechu, logwood, dragon's blood, oak bark, etc., have been used with adrantage. 


\section{STONES IN TERE KIDINEYS.}

These concretions, which are quite common in the horse, I are of a pale, dirty yellow color, elongated or conical in form, and much softer than any of the other varieties heretofore mentioned. "We have better evidence," says Mr. Blain, "than mere supposition; for urinary calculi (or stones in the kidneys), have been found in horses which have died with symptoms which might have been mistaken for very acute enter. itis, or inflammation of the bowels. We may also suppose that the early accumulations would occasion irregular and diminished secretion of urine, followed at length by a bloody purulent mixture with the water, until more active symptoms should arise, and carry off the horse. Concretions within the lidneys might be removed in their early state by remedies tending to decompose them in the urinary pelvis. For this purpose we have mineral acids, of which the hydrochloric, as holding the silicious matter in solution, is to be preferred. The mineral acids pass through the body unchanged, being emitted with the urine in a state of purity."

A better opportunity is afforded us of discovering calculus in the urinary organs, than in any other parts; for an examination of the urine, when placed under the microscope, will enable us to detect its presence. When these deposits are ascertained, give in every pail of water which the animal drinks, two drachms of hydrochloric (muriatic) acid, which will in a short time be drunk with a relish by him. 


\section{STONES IN THE BLADDER.}

These differ from stones in the kidneys in form and external appearance; presenting, in consequence of the constant washings of the calculus by the urine an uneven, or what is called a mulberry appearance; externally, it is of a reddish brown color. When these stones are quite large, very great inconvenience is occasioned to the animal.

Stones in the bladder may exist a long time before any perceptible symptoms of their existence are manifested. The urine is generally thick and of a whitish color, with frequent desire to roid the urine, accompanied with difficulty and pain; the urine occasionally presents a bloody appearance; in some cases all the symptoms of colic are present, rendering it difficult to distinguish between the two disorders. If the pain is severe, the animal paws violently, kicks at his sheath, lies down, rolls, and gets up again quickly, sweats in various parts of the body, giving off the odor of urine.

For treatment, we should first attempt the dissolution of the stones, as recommended for stones in the kidneys, or we should remove them by the operation of lithotomy, which will be described under the head of surgical operations. If they are small, they may sometimes be extracted through the urethra, a process which is very easy in the case of mares. 


\section{DISEASES OF THE FEET AND LEGS.}

\section{CONTRACTION OF THE HOOF.}

'To horses that are lept in cities, or in stony sections of the' country, this disease is one of the most common occurrence. In

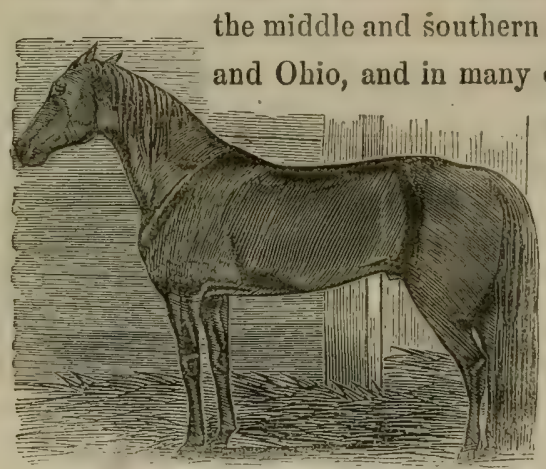
the Fast-Trotting stalion, aeorce M. PAtchen. iron band, the shoe.

shoeing of the horse is not called for except in frosty weather, contraction of the hoof is comparatively rare, in consequence of the feet being unfettered by that

This trouble is gradual in its approach; the first indication being a dry, brittle, unyielding hoof; the heels gradually becoming narrower, until they are painful. The hoof no longer accommodates itsslf to the soft structure within its limits, and, in consequence, the concussion is greater and the elasticity very much less. The parts therefore become bruised, and ferer ensues, which still further facilitates the contraction of the hoof by absorbing its moisture; lameness follows as the natural and inevitable result. Upon an examination of the animal sweenic is decided upon by the horseman as the disease to which he is subject; a disease, by the way, which, we beg to say, the veterinary surgeon never yet has met.

The primary cause of this trouble is, undoubtedly bad shoeing, the preventives of which have already been fully unfolded. 
Standing upon plank-floors has also a tendency to produce it, as it absorbs the moisture of the hoof, and renders it brittle and liable to crack. Traveling upon hard stony roads, with shoes that are beveled inwards, also predisposes the feet to this disorder.

The treatment must, necessarily, be slow in its operation; yet by careful management it is sure. The shoes must, in the first place, be removed, and the feet well poulticed for several days until the hoof and frogs become perfectly soft. The animal should then be carefully shod, as heretofore directed; apply daily, until the heels are fully spread, the following ointment; of rosin, four aunces; beeswax, four ounces; lard, two pounds; tallow, one pound; melt together, and, when cool, stir in four ounces of oil of turpentine.

\section{CORNS.}

The first effect of contraction of the hoof is to bruise.the sensitive parts within their horny limits at that part of the foot formed by the crust and bar, causing lameness, which may be acute or chronic. These bruises are commonly called corns. The reason why this portion of the foot should be so severely bruised is obvious. The crust and bar forming a triangular space between which a considerable portion of the sensitive laminæ lie, this bar by its resistance of the eneroachments of the crust, causes a twofold pressure upon the sensitive parts, acting much as a vice, and thereby diminishing the triangular space. Upon examination of the foot the horn is found hard, dry, and brittle, with a strong tendency to crack on very slight concussion. On removing a portion of the horn at the part of the foot indicated, the parts are found to be contused, sometimes slightly, and at 
others severely. In the latter case the feet are in such a condition as to require prompt attention, or a sloughing, or discharge of matter, may take place, forming a sinus, or pipe-like opening, through the quarter, sometimes passing through the coronet, and producing a condition, or disease, known as Quitter, which often terminates in permanent lameness and deformity.

When the lameness is of a chronic character, the poor beast, owing to his deprivation of speed, is compelled to suffer all kinds of barbarous treatment, such as roweling, setoning, etc., etc. As few believe corns to be of so serious a nature, the most are ready to attribute the lameness to a disease, or a supposed disease, which exists only in their disordered imaginations.

As symptomatic indications, it may be remarked that the horse extends one foot in advance of the other, and rests upon the toe, which causes a bending of the knee, with a hard, dry, brittle, and contracted hoof.

By way of treatment, the hoof, around the corn should be cut away so as to prevent pressure from the shoe; the corn should be well cut out, and burnt with a hot iron, butter of antimony, muriatic acid, caustic silver, or the permanganate of potash. He should then be carefully shod, and, if the frog is elastic, a bar shoe nicely fitted, with a perfectly level bearing, would be best; if, however, the frog is hard and unyielding, such a shoe may prove injurious. Flaxseed poultices frequently applied to the feet, together with the use of hoof ointment, will be found effectual; a run at grass without shoes will also prove beneficial. 


\section{QUITTER。}

This is an ulceration, or formation of pus, between the sensitive and insensible laminæ, or inner parts of the wall of the hoof, generally situated on the inside quarter, forming sinuses, or pipe-like openings. Neglected corns often produce this disease, as also caulking or bruises from any cause.

The first appearance upon the foot on the approach of this disease is a hard conical tumor, hot, red, and smooth, which soon becomes soft, breaks, and discharges pus. A probe should first be introduced by way of treatment, pointing out the direction of the sinuses; an injection of sulphate of zinc, one drachm dissolved in a pint of water, should be thrown into the opening in the foot by the means of a small syringe, once daily, and the foot should be occasionally washed with castile soap and water. The early treatment should consist in poulticing with flaxseed meal for several days. If the case is very slow, use two drachms of the chloride of zinc to a pint of water; inject in the same manner; cut away all loose parts of the horn, which will facilitate the cure. Glycerine has also been used by the author with marked bencit.

\section{THRUSH.}

This is a discharge of a matter from the cleft or division of the frog, which occasionally produces lameness. It originates from a filthy condition of the stable, the animal being allowed to stand in his dung, or upon foul litter. Horses that are well cared for are rarely troubled with it. The symptoms are a rottenness of the frog, accompanied by a discharge of fetid matter. Lameness may, or may not, be present. 
For treatment, wash the feet well with soap and water; fill the cleft with powdered sulphate of copper, and pack over it a little tow ; remove the filth from the stall, and the animal soon recovers. An ointment may also be used, made of equal parts of pine-tar and lard, melted over a slow fire; when cool, add sulphuric acid until ebullition ceases, and it is then fit for use.

\section{CANKER.}

This arises from neglected thrush, often proving very difficult to manage. It extends from the horny frog to the sensitive frog, and sometimes to the navicular joint, involving the surrounding parts, and causing much alteration or destruction of the structures affected. It is by no means always a local cliscase, but is influenced by a morbid or unhealthy condition of the blood. The anthor's attention was once called to a case of four years' standing, in which all the feet were involved, and the value of the animal thereby so depreciated that he was sold to a shoeing-smith of Philadelphia for the sum of trenty-five dollars, lis cost being some two hundred and fifty dollars. All treatment had failed up to that time; yet, notwithstanding the long resistance of the disease, it gradually yielded to constitutional treatment.

For treatment, all loose horn should be removed, that the parts may be properly dressed. If taken early, the following wash may be used with success; of nitrate of silver, half an ounce; water, one pint; shake well together, and use once a day. Or, the ointment of tar, lard, and sulphuric acid, recommencled in cases of thrush, may be usefully applied. Should this fail, apply once a day the following : of castor oil, one part; collodion, two parts; mix well together. Give internally half a drachm of powdered nux romica mixed in the feed, which 
should consist of green food, mashes, and a little hay. Corrosive sublimate in solution has been used with decided advantage; as also chloride of zinc, chloride of lime, butter of antimony, tincture of myrrb, sulphate of copper, glycerine, and many other preparations.

\section{SCRATCHES.}

This disease, called also cracked heels, generally arises from neglect, such as allowing the horse to stand in a filthy stall. It is generally confined to the hind feet, and consists in a swelling of the skin, causing in it one or more transverse cracks, which discharge a sanious (thin, serous, and reddish) matter at times; while in other cases the parts are almost dry but scurfy.

For treatment, wash well with soap and water; take a shaving, or other soft, brush, and make a lather of soap and water, with which mix a small quantity of powdered charcoal ; rub this well in the fetlock, and let it dry, after which it can be rubbed off. Two or three applications are generally successful. The collodion and castor oil will also answer a good purpose; a physic ball should first be given.

\section{GREASE HEELS.}

This is the result of weakness in the capillary vessers or the feet and legs, and is often preceded by dropsical effusions, which frequently exist upon the leg as far as the hock or knee. Common-bred horses are supposed to be more liable to this disease, while thorough-bred are comparatively free from its attacks.

The principal causes are, doubtless, over-feeding and want of exercise; since we generally find the disease associated with 
a , plethoric condition of the animal. As symptomatic, the skin at first is hot, red, swollen, and tender, and discharges a white

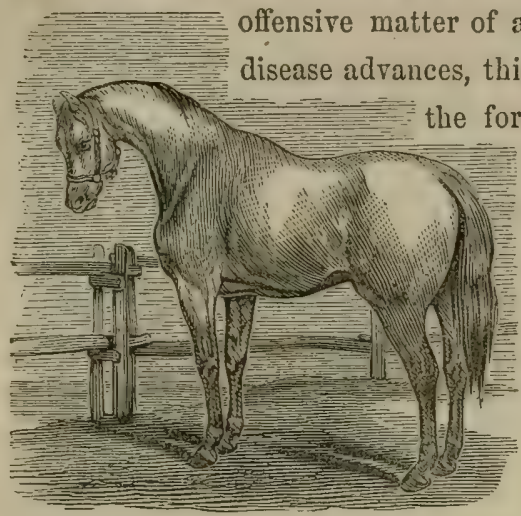

THE CHILDREN'S PET.

a greasy feeling. As the is discharge thickens into m of tears, and becomes hard, presenting a grapy appearance. Abscesses are sometimes formed about the heels, causing the sloughing array of a large portion of them.

This disease requires constitutional, as well as local, treatment. Give. internally for four days one of the following balls : of Barbadoes aloes, one ounce; pulverized gentian root, half an ounce; pulverized ginger, two drachms; mix with molasses, and divide into four balls. Follow this with half-drachm doses of mux vomica powdered; wash the parts well with soap and water, and apply flaxseed poultices, mixed with a solution of sulphate of zinc, mutil the inflammation is considerably reduced; then bathe carefully either with glycerine, or a solution of sulphate of zinc, or the castor oil and collodion wash. If the discharge is very offensive, use powdered charcoal and soap suds, allowing it to dry upon the legs; a solution of the chloride of lime may also be used; or a weak solution of corrosire sublimate is bene. ficial. 


\section{WATER FARCY.}

This disease, together with anasarca and cedema may be classed under a common head, as they are but modifications of the same disease, which depends upon general debility for its existence. Two stages are, however, said to exist; one with inflammation, and the other without; one occurring in old horses, and the other in young ones. One important difference should be noted; the term anasarca is too extensive in its application to be properly associated with this disease, the term cedema being preferable to it, as having a local meaning and being more circumscribed in its limits.

As symptoms, the legs, belly, sheath, and other parts become swollen, and leare the impression of the fingers behind after pressure. In old horses such pressure rarely causes pain, inflammation being absent; but in young horses the legs particnlarly are hot and painful to the touch.

In this disease we must depend npon tonic and diuretic medicines; tonic, for the purpose of building up the system; and diuretic, to increase the secretions. The two should be combined as follows: of sulphate of iron, two ounces; pulrerized gentian root, one ounce; pulverized ginger, half an ounce; nitrate of potash, one ounce; mix, and diride into eight powders, giving one night and morning, with good nourishing food, and allnwing no corn. Or, the following will be found very useful: of sulphate of copper, one ounce; pulverized gentian root, one and a half ounces; pulverized ginger, half an ounce; nitre, one ounce; ground anise seed, six drachms; mix, and diride into eight powders, giving one night and morning. Hand-rubbing and daily exercise will be necessary. 
WEED.

This is a disease similar to cedema, but makes its appearance above the hock, and extends downward. The skin is hot, and extremely sensitive to the touch; so much so that the animal throws the leg upward and outward as though to escape tor. ture. The veins of the leg, are full and corded.

For treatment, apply warm fomentations to the parts affected, and give a purging ball, followed by the powders recommended in the last disease:

\section{CRACKED HOOF.}

This disease, also called sand-crack, occur's only in the hoof that is dry, hard, brittle, and contracted. The hoof in a natural, elastic condition can be bruised, but not split up if double the force that splits the dry, contracted hoof is applied. This crack occurs most generally at the quarters, and almost always in the fore feet, they being almost alone subject to contraction. If the crack extends through the hoof it causes very painful lameness.

For treatment, the foot must first be carefully examined to see that no dirt has worked in under the hoof; the loose parts of the horn must be cut away; a pledget of tow, saturated with - sulphate or chloride of zinc, or tincture of myrrh, should be applied, and a bandage carefully put on to keep it in place and keep out the dirt. As soon as the new horn has grown down a little, draw a line across the top of the crack with a drawing-knife or firing-iron, and apply a little tar or hoof ointment. If the crack is at the toe, a shoe with a band running across from the heels to a little below the coronet in front, and united 
by two screws, will often be all that is required, and the horse may be kept at work; but in quarter-crack it is unsafe to use the animal, particularly if it extends through to the soft parts. If the frog is in a bealthy condition, which is rarely the case, a bar shoe, eased at the quarter, will be found beneficial.

\section{SOLE BRUISE AND GRAVIL.}

Accidents frequently occur to the feet of horses from their striking them forcibly upon stones and other hard substances. Pressure of the shoe upon the sole is the occasional cause of bruises of that part of the foot; and tender heels more frequently arise from bruises than from any other cause.

For treatment, if pus is secreted within the hoof-which may be discovered by the acute pain caused by a light tap of a hammer on that part of the hoof under which the matter is situated-the hoof must be cut through, that the matter may escape, as it will gradually work its way upward and make its appearance at the top of the boof, thus rendering the treatment more difficult. After the matter escapes through the opening so made, throw in an injection of sulphate of zinc in solution, one drachm to a pint of water. For the treatment will be the same as recommended in quitter. Gravel sometimes works into these wounds, which must always be removed, and the parts carefully washed.

\section{PRICKING.}

This is an accident of too frequent occurrence, and happens in various ways, as by treading upon sharp bodies, such as broken glass, nails, etc., etc. It occuro more frequently, how- 
ever, in shoeing, owing to the nail not being properly pointed, or, in some cases, from the iron not being good splits, one part turning inward and the other outward. These accidents are not always the fault of the smith, and he should not be unjustly censured for what he could not obviate. If such punctures are properly attended to, serious consequences rarely ensue. The practice of closing up the wound after removing the nail, glass, or other sharp substance cannot be too strongly condemned. It is doubtless in consequence of this senseless practice that so many horses are lost from lock-jaw, which does not generally make its appearance until the animal has apparently recorered from the wound though npon an examination of the foot pus will often be found secreted within the hoof.

When a horse picks up a nail, or is pricked by the smith, a poultice should at once be applied to the foot, and kept on for several days; a cathartic ball should also be given, that the bowels may be in good order; after the removal of the poultice, apply the tar ointment, and no further trouble may be anticipated.

\section{FALSE QUARTER.}

This is an imperfect formation of horn at the quarter, which is generally of a lighter color than the other part of the hoof, and is divided by a seam from the top to the bottom. It is the result of injury from quitter and other diseases, rendering the heels weak, and requires the protection of a bar shoe, which should never bear unon it, as it may occasion lameness. 19. 


\section{FOUNDER.}

Founder, or laminitis, is an inflammatory condition of the lamince of the feet, which are the most sensitive parts of these important appendages. Founder is said to be produced by various causes, such as hard driving, watering when warm, standing in a draught of air, or upon plank floors, and many others.

The author, however, views it in a different light, attributing its existence principally to one gencral cause, namely, contraction of the hoof, the causes before named being the immediate or exciting causes. This view is sustained by many facts. Founder does not occur in one case out of fifty in a healthy, open foot; nor are the hind feet often inrolved, as they are rarely in a contracted condition.

The symptoms are a full, quick pulse, from sixty upwards; accelerated respiration; the fore feet are hot and tender, the animal for relief throwing his body back upon the hind legs, extending the fore legs until he rests upon the heels, and sometimes lying down, particularly if the hind feet are involved; the animal also manifests much pain.

If the animal is in full condition, two quarts of blood should be taken from each of the fore feet; an active purging ball should be given, followed by one-drachm doses of belladonna made into pills every four hours ; poultices of flaxseed meal should be applied to the feet for several days; injections of soap and water, also ought not to be neglected. By this treatment the animal is usually well again in a week, or even less; but if the disease is neglected until it becomes chronic, the animal will ever after remain unsound, though he may be 
rendered useful. From the alteration or disorganization of structure that takes place, there can little be done in the chronic stage except careful shoeing, which the smith should understand.

\section{PUMICED FOOT.}

This is called by horsemen a falling of the sole. It is preceded by founder, and is, in reality, one of the terminations of that disease, arising from the slow, continued inflammation of chronic founder, which causes absorption of the outer edge of the coffin bone, the latter thereby gradually losing its concare surface. and becoming convex. The sole, yielding to this gradual change, becomes flat, or, in some instances, convex. Very little can be done in such cases by way of treatment; yet by careful shoeing the animal may be rendered useful, although never sound.

\section{CORINITIS.}

This is an inflammation of the coronary ligament, situated within the upper part of the hoof and between the hoof and the hair. This ligament secretes the horn forming the wall or crust of the hoof, and when diseased ceases to perform its function, or performs it very imperfectly; as a consequence, the coronet, or upper margin of the hoof, is contracted, which causes the soft parts to bulge out in such a manner that it has often been mistaken for ring-bone. This contraction often causes lameness. The most frequent causes are, standing upon plank floors, hard driving, and the neglect to apply softening applications to the hoof.

For treatment, apply a flaxseed poultice for several days, and 
then a fy blister well rubbed in around the upper margin of the hoof; afterward use the hoof ointment once a day, until the coronet comes up full.

\section{NAVICULARTHRITIS.}

Coffin-joint lameness, as it is generally termed, is a disease of very common occurrence, and often troublesome to manage. This joint is formed by the union of three bones: the os pedis, or coffin-bone, situated immediately within the hoof; the coronary, or small pastern bone, the lower half of which is situated within the upper part of the hoof, called the coronet, and uniting with the
os pedis; and the navicular, situated be-
THE FAMOE thom two and behind THE FAMOUS TROTTING MARE, FLORA TEMPLE. concussion by the fatty frog, the sensible frog, and the horny frog, situated beneath it, and forming a soft elastic cushion on which it may rest. So long as the foot remains in a healthy condition, there is little danger of the occurrence of this disease. Even though the foot be strained very considerably, and a high degree of inflammatory action be produced, this discase will hardly arise, unless the inflammation becomes chronic. The author regards its origin as mainly due to a contracted condition of the feet, which, in fact, is the predisposing cause. 
Rarely, indeed, is navicular-joint lameness found existing in feet that have open heels and elastic frogs. If from any cause these frogs lose their moisture, they also lose their elasticity, and the foot therefore strikes the ground with a jar ; inflammation of a chronic character sets in; the synovia (joint-oil) be. comes absorbed; and caries of the bones is established, which destroys their articular surfaces and causes excessive lameness. Occasionally, owing to some new injury, acute inflammation sets in, causing new depositions of bone to be thrown out, and uniting the three bones together; which union is called anchylosis. This condition may be known by stiffness, and the animal walking upon the toe.

The symptoms of this disease have been confounded with those of another disease of the foot, which has been discovered by recent investigations. The horse is found to go lame upon coming out of the stable, which wears off after traveling some distance; one foot is observed in advance of the other when the animal is at rest; as the disease advances, the lameness becomes more frequent, until at last it is permanent. Various kinds of treatment have been resorted to, but with little success, such as blistering, firing, etc. Of late years, the frog seton has been introduced with very decided benefit. Should this, too, fail, there is no hope but in the operation of nerving, which should only be performed in certain cases mentioned under the head of neurotomy.

OSSIFICATION OF THE LATERAL CARTILAGES.

This is a transformation to bone of two projections of cartilage, or gristle, springing from each side of the coffin bone posteriorly, and known as the lateral cartilages. This disease 
was at one time called ring-bone, but the ring-bone of the present day is quite a different disease. It arises from concussion, and will rarely be found in any but contracted feet.

The treatment in these cases is only palliative, as the disease cannot be eradicated by any course of medical treatment. The first endeavor should be to expand the heels by applying poultices to the feet, together with the hoof ointment.

\section{WIND GALLS.}

Wind galls are puffy swellings about the joints, found above the fetlock on both the hind and fore legs. They are techni. cally known as bursal enlargements, that is, a distended condition of the burse or synovial sacs, which contain tho synovia, or joint oil. The animal suffers no inconvenience, apparently, from their presence upon his limbs, they evidently. causing no pain.

It is seldom that any treatment is resorted to, except in the case of a very valuable animal. Blister's are commonly applied, but they are not attended with any permanent benefit. The application of cold water and compresses, secured by means of bandaging the legs, has proven the most efficacious.

\section{SPRUNG OR BROKEN KNEES.}

This trouble does not always result from an injury of the leg, or strain of the tendons; it is more often found in horses that have bad corns in the feet, or troubled with naricular disease, than in any others. The animal raising his heels to prevent pressure upon the tender parts, bends the knee, which bending becomes finally, from the altered position of the limb, 
a permanent deformity. Horses with sprung knees are unsafe for saddle purposes, owing to their consequent liability to stumble.

Respecting the treatment, it may be said that six out of every ten sprung-lineed horses will be found to have corns. If these be of recent growth, there is a fair prospect of straightening the limbs by removing the corns as directed uncler the head of that disease; by the removal of these the heels are brought to the ground, and the limb becomes straight. Under any other circumstances all treatment proves useless.

\section{BREAKING DOWI.}

This accident occurs in running, jumping, racing, etc. It is sometimes called a strain of the back sinews, and lets the animal down upon the fetlock, in consequence of a rupture of the ligament of the pastern. Horses meeting with this accident are of little value ever after, as they always remain weak in the fetlock. Unless the animal is quite young and valuable, the treatment would cost more than the animal's value. The French treat these cases very successfully by the application of instruments which keep the limb in its proper position until. the parts have again healed and become strong. This is the only course to be pursued with any possible chance of a suc. cessful termination of the case.

\section{STRAINS OF THE KNETS.}

Strains of this joint occur in young horses while being broken into harness more often, probably, than at any other period of the animal's life. This results from the tenderness 
of the parts at that time, not one in twenty having them having arrived at maturity. These strains often prove troublesome to manage, and occasionally leave a stiff knee as the result.

Treatment-Bleeding from the plantar, or plate vein; warm fomentations to the part; when the inflammation is reduced, apply once a day for several days the following ointment: iodine ointment, one ounce; blue, or mercurial ointment, half an ounce; mix well together.

\section{STRAIN OF TEE HIP JOINT.}

This occurs in falling, slipping, getting up, etc. The symptoms are a dragging motion of the limb; the lameness passing off after the animal gets warmed up, and returning upon his becoming again cool, the horse being then even more stiff and lame than before leaving the stable.

For treatment, apply cold water; a purging ball and rest are all that are requisite to effect a cure. Careful usage for some time after will be very necessary.

\section{SHOULDER STRAIN.}

This, which is of rare occurrence, arises from severe blows, or concussions; slipping so as to throw the legs apart forcibly; falling in the shafts of a hearily laden cart, etc. The symptoms are usually well marked; the horse is quite lame, both when walking and trotting; the leg drags with the toe on the ground, having an outward or circular motion.

Local bleeding is generally useful by way of treatment; three or four quarts may be taken from the plate vein, which runs down the inside of the leg. If, however, the animal is in a debilitated condition, bleeding should not be practised. 
Foment the shoulder well with hot water frequently; a seton will often be found beneficial. After fomenting two or threo days, use the following liniment: laudanum, one ounce; spirits of camphor, one ounce; tincture of myrrh, one ounce; castile soap, one ounce; alcohol, one pint. Or, sweet oil, one pint; spirits of hartshorn, three ounces; shake well together.

\section{OPEN JOINTS.}

Tirese are generally the result of a punctured wound; the capsular ligament that surrounds the joint and confines the joint oil within its proper limits being thereby penetrated. These accidents are often attended with serious results, from the inflammation that is likely to arise from such an injury.

For treatment, efforts should first be made to close the wound, that the escape of the oil which lubricates the joint may be prevented. If the wound is small, it may be closed by means of a hot iron; if large, shave off all the hair around the opening, apply a piece of linen cloth well saturated with collodion, and bandage the part. Care must be taken to have the skin around the wound perfectly dry, or the collodion will not adhere. Shoemaker's wax, or common glue, applied in the same way, will frequently answer the purpose. The animal must be kept perfectly quiet, his bowels opened, and he be kept upon his feet for several days; if, however, the collodion adheres well, this is not of so much importance.

\section{SWEENIE.}

This imaginary disease has been the occasion of the infliction of much cruelty and unnecessary torture upon the borse. No 
respectable veterinary author recognizes any such disease. The symptoms which accompany its supposed existence are but sympathetic effects, or atrophy of the muscles of the shoulder. The attention of the horse-owner is directed to a wasting away or lessening of these muscles, which from want of action naturally become smaller or contracted; upon the animal's regaining the natu ral use of the limb, the muscles are again developed, as the muscles of the smith's arm by the constant mer. Cases called the sweenie are invariably the result of injury as the knee, ofs (n) foot, etc.When the $(-1)$ animal picks up the foots the ground, it may be depended upon is not in THE EQUESTRIENNE.

that the injury the shoulder; if however, the leg drags with the toe on the ground, the injury may be looked for in that locality. It is, however, more easy to decide a case of shoulder lameness than any other to which the $\operatorname{limb}$ is liable.

\section{ostrIts.}

This is an inflammation of the bone, occasioning lameness of an obscure nature, and is one of the most difficult of alp cases of lameness to detect. Where it occurs in the cannon bone, it is often mistaken for a thickening of the integuments.

Treatment_Cold bandages, lead water, rest, with daily half-drachm doses of iodide of potassa dissolved in a pail of 
water, will usually prove successful if the treatment be persereringly adopted.

\section{CAPUIET AND CAPPED HOCK.}

There are generally serous abscesses, produced by blows, bruises, strains, or injuries from any cause. Capulet is an enlargement at the point of the elbow, and is generally caused by lying on the heels of the shoe, which bruise the part. Capped hock is found at the point of the hock joint, and is usually cansed by kicking against the sides of the stall.

By way of treatment, first open the part; if it contains fluid, which will be known by the soft elastic feeling, throw in with a syringe an injection of the tincture of iodine diluted with nlcohol; a solution of the sulphate of zinc may in incipient cases answer the purpose. If fluid is not formed, blisters will often succeed. In cases of capulet, have the heels of the shoes shortened, or bind the feet at night to prevent injury.

\section{CARIES OE THE BONES.}

This is, perhaps, the most common of all the diseases to which the horse is subject, and its frequency can only be accounted for, by the abuses to which he is subjected. It generally arises from a low, inflammatory condition of the joints. these parts being principally affected ; an ulceration of the heads of the bones is established, generally in young horses, which is called, from the destruction which it occasions, caries, or decay. It will usually be found preceding spavin, ring-bone, stiff back, and other anchylosed conditions of the bones, and can best be illustrated under the heads of Spavin and Ring-bone. 


\section{BONE SPAVIN.}

This is a disease of such common occurrence that almost all horsemen think they fully understand its nature, pathological condition, and treatment. It is generally regarded by veterinary authors as a very serions injury, destructive to the utility of the animal, and very frequently reducing his value essentially in consequence of the blemishes. Where, however, there are no outward blemishes, as is the case in four out of every five spavined horses, the price of the animal is not affected, unless he is lame, since the disease is not discovered. There are, at this day, thousands of spavined horses traveling our roads, in not one of whom would the most experienced horsemen the world ever produced be able to determine the fact so long as the animal lives. In all such cases no external enlargement is found, but, on the contrary, the limb is clean and smooth. In the absence of enlargement, or spavin-bunch, as it is sometimes called, on the inside of the hock-joint, horsemen are unwilling to believe that spavin exists. The books, indeed, teach us to look there, and there only, for it; but the author's experience teaches him that the enlargement, where any exists, appears almost as often upon the frout part of the hock as it does upon the inside.

Spavin generally arises from a strain, jar, or blow upon the hock-joint, causing an inflammatory condition of the cartilaginous cushions which cover the articular surfaces, or points of union, of each bone, or of the ligaments which surround the joints and bind the bones together; sometimes, indeed, both are involved. As this inflammatory condition is the exciting canse, spavin, or ulceration of the parts, speedily follows the 
neglect to remore it. When the inflammation is acute, the synovial fluid, or joint-oil, is soon absorbed; the cartilages of the joint are turned to bone, and uniting, one with the other, form one solid mass, destroying the elasticity as well as the mobility of the parts involved, and constituting what is called anchylosis of the hock-joint. This anchylosis, or union of bone, is not always general, there being in many cases but two, three, or four of the bones involved. When these changes are confined to the cartilage, external enlargement, or spavin-bunch, is nerer found. This the author calls sparin without any external indication.

When, however, the ligaments surrounding the joint are conrerted into bony substance, external enlargement in all cases exists. When a low, inflammatory action is found going on within the joint, it is an evidence of ulceration, in which, instead of new bone being thrown out, as in the acute stage, the natural bone is gradually decaying or rotting away. Hence arises the difficulty often experienced in the treatment of this disease.

As symptoms, the horse is very lame on leaving the stable, but when he is warmed up the lameness passes off; the leg is drawn up quickly with a kind of jerk; and there is a peculiar hard tread, which can only be distinguished by close observation. Where the bones are all united together, whether there is external enlargement or not, there is a peculiar twist of the heel outrards, which is more readily observed in the walk, and which the author has always found an infallible symptom of complete anchylosis.

Both spavin and ring-bone are incurable diseases. The lameness may be removed, but the disease, when once estab- 
lished, cannot, because the elasticity, mobility, and function of the joint are all destroyed in proportion to the extent of the disease. The spavined animal, therefore, comes down with a hard, jarring tread. The removal of the lameness depends upon perfect union or solidifying of the diseased bones. In

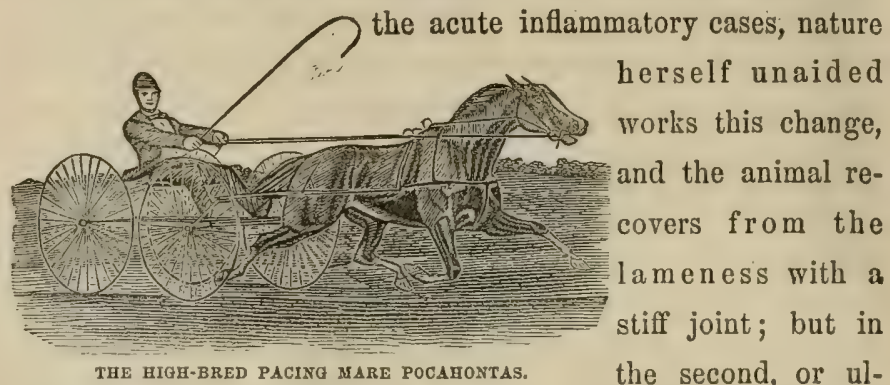
cerative stage, assistance is required. We, therefore, endeavor to excite an active inflammation in the joint in order to overcome this ulcerative process, and induce new deposits of bone to be thrown out. Many modes have been adopted to secure the desired end, some of which are of a most barbarous character. Sharp instruments have been struck with considerable force into the joint, creating a tremendous fire, which soon checks the ulceration. This practice, although often successful, is unnecessarily severe, and cruel in the extreme. All kinds of caustic applications have been used, many of which have destroyed both the disease and the animal. Blistering the parts, the action being kept up for three or four weeks, often proves successful; firing is also practised; setons in the hock are frequently used with advantage. The following ointment is recommended; bin-iodide of mercury, on $\theta$ drachm; lard, two ounces; mix well together. Shave off the 
hair, and rub the part once a day for six or eight days; then wash the parts well with proof spirits. If the desired effect is not produced, repeat it.

\section{RING-BONE.}

This is a disease of the same nature as sparin, its locality alone giving it a different name; the same alterations of structure takes place; the same termination follows, and the same treatment is indicated. Contraction of the coronary ligaments is sometimes mistaken for ring-bone, and the poor beast is severely tortured in consequence. Contraction of this ligament produces a bulging of the soft parts around the coronet, causing the hair to turn downward and inward upon the hoof, giving it much the appearance of ring-bone. As in all such cases the heels are pressed close aud painfully together, there is great necessity of distinguishing between the two before any application is made.

\section{SPLINT.}

This is an exostosis, or bony enlargement, arising from blows upon, or strains of, the splint bones, which are situated one on each side of the cannon bones and posterior to them. Splints are so common that few horses reach the age of eight years without having them, although they are not always visible to the eye at that period, having perhaps spread over a large surface of bone, or become flattened; which circumstance has given rise to the opinion among horsemen that old horses are not affected with splints. This, however, is a mistake; since a splint once formed is never afterward removed during the life of the animal. The nature of a splint is very similar to 
that of a sparin, but its course is somewhat different. When the injury is first received, the enlargement becomes quite prominent; but, as time advances, it generally disappears from view, even without the aid of man, spreading itself between the cannon and splint bones, thus lessening its size externally. Splints are not regarded as unsoundness, unless they cause lameness, which rarely occurs, particularly if they are situated near the middle of the bone; but if they are situated either at the upper or lower portions, or heads, lameness is almost always the result. This is easily explained; the bone, it will be observed, curves from above downward and outward, so that the lower extremity sets off from the body of the cannon bone; the upper heads, where it unites with the bones of the knee and hock, slant or bevel inward, and as the weight of the animal is thrown upon them, the upper heads are forced outward, while the lower ones are thrown inward. By this simple arrangement a rocking motion of these bones takes place, so that at the centre there is very little mobility, and if the injury is above, it causes lameness in consequence of tension; if below, from pressure; but, if it is in the centre, it seldom causes lameness at all, though the injury is greater.

When lameness occurs, the union of the bones should be hastened by increasing the inflammatory action; this is best done by active blistering, which soon removes the lameness.

CURB.

This is a swelling on the back part of the hock joint below the cap, generally arising from a strain, or breaking down of the hock. Some horses naturally have what are called curb- 
hocks, though they are not always attended with any serions disadvantages. There is a predisposition to weakness, which renders them suspicious.

If the curb arises from recent injury, a little blood may with adrantage be taken from the sephena vein running up the inside of the thigh; cold water applications should be kept upon the parts; cloths wet with tincture of arnica, half a pint to a gallon of water, are very useful; or, the following ointment will be found of service: dry iodine, one drachm; iodide of potassa, one drachm; lard, one ounce; mix well together, and use once a day.

\section{STRING HALT.}

This disease has never been very satisfacturily accounted for by veterinary authors. It consists in a sudden, spasmodic raising of the hind limbs, though it is said to have occurred in the fore legs. The author has found, upon an examination after . death of the hock-joint of several animals affected with this disease, that a little roughness from exostosis existed on the os calcis, or bone forming the cap of the hock, where the perforanstendon plays over; in other cases the tendon has been found almost entirely surrounded with a bony case, which interfered very materially with its action. He is inclined, therefore, to regard these as the general causes of the disease.

No treatment as yet practised has proved successful; though there are recorded isolated cases of spontaneous cure.

BLOOD SPAVIN, BOG SPAVIN, AND THOROUGHPIN.

These constitute one disease, occasioned by an over secretion (f joint oil in the hock joint, which causes a distention of the 80 
capsular ligament, or bursa, presenting soft puffy swellings about the joint. Blood and bog spavin appear on the front and inside of the joint; while thoroughpin extends through from one side of the joint to the other. These diseases are so common and so well marked as not to be easily mistaken. The causes are violent exercise, throwing the animal upon his haunches, running, jumping, etc.

As it seldom causes lameness, treatment is rarely needed; if requisite, blistering, bandaging with compresses, and rest are the most successful.

\section{FRACTURES.}

Experience has established the fallacy of destroying every horse that meets with a fractured limb. Fractures may occur in any bone of the body, and yet a perfect union of the parts may take place, provided the fracture is a simple one; compound fractures, even, are occasionally united.

For treatment, the animal should first be placed in the most comfortable position, and the parts adjusted as nearly as possible, retaining them by proper bandages, splints, etc. Should the fracture be in the small or lower part of the leg, sole leather, softened in water and moulded to the limb, retaining it in place by bandages, forms a very good splint.

Fractures of the skull sometimes require the operation of trephining, (explained under the head of Surgicax CASES, in order to replace the parts perfectly; after which the bowels should be opened, and the animal kept on moderate diet.

Fractures of the pelvis, or haunch bones, will, in nine cases out of ten, become united by proper management, no matter how bad the crushing, and the animal may again be rendered 
serviceable. The author never hesitates to treat fractures of these bones in horses that are of sufficient value to warrant it. Indeed, union of the parts in such fractures will often take place, even if the animal be turned into a field without any treatment; though, perhaps, more deformity will be left than if proper care had been exercised. The horse, if active and high-strung, should be kept upon his feet by tying up the head short for several days, and then the slings may be placed under him; if this is done at first, the animal being full of fire throws himself off his feet, and all efforts to remedy the fracture will prove a failure. From six to eight weeks, according to the age of the animal, are necessary to complete the union of the parts.

Some practical knowledge is requisite, in order to discriminate cases of fracture of the limbs that are likely to be successfully treated; but fractures of the haunch bones rarely fail to unite, with proper management. The animal should be kept on bran mashes, gruel, and green food during the treatment.

DISEASES OF THE HEART.

Diseases of the heart are less understood by the members of 'the veterinary profession generally than any other class of diseases (with, perhaps, one or two exceptions,) to which horses are subject. This want of information in this country, is attributable to the comparative infancy of veterinary science, the obscurity of the symptoms by which these diseases are characterized, the consequent confounding of them with other diseases, 
and to the comparative silence of veterinary authors upon this important subject.

Diseases of the heart in this animal are not suspected by the farrier, (shoeing-smith) or horseman; yet they are by no means of unfrequent occurrence. During the session of the Veterinary College of Philadelphia for 1859-60, the author had then opportunities of presenting to the class well-marked cases of disease of this organ, as also one very interesting case of rupture of the beart, or rather of the aorta, or great artery leading from the heart, at the point where it leaves that important organ. The latter case was that of a bry mare which had been used in an oyster cart; she ate ber feed at niglit as usual, in apparent good health, and was found dead in her stall the next morning.

\section{PERICARDITIS.}

This disease, as its name implies, is an inflammation of the pericardium, the bag or sac which surrounds the heart, and known to butchers as the heart-bag. After death arising from pleuritic affections effusions are quite commonly found within this sac, which are attributed to the sympathy existing between the pericardium and the pleura. The fluid is sometimes of a bright yellow color, while at others it is of a turbid character with considerable lymph floating in it, which collects in a mass forming a thick layer upon the internal surface of the sac, causing cousiderable thickening of its walls, and extending over the heart in like manner; adhesions between the two sometimes take place. Percival mentions an instance in which this collection was converted into a substance of the nature of gristle of considerable thickness. This disease rarely exists alone, but is of a secondary character. 
The atteudant symptoms are palpitation of the heart, quickened respiration, sometimes accompanied with a dry cough, with a pulse quick, rising to sixty or seventy a minute, full, hard, and strong. "Mr. Pritchard, V. S., Wolverton," says Mr. Percival, "with laudable zeal for the promotion of our art, so long ago as the year 1833, furnished the veterinarian with some practical communications on this subject, which we shall find it advantageous to revive upon the present occasion. His observations relate particularly to the type termed Hydrops Pericardii, which implies the stage of pericarditis when effu-

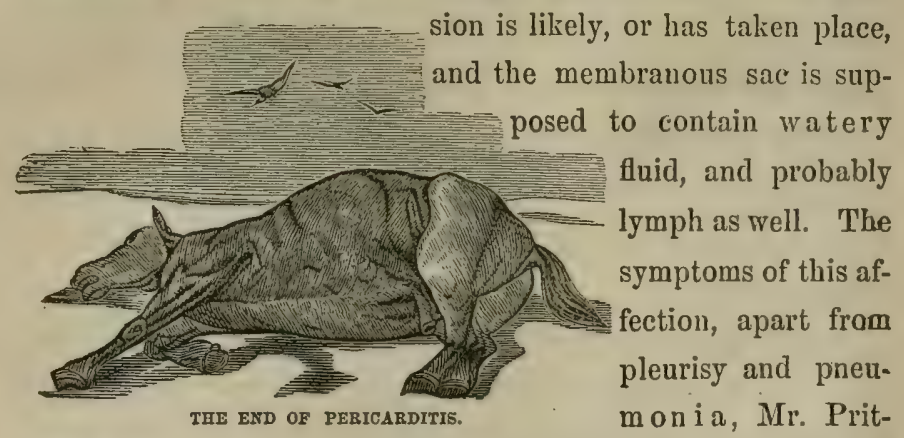
chard informs us, are well-marked. They are palpitation of the heart, the carotid arteries (passing up the neck) beating forcibly and being readily recognized in applying the finger to their course in the neck. There is a good flow of blood through the jugulars; a copious return of blood through the neck, when the state of the pulse is considered; the surface of the body and the extremities are warm; and these latter symptoms continue within one or two hours of the horse's death. *** In addition to the above symptoms, there is such an expression of alarm and anxiety in the countenance of the animal as no other malady produces." 
There is no treatment as yet known by which this disease can be reached.

\section{CARDITIS.}

This is an inflammation of the muscular structure of the heart comparatively rare, or at least supposed to be so.

In this affection the animal will be found lame, generally in the off fore-leg, but upon examination no cause will be found sufficient to account for it. This lameness may appear and disappear several times previous to the attack's manifesting itself in a more positive form, leaving the impression that the lameness was rheumatic. We next find the animal refusing his feed; his heart palpitates violently; he occasionally gasps, and gnashes his teeth; pulse full, hard, and quick; there is a wild expression of the eyes; respiration quickened; mouth hot and dry; and the temperature of the legs varies from moderate to cold.

For treatment cold water should be frequently given; take one drachm of white hellebore, and divide it into five powders; give one of these on the tongue every three or four hours. Bleeding has been recommended; but the author has not witnessed any advantages from it, and therefore would on no account advise it.

\section{ENDOCARDITIS.}

This disease, called also palpitation of the heart, or, more commonly, thumps, is an inflammation of the lining membrane of the heart, and is generally associated with pericarditis; the inflammation readily extending itself from one part to the other in consequence of their proximity.

The symptoms are a violent palpitation of the heart, which 
can often be observed at the distance of several yards from the animal; pulse full and hard, but not quickened. Although this disease is regarded as incurable, we can still palliate the symptoms so as to allow of the animal's return to work the next day.

For treatment, give one of the following powders every three hours; of nitrate of potassa one ounce; pulverized digitalis two drachms; mix, and divide into five powders. Subsequent attacks may be warded off by keeping the bowels regular.

\section{DISEASES OF THE HEAD.}

\section{OSTEO-SARCOMA.}

This disease, called commonly Big Head, is not mentioned by veterinary authors in Europe, and so far as the author can learn, seems to be peculiar to the Western and Southern States. It appears, from the rather unsatisfactory accounts at the author's command, to originate in the osseous, or bony, structure of the face. The bones become much swollen, and are represented as presenting a soft, spongy, or cellular appearance, the cells being filled with a substance like jelly. This appearance, however, does not correspond externally with several specimens in the author's possession, in which the external surface of the bones appears to be perfect, but very thin, and very much enlarged.

The symptoms are a swelling of the bones of the face from the eye to the nose; puffy swelling about the limbs; stiffness 
about the joints; pulse slightly accelerated, and soft; coat rough and staring, with considerable debility.

The treatment usually practised has been to make an incision through the skin and insert a small quantity of arsenic into the wound; or else to score the face with a red-hot iron; which latter mode is said to have effected a perfect cure in many cases. Neither of these operations, however, strikes us as being very scientific. The author's friend, G. W. Borler, of Cincinnati, Ohio, has had some experience in the treatment of this disease, and has been very successful. The course pursued by him is to rub the swollen parts well once a day with the following ointment: of mercurial ointment one ounce, and of iodine ointment two ounces; mix well together for use. Give internally at the same time one of the following powders night and morning : calomel one ounce; iodide of potassa two ounces; pulverized gentian root one and a half ounces; to be made into twenty powders. The animal must be kept in a dry, well ventilated stable, and the body kept warm so long as this medicine is given.

\section{INFLAMMATION OF THE BRAIN.}

This disease, known also as phrenitis, or, more generally, mad staggers, arises from various causes, such as blows, overfeeding and little exercise, too tight a collar, etc., etc.,

A heaviness of the head is first noticed; an unwillingness to move about; the lining membrane of the eyelids much reddened; appetite indifferent or lost; a peculiar dullness of the eyes; and finally, delirium or madness. The animal be, comes unmanageable; beslavers all that comes within his reach, whether man, horse, or anything else; and plunges violently about the stall, or wherever he may chance to be. 
As this disease is occasioned by a determination of blood to

- the head, it is necessary to use the lancet; this should be done freely, and that too before the delirious stage comes on, otherwise it cannot be done properly or beneficially. Cloths wet in cold water should be applied to the head; or, what is better, bags of broken ice. Open the bowels with the following, made into a ball: Barbadoes aloes one ounce; pulverized ginger one drachm; pulverized gentian root two drachms; mix with molasses sufficient to form the ball. Give also injections of castile soap and water. Give no food for twenty-four hours; but small quantities of water may be frequently given. After the recovery of the animal he should be fed very sparingly, and not exposed to the hot noonday sun.

If the occasion of the attack be a tight collar, the remedy is simple and easy; if from over-feeding, the quantity of food should be lessened; but little is to be expected by way of treatment.

\section{MEGRIMS.}

This is a sudden determination of blood to the head, generally attacling horses while at work, or in harness upon the road. Those of a plethoric character are most subject to these attacks.

The horse suddenly stops in the road, shakes his head, and sometimes goes on again; at other times he falls in a state of unconsciousness, the whole system appears convulsed, with the eyes wild in appearance and constantly rolling.

Bleeding upon the appearance of the first symptoms gives almost immediate relief; after which the bowels must be opened, for which purpose give one and a half pints of linseed oil, or the aloes ball will answer; bran mashes should be given for a 
few days. These attacks may be prevented in the case of horses subject to them by moderate feeding and driving, and in warm weather by keeping the forehead shaded by a canvas or cloth hood elevated on a wire framework about two inches from the forehead so as to protect the brain, and admit a free passage of air between the two. The author believes that he was the first to introduce this hood, which can be attached to the bridle, and made as ornamental as may be desired. The use of hoods of this kind in very hot weather would prevent the frequent falling of horses in our streets from over-heating; as the heat of the sun principally affects the brain in all these cases.

\section{VERTIGO.}

This disease generally arises from water in the cranial case, causing pressure upon the brain. The animal is generally attacked in harness, as in the preceding disease ; this arises from the fact that the exercise causes the vessels of the brain to become more active, fuller, and more distended with blood, and consequently there is greater pressure upon this sensitive organ.

The symptoms are similar to those of megrims, with, perhaps, the addition of rearing, dropping suddenly as though struck with death, and rising in a few moments as if, nothing had happened, etc.

The treatmeut mainly consists in keeping the bowels in good order; working moderately; giving no corn, and but little hay.

\section{EPILEPSY.}

This disease takes its name from the suddenness of its attack. The animal is apparently in a perfect state of health, when suddenly he falls to the ground, generally (as in the two preceding 
cases), while in harness, without any manifest cause. He remains in this condition for a short time, and then appears as well as ever; although occasionally a considerable degree of stupor is manifested for some time after.

It may be occasioned by blows, wounds, and other injuries about the head; water in the brain; tumors; violent derangement of the nervous system; worms; constipation of the bowels; plethora, etc.

The same course of treatment should be pursued as in vertigo; these diseases in their symptoms, causes, etc., being so intimately connected as scarcely to be distinguishable from each other.

\section{STOMACH STAGGERS.}

This disease arises principally from over-feeding. The animal appears dull and sleepy, with a disposition to pitch forward; stands with his head resting against a wall, manger, or the like, or, if at pasture, against a tree; if he is led out of the stable, this will be observed as an involuntary action, in consequence of which the head is often much cut and bruised by coming in contact with hard or rough substances; there is constipation of the bowels; pulse scarcely changed from the usual standard; as the attack is severe, the breathing becomes more and more labored.

Blaine regards these symptoms as the first stage of mad staggers; but this the author deems a mistake, as animals that aie from this disease, having presented the above symptoms, scarcely have any very marked change in the cerebral region, or the brain.

From the mode of treatment recommended by European authors of high repute, the author infers that the attacks are 
less severe in this country than in Europe, or else that the severe treatment there practised is more injurious than the disease itself. The whole cause of the disease being apparently

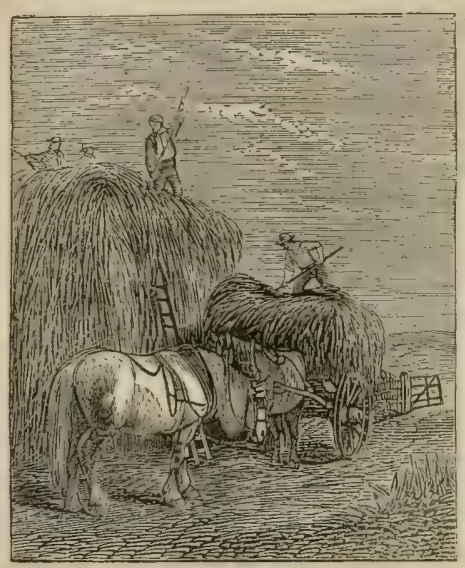
in the distended condition of the stomach from the presence of undigested food, all food should be remored from the manger, and none given for forty-eight hours. Give internally the following ball: Barbadoes aloes one ounce; pulverized ginger two drachms; croton oil six drops; mix with molasses, and give HATING SCENE. in the usual manner. Injections of soap and water should. be given, until the bowels are opened; or, what is far preferable when convenient, tobacco-smole injections. Two drachms of the extract of belladonna dissolved in a pail of water, given to drink once a day for a week, will prove beneficial. Bleeding in these cases is, as a general rule, unnecessary and uncalled for. Food should now be given very sparingly; and no corn should be given at any time to the animal after such an attack, in consequence of its tendency to heat the blood, and produce a plethoric condition of the system. 


\section{DISEASES OF THE EYE.}

\section{AMAUROSIS.}

In this disease, called also Gutta Serena, or, more generally"? Glass Eye, we find the eyes bright and clear, with a peculiar glassy appearance about them not observed in an eye where vision is perfect; although no alteration in the structure of the eye has taken place, yet the horse is partially or totally blinc. A mere examination of such eyes would not enable us to pronounce upon the blindness of the animal; but if be be taken from a dark stable to a strong light, it will readily be detected, as the light causes no change to take place in the pupil.

This disease is regarded as paralysis of the optic nerve; in some cases yielding readily to medical treatment, and in others proving incurable. Horses are often sold witl this disease upon them as perfectly sound, and the first intimation which the purchaser receives of his horse's being blind is his running against a wall-fence, post, or any thing that may chance to be in his way. It sometimes makes its appearance very suddenly; occasionally it exists in a temporary form as a sympathetic affection, as in apoplexy; it also at times occur's during the period of gestation, etc.

Constitutional treatment only is likely to succeed in these cases. A physic ball should be given to open the bowels, composed of Barbadoes aloes six drachms; pulverized ginger one drachm; pulverized gentian root two drachms; mix with molasses. After the ball has operated (which should be in twenty-four hours, if the aloes are good), give morning and evening half a drachm 
of nux romica mixed in the feed. The author has never witnessed any beneficial results from bleeding, although it is recommended by some writers.

\section{INFLAMMATION OF THE MEMBRANA NICTITANS.}

This affection is commonly called the haw, or hooks. The membrane affected is somewhat triangular in form, concave on the inner side, and convex externally. It is mainly composed of cartilage, or gristle, and is situated between the eye ball and the side of the orbit, at the inner corner of the eye. In a perfectly healthy condition but a very small portion of this membrane is visible; but when in a state of inflammation it bulges out very considerably. A portion of the membrane covering it becoming, as it were, folded upon itself presents a hooklike appearance, which has been regarded by farriers as a foreign substance, to which the name of "hooks" has been given, and its removal with the knife recommended by them. It so happens, however, that this membrane is placed in the eye, or attached thereto, to serve a useful purpose: that of cleansing the eye from dirt, or any foreign substance that may chance to get into it, which is accomplished by throwing it over the ball of the eye, and removing any obstruction. Injury must result from cutting away any portion of this membrane, as its function is in part destroyed; since the animal can no longer throw it over the ball of the eye with the same facility as before the operation was performed. In point of fact, wherever the hooks, as they are called, are cut out, it will be observed that whenever any foreign substance gets into the eye, the animal makes a spasmodic effort to throw this mem- 
brane over the eye ball, often failing to accomplish it; and thus the eye is rendered more liable to injury ever after.

Whenever this membrane becomes tumefied, instead of cutting it out, open the bowels, and apply cold water to the eye several times a day. If much inflammation exists, bleed from the small vein just below the eye, the course of which vein in all thin-skinned animals is quite distinctly marked.

\section{SINPLE OPHTHAIMIA.}

This disease arises sometimes from a blow inflicted by a passionate groom, or from some other external injury, or from a foreign body entering the eye, causing such an irritation in that delicate organ as sometimes to terminate in blinduess.

The symptoms are considerable swelling and inflammation of the eye lids, their under surfaces being very much reddened, and the vessels highly injected with blood; there is also a cloudy appearance over the cornea, or transparent part of the eye.

For treatment, if the animal is in a plethoric condition, take six or eight quarts of blood from the jugular vein, regulating the quantity by the action on the pulse; otherwise general bleeding should not be undertaken. The bowels should be freely opened with Barbadoes aloes, six drachms; pulverized ginger root, one drachm; and pulverized gentian root, one drachm, made into a ball. Bathe the eye freely with cold water; after which apply with a syringe either of the following washes: laudanum, six drachms; rain, or distilled water, one pint; mix the two, and shake well before using:-or, take half an ounce of the extract of belladonna dissolved in one 
pint of rain water. Give internally one drachm of powdered colchicum morning and evening, in a bran mash; no grain should be given during the treatment; coln should be especially avoided.

\section{SPECIFIC OPHTHAIMIA.}

Inflammation of the eye, or specific ophthalmia, is known to horsemen as moon-blindness, from the influence which the moon is supposed to exert upon it. This, however, is one of the many popular delusions which fill the pages of many useless works on farriery. When a horse is once attacked with this disease, he is ever after liable to subsequent attacks, at intervals varying from one to six months, and generally terminating in blindness. This termination may, however, be warded off for a long time by proper management; each subsequent attack rendering such a termination more and more certain, from the increased alteration in the structures of the eye.

The horse may appear perfectly well, and the eyes clear and bright one day, and the next morning usually one eye will be found closed, more particularly if it is exposed to a strong light; little or no swelling will be observed; the lining membrane of the eye lid is quite red, and the eye exceedingly watery and tender.

The causes of this disease are mainly attributable to bereditary predisposition, or to confinement in dark stables, and suclden exposure to strong light. Badly ventilated stables, in consequence of which the eyes are continually exposed to the strong fumes of ammonia arising from the urine, as also hard work in a small collar, are supposed to be exciting causes. 
These cases require prompt attention, in order to ward off the serious consequences which otherwise are in store for the unfortunate animal. The bowels should first be opened with the purging ball recommended in simple ophthalmia. Give bran mashes only, and when the bowels are opened, give one of the following powders night and morning on the tongue:pulverized colchicum, one and a half ounces; saltpetre, two ounces; divide into twelve powders. These will last one week, and by that time the eye will usually become clear and bright. Use as an injection for the eye, tincture of opium, one ounce; rain, or distilled water, one pint:-or, if more conrenient, mix half an ounce of the extract of belladonna in one pint of water, and use in the same manner. If the animal is in a plethoric condition, bleeding will be found advantageous; the quantity to be regulated by the condition of the pulse. Place the animal in a cool, well-rentilated location, free from any ammoniacal gases.

\section{CATARACT.}

This disease, which is one of the terminations of specific ophthalmia, is an opacity of the crystalline lens, situated directly behind the pupil, through which it is visible. The first indications of cataract noticed are one or more white spots making their appearance within the eye, gradually enlarging, and at last blending with each other until the animal becomes totally blind. Not much can be done in such cases by way of treatment. Its removal by the operation practised upon the human eye, and known as "couching," is hardly advisable, as the horse is forever after unsafe, being very apt to 21 
shy at almost every object which he encounters, in consequence of his sight being but partially restored by the operation.

WAIL FYE.

This peculiar appearance of the iris in some horses is not the result of disease, but is occasioned by the absence of what is called the pigment, which gives color to the eye. This pigment is secreted upon the inside of the iris, and where it does not exist, the iris, or that part of the eye which surrounds the pupil (so called from its brilliancy) remains white. Percival says: "It is a remarkable fact that this variety of hue in the iris corresponds with the color of the hair; bay and chestnut horses have hazel eyes; brown horses have brownish eyes; and very dark brown or black horses, ejes of a still darker, dusky brown shade. This curious relation is still more observable in human beings; the diversity of colors and hues in their irides being infinitely greater than any thing we behold among any one species of animals. Cream-colored and milk-white horses have wall eyes, and albinos have red eyes; in both which instances the iris is said to be destitute of any coloring matter whatever."

\section{MISCELLANEOUS DISEASES.}

\section{POLL EVIL.}

This disease arises from blows inflicted upon the poll, or back part of the head, of animals whose blood is impure, or in a morbid condition. Horses going in or out of stables with 
low doorways is requentiy strike their polls; pulling back upon the halier, and blows inflicted by passionate grooms, are among the exciting causes of this much dreaded complaint. The same injuries inflicted upon an animal in perfect health seldom cause any essential trouble; but when the blood is in a morbid condition, fistulous abscesses are formed, which are seldom curable by merely local treatment, even when the disease is treated in its earliest stages.

The author has no fhith in the seton, so highly recommended in such cases, but depends principally upon constitutioual treatment, which consists in first changing the condition of the blood from an unhealthy standard to a healthy one. This may be done by the proper use of alterative medicines, given in either of the following forms: Socotrine aloes pulverized, four ounces; soft soap, four ounces; linseed meal, one and a half pounds; mix with molasses so as to form a mass; dose, one ounce twice a day:-or, Socotrine aloes, eight ounces; soft soap, eight ounces; linseed meal, one and a half pounds; mix and dose as before:-or, the following powder may be used: sublimed sulphur, $t w o$ pounds; sesqui-sulphuret of antimony in powder, one pound : dose, a tablespoonful twice a day in the feed. The sesquisulphuret of antimony slsould never be purchased in a powdered

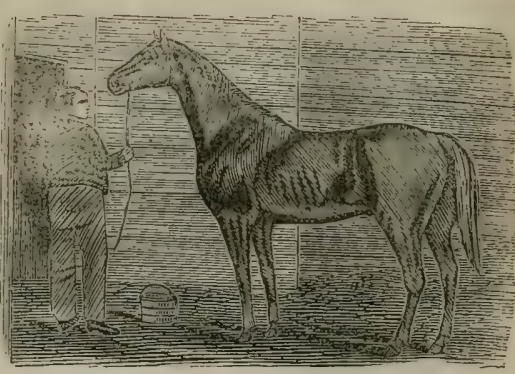
THE RONNING STALLION AMERICAN ECZIESR.

form, as it is cften adulterated with lead, arsenic, magnesia or iron; but should always be procured in conical masses. 
If the abscess is soft and pointing, it should be oyened, and a solution of zinc, two drachms to a cquart of water, injectea into the opening once or twice a day. A saturated solution of corrosive sublimate is sometimes used advantageously; though the zinc is much safer in the hands of inexperienced persons. The nux romica, in half-drachm doses, is also used as an internal remedy with good effect.

\section{FISTULA OF THE WITHERS.}

This is precisely the same as poll evil, its location alone giving it a different name, and requires the same course of treatment. Its location is upon the raised part along the back, and over the shoulders, known as the withers, and it is caused by bruises from the forepart of the saddle, and other causes.

\section{MELANOTIC TUMORS.}

Swellings are generally termed tumors; but tumors proper are swellings in any part of the animal not attended by inflammation, comprehending bony, fatty, fibrous, melanotic, etc. For their removal an operation is generally requisite, which should be left to the veterinary surgeon. Melanotic, or black tumors are, however, peculiar to gray horses, and operations upon this class would be of little use, as the entire system is usually filled with them; where one is seen, many more may be suspected. The author presented to the Boston Veterinary Institute, some years ago, a large cluster, fifty or sixty in number, taken from the abdominal cavity of a gray norse, aî̀ uniteâ together by membranous attacỉments; and 
there could not have been less than ten thousand of these tumors in the animal from which this specimen was taken. They will frequently be found about the tail of gray horses, not being found in horses of any other color.

\section{GIANDERS.}

This fatal and much dreaded disease has baffled the efforts of veterinary surgeons in all ages of the world, and still continues so to do. It is decidedly contagious; yet as different diseases are often confounded with it, which may be detected by the competent practitioner, no animal should be condemned until the symptoms peculiar to glanders, which cannot well be mistaken if the disease is fully developed, have manifested themselves. The suspected animal should be removed and kept from all possible contact with any others. The author has deposited in the museum of the Veterinary College of Philadelphia the heads of a number of horses that were killed as glandered animals, and yet not one of them was so; the suspicious symptoms in each case arising from carions teeth. Animals afflicted with ozena have also frequently been killed as glandered; and in one case which recently came under the author's notice, where the animal was Eilled as glandered, the cause of all the difficulty was the âlling up of the frontal sinuses by bony deposits.

It is necessary for the attendant to use the utmost caution when about a glandered horse, as the disease is freely communicated from the animal to man by inoculation. Of some sixty-seven cases reported in the Veterinarian of London as occurring in man, but three recovered, notwithstanding the 
utmost exertions of the ablest physicians that could be pro cured.

The most common cause of this disease is the impure air of close, ill-ventilated, and filthy stąbles, which acts injuriously upon the organs of respiration, destroys the constitution, debilitates the system, and renders it susceptible to the attacks of disease. Neglected catarrb, also, sometimes terminates in glanders; hard work and bad provender, together with sudden changes from exposure to cold and wet weather to hot stables, are likewise reckoned among the causes.

The symptoms are, discharges from one or both nostrils, of a glossy, thick, gluey nature, frequently sticking about the nostrils in considerable masses. This is a peculiarity which other discharges do not possess. This discharge is not always copious, as is generally supposed. The Schneiderian membrane of the nose changes to a dusky, or dirty yellow, or leaden hue; ulcers appear upon the membrane; a peculiar raising of the nasal bones will be observed, which the author has never noticed in any other disease; the discharge is sometimes mixed with blood, and is often fetid; and one or both of the submaxillary glands are swollen and adhere to the jaw bone. Too much reliance, however, should not be placed upon this swelling, as it frequently accompanies other diseases; but the character of the discharge, and the raising of the nasal bones are peculiarities not easily mistaken when the disease is de. veloped. As all the other symptoms will be found accompanying other diseases, too much care cannot be exercised in deciding upon a case of this disease previous to a full development of the symptoms.

All treatment thus far has proven a failure. 
FARCY.

This is regarded by the author as an incipient stage of glanders, or as a type of the same disease, and with proper management is curable. Experiments prove that the virus from a farcied horse will produce glanders by inoculation in a sound one, and that the glandered matter will in like manner produce farcy. There are two distinct varieties or stages of farcy : one, which is called bution farcy, is altogether superficial, being confined to the lymphatic vessels of the skin, and readily yields to medical treatment; the other variety makes its appearance in the extremities, generally upon the inside of the hind legs, which become completely engorged; but the swelling is very different from the ligamentary thickening, or from œdema, being very uneven or lumpy, excessively tender, and painful to the touch. Small abscesses are formed, which at first discharge a healthy pus, but soon ulcerate, and discharge a thin, sanious matter. These abscesses, or tumors, first make their appearance on the inside of the hind legs, and then on the fore ones in like manner; the neck and lips come next in turn, and they may afterward appear in all parts of the body, when glanders will begin to manifest itself.

By way of treatment, good wholesome food is all important. Sulphate of copper in two-drachm doses, combined with one or two drachms of pulverized gentian root, will often prove successful; corrosive sublimate, also, in ten or fifteen grain doses, night and morning, has often been advantageously used; the doses may be increased to a scruple, or even half a drachm, if the animal bears the medicine well. If the animal is much debilitated, give calomel in half-drachm doses instead 
of the sublimate, or the sulphuret of mercury may be substituted. The use of arsenic has also been attended with good success, but the author has been more fortunate with the muriate of baryta in half-drachm doses, than with any other preparation in use. All the tumors should be opened, and caustic carefully applied to each; sulphate of copper, nitrate of silver, the per-manganate of potash, or the red-hot iron, are the best applications. The following ointment should be rubbed along the corded ressels once a day: blue ointment, two ounces; hydriodate of potash, two drachms; lard, two ounces; mix well. Or, the red oxide of mercury, two drachms to the ounce of lard is very good.

\section{SCARLET FEVER.}

This disease, otherwise called scarlatina, has too frequently been confounded with farcy, notwithstanding the two diseases present very different symptoms. It is easily managed, yielding readily to medical treatment.

For' several days previous to any very noticeable symptoms being manifest, the animal is off his feed, dull and mopy, with mouth hot and dry; slight or copious discharges from the nose, mixed with blood; the Schneiderian membrane highly colored, and presenting numerous scarlet blotches, irregular in form, and containing a thin, reddish fluid; these blotches sometimes present a pustular appearance, but upon passing the finger over them, nothing of that character can be discovered; the whole body is covered with similar spots, which sometimes require close examination to discover them; in other cases, little pustules are formed, which break, and dis. 
charge a thin sanious fluid of a reddish color and gluey nature; swellings of the legs, sheath, and belly, are usually attending symptoms; the respiration is quick; the pulse is full and accelerated, and there is a disinclination to move.

For treatment, the extract of belladonna alone appears to be a specific in this disease. It should be given in doses of from one half to two drachms, dissolved in a pail of water, and given to the animal to drink. No hay should be placed before him; soft mashes only should be allowed, until he is convalescent. This treatment, so simple yet so effective, has been pursued by the author's friend, Dr. Bowler, of Cincinuati, and himself, for the last ten years, with uniform success, not a single case having been lost. It is true that the disease is not of very common occurrence; yet during that period the author has had over thirty cases.

\section{MANGE.}

Diseases of the skin are less numerous in the horse than perhaps, most other animals; a circumstance doubtless arising from the great care taken of our better class of horses to keep the skin clean, thereby promoting its healthy action. Mange is identical with the itch in the human body, and is an infectious disease, the intolerable itching being caused by minute insects, called acari. They are first observed with the aid of a powerful microscope along the mane and the root of the tail, causing a scurfy appearance of the skin. This appearance rapidly extends to the neck and body; spots denuded of hair will appear, which gradually run into continuous scabby patches. As the disease advances, it thickens and puckers 
the skin, particularly of the neck, withers and loins. This dis. ease is easily cured if properly managed.

The natural history of these insects is not well known. They live only upon, or beneath, the skin of animals. There appears to be a distinct variety, peculiar to each species of animals. They live for a considerable time after being removed from the skin, but for how long a period is not pre-

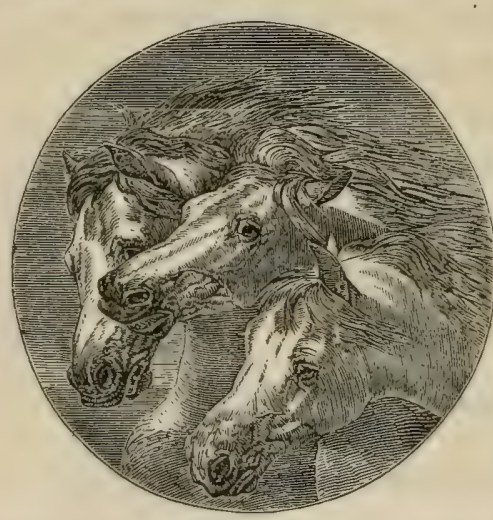

THE THREE FRIENDS. cisely known. According to experiments made it appears that they can live in pure water for three hours; in strong vinegar, alcohol, and in a solution of kali carbonicum, twenty minutes; in a solution of sulphuric acid, twelve minutes; in turpentine, nine minutes; and in a solution of arsenic, four minutes. When they are not exposed to such violent and destructive immersions, it has been said that they will retain life for six or eight days. From a comparison of the acari of mangy animals, it is supposed that the variety peculiar to the horse can live for a much longer period. Mangy horses have been removed from their stalls, washed with various preparations, put into another stable, and completely freed from the effects of the disease; but upon returning to their former stalls, or using unwashed their accustomed harness, the disease soon showed symptoms of its return. This fact accounts for the trouble experienced in curing this disease. The insect is 
rubbed off upon the sides of the stall, or clings to the liarness, again to come in contact with the animal.

For treatment, the animal should be stripped of all harness, well washed with acetic acid, and turned into a loose box stall away from that in which he has been standing. If this course is adopted, one or two washings will generally suffice. The harness also should be well washed, and not used for two or three months; nor should the horse be replaced in his former stall for a less period, and not eren then until it has been thoroughly cleaned and white washed. A wash of white hellebore and water has been much and beneficially used for this disease; and in inveterate cases corrosive sublimate in solution is recommended, though there is some danger of its absorption; if this should occur, the animal would quite likely be destroyed. A mixture of sulphur, oil, and turpentine is highly recommended; but the author has never witnessed the superior qualities of any of these preparations over the acetic acid.

\section{BURFEIT.}

This disease appears all over the body in the form of pustules, which seem scaly, and then appear to get entirely well, while fresh ones make their appearance, and follow in the same course. The hair is rough, staring, and unhealthy in appearance; the legs sometimes become much swollen, and there is general debility. This disease is supposed to arise from bad grooming, bad management, and unwholesome food, together with a general plethoric state of the system.

For treatment, bleed the animal if plethoric, taking from 
the neck vein from four to six quarts; in the absence of plethora, the lancet must not be used. Give a strong purging ball, followed by one of these powders twice a day: saltpetre, one and a half ounces; flower of sulphur, two ounces; black antimony, one ounce; mix and divide into eight powders.

\section{HIDE BOUND.}

This is a condition of the skin, caused by some morbid action in the system. Derangement of the digestive organs will induce it. The animal must be treated for the disease under' which it is laboring.

\section{STRAINS OF THE IOINS.}

Strains are of very frequent occurrence in the horse, in consequence, doubtless, of the great amount of labor demanded of him, which often taxes his powers to the utmost. These strains frequently give rise to serious trouble, rendering the animal unfit for work and often establishing an incurable lameness. Strains of the loins occur most frequently in draft horses, particularly in those used in the shafts of drays or carts. Such animals on going down hill heavily loaded are very apt to become injured; at times the injury is so great that the spinal marrow becomes affected, causing paralysis of the hind extremities, and rendering the animal comparatively useless ever after. When the injury is very severe, bleeding should be resorted to, if the animal can bear it. The following liniment will be found an excellent application for strains of all kinds : laudanum, gum camphor, spirits of turpentine, tincture of myrrh, castile soap, oil origanum, nitrous ether: ot each one ounce; 
alcohol, one quart; mix all together, and shake well before using; apply two or three times as occasion may require.

PALSY.

This is a loss of power in the nervous system. General palsy is never found in the horse, it being always partial or limited in extent, and described uncler two heads, paraplegia and hemiplegra. The first is a paralysis of the hind extrenrities, which is of very frequent occurrence; it sometimes occurs as a sym. pathetic affection, in which cases it disappears with the other symptoms of the disease. The second form is a palsy of one side of the body only, and is of very rare occurrence. When paralysis arises from strains whereby the spinal cord is injured, it causes the most acute suffering, and the animal usually dies in a few days. When the pressure upon the spinal cord is not great, the animal is sometimes rendered useful for ordinary purposes, but very rarely becomes sound.

For treatment, first open the bowels if they are the least costive, and give internally one of the following powders night and morning; nux vomica, one ounce; pulverized gentian root, two ounces; Jamaica ginger, one ounce ; mix, and divide into twelve powders. Apply warm sheep-skins to the loins, succeeded by the following application: linseed oil, one pint; spirits of hartshorn, four ounces; shake well before using. Perfect rest and moderate diet are necessary.

\section{LOCKED JAW.}

This distressing malady, otherwise known as tetanus or trismus, is one generally arising from neglected wounds, such as 
are occasioned by a horse's picking up a nail; in which case the wound, instead of being kept open by the owner, or his attendant, is suffered to close up, in consequence of which, if there is the slightest disposition to ulceration, matter is formed under the horn or hoof, which develops the most alarming symptoms, usually in abont two weeks after the wound has healed. When locked jaw is the result of wounds, it is called symptomatic, or traumatic; when existing without apparent cause, it is called idiopathic. The latter is said to be caused in some cases by the action of bots and of worms in the intestines.

The first symptoms observable are a stiff, straggling gait behind; rigidity of the muscles of the jaw, completely locking the jaws together; the tongue is sometimes swollen, and considerable saliva flows from the mouth. As the disease progresses, the muscles throughout the body become rigid; the animal turns as though there was not a joint in the body; the nose is poked out, the nostrils dilated, and respiration disturbed; the bowels are almost invariably constipated; on elevating the head, a spasmodic or flickering motion of the eye will be observed, exposing little more than the white parts. When the clisease is confined to the head and neck, it is called trismus; when extended to all parts of the body, it is termed tetanus.

There can scarcely be any principle laid down to govern the treatment of this disease, as cases have recovered under all kinds of treatment. The great object is to get the bowels opened; when this is accomplished, the cases usually have a favorable termination; but when the jaws are firmly set, the prospects are very limited. Give, if possible, by the mouth one ounce of aloes, ten drops of croton oil, two drachms of pulverized gentian root, and one drachm of ginger; make into one ball with molasses. 
If this cannot be given, keep a ball of aloes in the mouth, the action of which may be increased by adding to the ball two drachms of calomel, and omitting the croton oil. Give injections of belladonna, h alf an ounce dissolved in a pail of water. Opium has been much used, but is giving way to other preparations. Give upon

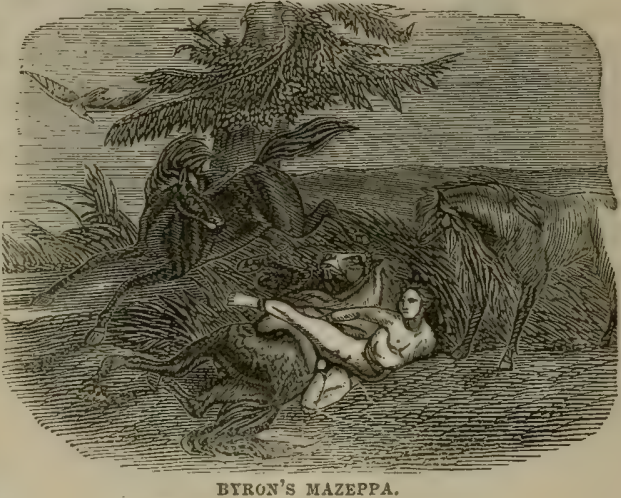

"They left me there to my despair, Link' $d$ to the dead and stiffening wretch." the tongue every hour twenty drops of the following mixture: bydrocyanic acid and tincture of aconite, of each one ounce; mix, and shake, well together. Blistering the back, from the head to the tail, has succeeded in some cases. Chloroform has been highly recommended, but appears to have only a temporary effect; it is given in doses of from one to two drachms.

\section{RHEUMATISM.}

This disease is quite common in the Western States. The symptoms are stiffness, lameness, and shifting from one limb to another; sometimes tumefaction is observable about the extremities. The lameness is sometimes absent, and appears to be influenced by changes in the weather.

For treatment, poultice the feet with mustard and flaxseed meal. Give internally of nux romica, one ounce; pulverized gentian root, one and a balf ounces; pulverized ginger, one 
ounce; mix, and divide into twelve powders; give one every night in the feed.

The most successful treatment which the author has found, when the above has failed to effect a perfect cure, is that recommended by Dr. Bowler, of Cincinnati, whose experience in baffling this disease has been quite considerable. It is as follows:-if the animal is plethoric, bleed freely and give a strong cathartic; follow every morning with one of the following balls : pine tar, two ounces; pulverized gentian root, one ounce; mix all together, and divide into eight balls. Keep the body warm, and give no corn.

\section{CRAMP.}

This complaint occasions considerable alarm to the owner of a horse, from the peculiarity of the symptoms. A horse is found to go suddenly lame, lameness continuing, dragging one leg after him as though it were dislocated or broken. Upon taking a whip and striking him, he will sometimes go two or three steps in a natural way, and then the leg drags again. Such instances have been pronounced fractures by the farrier, and even by the young veterinarian such a mistake has been made; indeed, there are instances of the horse's having been killed by order of the medical attendant.

Treatment. Friction by hand-rubbing, and application of the liniment recommended for strains. Usually the animal will be found all right upon the following day.

\section{HYDROCELE.}

This disense commonly known as dropsy of the testicles, scmetimes affects the stallion. It consists of a collection of 
serum in the tunica vaginalis, or bag containing the testes, fluctuating when pressed by the hand, but free from tenderness or pain. Its causes are obscure, but it is supposed to result from injuries, such as strains, etc.

For treatment, the scrotum should be punctured, and a weak solution of tincture of iodine injected into the tunica vaginalis; or equal parts of port wine, and water of zinc lotion, or lime water, may be used with very good effect. The animal should be well secured before these preparations, particularly the first, are used, as the pain thereby caused may render him for the time unmanageable.

\section{WARTS.}

These fungous growths appear in the horse most frequently aiout the mouth, nose, and lips; but they are occasionally found upon other parts of the body. They are sometimes found in large numbers about the lips of colts, and are generally rubbed off, or drop off; if, however, they grow large and become deeply rooted, they may be cut off by passing a needle through the centre armed with double thread, and tied tightly around the neck on each side. This prevents the possibility of the ligatures being rubbed off. Or, they may be painted over with the per-manganate of potash, a few applications of which will cntirely destroy warts of a large size; or they may be removed with a knife.

\section{SIT-FASTS.}

These are dark, hard, scabby spots upon the back, which are dead skin and cannot be easily remored; but by poulticing for cereral days they become soft and may be torn off. Tincture 
of myrrh applied two or three times a day will generally effect a cure after the dead skin is removed.

WARBIES.

Whese arise from bruises, which cause superficial swellings that sometimes suppurate. They should be freely opened and the matter well washed out. A solution of sulphate of zinc, or alum-water, is all that is required to effect a cure.

\section{SADDLE OR HARNESS GALLS.}

These are bruises caused by friction and moisture, occurring most frequently in warm weather; the parts are rubbed raw, and sometimes bleed. The treatment is simple and effectual. Bathe the parts several times a day with one pint of water and half a pint of tincture of myrrh.

\section{MALLANDERS AND SELLENDERS.}

These are scurfy eruptions of the back part of the knee joint and the front part of the hock joint. They sometimes occasion much pain, and lameness in consequence. They constitute but one disease, the names having reference to the fore and hind extremities; mallenders being applied to eruptions upon the fore extremities, and sellenders to those upon the hind ones.

For treatment, wash the parts well with castile soap and water, and apply the following : lard, four ounces, and Goulard's extract, one ounce, well mixed. 


\section{ULCERATION OF THE UDDER.}

Mares are sometimes subject to this disease, which is caused by the milk's coagulating in the bag, and causing inflammation and suppuration. The udder becomes swollen, hot, tender, hard, and knotty. A flaxseed poultice should at once be applied, when the abscess will soon be brought to a head, which will be known by its smooth, polished appearance and its soft feeling. It should then be lanced, and the udder bathed twice a day with lard melted as hot as the animal can bear. Sometimes it becomes necessary to inject a solntion of the sulphate of zinc into the opening; but in ordinary cases the hot lard is sufficient, if properly applied.

\section{INFLAMED VEINS,}

The jugular or neck vein sometimes becomes inflamed in consequence of being injured by a bungling bleeder. A swelling is first noticed, followed by a gaping in the incision in the neck, from which an acrid fluid oozes.

For treatment, bathe the part well with cold water, into which a small portion of tincture of myrrh is thrown, and with wp purging ball a cure is soon effected.

\section{SURGICAL CASES.}

It frequently becomes necessary, in order to relieve the animal from some painful disease, to resort to operations in surgery; this, in fact, has of late years become an important 
branch of veterinary practice. When it becomes nernssary to use the knife, the animal should be spared all useless torture. In severe operations, humanity dictates the use of some anæsthetic agent to render the animal insensible to pain. Chloroform is the most powerful of this class, and may be administered with perfect safety, provided a moderate quantity of atmospheric air is inhaled with or during its administration. Sulphuric ether acts very feebly upon the horse, and cannot therefore be successfully used. Chloric ether answers a very good purpose, but pure chloroform is preferable. In minor operations, the twitch, the side-hobble, or the foot-strap, is all. that is necessary. When a horse is to be cast for an operation, force must be used for its accomplishment. The patent hobbles have been preferred for that purpose by veterinary surgeons generally, though the author prefers a modification of the cast-rope and the patent hobbles. This improvement consists in having a heavy, well-padded leathern collar, each layer burned in with rosin, after the style of the old-fashioned firebuckets; at the bottom of this collar a strong ring is attacher, secured by an iron band; through this ring the rope is passed; around the body a strong leathern band is buckled, which connects with the top of the collar by a cross strap, which keeps it in place; a hobble band is placed upon each hind fetlock, through the $\mathrm{D}$ of which the rope is passed; on each sicle of the collar a strong ring is firmly secured, through which the rope also passes, the ends of which are then pulled upon by one or two men on each side, and the animal let quietly down. The author is convinced by experience that.this arrangement is far preferable to any hobble arrangement yet seen. It is a mistaken idea that horses must be cast for every bittle operation; in truth, but few operations require it. 


\section{BIEEDING.}

Blood-letting in former times was regarded as the sheet anchor in veterinary practice; but that day has past. The practice of bleeding horses upon all occasions cannot be too strongly condemned; the cases where blood-letting proves beneficial being comparatively few. Before using the lancet the pulse must be examined, the condition of the animal considered, and the effects upon that pulse must decide the quantity of blood to be taken. The pulse will be found following the front margin of the masseter muscle, which muscle forms the fleshy parts of the head upon each side, called the cheeks. By following the front part of this muscle downward with the thumb, until near the base of the lower jaw, and then passing the forefingers under, or inside of the jaw, the pulse will be readily felt; or, to point its LADY SUFFOLK.

location out with more certainty, if an imaginary line is drawn perpendicularly from the front part of the ear downward, it will cross the point where the pulse is located and felt.

In a healthy condition the pulse beats from thirty-six to forty times a minute; variation above or below this standard indicates a morbid condition of the system. This fact should be born in mind in the description of any disease. When bleeding is necessary, the neck never should be corded, as much injury has at times been caused by this practice. All that is requisite is to raise the jugular vein by pressing upon 
it with the fingers of the left hand, using the lance with the right. The old-fashioned mode of bleeding with the fleam and blood-stick is a bungling operation, frequently requiring several trials before bringing blood, the result of which is an inflamed rein. A more convenient, a more certain, and a moro satisfactory method is by using a spring lance, made for the purpose, which never fails in bringing blood upon the first trial. It is so contrived as to straddle the vein of the neck, which leeps it firm, and prevents its rolling, so that it is im. possible to miss bringing the blood when it is once placed upon the vein and sprung. By this method of bleeding, the covering of the eye and the cording of the neck are unnecessary, and the operation can easily be accomplished by one person. After the vein has been opened, the blood-pail pressed against the vein will cause the blood to flow freely. When the desired quantity has been drawn, the vein must be carefully closed by passing a pin through the centre of the opening, taking up the skin upon both sides, and tying with hair from the mane or tail. The pin may be removed in about twenty-four hours.

\section{NEUROTOMY OR NERVING.}

This is one of the most important operations in reterinary practice, and one that has been much abused, not only in Europe, but even more so in the United States. Its useful. ness was first demonstrated by Assistant Professor Sewell, of the Veterinary College of London. The operation consists in cutting out a portion of the metacarpal nerves on each side of the legs, thus destroying the sensibility of the foot. From the instantaneous relief experienced by the animal in all cases 
of foot lameness, no matter from what cause, an opportunity has been afforded to dishonest persons for imposing upon the public by availing themselves of this practice; an opportunity, it need not be said, which has been freely used, and thus a valuable operation has been brought into undeserved disrepute. The cases likely to be benefited by this operation are fow, and should be selected with great care; otherwise the loss of the animal's hoof may be, and often is, the termination of the case.

This operation is recommended by veterinary authors in incurable cases of lameness of the navicular joint; but suffcient caution is not impressed upon the mind of the reader, to enable him to guard against the fatal results which too often follow.

In deciding upon a case for this operation, an animal should be selected with a foot as free from contraction as possible; free from corns; comparatively free from inflammation; with a concave ground surface; open heels; hoof free from rings or roughness; and no bony deposits within the hoof. In such a case, the operation may be performed with success. A horse that has been foundered should not, under any circumstances, be operated upon, as ossification of the laminæ frequently follows such an attack; nor a horse affected with ossification of the lateral cartilages, corns, or badly contracted hoof; for these are the cases where loss of the hoof is likely to follow, rendering the animal useless.

After the operation has been performed, care should be taken in driving the animal ; for it should be remembered that no matter what accident may happen to the foot, the animal is unconscious of pain. The feet should be frequently exam- 
ined to see whether the horse has picked up a nail, or other wise injured the foot; for such injuries would otherwise remain undiscovered until too late to save the animal's life or usefulness. The smith should be informed of the operation, in order to guard against pricking the animal's foot in shoeing.

It is necessary previous to the operation that the feet should be perfectly cool, which condition may be obtained by frequent bathings with cold water for several days previous. The horse is cast, the foot to be operated upon loosened, and brought forward by an assistant, it resting upon a bed of straw. A vertical incision is made about two inches above the fetlock, between the cannon bone and back sinew, raising up with the forceps the cellular membrane, and carefully dissecting out the nerve. The precaution should be taken of placing the finger upon it, as the artery has been taken up and cut off before the mistake was discovered. Having fairly exposed the nerve, pass a curved needle armed with strong thread under it, and by carefully drawing it up and down the nerve may be readily separated. A sheathed knife is then passed under the nerve, and by a quick motion the nerve is severed at the upper part. After the struggles of the animal cease, the cut nerve may be raised with the forceps, and from one-half of an inch to an inch removed. This second cut causes no pain. The wound is then closed by three single stitches. After operating upon both sides in like manner, the animal is allowed to rise. Bandages should then be placed upon the leg, and kept saturated for several days with cold water. 


\section{IITHОTOMY.}

Operations for stone in the bladder of the horse have been practised since 1774 , and in many cases very successfully. In performing this operation, an ordinary scalpel, a probe-pointed bistoury, a fluted whalebone staff, and a pair of curved forceps are necessary. The animal should be placed upon his back with the hind legs drawn well forward; a whalebone staff is passed up the urethra, which may be felt a little below the anus; an incision, one and a balf or two inches in length is made directly upon it, obliquely to one side, cutting through the urethra and the neck of the bladder; the forceps are next introduced, and the stone removed; after which the parts are carefully closed by means of the quill suture, which in this operation is far superior to the interrupted one, as it more effectually prevents the dribbling of urine through the wound, which always occurs with the interrupted one, and therefore causes a more speedy union of the parts.

\section{TREPHINING.}

This operation consists in cutting out circular pieces of bone with a circular saw, called a trephine, and is most generally performed in cases of fracture of the skull, or face. The bone removed must be from the sound part contiguous to the fracture, so as to enable an elevator to be passed inside of the cranial case, for the purpose of pushing back the broken bone to its proper place, and remoring all detached pieces. This operation is also performed in cases of ozena, by removing a piece of bone over the frontal sinuses, situated immediately between the eyes, in order to expose the diseased parts at once, that they may bo. washed with proper injections. 


\section{TENOTOMY.}

This operation is practised for the purpose of strengthening crooked legs or sprung knees. It consists in dividing the flexor tendons, in order to bring the limb straight. There are but few cases, however, in which the operation would be of much service, and therefore care must be exercised in selecting such cases as are proper. It would hardly be proper in a young horse, as other means less objectionable often succeed. In old horses it would not be prudent, as their limbs are generally stiff and permanently set; nor would it be successful in cases where anchylosis or stiff joint existed, as is often found in connection with crooked legs and sprung knees.

\section{COUCHING.}

This is an operation upon the eye for the purpose of remoring a cataract from the axis of vision. A couching needle is passed through the sclerotic coat of the eye a little behind the cornea, passing it upward behind the iris to where the cataract is located, pressing it downward into the vitreous humor behind the iris, where it remains. This operation has not been very successful in the horse, by reason of the imperfect restoration of the sight thereby afforded, which causes them in almost every instance to shy at every object which they encounter, thus rendering them dangerous upon the road.

\section{TAPPING THE CEEST.}

This operation consists in passing a round, pointed instrument, sheathed with a canula, into the chest, in order to draw 
off any accumulation of fluid that may have taken place in the viscus. The instrument is passed, after first making a small incision through the skin, between the eighth and ninth ribs, but not too low down. It is pushed gently forward until it penetrates the pleura, or lining membrane of the chest. The stellet is then withdrawn, and the canula is kept in place until the fluid ceases to run. If, however, a large quantity exists, all of it should not be taken away at one time; for the pressure upon the lungs having been so great, if such sudden relief is afforded, nature, unable to accommodate herself to so rapid an alteration gives way, and the animal consequently dies. It should therefore be taken away at one, two, or three tappings, as occasion may require. Good wholesome food should be allowed.

\section{PERIOSTEOTOMY.}

This operation is most generally performed for painful splints. It consists in cutting though the periosteum, or membrane covering the surface of all bones, over the splint or node, which immediately gives relief. This operation requires the aid of an experienced man.

\section{AMPUTATION OF THE PENIS.}

This operation is occasionally called for in the horse, particularly in cases of paraphymosis, or protrusion of the penis, that have resisted all other modes of treatment. The operation, as performed in England, is unnecessarily tedious, and not as successful as it should be. It is only requisite in performing this operation to place a twitch upon the animal, and while he is standing to take the penis in the left hand, and with an ampu- 
tating knife in the right to sever it at one strokc. The hemorrhage, although considerable, need not occasion any alarm. A piece of cotton or soft sponge, saturated with spirits of tur pentine or any other styptic, and placed in the sheath, will soon cause the hemorrhage to cease. Fear of hemorrhage, may deter some persons from performing what may appear a bold operation; but the author has not known a single operation performed in this way to have a fatal termination; whereas witb the English mode of operating it frequently does so, beside, even if it is successful, rendering the animal useless for a much greater period of time.

\section{CESOPHAGOTOMY.}

This operation is occasionally resorted to where any foreign substance, as an apple, potato, carrot, and the like, has lodged in the œsophagus, or gullet. Where such obstructions exist, gentle manipulations with the hand should first be resorted to; if these are not successful in removing them, the probang is called for, and in case of failure thus to dislodge them, this operation is the only remaining resort. It is not necessary to cast the animal. Cut down directly upon the swollen part of the throat, and remove the obstruction. The wound may then be closed by means of the interrupted suture; that is, by single stitches, at proper distances apart, allowing the ends to hang out of the external wound, which may be closed in the same manner. The animal should be kept on gruel for several days. If the gruel is seen to ooze out of the wound when he is swallowing, it should be carefully washed away with cold water. The parts should be syringed with a weak solution of sulphate of zinc, chloride of zinc, or tincture of myrrh. 


\section{HERNIA.}

By the term hernia surgeons understand a rupture, or protrasion of some of the viscera out of the abdomen, forming a soft tumor. In human practice there are hernias occurring in all the viscera of the body; but in the equine race they are confined, with rare exceptions, to the abdominal viscera, the inguinal hernia being the most common. This appear's in the groin, and is a protrusion of the intestine through the abdominal ring; which in the stallion frequently passes down into the scrotum, or bag, constituting scrotal hernia. These hernias sometimes occur during castration in consequence of the violent struggles of the animal. In such cases it is best to administer chloroform at once in order to quiet the animal and prevent violent strugglings. The animal should be put upon his back, and one hand passed up the rectum, and one or two fingers of the other placed upon the scrotum, when by careful manipulations the intestine can generally be replaced. If, however, a reduction cannot be effected, an operation will be n ecessary. The hernia should be exposed by cutting through the integument a little upon one side, and coming down upon the hernia, the finger is placed upon it,

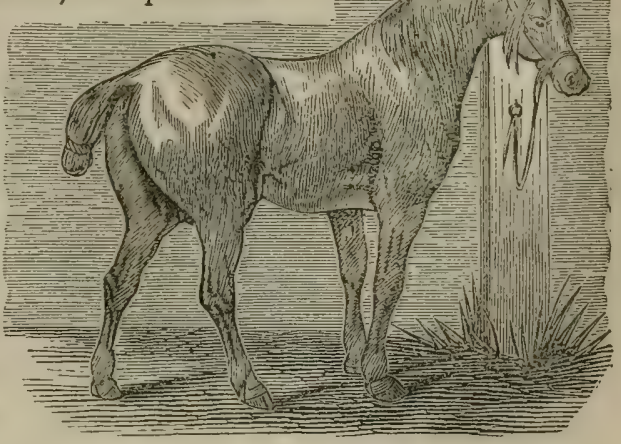

GOOD FOR HEAVT DRAFTS.

and a reduction effected by careful manipulation. Care should be taken that the nails upon the hand are trimmed close, in 
order to prevent wounding the intestine. The wound should then be closed by means of the interrupted suture. A folded cloth should then be applied to the part, and retained by means of a continuous bandage crossed between the legs from side to side in the form of the figure 8 . Sometimes the intestine becomes strangulated, constituting strangulated hernia, the reduction of which requires an operation as before mentioned. If, however, it is found impossible, then to reduce it, the finger should be passed through the opening, if possible, and a probe-pointed bistoury following upon it, enlarge the opening and replace the intestine. The same treatment as before indicated will be necessary.

The symptoms of strangulated hernia are very similar to those of acute enteritis, or inflammation of the bowels. These may be regarded as the only heruias to which the horse is liable.

\section{ROWELING.}

Rowels were formerly much used, but of late years the seton has superseded them. The rowel consists of a round piece of sole leather, cut out in the centre wound round with tow, which is saturated before using with digestive ointment. The skin is cut through, and dissected upon each side sufficiently to admit the rowel. This is used principally under the jaws and in the breast. The seton answers the same purpose, and is much more convenient. It consists in arming a needle made for the purpose with tape and passing it through the part desired, the seton being saturated with the same ointment as the rowel. 
FIRING.

\section{FIRING.}

The object in firing a horse is to produce an external inflammation where counter-action is required, as in spavin, ringbone, curbs, etc. The operation may be performed upon the animal while standing, by placing a twitch and side line upon him; but if the surface to be fired is extensive, and the animal high strung, it is better to cast him, particularly where a number of oblique, vertical, or horizontal lines are to be drawn. Firing is not practised at the present day to the extent that it formerly was, and when it is practised every endeavor should be made to prevent, as far as possible, the blemishes which always follow the operation. Various forms of irons have been adopted to accomplish this end. The author gives the preference to the feathered iron, which is brought down to a very fine edge, and, opinions are entertained by veterinary surgeons as to the advantages resulting from deep firing as compared with those accruing from surface firing. In the author's judgment, if firing is resorted to at all, it should be done effectually. His attention has recently been called to a firing iron devised by A. Maillard, Esq., of Bordentown, New Jersey, which is the best adapted instrument that has ever passed under his notice. It consists of two pices of iron, octagonal in form, about one and a half inches long by one and a quarter wide, one piece containing five round-pointed projections, placed one at each corner and one at the centre, and the other four points, so arranged as, when fitted together, to fill up the intermediate spaces of its opposite; both irons being used alternately on the same parts without extending the surface fired. This iron will probably supersede any iron in use, and thanks are due to the inventor for his in- 
genuity in producing it. Pointed instruments have been beforo used, but far inferior in their arrangement.

\section{TRÁCHEOTONY.}

This operation is occasionally called for in cases of strangles, when the swelling threatens suffocation, as it is often the only means of saving the animal's life. It consists in making a longitudinal incision through the skin immediately over the windpipe and below the larynx, cutting through the cartilaginous rings (two or more, as occasion requires), and inserting in the opening a tube of silver made for the purpose, through which the animal breathes, instead of through the nostrils. A circular piece is sometimes cut out of the windpipe in order to admit the tube more freely, which is certainly the better mode of performing the operation. In a case of emergency, a piece of elder with the pith pushed out will answer temporary purposes. It should be well secured from slipping into the windpipe by means of a piece of string. 


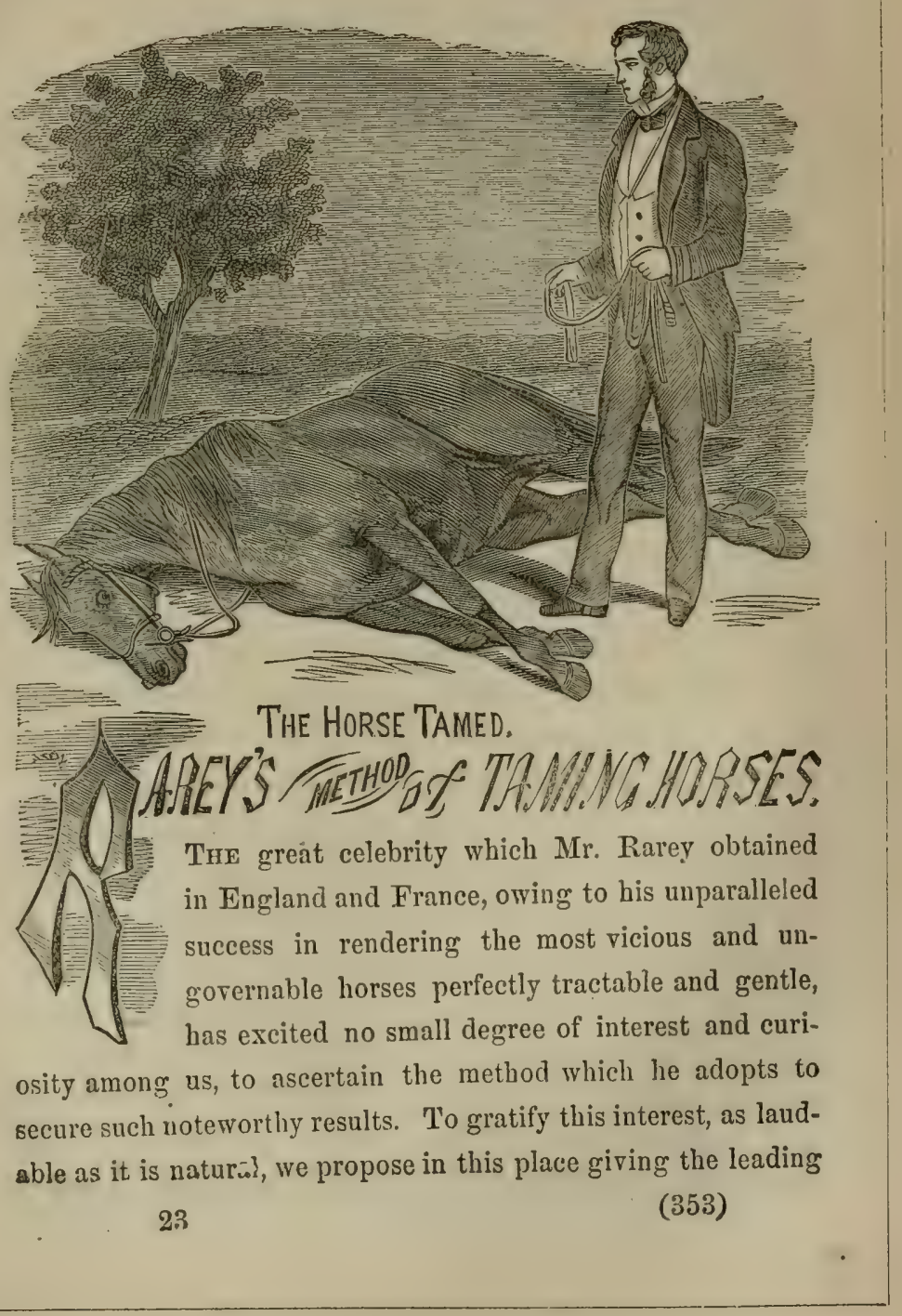


features of his method, as gleaned from the various Englisk publications bearing upon the subject, especially from the little work, entitled "The Art of Taming Horses. By J. S. Rarey," and edited by the Hunting Correspondent of "The Illustrated London News."

It is needless to premise, that not every man can become a Rarey, by the perusal of this, or of any other treatise upon the art of breaking horses; yet it is not claiming too much for this system to say, that by its use the large majority of horses may be broken more expeditiously, more effectually, and with far more satisfaction and pleasure to the breaker than by the adoption of any other now known. It is no slight gain, to be able to transfer the breaking of horses from ignorant, impatient, and disagrecable persons to those who can in every respect appreciate the noble qualities of the animal and who will therefore deal with him as his high rank in the scale of creation demands.

The three fundamental principles of the Rarey theory are: first, that the horse is so constituted by nature that he will not offer resistance to any demand made of him which he fully comprehends, if such demand is made in a way consistent with the laws of his nature; second, that he has no consciousness of his strength beyond his experience, and can be handled according to our will without force; and third, that we can, in compliance with the laws of his nature, by which he examines all things new to him, take any object however frightful around, over, or on him, that does not inflict pain, without causing him to fear.

As to the first proposition:- the horse, although possessed of some faculties superior to man's yet being deficient in reasoning powers, has no knowledge of right or wrong, of free will and independeut government, and is not aware of any imposition 
practised upon him, however unreasonable it may be. II cannot, consequently, decide as to what he should, or should not do, not having the requisite faculties to enable him to argue the justice of the thing demanded of him. Had he such faculties, taking into consideration his superior strength, he would be useless to man as a servant. If he had mind in proportion to his strength, he would roam through the fields at large, yielding service to no one. His nature has been wisely formed to be operated upon by the knowledge of man according to the dictates of his will, and he may properly be termed an unconscious submissive servant. This truth is verified in every day's experience by the abuse to which he is subjected. Any one who chooses to be so cruel can mount the noble steed, and run him till he drops with fatigue, or, as is often the case with the more spirited, falls dead beneath his rider. If he had the power to reason, would he not rear and pitch his rider, rather than suffer him to run him to death? Happily for us, he has no thought of disobedience, except by impulse caused by the violation of the law of his nature. If then, he is disobedient, it is the fault of man.

As to the second: the fact that the horse is unconscious of the amount of his strength, can be proven to the satisfaction of any one. Were it otherwise, the light rehicle in which he is placed, the slender reins and harness which guide and confine bim, would be snapped asunder in an instant, at his own volition; no hitching-post could restrain him against his will, no saddle girth be placed around his body. These facts, made common by every-day occurrence, are not regarded as anything wonderful. Their continued existence serves to remore us from all consideration of them. 
As to the third: there being, as we know from a natural course of reasoning, some cause for every impulse or movement of either mind or action, and this law governing every action or movement of the animal kingdom, there must be some cause bcfore fear can exist; and if fear exists from the effects of imagination, and not from the infliction of real pain, it can be remored by complying with those laws of nature, by which the horse examines an object, and determines upon its innocence or harm.

A log or stump by the roadside, for example, may be, in the imagination of the horse, some great beast about to pounce upon him; but after he is taken up to it, and allowed to stand by it for a little time, and to touch it with his nose, and to go through his process of examination, he will not care anything more about it. The same principle and process will liare the same effect with any other object, however frightful in appearance, in which there is no harm.

These principles being taken as the basis, whaterer obstacles oppose the proper breaking of horses are readily surmounted by the Rarey method, commencing with the first steps to be taken with the colt, and thence proceeding through the whole task of breaking.

IIow to Call a Colt from Pasture.-Go to the pasture and walk around the whole herd quietly, and at such a distance as not to cause them to scare and run. Then approach them very slowly, and if they stick up their heads and seem to be frightened, stand still until they become quiet, so as not to make them run before you are close enough to drive them in the direction you want them to go. And when you begin to drive, do not flourish your arms or halloo, but gently fol- 
low them, leaving the direction open that you wish them to take. Thus taking advantage of their ignorance, you will be able to get them into the pound as easily as the hunter drives the quails into his net. For, if they have always run in the pasture uncared for (as many horses do in prairie countries , and on large plantations), there is no reason why they should not be as wild as the sportman's birds, and require the same gentle treatment, if you want to get them without trouble; for the horse, in his natural state is as wild as a stag, or any of the undomesticated animals, though more easily tamed.

How to Stable a Colt without trouble. - The next step will be, to get the horse into a stable or shed. This should be done as quielly as possible, so as not to excite any suspicion in the horse of any danger befalling him. The best way to do this is to lead a broken horse into the stable first, and hitch him, then quietly walk around the colt and let him go in of his own accord. This should be undertaken slowly and considerately, as one wrong move may frighten your horse, and make him think it necessary to escape at all hazards for the safety of his life-and thus make two hours' work of a ten minutes' job; and this would be all your own fault, and entirely unnecessary-for he will not run unless you run after him, and that would not be good policy unless you knew that you could outrun him, for you will have to let him stop of his own accord after all. But he will not try to break away unless you attempt to force him into measures. If he does not see the way at once, and is a little fretful about going in, do not undertake to drive him, but give him a little less room outside, by gently closing in around him. Do not raise your arms, but let them hang at your side, for you might as well raise a club: the horse has never studied anatomy, 
and does not know but that they will unhinge themselves and fly at him. If he attempts to turn back, walk before him, but do not run; if he gets past you, encircle him again in the same quiet manner, and he will soon find that you are not going to hurt him; and then you can walk so close around him that he will go into the stable for more room, and to get further from you. As soon as he is in, remore the quiet horse and shut the door. This will be his first notion of confinement-not knowing how he got into such a place, nor how to get out of it. That he may take it as quietly as possible, see that the shed is entirely free from dogs, chickens, or anything that would annoy him. Then give him a few ears of corn, and let him remain alone fifteen or twenty minutes, until he has examined his apartment, and become reconciled to his

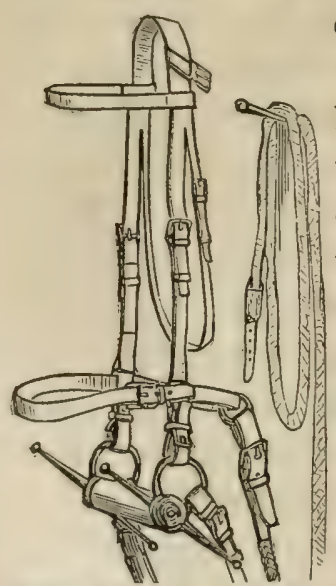

BRIDLE WITI A WOODEN GATBIT FOR CONQUERING VICIOUS HORSES. confinement.

While he is eating, see that your halter is ready and all right, and determine for yourself the best mode of operation. Always use a leather halter, and be sure to have it made so that it will not draw tight around his nose if he pulls on it. It should be of the right size to fit his head easily and nicely, so that the nose-band will not be too tight or too loose. Never put a rope balter on an unbroken colt, under any circumstances whatever. Rope halters have caused more horses to hurt or kill themselves than would pay for twice the cost of all the leather halters that have ever been used for the 
purpose of breaking colts. It is almost impossible to break a colt that is very wild with a rope halter, without having him pull, rear, and throw himself, and thus endanger his life; and this, because it is just as natural for a horse to try to get his head out of anything that hurts it, or feels unpleasant, as it would be for you to try to get your hand out of a fire. The cords of the rope are hard and cutting; this makes him raise his head and draw on it, and as soon as he pulls, the slip noose (the way rope halters are always made) tightens, and pinches his nose, and then he will struggle for life, until, perchance, he throws himself. But this is not the worst. A horse that has once pulled on his halter can never be as well broken as one that has never pulled at all.

Before anything more is attempted with the colt, some of the characteristics of his nature must be noticed, that his motions may be better understood. Every one that has ever paid any attention to the horse, has noticed his natural in. clination to smell ererything which to him looks new and frightful. This is their strange mode of examining everything. And when they are frightened at anything, though they look at it sharply, they scem to have no confidence in their eyesight alone, but must touch it with their nose before they are entirely satisfied; and, as soon as they have done that, all seems right.

If you want to satisfy yourself of this characteristic of the horse, and to learn something of importance concerning the peculiarities of his nature, etc., turn him into the barn yard, or a large stable will do, and then gather up something that you know will frighten him-a red blanket, buffalo robe, or something of that kind. Hold it up so that he can see it, he 
will stick up his head and snort. Then throw it down fomewhere in the centre of the lot or barn, and walk off to. one side. Watch his motions, and study his nature. If he is frightened at the object, he will not rest until he has touched

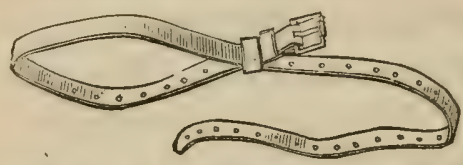

it with his nose. He will begin to walk around the robe and snort, all the time STRAP FOR THE RIGHT Fore LEG. (See pages getting a little closer, until 366-370.)

he finally gets within reach of it. He will then very cautiously stretch out his neck as far as he can reach, merely touching it with his nose, as though he thought it was ready to fly at him. But after he has repeated these touches for a few times, for the first time (though he has been looking at it all the while) he seems to have an idea of what it is. When he has found, by the sense of feeling, that it is nothing that will do him any harm, he is ready to play with it. If you watch him closely, you will see him take hold of it with his teeth, and raise it up, and pull at it; and in a few minutes you can see that he has not that same wild look about his eye, but that he stands like a horse biting at some familiar stump.

Yet the horse is never so well satisfied wnen he is about anything that has frightened him, as when he is standing with his nose to it; and in nine cases out of ten, you will see some of that same wild look about him again, as he turns to walk from it. You will, probably, see him looking back very suspiciously as he walks away, as though he thought it might come after him yet.* In all probability he will have to go back and make another examination before he is satisfied; but he will familiarize himself with it, and if he should run in that field for a few 
days, the robe that frightened him so much at first will be no more to him than a familiar stump.

It might very naturally be supposed from the fact of the horse's applying his nose to everything new to him, that he always does so for the purpose of smelling these objects; but it is as much or more for the purpose of feeling, and he makes use of his nose, or muzzle (as it is sometimes called), as we would of our hands; because it is the only organ by which he can touch or feel anything with much susceptibility.

He invariably makes use of the four senses-SEEING, HEARING, SIIELLING, and FEELING-in all of his examinations, of which the sense of feeling is, perhaps, the most important. In the experiment with the robe, his gradual approach and final touch with his nose was as much for the purpose of feeling as anything else, his sense of smell being so keen that it would not be necessary for him to touch his nose against anything in order to get the proper scent; for it is said that a horse can smell a man at a distance of a mile. Besides, if the scent of the robe was all that was necessary, he could get that several rods off; whereas, we know from experience, that if a horse sees and smells a robe a short distance from him, he is very much frightened (unless he is used to it) until he touches or feels it with his nose; which is a positive proof that feeling is the controlling sense in this case.

It is a prevalent opinion among horsemen generally that the sense of smell is the governing sense of the horse; and with that view many receipts of strong-smelling oils, etc., have been concocted in order to tame him. All of these as far as the scent goes, have no effect whatever in taming him, or conveying any idea to his mind; thongh the acts that accom- 
pany these efforts-handling him, touching him about the nose and head, and patting him, as you are directed to do, after administering the articles, may have a very great effect, which is mistaken for the effect of the ingredients used.

Approaching a Colt.-In order to take horses as we find them, of all kinds, and to train them to our liking, we should always take with us, when we go into a stable to train

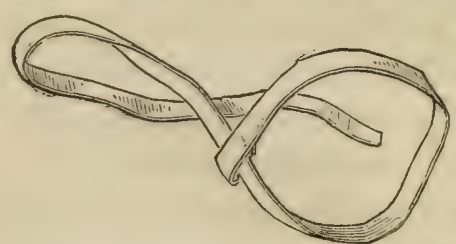

a colt, a long switch whip (whalebone buggy whips are the best) with a good silk cracker, so as to cut keenly and make a sharp report. strap for the off fore Leg. (See p. 370.) This, if handled with dexterity, and rightly applied, accompanied with a sharp, fierce word, will be sufficient to enliven the spirits of any horse. With this whip in your right hand, with the lash pointing backward, enter the stable alone. It is a great disadrantage in training a horse to have any one in the stable with you; you should be entirely alone, so as to have nothing but yourself to attract his attention. If he is wild, you will soon see him on the opposite side of the stable from you; and now is the time to use a little judgment.

Accordingly, when you have entered the stable, stand still, and let your horse look at you a minute or two, and as soon as he is settled in one place, approach him slowly, with both arms stationary, your right hanging by your side, holding the whip as directed, and the left bent at the elbow, with your hand projecting. As you approach him, go not too much toward his head or croup, so as not to make him move either forward or backward, thus leeping your horse stationary; if 
he does move a little either forward or backward, step a little to the right or left very cautiously; this will keep him in one place. As you get very near him, draw a little to his shoulder, and stop a few seconds. If you are in his reach he will turn his head and smell your hand, not that he has any preference for your hand, but because that is projecting, and is the nearest portion of your body to the horse. This all colts will do, and they will smell your naked hand just as quickly as they will of anything that you can put in it.

As soon as he touches your hand with his nose, caress him as before directed, always using a very light, soft hand, merely touching the horse, always rubbing the way the hair lies, so that your hand will pass along as smoothly as possible. As you stand by his side, you may find it more convenient to rub his neck or the side of his head, which will answer the same purpose as rubbing his forehead. Favor every inclination of the horse to smell or touch you with his nose. Always follow each touch or communication of this kind with the most tender and affectionate caresses, accompanied with a kind look, and pleasant word of some sort, such as, "Ho! my little boy-ho! my little boy !" "Pretty boy !" "Nice lady !" or something of that kind, constantly repeating the same words, with the same kind, steady tone of roice; for the horse soon learns to read the expression of the face and voice, and will know as well when fear, love, or anger prevails, as you know your own feelings; two of which, fear and anger, a good borseman should never feel.

If your horse, instead of being wild, seems to be of a stubborn or mulish disposition; if he lays back his ears as you approach him, or turns his heels to kick you, he has not that regard 
or fear of man that he should have, to enable jou to handle nim quickly and easily; and it might be well to give him a few sharp cuts with the whip, about the legs, pretty close to the body. It will crack keenly as it plies around his legs, and the crack of the whip will affect him as much as the stroke; besides, one sharp cut about his legs will affect him more than two or thrce over his back, the skin on the inner part of his legs or about his flank being thinner, more tender, than on his back. Do not whip him much-just enough to frighten him; it is not because we want to hurt the horse that we whip him-we only do it to frighten vice and stubbornness out of him. Whatever you do, do quickly, sharply, and with a good deal of fire, but always without anger. If you are going to frighten him at all, you must do it at once. Never go into a pitched battle with your horse, and whip him until he is mad and will fight you ; it would be better not to touch him at all, for you will establish, instead of fear and respect, feelings of resentment, hatred, and ill-will. If you can succeed in frightening him, you can whip him without making him mad; for fear and anger never exist together in the horse, and as soon as one is visible, the other disappears. After you have frightened him, so that he will stand up straight and pay some attention to you, approach him again, and caress him a good deal more than you whipped him; then you will excite the two controlling passions of his nature, love and fear, and as soon as be learns what you require, he will obey quickly.

How to Halter and Lead a Colt.-As soon as you hare tamed the colt a little, take the halter in your leit hand, and approach him as before, and on the same side that you have tamed him. If he is very timid about your approaching closely to hin, you can get up to him quicker by making the whip a 
part of your arm, and reaching out very gently with the butt end of it, rubbing him lightly on the neck, all the time getting a little closer, shortening the whip by taking it up in your hand, until you finally get close enough to put your hands on him. If he is inclined to hold his head from you, put the end of the halter-strap around his neck, drop your whip, and draw very gently; he will let his neck give, and you can pull his head to you. Then take hold of that part of the halter which buckles over the top of his head, and pass the long side, or that part which goes into the buckle, under his neck, grasping it on the opposite side with your right hand, letting the first strap loose -the haltel will be sufficient to hold his head to you. Lower the halter a little, just enough to get his nose into that part which goes around it; then raise it somewhat, and fasten the top buckle, and you will have it all right. The first time you halter a colt you should stand on the left side, pretty well back to his shoulder, only taking hold of that part of the halter that goes around his neck; then with your two hands about his neck you can hold his head to you, and raise the halter on it without making him dodge by putting your hands about his nose. You should have a long rope or strap ready, and as soon as you have the halter on, attach this to it, so that you can let him walk the length of the stable without letting go of the strap, or without making him pull on the halter, for if you only let him feel the weight of your hand on the halter, and give him rope when he runs from you, he will never rear, pull, or throw himself, yet you will be holding him all the time, and doing more toward gentling him than if you had the power to snub him right up, and hold him to one spot; because he does not know anything about his strength, and if you don't do anything to make him pull, he 
will never know that he can. In a few minutes jou can begin to control him with the halter; then shorten the distance between yourself and the horse by taking up the strap in your hand.

As soon as he will allow you to hold him by a tolerably short strap, and to step up to him without flying back. You can

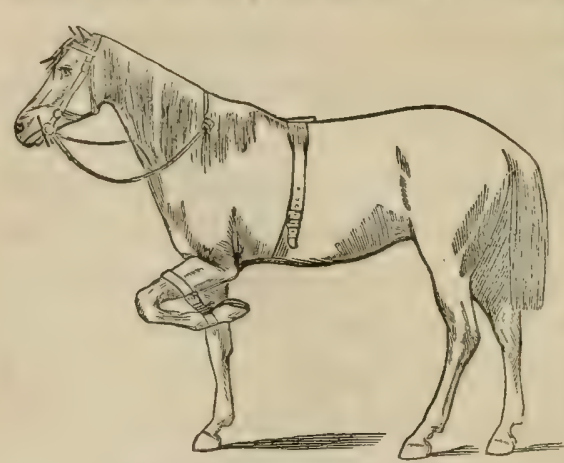

TAMrNa THE ноRge. (See page 368.) begin to give him some idea about leading. But to do this, do not go before and attempt to pull him after you, but commence by pulling him very quietly to one side. $\mathrm{He}$ has nothing to brace either side of his neck, and will soon yield to a steady, gradual pull of the halter; and as soon as you have pulled him a step or two to one side, step up to him and caress him, and then pull him again, repeating this operation until you can pull him around in every direction, and walk about the stable with him, which you can do in a few minutes, for he will soon think when you have made him step to the right or left a fer times, that he is compeller to follow the pull of the halter, not knowing that he has the power to resist your pulling; besides, you have handled him so gently that he is not afraid of you, and 5ou always caress him when he comes up to you, and he likes that, and would just as lief follow you as not. After he has had a few lessons of that kind, if you turn him out in a field, he will come up to you every opportunity he gets. 
You should lead him about in the stall some time before you take him out, opening the door so that he can see out, leading him up to it and back again, and past it. Sec that there is nothing ont he outside to make him jump when you take him out, and as you go out with him, try to make him go very slowly, catching hold of the halter close to the jaw with your left hand, while the right is resting on the top of the neck, holding to his mane. After you are out with bim a little while, you can lead him about as you please.

Don't let any second person come up to you when you first take him out; a stranger taking hold of the halter would frighten him, and make him run. There should not even be any one standing near him, to attract his attention or scare him. If you are alone, and manage him rightly, it will not require any more force to lead or hold him than it would to manage a broken horse.

How to Tie up a ColT.-If you want to tie up your colt, pat him in a tolerably wide stall, which should not be too long, and should be connected by a bar or something of that kind to the partition behind it; so that, after the colt is in he cannot go far enough back to take a straight, backward pull on the halter; then by tying him in the centre of the stall, it would be impossible for him to pull on the halter, the partition behind prerenting him from going back, and the halter in the centre checking him every time he turns to the right or left. In a stall of this kind you can break any horse to stand tied with a light strap, anywhere, without his ever knowing anything about pulling. For if you have broken your horse to lead, and have taught him the use of the halter (which you should always do before you hitch him to anything), you can hitch him in any kind of 
a stall, and if you give him something to eat to keep him up to his place for a few minutes at first, there is not one colt in fif:y that will pull on his halter.

How to Taue a Horse.-Take up one fore-foot and bend his knee till his hoof is bottom upward, and nearly touching his body; then slip a loop over his knee, and up until it comes above the pastern-joint, to lieep it up, being careful to draw the loop together between the hoof and pastern-joint with a second strap of some kind to prevent the loop from slipping down and coming off. This will leare the horse standing on three legs; you can now handle him as you wish, for it is utterly impossible for him to kick in this position. There is something in this operation of taking up one foot, that conquers a horse quicker and better than anything else you can do to him. There is no process in the world equal to it to break a kicking horse, as there is a principle of this lind in his nature that by conquering one member, you conquer, to a great extent, the whole borse.

This will conquer him better than anything you could do, and without any possible danger of hurting himself or you either, for you can tie up bis foot and sit down and look at him until he gives up. When you find that he is conquered, go to him, let down his foot, rub his leg with your hand, caress him, and let him rest a little; then put it up again. Repeat this a few times, always putting up the same foot, and he will soon learn to travel on three legs, so that you can drive him some distance. As soon as he gets a little used to this way of traveling, put on your harness, and hitch him to a sulky. If he Is the worst licking horse that ever raised a foot, you need not be fearful of his doing any damage while he has one foot up, 
for he cannot kick, neither can he rum fast enough to do any harm. And if he is the wildest horse that erer had harness on, and has run away every time he has been hitched, you can now hitch him in a sulky, and drive him as you please. If he wants to run, jou can let him have the lines, and the whip too, with perfect safety, for he can go but a slow gait on three legs, and will soon be tired, and willing to stop; only hold him enough to guide him in the right direction, and he will soon be tired and willing to stop at the word. Thus you will effectually cure him at once of any further notion of running off. Kicking horses have always been the dread of everybody; but by this new method you can harness them to a rattling sulky; plough, wagon, or anything else in its worst shape. They may be frightened at first, but cannot kick, or do anything to hurt themselres, and will soon find that you do not intend to hurt them, and then they will not care anything more about it. You can then let down the leg and drive along gently without any further trouble. By this new process a bad kicking horse can be taught to go gentle in harness in a few hours' time.

How to MAKe a Honse lie Down.-To make a horse lie down, bend his left fore-leg and slip a loop orer it, so that he cannot get it down. Then put a surcingle round his body, and fasten one end of a long strap around the other fore-leg, just above the hoof. Place the other end under the before-described surcingle, so as to keep the strap in the right direction; take a short bold of it with your right hand; stand on the left side of the horse, grasp the bit in your left hand, pull steadily on the strap with your right; bear against his shoulder till you cause him to move. As soon as he lifts his weight, your pulling will raise the other foot, and he will have to come on his knees. 
Keep the strap tight in your hand, so that he cannot straighten his leg if he rises up. Hold him in this position, and turn his

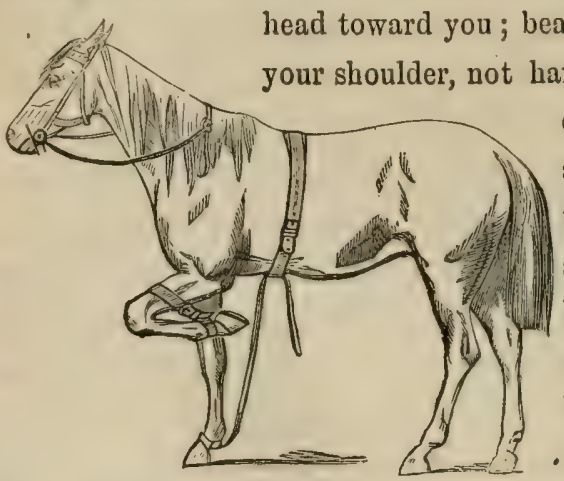

TEACHTNG TBE HORSE TO LIE DOWN equal pressure, and in about ten minutes he will lie down. As soon as he lies down, he will be completely conquered, and you can handle him as you -please. Take off the straps, and straighten

out his legs; rub him lightly about the face and neck with your hand the way the hair lies; handle all his legs, and after he has lain ten or twenty minutes, let him get up again. After resting him a short time, make him lie down as before. Repeat the operation three or four times, which will be sufficient for one lesson. Give him two lessons a day, and when you have reached four lessons, he will lie down by taking hold of one foot. As soon as he is well broken to lie down in this way, tap him on the opposite leg with a stick when you take hold of his foot, and in a few days he will lie down from the mere motion of the stick.

To Accustom a Horse to Strange Sounds and Sights.It is an excellent practice to accustom all horses to strange sounds and sights, and of very great importance to young horses which are to be ridden or driven in large towns, or used as chargers. Although some horses are very much more timid and nervous than others, the very worst can be very 
much improved by acting on the first principles laid down in the introduction to this article-that is, by proving that the strange sights and sounds will do them no harm.

When a railway is first opened, the sheep, the cattle, and especially the horses, grazing in the neighboring fields, are terribly alarmed at the sight of the swift, dark, moving trains, and the terrible snorting and hissing of the steam engines. They start away-they gallop in circles-and when they stop, gaze with head and tail erect, until the monsters have disappeared. But from day to day the live stock become more accustomed to the sight and sound of the steam horse, and after a while they do not even cease grazing when the train passes. They have learned that it will do them no harm. The same result may be observed with respect to young horses when first they are brought to a large town, and have to meet great loads of hay, omnibuses crowded with passengers, and other strange or noisy objects; if judiciously treated, not flogged and ill-used, they lose their fears without losing their high courage.

To accustom a Horse to a Drum.-Place it near him on the ground, and withont forcing him, induce him to smell it again and again, until he is thoroughly accustomed to it. Then lift it up, and slowly place it on the side of his neck, where he can see it, and tap it gently with a stick or your finger. If he starts, pause, and let him carefully examine it. Then commence again, gradually moving it backward until it rests upon his withers, by degrees playing louder and louder, pausing always when he seems alarmed, to let him look at it and smell, if needful. In a very few minutes you may play with all your force, without his taking any notice. When 
this practice has been repeated a few times, your horse, however spirited, will rest his nose nnmoved on the big drum, while the most thundering piece is played.

To teach a Horse to bear an Umbrella.-Go through the same cautious forms, let him see it, and smell it, open it by degrees, gain your point inch by inch, passing it always from his eyes to his neck, and from his neck to his back and tail; and so with a riding-habit; in half an hour any horse may be taught that it will not hurt him, and then the difficulty is over.

To fire off a Horse's back.-Begin with caps, and, by degrees, as with the drum. Instead of lengthening the reins, stretch the bridle hand to the front, and raise it for the carbine to rest on, with the muzzle clear of the horse's head, a little to one side. Lean the body forward without rising in the stirrups. Avoid interfering with the horse's mouth, or exciting his fears by suddenly closing your legs either before or after firing-be quiet yourself, and your horse will be quiet. The colt can learn to bear a rider on his bare back during his first lessons, when prostrate and powerless, fast bound by straps: The surcingle has accustomed him to girths, he leads well, and has learned that when the right rein is pulled he must go to the right, and when the left rein to the left. You may now teach him to bear the BIT and the SADDLE, if you have not placed it upon his back while on the ground.

How to Accuston a Horse to a Bit.-You should use a large, smooth, snaffle bit, so as not to hurt his mouth, with a bar to each side, to prevent the bit from pulling through either way. This you should attach to the head-stall of your 
bridle, and put it on your colt without any reins to it, and let him run loose in a large stable or shed some time, until he becomes a little used to the bit, and
will bear it without trying: to get it out
of his mouth. It would be well, if con-
venient, to repeat this several times,
before you do anything more
with the colt; as soon as he will
bear the bit; attach a single rein
to it. You
should al so hold or lead him about without pulling at the bit much. $\mathrm{He}$ is now ready for the saddle.

The Proper Way to Bit a CoLT.-Farmers often put bitting harness on a colt the first thing they do to him, buckling up the bitting as tight as they can draw it, to make him carry his head high, and then turn him out in a field to run half a day at a time. This is one of the worst punishments that could be inflicted on the colt, and is very injurions to a young borse that has been used to running in pasture with his head down. Colts have been so seriously injured in this way that they have never recovered. 
A horse should be well accustomed to the bit before you put on the bitting harness, and when you first bit him you should only rein his head up to that point where he naturally holds it, let that be high or low; he will soon learn that he cannot lower his head, and that raising it a little will loosen the bit in his mouth. This will give him the idea of raising his head to loosen the bit, and then you can draw the bitting a little tighter every time you put it on, and he will still raise his head to loosen it; by this means you will gradually get his head and neck in the position you want him to carry them, and give him a nice and graceful carriage without hurting him, making him mad, or cansing his mouth to get sore.

If you put the bitting on very tight the first time, he cannot raise his head enough to loosen it, but will bear on it all the time, and parv, sweat, and throw himself. Many horses hare been killed by falling backward with the bitting on; their heads being drawn np strike the ground with the whole weight of the body. Horses that have their heads drawn up tightly should not have the bitting on more than fifteen or twenty minutes at a time.

How to SAdDle a ColT.-The first thing will be to tie each stirrup-strap into a loose knot to make them short, and prerent the stirrups from flying about and hitting him. Then double up the skirts and take the saddle under your right arm, so as not to frighten him with it as you approach. When you get to him rub him gently a few times with your hand, and then raise the saddle very slowly, until he can see it, and smell and feel it with his nose. Then let the skirt loose, and rub it very gently against his neck the way the hair lies, letting him hear the rattle of the skirts as he feels them 
against him; each time getting a little further backward, and finally slipping it over his shoulders on his back. Shake it a little with your hand, and in less than five minutes you can rattle it about over his back as much as you please, and pull it off and throw it on again, without his paying much attention to it.

As soon as you have accustomed him to the saddle, fasten the girth. Be careful how you do this. It often frightens the colt when he feels the girth binding him, and making the saddle fit tight on his back. You should bring up the girth very gently, and not draw it too tight at first, just enough to hold the saddle on. Move him a little, and then girth it as tight as you choose, and he will not mind it.

You should see that the pad of your saddle is all right before you put it on, and that there is nothing to make it hurt him, or feel unpleasant to his back. It should not have any loose straps on the back part of it, to flap about and scare him. After you have saddled him in this way, take a switch in your right hand to tap him up with, and walk about in the stable a few times with your right arm over your saddle, taking hold of the reins on each side of his neck with your right and left hands, thus marching him about in the stable until you teach him the use of the bridle and can turn him about in any direction, and stop him by a gentle pull of the rein. Always caress bim, and loose the reins a little every time you stop him.

You should always be alone, and have your colt in some light stable or shed, the first time you ride him; the loft should be high, so that you can sit on his back without endangering your head. You can teuch him more in two hour's time in a 
stable of this kind, than you could in two weeks in the common way of breaking colts, out in an open place. If you follow my course of treatment, you need not run any risk, or have any trouble in riding the worst kind of horse. You take him a step at a time, until you get up a mutual confidence and trust between yourself and horse. First teach him to lead and stand hitched; next acquaint him with the saddle, and the use of the bit; and then all that remains is to get on him without scaring him, and you can ride him as well as any horse.

How to Mount the CoLT.-First gentle him well on both sides, about the saddle, and all over until he will stand still without holding, and is not afraid to see you anywhere about him. As soon as you have him thus gentled, get a small block, about one foot or eighteen inches in height, and set it down by the side of him, about where you want to stand to mount him; step up on this, raising yourself very gently; horses notice every change of position very closely, and if you were to step up suddenly on the block, it would be very apt to scare him; but by raising yourself gradually on it, he will see you without being frightened, in a position very nearly the same as when you are on his back.

As soon as he will bear this withont alarm, untie the stirrup. strap next to you, and put your left foot into the stirrup, and stand square over it, holding your knee against the horse, and your toes out, so as not to touch him under the shoulder with the toe of your boot. Place your right hand on the front of the saddle, and on the opposite side of you, taking hold of a portion of the mane and the reins, as they hang loosely over his neck, with your left hand; then gradnally bear your weight 
on the stirrup, and on your right hand, until the horse feels your whole weight on the saddle; repeat this several times, each time raising yourself a little higher from the block, until he will allow you to raise your leg over his croup, and place yourself in the saddle.

There are three great advantages in having a block from which to mount. First, a sudden change of position is very apt to frighten a young horse who has never been handled; he will allow you to, walk up to him, and stand by his side without scaring at you, because you have gentled him to that position; but if you get down on your hands and knees and crawl toward him, he will be very much frightened; and upon the same principle, he

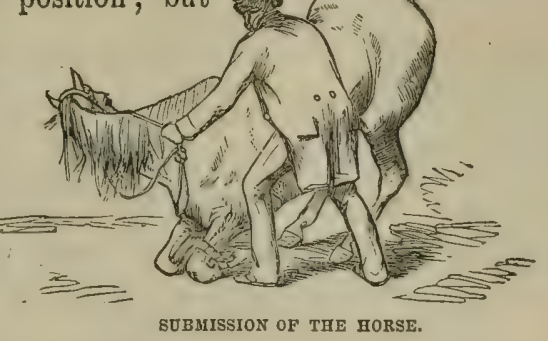
would be frightened at your new position if you had the power to bold yourself over his back without touching him. The first great advantage of the block, then, is to gradually gentle bim to that new position in which he will see you when you ride him.

Secondly, by the process of leaning your weight in the stirrup, and on your hand, you can gradually accustom him to your weight, so as not to frighten him by having him feel it all at once. And, in the third place, the block elevates you so that you will not have to make a spring in order to get upon the horse's back, but from it you can gradually raise yourself into the saddle. When you talie these precautions, 
there is no horse so wild but that you can mount him without making him jump. When mounting, your horse should always stand without being held. A horse is never well broken when he has to be held with a tight rein when mounting; and a colt is never so safe to mount as when you see that assurance of confidence, and absence of fear, which cause him to stand without holding.

An improved plan of mounting is to pass the palm of the right hand on the off-side of the saddle, and as you rise lean your weight on it; by this means you can mount with the girth loose, or without any girth at all.

How to Ride a CoLT. - When you want him to start do not touch him on the side with your heel, or do anything to frighten him and make him jump. But speak to him lindly, and if he does not start pull him a little to the left until he starts, and then let him walk off slowly with the reins loose. Walk him around in the stable a few times until he gets used to the bit, and you can turn him about in every direction and stop him as you please. It would be well to get on and off a good many times until he gets perfectly used to it before you take him out of the stable.

After you have trained him in this way; which should not take you more than one or two hours, you can ride him anywhere you choose without ever having him jump or make any effort to throw you.

When you first take him out of the stable be very gentle with him, as he will feel a little more at liberty to jump or run, and be a little easier frightened than he was while in the stable. But after handling him so much in the stable he will be pretty well broken, and you will be able to manage him without trouble or danger. 
When you first mount him take a little the shortest hold on the left rein, so that if anything frightens him you can prevent him from jumping by pulling his head round to you. This operation of pulling a horse's head round against his side will prevent any horse from jumping ahead, rearing up, or running away. If he is stubborn and will not go, you can make him move by pulling his head round to one side, when whipping would hare no effect. And turning him round a few times will make him dizzy, and then by letting him have his head straight, and giving him a little touch with the whip, he will go along without any trouble.

Never use martingales on a colt when you first ride him; every movement of the hand should go right to the bits in the direction in which it is applied to the reins, without a martingale to change the direction of the force applied. You can guide the colt much better without it, and teach him the use of the bit in much less time. Besides, martingales would prevent you from pulling his head round if he should try to jump.

After your colt has been ridden until he is gentle and well accustomed to the bit, you may find it an advantage, if he carries his head too high or his nose too far out, to put martingales on him.

You should be careful not to ride your colt so far at first as to heat, worry, or tire him. Get off as soon as you see that he is a little fatigued; gentle him, and let him rest; this will make him kind to you, and prevent him from getting stubborn or mad.

To Break a Horse to Harness.-Take him in a light stable, as you did to ride him; take the harness, and go through the same process that you did with the saddle, until you get him 
familiar with it, so that you can put it on him, and rattle it about without his caring for it. As soon as he will bear this, put on the lines, caress him as you draw them over him, and drive him about in the stable till he will bear them orer his hips. The lines are a great aggravation to some colts, and often frighten them as much as if you were to raise a whip orer them. As soon as he is familiar with the haruess and lines, take him out and put him by the side of a gentle horse. Always use a bridle without blinkers when you are breaking a horse to harness.

Lead him to and around a light gig or phacton; let him look at it, touch it with his nose, and stand by it till he cloes not care for it: then pull the shafts a little to the left, and stand your horse in front of the off-wheel. Let some one stand on the right side of the horse, and hold him by the bit, while you stand on the left side, facing the sulky. This will keep him straight. Run your left hand back, and let it rest on his hip, and lay

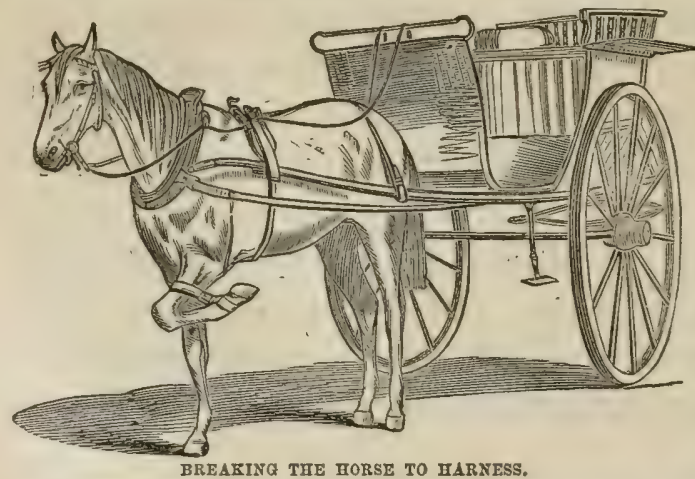

hold of the shafts with your : right, bring ing them up very gently to the left hand, which still remains stationary. Do not let anything but your arm touch his back, and as soon as you have the shafts square over him, let the person on the opposite side take hold of one of them, and lower them very gently 
to the shaft-bearers. Be very slow and deliberate about hitching; the longer time you take the better, as a general thing. When you have the shafts placed, shake them slightly, so that he will feel them against each side. As soon as he will bear them without scaring, fasten your braces, etc., and start him along very slowly. Let one man lead the horse, to keep him gentle, while the other gradually works back with the lines till he can get behind and drive him. After you have driven him in this way a short distance, you can get into the sulky, and all will go right. It is very important to have your horse go gently when you first hitch him. After you have walked him awhile, there is not half so much danger of his scaring. Men do very wrong to jump up behind a horse to drive him as soon as they have him hitched. There are too many things for him to comprehend all at once. The shafts, the lines, the harness, and the rattling of the sulky, all tend to scare him, and he must be made familiar with them by degrees. If your horse is very wild, one foot had better be put up the first time you drive him. With the leg strapped up, the lighter the gig the better, and four wheels are better than two. 


\section{WARRANTY.}

In the purchase of a horse the buyer should take with the receip? what is termed in law a warranty. The best way of expressing it is in this form:

Philadelphia, August 1, 18-.

Received of William Ingalls three hundred dollars, for a black mare, warranted only five years old, sound, free from vice, and quiet to ride and drive.

$\$ 300$.

EDWARD RIDDLE.

A receipt, which includes simply the word "warranted," extends merely to soundness. "Warranted sound," has no greater extent; the age, freedom from rice, and quietness to ride and drive should all be especially named. This warranty embraces every cause of unsoundness that can be detected, or that is inherent in the constitution of the animal at the time of sale, as well as every ricious habit which he has previously shown. In order to establish a breach of the warranty, and then be enabled to return the horse or recover the price paid, the purchaser must prove that it was unsound or viciously disposed at the time of sale. In case of cough, the horse must have been heard to congh previously to the purchase, or as he was led home, or as soon as he had entered the stable of the purchaser. Coughing, even on the following morning, will not be sufficient; for it is possible that he might have caught cold by a change of stabling. If he is lame, it must be proved to arise from a cause that could not have occurred after he was in the purchaser's possession. No price will imply a warranty, or be deemed equivalent to one; the warranty must be expressly stated.

A fraud in the seller must be proved, in order that the buyer may

- be enabled to return the horse or maintain an action for the price. The warranty should be given at the time of sale. A warranty or a promise to warrant the horse, given at any period previous to the sale, is of no effect; for the horse is a very perishable commodity, and his constitution and his usefulness may undergo a considerable change in a few days. A warranty after the sale is also of no effect, as it is given without any legal consideration. In order to complete the purchase, there must be a transfer of the animal, or a written memorandum of agreement, or the payment of some sum, however Emall, as earnest-money. No verbal promise to buy or sell is binding without one of these accompaniments; and the moment either (382) 
of them is effected, the legal transfer of property, or its delivery, is made, and whatever may happen to the horse, the seller retains, or is entitled to, the money. If the purchaser exercises any act of ownership-as by using the animal without leave of the seller, or by having any operation performed upon him, or medicines given to him-he makes him his own.

If the horse should afterward be discovered to have been unsound at the time of warranty and sale, the buyer may return him. Although not legally compelled to give notice to the seller of the discorered unsoundness, it is best that such notice should be given. The animal should then be tendered at the house or stable of the seller. If he refuses to receive the animal, humanity dictates that he should be sent to a livery stable, in preference to tying him up in the street; an action can be maintained, after the horse has been tendered, for the necessary expenses of keeping him as well as for the price paid. The keep, however, can be recovered only for the time that necessarily intervened between the tender and the determination of the action. It is not legally necessary to return the animal as soon as the unsoundness is discovered. The animal may be kept for a reasonable time afterward, and even proper medical means may be resorted to for the removal of the unsoundness; but courtesy, and indeed justice, will require that the notice should bo given as soon as possible. Although it is laid down, upon the authority of an eminent English judge, that "no length of time elapsed after the sale, will alter the nature of a contract originally false," yet there are recorded cases in which the buyer was prevented from maintaining his action, because he did not give notice of the unsoundness within a reasonable time after its discovery. What will constitute this reasonable time, depends upon many circumstances. It was formerly supposed that the buyer had no right to have the horse medically treated, and that he would vitiate the warranty by so doing. The question, however, in such a case would be, whether the animal was injured, or his ralue lessened, by such treatment. It may be remarked that it is generally most prudent to refrain from all medical treatment, since the means adopted, no matter how skillfuliy used, may have an unfortunate effect, or what is done may be misrepresented by ignorant or interested observers.

When a horse is returned, and an action brought for the price, it is indispensable that in every respect, except the alleged unsoundness, the animal should be as perfect and valuable as whon he was bought. 
The purchaser may, possibly, like the horse, notwithstanding his discove jerect; in which case se may resain rim and kring cis action 1 ... ino cerreciation in value on accoun ct the unsounciress. Few, however, will do this, because the retaining of the animal will give rise to a suspicion that the defect is of no great consequence, and consequently will occasion much cavil about the amount of damages; the suit terminating, probably, in the recovery of slight, if any, damages.

Where there is no warranty, an action may be brought on the ground of fraud; but as this is very difficult to be maintained, few persons will hazard it. It will in such a case, be necessary to prove that the seller knew the defect, and that the buyer was imposed upon by his false representations; and that, too, under circumstances in which a person of ordinary carefuluess and circumspection might have been imposed upon. If the defect was palpably evident, the purchaser has ne remedy, for he should have exercised more caution; but if a warranty was given, it covers every unsoundness, evident or concealed. Although a person should ignorantly or carelessly buy a blind horse, warranted sound, he may return itthe warranty is his protection, and prevents him from examining the horse as closely as he otherwise would have done; but if he buys a blind horse, supposing him to be sound, and without a warranty, he is without any remedy. The law supposes every one to exercise common circumspection and common sense.

A person should have a more thorough knowledge of horses than most possess, together with perfect confidence in the seller, who ventures to buy a horse without a warranty. If a person buy a horse warranted sound, and discovering no defect in him, sells him again, relying upon his warranty, and the unsoundness is discovered by the second purchaser, and the horse returned to the first buyer, or an action commenced against him, the latter has his claim upon the first seller, and may demand of him not only the price of the horse, or the difference in value, but all expenses which may necessarily have been incurred.

Exchanges, whether of one horse absolutely for another, or where a sum of money is paid in addition by one of the parties, stand upon precisely the same ground as simple sales. If there is a warranty apon either side, and that is broken, the exchange is vitiated; if there is no warranty, deceit must be proved.

THE END. 
CATTLE AND THEIR DISEASES. 



\section{P R E F A C E.}

A MARKED interest has of late years been manifested in our country relative to the subject of breeding and rearing domestic cattle. This has not been confined to the dairyman alone. The greater portion of intelligent agriculturists have perceived the necessity of paying more attention than was formerly devoted to the improvement and perfection of breeds for the uses of the table as well. In this respect, European cattle-raisers have long taken the precedence of our own.

The gratifying favor with which the anthor's former publication, "The Horse and his Diseases," has been received by the public, has induced him to believe that a work, similar in spirit and general treatment, upon Cattle, would not be without interest for the agricultural community.

In this belief, the present treatise has been prepared. The author has availed himself of the labors of others in this connection; never, however, adopting results and conclusions, no matter how strongly endorsed, which have been contradicted by his own observation and experience. In a field like the one in question, assuredly, if anywhere, some degree of independent judgment will not be censured by those who are familiar with the sad consequences resulting from the attempted application of theories now universally exploded, but which in the day and generation of their originators were sanctioned and advocated by those who claimed to be magnates in this department. 
To the following works, especially, the author acknowledges himself indebted: American Farmer's Encyclopœdia ; Stephens's Book of the Farm; Flint's Milch-Cows and Dairy Farming; Laurence on Cattle; Allen's Domestic Animals; Youatt and Martin on Cattle; Thomson's Food of Animals; Allen's Rural Architecture; Colman's Practical Agriculture and Rural Economy; Goodale's Breeding of Domestic Animals; and Prof. Gamgee's valuable contributions to veterinary science.

Particular attention is requested to the division of "Diseases." Under this head, as in his former work, the author has endeavored to detail the symptoms of the most common ailments of cattle in such a manner that every farmer and cattle-owner can at once understand them, and also to suggest such procurable remedies as a wide experience has proved to be most efficacious.

A generous space has been devoted to the consideration of that fatal epidemic, now generally known as "Pleuro-Pneumonia," as it has manifested itself in Europe and this country, in the belief that a matter of such vital importance to the stock-raiser ought to receive a complete exposition in a work like the present. As the author's personal experience in connection with the treatment of this peculiar disease has been, perhaps, as large and varied as that of any American practitioner, he is not without the hope that his views upon the matter may prove productive of some benefit to others.

Should the present rolume prove as acceptable to those interested as did his former work, the author will be abundantly satisfied that he has not mistaken in this instance the wants of the public. 


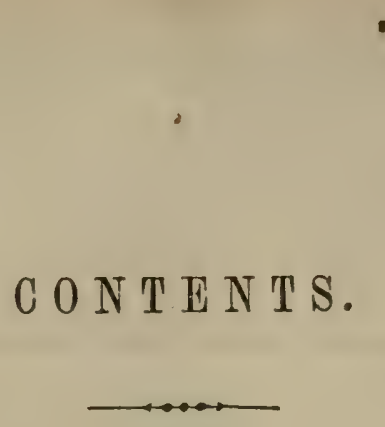

HISTURY AND BREEVंS OF̂ CATTLE,

Tre British $0 \mathbf{x}$,

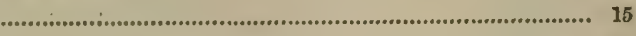

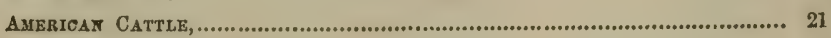

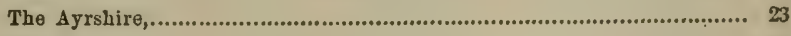

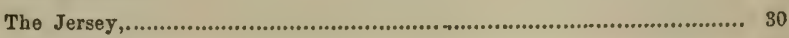

The Short-Horns, ....................................................................... 32

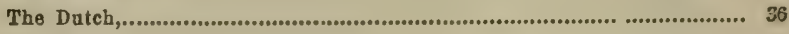

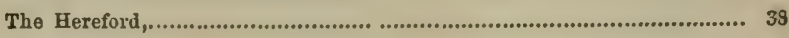

The North-Devon, ........................................................................ 41

Native Cattle, ........................................................................... 13

NATURAL History OF CATTLE, ......................................................

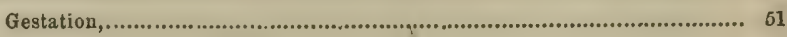

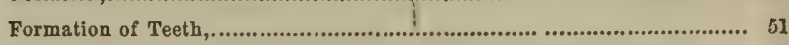

Points of a Good Cow, ,............................................................... 67

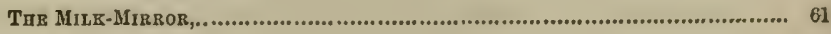

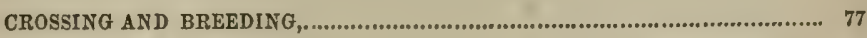

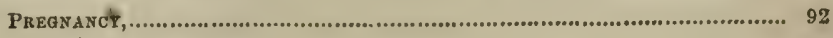

TREATMENT BEFORE CALPING, ......................................................... 93

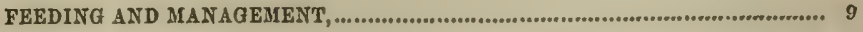

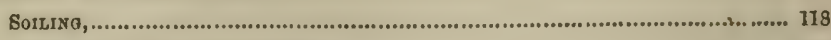

CULTURE OF GRASSES FOR FODDER, .................................................. 122

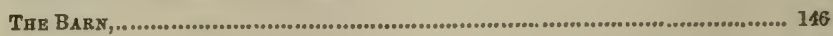

MILXING, ............................................................................... 155

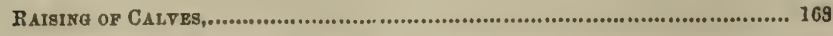

PoINTS of FAT CATTLE, ................................................................... 183

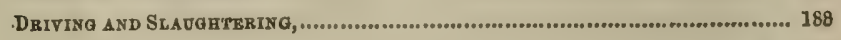


DISEA SES AND THEIR REMEDIES, ................................................. 205

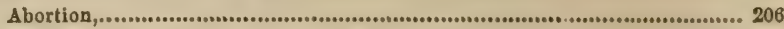

Apoplexy, .................................................................. 215

Black -Water, .................................................................. 215

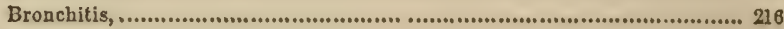

Consumption, ........................................................................ 217

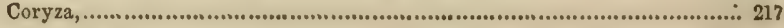

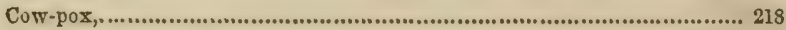

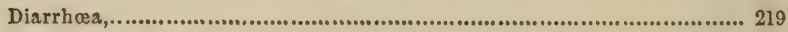

Dysentery, ........................................................................... 220

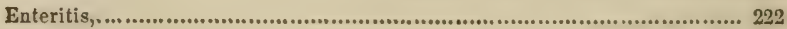

Epizoötics, ................................................................... 224

Epizoötic Catarrh,.................................................................. 234

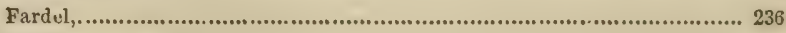

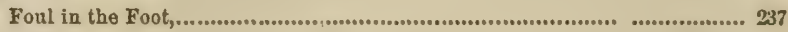

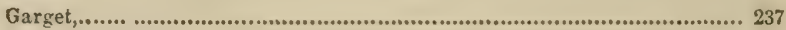

Gastro-enteritis, .................................................................. 238

Hoose, .............................................................................. 258

Hoove, ............................................................................... 239

Hydatids, ........................................................................ 240

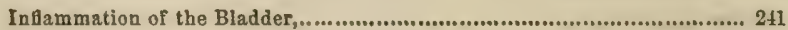

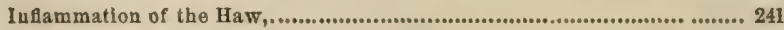

Inflammation of the Kidneys,....................................................... 242

Inflammation of the Liver, .......................................................... 242

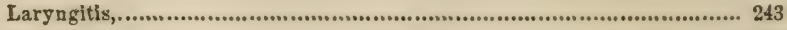

Lice, ............................................................................... 244

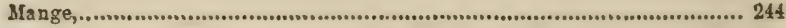

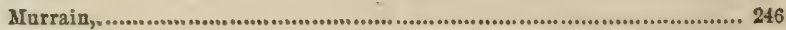

Navel-ill, ................................................................................ 247

Obstructions in the CEsophagus,................................................. 247

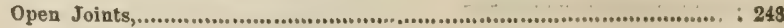


DISEASES AND THEIR REMEDIES-Continued.

Parturition, ,............................................................................... 248

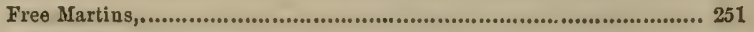

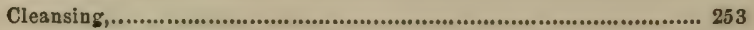

Inversion of the Uterus, ........................................................... 253

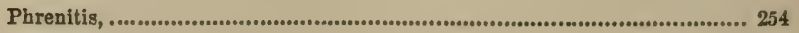

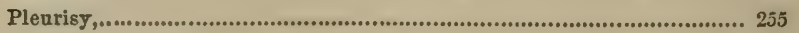

Pleuro-pneumonia, ....................................................................... 256

Pneumonia, ................................................................................. 300

Protrusion of the Bladder, ................................................................ 302

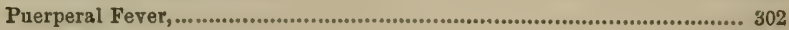

Quarter Evil, .................................................................................... 303

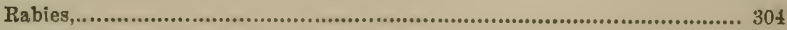

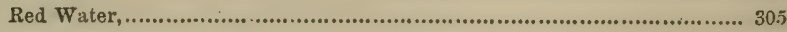

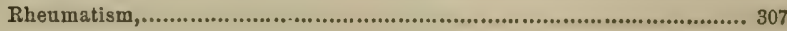

Strangulation of the Intestines, ........................................................... 308

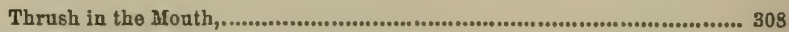

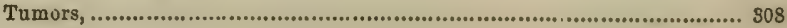

Ulcers about the Joints, ................................................................. 312

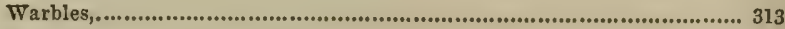

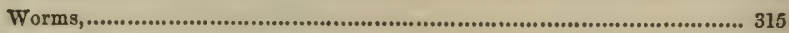

Worms in the Bronchial Tubes, ...................................................... 316

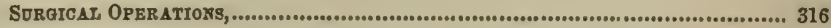

Castration, ........................................................................... 316

Tracheotomy, ........................................................................... 319

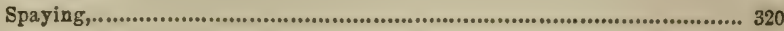

List of Medicines USED IN T'REatikg CatriE,............................................ 330

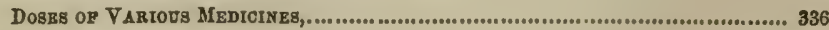




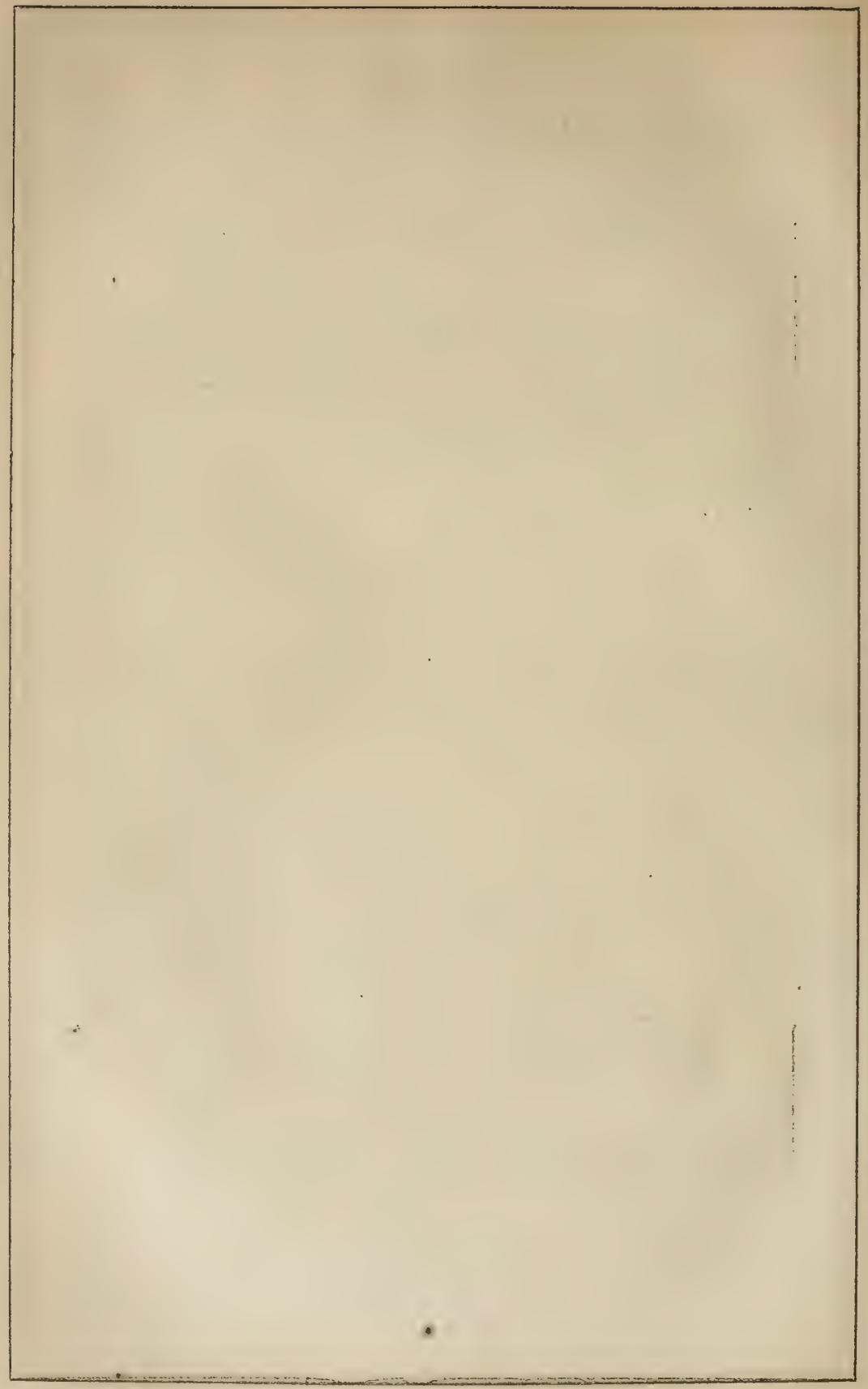




\section{ILLUSTRATIONS.}

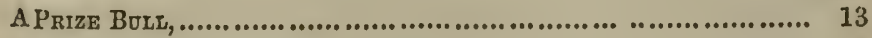

The WELL-FED BeAsTS , ................................................ 19

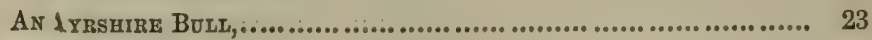

A SHRT-HORN BULt, ................................................... 33

A Norit DeVoN StEER, ............................................ 41

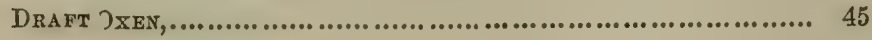

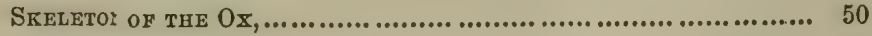

TeEth Ат Birth, .................................................... 52

TEETH AT EECOND WEEK, .......................................... 52

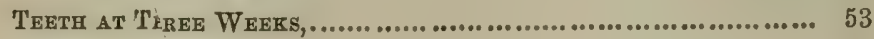

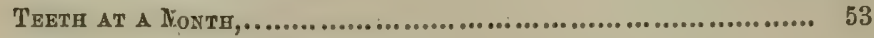

TeEth at Fivèto Eight MIonths, ..................................... 53

Ten Months Teith, .................................................... 53

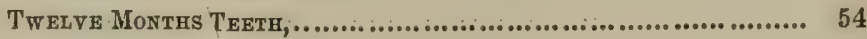

Fifteen Months IeETH, ........................................... 54

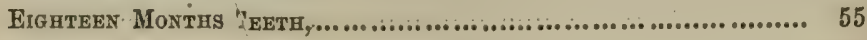

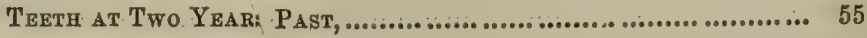

TEETH AT ThreE YeAiS PAST, .......................................... 56

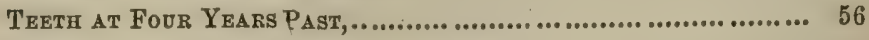

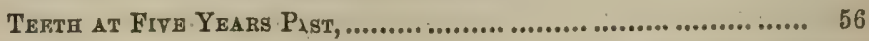

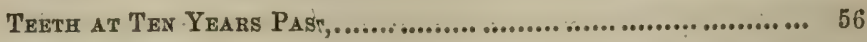

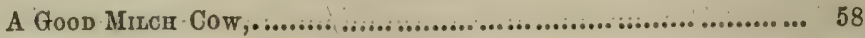

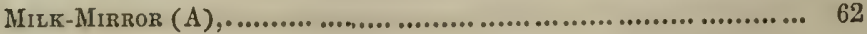

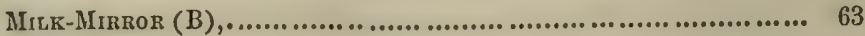

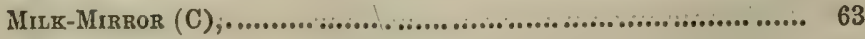

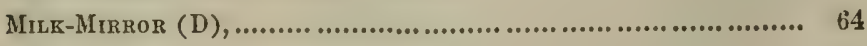

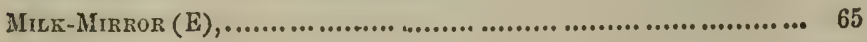




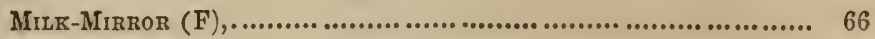

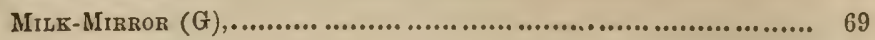

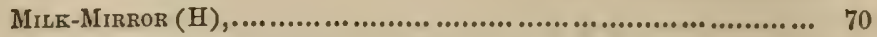

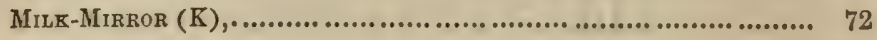

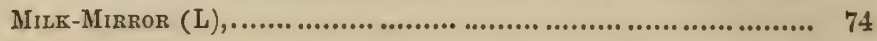

OW AND CALF, ........................................................ 77

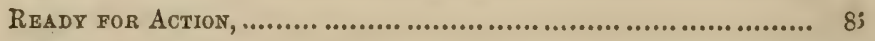

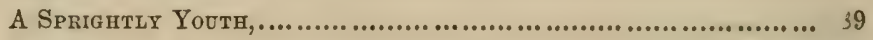

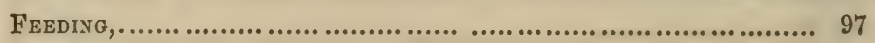

THe Famili Pets, ........................................................ 102

Buting Cattle, ..................................................... 107

Calina in the Cattle, .............................................. 112

"ON the RAMPAGE,"

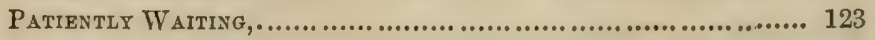

A Chatce for a Selection, ............................................. 129

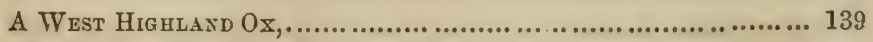

BARN for ThiRTY-Fodr Cotws aNd Three Yoke of OXEN,............ 150

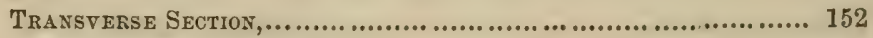

ROOM OVER THE Cow-ROOM, .......................................... 153

The Preferable Method, ............................................. 159

Maternat Affection, .................................................. 168

FROLICSOME, ........................................................ 177

Points of CATtLE, .................................................. 185

A Frontispiece, .................................................... 190

Scotch Mode of CutTisg UP BeEF, .................................. 195

ENGLISH MODE OF CUTTING UP BEEF, ................................. 197

DisEASES AND THEIR REMFDIES, ......................................... 205

A ChAT ON THE ROAD, ............................................... 218

The Mad BUdL, .................................................... 230

Ax Aberdeenshire Polled BdLl, ..................................... 244

TAKiNG aN OBSERVATION, ............................................... 256

The TwiNS, .......................................................... 268

A Rurat Scene, .................................................... 285

TAKING IT EASILY, ..................................................... 299

HONE AGAIN ........................................................ 313 


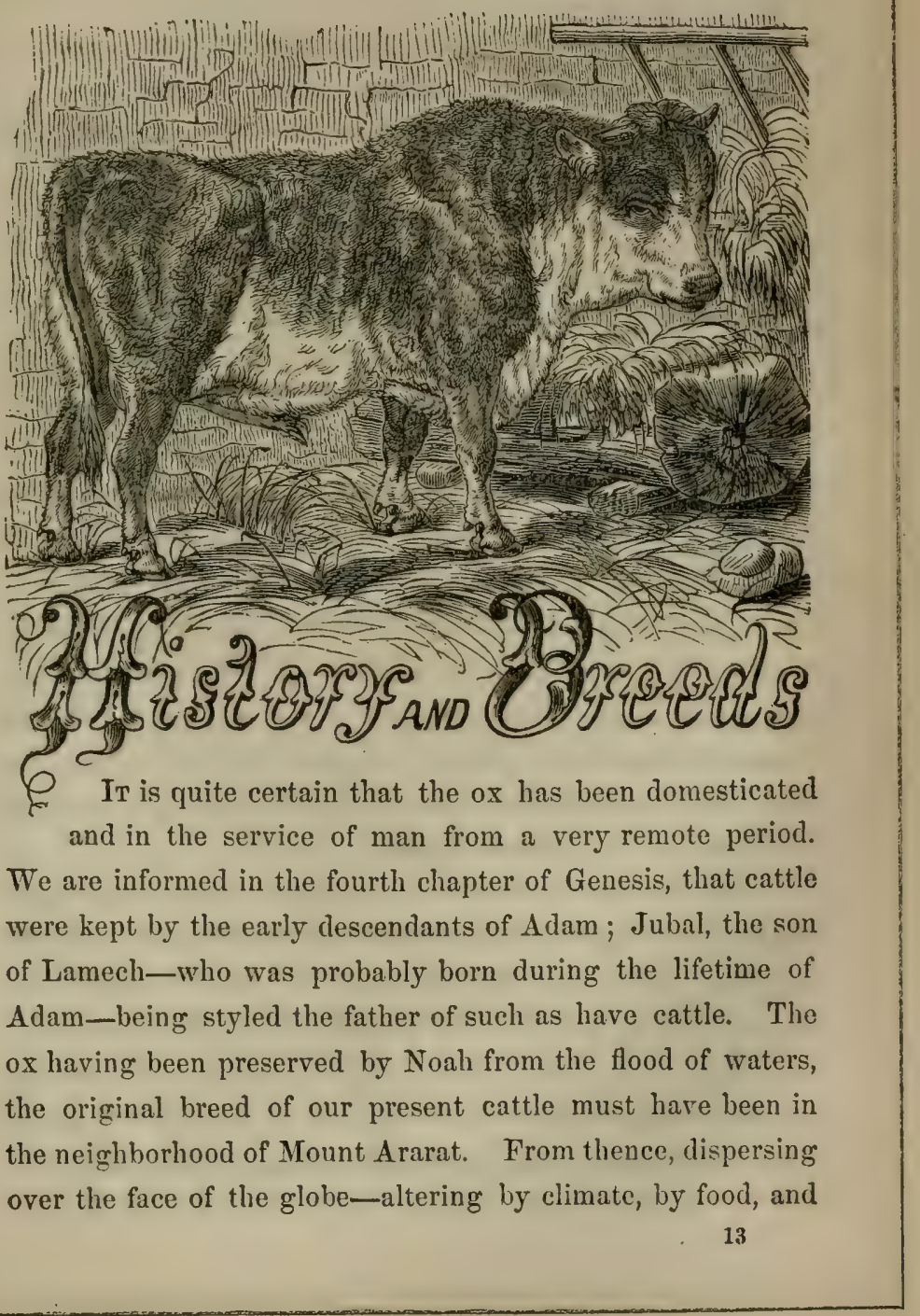


by cultivation-originated the various breeds of modern ages.

That the value of the $o x$ tribe has been in all ages and climates highly appreciated, we have ample evidence. The natives of Egypt, India, and Hindostan, seem alike to have placed the cow amongst their deities; and, judging by her usefulness to all classes, no animal could perhaps have been selected whose value to mankind is greater. The traditions, indeed, of every Celtic nation enroll the cow among the earliest productions, and represent it as a kind of divinity.

In nearly all parts of the earth cattle are employed for their labor, for their milk, and for food. In southern Africa they are as much the associates of the Caffre as the horse is of the Arab. They share his toils, and assist him in tending his herds. They are even trained to battle, in which they become fierce and courageous. In central Africa the proudest ebony beauties are to be seen upon the backs of cattle. In all ages they have drawn the plough. In Spain they still trample out the corn; in India they raise the water from the deepest wells to irrigate the thirsty soil of Bengal. When Cæsar invaded Britain they constituted the chief riches of its inhabitants; and they still form no inconsiderable item in the estimate of that country's riches.

The parent race of the $x$ is said to have been much larger than any of the present rarieties. The Urus, in his wild state at least, was an enormous and fierce animal, and ancient legends have thrown around him an air of mystery. In almost every part of the continent of Europe and in every district of England, skulls, evidently belonging to cattle, have been found, far exceeding in bulk any now known. 
As the various breeds of cattle among us were introduced into this country from Great Britain, we propose, before going into the details of the leading American breeds, to glance somewhat briefly at the history of

\section{THE BRITISH OX.}

In the earliest and most reliable accounts which we possess of the British Isles-the Commentaries of Cæsar-we learn that the ancient Britons possessed great numbers of cattle. No satisfactory dêscription of these cattle occurs in any ancient author; but, with occasional exceptions, we know that they possessed no great bulk or beauty. Cæsar tells us that the Britons neglected tillage and lived on milk and flesh; and this account of the early inhabitants of the British Isle is corroborated by other authors. It was such an occupation and mode of life as suited their state of society. The island was divided into many little sovereignties; no fixed property was secure; and that alone was valuable which could be hurried away at the threatened approach of the invader. Many centuries after this, when-although one sovereign seemed to reign paramount over the whole of the kingdom-there continued to be endless contests among the feudal barons, and therefore that property alone continued to be valuable which could be secured within the walls of the castle, or driven beyond the assailant's reach-an immense stock of provisions was always stored up in the various fortresses, both for the rassals and the cattle; or it was contrived that the latter should be driven to the domains of some friendly baron, or concealed in some inland recess.

When the government became more powerful and settled, 
and property of every kind was assured a proportionate degree of protection, as well as more equally divided, the plough came into use; agricultural productions were oftener cultivated, the reaping of which was sure after the labor of sowing. Cattle were then comparatively neglected and for some centuries injuriously so. Their numbers diminished, and their size also seems to bave diminished; and it is only within the last century and a half that any serious and successful efforts have been made materially to improve them.

In the comparatively roving and uncertain life which the earlier inhabitants led, their cattle would sometimes stray and be lost. The country was at that time overgrown with forests, and the beasts betook themselves to the recesses of these woods, and became wild and sometimes ferocious. They, by degrees, grew so numerous as to be dangerous to the inhabitants of the neighboring districts. One of the chronicles asserts that many of them harbored in the forests in the neighborhood of London. Strange stories are told of some of them, and, doubtless, when irritated, they were fierce and dangerous enough. As, however, civilization advanced, and the forests became thinned and contracted, these animals were seen more rarely, and at length almost disappeared. A few of them, however, are still to be found in the parks of some of the leading English noblemen, who keep them for ornament and as curiosities.

The color of this wild breed is invariably white, the muzzle being black; the whole of the inside of the ear, and about one-third of the outside, from the tips downward, red; horns white, with black tips, very fine, and bent upward; some of 
the bulls have a thin, upright mane, about an inch and a half or two inches long. The beef is finely marbled and of excellent flavor.

At the first appearance of any person they set off in full gallop, and at the distance of about two hundred yards, make a wheel around and come boldly up again in a menacing manner; on a sudden they make a full stop at the distance of forty or fifty yards, looking wildly at the object of their surprise; but upon the least motion they all again turn round and fly off with equal speed, but not to the same distance, forming a shorter circle; and, again returning with a more threatening aspect than before, they approach probably within thirty yards, when they again make another stand, and then fly off; this they do several times, shortening their distance and advancing nearer and nearer, till they come within such short distance that most persons think it prudent to leave them.

When the cows calve, they hide their calves for a week or ten days in some retired situation, and go and suckle them two or three times a day. If any persons come near the calves they clap their heads close to the ground to hide themselves-a proof of their native wildness. The dams allow no one to touch their young without attacking with impetuous ferocity. When one of the herd happens to be wounded, or has grown weak and feeble through age or sickness, the rest set on it and gore it to death.

The breeds of cattle which are now found in Great Britain, are almost as various as the soil of the different districts or the fancies of the breeders. They have, however, been very conveniently classed according to the comparative size of the 2 
horns; the long-horns, originally from Lancashire, and established through most of the midland counties; the short-horns, generally cultivated in the northern counties and in Lincolnshire, and many of them found in every part of the kingdom where the farmer pays much attention to his dairy, or where a large supply of milk is desired; and the middle-horns, a distinct and valuable breed, inhabiting, principally, the north of Devon, the east of Sussex, Herefordshire, and Gloucestershire; and of diminished bulk and with somewhat different character, the cattle of the Scottish and Welsh mountains. The Alderney, with its crumpled horn, is found on the southern coast; while the polled, or hornless, cattle prevail in Suffolk, Norfolk, and Galloway, whence they were first derived.

These leading breeds, however, have been intermingled in every possible way. They are found pure only in their native districts, or on the estate of some wealthy and spirited individuals. Each county has its own mongrel breed, often difficult to be described, and not always to be tracedneglected enough, yet suited to the soil and the climate; and among small farmers, maintaining their station, in spite of attempts at improvements by the intermixture or the substi tution of foreign varieties.

Much dispute has arisen as to the original breed of British cattle. The battle has been sharply fought between the advocates of the middle and of the long-horns. The shorthorns and the polls are out of the lists; the latter, although it has existed in certain districts from time immemorial, being probably an accidental variety. The weight of argument 
appears at present to rest with the middle horns; the longhorns being evidently of Irish extraction.

Great Brituin has shared the fate of other nations, and oftener than they been overrun and subjugated by invaders. As the natives retreated they carried with them some portion of their property, consisting, in the remote and early times, principally of cattle. They drove along

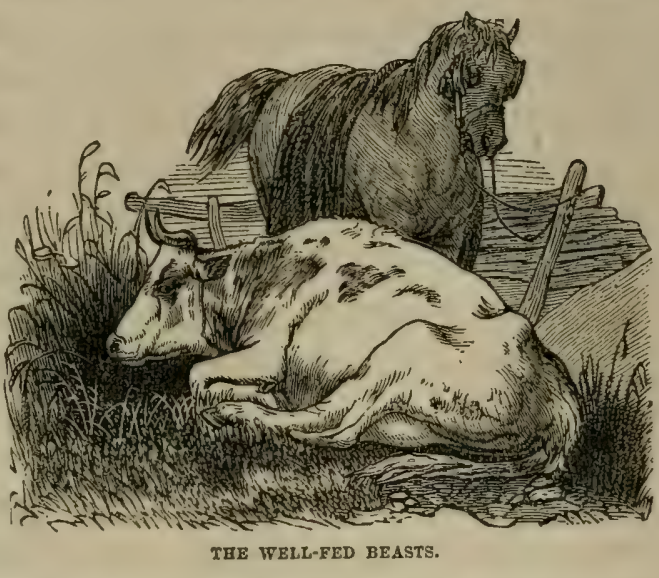
with them as many as they could, when they retired to the fortresses of North Devon and Cornwall, or the mountainous region of Wales, or when they took refuge in the retirement of East Sussex; and there, retaining all their prejudices, manners, and customs, were jealous of the preservation of that which reminded them of their native country before it yielded to a foreign yoke.

In this way was preserved the ancient breed of British cattle. Difference of climate produced some change, particularly in their bulk. The rich pasturage of Sussex fattened the ox into its superior size and weight. The plentiful, but not so luxuriant, herbage of the north of Devon produced a smaller and more active animal; while the privations of Wales lessened the bulk and thickened the hide of the Welsh 
stock. As for Scotland, it set its invaders at defiance; or its inhabitants retreated for a while, and soon turned again on their pursuers. They were proud of their country, and of their cattle, their choicest possession; and there, also, the cattle were preserved, unmixed and undegenerated.

Thence it has resulted, that in Devon, in Sussex, in Wales, and in Scotland, the cattle have been the same from time immemorial; while in all the eastern coasts and through every district of England, the breed of cattle degenerated, or lost its original character; it consisted of animals brought from all the neighboring, and some remote districts, mingled in every possible variety, yet conforming to the soil and the climate.

Careful observations will establish the fact, that the cattle in Devonshire, Sussex, Wales, and Scotland are essentially the same. They are middle horned; not extraordinary milkers, and remarkable for the quality rather than the quantity of their milk; active at work, and with an unequalled aptitude to fatten. They have all the characters of the same breed, changed by soil, climate, and time, yet little changed by man. The color, even, may be almost traced, namely: the red of the Devon, the Sussex, and the Hereford; and where only the black are now found, the recollection of the red prevails.

As this volume is intended especially for the farmers of nur own country, it is deemed unnecessary in this connection to present any thing additional under the present head, except the names of the prominent species of British cattle. These are, commencing with the middle horns, the North Deron, the Hereford, the Sussex, the Welsh (with the rarieties of 
the Pembrokeshire, the Glamorganshire, the Radnor black, the Anglesea and some others); and the Scotch with its chief varieties, the West Highlanders, the North Highlanders, the North Eastern, the Fife, the Ayrshire, and the Galloways.

As to the long horns, which came originally from Craven, in Yorkshire, it may be remarked that this breed has been rapidly disappearing of late, and has everywhere given place to better kinds. Of this species there are-or perhaps weretwo leading classes, the Lancashire and the Leicestershire improved.

Of the short horns, the leading breeds are the Dutch, the Holderness, the Tecswater, the Yorkshire, the Durham, the Northumberland, and some others.

\section{AMERICAN CATTLE.}

The breeds of cattle which stock the farms of the United States are all derived from Europe, and, with few exceptions, from Great Britain. The highest breeds at the present time are of comparatively recent origin, since the great improvements in breeding were only commenced at about the period of the American Revolution. The old importations made by the early settlers, must consequently have been from comparatively inferior grades.

In some sections of the Union, and more particularly in New England, the primitive stock is thought to have undergone considerable improvement; whilst in many parts of the Middle, and especially of the Southern States, a greater or less depreciation has ensued. The prevailing stock in the Eastern States is believed to be derived from the North 
Derons, most of the excellent marks and qualities of which they possess. For this reason they are very highly esteemed, and have been frequently called the American Devon. The most valuable working oxen are chiefly of this breed, which also contributes so largely to the best displays of beef found in the markets of Boston, New York, and Philadelphia. By means of this domestic stock, and the importations still extensively made of selections from the short horns, and others of the finest European breeds, the cattle, not only of New England, but of other sections, are rapidly improving, especially in the Middle and Western States.

A brief sketch of the principal breeds of American cattle, as well as of the grades or common stock of the country, will be of service to the farmer in making an intelligent selection with reference to the special object of pursuit-whether it be the dairy, the production of beef, or the raising of cattle for work.

In selecting any breed, regard should be had to the circumstances of the individual farmer and the object to be pursued. The cow most profitable for the milk dairy, may be very unprofitable in the butter and cheese dairy, as well as for the production of beef; while, for either of the latter objects, the cow which gave the largest quantity of milk might be very undesirable. A union and harmony of all good qualities must be secured, so far as possible. The farmer wants a cow that will milk well for some years; and then, when dry, fatten readily and sell to the butcher for the highest price. These qualities, often supposed to be utterly incompatible, will be found united in some breeds to a greater extent than in others; while some peculiarities of 
form have been found, by observation, to be better adapted to the production of milk and beef than others.

It is proposed, therefore, to sketch the pure breeds now found in America.

\section{THE AYRSHIRE.}

This breed is justly celebrated throughout Great Britain and this country for its excellent dairy qualities. Though

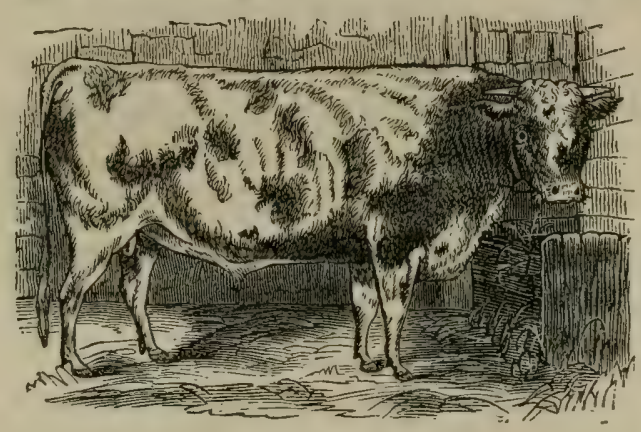

AN ATRSEIRE BTLL.

the most recent in their origin, they are pretty distinct from the Scotch and English races. In color, the pure Aryshires are generally red and white, spotted or mottled, not roan like many of the short horns, but often presenting a bright contrast of colors. They are sometimes, though rarely, nearly or quite all red, and sometimes black and white; but the favorite color is red and white brightly contrasted; and, by some, strawberry-color is preferred. The head is small, fine and clean; the face long and narrow at the muzzle, with a sprightly, yet generally mild expression; eye small, smart and lively; the horns short, fine, and slightly twisted upward, set wide apart at the roots; the neck thin; body enlarging from fore to hind quarters; the back straight and narrow, but broad across the loin; joints rather loose and open; ribs rather flat; hind quarters rather 
thin; bone fine; tail long, fine, and bushy at the end; hair generally thin and soft; udder light color and capacious, extending well forward under the belly; teats of the cow of medium size, generally set regularly and wide apart; milkveins prominent and well developed. The carcass of the pure bred Ayrshire is light, particularly the fore quarters, which is considered by good judges as an index of great milking qualities; but the pelvis is capacious and wide over the hips.

On the whole, the Ayrshire is good looking, but wants some of the symmetry and aptitude to fatten which characterize the short horn, which is supposed to have contributed to build up this valuable breed on the basis of the original stock of the county of Ayr, which extends along the eastern shore of the Firth of Clyde, in the southwestern part of Scotland.

The original stock of this country are described as of a diminutive size, ill fed, ill shaped, and yielding but a scanty return in milk. They were mostly of a black color, with large stripes of white along the chine and ridge of their backs, about the flanks, and on their faces. Their horns were high and crooked, having deep ringlets at the root-the surest proof that they were but scantily fed; the chine of their backs stood up high and narrow; their sides were lank, ehort, and thin; their hides thick and adhering to the bones; their pile was coarse and open; and few of them gave more than six or eight quarts of milk a day when in their best condition, or weighed, when fat, more than from a hundred to a hundred and sixty pounds avoirdupois, rejecting offal.

A wonderful change has since been made in the condition, 
aspect, and qualities of the Ayrshire dairy stock. They are now almost double the size, and yield about four times the quantity of milk that the Ayrshire cows formerly yielded. A large part of this improvement is due to better feeding and care, but much, no doubt, to judicious crossing. Strange as it may seem, considering the modern origin of this breed, all that is certainly known touching it is, that about a century and a half ago there was no such breed as Ayrshire in Scotland. The question has therefore arisen, whether these cattle came entirely from a careful selection of the best native breed. If they did, it is a circumstance without a parallel in the history of agriculture. The native breed may indeed be ameliorated by careful selection; its value may be incalculably increased; some good qualities, some of its best qualities, may be developed for the first time; but yet there will be some resemblance to the original stock, and the more the animal is examined, the more clearly can be traced the characteristic points of the ancestor, although every one of them is improved.

Youatt estimates the daily yield of an Ayrshire corw, for the first two or three months after calving, at five gallons a day, on an average; for the next three months, at three gallons; and for the next four months, at one gallon and a half. This would give eight hundred and fifty gallons as the annual average; but, allowing for some unproductive cows, he estimates the average of a dairy at six hundred gallons a year for each cow. Three gallons and a half of the Ayrshire cow's milk will yield one and a half pounds of butter. Some have estimated the yield still higher.

One of the four cows originally imported into this country 
by John P. Cushing, Esq., of Massachusetts, gave in one year three thousand eight hundred and sixty-four quarts, beer measure, or about nine hundred and sixty-six gallons, at ten pounds the gallon; being an average of over ten and a half beer quarts a day for the entire year. The first cow of this breed, imported by the Massachusetts Society, for the Promotion of Agriculture, in 1837, yielded sixteen pounds of butter a week for sereral successive weeks, on grass feed only. It should be borne in mind, in this connection, that the climate of New England is less favorable to the production of milk than that of England and Scotland, and that no cow imported after arriving at maturity can be expected to yield as much, under the same circumstances, as one bred on the spot where the trial is made, and perfectly acclimated.

On excellent authority, the most approved shape and marks of a good dairy cow are as follows: Head small, long, and narrow toward the muzzle; horns small, clear, bent, and placed at considerable distance from each other; eyes not large, but brisk and lively; neck slender and long, tapering toward the head, with a little loose skin below; shoulders and fore quarters light and thin; hind quarters large and broad; back straight, and joints slack and open ; carcass deep in the rib; tail small and long, reaching to the heels; legs small and short, with firm joints; udder square, but a little oblong, stretching forward, thin skinned and capacious, but not low hung; teats or paps small, pointing outward, and at a considerable distance from each other; milk-veins capacious and prominent; skin loose, thin, and soft like a glove; hair short, soft, and woolly; general figure, when in flesh, handsome and well proportioned. 
If this description of the Ayrshire cow be correct, it will be seen that her head and neck are remarkably clean and fine, the latter swelling gradually toward the shoulders, both parts being unencumbered with superfluous flesh. The same general form extends backward, the fore quarters being light, the shoulders thin, and the carcass swelling out toward the hind quarters, so that when standing in front of her it has the form of a blunted wedge. Such a structure indicates very fully developed digestive organs, which exert a powerful influence on all the functions of the body, and especially on the secretion of the milky glands, accompanied with milkveins and udder partaking of the same character as the stomach and viscera, being large and capacious, while the external skin and interior walls of the milk-glands are thin and elastic, and all parts arranged in a manner especially adapted for the production of milk.

A cow with these marks will generally be of a quiet and docile temper, which greatly increases her value. A cow that is of a quiet and contented disposition feeds at ease, is milked with ease, and yields more than one of an opposite temperament; while, after she is past her usefulness as a milker, she will easily take on fat, and make fine beef and a good quantity of tallow, because she feeds freely, and when dry the food which went to make milk is converted into fat and flesh. But there is no breed of cows with which gentle ness of treatment is so indispensable as with the Ayrshire, on account of her naturally nervous temperament. If she receives other than kind and gentle treatment, she will often resent it with angry looks and gestures, and withhold her milk; and if such treatment is long continued, will dry up; 
but she willingly and easily yields it to the hand that fondles her, and all her looks and movements toward her friends are quiet and mild.

The Ayrshires in their native country are generally bred for the dairy, and for no other object; and the cows have justly obtained a world-wide reputation for this quality. The oxen are, however, very fair as working cattle, though they cannot be said to excel other breeds in this respect. The Ayrshire steer may be fed and turned at three years old; but for feeding purposes the Ayrshires are greatly improved by a cross with the short horns, provided regard is had to the size of the animal. It is the opinion of good breeders that a high-bred short horn bull and a large-sized Ayrshire cow will produce a calf which will come to maturity earlier, and attain greater weight, and sell for more money than a pure-bred Ayrshire.' This cross, with feeding from the start, may be sold fat at two or three jears old, the improvement being most noticeable in the earlier maturity and size.

In the cross with the short horn, the form ordinarily becomes more symmetrical, while there is, perhaps, little risk of lessening the milking qualities of the offspring, if sufficient regard is paid to the selection of the individual animals to breed from. It is thought by some that in the breeding of animals it is the male which gives the external form, or the booy and muscular system of the young, while the female imparts the respiratory organs, the circulation of the blood, the organs of secretion, and the like.

If this principle be true, it follows that the milking qualities come chiefly from the mother, and that the bull cannot 
materially alter the conditions which determine the trarsmission of these qualities, especially when they are as strongly marked as they are in this breed.

Until, however, certain mooted questions connected with breeding are definitively settled, it is the safest plan, in breeding for the dairy, to adhere to the rule of selecting only animals whose progenitors on both sides have been distinguished for their milking qualities.

It may be stated, in conclusion, that for purely dairy purposes the Ayrshire cow deserves the first place. In consequence of her small, symmetrical, and compact body, combined with a well-formed chest and a capacious stomach, there is little waste, comparatively speaking, through the - respiratory system; while at the same time there is very complete assimilation of the food, and thus she converts a very large proportion of her food into milk. So remarkable is this fact, that all dairy farmers who have any experience on the point, agree in stating that an Ayrshire cow generally gives a larger return of milk for the food consumed than $a$ cow of any other breed. The absolute quality may not be so great, but it is obtained at a less cost; and this is the point upon which the question of profit depends. The best milkers which have been known in this country were grade Ayrshires, larger in size than the pure bloods, but still sufficiently high grades to give certain signs of their origin This grade would seem to possess the advantage of combining, to some extent, the two qualities of milking and adaptation to beef; and this is no small recommendation of the stock to farmers situated as American farmers are, who 
wish for milk for some years and then to turn over to the outcher.

\section{THE JERSEY.}

These cattle are now widely known in this country. Many of them have been imported from an island of the same name in the British Channel, near the coast of France, and they may now be considered, for all practical purposes, as fully acclimated. They were first introduced, upward of thirty years ago, from the channel islands, Alderney, Guernsey, and Jersey.

This race is supposed to have been originally derived from Normandy, in the northern part of France. The cows have been long celebrated for the production of very rich milk and cream, but till within the last twenty-five or thirty years they were comparatively coarse, ugly, and ill-shaped. Improvements have been very marked, but the form of the animal is still far from satisfying the eye.

The head of the pure Jersey is fine and tapering, the cheek small, the throat clean, the muzzle fine and encircled with a light stripe, the nostril high and open; the horns smooth, crumpled, but not very thick at the base, tapering and tipped with black; ears small and thin, deep orange color inside; eyes full and placid; neck straight and fine; chest broad and deep; barrel hoofed, broad and deep, well ribbed up; back straight from the withers to the hip, and from the top of the hip to the setting of the tail; tail fine, at right angles with the back, and hanging down to the hocks; skin thin, light color, and mellow, covered with fine soft hair; fore legs short, straight and fine below the knee, urm swelling and full 
above; hind quarters long and well filled; hind legs short and straight below the hocks, with bones rather fine, squarely placed, and not too close together; hoofs small; udder full in size, in line with the belly, extending well up behind; teats of medium size, squarely placed and wide apart, and milk-veins very prominent. The color is generally cream, dun, or yellow, with more or less of white, and the fine head and neck give the cows and heifers a fawn-like appearance, and make them objects of attraction in the park; but the hind quarters are often too narrow to work well, particularly to those. who judge animals by the amount of fat which they carry.

It should be borne in mind, however, that a good race of animals is not always the most beautiful, as that term is generally understood. Beauty in stock has no invariable standard. In the estimation of some, it results mainly from fine forms, small bones, and close, compact frames; whilo others consider that structure the most perfect, and therefore the most beautiful, which is best adapted to the use for which it is destined. With such, beauty is relative. It is not the same in an animal designed for beef and in one designed for the dairy or for work. The beauty of a milch cow is the result of her good qualities. Large milkers are very rarely cows that please the eye of any but a skillful judge. They are generally poor, since their food goes mainly to the production of milk, and because they are selected with less regard to form than to good milking qualities. The prevailing opinion as to the beauty of the Jersey, is based on the general appearance of the cow when in milk-no experiments in feeding exclusively for beef having been made public, and 
no opportunity to form a correct judgment from actual observation having been furnished; and it must be confessed that the general appearance of the breed would amply justify the hasty conclusion.

The bulls are usually very different in character and disposition from the cows, and are much inclined to become restive and cross at the age of two or three years, unless their treatment is uniformly gentle and firm.

The Jersey is to be regarded as a dairy breed, and that almost exclusively. It would not be sought for large dairies kept for the supply of milk to cities; for, though the quality would gratify the customer, the quantity would not satisfy the owner. The place of the Jersey cow is rather in private establishments, where the supply of cream and butter is a sufficient object; or, in limited numbers, to add richness to the milk of large butter dairies. Even one or two good Jersey cows with a herd of fifteen or twenty, will make a great difference in the quality of the milk and butter of the whole establishment; and they would probably be profitable for this, if for no other object.

\section{THE 'SHORT HORNS.}

No breed of cattle has commanded more universal admiration during the last half century than the improved short horns, whose origin can be traced back for nearly a hundred years. According to the best authorities, the stock which formed the basis of improvement existed equally in Yorkshire, Lincolnshire, Northumberland, and the adjoining counties; and the pre-eminence was accorded to Durham, 
which gave its name to the race, from the more correct principles of breeding which seem to have obtained there.

There is a dispute among the most eminent breeders as to how far it owes its origin to early importations from Holland, whence many superior animals were brought for the purpose of improving the old long horned breed. A large race of cattle had existed for many years on the western shores of the continent of Europe. As early as 1633, they were imported from Denmark into New England in considerable numbers, and thus laid the foundation of a valuable stock in

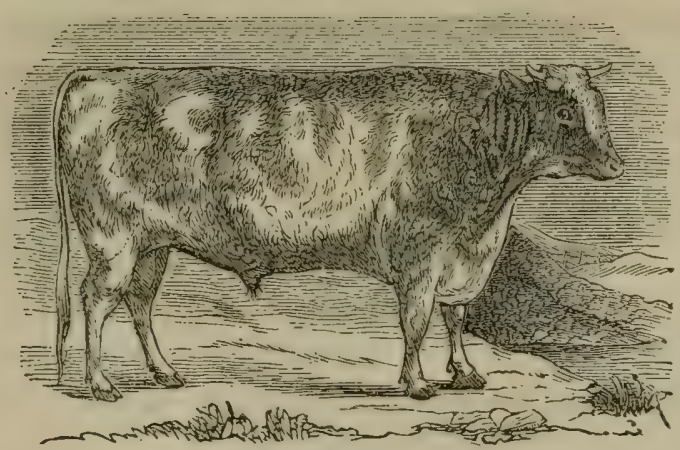

A BHORT HORN BOLL.

this country. They extended along the coast, it is said, through Holland to France. The dairy formed a prominent branch of farming at a very early date in Holland, and experience led to the greatest care in the choice and breeding of dairy stock. From these cattle many selections were made to cross over to the counties of York and Durham. The prevailing color of the large Dutch cattle was black and white, beautifully contrasted.

The cattle produced by these crosses a century ago were known by the name of "Dutch." The corvs selected for crossing with the early imported Dutch bulls were generally long horned, large boned, coarse animals, a fair type of which 3 
was found in the old "Holderness" breed of Yorkshire-slow feeders, strong in the shoulder, defective in the fore quarter, and not very profitable to the butcher, their meat being coarse and uninviting. Their milking qualities were good, surpassing those, probably, of the improved short horns. Whatever may be the truth with regard to these crosses, and however far they proved effective in creating or laying the foundation of the modern improved short horns, the results of the efforts made in Yorkshire and some of the adjoining counties were never so satisfactory to the best judges as those of the breeders along the Tees, who selected animals with greater reference to fineness of bone and symmetry of form, and the animals they bred soon took the lead and excited great emulation in improvement.

Importations of short horns have been frequent and extensive into the United States within the last few years, and this famous breed is now pretty generally diffused over the country.

The high-bred short horn is easily prepared for a show, and, as fat will cover faults, the temptation is often too great to be resisted; and hence it is not uncommon to see the finest animals rendered unfit for breeding purposes by over-feeding. The race is susceptible of breeding for the production of milk, as several families show, and great milkers have often been known among pure-bred animals; but it is more common to find it bred mainly for the butcher, and kept accordingly. It is, however, a well-known fact, that the dairies of London are stocked chiefly with short horns and Yorkshires, or high grades between them, which, after being milked as long as profitable, feed equal, or nearly so, to pure-bred short horns. 
It has been said, by very good authority, that the short horns improve every breed with which they cross.

The desirable characteristics of the short horn bull may be summed up, according to the judgment of the best breeders, as follows: He should have a short but fine head, very broad across the eyes, tapering to the nose, with a nostril full and prominent; the nose itself should be of a rich flesh color; eyes bright and mild; ears somewhat large and thin ; horns slightly covered and rather flat, well set on; a long, broad, muscular neck; chest wide, deep, and projecting ; shoulders fine, oblique, well formed into the chine; fore legs short, with upper arm large and powerful; barrel round, deep, well-ribbed horns; hips wide and level; back straight from the withers to the setting on of the tail, but short from hips to chine; skin soft and velvety to the touch; moderately thick hair, plentiful, soft, and mossy. The cow has the same points in the main, but her head is finer, longer, and more tapering; neck thinner and lighter, and shoulders more narrow across the chine.

The astonishing precocity of the short horns, their remarkable aptitude to fatten, the perfection of their forms, and the fineness of their bony structure, give them an advantage over most other races when the object of breeding is for the shambles. No animal of any other breed can so rapidly transform the stock of any section around him as the improved short horn bull.

It does not, however, follow that the high-bred short horns are unexceptionable, even for beef. The very exaggeration, so to speak, of the qualities which make them so valuable ior the improvement of other and less perfect races, may become a fault when wanted for the table. The very rapidity with 
which they increase in size is thought by some to prevent their meat from ripening up sufficiently before being hurried off to the butcher. The disproportion of the fatty to the muscular flesh, found in this to a greater extent than in races coming more slowly to maturity, makes the meat of the thorough-bred short horn, in the estimation of some, less agreeable to the taste, and less profitable to the consumer; since the nitrogenous compounds, true sources of nutriment, are found in less quantity than in the meat of animals not so highly bred.

In sections where the climate is moist, and the food abundant and rich, some families of the short horns may be valuable for the dairy; but they are most frequently bred exclusively for beef in this country, and in sections where they have attained the highest perfection of form and beauty, so little is thought of their milking qualities that they are often not milked at all, the calf being allowed to run with the dam.

THE DUTCH.

This short horned race, in the opinion of many-as has been previously remarked-contributed largely, about a century ago, to build up the Durham or Teeswater stock. It has been bred with special reference to dairy qualities, and is eminently adapted to supply the wants of the dairy farmer. The cows of North Holland not only give a large quantity, but also a very good quality, so that a yield of sixteen to twenty-five quarts, wine measure, at every milking, is not rare.

The principles upon which the inhabitants of Holland practise, in selecting a cow from which to breed, are as 
follows: She should have, they say, considerable size-not less than four and a half or five feet girth, with a length of body corresponding; legs proportionally short; a finely formed head, with a forehead or face somewhat concave; clear, large, mild and sparkling eyes, yet with no expression of wildness; tolerably large and stout ears, standing out from the head; fine, well curved horns; a rather short, than long, thick, broad neck, well set against the chest and withers; the front part of the breast and shoulders must be broad and fleshy; the low-hanging dewlap must be soft to the touch; the back and loins must be properly projected, somewhat broad, the bones not too sharp, but well corered with flesh; the animal should have long curved ribs, which form a broad breast bone; the body must be round and deep, but not sunken into a hanging belly; the rump must not be uneven, the hip-bones should not stand out too broad and spreading, but all the parts should be level and well filled up; a fine tail, set moderately high up and tolerably long, but slender, with a thick, bushy tuft of hair at the end, hanging down below the hocks; the legs must be short and low, but strong in the bony structure; the knees broad, with flexible joints; the muscles and sinews must be firm and sound, the hoofs broad and flat, and the position of the legs natural, not too close and erowded; the hide, covered with fine glossy hair, must be soft and mellow to the touch, and set loose upon the body. A large, rather long, white and loose udder, extending well back, with four long teats, serves also as a characteristic mark of a good milch cow. Large and prominent milkveins must extend from the navel back to the udder; the lielly of a good milch cow should not be too deep and hang- 
ing. The color of the North Dutch cattle is mostly variegated. Cows with only one color are no favorites. Red or black variegated, gray and blue variegated, roan, spotted and white variegated cows, are especially liked

\section{THE HEREFORJ.}

These cattle derive their name from a county in the western part of England. Their general characteristics are a white face, sometimes mottled; white throat, the white generally extending back on the neck, and sometimes, though rarely, still further along on the back. The color of the rest of the body is red, generally dark, but sometimes light. Eighty years ago the best Hereford cattle were mottled or roan all over; and some of the best herds, down to a comparatively recent period, were either all mottled, or had the mottled or speckled face.

The expression of the face is mild and lively; the forehead open, broad, and large; the eyes bright and full of vivacity ; the horns glossy, slender and spreading; the head small, though larger than, and not quite so elear as, that of the Devons; the lower jaw fine; neck long and slender; chest deep; breast-bone large, prominent, and very muscular; the shoulder-blade light; shoulder full and soft; brisket and loins large; hips well developed, and on a level with the chine; hind quarters long and well filled in; buttocks on a level with the back, neither falling off nor raised above the hind quarters; tail slender, well set on; hair fine and soft; body round and full ; carcass deep and well formed, or cylindrical; bone small; thigh short and well made; legs short and straight, and slender below the knee; as handlers very 
excellent, especially mellow to the touch on the back, the shoulder, and along the sides, the skin being soft, flexible, of medium thickness, rolling on the neck and the hips; hair bright; face almost bare, which is characteristic of pure Herefords.

They belong to the middle horned division of the cattle of Great Britain, to which they are indigenous, and have been improved within the last century by careful selections.

Hereford oxen are excellent animals, less active but stronger than the Devons, and very free and docile. The demand for Herefords for beef prevents their being much used for work in their native county, and the farmers there generally use horses instead of oxen.

It is generally conceded that the qualities in which Herefords stand pre-eminent among the middle-sized breeds are in the production of oxen and their superiority of flesh. On these points there is little chance of their being excelled. It should, however, be borne in mind that the best oxen are not produced from the largest cows; nor is a superior quality of flesh, such as is considered very soft to the touch, with thin skin. It is the union of these two qualities which often characterizes the short horns; but Hereford breeders-as a recent writer remarks-should endeavor to maintain a higher standard of excellence-that for which the best of the breed have always been esteemed-a moderately thick, mellow hide, with a well apportioned combination of softness with elasticity. A sufficiency of hair is also desirable, and if accompanied with a disposition to curl moderately, it is more in esteem; but that which has a harsh and wiry feel is objectionable. 
In point of symmetry and beauty of form, the well bred Herefords may be classed with the improved short horns, though they arrive somewhat more slowly at maturity, and never attain such weight. Like the improved short horns, they are chiefly bred for beef, and their beef is of the best quality in the English markets, commanding the highest price of any, except, perhaps, the West Highlanders. The short horn produces more beef at the same age than the Hereford, but consumes more food in proportion.

The Herefords are far less generally spread over England than the improved short horns. They have seldom been bred for milk, as some families of the latter have; and it is not very unusual to find pure-bred cows incapable of supplying milk sufficient to nourish their calves. They have been imported to this country to some extent, and several fine herds exist in different sections; the earliest importations being those of Henry Clay, of Kentucky, in 1817.

The want of care and attention to the udder, soon after calving, especially if the cow be on luxuriant grass, often injures her milking properties exceedingly. The practice in the county of Hereford has generally been to let the calves suckle from four to six months, and bull calves often run eight months with the cow. But their dairy qualities are perhaps as good as those of any cattle whose fattening properties have been so carefully developed; and, though it is probable that they could be bred for milk with proper care and attention, yet, as this change would be at the expense of other qualities equally valuable, it would evidently be wiser to resort to other stock for the dairy. 
THE NORTH DEVONS.

This beautiful race of middle horned cattle dates further back than any well established breed among us. It goes generally under the $\mathrm{si} \mathrm{m} \mathrm{p} 1 \mathrm{e}$ nam e of Devon; but the cattle of the southern part of the county, from which

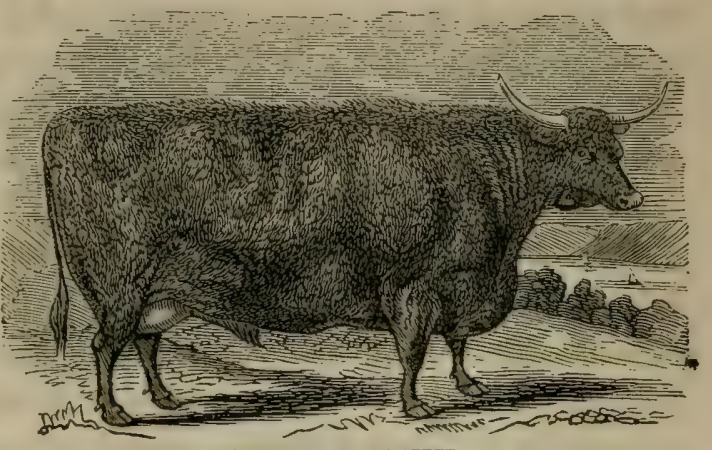

A NORTH DEYON STEER.

the race derives its name, differ somewhat from those of the northern, having a larger and coarser frame, and far less tendency to fatten, though their dairy qualities are superior.

The North Devons are remarkable for hardihood, symmetry and beauty, and are generally bred for work and for beef, 'rather than for the dairy. The head is fine and well set on; the horns of medium length, generally curved; color usually bright blood-red, but sometimes inclining to yellow; skin thin and orange-yellow; hair of medium length, soft and silky, making the animals remarkable as handlers; muzzle of the nose white; eyes full and mild; ears yellowish, or orange-color inside, of moderate size; neck rather long, with little dewlap; shoulders oblique; legs small and straight, with feet in proportion; chest of good width; ribs round and expanded; loins of first-rate quality, long, wide, and fleshy; hips round, of medium width; rump level; tail full near the 
setting on, tapering to the tip; thighs of the bull and ox muscular and full, and high in the flank, though in the cow sometimes thought to be light; the size medium, generally called small. The proportion of meat on the valuable parts is greater, and the offal less, than on most other breeds, while it is well settled that they consume less food in its production. The Devons are popular with the Smithfield butchers, and their beef is well marbled or grained.

As working oxen, the Devons perhaps excel all other races in quickness, docility, beauty, and the ease with which they are matched. With a reasonable load, they are said to be nequal to horses as walkers on the road, and when they are no longer wanted for work they fatten easily and turn well.

As milkers, they do not excel-perhaps they may be said not to equal-the other breeds, and they have a reputation of being decidedly below the average. In their native country the general average of the dairy is one pound of butter a day during the summer. They are bred for beef and for work, and not for the dairy; and their yield of milk is small, though of a rich quality. Several animals, however; of the celebrated Patterson herd would have been remarkable as milkers even among good milking stock.

Still, the faults of the North Devon cow, considered as a dairy animal, are too marked to be overlooked. The rotundity of form and compactness of frame, though they contribute to her remarkable beauty, constitute an objection to her for this purpose: since it is generally admitted that the peculiarity of form which disposes an animal to take on fat is somewhat incompatible with good milking qualities. On this account, Youatt-who is standard authority in such 
matters-says that for the dairy the North Devon must be acknowledged to be inferior to several other breeds. The milk is good, and yields more than the average proportion of cream and butter; but it is deficient in quantity. He also maintains that its property as a milker could not be im proved without producing a certain detriment to its grazing qualities. Distinguished Devon breeders themselves have come to the same conclusion upon this point. The improved North Devon cow may be classed, in this respect, with the Hereford, neither of which has well developed milk-vesselsa point of the utmost consequence to the practical dairyman.

\section{NATIVE CATTLE.}

The foregoing comprise the pure-bred races in America; for, though other and well-established breeds-like the Galloways, the long horns, the Spanish, and others-have, at times, been imported, and have had some influence on our American stock, yet they have not been kept distinct to such an extent as to become the prevailing stock of any particular section.

A large proportion, however-by far the largest proportion, indeed-of the cattle known among us cannot be included under any of the races to which allusion has been made; and to the consideration of this class the present article is devoted.

The term "breed"-as was set forth in the author's treatise, "The Horse and his Diseases"-when properly understood, applies only to animals of the same species, possessing, besides the general characteristics of that species, other characteristics peculiar to themselves, which they owe 
to the influence of soil, climate, nourishment, and the habits of life to which they are subjected, and which they transmit with certainty to their progeny. The characteristics of certain breeds or families are so well marked, that, if an ndividual supposed to belong to any one of them were to produce an offspring not possessing them, or possessing them only in part, with others not belonging to the breed, it would be just ground for suspecting a want of purity of blood.

In this view, no grade animals, and no animals destitute of fixed peculiarities or characteristics which they share in common with all other animals of the class of which they are a type, and which they are capable of transmitting with certainty to their descendants, can be recognized by breeders as belonging to any one distinct race, breed, or family.

The term "native" is applied to a vast majority of our American cattle, which, though born on the soil, and thus in one sense natives, do not constitute a breed, race, or family, as correctly understood by breeders. They do not possess characteristics peculiar to them all, which they transmit with any certainty to their offspring, either of form, size, color, milking or working properties.

But, though an animal may be made up of a mixture of blood almost to impurity, it does not follow that, for specific purposes, it may not, as an individual animal, be one of the best of the species. Indeed, for particular purposes, animals might be selected from among those commonly called "natives" in New England, and "scrubs" at the west and south, equal, and perhaps superior, to any among the races produced by the most skillful breeding. 
There can be no objection, therefore, to the use of the term "native," when it is understood as descriptive of no known breed, but only as applied to the common stock of a country, which does not constitute a breed. But perhaps the entire class of animals commonly called "natives" would be more accurately described as grades; since they are well known to have sprung from a great variety of cattle procured at different times and in different places on the continent of Europe, in England, and in the Spanish West Indies, brought together without any regard to fixed principles of breeding, but only from individual convenience, and by accident.

The first importations to this country were doubtless those taken to Virginia previous to 1609 , though the exact date of their arrival is not known. Several cows were carried there from the West Indies in 1610, and in the next year no less than one hundred arrived there from abroad.

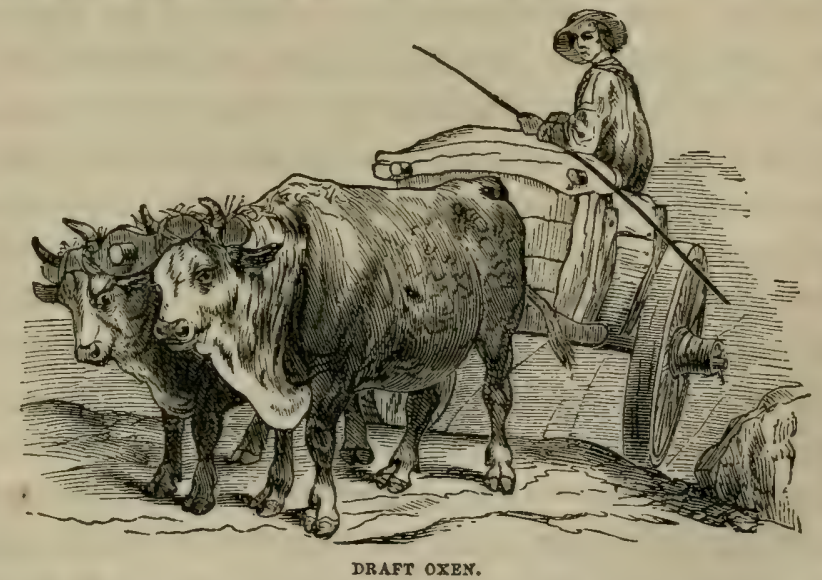

The earliest cattle imported into New England arrived in 1624. At the division of cattle which took place three years 
after, one or two are distinctly described as black, or black and white, others as brindle, showing that there was no uniformity of color. Soon after this, a large number of cattle were brought over from England for the settlers at Salem. These importations formed the original stock of Massachusetts.

In 1725, the first importation was made into New York from Holland by the Dutch West India Company, and the foundation was then laid for an exceedingly valuable race of animals, which subsequent importations from the same country, as well as from England, have greatly improved. The points and value of this race in its purity have been already adverted to under the head of the Dutch cattle.

In 1627 , cattle were brought from Sweden to the settlements on the Delaware, by the Swedish West India Company. In 1631, 1632, and 1633, several importations were made into New Hampshire by Captain John Mason, who, with Gorges, had procured the patent of large tracts of land in the vicinity of the Piscataqua river, and who immediately formed settlements there. The object of Mason was to carry on the manufacture of potash. For this purpose he employed the Danes; and it was in his voyage to and from Denmark that he procured many Danish cattle and horses, which were subsequently scattered over that entire region, large numbers being driven to the vicinity of Boston and sold. These Danish cattle are described as large and coarse, of a yellow color; and it is supposed that they were procured by Mason as being best capable of enduring the severity of the climate and the hardships to which they would be subjected. 
However this may have been, they very soon spread among the colonists of the Massachusetts Bay, and have undoubtedly left their marks on the stock of the New England and the Middle States, which exist to some extent even to the present day, mixed in with an infinite multitude of crosses with the Devons, the Dutch cattle already alluded to, the black cattle of Spain and Wales, and the long horn and the short horn-most of which crosses were accidental, or due to local circumstances or individual convenience. Many of these cattlè, the descendants of such crosses, are of a very high order of merit; but to which particular cross this is due, it is impossible to say. They generally make hardy, strong, and docile oxen, easily broken to the yoke and quick to work, with a fair tendency to fatten when well fed; while the cows, though often ill-shaped, are sometimes remarkably good milkers, especially as regards the quantity which they give.

Indeed, it has been remarked by excellent judges of stock, that if they desired to select a dairy of cows for milk for sale, they would make their selection from cows commonly called native, in preference to pure-bred animals of any of the established breeds, and that they believed they should fiud such a dairy the most profitable.

In color, the natives, made up as already indicated, are exceedingly various. The old Denmarks, which to a considerable extent laid the foundation of the stock of Maine and New Hampshire, were light yellow. The Dutch of New York and the Middle States, were black and white; the Spanish and Welsh were generally black; the Devons, which are supposed to have laid the foundation of the stock of some 
of the States, were red. Crosses of the Denmark with the Spanish and Welsh naturally made a dark brindle; crosses of the Devon often made a lighter or yellowish brindle; while the more recent importations of Jerseys and short horns have generally produced a beautiful spotted progeny The deep red has long been a favorite color in New Eugland; but the prejudice in its favor is fast giving way to more variegated colors.

Among the earlier importations into this country were also several varieties of hornless cattle, which have been kept measurably distinct in some sections; or where they have been crossed with the common stock there has been a tendency to produce hornless grades. These are not unfrequently known as "buffalo cattle." They were, in many cases, supposed to belong to the Galloway breed; or, which is more likely, to the Suffolk dun, a variety of the Galloway, and a far better milking stock than the Galloways, from which it sprung. These polled, or hornless cattle vary in color and qualities, but they are usually very good milkers when well kept, and many of them fatten well, and attain good weight.

The Hungarian cattle have also been imported, to some extent, into different parts of the country, and have been crossed upon the natives with some success. Many other strains of blood from different breeds have also contributed to build up the common stock of the country of the present day; and there can be no question that its appearance and value have been largely improved during the last quarter of a century, nor that improrements are still in progress which will lead to satisfactory results in the future. 
But, though we already have an exceedingly valuable foundation for improvement, no one will pretend to deny that our cattle, as a whole, are susceptible of it in many respects. They possess neither the size, the symmetry, nor the early maturity of the short horns; they do not, as a general thing, possess the fineness of bone, the beauty of form and color, nor the activity of the Devons or the Herefords; they do not possess that uniform richness of milk. united with generous quality, of the Ayrshires, nor the surpassing richness of milk of the Jerseys: but, above all, they do not possess the power of transmitting the many good qualities which they often have to their offspring-which is the characteristic of all well established breeds.

It is equally certain, in the opinion of many good judges, that the dairy stock of the country has not been materially improved in its intrinsic good qualities during the last thirty or forty years. This may not be true of certain sections, where the dairy bas been made a special object of pursuit, and where the custom of raising the best male calves of the neighborhood, or those that came from the best dairy cows, and then of using only the best formed bulls, has long prevailed. Although in this way some progress has, doubtless, been made, there are still room and need for more. More attention must be paid to correct principles of breeding before the satisfactory results which every farmer should strive to reach can be attained.

Having glanced generally at the leading breeds of cattle in Great Britain, and examined, more in detail, the various breeds in the United States, the next subject demanding attention is, 


\section{THE NATURAL HISTORY OF CATTLE.}

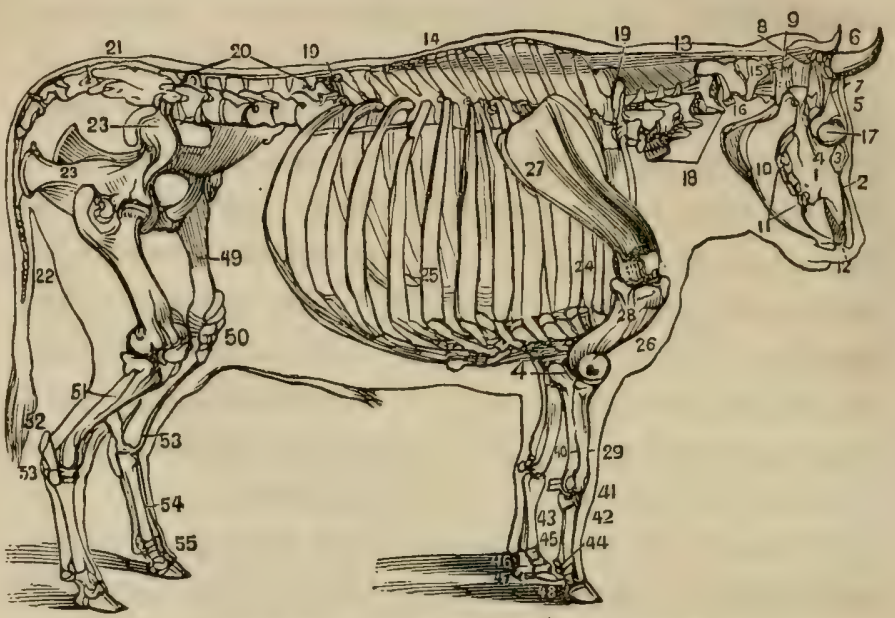

SKELETON OF THE OY $\triangle 9$ COVERED BY THE MUSCLES.

1. The upper jaw-bone. 2. The nasal bone, or bone of the nose. 3. The lachrymal bone. 4. The malar, or cheek bone. 6. The frontal bone, or bone of the forehead. 6. The horns, being processes or continuations of the frontal. 7. The temporal bone. 8. The parietal bone, low in the temporal fossa. 9. The occipital bone, deeply depressed below the crest or ridge of the head. 10. The lower jaw. 11. 'The grinders. 12. The nippers, found on the lower jaw alone. 13. The ligament of the neck, and its attachments. 14. The atlas, 16. The dentata. 17. The orbits of the eye. 18. The vertebræ, or bones of the neck. 19. The bones of the back. 20. The bones of the loins. 21. The sacrum. 22. The bones of the tail. 23. The hauph and pelvis. 24. The eight true ribs. 25. The false ribs, with their cartilages. 26. The sternum. 27. The scapula, or shoulder-blade. 28. The humerus, or lower bone of the shoulder. 29. The radius, or principal bone of the arm. 40. The ulna, its upper part forming the elbow. 41. The small bones of the knee. 42. The large metacarpal or shank bone. 43. The smaller or splint bone. 44. The sessamoid bones. 45. The bifurcation at the pasterns, and the two larger pasterns to each foot. 46. The two smaller pasterns to each foot. 47. The two coffin bones to each foot. 48. The navieular bones. 49. The thich bone. 50. The patella, or bone of the knee. 51. The tibia, or proper leg bone. 52. The noint of the hock. 53. The small honee of the hock. 54. The metatarsals, or larger bones of the hind leg. 55. The pasteras and feet.

Division. Vertebrata-possessing a back-bone.

Class. Mammalia-such as give suck. 
ORDER. Ruminantia-chewing the cud.

FAMILY. With horns.

Genus. Bovida - the ox tribe.

Of this tribe there are eight species:

Bos'urus, the ancient bison.

Bos bison, the American buffalo.

Bos moschatus, the musk ox.

Bos frontalis, the gayal.

Bos grunniens, the grunting ox.

Bos caffer, the South African buffalo.

Bos bubalus, the common buffalo.

Bos taurus, the common domestic ox.

\section{GESTATION.}

The usual period of pregnancy in a cow is nine calendar months, and something over: at times as much as three weeks. With one thousand and thirty one cows, whose gestations were carefully observed in France, the average period was about two hundred and eighty-five days.

\section{FORMATION OF TEETH.}

It is of the utmost importance to be able to judge of the age of a cow. Few farmers wish to purchase a cow for the dairy after she has passed her prime, which will ordinarily be at the age of nine or ten years, varying, of course, accord. ing to care, feeding, \&c., in the earlier part of her life.

The common method of forming an estimate of the age of cattle is by an examination of the horn. At three years old, as a general rule, the horns are perfectly smooth; after this, a ring appears near the nob, and annually afterward a new 
one is formed, so that, by adding two years to the first ring, the age is calculated. This is a very uncertain mode of

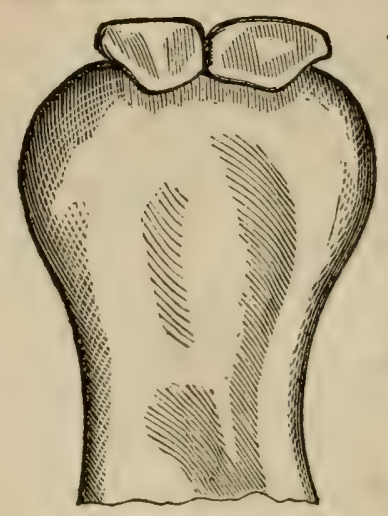
judging. The rings are distinct only in the cow; and it is well known that if a heifer goes to bull when she is two years old, or a little before or after that time, a change takes place in the horn and the first ring appears; so that a real three-year-old would carry the mark of a four-year-old.

The rings on the horns of a bull TEETH AT BIRTE. are either not seen until five, or they cannot be traced at all ; while in the ox they do not appear till he is five years old, and then are often very indistinct. In addition to this, it is by no

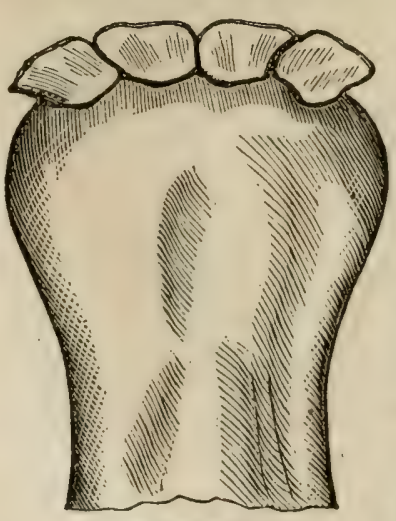

SECOND WEEK. means an uncommon practice to file the horns, so as .to make them smooth, and to give the animal the appearance of being much younger than it really is. This is, therefore, an exceedingly fallacious guide, and cannot be relied upon by any one with the degree of confidence desired.

The surest indication of the age in cattle, as in the horse, is given by the teeth.

The calf, at birth, will usually have two incisor or front teeth-in some cases just appearing through the gums; in 
others, fully set, varying as the cow falls short of, or exceeds, her regular time of calving. If she overruns several days,

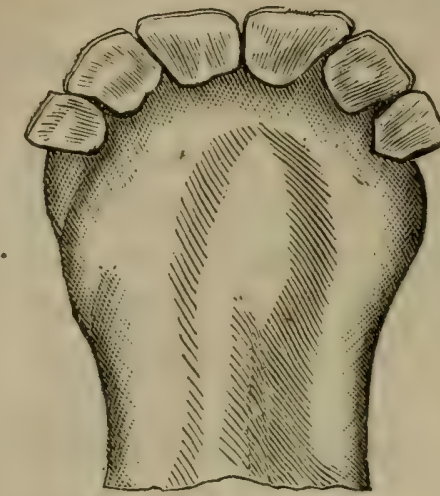

THREE WEEES.

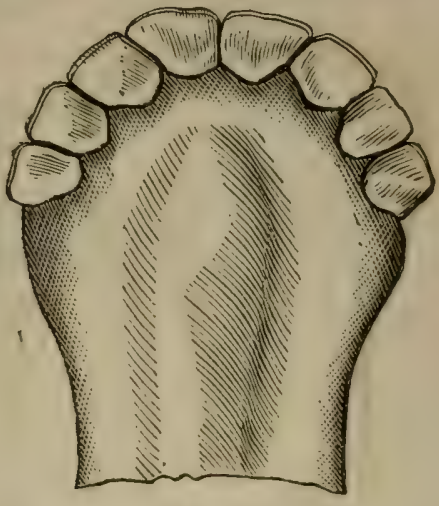

EONTR.

the eeth will have set and attained considerable size, as appears in the cut representing teeth at birth. During the second week, a tooth will usually be added on each side, and

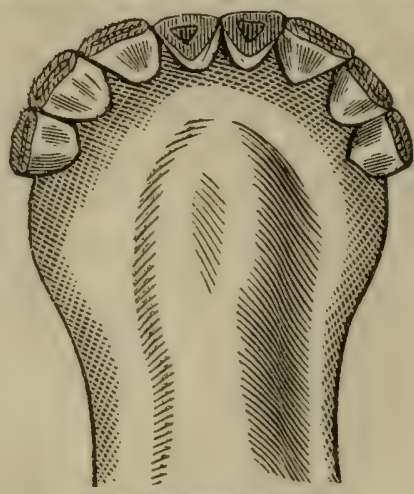

PIVE TO EICET MONTES.

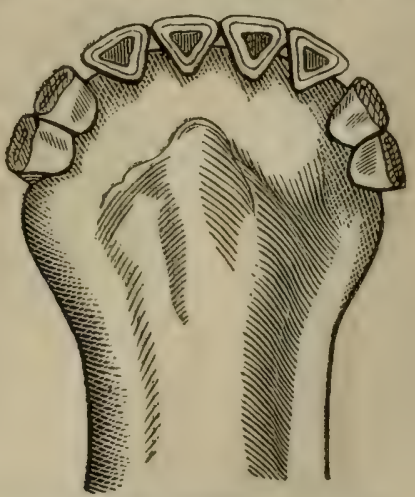

TEN YONTHS.

the mouth will generally appear as in the next cut; and before the end of the third week, the animal will generally have six incisor teeth, as denoted in the cut representing 
teeth at the third week; and in a week from that time the full number of incisors will have appeared, as seen in the

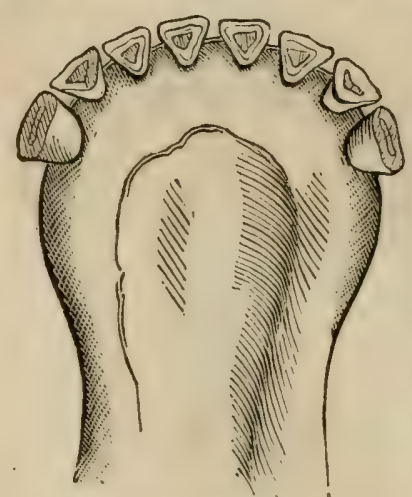

TWELVE MONTHS. next cut.

These teeth are temporary, and are often called milk-teeth. Their edge is very sharp; and as the animal begins to live upon more solid food, this edge becomes worn, showing the bony part of the tooth beneath, and indicates with considerable precision the length of time they have been used. The centre, or oldest teeth show the marks of age first, and often become somewhat worn before the corner teeth appear. At eight

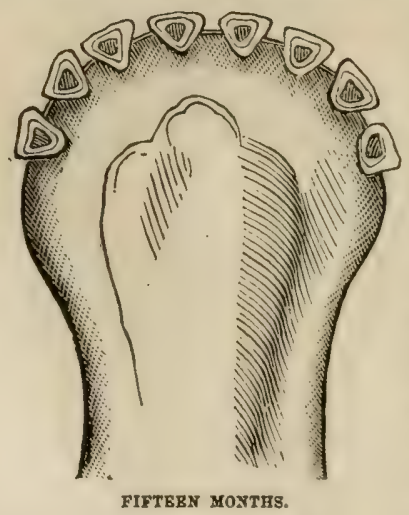
weeks, the four inner teeth are nearly as sharp as before. They appear worn not so much on the outer edge or line of the tooth, as inside this line; but, after this, the edge begins gradually to lose its sharpness, and to present a more flattened surface; while the next outer teeth wear down like the four central ones; and at three months this wearing off is very apparent, till at four months all the incisor teeth appear worn, but the inner ones the most. Now the teeth begin slowly to diminish in size by a 
Find of contraction, as well as wearing down, and the distance apart becomes more and more apparent.

From the fifth to the eighth month, the inner teeth will usually appear as in the cut of the teeth at that time; and at ten months, this change shows more clearly, as represented in the next cut, and the spaces between them begin to show very plainly, till at a year old they ordinarily present the appearance of the following cut;

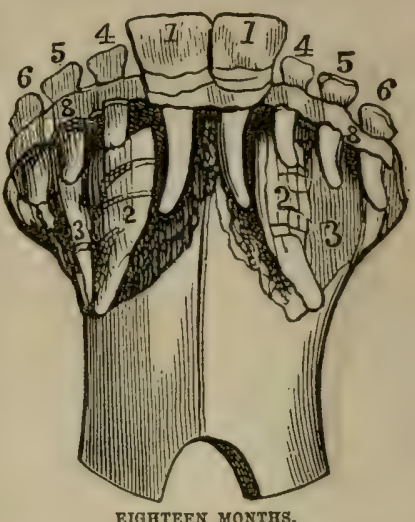
and at the age of fifteen months, that shown in the next, where the corner teeth are not more than half the original size, and the centre ones still smaller.

The permanent teeth are now rapidly growing, and preparing to take the place of the milkteeth, which are gradually $a b$ sorbed till they disappear, or are pushed out to give place to the two permanent central incisors, which at a year and a half will generally present the ap-

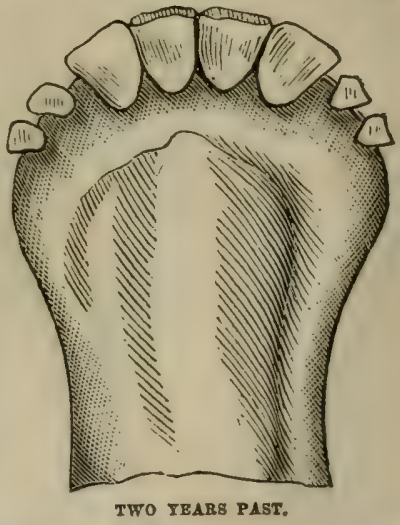
pearance indicated in the cut, which shows the internal structure of the lower jaw at this time, with the cells of the teeth, the two central ones protruding into the mouth, the next two pushing up, but not quite grown to the surface, 
with the third pair just perceptible. These changes require time; and at two years past the jaw will usually appear as

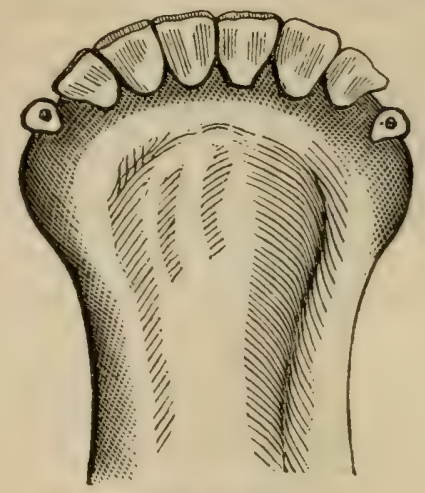

THREE TEARS PAST.

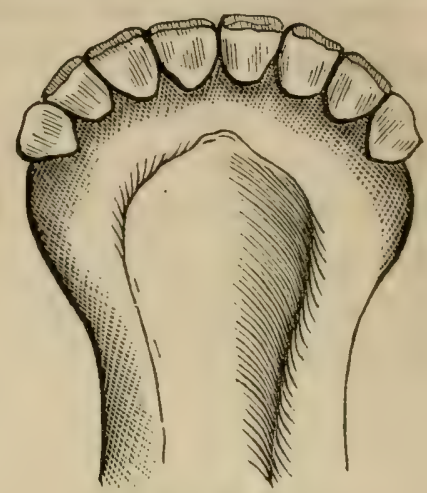

FOER TEARS PAST.

in the cut, where four of the permanent central incisors are seen. After this, the other milk-teeth decrease rapidly, but are slow to disappear; and at three years old, the third pair

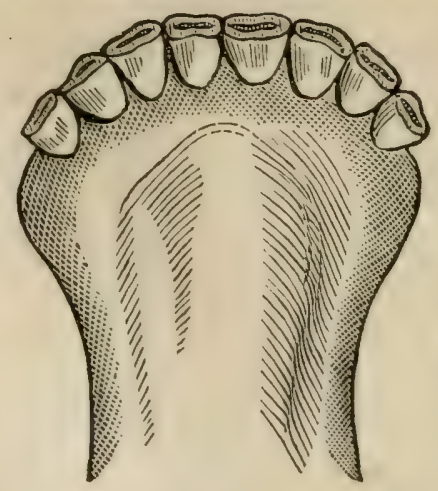

PIVE TEARS PAST.

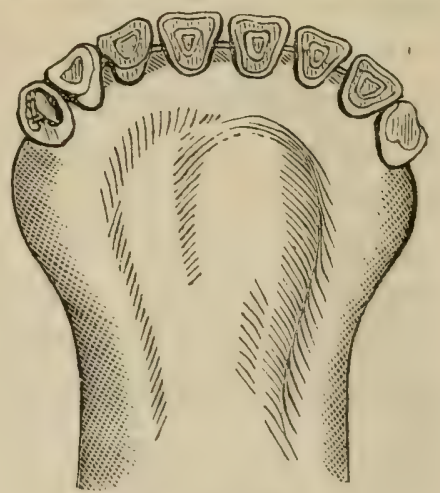

TEN YEARS PAST.

of permanent teeth are but formed, as represented in the cut; and at four years the last pair of incisors will be up, as in the cut of that age; but the outside ones are not yet fully 
grown, and the beast can hardly be said to be full-mouthed till the age of five years. But before this age, or at the age of four years, the two inner pairs of permanent teeth are beginning to wear at the edges, as shown in the cut; while at five years old the whole set becomes somewhat worn down at the top, and on the two centre ones a darker line appears in the middle, along a line of harder bone, as appears in the appropriate cut.

Now will come a year or two, and sometimes three, when the teeth do not so clearly indicate the exact age, and the judgment must be guided by the extent to which the dark middle lines are worn. This will depend somewhat upon the exposure and feeding of the animal; but at seven years these lines extend over all the teeth. At eight years, another change begins, which cannot be mistaken. A kind of absorption begins with the two central incisors-slow at first, but perceptible-and these two teeth become smaller than therest, while the dark lines are worn into one in all but the corner teeth, till, at ten years, four of the ceniral incisors have become smaller in size, with a smaller and fainter mark, as indicated in the proper cut. At eleven, the six inner teeth are smaller than the corner ones; and at twelve, all become smaller than they were, while the dark lines are nearly gone, except in the corner teeth, and the inner edge is worn to the gum.

\section{POINTS OF A GOOD COW.}

After satisfaction is afforded touching the age of a cow, she should be examined with reference to her soundness of constitution. A good constitution is indicated by large 
Jungs, which are found in a deep, broad, and prominent chest, broad and well-spread ribs, a respiration somewhat slow and regular, a good appetite, and if in milk a strong inclination to drink, which a large secretion of milk almost invariably stimulates. In such a cow the digestive organs are active and energetic, and they make an abundance of good blood, which in turn stimulates the activity of the nervous system, and furnishes the milky glands with the means of abundant

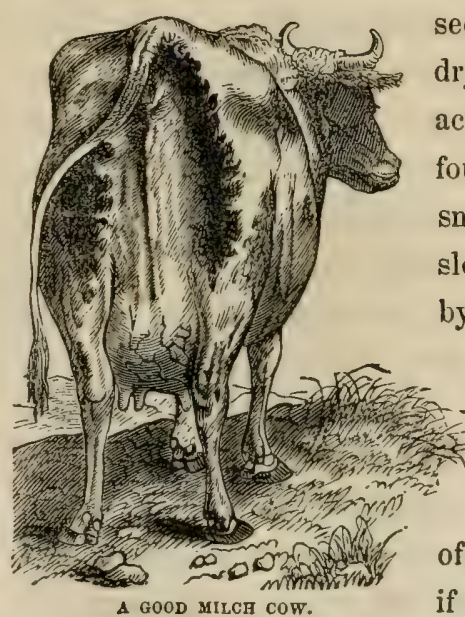

secretion. Such a cow, when dry, readily takes on fat. When activity of the milk-glands is found united with close ribs, small and feeble lungs, and a slow appetite, often attended by great thirst, the cow will generally possess only a weak and feeble constitution; and if the milk is plentiful, it will generally be of bad quality, while the animal, if she does not die of diseased lungs, will not readily take on fat, when dry and fed.

In order to have no superfluous flesh, the cow should have a small, clean, and rather long head, tapering toward the muzzle. A cow with a large, coarse head will seldom fatten readily, or give a large quantity of milk. A coarse head increases the proportion of weight of the least valuable parts, while it is a sure indication that the whole bony structure is too heavy. The mouth should be large and broad; the eye bright and sparkling, but of a peculiar placidness of expres- 
sion, with no indication of wildness, but rather a mild and feminine look. These points will indicate gentleness of disposition. Such cows seem to like to be milked, are fond of being caressed, and often return caresses. The horns should be small, short, tapering, yellowish, and glistening. The neck should be small, thin, and tapering toward the head, but thickening when it approaches the shoulder; the dewlaps small. The fore quarters should be rather small when compared with the hind quarters. The form of the barrel will be large, and each rib should project further than the preceding one, up to the loins. She should be well formed across the hips and in the rump.

The spine or backbone should be straight and long, rather loosely hung, or open along the middle part, the result of the distance between the dorsal vertebræ, which sometimes causes a slight depression, or sway back. By some good judges, this mark is regarded as of great importance, especially when the bones of the hind quarters are also rather loosely put together, leaving the rump of great width and the pelvis large, and the organs and milk-vessels lodged in the cavities largely developed. The skin over the rump should be loose and flexible. This point is of great importance; and as, when the cow is in low condition or very poor, it will appear somewhat harder and closer than it otherwise would, some practice and close observation are required to judge well of this mark. The skin, indeed, all over the body, should be soft and mellow to the touch, with soft and glossy hair. The tail, if thick at the setting on, should taper and be fine below.

But the udder is of special importance. It should be large 
in proportion to the size of the animal, and the skin thin, with soft, loose folds extending well back, capable of great distension when filled, but shrinking to a small compass when entirely empty. It must be free from lumps in every part, and provided with four teats set well apart, and of medium size. Nor is it less important to observe the milkveins carefully. The principal ones under the belly should be large and prominent, and extend forward to the navel, losing themselves, apparently, in the very best milkers, in a large cavity in the flesh, into which the end of the finger can be inserted; but when the cow is not in full milk, the milkvein, at other times very prominent, is not so distinctly traced; and hence, to judge of its size when the cow is dry, or nearly so, this vein may be pressed near its end, or at its entrance into the body, when it will immediately fill up to its full size. This vein does not convey the milk to the udder, as some suppose, but is the channel by which the blood returns; and its contents consist of the refuse of the secretion, or of what has not been taken up in forming milk. There are also veins in the udder, and the perineum, or the space above the udder, and between that and the buttocks, which it is of special importance to observe. These veins should be largely developed, and irregular or knotted, especially those of the udder. They are largest in great milkers.

The knotted veins of the perineum, extending from above downwards in a winding line, are not readily seen in young heifers, and are very difficult to find in poor cows, or those of only a medium quality. They are easily found in very good milkers, and if not at first apparent, they are made so by pressing upon them at the base of the perineum, when 
they swell up and send the blood back toward the vulva. They form a kind of thick network under the skin of the perineum, raising it up somewhat, in some cases near the vulva, in others nearer down and closer to the udder. It is important to look for these veins, as they often form a very important guide, and by some they would be considered as furnishing the surest indications of the milking qualities of the cow. Full development almost always shows an abundant secretion of milk; but they are far better developed after the cow has had two or three calves, when two or three years' milking has given full activity to the milky glands, and attracted a large flow of blood. The larger and more prominent these veins the better. It is needless to say that in observing them some regard should be had to the condition of the cow, the thickness of skin and fat by which they may be surrounded, and the general activity and food of the animal. Food calculated to stimulate the greatest flow of milk will naturally increase these veins, and give them more than usual prominence.

\section{THE MILK-MIRROR.}

The discovery of M. Guenon, of Bordeaux, in France-a man of remarkable practical sagacity, and a close observer of stock-consisted in the connection between the milking qualities of the cow and certain external marks on the udder, and on the space above it, called the perineum, extending to the buttocks. To these marks he gave the name of milkmirror, or escutcheon, which consists in certain perceptible spots rising up from the udder in different directions, forms and sizes, on which the hair grows upward, whilst the hair 
on other parts of the body grows downward. The reduction of these marks into a system, explaining the value of particu-

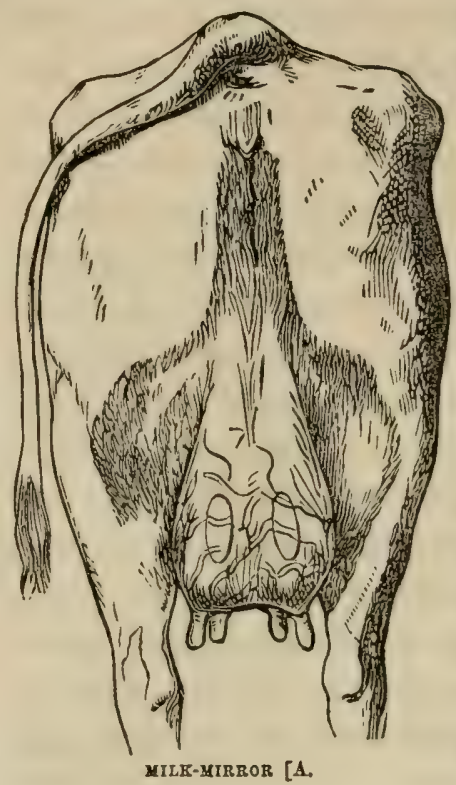
lar forms and sizes of the milk-mirror, belongs exclusively to Guénon.

He divided the milk-mirror into eight classes, and each class into eight orders, making in all no less than sixty-four divisions, which he afterward increased by subdivisions, thus rendering the whole system complicated in the extreme, especially as he professed to be able to judge with accuracy, by means of the milk-mirror, not only of the exact quantity a cow would give, but also of the quality of the milk, and of the length of time it would continue. He endeavored to prove too much, and was, as a matter of consequence, frequently at fault himself.

Despite the strictures which have been passed upon Guenon's method of judging of cows, the best breeders and judges of stock concur in the opinion, as the result of their observations, that cows with the most perfectly developed milk-mirrors are, with rare exception, the best milkers of their breed; and that cows with small and slightly developed milk-mirrors are, in the majority of cases, bad milkers. There are, undoubtedly, cows with very small mirrors, which 
are, nevertheless, very fair in the yield of milk; and among those with middling quality of mirrors, instances of rather

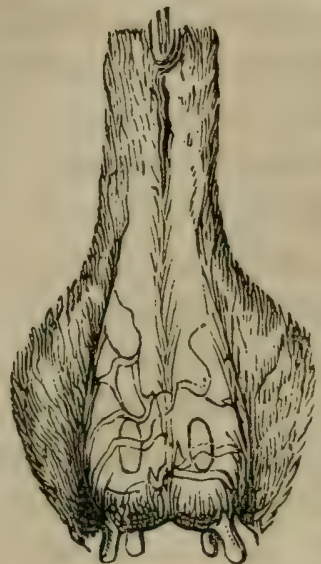

MILK·MIRROR [B.] more than ordinary milkers often occur, while at the same time it is true that cases now and then are found where the very best marked and developed mirrors are found on very poor milkers. These apparent exceptions, however, are to be explained, in the large majority of cases, by causes outside of those which affect the appearance of the milkmirror. It is, of course, impossible to estimate with mathematical accuracy either the quantity, quality, or duration of the milk, since it is affected by so many chance circumstances, which cannot always be known or estimated

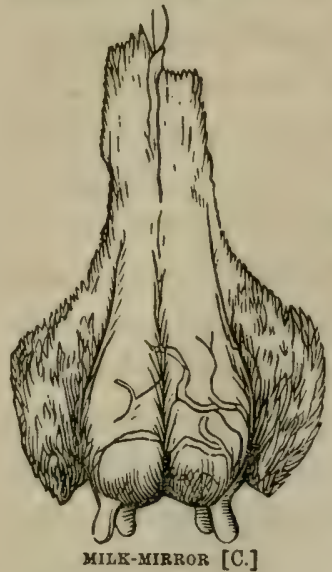
by even the most skillful judges; such, for example, as the food, the treatment, the temperament, accidental diseases, inflammation of the udder, premature calving, the climate and season, the manner in which she has been milked, and a thousand other things which interrupt or influence the flow of milk, without materially changing the size or shape of the milk-mirror. It has, indeed, been very justly observed that we often see cows equally well formed, with precisely the same milk- 
mirror, and kept in the same circumstances, yet giving neither equal quantities nor similar qualities of milk. Nor could it be otherwise; since the action of the organs depends, not merely on their size and form, but, to a great extent, on the general condition of each individual.

The different forms of milk-mirrors are represented by the shaded parts of cuts, lettered A, B, C, D ; but it is necessary to premise that upon the cows themselves they are always partly concealed by the thighs, the udder, and the folds of the skin, which are not shown, and therefore they are not always so uniform in nature as they appear in the cuts.

Their size varies as the skin is more or less folded or stretched; while the cuts represent the skin as uniform or free from folds, but not stretched out. It is usually rery easy to distinguish the milk-mirrors by the upward direction of the hair which forms them. They are sometimes marked

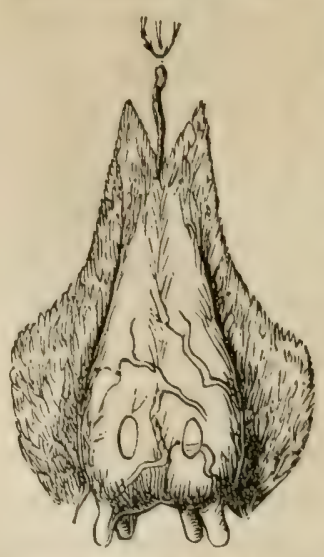

MILK.MIRROR [D.] by a line of bristly hair growing in the opposite direction, which surrounds them, forming a sort of outline by the upward and downward growing hair. Yet, when the hair is very fine and short, mixed with longer hairs, and the skin much folded, and the udder voluminous and pressed by the thighs, it is necessary, in order to distinguish the part enclosed between the udder and the legs, and examine the full size of the mirrors, to observe them attentively, and to place the legs wide apart, and to smooth out the slin, in order to avoid the folds. 
The mirrors may also be observed by holding the back of the hand against the perineum, and drawing it from above downward, when the nails rubbing against the up-growing hair, make the parts covered by it very perceptible.

As the hair of the milk-mirror has not the same direction as the hair which surrounds it, it may often be distinguished by a difference in the shade reflected by it. It is then sufficient to place it properly to the light in order to see the difference in shade, and to make out the part covered by the upward-growing hair. Most frequently, however, the hair of the milk-mirror is thin and fine, and the color of the skin can easily be seen. If the eye alone is trusted, we shall often be deceived.

In some countries cattledealers shave the back part of the cow. Just after this

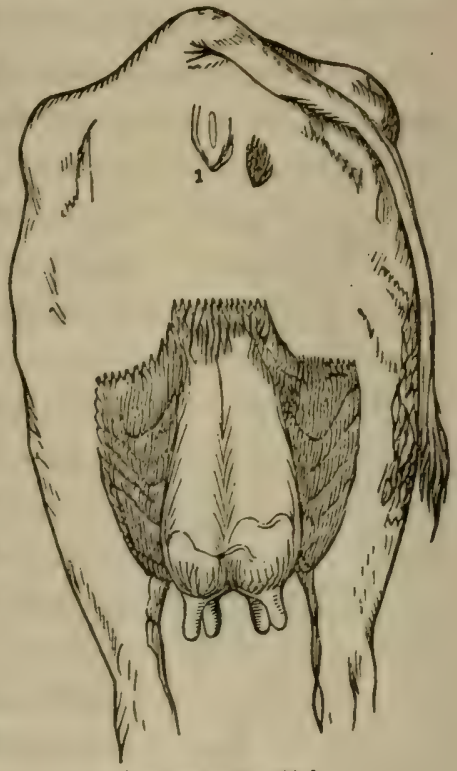

MILK·MIRROR [E.] operation the mirrors can neither be seen nor felt; but this inconvenience ceases in a few days. It may be added that the shaving-designed, as the dealers say, to beautify the cow-is generally intended simply to destroy the milk-mirror, and to deprive buyers of one means of judging of the milking qualities of the cows. It is unnecessary to add that the cows most carefully shaven are those which are badly 5 
marked, and that it is prudent to take it for granted that cows so shorn are bad milkers.

Milk-mirrors vary in position, extent, and the figure which they represent. They may be divided according to their position, into mirrors or escutcheons, properly so called, or into lower and upper tufts, or escutcheons. The latter are very small in comparison with the former, and are situated in close proximity to the vulva, as seen at 1 , in cut $\mathrm{E}$. They are very common on cows of bad milking races, but are very rarely seen on the best milch cows. They consist of one or

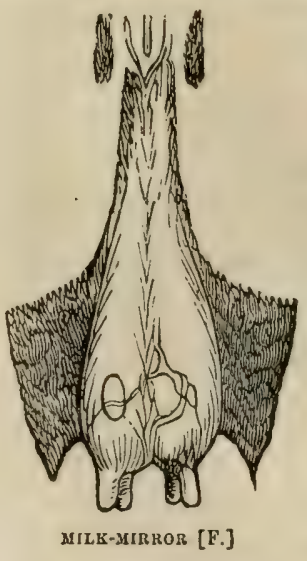
two ovals, or small bands of up-growing hair, and serve to indicate the continuance of the flow of milk. The period is short, in proportion as the tufts are large. They must not be confounded with the escutcheon proper, which is often extended up to the vulva. They are separated from it by bands of hair, more or less large, as in cut marked $\mathrm{F}$.

Milk-mirrors are sometimes symmetrical, and sometimes without symmetry. When there is a great difference in the extent of the two halves, it almost always happens that the teats on the side where the mirror is best developed give more milk than those of the opposite side. The left half of the mirror, it may be remarked, is almost always the largest ; and so, when the perinean part is folded into a square, it is on this side of the body that it unfolds. Of three thousand cows in 
Denmark, but a single one was found, whose escutcheon varied even a little from this rule.

The mirrors having a value in proportion to the space which they occupy, it is of great inportance to attend to all the rows of down-growing hairs, which diminish the extent of surface, whether these tufts are in the midst of the mirror, or form indentations on its edges.

These indentations, concealed in part by the folds of the skin, are sometimes seen with difficulty; but it is important to take them into account, since in a great many cows they materially lessen the size of the mirror. Cows are often found, whose milk-mirrors at first sight appear very large, but which are only medium milkers; and it will usually be found that lateral indentations greatly diminish the surface of up-growing hair. Many errors are committed in estimating the value of such cows, from a want of attention to the real extent of the mirror.

All the interruptions in the surface of the mirror indicate a diminution in the quantity of the milk, with the exception, however, of small oval or elliptical plates which are found in the mirror, on the back part of the udders of the best cows, as represented in the cut already given, marked $\mathbf{A}$. These ovals have a peculiar tint, which is occasioned by the downward direction of the hair which forms them. In the best cows these ovals exist with the lower mirrors very well developed, as represented in the cut just named.

In short, it should be stated that, in order to determine the extent and significance of a mirror, it is necessary to consider the state of the perineum as to fat, and that of the fullness of the udder. In a fat cow, with an inflated udder, the mirror 
would appear larger than it really is; whilst in a lean cow, with a loose and wrinkled udder, it appears smaller. Fat will cover faults-a fact to be borne in mind when selecting a cow.

In bulls, the mirrors present the same peculiarities as in cows; but they are less varied in their form, and especially much less in size.

In calves, the mirrors show the shapes which they are afterwards to have, only they are more contracted, because the parts which they cover are but slightly developed. They are easily seen after birth; but the hair which then covers them is long, coarse, and stiff; and when this hair falls off, the calf's mirror will resemble that of the cow, but will be of less size.

With calves, however, it should be stated, in addition, that the milk-mirrors are more distinctly recognized on those from cows that are well kept, and that they will generally be fully developed at two years old. Some changes take place in the course of years, but the outlines of the mirror appear prominent at the time of advanced pregnancy, or, in the case of cows giving milk, at the times when the udder is more distended with milk than at others.

M. Mayne, who has explained and simplified the method of M. Guénon, divides cows, according to the quantity which they give, into four classes : first, the very good; second, the good; third, the medium; and fourth, the bad.

In the FInst class he places cows, both parts of whose milk mirror, the mammary-the tuft situated on the udder, the legs and the thighs-and the perinean-that on the perineum, extending sometimes more or less out upon the 
thighs-are large, continuous, and uniform, covering at least a great part of the perineum, the udder, the inner surface of the thighs, and extending more or less out upon the legs, as in cut A, with no interruptions, or, if any, snall ones, oval in form, and situated on the posterior face of the udder.

Such mirrors are found on most very good cows, but may also be found on cows which can scarcely be called good,

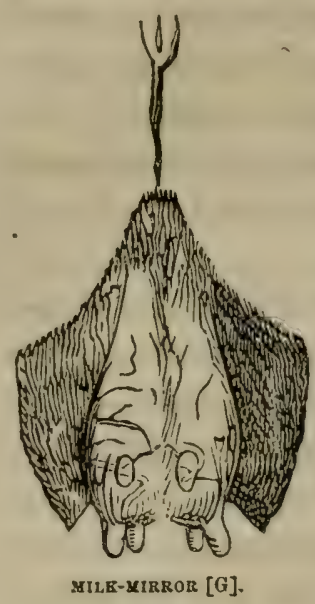
and which should be ranked in the next class. But cows, whether having very well developed mirrors or not, may be reckoned as very good, and as giving as much milk as is to be expected from their size, food, and the hygienic circumstances in which they are kept, if they present the following characteristics : veins of the perineum large, as if swollen, and visible on the exterior-as in cut $\mathbf{A}$-or which can easily be made to appear by pressing upon the base of the perineum; veins of the udder large and knotted; milk-veins large, often double, equal on both sides, and forming zig-zags, under the velly.

To the signs furnished by the veins and by the mirror, may be added also the following marks: a uniform, very. large, and yielding udder, shrinking much in milking, and covered with soft skin and fine hair; good constitution, full chest, regular appetite, and great propensity to drink. Such cows rather incline to be poor than to be fat. The skin is 
soft and yielding; short, fine hair; small head; fine horns; bright, sparkling eye ; mild expression ; feminine look ; with a fine neck.

Cows of this first class are very rare. They give, even when small in size, from ten to fourteen quarts of milk a day; and the largest sized from eighteen to twenty-six quarts a day, and even more. Just after calving, if arrived at mafurity and fed with good, wholesome, moist food in sufficient quantity and quality, adapted to promote the secretion of milk, they can give about a pint of milk for every ten ounces of hay, or its equivalent, which they eat.

They continue in milk for a long period. The best never go dry, and may be milked even up to the time of calving, giving from eight to ten quarts of milk a day. But even the best cows often fall short of the quantity of milk which they are able to give, from being fed on food which is too dry, or

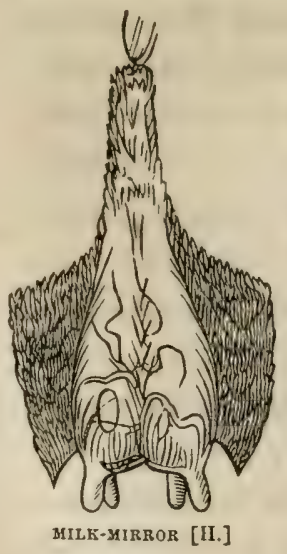
not sufficiently varied, or not rich enough in nutritive qualities, or deficient in quantity.

The SECOND class is that of good cows; and to this belong the best commonly found in the market and among the cow-feeders of cities.

They have the mammary part of the milk-mirror well developed, but the perinean part contracted, or wholly wanting, as in cut $\mathrm{G}$; or both parts of the mirror are moderately developed, or slightly indented, as in cut II. Cut $\mathrm{E}$ belongs also to this class, in the lower part; but it indicates a cow, which-as 
the upper mirror, 1, indicates-dries up sooner when agrain in calf.

These marks, though often seen in many good cows, should be considered as certain only when the veins of the perineum form, under the skin, a kind of network, which, without being very apparent, may be felt by a pressure on them; when the milk-veins on the belly are well-developed, though less knotty and less prominent than in cows of the first class; in short, when the udder is well developed, and presents veins which are sufficiently numerous, though not very large.

It is necessary here, as in the preceding class, to distrust cows in which the mirror is not accompanied by large. veins. This remark applies especially to cows which have had several calves, and are in full milk. They are medium or bad, let the milk-mirror be what it may, if the veins of the belly are not large, and those of the udder apparent.

The general characteristics which depend on form and constitution combine, less than in cows of the preceding class, the marks of good health and excellent constitution with those of a gentle and feminine look.

Small cows of this class give from seven to ten or eleven quarts of milk a day, and the largest from thirteen to seventeen quarts. They can be made to give three-fourths of a pint of milk, just after calving, for every ten ounces of hay consumed, if well cared for, and fed in a manner favorable to the secretion of milk.

They hold out lnng in milk, when they have no upper mirrors or tufts. At seven or eight months in calf, they may give from five to eight quarts of milk a day.

The tHIRD class consists of middling cows. When the 
milk-mirror really presents only the mammary or lower part slightly indicated or developed, and the perinean part con-

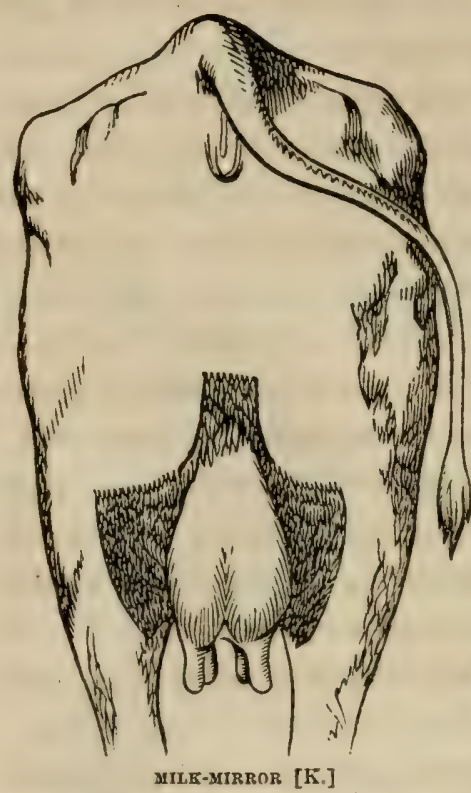
tracted, narrow, and irregular-as in cut K-the cows are middling. The udder is slightly developed or hard, and shrinks very little after milking. The veins of the perineum are not apparent, and those which run along the lower side of the abdomen are small, straight, and sometimes unequal. In this case the mirror is not symmetrical, and the cow gives more milk on the side where the vein is the largest.

These cows have large heads, and a thick, hard skin. Being ordinarily in good condition, they are beautiful to look at, and seem to be well formed. Many of them are nervous and restive, and not easily approached.

Cows of this class give, according to size, from three or four to ten quarts of milk. They very rarely give, even in the most favorable circumstances, half a pint of milk for every ten ounces of hay which they consume. The milk diminishes rapidly, and dries up wholly the fourth or fifth month in calf.

The forrth class is composed of bad cows. As they are 
commonly in good condition, these cows are often the most beautiful of the herd and in the markets. They have fleshy thighs, thick and hard skin, a large and coarse neck and head, and horns large at the base.

The udder is hard, small and fleshy, with a skin covered with long, rough hair. No veins are to be seen either on the perineum or the udder, while those of the belly are slightly developed, and the mirrors are ordinarily small, as in cut $\mathrm{L}$.

With these characteristics, cows gire only a few quarts of milk a day, and dry up in a short time after calving. Some of them can scarcely nourish their calves, even when they are properly cared for and well fed.

Sickly habits, chronic affections of the digestive organs, the chest, the womb, and the lacteal system, sometimes greatly affect the milk secretion, and cause cows troubled with them to fail from the first or second to the third, and sometimes to the fourth class.

Without pushing this method of judging of the good milking qualities of cows into the objectionable extreme to which it was carried by its originator, it may be safely asserted that the milk-mirror forms an important additional mark or point for distinguishing good milkers; and it may be laid down as a rule that, in the selection of milch cows, as well as in the choice of young animals for breeders, the milk-mirror should, by all means, be examined and considered; but that we should not limit or confine ourselves exclusively to it, and that other and long-known marks should be equally iegarded.

There are eases, however, where a knowledge and careful 
examination of the form and size of the mirror become of the highest importance. It is well known that certain signs or marks of great milkers are developed, only as the capacities of the animal herself are fully and completely developed

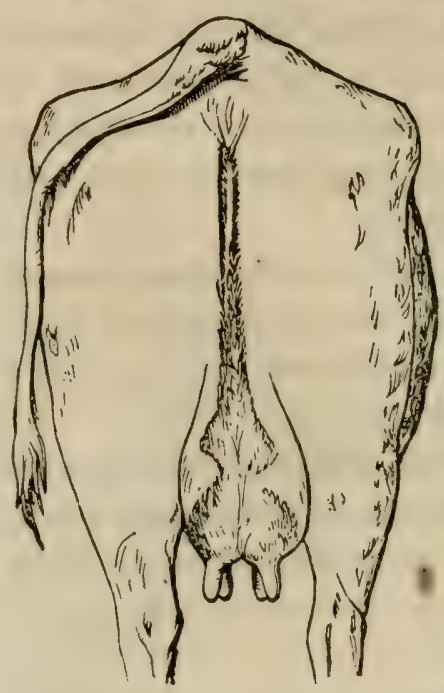

MILK-MIRROR [L.] by age. The milk-veins, for instance, are never so large and prominent in heifers and young cows as in old ones, and the same may be said of the udder, and of the veins of the udder and perineum; all of which it is of great importance to observe in the selection of milch cows. Those signs, then, which in cows arrived at maturity are almost sufficient in themselves to warrant a conclusion as to their merits as milkers, are, to a great extent, wanting in younger animals, and altogether in calves, as to which there is often doubt whether they shall be raised; and here a knowledge of the form of the mirror is of immense advantage, since it gives, at the outset and before any expense is incurred, a somewhat reliable means of judging of the future milking capacities of the animal; or, if a male, of the probability of his transmitting milking qualities to his offspring.

It will be seen, from an examination of the points of a good milch cow. that, though the same marks which indicate 
the greatest milking qualities may not always indicate the greatest aptitude to fatten, yet that the signs which denote good fattening qualities are included among the signs favorable to the production of milk; such as soundness of constitution, marked by good organs of digestion and respiration, fineness and mellowness of the skin and hair, quietness of disposition-which inclines the animal to rest and lie down while chewing the cud-and other marks which are relied on by graziers in selecting animals to fatten.

In buying dairy stock the farmer generally finds it for his interest to select young heifers, as they give the promise of longer usefulness. But it is often the case that older. cows are selected with the design of using them for the dairy for a limited period, and then feeding them for the butcher. In either case, it is advisable, as a rule, to choose animals in low or medium condition. The farmer cannot commonly afford to buy fat; it is more properly his business to make it, and to have it to sell. Good and well-marked cows in poor condition will rapidly gain in flesh and products when removed to better pastures and higher keeping, and they cost less in the original purchase.

It is, perhaps, superfluous to add that regard should be had to the quality of the pasturage and keeping which a cow has previously had, as compared with that to which she is to be subjected. The size of the animal should also be considered with reference to the fertility of the pastures into which she is to be put. Small or medium-sized animals accommodate themselves to ordinary pastures far better than large ones. Where a very large cow will do well, two small ones will usually do better; while the large animal might fail 
entirely where two small ones would do well. It is better to have the whole herd, so far as may be, uniform in size; for, if they vary greatly, scme may get more than they ner , and others will not have rnough. This, however, rans it Iways be brought about. 


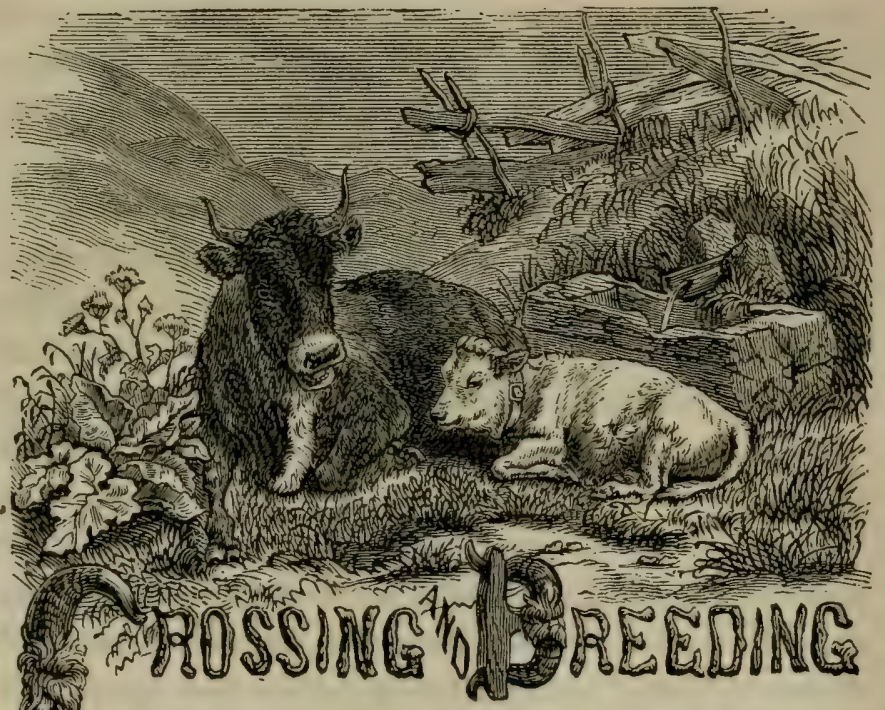

THE raising of cattle has now become a source of profit in many sections,-to a greater extent, at least, than formerly-and it becomes a matter of great practical importance to our farmers to take the proper steps to improve them. Indeed, the questions-what are the best breeds, and what are the best crosses, and how shall I improve my stock-are now asked almost daily; and their practical solution would add many thousand dollars to the aggregate wealth of the farmers of the country, if they would all study their own interests. 
The time is gradually passing away when the intelligent practical farmer will be willing to put his cows to any bull, simply because his services may be had for twenty-five cents; for, even if the progeny is to go to the butcher, the calf sired by a pure-bred bull-particularly of a race distinguished for fineness of bone, symmetry of form, and early maturity--will bring a much higher price at the same age than a calf sired by a scrub. Blood has a money value, which will, sooner or later, be generally appreciated.

The first and most important object of the farmer is to get the greatest return in money for his labor and his produce; and it is for his interest to obtain an animal-a calf, for example-that will yield the largest profit on the outlay. If a calf, for which the original outlay was five dollars, will bring at the same age and on the same keep more real net profit than another, the original outlay for which was not twenty-five cents, it is certainly for the farmer's interest to make the heavier original outlay and thus secure the superior animal. Setting all fancy aside, it is merely a question of dollars and cents; but one thing is certain-and that is, that no farmer can afford to keep poor stock. It eats as much, and requires nearly the same amount of care and attention, as stock of the best quality; while it is equally certain that stock of ever so good a quality, whether grade, native, or thoroughbred, will be sure to deteriorate and sink to the level of poor stock by neglect and want of proper attention.

How, then, is our stock to be improved? Not, certainly, by that indiscriminate crossing, with a total disregard of all well-established principles, which has thus far marked our efforts with foreign stock, and which is one prominent reason 
why so little improvement has been made in our dairles; nor by leaving all the results to chance, when, by a careful and judicious selection, they may be within our own control.

We want cattle for distinct purposes, as for milk, heef, or labor. In a large majority of cases-especially in the dairy districts, at least, comprising the Eastern and Middle Statesthe farmer cares more for the milking qualities of his cows, especially for the quantity they give, than for their fitness for grazing, or aptness to fatten. These latter points become more important in the Western and some of the Southern States, where much greater attention is paid to breeding and to feeding, and where comparatively slight attention is given to the productions of the dairy. A stock of cattle which would suit one farmer might be wholly unsuited to another; and in such particular case the breeder should have some special object in view, and select his animals with reference to it.

There are, however, some well-defined general principles that apply to breeding everywhere, and which, in many cases, are not thoroughly understood. To these attention will now be directed.

The first and most important of the laws to be considered in this connection is that of similarity. It is by virtue of this law that the peculiar characters, properties, and qualities of the parents-whether external or internal, good or bad, healthy or diseased-are transmitted to their offspring. This is one of the plainest and most certain of the laws of nature. The lesson which it teaches may be stated in five words:Breed only from the best.

Judicious selection is indispensable to success in breeding, 
and this should have regard to every particular-general appearance, length of limb, shape of carcass, development of chest; in cattle, to the size, shape, and position of the udder, thickness of skin, touch, length and texture of hair, docility, and all those points which go to make up the desirable animal.

Not only should care be exercised to avoid structural defects, but especially to secure freedom from hereditary diseases; as both defects and diseases appear to be more easily transmissible than desirable qualities. There is, oftentimes, no obvious peculiarity of structure or appearance which suggests the possession of diseases or defects which are transmissible; and for this reason, special care and continued acquaintance are requisite in order to be assured of their absence in breeding animals; but such a tendency, although invisible or inappreciable to careless observers, must still, judging from its effects, have as real and certain an existence as any peculiarity of form or color.

In neat cattle, hereditary diseases do not usually show themselves at birth; and sometimes the tendency remains latent for many years, perhaps through one or two generations, and afterward breaks out with all its former severity. The diseases which are found hereditary in cattle are scrofula, consumption, dysentery, diarrhœa, rheumatism, and malignant tumors. As these animals are less exposed to the exciting causes of disease, and less liable to be overtasked or subjected to violent changes of temperature, or otherwise put in jeopardy, their diseases are not so numerous as those of the hurse, and what they have are less violent, and generally of a chronic character. 
With regard to hereditary diseases, it is eminently truo that "an ounce of prevention is worth a pound of cure." As a general and almost invariable rule, animals possessing either defects or a tendency to disease, should not be employed for breeding. If, however, for special reasons it seems desirable to breed from one which has some slight defect of symmetry, or a faint tendency to disease-although for the latter it is doubtful whether the possession of any good qualities can fully compensate-it should be mated with one which excèls in every respect in which it is itself deficient, and on no account with one which is near of kin to it.

There is another law, by which that of similarity is greatly modified-the law of Variation or divergence.

All animals possess a certain flexibility or pliancy of organization, which renders them capable of change to $\mathbb{a}$ greater or less extent. When in a state of nature, variations are comparatively slow and infrequent; but when in a state of domestication they occur much oftener and to a much greater extent. The greater variability in the latter case is doubtless owing, in some measure, to our domestic productions' being reared under conditions of life not so uniform as, and different from, those to which the parent species was exposed in a state of nature.

Among what are usually reckoned the more active causes of variation may be named climate, food, and habit. Animals in a cold climate are provided with a thicker covering of hair than in warmer ones. Indeed, it is said that in some of the tropical provinces of South America, there are cattle which have an extremely rare and fine fur, in place of the ordinars 
pile of hair. The supply of food, whether abundant or scanty, is one of the most efficient causes of variation known to be within the control of man. A due consideration of the natural effects of climate and food is a point worthy the careful attention of the stock-husbandman. If the breeds employed be well adapted to the situation, and the capacity of the soil be such as to feed them fully, profit may be safely anticipated. Animals are to be regarded as machines for converting herbage into money.

The bestowal of food sufficient, both in amount and quality, to enable animals to develop all the excellencies inherent in them, and yield all the profit of which they are capable, is something quite distinct from undue forcing or pampering. The latter process may produce wonderful animals to look at, but neither useful nor profitable ones, and there is danger of thus producing a most undesirable variation, since in animals the process may be carried far enough to produce barrenness. Instances are not wanting, particularly among the more recent improved short-horns, of impotency among the males and of barrenness among the females; and in some cases where the latter have borne calves, they have failed to secrete sufficient milk for their nourishment. Impotency in bulls of various breeds has, in many instances, occurred from toc high feeding, especially when connected with a lack of sufficient exercise. A working bull, though perhaps not so pleasing to the eye as a fat one, is a surer stock-getter; and his progeny is more likely to inherit full health and vigor.

Habit has a decided influence toward producing variations. We find in domestic animals that use-or the demand created by habit-is met by a development or change in the 
organization adapted to the requirement. For instance, with cows in a state of nature, or where required only to suckle their young, the supply of milk is barely fitted to the requirement. If more is desired, and the milk is drawn completely and regularly, the yield is increased and continued longer. $\mathrm{By}$ keeping up the demand there is induced, in the next 'generation,

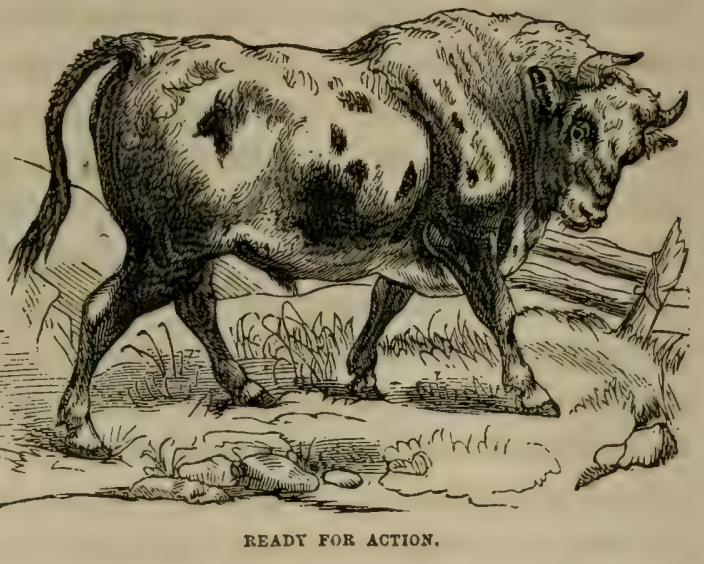

a greater development of the secreting organs, and more milk is given. By continuing the practice, by furnishing the needful conditions of suitable food and the like, and by selecting in each generation those animals showing the greatest tendency toward milk, a breed specially adapted for the dairy may be established. It is just by this mode that the Ayrshires have, within the past century, been brought to be what they are-a breed giving more good milk upon a certain amount of food than any other.

It is a fact too well established to be controverted, that the first male produces impressions upon subsequent progeny by other males. To what extent this principle holds, it is impossible to say. Although the instances in which it is known to be of a very marked and obvious character may be 
comparatively few, yet there is ample reason to believe that, although in a majority of cases the effect may be less noticeable, it is not less real; and it therefore demands the special attention of breeders. The knowledge of this law furnishes a clue to the cause of many of the disappointments of which practical breeders often complain, and of many variations otherwise unaccountable, and it suggests particular caution as to the first male employed in the coupling of animals-a matter which has often been deemed of little consequence in regard to cattle, inasmuch as fewer heifers' first calves are reared, than those are which are borne subsequently.

The phenomenon_or law, as it is sometimes called-of atarism, or ancestral influence, is one of considerable practical importance, and well deserves the careful attention of the breeder of farm stock.

Every one is aware that it is by no means unusual for a child to resemble its grandfather, or grandmother, or even some ancestor still more remote, more than it does either its own father or mother. The same occurrence is found among our domestic animals, and oftener in proportion as the breeds are crossed or mixed up. Among our common stock of neat cattle, or natives-originating, as they did, from animals brought from England, Scotland, Denmark, France, and - Spain, each possessing different characteristics of form, color, and use, and bred, as our common stock has usually been, indiscriminately together, with no special object in view, with no attempt to obtain any particular type or form, or to secure adaptation for any particular purpose-frequent opportunities are afforded of witnessing the results of this law of hereditary transmission. So common, indeed, is its oceur- 
rence, that the remark is often made, that, however good a cow may be, there is no telling beforehand what sort of a calf she may have. The fact is sufficiently obvious, that certain peculiarities often lie dormant for a generation or two and then reappear in subsequent progeny. Stockmen often speak of it as "breeding back," or "crying back."

The lesson taught by this law is very plain. It shows the importance of seeking thorough-bred or well-bred animals; and by these terms are simply meant such as are descended from a line of ancestors in which for many generations the desirable forms, qualities, and characteristics have been uniformly shown. In such a case, even if ancestral influence does come in play, no material difference appears in the offspring, the ancestors being all essentially alike. From this stand-point we best perceive in what consists the money value of a good "pedigree." This is raluable, in proportion as it shows an animal to be descended, not only from such as are purely of its own race or breed, but also from such individuals of that breed as were specially noted for the excellencies for which that particular breed is esteemed.

Probably the most distinctly marked evidence of ancestral influence among us, is to be found in the ill-begotten, roundheaded calves, not infrequently dropped by cows of the common mixed kind, which, if killed early, make very blue veal, and if allowed to grow up, become exceedingly profitless and unsatisfactory beasts; the heifers being often barren, the cows poor milkers, the oxen dull, mulish beasts, yielding flosh of very dark color, of ill flavor and destitute of fat.

The relative influence of the male and female parents upon the characteristics of progeny has long been a fruitful 
subject of discussion among breeders. It is found in experience that progeny sometimes resembles one parent more than the other-sometimes there is an apparent blending of the characteristics of both-sometimes a noticeable dissimilarity to either, though always more or less resemblance somewhere-and sometimes the impress of one may be seen upon a portion of the organization of the offspring, and that of the other parent upon another portion; yet we are not authorized from such discrepancies to conclude that it is a matter of chance; for all of nature's operations are conducted in accordance with fixed laws, whether we be able fully to discover them or not. The same causes always produce the same results. In this case, not less than in others, there are, beyond all doubt, certain fixed laws; and the varying results which we see are easily and sufficiently accounted for by the existence of conditions or modifying influences not fully open to our observation.

It may be stated, on the whole-as a result of the varied investigations to which this question has given rise-that the evidence, both from observation and the testimony of the best practical breeders, goes to show that each parent usually contributes certain portions of the organization to the offspring, and that each has a modifying influence upon the other. Facts also show that the same parent does not always contribute the same portions, but that the order is at times, and not rarely, reversed. Where animals are of distinct species or breeds, transmission is usually found to be in harmony with the principle, that the male gires mostly the outward form and locomotive system, and the female chiefly the interior system, constitution and the like. Where 
the parents are of the same breed, it appears that the proportions contributed by each are governed, in a large measure; by the condition of each in regard to age and rigor, or by virtue of individual potency or superiority of physical endowment. This potency or power of transmission, seems to be legitimately connected with high breeding, or the concentration of fixed qualities, obtained by continued descent for many generations from such only as possess in the highest degree the qualities desired:

Practically, the knowledge obtained dictates in a most emphatic manner that every stock-grower use his utmost endeavor to obtain the services of the best sires; that is, the best for the ends and purposes in view-that he depend chiefly on the sire for outward form and symmetry-and that he select dams best calculated to develop the good qualities of the male, depending chiefly upon these for freedom from internal disease, for hardihood and constitution, and, generally, for all qualities dependent upon the vital or nutritive system. The neglect of the qualities of the dam, which is far too common-miserably old and inferior animals being often employed-cannot be too strongly censured.

With regard to the laws which regulate the sex of the progeny very little is known. Many and extensive observations have been made, without reaching any definite conclusion. Nature seems to have provided that the number of each sex produced, shall be nearly equal; but by what means this result is attained, has not as yet been discovered.

It has long been a disputed point, whether the system of breeding in-and-in, or the opposite one of frequent crossing, has the greater tendency to improve the character of stock. 
This term, in-and-in, is often very loosely used and as variously understood. Some confine the phrase to the coupling of those of exactly the same blood, as brothers and sisters, while others include in it breeding from parents and offsprings; and others still employ it to embrace those of a more distant relationship. For the last, the term breedingin, or close breeding, is generally deemed more suitable.

The current opinion is decidedly against the practice of breeding from any near relatives; it being usually found that degeneracy follows, and often to a serious degree; but it is not proved that this degeneracy, although very common and even usual, is yet a necessary consequence. That ill effects follow, in a majority of cases, is not to be doubted; but this is easily and sufficiently accounted for upon quite other grounds. Perhaps, however, the following propositions may be safely stated: That in general practice, with the grades and mixed animals common in the country, close-breeding should be scrupulously avoided as highly detrimental. It is better always to aroid breeding from near relatives whenever stock-getters of the same breed and of equal merit can be obtained which are not related. Yet, where this is not possible, or where there is some desirable and elearly defined purpose in view-as the fixing and perpetuating of some valuable quality in a particular animal not common to the breed-and the breeder possesses the knowledge and skill needful to accomplish his purpose, and the animals are perfect in health and development, close breeding may be practised with advantage.

The practice of crossing, like that of close breeding, has its strong and its weak side. Judiciously practised, it offers 
a means of providing animals for the bulcher, often superior to, and more profitable than, those of any pure breed. It is also admissible as the foundation of a systematic and wellconsidered attempt to establish a new breed. But when crossing is practised injudiciously and indiscriminately, and especially when so done for the purpose of procuring breeding animals, it is scarcely less objectionable than careless in-andin breeding.

The profitable style of breeding for the great majority of farmers to adopt, is neither to cross nor to breed from close affinities-except in rare instances, and for some specific and clearly understood purposebut to breed in the line; that is, to select the breed or race best adapted to fulfil the require-

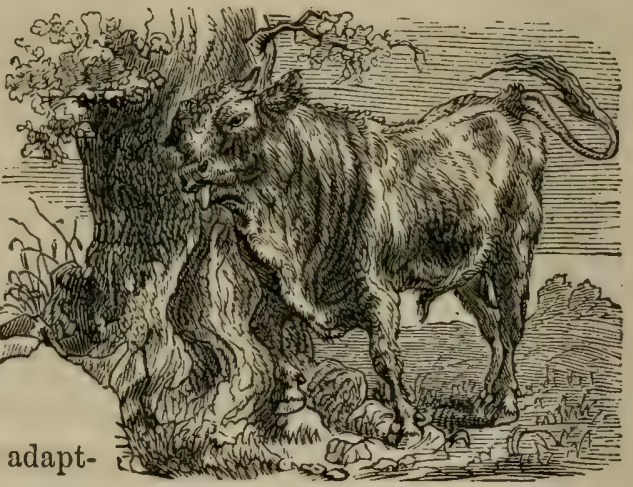
ment demanded, whether it be for the dairy, for labor, or for such combination of these as can be had without too great a sacrifice of the principal requisite, and then to procure a pure-bred male of the kind determined upon, and breed him to the females of the herd; and if these be not such as are calculated to develop his qualities, endeavor by purchase or exchange to procure such as will. Let the progeny of these be bred to another pure-bred male of the same breed, but as distantly related to the first as may be. Let this plan be 
faithfully pursued, and, although we cannot, without the intervention of well-bred females, procure stock purely of the kind desired, yet in several generations-if proper care be given to the selection of males, that each one be such as to retain and improve upon the points gained by his predeces sor-the stock, for most practical purposes, will be as good as if thorough-bred. If this plan were generally adopted, and a system of letting or exchanging males established, the cost might be brought within the means of most persons, and the advantages which would accrue would be almost beyond belief.

A brief summing-up of the foregoing principles may not be inappropriate here.

The law of similarity teaches us to select animals for breading which possess the desired forms and qualities in the greatest perfection and best combination.

Regard should be had, not only to the more obvious ch:aracteristics, but also to such hereditary traits and tendencies as may be hidden from cursory observation and demand careful and thorough investigation.

From the hereditary nature of all characteristics, whether good or bad, we learn the importance of having all desirable qualities thoroughly inbred; or, in other words, so firmly in each generation that the next is warrantably certain to present nothing worse-that no ill results follow from breeding back to some inferior ancestor-that all undesirable traits or points be, so far as possible, bred-out.

So important is this consideration, that, in practice, it is decidedly preferable to employ a male of ordinary external appearance-provided his ancestry be all which is desired- 
rather than a grade, or cross-bred animal, although the latter be greatly his superior in personal beauty.

A knowledge of the law of variation teaches us to avoid, for breeding purposes, such animals as exhibit variations unfavorable to the purpose in view; to endeavor to perpetu ate erery real improvement gained; as well as to secure, as far as practicable, the conditions necessary to induce or continue any improvement, sach as general treatment, food, climate, habits, and the like.

Where the parents do not possess the perfections desired, selections for coupling should be made with critical reference to correcting the faults or deficiencies of one by corresponding excellencies in the other.

To correct defects, too much must not be attempted at once. Pairing those very unlike oftener results in loss than gain. Avoid all extremes, and endeavor by muderate degrees to attain the end desired.

Crossing, between different breeds, for the purpose of oltaining animals for the shambles, may be advantageously practised to a considerable extent, but not for the production of breeding animals. As a generai rule, cross-bred males should not be employed for propagation, and cross-bred females should be served by thorough-bred males.

In ordinary practice, breeding from near relatives is to be scrupulously avoided. For certain purposes, under certain conditions and circumstances, and in the hands of a skillful breeder, it may be practised with advantage-but not otherwise.

In a large majority of cases_other things being equalwe may expect in progeny the outward form and general 
structure of the sire, together with the internal qualities, constitution, and nutritive system of the dam; each, however, modified by the other.

Particular care should always be taken that the male by nhich the dan first becomes pregnant is the best which can ve obtained; also, that at the time of sexual congress both are in vigorous health.

Breeding animals should not be allowed to become fat, but always kept in thrifty condition; and such as are intended for the butcher should never be fat but once.

In deciding with what breeds to stock a furm, endeavor to select those best adapted to its surface, climate, and degree of fertility; also, with reference to probable demand and proximity to markets.

No expense incurred in procuring choice animals for propagation, no amount of skill in breeding, can supersede, or compensate for, a lack of liberal feeding and good treatment. The better the stock, the better care they deserre.

\section{PREGNANCY}

The symptoms of pregnancy in its early stage were formerly deemed exceedingly unsatisfactory. The period of being in season-which commonly lasts three or four days, and then ceases for a while, and returns in about three weeks-might entirely pass over; and, although it was then probable that conception had taken place, yet in a great many instances the hopes of the breeder were disappointed. It was not until between the third and fourth month, when the belly began to enlarge-or, in many cases, considerably later-and when the motions of the fœtus might be seen, or, 
at all events, felt by pressing on the right flank, that the farmer could be assured that his cow was in calf.

That greatest of improvements in veterinary practice, the application of the ear to the chest and belly of various animals, in order to detect by the different sounds-which, after a short time, will be easily recognized-the state of the circulation through most of the organs, and consequently, the precise seat and degree of inflammation and danger, has now enabled the breeder to ascertain the existence of pregnancy at as early a stage as six or eight weeks. The beating of the heart of the calf may then be distinctly heard, twice, or more than twice, as frequent as that of the mother; and each pulsation will betray the singular double beating of the fotal heart. This will also be accompanied by the audible rushing of the blood through the ressels of the placenta. The ear should be applied to the right flank; beginning on the higher part of it, and gradually shifting downward and backward. These sounds will thus soon be heard, and cannot be mistaken.

\section{TREATMENT BEFORE CALVING.}

Little alteration needs to be made in the management of the cow for the first seven months of pregnaney; except that, as she has not only to yield milk for the profit of the farmer, but to nourish the growing fœtus within, she shoul be well, yet not too luxuriantly, fed. The half-starred cow will not adequately discharge this double duty, nor provide sufficient nutriment for the calf when it has dropped; while the cow in high condition will be dangerously disposed to inflammation and fever, when, atthe time of parturition, she is 
otherwise so susceptible of the power of every stimulus. It the season and the convenience of the farmer will allow, sh will be better at pasture, at least for some hours each day than when confined altogether to the cow-house.

At a somewhat uncertain period before she calves, there will be a new secretion of milk for the expected little one; and under the notion of somewhat recruiting her strength, in order better to enable her to discharge her new duty-but more from the uniform testimony of experience that there is danger of local inflammation, general fever, garget in the udder, and puerperal fever, if the new milk descends while the old milk continues to flow-it has been usual to let the cow go dry for some period before parturition. Farmers and breeders have been strangely divided as to the length of this period. It must be decided by circumstances. A cow in good condition may be milked for a much longer period than a poor one. Her abundance of food renders a period of respite almost unnecessary; and all that needs to be taken care of, is that the old milk should be fairly gone before the new milk springs. In such a cow, while there is danger of inflammation from the sudden rush of new milk into a bag already occupied, there is almost always considerable danger of indurations and tumors in the teats from the habit of secre. tion being too long suspended. The emaciated and overmilked beast, however, must rest a while before she can again advantageously discharge the duties of a mother.

If the period of pregnancy were of equal length at all times and in all cows, the one that has been well fed might be milked until within a fortnight or three weeks of parturition, while a holiday of two months should be granted to the 
poorer beast; but as there is much irregularity about the time of gestation, it may be prudent to take a month or five weeks, as the average period.

The process of parturition is necessarily one that is accompanied with a great deal of febrile excitement; and, therefore, when it nearly approaches, not only should a little care be taken to lessen the quantity of food, and to remore that which is of a stimulating action, but a mild dose of physic, and a bleeding regulated by the condition of the animal, will be very proper precautionary measures.

A moderately open state of the bowels is necessary at the period of parturition in the cow. During the whole time of pregnancy her enormous stomach sufficiently presses upon and confines the womb; and that pressure may be productive of injurious and fatal consequences, if at this period the rumen is suffered to be distended by innutritious food, or the manyplus takes on that hardened state to which it is occasionally suhject. Breeders have been sadly negligent in this respect.

The springing of the udder, or the rapid enlargement of it from the renewed secretion of milk-the enlargement of the external parts of the bearing (the former, as has been said by some, in old cows, and the latter in young ones)-the appearance of a glaring discharge from the bearing-the evident dropping of the belly, with the appearance of leanness and narrowness between the shape and the udder-a degree of uneasiness and fidgetiness-moaning occasionally-accelerated respiration-all these symptoms will announce that the time of calving is not far off. The cow should be brought near home, and put in some quiet, sheltered place. In cold or stormy weather she should be noused. 
Her uneasiness will rapidly increase-she will be continually getting up and lying down-her tail will begin to be elevated and the commencement of the labor-pains will soon be evident.

In most cases the parturition will be natural and easy, and the less the cow is disturbed or meddled with, the better. She will do better without help than with it; but she should be watched, in order to see that no difficulty occurs which may require aid and attention. In cases of difficult parturition the aid of a skillful veterinary surgeon may be required. 


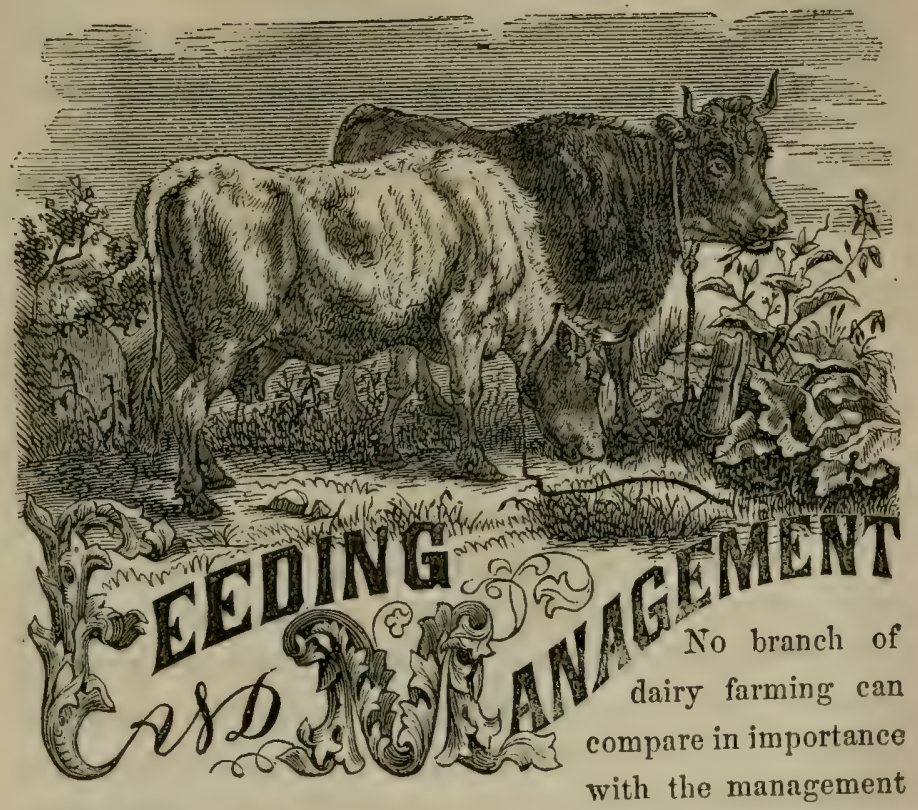

of cows. The highest success will depend upon it, whatever breed be selected, and whatever amount of care and attention be given to the points of the animals; for experience will show that very little milk comes out of the bag, that is not first put into the throat. It is poor economy, therefore, to attempt to keep too many cows for the amount of feed one has; for it will generally be found that one good cow wellbred and well fed will rield as much as two ordinary cows 
kept in the ordinary way; while a saving is effected both in labor and room required, and in the risks on the capital invested. If an argument for the larger number on poorer feed is urged on the ground of the additional manure-which $s$ the only basis upon which it can be put-it is enough to say that it is a very expensive way of making manure. It is not too strong an assertion, that a proper regard to profit and economy would require many an American farmer to sell off nearly half of his cows, and to feed the whole of his hay and roots hitherto used into the remainder.

An animal, to be fully fed and satisfied, requires a quantity of food in proportion to its live weight. No feed is complete that does not contain a sufficient amount of nutritive elements; hay, for example, being more nutritive than straw, and grains than roots. The food, too, must possess a bulk sufficient to fill up to a certain degree the organs of digestion of the stomach; and, to receive the full benefit of its food, the animal must be wholly satisfied-since, if the stomach is not sufficiently distended, the food cannot be properly digested, and of course many of the nutritive principles which it contains cannot be perfectly assimilated. An animal regularly fed eats till it is satisfied, and no more than is requisite. A part of the nutritive elements in hay and other forage plants is needed to keep an animal on its feetthat is, to keep up its condition-and if the nutrition of its food is insufficient for this, the weight decreases, and if it is more than sufficient the weight increases, or else this excess is consumed in the production of milk or in labor. About one sixtieth of their live weight in hay, or its equiralent, will keep horned cattle on their feet; but, in order to be 
cnmpletely nourished, they require about one thirtieth in dry substances, and four thirtieths in water, or other liquid contained in their food. The excess of nutritive food over and above what is necessary to sustain life will go, in milch cows, generally to the production of milk, or to the growth of the fœtus, but not in all cows to an equal extent; the tendency to the secretion of milk being much more developed in some than in others.

With regard, however, to the consumption of food in proportion to the live weight of the animal, it must be taken, in common with all general principles, with some qualifications. The proportion is probably not uniform as applied to all breeds indiscriminately, though it may be more so as applied $t$ ? animals of the same breed. The idea of some celebrated stock-raisers has been that the quantity of food required depends much upon the shape of the barrel; and it is well known that an animal of a close, compact, well-rounded barrel, will consume less than one of an opposite make.

The variations in the yield of milch cows are caused more by the variations in the nutritive elements of their food than by a change of the form in which it is giren. A cow, kept through the winter on mere straw, will cease to give milk; and, when fed in spring on green forage, will give a fair quantity of milk. But she owes the cessation and restora. tion of the secretion, respectively, to the diminution and increase of her nourishment, and not at all to the change of form, or of outward substance in which the nutriment is administered. Let cows receive through winter nearly as large a proportion of nutritive matter as is contained in the clover, lucerne, and fresh grass which they eat in summer, 
and, no matter in what precise substance or mixture that matter be contained, they will yield a winter's produce of milk quite as rich in caseine and butyraceous ingredients as the summer's produce, and far more ample in quantity than almost any dairyman with old-fashioned notions would imagine to be possible. The great practical error on this subject consists, not in giving wrong kinds of food, but in not so proportioning and preparing it as to render an average ration of it equally rich in the elements of nutrition, and especially in nitrogenous elements, as an average ration of the green and succulent food of summer.

We keep too much stock for the quantity of good and nutritious food which we have for it; and the consequence is, that cows are, in nine cases out of ten, poorly wintered, and come out in the spring weakened, if not, indeed, positively diseased, and a long time is required to bring them into a condition to yield a generous quantity of milk.

It is a hard struggle for a cow reduced in flesh and in blood to fill up the wasted system with the food which would otherwise have gone to the secretion of milk; but, if she is well fed, well housed, well littered, and well supplied with pure, fresh water, and with roots, or other moist food, and properly treated to the luxury of a frequent carding, and constant kindness, she comes out ready to commence the manufacture of milk under farorable circumstances.

Keep the cows constantly in good condition, ought, therefore, to be the motto of every dairy farmer, posted up over the barn, and on and over the stalls, and over the milk-room, and repeated to the boys whenever there is danger of forgetting it. It is the great secret of success; and the difference 
between success and failure turns upon it. Cows in milk require more food in proportion to their size and weight than either oxen or young cattle.

In order to keep cows in milk well and economically, regularity is next in importance to a full supply of wholesome and nutritious food. The animal stomach is a very nice chronometer, and it is of the utmost importance to observe regular hours in feeding, cleaning, and milking. This is a point, also, in which very many farmers are at fault-feeding whenever it happens to be convenient. The cattle are thus kept in a restless condition, constantly expecting food when the keeper enters the barn; while, if regular hours are strictly adhered to, they know exactly when they are to be fed, and they rest quietly till the time arrives. If one goes into any well-regulated dairy establishment an hour before feeding, scarcely an animal will rise to its feet; while, if it happens to be the hour of feeding, the whole herd will be likely to rise and seize their food with an avidity and relish not to be mistaken.

With respect to the exact nurture to be pursued, no rule could be prescribed which would apply to all cases; and each individual must be governed much by circumstances, both regarding the particular kinds of feed at different seasons of the year, and the system of feeding. It has been foundit may be stated-in the practice of the most successful dairymen, that, in order to encourage the largest secretion of milk in stalled cows, one of the best courses is, to feed in the morning, either at the time of milking-which is preferred by many-or immediately after, with cut feed, consisting of hay; oats, millet, or cornstalks, mixed with shorts, and Indian, 
linseed, or cotton-seed meal, thoroughly moistened with water. If in winter, hot or warm water is far better than cold. If given at milking-time, the cows will generally give down their milk more readily. The stalls and mangers should first be thoroughly cleansed.

Roots and long hay may be given during the day; and at the evening milking, or directly after, another generous meal

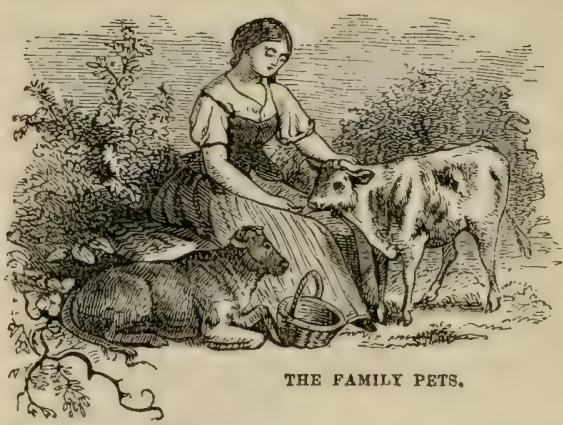
of cut feed, well moistened and mixed, as in the morning. No very concentrated food, like grains alone, or oil-cakes, should be fed early in the morning on an empty stomach, although it is sanctioned by the practice in the London milk-dairies. The processes of digestion go on best when the stomach is sufficiently distended; and for this purpose the bulk of food is almost as important as the nutritive qualities. The flavor of some roots, as cabbages and turnips, is more apt to be imparted to the flesh and milk when fed on an empty stomach than otherwise. After the cows have been milked and have finished their cut feed, they are carded and curried down, in well-managed dairies, and then either watered in the stall_which, in very cold or stormy weather, is far preferable-or turned out to water in the yard. While they are out, if they are let out at all, the stables are put in order; and, after tying them up, they are fed with long hay, and left to themselves till the next feeding 
time. This may consist of roots-such as cabbages, beets, carrots, or turnips sliced-or of potatoes, a peck, or-if the cows are very large-a half-bushel each, and cut feed again at the evening milking, as in the morning; after which, water in the stall, if possible.

The less cows are exposed to the cold of winter, the better. They eat less, thrive better, and give more milk, when kept housed all the time, than when exposed to the cold. A case is on record, where a herd of cows, which had usually been supplied from troughs and pipes in the stalls, were, on account of an obstruction in the pipes, obliged to be turned out thrice a day to be watered in the yard. The quantity of milk instantly decreased, and in three days the diminution became very considerable. After the pipes were mended, and the cows again watered, as before, in their stalls, the flow of milk returned. This, however, must be gorerned much by the weather; for in very mild and warm days it may be judicious not only to let them out, but to allow them to remain out for a short time, for the purpose of exercise.

Any one can arrange the hour for the several processes named above, to suit himself; but, when once fixed, it should be rigidly and regularly followed. If the regular and full feeding be neglected for even a day, the yield of milk will immediately decline, and it will be very difficult to restore it. It may be safely asserted, as the result of many trials and long practice, that a larger flow of milk follows a complete system of regularity in this respect than from a higher feeding where this system is not adhered to.

One prime object which the dairyman should keep constantly in view is, to maintain the animal in a sound and 
healthy condition. Without this, no profit can be expected from a milch cow for any considerable length of time; and, with a view to this, there should be an occasional change of food. But, in making changes, great care is requisite in order to supply the needful amount of nourishment, or the cow will fall off in flesh, and eventually in milk. It should, therefore, be remembered that the food consumed goes not alone to the secretion of milk, but also to the growth and maintenance of the bony structure, the flesh, the blood, the fat, the skin, and the hair, and in exhalations from the body. These parts of the body consist of different organic constituents. Some are rich in nitrogen, as the fibrin of the blood and albumen; others destitute of it, as fat; some abound in inorganic salts, phosphate of lime, and salts of potash. To explain how the constant waste of these substances may be supplied, a celebrated chemist observes that the albumen, gluten, caseine, and other nitrogenized principles of food, supply the animal with the materials requisite for the formation of muscle and cartilage; they are, therefore, called fleshforming principles.

Fats, or oily matters of the food, are used to lay on fat, or for the purpose of sustaining respiration.

Starch, sugar, gum, and a few other non-nitrogenized substances, consisting of carbon, oxygen, and hydrogen, supply the carbon given off in respiration, or they are used. for the production of fat.

Phosphate of lime and magnesia in food principally furnish the animal with the materials of which the bony skèleton of its body consists.

Saline substances-chlorides of sodium and potassium, 
sulphate and phosphate of potash and soda, and some other mineral matters occurring in food-supply the blood, juice of flesh, and various animal juices, with the necessary mineral constituents.

The healthy state of an animal can thus only be preserved by a mixed food; that is, food which contains all the proximate principles just noticed. Starch or sugar alone cannot sustain the animal body, since neither of them furnishes the materials to build up the fleshy parts of the animal. When fed on substances in which an insufficient quantity of phosphates occurs, the animal will become weak, because it does not find any bone-producing principle in its food. Due attention should, therefore, be paid by the feeder to the selection of food which contains all the kinds of matter required, nitrogenized as well as non-nitrogenized, and mineral substances; and these should be mixed together in the proportion which experience points out as best for the different kinds of animals, or the particular purpose for which they are kept.

Relative to the nutrition of cows for dairy purposes, milk may be regarded as a material for the manufacture of butter and cheese; and, according to the purpose for which the milk is intended to be employed, whether for the manufacture of butter or the production of cheese, the cow should be differently fed.

Butter contains carbon, oxygen, and hydrogen, and no nitrogen. Cheese, on the contrary, is rich in nitrogen. Food which contains much fatty matter, or substances which in the animal system are readily converted into fat, will tend to increase the proportion of cream in milk. On the other 
hand, the proportion of caseine or cheesy matter in milk is increased by the use of highly nitrogenized food. Those, then, who desire much cream, or who produce cream for the manufacture of butter, select food likely to increase the proportion of butter in the milk. On the contrary, where the principal object is the production of milk rich in curd-that is, where cheese is the object of the farmer-clover, peas, bran-meal, and other plants which abound in legumine-a nitrogenized organic compound, almost identical in properties and composition with caseine, or the substance which forms the curd of milk-will be selected.

And so the quality, as well as the quantity, of butter in the milk, depends on the kind of food consumed and on the general health of the animal. Cows fed on turnips in the stall always produce butter inferior to that of cows living upon the fresh and aromatic grasses of the pastures.

Succulent food in which water abounds-the green grass of irrigated meadows, green clover, brewers' and distiller's' refuse, and the like-increases the quantity, rather than the quality, of the milk; and by feeding these substances the milk-dairyman studies his own interest, and makes thin milk without diluting it with water-though, in the opinion of some, this may be no more legitimate than watering the milk.

But, though the yield of milk may be increased by succubent or watery food, it should be given so as not to interfere with the health of the cow.

Food rich in starch, gum, or sugar, which are the respiratory elements, an excess of which goes to the production of fatty matters, increases the butter in milk. Quietness promotes the secretion of fat in animals and increases the butter. 
Cheese will be increased by food rich in albumen, such as the leguminous plants.

The most natural, and of course the healthiest, food for milch cows in summer, is the green grass of the pastures;

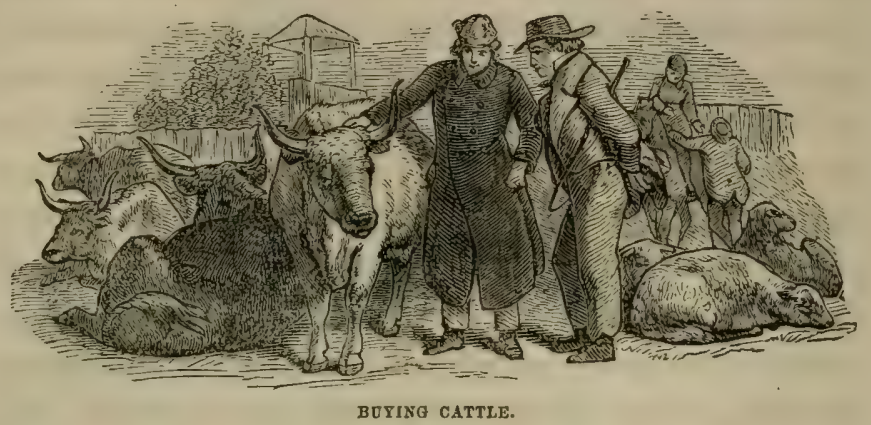

and when these fail from drought or over-stocking, the complement of nourishment may be made up with green clover, green oats, barley, millet, or corn-fodder and cabbageleaves, or other succulent vegetables; and if these are wanting, the deficiency may be partly supplied with shorts, Indian-meal, linseed or cotton-seed meal. Green grass is more nutritious than hay, which always loses somewhat of its nutritive properties in curing; the amount of the loss depending chiefly on the mode of curing, and the length of exposure to sun and rain. But, apart from this, grass is more easily and completely digested than hay, though the digestion of the latter may be greatly aided by cutting and moistening, or steaming; and by this means it is rendered more readily available, and hence far better adapted to promote a large secretion of milk-a fact too often overlooked even by many intelligent farmers.

In autumn, the best feed will be the grasses of the pastures, 
so far as they are available, green-corn fodder, cabbage, carrot, and turnip leaves, and an addition of meal or shorts. Toward the middle of autumn, the cows fed in the pastures will require to be housed regularly at night, especially in the more northern latitudes, and put, in part at least, upon hay. But every farmer knows that it is not judicious to feed out the best part of his hay when his cattle are first put into the barn, and that he should not feed so well in the early part of winter that he cannot feed better as the winter advances.

At the same time, it should always be borne in mind that the change from grass to a poor quality of hay or straw, for cows in milk, should not be too sudden. A poor quality of dry hay is far less palatable in the early part of winter, after the cows are taken from grass, than at a later period; and, if it is resorted to with milch cows, will invariably lead to a falling off in the milk, which no good feed can afterward -wholly restore.

It is desirable, therefore, for the farmer to know what can be used instead of his best English or upland meadow hay, and yet not suffer any greater loss in the flow of milk, or in condition, than is absolutely necessary. In some sections of the Eastern States, the best quality of swale hay will be used; and the composition of that is as variable as possible, depending on the varieties of the grasses of which it was made, and the manner of curing. But, in other sections, many will find it necessary to use straw and other substitutes. Taking good English or meadow hay as the standard of comparison, and calling that one, 4.79 times the weight of rye-straw, or 3.83 times the weight of oat-straw, contains the same amount of nutritive matter; that is, it would take 
4.79 times as good rye-straw to produce the same result as good meadow hay.

In winter, the best food for cows in milk will be good sweet meadow hay, a part of which should be cut and moistened with water-as all inferior hay or straw should be-with an addition of root-crops, such as turnips, carrots, parsnips, potatoes, mangold-wurtzel, with shorts, oil-cake, Indian meal, or bean meal.

It is the opinion of most successful dairymen that the feeding of moist food cannot be too highly recommended for cows in milk, especially to those who desire to obtain the largest quantity. Hay cut and thoroughly moistened becomes more succulent and nutritive, and partakes more of the nature of green grass.

As a substitute for the oil-cake, hitherto known as an exceedingly valuable article for feeding stock, there is probably nothing better than cotton-seed meal. This is an article whose economic value has been but recently mado known, but which, from practical trials already made, has proved eminently successful as food for milch cows. Chemists have decided that its composition is not inferior to that of the best flaxseed cake, and that in some respects its agricultural value surpasses that of any other kind of oil-cake.

It has been remarked by chemists, in this connection, that the great value of linseed-cake, as an adjunct to hay, for fa cattle and milch cows, has been long recognized; and that it is undeniably traceable, in the main, to three ingredients of the seeds of the oil-yielding plants. The value of food depends upon the quantities of matters it contains which may be appropriated by the animal which consumes the food 
Now, it is proved that the fat of animals is derived from the starch, gum, and sugar, and more directly and easily from the oil of the food. These four substances, then, are fatformers. The muscles, nerves, and tendons of animals, the brine of their blood and the curd of their milk, are almost identical in composition with, and strongly similar in many of their properties to, matters found in all vegetables, but chiefly in such as form the most concentrated food. These blood (and muscle) formers are characterized by containing about fifteen and a half per cent. of nitrogen; and hence are called nitrogenous substances. They are, also, often designated as the albuminous bodies.

The bony framework of the animal owes its solidity to phosphate of lime, and this substance must be furnished by the food. A perfect food must supply the aninal with these three classes of bodies, and in proper proportions. The addition of a small quantity of a food, rich in oil and albuminous substances, to the ordinary kinds of feed, which contain a large quantity of vegetable fibre or woody matter, more or lcss indigestible, but, nevertheless, indispensable to the herbivorous animals, their digestive organs being adapted to a bulky food, has been found highly advantageous in practice. Neither hay alone nor concentrated food alone gives the best results. A certain combination of the two presents the most advantages.

Some who have used cotton-seed cake have found difficulty in inducing cattle to eat it. By giving it at first in small doses, mixed with other palatable food, they soon learn to 'eat it with relish. Cotton-seed cake is much richer in oils and albuminous matters than the linseed cake. A corre- 
spondingly less quantity will therefore be required. Three pounds of this cotton-seed cake are equivalent to four of linseed cake of average quality.

During the winter season, as has been already remarked, a frequent change of food is especially necessary, both as contributions to the general health of animals, and as a means of stimulating the digestive organs, and thus increasing the secretion of milk. A mixture used as cut feed and well moistened is now especially beneficial, since concentrated food, which would otherwise be given in small quantities, may be united with larger quantities of coarser and less nutritive food, and the complete assimilation of the whole be better secured. On this subject it has been sensibly observed that the most nutritious kinds of food produce little or 110 effect when they are not digested by the stomach, or if the digested food is not absorbed by the lymphatic vessels, and not assimilated by the various parts of the body. Now, the normal functions of the digestive organs not only depend upon the composition of the food, but also on its volume. The volume or bulk of the food contributes to the healthy action of the digestive organs, by exercising a stimulating effect upon the nerves which govern them. Thus the whole organization of ruminating animals necessitates the supply of bulky food, to keep the animal in good condition.

Feed sweet and nutritious food, therefore, frequently, regu. larly, and in small quantities, and change it often, and the best results may be confidently anticipated. If the cows are not in milk, but are to come in in the spring, the difference in feeding should be rather in the quantity than the quality, 
if the highest jield is to be expected from them during the coming season.

'The most common feeding is hay alone, and oftentimes very poor hay at that. The main point is to keep the animal

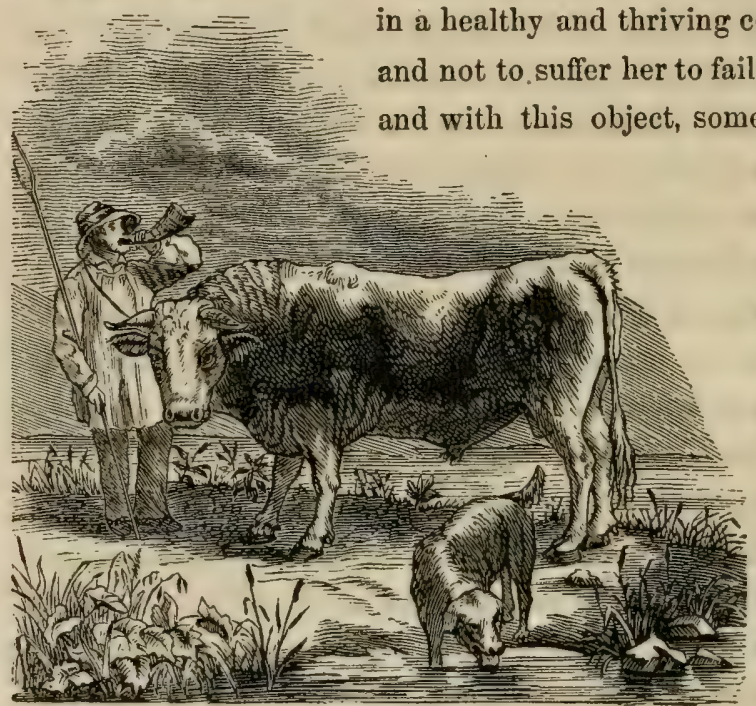

calliNo iN the catThe.

a $n$ d variety of food are highly im portant. $\mathrm{T} 0$. ward the close of winter, a herd of cows will be-

gin to come in, or approach their time of calving. Care should then be taken not to feed too rich or stimulating food for the last week or two before this event, as it is often attended with ill consequences. A plenty of hay, a few potatoes or shorts, and pure water will suffice.

In spring, the best feeding for dairy cows will be much the same as that for winter; the roots in store over winter, such as carrots, mangold wurtzel, turnips, and parsnips, furnishing very valuable aid in increasing the quantity and improving the quality of milk. Toward the close of this 
season, and before the grass of pastures is sufficiently grown to make it judicious to turn out the cows, the best dairymen provide a supply of green fodder in the shape of winter rye, which, if cut while it is tender and succulent, and before it is half grown, will be greatly relished. Unless cut young, however, its stalk soon becomes hard and unpalatable.

All practical dairymen agree in saying that a warm and well-ventilated barn is indispensable to the promotion of the highest yield of milk in winter; and most agree that cows in milk should not be turned out, even to drink, in cold weather; all exposure to cold tending to lessen the yield of milk.

- In the London dairies, in which, of course, the cows are fed so as to produce the largest flow of milk, the treatment is as follows: The cows are kept at night in stalls. About three A. M. each has a half-bushel of grains. When milking is finished, each receives a bushel of turnips (or mangolds), and shortly afterward, one tenth of a truss of hay of the best quality. This feeding occurs before eight A. M., when the animals are turned into the yard. Four hours after, they are again tied up in their stalls, and have another feed of grains. When the afternoon milking is over (about three P. M.), they are fed with a bushel of turnips, and after the lapse of an hour, hay is given them as before. This mode of feeding usually continues throughout the cool season, or from November to March. During the remaining months they are fed with grains, tares, and cabbages, and a proportion of rowen, or second-cut hay. They are supplied regu larly until they are turned out to grass, when they pass the whole of the night in the field. The yield is about six hundred and fifty gallons a year for each cow. 
Mr. IIarley-whose admirable dairy establishment was erected for the purpose of supplying the city of Glasgow with a good quality of milk, and which has contributed more than any thing else to improve the quality of the milk arnished to all the principal cities of Great Britain-adopted he following system of feeding with the greatest profit: In the early part of the summer, young grass and green barley, the first cutting especially, mixed with a large proportion of old hay or straw, and a good quantity of salt to prevent swelling, were used. As summer advancerl, less hay and straw were given, and as the grass approached ripeness, they were discontinued altogether; but young and wet clover. was never given without an admixture of dry provender. When grass became searce, young turnips and turnip leaves were steamed with hay, and formed a good substitute. As grass decreased, the turnips were increased, and at length became a complete substitute. $A$ s the season advanced, a large proportion of distillers' grains and wash was given with other food, but these were found to have a tendency to make the cattle grain-sick; and if this feeding were long-continued, the health of the cows became affected. Boiled linseed and short-cut wheat-straw mixed with the grains, were found to prevent the cows from turning sick. As spring approached, Swedish turnips, when cheap, were substituted for yellow turnips. These two roots, steamed. with hay and other mixtures, afforded safe food till grass was again in season. When any of the cows were surfeited, the food was withheld till the appetite returned, when a small quantity was given, and increased gradually to the full allowance.

But the most elaborate and raluable experiments in the 
feeding and management of milch cows, are those made, not long since, by Mr. T. Horsfall, of England, and published in the Journal of the Royal Agricultural Society. His practice, though adapted more especially, perhaps, to his own section, is nevertheless of such general application and importance as to be worthy of attention. By his course of treatment he found that he could produce as much and as rich butter in winter as in summer.

His first object was to afford a full supply of the elements of food adapted to the maintenance, and also to the produce of the animal; and this could not be effected by the ordinary food and methods of feeding, since it is impossible to induce a cow to consume a quantity of hay requisite to supply the waste of the system, and keep up, at the same time, a full yield of the best quality of milk. He used, to some extent, cabbages, kohl rabi, mangolds, shorts, and other substances, rich in the constituents of cheese and butter. "My food for milch cows," says he, "after having undergone rarious modifications, has for two seasons consisted of rape cake five pounds, and bran two pounds, for each cow, mixed with a sufficient quantity of bean-straw, oat-straw, and shells of oats, in equal proportions, to supply them three times a day with as much as they will eat. The whole of the materials are moistened and blended together, and, after being well steamed, are giren to the animal in a warm state. The attendant is allowed one pound to one pound and a half per cow, according to circumstances, of bean-meal, which he is charged to give to each cow in proportion to the yield of milk; those in full milk getting each two pounds per day, others but little. It is dry, and mixed with the steamed 
food on its being dealt out separately. When this is eaten up, green food is given, consisting of cabbages, from October to December, kohl rabi till February, and mangold till grass time, with a view to nicety of flavor. I limit the quantity of green food to thirty or thirty-five pounds per day for each. After each feed, four pounds of meadow hay, or twelve pounds per day, is given to each cow. They are allowed water twice a day, to the extent which they will drink."

Bean-straw uncooked having been found to be hard and unpalatable, it was steamed to make it soft and pulpy, when it possessed an agreeable odor, and imparted its flavor to the whole mass. It was cut for this purpose just before ripening, but after the bean was fully grown, and in this state was found to possess nearly double the amount of albuminous matter, so valuable to milch cows, of good meadow or upland hay. Bran or shorts is also vastly improved by steaming or soaking with hot water, when its nutriment is more readily assimilated. It contains about fourteen per cent. of albumen, and is rich in phosphoric acid. Rape-cake was found to be exceedingly valuable. Linseed and cotton-seed cake may probably be substituted for it in this country.

Mr. Horsfall turned his cows in May into a rich pasture, lousing them at night, and giving them a mess of the steamed mixture and some hay morning and night; and from June to October they had cut grass in the stall, besides what they got in the pasture, and two feeds of the steamed mixture a day. After the beginning of October the cows were kept housed. With such management his cows generally yielded from twelve to sixteen quarts of milk (wine measure) a day, for about eight months after calving, when they fell off in 
milk, but gained in flesh, up to calving-time. In this course of treatment the manure was far better than the average, and his pastures constantly improved. The average amount of butter from every sixteen quarts of milk was $t$ we nty-five o u n c es-a proportion

far larger than the average.

How widely does this course

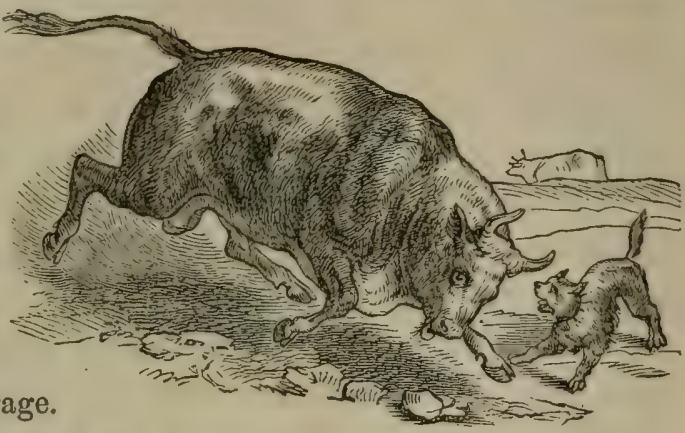
"ON THE RAMPAGE." of treatment differ from that of most farmers! The object with many seems to be, to see with how little food they can keep the cow alive. From a correct point of view, the milch cow should be regarded as an instrument of transformation. The questionn should be-with so much hay, so much grain, so many roots, how can the most milk, or butter, or cheese, be made? The conduct of a manufacturer who owned good machinery, and an abundance of raw material, and had the labor at hand, would be considered very senseless, if he hesitated to supply the material, and keep the machinery at work, at least so long as he could run it with profit.

Stimulate the appetite, then, and induce the cow to eat, by a frequent change of diet, not merely enough to supply the constant waste of her system, but enough and to spare, of a food adapted to the production of milk of the quality desired. 


\section{SOILING.}

Of the advantages of soiling milch cows-that is, feeding exclusively in the barn-there are yet many conflicting opinions. As to its economy of land and feed there can be no question, it being generally admitted that a given number of animals may be abundantly fed on a less space; nor is there much question as to the increased quantity of milk yielded in stall feeding. Its economy, in this country, turns rather upon the cost of labor and time; and the question raised by the dairyman is, whether it will pay-whether its advantages are sufficient to balance the extra expense of cutting and feeding, over and above cropping on the pasture. The importance of this subject has been strongly impressed upon the attention of farmers in many sections of the country, by a growing conviction that something must be done to improve the pastures, or that they must be abandoned altogether.

Thousands of acres of neglected pasture-land in the older States are so poor and worn out that from four to eight acres furnish but a miserable subsistence for a good-sized cow. No animal can flourish under such circumstances. The labor and exertion of feeding are too great, to say nothing of the vastly inferior quality of the grasses in such pastures, compared with those on more recently seeded lands. True economy would dictate that such pastures should either be allowed to run to wood, or be devoted to sheep-walks, or ploughed and improved. Cows, to be able to yield well, must have plenty of food of a sweet and nutritious quality; 
and, unless they find it, they wander over a large space, if at liberty, and thus deprive themselves of rest.

If a farmer or dairyman unfortunately owns such pastures, there can be no question that, as a matter of real economy, he had better resort to the soiling system for his milch cows; by which means he will largely increase his annual supply of good manure, and thus have the means of improving, and bringing his land to a higher state of cultivation. A very successful instance of this management occurs in the report of the visiting committee of an agricultural society in Massachusetts, in which they say: "We have now in mind a farmer in this county who keeps seven or eight cows in the stable through the summer, and feeds them on green fodder, chiefly Indian corn. We asked him his reasons for it. His answer was: 1. That he gets more milk than he can by any other method. 2. That he gets more manure, especially liquid manure. 3. That he saves it all, by keeping a supply of mud or mould under the stable, to be taken out and renewed as often as necessary. 4. That it is less troublesome than to drive his cows to pasture; that they are less vexed by flies, and have equally good health. 5. That his mowing land is every year growing more productive, without the expense of artificial manure.-He estimates that on an acre of good land twenty tons of green fodder may be raised. That which is dried is cut fine, and mixed with meal or shorts, and fed with profit. He believes that a reduced and worn-out farm-supposing the land to be naturally goodcould be brought into prime order in five years, without any extra outlay of money for manure, by the use of green fodder in connection with the raising and keeping of pigs ; not fat- 
tening them, but selling at the age of four or five months." He keeps most of his land in grass, improving its quality and productiveness by means of top-dressing, and putting money in his pocket-which is, after all, the true test both for theory nd practice.

Another practical case on this point is that of a gentleman in the same State who had four cows, but not a rod of land on which to pasture them. They were, therefore, never out of the barn-or, at least, not out of the yard-and were fed with grass, regularly mown for them; with green Indian corn and fodder, which had been sown broadcast for the purpose; and with about three pints of meal a day. Their produce in butter was kept for thirteen weeks. Two of them were but two years old, having calved the same spring. All the milk of one of them was taken by her calf for six weeks out of the thirteen, and some of the milk of the other was taken for family use, the quantity of which was not measured. These heifers could not, therefore, be estimated as equal to more than one cow in full milk. And yet from these cows no less than three hundred and eighty-nine pounds of butter were made in the thirteen weeks. Another pound would have made an average of thirty pounds a week for the whole time.

It appears from these and other similar instances of soiling, or stall-feeding in summer on green crops cut for the purpose, that the largely increased quantity of the yield fully compensates for the slightly deteriorated quality. And not only is the quantity yielded by each cow increased, but the same extent of land, under the same culture, will carry double or treble the number of ordinary pastures, and keep 
them in better condition. There is also a saving of manure. But with us the economy of soiling is the exception, and not the rule.

In adopting this system of feeding, regularity is required as much as in any other, and a proper variety of food. A succession of green crops should be provided, as near as convenient to the stable. The first will naturally be winter rye, in the Northern States, as that shoots up with great luxuriance. Winter rape would probably be an exceedingly valuable addition to the plants usually cultivated for soiling in this country, in sections where it would withstand the severity of the winter. Cabbages, kept in the cellar or pit, and transplanted early, will also come in here to advantage. and clover will very soon follow them; oats, millet, anc green Indian-corn, as the season advances; and, a little later still, perhaps, the Chinese sugar-cane, which should not be cut till headed out. These plants, in addition to other cultivated grasses, will furnish an unfailing succession of steculent and teuder fodder ; while the addition of a little Irdian, linseed, or cotton-seed meal will be found economical.

In the vicinity of large towns and cities, where the sbject is too often to feed for the largest quantity, without reference to quality, an article known as distillers' swill, or still-slop, is extensively used. This, if properly fed in limited quantities, $\mathrm{n}$ combination with other and more bulky food, may be a valuable article for the dairyman; but, if giren-as it too often is-without the addition of other kinds of food, it soon affects the health and constitution of the animals fed on it. This swill contains a considerable quantity of water, some nitrogenous compounds, and some inorganic matter, in the 
shape of phosphates and alkaline salts found in the different kinds of grain of which it is made up, as Indian corn, wheat, barley, rye, and the like. Where this forms the principal food of milch cows, the milk is of a very poor quality-blue in color, and requiring the addition of coloring substances $t$ make it saleable. It contains, often, less than one per cent. of butter, and seldom over one and three-tenths or one and a half per cent. - while good, saleable milk should contain from three to five per cent. 'It will not coagulate, it is said, in less than five or six hours; while good milk will invariably congulate in an hour or less, under the same conditions. Its effect on the system of young children is, therefore, very destructive, causing diseases of various kinds, and, if continued, death.

So pernicious have been the consequences resulting from the use of this "swill-milk," as it is called, in the largest city of this country, that the Legislature of the State of New York, at a recent session (1S61-2), interfered in behalf of the community by making the sale of the article a penal offence.

\section{CULTURE OF GRASSES FOR FODDER.}

As has been already stated, the grasses in summer, and hay in winter, form the most natural and important food for milch cows; and, whatever other crops come in as additional, these will form the basis of all systems of feeding.

The nutritive qualities of the grasses differ widely; and their value as feed for cows will depend, to a considerable extent, on the management of pastures and mowing-lands. Some considerations bearing upon the subject of the proper 
cultivation of these leading articles of food are, therefore, proposed in this article.

If the turf of an old pasture is.carefully examined, it will be found to contain a large variety of plants and grasses adapted for forage; some of them valuable for one purpose, and some for another. Some of them, though possessing a lower percentage of nutritive constituents than others, are

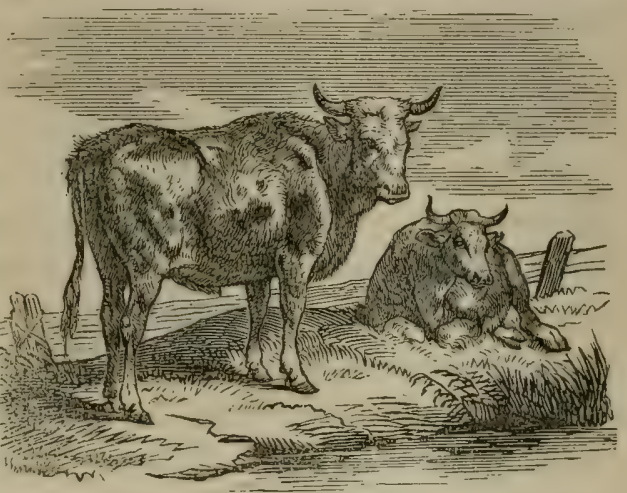

PATIENTLY WAITING.

particularly esteemed for an early and luxuriant growth, furnishing sweet feed in early spring, before other grasses appear; some of them, for starting more rapidly than others, after having been eaten off by cattle, and, consequently, of great value as pasture grasses. Most grasses will be found to be of a social character, and to do best in a large mixture with other varieties.

In forming a mixture for pasture grasses, the peculiar qualities of each species should, therefore, be regarded: as the time of flowering, the habits of growth, the soil and location on which it grows best, and other characteristics.

Among the grasses found on cultivated lands in this country, the following are considered as among the most valuable for ordinary farm cultivation; some of them being 
adapted to pastures, and others almost exclusively to mowing and the hay-crop: Timothy, Neadow Foxtail, June or Kentucky Blue Grass, Fowl Meadow, Rough-stalked Meadow, Orchard Grass, Perennial Rye Grass, Italian Rye Grass, Redtop, English Bent, Meadow Fescue, Tall Oat Grass, Sweet-scented Vernal, Hungarian Grass, Red Clover, White or Dutch Clover, and some others.

Of these, the most valuable, all things considered, is Tпмотну. It forms a large proportion of what is commonly called English, or in some sections meadow, hay, though it originated and was first cultivated in this country. It contains a large percentage of nutritive matter, in comparison with other agricultural grasses. It thrives best on moist, peaty, or loamy soils, of medium tenacity, and is not well suited to very light, sandy lands. On very moist soils, its root is almost always fibrous; while on dry and loamy ones it is bulbous. On soils of the former description, which it especially affects, its growth is rapid, and its yield of hay large, sometimes amounting to three or four tons the acre, depending much, of course, upon cultivation. But, though very valuable for hay, it is not adapted for pasture, as it will neither endure severe grazing, nor is its aftermath to be compared with that of meadow foxtail, and some of the other grasses.

June Grass, better known in some sections as Kentucky Blue Grass, is very common in most sections of the country, especially on limestone lands, forming a large part of the turf, wherever it flourishes, and being held in universal esteen as a pasture grass. It starts early, but varies much in sizo and appearance, according to the soil; growing in somo 
places with the utmost Iuxuriance, and forming the predominant grass; in others, yielding to the other species. If cut at the time of flowering, or a few days after, it makes a good and nutritious hay, though it is surpassed in nutritive qualities by several of the other grasses. It starts slowly after having been cut, especially if not cut very early. But its herbage is fine and uniform, and admirably adapted to larwns, growing well in almost all soils, though it does not endure very severe droughts. It withstands, however, the frosts of winter better than most other grasses.

In Kentucky-a section where it attains its highest perfection and luxuriance, ripening its seeds about the tenth of June-and in latitudes south of that, it sometimes continues green through the mild winters. It requires three or four years to become well set, after sowing, and it does not attain its highest yield as a pasture grass till the sod is even older than that. It is not, therefore, suited to alternate husbandry, where land usually remains in grass but two or three years before being ploughed up. In Kentucky, it is sown any time in winter when the sun is on the ground, three or four quarts of seed being used to the acre. In spring the seeds germinate, when the sprouts are exceedingly fine and delicate. Stock is not allowed on it the first year.

The MEAdow FoxtaIL is also an excellent pasture grass It somewhat resembles Timothy, but is earlier, has a softer spike, and thrives on all soils except the dryest. Its growth is rapid, and it is greatly relished by stock of all kinds. Its stalks and leaves are too few and light for a field crop, and it shrinks too much in curing to be valuable for hay. It flourishes best in a rich, moist, and rather strong soil, sending 
up a luxuriant aftermath when cut or grazed off, which is much more valuable, both in quality and nutritive value, than the first crop. In all lands designed for permanent pasture, therefore, it should form a considerable part of a nixture. It will endure almost any amount of forcing, by liquid manures or irrigation. It requires three or four years, after soiling, to gain a firm footing in the soil. The seed is covered with the soft and woolly husks of the flower, and is consequently light; weighing but five pounds to the bushel, and containing seventy-six thousand seeds to the ounce.

The Orchard Grass, or Rough Cocksfoot, for pastures, stands pre-eminent. This is a native of this country, and was introduced into England, from Virginia, in 1764, since which time its cultivation has extended into every country of Europe, where it is universally held in very high estimation. The fact of its being very palatable to stock of all kinds, its rapid growth, and the luxuriance of its aftermath, with its power of enduring the cropping of cattle, have given it a very high reputation, especially as a pasture grass. It blossoms earlier than Timothy; when green, is equally relished by milch cows; requires to be fed closer, to prevent its forming tufts and growing up to seed, when it becomes hard and wiry, and loses much of its nutritive quality. As it blossoms about the same time, it forms an admirable mixture with red clover, either for permanent pasture or mowing. It resists drought, and is less exhausting to the soil than either rye grass or Timothy. The seed weighs twelve pounds to the bushel, and when sown alone requires about two bushels to the acre.

The Rough-Stalked Meadow Grags is somewhat less 
common than the June grass, but is considered equally valuable. It grows best on moist, sheltered meadows, where it flowers in June and July. It is readily distinguished from June grass by its having a rough sheath, while the latter has a smooth one, and by having a fibrous root, while the root of the other is creeping. It possesses very considerable nutritive qualities, and comes to perfection at a desirable time, and is exceedingly relished by cattle, horses and sheep. For suitable soils it should form a portion of a mixture of seeds, producing, in mixture with other grasses which serve to shelter it, a large yield of hay, far above the average of grass usually sown on a similar soil. It should be cut when the seed is formed. Seven pounds of seed to the acre will make a good sward. The grass loses about seventy per cent. of its weight in drying. The nutritive qualities of its aftermath exceed very considerably those of the crop cut in the flower or in the seed.

Fowl Meadow Grass is another indigenous species, of great value for low and marshy grounds, where it flourishes best; and, if cut and properly cured, makes a sweet and nutritious hay, which, from its fineness, is eaten by cows without waste. According to Sinclair-who experimented, with the aid of Sir Humphrey Dary, to ascertain its comparative nutritive properties-it is superior in this respect to either mearlow foxtail, orchard grass, or tall meadow oat grass; but it is probable that he somewhat overrates it. If allowed to stand till nearly ripe, it falls down, but sends up innumerable flowering stems from the joints, so that it continues green and luxuriant till late in the season. It thrives best in mixture with other grasses, and deserves a prominent 
place in all mixtures for rich, moist pastures, and low mowing-lands.

Rye Grass has a far higher reputation abroad than in this country, and probably with reason; for it is better adapted to a wet and uncertain climate than to a dry and hot one. It varies exceedingly, depending much on soil and culture; but, when cut in the blossom to make into hay, it possesses very considerable nutritive power. If allowed to get too ripe, it is hard and wiry, and not relished by cows. The change from a juicy and nutritious plant to a woody fibre, containing but little soluble matter, is very rapid. Properly managed, however, it is a tolerably good grass, though not to be compared to Timothy, or orchard grass.

REDTOP is a grass familiar to every farmer in the country. It is the Herd's grass of Pennsylvania, while in New York and New England it is known by a great variety of names and assumes a great variety of forms, according to the soil in which it grows. It is well adapted to almost every soil, though it seems to prefer a moist loam. It makes a profitable crop for spending, in the form of hay, though its yield is less than that of Timothy. It is well suited to our permanent pastures, where it should be fed close, otherwise it becomes wiry and innutritious, and cattle refuse it. It stands the climate of the country as well as any other grass, and so forms a valuable part of any mixture for pastures and permanent mowing-lands; but it is, probably, rather overrated by us.

ENGLisu Bent, known also by a number of other names, is largely cultivated in some sections. It closely resembles redtop, but may be distinguished from it by the roughness of 
the sheaths when the hand is drawn from above downward. It possesses about the same qualities as redtop.

Meadow Fescue is one of the most common of the fescue grasses, and is said to be the Randall grass of Virginia. It is an excellent pasture grass, forming a very considerable portion of the turf of old pasture lands and fields; and is more extensively propagated and diffused from the fact that it ripens its seeds before most other grasses are cut, and sheds them to spring up and cover the ground. Its long and tender leaves are much relished by cattle. It is rarely sown in this country, notwithstanding its great and acknowledged value as a pasture grass. If sown at all, it should be in mixture with other grasses, as orchard grass, and rye grass,' or June grass. It is of much greater value at the time of flowering than when the seed is ripe.

The Tall Oat Grass is the Ray grass of France. It furnishes a luxuriant supply of foliage, is valuable either for

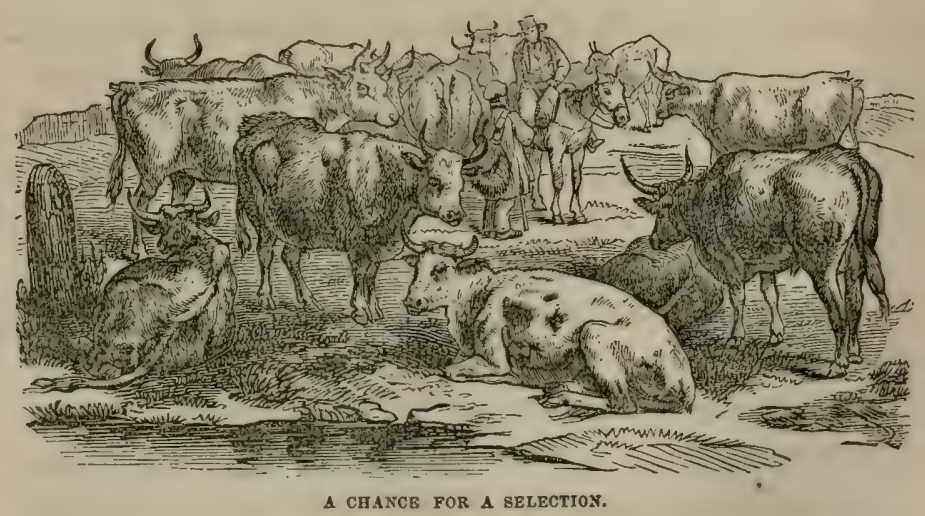

hay or for pasture, and has been especially recommended for soiling purposes, on account of its early and luxuriant 9 
growth. It is often found on the borders of fields and hedges, woods and pastures, and is sometimes very plenty in mowing-lands. After having been mown it shoots up a very thick aftermath, and, on this account, partly, is regarded of nearly equal excellence with the common foxtail.

It grows spontaneously on deep, sandy soils, when once naturalized. It has been cultivated to a considerable extent in this country, and is esteemed by those who know it mainly for its early, rapid, and late growth, making it very well calculated as a permanent pasture grass. It will succeed on tenacious clover soil.

The Sweet-Scented Vernad Grass is one of the earliest in spring and one of the latest in autumn; and this habit of growth is one of its chief excellencies, as it is neither a nutritious grass, nor very palatable to stock of any kind, nor does it yield a very good crop. It is very common in New England and all over the Middle States, coming into old worn-out fields and moist pastures spontaneously, and along every roadside. It derives its name from its sweetness of odor when partially wilted or crushed in the hand, and it is this chiefly which gives the delicious fragrance to all newmown hay. It is almost the only grass that possesses a strongly-marked aromatic odor, which is imparted to other grasses with which it is cured. Its seed weighs eight pounds to the bushel. In mixtures for permanent pastures it may be of some value.

Hungarian Grass, or millet, is an annual forage plant, introduced into France in 1815 , and more recently into this country. It germinates readily, and withstands the drought remarkably, remaining green when other grasses are parched 
and dried up. It has numerous succulent leaves which furnish an abundance of sweet fodder, greatly relished by stock of all kinds. It attains its greatest luxuriance on soils of medium consistency and richness, but does rery well on light and dry plains.

RED Clover is an artificial grass of the leguminous family, and one of the most valuable cultivated plants for feeding to dairy cows. It flourishes best on tenacious soils and stiff loams. Its growth is rapid, and a few months after sowing are sufficient to supply an abundant sweet and nutritious food. In the climate of New England, clover should be sown in the spring of the year, while most of the natural grasses do far better when sown in the fall. It is often sown with perfect success on the late snows of March or April, and soon finds its way down into the soil and takes a vigorous hold with its root. It is valuable not only as a forage plant, but as shading the ground, and thereby increasing its fertility.

The introduction of clover among the cultivated plants of the farm bas done more, perhaps, for modern agriculture than that of any other single plant. It is now considered indispensable in all good dairy districts.

White Clover, often called Honeysuckle, is also widely diffused over this country, to which it is undoubtedly indigenous. As a mixture in all pasture grasses it holds a very high rank, as it is exceedingly sweet and nutritious, and relished by all kinds of stock. It grows most luxuriantly in moist grounds and moist seasons, but easily accommodates itself to a great variety of circumstances.

With respect to the mixtures of grass-seeds most profitable 
for the dairy farmer, no universal rule can be given, as they depend very much upon the nature of the soil and the locality. The most important point to be observed, and the one as to which, probably, the greatest deficiency exists, is to use a large number of species, with smaller quantities of each than those most commonly used. This is Nature's rule; for, in examining the turf of a rich old pasture, a large number of different species will be found growing together, while, if the turf of a field sown without two or three species is examined, a far less number of plants is found to the square foot, even after the sod is fairly set. In the opinion of the most competent judges, no improvement in grass culture is more important than this.

As an instance of what he would consider an improvement on the ordinary mixtures for permanent pastures, Mr. Flint, in his "Milch Cows and Dairy Farming," suggests the following as likely to give satisfactory results, dependent, of course, to a considerable extent, on the nature and preparation of the soil :

Meadow Foxtail, flowering in May and June, 2 pounds.

Orchard Grass,

Sweet-scented Vernal, “

Meadow Fescue,

Redtop,

June Grass,

Italian Rye Grass,

Perennial do.,

Timothy,

Rough-stalked Meadow Grass,

Perennial Clover, flowering in June,

" "May to September 5-40" 
For mowing-lands the mixture would, of course, be somewhat changed. The meadow fortail and sweet-scented vernal would be left out entirely, and some six or eight pounds added to the Timothy and red clover. The proper time to lay down lands to grass in the latitude of New England is August or September, and no grain crop should be sown with the seed.

Stiff or clayey pastures should never be overstocked, but when fed pretty close the grasses are far sweeter and more nutritious than when they are allowed to grow up rank and coarse; and if, by a want of sufficient feeding, they get the start of the stock, and grow into rank tufts, they should be cut and removed, when a fresh grass will start up, similar to the aftermath of mowing-lands, which will be eaten with avidity. Grasses for curing into hay should be cut either at the time of flowering, or just before, especially if designed for milch cows. They are then more succulent and juicy, and, if properly cured, form the sweetest food.

Grass cut in the blossom will make more milk than if allowed to stand later. Cut a little before the blossoming; it will make more than when in blossom, and the cows prefer it, which is by no means an unimportant consideration, since their tastes should always be consulted. Grass cut somewhat green, and properly cured, is next to fresh, green grass in palatable, nutritive qualities. Every farmer knows the milk-producing properties of rowen, or second crop, which is generally cut before it ripens:

No operation on the farm is of greater importance to the dairyman than the cutting of his grass and the manner of curing hay; and in this respect the practice over the country 
generally is susceptible of very marked improvement. The chief object is to preserve the sweetness and succulence of the grass in its natural state, so far as possible; and this object cannot be attained by exposing it too long to the scorching suns and drenching rains to which our elimate is liable. As a general thing, farmers try to make their hay too much.

As to the best modes of curing clover, the following, among others, is adopted by many successful farmers: What is mown in the morning is left in the swath, to be turned over early in the afternoon. At about four o'clock, or while it is still warm, it is put into small cocks with a fork, and, if the weather is favorable, it may be housed on the fourth or fifth day, the cocks being turned over on the morning of the day in which it is to be carted. By this method all the heads and leaves are saved, and these are more valuable than the stems. For new milch cows in winter scarcely any food is better. It will cause them to give as great a flow of milk as any hay, unless it be good rowen.

INDIAN CORN makes an exceedingly valuable fodder, both as a means of carrying a herd of milch cows through our severe droughts of summer, and as an article for soiling cows kept in the stall. No dairy farmer will neglect to sow an extent in proportion to the number of cows which he keeps. The most common practice is, to sow in drills from two and a half to three feet apart, on land well tilled and thoroughly manured, making the drills from six to ten inches wide with the plough, manuring in the furrow, dropping the kernels about two inches apart, and covering with the hoe. In this mode of culture, the cultivator may be used between the 
rows when the corn is from six to twelve inches high, and, unless the ground is very weedy, no other after culture is needed. The first sowing usually takes place about the middle of May, and this is succeeded by other sowings, at intervals of a week or ten days, till July; in order to have a. succession of green fodder; but, if it is designed to cut it up to cure for winter use, an early sowing is generally preferred, in order to be able to cure it in warm weather, in August or early in September. Sown in this way, about three or four bushels of corn are required for an acre; since, if sown thickly, the fodder is better, the stalks smaller, and the waste less.

The chief difficulty in curing corn cultivated for this purpose, and after the methods just spoken of, arises from the fact that it comes at a season when the weather is often colder, the days shorter, and the dews heavier, than when the curing of hay takes place. Nor is the curing of corn cut up green so easy and simple as that of the drying of stalks of Indian corn cut above the ear, as in the common practice of topping. The plant is then riper, less juicy, and cures more readily.

The method sometimes adopted is to cut and tie into small bundles, after it is somewhat wilted, and then to stook upon the ground, where it is allowed to stand, subject to all the changes of weather, with only the protection of the stook itself. The stooks consist of bunches of stalks first bound into small bundles, and are made sufficiently large to prevent the wind from blowing them over. The arms are thrown around the tops to bring them as closely together as possible, when the tops are broken over or twisted together, or other. 
wise fastened, in order to make the stook "shed tne rain" as well as possible. In this condition they remain out until they are sufficiently dried to be put in the barn. Corn fodder is very excellent for young dairy stock.

Comion Millet is another very valuable crop for fodder in soiling, or to cure for winter use, but especially to feed out during the usual season of drought. Many varieties of millet are cultivated in this country, the ground being prepared and treated as for oats. If designed to cut for green fodder, half a bushel of seed to the acre should be used; if to ripen seed, twelve quarts, sown broadcast, about the last of May or early in June. A moist loam or muck is the best soil adapted to millet; but very great crops have been grown on dry upland. It is very palatable and nutritious for milch cows, both green and when properly cured. The curing should be very much like that of clover, care being taken not to over-dry it. For fodder, either green or cured, it is cut before ripening. In this state all cattle eat it as readily as green corn, and a less extent will feed them. Millet is worthy of a widely-extended cultivation, particularly on dairy farms. Indian millet is another cultivated variety.

Rye, as a fodder plant, is chiefly valuable for its early growth in spring. It is usually sown in September or October-from the middle to the end of September being, perhaps, the most desirable time-on land previously cultivated and in good condition. If designed to ripen only, a bushel of seed is required to the acre, evenly sown; but, if intended for early fodder in spring, two or two and a half bushels of seed per acre should be used. On warm land the rye can be cut green the last of April or the first of May. 
Care should be taken to cut early; since, if it is allowed to advance too far torvards maturity, the stalk becomes hard and unpalatable to cows.

OATs are also sometimes used for soiling, or for feeding green, to eke out a scanty supply of pasture feed; and for this purpose they are valuable. They should be sown on well-tilled and well-manured land, about four bushels to the acre, towards the last of April or the first of May. If the whole crop is to be used as green fodder, five bushels of seed will not be too much for good, strong soil. They will be sufficiently grown to cut by the first of July, or in some sections earlier, depending upon the location.

The Chinese Sugar-Cane also may deserve attention as a fodder plant. Experiments thus far made would seem to show that when properly cultivated, and cut at the right time, it is a palatable and nutritious plant, while many of the failures have been the result of too early cutting. For a fodder crop the drill culture is preferable, both on account of the larger yield obtained and because it is thus prevented from becoming too hard and stalky.

Of the root crops the Potato is the first to be mentioned. This produces a large quantity of milk, though the quality is inferior. The market value of this root is, at times, too great to allow of feeding extensively with it, even in milk dairies, where it is most valuable as a food for cows; still, there are locations where it may be judicious to cultivate this root for dairy feed, and in all circumstances there is a certain portion of the crop of unmarketable size, which will be of value fed to milch cows or swine. It should be planted in April or May, but in many sections in June, on good mellow soil, first 
thoroughly plowed and harrowed, then furrowed three feet apart, and manured in the furrows with a mixture of ashes, plaster of Paris, and salt. The seed may be dropped in the furrows, one foot apart, after the drill system-or in hills, two and a half or three feet apart-to be covered with the plough by simply turning the furrows back, after which the whole should be rolled with the field-roller, when it can be done.

If the land is not already in good heart from continuea cultivation, a few loads of barnyard manure may be spread, and plowed under by the first plowing. Used in this way it is far less liable to cause the rot, than when it is put in the hill. If a sufficient quantity of wood-ashes is not at hand, sifted coal-ashes will answer the purpose, and these are said to be valuable as a preventive of rot. In this way, one man, two boys, and a horse can plant from three to four acres a day on mellow land.

By another method two acres a day on the sod have been planted. The manure is first spread upon the grass, and then a furrow made by a yoke of oxen and one man, another following after and dropping, a foot apart, along the outer edge of the furrow on the grass. By quick work, one hand can nearly keep up with the plow in dropping. When arrived at the end of the piece, a back furrow is turned up to the potatoes, and a good plowman will cover nearly all without difficulty. On the return furrow, the man or boy who dropped follows after, covering up any that may be left or displaced, and smoothing off the top of the back-furrows when necessary. Potatoes thus planted have come out finely. 
The cost of cultivation in this mode, it must be evident, is but trifling, compared with the slower method of hand-planting. It requires a skillful ploughman, a quick, active lad, and a good yoke of oxen, and the extent of the work will depend somewhat upon the state of the turf. The nutritive equivalent for potatoes in a hundred pounds of good hay is 319 pounds; that is, it will take 3.19 pounds of potatoes to afford the same amount of nourishment as one pound of hay. The great value of roots is as a change or condiment calculated to keep the animal in a healthy condition.

The CARrot is somewhat extensively fed, and is a valuable root for milch cows. This, like the potato, has been cultivated and improved from a wild plant. Carrots require a deep, warm, mellow soil, thoroughly cultivated, but clean, and free

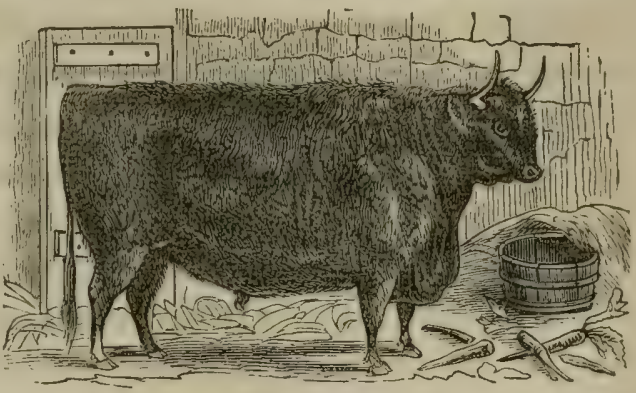

A WEST HIGRLAND OX.

from weed-seed. The difference between a very good profit and a loss on the crop depends much upon the use of land and manures perfectly free from foul seeds of any kind. Ashes, guano, seaweed, ground bones, and other similar substances, or thoroughly-rotted and fermented compost, will answer the purpose.

After plowing deep, and harrowing carefully, the seed should be planted with a sced-sower, in drills about eighteen inches apart, at the rate of four pounds to the acre, about the 
middle of May. The difference between sowing on the fifteenth of May and on the tenth of June in New England is said to be nearly one-third in the crop on an average of years. In weeding, a little wheel-hoe is invaluable, as with it a large part of the labor of cultivation is saved. A skillful hand can run this hoe within a half an inch of the young plants without injury, and go over a large space in the course of a day, if the land was properly prepared in the first place.

The American farmer should always plan to economize labor, which is the great item of expense upon a farm. By this is not meant that he should strive to shirk or avoid work, but that he should make the least amount of work accomplish the greatest and most profitable results. Laborsaving machinery on the farm is applied, not to reduce the number of hours of labor, or to make the owner a man of leisure-who is, generally, the unhappiest man in the worldbut to enable him to accomplish the greatest results in the same time that he would be compelled to obtain smaller ones.

Carrots will continue to grow and increase in size late into the fall. When ready to dig, plow around as near to the outside rows as possible, turning away the furrow from the row. Then take out the carrots, pulling off the tops, and throw the carrots and tops into separate heaps on the plowed furrows. In this way a man and two boys can harvest and put into the cellar upwards of a hundred bushels a day.

The Turnip, and the Swedish turnip, or ruta baga, are also largely cultivated as a field crop to feed to stock; and for this purpose almost numberless varieties are used, furnishing a great amount of succulent and nutritious food, late into 
winter, and, if well-kept, late into spring. The chief objection to the turnip is, that it taints the milk. This may be remedied-to a considerable extent, if not wholly-by the use of salt, or salt hay, and by feeding at the time of milking, or immediately after, or by steaming before feeding, or put ting a small quantity of the solution of nitre into the pail, and milking upon it.

Turnips may be sown any time in June, in rich land, well mellowed by cultivation. Very large crops are obtained, sown as late as the middle of July, or the first of August, on an inverted sod. The Michigan, or double-mould-board plow leaves the land light, and in admirable condition to harrow, and drill in turnips. In one instance, a successful root-grower cut two tons of hay to the acre, on the twentythird of June, and after it was removed from the land spread eight cords of rotten kelp to the acre, and plowed in; after which about three cords of fine old compost manure were used to the acre, which was sown with ruta baga seed, in drills, three feet apart, plants thinned to eight or ten inches in the drill. No after cultivation was required. On the fifteenth of November he harvested three hundred and seventy bushels of splendid roots to the acre, carefully measured off.

The nutritive equivalent of Swedish turnips as compared with good meadow hay is 676 , taking hay as a standard a 100 ; that is, it would require 6.76 pounds of turnips to furnish the'same nutriment as one pound of good hay; but fed in connection with other food-as hay, for example-perhaps five pounds of turnips would be about equal to one pound of hay 
The English or round turnip is usually sown broadcast after some other crop, and large and valuable returns are often obtained. The Swede is sown in drills. Both of these varieties are used for the production of milk.

The chief objection to the turnip crop is that it leaves many kinds of soil unfit for a succession of some other crops, like Indian corn, for instance. In some sections, no amount of manuring appears to make corn do well after turnips or ruta bagas.

The Mangold Wurtzed, a variety of the common beet, is often cultivated in this country with great success, and fed to cows with advantage, furnishing a succulent and nutritive food in winter and spring. The crop is somewhat uncertain. When it does well, an enormous yield is often obtained; but, not rarely, it proves a failure, and is not, on the whole, quite as reliable as the ruta baga, though a more valuable crop when the yield is good. It is cultivated like the common beet in moist, rich soils, three pounds of seed to the acre. The leaves may be stripped off, towards fall, and fed out, without injury to the growth of the root. Both mangolds and turnips should be cut with a root-cutter, before being fed out.

The PARsnip is a very sweet and nutritious article of fodder, and adds richness and flavor to the milk. It is worthy of extended culture in all parts of the country where dairy husbandry is pursued. It is a biennial, easily raised on deep, rich, well-cultivated and well-manured soils, often yielding enormous crops, and possessing the decided advantage of withstanding the severest winters. As an article of spring feeding, therefore, it is exceedingly valuable. Sown 
in April or May, it attains a large growth before winter. Then, if desirable, a part of the crop may be harvested for winter use, and the remainder left in the ground till the frost is out, in March or April, when they can be dug as wanted, and are exceedingly relished by milch corvs and stock of all kinds. They make an admirable feed at the time of milking, and produce the richest cream, and the yellowest and finestflavored butter, of any roots used among us. The best dairy farmers on the Island of Jersey often feed to their cows from thirty to thirty-five pounds of parsnips a day, in addition to hay or grass.

Both practical experiment and scientific analysis prove this root to be eminently adapted to dairy stock, where the richness of milk or fine-flavored butter is any object. For mere milk-dairies, it is not quite so valuable, probably, as the Swedish turnip. The culture is similar to that of carrots, a rich, mellow, and deep loam being best; while it has a great advantage over the carrot in being more hardy, and rather less liable to injury from insects, and more nutritive. For feeding and fattening stock it is eminently adapted.

To be sure of a crop, fresh seed must be had, as it cannot be depended on for more than one year. For this reason the largest and straightest roots should be allowed to stand for seed, which, as soon as nearly ripe, should be taken out and spread out to dry, and carefully kept for use. For field culture, the hollow-crowned parsnip is the best and most profitable; but on thin, shallow soils the turnip-rooted variety should be used. Parsnips may be harrested like carrots, by plowing along the rows. Let butter or cheese dairy- 
men give this crop a fair and full trial, and watch its effect in the quality of the milk and butter.

The KонL RABI is also cultivated to a considerable extent in this country for the purpose of feeding stock. It is supposed to be a hybrid between the cabbage and the turnip and is often called the cabbage-turnip, having the root of the former, with a turnip-like or bulbous stem. The special reason for its more extensive cultivation among us is its wonderful indifference to droughts, in which it seems to flourish best, and to bring forth the most luxuriant crops. It also withstands the frosts remarkably, being a hardy plant. It yields a somewhat richer quality of milk than the ordinary turnip, and the crop is generally admitted to be as abundant and profitable. Very large crops of it have been produced by the ordinary turnip or cabbage cultivation. As in cabbage-culture, it is best to sow the seed in March or April, in a warm and well-enriched seed-bed; from which it is transplanted in May, and set out after the manner of cabbages in garden culture. It bears transplanting better than most other roots. Insects injure it less than the turnip, dry weather favors it, and it keeps well through winter. For these reasons, it must be regarded as a valuable addition to our list of forage plants adapted to dairy farming. It grows well on stronger soils than the turnip requires.

Linseed Meat is the ground cake of flaxseed after the oil is pressed out. It is very rich in fat-forming principles, and given to milch cows increases the quality of butter, and keeps them in condition. Four or five pounds a day are suficient for cows in milk, and this amount will effect a great saving in the cost of other food, and at the same time 
make a rery rich milk. It is extensively manufactured in this country, and largely exported, but it is worthy of more general use here. It must not be fed in too large quantities to milch cows, for it would be liable to give too great a tendency to fat, and thus affect the quantity of the milk.

CotTon-SEed MeaL is an article of comparatively recent introduction. It is obtained by pressing the seed of the cotton-plant, which extracts the oil, when the cake is crushed or ground into meal, which has been found to be a very valuable article for feeding stock. From analysis it is shown to be equal or superior to linseed meal. Practical experiments only are needed to establish it. It can be procured in market at a reasonable price.

The Manunes used in this country for the culture of the above named plants are mostly such as are made on the farm, consisting chiefly of barnyard composts of various kinds, with often a large admixture of peat-mud. There are few farms that do not contain substances, which, if properly husbanded, would add very greatly to the amount of manure ordinarily made. The best of the concentrated manures, which it is sometimes necessary to use, for want of time and labor to prepare enough upon the farm, is, unquestionably, Peruvian guano. The results of this, when properly applied, are well known and reliable, which can hardly be said of any other artificial manure offered for the farmer's notice. The chief objection to depending upon manures made off the farm is, in the first place, their great expense; and in the second-which is equally important-the fact, that, though they may be made valuable, and produce at one time the best results, a want of care in the manufacture, or designed fraud, may - 10 
make them almost worthless, with the impossibility of detecting the imposition, without a chemical analysis, till it becomes too late, and the crop is lost.

It is, therefore, safest to rely mainly upon the home manufacture of manure. The extra expense of soiling cattle, saving and applying the liquid manure, and thus bringing the land to a higher state of cultivation, when it will be capable of keeping more stock and furnishing more manure, would offer a surer road to success than a constant outlay for concentrated fertilizers.

\section{THE BARN.}

The farm barn, next to the farm house, is the most important structure of the farm itself, in the Northern and Middle States; and even at the South and Southwest, where barns are less used, they are of more importance in the economy of farm management than is generally understood. Indeed, to the eyes of a person of taste, a farm or plantation appears incomplete, without good barn accommodations, as much as without good household appointments-and without them, no agricultural establishment can be complete in all its proper economy.

The most thorough barn structures, perhaps, to be seen in the United States, are those of the State of Pennsylvania, built by the German farmers of the lower and central counties. They are large, and expensive in their construction; and, in a strictly economical point of view, are, perhaps, more costly than is required. Tet, there is a substantial durability about them, that is exceedingly satisfactory, and, where the 
pecuniary ability of the farmer will admit, they may well furnish models for imitation.

In the structure of the barn, and in its interior accommodation, much will depend upon the branches of agriculture to which the farm is devoted. A farm cultivated in grain chiefly requires but little room for stabling purposes. Storage for grain in the sheaf, and granaries, will require its room; while a stock farm requires a barn with extensive hay storage, and stables for its cattle, horses, and sheep, in all climates which do not admit of such stocks living through the winter in the field, as is the case in the great grazing districts west of the Alleghanies. Again, there are wide districts of country where a mixed husbandry of grain and stock is pursued, which require barns and outbuildings accommodating both.

It may be well here to remark that many designers of barns, sheds, and "other out-buildings for the accommodation of farm stock, have indulged in fanciful arrangements for the comfort and convenience of animals, which are so complicated that when constructed, as they sometimes are, the practical, common-sense farmer will not use them; and by reason of the learning which is required for their use, they are altogether unsuitable for the treatment and use which they generally receive from those who have the daily care of the stock for which they are intended, and for the rough usage which they experience from the animals themselves. A very pretty and plausible arrangement of stabling, feeding, and all the other requirements of a barn establishment may be thus got up by an ingenious theorist at the fireside, which will work charmingly as he dilates upon its good qualities, untried; but, which, when subjected to experiment, will be 
utterly worthless for practical use. There can be no doubt that the simplest plan of construction, consistent with an economical expenditure of the material of food for the consumption of stock, is by far the most preferable.

Another item to be considered in this connection, is the comparative value of the stock, the forage fed to them, and the labor expended in feeding and taking care of them. To illustrate: Suppose a farm to lie in the vicinity of a large town or city. Its value is, perhaps, a hundred dollars an acre. The hay cut upon it is worth fifteen dollars a ton, at the barn, and straw and coarse grains in proportion, and hired labor ten or twelve dollars a month. Consequently, the manager of this farm should use all the economy in his power, by the aid of cutting-boxes and other machinery, to make the least amount of forage supply the wants of his stock; and the internal economy of his barn should be arranged accordingly, since labor is his cheapest item, and food his dearest. Therefore, any contrivance by which to work up his forage the closest-by way of machinery, or manual labor-so that it shall serve the purposes of keeping his stock, is true cconomy; and the making and saving of manures are items of the first importance. His buildings and their arrangements throughout should, for these reasons, be constructed in accordance with his practice.

If, on the other hand, lands are cheap and productive, and labor comparatively dear, a different practice will prevail. The farmer will feed his hay from the mow without cutting. The straw will be stacked out, and the cattle turned to it, to pick what they like of it, and make their beds of the remainder; or, if it is housed, he will throw it into racks, and 
the stock may eat what they choose. To do this requires but one-third, or one-half of the labor which is required by the other mode, and the saving in this makes up, and perhaps more than makes up, for the increased quantity of forage consumed.

Again, climate may equally affect the mode of winterfeeding the stock. The winters may be mild. The hay may be stacked in the fields when gathered, or put into small barns built for hay storage alone; and the manure, scattered over the fields by the cattle, as they are fed from either of them, may be knocked to pieces with the dung-beetle, in the spring, or harrowed and bushed over the ground; and with the very small quantity of labor required in all this, such practice will be more economical than any other which can be adopted.

In latitudes, however, in which it becomes necessary to stall-feed during several months of the year, barns are indispensable. These should be warm, and at the same time well ventilated. The barn should be arranged in a manner suitable to keeping hay and other fodder dry and sweet, and with reference to the comfort and health of the animals, and the economy of labor and manure. The size and finish will, of course, depend on the wants and means of the farmer or dairyman; but many little conveniences, it should not be forgotten, can be added at comparatively trifling cost.

The accompanying cut of a barn is given merely as an illustration of a convenient arrangement for a medium-sized dairy, and not as being adapted to all circumstances or situations. This barn is supposed to stand upon a side-hill or an inclined surface, where it is easy to have a cellar, if desired $i$ 
and the cattle-room, as shown in the cut, is in the second story, or directly over the cellar, the bottom of which should

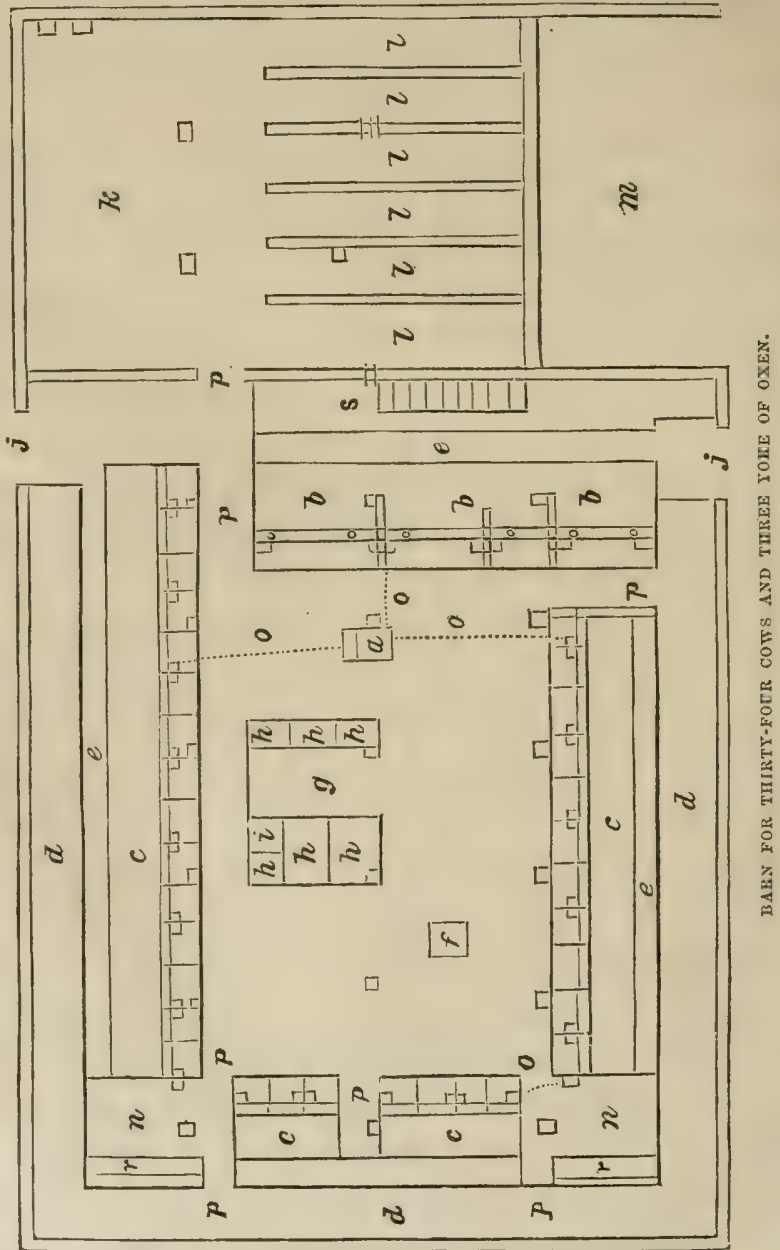

be somewhat dished, or lower in the middle than around the outer sides, and carefully paved, or laid in cement. 
On the outside is represented an open shed, $m$, for carts and wagons to remain under cover, thirty feet by fifteen, while $l l l . l l l$ are bins for vegetables, to be filled through scuttles from the floor of the story above, and surrounded by solid walls. The area of this whole floor equals one hundred feet by fifty-seven. $k$, is an open space, nearly on a level with the cow-chamber, through the door $p$. $s$, stairs to the third story and to the cellar. $d d d$, passage next to the walls, five feet wide, and nine inches above the dung-pit $e e e$, dung-pit, two feet wide, and seven inches below the floor where the cattle stand. The manure drops from this pit into the cellar below, five feet from the walls, and quite around the cellar. $c c c$, plank floor for cows, four feet six inches long. $b b b$, stalls for three yoke of oxen, on a platform five feet six inches long. $n n$, calf-pens, which may also be used for cows in calving. $r r$, feeding-troughs for calves. The feeding-boxes are made in the form of trays, with partitions between them. Water comes in by a pipe, to cistern $a$. This cistern is regulated by a cock and ball, and the water flows by dotted lines, ooo, to the boxes; each box being connected by lead pipes well secured from frost, so that, if desired, each animal can be watered without leaving the stall, or water can be kept constantly before it. A scuttle, through which sweepings and refuse may be put into the cellar, is seen at $f$. $g$ is a bin receiving cut hay from the third story, or hay-room. $h h \hbar h h h$, bins for grain-feed. $i$ is a tunnel to conduct manure or muck from the hay-floor to the cellar. $j j$, sliding-doors on wheels. The corws all face toward the open area in the centre.

This cow-room may be furnished with a thermometer, 
cluck, etc., and should always be well ventilated by sliding windows, which at the same time admit the light.

The next cut is a transverse section of the same cow-room; $a$ being a walk behind the cows, five feet wide; $b$, dung.pit; $c$, cattle-stand; $d$, feeding-trough, with a bottom on a level

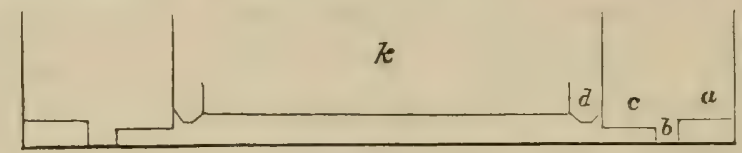

TRANSVERSE SECTION.

with the platform where the cattle stand; $k$, open area, fortythree feet, by fifty-six.

The story above the cow-room-as represented in the next cut-is one hundred feet by forty-two; the bays for hay, ten on each side, being ten feet front and fifteen feet deep; and the open space, $p$, for the entrance of wagons, carts, etc., twelve feet wide. $b$, hay-scales. $c$, scale beam. $m m \mathrm{~mm} \mathrm{~m} \mathrm{~m}$, ladders reaching almost to the roof. $l l l$, etc., scuttle-holes for sending regetables directly to the bins, $l l l$, etc., below. $a a b b$, rooms on the corners for storage. $d$, scuttles; four of which are used for straw, one for cut hay, and one for muck for the cellar. $n$ and the other small squares are eighteen-feet posts. $f$, passage to the tool-house, a room one hundred feet long by cighteen wide. $o$, stairs leading to the scaffold in the roof of the tool-house. $i i$, benches. $g$, floor. $h$, boxes for hoes, shovels, spades, picks, iron bars, old iron, etc. $j j j$, bins for fruit. $k$, scuttles to put apples into wagous, etc., in the shed below. One side of this toolhouse may be used for plows and large implements, hayrigging, harness, etc.

Proper ventilation of the cellar and the cow-room aroids 
THE BARN.

the objection that the hay is liable to injury from noxious gases.

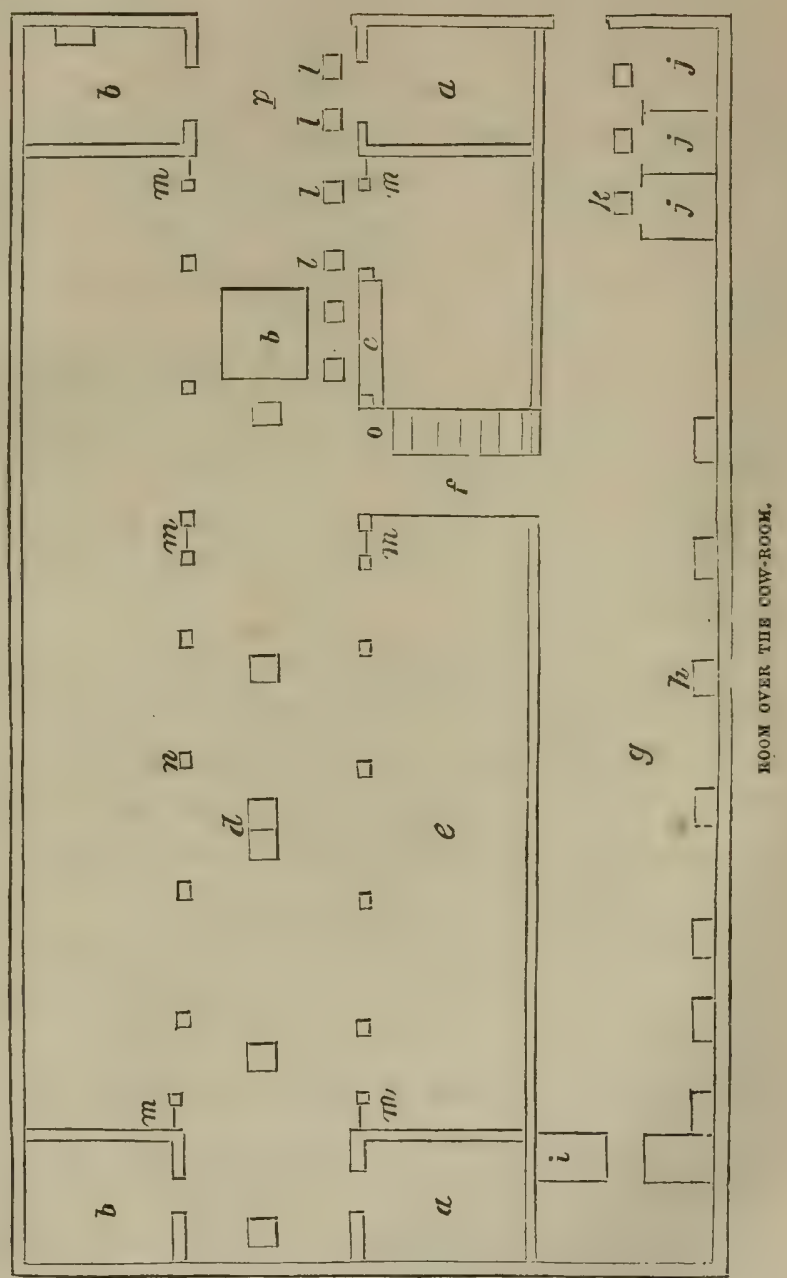

The excellent manure-cellar beneath this barn extends only 
under the cow-room. It has a drive-way through doors on each side. No barn-cellar should be kept shut up tight, even in cold weather. The gases are constantly escaping from the manure, unless held by absorbents, which are liable not only to affect the health of the stock, but also to injure the quality of the hay. To prevent this, while securing the important advantages of a manure-cellar, the barn may be furnished with good-sized ventilators on the top, for every twenty-five feet of its length, and with wooden tubes leading from the cellar to the top.

There should also be windows on different sides of the cellar to admit the free circulation of air. With these precautions, together with the use of absorbents in the shape of loam and muck, there will be no danger of rotting the timbers of the barn, or of risking the bealth of the cattle or the quality of the hay.

The temperature at which the cow-room should be kept is somewhere from fifty to sixty degrees, Fahrenheit. The practice and the opinions of successful dairymen differ somewhat on this point. Too great heat would affect the health and appetite of the herd; while too low a temperature is equally objectionable, for various reasons.

The most economical plan for room in tying cattle in their stalls, is to fasten the rope or chain, whichever is used-the wooden stanchion, or stanchel, as it is called, to open and shut, enclosing the animal by the neck, being oljectionableinto a ring, which is secured by a strong staple into a post. This prevents the cattle from interfering with each other, while a partition effectually prevents any contact from the animals on each side of it, in the separate stalls. 
There is no greater benefit for cattle, after coming into winter-quarters, than a systematic regularity in every thing pertaining to them. Every animal should have its own particular stall in the stable, where it should always be kept. The cattle should be fed and watered at certain fixed hour's of the day, as near as may be. If let out of the stables for water, unless the weather is very pleasant-when they may be permitted to lie out for a short time-they should be immediately put back, and not allowed to range about with the outside cattle. They are more quiet and contented in their stables than elsewhere, and waste less food than if permitted to run out; besides being in every way more comfortable, if properly bedded and attended to, as every

- one will find upon trial. The habit which many farmers have, of turning their cattle out of the stables in the morning, in all weathers-letting them range about in a cold yard, hooking and annoying each other-is of no possible benefit, unless it be to rid them of the trouble of cleaning the stables, which pays more than twice its cost in the saving of manure. The outside cattle, which occupy the yard-if there are any -are all the better that the stabled ones do not interfere with them. They become habituated to their own quarters, as do the others, and all are better for being, respectively, in their proper places.

\section{MILKING.}

The manner of milking exerts a more powerful and lasting influence on the productiveness of the cow than most farmers are aware. That a slow and careless milker soon dries up the best of cevs, every practical farmer and dairyman knows; 
but a careful examination of the beautiful structure of the udder will serve further to explain the proper mode of milking, in order to obtain and keep up the largest yield.

The udder of a cow consists of four glands, disconnected from each other, but all contained within one bag or cellular membrane; and these glands are uniform in structure. Each gland consists of three parts: the glandular, or secreting part, tubular or conducting part, and the teats, or receptacle, or receiving part. The glandular forms by far the largest portion of the udder. It appears to the naked eye composed of a mass of yellowish grains; but under the microscope these grains are found to consist entirely of minute bloodvessels forming a compact plexus, or fold. These vessels secrete the milk from the blood. The milk is abstracted from the blood in the glandular part; the tubes receire and deposit it in the reservoir, or receptacle; and the splincter at the end of the teat retains it there until it is wanted for use.

This must not be understood, however, as asserting that all the milk drawn from the udder at one milking is contained in the receptacle. The milk, as it is secreted, is convejed to the receptacle, and when that is full, the larger tubes begin to be filled, and next the smaller ones, until the whole become gorged. When this takes place, the secretion of the milk ceases, and absorption of the thinner or more watery part commences. Now, as this absorption takes place more readily in the smaller or more distant tubes, it is, invariably found that the milk from these, which comes last into the receptacle, is much thicker and richer than what was first drawn off. This milk has been significantly styled afterings, or strippings; and should this gorged state of the tubes be 
permitted to continue beyond a certain time, serious mischief will sometimes occur; the milk becomes too thick to flow through the tubes, and soon produces, first irritation, then inflammation, and Jastly suppuration, and the function of the gland is materially impaired or altogether destroyed. Hence the great importance of emptying these smaller tubes regularly and thoroughly, not merely to prevent the occurrence of disease, but actually to increase the quantity of milk; for, so long as the smaller tubes are kept free, milk is constantly forming; but whenever, as has already been mentioned, they become gorged, the secretion of milk ceases until they are emptied. The cow herself has no power over the sphincter at the end of her teat, so as to open it, and relieve the overcharged udder; neither has she any power of retaining the milk collected in the reservoirs when the spasm of the sphincter is overcome.

Thus is seen the necessity of drawing away the last drop of milk at every milking; and the better milker the cow, the more necessary this is. What has been said demonstrates, also, the impropriety of holding the milk in cows until the udder is distended much beyond its ordinary size, for the sake of shorwing its capacity for holding milk-a device to which many dealers in cows resort.

Thus much of the internal structure of the udder. Its external form requires attention, because it indicates differen properties. Its form should be spheroidal, large, giving an idea of capaciousness; the bag should have a soft, fine skin, and the hind part upward toward the tail be loose and elastic. There should be fine, long hairs scattered plentifully over the surface, to keep it warm. The teats should not seem to be 
contracted, or funnel-shaped, at the inset with the bag. In the former state, teats are very apt to become corded, or spindled; and in the latter, too much milk will constantly be pressing on the lower tubes, or receptacle. They should drop naturally from the lower parts of the bag, being neither too short, snall, or dumpy, or long, flabby, and thick, but, perhaps, about three inches in length, and so thick as just to fill the hand. They should hang as if all the quarters of the udder were equal in size, the front quarters projecting a little forward, and the hind ones a little more dependent. Each quarter should contain about equal quantities of milk; though, in the belief of some, the hind quarters contain rather the most.

Largely developed milk-veins_as the subcutaneous veins along the under part of the abdomen are commonly calledare regarded as a source of milk. This is a popular error, for the milk-vein has no connection with the udder; yet, although the office of these is to convey the blood from the fore part of the chest and sides to the inguinal vein, yet a large milk-vein certainly indicates a strongly developed vascular system-one favorable to secretions generally, and to that of the milk among the rest.

Milking is performed in two ways, stripping and handling. Stripping consists in seizing the teat firmly near the root between the face of the thumb and the side of the fore-finger, the length of the teat passing through the other fingers, and in milking the hand passes down the entire length of the teat, causing the milk to flow out of its point in a forcible stream. The action is renewed by again quickly elevating the hand to the root of the teat. Both hands are employed 
at the operation, each having hold of a difierent teat, and being moved alternately. The two nearest teats are commonly first milked, and then the two farthest. Handling is done by grasping the teat at its root with the fore-finger like a hoop, assisted by the thumb, which lies horizontally over the fore-finger, the rest being also seized by the other fingers. Milk is drawn by pressing upon the entire length of the teat in alternate jerks with the entire palm of the hand. Both hands being thus employed, are made to press alternately, but so quickly followirg each other that the alternate streams of milk sound to the ear like one forcible, continued stream. This continued stream is also produced by stripping. Stripping, then, is performed by pressing and passing certain fingers along the teat; haudling, by the whole hand doubled, or fist, pressing the teat steadily at one place. Hence the origin of both names.

Of these two
modes, hand-
ling is the pre-
ferable, since
it is the more
natural method
-imitating, as
it does, the it does, the suckling of the

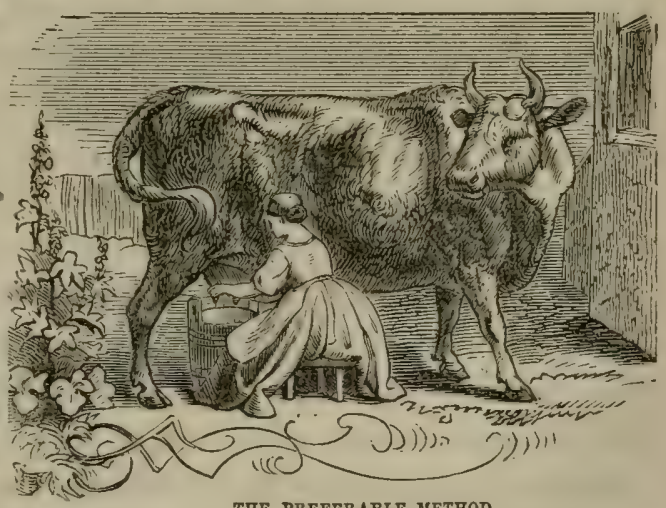
THE PREFERABLE METHOD.

calf. When a calf takes a teat into its mouth, it makes the tongue and palate by which it seizes it, play upon the teat by alternate pressures or pulsations, while retaining the teat in the same position. It is thus obvious that handling is 
somewhat like sucking, whereas stripping is not at all like it. It is said that stripping is good for agitating the udder, the agitation of which is conducive to the withdrawal of a large quantity of milk; but there is nothing to prevent the agitation of the udder as much as the dairymaid pleases, while holding in the other mode. Indeed, a more constant vibration could be kept up in that way by the vibrations of the arms than by stripping. Stripping, by using an unconstrained pressure on two sides of the teat, is much more apt to press it unequally, than by grasping the whole teat in the palm of the hand; while the friction occasioned by passing the finger and thumb firmly over the outside of the teat, is more likely to cause heat and irritation in it than a steady and full grasp of the entire hand. To show that this friction causes an unpleasant feeling even to the dairymaid, she is obliged to lubricate the teat frequently with milk, and to wet it at first with water; whereas the other mode requires no such expedients. And as a further proof that stripping is a mode of milking which may give pain to the cow; it cannot be employed, when the teats are chapped, with so much ease to the cow as handling.

The first requisite in the person that milks is, of course, the utmost cleanliness. Without this, the milk is unendurable. The udder should, therefore, be carefully cleaned before the milking commences.

Milking should be done fast, to draw away the milk as quickly as possible, and it should be continued as long as there is a drop of milk to bring away. This is an issue which cannot be attended to in too particular a manner. If any milk is left, it is re-absorbed into the system, or else becomes caked, 
and diminishes the tendency to secrete a full quantity afterward. Milking as dry as possible is especially necessary with young cows with their first calf; as the mode of milking and the length of time to which they can be made to hold ont, will have very much to do with their milking qualities as lung as they live. Old milk left in the receptacle of the teat soon changes into a curdy state, and the caseous matter not being at once removed by the next milking, is apt to irritate the lining membrane of the teat during the operation, especially when the teat is forcibly rubbed down between the finger and thumb in stripping. The consequence of this repeated irritation is the thickening of the lining membrane, which at length becomes so hardened as to close up the orifice at the end of the teat. The hardened membrane may be easily felt from the outside of the teat, when the teat is said to be corded. After this the teat becomes deaf, as it is called, and no more milk can afterward be drawn from the quarter of the udder to which the corded teat is attached.

The milking-pail is of various forms and of various materials. The Dutch use brass ones, which are brilliantly scoured every time they are in use. Tin pitchers are used in some places, while pails of wood in cooper-work are employed in others. A pail of oak, having thin staves bound together by bright iron hoops, with a handle formed by a stave projecting upward, is convenient for the purpose, and may be kept clean and sweet. One nine inches in diameter at the bottom, eleven inches at the top, and ten inches deep, with an upright handle or leg of five inches, has a capacious enough mouth to receive the milk as it descends; and $\Omega$ sufficient height, when standing on the edge of its bottom on 
the ground, to allow the dairy-maid to grasp it firmly with her knees while sitting on a small three-legged stool. Of course, such a pail cannot be milked full; but it should be large enough to contain all the milk which a single cow can ive at a milking; because it is undesirable to rise from a ow before the milking is finished, or to exchange one dish for another while the milking is in progress.

The cow being a sensitive and capricious creature, is, oftentimes so easily offended that if the maid rise from her before the milk is all withdrawn, the chances are that she will not again stand quietly at that milking; or, if the vessel used in milking is taken away and another substituted in its place, before the milking is finished, the probalility is that she will hold her milk-that is, not allow it to flow. This is a curious property which cows possess, of holding up or keeping back their milk. How it is effected has nerer been satisfactorily ascertained; but there is no doubt of the fact that when a cow becomes irritated, or frightened from any cause, she can withhold her milk. Of course, all cows are not affected in the same degree; but, as a proof how sensitive cows generally are, it may be mentioned that very few will be milked so freely by a stranger the first time, as by one to whom they have been accustomed.

There is one side of a cow which is usually called the milking side-that is the com's left side-because, somehow, custom has established the practice of milking her from that side. It may have been adopted for two reasons: one, because we are accustomed to approach all the larger domesticated animals, by what we call the near side-that is, the nnimal's left side-as being the most conrenient one for 
ourselves; and the other reason may have been, that, as most people are right-handed, and the common use of the right hand has made it the stronger, it is most conveniently employed in milking the hinder teats of the cow, which are often most difficult to reach on account of the position of the hind legs and the length of the hinder teats, or of the breadth of the hinder part. of the udder. The near side is most commonly used in this country and in Scotland; but in many parts of England the other side is preferred. Whichever side is selected, that should uniformly be used, as cows are very sensitive to changes.

In Scotland it is a rare thing to see a cow milked by any other person than a woman, though men are very commonly employed at it in this country and in England. One nerer sees a man milking a cow without being impressed with the idea that he is usurping an office which does not become him; and the same thought seems to be conveyed in the terms usually applied to the person connected with cows-a dairymaid implying one who milks cows, as well as performs the other duties connected with the dairy-a dairy-man meaning one who orvns a dairy. There can be but little question that the charge of this branch of the dairy should generally be entrusted to women. They are more gentle and winning than men. The same person should milk the same cow regularly, and not change from one to another, unless there are special reasons for it.

Cows are easily rendered troublesome on being milked; and the kicks and knocks which they usually receive for their restlessness, only render them more fretful. If they cannot be overcome by kindness, thumps will nerer make then. 
better. The truth is, restless habits are continued in them by the treatment which they receive at first, when, most probably, they have been dragooned into submission. Their teats are tender at first; but an unfeeling, horny hand tugs at them at stripping, as if the animal had been accustomed to the operation for years. Can the creature be otherwise than uneasy? And how can she escape the wincing but by flinging out her heels? - Then hopples are placed on the hind fetlocks, to keep her heels down. The tail must then be held by some one, while the milking is going on; or the hair of its tuft be converted into a double cord, to tie the tail to the animal's leg. Add to this the many threats and scoldings uttered by the milker, and one gets a not very exaggerated impression of the "breaking-in."

Some cows, no doubt, are very unaccomodating and provoking; but, neverthcless, nothing but a rational course toward them, administered with gentleness, will ever render them less so There are cows which are troublesome to milk for a few times after calving, that become quite quict for the remainder of the season; others will kick pertinaciously at the first milking. In this last case the safest plan-instead of hoppling, which only irritates-is for the dairy-maid to thrust her head against the flank of the cow, and while standing on her feet, stretch her hands forward, get hold of the teats the best way she can, and send the milk on the ground; and in this position it is out of the power of the cow to hurt her. These ebullitions of feeling at the first milking after calving, arise either from feeling pain in a tender state of the teat, most probably from inflammation in the lining membrane of the receptacle; or they may arise from titillation of the skin 
of the udder and teat, which becomes the more sensible wo the affection from a heat which is wearing off.

At the age of two or three years the milking glands nave not become fully developed, and their largest development will depend very greatly upon the management after the first calf. Cows should have, therefore, the most milk-producing food; bo treated with constant gentleness; never struck, or spoken harshly to, but coaxed and caressed; and in ninetynine cases out of a hundred, they will grow up gentle and quiet. The hundredth had better be fatted and sent to the butcher. Harshness is worse than useless. Be the cause of irritation what it may, one thing is certain, that gentle discipline will overcome the most turbulent temper. Nothing does so much to dry a cow up, especially a young cow, as the senseless treatment to which she is too often subjected.

The longer the young cow, with her first and second caif, is made to hold out, the more surely will this habit be fixed upon her. Stop milking her four months before the next calf, and it will be difficult to make her hold out to within four or six weeks of the time of calving afterward. Induce her, if possible, by moist and succulent food, and by careful milking, to hold out even up to the time of calving, if you desire to milk her so long, and this habit will be likely to be fixed upon her for life. But do not expect to obtain the full yicld of a cow the first year after calving. Some of the very best cows are slow to develop their best qualities; and no cow reaches her prime till the age of five or six years.

The extreme importance of care and attention to these points cannot be overestimated. The wild cows grazing on the plains of South America, are said to give not more than 
three or four quarts a day at the height of the flow; and many an owner of large herds in Texas, it is said, has too little milk for family use, and sometimes receives his supply of butter from the New York market. There is, therefore, a constant tendency in milch cows to dry up; and it must be guarded against with special care, till the habit of yielding a large quantity, and yielding it long, becomes fixed in the young animal, when, with proper care, it may easily be kept up.

Corws, independently of their power to retain their milk in the udder, afford different degrees of pleasure in milking them, even in the quietest mood. Some yield their milk in a copious flow, with the gentlest handling that can be given them; others require great exertion to draw the milk from them even in streams no larger than a thread. The udder of the former will be found to have a soft skin and short teats; that of the latter will have a thick skin, with long rough teats. The one feels like velvet; the other is no more pleasant to the touch than untanned leather. To induce quiet and persuade the animal to give down her milk freely, it is better that she should be fed at milking-time with cut feed, or roots, placed within her easy reach.

If gentle and mild treatment is observed and persevered in, the operation of milking, as a general thing, appears to be a pleasure to the animal, as it undoubtedly is; but, if an opposite course is pursued-if at every restless movement, caused, perhaps, by pressing a sore teat, the animal is harshly spoken to-she will be likcly to learn to kick as a habit, and it will be difficult to overcome it ever afterward.

Whatever may be the practice un other occasions, there can 
be no doubt that, for some weeks after calving, and in the height of the flow, cows ought, if possible, to be milked regularly three times a day-at early morning, noon, and night. Every practical dairyman knows that cows thus milked give a larger quantity of milk than if milked only twice, though it may not be quite so rich; and in young cows, no doubt, it has a tendency to promote the development of the udder and milk-veins. A frequent milking stimulates an increased secretion, therefore, and ought never to be neglected in the milk-dairy, either in the case of young cows, or very large milkers, at the height of the flow, which will commonly be for two or three months after calving.

There being a great difference in the quality as vell as in the quantity of the milk of different cows, no dairyman should neglect to test the milk of each new addition to his dairy stock, whether it be an animal of his own raising or one brought from abroad. A lactometer-or instrument for testing the comparative richness of different species of milk -is very convenient for this purpose; but any one can set the milk of each cow separately at first, and give it a thorough trial, when the difference will be found to be great. Economy will dictate that the cows least to the purpose should be disposed of, and their places supplied with better ones.

\section{THE RAISING OF CALVES.}

It has been found in practice that calves properly bred and raised on the farm have a far greater intrinsic value for that farm, other things being equal, than any that can be procured elsewhere; while on the manner in which they are raised will depend much of their future usefulness and profit. 
These considerations should have their proper weight in deciding whether a promising calf from a good cow and bull shall be kept, or sold to the butcher. But, rather than raise a calf at hap-hazard, and simply because its dam was cclebrated as a milker, the judicious farmer will prefer to judge of the peculiar characteristics of the animal itself. This will often save the great and useless outlay which has sometimes been incurred in raising calves for dairy purposes, which a more careful examination would have rejected as unpromising.

The method of judging stock which has been recommended in the previous pages is of practical utility here, and it is safer to rely upon it to some extent, particularly when other appearances concur, than to go on blindly. The milk-mirror on the calf is, indeed, small, but no smaller in proportion to its size than that of the cow; while its shape and form can generally be distinctly seen, particularly at the end of ten

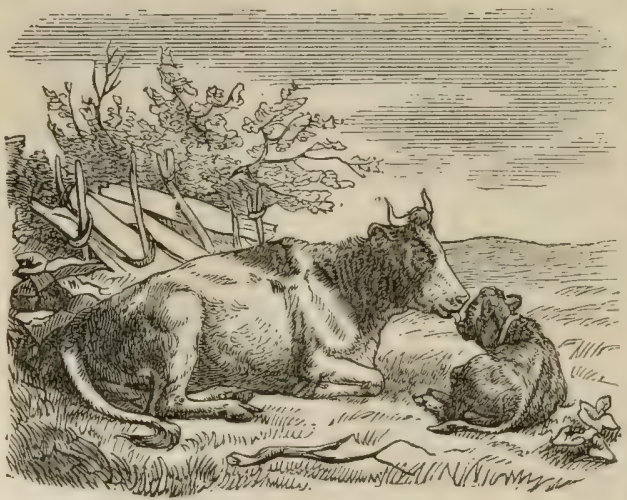

MATERNAL AFFECTION. or twelve weeks. The development of the udder, and other peculiarities, will give some indication of the future capacities of the animal, and these should bè carefully studied. If we except the manure of young stock, the calf is the first product of the cow, and as such demands our attention, whether it is to be 
raised or hurried off to the shambles. The practice adopted in raising calves differs widely in different sections of thy. country, being governed very much by local circumstances, as the vicinity of a milk-market, the ralue of milk for the dairy, the object of breeding, whether mainly for beef, for work, or for the dairs, etc.; but, in general, it may be said, that, within the range of thirty or forty miles of good vealmarkets, which large towns furnish, comparatively few are raised at all. Most of them are fattened and sold at ages varying from three to eight or ten weeks; and in milk-dairies still nearer large towns and cities they are often hurried off at one or two days, or, at most, a week old. In both of these cases, as long as the calf is kept it is generally allowed to suck the cow, and, as the treatment is very simple, there is nothing which particularly calls for remark, unless it be to condemn the practice entirely, upon the ground that there is a more profitable way of fattening calves for the butcher, ami to say that allowing the calf to suck the cow at all is objectionable on the score of economy, except in cases where it is rendered necessary by the hard and swollen condition of the udder.

If the calf is so soon to be taken away, it is better that the cow should not be suffered to become attached to it at all; since she is inclined to withhold her milk when it is removed, and thus a loss is sustained. The farmer will be governed by the question of profit, whatever course it is decided to adopt. In raising blood-stock, however, or in raising beef cattle, without any regard to economy of milk, the system of suckling the calves, or letting them run with the cow, may 
and will be adopted, since it is usually attended with some. what less labor.

The other course, which is regarded as the best where the calf is to be raised for the dairy, is to bring it up by hand. This is almost universally done in all countries where the raising of dairy cows is best understood-in Switzerland, Holland, some parts of Germany, and England. It requires rather more care, on the whole; but it is decideclly preferable, since the calves cost less, as the food can be easily modified, and the growth is not checked, as is usually the case when the calf is taken off from the cow. Allusion is here made; of course, to sections where the milk of the cow is of some account for the dairy, and where it is too valuable to be devoted entirely to nourishing the calf. In this case, as soon as the calf is dropped the cow is allowed to lick off the slimy moisture till it is dry, which she will generally do from instinct, or, if not, a slight sprinkling of salt over the body of the calf will immediately tempt her. The calf is left to

- suck once or twice, which it will do as soon as it is able to stand. It should, in all cases, be permitted to have the first milk which comes from the cow, which is of a turbid, yellowish color, unfit for any of the purposes of the dairy, but somewhat purgative and medicinal, and admirably and wisely designed by Nature to free the bowels and intestines of the new-born animal from the mucous, excrementitious matter always existing in it after birth. Too much of this new milk may, however, be hurtful even to the new-born calf, while it should never be given at all to older calves. The best course would seem to be-and such is in accordance with the experience of the most successful stock-raisers-to milk the cow 
dry immediately after the calf has sucked once, especially if the udder is painfully distended, which is often the case, and to leave the calf with the cow during one day, and after that to feed it by putting the fingers into its mouth, and gently bringing its muzzle down to the milk in a pail or trough when it will imbibe in sucking the fingers. No great diffculty will be experienced in teaching the calf to drink when taken so young, though some take to it much more readily than others. What the calf does not need should be given to the cow. Some, however, prefer to milk immediately after calving; and, if the udder is overloaded, this may be the best course, though the better practice appears to be, to leave the cow as quietly to herself as possible for a few hours. The less she is disturbed, as a general thing, the better. The after-birth should be taken from her immediately after it is dropped. It is customary to give the cow, as soon as convenient after calving, some warm and stimulating drink-a little meal stirred into warm water, with a part of the first milk which comes from her, seasoned with a little salt.

In many cases the calf is taken from the cow immediately; and before she has seen it, to a warm, dry pen out of her sight, and there rubbed till it is thoroughly dry; and then, when able to stand, fed with the new milk from the cow, which it should have three or four times a day, regularly, for the first fortnight, whatever course it is proposed to adopt afterwards. It is of the greatest importance to give the young calf a thrifty start. The milk, unless coming directly from the cow, should be warned.

Some object to removing the calf from the cow in this way, 
on the ground of its apparent cruelty. But the objection to letting the ealf suck the cow for several days, as they do, or inceed of leaving it with the cow for any length of time, is, that she invariably becomes attached to it, and frets and withholds her milk when it is at last taken from her. She probably suffers much more, after this attachment is once formed, at the removal of the object of it, than she cloes at its being taken at first out of her sight. The cow's memory is far more retentive than many suppose; and the loss and injury sustained by removing the calf after it has been allowed to suck her for a longer or shorter period are never known exactly, because it is not usually known how much milk the calf takes; but it is, without doubt, very considerable. If the udder is all right, there seems to be no good reason for leaving the calf with the cow for two or three days, if it is then to be taken away.

The practice in Holland is to remove the calf from its mother even before it has been licked, and to take it into a corner of the barn, or into another building, out of the cow's sight and hearing, put it on soft, dry straw, and rub it dry with some hay or straw, when its tongue and gums are slightly rubbed with salt, and the mucus and saliva removed from the nostrils and lips. After this has been done, the calf is made to drink the milk first taken as it comes from the mother. It is slightly diluted with water, if taken last from the udder; but, if the first of the milking, it is given just as it is. The calf is taught to drink in the same manner as in this country, by putting the fingers in its mouth, and bringing it down to the milk, and it soon gets so as to drink nnaided It is fed, at first, from four to six times a day, or 
even oftener; but soon only three times, at regular intervals. Its food for two or three weeks is clear milk, as it comes warm and fresh from the cow. This is never omitted, as the milk during most of that time possesses certain qualities which are necessary to the calf, and which cannot be effectu ally supplied by any other food. In the third or fourth week the milk is skimmed, but warmed to the degree of fresh milk; though, as the calf grows a little older, the milk is given cold, while less care is taken to give it the milk of its own mother, that of other cows now answering equally well. In some places, calves are fed on buttermilk at the age of two weeks and after; but the change from new milk, fresh from the cow, is made gradually, some sweet skimmed milk and warm water being first added to it.

At three weeks old, or thereabouts, the calf will begin to eat a little sweet, fine hay, and potatoes cut fine, and it rery soon becomes accustomed to this food. Many now begin to give linseed-meal mixed into hot water, to which is added some skim-milk or buttermilk; and others use a little bran cooked in hay-tea, made by chopping the hay fine and pouring on boiling-hot water, which is allowed to stand awhile on it. An egg is frequently broken into such a mixture. Others still take pains at this age to have fresh linseed-cake, broken into pieces of the size of a pigeon's egg ; putting one of these into the mouth after the meal of milk has been finished, and when it is eager to suck at any thing, in its way. It will very soon learn to eat linseed-meal. A little sweet clover is put in its way at the age of about three weeks, and it will soon begin to eat that also.

In this manner the feeding is continued from the fourth to 
the seventh week, the quantity of solid food being gradually increased. In the sixth or seventh week the milk is by degrees withheld, and water or buttermilk used instead; and soon after this, green food mray be safely given, increasing it gradually with the hay to the age of ten or twelve weeks, when it will do to put them upon grass alone, if the season is farorable. A lot as near the house as possible, where they can be easily looked after and frequently visited, is the best. Calves should be gradually accustomed to all changes; and even after having been turned out to pasture, they ought to be put under shelter if the weather is not dry and warm. The want of care and attention relative to these little details will be apparent sooner or later; while, if the farmer gives his personal attention to these matters, he will be fully paid in the rapid growth of his calves. It is especially necessary to see that the troughs from which they are fed, if troughs are used, are kept clean and sweet.

But there are some-even among intelligent farmers-who make a practice of turning their calves out to pasture at the tender age of two or three weeks-and that, too, when they have sucked the cow up to that time-and allow them nothing in the shape of milk and tender care. This, certainly, is the poorest pessible economy, to say nothing of the manifest cruelty of such treatment. The growth of the calf is checked, and the system receives a shock from so sudden a change, from which it cannot soon recover. The careful Dutch breeders bring the calves either skimmed milk or buttermilk to drink several times a day after they are turned to grass, which is not till the age of ten or twelve weeks; and, if the weather is chilly, the milk is warmed for them. 
They put a trough generally under a covering, to which the calves may come and drink at regular times. Thus, they are kept tame and docile.

In the raising of calves, through all stages of their growth, great care should be taken neither to starve nor to over-feed. A calf should never be surfeited, and never be fed so highly that it cannot be fed more highly as it advances. The most important part is to keep it growing thriftily without getting too fat, if it is to be raised for the dairy.

The calves in the dairy districts of Scotland are fed on the milk, with seldom any admixture; and they are not permitted to suck their dams, but are taught to drink milk by the hand from a dish. They are generally fed on milk only for the first four, five, or six weeks, and are then allowed from two to two and a half quarts of new milk each meal, twice in the twenty-four hours. Some never give them any other food when young except milk, lessening the quantity when the calf begins to eat grass or other food, which it generally does when about five weeks old, if grass can be had; and withdrawing it entirely about the seventh or eighth week of the calf's age. But, if the calf is reared in winter, or early in spring, before the grass rises, it must be supplied with at

- least some milk until it is eight or nine weeks old, as a calf will not so soon learn to eat hay or straw, nor fare so well on hem alone as it will on pasture. Some feed their calves reared for stock partly with meal mixed in the milk after the third or fourth week. Others introduce gradually some new whey into the milk, first mixed with meal; and, when the calf gets older, they withdraw the milk, and feed it on whey and porridge. Hay-tea, juices of peas and beans, or 
pea or bean-straw, linseed beaten into powder, treacle, etc., have all been sometimes used to advantage in feeding calves; but milk, when it can be spared, is, in the judgment of the Scotch breeders, by far their most natural food.

In Galloway, and other pastoral districts, where the calve are allowed to suck, the people are so much wedded to their own customs as to argue that suckling is much more nutritious to the calves than any other mode of feeding. That it induces a greater secretion of saliva, which, by promoting digestion, accelerates the growth and fattening of the young animal, cannot be doubted; but the secretion of that fluid may likewise be promoted by placing an artificial teat in the mouth of the calf, and giving it the milk slowly, and at the natural temperature. In the dairy districts of Scotland, the dairymaid puts one of her fingers into the mouth of the calf when it is fed, which serves the purpose of a teat, and will have nearly the same effect as the natural teat in inducing the secretion of saliva. If that, or an artificial teat of leather, be used, and the milk be given slowly before it is cold, the secretion of saliva may be promoted to all the extent that can be necessary; besides, secretion is not confined to the mere period of eating, but, as in the human body, the saliva is formed and part of it swallowed at all times. As part of the saliva is sometimes seen dropping from. the mouths of the calves, it might be advisable not only to give them an artificial teat when fed, but to place, as is frequently done, a lump of chalk before them to lick, thus leading them to swallow the saliva. The chalk would so far supply the want of salt, of which cattle are often so improperly deprived, and it would also promote the formation of saliva. Indeed, calves are 
very much disposed to lick and suck every thing which comes within their reach, which seems to be the way in which Nature teaches them to supply their stomachs with saliva.

But though sucking their dams may be most advantageous in that respect, yet it has also some disadvantages. The cow

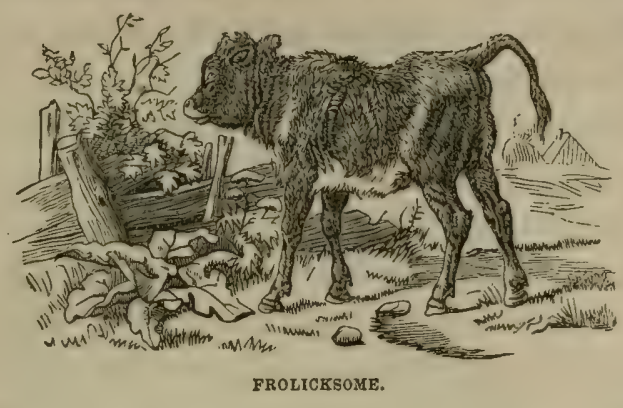

is always more injured than the calf is benefited by that mode of feeding. She becomes so fond of the calf that she does not, for a long time after, yield her milk freely to the dairyman. The calf does not when young draw off the milk completely, and when it is taken off by the band, the cow withholds a part of her milk, and, whenever a cow's udder is not completely emptied every time she is milked, the lactic secretion-as before stated-is thereby diminished.

Feeding of calves by hand is also, in various respects, advantageous. Instead of depending on the uncertain, or perhaps precarious supply of the dam, which may be more at first than the young animal can consume or digest, and at other times too little for-its supply, its food can, by handfeeding, be regulated to suit the age, appetite, and the purposes for which the calf is intended; other admixtures or substitutes can be introduced into the milk, and the quantity gradually increased or withdrawn at pleasure. This is highly necessary when the calves are reared for stock. The milk is 
in that case diminished, and other food introduced so gradually that the stomach of the young animal is not injured as it is when the food is too suddenly changed. And, in the case of feeding calves for the butcher, the quantity of milk is not limited to that of the dam-for no cow will allow a strangercalf to suck her-but it can be increased, or the richest or poorest parts of the milk given at pleasure.

Such are, substantially, the views upon this subject which are entertained by the most judicious farmers in the first dairy districts of Scotland.

In those districts-where, probably, the feeding and management of calves are as well and as judiciously conducted as in any other part of Great Britain-the farmers' wives and daughters, or the female domestics, have the principal charge of young calves; and they are, doubtless, much better calculated for this duty than men, since they are more inclined to be gentle and patient. The utmost gentlenessas has been already remarked, in another connection-should always be observed in the treatment of all stock; but especially of milch cows, and calves designed for the dairy. Persevering kindness and patience, will, almost invariably, overcome the most obstinate natures; while rough and ungentle handling will be repaid in a quiet kind of way, perhaps, by withholding the milk, which will always have a tendency to dry up the cow; or, what is nearly as bad, by kicking anc other modes of revenge, which often contribute to the personal discomfort of the milker. The disposition of the cow is greatly modified, if not, indeed, wholly formed, by her treatment while young; and therefore it is best to handle calves as much as possible, and make pets of them, lead them 
with a halter, and caress them in various ways. Calves managed in this way will always be docile, and suffer themselves to be approached and handled, both in the pasture and in the barn.

With respect to the use of hay-tea-often used in this country, but more common abroad, where greater care and attention are usually bestowed upon the details of breeding -Youatt says: "At the end of three or four days, or perhaps a week, or near a fortnight, after a calf has been dropped, and the first passages have been cleansed by allowing it to drink as much of the cow's milk as it feels inclined for, let the quantity usually allotted for a meal be mixed, consisting, for the first week, of three parts of milk and one part of bay-tea. The only nourishing infusion of hay is that which is made from the best and sweetest hay, cut by a chaff-cutter into pieces about two inches long, and put into an earthen vessel; over this, boiling water should be poured, and the whole allowed to stand for two hours, during which time it ought to be kept carefully closed. After the first week, the proportions of milk and hay-tea may be equal; then composed of two-thirds of hay-tea and one of milk; and at length, one-fourth part of milk will be sufficient. This food should be given to the calf in a lukewarm state at least three, if not four times a day, in quantities averaging three quarts at a meal, but gradually increasing to four quarts as the calf grows older. Toward the end of the second month, beside the usual quantity given at each meal-composed of three parts of the infusion and one of milk-a small wisp or bundle of hay is to be laid before the calf, which will gradually come to eat it; but, if the weather is favorable, as in the month of 
May, the beast may be turned out to graze in a fine, sweet pasture, well sheltered from the wind and sun. This diet may be continued until toward the latter end of the third month, when, if the calf grazes heartily, each meal may be reduced to less than a quart of milk, with hay-water; or skimmed milk, or fresh buttermilk, may be substituted for new milk. At the expiration of the third month, the animal will hardly require to be fed by hand; though, if this should still be necessary, one quart of the infusion given daily-which, during the summer, need not be warmed-will suffice." The hay-tea should be made fresh every two days, as it soon loses its nutritious quality.

This and other preparations are given, not because they are better than milk, - than which nothing is better adapted to fatten a calf, or promote its growth,-but simply to economize by providing the simplest and cheapest substitutes. Experience shows that the first two or three calves are smaller than those which follow; and hence, unless they are pure-bred, and to be kept for the blood, they are not generally thought to be so desirable to raise for the dairy as the third or fourth, and those that come after, up to the age of nine or ten years. Opinions upon this point, however, differ.

According to the comparative experiments of a German agriculturist, cows which as calves had been allowed to suck their dams from two to four weeks, brought calves which weighed only from thirty-five to forty-eight pounds; while others, which as calves had been allowed to suck from five to eight weeks, brought calves which weighed from sixty to eighty pounds. It is difficult to see how there can be so 
great a difference, if, indeed, there be any; but it may be worthy of careful observation and experiment, and as such it is stated here. The increased size of the calf would be due to the increased size to which the cow would attain; and if as a calf she were allowed to run in the pasture with her dam for four or five months, taking all the milk she wanted, she would doubtless be kept growing on in a thriving condition. But taking a calf from the cow at four or even eight weeks must check its growth to some extent; and this may be avoided by feeding liberally, and bringing up by hand.

After the calf is fully weaned, there is nothing very peculiar in the general management. A young animal will require for the first few months_say up to the age of six months-an average of five or six pounds daily of good hay, or its equivalent. At the age of six months, it will require from four and a half to five pounds; and at the end of the year, from three and a half or four pounds of good hay, or its equivalent, for every one hundred pounds of its live weight; or, in other words, about three and a half or four per cent. of its live weight. At two years old, it will require three and a half, and some months later, three per cent. of its live weight daily in good hay, or its equivalent. Indian-corn fodder, either green or cured, forms an excellent and wholesome food at this age.

The heifer should not be pampered, nor yet poorly fed or half starved, so as to receive a check in her growth. An abundant supply of good healthy dairy food and milk will do all that is necessary up to the time of her having her first calf-which should not ordinarily be till the age of three years, though some choose to allow them to come in at two, 
or a little over, on the ground that it early stimulates the secretion of milk, and that this will increase the milking propensity through life. This is undoubtedly the case, as a general rule; but greater injury is at the same time done by checking the growth, unless the heifer has been fed up to large size and full development from the start-in which case she may perhaps take the bull at fifteen or eighteen months without injury. Even if a heifer comes in at two years, it is generally deemed desirable to let her run barren for the following year, which will promote her growth and more perfect development.

The feeding which young stock often get is not such as is calculated to make good-sized or valuable cattle of them. They are often fed on the poorest of hay or straw through the winter, not infrequently left exposed to cold, unprotected and unhoused, and thus stinted in their growth. This is, surely, the very worst economy, or rather it is no economy at all. Properly viewed, it is an extravagant wastefulness which no farmer can afford. No animal develops its good points under such treatment; and if the starving system is to be followed at all, it had better be after the age of two or three years, when the animal's constitution has attained the strength and vigor which may, possibly, enable it to resist ill treatment.

To raise up first-rate milkers, it is absolutely necessary to feed on dairy food even when they are young. No matter how fine the breed is, if the calf is raised on poor, short feed, it will never be so good a milker as if raised on better keeping; and hence, in dairy districts, where calves are raised at all, they ought to be allowed the best pasture during the 
summer, and good, sweet and wholesome food during the winter.

\section{POINTS OF FAT CATTLE.}

Thatever theoretical objections may be raised against over-fed cattle, and great as may be the attempts to disparage the mountains of fat,-as highly-fed cattle are sometimes designated,-there is no doubt of the practical fact, that the best butcher cannot sell any thing but the best fatted beef; and of whatever age, size, or shape a half-fatted ox may be, he is never selected by judges as fit for human food. Hence, a well-fatted animal always commands a better price per pound than one imperfectly fed, and the parts selected as the primest beef are precisely the parts which contain the largest deposits of fat. The rump, the crop, and the sirloin, the very favorite cuts, - which always command from twenty to twenty-five per cent. more than any other part of the ox,are just those parts on which the largest quantities of fat are found; so that, instead of the taste and fashion of the age being against the excessive fattening of animals, the fact is, practically, exactly the reverse. Where there is the most fat, there is the best lean; where there is the greatest amount of muscle, without its share of fat, that part is accounted inferior, and is used for a different purpose; in fact, so far from fat's being a disease, it is a condition of muscle, necessary to its utility as food,-a source of luxury to the rich, and of comfort to the poor, furnishing a nourishing and healthy diet for their families.

Fattening is a secretive power which grazing animals possess, enabling them to lay by a store of the superfluous 
food which they take for seasons of cold or scarcity. It collects round the angular bones of the animal, and gives the appearance of rotundity; hence the tendency to deposit fat is indicated, as has been stated, by a roundness of form, as opposed to the fatness of a milk-secreting animal. But its greatest use is, that it is a store of heat-producing aliment, laid up for seasons of scarcity and want. The food of animals, for the most part, may be said to consist of a sac- charine, an oleaginous, and an albuminous principle. To the first belong all the starchy, saccharine, and gummy parts of the plants, which undergo changes in the digestive organs similar to fermentation before they can be assimilated in the system; by them also animal heat is sustained. In indolent animals, the oily parts of plants are deposited and laid up as fat; and, when vigor and strength fail, this is taken up and also used in breathing to supply the place of the consumed saccharine matter. The albuminous, or gelatinous principle of plants is mainly useful in forming muscle; while the ashes of plants, the unconsumable parts, are for the supply, mainly, of bone, hair, and horn, but also of muscle and of blood, and to supply the waste which continually goes on.

Now, there are several qualities which are essentially characteristic of a disposition to fatten. There have not, as yet, been any book-rules laid down, as in the case of $\mathbf{M}$. Guénou's indications of milking-cows; but there are, nevertheless, marks so definite and well understood, that they are comprehended and acted upon by every grazier, although they are by no means easy to describe. It is by skillful acumen that the grazier acquires his knowledge, and not by theoretical rules; observation, judgment, and experience, 
powerful perceptive faculties, and a keen and minute comparison and discrimination, are essential to his success.

The first indication upon which he relies, is the touch. It is the absolute criterion of quality, which is supposed to be

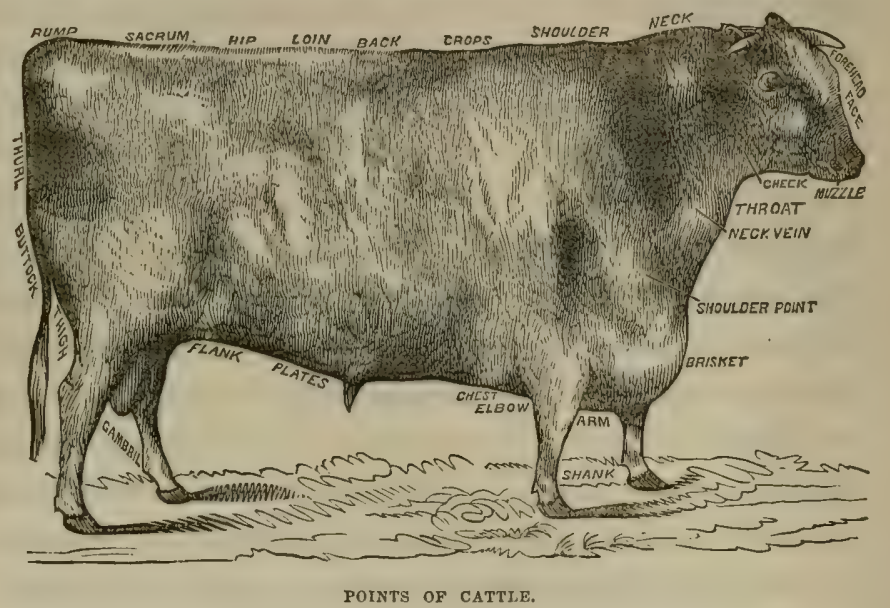

the keystone of perfection in all'animals, whether for the pail or the butcher. The skin is so intimately connected with the internal organs, in all animals, that it is questionable whether even our schools of medicine might not make more use of it in a diagnosis of disease. Of physiological tendencies in cattle, however, it is of the last and most vital importance. It must neither be thick, nor hard, nor adhere firmly to the muscles. If it is so, the animal is a hard grazer, a difficult and obstinate feeder-no skillful man will purchase it-such a creature must go to a novice, and even to him at a price so low as to tempt him to become a purchaser. On the other hand, the skin must not be thin, like paper, nor flaccid, nor loose in the hand, nor flabby. 
This is the opposite extreme, and is indicative of delicateness, bad, flabby flesh, and, possibly, of inaptitude to retain the fat. It must be elastic and velvety, soft and pliable, presenting to the touch a gentle resistance, but so delicate as to give pleasure to the sensitive hand-a skin, in short, which seems at first to give an indentation from the pressure of the fingers, but which again rises to its place by a gentle elasticity.

The hair is of nearly as much importance as the skin. A hard skin will have straight and stiff hair; it will not have a curl, but be thinly and lankly distributed equally orer the surface. A proper grazing animal will have a mossy coat, not absolutely curled, but having a disposition to a graceful curl, a semifold, which presents a waring inequality; but as different from a close and straightly-laid coat, as it is from one standing off the animal at right angles, a strong symptom of disease. It will also, in a thriving animal, be licked here and there with its tongue, a proof that the skin is duly performing its functions.

There must be, also, the full and goggle eye, bright and pressed outward by the fatty bed below; because, as this is a part where Nature always provides fat, an animal capable of developing it to any considerable extent, will have its indications here, at least, when it exists in excess.

So much for feeding qualities in the animal, and their conformations indicative of this kindly disposition. Next come such formations of the animal itself as are favorable to the growth of fat, other things being equal. There must be size where large weights are expected. Christmas beef, for instance, is expected to be large as well as fat. The symbol 
of festivity should be capacious, as well as prime in quality. But it is so much a matter of choice and circumstance with the grazier, that profit alone will be his guide. The axiom will be, however, as a general rule, that the better the grazing soil the larger the animal may be; the poorer the soil, the smaller the animal. Small animals are, unquestionably, much more easily fed, and they are well known by experienced men to be best adapted to second-rate feeding pastures.

But, beyond this, there must be breadth of carcass. This is indicative of fattening, perhaps, beyond all other qualifcations. If rumps are favorite joints and produce the best price, it is best to have the animal which will grow the Inngest, the broadest, and the best rump; the same of crup, and the same of sirloin; and not only so, but breadth is essential to the consumption of that quantity of food which is necessary to the development of a large amount of fat in the animal. Thus, a deep, wide chest, favorable for the respiratory and circulating functions, enables it to consume a large amount of food, to take up the sugary matter, and to deposit the fatty matter,-as then useless for respiration, but afterwards to be prized. A full level crop will be of the same physiological utility; while a broad and open framework at the hips will afford scope for the action of the liver and kidneys.

There are other points, also, of much importance; the head must be small and fine; its special use is indicative of the quick fattening of the animal so constructed, and it is also indicative of the bones being small and the legs short. For constitutional powers, the beast should have his ribs extended well towards the thigh-bones or hips, so as to leave 
as little unprotected space as possible. There must be no angular or abrupt points; all must be round, and broad, and parallel. Any depression in the lean animal will give a deficient deposit of flesh and fat at that point, when sold to the butcher, and thus deteriorate its value; and hence the animal must be round and full.

But either fancy, or accident, or skill-it is unnecessary to decide which-has associated symmetry with quality and conformation, as a point of great importance in animals calculated for fattening; and there is no doubt that, to a certain extent, this is so. The beast must be a system of mathematical lines. To the advocate of symmetry, the setting-on of a tail will be a condemning fault; indeed the ridge of the back, like a straight line, with the outline of the belly exactly parallel, viewed from the side, and a depth and squareness when viewed from behind,-which remind us of a geometrical cube, rather than a vital economy,-may be said to be the indications of excellence in a fat ox. The points of excellence in such an animal are outlined under the subsequent head, as developed in the cutting up after slaughter.

$\mathrm{Now}$, these qualities are inherent in some breeds; there may be eases and instances in all the superior breeds, and in most there may be failures.

\section{DRIVING AND SLAUGHTERING.}

It is necessary that cattle which have been disposed of to the dealer or butcher, or which are intended to be driven to market, should undergo a preparation for the journey. If they were immediately put to the road to travel, from feeding on grass or turnips, when their bowels are full of undi- 
gested vegetable matter, a scouring might ensue which would render them unfit to pursue their journey; and this complaint is the more likely to be brought on from the strong propensity which cattle have to take violent exercise upon feeling themselves at liberty after a long confinement. They in fact, become light-headed whenever they leave the barn 0. enclosure, so much so that they actually "frisk and race and leap," and their antics would be highly amusing, were it not for the apprehension that they may hurt themselves against some opposing object, as they seem to regard nothing before them.

On being let out for the first time, cattle should be put for awhile into a larger court, or on a road well fenced with enclosures, and guarded by men, to romp about. Two or three such allowances of liberty will render them quiet; and, in the mean time, to lighten their weight of carcass, they should have hay for a large proportion of their food. These precautions are absolutely necessary for cattle which have been confined in barns; otherwise, accidents may befall them on the road, where they will at once break loose. Even at home serious accidents sometimes overtake them, such as the breaking down of a horn, casting off a hoof, spraining a tendon, bruising ribs, and heating the whole body violently; and, of course, when any such ill luck befalls, the animal affected must be left behind, and become a drawback upo the value of the rest, unless kept for some time longer.

Having the cattle prepared for travel, the drover takes the road very slowly for the first two days, not exceeding seven or eight miles a day. At night, in winter, they should be put into an open court, and supplied with hay, water; and a 
very few turnips; for, if roots are suddenly withdrawn from them,-since it is taken for granted that these have formed a

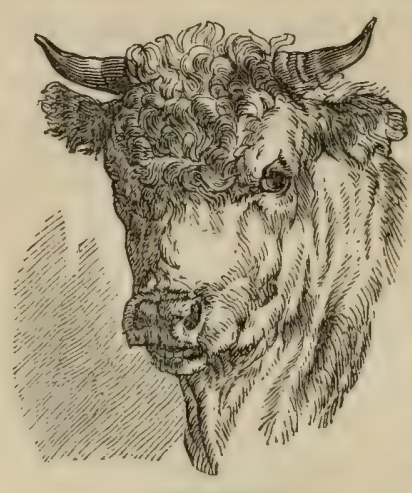

staple portion of their food,their bellies will become shrunken up into smaller dimensions-a state very much against a favorable appearance in market. After the first two days they may proceed faster, say twelve or thirteen miles a day, if very fat; and fifteen, if moderately so. When the $\triangle$ FroNTISPIECE. journey is long and the beasts get faint from travel, they should have corn to support them. In frosty weather, when the roads become very hard, they are apt to become shoulder-shaken, an effect of founder; and if sleet falls during the day, and becomes frozen upon them at night, they may become so chilled as to refuse food, and shrink rapidly away. Cattle should, if possible, arrive the day before in the neighborhood of a distant market, and be supplied with a good feed of roots and hay, or grass, to make them look fresh and fill them up again; but if the market is at but short distance, they can travel to it early in the morning.

In driving cattle the drover should have no dog, which will only annoy them. He should walk either before or behind, as he sees them disposed to proceed too fast or to loiter upon the road; and in passing carriages, the leading ox, after a little experience, will make way for the rest to follow. On putting oxen on a ferry-boat the shipping of the first one 
nnly is attended with much trouble. A man on each side should take hold of a horn, or of a halter made of any piece of rope, should the beast be hornless, and two other men, one on each side, should push him up behind with a piece of rope held between them as a breeching, and conduct him along the plank into the boat; if it have low gunwales, a man will be required to remain beside him until one or two more of the cattle follow their companion, which they will most readily do. From neglecting this precaution in small ferry-boats, the first beast sometimes leaps into the water, when it becomes a difficult task to prevent some of the rest doing the same thing.

Whatever time a lot of cattle may take to go to a market, they should never be overdriven. There is great difference of management in this respect among drovers. Some like to proceed upon the road quietly, slowly, but surely, and to reach the market in a placid, cool state. Others, again. drive smartly along for some distance, and then rest to cool awhile, when the beasts will probably get chilled and have a staring coat when they reach their destination; while others like to enter the market with their beasts in an excited state, imagining that they then look gay; but distended nostrils, loose bowels, and reeking bodies are no recommendations to a purchaser. Good judges are shy of purchasing cattle in a heated state, because they do not know how long they may have been in it; and to cover any risk, will give at least five dollars a head below what they would have offered for them in a cool state. Some drovers have a habit of thumping at the hindmost beast of the lot with a stick while on the road. This is a censurable practice, as the flesh, where it is 
thumped, will bear a red mark after the animal has been slaughtered,-the mark receiving the appropriate name of blood-burn,--and the flesh thus affected will not take on salt, and is apt to putrefy. A touch up on the shank, or any tendonous part, when correction is necessary, is all that is required; but the voice, in most cases, will answer as well. The flesh of overdriven cattle, when slaughtered, never becomes properly firm, and their tallow has a soft, melted appearance.

A few large oxen in one lot look best in a market on a position rather above the eye of a spectator. When a large lot is nearly alike in size and appearance, they look best and most level on a flat piece of ground. Very large fat oxen never look better than on ground on the same level with the spectator. An ox, to look well, should hold his head on a line with the body, with lively ears, clear eye, dewy nose, a well-licked hide, and should stand firmly on the ground on all his feet. These are all symptoms of high health and good condition. Whenever an ox shifts his standing from one foot to another, he is foot-sore, and has been driven far. Whenever his head hangs down and his eyes water, he feels ill at ease inwardly. When his coat stares, he has been overheated some time, and has got a subsequent chill. All these latter symptoms will be much aggravated in cattle that have been fed in a barn.

Cattle are made to'fast before being slaughtered. The time they should stand depends upon their state on their arrival at the shambles. If they have been driven a considerable distance in a proper manner, the bowels will be in a tolerably empty state, so that twelve hours may suffice; 
but if they are full and just off their food, twenty-four hours will be required. Beasts that have been overdriven, or much struck with sticks, or in any degree infuriated, should not be immediately slaugltered, but allowed to stand on dry food, such as hay, until the symptoms disappear. These precautions are absolutely necessary that the meat may be preserved in the best state.

The mode of slaughtering cattle varies in different countries. In the great slaughtter-houses at Montmartre, in Paris, they are slaughtered by bisecting the spinal cord of the cerical vertebræ; and this is accomplished by the driving of a sharp-pointed chisel between the second and third vertebræ, with a smart stroke of a mallet, while the animal is standing, when it drops, and death or insensibility instantly ensues, and the blood is let out immediately by opening the bloodvessels of the neck. The plan adopted in England is, first to bring the ox down on his knees, and place his under-jaw upon the ground by means of ropes fastened to his head and passed through an iron ring in the floor of the slaughterhouse. He is then stunned with a few blows from an iron axe made for the purpose, on the forehead, the bone of which is usually driven into the brain. The animal then falls upon his side, and the blood is let out by the neck. Of the two modes, the French is apparently the less cruel, for some oxen require many blows to make them fall. Some butchers, however, allege that the separation of the spinal cord, by producing a general nervous convulsion throughout the body, prevents the blood from flowing as rapidly and entirely out of it as when the ox is stunned in the forehead. The skin is then taken off to the knees, when the legs are disjointed, and 13 
also off the head. The carcass is then hung up by the tendons of the hough on a stretcher, by a block and tackle, worked by a small winch, which retains in place what rope it winds up by means of a wheel and ratchet.

After the carcass has hung for twenty-four hours, it should be cut down by the back-bone, or chine, into two sides. This is done either with the saw, or chopper; the saw making the neatest job in the hands of an inexperienced butcher, though it is the most laborious; and with the chopper is the quickest, but by no means the neatest plan, especially in the hands of a careless workman. In London, the chine is equally divided between both sides; while in Scotland, one side of a carcass of beef has a great deal more bone than the other, all the spinous processes of the vertebræ being left upon it. The bony is called the lying side of the meat. In London, the divided processes in the fore-quarters are broken in the middle when warm, and chopped back with the flat side of the chopper, which has the effect of thickening the fore and middle ribs considerably when cut up. The London butcher also cuts the joints above the hind knee, and, by making some incisions with a sharp knife, cuts the tendons there, and drops the flesh of the hind-quarter on the flank and loins, which causes it to cut up thicker than in the Scotch mode. In opening the hind-quarter he also cuts the aitch bone, or pelvis through the centre, which makes the rump look better. Some butchers in the north of England score the fat of the closing of the hind-quarter, which has the effect of making that part of both heifer and ox look like the udder of an old cow. There is far too much of this scoring practised in Scotland, which prevents the pieces from retain- 
ing-which they should, as nearly as possible-their natural appearance.

In cutting up a carcass of beef the London butcher displays great expertness; he not only discriminates between the qualities of its different parts, but can cut out any piece to gratify the taste of his customers. In this way he makes the best use of the carcass and realizes the largest value for it, while he gratifies the taste of every grade of customers. A figure of the Scotch and English modes of cutting up a carcass of beef will at once show the difference; and upon being informed where the valuable pieces lie, an opinion can be formed as to whether the oxen the farmer is breeding or feeding possess the properties which will enable him to demand the highest price for them.

The sirloin is the principal roasting-piece, making a very handsome dish, and is a universal favorite. It consists of $\mathrm{t}$ w o portions, the Scotch and English sides; the former is above the lumbar bones, and is somewhat hard in ill-fed cattle; the latter

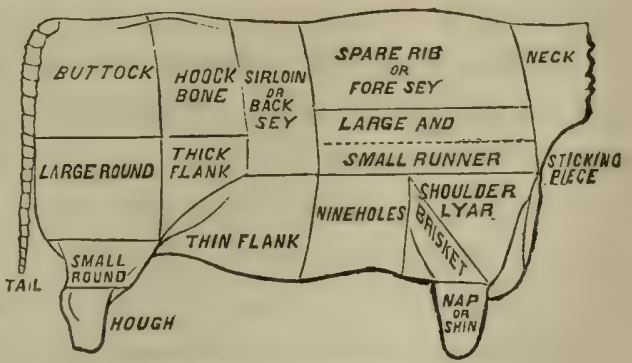

SCOTCH MODE OF CUTTING CP BEEF. consists of the muscles under these bones, which are generally covered with fine fat, and are exceedingly tender. The better the beast is fed, the larger is the under muscle, better covered with fat, and more tender to eat. The hook-bone and the buttock are cut up for steaks, becf-steak pie, or 
minced collops, and both these, together with the sirloin, bring the highest price. The large round and the small round are both well known as excellent pieces for salting and boiling, and are eaten cold with great relish. The bough is peculiarly suited for boiling down for soup, having a large proportion of gelatinous matter. Brown soup is the principal dish made of the hough, but its decoction forms an excellent stock for various dishes, and will keep in a state of jelly for a considerable time. The thick and the thin flank are both admirable pieces for salting and boiling. The tail, insignificant as it may seem, makes a soup of a very fine flavor. Hotel-keepers have a trick of seasoning brown soup or rather beef-tea, with a few joints of tail, and passing it off for genuine ox-tail soup. These are all the pieces which constitute the hind-quarter; and it will be seen that they are valuable both for roasting and boiling, not containing a single coarse piece.

In the fore-quarter, is the spare rib, the six ribs of the back end of which make an excellent roast, and when taken from the side opposite to the lying one, being free of the bones of the spine, it makes a large one; and it also makes excellent beefsteaks and beefsteak pie. The two runners and the nineholes make salting and boiling pieces; but, of these, the nineholes is much the best, as it consists of layers of fat and lean without any bone; whereas the fore parts of the runners have a piece of shoulder-blade in them, and every piece connected with that bone is more or less coarse-grained. The brisket eats very well boiled fresh in broth, and may be cooked and eaten with boiled greens or carrots. The shoulder-lyar is a coarse piece, and fit only for boiling fresh 
to make into broth or beef-tea. The nap, or shin, is analogous to the hough of the hind-leg, but not so rich and fine, there being much less gelatinous matter in it. The neck makes good broth; and the sticking-piece is a great favorite with some epicures, on account of the pieces of rich fat in it. It makes an excellent stew, as also sweet barleybroth, and the meat eats well when boiled in it.

These are all the pieces of the fore-quarter; and it will be seen that they consist chiefly of boiling-pieces, and some of them none of the finest-the roasting-piece being confined to the six ribs of the spare rib, and the finest boiling-piece, corned, only to be found in the nineholes.

The loin is the principal roasting-piece; the rump is the favorite stenk-piece; the aitch-bone, the favorite stew; the buttock, the thick flank, and the thin flank are all excellent boiling.pieces when corned; the hock andsthe shin make soup and afford stock for the various requirements of the culinary art; and the tail furnishes ox-tail soup-a favorite English luncheon. These

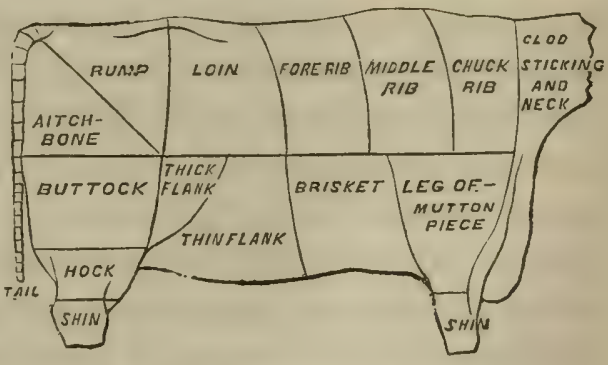

ENGLISH MODE OF CUTTING UP BEEF.

are all the pieces of the hind-quarter, and they are valuable of their respective kinds.

In the fore-quarter, the fore-rib, middle-rib, and chucklerib are all roasting-pieces, not alike good; but in removing the part of the shoulder-blade in the middle-rib, the spare- 
ribs below make a good broil or roast; the neck makes soup, being used fresh, boiled; the back end of the brisket is boiled, corned, or stewed; the leg-of-mutton piece is coarse, but is as frequently stewed as boiled; the shin is put to the same use as the shin and hock of the hind-quarter.

On comparing the two modes of cutting-up, it will be ob served that in the English there are more roasting-pieces than in the Scotch, a large proportion of the fore-quarter being used in that way. The plan, too, of cutting the loin between the rump and aitch-bone in the hind-quarter, lays open the steak-pieces to better advantage than in the Scotch bullock. Extending the comparison from one part of the carcass to the other, in both methods, it will be seen that the most valuable pieces-the roasting-occupy its upper, and the less valuable-the boiling-its lower part. Every beast, therefore, that fays on beef more upon the upper part of its body is more valuable than one that lays the same quantity of flesh on its lower parts.

It is deemed unnecessary to enter into details as to the modes of cutting-up most in vogue in this country, as there is a needlessly great want of uniformity.

Of the qualities of beef obtained from the different breeds of cattle in England, there is no better meat than from the West Highlanders for fineness of grain and cutting up into convenient pieces for family use. The Galloways and Angus, when fattened in English pastures, are great favorites in the London market. The Short Horns afford excellent steaks, being thick of flesh, and the slice deep, large and juicy, and their covered flanks and nineholes are always thick, juicy, and well-mixed. The Herefords are somewhat similar to the Short 
Horns, and the Devons, may, perhaps, be classed among the Galloways and Angus, while the Welsh cannot be compared to the West Highlanders. Taking, then, the breeds of Scotland as suppliers of good beef, they seem to be more valuable for the table than those of England.

There are, perhaps, not sufficient data in existence to determine the true proportion of offal of all kinds to the beef of any given fat ox; but approximations have been made, which may serve the purpose until the matter is investigated by direct experiment, under various circumstances. The dead weight bears to the live weight a ratio varying between .571 and .605 to 1 ; and on applying one or the other multiplier to the cases of the live weight, a pretty correct approximation is reached. The tallow is supposed to be eight one-hundredths of the live weight; so that the multiplier is the decimal.08. The hide is supposed to be five one-hundredths of the live weight; so to obtain its weight, a multiplier, .05, is used. The other offals are supposed to be in a proportion of about one-fourth of the live weight; so that the multiplier, .28 , is as near as can be proposed under existing experience.

Beef is the staple animal food of this country, and it is used in various states-fresh, salted, smoked, roasted, and boiled. When intended to be eaten fresh, the ribs will keep the best, and with care will keep five or six days in summer, and in winter ten days. The middle of the loin is the next best, and the rump the next. The round will not keep long, unless it is salted. The brisket is the worst, and will not keep more than three days in summer, and in winter a week.

In regard to the power of the stomach to digest beef, that 
which is eaten boiled with salt only, is digested in two hours and forty-five minutes. Beef, fresh, lean, and rarely-roasted, and a beefsteak broiled, takes three hours to digest; that fresh, and dry-roasted, and boiled, eaten with mustard, is digested in three and a half hours. Lean fresh beef fried, requires four hours, and old hard salted beef boiled, does not digest in less than four and a quarter hours. Fresh beef-suet boiled takes five and a half hours.

The usual mode of preserving beef is by salting; and, when intended to keep for a long time, such as for the use of shipping, it is always salted with brine; but for family use it should be salted only with good salt; for brine dispels the juice of meat, and saltpetre only ser res to make the meat dry, and give it a disagreeable and unnatural red color. Various experiments have been made in curing beef with salt otherwise than by hand-rubbing, and in a short space of time; and also to preserve it from putrefaction by other means than salt. Some packers put meal in a copper which is rendered air-tight, and an air-pump then creates a vacuum within it, thereby extracting all the air out of the meat; then brine is pumped in by pressure, which, entering into every pore of the meat formerly occupied by the air, is said to place it in a state of preservation in a fer minutes. The carcass of an ox was preserved, in France, for two years from putrefaction by injecting four pounds of saline mixture into the carotid artery. Whether any such contrivance can be made available for family purposes, seems doubtful.

Cattle, when slaughtered, are useful to man in various other ways than by affording food from their flesh,-their offal of tallow, hides, and horns, forming extensive articles 
of commerce. Of the hide, the characteristics of a good one for strong purposes are strength in its middle, or butt, as it called, and lightness in the edges, or offal. A bad hide is the opposite of this-thick in the edges and thin in the middle. A good hide has a firm texture; a bad one, loose and soft. A hide improves as the summer adrances, and it continues to improve after the new coat of hair in autumn until November or December, when the coat gets rough from the coldness of the season, and the hide is then in its best state. It is surprising how a hide improves in thickness after the cold weather has set in. The sort of food does not seem to affect the quality of the bide; but the better it is, and the better cattle have been fed, and the longer they have been well fed, even from a calf, the better the hide. From what has been said of the effect of weather upon the hide, it. seems a natural conclusion that a hide is better from an ox that has been fed in the open air, than from one that has been kept in the barn. Dirt adhering to a hide injures it, particularly in stall-fed animals; and any thing that punctures a hide, such as warbles arising from certain insects, is also injurious. The best hides are obtained from the West Highlanders. The Short Horus produce the thinnest hides, the Aberdeenshire the next, and then the Angus. Of the same breed, the ox affords the strongest hide; but, as hides are applied to various. uses, the cow's, provided it be large, may be as valuable as that of the ox. The bull's hide is the least valuable. Hides are imported from Russia and South America.

Hides, when deprived of their hair, are converted into leather by an infusion of the astringent property of bark. 
The old plan of tanning used to occupy a long time; but, such was the value of the process, that the old tanners used to pride themselves upon producing a substantial article-which is more than ean be said in many instances under modern improved modes, which hasten the process, much to the injury of the article produced. Strong infusions of bark make leather brittle; one hundred pounds of skin, quickly tanned in a strong infusion, produce one hundred and thirty-seven pounds of leather; while a weak infusion produces only one hundred and seventeen and a half,--the additional nineteen and a half pounds serving only to deteriorate the leather, and causing it to contain much less textile animal solid. Leather thus highly charged with tanning is so spongy as to allow moisture to pass readily through its pores, to the great discomfort and injury of those who wear shoes made of it. The proper mode of tanning lasts a year, or a year and a half, according to the quality of the leather wanted and the nature of the hides. A perfect leather can be recognized by its section, which should have a glistening marbled appearance, without any white streaks in the middle. The hair which is taken off hides in tanning, is employed to mix with plaster, and is often surreptitiously put into hair-mattresses.

The principal subtances of which glue is made are the parings of ox and other thick hides, which form the strongest article and the refuse of the leather-dresser. Both afford from forty-five to fifty-five per cent. of glue. The tendons, and many other offals of slaughter-houses, also afford materials, though of an inferior quality, for this purpose. The refuse of tanneries-such as the ears of oxen and calves 
-are better articles. Animal skins also, in any form, uncombined with tannin, may be worked into glue.

Ox-tallow is of great importance in the arts. Candles and soap are made of it, and it enters largely into the dressing of leather and the use of machinery. Large quantities are annually exported from Russia. Ox-tallow consists of seventy-six parts of stearine and twenty-four of oleine, out of one hundred parts.

The horns of oxen are used for many purposes. The horn consists of two parts : an outward horny case, and an inward conical-shaped substance, somewhat intermediate between indurated hair and bone, called the fluid of the horn. These two parts are separated by means of a blow upon a block of wood. The horny exterior is then cut into three portions by means of a frame saw. The lowest of these, next the root of the horn, after undergoing several processes by which it is rendered flat, is made into combs. The middle of the horn, after having been flattened by heat, and its transparency improved by oil, is split into thin layers, and forms a substitute for glass in lanterns of the commonest kind. The tip of the horns is used by makers of knifehandles and of the tops of whips, and for other similar purposes. The interior, or core of the horn, is boiled down in water. A large quantity of fat rises to the suriace; this is put aside, and sold to the makers of yellow soap. The liquid itself is used as a kind of glue, and is purchased by the cloth-draper for stiffening. The bony substance remaining behind is then sent to the mill, and, after having been ground down, is sold to farmers for manure.

Besides these various purposes to which the different parts 
of the horn are applied, the clippings which arise in combmaking are sold to the farmer for manure, as well as the shavings which form the refuse of the lantern-makers. Horn, as is well known, is easily rendered soft and pliant in warm water; and by this peculiarity and its property of adLering like glue, large plates of horn can be made by cementing together the edges of small pieces rendered flat by a peculiar process, as a substitute for glass. Imitation of tortoise-shell can be given to horn by means of various metallic solutions. Horn, also, when softened, can be Imprinted with any pattern, by means of dies 


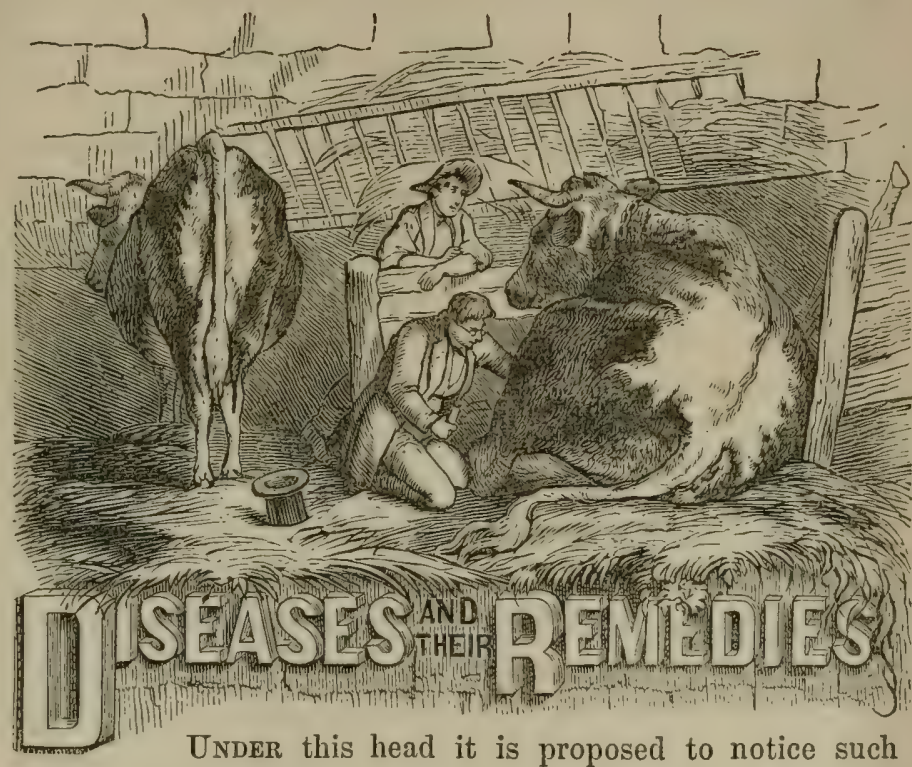

diseases as are most common among cattle, together with their symptoms, and to suggest such treatment of the same as has been found in the practice of the author, in the main, effective. He is aware that much more space might have been appropriated to this head, as has been the case in other treatises of this class; but he doubts the propriety of multiplying words about diseases which are of very rare occurrence, deeming it more fitting to leave such instances exclusively to the intelligent consideration of the reliable veterinary practitioner. 
For conrenience of reference, the diseases here noticed have been arranged in alphabetical order; the whole concluding with information as to two or three operations which cannot be uninteresting to, or unprofitable for, the reader.

\section{ABORTION.}

The cow is, more than any other animal, subject to abortion, or slinking, which takes place at different periods of pregnancy, from half of the usual time to the seventh, or almost to the eighth month. The symptoms of the approach of abortion, unless the breeder is very much among his stock, are not often perceived; or, if perceived, they are concealed by the person in charge, lest he should be accused of neglect or improper treatment.

The cow is somewhat off her feed-rumination ceases-she is listless and dull_the milk diminishes or dries up-the motions of the fotus become more feeble, and at length cease altogether-there is a slight degree of enlargement of the belly-there is a little staggering in her walk-when she is down she lies longer than usual, and when she gets up she stands for a longer time motionless.

As the abortion approaches, a yellow or red glairy fluid runs from the vagina (this is a symptom, which rarely, or never, deceives) her breathing becomes laborious and slightly convulsive. The belly has for several days lost its natural rotundity, and has been evidently falling,--she begins to moan,- the pulse becomes small, wiry, and intermittent. At length labor comes on, and is often attended with much difficulty and danger.

If the abortion has been caused by blows or violence, 
whether from brutality, or the animal's having been teased by other cows in season, or by oxen, the symptoms are more intense. The animal suddenly ceases to eat and to ruminate -is uneasy, paws the ground, rests ber head on the manger while she is standing, and on her flank when she is lying down-hemorrhage frequently comes on from the uterus, or when this is not the case the mouth of that organ is spasmodically contracted. The throes come on, are distressingly violent, and continue until the womb is ruptured. If all these circumstances be not observed, still the labor is protracted and dangerous.

Abortion is sometimes singularly frequent in particular districts, or on particular farms, appearing to assume an epizoötic or epidemic form. This has been accounted for in various ways. Some have imagined it to be contagious. It is, indeed, destructively propagated among the cows, but this is probably to be explained on a different principle from that of contagion. The cow is a considerably imaginative animal, and highly irritable during the period of pregnancy. In abortion, the fœtus is often putrid before it is discharged; and the placenta, or afterbirth, rarely or never follows it, but becomes decomposed, and, as it drops away in fragments, emits a peculiar and most noisome smell. This smell seems to be peculiarly annoying to the other cows : they sniff at it and then run bellowing about. Some sympathetic influence is exercised on their uterine organs, and in a few days a greater or less number of those that had pastured together likewise abort. Hence arises the rapidity with which the fœtus is usually taken away and buried deeply, and far from the cows; and hence the more effectual preventive of smearing 
the parts of the cow with tar or stinking oils, in order to conceal or subdue the smell; and hence, too, the inefficacy, as a preventive, of removing her to a far-distant pasture.

The pastures on which the blood or inflammatory fever is most prevalent are those on which the cows oftenest slink their calves. Whatever can become a source of general excitation and fever is likely, during pregnancy, to produce inflammation of the womb; or whatever would, under other circumstances, excite inflammation of almost any organ, has at that time its injurious effect determined to this particular one.

Every farmer is aware of the injurious effect of the coarse, rank herbage of low, marshy, and woody countries, and he regards these districts as the chosen residence of red water; it may be added, that they are also the chosen residence of abortion. Hard and mineral waters are justly considered as laying the foundation of many diseases among cattle, and of abortion among the rest.

Some careful observers have occasionally attributed abortion to disproportion in size between the male and the female. Farmers were formerly too fond of selecting a great overgrown bull to serve their dairy or breeding cows, and many a heifer, or little cow, was seriously injured; and she either cast her calf, or was lost in parturition. The breeders of cattle in later years are beginning to act more wisely in this matter.

Cows that are degenerating into consumption are exceedingly subject to abortion. They are continually in heat; they rarely become pregnant, or if they do, a great proportion of them cast their calves. Abortion, also, often follows a 
sudden change from poor to luxuriant food. Cows that have been out, half-starved in the winter, when incautiously turned on rich pasture in the spring, are too apt to cast their calves from the undue general or local excitation that is set up. Hence it is, that when this disposition to abort first appears in a herd, it is naturally in a cow that has been lately purchased. Fright, from whatever cause, may produce this trouble. There are singular cases on record of whole herds of cows slinking their calves after having been terrified by an unusually violent tbunder-storm. Commerce with the bull soon after conception is also a frequent cause, as well as putrid smells_other than those already noticed-and the use of a diseased bull. Besides these tangible causes of abortion, there is the mysterious agency of the atmosphere. There are certain seasons when abortion is strangely frequent, and fatal ; while at other times it disappears in a manner for several successive years.

The consequences of premature calving are frequently of a very serious nature; and even when the case is more favorable, the results are, nevertheless, very annoying. The animal very soon goes again to heat, but in a great many cases she fails to become pregnant; she almost invariably does so, if she is put to the bull during the first heat after abortion. If she should come in calf again during that season, it is very probable that at about the same period of gestation, or a little later, she will again abort: or that when she becomes in calf the following year, the same fatality will attend her. Some say that this disposition to cast her young gradually ceases; that if she does miscarry, it is at a later and still later period of pregnancy; and that, in about three 
or four years, she may be depended upon as a tolerably safe breeder. He, however, would be sadly inattentive to his own interests who keeps a profitless beast so long.

The calf very rarely lives, and in the majority of cases it is born dead or putrid. If there should appear to be any chance of saving it, it should be washed with warm water, carefully dried, and fed frequently with small quantities of new milk, mixed, according to the apparent weakness of the animal, either with raw eggs or good gruel; while the bowels should, if occasion requires, be opened by means of small doses of castor-oil. If any considerable period is to elapse before the natural time of pregnancy would have expired, it will usually be necessary to bring up the little animal en. tirely by hand.

The treatment of abortion differs but little from that of parturition. If the farmer has once been tormented by this pest in his dairy, he should carefully watch the approaching symptoms of casting the calf, and as soon as he perceives them, should remove the animal from the pasture to a comfortable cow-house or shed. If the discharge be glairy, but not offensive, he may hope that the calf is not dead; he will be assured of this by the motion of the fœtus, and then it is possible that the abortion may still be avoided. He should hasten to bleed her, and that copiously, in proportion to her age, size, condition, and the state of excitation in which he may find her; and he should give a dose of physic immediately after the bleeding. When the physic begins to operate, he should administer half a drachm of opium and half an ounce of sweet spirits of nitre. Unless she is in a state of great debility, he should allow nothing but gruel, 
and she should be kept as quiet as possible. By these means he may occasionally allay the general or local irritation that precedes or causes the abortion, and the cow may yet go to her full time.

Should, however, the discharge be fetid, the conclusion will be that the fœtus is dead, and must be got rid of, and that as speedily as possible. Bleeding may even then be requisite, if much fever exists; or, perhaps, if there is debility, some stimulating drink may not be out of place. In other respects the animal must be treated as if her usual time of pregnancy had been accomplished.

Much may be done in the way of preventing this habit of abortion among cows. The foetus must be got rid of immediately. It should be buried deep, and far from the cowpasture. Proper means should be taken to hasten the expulsion of the placenta. A dose of physic should be given; ergot of rye administered; the hand should be introduced, and an effort made, cautiously and gently, to detach the placenta; all violence, however, should be carefully avoided; for considerable and fatal hemorrhage may be speedily produced. The parts of the cow should be well washed with a solution of the chloride of lime, which should be injected up the vagina, and also given internally. In the mean time, and especially after the expulsion of the placenta, the cow-house should be well washed with the same solution.

The cow, when beginning to recover, should be fattened and sold. This is the first and the grand step toward the prevention of abortion, and he is unwise who does not immediately adopt it. All other means are comparatively 
inefficient and worthless. Should the owner be reluctant to part with her, two months, at least, should pass before she is permitted to return to her companions. Prudence would probably dictate that she should never return to them, but be kept, if possible, on some distant part of the farm.

Abortion having once occurred among the herd, the breecing corvs should be carefully watched. Although they should be well fed, they should not be suffered to get into too high condition. Unless they are decidedly poor and weak, they should be bled between the third and fourth months of pregnancy, and a mild dose of physic administered to each. If the pest continues to reappear, the owner should most carefully examine how far any of the causes of abortion that have been detected, may exist on his farm, and exert himself to thoroughly remove them.

An interesting paper upon this subject may be found in the Veterinary Review, vol. 1., p. 434, communicated by Prof. Henry Tanner, of Queen's College, Birmingham, England. As it suggests a theory as to the origin of this disease which is, to say the least, quite plausible, we transfer the article:-

"I shall not go into any notice of the general subject of abortion, but rather restrict my remarks to a cause which is very much overlooked, and jet which is probably more influential than all other causes combined. I refer to the growth of ergotized grass-seeds in our pastures.

"The action of ergot of rye (secale cornutum) upon the womb is well known as an excitant to powerful action, which usually terminates in the expulsion of the fœtus. We have a 
similar disease appearing on the seeds of our grasses, but especially on the rye grass, and thus we have an ergot of the seeds of rye grass produced, possessing similar exciting powers upon the womb to those produced by the ergot of rye.

"Two conditions are necessary for the production of this ergot upon the seed of rye grass. The first is, the grass must be allowed to run to seed; and the second is, that the climate must be favorable for encouraging the development of the ergot.

"In practice, we find that on land which has been fed on during the summer, unless it has been grazed with unusual care, much of the grass throws up seed-stalks and produces seed. In districts where the climate is humid and rain abundant, as well as in very wet seasons, these seeds become liable to the growth of this ergot. Cattle appear to eat it with a relish, and the result is that abortion spreads rapidly through the herd. Heifers and cows, which, up to the appearance of the ergot, have held in calf, are excited to cast their calves by consuming it in their food. The abortion having once commenced, we know that the peculiarly sensitive condition of the breeding animal will cause its extension, even where the original cause may not be in operation; but their combined action renders the loss far more serious. If we add to this the tendency which an animal receives from her first abortion, to repeat it when. next in calf, we see how seriously the mischief becomes multiplied.

"A somewhat extended observation, added to my own experience, has led me to the conviction that very much of the 
loss arising from abortion in our cows may be traced to the cause I have named. I feel assured the influence is even more extended than I have'stated; for not only would the fœtus be thrown off in its advanced stage, but also in its earlier growth, thus causing great trouble to breeders of high-bred stock, the repeated turning of cows to the bull, and at most irregular intervals.

"The remedy differs in no respect from the ordinary mode of treatment, except that it compels a removal of the stock from the influence of the cause. Much, however, may be done by way of prevention; and this I shall briefly notice.

"It simply consists in keeping breeding cows and heifers upon land free from these seeds. Grass which has been grazed during the summer, will very generally, in a humid climate, have some of this ergotized seed; but I have not observed it produced before the end of July, or early in August; and I doubt its existence, to any injurious degree, up to this time. We may, therefore, consider such ground safe up to this period. If the breeding stock are then removed to grass land which, having been mown for this operation is a guaranty against any seeds remaining, it will seldom, if ever, happen that any injury will result from the production of ergotized grass later in the season.

"I will not venture to say that such will not appear in some cases where the grass has been cut early and has been followed by a rapid growth; but, at any rate, we have grazing land free from this excitant from July until September; and in the grass which has been mown late, I do not consider that there is the least fear of ergot's being again formed in that season. In this manner a farmer may keep 
grass land for his breeding stock entirely free from ergotized grass; and, consequently, so far as this cause is concerned, they will be free from abortion. How far young heifers may be prejudicially influenced, before they are used for breeding, by an excitement of the womb, appears to me to be a subject worthy of some attention on the part of the veterinary profession."

\section{APOPLEXY.}

This is a determination of blood to the head, causing pressure upon the brain. Animals attacked with this disease are generally in a plethoric condition. The usual symptoms are coma (a sleepy state), eyes protruding, respiration accelerated finally, the animal falls, struggles, and dies.

In such cases, bleeding should be resorted to at an early period; give in drink one pound of Epsom-salts.

\section{BIACK WATER.}

This is simply an exaggerated stage of the disease known as Red Water,- to which the reader is referred in its appropriate place,- the urine being darker in color in consequence of the admixture of venous blood.

The symptoms are similar, though more acute. There is constipation at first, which is followed by diarrhœa, large quantities of blood passing away with the evacuations from the bowels; symptoms of abdominal pain are present; the loins become extremely tender; and the animal dies in a greatly prostrated condition.

The treatment does not differ from that prescribed in case of Red Water. 


\section{BRONCHITIS.}

The trachea and bronchial tubes are frequently the seat of inflammation, especially in the spring of the year,-the symptoms of which are often confounded with those of other pulmonary diseases. This inflammation is frequently preceded by catarrhal affections; cough is often present for a long time before the more acute symptoms are observed. Bronchitis occasionally makes its appearance in an epizoötic form.

Symptoms. - A peculiarly anxious expression of the countenance will be observed; respiration laborious; a husky, wheezing, painful cough; on placing the ear to the windpipe a sonorous râle is heard; symptomatic ferer also prevails to a greater or less extent.

Treatment.-Counter-irritation should be early resorted to; strong mustard, mixed with equal parts of spirits of harts. horn and water, and made into a thin paste, should be applied all along the neck, over the windpipe, and to the sides, and should be well rubbed in; or the tincture of cantharides, with ten drops of castor-oil to each ounce, applied in the same manner as the former, will be found equally effective. Give internally ten drops of Fleming's tincture of aconite every four hours, until five or six doses have been given; after which give one of the following powders twice a day: nitrate of potash, one ounce; Barbadoes aloes, one ounce; Jamaica ginger, half an ounce; pulverized-gentian root, one ounce; mix and divide into eight powders. If necessary a pound of salts may be given. 


\section{CONSUMPTION}

This affection-technically known as phthrsis pulmonalis -is the termination of chronic disease of the lungs. These organs become filled with many little cysts, or sacks, containing a yellowish or yellowish-white fluid, which in time is hardened, producing a condition of the lungs known as tuberculous. These tubercles in turn undergo another change, becoming soft in the centre and gradually involving the whole of the hardened parts, which, uniting with adjoining ones, soon forms cysts of considerable size. These cysts are known as abscesses.

No treatment will be of much service here. It is, therefore, better, if the animal is not too poor in flesh, to have it slaughtered.

\section{CORYZA}

In the spring, and late in the fall, catarrhal affections are quite common, occurring frequently in a epizoötic form. Coryza, or nasal catarrh,_commonly called a cold in the head,-is not very common among cows. As its name implies, it is a local disease, confined to the lining membrane of the nose; and, consequently, the general system is not usually disturbed.

Symptoms. - The animal will be observed to sneeze; the Schneiderian membrane (membrane of the nose) is heightened in color; cough sometimes accompanies; there is also a muco-purulent discharge from the nose. Neglect to attend to these early symptoms frequently occasions disease of a 
more serious nature; in fact, coryza may be regarded as the forerunner of all epizoötic pulmonary disorders.

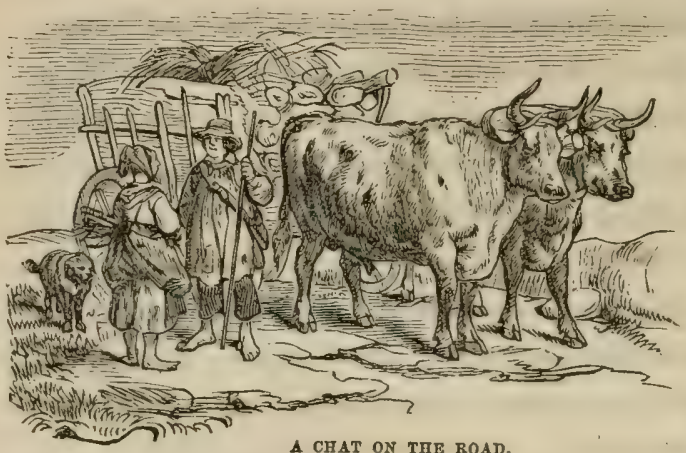

A CHAT ON THE ROAD.
Treatment. - The a $\mathrm{n}$ i $\mathrm{ma} \mathrm{l}$ should be kept on a low diet for a few days; the nostrils occasionally s te a m ed,

and one of the following powders given night and morning, which, in most cases, will be all the medicine required: nitrate of potassa, one ounce; digitalis leares pulverized and tartrate of antimong, of each one drachm ; sulphate of copper, two drachms ; mix, and divide into eight powders. Should the clisease prove obstinate, give for two or three days two ounces of Epsom-salts at a dose, dissolved in water, three times a day.

\section{COW-POX.}

Two varieties of sore teats occur in the cow, in the form of pustular eruptions. They first appear as small vesicles containing a purulent matter, and subsequently assume a scabby appearance, or small ulcers remain, which often prove troublesome to heal. This latter is the cow-pox, from which Jenner derived the vaccine matter.

Treatment.-Foment the teats well with warm water and Castile-soap; after which, wipe the bag dry, and dress with 
citrine ointment. The preparations of iodine have also been recommended, and they are very serviceable.

\section{DIARRHCEA.}

Cattle are frequently subject to this disease, particularly in the spring of the year when the grass is young and soft. Occasionally it assumes a very obstinate form in consequence of the imperfect secretion of gastric juice; the foeces are thin, watery, and fetid, followed by very great prostration of the animal.

The symptoms of diarrhœa are too well known to require any detailed description.

Treatment.-If in a mild form, the diet should be low; give two ounces of Epsom-salts, twice a day. In a more obstinate form, give two drachms of carbonate of soda in the food. Oak-bark tea will be found rery useful in these cases; or one of the following powders, twice a day, will be found very advantageous : pulverized opium and catechu, each one and a half ounces; prepared chalk, one drachm; to be given in the feed.

Calves are particularly subject to this disease, and it often proves fatal to them. It sometimes assumes an epizoötic form, when it is generally of a mild character. So long as the calf is lively and feeds well, the farmer should entertain no fear for him; but if he mopes about, refuses his food ceases to ruminate, wastes in flesh, passes mucus and blood with the foces, and exhibits symptoms of pain, the case is a dangerous one.

In such an emergency, lose no time, but give two or three sunces of Castor-oil with flour-gruel, or two ounces of salts 
at a dose, followed with small draughts of oak-bark tea; or give, twice a day, one of the following powders : pulverized eatechu, opium, and Jamaca ginger, of each half an ounce; prepared chalk, one ounce; mix, aud divide into twelve powders. Bran washes, green food, and flour-gruel should be given, with plenty of salt.

\section{DYSENTERY}

This disease is very frequently confounded with the foregoing. A distinction, however, exists,-since inflammation appears in this disease, while it is absent in the former. In this affection, inflammation of the large intestines takes place, which is attended with diarrhoa. The foces are covered with blood; the animal rapidly becomes prostrated, and death frequently comes to his relief.

Touatt says: "It is, however, with dysentery that the practitioner is most loth to cope, -a disease that betrays thousands of cattle. This, also, may be either acute or chronic. Its causes are too often buried in obscurity, and its premonitory symptoms are disregarded or unknown. There appears to be a strong predisposition in cattle to take on this disease It seems to be the winding-up of many serious complaints, and the foundation of it is sometimes laid by those that appear to be of the most trifling nature. It is that in cattle which glanders and farcy are in the horse,--the breaking up of the constitution.

"Dysentery may be a symptom and concomitant of other diseases. It is one of the most fearful characteristics of murrain ; it is the destructive accompaniment, or consequence, of phthisis. It is produced by the sudden disappearance of 
a cutaneous eruption; it follows the cessation of chronic hoose; it is the consequence of the natural or artificial suspension of every secretion. Were any secretion to be particularly selected, the repression of which would produce dysentery, it would be that of the milk. How often does the farmer observe that no sooner does a milch cow cease her usual supply of milk than she begins to purge! There may not appear to be any thing else the matter with her; but she purges, and, in the majority of cases, that purging is fatal.

"It may, sometimes, however, be traced to sufficient causes, exclusive of previous disease. Unwholesome foodexposure to cold-neglect at the time of calving-low and marshy situations-the feeding in meadows that have been flooded, where it is peculiarly fatal-the grazing (according to Mr. Leigh, and our experience confirms his statement) upon the clays lying over the blue lias rock-the neighborhood of woods and of half-stagnant rivers-the continuation of unusually sultry weather-overwork, and all the causes of acute dysentery, may produce that of a chronic nature; an acute dysentery-neglected, or badly, or even most skillfully treated-may degenerate into an incurable cbronic affection. Half starve a cow, or overfeed her, milk her to exhaustion, or dry her milk too rapidly-and dysentery may follow.

"The following will, probably, be the order of the symptoms, if they are carefully observed: There will be a little dullness or anxiety of countenance, the muzzle becoming short or contracted; a slight shrinking when the loins are pressed upon; the skin a little harsh and dry; the hair a little rough; there will be a slight degree of uneasiness and shivering that scarcely attracts attention; then-except it bo 
the degeneracy of acute into chronic dystentery-constipation may be perceived. It will be to a certain extent, olstinate; the excrement will voided with pain; it will be dry, hard, and expelled in small quantities. In other cases, perhaps, purging will be present from the beginning; the animal will be tormented with tenesmus, or frequent desire to void its excrement, and that act attended by straining and pain, by soreness about the anus, and protrusion of the rectum, and sometimes by severe colicky spasms. In many cases, however, and in those of a chronic form, few of these distressing symptoms are observed, even at the commencement of the disease; but the animal voids her foces oftener than it is natural that she should, and they are more fluid than in a state of health; while at the same time she loses her appetite and spirits and condition, and is evidently wasting away."

Treatment.-Give one drachm of the extract of belladonna, three times a day, dissolved in water; or calomel and powdered opium, of each one drachm three times daily. As soon as the inflammatory stage passes by, give one of the following three times daily, in their gruel : nitrate of potash pulverized, gentian-root pulverized, of each one ounce; pulverized Jamaica ginger, one half an ounce; pulverized caraway, or anise-seed, six drachms. A bottle of porter given once or wice a day, will be found of very great advantage.

\section{ENTERITIS.}

This is an inflammation of the external or internal coat of the intestines, sometimes attended with violent purging; especially when it is confined to the internal coats. Oxen in 
good condition are more subject to this disease than are cows. It most freqently occurs in dry, bot weather. It is sudden in its attacks, and often fatal in its termination.

Symptoms. - The animal is dull, and not disposed to move about; the muzzle is dry, and the coat staring; the anmmal yields, on pressure of the loins; a weak, staggering gait, when forced to move; respiration hurried; pulse accelerated but small; eyes red, full and fiery; head protruding; mouth, ears, and horns hot; appetite bad; rumination ceases; the bowels become constipated; the animal moans continually, and froths at the mouth. These symptoms violently increase as the disease advances. The animal becomes more depressed and feeble, grinds his teeth, and appears half unconscious, and dies in convulsions.

Of the causes of this disease, Youatt, who is almost the only authority we have upon this subject; says: "It seems occasionally to be epidemic; for several instances of it occur, of the same character, and in the same district. M. Cruzel gives an illustration of this in his description of the disease that destroyed so many cattle, in the years 1826 to 1827, in the Department de la Nievre. Out of two bundred and eighteen cattle belonging to three farmers, one hundred and thirteen were attacked by this disease, and eighty-three of them died. One farmer in a neighboring district had nineteen head of cattle, all of which sickened, but only three were lost. These were unusually hot summers. The upland pasture was burnt up, or what remained of it was rendered unusually stimulating; and the acrid plants of the marshes and low grounds accquired additional deleterious agency. 
"When isolated cases occur, they may generally be attributed to mismanagement. Exposure to cold, or the drinking of cold water when overheated with work; too hard work in sultry weather; the use of water stagnant, impure, or containing any considerable quantity of metallic salts; the sudden revulsion of some cutaneous eruption; the crowding of animals into a confined place; too luxuriant and stimulating food generally; and the mildewed and unwholesome food on which cattle are too often kept, are fruitful sources of this complaint."

Treatment.-In the early stage of the disease, give an active purge, and follow it with ten drops of Fleming's tincture of aconite, 'four times daily, for two days; then give drachm doses of the extract of belladonna; give no food for twenty-four or forty-eight hours, according to circumstances. Bleeding, if done early, is often beneficial. Counter-irritants to the belly are also recommended; the best are mustard, hartshorn, and water, mixed together-or tincture of cantharides, with one drachm of croton-oil added to every ounce

\section{EPIZOÖTICS.}

Diseases of this class have the same relation to the inferior animals that epidemic diseases have to man. Of course, they assume a very pestilential character. Scarcely a yerir passes away without diseases of this nature making their appearance in some parts of the world. They occur at all seasons of the year, but more generally prevail in the spring and fall. The period of their duration varies from months to years. They are, at times, mild in their attacks, and yield readily to 
proper treatment; at other times, they become painful pestilences, destroying every thing in their course.

The causes are generally sought for in some peculiar condition of the atmosphere. The use of the milk and flesh of diseased cattle has frequently been productive of malignant diseases in the human family.

Silius Italicus describes a fearful epizoötic, which first attacked the $d o g$, then the feathered biped, then horses, and cattle, and, last of all, the human being.

"On mules and dogs the infection first began, And, last, the vengeful arrows fired in man."

Epizoötics, occurring in rats, cats, dogs, horses, and cattle, which were followed in the succeeding years by more fearful ones which attacked the human family, are numerously recorded. These scourges have appeared in all ages of the world; but, as time and space will not allow our entering upon an extended consideration of them,-however interesting they might be to the general reader,-we shall content ourselves by quoting, somewhat in brief, from the lectures of the late William Youatt on these fatal maladies:-

"In the year 801, and at the commencement of the reign of Charlemagne, an epidemic disease devastated a great portion of his dominions. This was attributed to the villainy of the Duke of Benevento, who was said to have employed a great many persons in scattering an enchanted powder over - the fields, which destroyed both the cattle and the food of the cattle. M. Paulet seems inclined to give full credence to this, and says that history offers many proofs of this destructive and diabolical practice. He affirms that many persons 
were punished in Germany, France, and, particularly, at Toulouse, for the commission of this crime. Several of the suspected agents of these atrocities were put to the torture. and made full confession of their crime.

"Of the occurrence of these diseases from the year 800 to 1316, - an interval of mental darkness, and of horrors and calamities of every kind,-history records twenty cases, more or less destructive, and extending, with greater or less devastation, over France and Germany, Italy and England. Of these twenty, four date their origin from an excessive moisture in the air, accompanied by almost continual rains, and flooding the country to a considerable extent. One was supposed to be the consequence of long-continued drought and excessive heat; one was traced to the influence of an eclipse of the sun; another, to a comet; and a fourth, to a most unusually stormy winter. The reader will have the kiudness to remember that we are here expressing the opinions of the writers of the day, and by no means, our own belief of the matter.

"Of the four which trace their origin to extreme wet and its consequences, the first occurred in France, in 820 , after a long continuance of rain; and it was equally fatal to men and cattle. The second, which was equally fatal to both, appeared in Lorraine, in 889 . The third broke out among the cavalry of the army of Arnoul, in its passage over the Alps, on its return to Italy. The fourth pervaded the whole of England in 1125, and was equally fatal to the biped and the quadruped.

"That which followed excessive heat and drought, was generally prevalent throughout Europe, but especially so in 
Germany. It attacked oxen, sheep, and pigs. It appeared in 994 , and lasted six months.

"The one which was attributed to the comet, and which principally attacked cattle, appeared in France in 943. Almost every animal perished.

"Another, that was supposed to be connected with an eclipse of the sun, was prevalent throughout the greater part of Germany, among men and animals, in 989.

"The disease, which was the consequence of a cold and boisterous winter, was principally prevalent in France, in 887 , and committed sad ravages among the herds of cattle and sheep.

"Of the twelve others, of which authors do not indicate the cause, the first was in France, in 810 , and principally among cattle. The second was also in France, in 850, and almost depopulated the country of cattle. The third, in 868, was common to all animals in France. The fourth, in 870 , was in the same country, and caused severe loss among cattle. The fifth prevailed on the Rhine and in Germany, and destroyed an almost incalculable number of cattle. The sixth attacked the horses of the army of Arnoul in Lorraine, in 888. The seventh, in 940 , destroyed a vast number of cattle in France, Italy, and Germany. The eighth and ninth were in France, in 941 and 942 , and almost all the cattle in the country perished. The tenth pestilence broke out in England, in the year 1041, and frightful was its devastation among all animals, and, particularly, horned cattle. The eleventh also devastated our country, in 1103, and the ravages were dreadful. The twelfth was chiefly fatal in Germany, and particularly in Gueldres, in 1149. 
"These twenty pestilences occurred in the space of 506 years. Five or six of them were most prevalent among cattle; two were almost confined to horses; twelve included, to a greater or less degree, almost every species of quadrupeds; and four extended to the human being. Among these the ravages of eight were most destructive in France; as many in Germany; and four in Italy and England.

"As far as we have hitherto proceeded, it will also appear that cattle are more subject to these diseases than any other species of domesticated animals, and that the pestilence is always most fearful among them. It is also evident that the maladies which proceed from cold or humidity are more frequent in the temperate and southern parts of Europe than those which depend upon drought, or almost any other cause.

"The malady lingers in different countries, in proportion to its want of power to accomplish at once all its devastation.

"After this time, there are few satisfactory accounts of these diseases for more than five centuries. We only know that, occasionally suspending their ravages,-or, rather, visiting new districts when they had ceased to desolate others - they have continued to be objects of terror and instruments of devastation, even unto the present day; and it is only within a few years that they have been really understood, and have become, to a certain degree, manageable."

In the United States, epizoötic diseases have been of frequent occurrence; but, owing to the want of properly qualified veterinary surgeons, they have not, until within a very recent period, been properly described or understood. 
The day, however, is fast approaching when this void will be filled, and when epizoötic and other diseases will be correctly noted and recorded. The necessity for this must have been forcibly impressed upon the minds of the inhabitants of our country from the experience of the last ten or twelve years.

Respecting the late epizoötic among cattle in Portage County, Ohio, William Pierce, V.S., of Ravenna, thus describes the symptoms as they appeared, in a letter to the author: "A highly-colored appearance of the sclerotic coat of the eye, also of the conjunctiva (a lining membrane of the eyelid) and the Schneiderian nembrane of the nose; a high animal heat about the head and horns; a highly inflammatory condition of the blood; contraction of all the abdominal viscera; hurried respiration; great prostration and nervous debility; lameness; followed by gangrene of the extremity of the tail, and the hind-feet; terminating in . mortification and death."

Mr. Pierce is convinced that these symptoms are produced by the continued use of the ergot, or spur of the June grass,the effects being similar to those produced upon the human family by long-continued use of ergot of rye. This disease assumes both an acute and chronic form.

The same gentleman also says: "Ordinary observers, as well as those who claim to be scientific, have entertained very conflicting opinions as to its general character; some regarding it as epizoötic, others as contagious; some attributing it to atmospheric influence, others to foulings in the stable or yard. Others, again, attribute it to freezing of the feet in winter. Cattle-doctors in a majority of cases, fail to cure it I have, however, by a simple course of treatment, effected 
many signal cures. Some parties are so confident of the contagious character of the disease that they refuse to drive cattle along a road where it is known to exist. They even, oftentimes, wash their boots previous to entering their barnyards, after walking over the ground where such diseased cattle have been running.

"Caution is both proper and commendable. I do not, however, regard it as a contagious disease, nor can it be transmitted by inoculation. The calf is carried during the progress of the disease, and delivered in apparently good health. The milk of the cow appears to be unaffected and harmless. I call this disease sphacial fever, or gangrenous fever.

"The ergot, or spur of the hay, is confined to the June grass, as far as my observation extends; owing, probably, to its early

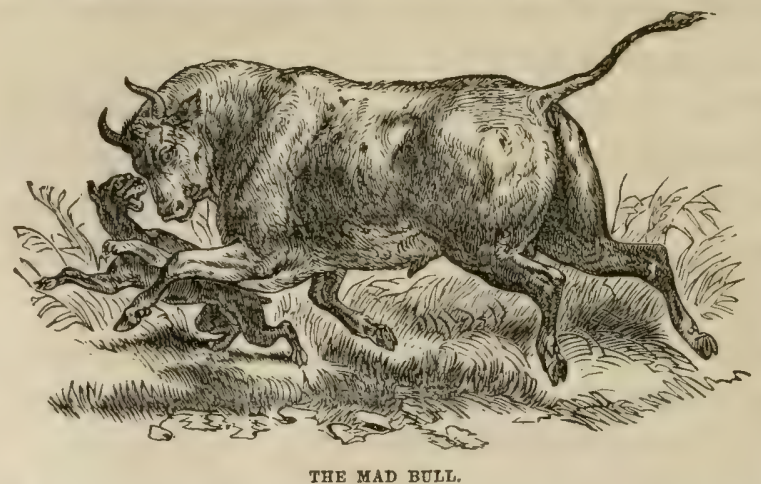

maturit $y$. M o s t other $\mathrm{kinds}$ of grass are cut before $t \mathrm{~h} e$ s e e d s have matured sufficiently to produce the spur. I was suspicious of the foulness of the feed before I examined any hay, and have found the spur in the hay wherever the diesase is found.

"Mr. Sanford, of Edinburgh, Ohio, purchased one half of 
a mow of hay from Mr. Bassett, of Randolph, which was removed to his farm in Randolph, eight miles distant. Of this hay, Mr. Sanford fed eleven cows some six or eight weeks. Mr. Bassett had been feeding the same to four cows. At about the same time, both heads began to show lameness. I visited Mr. S. after he had lost six cows, and examined the remaining five, four of which were lame and the other showed symptoms of the disease. He had two other cows, one of which was loaned to a neighbor, and the other was fed upon different hay, for convenience. The loaned cow was returned about the first of March,ning with the ailing ones until the 24th of April, when I saw them sound and in good health.

“I then visited Mr. Bassett's stock, which $I$ found infected with the same disease,-he having lost one, and the remaining three being lame, and much debilitated. The hoofs were sloughing off. Some of the same hay remained in the snow, which, upon examination, exhibited an abundance of the spur. Upon inquiry, I found that no such disease existed between the two farms, or in the neighborhood of either Mr. S. or Mr. B. The peculiarity of this circumstance at once swept away the last vestige of doubt from my mind. Mr. E. Chapman, of Rootstown, accompanied me, and can vouch for the correctness of these statements.

"He hooted at my opinions, asserting that he understood the disease, and that it was caused by the freezing of the feet. He has since, however, abandoned that, idea, and bonestiy 'acknowledged the corn.' This ergot is regarded by some as a parasitic fungus, formed in other grains, an abundant vegeto-animal substauce, and much disposed to putrefac- 
tion. We appear to be in the dark regarding its real composition. The little which has been written upon the subject, appears to be founded upon hypothesis, and that the most obscure. The articles to which I refer may differ in quality or property to a considerable extent, and we may forever remain in the dark, unless chemical investigation be instituted.

"In this particular disease, there appears to be singularity in the symptoms through all its various stages, which is likely to originate in the peculiarity of the cause which produces them. The effects and symptoms arising from the continued use of the ergot of rye, as manifested in the human system, have been but briefly hinted at by authors, and, probably, some of them are only reasonable conjectures. All they say is, that it produces violent headache, spaculation in the extremities, and death. Hitherto, its effects upon the inferior animal have been subjected to no investigation, and its peculiarity in the symptoms, differing from like phenonema by other causes, may yet be demonstrated. I am not alone in my opinion of this disease. I have taken counsel of those whose judgment cannot be questioned. Whatever difference of opinion exists is attributable to a want of investigation, and it will continue to exist until this singular phenonemon is clearly accounted for. Every opinion should be thoroughly criticized till facts are obtained. Every man's opinion is sacred to himself, but we should yield to conviction.

"Two classes of this disease are exhibited: one, of irritation, and the other, of debility; one, an acute, the other, a chronic form. The point at which it assumes the chronic 
form is between conjestion and gangrene. By close observation we can discover these to be different and higher degrees of the same disease. All subsequent degrees are dependent upon the first.

"The first symptom, or degree, is, probably, an attack upon the systematic circulation, produced by a certain medicinal and deleterious property existing in the ergot, and communicated to the blood through the absorption of the tongue. 'This is more evident from the fact that the digestive organs retain their normal condition till the last stages of the chronic form. The blood in the first two stages is healthy, and the peculiar influence is only apparent in the subsequent stages; as evidenced by the fact that the muscles and general good appearance, as well as life itself, last longer than could be possible, if this deleterious influence were exhausted upon the digestive organs and the blood, in its first stages. And, as we suppose that fever and congestion constitute an attack upon the red blood, which is exhibited by hurried pulsation, we might rationally infer that the next degree would be gangrene of the globule, causing sloughing, the same as if it were carried to the muscles, or surface. This sloughing of the globule would be the same as if exhibited on any other part of the organization, for the fibrin is identical with muscle, as albumen is identical with the white of an egg; and since congestion is the forerunner of gangrene at the extremities, or on the surface, so fever and quick pulsation are the forerunners of congestion of the blood. Gangrene cannot ensue without obstruction in the blood-vessels; and congestion cannot take place without obstruction in that which sustains the globule. As gangrene, 
then, is the first stage of decomposition of animal matter, so is congestion the first stage of decomposition of the globule; and as mortification is death in the organized body, so is congestion death in the organized globule.

"It appears evident that this disease, in all its forms and degrees of intensity, seeks vent or release; in other words, Nature conflicting with it, throws it off its track, or balance, and offers means of escape, or shows it a door by which it may make its exit. In the first stage of the disease, the dermoid (skin) tissues make the effort. In the inflammatory, the serous, and the congestive, the mucous gangrene seeks vent; if obtained, mortification is prevented; if not, mortifsation directly supervenes, and death terminates the case.

"In the case to which I refer, observation confirms my opinion that absolute mortification without vent determines the gangrene of the blood, and is hardly curable; but that gangrene's finding vent determines it to be curable, and the "ecovery highly probable."

\section{EPIZOÖTIC CATARRH.}

Catarrh frequently assumes an epizoötic form of a very virulent character, originating spontaneously and extending over a large section of country at or about the same time A cold spring succeeding a mild winter, is peculiarly productive of malignant catarrh. This is one of the most distressing and fatal diseases to which cattle are subject.

Symptoms.-The animal appears dull, and unwilling to move about, staggering when forced to do so; obstinate :ostiveness is usually one of the earliest symptoms, succeeded by diarrhœe, which is equally difficult of management; some- 
times, however, diarrhœa is present from the first; tne animal loses flesh rapidly; the coat is staring; appetite is lost; tumors form about the head, neck, back, and joints, which appear to be filled with air, and upon pressure cause a crepitating sound; saliva flows from the mouth, becoming very fetid as the disease progresses. The animal always dies of putrefaction.

Treatment.-This disease should be treated early, or not at all. Good nursing is very essential. When costiveness is present, give Barbadoes aloes, one ounce; croton-oil, ten drops; mix together; or give one pint of linseed-oil, to which add from ten to twenty drops of castor-oil. If the bowels are not open in twenty-four hours, give four ounces of sulphate of magnesia every six hours until they are opened. Follow this with tincture of aconite, ten drops in water, cvery four hours, until the fever has abated.

Bleeding has been recommended by some writers; but the author has failed to experience any benefit from resorting to it, but, on the contrary, has seen much injury resuit from the use-or, rather, the abuse-of the lancet. He is, indeed, inclined to attribute much of the fatality attending this disease to indiscriminate blood-letting.

When much debility exists, the animal should be sustained by tonics and stimulants. One ounce of nitric ether and half an ounce of tincture of opium, given in a little water, will b found beneficial. It should be given twice a day. Pulverized gentian-root, one ounce; Jamaica ginger, half an ounce; pulverized cloves, half an ounce; mixed, and divided into four powders, one to be given at night and at morning; will be found useful, in place of the opium and ether. 


\section{FARDEL。}

This disease is properly known by the name of clue-bound. The manyplus, or omasum (third stomach), frequently becomes so choked up with food that it is hard and dry, and the operation of the digestive organs is very seriously impaired. The animal eats voraciously, for a time, but stops suddenly and trembles; the countenance assumes a peculiarly haggard appearance; there is a wild expression of the eye; a foaming at the mouth; a tendency to pitch forward, and at times a falling head-foremost to the gromd. Occasionally, the symptoms are very active, speedily terminating in death. There are few diseases of a constitutional character in which the stomach is not, more or less, sympathetically involved.

"Toward the end of September, 1746, a great number of cows died at Osterwich, in the principality of Halberstadt. Lieberkuhn, a celebrated physician,-there were no veterinary surgeons at that time,-was sent to examine into the nature of the disease, which was supposed to be one of the species of murrain that was then committing such ravages among the cattle in various parts of the Continent. There were none of the tumors, or pestilential buboes, that, in an earlier or later period of the malady, usually accompanied and characterized murrain; but upon inspection of the dead bodies, considerable peritoneal inflammation was found; the first and second stomachs were filled with food, but the third stomach was the palpable seat of the disease; its leaves were black and gangrened. The mass contained between the leaves was black, dry, and so hard that it could scarcely be cut with a scalpel. It intercepted the passage of the food 
from the first two stomachs to the fourth; and this latter stomach was empty and much inflamed. Neither the heart, nor the lungs, nor the intestines exhibited any trace of disease. Twelve cows were opened, and the appearanes were nearly the same in all of them."

Treatment.-Give one and a half pounds of Epsom-salts, dissolved in three pints of water; or one quart of potash, three times daily, dissolved in water, will be found useful in this disease

FOUL IN THE FOOT.

This is caused by hard or irritating substances making their way in between the claws of the foot, causing inflammation, and sometimes ulceration, in the parts. The pasterns swell, and the animal becomes lame.

The foot should be thoroughly washed, and all foreign substances removed. A pledget of tow, saturated with tar and sprinkled with powdered sulphate of copper, should be inserted between the claws. This usually requires but one or two applications.

\section{GARGET.}

This is a hard, knotty condition of the udder, which sometimes follows calving, in consequence of the sudden distention of the bag with milk; and the inflammation which supervenes causes a congealed or coagulated condition of the milk to take place, of which, if neglected, suppuration and abscesses are the result.

Treatment.-Let the calf suck the dam as speedily as possible, and, if the hardness is not then removed, foment 
the udder with warm water; after which, wipe it dry, and apply to the entire surface melted lard as hot as the animal will bear. This is, generally, all that is required, the most obstinate cases yielding to it. If abscesses form, they should ve lanced.

\section{GASTRO-ENTERITIS.}

This disease-otherwise known as wood-evil, or moor-illarises from eating the buds of oak, young ash, and other trees, which are of a very highly stimulating or irritating character. As the intestinal canal is liable to inflammatory action from irritant substances admitted into it, animals are lound to become diseased from eating too freely of these vegetable substances.

Symploms. - Loss of appetite and suspended rumination; mouth hot; skin dry; pulse from sixty to seventy; swelling and pain of the belly; obstinate constipation; fæces hard and covered with blood; urine of a strong odor, highly colored, and voided with difficulty.

Treatment.-The animal should be bled, and a strong purgative administered, followed by aconite and belladonna, as in enteritis. Injections of Castile-soap and water should be freely used; the application of the mustard, hartshorn, and water to the belly will alsc be found very beneficial.

\section{HOOSE.}

This disease-known also as catarrh-is occasionally tho sequence of coryza, but more frequently it arises from an impure atmosphere; consequently, in cow-houses where animals are crowded together in numbers, it is most frequently 
found. Scanty provender, and of an inferior quality, is among the exciting causes of hoose, producing, as it does, a debilitated state of the system, which, upon exposure of the animal to cold, or wet, hastens the disorder. Some breeds of cattle are peculiarly liable to this disease, which, if not arrested in its early stage, runs on, involving the lungs, and frequently terminating in consumption. Of all our domestic animals, neat cattle are most subject to pulmonary diseases. This is attributable to the neglect and exposure which are far too often their lot. Butchers will testify that a large portion of all cattle slaughtered have abscesses and other diseases of the lungs.

Symptoms.-I Loss of appetite; muzzle dry; coat rough, or staring; respiration quickened; horns hot; ears, nose, and legs cold; husky cough; pulse from sixty to seventy, small and thready; howels frequently constipated.

Treatment.-Give one ounce of the following powders every six hours, until the bowels are opened: Barbadoes aloes, one and half ounces; nitrate of potassa, half an ounce; ginger, six drachms; mix and divide into six powders. Setons in the dewlap are often of great benefit.

\section{HOOVE.}

Hoove, or blown, so common, and often so speedily fatal in cattle, is the result of fermentation in the rumen, or paunch, in consequence of the animal's having eaten large quantities of wet grass, luxuriant clover, turnips, etc. An accumulation of gas is the result of this fermentation, which greatly disturbs the baunch and left side of the belly, causing much pain to the animal, and frequently threatening suffocation. 
Treatment.-Drench the animal with one ounce of spirits of hartshorn in one quart of water, the object being to neutralize the gas which is present in the rumen; or, two ounces of table salt dissolved in one quart of water will be found very effectual. If these do not speedily give relief, an activ purge should be given. Injections of soap and water should be freely used. If the case still proves obstinate, and the life of the animal is threatened, the paunch should be punctured. For this purpose, the trochar-an instrument specially adapted-should be used; but, in the absence of an instrument, an ordinary pocket-knife may be employed, taking care not to make a large opening. The proper point to operate is midway between the last rib and the prominent point of the hip-bone, about twelve inches from the centre of the back or loins. Few cases have a fatal termination where this operation has been properly performed.

\section{HYPATIDS,}

Worms in the brain occasionally occur, causing great uneasiness to the animal and generally proving fatal.

The symptoms are, loss of appetite; suspended rumination; a fevered condition of the system; horns and ears hot; respiration disturbed; coat staring, etc. No course of treatment will prove efficacious in this disease.

Pressure on the brain may occur from an accumulation of water, tumors, bruises, etc., in the cranial case. In either case, the same effects are produced as are observed in apo. plexy. 


\section{INFLAMMATION OF THE BLADDER.}

Inflammation of the bladder generally accompanies inflammation of the kidneys, though it is sometimes found disconnected and alone. It is occasionally caused by calculous concretions in the bladder,-which should be removed,causing very acute abdominal pain to the animal. She makes frequent efforts to stale, passing but a few drops of urine at a time. The pulse is full and rapid; mouth clammy ; nose dry ; eyes bloodshot; appetite lost; moaning, and walking with a staggering gait.

Treatment.-Inject into the bladder one quart of tepid water, and from one to two ounces of tincture of opium mixed together. Give internally one of the following powders every hour until relieved; nitrate of potassa, one ounce; tartrate of antimony, and pulverized digitalis leaves, each one drachm; mix, and divide into six powders. Mucilaginous draughts should be freely given.

Rupture of the bladder sometimes occurs, but there are no symptoms by which it may be known; and, if there were, no service could be rendered in the way of repairing the injury; - the animal must die.

\section{INFLAMMATION OF TRE HAW.}

The ox, like the horse, has a membrane of semilunar form in the inner corner of the eye, which is capable of being thrown over the entire eyeball, for the purpose of cleansing the eye from any foreign substance which may get into it. This membrane is commonly called the haw, and is suscepti- 
ble of attacks of inflammation, which cause it to swell, frequently even closing up the eye.

Treatment.-Give a dose of physic, and, if the animal is plethoric, extract a little blood from the vein on the same side as the affected eye. Apply to the eye either of the following washes : tincture of opium, one ounce; rain-water, one pint; or, tincture of aconite, one drachm, to one pint of water. Bathe two or three times a day.

\section{INELAMMATION OF THE KIDNEYS.}

This disease-sometimes called nephritis-occurs occasionally in cattle in consequence of their eating bad or unwholesome food, or of the abuse of diureties, etc.

The symptoms are very insidious in their approach. The loins are very tender upon pressure; the urine is voided in small quantities. As the disease advances, the symptoms become more marked and acute. The animal is dull, and feeds daintily; the evacuation of urine is attended with increased pain, and the urine is highly colored and bloody; the nose is dry; the horns, ears, and extremities are cold; respization burried; the pulse full, hard, and throbbing.

Treatment.-Give one pint of linseed-oil and ten drops of castor-nil, mixed together; follow this with small doses of salts once a day, for three or four days; give injections of water, one half a gallon to two ounces of tincture of arnica. Mustard applications to the loins are also very useful.

\section{INFLAMMATION OF THE LIVER.}

Discases of the liver are of very common occurrence,-a fact with which all beef-butchers are familiar. Perhaps no 
organ in the animal economy is so liable to disease. The obscurity of the symptoms and the good condition of the animal prevent its discovery, as a general thing, during its lifetime. When, however, the disease assumes an active form,-known as the yellows, jaundice, or inflammation of the liver,-the symptoms are more readily detected.

Symptoms.-A yellowish color of the eye will be observed; skin, urine, etc., highly colored; soreness, on pressure, on the right side; loss of appetite; dullness; constipation of the bowels, etc.

Treatment.-Calomel is the most reliable medicine known to practitioners for diseases of the liver. Its abuse, however, has brought it into disrepute. Yet, as with ordinary care it may be advantageously used, we will prescribe it as that upon which the most dependence is to be placed, and in doing so, will endearor to have it used safely. Bleeding. has been recommended: but the author has never found any benefit resulting. Give Epsom-salts, in doses of four ounces each, every night, with one scruple of calomel, antil the animal is relieved. Mustard and water should be frequently applied to the right side, and well rubbed in.

\section{IARYNGITIS.}

This disease is of rare occurrence in cattle. In it, the mucous membrane lining the larynx is in a very irritable condition; the least pressure upon the parts affected causes intensely excruciating pain; the respiration becomes quick, painful, and laborious; the animal often appears to be hungry, yet does not eat much, in consequence of the pain occasioned by the act of swallowing. 
Treatment.-Apply to the throat externally strong mustard, mixed, with equal parts of aqua ammonia and water, to a tlin

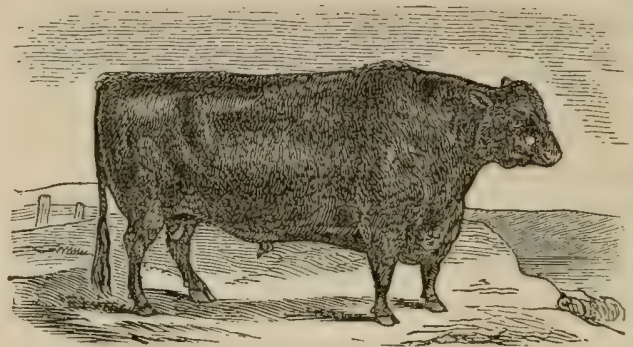

AN ABERDERNSHIRE POLLED BULL.

paste, every hour, until it produces an effect upon the skin; sponging the parts each time with warm water before applying the mustard. The animal should not be bled. Give upon the tongue, or in drink, half-drachm doses of nitrate of potassa, every three or four hours, until relief is obtained. If suffocation threatens, the operation of tracheotomy is the only resort.

Cloths saturated with cold water, wrapped around the neck so as to cover the larynx, frequently afford relief. A purgative will also be found useful.

\section{IICE.}

Cattle are very subject to lice, particularly when they are neglected, half-starved, and in poor condition. Good care and good feeding-in connection with the treatment recommended in mange, to which the reader is referred-will comprise all that is requisite.

\section{MANGE.}

Mange, or leprosy, is one of the most unpleasant and diffcult diseases to manage of all the ailments to which cattle are subject requiring the nicest eare and attention to render 
it easy of cure. An auimal badly nursed will not, under the most skillful treatment, quickly recover. Its causes are, in the main, due to poor food, which produces a debilitated condition of the system, and in connection with a want of cleanliness, causes a development of the acari, or minuto insects, exciting very great irritation upon the skin and causing the cow to rub herself against every object with which she comes in contact. The hair falls off; a scurfy appearance of the skin is perceptible; and the animal is poor in condition and in milk. The great trouble in treating this disease springs from its contagious character; for, no sooner is the animal, oftentimes, once free from the acari than it comes in contact with some object against which it has previously been rubbing, when the acari which were left upon that object are again brought in contact with the animal, and the disease is reproduced. If, immediately after the proper applications are made, the animal is removed to other quarters, and not allowed to return to the former ones for six or eight weeks, there is, generally speaking, but little trouble in treating the disease.

Take the animal upon a warm, sunny day, and with a scrubbing-brush cleanse the skin thoroughly with Castilesoap and water; when dry, apply in the same manner the following mixture; white hellebore, one ounce; sulphur flower, three ounces; gas-water, one quart; mix all well together. One or two applications are, generally, all that will be required. Give internally one of the following powders in the feed, right and morning: flowers of sulphur, two ounces; black antimony, one ounce; nitrate of potassa, one ounce; mix, and divide into eight powders. 


\section{MURRAIN.}

This is one of the most malignant diseases to which cattle are liable. Fortunately, however, true murrain is comparatively rare in this great stock-raising country.

The entire system seems to partake of the disease. The first indication of its approach is a feverish condition of the system, attended with a frequent and painful cough; the pulse is small, hard, and rapid. As the disease advances, the respiration becomes disturbed; the flanks heave; vesicular eruption is observed upon the teats, mouth, and feet; the horns are cold; the animal is sometimes lame; constipation and, sometimes, diarrhœa are accompanying symptoms; foces black and fetid; the eyes weep and become much swollen; great tenderness along the spine; a brown or bloody discharge from the nose and mouth; the animal moans incessantly, grinds his teeth, rarely lies down, but to get up again quickly; finally, the breath becomes very offensive ; tumors make their appearance in various parts of the body, which, in favorable cases, suppurate, and discharge a fetid matter.

Treatment.-Give one fourth of a pound of Epsom-salts, with one drachm of Jamaica ginger, twice a day, for two or three days. A bottle of porter, twice a day, will be found serviceable. Very little medicine is required internally in this disease, but much depends upon good nursing. External applications are chiefly to be depended upon. A solution of chloride of lime should be applied to the eruptions, or a solution of the chloride of zinc, twenty grains to an ounce of water; or, of sulphate of zinc, two drachms to a 
pint of water; or pulverized charcoal applied to the parts will be found useful.

\section{NAVEL-ILL.}

Inflammation of the navel in calves occasionally occurs, causing redness, pain, and sudden swelling in the part affected. This disease, if not promptly attended to, speedily carries off the creature.

Treatment.-Foment the part well with warm hop-tea; after which, the application of a cloth, well saturated with lead-water and secured by bandages, should be applied. Internally, doses of Epsom-salts, of two ounces each, dissolved in half a pint of water, should be given until the bowels are acted upon. After the inflammation has subsided, to counteract the weakness which may. follow, give a bottle of porter two or three times a day.

\section{OBSTRUCTIONS IN THE GSOPHAGUS.}

Choking in cattle is of common occurrence, in consequence of turnips, potatoes, carrots, or other liard substances, becoming lodged in the œsophagus, or gullet.

These obstructions can sometimes be removed by careful manipulations with the hand; but, where this can not be accomplished, the flexible probang should be employed. This is a long India-rubber tube, with a whalebone stillet running through it, so as to stiffen it when in use. This instrument is passed down the animal's throat, and the offending substance is thus pushed down into the stomach. 


\section{OPEN JOINTS.}

Opening of the joint generally results from accidents, from puncturing with sharp substances, from kicks, blows, etc. These injuries cause considerable nervous irritation in the system, and sometimes cause lock-jaw and death.

Treatment.-Close up the wound as speedily as possible. The firing-iron will sometimes answer the purpose very well. The author depends more upon the application of collodionas recommended in his work upon "The Horse and His Diseases" for the same trouble-than upon any other remedy. It requires care in its application, in order to make it adhere firmly. Shoemakers'-wax, melted and applied, answers a very good purpose.

\section{PARTURITION.}

In natural labor-as has been suggested in a former part of this work-the aid of man is rarely required in bringing away the calf. But it not infrequently happens that, from malformation or wrong presentation, our assistance is required in order to deliver the animal.

The brute force, which has been far too often heretofore resorted to, should no longer be tolerated, since the lives of many valuable animals have been sacrificed by such treatment. Very often, by gentle manipulation with the greased hand, the womb can be so dilated as to afford a comparatively easy exit for the foetus.

If, however, the calf is presented wrong, it must be pushed back and placed in its proper position, if possible. In natural labor, the fore-legs, with the head lying between 
them, are presented; in which position-unless deformity, either in the pelvis of the cow, or in the foetus, exists-the calf is passed with little difficulty, and without assistance. It sometimes happens that the head of the fotus is turned backward. When this happens, the attendant should at once strip himself to the waist, bathe his arms and hands with a little sweet-oil, or lard, and introduce them into the vagina, placing a cord around both fore-feet, and then, pushing them back, search for the head, which is to be brought forward to its proper position. The feet are next to be brought up with it. No force should be used, except when the cow herself makes the effort to expel the calf; otherwise, more harm than good may be done.

A case of this kind recently occurred in the author's practice, being the third within a year. The subject was a cow belonging to William Hance, Esq., of Bordentown, New Jersey. After she had been in labor for some twenty hours, he was called upon to see her. Upon inquiry, he found that several persons had been trying, without success, to relieve her. She was very much prostrated, and would, doubtless, have died within two or three hours, had no relief been afforded. The legs of the foetus protruded as far as the linees; the head was turned backward, and with the body, pressed firmly into the vagina, so that it was impossible to return it, or to bring the head forward. The operation of embryotomy was, therefore, at once performed, by cutting away the right shoulder, which enabled the operator, with the aid of his appropriate hooks, to bring the head forward, when the calf came away without further trouble,- - the whole operation not requiring fifteen minutes. The uterus was 
then washed out, and the animal placed in as comfortable a position as possible, and a stimulating draught given, composed of two ounces of nitric ether, one ounce of tincture of opium, and a half pint of water. This was followed with a few doses of Fleming's tincture of aconite, ten drops in a little water, every few hours. In a few days the animal had entirely recovered.

Occasionally, the head comes first, or the head and one leg. In such cases, a cord should be slipped around the jaw and leg, and these then pushed back, so as to allow the other leg to be brought up. When this cannot be done, the foetus can, in most cases, be removed in the original position.

Breech, side, back, and other presentations sometimes occur; in all of which instances, the foetus must be turned in such a position that it can be brought away with as little trouble as possible. When this cannot be accomplished, the only resort is embryotomy, or cutting up of the fœtus, which operation can only be safely performed by the qualified veterinary surgeon.

Since writing the above, another case has occurred in the author's practice. The cow-belonging to Samuel Barton, Esq., near Bordentown, New Jersey-had been in labor some eighteen hours; upon an examination of the animal, the calf was found to be very much deformed, presenting backwards,-one of the hind-legs having been pulled off by the person or persons assisting her previous to the author's arrival. Finding it impossible to deliver her in the usual way, emrbyotomy was in this instance employed. By this means, after taking out the intestines, lungs, etc., of the foetus, and cutting away its hind-quarters, the fore-parts 
were brought away. The head presented a singular appearance; the under jaw was so trvisted as to bring the front teeth on the side of the face; the spinal column or backbone, was turned twice around, resembling a spiral string; the front legs were over the back; the ribs were much contorted; the hind-parts were as much deformed; and, taken altogether, the deformity was the most singular which has been brought under the author's observation.

Free Martins. - It has long been supposed by stockbreeders, that if a cow produce twins, one of which is a male and the other a female, the female is incapable of producing young, but that the male may be a useful animal for breeding purposes. Many instances have occurred when the twin sister of a bull has never shown the least desire for the male.

This indifference to sexual commerce arises, doubtless, from the animal's being but imperfectly developed in the organs of generation. This fact has been established by the investigations of Mr. John Hunter, who had three of these animals slaughtered for anatomical examination. The result is thus reported: "The external parts were rather" smaller than is customary in the cow. The vagina passed on, as in the cow, to the opening of the urethra, and then it began to contract into a small canal, which passed on into the division of the uterus into the two horns; each horn passed along the edge of the broad ligament laterally toward the ovaria.

"At the termination of these horns were placed both the ovaries and the testicles. Both were nearly of the same size, which was about as large as a small nutmeg. T'o the ovaria, I could not find any Fallopian tube. 
"To the testicles were vasa deferentia, but they were imperfect. The left one did not come near the testicle; the right one only came close to it, but did not terminate in the body called the epididymis. They were both pervious and pened into the vagina, near the opening of the urethra.

"On the posterior surface of the bladder, or between the uterus and the bladder, were the two bags, called vesiculoe seminales in the male, but much smaller than they are in the bull. The ducts opened along with the vasa deferentia. This animal, then, had a mixture of all the parts, but all of them were imperfect."

Well-authenticated cases have, however, occurred where. the female has bred, and the offspring proved to be good milkers. There are several instances on record of cows' giving birth to three, four, and even five calves at a time. There were on exhibition, in 1862, at Bordentown, New Jersey, three free martins, two sisters and a brother, which were beautiful animals. These were from a cow belonging to Mr. Joab Mershon, residing on Biles Island, situated in the Delaware River, a short distance above Bordentown. They were calved November 1st, 185s, and were therefore nearly four years of age. They had never shown the least desire for copulation. Their aggregate weight was 4300 pounds.

We extract the following from the London Veterinarian, for 1554:- "A cow, belonging to Mr. John Marshall, of Repton, on Wednesday last, gave birth to five, live healthy calves, all of which are, at the time I write, alive and vigorous, and have every appearance of continuing so. They are all nearly of a size, and are larger and stronger than could be supposed. Four of them are bull-calves. 
"The dam is by no means a large one, is eleven years old, of a mongrel breed, and has never produced more than one offspring at any previous gestation. I saw her two days after she had calved, at which time she was ruminating, and did not manifest any unusual symptoms of exhaustion. I may mention that the first four calves presented naturally; the fifth was a breech-presentation."

Cleansing.-The placenta, or after-birth, by which the foetus is nourished while in embryo, should be removed soon after calving. Generally, it will come away without any assistance. This is what is called "cleansing after calving."

- When, however, it remains for some time, its function having been performed, it becomes a foreign body, exciting uterine contractions, and therefore injurious. The sooner, then, it is removed, the better for the animal as well as the owner. To accomplish this, the hand should be introduced, ancl, by pulling gently in various directions, it will soon yield and come away. Should it be allowed to remain, it rapidly decomposes, producing a low, feverish condition of the system, which greatly interferes with the general health of the animal.

INVERSION OF THE UTERUs. - The uterus is sometimes turned inside out after calving. This is, generally, the result of debility, or severe labor. The uterus should be replaced as carefully as possible with the hands, care being taken that no dirt, straw, or other foreign substance adheres to it. Should it again be expelled, it would be advisable to quiet the system

- by the use of an anæsthetic, as chloroform, or-which is much safer-chloric ether. As soon as the animal is under the influence of this, the uterus may be again replaced. The 
hind-quarters should be raised as high as possible, in order to favor its retention.' The animal should have a little gruel and a bottle of porter given to her every five or six hours, and the vulva should be bathed frequently with cold water.

\section{PHRENITIS.}

Inflammation of the brain is one of those dreadful diseases to which all animals are liable. It is known to the farmer as frenzy, mad staggers, etc.

The active symptoms are preceded by stupor; the animal stubbornly stands in one position; the eyes are full, red, and fiery ; respiration rapid; delirium soon succeeds; the animal, . bellowing, dashes wildly about, and seems bent on mischief, rushing madly at every object which comes in its way.

The causes of this disease are overwork in warm weather, a plethoric condition of the system, and too stimulating food. Prof. Gamgee, of the Edinburgh Veterinary College, relates a case resulting from the presence within the external meatus of a mass of concrete cerumen, or wax, which induced inflammation of the ear, extending to the brain.

Treatment.-As this is attended with considerable risk, unless it is taken prior to the frenzied stage, bleeding almost to fainting should be resorted to, and followed by a brisk purge. Take one ounce of Barbadoes aloes, and ten to fifteen drops of Croton-oil ; mix the aloes with one pint of water and the oil, using the mixture as a drench. One pound of Epsomsalts will answer the purpose very well, in cases where the aloes and oil cannot be readily obtained. Application of bags of broken ice to the head, is very beneficial. Spirits of turpentine, or mustard, together with spirits of hartshorn and 
water should be well rubbed in along the spine, from the neck to the tail.

\section{PLEURISY.}

This is an inflammation of the pleura, or the serous membrane which lines the carity of the chest, and which is deflected over the lungs. Inflammation of this membrane rarely occurs in a pure form, but is more generally associated with inflammation of the tissue of the lungs. If this disease is not attended to at an early period, its usual termination is in hydrothorax, or dropsy of the chest. The same causes which produce inflammation of the lungs, of the bronchia, and of the other respiratory organs, produce also pleurisy.

Symptoms.-The respiration is quick, short, and painful; pressure between the ribs produces much pain; a low, short, painful cough is present; the respiratory murmur is much diminished,-in fact, it is scarcely audible. This condition is rapidly followed by effusion, which may be detected from the dullness of the sounds, on applying the ear to the lower part of the lungs. The febrile symptoms disappear; the animal for a few days appears to improve, but soon becomes weak, languid, and often exhausted from the slightest exertion.

Treatment.-The same treatment in the early stage is enjoined as in inflammatory pneumonia, which the reader will consult_counter-irritation and purgatives. Bleeding never should be resorted to. When effusion takes place, it is necessary to puncture the sides with a trochar, and draw away the fluid, giving internally one of the following purges three times a day : rosin, eight ounces; saltpetre, two ounces: mix, and divide into eight powders. Half-drachm doses of 
the iodide of potash, dissolved in water, to be given three times daily, will be found useful in this disease.

\section{PLEURO-PNEUMONIA.}

This disease, as its name implies, is an inflammatory condition of the lungs and the pleura, or the enveloping membrane of the lungs and the lining membrane of the chest. It is sometimes called contagious, infectious, and epizoötic pleuro-pnoumonia,-contagious or infectious, from its supposed property of transmission from the diseased to the healthy animal.

$\Lambda$ contagious character the author is not ready to assign to it,-contagious, as he understands it, heing strictly applicable to those diseases which depend upon actual contact with the poison that it may be communicated from one animal to

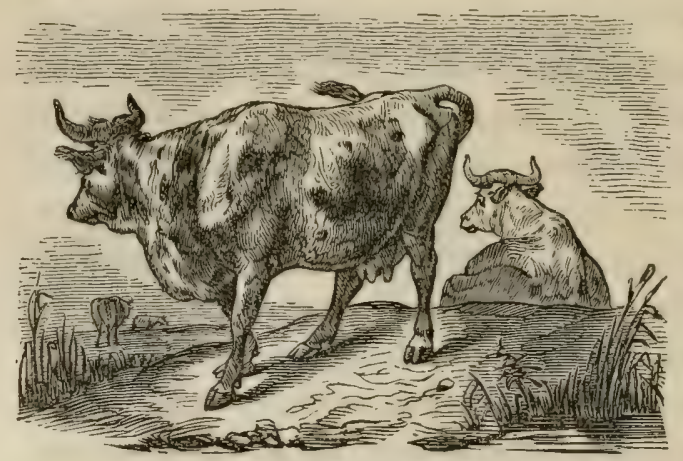

TAKING AN OBSERVATLON. another. This does not necessarily imply the actual touching of the animals themselves; for it may be c o m m u n i cated from the poison left in the trough, or other places where the diseased animal has been brought in contact with some object, as is often the case in glanders in the horse; the matter discharged from the nose, and left upon the manger, readily communicating 
that disease to healthy animals coming in contact with it. Contagious diseases, therefore, travel very slowly, starting, as they do, at one point, and gradually spreading over a iarge district, or section of country.

This disease is, however, regarded by the author as infectious; by which term is meant that it is capable of being communicated from the diseased to the healthy animal through the medium of the air, which has become contaminated by the exhalations of poisonous matter. The ability to inoculate other animals in this way is necessarily confined to a limited space, sometimes not extending more than a few yards. Infectious diseases, accordingly, spread with more rapidity than contagious ones, and are, consequently, more to be dreaded; since we can avoid the one with comparatively little trouble, while the other often steals upon us when we regard ourselves as beyond its influence, carrying death and destruction in its course.

The term by which this disease is known, is a misnomer. Pleuro-pneumonia proper is neither a contagious, nor an infectious disease; hence, the denial of medical men that this so-called pleuro-pneumonia is a contagious, or infectious disease, has been the means of unnecessarily exposing many animals to its poisonous influence.

In the Recuéil de Médécine Vétérinaire, for 1833, will be found a very interesting description of this fatal malady. The author, M. Lecoy, Assistant Professor at the Veterinary School of Lyons, France, says: "There are few districts in the arrondissement of Avesnes where more cattle are fattened than in that of Soire-le-Chateau. The farmers being unable to obtain a sufficient supply of cattle in the district, are 17 
obliged to purchase the greater part of them from other provinces; and they procure a great number for grazing from Franche Comté. The cattle of this country are very handsome; their forms are compact; they fatten rapidly; and they are a kind of cattle from which the grazer would derive most advantage, were it not that certain diseases alssorb, by the loss of some of the animals, the profits of the rest of the herd. Amongst the diseases which most frequently attack the cattle which are brought from the North, there is one very prevalent in some years, and which is the more to be dreaded as it is generally incurable; and the slaughter of the animal, before he is perceptibly wasted, is the only means by which the farmer can avoid losing the whole value of the beast.

"This disease is chronic pleuro-pneumonia. The symptoms are scarcely recognizable at first, and often the beast is ill for a long time without its being perceived. He fattens well, and when he is slaughtered the owner is astonished to find scarcely half of the lungs capable of discharging the function of respiration. When, however, the ox has not sufficient strength of constitution to resist the ravages of disease, the first symptom which is observed is diminution, or irregularity of appetite. Soon afterwards, a frequent, dry cough is heard, which becomes feeble and painful as the disease proceeds. The dorso-lumbar portion of the spine (loins) grows tender; the animal flinches when the part is pressed upon, and utters a peculiar groan, or grunt, which the graziers regard as decisive of the malady.

"Quickly after this, the movements of the flanks become irregular and accelerated, and the act of respiration is accom- 
panied by a kind of balancing motion of the whole body. The sides of the chest become as tender as the loins, or more so; for the animal immediately throws himself down, if pressed upon with any force. The elbows become, in many subjects, more and more separated from the sides of the chest. The pulse is smaller than natural, and not considerably increased. The muzzle is hot and dry, alternately. The animal lies down as in a bealthy state, but rumination is partially or entireiy suspended. The foces are harder than they should be; the urine is of its natural color and quantity; the mouth is often dry; and the horns and ears retain their natural temperature.

"This first stage of the disease sometimes continues diring a month, or more, and then, if the animal is to recover, or at least, apparently so, the symptoms gradually disappear. First of all, the appetite returns, and the beast begins to acquire a little flesh. The proprietor should then make haste and get rid of him; for it is very rare that the malady, however it may be palliated for a while, does not reuppear with greater intensity than before.

"In most cases, the disease continues to pursue its course toward its termination without any remission,-every symptom gradually increasing in intensity. The respiration becomes more painful; the head is more extended; the eyes are brilliant; every expiration is accompanied with a grunt, and by a kind of puckering of the angles of the lips; the cough becomes smaller, more suppressed, and more painful; the tongue protrudes from the mouth, and a frothy mucus is abundantly discharged; the breath becomes offensive; a purulent fluid of a bloody color escapes from the nostrils; 
diarrhœa, profuse and fetid, succeeds to the constipation; the animal becomes rapidly weaker; he is a complete skeleton, and at length he dies.

"Examination after death discloses slight traces of inflammation in the intestines, discoloration of the liver, and a hard, dry substance contained in the manyplus. The lungs adhere to the sides and to the diaphragm by numerous bands, evidently old and very firm. The substance of the lungs often presents a reddish-gray hepatization throughout almost its whole extent. At other times, there are tubercles in almost every state of hardness, and in that of suppuration. The portion of the lungs that is not hepatized is red, and gorged with blood. Besides the old adhesions, there are numerous ones of recent date. The pleura is not much reddened, but by its thickness in some points, its adhesion in others, and the effusion of a serous fluid, it proves how much and how long it has participated in the inflammatory action. The trachea and the bronchia are slightly red, and the right side of the head is gorged with blood.

"In a subject in which, during life, I could scarcely feel the beating of the heart, I found the whole of the left lobe of the lungs adhering to the sides, and completely, hepatized. In another, that had presented no sign of disease of the chest, and that for some days before his death vomited the little fodder which he could take, the whole of that portion of the œsophagus that passed through the chest was surrounded with dense false membranes, of a yellowish hue, ranging from light to dark, and being in some parts more than an inch in thickness, and adhering closely to the mus- 
cular membrane of the tube, without allowing any trace to be perceived of that portion of the mediastinal pleura on which this unnatural covering was fixed and developed.

"The cattle purchased in Franche Comté are brought to Avesnes at two periods of the year-in autumn and in the spring. Those which are brought in autumn are much more subject to the disease than those which have arrived in the spring; and it almost always happens that the years in which it shows itself most generally are those in which the weather was most unfavorable while the cattle were on the road. The journey is performed by two different routes,- through Lorraine and through Champagne,-and the disease frequently appears in cattle that have arrived by one of these routes. . The manner in which the beasts are treated, on their arrival, may contribute not a little to the development of the malady. These animals, which have been driven long distances in bad weather, and frequently half starved, arrived famished, and therefore the more fatigued, and some of them lame. Calculating on their ravenous appetite, the graziers, instead of giving them wholesome food, make them consume the worst that the farm contains,-musty and mouldy fodder; and it is usually by the cough, which the eating of such food necessarily produces, that the disease is discovered and first dereloped.

"Is chronic pleuro-pneumonia contagious? The farmers believe that it is, and I am partly of their opinion. When an animal falls sick in the pasture, the others, after his removal, go and smell at the grass where he has lain, and which he has covered with his saliva, and, after that, new cases succeed to the first. It is true that this fact is not 
conclusive, since the disease also appears in a great number of animals that have been widely separated from each other. But $I$ have myself seen three cases in which the cattle of the country, perfectly well before, have fallen ill, and died with the same symptoms, excepting that they have been more acute, after they have been kept with cattle affected with this disease. This circumstance inclines me to think that the disease is contagious; or, at least, that, in the progress of it, the breath infects the cow-house in which there are other animals already predisposed to the same disease. I am induced to believe that most of the serious internal diseases are communicated in this manner, and particularly those - which affect the organs of respiration, when the animals are shut up in close, low, and badly-ventilated cow-houses." [Rec. de Méd. Vét. Mai, 1833.]

No malady can be more terrible and ruinous than this among dairy-stock; and its spread all over the country, together with its continuance with scarcely any abatement, must be attributed to the combination of various causes. The chief are : first, the very contagious or infectious nature of the disorder; second, inattention on the part of Government to the importation and subsequent sale of diseased animals; and, third, the recklessness of purchasers of dairy or feeding cattle.

This disease may be defined as an acute inflammation of the organs of the chest, with the development of a peculiar and characteristic poison, which is the active element of infection or contagion. It is a disease peculiar to the cattle tribe, notwithstanding occasional assertions regarding observations of the disease among horses, sheep, and other 
animals,- which pretended observations have not been well attested.

The infectious, or contagious nature of this virulent malady is incontestibly substantiated by an overwhelming amount of evidence, which cannot be adduced at full length here, but which may be classified under the following heads : first, the constant spreading of the disease from countries in which it rages to others which, previously to the importation of diseased animals, had been perfectly free from it. This may be proved in the case of England, into which country it was carried in 1842, by affected animals from Holland. Twelve months after, it spread from England to Scotland, by means of some cattle sold at All-Hallow Fair, and it was only tivelve months afterward that cattle imported as far north as Inverness took the disease there. Lately, a cow taken from England to Australia was observed to be diseased upon landing, and the evil results were limited to her owner's stock. who gave the alarm, and ensured an effectual remedy against a wider spread. Besides, the recent importation of pleuropneumonia into the United States from Holland appears to have awakened our agricultural press generally, and to have convinced them of the stubborn fact that our cattle have been decimated by a fearfully infectious, through probably preventable, plague. A letter from this country to an English author says: "Its (pleuro-pneumonia's) contagious character seems to be settled beyond a doubt, though some of the V.S. practitioners deny it, which is almost as reasonable as it would be to deny any other well-authenticated historic fact. Every case of the disease is traceable to one of two sources; either to Mr. Chenery's stock in Belmont (near 
Boston, Massachusetts), into which the disease was introduced by his importation of four Dutch cows from Holland, which arrived here the $23 \mathrm{~d}$ of last May; or else to one of the three calves which he sold to a farmer in North Brookfield, Masachusetts, last June."

2dly. Apart from the importation into countries, we have this certain proof-to which special attention was drawn several years ago-that cattle-dealers' farms, and public markets, constitute the busy centres of infection. Most anxious and careful inquiries have established the proposition that in breeding-districts, where the proprietors of extensive dairies-as in Dumfries, Scotland, and other places-abstain from buying, except from their neighbors, who have never had diseases of the lungs amongst their stock, pleuro-pneumonia has not been seen. There is a wide district in the vicinity of Abington, England, and in the parish of Crawford, which has not been visited by this plague, with the exception of two farms, into which market-cattle had been imported and thus brought the disease.

$3 d l y$. In 1854 appeared a Report of the Researches on Pleuro-Pneumonia, by a scientific commission, instituted by the Minister of Agriculture in France. This very able pamphlet was edited by Prof. Bouley, of Alfort, France. The members of the commission belonged to the most eminent veterinarians and agriculturists in France. Magendie was President; Regnal, Secretary; besides Rayer, the renowned comparative pathologist; Yvart, the Inspector-General of the Imperial Veterinary Schools; Renault, Inspector of the Imperial Veterinary Schools; Delafond, Director of Alfort College; Bouley, Lassaigne, Baudemont, Doyére, Manny de 
Morny, and a few others representing the public. If such a commission were occasionally appointed in this country for similar purposes, how much light would be thrown on subjects of paramount importance to the agricultural community !

Conclusions arrived at by the commission are too important to be overlooked in this connection. The reader must peruse the Report itself, if he needs to satisfy himself as to the care taken in conducting the investigations: but the foregoing names sufficiently attest the indisputable nature of the facts alluded to.

In instituting its experiments, the commission had in view the solving of the following questions:-

Istly. Is the epizoötic pleuro-pneumonia of cattle suscepti. ble of being transmitted from diseased to healthy animals by cohabitation?

$2 d l y$. In the event of such contagion's existing, would ail the animals become affected, or what proportion would resist the disease?

3dly. Amongst the animals attacked by the disease, how many recover, and under what circumstances? How many succumb?

4thly. Are there any animals of the ox species decidedly free from any susceptibility of being affected from the contagion of pleuro-pneumonia?

5thly. Do the animals, which have been once affected by a mild form of the disease, enjoy immunity from subsequent attacks?

$6 t h l y$. Do the animals, which have once been affected by the disease in its active form, enjoy such immunity?

To determine these questions, the commission submitted 
at different tines to the influence of cohabitation with diseased animals forty-six perfectly healthy ones, chosen from districts in which they had never been exposed to a similar influence.

Of these forty-six animals, twenty were experimented on at Pomeraye, two at Charentonneau, thirteen at Alfort, and eleven, in the fourth experiment, at Charentonneau.

Of this number, twenty-one animals resisted the disease when first submitted to the influence of cohabitation, ten suffered slightly, and fifteen took the disease. Of the fifteen affected, four died, and eleven recovered. Consequently, the animals which apparently escaped the disease at the first trial amounted to 45.65 per cent, and those affected to 21.73 per cent. Of these, 23.91 per cent. recovered, and 8.69 per cent. died. But the external appearances in some instances proved deceptive, and six of the eleven animals of the last experiment, which were regarded as having escaped free, were found, on being destroyed, to bear distinct evidence of. having been affected. This, therefore, modifies the foregoing calculations, and the numbers should stand thus :-

15 enjoy immunity,

10 indisposed,

17 animals cured, 4 dead,

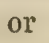

"

"

"

32.61 per cent.

21.73 "

36.95 "

8.98 "

Of the forty-two animals which were exposed in the first experiments at Pomeraye and Charentonneau, and which escaped either without becoming affected, or recovering, eighteen were submitted to a second trial; and of these eighteen animals, five had, in the first experiment, suffered from the disease and had recovered; five had now become affected: and four had been indisposed. The four animals 
submitted to the influence of contagion a third time, had been affected on the occasion of the first trial. None of the eighteen animals contracted the disease during these renewed exposures to the influence of contagion.

From the results of these experiments, the commission drew the following conclusions :-

1stly. The epizoötic pleuro-pneumonia is susceptible of being transmitted from diseased to healthy animals by cohabitation.

$2 d l y$. All the animals exposed do not take the disease; some suffer slightly, and others not at all.

$3 d l y$. Of the affected animals, some recover and others die. 4thly. The animals, whether slightly or severely affected, possess an immunity against subsequent attacks.

These are the general conclusions which the commission deemed themselves authorized to draw from their experiments. The absolute proportion of animals which become affected, or which escape the disease, or of those which die and which recover, as a general rule, cannot be deduced from the foregoing experiments, which, for such a purpose, are too limited. The commission simply state the numbers resulting from their experiments. From these it transpires that forty five of the animals became severely affected with pleuro. pneumonia, and twenty-one per cent. took the disease slightly, making the whole sixty-six per cent. which wer more or less severely attacked. Thirty-four per cent. remained free from any malady. The proportion of animals which re-acquired their wonted appearance of health amounted to eighty-three per cent., whereas serenteen per cent. dicd. Many minor points might be insisted on, but it is sufficient 
here to say, that the most careful analysis of all facts has proved to practical veterinarians, as well as to experienced agriculturists, and must prove to all who will calmly and dispassionately consider the point, that pleuro-pneumonia is pre-eminently an infectious, or contagious disease.

Symptoms.-From the time that an animal is exposed to the contagion to the first manifestation of symptoms, a certain period elapses. This is the period of incubation. It varies from a fortnight to forty days, or even several months. The first signs, proving that the animal has been seized, can scarcely be detected by any but a professional man; though, if a proprietor of cattle were extremely careful, and had pains-taking individuals about his stock, he would invariably notice a slight shiver as ushering in the disorder, which for several days, even after the shivering fit, would limit itself to

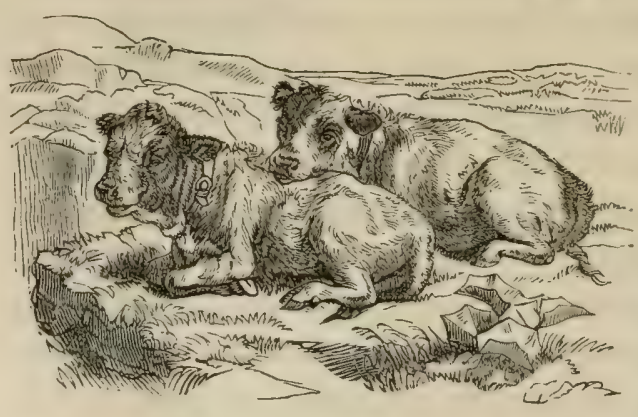

THE TWING.

slight interference in breathing, readily detected on auscultation. Perhaps a cough might be noticed, and that the appetite and milk-secretion

diminished. The animal becomes costive, and the shivering fits recur. The cough becomes more constant and oppressive; the pulse full and frequent, usually numbering about eighty per minute at first, and rising to upwards of one hundred. The temperature of the body rises, and all the symptoms of 
acute fever set in. A moan, or grunt, in the early part of the disease indicates a dangerous attack, and the alae nasi (cartilages of the nose) rise spasmodically at each inspiration; the air rushes through the inflamed windpipe and bronchial tubes, so as to produce a loud, coarse respiratory murmur; and the spasmodic action of the abdominal muscles indicates the difficulty the animal also experiences in the act of expiration. Pressure over the intercostal (between the ribs) spaces, and pressing on the spine, induce the pain so characteristic of pleurisy, and a deep moan not infrequently follows such an experiment. The eyes are bloodshot, mouth clammy, skin dry and tightly bound to the subcutaneous textures, and the urine is scanty and high-colored.

Upon auscultation, the characteristic dry, sonorous râle of ordinary bronchitis may be detected along the windpipe, and in the bronchial tubes. A loud sound of this description is, not infrequently, detected at the anterior part of either side of the chest; whilst the respiratory murmur is entirely lost, posteriorly, from consolidation of the lungs. A decided leathery, frictional sound is detected over a ionsiderable portion of the thoracic surface. As the disease advances, and gangrene, with the production of cavities in the lungs, ensues, loud, cavernous râles are heard, which are more or less circumscribed, occasionally attended by a decided metallic noise. When one lobe of the lungs is alone affected, the morbid sounds are confined to one side, and on the healthy side the respiratory murmur is uniformly louder all over.

By carefully auscultating diseased cows from day to day, interesting changes can be discovered during the animal's lifetime. Frequently, the abnormal sounds indicate progres- 
sive destruction; but, at other times, portions of the lungs that have been totally impervious to air, become the seat of sibilant râles, and gradually, a healthy respiratory murmur proves that, by absorption of the materials which have been plugging the tissues of the lungs, resolution is fast advancing. Some very remarkable cases of this description have been encountered in practice.

Unfortunately, we often find a rapid destruction of the tissues of the lungs, and speedy dissolution. In other instances, the general symptoms of hectic, or consumption, attend lingering cases, in which the temperature of the body becomes low, and the animal has a dainty appetite, or refuses all nourishment. It has a discharge from the eyes, and a fetid, sanious discharge from the nose. Not infrequently, it coughs up disorganized lung-tissue and putrid pus. Great prostration, and, indeed, typhus symptoms, set in. There is a fetid diarrhoa, and the animal sinks in the most emaciated state, often dying from suffocation, in consequence of the complete destruction of the respiratory structures.

Post mortem appearances.-In acute cases, the cadaverous lesions chiefly consist in abundant false membranes in the trachea, or windpipe, and closure of the bronchial tubes by plastic lymph. The air-vesicles are completely plugged by this material, and very interesting specimens may be obtained by careful dissection, in the shape of casts of the bronchial tubes and air-vesicles, clustered together like bunches of grapes. On slicing the lungs in these cases, hepatization is observed, presenting a very peculiar appearance, which is, in q great measure, due to the arrangement of the lung-tissue in rattle. The pulmonary lobules are of a deep-red or brown 
color, perfectly consolidated, and intersected or separated, one from the other, by.lighter streaks of yellowish-red lymph, occupying the interlobular, areolar tissue. In the more chronic cases, the diseased lobes and lobules are found partly separated from the more healthy structures.

This occurs from gangrene, and putrefactive changes, or in some instances, from the ulcerative process, so constantly observed in the segregation of dead from living tissues. Abscesses are not infrequently found in different parts of the lungs. Sometimes circumscribed, at others connected with bronchial tubes, and not infrequently communicating with the pleural cavity. True empyema is not often seen; but, at all times, the adhesions between the costal and visceral pleura are extensive, and there is much effusion in the chest. In dressed carcasses of cows that have been slaughtered from pleuro-pneumonia, even though the disease has not been far advanced, it will be found that the butcher has carefully scraped the serous membrane off the inner surface of the ribs, as it would otherwise be impossible for him to give the pleura its healthy, smooth aspect, from the firm manner in which the abundant false membranes adhere to it. The direased lungs sometimes attain inordinate weight. They have been known to weigh as much as sixty pounds.

Treatment.-The veterinary profession is regarded by many who have sustained heavy losses from pleuro-pneumonia, as deeply ignorant, because its members cannot often cure the disease. Persons forget that there are several epidemics which prove equally difficult to manage on the part of the physician, such as cholera, yellow fever, etc. The poison in these contagious, epizoötic diseases is so virulent that the 
animals may be regarded as dead from the moment they are attacked. Its elimination from the system is impossible, and medicine cannot support an animal through its tardy, exhausting, and destructive process of clearing the system of so potent a virus. All antiphlogistic means have failed, suc as blood-letting and the free use of evacuants. Derivatives, in the form of mustard-poultices, or more active blisters, are attended with good results. Stimulants have proved of the greatest service; and the late Prof. Tessona, of Turin, strongly recommended, from the very onset of the disease, the administration of strong doses of quinine. Maffei, of Ferrara, states that he has obtained great benefit from the employment of ferruginous tonics and manganese in the very acute stage of the malady, supported by alcholic stimulants. Recently, the advantages resulting from the use of sulphate of iron, both as a preventive and curative, have been exhibited in France. It would appear that the most valuable depurative method of treatment yet resorted to is by the careful use of the Roman bath. Acting, like all other sudorifics in cases of fever and blood diseases, it carries off by the skin much of the poison, without unduly lowering the vital powers.

Prevention.-The rules laid down in Denmark, and indeed in many other places, appear the most natural for the prevention of the disease. If they could be carried out, the lisease must necessarily be stopped; but there are practical and insuperable difficulties in the way of enforcing them. Thus, a Dr. Warneke says, prevention consists in "the avoidance of contagion; the slaughter of infected beasts; the prohibition of keeping cattle by those whose cattle have 
been slaughtered, for a space of ten weeks after the last case occurring; the disinfection of stalls racated by slanghtering; the closing of infected places to all passing of cattle; especial attention to the removal of the dung, and of the remains of the carcasses of slaughtered beasts; and, finally, undeviating severity of the law against violators."

Dr. Williams, of Hasselt, suggested and carried out, in 1851, the inoculation of the virus of pleuro-pneumonia, in order to induce a mild form of the disease in healthy animals, and prevent their decimation by the severe attacks due to contagion. He met with mucb encouragement, and perhaps more opposition. Didot, Corvini, Ercolani, and many more accepted Dr. Williams's facts as incontestable, and wrote, advocating his method of checking the spread of so destructive a plague.

The first able memoir which contested all that has been said in favor of inoculation, appeared in Turin, and was written by Dr. Riviglio, a Piedmontese veterinary surgeon. This was supported by the views of many others. Prof. Simonds wrote against the plan, and, in 1854, the French commission, whose report has been before mentioned, confirmed, in part, Riviglio's views, though, from the incompleteness of the experiments, further trials were recommended.

Inoculation is performed as follows : A portion of diseased lung is chosen, and a bistoury or needle made to pierce it so as to become charged with the material consolidating the lung, and this is afterward plunged into any part, but, more particularly, toward the point of the tail. If operated severely, and higher up, great exudation occurs, which spreads upward, invades the areolar tissue round the rectum and other pelvic 
orgais, and death soon puts an end to the animal's excruciating suffering. If the operation is properly performed with lymuh that is not putrid, and the incisions are not made too deep, the results are limited to local exudation and swelling, general symptoms of fever, and gradual recovery. The most common occurrence is sloughing of the tail ; and in London, at the present time, dairies are to be seen in which all the cows have short-tail stumps.

Dr. Williams and others have gone too far in attempting to describe a particular corpuscle as existing in the lymph of pleuro-pneumonia. All animal poisons can be alone discovered from their effects. In structure and chemical constitution, there is no difference, and often the most potent poisons are simple fluids. The Belgian Commission, appointed to investigate the nature and influence of inoculation for pleuro-pneumonia, very justly expressed an opinion that Dr. Williams had not proved that a specific product, distinguished by anatomical characters, and appreciable by the microscope, existed in this disease.

The all-important question, "Is inoculation of service?" has to the satisfaction of most been solved. The Belgian and French commissions, the observations of Riviglio, Simond, Herring, and many others, prove that a certain degree of preservative influence is derived by the process of inoculation. It does not, however, arrest the progress of the disease. It certainly diminishes to some extent-though often very slightly so-the number of cases, and, particularly, of severe ones. This effect has been ascribed to a derivative action, independent of any specific influence, and, indeed, similar to that of introducing setons in the dewlap. 
In London, some dairymen have considerable faith in inoculation, though its effect is uncertain, and the manner of its working a mystery. The best counsel, in the premises, which can be given to the keeper of dairy stock is, to select his own animals from healthy herds, and strictly to aroid public markets. In many instances, a faithful observance of these injunctions has been sufficient to prevent the invasion of this terrible disease. [Gamgee.]

The existence of this disease in the United States was not generally known until the year 1859, when Mr. Chenery, of Belmont, near Boston, Massachusetts, imported several cows from Holland, which arrived in the early part of the spring of that year. Some of the animals were sick when they arrived, but the true nature of the disease was not at that time suspected. Several of them were so bad that they were carried in trucks to Mr. Chenery's barn. Some two months passed away before the character of the disease was discovered.

Upon the facts becoming known, the citizens of Massachusetts became panic-stricken, as the disease was rapidly spreading over that State. An extra session of the Legislature was speedily convened, when a Joint Special Commit. tee was appointed, to adopt and carry out such measures as in their judgment seemed necessary for the extirpation of this monster, pleuro-pneumonia.

The Committee met in the Hall of the House of Representatives, Thursday, May, 31, 1860, to receive evidence as to the contagious or infectious character of the disease, in order to determine concerning the necessity of legislative action: 
Mr. Walker, one of the commissioners appointed by the Guvernor, made the following statement: "The disease was introduced into North Brookfield from Belmont. Mr. Curtis Stoddard, a young man of North Brookfield, went down, the very last of June, last year, and purchased three calves of Mr. Chenery, of Belmont. He brought these calves up in the cars to Brookfield. On their way from the depôt to his house, about five miles, one of the calves was observed to falter, and when he got to his house, it seemed to be sick, and in two or three days exhibited very great illness; so much so, that his father came along, and, thinking he could take better care of it, took the calf home. He took it to his own barn, in which there were about forty head of cattle; but it grew no better, and his son went up and brought it back again to his own house. In about ten days after that, it died. His father, who had had the calf nearly four days, in about a fortnight afterward observed that one of his oxen was sick, and it grew worse very fast and died. Two weeks after, a second also sickened, and died. Then a third was attacked and died, the interval growing wider from the attack of one animal to that of another, until he had lost eight oxen and cows. Young Stoddard lost no animal by the infection,-that is, no one died on his hands. Prior to the appointment of this Commission, about the first of November,-for reasons independent of this disease, which I don't suppose he then knew the nature of,- he sold off his stock. He sold off eleven heifers, or young animals, and retained nine of the most valuable himself; which shows that he did not then know any thing was the matter with them.

"These nine were four oxen, and fire young cattle. The 
four he took to his father's, three of the others to his uncie's, and the remaining two to his father-in-law's ; distributing them all among his friends,-which furnishes another proof that he did not suppose he was doing any mischief. He disposed of his herd in that way. From this auction, these eleven animals went in different directions, and wherever they went, they scattered the infection. Without a single failure the disease has followed those cattle; in one case, more than two hundred cattle having been infected by one which was sold at Curtis Stoddard's auction, when he was entirely ignorant of the disease.

"When the commission was appointed, they went and examined his cattle, and were satisfied that they were diseased, -at least, some of them. They examined his father's herd, and found that they were very much diseased; and when we came to kill Curtis Stoddard's cattle, seven of the nine head were diseased. Two were not condemned, because the law says, 'Cattle not appearing to be diseased, shall be appraised.' Nevertheless, it proved that these animals were diseased; so that his whole herd was affected.

"In regard to Leonard Stoddard's cattle, he lost fourteen of his animals before the commissioners went to his place. They took eighteen more, all of which were diseased,-most of them very bad cases,-indeed, extreme cases. That left eight heads, which were not condemned, because not appearing to be diseased. Here I remark, that when this disease is under the shoulder-blade, it cannot be detected by percussion. The physicians did not say that the animal was not diseased, but that they did not see sufficient evidence upon which to condemn. Such animals were to be paid for, upon the ground 
of their not appearing to be diseased. Nevertheless, it is proper to state that the remaining eight which were not condemned, were suspected to be diseased, and we told Mr. Stoddard that we had the impression that they were diseased. notwithstanding appearances. He said, "There is a threeyear-old animal that has never faltered at all. She has never manifested the slightest disease. If you will kill her, and she is diseased, I shall make up my mind that I have not a well animal in my stalls.' We killed the animal, and found her to be badly diseased.

"Thus, the first two herds were all infected by the disease; and in the last of Curtis Stoddard's oxen which we killed, we found a cyst in the lungs of each. One of these lungs is now in this building, never having been cut open, and medical men can see the eyst which it contains. I have said in what manner Mr. Curtis Stoddard's cattle spread the infection.

"In regard to Mrr. Leonard Stoddard's : in the first place, he kept six or eight oxen which he employed in teaming. He was drawing some lumber, and stopped over night, with his oxen, at Mr. Needham's. Needham lost his whole herd. He lost eight or ten of them, and the rest were in a terrible condition. Seven or eight more were condemned, and his whole herd was destroyed, in consequence of Mr. Stoddard's stopping with him over night. Mr. Stoddard sold an animal to Mr. Woodis of New Braintree. He had twenty-three fine cows. It ruined his herd utterly. Seven or eight animals died before the commissioners got there. Mr. L. Stoddard also sold a yoke of cattle to Mr. Olmstead, one of his neighbors, who had a rery good herd. They stajed only 
five days in his hands, when they passed over to Mr. Doane. In these five days they had so infected his herd that it was one of the most severe instances of disease that we have had. One third were condemned, and another third were passed over as sound, whether they were so, or not. They did not appear to be diseased. The cattle that were passed from Mr. Stoddard through Mr. Olmstead to Mr. Doane, were loaned by Mr. D. to go to a moving of a building from Oakham to New Braintree. They were put in with twentytwo yoke of cattle, and employed a day and a half. It has since been proved that the whole of these cattle took the contagion. They belonged to eleven different herds, and of course, each of these herds formed a focus from which the disease spread. Now, in these two ways the disease has spread in different directions.

"But, when the commissioners first commenced; they had no idea that the disease extended further than those herds in which there were animals sick. Hence, their ideas and the ideas of those who petitioned for the law, did not extend at all to so large a number of herds as have since been proved to be diseased, because they only judged of those who manifested disease. As soon as we began in that circle, we found a second circle of infection, and another outside of that; and by that time it had branched off in various directions to various towns. It assumed such proportions that it was very evident that the commissioners had not the funds to perform the operations required by the law. The law confines the commissioners to one operation,- - killing and burying. No discretionary power is given at all. The commissioners became entirely dissatisfied with that condition of 
things, because other measures besides merely killing and burying, are quite as necessary and important. When they arrived at that point and discovered to what extent the infection had spread, they stopped killing the herds, and I believe there has not been a herd killed for twenty days.

"The policy was then changed to circumscribing the disease, by isolating the herds just as fast as possible and as surely as possible. A man's herd has been exposed. There is no other way than to go and examine it, and take the diseased animals away. Then he knows the animals are diseased, and his neighbors know it. That has been the business of the commissioners for the last twenty days; and the facts that they have no discretionary power whatever, and that they were entirely circumscribed in their means, and that it was hard for the farmers to lose their stock and not be paid for it,-induced them to petition the Governor, in connection with the Board of Agriculture, for the calling of a session of the Legislature, to take measures for the extinction of the disease."

In response to a question, "Whether any animals that had once been affected, had afterward recovered?"-the same gentleman stated that instances had occurred where cattle had been sick twice, and had, apparently, fully recorered; they ruminated readily, and were gaining flesh. Upon examination, however, they were pronounced diseased, and, when killed, both lungs were found in a hopeless case, very badly diseased.

Dr. George B. Loring, another of the commissioners, stated that eight hundred and forty-two head of cattle had, at that time, been killed, and that, from a careful estimate, 
there still remained one thousand head, which should either be killed, or isolated for such a length of time as should asstablish the fact that they had no disease about them. Twenty thousand dollars and upwards had already been appraised as the value of the caitle then killed.

As to disinfecting measures, the farmers who had lost cattle were requested to whitewash their barns thoroughly, and some tons of a disinfecting powder were purchased for the advantage of the persons who wished to use it. An early application was advised, that the barns might be in readiness for hay the then coming season.

The practice adopted by the commissioners was, to appraise the cattle whenever a herd was found which had been exposed, and a surgeon was appointed to pass judgment upon the number of diseased animals. After that judgment, the remaining animals that were pronounced sound were killed. and passed to the credit of the owner, after an appraisement made by these persons. The fair market-prices were paid. areraging about thirty-three dollars a head. At the time of the meeting of the committee, some seventy cattle had died of the disease.

An examination was made of some of the animals killed. and the following facts obtained :-

Case 1.-This cow had been sick for nineteen days; was ceble, without much appetite, with diarrhœa, cough, shortness of breathing, hair staring, etc. Percussion dull orer the whole of the left side of the chest; respiration weak Killed by authority. Several gallons of serum were found in the left side of the chest; a thick, furzy deposit of lymph over all the pleura-costalis. This lymph was an inch in 
thickness, resembling the relrety part of tripe, and quite firm. There was a firm deposit of lymph in the whole left lung, but more especially at its base, with strong adhesions to the diaphragm and pleura-costalis near the spine. The lung was hard and brittle, like liver, near its base. Yo pus. Right lung and right side of chest healthy.

Case 2.-This cow was taken very sick, January 30th. In fourteen days, she began to get better. April 12th, she is gaining flesh, breathes well, hair healthy, gives ten quarts of milk a day, and in all other respects bids fair for a healtluy animal hereafter, except a slight cough. Percussion dull over base of the left lung, near the spine, and respiration feeble in the same regions.

Autopsy.-Left lung strongly adherent to diaphragm and costal pleura; the long adhesions well smoothed off; pleuracostalis shining and healthy. Also, the surface of the lung, when there were no adhesions, sound and right; all the lung white, and free for the entrance of air, except the base, in which was a cyst containing a pint or two of pus. Loose in this pus mas a hard mass, as large as a two-quart measure, looking like marble; when cut through its centre, it appeared like the brittle, hardened lining in case 1. It appeared as though a piece of lung had been detached by suppuration and enclosed in an air-tight cyst, by which decomposition was prevented. The other lung and the chest were sound. It is to be inferred, as there were adhesions, that there had been pleurisy and deposit of lymph and serum, as in case 1 , and that Nature had commenced the cure by absorbing the serum from the chest, and the lymph from the free pleural surface, and smoothed off every thing to a good working condition. 
The lump in the cyst was brittle and irregular on its surface, as though it was dissolving in the pus. No good reason can be given why Nature should not consummate the work which she had so wisely begun.

Case 3.-This cow had been sick fourteen days; was coughing and breathing badly; percussion dull orer both chests, and respiration feeble. Killed.

Autopsy.-Both chests flled with rater; deposits of lymph orer all the pleura-costalis, presenting the same velvety, furzy appearance as in Case 1. Both lungs were hardened at the base, and the left throughout its whole extent, and firmly adherent to diaphragm and costal pleura, near the spine. The right lung had nearly one-third of its substance in a condition for the entrance of air; but this portion, eren, was so compressed with the water, that a few hours longer would have terminated the case fatally without State aid. This case had not proceeded far enough for the formation of the cyst or pus.

In Mr. Needham's herd, about trenty-eight days intervened between the first and second case of disease, instead of about fourteen, as in Mr. Olmstead's.

Case 4.-A nice heifer, in fair condition, eating well, only having a slight cough. Percussion dull over base of the left lung.

Autopsy.-Base of left lung adherent to diaphragm and costal pleura; lung hardened. On cutting into base, found ulceration and a head of Timothy grass, four or fire inches long. Animal in every other way well.

Case 5.-This cow was taken, January 1st, with a cough, difficulty of breathing, and the other symptoms of the disease, 
and continued sick till March 1st. On taking her out, April 12th, to be slaughtered, she capered, stuck up her tail, snuffed, and snorted, showing all the signs of feeling well and vigorous.

Autopsy.-Right lung firmly adherent to diaphragm and ostal pleura, near the spine. Base of lung hardened, containing a cyst with a large lump, of the size of a two-quart measure, floating in pus; outside of the lump was of a dirty yellow-white, irregular, brittle, and cheesy ; the inside mottled, or divided into irregular squares; red like muscle, and breaking under the finger, like liver. Costal pleura smooth, shining; adhesions where there was motion; card-like and polished; no serum; lung apparently perforning its functions well, except for a short distance above the air-tight cyst, where it was still hardened. It would seem as though Nature was intending to dissolve this lunp, and carry it off by absorption. She knows how, and would have done it, in the opinion of the writer, had she been allowed sufficient time.

Case 6. -Was taken December 18th, and was very sick; in three weeks she was well, except a cough, quite severe, and so continued till about the first of March, when she coughed harder and grew worse till seven days before she was killed, April 12th, when she brought forth a calf, and then commenced improving again.

Autopsy.-Right lung adherent to diaphragm and costal pleura. At its base, was a flabby, fluctuating cyst. In cutting into it, the lump was found to be breaking up by decomposition, and scenting badly. Every thing else normal. Thas not the cyst broken through by some accident, thus 
letting in the air, when she grew worse? Would she not, probably, have overcome this disagreeable accident, and recovered, in spite of it? This cow's hair did not look well, as did that of those in which the cyst was air-tight; but still she was beginning to eat well again, and appeared in a tolerable way for recovery.

Case 7.- This heifer had coughed slightly for six weeks, but the owner said he thought no one going into his herd would notice that any thing was the matter with her.

Autopsy.-Slight adhesions of lung to diaphragm. Near these adhesions are small cysts, of the size of a walnut, containing pus and cheesy matter; about the cysts a little way the lung was hardened, way for half an inch. There were several cysts, and they appeared as though the inflammation at-

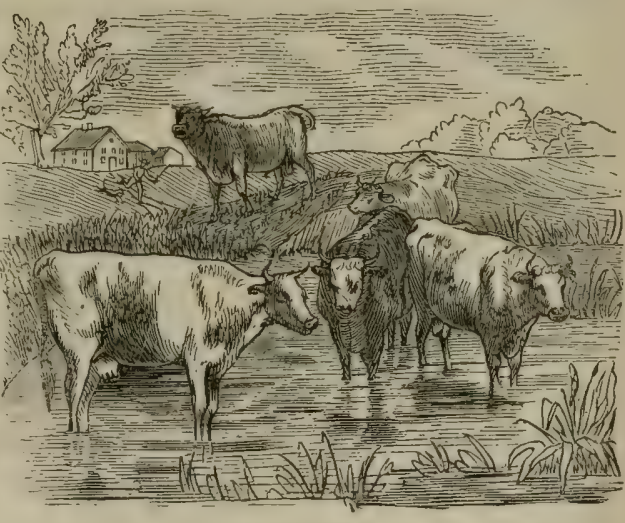
A RURAL SCENE. tacked only the different lobes of the lungs, leaving others healthy between,-Nature throwing out coagulable lymph around the diseased lobe, and forming thereby an air-tight cyst, cutting around the diseased lobe by suppuration, so that it could be carried off by absorption.

In the herd to which this animal belonged, nine days after the first cow died, the second case occurred. First cow was 
sick five weeks. The time of incubation could not have been over six weeks,--probably not over three weeks. Of these cows, one improved in eight weeks, the other in three weeks.

Case 8. - This cow had been sick three weeks. Killed.

Autopsy.-Large quantities of serum in left chest; lung adherent, and hardened at base. On cutting into the hardened lung, one side of the lump was found separated from the lung, with pus between the lines of separation, and the forming coat of the cyst outside of the pus; the other side of the lump was part and parcel of the hardened lung which had not yet had time to commence separation. The costal pleura was covered with organized lymph to the thickness of an inch, with the usual characteristics. The right chest contained a small quantity of serum, and had several small, hardened red spots in that lung, with some tender, weak adhesions; but most of the right lung was healthy.

Case 9. - Sick four weeks. Killed.

Autopsy.-Right lung hardened at base; adherent to diaphragm and costal pleura; lump separated on one side only. Cyst beginning to form, outside of separation; pus between cyst and lump, but in a very small quantity.

These two cases settle the character of the lump, and the manner of the formation of the cyst; the lump being lung and lymph, cut out by suppuration,-the cyst being organized,. smoothed off by suppuration, friction, etc.

Case 10.-Killed. Hair looked badly; but the cow, it was said, ate, and appeared well. This case, however, oc 
curred in a herd, of which no reliable information, in detail, could be procured.

A utopsy.-Base of lung hardened, adherent to diaphragm ; containing a cyst, in which was a lump, of the size of a quart measure, but little pus. This lump had air-tubes running through it, which were not yet cut off by suppuration; and in one place, the cyst was perforater by a bronchial tube, letting in the external air to the lump, which was undergoing disorganization, and swelling badly. When cut into, it did not prevent the red, mottled, organized appearance of those cases with air-tight cysts.

Quite a number of other cases were examined, but these ten present all the different pbases. One or two cases are needed of an early stage of the disease, to settle the point, whether; in all cases, the primary disease is lung fever, and the pleurisy a continuation, merely, of the primary disease; together with some six or eight cases, during five, six, seven, eight months from attack, and so on till entire, final recovery. Some cases were sick almost a year since, and are now apparently quite well; perhaps all the lump and pus are not yet gone. Many practitioners think that no severe case will ever recover, and some think that none ever get entirely well. Others, however, can see no reason why, as a general rule, all single cases should not recover, and all double cases die.

The disease was the most fatal in Mr. Chenery's (the original) herd, although it was the best-fed and the warmeststabled. He attributed the fatality, in part, to a want of sufficient ventilation. The other herds, in which all the fatal cases occurred in two hours, consisted, originally, one of forty-eight head, of which thirteen died, or were killed, to 
prevent certain death; of twenty-three head, of which seven died; of twenty-two head, of which eight died; of twentytwo head, of which eight also died; and of twenty-one head, of which four died. A little less than thirty per cent., therefore, of these herds died.

This estimate excludes the calves. Most of the cows which had not calved before being attacked, lost their calves prematurely. The probable time of incubation, as deduced from those Massachusetts cases, is from two to three weeks; of propagation, about the same time; the acute stage of the disease lasting about three weeks.

The author's attention was first directed to this disease, upon its appearance in Camden and Gloucester counties, New Jersey, in the year 1859, at about the same time it made its advent in Massachusetts. The singularity of this coincidence inclined him for the time to regard the disease as an epizoötic-having its origin in some peculiar condition of the atmosphere-rather than as a contagious, or infectious disease, which position was at that time assumed by him.

This opinion was strengthened by the fact, that no case occurring in New Jersey could be traced to a Massachusetts origin, in which State it was claimed that the disease never had existed in this country previous to its introduction there. It was, therefore, denied by the veterinary surgeons in the Eastern States, that the disease in New Jersey was the true European pleuro-pneumonia, but it was called by them the swill-milk disease of New York City, and it was assigned an origin in the distillery cow-houses in Brooklyn and Williamsburg.

In 1860 it found its way across the Delaware River into 
Philadelphia, spreading very rapidly in all directions, particularly in the southern section of the county, known as The Neck,-many of the dairymen losing from one third to one half of their herds by its devastating influence. In order to save themselves-in part, at least-from this heavy loss, many of them, upon the first indications of the malady, sent their animals to the butcher, to be slaughtered for beef. In 1861 the disease found its way into Delaware, where its ravages were severely felt. So soon, however, as it became known that the disease was infectious or contagious, an effort was made to trace it to its starting-point; but, in consequence of the unwillingness of dairymen to communicate the fact that their herds were affected with pleuro-pneumonia, all efforts proved fruitless. In 1860 the disease found its way up the Delaware to Riverton, a short distance above the city of Philadelphia. A cattle-dealer, named Ward, turned some cattle into a lot, adjoining which several others were grazing. The residents of this place are chiefly the families of gentlemen doing business in the city, many of whom lost their favorite animals from this destructive malady.

The first case occurring at this place, to which the author's attention was called, was a cow belonging to Mr. D. Parrish, which had been exposed by coming in contact with Ward's cattle, had sickened, and died. An anxiety having been manifested to ascertain the cause of the death, the author made an examination of the animal, which, upon dissection, proved the disease to be a genuine case of the socalled pleuro-pneumonia. This examination was made A ugust 20th, 1860, at the time of the Massachusetts excitement. Two cows, belonging to Mr. Rose, of the same place, 19 
had been exposed, and both had taken the disease. His attention having been called to them, he placed them under the author's treatment, and by the use of diffusible stimulants and tonics, one of these animals recovered, while the other was slaughtered for an examination, which revealed all the morbid conditions so characteristic of this disease.

The next case was a cow belonging to Mr. G. H. Roach, of the same place, which had been grazing in a lot adjoining that of Mr. Parrish. This cow was killed in the presence of Charles Wood, V.S., of Boston, Mass., and Arthur S. Copeman, of Utica, N. Y., who was one of a committee appointed by the New York State Agricultural Society for the purpose of investigating the disease. Both of these gentlemen having witnessed the disease in all its forms, as it appeared in Massachusetts, were the first to identify this case with those in that State.

Upon opening the cow, the left lung was found to be completely consolidated, and adhered to the left side, presenting the appearance usual in such cases. As she was with calf, the lungs of the fotus were examined, disclosing a beautiful state of red hepatization.

The author's attention was next called to the herd of Mr. Lippincott, a farmer in the neighborhood, who had lost several cattle by the disease; but as he had been persuaded that treatment was useless, he abandoned the idea of attempting to sare his stock in that way. From Riverton it soon spread to Burlington, some ten miles farther up the river, where it carried off large numbers of valuable cattle, and it continued in existence in that neighborhood for some time.

The disease was not then confined to these localities alone, 
but has spread over a large extent of country,--and that, too, prior to its appearance in Massachusetts, as will be shown by extracts from the following letters, published in the Country Gentleman :-

"We have a disease among the cattle here, I will class it under these names,-congestion of the lungs, terminating with consumption, or dropsy of the chest. Now, I have treated two cases; one five years since, as congestion,-and the first is still able to eat her allowance, and give a couple of pails of milk a day,-and the other, quite recently. The great terror of this disease is, that it is not taken in its first stages, which are the same in the cow as in the man-a difficulty in breathing, which, if not speedily relieved, terminates in consumption or dropsy. I have no doubt that consumption is contagious; but is that a reason why every one taken with congestion should be killed to check the spread of consumption? So I should reason, if I had pleuro-pneumonia in $\mathrm{my}$ drove of cattle.

J. BALDWIN.

"Newark, N. J., June 11, 1860."

"I notice that a good deal of alarm is felt in different parts of the country about what is called the cattle-disease.

"From the diagnosis given in the papers, I have no doulbt this is pleuro-pneumonia, with which $I$ had some acquaintance a few years ago. If it is the same, my observation and experience may be of some service to those suffering now.

"It was introduced into my stock, in the fall of 1853, by one of my own cows, which, in the spring of that year, I had sent down to my brother in Brooklyn, to be used during the summer for milk. She was kept entirely isolated through 
out the summer, and in November was sent, up by the boat. There were no other cattle on the bcat at the time, nor could I learn that she had come in contact with any in passing through the streets on her way to the boat; and she certainly did not, after leaving it, until she mingled with her old companions, all of whom were then, and long afterward, perfectly well. After she had been home about two weeks, we noticed that her appetite failed, and her milk fell off: she seemed dull and stupid, stood with her head down, and manifested a considerable degree of languor.

"Soon her breathing became somewhat hurried, and with a decided catch in it; she ground her teeth; continued standing, or, if she lay down, it was only to jump up again instantly. Her cough increased, and so, too, a purulent and bloody discharge from her nostrils and mouth. The excrement was fetid, black, and hard.

"In this case, we twice administered half a pound of Epsom-salts, and afterward, a bottle of castor-oil. Tery little but a temporary effect was produced by these doses.

"The symptoms all increased in intensity; strength diminished; limbs drawn together; belly tucked up, etc.; until the eight day, when she partly lay, and partly fell down, and never rose again.

"In a post-mortem examination, the lungs were gorged with black, fetid blood; the substance of them thickened and pulpy. The pleura and diaphragm also showed a good deal of disease and some adhesion. This cow, on her arrival here, was put in her usual place in the stable, between others. She remained there for two or three days after she was taken sick, before we removed her to the hospital. 
"In about three weeks from the time she died, one and then the other of those standing on either side of her were attacked in the same way, and with but two days between. This, certainly, looks very much like contagion; but my attention had not before been called to this particular disease, and to suppose inflammation or congestion of the lungs contagious was so opposed to my preconceived notions, that I did not even then admit it; and these animals were suffered to remain with the others until their own comfort seemed to require the greater liberty of open pens.

"One of them was early and copiously bled twice, while Epsom-salts were administered, both by the stomach and with the injective-pump. The other we endeavored to keep nauseated with ipecacuanha, and the same time to keep ner bowels open by cathartic medicine. All proved to be of no avail. They both died,-the one in ten, the other in thirteen days. Before these died, however, others were taken sick. And thus, later, I had eight sick at one time.

"The leading symptoms in all were the same, with minor differences; and so, too, was the appearance after death, on examination.

"Of all that were taken sick (sixteen) but two recovered; and they were among those we did the least for, after we had become discouraged about trying to cure them. In all the last cases we made no effort at all, but to keep them as comfortable as we could. In one case, the acute character of the disease changed to chronic, and the animal lived six or eight weeks, until the whole texture of the lungs had become destroyed. She had become much emaciated, and finally died with the ordinary consumption. 
"At the time the first case appeared, I had a herd of thirty-one animals, all valuable Ayrshires, in fine condition and healthy. In all the first cases, I had a veterinary surgeon of considerable celebrity and experience, and every ordinary approved method of treatment was resorted to and persevered in. The last cases-as before intimated-we only strove to make comfortable.

"After I had paid the third or fourth forfeit, I began to awake up to the idea that the disease was, in a high degree, contagious, whether I would have it so or not; and that my future security was in prevention, and not in remedy. I therefore separated all the remaining animals; in no instance having more than two together, and generally but one in a place.

" 111 were remored from the infected stalls, and put into quarantine. Isolated cases continued to occur after this for some weeks, but the spread of the disease was stayed; nor did a single case occur after this, which we did not think we traced directly to previous contact.

"It is impossible to account for the first case of which I have spoken. But, as the cow in that case was put into a sale-stable in New York while waiting for the boat,- - though there were no cattle then present,-yet I have supposed it not unlikely that diseased animals had been there, and had left the seeds of the disease.

"But, account for this case as we may, -and I have no doubt it is sometimes spontaneous,- $-\mathrm{I}$ feel convinced it is very highly contagious; and that the only safety to a herd into which it has been introduced, is in complete isolation, -and in this I feel as convinced that there is safety. My 
cattle were not suffered to return to the barn-yard or to any part of the cattle-barns, except as invalids were sent to 'the hospital' to die, until late the next fall, i.e., the fall of 1854 . In the mean time, the hay and straw had all been remored; the stables, stalls, cribs and all thoroughly scrubbed with ashes and water, fumigated, and whitewashed with quicklime. I have had no case since, and am persuaded I should have aroided most of those I had before, if I had reasonably admitted the evidence of my senses in the second and third cases.

E. P. Prentice.

\section{Mount Hope, June 14tb, 1860."}

The author's experience with the disease, during the last year in New Jersey, proves the effeacy of remedial agents when applied in the early stages of the disease. Late in the spring of 1861, Mr. J. E. Hancock, of Burlington County (residing near Columbus, N. J.), purchased some cattle in the Philadelphia market, which, after they were driven home, he turned in with his other stock. Soon after this purchase, one of the animals sickened and died. This was in August; after which time Mr. H. lost eight cows,-having, at the time of the death of the last animal, some five others sick with the same disorder.

The author was called in, December 8th, 1861, and the five animals then placed under his treatment. On the 12th of December, in the same year, one of these cows, at his suggestion, was killed, which, upon the post-mortem examination, beautifully illustrated the character of the disease. The right lung was comparatively healthy; the left one completely hepatized, or consolidated, and so enlarged as to fill up the left cavity of the chest to its utmost capacity. This 
lung weighed thirty pounds. There was no effusion in the chest, but there was considerable adhesion of the pleuracostalis and pleura-pulmonalis. All the other tissues appeared to be healthy.

To the remaining animals, was administered the following: aqua ammonia, three drachms; nitric ether, one ounce; pulverized gentian-root, half an ounce; mixed with one quart of water, and drenched three times a day. The last thing at night was given a teaspoonful of phosphate of lime, mixed in a little feed, or in gruel. Setons, or rowels, in the dewlap are also very beneficial. Under this treatment they all did well.

Soon after the introduction of the disease into this herd, it found its way to the herd of William Hancock, a brother of the former gentleman, who had an adjoining farm. In this herd one cow died, and the disease was found by the author developed in four more cows and two oxen, all of whichwith a single exception_-did well under the above treatment. The disease afterward showed itself in the herd of John Pope, half a mile distant, who lost nine animals by it.

Thursday, December 19th, was selected for the purpose of making an examination of the Hancock herds; but, after some ten or twelve animals had been examined and all pronounced tainted with the disease, the owners concluded to stop the investigation, expressing themselves dissatisfied with the result, as not one of the animals examined had shown any symptoms of disease. In order to convince them of the correctness of the diagnosis, a cow was selected and destroyed, which the Hancocks believed to be in perfect health. Upon opening the animal, several small patches of hepatized 
lung were brought into view. Upon making a longitudinal section of the lump, as both were involved, they presented a red, speckled appearance. All the other tissues were healthy. The symptoms in these cases were quite different from any which had been previously seen in an experience of three fears with the disease in and about Philadelphia, inasmuch as they were not preceded by cough; in fact, cough did not appear in many of the animals at any time during the progress of the disease. The animals looked, ate, and milked well, previously to the development of the disease, so that the owners were thrown completely off their guard by these deceptive symptoms of health. Knowing the uncertain character of this disease, and wishing to stay its ravages, a suggestion was made by the author as to the propriety of having the entire herd killed for beef. This was done the more readily, as the sale of the meat is legalized in Europe, it being regarded as uninjured, and therefore wholesome meat. This suggestion was acted upon, and thus these two farms were rid of this dreadful scourge at one blow.

Mr. A. Gaskill, of Mount Holly, N. J., purchased a cow from one of the Hancocks, for his own family use, which was sent to Mr. Frank Lippincott's to pasture and turned in with Mr. L.'s own herd. Soon after, this cow sickened and died. This was soon followed by the loss of six of Mr. L.'s own cattle,-three oxen, two cows, and one stcer. From this herd, it was communicated to the Widow Lippincott's, who occupied a neighboring farm ; as also to $\mathrm{Mr}$. Cleavenger's, who lost four animals; and to Mr. Smith's, who had, at one time, seven animals sick; and from Cleavenger's to Noaknuts, who lost two cows. Some two or three cows, 
belonging to Mr. Logan, in the same neighborhood, got upon the road and broke into Mr. Lippineott's pasture, mixing with his herd. As soon as Mr. Logan was informed of the fact, he isolated these cows by enclosing them in a pen at some distance from his other cattle; but they managed to break out, and mingled with his other stock. It could scarcely bo expected that his herd could escape the disease, considering the exposure to which they had been subjected. The disease manifested itself in the herds of several other farmers in the country, but space will not allow a more extended notice of the subject.

The treatment which has been found most successful in this country is as follows, all of which has been tested by the author upon various occasions: In the acute, inflammatoly stage of the disease, give ten drops of Flemming's tincture of aconite in water, every four hours, until a change takes place; follow this with aqua ammonia, three drachms; nitric ether, one ounce; pulverized gentian-root, one half an ounce; water, one quart. Drench three times a day, and give, late in the eveniug, a tablespoonful of phosphate of lime, in a little feed, or drench with gruel. Put setons, or rowels in the dewlap, so as to have a dependent opening.

This course las been found very advantageous. Or, the following will be found quite satisfactory; nitrate of potash, two drachms; camplor, half a drachm ; tartrate of antimony, half a drachm; mix, and give in a little gruel, night and morning. Or, the following: Glauber-salts, four ounces; water, one pint; give twice a day. A gill of cold-drawn castor-oil, added to the above, would be beneficial. Continue until the bowels are freely opened. The following has 
also been found efficacious: sulphate of magnesia, eight ounces; nitrate of potash and pulverized Jamaica gingerroot, of each one ounce. Repeat as often as may be required. Apply externally the following ointment to the sides; biniodide of mercury, four drachms; castor-oil, half an ounce; lard, four ounces; mix for use.

Preventive measures._-1st. The complete isolation of all herds in which the disease has made its appearance. $2 \mathrm{~d}$. Such animals as show symptoms of the disease should be placed under proper treatment. 3d. In England, it is recommended that animals recovering from the disease should be fattened and slaughtered for beef, as they are not safe even after their apparent recovery. 4th. All animals beyond medical treatment should be killed and buried; recompense in part, at least, being made to the owners. 5th. No animal, healthy or diseased, should be allowed to run at large upon the public highway so long as the disease may exist in its neighborhood.

The united action of all those interested would soon

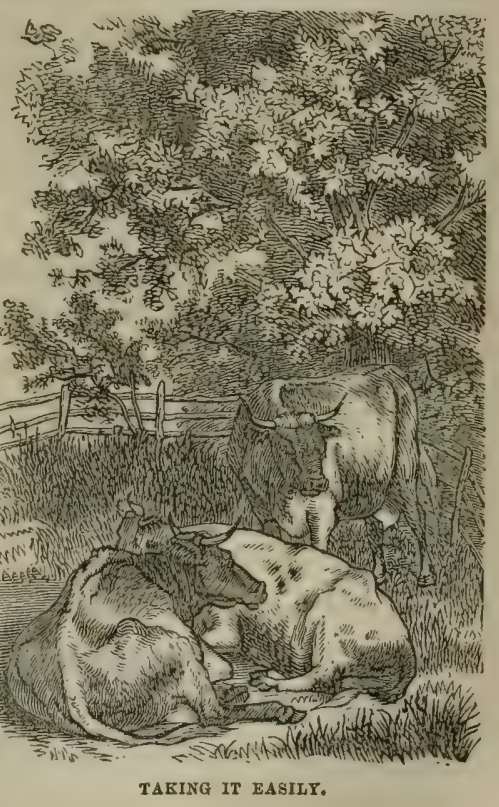
rid the country of a disease which has smitten all Europe.

The author takes this occasion to acknowledge the receipt 
of two very ably written articles upon this subject, which, in consequence of their length and the comparatively limited space allotted, he is reluctantly compelled to omit. One is from the pen of R. McClure, V.S., and the other from Isaiah Michener, V.S. For the benefit of his readers, however, he desires to make a single extract from the last-named communication, without being considered as endorsing the opinion advanced therein :-

"I am inclined to favor the hypothesis that pleuro-pneumonia is produced by animalculæ, and that these enter the lungs by myriads, and thereby set up irritation and inflammation, which lead to all the phenomena and pathological conditions which are to be found upon dissection. This is my opinion of the cause of the malignant pleuro-pneumonia which has existed in the United States for the last seven years."

After writing the foregoing, the author was informed that this disease had made its appearance in Mr. Logan's herd, already mentioned as exposed. He was called to visit the herd of Mr. G. Satterthwaite, who likewise lost two cows, and had two cors and a calf sick at the time of sending for him.

\section{PNEUMONIA.}

There are two conditions of the lungs known as pneumenia,--one, the inflammatory, and the other, the congestive stage. . The former may follow an attack of bronchitis, or it may have a spontaneous origin. The congestive is generally the result of cold suddenly applied to an overheated animal, 
causing a determination of blood to the lungs, which sometimes causes death by suffocation.

Symptoms. - The disease is preceded by a shivering fit; dry skin; staring coat; clammy mouth ; short cough; Schneiderian membrane (of the nose) very much reddened; respirntion hurried or laborious. In the congestive stage, upon applying the ear to the sides, no sound will be detected; while in the inflammatory stage, a crackling or crepitating sound will be distinctively heard.

Treatment.-In the congestive stage, plenty of pure air will be necessary. Bleed freely; and give in drench one pound of Glauber-salts, with two drachms of Jamaica ginger. Nothing more will be required by way of treatment.

In the inflammatory stage, bleeding should seldom be resorted to, except where the animal is in full condition. Apply the following blister to the sides, well rubbed in : oil of turpentine, one ounce; croton-oil, twelve drops; aqua ammonia, half an ounce; linseed-oil, four ounces; mix all together. Give interually one pound of salts in drench, and follow with one of the following powders every four hours: nitrate of potash, one ounce; tartrate of antimony and pulverized digitalis leaves, of each, one drachm ; mix all together, and divide into eight powders. Or the following may be given with equal advantage : nitrate of potash, one and a half ounces; nitrate of soda, six ounces; mix, and divide into six powders; one to be given in wash or gruel every six hours. 


\section{PROTRUSION OF THE BLADDER.}

This sometimes occurs during the throes in difficult cases of parturition in cows, and the aid of a skillful veterinary surgeon is requisite to replace the inverted bladder.

\section{PUERPERAL FEVER.}

This disease-milk fever, or dropping after calving-rarely occurs until the animal has attained mature age. The first symptoms make their appearance in from one to five or six days after parturition. It appears to be a total suspension of nervous function, independent of inflammatory action, which is suddenly developed, and, in favorable cases, as suddenly disappears. It is called dropping after calving, from its following the parturient state.

Symptoms.-Tremor of hind legs; a staggering gait, which soon terminates in loss of power in the hind limbs; pulse rises to sixty or eighty per minute; milk diminishing in quantity as the disease progresses; the animal soon goes down, and is unable to rise, moans piteously; eyes set in the head; general stupor; and slow respiration.

Treatment.-This disease, though generally regarded as a febrile disorder, will not yield to the general practice of taking blood, as a large majority of the cases so treated die. The bowels must be opened, but the veins never. Give Epsom-salts, one pound; Jamaica ginger, two ounces; dissolve in warm water, one quart, and drench. The author usually gives with good effect, some five or six hours after the salts, two ounces of nitric ether and one ounce of tincture of opium, in half a pint of water. Rub well in, along the 
back and loins, the following: strong mustard, three ounces; aqua ammonia and water, each one and a half ounces. Some modifications in the treatment of this disease, as mell as of most others, will be necessary under certain circumstances, which can only be determined by the reterinary practitioner.

\section{QUARTER FVIL.}

In some sections of the country, this disease-known by the other names of black quarter, and joint murrain-is quite common among young cattle, and is generally fatal in its termination. There is little or no warning of its approach. The first animals in a herd to be attacked are generally those in a full, plethoric condition.

Symptoms. - The joints suddenly become swollen, and so painful as to produce severe lameness, particularly in the hind parts. General irritative fever exists in the system, attended with great tenderness of the loins; the head is - polied out; eyes red and bulging; the roots of the horns, as well as the breath, are hot; the muzzle dry, and nostrils expanded; pulse rises to seventy or eighty, full and hard; respiration is hurried; the animal is constantly moaning, and appears to be unconscious of surrounding objects; the swelling of the limbs extends to the shoulder and haunch; the animal totters, falls and dies in from twelve to twenty-four hours.

Treatment.-Early bleeding is requisite here, to be followed by active purgatives; after which, give one of the following powders every half hour: nitrate of potassa, two ounces; tartrate of antimony and pulverized digitalis, of each one and a half drachms; mix, and divide into eight powders. These should not be renewed. Cold linseed tea should be freely given. 


\section{RABIES.}

Hydrophobia in cattle is the result of the bite of a rabid dog, from which bite no animal escapes. The effects produced by the wound made by the teeth of such an animal, after the virus is once absorbed into the circulation of the blood, are so poisonous that all treatment is useless. The proper remedies must be instantly applied to prevent this absorption, or the case is utterly hopeless. Among men, nine out of every ten bitten by rabid dogs escape the terrible effects resulting from this dreadful disorder, without resorting to any applications to prevent it. It is a well-established fact, that men, when bitten by dogs, are generally wounded in some part protected by their clothing, which guards them from the deleterious effects of the saliva which covers the teeth, and which, at such times, is deadly poison. The teeth, in passing through the clothing, are wiped clean, so that the virus is not introduced into the blood; hence the comparatively few cases of rabies occurring in man. When, however, the wound is made upon an exposed surface, as the flesh of the hand, or of the face, this fatal disease is developed in spite of every precaution, unless such precautions are immediately taken. For this reason, cattle when bitten, do not escape the disease.

Symptoms.-The animal separates itself from the rest of the herd, standing in a kind of stupor, with the eyes halfclosed; respiration natural; pulse quickened; temperature of body and limbs natural ; the slightest noise agitates, causing the eyes to glare and exciting bellowing; the bark of a dog produces the most violent effects; the animal foams at 
the mouth and staggers as it walks; if water is offered, the muzzle is plunged into it, but the victim cannot drink; in making the effort, the most fearful consequences are produced. The animal now seeks to do mischief,-and the quicker it is then destroyed, the better.

Treatment.-This must be applied quickly, or not at all. The moment an animal is bitten, that moment the wound should be searched for, and when found, should be freely opened with a knife, and lunar caustic, caustic potash, or the per-manganate of potash at once applied to all parts of the wound, care being taken not to suffer a single scratch to escape. This, if attended to in time, will save the animal.

\section{RED WATER.}

This disease derives its name from the color of the urine voided in it. It is one of the most common complaints of horned cattle, and one of the most troublesome to manage.

Symptoms.-Respiration hurried; rumination ceases; a high degree of fever presented; the animal moans, arches the back, and strains in passing the urine, which is tinged with blood, or presents the appearance of pure blood. Prof. Gamgee, of the Edinburgh Veterinary College, says: "The cause is almost invariably feeding on turnips that have grown on damp, ill-drained land; and very often a change of diet stops the spread of this disease in the byre. Other succulent food, grown under similar circumstances, may produce the same symptoms, tending to disturb the digestive organs and the blood-forming process.

"In the course of my investigations as to the cause of various cattle-diseases, and of red water in particular. I have 
found that it is unknown on well-drained farms and in dairies where turnips are used only in a moderate degree. The lands of poor people furnish the roots most likely to induce this disorder; and I can confirm the statement of the late $\mathrm{Mr}$. Cumming, of Elton, who, in his very interesting essay upon this subject, says, particularly in reference to Aberdeenshire, that it is ' a disease essentially attacking the poor man's cow; and to be seen and studied, requires a practice extending into the less favorably situated parts of the country. On large farms, where good stock is well kept, and in town dairies, where artificial food is used to supplement the supply of turnips, it is' seldom now seen.'

"Symptoms. - General derangement attracts the dairyman's attention, and, upon observing the urine which the animal has voided, it is seen to be of a red, or of a reddish brown, or claret color; sometimes transparent, at others clear. The color increases in depth; other secretions are checked; the animal becomes hide-bound, and the milk goes off. Appetite and rumination are suspended; the pulse becomes extremely feeble and frequent, though-as in all debilitating, or anæmic, disorders-the heart's action is loud and strong, with a decided venous pulse, or apparent regurgitation, in the large veins of the neck.

"In some cases, if eren a small quantity of blood be withdrawn, the animal drops in a fainting state. In red water, the visible mucous membranes are blanched, and the extremities cold, indicating the languid state of the blood's circulation and the poverty of the blood itself. Constipation is one of the most obstinate complications; and many veterinary surgeons-aware that, if the bowels can be acted on, the 
animal is cured-nave employed purgatives in quantities far too large, inducing at times even death. Occasionally, diarrhœa is one of the first, and not of the unfarorable, symptoms."

Treatment.-Give one pint of linseed-oil ; clysters of soap and water should be freely used; and give plenty of linseedtea to drink. When the urine is abundant, give one ounce of tincture of opium, with one drachm of powdered aloes, three times, at intervals of six or eight hours.

\section{RHEUMATISM.}

This is a constitutional inflammatory affection of the joints, affecting the fibrous tissue and serous, or synovial membrane. It is caused by exposure to cold and wet; being quite common in low, marshy sections.

Symptoms._Loss of appetite; upon forcing the animal to move, every joint seems stiffened; nose dry; coat staring; constipation is also an attendant symptom; the joints, ono or more, become sivollen and painful. This may be regarded as a metastic, or shifting disease; first one part, and then another, seems to be affected.

Treatment.-Mild purgatives should be used; one-halfounce doses of colchicum-root pulverized will be found useful; one-ounce balls of pine-tar may also be given with advantage. As a local application, the author has found nothing to equal kerosene oil, one pint, to two ounces of aqua ammonia, well rubbed in, two or three times a day. 


\section{STRANGULATION OF THE INTESTINES.}

This disease in cattle,-popularly styled Knot, or Gut-tie,in consequence of the peculiar arrangement of the abdominal viscera, is of very rare occurrence. When, however, it does occur, the symptoms accompanying are those of inflammation of the intestines.

No kind of treatment will be successful, and the poor brute must suffer until death comes to its relief.

\section{THRUSH IN THE MOUTH.}

Aptha, or thrush in the mouth, is a vesicular disease of the mouth, sometimes occurring as an epizoötic. It is often mistaken for blain,-inflammation of the tongue, or black tongue,-and usually occurs in the winter, or early in the spring. It appears in the form of vesicles, or pustules all over the mouth, occasionally extending to the outside of the lips. These pustules break, discharging a thin, sanious fluid, leaving minute ulcers in their places.

This disease yields readily to treatment, when it is properly applied. Three ounces of Epsom-salts, once a day for three or four days, should be given in drench; wash the mouth well with a solution of alum, tincture of myrrh, or vinegar and honey, and it will disappear in a few days.

\section{TUMORS.}

These enlargements so common in cattle, have been so admirably described, in the Veterinarian for 1843, by John $\mathrm{R}$ alph, V.S.,-who has been so successful in the treatment of these morbid growths, that the benefit of his experience is 
here given. He says: "Of all the accidental productions met with among cattle, with the exception of wens, a certain kind of indurated tumor, chiefly situated about the head and throat, has abounded most in my practice.

"The affection often commences in one of the thyroid glands, which slowly but gradually increases in size, feels firm when grasped, and evinces very little tenderness. Generally the attendant is alarmed by a snoring or wheezing noise emitted by the animal in respiration, before he is aware of the existence of any tumefaction. This continues to increase, embracing in its progress the adjacent cellular and muscular tissues, and frequently the submaxillary and parotid glands. It becomes firmly attached to the skin through which an opening is ultimately effected by the pressure of pus from the centre of the tumor.

The swelling often presents an irregular surface, and various centres of maturation exist ; but the evacuations only effect a partial and temporary reduction of its bulk, in consequence of the continued extension of the morbid growth and ulcerative process which often proceed towards the pharynx, rendering respiration and deglutition still more difficult, until at length the animal sinks from atrophy or phthisis pulmonalis.

"In the early part of my practice, having been frustrated in my attempts to establish healthy action in these ulcers, and referring to the works that $I$ had on surgery for information, I concluded that they bore some resemblance to cancer in the human being, and determined to attempt extirpation. Subsequently, numerous cases have occurred in which $\mathrm{I}$ have successfully carried that determination into effect. I have 
had some instances of failure, which failure always arose from some portion of the morbid growth having been left.

"In the first stage, I have reason to believe that the tumor may be dispersed by the general and topical use of the iodurets. After the suppuration, I have tried them in vain.

"As soon as the nature of the tumor is clearly developed, I generally attempt its removal, and, when most prominent by the side of the larynx, I proceed in the following manner: -Having cast the beast, turned the occiput toward the ground, and bolstered it up with bundles of straw, I proceed to make an incision through it, if the skin is free, parallel with, and over, and between the trachea and sterno-maxillaris, extending it sufficiently forward into the inter-maxillary spaces. If I find it firmly attached to the apex of the tumor, I then enclose it in a curvilinear incision and proceed to detach the healthy skin to beyond the verge of the tumor.

"Its edges being held by an assistant, the knife is directed downwards through the subcutaneous parts, and all those that exhibit the slightest change from healthy structure are removed.

"By tying any considerable blood-ressel before dividing it, and by using the handle of the scalpel and the fingers in detaching the portion of the parotid gland towards the ear the hemorrhage was always inconsiderable.

"The wound is then treated in the ordinary way; except that detergents and even antiseptics are often needed to arouse healthy action, and the addition of some preparation of iodine is often made to the digestive. In directing the constitutional treatment, our chief aim must be to support 
the animal system with plenty of gruel until rumination is restored.

"I need not note that the operation should be performed after the animal has fasted some hours.

"As the success of the operation depends on an entire removal of the diseased parts, and as the submaxillary and parotid glands, with important branches of nerves and bloodvessels, are often enveloped therein, we must not hesitate to remove the former, nor to divide the latter. It has occasionally happened that a rupture has been made in the œsophagus, or pharyns, during the operation. In that case, a portion of the gruel with which the animal is drenched escapes for a few days; but I always found that the wound healed by granulation, without any particular attention.

"The weight of these tumors varies from a few ounces to some pounds. One that $I$ remored from a two-year-old Galloway bullock, weighed six pounds and a quarter. A considerable portion of the skin that covered it was excised and included in the above weight. It comprebened one of the parotid glands, and I had to divide the trunk of the carotid artery and jugular vein.

"This affection may be distinguished from parotiditis and other phlegmasice by the action of constitutional disturbance, and heat, and tenderness, and by the lingering progress it makes. I was once called to a bull laboring under alarming dyspnca that had gradually increased. No external en largement was perceptible; but on introducing my hand into the mouth, a large polypus was found hanging from the velum palati into the pharynx, greatly obstructing the elevation of the epiglottis and the passage of food. After 
performing tracheotomy, to prevent suffocation, I passed a ligature around its pedicle in the way suggested by the old anatomist, Cheselden.

"A section of one of these tumors mostly displays several abscesses, with matter varying in consistency and often very fetid, enclosed in what seems to me to be fibro-cartilaginous cysts, the exterior of which sometimes gradually disappears in the surrounding more vascular abnormal growth. Osseous matter (I judge from the grating of the scalpel upon it) occasionally enters into the composition of the cysts.

"I have treated this affection in cattle of the Long-horned, Short-horned, Galloway, and Highland breeds; and from the number of bulls in this class of patients, have reason to conclude that they are more liable to it than the female.

"About twelve months ago, I examined the head of a cow, on the right facial region of which there existed an enormous tumor, extending from the eye to the lips, and which I mistook during life for a periosteal enlargement. On cutting into it, my mistake was evident. There was scarcely a trace of the original bones beneath the mass; even those forming the nasal sinuses on that side were replaced by a formation much resembling the cysts before alluded to, and full of abscesses. The progress of the disease was decisively marked in the inferior rim of the orbital cavity, where the osseous matter was being remored, and the morbid structure deposited."

ULCERS ABOUT THE JOINTS.

Occasionally, the joints assume a tumefied appearance, generally ulcerating, and causing painful wounds.

Treatment.-The application of one part of alum to two 
WARELES.

parts of prepared chalk, powdered and sprinkled upon the parts, is usually all that is required.

\section{WARBLES.}

It has been a prevalent opinion among farmers, that warbles are so many evidences of the good condition of their cattle. It must, however, be borne in mind that the warbles are the larvo of the cestrus bovis, which is said to be the most beautiful variety of gad-fly. This fly, judging from the objects of its attack, must be particularly choice in its selection of animals upon which to deposit its eggs, as it rarely chooses those poor in flesh, or in an un.

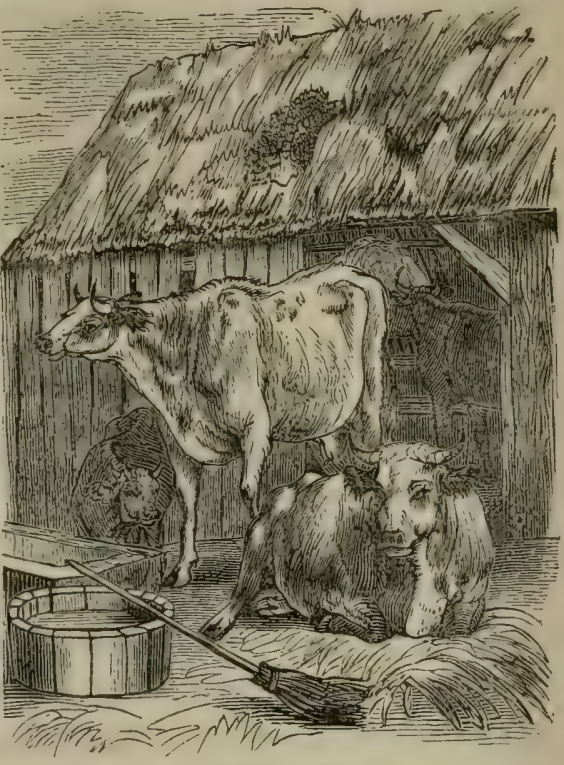

BOME AGAIN. healthy condition. From this circumstance, probably, has arisen the opinion above-mentioned.

These warbles-or larvo of the oestrus bovis-so nearly resemble bots in the horse-or larve cestrus equi-that, were it not for their increased size, they might readily be mistaken the one for the other. There is, however, one other difference, and that is in the rings which encircle the body; those 
of the former being perfectly smooth, while those of the latter are prickly, and from one third to one half smaller.

The author was called, in the year 1856 , to see the prize cow, Pet, belonging to James Kelly, of Cleveland, Ohio, whose extraordinary yield of butter and milk had been reported in the Ohio Farmer, a short time previous to his risit. This animal was found by him in rather poor condition; the causes of which he could only trace to the existence of these worms, comfortably located, as they were, beneath the animal's hide, and forming small tumors all along the spinal column, each being surrounded by a considerable quantity of pus. A number of these were removed by means of a curved bistoury and a pair of forceps, since which time-as he has been informed-the animal has rapidly improved, regaining her former good condition.

Some may urge that this is an isolated case; but an examination of cattle for themselves, will convince them to the contrary. It may be added, that two other cows, belonging to the same gentleman, were also examined at the same time,one of them being in good condition, and the other, out of condition. From the back of the latter several of these insects were remored, since which time she also has much improved. The former was entirely free from them. These cows were all kept in the same pasture, received the same care, and were fed on the same food, and at the same time; and as the removal of these larvae has been productive of such beneficial results, have we not a right to infer that these insects are injurious?

If we go further and examine, in the spring of the year, all cattle which are subject to them, instead of finding them in 
the fine condition which one would naturally expect,-considering the abundance of fresh young grass whose rigorous life they may incorporate into their own,-they are out of condition, and out of spirits, with a laggard eye, a rough coat, and, in some cases, a staggering gait, as though their strength had failed in consequence.

How shall such attacks be prevented? During the months of August and September this gad-fly is busily engaged in depositing its eggs. Some are of the opinion that they are placed on the hairs of the animal; others, that the skin is perforated, and the egg deposited in the opening, which would account for the apparent pain manifested by cattle at and after the time of such deposit. Be this as it may, it is certain that the maggot works its way into the muscular fibre of the back, and depends upon the animal's blood for the nourishment which it receives.

- The author has been informed, by persons in whom he ought to have confidence, that the free use of the card, during the above-named months, is a specific protection against the attacks of the oestrus bovis. He repeats this information here, not without diffidenee; since so large a majority of stock-owners evince, by their lack of familiarity with the practical use of this convenient and portable instrument, an utter disbelief in its reliability and value.

\section{WORMS.}

Cattle are not so subject to worms proper as are the other domestic animals; nor, when these parasites do exist, is any injurious effect apparent, except it be in the case of young calves of a weakly constitution. Worms are most commonly 
located in the small intestines, and cause there considerable mritation, and consequently, general emaciation, or at least a tendency to it.

The cause, however, is easily removed by administering oses of sulphate of iron, one-half drachm each, in molasses nce or twice a day.

\section{WORMS IN THE BRONCHIAL TUBES.}

Inflammation of the bronchial tubes is often caused by worms of the strongylus species. Upon examination after death, the bronchial passages are completely blocked-up by these hangers-on.

Symptoms.-A rough, staring coat; hide-bound; painful cough ; respiration hurried, etc.

Treatment.-But little can be done by way of treatment in this disease. The administration of small doses of spirits of turpentine has, in some instances, proved successful.

\section{SURGICAL OPERATIONS.}

\section{CASTRATION.}

The period most commonly selected for this operation is between the first and third months. The nearer it is to the expiration of the first month, the less danger attends the operation.

Some persons prepare the animal by the administration of a dose of physic; but others proceed at once to the operation when it best suits their convenience, or that of the farmer. Care, however, should be taken that the roung 
nnimal is in perfect health. The mode formerly practised was simple enough:-a piece of whip-cord was tied as tightly as possible around the scrotum. The supply of blood being thus completely cut off, the bag and its contents soon became livid and dead, and were suffered to hang, by som careless operators, until they dropped off, or they were cut off on the second or third day.

It is now, however, the general practice to grasp the scrotum in the hand, between the testicles and the belly, and to make an incision in one side of it, near the bottom, of sufficient depth to penetrate through the inner covering of the testicle, and of sufficient length to admit of its escape. The testicle immediately bursts from its bag, and is seen hanging by its cord.

The careless or brutal operator now firmly ties a piece of small string around the cord, and having thus stopped the circulation, cuts through the cord, half an inch below the ligature, and removes the testicle. $\mathrm{He}$, however, who has any feeling for the poor animal on which he is operating, considers that the only use of the ligature is to compress the blood-vessels and prevent after-hemorrhage, and, therefore. saves a great deal of unnecessary torture by including them alone in the ligature, and afterwards dividing the rest of the cord. The other testicle is proceeded with in the same way and the operation is complete. The length of the cord shoul be so contrived that it will immediately retract, or be dramn back, into the scrotum, but not higher, while the ends of the string hang out through the wound. In the course of about a week, the strings will usually drop off, and the wounds will speedily heal. There will rarely be any occasion to make 
any application to the scrotum, except fomentation of it, if much swelling should ensue.

A few, whose practice cannot be justified, seize the testicle as soon as it escapes from the bag, and, pulling violently, reak the cord and tear it out. It is certain that when a blood-ressel is thus ruptured, it forcibly contracts, and very little bleeding follows; but if the cord breaks high up, and retracts into the belly, considerable inflammation has oceasionally ensued, and the beast has been lost.

- The application of torsion-or the twisting of the arteries by a pair of forceps which will firmly grasp them-has, in a great degree, superseded every other mode of castration, both in the larger and the smaller domesticated animals. The spermatic artery is exposed, and seized with the forceps, which are then closed by a very simple mechanical contrivance; the ressel is drawn a little out from its surrounding tissue, the forceps are turned around seven or eight times, and the vessel liberated. It will be found to be perfectly closed; a small knot will have formed on its extremity; it will retract into the surrounding surface, and not a drop more of blood will flow from it; the cord may then be divided, and the bleeding from any little vessel arrested in the same way. Neither the application of the hot iron, nor of the wooden clamps, whether with or without caustic, can be necessary in the castration of the calf.

A new instrument was introduced in France, some few years since, for this purpose, called the acraseur,-so constructed as to throw a chain over the cord, which is wound up by means of a screw working upon the chain, and at the 
same time the cord is twisted off. No bleeding follows this method of operating.

This instrument is constructed upon the same principle as the acraseur for use in the human family, for the removal of hemorrhoids, etc., the dimensions of the two only varying.

The advantages resulting from the use of this instrument over all other methods are, that the parts generally heal within a week,-the operation is not so painful to the animal,-it is less troublesome to the operator,-also to the owner of the animal,-and lastly, it is a safer and more scientific operation. Its success in France soon gave it a reputation in England, and recently it has been introduced by the author into this country, and with the best results. Contractors, hearing of the success attending this new mode of operating, have visited him from all parts of the country to witness its performance, and not one bas returned without leaving an order for this instrument,-so well convinced have they been of its decided superiority over all other methods.

\section{TRACHEOTOMY.}

In consequence of the formation of tumors about the throat in cattle, from inflammation of the parotid gland, blain, etc., so characteristic of this species of animals, it sometimes becomes necessary to perform this operation in order to save their lives. It never fails to give instant relief.

After the animal has been properly secured,-which is done by an assistant's holding the nose with one hand, and one of the horns with the other,-the operator draws the skin tight over the windpipe with the thumb and fingers of nis left hand; then, with the scalpel in his right, cuts through the 
skin, making an incision about three inches long, dissecting up the skin on each side, which brings the trachea, or windpipe, in full view. He then cuts out a piece of the cartilaginous rings, about two inches long and about half an inch wide. This simple operation has saved the lives of very many valuable animals. The wound readily heals, and seldom leaves any perceptible blemish, if the work is properly performed.

\section{SPAYING.}

To secure a more uniform flow and a richer quality of milk, cows are sometimesspayed, or castrated. The milk of spayed cows is pretty uniform in quality; and this quality will be, on an average, a little more than before the operation was performed. In instances where the results of this operation have been carefully noted,-and the operation is rarely resorted to in this country, in comparison with the custom in France and other continental countries,- - the quality of the milk has been greatly improved, the yield becoming regular for some years, and varying only in accordance with the difference in the succulence of the food.

The proper time for spaying is about five or six weeks after calving, or at the time when the largest quantity of milk is given. There seems to be some advantages in spaying for milk and butter dairies, where attention is not paid to the raising of stock. The cows are more quiet, never being liable to returns of seasons of heat. which always more or less affect the milk, both in quantity and quality. They give milk nearly uniform in these respects, for several years, provirled the food is uniformly succulent and nutritious. Their milk is influenced like that of other cows, though to a 
less extent, by the quality and quantity of food; so that in winter, unless the animal is properly attended to, the yield will decrease somewhat, but will rise again as good feed returns. This uniformity for the milk-dairy is of immense advantage. Besides, the cow, when old and inclined to dry up, takes on fat with greater rapidity, and produces a juicy and tender beef, superior, at the same age, to that of the ox.

The following method of performing this operation is sanctioned by the practice of eminent veterinary surgeons in France :-

Having covered the eyes of the cow to be operated upon, she is placed against a wall, provided with five rings firmly fastened and placed as follows : the first corresponds to the top of the withers; the second, to the lower anterior part of the breast; the third is placed a little distance from the angle of the shoulder; the fourth is opposite to the anterior and superior part of the lower region; and the fifth, which is behind, answers to the under-part of the buttocks. A strong assistant is placed between the wall and the head of the animal, who firmly holds the left horn in his left hand, and with his right, the muzzle, which he elevates a little. This done, the end of a long and strong-plaited cord is passed through the ring which corresponds to the lower part of the breast, and fastened; the free end of the cord is brought along the left flank, and through the ring which is below and in front of the withers. This is brought down along the breast behind the shoulder and the angle of the fore-leg in order to pass it through the third ring; then it must be passed around against the outes' angle of the left hip, and fastened 
after having been drawn tightly to the posterior ring, by a simple bow-not.

The cow being thus firmly fixed to the wall, a cord is firstened by a slip-noose around her hocks, to keep them ogether in such a manner that she cannot kick the operator, the free end of the cord and the tail being held by an assistant. 'The cow thus secured cannot, during the operation, move forward, nor lie down, and the operator has all the ease desirable, and is protected from accident.

The operator next-placed opposite to the animal's left flank, with his back turned a little toward the head of the animal-cuts nff the hair which covers the hide in the middle of the flanks, at an equal distance between the back and hip, for the space of thirteen or fourteen centimetres in circumference (the French centimetre is rather more than thirty-nine one hundredths of an inch); a convex bistoury is placed, opened, between his teeth, the edge out, the joints to the left; then, with both hands, he seizes the hide in the middle of the flank, and forms of it a wrinkle of the requisite elevation, running lengthwise of the body. The assistant seizes with his right hand the right side of this wrinkle; the operator takes the bistoury and cuts the wrinkle, at one stroke, through the middle; the wrinkle having been suffered to go down, a separation of the hide is presented, of sufficient length to admit the introduction of the hand; the edges of the hide are separated with the thumb and forefinger of the left hand, and in like manner the abdominal muscles are cut through, for the distance of a centimetre from the lower extremity of the incision made in the hide,--the iliac slightly obliquely, and the lumbar across; a puncture of the peritoneum, at the upper 
extremity of the wound, is then made with the straight bistoury; the buttoned bistoury is then introduced, and moved obliquely from above to the lower part, up to the termination of the incision made in the abdominal muscles.

The flank being opened, the right hand is introduced into the abdomen, and directed along the right side of the cavity of the pelvis, behind the paunch, and underneath the rectum, to the matrix; after the position of these viscera is ascertained, the organs of reproduction, or oraries, are searched for, which are at the extremity of the matrix; when found, they are seized between the thumb and fore-finger, detached completely from the ligaments which keeps them in their place, and by a light pull, the cord and the vessels, the uterine or Fallopian tube, are separated at their place of union with the ovarium, by means of the nails of the thumb and forefinger, which present themselves at the point of touch, thus breaking the cord and bringing away the ovary.

The hand is again introduced into the abdominal cavity, and the remaining ovaries brought away in like manner. A suture is then placed of three or four double threads, waxed at an equal distance, and at two centimetres, or a little less, from the lips of the wound, passing it through the divided tissues; a movement is made from the left hand with the piece of thread; having reached that point, a fastening is made with a double knot, the seam placed in the intervals of the thread from the right, and as the lips of the wound are approached, a fastening is effected by a simple knot, with a bow, care being taken not to close too tightly the lower part of the seam, in order to allow the suppuration, which may be established in the wound. to escape. The wound is then 
covered up with a pledget of lint, kept in its place by three or four threads passed through the stitches, and the operation is complete.

It happens, sometimes, that in cutting the muscles before mentioned, one or two of the arteries are severed. Should much blood escape, a ligature must be applied before opening the peritoneal sac; since, if this precaution is omitted, blood will escape into the abdomen, which may occasion the most serious consequences.

For the first eight days succeeding, the animal should hare a light diet, and a soothing, lukewarm draught; if the weather should be cold, cover with a woollen corering. She nust be prevented from licking the wound, and from rubbing it against other bodies. The third day after the operation, bathe morning and evening about the wound with water of mallows lukewarm, or anoint it with a salve of hog's lard, and administer an emollient glyster during three or four days.

Eight days after the operation, take away the bandage, the lint, the fastenings, and the thread. The wound is at that time, as a general thing, completely cicatrized. Should, howerer, some slight suppuration exist, a slight pressure must be used above the part where it is located, so as to cause the pus to leave, and if it continues more than five or six days, emollients must be supplied by alcotized water, or chloridized, especially in summer. The animal is then to be brought back gradually to her ordinary nourishment.

In some cows, a swelling of the body is observable a short time after having been spayed, attributable to the introduction of cold air into the abdomen during the operation; but this derangement generally ceases within twenty-four hours. 
Should the contrary occur, administer one or two sudorific draughts, such as wine, warm cider, or a half-glass of brandy, in a quart of warm water, - treatment which suffices in a short time to restore a healthy state of the belly,- the animal at the same time being protected by two coverings of wool.

The only precaution, in the way of management, to be observed as a preparative for the operation is, that on the preceding evening not so copious a meal should be given. The operation should also be performed in the morning before the animal has fed, so that the operator may not find any obstacle from the primary digestire organs, especially the paunch, which, during its state of ordinary fullness, might prevent operating with facility.

The advantages of spaying milch-cows are thus summed up by able French writers: First, rendering permanent the secretion of milk, and having a much greater quantity within the given time of every year; second, the quality of milk being improved; third, the uncertainty of, and the dangers incident to, breeding being, to a great extent, avoided; fourth, the increased disposition to fatten even when giving milk freely, or when, from excess of age or from accidental circumstances, the secretion of milk is otherwise checked; fifth, the very short time required to produce a marketable condition ; and sixth, the meat of spayed cattle being of a quality superior to that of ordinary cattle.

This operation would seem to have originated in this country The London Veterinary Journal of 1834 contains the following, taken from the United States Southern Agriculturist:- "Some years since, I passed a summer at Natchez, and put up at a hotel there, kept by Mr. Thomas 
Winn. During the time that I was there I noticed two remarkably fine cows, which were kept constantly in the stable, the servant who had charge of the horses, feeding them regularly three times a day with green guinea grass, cut with a sickle. These cows had so often attracted my attention, on account of the great beauty of their form, and deep red color, the large size of their bags, and the high condition in which they were kept, that I was at length induced to ask Mr. Winn to what breed of cattle they belonged, and his reasons for keeping them constantly in the stable in preference to allowing them to run in the pasture, where they could enjoy the benefit of air and exercise, and at the same time crop their own food, and thereby save the labor and trouble of feeding them?. Mr. Winn, in reply to these in. quiries, stated that the two cows which I so much admired were of the common stock of the country, and he believed, of Spanish origin; but they were both spayed cows, and that they had given mills either two or three years. Considering this a phenomenon (if not in nature at least in art), I made further inquiries of Mr. Winn, who politely entered into a very interesting detail, communicating facts which were as extraordinary as they were novel. Mr. Winn, by way of preface, observed that he, in former years, had been in the habit of reading English magazines, which contained accounts of the plowing-matches which were annually held in some of the southern counties of England, performed by cattle, and that he had noticed that the prizes were generally adjudged to the plowman who worked with spayed heifers; and although there was no connection between that subject and the facts which he should state, it was, nevertheless, the 
cause that first directed his mind into the train of thought and reasoning which finally induced him to make the experiments, which resulted in the discovery of the facts which he detailed, and which I will narrate as accurately as my memory will enable me to do it, after the lapse of more than twenty years. Mr. Winn's frequent reflections had (he said) led him to the belief 'that if cows were spayed soon after calving, and while in a full flow of milk, they would continue to give milk for many years without intermission, or any diminution of quantity, except what would be caused by a change from green to dry, or less succulent food." To test this hypothesis, Mr. Winn caused a very good cow, then in full milk, to be spayed. The operation was performed about one month after the cow had produced her third calf; it was not attended with any severe pain, or much or long continued fever. The cow was apparently well in a few days, and very soon yielded her usual quantity of milk, and continued to give freely for several years without any intermission or diminution in quantity, except when the food was scarce and dry; but a full flow of milk always came back upon the return of a full supply of green food. This cow ran in the Mississippi low grounds or swamp near Natchez, got cast in deep mire, and was found dead. Upon her death, Mr. Winn caused a second cow to be spayed. The operation was en tirely successful. The cow gave milk constantly for severa years, but in jumping a fence stuck a stake in her bag, that inflicted a severe wound, which obliged Mr. Winn to kill her. Upon this second loss, Mr. Winn had two other cows spayed, and, to prevent the recurrence of injuries from similar causes with those which had occasioned him the loss of the first two 
spayed cows, he resolved to keep them always in the stable, or some safe enclosure, and to supply them regularly with green food, which that climate throughout the greater part of, if not all, the year enabled him to procure. The result, in regard to the last two spayed cows, was, as in the case of the first two, entirely satisfactory, and fully established, as Mr. Winn believed, the fact, that the spaying of cows, while in full milk, will cause them to continue to give milk during the residue of their lives, or, until prevented by old age. When I saw the last two spayed cows it was, I believe, during the third year that they had constantly given milk after they were spayed. The character of Mr. Winn (now deceased) was highly respectable, and the most entire confidence could be reposed in the fidelity of his statements; and as regarded the facts which he communicated in relation to the several cows which he had spayed, numerous persons with whom I became acquainted, fully confirmed his statements."

In November 1861, the author was called to perform this operation upon the short-horn Galloway cow, Josephine the Second, belonging to Henry Ingersoll, Escy., of this city. This corv was born May Sth, 1860. The morning was cold and cloudy. About ten o'clock the cow was cast, with the assistance of R. McClure, V.S., after which she was placed under the influence of chloric ether. He then made an incision, about five inches in length, through the skin and walls of the abdomen, midway between the pelvis bone and the last rib on the left side, passing in his right hand, cutting away the ovaries from the Fallopian tubes with the thumbnail. The opening on the side was then closed by means of 
the interrupted suture. The animal recovered from the influence of the anæsthetic in about fifteen minutes, when she was allowed to rise, and walk back to her stall.

Upon the morning of the second day succeeding the operation, the animal was visited and found to be in good spirits, apparently suffering very little pain or inconvenience from the operation, and the wound healing nicely.

Since that time, he has operated upon some twenty cows, all of which, with a single exception, have thus far proved satisfactory.

Several of these cows are under the direction of a com. mittee from the Philadelphia Society for promoting Agriculture, whose duty it is to have a daily record kept of each cow's yield of butter and milk, for one year from the time of spaying. Their report will be perused by the agricultural community with much interest.

The author's own experience will not justify him in speaking either in favor of, or against, this operation; as sufficient time has not as yet elapsed to satisfy him as to its relative advantages and disadvantages. He, however, regards the operation as comparatively safe. The French estimate the loss at about fifteen per cent, and the gain at thirty per cent. Of those upon which he has operated, not a single animal died. 


\section{A LIST OF MEDICINES USED IN TREATING CATTLE.}

The medicines used in the treatment of the diseases of cattle, are essentially the same as those in vogue for the diseases of the human being and the horse,- the only difference being in their combination and the quantities administered.

Absorbents. -Medicines which destroy acidities in the stomach and bowels; such as chalk, magnesia, etc.

Alteratives. - Medicines which restore the healthy functions of secretion, by gradually changing the morbid action in an impaired constitution. Those in most common use are Ethiops mineral, antimony, rosin, sulphur, etc., which form the principal ingredients in all condition-powders, and are chiefly useful in diseases of the skin, such as hide-bound, mange, surfeit, etc.

Alterative Powder.-Sulphur pulverized, one pound; black antimony, one half a pound; nitrate of potassa, four ounces; sulphate of iron, one half a pound; linseed meal, one pound; mix well; dose, one half an ounce, night and , morning.

AnTacids.-Agents which neutralize, by their chemical nction, acids in the stomach; as ammonia, carbonate of potassa, chalk, lime-water, magnesia, and soda.

A nthelinntics.-Remedies used for the expulsion of worms from the stomach and intestines. These may act chemically or by their cathartic operation. The most 
reliable are Ethiops mineral, uux vomica, preparations of mercury, wormwood, etc.

Antuelamntic Porders. - Nux romica, in one half-drachm doses, two or three times daily, to an ox or cow; for calres, the dose must be diminished, according to age.

Axтinotes.-Medicines which neutralize the effects of poisons by a chemical union, forming an insoluble compound, or a mild, harmless one. Alkaline solutions are antidotes for the mineral acids; as soap in solution, a simple remedy, and always at hand. Lard, magnesia, and oil are antidotes for poisoning by arsenic ; albumen,-in the form of the white of an egg,-milk, etc., for corrosive sublimate, and other mercurial preparations.

Antiseptics. - Medicines which prevent putridity in animal substances, and arrest putrefaction, when already existing. These are used both externally and internally. The chief specifics of this class are the acids, alcohol, ammonia, asafœtidla, camphor, charcoal, chloride of lime, cinchona, ether, and opium.

Antispasurodics.-Medicines which exert their power in allaying inordinate motions or spasms in the system, arising from various causes, such as debility, worms, etc. Those most generally in use are ammonia, asafœtida, camphor, cinchona, ether, lactacarium, mercury, and opium.

Antispasmodic DRAUGHT. - Tincture of opium, one ounce; nitric ether, two ounces; water, one-half pint. Mix for drench; if repeated, it should be followed by a purgative, as soon as the spasms have subsided. Or, use the following: sulphuric ether, one to two ounces; water, one-half pint. Mix for drench; repeat every hour, if necessary. 
Aromatrcs. - Medicines possessing a grateful, spicy scent, and an agreeable, pungent taste; as anise-seed, cardamoms, cinnamon, cloves, ginger, etc. They are principally used in combination with purgatives, stomachics, and tonics.

Astringents.-Medicines which serve to diminish excessive discharges, as in diabetes, diarrhœa, etc. The principal agents of this class are the acids, alum, chalk, lime-water, opium, and the sulphate of copper, lead, iron, or zinc.

Astringent powder.-Opium, one drachm; prepared chalk, balf an ounce; Jamaica ginger, six drachms. Mix, and divide into four powders; one to be given every hour, in a little flour gruel. Or, the following: opium, one drachm; catechu, two drachms; prepared chalk, one ounce. Mix, and divide into four powders; to be given as before.

Cardiacs. - Cordials-so termed, from their possessing warm and stimulating properties-given to invigorate the system.

Cathartics.-Medicines - also known as purgativeswhich cause free eracuations of the bowels. The only purgatives used by the author in his cattle practice, as a general rule, are aloes, cream of tartar, Epsom-salts, lard and linseedoil. These answer all the indications, where purgatives are useful; indeed, no better purgative for cattle can be found than Epsom-salts, combined with a carminative or aromatic clrug, such as ginger.

Caustics. - Substances which burn or destroy parts, by combining with them and causing their disorganization; used to destroy unhealthy action, or morbid growths, such as foul ulcers, foul in the foot, warts, etc. The most powerful remedial of this class is actual cauterization with a red-hot 
iron; caustic potash, lunar caustic, nitrous and sulphuric acids, permanganate of potash, etc., are also used.

Condials.-Best brandy, three ounces; orange peel, one drachm; tepid water, one pint. Mix all together, for one dose. Or, this for a single dose: ale, one pint; Jamaica ginger, two drachms. Or, the following, also a single dose : allspice, three drachms; ginger, one drachm; caraway seeds, two drachms.

Dexulcents. -Mucilaginous medicaments, which have the power of diminishing the effects of stimulating substances upon the animal system. Of this class, garden rue, or marsh-mallow, gum-arabic, and gum-tragacanth are the most useful.

Detergents. - Agents which remore foulness from ulcers.

Detergent Powder.-Prepared chalk, two ounces; alun, one ounce. Mix; to be sprinkled on the part, after washing with Castile-soap and water. This powder is also an admirable application for foot-rot in sheep.

Diaphonetics. - Agents which increase the natural discharge through the pores of the skin, and in some animals induce perspiration.

Digestrves._Medicines which promote suppuration.

Draestive Orntuent.-Mix together equal portions of spirits of turpentine and lard. Or, mix together with a gentle heat the following: Venetian turpentine, one ounce; lard, one ounce; pulverized sulphate of copper, two drachms. Or this, mixed : rosin, two ounces; spirits of turpentine, one ounce; red precipitate, one-half an ounce; lard, two ounces.

Divretics. - Medicines that stimulate the action of the kidneys, and augment the secretion of urine. These are very 
useful in swellings of the legs or body. Take of nitrate of potash and rosin, each six drachms; mix, and divide in three powders; one to be given daily. Or, the following: spirits of turpentine, half an ounce; Castile-soap, one ounce; Jamaica ginger one drachm; opium, one drachm. Mix: and divide in two balls; one to be given each day.

Emollients.-Medicines which relax the lining tissues, allay irritation, and soften the parts involved,-_enerally of a mucilaginous, or oily character. Lard, linseed meal, and marsh-mallows are chiefly used.

Lithontriptics. -Medicines possessing the power of dissolving calculi, or stones in the urinary passages; composed principally, according to the researches of modern chemists, of lithic or uric acid. The preparation most successfully employed by the author in such cases is muriatic acid, in doses of from one to two drachms, in a pail of water, once or twice a day.

NARCotics.-Medicines that stupefy, and produce sleep. Belladonna, camphor, hyoscyamus and opium, are among the narcotics in common use.

Nauseants.-Agents which cause loss of appetite, and produce the sensation of vomiting, without affecting it. For this purpose, aloes, tartrate of antimony, white hellebore, etc., are used.

Parturients. - Agents which act upon the uterus. In cases of difficult parturition, or calving, resort is occasionally had to them. Ergot of rye is the most powerful.

Refrigerants.-Cooling applications, which reduce the temperature of the blood and body; as cold water, ether, ?ead-water, etc. 
Rubefacients. - Meclicines which gently irritate the skin, producing redness on white surfaces. Of this class, are aqua ammonia, creosote, mustard, turpentine, etc.

Sedatives.-Agents which depress the vital energies, without destroying life; as aconite, digitalis, hellebore, hydrochloric acid, hyoscyamus, opium, and tartrate of antimony.

TonIcs.-Medicines which increase the action of the muscular system; giving strength and vigor to the animal. These are among the most useful remedies known to man, and are beneficial in all cases of debility, toning up the stomach, and improving the appetite and condition of the animal.

Tonic Potrder - Pulverized gentian-root, one ounce; Jamaica ginger, one half an ounce; anise-seed, six drachms. Mix, and divide in eight powders; one to be given night and morning.

Traumatics. - Medicines which excite the healing process of wounds; as aloes, friar's balsam, myrrh, rosin, sulphate of copper or zinc, tar, etc.

Traumatic Lotion.-Mix tincture of aloes, one ounce; tincture of myrrh, two ounces. Or, melt together, tar, one ounce; rosin, two ounces; lard, four ounces. Or, mix sulphate of zinc, one drachm; rain-water, one half pint. Or, use the following, the celebrated friar's balsam; benzoin, in powder, four ounces; balsam of Peru, two ounces; Socotrine aloes, one half ounce; rectified spirits, one quart. Digest for ten or twelve days; then filter for use. 


\section{DOSES OF TARIOUS REMEDIES USED IN CATTLE PRACTICE.}

Aconite.-[Monk's hood; Wolf's bane.] An active poison. Used as a sedative in tincture; ten to twenty drops in water.

Ethiops Mrnerat. - [Hydrargyri Sulphuretum.] One to two drachms.

ALcomoL. - A stimulant; three to six ounces.

ALLSPICE - [Pimento berries.] Aromatic; two to four drachms.

Alozs.-Cathartic and tonic; tonic dose, one half to one drachm-cathartic, one to two ounces.

Arun.-[Alumen.] Irritant, astringent, and sedative; two to four drachms.

Amonia-[Aqua ammonia; Liquor ammonia; Hartshorn.] Principally used in combination with mustard, as an external irritant, and internally, as a diffusible stimulant; two to six drachms. Of carbonate of ammonia, three to six drachms.

ANISE-SEED. - [Fruit of the Pimpinella Anisum.] One to two drachms.

Antrunony. - [Sulphate of Antimony.] Used in conditionpowders; one to three drachms. Muriate of antimony. [Oil, or butter, of antimony.] Caustic; very good in foul in the foot. Tartarized antimony. [Tartar emetic.] One to four drachns. The author, in the last instance, varies from the duse prescribed by veterinary authors, never giving it in more 
than one-half-drachm doses, believing its action thus more certain and satisfactory.

AsAFETIDA. - Stimulant; two to four drachms.

Axunge.-[Hog's Lard.] Ointment, principally; may be used as purgative in doses of from one to one and a half pounds.

Balsam of Peru.-Stimulant, and tonic; two to four drachims.

Beluadonna. - [Deadly Nightshade. $]$ Narcotic, antispasmodic, and irritant poison; one to two drachms.

Benzoin.-[Gum Benjamin.] Ointment; see Traumatics.

CALOMEL.-[Hydrargyri Chloridum.] One half to one drachm.

CAMOMILE.-[Anthemis.] Stomachic, carminative, and tonic; one to two ounces.

CAMrhor.-[Camphora Officinarum.] Narcotic and irritant; in small doses, sedative and stimulant; one to four drachms.

Cantharides. - [Spanish Flies.] Internally, stimulant and diuretic; twenty to thirty grains. Externally, vesicant; used in form of ointment, or tincture..

Caraway.-[Fruit of the Carum Carisi.] Used chietly for flavoring purposes.

Cardamoms. - [Fruit of the Eleltaria Cardamomum.] Used to communicate an agreeable flavor to other medicines

Catechu. - [Acacia Catechu. $]$ Astringent, and antiseptic ; three to six drachms.

CHALK. - [Carbonate of Lime; Calcis Carbonas.] Two to three ounces. 
Charcoax.-[Carbo Ligni.] Antiseptic; one half to one ounce.

Cinchona.-[Peruvian Bark.]. Astringent and tonic; one to two ounces.

Copper, Sulphate of.-[Blue Vitriol. $]$ Tonic and astringent; two to four drachms.

Creosote.-[Creosotum.] A sedative, anodyne, astringent, narcotic, and irritant poison; fifteen to twenty drops.

Croton OrL._[Crotonis Oleum.] Internally, as a cathartic, six to ten drops in linseed-oil; externally, as a counter-irritant.

Digitalis. \&[Fox Glove.] Sedative and diuretic; one to two scruples.

Erson-Salts.-[Sulphate of magnesia.] Cathartic; one nound, combined with ginger.

Engor.-[Spurred rye.] Parturient; two to six drachms.

ETHer._-Stimulant, narcotic, and anæsthetic; one to two ounces.

Gentran.-[Root of Gentiana lutea]. Stomachic and tonic; one to two ounces.

Ginaer-[Zengiber officinale.] Stomachic, carminative, and slightly tonic; one to two ounces.

Gum-arabic.-[Gummi Acacice.] Demulcent and emollient; one to two ounces.

Gun-tragacanth. Same action and same doses as the former.

HeLI.EBoRE.-[Helleborus.] Irritant poison, and sedative; twenty to thirty grains.

Iroscranus. - [Henbane.] Narcotic, anodyne, and antispasmodic; ten to twenty grains. 
IoDINe.-[Iodineum.] Internally, as a tonic; two to three scruples; also as a tincture, and in ointments for reducing enlargements of the soft tissues.

Iron, Sulphate of.-[Ferri Sulphas; Green Vitriol, Copperas.] Irritant, astringent, and tonic; two to four drachms.

Koosso. Anthelmintic; two to four drachms.

Lime, Chloride of. Antiseptic; dose internally, one to two drachms.

LINSEED oIL. Cathartic; one pint.

Lunar Caustic. - [Nitrate of Silver.] Used as a caustic.

Magnesta.-[See ÉpSom-Salts.]

Marse-Mallow. - [Althece Radix.] Demulcent and emollient; principally used for poultices and fomentations.

Muriatic Acid.-[Hydrochloric Acid; Spirit of Salt.] tonic, irritant, and caustic; dose internally, one to two drachms.

MUUstard.-[Sinapis.] Counter-irritant; used principally as an external application.

MrrrH.-Stimulating tonic to unhealthy sores; seldom used internally.

Nirric ACID._-_Aqua fortis.] Astringent and tonic; one to two drachms in water. Used also as a caustic.

Nux Vomica.-[Seeds of Strychnos.] In large doses, a deadly poison; in medicinal doses, a powerful tonic and anthelmintic; one half to one drachm.

OpIux.-[Papaver Somniferum.] Narcotic, sedative, anodyne, stimulant, and anti-spasmodic ; two to four drachms.

Potash, Carbonate of.-[Potassce Carbonas.] Antacid and diuretic; three to six drachms. 
Potasi, Caustic.- - [ Potassa fusa. ] Used only as a caustic. Potassa, Permanganate of.-Used externally as a caustic.

Rosin.-Diuretic; two to three ounces.

Salt, Common.-[Chloride of Sodium.] Irritant, cathar tic, stimulant, and antiseptic; one to one and a half pounds.

Salts, Glauber.-[Sulphate of Soda.] Cathartic and diuretic; one to one and a half pounds.

Saltpetre.-[Nitrate of Potassa.] Diuretic, febrifuge, and refrigerant; one half to one ounce.

Sublimate, Corrosrve.-[Prolockloride of Mercury.] Seldom used internally; externally, caustic and stimulant.

Sulphur.-[Brimstone.] Stimulant and laxative; three to four ounces.

Sulphuric AcID.-Irritant, caustic, and astringent; two to three drachms.

Tartar, Cream of.-[Potassce Tartras. $]$ Cathartic; three to four ounces.

Turpentine.-Stimulant, anthelmintic, diuretic, and laxative; one to two ounces.

Zinc, Sulphate OF. $-[$ White Vitriol. $]$ Astringent and tonic; one to two drachms. 
SHEEP, SWINE, AND POULTRY. 



\section{PREFACE.}

Excouraged by the farorable reception of his former works, the author presents in the following pages what is intended by him as a popular compendium relative to Sheep, Swine, and Poultry.

It would not have been a difficult matter to collect material bearing upon each distinct class sufficient for an entire volume of the present size. Indeed, the main trouble experienced has been the selecting of such facts and suggestions only as seemed to him of paramount practical importance. He has not deemed it advisable to cumber his work with items of information which could be of serrice to particular sections and localities only; but has rather endearored to present, in a concise, yet comprehensible shape, whatever is essential to be understood concerning the animals in question.

'The amateur stock-raiser and the wealthy farmer will, of course, call to their aid all the works, no matter how expensive or voluminous, which are to be found bearing upon the subject in which they are for the time interested. The present volume can scarcely be expected to fill the niche which such might desire to see occupied.

The author's experience as a veterinary surgeon among the great body of our farmers convinces him that what is needed by them in the premises is a treatise, of conrenient size, containing the essential features of the treatment and management of each, couched in language free from technicality or rarely scientific expressions, and fortified by the results of actual experience upon the farm.

Such a place the author trusts this work nay occupy. He hopes that, while it shall not be entirely destitute of interest for any, it will prove acceptable, in a peculiar degree, to that numerous and thrifty class of citizens to which allusion has already been made.

The importance of such a work at the present time cannot well be overrated. Take the subject of sheep, for example: the scarcity of cotton, resulting from the war in which the nation is engaged, has 
caused a great and lucrative development of the wool trade. More than a million of men in the service of the Government wear nothing but woollen; and in the community generally, light fabrics of wool are more in demand than ever before. In 1860, our imports of wool from England were less than three millions of pounds; in 1861, they were upward of ten millions; in 1862, more than eleven and a half millions; while in 1863, at the port of New York, the imports for the first five months were upward of twenty-one millions of pounds.

Relative to swine, moreover, it may be said that they form so considerable an item of our commerce that a thorough information as to the best mode of raising and caring for them is highly desirable; while our domestic poultry contribute so much, directly and indirectly, to the comfort and partial subsistence of hundreds of thousands, that sensible views touching that division will be of service in almost every household.

To those who are familiar with the author's previous works upon the Horse and Cattle, it is needless to say any thing as to the method adopted by him in discussing the subject of Diseases. To others he would say, that only such diseases are described as are likely to be actually encountered, and such curatives recommended as his own personal experience, or that of others upon whose judgment he relies, has satisfied him are rational and valuable.

The following works, among others, have been consulted: Randall's Sheep Husbandry; Youatt on Sheep; Goodale's Breeding of Domestic Animals; Allen's Domestic Animals; Stephens's Book of the Farm; Youatt on the Hog; Richardson on the Hog; Dixon and Kerr's Ornamental and Domestic Poultry; Bennett's Poultry Book; and Browne's American Poultry Yard.

To those professional brethren who have so courteously furnished him with valuable information, growing out of their own observation and practice, he acknowledges himself especially indebted; and were he certain that they would not take offence, he would be pleased to mention them here by name.

Should the work prove of service to our intelligent American farmers and stock-breeders as a body, the author's end will have been attained. 


\section{O N T ENTS.}

\section{SHEEP AND THEIR DISEASES.}

\section{HISTORT AND VARTETIES.}

PAGE

American Seeep

15

Native Sheep.

The Spanish Merino

The Saxon Merino.

The New Leicester.

The South-Down.

The Cotswold.

The Cheviot.

The Lincoln

NATURAL IISTORY OF THE SHEEP............................................. 57

Formation of the Teeth............................................................ 59

Structure of the Skin................................................................. 63

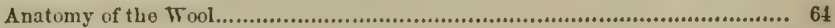

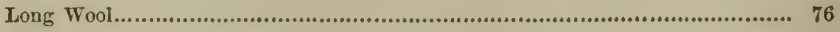

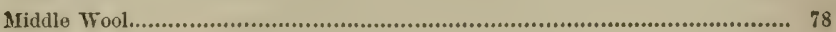

Short Wool................................................................................... 80

CROSSING AND BREEDING.............................................................. 81

BRERDing........................................................................... 81

Points of the Merino.................................................................. 93

Breeding Merinos.............................................................................. 97

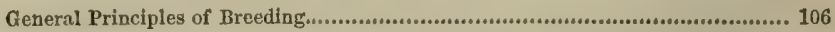

Uge of Rams............................................................................. 112

Lambing........................................................................................ 117

Management of Lambs............................................................ 121

Castration and Docking................................................................ 127 


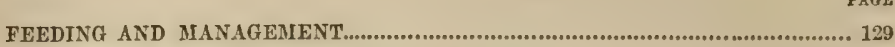

FEEDING......................................................................... 129

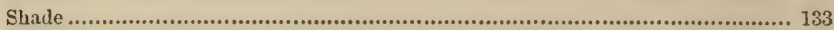

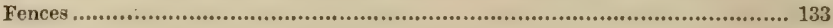

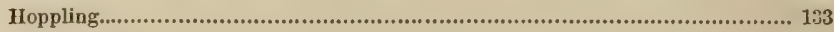

Dangerous Rams........................................................................ 13!

Prairie Feeding..................................................................... 135

Fall Feeding,.................................................................................. 137

Winter Feeding..................................................................... 137

Feeding with other Stock............................................................... 142

Division of Flocks................................................................... 142

Regularity in Feeding............................................................... 143

Effect of Food................................................................................. 144

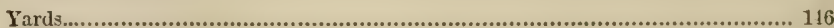

Feeding-Racks ..................................................................... 147

Troughs .............................................................................. 150

Barns and Sheds.................................................................. 151

Sheds .............................................................................. 155

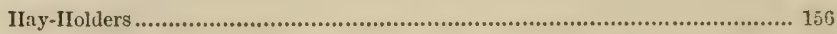

Tagging

Washing........................................................................... 100

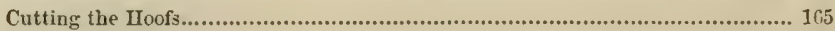

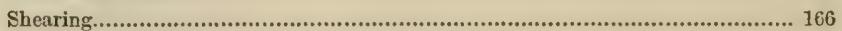

Cold Storms....................................................................... 171

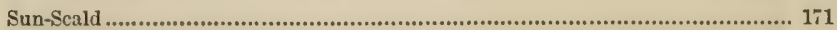

Ticks................................................................................. 171

Marking or Branding............................................................. 172

Maggots.............................................................................. 173

Shortening the Horns.............................................................. 17t

Selection and Division.............................................................. 174

The Crook....................................................................................... 176

Driving and Slaughtering............................................................ $17 t$

Driving........................................................................... 177

Points of Fat Sheep.................................................................. 181

Slaughtering................................................................................. 18t

Cutting Up................................................................................. 186

Relative qualities........................................................................ 187

Contributions to Manufactures........................................................... 191 


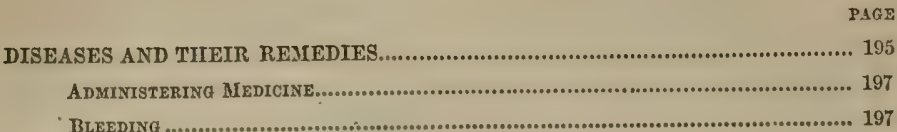

FEELING XHE PULSE.................................................................................... 199

Apoplexy .................................................................................... 200

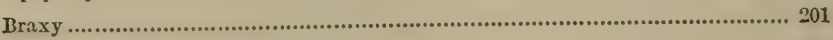

Bronchitis........................................................................... 201

Catarrh.............................................................................. 202

Malignant Epizoötic Catarrh.......................................................... 203

Colic ................................................................................. 205

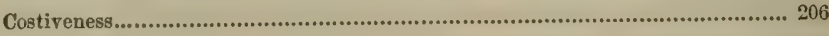

Diarrhcea............................................................................. 206

Disease of the Biflex Canal.................................................................... 207

Dysentery,........................................................................... 208

Flies........................................................................................ 209

Fouls ..................................................................................... 209

Fractures ............................................................................ 210

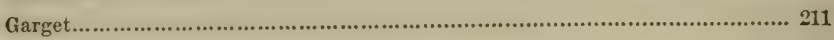

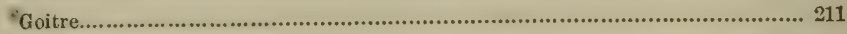

Grub in the Head.................................................................. 212

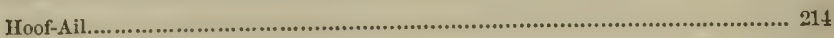

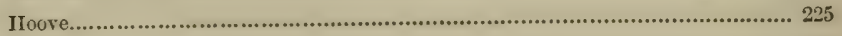

Irydatid on the Brain .............................................................. 226

Obstruction of the Gullet................................................................. 228

Ophthalmia .................................................................................... 229

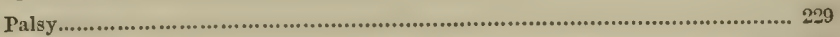

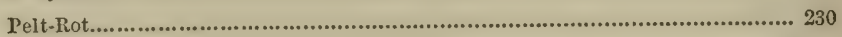

Pneumonia........................................................................ 230

Poison.............................................................................. 232

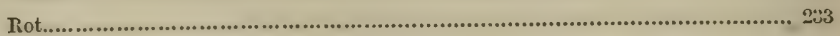

Scab................................................................................ 236

Small-Pox........................................................................ 233

Sore Face........................................................................... 212

Sore Mouth.............................................................................. 243

Ticks................................................................................ $\$ 13$ 


\section{ILLUSTRATIONS.}

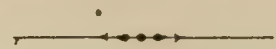

PAGB

A Leicester RaMr.................................................., 15

Rocky Mountain SheeP........................................... 19

A Merino RaM...................................................... 25

A SPANish SHeEp-DoG............................................... 28

Odt at Pastuke................................................. 35

A Coustry Scene................................................... 41

A Sovth-Dowx RAM............................................. 47

THE Cotsword................................................ 52

А Снеттот Ешт.................................................... 54

Skeletox ow the Sheep as Covered by the MIdscles................ 57

The Wallachitan SheEP............................................ 64

The Happy Trio................................................... 81

The Scotcu Sheep-Dog or Colley................................. 100

EWE AX̃ LaMbs.................................................. 117

Feeding and Management............................................ 129

A Covered Salting-Box......................................... 130

A Convexiext Box-RaCk......................................... 147

A HoLE-RACK...................................................... 148

The Hopper-RACk.................................................. 150

An Econonical Suefp-Trovgh................................. 151

SHEEP-BARN with SHEDS.......................................... 152

A SHEd of RAILS.................................................. 155

Washing Apparatus............................................... 162

ToE-NipPERS . ........................................................ 166

FLEECE ............................................................. 167

Shepherd's Crook................................................. 176

The Shepherd axd his Flock......................................... 179

Drover's of Butchen's DoG........................................... 185

QUIET ENJOYMENT. .................................................. 195

An English RAck for Feeding Sheep............................. 203

A Barrack for Stoking SHeep Fodder............................ 228

THe Broad-TAILEd SheEP.......................................... 236 8 


\section{CONTENTS.}

\section{SWINE AND THEIR DISEASES.}

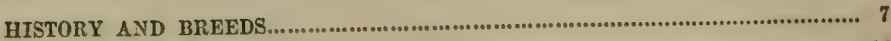

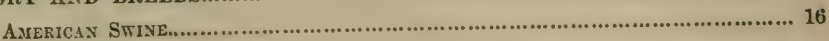

The Byefield

The Bedford..................................................................................... 18

The Leicester.......................................................................... 19

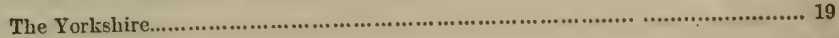

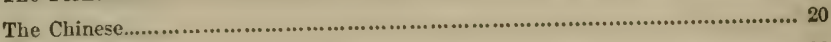

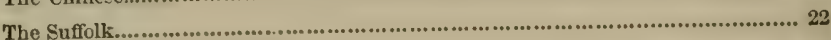

The Berkshire ................................................................................. 23

NatUR.AL IIrstory OF THE IIOG............................................................. 25

Formation of the Teeth..................................................................... 27

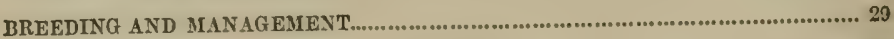

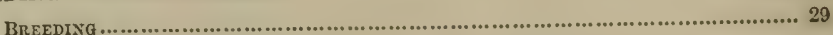

Points of a Good Hog......................................................................... 36

Treatment during Pregnancy.................................................................... 38

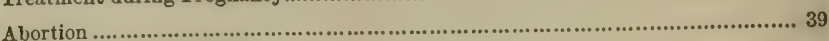

Parturition..................................................................................... 41

Treatment while Suckling................................................................... 44

Treatment of Young Pigs....................................................................... 45

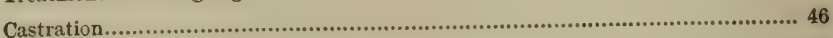

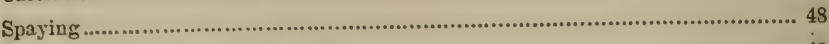

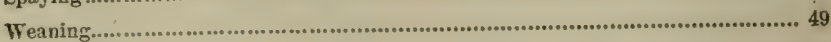

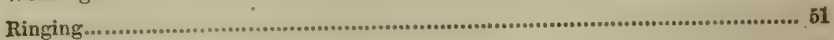

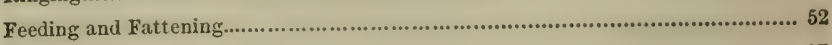

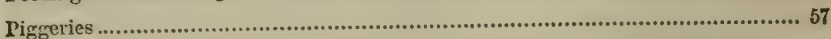

Slaughtering...................................................................................... 60

Pickling and Curing.............................................................................6. 62

Value of the Carcass................................................................................ 66 
DISEASES AND TIIEIR REMEDIES.

PAGE

Catching the Pig................................................................................ 70

Bleeding.......................................................................... 71

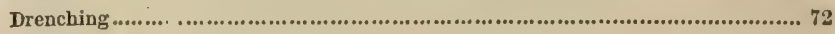

Catarrh................................................................................... 72

Cholera............................................................................... 73

Crackings.................................................................................. 76

Diarrbcea.............................................................................. 76

Fever............................................................................... 77

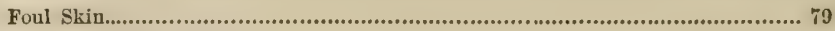

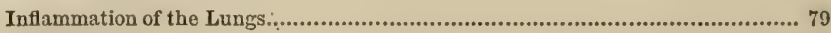

Jaundice................................................................................. 80

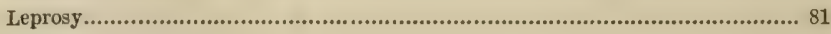

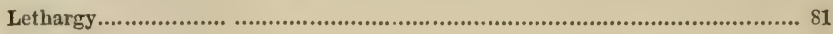

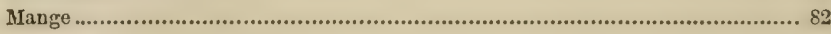

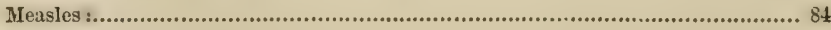

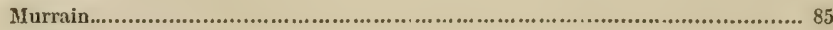

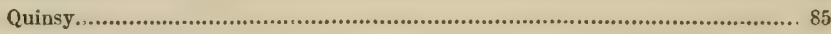

Staggers............................................................................. 85

Swelling of the Spleen.............................................................. 85

Surfeit .............................................................................. 87

Tumors............................................................................. 87

\section{ILLUSTRATIONS.}

THE WIID BoAR 00000000000000000000000000000000000

The Wild Boar at Bat.......................................... 14

The Chinese HoG.................................................. 21

THE SUFFoLK. .................................................... 22

A Berkshire BoAR.............................................. 23

Skeleton of the Hog as Covered ry the Muscj.es................... 25

The Old Country Well............................................... 29

WILD HoGs....................................................... 41

The Old English Hog............................................ 61

A Wicked-Looking SPECideN...................................... 69

Hunting THE WILd BoAR........................................... 77 


\section{0 N TE N TS.}

\section{POULTRY AND THEIR DISEASES.}

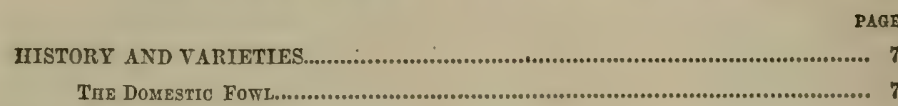

The Bantam............................................................................................... 10

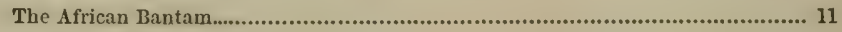

The Bolton Gray................................................................................... 13

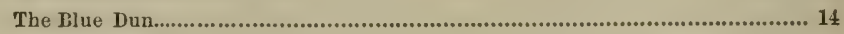

The Chittagong......................................................................................... 15

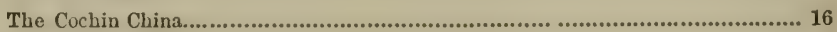

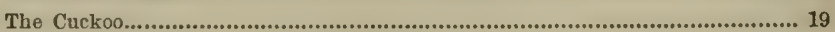

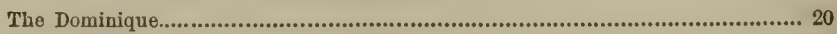

The Dorking............................................................................................... 20

The Fawn-colored Dorking......................................................................... 23

The Black Dorking.................................................................................. 23

The Dunghill Fowl................................................................................. 24

The Frizzled Fowl......................................................................................... 24

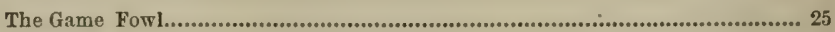

The Mexican Hen-Cock..................................................................... 27

The Wild Indian Game............................................................................ 28

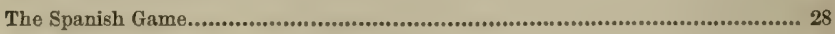

The Guilderland....................................................................................... 29

The Spangled Hamburgh..................................................................... 30

The Golden Spangled............................................................................. 30

The Silver Spangled......................................................................... 31

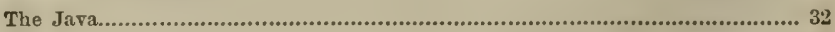

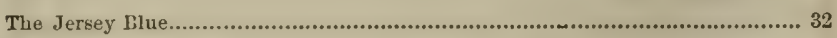

The Lark-Crested Fowl.................................................................. 32 


\section{CONTENTS.}

IISTORX AND VARIETIES-Continued.

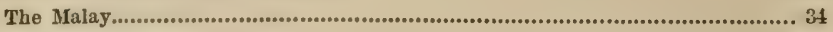

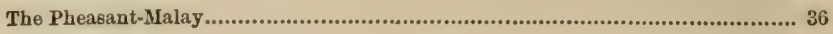

The Plymouth Rock.......................................................................

The Poland............................................................................................... 38

The Black Polish ................................................................................. 40

The Golden Polands...................................................................................... 41

The Silver Polands............................................................................. 43

The Black-topped White...................................................................... 44

The Shanghae...................................................................................... 44

The White Shanghae......................................................................... 47

The Silver Pheasant............................................................................... 48

The Spanish..................................................................................... 49

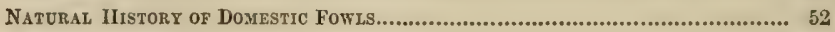

The Guinea Fowl.............................................................................. 58

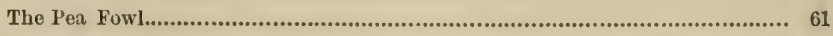

The Turkey........................................................................................ 66

The Wild Turkey....................................................................................66 66

The Domestic Turkey ...................................................................... 71

The Duck................................................................................... 74

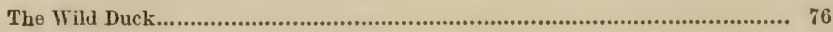

The Domestic Duck........................................................................ 78

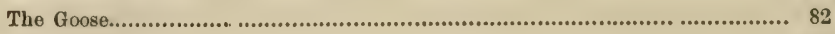

The Wild Goose............................................................................ 82

The Domestic Goose............................................................................. 84

The Bernacle Goose......................................................................... 87

The Bremen Goose........................................................................ 89

The Brent Goose................................................................................. 90

The China Goose.............................................................................. 91

The White China.................................................................................. 93

The Egyptian Goose................................................................................ 94

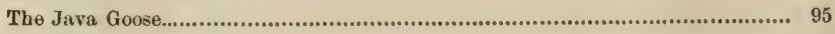

The Toulouse Goose........................................................................... 95

The White-fronted Goose..................................................................... 96

The Anatomy of the Egg...................................................................... 97

BREEDING AND MANAGEMENT............................................................... 101

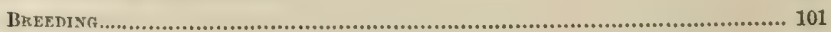

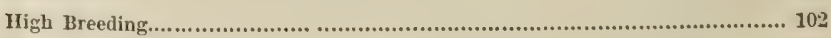

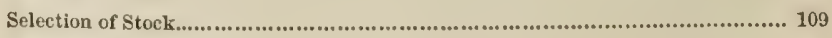

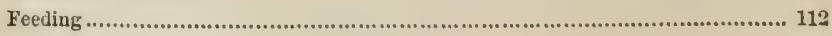


BREEDING AND MANAGEMENT-Continued.

PAGE

Bran.

Millet 116

Rice

Potatoes.

Green Food.

Earth-Worms

Animal Food

Insects

Laying

Preservation of Eggs............................................................................. 123

Choice of Eggs for Sitting................................................................. 126

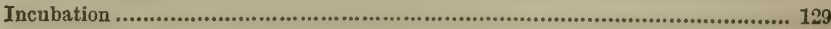

Incubation of Turkeys............................................................. 133

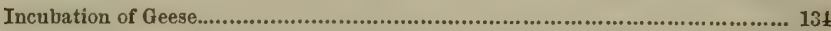

Rearing of the Young................................................................. 135

Rearing of Guinea Fowls.................................................................... 138

Rearing of Turkeys.................................................................... 139

Rearing of Ducklings................................................................. 141

Rearing of Goslings.............................................................. 143

Caponizing.................................................................................. 144

Fattening and Slaughtering......................................................... 148

Slaughtering and Dressing.......................................................... 152

Poultry-House8......................................................................... 151

DISEASES AND THEIR REMEDIES..................................................... 158

Asthma ............................................................................. 159

Costiveness.............................................................................. 160

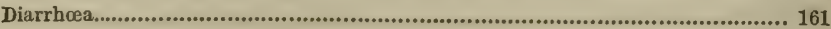

Fever.................................................................................. 162

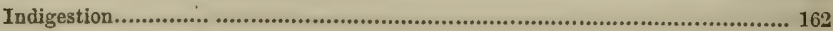

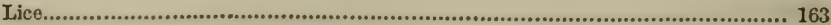

Loss of Feathers..........................................................ici................... 165

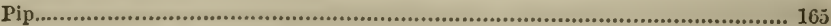

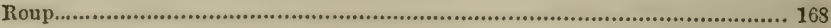

Wounds and Sores............................................................................... 170 


\section{ILLUSTRATIONS.}

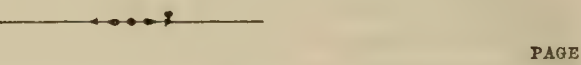

VARIETIES OF FoWL............................................... 7

Tue BantaM.................................................. 11

Bактал.......................................................... 12

Bolton Grays or Creole Fowl................................... 13

Cochin Снinas...................................................... 17

White DoRK1NGs.................................................. 21

Grax Gane Fow

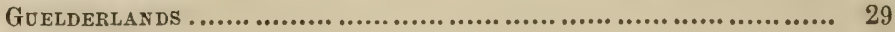

HAMBURGH FowLS............................................. 30

MALAYS........................................................... 34

Poland Fowls.................................................. 39

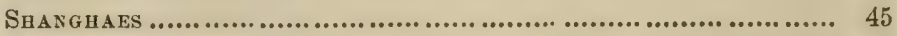

White Shakguafs.......................................... 47

Spayisi Fowls.................................................... 49

The Gutwea Fowl.................................................. 59

THE PEA FowL.................................................. 62

The WILD TURKeY.............................................. 66

The Donestid TukKeY............................................. 72

THe Erder Duck................................................... 75

WILD Duck............................................................ 77

ROUEN DUCK.......................................................... 79

WILD or CANada Goose............................................ 83

A Bremen Goose....................................................... 89

ChiNA or HoNg Kong Goose.......................................... 91

BARNYARD SCFNE....................................................... 101

Fighting Cocks........................................................ 109

ON THE WATCH....................................................... 120

Marquee of Text-Shaped Coops.......................................... 136

DUCK-PoNd AND HoUses......................................... 141

A Bad Style of Slaughtering..................................... 148

Rustic Poultry-Hodse............................................... 155

A F Ancy Coop in Chinese on Gothic Style......................... 156

AMONG THE STRAW.................................................... 158

Pramie Hexs.......................................................... 163

Swans............................................................ 168 


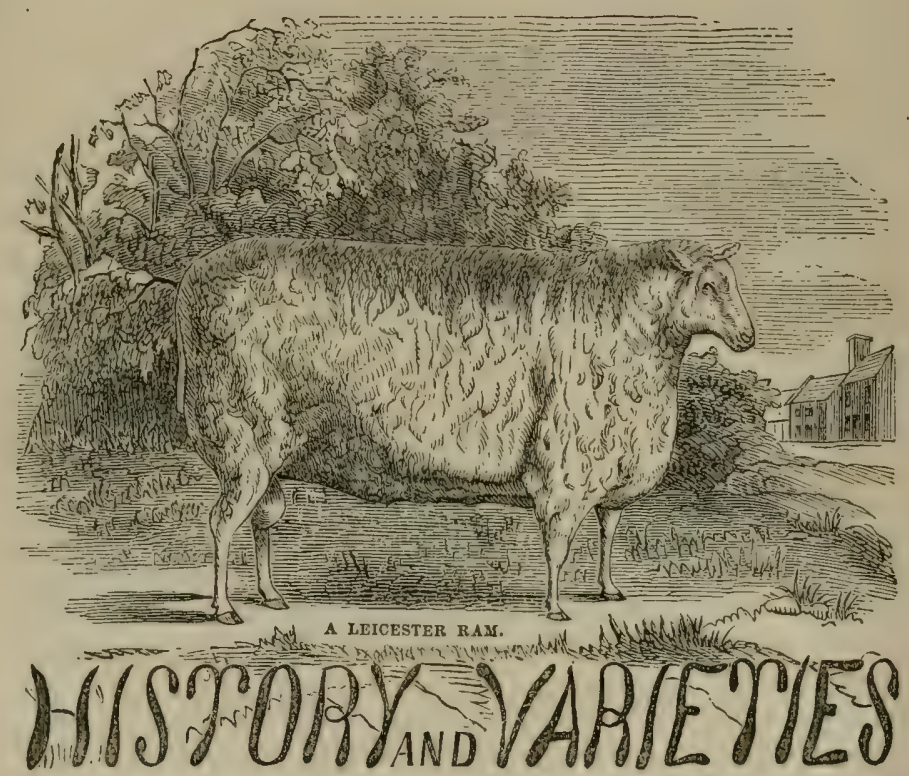

Wiтr a single exception-that of the dog-there is no member of the beast family which presents so great a diversity of size, color, form, covering, and general appearance, as characterizes the sheep; and none occupy a wider range of climate, or subsist on a greater variety of food. This animal is found in every latitude between the Equator and the Aretic circle, ranging over barren mountains and through fertile valleys, feeding upon almost every species of edible foragethe cultivated grasses, clovers, cereals, and roots-browsing on aromatic and bitter. herbs alike, cropping the leaves and 
barks from stunted forest shrubs and the pungent, resinous evergreens. In some parts of Norway and Sweden, when other resources fail, he subsists on fish or flesh during the long, rigorous winter, and, if reduced to necessity, even devours his own wool.

In size, he is diminutive or massive; he has many horns, or but two large or small spiral horns, or is polled or hornless. His tail may be broad, or long, or a mere button, discoverable only by the touch. His covering is long and coarse, or short and hairy, or soft and furry, or fine and spiral. His color varies from white or black to every shade of brown, dun, buff, blue, and gray. This wide diversity results from long domestication under almost every conceivable variety of condition.

Among the antediluvians, sheep were used for sacrificial offerings, and their fleeces, in all probability, furnished them with clothing. Since the deluge their flesh has been a favorite food among many nations. Many of the rude, wandering tribes of the East employ them as beasts of burden. The uncivilized-and, to some extent, the refined-inhabitants of Europe use their milk, not only as a beverage, but for making into cheese, butter, and curds-an appropriation of it which is also noticed by Job, Isaiah, and other Old Testament writers, as well as most of the Greek and Roman authors. The ewe's milk scarcely differs in appearance from that of the cow, though it is generally thicker, and yields a pale, yellowish butter, which is always soft and soon becomes rancid. In dairy regions the animal is likervise frequently employed at the tread-mill or horizontal wheel, to pump water, churn milk, or perform other light domestic work. 
The calling of the shepherd bas, from time immemorial, been conspicuous, and not wanting in dignity and importance. Abel was a keeper of sheep; as were Abraham and his descendants, as well as most of the ancient patriarchs. Job possessed fourteen thousand sheep. Rachel, the favored mother of the Jewish race, "came with her father's sheep, for she kept them." The seven daughters of the priest of Midian "came and drew water for their father's flocks." Moses, the statesman and lawgiver, "learned in all the wisdom of the Egyptians," busied himself in tending "the flocks of Jethro, his father-in-law." David, too, that swect singer of Israel and its destined monarch-the Jewish hero, poet, and divine-was a kecper of sheep. To shepherds, "abiding in the ficld, keeping watch over their flocks by night," came the glad tidings of a Saviour's birth. The Hebrew term for sheep signifies, in its etymologs, fruitfulness, abundance, plent 5 -indicative of the blessings which they were destined to confer upon the human family. In the Holy Scriptures, this animal is the chosen symbol of purity and the gentler virtues, the victim of propitiatory sacrifices, and the type of redemption to fallen man.

Amons profane writers, Homer and Hesiod, Virgil and Theocritus, introduce them in their pastoral themes; while their heroes and demi-gods-Mercules and Ulysses, Encas and Numa-carefully perpetuate them in their domains.

In modern times, they hare engaged the attention of the most enlightened nations, whose prosperity has been intimately linked with them, wherever wool and its manufactures have been regarded as essential staples. Spain and Portugal, during the two centuries in which they figured as the most 2 
enterprising European countries, excelled in the production and manufacture of wool. Flanders, for a time, took precedence of England in the perfection of the arts and the enjoyments of life; and the latter country then sent what little wool she raised to the former to be manufactured. This being soon found highly impolitic, large bounties were offered by England for the importation of artists and machinery; and by a systematic and thorough course of legislation, which looked to the utmost. protection and increase of wool and woollens, she gradually carried their production beyond any thing the world had ever seen.

Of the original breed of this invaluable animal, nothing certain is known; four varieties having been deemed by naturalists entitled to that distinction.

These are, 1. The Musimon, inhabiting Corsica, Sardinia, and other islands of the Mediterranean, the mountainous parts of Spain and Greece, and some other regions bordering upon, that inland sea. These have been frequently domesticated and mixed with the long-cultivated breeds.

2. The Argali ranges over the steppes, or inland plains of Central Asia, northward and eastward to the ocean. They are larger and hardier than the Musimon and not so easily tamed.

3. The Rocky Mlountain Sheep-frequently called the Bighorn by our western hunters-is found on the prairies west of the Mississippi, and throughout the wild, mountainous regions extending through California and Oregon to the Pacific. They are larger than the Argali-which in other respects they resemble_and are probably descended from them, since they could easily cross upon the ice at Behring's Straits, from the 
north-eastern coast of Asia. Like the Argali, when caught young they are readily tamed; but it is not known that they have ever been bred with the domestic sheep. Before the country was overrun by the white ram, they probably inhabited the region bordering on the Mississippi. Father Hennepin-a French Jesuit, who wrote some two hundred years ago-often speaks of meeting with goats in his travels through

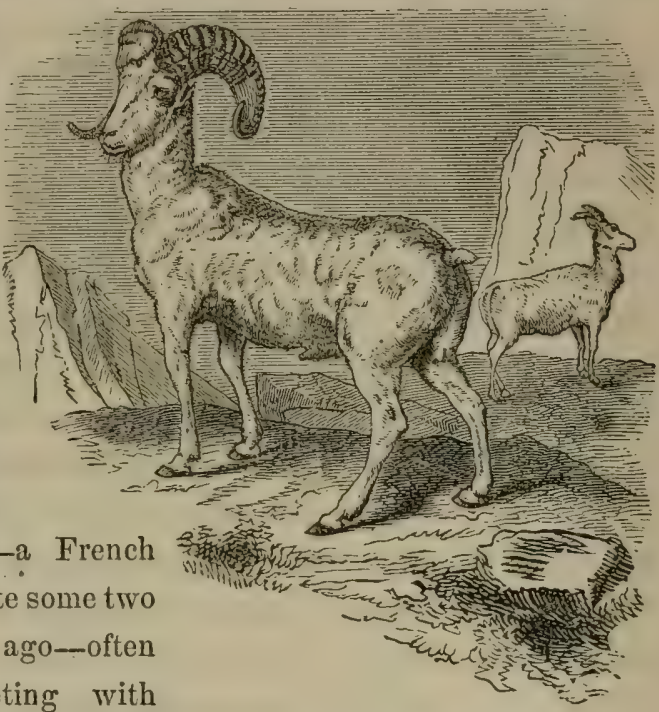

ROCKY MOUNTAIN SHEEP. the territory which is now embraced by Illinois, Wisconsin, and a portion of Minnesota. The wild, clambering propensities of these animals-occupying, as they do, the giddy heights far beyond the reach of the traveller-and their outer coating of hair-supplied underneath, however, with a thick coating of soft wool-give them much the appearance of goats. In summer they are generally found single; but when they descend from their isolated, rocky heights in winter, they are gregarious, marching in flocks under the guidance of leaders.

4. The Bearded Sheep of Africa inhabit the mountains of Barbary and Egypt. They are covered with a soft, reddish 
hair, and have a mane hanging below the neck, and large locks of hair at the ankle.

Many varieties of the domesticated sheep_that is, all the subjugated species-apparently differ less from their wild namesakes than from each other.

The fat-rumped and the broad-tailed sheep are much more extensively diffused than any other, and occupy nearly all the south-eastern part of Europe, Western and Central Asia, and Northern Africa. They are supposed, from various passages in the Pentateuch in which "the fat and the rump" are spoken of in connection with offerings, to be the varieties which were propagated by the patriarchs and their descendants, the Jewish race. They certainly give indisputable evidence of remote and continued subjugation. Their long, pendent, drowsy ear's, and the highly artificial posterior developments, are characteristic of no wild or recently domesticated race.

This breed consists of numerous sub-varieties, differing in all their characteristics of size, fleece, color, etc., with quite as many and marked shades of distinction as the modern European varietics. In Madagascar, they are covered with hair; in the south of Africa, with coarse wool; in the Levant, and along the Mediterrancan, the wool is comparatively fine; and from that of the fat-rumped sheep of Thibet the exquisite Cashmere shawls of commerce are manufactured. Both rams and ewes are sometimes bred with horns, and sometimes without, and they exhibit a great diversity of color. Some yield a carcass of scarcely thirty pounds, while others have weighed two hundred pounds dressed. The tail or rump varies greatly, according to the purity and style of breeding; some are less than one-eighth, while others exceed one-third of the entire 
dressed weight. The fat of the rump or tail is esteemed a great delicacy; in hot climates resembling oil, and in colder, suet.

It is doubtful whether sheep are indigenous to Great Britain; but they are mentioned as existing there at very early periods.

\section{AMERICAN SHEEP.}

In North America, there are none, strictly speaking, except the Rocky Mountain breed, already mentioned. The broadtailed sheep of $A$ sia and Africa were brought into the United States about seventy years ago, under the name of the Tunisian Mountain sheep, and bred with the native flocks. Some of them were subsequently distributed among the farmers of Pennsylvania, and their mixed descendants were highly prized as prolific, and good nurses, coming early to maturity, attaining large weight, of a superior quality of carcass, and yielding a heary fleece of excellent wool. The principal objection made to them was the difficulty of propagation, which always required the assistance of the shepherd. The lambs were dropped white, red, tawny, bluish, or black; but all, excepting the black, grew white as they approached maturity, retaining some spots of the original color on the cheeks and legs, and sometimes having the entire head tawny or black. The few which descended from the original importations have become blended with American flocks, and have long ceased to be distinguishable from them. The common sheep of Holland were early imported by the Dutch emigrants, who originally colonized New York; but they, in like manner, have long since ceased to exist as a distinct variety.

Improved European breeds have been so largely introduced 
during the present century, that the United States at present possesses every known breed which could be of particular benefit to its husbandry. By the census of 1860 , there were nearly twenty-three and a half millions of sheep in this country, yielding upwards of sixty and a half million pounds of wool. An almost infinite variety of crosses have taken place between the Spanish, English, and "native" families; carried, indeed, to such an extent that there are, comparatively speaking, few flocks in the United States that preserve entire the distinctive characteristics of any one breed, or that can lay claim to unmixed purity of blood.

The principal breels in the United States are the so-called "Natives;" the Spanish and Saxon Merinos, introduced from the countries whose names they bear: the New Leicester, or Bakewell; the South-Down; the Cotswold; the Cheviot; and the Lincoln-all from England.

\section{NATIVE SHEEP.}

This name is popularly applied to the common coarse-woolled sheep of the country, which existed here previously to the importation of the improved breeds. These were of foreign and mostly of English origin, and could probably claim a common descent from no one stock. The early settlers, emigrating from different sections of the British Empire, and a portion of them from other parts of Europe, brought with them, in all probability, each the favorite breed of his own immediate neighborhood, and the admixture of these formed the mongrel family now under consideration. Amid the perils of war and the in. cursions of beasts of prey, they were carefully preserved. As 
early as 16\%6, New England was spoken of as "abounding with sheep."

These common sheep yielded a wool suitable only for the coarsest fabrics, averaging, in the hands of good farmers, from three to three and a half pounds of wool to the fleece. They were slow in arriving at maturity, compared with the improved English breeds, and yielded, when fully grown, from ten to fourteen pounds of a middling quality of mutton to the quarter. They were usually long-legged, light in the forequarter, and narrow on the breast and back; although some rare instances might be found of flocks with the short legs, and some approximation to the general form of the improved breeds. They were excellent breeders, often rearing, almost entirely destitute of care, and without shelter, one hundred per cent. of lambs; and in small flocks, a still larger proportion. These, too, were usually dropped in March, or the earlier part of April. Restless in their disposition, their impatience of restraint almost equalled that of the untamed Argali, from which they were descended; and in many sections of the country it was common to see from twenty to fifty of them roving, with little regard to enclosures, over the possessions of their owner and his neighbors, leaving a large portion of their wool-adhering to bushes and thorns, and the remainder placed nearly beyond the possibility of carding, by the toryweed and burdock, so common on new lands.

To this general character of the native flocks, there was but one exception-a considerably numerous and probably accidental variety, known as the Otter breed, or Creepers. These were excessively duck-legged, with well-formed bodies, full chests, broad backs, yielding a close, heavy fleece, of medium quality 
of wool. They were deserved favorites where indifferent stone or wood fences existed, since their power of locomotion was absolutely limited to their enclosures, if protected by a fence not less than two feet high. The quality of their mutton equalled, while their aptitude to fatten was decidedly superior to, their longer-legged contemporaries. The race is now quite extinct.

An excellent variety, called the Arlington sheep, was produced by General Washington, from a cross of a Persian ram upon the Bakewell, which bore wool fourteen inches in length, soft, silky, and admirably suited to combing. These, likewise, have long since become incorporated with the other flocks of the country.

The old common stock of sheep, as a distinct family, have nearly or quite disappeared, owing to universal crossing, to a greater or less extent, with the foreign breeds of later introduction. The first and second cross with the Merino resulted in a decided improvement, and produced a rariety exceedingly valuable for the farmer who rears wool solely for domestic purposes. The fleeces are of uneven fineness, being hairy on the thighs, dew-lap, etc.; but the general quality is much improved, the quantity is considerably augmented, the carcass is more compact and nearer the ground, and they have lost their unquiet and roving propensities. The cross with the Saxon, for reasons hereafter to be given, has not generally been so successful. With the Leicester and Downs, the improvement, so far as form size, and a propensity to take on fat are concerned, is manifest. 
THE SPANISH MERINO.

The Spanish sheep, in different countries, has, either directly or indirectly, effected a complete revolution in the character of the fleece. The race is unquestionably one of the most an. cient extant. The early writers on agriculture and the veterinary art describe various breeds of sheep as existing in Spain, of differe $\mathrm{n}$ colors-

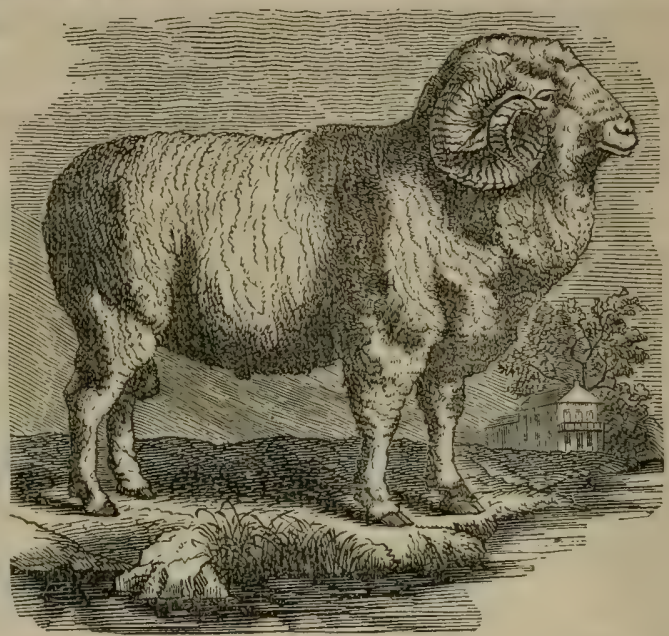

A MERINO RAM.

black, red, and tawny. The black sheep yielded a fine fleece, the finest of that color which was then known; but the red fleece of Brtica-a considerable part of the Spanish coast on the Mediterranean, comprising the modern Spanish provinces of Gaen, Cordova, Seville, Andalusia, and Granada, which was early colonized by the enterprising Greeks-was, according to Pliny, of still superior quality, and "had no fellow."

These sheep were probably imported from Italy, and of the Tarentine breed, which had gradually spread from the coast of Syria, and of the Black Sea, and had then reached the western extremity of Europe. Many of them mingled with and inproved the native breeds of Spain, while others continued to exist as a distinct race, and, meeting with a climate and an 
herbage suited to them, retained their original character and value, and were the progenitors of the Merinos of the present day. Columella, a colonist from Italy, and uncle of the writer of an excellent work on agriculture, introduced more of the Tarentine sheep into Brtica, where he resided in the reign of the Emperor Claudius, in the year 41, and otherwise improved on the native breed; for, struck with the beauty of some African rams which had been brought to Rome to be exhibited at the public games, he purchased them, and conveyed them to his farm in Spain, whence, probably, originated the better varieties of the long-woolled breeds of that country.

Before his time, however, Spain possessed a valuable breed; since Strabo, who flourished under Tiberius, speaking of the beautiful woollen cloths that were worn by the Romans, says that the wool was brought from Truditania, in Spain.

The limited region of Italy-overrun, as it repeatedly was, by hordes of barbarians during and after the times of the latest emperors-soon lost her pampered flocks; while the extended regions of Spain-intersected in every direction by almost impassable mountains-could maintain their more hardy race, in defiance of revolution or change.

To what extent the improvements which have been noticed - were carried is unknown; but as Spain was at that time highly civilized, and as agriculture was the farorite pursuit of the greater part of the colonists that spread over the vast territory, which then acknowledged the Roman power, it is highly probable that Columella's experiments laid the foundation for a general improvement in the Spanish sheep-an improvement, moreover, which was not lost, nor even materially impaired, during the darker ages that succeeded. 
The Merino race possess inbred qualities to an extent surpassed by no others. They have been improved in the general weight and evenness of their fleece, as in the celebrated flock of Rambouillet; in the uniformity and excessire fineness of the fibre, as in the Saxons; and in their form and feeding qualities, in various countries; but there has never yet been deterioration, either in quantity or quality of fleece or carcass, wherever they have been transported, if supplied with suitable food and attention. Most sheep annually shed their wool if unclipperl; while the Merino retains its fleece, sometimes for five years, when allowed to remain unshorn.

Conclusive evidence is thus afforded of continued breeding among themselves, by which the very constitution of the woolproducing organs beneath the skin have become permanently established; and this property is transmitted to a great extent, eren among the crosses; thus marking the Merino as an ancient and peculiar race.

The remains of the ancient varieties of color, also, as noticed by Pliny, Solinus, and Columella, may still be discovered in the modern Merino. The plain and indeed the only reason. that can be assigned for the union of black and gray faces with white bodies, in the same breed, is the frequent intermixture of black and white sheep, until the white prevails in the fleece, and the black is confined to the face and legs. It is still apt to break out occasionally in the individual, unless it is fixed and concentrated in the face and legs, by repeated crosses and a careful selection; and, on the contrary, in the Merino SouthDown the black may be reduced by a few crosses to small spots about the legs, while the Merino hue overspreads the countenance. This huc-variously described as a velvet, a 
buff, a fawn, or a satin-colored countenance, but in which a red tinge not infrequently predominates, still indicates the original colors of the indigenous breeds of Spain; and the black wool, for which Spain was formerly so much distinguished, is still inclined to break out occasionally in the legs and ears of the Merino. In some flocks half the ear is invariably brown, and a coarse black hair is often discernible in the finest pile.

The conquest, in the eighth century, by the Moors of those fine provinces in the south of Spain, so far from checking,

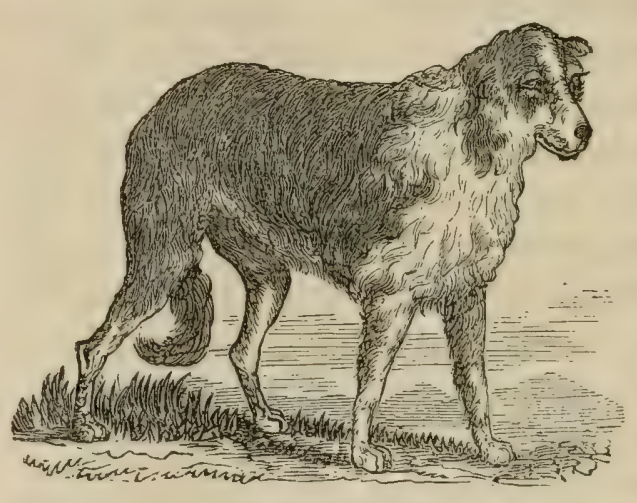

A BPANISH BHEEP DOG.

served rather to encourage the production of fine wool. The conquerors were not only enterprising, but highly skilled in the useful arts, and carried on extensive manufactories of fine woollen goods, which they exported to different countries. The luxury of the Moorish sovereigns has been the theme of many writers; and in the thirteenth century, when the woollen manufacture flourished in but few places, there were found in Seville no less than sixteen thousand looms. A century later, Barcelona, Perpignan, and Tortosa were celebrated for the fineness of their cloths, which became staple articles of trade throughout the greater part of Europe, as well as on the coast of Africa.

After the expulsion of the Moors, in the fifteenth century, 
by Ferdinand and Isabella, the woollen manufacture languished, and was, in a great degree, lost to Spain, owing to the rigorous banishment of nearly one million industrious Moors, most of whom were weavers. As a consequence, the sixteen thousand looms of Seville dwindled down to sixty. The Spanish government perceived its fatal mistake too late, and subsequent efforts to gain its lost vantage-ground in respect to this manufacture proved fruitless. During all that time, however, the Spanish sheep appear to have withstood the baneful influence of almost total neglect; and although the Merino flocks and Merino wool have improved under the more careful management of other countries, the world is originally indebted to Spain for the most valuable material in the manufacture of cloth.

The perpetuation of the Merino sheep in all its purity, amid the convulsions which changed the entire political framervork of Spain and destroyed every other national improvement, strikingly illustrates the primary determining power of blood or breeding, as well as the agency of soil and climate-possibly too much underrated in modern times.

These Spanish sheep are divided into two classes: the stationary, or those that remain during the whole of the year on a certain farm, or in a certain district, there being a sufficient provision for them in winter and in summer; and the migralory, or those which wander some hundreds of miles twice in the year, in quest of pasturage. The principal breed of stationary sheep consists of true Merinos; but the breeds most sought for, and with which so many countries have been enriched, are the Merinos of the migratory description, which pass the summer in the mountains of the north, and the winter on the plains toward the south of Spain. 
The first impression made by the Merino sheep on one unacquainted with its value would be unfavorable. The wool lying closer and thicker over the body than in most other breeds, and being abundant in yolk-or a peculiar secretion from the glands of the skin, which nourishes the wool and causes it to mat closely together-is covered with a dirty crust, often full of cracks. The legs are long, yet small in the bone; the breast and the back are narrow, and the sides somewhat flat; the fore-shoulders and bosoms are heavy, and too much of their weight is carried on the coarser parts. The horns of the male are comparatively large, curved, and with more or less of a spiral form; the head is large, but the fore. head rather low. A few of the females are horned; but, generally speaking, they are without horns. Both male and female have a peculiar coarse and unsighitly growth of hair on the forehead and cheeks, which the careful shepherd cuts away before the shearing-time; the other part of the face has a pleasing and characteristic velvet appearance. Under the throat there is a singular looseness of skin, which gires them a remarkable appearance of throatiness, or hollowness in the neck. The pile or hair, when pressed upon, is hard and unyielding, owing to the thickness into which it grows on the pelf, and the abundance of the yolk, retaining all the dirt and gravel which falls upon it; but, upon examination, the fibre exceeds, in fineness and in the number of serrations and curves, that which any other sheep in the world produces. The average weight of the flece in Spain is eight pounds from the ram, and five from the ewe. The staple differs in length in different provinces. When fatted, these sheep will weigh from twelve to sixteen pounds per quarter. 
The excellence of the Merinos consist in the unexampled fineness and felting property of their wool, and in the weight of it yielded by each individual sheep; the closeness of that wool, and the luxuriance of the yolk, which enable them to support extremes of cold and wet quite as well as any other breed; the readiness with which they adapt themselves to every change of climate, retaining, with common care, all their fineness of wool, and thriving under a burning tropical sun, and in the frozen regions of the north; an appetite which renders them apparently satisfied with the coarsest food; a quietness and patience into whatever pasture they are turned; and a gentleness and tractableness not excelled in any other breed.

Their defects-partly attributable to the breed, but more to the improper mode of treatment to which they are occasionally subjected-are, their unthrifty and unprofitable form; a tenclency to abortion, or barrenness; a difficulty of yeaning, or giving birth to their young; a paucity of milk; and a too frequent neglect of their lambs. They are likewise said, notwithstanding the fineness of their wool, and the beautiful red color of the skin when the fleece is parted, to be more subject to cutaneous affections than most other breeds. Man, however, is far more responsible for this than Nature. Every thing was sacrificed in Spain to fineness and quantity of wool. These were supposed to be connected with equality of temperature, or, at least, with freedom from exposure to cold ; and, therefore, twice in the year, a journey of four hundred miles was undertaken, at the rate of eighty or a hundred miles per week-the spring journey commencing when the lambs were scarcely four months old. It is difficult to say in what way the wool of the 
migratory sheep was, or could be, benefited by these periodical journeys. Although among them is found the finest and most valuable wool in Spain, yet the stationary sheep, in certain provinces-Segovia, Leon, and Estremadura-are more valuable than the migratory flocks of others. Moreover, the fleece of some of the German Merinos-which do not travel at all, and are housed all the winter-greatly excceds that obtained from the best migratory breed-the Leonese-in fineness and felting property; and the wool of the migratory sheep has been, comparatively speaking, driven out of the market by that from sheep which never travel. With respect to the carcass, these harassing journeys, occupying one-quarter of the year, tend to destroy all possibility of fattening, or any tendency toward it, and the form and the constitution of the flock are deteriorated, and the lives of many sacrificed.

The first importation of Merinos into the United States took place in 1801 ; a banker of Paris, Mr. Delessert, having shipped four, of which but one arrived in safety at his farm near Kingston, in New York; the others perished on the passage. The same year, Mr. Seth Adams, of Massachusetts, imported a pair from France. In 1802, Chancellor Livingston, then American Minister at the court of Versailles, sent two choice pairs from the Rambouillet flock-which was started, in 1786 , by placing four hundred ewes and rams, selected from the choicest Spanish flocks, on the royal farm of that name, in France-to Claremont, his country-seat, on the Hudson river. In the latter part of the same year, Colonel Humphreys, American Minister to Spain, shipped two hundred, on his departure from that country. The largest importations, however, were made through Hon. William Jarvis, of Vermont, 
then American Consul at Lisbon, Portugal, in 1809, 1810, and 1811, who succeeded in obtaining the choicest sheep of that country. Tarious subsequent importations took place, which need not be particularized.

The cessation of all commercial intercourse with England, in 1808 and 1809, growing out of difficulties with that country, directed attention, in an especial manner, toward manufacturing and wool-growing. The Merino, consequently, rose into importance, and so great was the interest aroused, that from a thousand to fourteen hundred dollars a head was paid for then. Some of the later importations, unfortunately, arrived in the worst condition, bringing with them those scourges of the. sheep family, the scab and the foot-rot: which erils, together with increased supply, soon brought them down to less than a twentieth part of their former price. When, however, it was established, by actual experiment, that their wool did not deteriorate in this country, as had been feared by many, and that they became readily acclimated, they again rose into faror. The prostration of the manufacturing interests of the country, which ensued soon afterwards, rendered the Merino of comparatively little value, and ruined many who had purchased them at their previous high prices. Since that period, the valuation of the sheep which bear the particular wool has, as a matter of course, kept pace with the fluctuations in the price of the wool.

The term Merino, it must be remembered, is but the general appellation of a breed, comprising several varieties, presenting essential points of difference in size, form, quality and quantity of wool. These families have generally been merged, by interbreeding, in the United States and other countries which have 
received the race from Spain. Purity of Merino blood, and actual excellence in the individual and its ancestors, form the only standard in selecting sheep of this breed. Families have, indeed, sprung up in this country, exhibiting wider points of difference than did those of Spain. This is owing, in some cases, doubtless, to particular causes of breeding; but more often, probably, to concealed or forgotten infusions of other blood. The question, which has been at times raised, whether there are any Merinos in the United States, descendants of the early importations, of unquestionable purity of blood, has been conclusively settled in the affirmative.

The minor distinctions among the various families into which, as has already been intimated, the American Merino has diverged, are numerous, but may all, perhaps, be classed under three general heads.

The first is a large, short-legged, strong, exceedingly hardy sheep, carrying a heavy fleece, ranging from medium to fine, free from hair in properly bred flocks; somewhat inclined to throatiness, but not so much so as the Rambouillets; bred to exhibit external concrete gum in some flocks, but not commonly so; their wool rather long on back and belly, and exceedingly dense; wool whiter within than the Rambouillets; skin the same rich rose-color. Sheep of this class are larger and stronger than those originally imported, carry much heavier fleeces, and in well-selected flocks, or individuals, the fleece is of a decidedly better quality.

The second class embraces smaller animals than the preceding; less hardy; wool, as a general thing, fincr, and covered with a black, pitchy gum on its extremities ; flece about onefourth lighter than in the former class. 
The third class, bred at the South, mostly, includes animals still smaller and less hardy, and carrying still finer and lighter fleeces. The fleece is destitute of external gum. The sheep and wool have a close resemblance to the Saxon; and, if not actually mixed with that blood, they have been formed into a similar variety, by a similar course of breeding.

The mutton of the Merino, notwithstanding the prejudices existing on the subject, is shortgrained, and of good flavor, when killed at a proper age, and weighs from ten to fourteen pounds to the quarter. It is remarkable for its longevity, retaining its teeth,

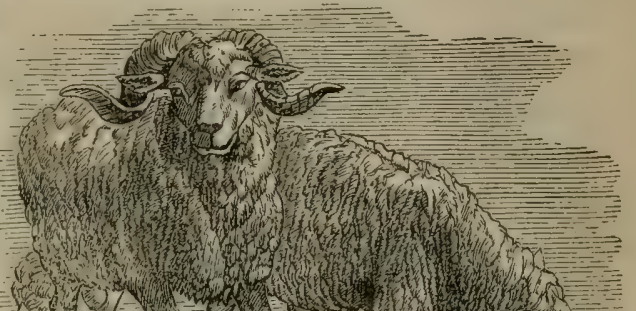
(I)
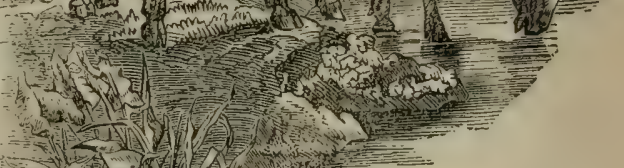

and continuing to breed two or three years longer than the common sheep, and at least half a dozen years longer than the improred English breeds. It should, however, be remarked, in this connection, that it is correspondingly slow in arriving at maturity, as it does not attain its full growth before three years of age; and the ewes, in the best managed flocks, are rarely permitted to breed before they reach that age. 
The Merino is a far better breeder than any other fine-woolled sheep, and its lambs, when newly dropped, are claimed to be hardier than the Bakewell, and equaliy so with the high-bred South-Down. The ewe, as has been intimated, is not so good a nurse, and will not usually do full justice to more than one lamb. Eighty or ninety per cent. is about the ordinary number of lambs reared, though it often reaches one hundred per cent, in carefully managed or small flocks.

Allusion has heretofore been made to the cross between the Merino and the native sheep. On the introduction of the Saxon family of the Merinos, they were universally engrafted on the parent stock, and the cross was continued until the Spanish blood was nearly bred out. When the almixture took place with judiciously selected Saxons, the results were not unfarorable for certain purposes. These instances of judicious crossing were, unfortunately, rare. Fineness of wool was made the only tests of excellence, no matter how scanty its quantity, or how diminutive or miserable the carcass. The consequence was, as might be supposed, the ruin of most of the Merino flocks.

\section{THE SAXON MERINO.}

The indigenous breed of sheep in Saxony resembled that of the neighboring states, and consisted of tro distinct varieties-one bearing a wool of some value, and the other yielding a fleece applicable only to the coarsest manufactures.

At the close of the seven years war, Augustus Frederic, the Elector of Saxony, imported one hundred rams and two hundred ewes from the most improved Spanish flocks, and placed a part of them on one of his own farms, in the neighbor- 
hood of Dresden, which he liept ummixed, as he desired to ascertain how far the pure Spanish breed could be naturalized in that country. The other part of the flock was distributed on other farms, and devoted to the improvement of the Saxon sheep.

It was soon sufficiently apparent that the Merinos did not degenerate in Saxony. Many parcels of their wool were not inferior to the choicest Leonese fleeces. The best breed of the native Saxons was also materially improved. The majority of the shepherds were, however, obstinately prejudiced against the innovation; but the elector, resolutely bent upon accomplishing his object, imported an additional number, and compelled the crown-tenants, then occupying lands under him, to purchase a certain number of the sheep:

Compulsion was not long necessary; the true interest of the shepherds was discovered; pure Merinos rapidly increased in Saxony, and became perfectly naturalized. Indeed, after a considerable lapse of years, the fleece of the Saxon sheep began, not only to equal the Spanish, but to exceed it in fineness and manufacturing value. To this result the government very" materially contributed, by the establishment of an agricultural school, and other minor schools for shepherds, and by distributing various publications, which plainly and intelligibly showed the value and proper management of the Merino. The breeders were selected with almost exclusive reference to the quality of the fleece. Great care was taken to prevent exposure throughout the year, and they were housed on every slight emergency. By this course of breeding and treatment the size and weight of the flece were reduced, and that hardiness and vigor of constitution, which had universally charac- 
terized the migratory Spanish breed, were partially impaired. In numerous instances, this management resulted in permanent injury to the character of the flocks.

The first importation of Saxons into this country was made in 1823, by Samuel Heustan, a merchant of Boston, Massachusetts, and consisted of four good rams, of which two went to Boston, and the others to Philadelphia. The following year, seventy-seven-about two-thirds of which number only were pure-blooded-were brought to Boston, sold at public auction at Brooklyn, N.Y., as "pure-blooded electoral Saxons," and thus scattered over the country. Another lot, composed of grade sheep and pure-bloods, was disposed of, not long afterwards, by public sale, at Brighton, near Boston, and brought increased prices, some of them realizing from four hundred to five hundred and fifty dollars.

These prices gare rise to speculation, and many animals, of a decidedly inferior grade, were imported, which were thrown upon the market for the most they could command. The sales in many instances not half covering the cost of importation, the speculation was soon abandoned. In 1827, Henry D. Grove, of Hoosic, N. Y., a native of Germany, and a highly intelligent and thoroughly bred shepherd, who had accompanied some of the early importations, imported one hundred and fifteen choice animals for his own breeding, and, in the following year, eighty more. These formed the flock from which Mr. Grove bred, to the time of his decease, in 1844. The average weight of fleece from his entire flock, nearly all of which were ewes and lambs, was ten pounds and fourteen ounces, thoroughly washed on the sheep's back. This was realized after a short summer and winter's keep, when the 
quantity of hay or its equivalent fed to the sheep did not exceed one and a balf pounds, by actual weight, per day, except to the ewes, which received an additional quantity just before and after lambing. This treatment was attended with no disease or loss by death, and with an increase of lambs, equalling one for every ewe.

The Saxon Merino differs materially in frame from the Spanish; there is more roundness of carcass and fineness of bone, together with a general form and appearance indicative of a disposition to fatten. Two distinct breeds are noticed. One variety has stouter legs, stouter bodies, head and neck comparatively short and broad, and body round; the wool grows most on the face and legs; the grease in the wool is almost pitchy. The other breed, called Escurial, has longer legs, with a long, spare neck and head; very little wool on the latter; and a finer, shorter, and softer character in its flecce, but less in quantity.

From what has just been stated it will be seen that there are few Saxon flocks in the United States that have not been reduced to the quality of grade sheep, by the promiscuous admixture of the pure and the impure which were imported together; all of them being sold to our breeders as pure stock. Besides, there are very few flocks which have not been again crossed with the Native or the Merino sheep of our country, or with both. Those who early purchased the Merino crossed them with the Native; and when the Saxons arrived those mongrels were bred to Saxon rams. This is the history of three-quarters, probably, of the Saxon flocks of the United States.

As these sheep have now so long been bred toward the 
Saxon that their wool equals that of the pure-bloods, it may well be questioned whether they are any worse for the admixture; when crossed only with the Merino, it is, undoubtedly, to their advantage. 'The American Saxon, with these early crosses in its pedigree, is, by general admission, a hardier and more easily kept animal than the pure Escurial or Electoral Saxon. Climate, feed, and other causes have, doubtless, conspired, as in the case of the Merino, to add to their size and vigor; but, after every necessary allowance has been made, they generally owe these qualities to those early crosses.

The fleeces of the American Saxons weigh, on the average, from two or two and a quarter to three pounds. They are, comparatirely speaking, a tender sheep, requiring regular supplies of good food, good shelter in winter, and protection in cool weather from storms of all kinds; but they are evidently hardier than the parent German stock. In docility and patience under confinement, in late maturity and longevity, they resemble the Merinos, from which they are descended; though they do not mature so early as the Merino, nor do they ordinarily live so long. They are poorer nurses; their lambs are smaller, fatter, and far more likely to perish, unless sheltered and carefuliy watched; they do not fatten so well, and, being considerably lighter, they consume an amount of food considerably less.

Taken together, the American Saxons bear a much finer wool than the American Merinos; though this is not always the case, and many breeders of Saxons cross with the Merino, for the purpose of increasing the weight of their fleeces without deteriorating its quality. Our Saxon wool, as a whole, falls considerably below that of Germany; though individual 
specimens from Saxons in Connecticut and Ohio compare well with the highest German grades. This inferiority is nut attributable to climate or other natural causes, or to a waut of skill on the part of our breeders; but to the fact that but a very few of our manufacturers bave ever felt willing to make that discrimination in prices which would render it protitable to breed those small and delicate animals which produce this exquisite quality of wool.

\section{THE NEW LEICESTER.}

The unimproved Leicester was a large, heary, coarse-woolled breed of sheep, inhabiting the midland counties of England.

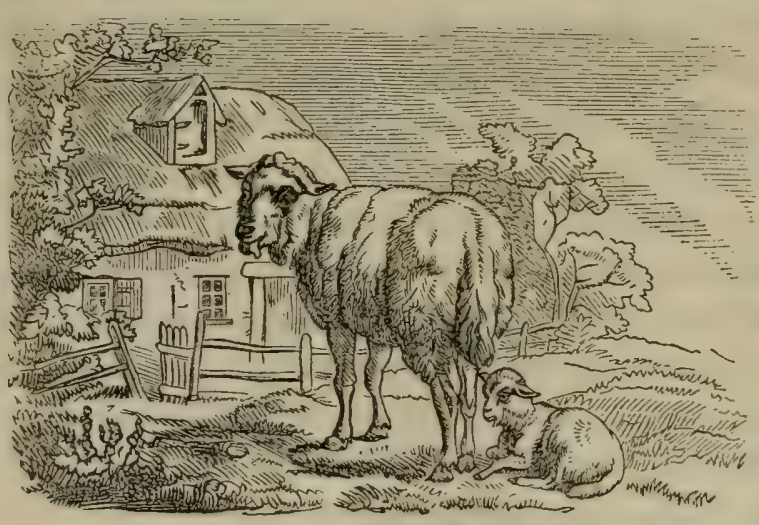

A COUNTRY BCENE.

It. was a

s $10 \mathrm{w}$ feeder, its flesh c o arsegrained, and with li t t le flavor. 'T h e b reeders of that period regarded only size and weight of fleece.

About the middle of the last century, Robert Bakewell, of Dishley, in Leicestershire, first applied himself to the improvement of the sheep in that country. Before his improvements, aptitude to fatten and symmetry of shape-that is, such shape as should increase as much as possible the most valuable parts 
of the animal, and diminish the offal in the same proportionwere entirely disregarded. Perceiving that smaller animals increased in weight more rapidly than the very large ones, that they consumed less food, that the same quantity of herbage, applied to feeding a large number of small sheep, would produce more meat than when applied to feeding the smaller number of large sheep, which alone it would support, and that sheep carrying a heavy fleece of wool possessed less propensity to fatten than those which carried one of a more moderate weight, he selected from the different flocks in his neighborhood, without regard to size, the sheep which appeared to him to have the greatest propensity to fatten, and whose shape possessed the peculiarities which, in his judgment, would produce the largest proportion of valuable meat, and the smallest quantity of bone and offal.

He was also of opinion that the first object to be attended to in breeding sheep is the value of the carcass, and that the flecee ought always to be a secondary consideration; and this for the obvious reason that, while the addition of two or three pounds of wool to the weight of a sheep's fleece is a difference of great amount, yet if this increase is obtained at the expense of the animal's propensity to fatten, the farmer may lose by it ten or twelve pounds of mutton.

The sort of sheep, therefore, which he selected were those possessed of the most perfect symmetry, with the greatest aptitude to fatten, and rather smaller in size than the sheep generally bred at that time. Having formed his stock from sheep so selected, he carefully attended to the peculiarities of the individuals from which he bred, and, so far as can be ascertained-for all of Mrr. Bakewell's measures were kept secret, 
even from his most intimate friends, and he died without throwing, voluntarily, the least light on the subject-did not object to breeding from near relations, when, by so doing, he brought together animals likely to produce a progeny possessing the characteristics which he wished to obtain.

Having thus established his flock, he adopted the practicewhich has since been constantly followed by the most eminent breeders of sheep-of letting rams for the season, instead of selling them to those who wished for their use. By this means the ram-breeder is enabled to keep a much larger number of rams in his possession; and, consequently, his power of selecting those most suitable to his flock, or which may be required to correct any faults in shape or quality. which may occur in it, is greatly increased. By cautiously using a ram for one season, or by observing the produce of a ram let to some other breeder, he can ascertain the probable qualities of the lambs which such ram will get, and thus avoid the danger of making mistakes which would deteriorate the value of his stock. The farmers, likewise, who hire the rams, have an opportunity of varying the rams from which they breed much more than they otherwise could do; and they are also enabled to select from sheep. of the best quality, and from those best calculated to effect the greatest improvement in their flocks.

The idea, when first introduced by him, was so novel that he had great difficulty in inducing the farmers to act upon it; and his first ram was let for sixteen shillings. So eminent, however, was his success, that, in 1787 , he let three rams, for a single season, for twelve hundred and fifty pounds (about six thousand two hundred dollars), and was offered ten hundred 
and fifty pounds (about five thousand two bundred dollars) for twenty ewes. Soon afterwards he received the enormous price of eight hundred guineas (or four thousand dollars) for two-thirds of the services of a ram for a single season, reserving the other third for himself.

The improved Leicester is of large size, but somewhat smaller than the original stock, and in this respect falls considerably below the coarser varieties of Cotswold, Lincoln, etc. Where there is a sufficiency of feed, the New Leicester is unrivalled for its fattening propensities; but it will not bear hard stocking, nor must it be compelled to travel far in search of its food. It is, in fact, properly and exclusively a lowland sheep. In its appropriate situation-on the luxuriant herbage of the highly cultivated lands of England-it possesses unequalled earliness of maturity ; and its mutton, when not too fat, is of a good quality, but is usually coarse, and comparatively deficient in flavor, owing to that unnatural state of fatness which it so readily assumes, and which the breeder, to gain weight, so generally feeds for. The wethers, having reached their second year, are turned off in the succeeding February or March, and weigh at that age from thirty to thirty-five pounds to the quarter. The wool of the New. Leicester is long, averaging, after the first shearing, about six inches; and the fleece of the American animal weighs about six pounds. It is of coarse quality, and little used in the manufacture of cloth, on account of its length, and that deficiency of felting properties common, in a greater or less extent, to all English breeds. As a combing wool, however, it stands first, and is used in the manufacture of the finest worsteds, and the like textures.

The high-bred Leicesters of Mr. Bakewell's stock became 
shy brecders and poor nurses; but crosses subsequently adopted have, to some extent, obviated these defects. The lambs are not, however, generally regarded as very hardy, and they require considerable attention at the time of yeaning, particularly if the weather is even moderately cold or stormy. The grown sheep, too, are much affected by sudden changes in the weather; an abrupt change to cold being pretty certain to be registered on their noses by unmistakable indications of catarrh or "suuffles."

In England, where mutton is generally eaten by the laboring classes, the meat of this variety is in rery great demand; and the consequent return which a sheep possessing such fine feeding qualities is enabled to make renders it a general favorite with the breeder. Instances are recorded of the most extraordinary prices having been paid for these animals. They have spread into all parts of the British dominions, and been imported into the other countries of Europe and into the United States.

They were first introduced into our own country, some forty years since, by Christopher Dunn, of Albany, N. Y. Subsequent importations have been made by Mr. Powel, of Philadelphia, and various other gentlemen. The breed, however, has never proved a farorite with any large class of American farmers. Our long, cold winters-but, more especially, our dry, scorching summers, when it is often difficult to obtain the rich, green, tender feed in which the Leicester delights-together with the general deprivation of green feed in the winter, rob it of its early maturity, and even of the ultimate size which it attains in England. Its mutton is too fat, and the fat and lean are too little intermixed to suit 
American taste. Its wool is not very salable, owing to the dearth of worsted manufactures in our country. Its early decay and loss of wool constitute an objection to it, in a country where it is often so difficult to advantageously turn off sheep, particularly ewes. But, notwithstanding all these disadvantages, on rich lowland farms, in the vicinity of considerable markets, it will always in all probability make a profitable return.

The head of the New Leicester should be hornless, long, small, tapering towards the muzzle, and projecting horizontally forward; the eyes prominent, but with a quiet expression; the ears thin, rather long, and directed backward; the neck full and broad at its base, where it proceeds from the chest, so that there is, with the slightest possible deviation, one continued horizontal line from the rump to the poll; the breast broad and full; the shoulders also broad and round, and no uneren or angular formation where the shoulders join either the neck or the back-particularly no rising of the withers, or hollow behind the situation of these bones; the arm fleshy throughout its whole extent, and even down to the knee; the bones of the leg small, standing wide apart; no looseness of skin about them, and comparatively void of wool; the chest and barrel at once deep and round; the ribs forming a considerable arch from the spine, so as, in some cases-and especially when the animal is in good condition-to make the apparent width of the chest eren greater than the depth; the barrel ribbed well home; no irregularity of line on the back or belly, but on the sides; the carcass very gradually diminishing in width towards the rump; the quarters long and full, and, as with the fore-legs, the muscles extending down to the hock; 
the thighs also wide and full; the legs of a moderate length; and the pelt also moderately thin, but soft and elastic, and covered with a good quantity of white wool, not so long as in some breeds, but considerably finer.

\section{THE SOUTH-DOWN.}

A long range of chalky hills, diverging from the chalky stratum which intersects England from Norfolk to Dorchester, is termed the SouthDowns. They enter the county of Sussex on the west side, and are continued almost in a direct line, as far as East Bourne, where they reach the sea. They may be regarded as occupying a space of more

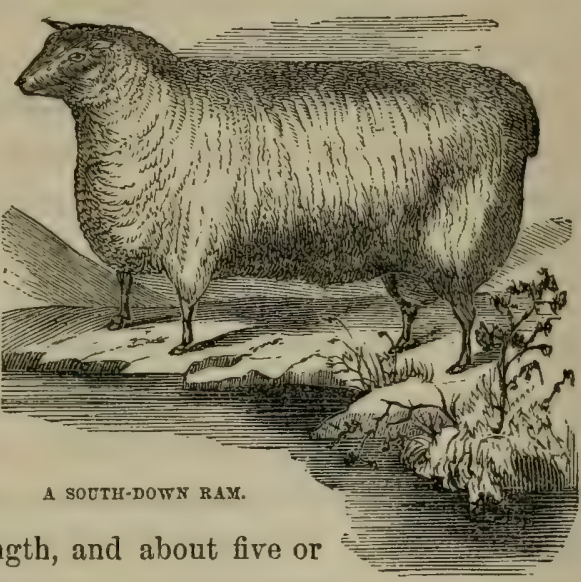
than sixty miles in length, and about five or six in breadth, consisting of a succession of open downs, with few enclosures, and distinguished by their situation and name from a more northern tract of similar elevation and soil, passing through Surrey and Kent, and terminating in the cliffs of Dover, and of the Forelands. On these downs a certain breed of sheep has been produced for many centuries, in greater perfection than elsewhere; and hence have sprung those successive colonies which have found their way abroad and materially benefited the breed of shortwoolled sheep wherever they have gone. 
It is only, however, within a comparatively recent period that they have been brought to their present perfection. As recently as 1776 they were small in size, and of a form not superior to the common woolled sheep of the United States; they were far from possessing a good shape, being long and thin in the neck, high on the shoulders, low behind, high on the loins, down on the rump, the tail set on very low, perpendicular from the hip-bones, sharp on the back; the ribs flat, not bowing, narrow in the fore-quarters, but good in the leg, although having big bones. Since that period a course of judicious breeding, pursued by Mr. John Ellman, of Glynde, in Sussex, has mainly contributed to raise this variety to its present value; and that, too, without the admixture of the slightest degree of foreign blood.

This pure, improved family, it will be borne in mind, is spoken of in the present connection; inasmuch as the original stock, presenting, with trifling modifications, the same characteristics which they exhibited seventy-five years ago, are yet to be found in England; and the intermediate space between these two classes is occupied by a varicty of grades, rising or falling in value, as they approximate to or recede from the improved blood.

The South-Down sheep are polled, but it is probable that the original breed was horned, as it is not unusual to find among the male South-Down lambs some with small horns. The dusky, or at times, black hue of the head and legs fully establishes the original color of the sheep, and, perhaps of all sheep; while the later period at which it was seriously attempted to get rid of this dingy hue proving unsuccessful, only confirms this view. Many of the lambs have been dropped entirely black. 
It is an upland sheep, of medium size, and its wool-which in point of length belongs to the middle class, and differs essentially from Merino wool of any grade, though the fibre in some of the finest flecces may be of the same apparent fineness with half or one-quarter blood Merino-is deficient in felting properties, making a fuzzy, hairy cloth, and is no longer used in England, unless largely mixed with foreign wool, even for the lowest class of cloths. As it has deteriorated, however, it has increased in length of staple, in that country, to such an extent that improved machinery enables it to be used as a combing-wool, for the manufacture of worsteds. Where this has taken place it is quite as profitable as when it was finer and shorter. In the United States, where the demand for combing-wool is so small that it is easily met by a better article, the same result would not probably follow. Indeed, it may well be doubted whether the proper combing length will be easily reached, or at least maintained in this country, in the absence of that high feeding system which has undoubtedly given the wool its increased length in England. The average weight of fleece in the hill-fed sheep is three pounds; on rich lowlands, a little more.

The South-Down, however, is cultivated more particularly for its mutton, which for quality takes precedence of all otherfrom sheep of good size-in the English markets. Its early maturity and extreme aptitude to lay on flesh, render it peculiarly valuable for this purpose. It is turned off at the age of two years, and its weight at that age is, in England, from eighty to one hundred pounds. High-fed wethers have reached from thirty-two to even forty pounds a quarter. Notwithstanding its weight, it has a patience of occasional short 4 
keep, and an endurance of hard stocking, equal to any other sheep. This gives it a decided advantage orer the bulkier Leicesters and Lincolns, as a mutton sheep, in hilly districts and those producing short and scanty herbage. It is hardy and healthy, though, in common with the other English varieties, much subject to catarrh, and no sheep better withstands our American winters. The ewes are prolific breeders and good nurses.

The Down is quiet and docile in its habits, and, though an industrious feeder, exhibits but little disposition to rove. Like the Leicester, it is comparatively a short-lived animal, and the fleece continues to decrease in weight after it reaches maturity. It crosses better with short and middle-woolled breeds than the Leicester. A sheep possessing such qualities, must, of necessity, be valuable in upland districts in the vicinity of - markets. The Emperor of Russia paid Mr. Ellman three hundred guineas (fifteen hundred dollars) for two rams; and, in 1800, a ram belonging to the Duke of Bedford was let for one season at eighty guineas (four hundred dollars), two others at forty guineas (two bundred dollars) each, and four more at twenty-eight guineas (one hundred and forty dollars) each. The first importation into the United States was made by Col. J. H. Powell, of Philadelphia. A subsequent importation, in 1834, cost sixty dollars a head.

The desirable characteristics of the South-Down may be thus summed up : The head small and hornless; the face speckled or gray, and neither too long nor too short; the lips thin, and the space between the nose and the eyes narrow; the underjaw or chap fine and thin; the ears tolerably wide and wellcovered with wool, and the forehead also, and the whole space 
between the ears well protected by it, as a defence against the fly ; the eye full and bright, but not prominent; the orbits of the eye, the eye-cap or bone not too projecting, that it may not form a fatal obstacle in lambing; the neck of a medium length, thin toward the head, but enlarging toward the shoulders, where it should be broad and high and straight in its whole course above and below.

The breast should be wide, deep, and projecting forward between the fore-legs, indicating a good constitution and a disposition to thrive; corresponding with this, the shoulders should be on a level with the back, and not too wide above; they should bow outward from the top to the breast, indicating a springing rib beneath, and leaving room for it; the ribs coming out horizontally from the spine, and extending far backward, and the last rib projecting more than others; the back flat from the shoulders to the setting on of the tail; the loin broad and flat; the rump broad, and the tail set on high, and nearly on a level with the spine.

The hips should be wide; the space between them and the last rib on each side as narrow as possible, and the ribs generally presenting a circular form like a barrel; the belly as straight as the back; the legs neither too long nor too short; the fore-legs straight from the breast to the foot, not bending inward at the knee, and standing far apart, both before and behind; the hock having a direction rather outward, and the twist, or the meeting of the thighs behind, being particularly full; the bones fine, yet having no appearance of weakness, and of a speckled or dark color; the belly well defended with wool, and the wool coming down before and behind to the 
knee and to the hock; the wool short, close, curled and fine, and free from spiry projecting fibres.

\section{THE COTSWOLD.}

The Cotswolds, until improved by modern crosses, were a very large, coarse, long-legged, fat-ribbed variety, light in the

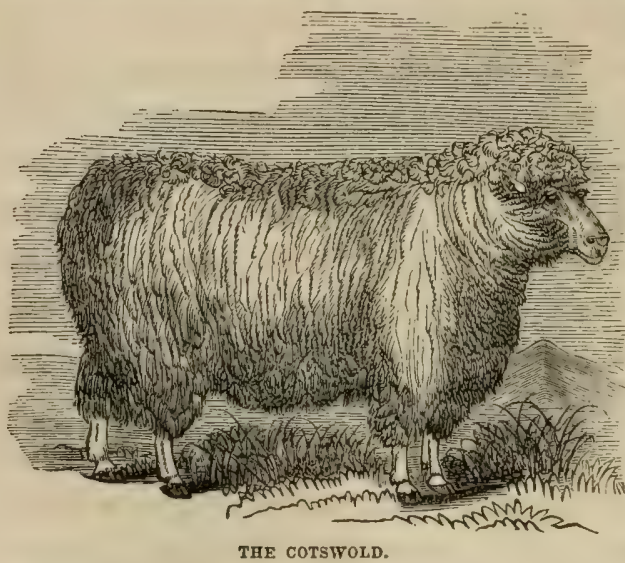
fore-quarter, and shearing a long, heary, coarse fleece of wool. They were formerly bred only on the hills, and fatted in the valleys, of the Severn and the Thames; but with the enclosures of the Cotswold hills, and the improvement of their cultivation, they have been reared and fatted in the same district. They were hardy, prolific breeders, and capital nurses; deficient in early maturity, and not possessing feeding properties equalling those of the South-Down or New Leicester.

They have been extensively crossed with the Leicester sheep-producing thus the modern or improved Cotswold-by which their size and fleece have been somewhat diminished, but their carcasses have been materially improved, and their maturity rendered earlier. The wethers are sometimes fattened at fourteen months old, when they weigh from fifteen to 
twenty-four pounds to a quarter; and at two vears old, increase to twenty or thirty pounds.

The wool is strong, mellow, and of good color, though rather coarse. six to eight inches in length, and from seven to eight pounds per fleece. The superior hardihood of the improved Cotswold over the Leicester, aud their adaptation to common treatment, together with the prolific nature of the ewes, and their abundance of milk, have rendered them in many places rivals of the New Leicester, and have obtained for them, of late years, more attention to their selection and general treatment, under which management still farther improvement has been made. They hare also been used in crossing other breeds, and have been mixed with the Hampshire Downs. Indeed, the improved Cotswold, under the name of new, or improved Oxfordshire sheep, have frequently been the successful candidates for prizes offered for the best long-woolled sheep at some of the principal agricultural meetings or shows in England. The quality of their mutton is considered superior to that of the Leicester; the tallow being less abundant, with a larger development of muscle or flesh.

The degree to which the cross between the Cotswold and Leicester may be carried, must depend upon the nature of the old stock, and on the situation and character of the farm. In exposed situations, and somewhat scanty pasture, the old blood should decidedly prevail. On a more sheltered soil, and on land that will bear closer stocking, a greater use may be made of the Leicester. Another circumstance that should guide the farmer is the object which he has principally in view. If he expects to derive his chief profits from the wool, he will look 
to the primitive Cotswolds; if he expects to gain more as a grazier, he will use the Leicester ram more freely.

Sheep of this breed, now of established reputation, have been imported into the United States by Messrs. Corning and Gotham, of Albany, and bred by the latter.

\section{THE CHEVIOT.}

On the steep, storm-lashed Cheviot hills, in the extreme north of England, this loreed first attracted notice for their

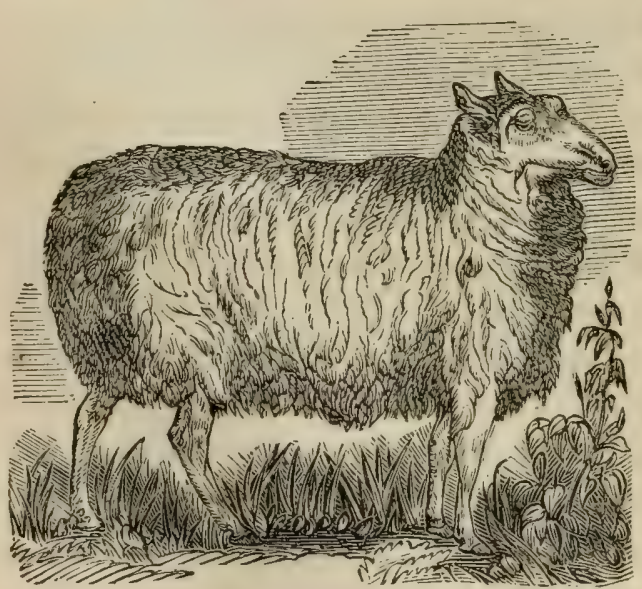

A CHEVTOT EWB.

great hardiness in resisting cold, and for feeding on coarse, heathery herbage. A cross with the Leicester, pretty generally resorted to, constitutes the improved variety.

The Cheviot readily amalgamates with the

Leicester-the rams employed in the system of breeding, which has been extensively introduced for producing the first cross of this descent, being of the pure Leicester breed-and the progeny is superior in size, weight of wool, and tendency to fatten, to the native Cheviot. The benefit, however, may be said to end with the first cross; and the progeny of this mixed descent is greatly inferior to the pure Leicester in form 
and fattening properties, and to the pure Cheviot in hardiness of constitution.

The improred Cheviot has greatly extended itself throughout the mountains of Scotland, and in many instances supplanted the black-faced breed; but the change, though often advantageous, has in some cases been otherwise-the latter being somewhat hardier, and more capable of subsisting on heathy pasturage. They are a hardy race, however; well suited for their native pastures, bearing, with comparative impunity, the storms of winter, and thriving well on poor keep. The purest specimens are to be found on the Scotch side of the Cheviot hills, and on the high and stony mountain farms which lie between that range and the sources of the Teviot. These sheep are a capital mountain stock, provided the pasture resembles those hills, in containing a good proportion of rich herbage. Though less hardy than the black-faced sheep of Scotland, they are more profitable as respects their feeding, making more flesh on an equal quantity of food, and making it more quickly.

They have white faces and legs, open countenances, lively eyes, and are without horns; the ears are large, and somewhat singular, and there is much space between the ears and eyes; the carcass is long; the back straight; the shoulders rather light; the ribs circular; and the quarters good. The legs are small in the bone, and covered with wool, as well as the body, with the exception of the face. The wether is fit for the butcher at three years old, and averages from twelve to eighteen pounds a quarter; the mutton being of a good quality, though inferior to the South-Down, and of less flavor than the 
black-faced. The Cheviot, though a mountain breed, is quiet and docile, and easily managed.

The wool is about the quality of Leicester, coarse and long, suitable only for the manufacture of low coatings and flushings. It closcly covers the body, assisting much in preserving it from the effects of wet and cold. The fleece averages about three and a half pounds. Formerly, the wool was extensively employed in making cloths; but having given place to the finer Saxony wools, it has sunk in price, and been confined to combing purposes. It has thus become altogether a secondary consideration.

The Cheviots have become an American sheep by their repeated importations into this country. The wool on several choice sheep, imported by Mr. Carmichael, of New York, was from five to seven inches long, coarse, but well suited to combing.

\section{THE IINCOLN.}

The old breed of Lincolnshire sheep was hornless, bad white faces, and long, thin, and weak carcasses; the ewes weighed from fourteen to twenty pounds a quarter; the three-year old wethers from twenty to thirty pounds; legs thick, rough and white; pelts thick; wool long-from ten to eighteen inchesand covering a slow-feeding, coarse-grained carcass of mutton.

A judicious system of breeding, which avoided Bakewell's errors, has wrought a decided improvement in this breed. The improved Lincolns possess a rather more desirable robustness, approaching, in some few specimens, almost to coarseness, as compared with the finest Leicesters; but they are more hardy, and less liable to disease. They attain as large a size, and 
yield as great an amount of wool, of about the same value. This breed, indeed, scarcely differs more from the Cotswold than do flocks of a similar variety, which have been separately bred for several generations, from each other. They are prolific, and when well-fed, the ewes will frequently produce two lambs at a birth, for which they provide liberally from their udders till the time for weaning. The weight of the fleece. varies from four to eight pounds per head.

Having alluded to the principal points of interest connected with the various breeds of sheep in the United States, our next business is with

THE NATURAL HISTORY OF THE SHEEP.

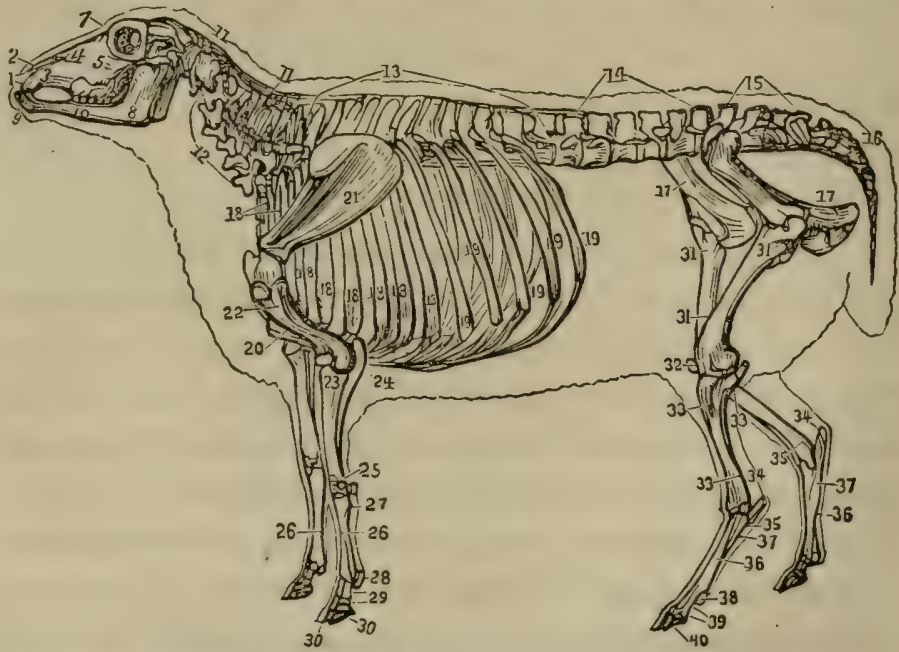

SEELETON OF THE SHEEP AS COVERED BY THE MUSCLES.

1. The intermaxillary bone. 2. The nasal bones. 3. The upper jaw. 4 The union of the nasal and upper jaw-bones. 5. The union of the molar and lachrymal bones. 6. The orbits of the eye. 7. The frontal bone. 8. The lower jaw. 9 The incisor teeth, or nippers, 10. The molars or grinders. 11. The ligament of the neck supporting the head. 12. The seven vertehra, or the bones of the neck. 13 The thirteen vertebræ, or bones of the back. 14. The six vertebræ of the loins. 15. The sacral bone. 
10. The bones of the tail, varying in, different breeds from twelve to twenty-one. 17. The haunch and pelvis. 15. The eight true ribs, with their cartilages. 19. The five false ribs, or those that are not attached to the breast-bone. 20. The breast-bone. 21. The seapula, or shoulder-blade. 22. The humerus, bone of the arm, or lower part of the shoulder. 23. The radius, or bone of the fore-arm. 24. The ulna or elbow. 25. The knee with its different bones. 26. The metacarpal or shank-bones-the larger bones of the leg. 27. A rudiment of the smaller metacarpal. 28. One of the sessamoid bones. 29. The first $t$ wo bones of the foot-the pasterns, 30. The proper bones of the foot. 31. The thigh-bone. 32. The stifle-joint and its bone-the patella. 33. The tibia, or bone of the upper part of the leg. 34. The point of the hock. 35. The other bones of the hock. 36. The metatarsal bones, or bone of the hind-leg. 37. Rudiment of the small metatarsal. 38. A sessamuid bone. 39. The first two bones of the footthe pasterns. 40. The proper bones of the foot.

Division. Vertebrata-possessing a back-bone.

Class. Mammalia-such as give suck.

ORder. Ruminantia-chewing the cud.

Family. Caprida-the goat kind.

Genus. Oris-the sheep family.

Of this Genus there are three varieties:

Oris, Amiron, or Argali.

Oris Musmon.

Oris Arres, or Domestic Sheep.

Of the latter-with which alone this treatise is concernedthere are about forty well known varieties. Between the oris, or sheep, and the capra, or goat, another genus of the same family, the distinctions are well marked, although considerable resemblance exists between them. The horns of the sheep have a spiral direction, while those of the goat have a direction upward and backward; the sheep, except in a single wild variety, has no beard, while the goat is bearded; the goat, in his highest state of improvement, when he is made to produce wool of a fineness unequalled by the sheep-as in the Cashmere breed-is mainly, and always, externally covered with hair, while the hair on the sheep may, by domestication, be reduced to a few coarse hairs, or got rid of altogether; and, 
finally, the pelt or skin of the goat has thickness very far exceeding that of the sheep.

The age of sheep is usually reckoned, not from the time that they are dropped, but from the first shearing; although the first year may thus include fifteen or sixteen months, and sometimes more. When doubt exists relative to the age, recourse is had to the teeth, since there is more uncertainty about the horn in this animal than in cattle; ewes that have been early bred, appearing always, according to the rings on the horn, a year older than others that have been longer kept from the ram.

\section{FORMATION OF THE TEETH.}

Sheep have no teeth in the upper jaw, but the bars or ridges of the palate thicken as they approach the forepart of the mouth; there also the dense, fibrous, elastic matter, of which they are constituted, becomes condensed, and forms a cushion or bed, which covers the converse extremity of the upper jaw, and occupies the place of the upper incisor, or cutting teeth, and partially discharge their functions. The herbage is firmly held between the front teeth in the lower jaw and this pad, and thus partly bitten and partly torn asunder. Of this, the rolling motion of the head is sufficient proof.

The teeth are the same in number as in the mouth of the ox. There are eight incisors or cutting-teeth in the forepart of the lower jaw, and six molars in each jaw above and below, and on either side. The incisors are more admirably formed for grazing than in the ox. The sheep lives closer, and is destined to follow the $o x$, and gather nourishment where that animal 
would be unable to crop a single blade. This close life not only loosens the roots of the grass, and disposes them to spread, but by cutting off the short suckers and sproutings-a wise provision of nature-causes the plants to throw out fresh, and more numerous, and stronger ones, and thus is instrumental in improving and increasing the value of the crop. Nothing will more expeditiously and more effectually make a thick, permanent pasture than its being occasionally and closely eaten down by sheep.

In order to enable the sheep to bite this close, the upper lip is deeply divided, and free from hair about the centre of it. The part of the tooth above the gum is not only, as in other animals, covered with enamel, to enable it to bear and to preserve a sharpened edge, but the enamel on the upper part rises from the bone of the tooth nearly a quarter of an inch, and presenting a convex surface outward, and a concave within, forms a little scoop or gorge of wonderfulexecution.

The mouth of the lamb newly dropped is either without incisor teeth or it has two. The teeth rapidly succeed to each other, and before the animal is a month old he has the whole of the eight. They continue to grow with his growth until he is about fourteen or sixteen months old. Then, with the same previous process of diminution as in cattle, or carried to a still greater degree, the two central teeth are shed, and attain their full growth when the sheep is two years old.

In examining a flock of sheep, however, there will often be very considerable difference in the teeth of those that have not been sheared, or those that have been once sheared; in some measure to be accounted for by a difference in the time of lambing, and likewise by the general health and vigor of the 
animal. There will also be a material difference in different animals, attributable to the good or bad keep which they have had. Those fed on good land, or otherwise well kept, will generally take the start of others that have been half starved, and renew their teeth some months sooner than these. There are also irregularities in the times of renewing the teeth, not to be accounted for by either of these circumstances; in fact, not to be explained by any known circumstance relating to the breed or the keep of the sheep. The want of improvement in sheep, which is occasionally observed, and which cannot be accounted for by any deficiency or change of food, may sometimes be justly attributed to the tenderness of the mouth when the permanent teeth are protruding through the gums.

Between two and three years old the next two incisors are shed; and when the sheep is actually three years old, the four central teeth are fully grown; at four years,old, he has six 'teeth fully grown; and at five years old-one year before the horse or the ox can be said to be full-mouthed-all the teeth are perfectly developed. The sheep is a much shorter-lived animal than the horse, and does not often attain the usual age of the ox. Their natural age is about ten years, to which age they will breed and thrive-well; though there are recorded instances of their breeding at the age of fifteen, and of living twenty years.

The careless examiner may be sometimes deceived with regard to the four-year-old mouth. He will see the teeth perfectly developed, no diminutive ones at the sides, and the mouth apparently full; and then, without giving himself the trouble of counting the teeth, he will conclude that the animal is five years old. A process of displacement, as well as of 
diminution, has taken place here; the remaining outside milkteeth have not only shrunk to less than a fourth part of their original size, but the four-year-old teeth have grown before them and perfectly conceal them, unless the mouth is completely opened.

After the permanent teeth have all appeared and are fully grown, there is no criterion as to the age of the sheep In most cases, the teeth remain sound for one or two years, and then, at uncertain intervals-either on account of the hard mork in which they have been employed, or from the natural effect of age-they begin to loosen and fall out; or, by reason of their natural slenderness, they are broken off. When favorite ewes, that have been kept for breeding, begin to lose condition, at six or seven years old, their mouths should be carefully examined. If any of the teeth are loose, they should be extracted, and a chance given to the animal to show how far, by browsing early and late, she may be able to make up * for the diminished number of her incisors. It frequently happens that ewes with broken teeth, and some with all the incisors gone, will keep pace in condition with the best in the flock; but they must be well taken care of in the winter, and, indeed, nursed to an extent that. would scarcely answer the farmer's purpose to adopt as a general rule, in order to prevent them from declining to such a degree as would make it very difficult afterward to fatten them for the butcher. It may certainly be taken as a general rule, that when sheep become broken-mouthed they begin to decline.

Causes of which the farmer is utterly ignorant, or orer which he has no control, will sometimes hasten the loss of the teeth. One thing, however, is certain-that close feeding, 
causing additional exercise, does wear them down; and that the sheep of farmers who stock unusually and unseasonably hard, lose their teeth much sooner than others do.

\section{THE STRUCTURE OF THE SKIN.}

The skin of the sheep, in common with that of most animals, is composed of three textures. Externally is the cuticle, or scarf-skin, which is thin, tough, deroid of feeling, and pierced by innumerable minute holes, through which pass the fibres of the wool and the insensible perspiration. It seems to be of a scaly texture; although is not so evident as in many other animals, on account of a peculiar substance-the yolk-which is placed on it, to protect and nourish the roots of the wool. It is, howerer, sufficiently evident in the scab and other cutaneous eruptions to which this animal is liable.

Below this cuticle is the rete mucosum, a soft structure; its fibres having scarcely more consistence than mucilage, and being with great difficulty separated from the skin beneath. This appears to be placed as a defence to the terminations of the blood-ressels and nerves of the skin, which latter are, in a manner, enveloped and covered by it. The color of the skin, and probably that of the hair or wool also, is determined by the rete mucosum; or, at least, the hair and wool are of the same color as this substance.

Beneath the rete mucosum is the cutis, or true skin, composed of numberless minute fibres crossing each other in every direction; highly elastic, in order to fit closely to the parts beneath, and to yield to the various motions of the body; and lense and firm in its structure, that it may resist external injury. Blood-ressels and nerves innumerable pierce it, and 
appear on its surface in the form of papillce, or minute eminences; while, through thousands of little orifices, the exhelant absorbents pour out the superfluous or redundant fluid. The true skin is composed, principally or almost entirely, of gelatine; so that, although it may be dissolved by long-continued boiling, it is insoluble in water at the common temperature. This organization seems to have been given to it, not only for the sake of its preservation while on the living animal, but that it may aflerwards become useful to man. The substance of the hide readily combining with the tanning principle, is converted into leather.

\section{THE ANATOMY OF THE WOOL.}

On the skin of most animals is placed a covering of feathers, fur, hair, or wool. These are all essentially the same in com-

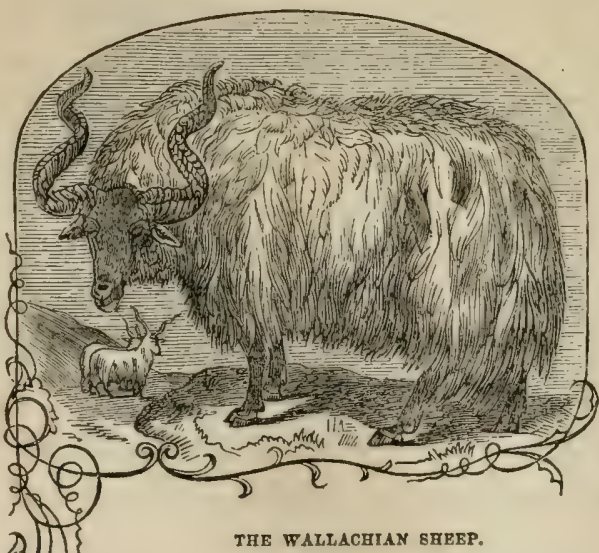
position, be in $g$ composed of an animal substance resembling coagulated albumen, together with sulphur, silica, carbonate and phosphate of lime, and oxides of iron and manganese.

Wool is not confined to the sheep. The under-hair of some goats is not only finer than the fleece of any sheep, but it occasionally has the crisped appearance of wool; being, in fact, 
wool of different qualities in different breeds-in some, rivalling or excelling that of the sheep, but in others very coarse. $\Lambda$ portion of wool is also found on many other animals; as the deer, elk, the oxen of Tartary and Hudson's Bay, the gnu, the camel, many of the fur-clad animals, the sable, the polecat, and several species of the dog.

Judging from the mixture of wool and hair in the coat of most animals, and the relative situation of these materials, it is not improbable that such was the character of the fleece of the primitive sheep. It has, indeed, been asserted that the primitive sheep was entircly covered with hair; but this is, doubtless, incorrect. There exists, at the present day, varieties of the sheep occupying extensive districts, that are clothed outwardly with hair of different degrees of fineness and sleekness; and underneath the external coat is a softer, shorter, and closer one, that answers to the description of fur-according to most travellers-but which really possesses all the characteristics of wool. It is, therefore, highly inprobable that the sheepwhich has now become, by cultivation, the wool-bearing animal in a pre-eminent degree-should, in any country, at any time, have ever been entirely destitute of wool. Sheep of almost every variety have at times been in the gardens of the London (Eng.) Zoölogical Society; but there has not been one on which a portion of crisped wool, although exceedingly small, has not been discovered beneath the hair. In all the regions over which the patriarchs wandered, and extending northward through the greater part of Europe and Asia, the sheep is externally covered with hair; but underneath is a fine, short, downy wool, from which the hair is easily separated. 
This is the case with the sheep at the Cape of Good Hope, and also in South America.

The change from hair to wool, though much influenced by temperature, has been chiefly effected by cultivation. Wherever hairy sheep are now found the management of the animal is in a most disgraceful state; and among the cultivated sheep the remains of this ancient hairy covering only exists, to any great extent, among those that are comparatively neglected or abandoned.

The filament of the wool has scarcely pushed itself through the pore of the skin, when it has to penetrate through another and singular substance, which, from its adhesiveness and color, is called the yolk. This is found in greatest quantity about the breast and shoulders-the very parts that produce the best, and healthiest, and most abundant wool-and in proportion as it extends, in any considerable degree, over other parts, the wool is then improved. It differs in quantity in different breeds. It is very abundant on the Merinos; it is sufficiently plentiful on most of the southern breeds, either to assist in the production of the wool, or to defend the sheep from the inclemency of the weather; but in the northern districts, where the cold is more intense and the yolk of wool is deficient, a substitute for it is sometimes sought by smearing the sheep with a mixture of tar, oil, or butter. Where there is a deficiency of yolk, the fibre of the wool is dry, harsh, and weak, and the whole fleece becomes thin and hairy; where the natural quantity of it is found, the wool is soft, oily, plentiful and strong.

This yolk is not the inspissated or thickened perspiration of the animal it is not composed of matter which has been acci- 
dentally picked up, and which has lodged in the wool; but it is a peculiar secretion from the glands of the skin, destined to be one of the agents in the nourishment of the wool, and at the same time, by its adhesiveness, to mat the wool together, and form a secure defence from the wet and cold.

Chemical experiments have established its composition, as follows : first, of a soapy matter with a basis of potash, which forms the greater part of it; second, a small quantity of carbonate of potash; third, a perceptible quantity of acetate of potash; fourth, lime, in a peculiar and unknown state of combination ; fifth, an atom of muriate of potash; sixth, an animal oil, to which its peculiar odor is attributable. All these materials are believed to be essential to the yolk, and not found in it by mere accident, since the yolk of a great number of samples_Spanish, French, English, and American-has been subjected to repeated analyses, with the same result.

The yolk being a true soap, soluble in water, it is not difficult to aceount for the comparaive ease with which sheep that have the natural proportion of it are washed in a running stream. There is, however, a small quantity of fatty matter in the fleece, which is not in combination with the alkali, and which, remaining attached to the wool, keeps it a little glutinous, notwithstanding the most careful washing.

The fibre of the wool haring penetrated the skin and escaped from the yolk, is of a circular form, generally larger toward the extremity, and also toward the root, and in some instances very considerably so. The filaments of white wool, when cleansed from grease, are semi-transparent; their surface in some places is beautifully polished, in others curiously incrusted, and they reflect the rays of light in a very pleasing 
manner. When viewed by the aid of a powerful achromatic microscope; the central part of the fibre has a singularly glittering appearance. Minute filaments, placed very regularly, are sometimes seen branching from the main trunk, like boughs from the principal stem. This exterior polish varies much in different wools, and in wools from the same breed of sheep at different times. When the animal is in good condition, and the fleece healthy, the appearance of the fibre is really brilliant; but when the state of the constitution is bad, the fibre has a dull appearance, and either a wan, pale light, or sometimes scarcely any, is reflected. As a general rule, the filament is most transparent in the best and most useful wools, whether long or short. It increases with the improvement of the breed, and the fineness and healthiness of the fleece; yet it must be admitted that some wools have different degrees of the transparency and opacity, which do not appear to affect their value and utility. It is, however, the difference of transparency in the same fleece, or in the same filament, that is chiefly to be noticed as improving the value of the wool.

As to the size of the fibre, the terms "fine" and "coarse," as commonly used, are but vague and general descriptions of wool. All fine fleeces have some coarse wool, and all coarse fleeces some fine. The most accurate classification is to distinguish the various qualities of wool in the order in which they are esteemed and preferred by the manufacturer-as the following: first, fineness with close ground, that is, thickmatted ground; second, pureness ; third, straight-laired, when broken by drawing; fourth, elasticity, rising after compression in the hand; fifth, staple not too long; sixth, color; seventh, what coarse exists to be very coarse; eighth, tenacity; and 
ninth, not much pitch-mark, though this is no disadvantage, except the loss of weight in scouring. The bad or disagreeable properties are-thin, grounded, tossy, curly-haired, and, if in a sorted state, little in it that is very fine; a tender staple, as elasticity, many dead white hairs, very yolky. Those who buy wool for combing and other light goods that do not need milling, wish to find length of staple, fineness of hair, whiteness, tenacity, pureness, elasticity, and not too many pitch-marks.

The property first attracting attention, and being of greater importance than any other, is the fineness of the pile-the quantity of fine wool which a fleece yields, and the degree of that fineness. Of the absolute fineness, little can be said, varying, as it does, in different parts of the same fleece to a very considerable degree, and the diameter of the same fibre often being exceedingly different at the extremity and the centre. The micrometer has sometimes indicated that the diameter of the former is five times as much as that of the latter; and, consequently, that a given length of yield taken from the extremity would weigh twenty-five times as much as the same length taken from the centre and cleansed from all yolk and grease. That fibre may be considered as coarse whose diameter is more than the five-hundredth part of an inch; in some of the most valuable samples of Saxony wool it has not exceeded the nine-hundredth part; yet in some animals, whose wool has not been used for manufacturing purposes, it is less than one twelve-hundredth part.

The extremities of the wool, and frequently those portions which are near to the root, are larger than the intermediate parts. The extremity of the fibre bas, generally, the greatest 
bulk of all. It is the product of summer, soon after shearingtime, when the secretion of the matter of the wool is increased, and when the pores of the skin are relaxed and open, and permit a larger fibre to protrude. The portion near the root is the growth of spring, when the weather is getting warm; and the intermediate part is the offspring of winter, when under the influence of the cold the pores of the skin contract, and permit only a finer hair to escape. If, however, the animal is well fed, the diminution of the bulk of the fibre will not be followed by weakness or decay, but, in proportion as the pile becomes fine, the value of the fleece will be in. creased; whereas, if cold and starvation should go hand-inhand, the woolly fibre will not only diminish in bulk, but in health, strength, and worth.

The variations in the diameter of the wool in different parts of the fibre will also curiously correspond with the degree of leat at the time the respective portions were produced. The fibre of the wool and the record of the meteorologist will singularly agree, if the variations in temperature are suffciently distinct from each other for any appreciable part of the fibre to form. It follows from this, that-the natural tendency to produce wool of a certain fibre being the samesheep in a hot climate will yield a comparatively coarse wool, and those in a cold climate will carry a finor, but at the same time a closer and a warmer fleece. In proportion to the coarseness of a fleece will generally be its openness, and its inability to resist either cold or wet; while the coat of softer, smaller, more pliable wool will admit of no interstices between its fibres, and will bid defiance to frost and storms.

The natural instinct of the sheep would seem to teach the 
wool-grower the adrantage of attending to the influence of temperature upon the animal. He is evidently impatient of heat. In the open districts, and where no shelter is near, he climbs to the highest parts of his walk, that, if the rays of the sun must still fall on him, he may nevertheless be cooled by the breeze; but, if shelter is near, of whatever kind, every shaded,spot is crowded with sheep. The wool of the Merinos after shearing-time is hard and coarse to such a degree as to render it very difficult to suppose that the same animal could bear wool so opposite in quality, compared with that which had been clipped from it in the course of the same season. As the cold weather advances, the fleeces recover their soft quality.

Pasture has a far greater influence on the fineness of the fleece. The staple of the wool, like every other part of the sheep, must increase in length or in bulk when the animal has a superabundance of nutriment; and, on the other hand, the secretion which forms the wool must decrease like every other, when sufficient nourishment is not afforded. When little cold has been experienced in the winter, and vegetation has scarcely been checked, the sheep yields an abundant crop of wool, but the fleece is perceptibly coarser as well as heavier. When the frost has been severe, and the ground long covered with snow, if the flock has been fairly supplied with nutriment, although the fleece may have lost a little in weight, it will have acquired a superior degree of fineness, and a proportional increase of value. Should, howrever, the sheep have been neglected and starved during this continued cold weather, the fleece as well as the carcass is thinner, and 
although it may have preserved its smallness of filament, it has lost in weight, and strength, and usefulness.

Connected with fineness is trueness of staple-as equal in growth as possible over the animals-a freedom from those shaggy portions, here and there, which are occasionally observed on poor and neglected sheep. These portions are always coarse and comparatively worthless, and they indicate an irregular and unhealthy action of the secretion of wool, which will also probablý weaken or render the fibre diseased in other parts. Included in trueness of fibre is another circumstance to which allusion bas already been made-a freedom from coarse hairs which project above the general level of the wool in various parts, or; if they are not externally seen, mingle with the wool and debase its qualities.

Soundness is closely associated with trueness. It means, generally speaking, strength of the fibre, and also a freedom from those breaches or withered portions of which something has previously been said. The eye will readily detect the breaches; but the hair generally may not possess a degree of strength proportioned to its bulk. This is ascertained by drawing a few hairs out of the staple, and grasping each of them singly by both ends, and pulling them until they break. The wool often becomes injured by felting while it is on the sheep's back. This is principally seen in the heary breeds, especially those that are neglected and half-starved, and generally begins in the winter season, when the coat has been completely saturated with water, and it increases until shearing-time, unless the cob separates from the wool beneath, and drops off.

Wool is generally injured by keeping. It will probably in- 
crease a little in weight for a few months, especially if kept in a damp place; but after that it will somewhat rapidly become lighter, until a very considerable loss will often be sustained. This, however, is not the moral of the case; for, except very great care is taken, the moth will get into the bundles and injure and destroy the staple; and that which remains untouched by them will become considerably harsh and less pliable. If to this the loss of the interest of money is added, it will be seen that he seldom acts wisely who hoards his wool, when he can obtain what approaches to a fair remunerating price for it.

Softness of the wool is evidently connected with the presence and quality of the yolk. This substance is undoubtedly designed not only to nourish the hair, but to give it richness and pliability. The growth of the yolk ought to be promoted, and agriculturists ought to pay more attention to the quantity and quality of yolk possessed by the animals selected for the purpose of breeding.

Bad management impairs the pliability of the wool, by arresting the secretion of the yolk. The softness of the wool is also much influenced by the chemical elements of the soil. A chalky soil notoriously deteriorates it; minute particles of the chalk being necessarily brought into contact with the fleece and mixing with it, have a corrosive effect on the fibre, and harden it and render it less pliable. The particles of chalk come in contact with the yolk-there being a chemical affinity between the alkali and the oily matter of the yolk-immediately unite, and a true soap is formed. The first storm washes a portion of it; and the wool, deprived of its natural pabulum and unguent, loses some of its vital properties-its pliability 
among the rest. The slight degree of harshness which has been attributed to the English South-Down has been explained in this way.

The felting property of wool is a tendency of the fibres to entangle themselves together, and to form a mass more or less difficult to unravel. By moisture and pressure, the fibres of the wool may become matted or felted together into a species of cloth. The manufacture of felt was the first mode in which wool was applied to clothing, and felt has long been in universal use for hats. The fulling of flannels and broadcloths is effected by the felting principle. By the joint influence of the moisture and the pressure, certain of the fibres are brought into more intimate contact with each other; they adhere-not only the fibres, but, in a manner, the threads-and the cloth is taken from the mill shortened in all its dimensions; it has become a kind of felt, for the threads have disappeared, and it can be cut in every direction with very little or no unravelling; it is altogether a thicker, warmer, softer fibre. This felting property is one of the most valuable qualities possessed by wool, and on this property are the finer kinds of wool especially valued by the manufacturer for the finest broadcloths. This naturally suggests a consideration of the various forms in the structure on which it depends.

The most evident distinction between the qualities of hair and wool is the comparative straightness of the former, and the crisped or spirally-curling form which the latter assumes. If a little lock of wool is held up to the light, every fibre of it is twisted into numerous minute corkscrew-like ringlets. This is especially seen in the fleece of the short-woolled sheeps; but, 
although less striking, it is obvious even in wool of the largest staple.

The spirally-curving form of wool used, erroneously, to be considered as the chief distinction between the covering of the goat and the sheep; but the under-coat of some of the former is finer than that of any sheep, and it is now acknowledged frequently to have the crisped and curled appearance of wool. In some breeds of cattle, particularly in one variety of the Devons, the hair assumes a curled and wavy appearance, and a few of the minute spiral ringlets hare been occasionally seen. It is the same with many of the Highlands; but there is no determination to take on the true crisped character, and throughout its whole extent, and it is still nothing but hair. On some foreign breeds, however, as the yak of Tartary, and the ox of Hudson's Bay, some fine and valuable wool is produced.

There is an intimate connection between the fineness of the wool and the number of the curves, at least in sheep yielding wool of nearly the same length; so that, whether the wool of different sheep is examined, or that from different parts of the same sheep, it is enough for the observer to take advice of the number of curves in a given space, in order to ascertain with sufficient accuracy the fineness of the fibre.

To this curled form of the wool not enough attention is, as a general thing, paid by the breeder. It is, however, that on which its most valuable uses depend. It is that which is essential to it in the manufactory of cloths. The object of the carder is to break the wool in pieces at the curves-the principle of the thread is the adhesion of the particles together by their curres; and the fineness of the thread, and consequent 
fineness of the cloth, will depend on the minuteness of these curves, or the number of them found in a given length of fibre.

It will readily be seen that this curling form has much to do with the felting property of wool; it materially contributes to that disposition in the fibres which enables them to attach and intwine themselves together; it multiplies the opportunities for this interlacing, and it increases the difficulty of unravelling the felt.

The felting property of wool is the most important, as well as the distinguishing one ; but it varies essentially in different breeds, and the usefulness and the consequent value of the fleece, for clothing purposes, at least, depend on the degree to which it is pursued.

The serrated-notched, like the teeth of a saw-edge of wool, which has been discovered by means of the microscope, is also, as well as the spiral curl, deemed an important quality in the felting property. Repeated microscopic observations have removed all doubts as to the general outline of the woolly fibre. It consists of a central stem or stalk, probably hollow, or, at least, porous, possessing a semi-transparency, not found in the fibre of hair. From this central stalk there springs, at different distances, on different breeds of sheep, a circlet of leafshaped projections.

\section{IONG WOOL.}

The most valuable of the long-woolled fleeces are of British origin. A considerable quantity is produced in France and Belgium; but the manufacturers in those countries acknowledge the superiority of the British wool. Long wool is distinguished, as its name would import, by the length of its 
staple, the average of which is about eight inches. It was much improved, of late years, both in England and in other countries. Its staple has, without detriment to its manufacturing qualities, become shorter; but it has also become finer, truer, and sounder. The long-woolled sheep has been improved more than any other breed; and the principal error which Bakewell committed having been repaired since his death, the long wool has progressively risen in value, at least for curling purposes. Some of the breeds have staples of double the length that has been mentioned as the average one. Pasture and breeding are the powerful agents here.

Probably because the Leicester blood prevails in, or, at least, mingles with, every other long-woolled breed, a great similarity in the appearance and quality of this fleece has become apparent, of late years, in every district of England. The short-woolled fleeces are, to a very considerable degree, unlike in fineness, elasticity, and felting property; the sheep themselves are still more unlike; but the long-wools have, in a great degree, lost their distinctive points-the Lincoln, for example, has not all of his former gaunt carcass, and coarse, entangled wool-the Cotswold has become a variety of the Leicester-in fact, all the long-woolled sheep, both in appearance and fleece, have almost become of one variety; and rarely, except from culpable neglect in the breeder, has the fleece been injuriously weakened, or too much shortened, for the most valuable purposes to which it is devoted.

In addition to its length, this wool is characterized by its strength, its transparency, its comparative stoutness, and the slight degree in which it possesses the felting property. Since the extension of the process of combing to wools of a shorter 
staple, the application of this wool to manufacturing purposes has undergone considerable change. In some respects, the : range of its use has been limited; but its demand has, on the whole, increased, and its value is more highly appreciated. Indeed, there are certain important branches of the woollen manufacture, such as worsted stuffs, bombazines, muslin-delaines, etc., in which it can never be superseded; and its rapid extension in the United States, within the past few years, clearly shows that a large and increasing demand for this kind of wool will continue at remunerating prices.

This long wool is classed under two divisions, distinguisbed both by length and the fineness of the fibre. The first-the long-combing wool-is used for the manufacture of hard yarn, and the worsted goods for which that thread is adapted, and requires the staple to be long, firm, and little disposed to felt. The short-combing wool has, as its name implies, a shorter staple, and is finer and more felty; the felt is also closer and softer, and is chiefly used for hosiery goods.

\section{MIDDLE WOOL.}

This article is of more recent origin than the former, but has rapidly increased in quantity and value. It can never supersede, but will only stand next in estimation to, the native English long fleece. It is yielded by the half-bred sheepa race that becomes more numerous every year-being a cross of the Leicester ram with the South-Down, or some other short-woolled ewe; retaining the fattening property and the early maturity of the Leicester, or of both; and the wool deriving length and straightness of fibre from the one, and fineness and feltiness from the other. The average length of 
staple is about fire inches. There is no description of the finer stuff-goods in which this wool is not most extensively and advantageously employed; and the nails, or portions which are broken off by the comb, and left in, whether belonging to this description of wool or to the long wool, are used in the manufacture of several species of cloth of no inferior quality or value.

Under the breed of middle wools must be classed those which, when there were but two divisions, were known by the name of short wools; and if English productions were alone treated of, would still retain the same distinctive appellation. To this class belong the South-Down and Cheviot; together with the fleece of several other breeds, not so numerous, nor occupying so great an extent of country. From the change, however, which insensibly took place in them all-the lengthening, and the increased thickness of the fibre, and, more especially, from the gradual introduction of other wools possessing delicacy of fibre, pliability, and felting qualities besond what these could claim, and at the same time, being cheaper in the market-they lost ground in the manufacture of the finer cloths, and have for some time ceased to be used in the production of them. On the other hand, the changes which have taken place in the construction of machinery have multiplied the purposes to which they may be devoted, and very considerably enhanced their value.

These wools, of late, rank among the combing wools; they are prepared as much by the comb as by the card, and in some places more. On this account they meet with a readier sale, at fair, remunerating prices, considering the increased weight of each individual fleece, and the increased weight and earlier 
maturity of the carcass. The South-Downs yield about seventenths of the pure short wools grown in the British kingdoms; but the half-bred sheep has, as has been remarked, encroached on the pure short-woolled one. The average staple of middlewoolled sheep is three and a half inches.

These wools are employed in the manufacture of flannels, army and navy cloths, coatings, heavy cloths for calico printers and paper manufacturers, woollen cords, coarse woollens, and blankets; besides being partially used in cassinettes, baizes, bockings, carpets, druggets, etc.

\section{SHORT WOOL.}

From this division every wool of English production is excluded. These wools, yielded by the Merinos, are employed, unmixed, in the manufacture of the finer cloths, and, combined with a small proportion of wool from the English breeds, in others of an inferior value. The average length of staple is about two and a half inches.

These wools even may be submitted to the action of the comb. There may be fibres only one inch in length; but if there are others from two and a half to three inches, so that the average of the staple shall be two inches, a thread suffciently tenacious may, from the improved state of machinery, be spun, and many delicate and beautiful fabrics readily woven, which were unknown not many years ago. 


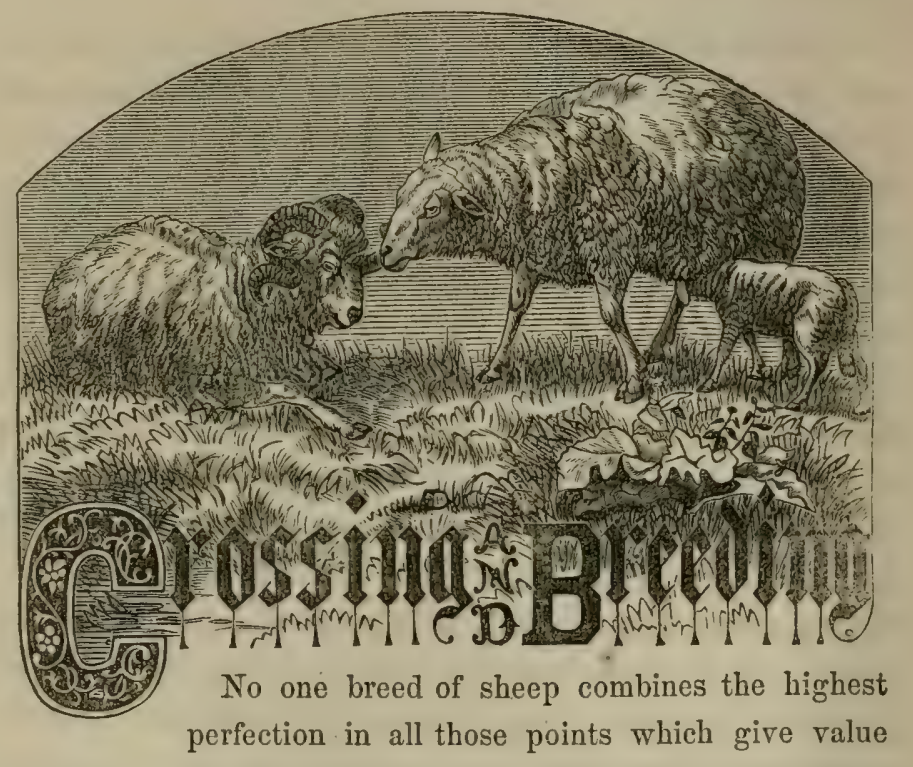

to this race of animals. One is remarkable for the weight, or early maturity, or excellent quality of its carcass, while it is deficient in quality or quantity of wool; and another, which is valuable for wool, is comparatively deficient in carcass. Some varieties will flourish only under certain conditions of food and climate; while others are much less affected by those conditions, and will subsist under the greatest variations of temperacure, and on the most opposite qualities of verdure.

In selecting a breed for any given locality, reference should 6 
be had, first, to the feed and climate, or the surrounding natural circumstances; and, second, to the market facilities and demand. Choice should then be made of that breed which, with the advantages possessed, and under all the circumstances, will yield the greatest net value of the marketable product.

Rich lowland herbage, in a climate which allows it to remain green during a large portion of the year, is favorable to the production of large carcasses. If convenient to a market where mutton finds a prompt sale and good prices, then all the conditions are realized which calls for a mutton-producing, as contradistinguished from a wool-yielding, sheep. Under such circumstances, the choice should undoubtedly be made from the improved English varieties-the South-Down, the New Leicester, and the improved Cotswolds or New Oxfordshire sheep. In deciding between these, minor and more specific circumstances must be taken into account. If large numbers are to be kept, the Downs will Lerd-remain thriving and healthy when kept together in large numbers-much better than the two larger breeds; if the feed, though generally plentiful, is liable to be somedrhat short during the droughts of summer, and there is not a certain supply of the most nutritious winter feed, the Downs will better endure occasional short keep; if the market demands a choice and high-flavored mutton, the Downs possess a decided superiority. If, on the other hand, but few are to be kept in the same enclosure, the large breeds will be as healthy as the Downs; if the pastures are somewhat wet or marshy, the former will better subsist on the rank herbage which usualiy grows in such situations; if they do not afford so fine a quality of mutton, they-particu- 
larly the Leicester-possess an carlier maturity, and give more meat for the amount of food cousumed, as well as yield more tallow.

The next point of comparison between the long and the middle woolled families, is the value of their wool. Though not the first or principal object aimed at in the cultivation of any of these breeds, it is, in this country, an important item or incident in determining their relative. profitableness. The Amcrican Leicester yields about six pounds of long, coarse, combing wool; the Cotswold, somewhat more; but this perhaps counterbalanced by these considerations; the Downs grow three to four pounds of a low quality of carding wool. None of these wools are very salable, at remunerating prices, in the American markets. Both, however, will appreciate in proportion to the increase of manufactures of worsted, flannels, baizes, and the like: The difference in the weight of the fleeces between the breeds is, of itself, a less important considcration than it would at first appear, for reasons which will be given when the connection between the amount of wool produced and the food consumed by the sheep is noticed.

The Cheviots are unquestionably inferior to the breeds above named, except in a capacity to endure a vigorous winter, and to subsist on healthy herbage. Used in the natural and artificial circumstances which surround sheepbusbandry in many parts of England-where the fattest and finest quality of mutton is consumed, as almost the only animal food of the laboring classes-the heavy, early-maturing New Leicester, and the still heavier New Oxfordshire sheep seem exactly adapted to the wants of producers and consumers, and are of unrivalled value. To depasture poorer 
soils, sustain a folding system, and furnish the mutton which supplies the tables of the wealthy, the South-Down meets an equal requirement.

Sufficient attention is by no means paid in many portions of the country to the profit which could be made to result from the cultivation of the sheep. One of the most serious defects in the prevalent husbandry of New England, for example, is the neglect of sheep. Ten times the present number might be easily fed, and they would give in meat, wool, and progeny, more direct profit than any other domestic animal, while the food which they consume would do more towards fertilizing the farms than an equal amount consumed by any other animal. It is notorious that the pastures of that section of the country have seriously deteriorated in fertility and become orerrun with worthless weeds and bushes to the exclusion of nutritious grasses.

With sheep-as well as with all other animals-much or prolonged exercise in pursuit of food, or otherwise, is unfarorable to taking on fat. Some seem to forget, in their earnest advocacy of the merits of the different breeds, that the general physical laws which control the development of all the animal tissues as well as functions, are uniform. Better organs will, doubtless, make a better appropriation of animal food; and they may be taught, so to speak, to appropriate it in particular directions: in one breed, more especially to the production of fat; in another, of muck, or lean meat; in yet another, of wool. But, these things being equal, large animals will always require more food than small ones. Animals which are to be carried to a high state of fatness must have plentiful and nutritious food, and they must exer- 
cise but little, in order to prevent the unnecessary combustion in the lungs of that carbon which forms nearly four-fifths of their fat. No art of breeding can counteract these established laws of Nature.

In instituting a comparison between breeds of shcep for wool-growing purposes, it is undeniable that the question is not, what variety will shear the heaviest or even the most valuable fleece, irrespective of the cost of production. Cost of feed and care, and every other expense, must be deducted, in order to fairly test the profits of an animal. If a large sheep consume twice as much food as a small one, and give but once and a-half as much wool, it is obviously more profitable-other things being equal-to keep two of the smaller sheep. The next question, then, is,-from what breed-with the same expense in other particulars-will the verdure of an acre of land produce the greatest value of wool?

And, first, as to the comparative amount of food consumed by the several breeds. There are no satisfactory experiments which show that breed, in itself considered, has any particular influence on the quantity of food consumed. It is found, with all varieties, that the consumption is in proportion to the live weight of the grown animal. Of course, this rule is not invariable in its individual application; but its general soundness has been satisfactorily established. Grown sheep take up between two and a half and three and a third per cent. of their weight, in what is equivalent to dry hay, to keep themselves in store condition.

The consumption of food, then, being proportioned to the weight, it follows that, if one acre is capable of sustaining three Merinos, weighing one hundred pounds each, it will sus- 
tain two Leicesters, weighing one hundred and fifty each, and two and two-fifth South-Downs, weighing one hundred and twenty-five each. Merinos of this weight often shear five pounds per fleece, taking flocks through. The herbage of an acre, then, would - give fifteen pounds of Merino wool, twelve of Leicester, and lout nine and three-fifths of South-Downestimating the latter as high as four pounds to the flecee. Even the finest and lightest-fleeced sheep known as Merinos average about four pounds to the flece; so that the feed of an acre would produce as much of the highest quality of wool sold under the name of Merino as it would of New Leicester, and more than it would of South-Down, while the former would be worth from fifty to one bundred per cent. more per pound than either of the latter.

Nor does this indicate all the actual difference, as in the foregoing estimate the lire weight of the English breeds is placed low, and that of the Merinos high. The live weight of the five-pound fine-fleceed Merino does not exceed ninety pounds; it ranges, in fact, from eighty to ninety; so that three hundred pounds of live weight_it being understood that all of these live weights refer to ewes in fair ordinary, or what is called store, condition-would give a still greater product of wool to the acre. It is perfectly safe, therefore, to say that the herbage of an acre will uniformly give nearly double the value of Merino that it will of any of the English long or middle wools.

What are the other relative expenses of these breeds? The full-blooded Leicester is in no respect a hardier sheep than the Merino, though some of its crosses are much hardicr than the pure-bred sheep: indeed, it is less hardy, under the most 
favorable crrcumstances. It is more subject to colds ; its constitution more readily gives way under disease; the lambs are more liable to perish from exposure to cold, when newly dropped. Under unfavorable circumstances-herded in large flocks, famished for feed, or subjected to long journeys-its capacity to endure, and its ability to rally from sad drawbacks, do not compare with those of the Merino. The highbred South-Down, though considerably less hardy than the unimproved parent stock, is still fairly entitled to the appellation of a hardy animal; it is, in fact, about on a pace with the Merino, though it will not bear as hard stocking, without a rapid diminution in size and quality. If the peculiar merits of the animal are to be considered in determining the expenses, as they surely should be, the superior fecundity of the SouthDown is a point in its favor, as well for a wool-producing as a mutton sheep. The ewe not only frequently produces twin lambs-as do both the Merino and Leicester-but, unlike the latter, she possesses nursing properties to do justice to them. This advantage, however, is fully counterbalanced by the superior longevity of the Merino. All the English mutton breeds begin to rapidly deteriorate in amount of wool, capacity to fatten, and general vigor, at about five years old; and their early maturity is no offset to this, in an animal kept for wool-growing purposes. This carly decay requires earlier and more rapid slaughter than is always economically convenient, or even possible.

It is well, on properly stocked farms, to slaughter or turn off the Merino wether at four or five years old, to make room for the breeding stock; but he will not particularly deteriorate, and he will richly pay the way with his fleece for several years 
longer. Breeding ewes are rarely turned off before eight, and are frequently kept until ten years old, at which period they exhibit no greater marks of age than do the Downs and Leicester at five or six. Instances are known of Merino ewes breeding uniformly until fifteen years old. The improved Cotswold is said to be hardier than the Leicester; but this variety, from their great size, and the consequent amount of food consumed by them, together with the other necessary incidents connected with the breeding of such large animals, is incrpacitated from being generally introduced as a wool-growing sheep. All the coarse races have one advantage orer the Merino: they are less subject to the visitation of the hoof-ail, and when untreated, this disense spreads with less violence and malignity among them. This has been explained by the fact that their hoofs do not grow long and turn under from the sides, as do those of the Merino, and thus retain dirt and filth in constant contact with the foot.

Taking into account all the circumstances connected with the peculiar management of each race, together with all the incidents, exigencies, and rislis of the husbandry of each, it may be confidently asserted that the expenses, other than those of feed, are not smaller per head, or even in the number required to stock an acre, in either of the Englisin breeds above referred to, than in the Merino. Indeed, it may well be doubted whether any of those English breeds, except the SouthDown, is on an equality, even, with the Mcrino, in these respects. For wool-growing purposes, the Merino, then, possesses a marked and decided superiority orer the best breeds and families of coarse-woolled sheep. As a mutton sheep, it is inferior to some of those breeds; although not so 
much as is popularly supposed. Many persons, who have never tasted Merino mutton, and who have, consequently, an unfavorable impression of it, would, if required to consume the fat and lean together, find it more palatable than the luscious and over-fat New Leicester. The mutton of the cross between the Merino and the Native would certainly be preferred to the Leicester, by anybody but an English laborer, accustomed to the latter, since it is short-grained, tender, and of good flavor. The same is true of the crosses with the English varieties, which will hereafter be treated of more particularly. Grade Merino wethers, half-bloods, for example, are favorites with the drover and butcher, being of good size, extraordinarily heavy for their apparent bulk, by reason of the shortness of their wool, compared with the coarse breeds, making good mutton, tallowing well, and their pelts, from the greater weight of wool on them, commanding an extra price. In speaking of the Merino in this connection, no reference is made to the Saxons, though they are, as is well known, pureblooded descendants of the former.

Assuming it, then, as settled, that it is to the Merino race that the wool-grower must look for the most profitable sheep, a few considerations are subjoined as to the adaptability of the widely diverse sub-varieties of the race to the wants and circumstances of different portions of the country.

Upon the first introduction of the Saxons, they were sought with avidity by the holders of the fine-woolled flocks of the country, consisting at that time of pure or grade Merinos. Under the decisive encouragement offered both to the woolgrower and the manufacturer by the tariff of 1828, a great impetus was given to the production of the finest wools, and 
the Sixon everywhere superseded, or bred out by crossing, the Spanish Merinos. In New York and New England, the latter almost entirely disappeared. In the fine-wool mania which ensued, weight of fleece, constitution, and every thing else, were sacrificed to the quality of the wool. Then came the tariff of 1832 , which, as well as that of 1828 , gave too much protection to both wool-grower and manufacturer, into whose pursuits agricultural and mercantile speculators madly rushed. Skill without capital, capital without skill, and in some cases, probably, thirst for gain without either, laid hold of these favored avocations. The natural and inevitable result followed. In the financial crisis of 1837 , manufacturing, and all other monetary enterprises which had not been conducted with skill and providence, and which were not based on an adequate and rast capital, were involved in a common destruction; and even the most solid and best conducted institutions of the country were shaken by the fury of the explosion. Trool suddenly fell almost fifty per cent. The grower began to be discouraged. The breeder of the delicate Saxons-and they comprised the flocks of nearly all the large wool-growers in the country, at that time-could not obtain for his wool its actual first cost per pound.

When the Saxon growers found that the tariff of 1842 brought them no relief, they began to give up their costly and carefully nursed flocks. The example once set, it became contagious; and then was a period when it seemed as if all the Saxon sheep of the country would be sacrificed to this reaction. Many abandoned wool-growing altogether, at a heary sacrifice of their fixtures for rearing sheep; others crossed with coarse-troolled breeds; and, rushing from one extreme to the 
other, some even crossed with the English mutton breeds; or some, witl more judgment, went back to the parent Merino stock, but usually selected the heariest and coarsest-woolled Merinos, and thus materially deteriorated the character of their wool. This period became distinguished by a mania for heary fleces. The English crosses were, however, speedily abandoned. The Merino regained his supremacy, lost for nearly a quarter of a century, and again became the popular favorite. It was generally adopted by those who were commencing flocks in the new Western States, and gives its type to the sheep of those regions.

The supply of fine wool, then, proportionably decreased, and that of medium and coarse increased. Wools, for convenience, may be classified as follows: superfine, the choicest quality grown in the United States, and never grown here excepting in comparatively small quantities; fine, good ordinary Saxon; good medium, the highest quality of wool usually known in the market as Merino; medium, ordinary Merino; ordinary, grade Merino and selected South-Down fleeces; and, coarse, the English long-wools, etc. This subdivision is, perhaps, minute enough for all practical purposes here.

It soon became apparent that, to sustain our manufacturing interest-that engaged in the manufacture of fine cloths-the diminution of fine wools should not only be at once arrested, but that the growth of them should be immediately and largely increased. An increased attention was accordingly bestowed upon this branch of industry, and sections of the country which had previously held aloof from wool-growing, embarked in that calling with commendable enterprise.

The climate north of forty-one degrees, or, beyond all dis- 
pute, north of forty-two degrees, is too severe for any variety of sheep commonly known, which bear either superfine or fine wools. In fact, the only such varicty in any thing like general use is the Saxon; and this, as has been remarked, is a delicate sheep, entirely incapable of safely withstanding our northern winters, without good shelter, good and regularly-administered food, and careful and skilful management in all other particulars. When the season is a little more than usually backhand, so that grass does not start prior to the lambing season, it is difficult to raise the lambs of the mature ewes; the young ewes will, in many instances, disown their lambs, or, if they own them, not have a drop of milk for them; and if, under such circumstances, as often happens, a northeast or a northwest storm comes driving down, bearing snow or sleet in its wings, or there is a sudden depression of the temperature from any cause, no care will save multitudes of lambs from perishing. If the time of having the lambs dropped is deferred, for the purpose of escaping these evils, they will not attain size and strength sufficient to enable them to pass safely through their first winter. North of the latitude last named, it is necessary, as a general rule, that they be dropped in the first half of May, to give them this requisite size and strength ; and occasional cold storms come, nearly every season, up to that period, and, not unfrequently, up to the first of June.

These considerations have had their weight even with the few large sheepholders in that section, whose farms and buildings have been arranged with exclusive reference to the rearing of these sheep; many of whom have adopted a Merino cross. With the ordinary farmers-the small sheep-owners, who, in the aggregate, grow by far the largest portion of the 
northern wools-the Saxon sheep is, for these reasons, in marked disrepute. They have not the necessary fixtures for their winter protection, and are unwilling to bestow the necessary amount of care on them. Besides, mutton and wool being about an equal consideration with this class, they want larger and earlier maturing breeds. Above all, they want a . strong, hardy sheep, which demands no more care than their cattle. The strong, compact, medium-woolled Merino, or, more generally, its crosses with coarse varieties, producing the wool classed as ordinary, is the common favorite. In the Northwest, this ais especially the case, where the climate is still worse for delicate sheep.

At the South, on the contrary-where these disadvantages do not exist to so great an extent, certainly - wool varying from good medium upward are more profitable staples for cultivation than the lower classes; and in that section a high degree of fineness in fleece has been sought in breeding the Merino-the four-pound fine-fleeced Merino having received marked attention. This is a far more profitable animal than the Saxon, other things being equal-which is not the case, since the former is every way a hardier animal and a better nurse; and, although about twenty pounds heavier, and therefore consuming more feed, this additional expense is more than counterbalanced by the additional care and risk attending the husbandry of the Saxon.

\section{POINTS OF THE MERINO.}

For breeding purposes, the shape and general appearance of the Merino should be as follows:-The head should be well carried up, and in the ewe hornless. It would be better, 
on many accounts, to have the ram also hornless, but, as horns are usually characteristic of the Merino ram, many prefor to see them. The face should be rather short, broad between the eyes, the nose pointed, and, in the ewe, fine and free from wrinkles. The eye should be bright, moderately prominent, and gentle in its expression. The neck should be straight-not curving downward-short, round, and stoutparticularly so at its junction with the shoulder, forward of the upper point of which it should not sink below the level of the back. The points of the shoulder should not rise to any perceptible extent above the level of the back. The back, to the hips, should be straight; the crops-that portion of the borly immediately back of the shoulder-blades-full; the rilss well arched; the body large and capacious; the flank well let down; the hind-quarters full and round-the flesh meeting well down between the thighs, or in the "twists.". The bosom should be broad and full; the legs short, well apart, and perpendicular-that is, not drawn under the body toward each other when the sheep is standing. Viewed as a whole, the Merino should present the appearance of a low, stout, plump, and-though differing essentially from the English mutton-sheep model-a highly symmetrical sheep.

The skin is an important point. It should be loose, singularly mellow, and of a rich, delicate pink color. A colorless skin, or one of a tawny, approaching to a butternut, hue, indicates bad breeding. On the subject of wrinkles, there is a difference of opinion. As they are rather characteristic of the Merino-like the black color in a Berkshire hog, or the absence of all color in Durham cattle-these wrinkles have been more regarded, by novices, than those points which give 
actual value to the animal; and shrewd breeders have not been slow to act upon this hint. Many have contended that more wool can be obtained from a wrinkled skin; and this view of the case has led both the Spanish and French breeders to cultivate them largely - the latter, to a monstrosity. An exceedingly wrinkled neck, however, adds but little to the weight of the fleec-not cnough, in fact, to compensate for the deformity, and the great impediment thus placed in the way of the shearer. A smoothly drawn skin, and the absence of all dead lap, would not, on the other hand, ,perhaps be desirable.

The wool should densely cover the whole body, where it can possibly grow-from a point between and a little below the eyes, and well up on the cheeks, to the knees and hocks. Short wool may show, particularly in young animals, on the legs, even below the knees and hocks; but long wool covering the legs, and on the nose, below the eyes, is unsightly, without value; while on the face it frequently impedes the sight of the animal, causing it to be in a state of perpetual alarm, and disqualifying it to escape real danger. Neither is this useless wool the slightest indication of a heavy fleececontrary to what seems to be thought by some. It is very often seen in Saxons shearing scarcely two pounds of wool, and on the very lightest fleeced Merinos.

The amount of gum which the wool should exhibit is another mooted point. Merino wool should be yolky, or oily, - prior to washing-though not to the extreme extent, occasionally witnessed, of giving it the appearance of being saturated with grease. The extreme tips may exhibit a sufficient trace of gum to give the fleece a darkish cast, 
particularly in the ram; but a black, pitchy gum, resembling half-hardened tar, extending an eighth or a quarter of an inch into the fleece, and which cannot be remored by ordinary washing, is decidedly objectionable. There is a white or yellowish concrete gum, not removable by common washing, which appears in the interior of some fleeces, and is equally objectionable.

The weight of fleece remaining the same, medium length of staple, with compactness, is preferable to long, open wool, since it constitutes a better safeguard from inclemencies of weatber, and better protects the animal from the bad effects of cold and drenching rains in spring and fall. The wool should be, as nearly as possible, of even length and thickness over the entire body. Shortness on the flank, and shortness or thickness on the belly, are serious defects.

Evenness of flece is a point of the first importance. Many sheep exhibit good wool on the shoulder and side, while it is far coarser and even hairy on the thighs, dew-lap, etc. Rams of this stamp should not be bred from by any one aiming to establish a superior fine-woolled flock; and all such ewes should gradually be excluded from those selected for breeding.

The style of the wool is a point of as much importance as mere fineness. Some very fine wool is stiff, and the fibres almost straight, like hair. It has a dry, cottony look; and is a poor, unsalable article, howerer fine the fibre. Softness of wool-a delicate, silky, highly elastic feel between the fingers or on the lips, is the first thing to be regarded. This is usually an index, or inseparable attendant, of the other good qualities; so much so, indeed, that an experienced judge can decide, with little difficulty, between the quality of two fleeces, 
in the durk. Wool should be finely serrated, or crimped from onc extremity to the other : that is, it should present a regular series of minute curves; and, generally, the greater the number of these curves in a given length, the higher the quality of the wool in all other particulars. The wool should open on the back of the sheep in connected masses, instead of breaking up into little round spiral ringlets of the size of a pipe-stem, which indicate thinness of fleece; and when the wool is pressed open each way with the hands, it should: be close enough to conceal all but a delicate rose-colored line of skin. The interior of the wool should be a pure, glittering white, with a lustre and liveliness of appearance not surpassed in the best silk.

The points in the form of the Merino which the breeder is called upon particularly to avoid are, a long, thin head, narrow between the eyes; a thin, long neck, arching downward before the shoulders; narrow loins; flat ribs; steep, narrow hind-quarters; long legs; thighs scarcely meeting at all ; and legs drawn far under the body at the least approach of cold. All these points were, separately or conjointly, illustrated in many of the Saxon flocks which have been swept from the country. Sufficient attention has already been paid to the points to be avoided in the fleece.

\section{BREEDING MERINOS.}

The first great starting-point, among pure-blood animals, is, that "like will beget like." If the sire and ewe are perfect in any given points, the offspring will generally be; if either is defective, the offspring-subject to a law which will possibly be noticed-will be half-way between the two; if both are 7 
defective in the same points, the progeny will be more so than either of its parents-it will inherit the amount of defect in both parents added together. There are exceedingly few perfect animals. Breeding, therefore, is a system of counterbalancing-breeding out-in the offspring, the defects of one parent, by the marked excellence of the other parent, in the same points. The highest blood confers on the parent possessing it the greatest power of stamping its own characteristics on its progeny; but, blood being the same, the male sheep possesses this power in a greater degree than the female. We may, therefore, in the beginning, breed from ewes possessing any defects short of cardinal ones, without impropriety, provided we possess the proper ram for that purpose; but, where a high standard of quality is aimed at, all ewes possessing even considerable defects should gradually be thrown out from breeding. Every year should add to the vigor of the selection.

But, from the beginning-and at the beginning, more than at any other time-the greatest care should be evinced in the selection of the ram. If he has a defect, that defect is to be inherited by the whole future flock; if it is a material oneas, for example, a hollow back, bad cross, or thin fleece, or a bighly uneven fleece-the flock will be one of low quality and little value. If, on the other hand, he is perfect, the defects in the female will be lessened, and gradually bred out. It being, however, difficult to find perfect rams, those should be taken which have the fewest and lightest defects, and none of these material, like those just enumerated. These defects are to be met and counterbalanced by the decided excellencesometimes, indeed, running into a fault-of the ewe, in the 
same points. If the ram, then, is a little too long-legged, the shortest-legged ewes should be selected for him; if gummy, the dryest-woolled; if his fleece is a trifle below the proper standard of fineness-but he has been retained, as often happens, for weight of fleece and general excellence-he is to be put to the finest and lightest-fleeced erves, and so on. With a selection of rams, this system of counterbalancing would require but little skill, if each parent possessed only a single fault. If the ewe be a trifle too thin-fleeced, and good in all other particulars, it would require no nice judgment to decide that she should be bred to an uncommonly thickfleeced ram. But most animals possess, to a greater or less degree, several defects. To select so that every one of these in the dam shall meet its opposite in the male, and the contrary, requires not only plentiful materials from which to select, but the keenest discrimination.

After the breeder has successfully established his flock, and given them an excellent character, he soon encounters a serious evil. He must "breed in-and-in," as it is calledthat is, interbreed between animals more or less nearly related in blood_or he must seek rams from other flocks, at the risk of losing or changing the distinctive character of his flock, hitherto so carefully sought, and built up with so much painstaking. The opponents of in-and-in breeding contend that it renders diseases and all other defects hereditary, and that it tends to decrease of size, debility, aud a general breaking up of the constitution. Its defenders, on the other hand, insist that, if the parents are perfectly healthy, this mode does not, of itself, tend to any diminution of healthfulness in the offspring; and they likewise claim-which must be conceded 
- that it enables the skilful breeder much more rapidly to bring his flock to a particular standard or model, and to kecp it there much more easily-unless it be true that, in course of time, they will dwindle and grow feeble.

So far as the effect on the constitution is concerned, both positions may be, to a certain extent, true. But it is,

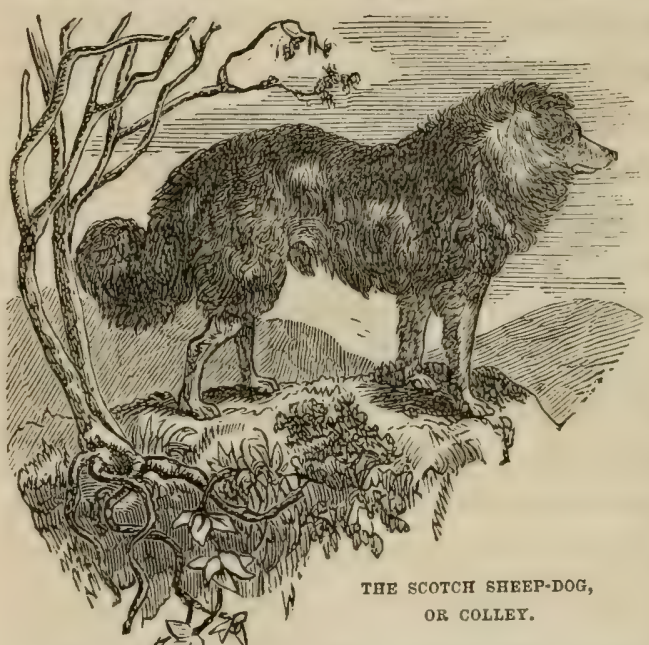
perhaps, difficult always to decide with certainty when an animal is not only free from disease, but from all tendency or predisposition towards it. A brother or sister may bè apparently healthymay be actually so-but may still possess a peculiarity of individual conformation which, under certain circumstances, will manifest itself. If these circumstances do not chance to occur, they may live until old age, apparently possessing a robust constitution. If tried together, their offspring-by a rule already laid down-will possess this individual tendency in a double degree. If the ram be interbred with sisters, half-sisters, daughters, granddaughters, etc., for several generations, the predisposition toward a particular disease-in the first place slight, now strong, and constantly growing stronger-will pervade, and become radi. 
cally incorporated into, the constitution of the whole flock. The first time the requisite exciting causes are brought to bear, the disease breaks out, and, under such circumstances, with peculiar severity and malignancy. If it be of a fatal character, the flock is rapidly swept away; if not, it becomes chronic, or periodical at frequently recurring intervals. The same remarks apply, in part, to those defects of the outward form which do not at first, from their slightness, attract the notice of the ordinary breeder. They are rapidly increased until, almost before thought of by the owner, they destroy the value of the sheep. That such are the common effects of in-and-in breeding, with such skill as it is commonly conducted, all know who bave given attention to the subject; and for these reasons the system is regarded with decided disapprobation and repugnance by nine out of ten of the best practical farmers.

The sheep-breeder can, however, aroid the effects of in-andin breeding, and at the same time preserve the character of his flock, by seeking rams of the same breed, possessing, as nearly as possible, the characteristics which he wishes to preserve in his own flock. If this rule is neglected-if he draws indiscriminately from all the different varieties or families of a breed-some large, and some small-some longwoolled, and some short-woolled-some medium, and some superfine in quality-some tall, and some squatty-some crusted over with black gum, and some entirely free from itbreeding will become a mere matter of hap-hazard, and no certain or uniform results can be expected. So many varieties cannot be fused into one for a number of generations-as is evidenced by the want of uniformity in the Rambouillet flock, 
which was commenced by a promiscuous admixture of all the Spanish families; and it not merely happens, as between certain classes of Saxons, that particular families can never be successfully amalgamated.

If, however, the breeder bas reached no satisfactory standard-if his sheep are deficient in the requisites which he desires-he is still to adhere to the breed-provided the desired requisites are characteristic of the breed he possesses -and select better animals to improve his own inferior ones. If he has, for instance, an inferior flock of South-Downs, and wishes to obtain the qualities of the best Down dams, he should seek for the best rams of that breed. But if he wishes to obtain qualities not characteristic of the breed he possesses, he must cross with a breed which does possess them. If the possessor of South-Downs wishes to convert them into a finewoolled sheep similar to the Merino, he should cross his flock steadily with Merino rams-constantly increasing the amount of Merino, and diminishing the amount of South-Down blood. To effect the same result, he would talie the same course with the common sheep of the country, or with any other coarse race.

There are those, who, forgetting that some of the finest varieties now in existence, of several kinds of domestic animals, are the result of crosses-bitterly inveigh against the practice of crossing, under any and all circumstances. It is, it must be admitted, an unqualified absurdity, as frequently conducted-as, for example, an attempt to unite the fleece of a Merino and the carcass of a Leicester, by crosses between those breeds; but, under the limitations already laid down, and with the objects specified as legitimate ones, this objec- 
tion to crossing savors of the most profound prejudice, or the most uublushing quackery. It is neither convenient, nor within the means of every man wishing to start a flock of sheep, to commence exclusively with full-bloods. With a few to breed rams from, and to begin a full-blood stock, the breeder will find it his best policy to purchase the best common sheep of his country, and gradually grade them up with Merino rams. In selecting the ewes, good shape, fair size, and a robust constitution, are the main points-the little difference in the quality of the common sheep's wool being of no consequence. For their wool, they are to look to the Merino; but good form and constitution they can and ought to possess, so as not to entail deep-rooted and entirely unnecessary evils on their progeny.

Satisfactory results have followed crossing a Down ramsmall, compact, exceedingly beautiful, fine and eren flececlwith large-sized Merino ewes. The half-blood ewes were then bred to a Merino ram, and also their female progeny, and so on. The South-Downs, from a disposition to take on fat, manifested themselves, to a perceptible extent, in every generation, and the wool of many of the sheep in the third generation-seven-eighths blood Merino, and one-eighth blood Down-was very even, and equal to medium, and some of them to good medium Merino. Their fleeces were lighter than the full-blood Merinos, but increased in weight with each succeeding cross back toward the latter. The mutton of the first, and even of the second cross was of a beautiful flavor, and retained, to the last, some of the superiority of SouthDown mutton.

Results are also noted of breeding Leicester ewes-taking 
one cross of the blood, as in the preceding case-toward the Merino. The mongrels, to the second generation-beyond which they were not bred-were about midway between the parent stock in size-with wool shorter, but far more fine and compact than the Leicester-their fleeces about the same weight, five pounds-and, altogether, they were a showy and profitable sheep, and well calculated to please the mass of farmers. Their fleeces, however, lacked evenness, their thighs remaining disproportionately coarser and heary.

$A$ difference of opinion exists in relation to the number of crosses necessary before it is proper to breed from a mongrel ram. Some high authorities assert that it does not admit of the slightest doubt that a Merino, in the fourth generation, from even the worst-woolled ones, is in every respect equal to the stock of the sire-that no difference need to be made in the choice of a ram, whether he is a full-blood, or a fifteensixteenths-and that, however coarse the fleece of the parent ewe may have been, the progeny in the fourth generation will not show it.

Others, however-while admitting that the only value of blood or pedigree, in breeding, is to insure the hereditary transmission of the properties of the parent to the offspring, and that, as soon as a mongrel reaches the point where he stamps bis characteristics on the progeny, with the same certainty that a full-blood does, he is equally valuable, provided he is, individually, as perfect an animal-contend that this cannot be depended upon, with any certainty, in rams of the fourth Merino cross. They assert that the offspring of such crosses invariably lack the style and perfection of thorough-bred flocks. The sixth, seventh, or eighth cross might be generally, 
and the last, perhaps, almost invariably, as good as pure-blood rams; yet pure blood is a fixed standard, and were every breeder to think himself at liberty to depart from it in his rams, each one more or less, according to his judgment or caprice, the whole blood of the country would become adulterated. No man, assuredly, can be authorized to sell a ram of any cross, whether the tenth, or even the twentieth, as a full. blood.

It is of the utmost importance for those commencing flocks, either of full-bloods, or by crossing, to select the choicest rams. A grown ram may, by methods which will hereafter be described, be made to serve from one hundred to one hundred and fifty ewes in a season. A good Merino ram will, moderatcly speaking, add more than a pound of wool to the fleece of the dam, or every lamb got by it, from a common-woolled ewe-that is, if the ewe at three years old sheared three pounds of wool, the lamb at the same age will shear four. This would give one hundred or one hundred and fifty pounds of wool for the use of a ram for a single season; and every lamb subsequently got by him adds a pound to this amount. Many a ram gets, during his life, eight huudred or one tbousand lambs. Nor is the extra amount of wool all. $\mathrm{He}$ gets from eight hundred to one thousand half-blooded sheep, worth double their dams, and ready to be made the basis of another and higher stride in improvement. A good ram, then, is as important and, it may be, quite as valuable an animal as a good farm-horse stallion. When the number of a ram's progeny are taken into consideration, and when it is seen over what an immense extent, even in his own direct offspring, his good or bad qualities are to be perpetuated, the folly of that 
cconomy which would select an inferior animal is sufficiently obvious.

It will be found the best economy in starting a flock, where the proper flocks from which to draw rams are not convenient, to purchase several of the same breed, of course, but of different strains of blood. Thus ram No. 2 can be put on the offspring of No. 1, and the reverse; No. 3 can be put on the offspring of both, and both upon the offspring of No. 3. The changes which can be rung on three distinct strains of blood, without in-and-in breeding close enough to be attended with any considerable danger, are innumerable.

The brother and sister, it will be born in mind, are of the same blood; the father and daughter, half; the father and granddaughter, one-fourth; the father and great-granddaughter, one-eighth; and so on. Breeding between animals possessing one-eighth of the same blood, would not be considered very close breeding; and it is not unusual, in rugged, well-formed families, to breed between those possessing one-fourth of the same blood.

If, however, these rams of different strains are bronght promiscuously, without reference to similarity of characteristics, there may, and probably will, be difference between them; and it might require time and skill to give a flock descended from them a proper uniformity of character. Those who breed rams for sale should be prepared to furnish different strains of blood, with the necessary individual and family uniformity.

GENERAL PRINCIPLES OF BREEDING.

Some few suggestions upon the general principles to be observed in breeding may not be superfluous here, referring 
the reader, who is disposed to investigate this subject in detail, to its full discussion in the author's treatise upon "Cattle and their Diseases."

As illustrative of the importance of breeding only from the best, taking care to avoid structural defects, and especially to secure freedom from heredilary diseases, since both defects and diseases appear to be more easily transmissible than desirable qualities, it may be remarked that scrofula is not uncommon among sheep, and presents itself in various forms. Sometimes it is connected with consumption; sometimes it affects the viscera of the abdomen, and particularly the mesenteric glands, in a manner similar to consumption in the lungs. The scrofulous taint has been known to be so strong as to affect the fotus, and lambs have occasionally been dropped with it; but much oftener they show it at an early age, and any affected in this way are liable to fall an easy prey to any ordinary or prevalent disease, which develops in such with unusual severity. Sheep are also liable to several diseases of the brain, and of the respiratory and digestive organs. Epilepsy, or "fits," and rheumatism sometimes occur.

The breeder's aim should be to grasp and render permanent, and increase so far as practicable, every variation for the better, and to reject for breeding purposes such as show a downward tendency. A remarkable instance of the success which has often attended the well-directed efforts of intelligent breeders, is furnisbed in the new Mauchamp-Merino sheep, which originated in a single animal-a product of the law of variationand which, by skilful breeding and selection, has become an established breed of a peculiar type, and possessing valuable properties. Samples of the wool of these sheep were shown 
at the great exhibition in London, in 1851, as well as at the subsequent great agricultural exhibition at Paris, and attracted much attention.

This breed was originated by Mons. J. L. Graux. In 1828, a Merino ewe produced a peculiar ram lamb, having a different shape from the ordinary Merino, and possessing wool singularly long, straight, and silky. Two years afterward, Mr. Graux obtained by this ram one ram and one ewe, having the silky character of wool. Among the produce of the ensuing year were four rams and one ewe with similar fleeces; and in 1833 , there were rams enough of the new sort to serve the whole flock of ewes. In each subsequent year, the lambs were of two kinds; one possessing the curled, elastic wool of the old Merinos, only a little longer and finer, and the other like the new breed. At last, the skilful breeder obtained a flock containing the fine, silky fleece with a smaller breed, broader flanks, and more capacious chest; and several flocks being crossed with the Mauchamp variety, the MauchampMerino breed is the result.

The pure Mauchamp wool is remarkable for its qualities as a combing-wool, owing to the strength, as well as the length and fineness of the fibre. It is found of great value by the manufacturers of Cashmere shawls, and similar goods, being second only to the true Cashmere fleece, in the fine, flexible delicacy of the fibre; and when in combination with Cashmere wool, imparting strength and consistency. The quantity of this wool has since become as great as that from ordinary Merinos, or greater, while its quality commands twenty-five per cent. higher price in the French market. Breeders, 
certainly, cannot watch too closely any accidental peculiarity of conformation or characteristic in their flocks.

The apparent influence of the male first having fruitful intercourse with a female, upon her subsequent offspring by other males, has been noticed by various writers. The following well-authenticated instances are in point:

A small flock of ewes, belonging to Dr. W. Wells, in the island of Granada, was served by a ram procured for the purpose. The ewes were all white and woolly; the ram was quite different, being of a chocolate color, and hairy like a goat. The progeny were, of course, crosses, but bore a strong resemblance to the male parent. The next season, Dr. Mells obtained a ram of precisely the same breed as the evies; but the progeny showed distinct marks of resemblance to the former ram, in color and covering. The same thing occurred on neighboring estates, under like circumstances.

Six very superior pure-bred black-faced horned ewes, belonging to $\mathrm{Mr}$. H. Shaw, of Leochel, Cushnie, were served by a white-faced hornless Leicester ram. The lambs were crosses. The next year they were served by a ram of exactly the same breed as the ewes themselves, and their lambs were, without an exception, hornless and brownish in the face, instead of being black and horned. The third year they were again served by a superior ram of their own breed; and again the lambs were mongrels, but showed less of the Leicester characteristics than before; and Mr. Shaw at last parted from these fine ewes withont obtaining a single pure-bred lamb.

To account for this result-seemingly regarded by most physiologists as inexplicable_Mr. James McGillivray, V. S., of Huntley, has offered an explanation, which has received the 
sanction of a number of competent writers. His theory is, that when a pure animal of any breed has been pregnant by an animal of a different breed, such pregnant animal is a cross ever after, the purity of her blood being lost, in consequence of her connection with the foreign animal, and herself becoming a cross forever, incapable of producing a pure calf of any breed.

To cross, merely for the sake of crossing, to do so without that care and vigilance which are highly essential, is a practice which cannot be too much condemned, being, in fact, a national evil, if pushed to such an extent as to do away with a useful breed of animals, and establish a generation of mongrels in their place-a result which has followed in numerous instanees amongst every breed of animals.

The principal use of crossing is to raise animals for the butcher. The male, being generally an aninal of a superior breed, and of a vigorous nature, almost invariably stamps his external form, size, and muscular development on the offspring, which thus bear a strong resemblance to him; while their internal nature, derived from the dam, well adapts them to the locality, as well as to the treatment to which their dams have been accustomed.

With sheep, where the peculiarities of the soil, as regards the goodness of feed, and exposure to the sererities of the weather, often prevent the introduction of an improved breed, the ralue of using a new and superior ram is often very considerable; and the weight of mutton is thereby materially increased, without its quality being impaired, while earlier maturity is at the same time obtained. It involves, however, more systematic attention than most farmers usually like to bestow, for it is necessary to employ a different ram for each 
purpose; that is, a native ram, for a portion of the ewes to keep up the purity of the breed, and a foreign ram, to raise the improved cross-bred animals for felting, either as lambs or sheep. This plan is adopted by many breeders of Leicester sheep, who thus employ South-Down rams to improve the quality of the mutton.

One inconvenience attending this plan is the necessity of fattening the maiden ewes as well as the wethers. They may, however, be disposed of as fat lambs, or the practice of spaying (fully explained in "Cattle and their Diseases") might be adopted, so as to increase the felting disposition of the animal. Crossing, therefore, should be adopted with the greatest caution and skill, where the object is to improve the breed of animals. It should never be practised carelessly or capriciously, but it may be advantageously pursued, with a view to raising superior and profitable animals for the butcher. For the latter purpose, it is generally advisable to use males of a larger breed, provided they possess a disposition to fatten; yet, in such cases, it is of importance that the pelvis of the female should be wide and capacious, so that no injury may arise in lambing, in consequence of the increased size of the heads of the lambs. The shape of the ram's head should be studied, for the same reason.

In crossing, however, for the purpose of establishing a new breed, the size of the male must give way to other more important considerations; although it will still be desirable to use a large female of the breed which is sought to be improved. Thus, the South-Downs have vastly improved the larger Hampshires, and the Leicester, the huge Lincolns and the Cotswolds. 


\section{USE OF RAMS.}

Merino rams are frequently used from the first to the tenth year, and even longer. The lambs of very old rams are commonly supposed not to be as those of middle-aged ones; though where rams have not been overtasked, and have been properly fed, little if any difference is discoverable in their progeny by reason of their sire's age. A ram lamb should not be used, as it retards his growth, injures his form, and, in many instances, permanently impairs his vigor and courage A yearling may run with thirty ewes, a two-year-old with from forty to fifty, and a threc-year-old with from fifty to sixty; while some very powerful, mature rams will serve seventy or eighty. Fifty, however, is enough, where they run with the ewes. It is well settled that an impoverished and overtasked animal does not transmit his individual properties so decidedly to his offspring as does one in full vigor.

Rams, of course, are not to be selected for ewes by mere chance, but according as their qualities may improve those of the ewes. It may not be superfluous, though seemingly a repetition, to state that a good ewe flock should exhibit these characteristics : strong bone, supporting a roomy frame, affording space for a large development of flesh; abundance of wool of a good quality, kecping the erves warm in inclement weather, and insuring profit to the breeder ; a disposition to fatten early, enabling the breeder readily to get rid of his sheep selected for the butcher; and a prolific tendency, increasing the flock rapidly, and being also a source of profit. Every one of these properties is advantageous in itself; but when all are combined in the same individuals of a flock, that flock is in a high state 
of perfection. In selecting rams, it should be observed whether or not they possess one or more of those qualities in which the ewes may be deficient, in which case their union with the ewes will produce in the progeny a higher degree of perfection than is to be found in the ewes themselves, and such a result will improve the state of the future ewe-flock; but, on the contrary, if the ewes are superior in all points to the rams, then, of course, the use of such will only serve to deteriorate the future ewe-flock.

Several rams running in the same flock excite each other to an unnatural and unnecessary activity, besides injuring each other by constant blows. It is, in every point of view, bad husbandry, where it can be avoided, and, as customarily managed, is destructive to every thing like careful and judicious breeding. The nice adaptation which the male should possess to the female is out of the question where half a dozen or more rams are running. promiscuously with two or three hundred ewes.

Before the rams are let out, the breeding ewes should all be brought together in one yard; the form of each noted, together with the length, thickness, quality and style of her woolascertained by opening the wool on the shoulder, thigh, and belly. When every point is thus determined, that ram should be selected which, on the whole, is best calculated to perpetuate the excellencies of each, both of fleece and carcass, and to best counterbalance defects in the mutual offspring. Every ewe, when turned in with the ram, should be given a distinct mark, which will continue visible until the next shearing. For this purpose, nothing is better than Venetian red and hog's lard, well incorporated, and marked on with a cob. The ewes for 8 
each ram require a differently shaped mark, and the mark should also be made on the ram, as noted in the sheep-book. Thus it can be determined at a glance by what ram the ewe was tapped, any time before the next shearing. The ewes selected for each ram are placed in different enclosures, and the chosen ram placed with them. Rams require but little preparation on being put among ewes. If their skin is red in the flanks when the sheep are turned up, they are ready for the ewes, for the natural desire is then upon them. Most of the ewes will be served during the second week the ram is among them, and in the third, all. It is better, however, not to withdraw the rams until the expiration of four weeks, when the flocks can be doubled, or otherwise re-arranged for winter, as may be necessary. The trouble thus taken is, in reality, slight-nothing, indeed, when the beneficial results are considered. With two assistants, several hundred ewes may be properly classified and divided in a single day.

Where choice rams are scarce, so that it is desirable to make the services of one go a great way, or where it is impossible to have separate enclosures_as on farms where there are a great number of breeding ewes, or where the shepherd system is adopted, to the exclusion of fences-resort may be had to another method. A hut should be built, containing as many apartments as the ram is desired to be used, with an alley between them, each apartment to be furnished with a feedingbox and trough in one corner, and gates or bars opening from each into the alley, and at each end of the alley. Adjoining these apartments, a yard should be inclosed, of size just sufficient to hold the flock of breeding ewes.

A couple of strong rams, of any quality, for about every 
hundred ewes, are then aproned, their briskets rubbed with Venetian red and hog's lard, and let loose among the ewes. Aproning is performed by sewing a belt of coarse sacking, broad enough to extend from the fore to the hind legs, loosely but strongly around the body. To prevent its slipping forward or back, straps are carried round the breast and back of the breech. It should be made perfectly secure, or all the labor of this method of coupling will be far worse than thrown away. The pigment on the brisket should be renewed every two or three days; and it will be necessary to change the . "teasers"-as these aproned rams are called-about once a week, as they do not long retain their courage under such unnatural circumstances. Twice a day the ewes are brought into the yard in fiont of the hut. Those marked on their rumps by the teasers are taken into the alley. Each is admitted once to the ram for which she is marked, and then goes out at the opposite end of the alley from which they entered, into a field separate from that containing the flock from which she was taken. A powerful and vigorous ram, from three to seven years old, and properly fed, can thus be made to serve from one hundred and fifty to even two hundred ewes, with no greater injury than from running loose with fifty or sixty. The labor here required is likewise more apparent than real, when the operation is conducted in a systematic manner.

Rams will do better, accomplish more, and last two or three years longer, if daily fed with grain, when on service, and it is better to continue it. In all cases, they should, after serving, be put on good pasture, as they will have lost a good deal of condition, being indisposed to settle during the tapping season. 
A ram should receive the equivalent of from half a pint to a pint of oats daily, when worked hard. They are much more conveniently fed when kept in huts. If suffered to run at large, they should be so thoroughly tamed that they will eat from a measure held by the shepherd. Careful breeders thus train their stock-rams, from the time they are lambs. It is very convenient, also, to have them halter-broke, so that they can be led about without dragging or lifting them. $\Lambda \mathrm{n}$ iron ring attached to one of the horns, near the point, to which a cord can be fastened for leading, confining, etc., is very useful and convenient. If rams are wild, it is a matter of considerable difficulty to feed them separately, and it can only bes effected by yarding the flock and catching them out. Some breeders, in addition to extra feeding, take the rams out of the flocks each night, shutting them up in a barn or stable by themselves. To this practice there is no objection, and it greatly saves their strength.

Rams should not be suffered to run with the ewes over a month, at least in the Northern States. It is much better that a ewe go dry than that she have a lamb later than the first of June. Besides, after the rutting season is over, the rams grow cross, frequently striking the pregnant ewes dangerous blows with their heavy horns, at the racks and troughs.

It is reasonably enough conjectured, that if procreation and the first period of gestation take place in cold weather, the fœtus will be fitted for the climate which rules during the early stages of its existence. If this be so-and it is certainly in accordance with the laws of Nature-fine-woolled sheep are most likely to maintain their excellence by deferring the connection of the male till the commencement of cold weather; 
and, in the Northern States, this is done about the first of December, thus bringing the yeaning time in the last of April, or the first of May, when the early grass affords a large supply and good quality of food.

\section{LAMBING.}

The ewe goes with young about five months, varying from one hundred and forty-five to one hundred and sixty-two days. Pregnant ewes require the same food as at all other times. Until two or three weeks preceding lambing, it is only necessary that they, like other store-sheep,
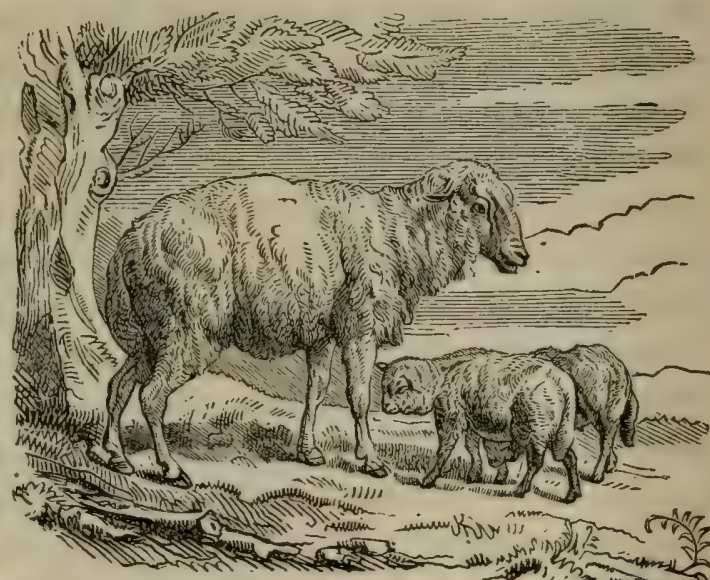

be kept in good, plump, ordinary condition; nor are any separate arrangements necessary for them

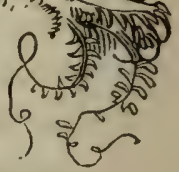
after that period, in a climate where they obtain sufficient succulent food to provide for a proper secretion of milk. In backward seasons in the North, where the grass does not start prior to the lambing-time, careful farmers feed their ewes on chopped roots, or roots mixed with oat and pea-meal, which is excelleut economy. Caution is, however, necessary to 
prevent injury or abortion, which is often the result of excessive fat, feebleness, or disease. The first may be remedied by bloodletting and spare diet; and both the last by restored health and generous food. Sudden frights, as from dogs or strange objects; long or severe journeys, great exertions, unwholesome food, blows in the region of the foetus, and some other causes, produce abortion.

Lambs are usually dropped, in the North, from the first to the fifteenth of May; in the South, they can safely come earlier. It is not expedient to bave them dropped when the weather is cold or boisterous, as they require too much eare; but the sooner the better, after the weather has become mild, and the herbage has started sufficiently to give the ewes that green food which is required to produce a plentiful secretion of milk. It is customary, in the North, to have fields of clover, or the earliest grasses, reserved for the early springfeed of the breeding-ewes; and, if these can be contiguous to their stables, it is a great convenience-for the ewes should be confined in the latter, on cold and stormy nights, during the lambing season.

If the weather be warm and pleasant, and the nights moderately warm, it is better to have the lambing take place in the pasture; since sheep are then more disposed to own their lambs, and take kindly to them, than in the confusion of a small inclosure. In the latter, sheep, unless particularly docile, crowd from one side to anuther when any one enters, running over young lambs, pressing them severely, etc.; ewes become separated from their lambs, and then run violently round from one to another, jostling and knocking them about; young and timid ewes, when so separated, will frequently 
neglect their lambs for an hour or more before they will again approach them, while, if the weather is severely cold, the lamb, it it has never sucked, is in danger of perishing. Lambs, too, when first dropped in a dirty inclosure, tumble about, in their first efforts to rise, and the membrane which adheres to them becomes smeared with dirt and dung; and the ewe's refusing to lick them dry much increases the hazard of freezing

In cold storms, however, and in sudden and severe weather, all this must be encountered; and, therefore, every shepherd should teach his sheep docility. It requires but a very moderately cold night to destroy the new-born Saxon lamb, which-the pure blood-is dropped nearly as naked as a child. During a severely cold period, of several days continuance, it is almost impossible to rear them, even in the best shelter. The Merino, Soutb-Down, and some other breeds, will endure a greater degree of cold with impunity. Where inclosures are used for yeaning, they should be kept elean by frequent litterings of straw-not enough, however, to be thrown on at any one time, to embarrass the lamb about rising.

The predisposing symptoms of lambing are, enlargement and reddening of the parts under the tail, and drooping of the flanks. The more immediate are, when the ewe stretches herself frequently; separating herself from her companions; exhibiting restlessness by not remaining in one place for any length of time; lying down and rising up again, as if dissatisfied with the place; pawing the ground with a forefoot; bleating, as if in quest of a lamb; and appearing fond of the lambs of other ewes. In a very few hours, or even shorter time, after the exhibition of these symptoms, the immediate 
symptom of lambing is the expulsion of the bag of water from the vagina. When this is observed, the ewe should be narrowly watched, for the pains of labor may be expected to come on immediately. When these are felt by her, the ewe presses or forces with earnestness, changing one place or position for another, as if desirous of relief.

The ewe does not often require mechanical assistance in parturition. Her labors will sometimes be prolonged for three or four hours, and her loud moanings will evince the extent of her pain. Sometimes she will go about several hours, and even resume her grazing, with the fore-feet and nose of the lamb protruding at the mouth of the vagina. If let alone, however, Nature will generally relieve her. In case of a false parturition of the foctus-which is comparatively rare-the shepherd may apply his thumb and finger, after oiling, to push back the lamb, and assist in gently turning it till the nose and forefeet appear. Where feebleness in expelling the fœtus exists, only the slightest aid should be rendered, and that to help the throes of the dam. The objection to interfering-except as a last resort-is, that the ewe is frightened when caught, and her efforts to expel the lamb cease. When aided, in any case, the gentlest force should be applied, and only in conjunction with the efforts of the ewe. The clearing, or placenta, generally drops from the ewe in the course of a very short time-in many cases, within a few minutes-after lambing. It should be carried away, and not allowed to lie upon the lambing-pound.

Common kale, or curly-greens, is excellent food for ewes that have lambed, as its nutritive matter, being mucilaginous, is wholly soluble in water, and beneficial in encouraging the 
necessary discharges of the ewe at the time of lambing. In these respects, it is a better food than Swedish turnips-upon which sheep are sometimes fed-which become rather too fibrous and astringent, in spring, for the secretion of milk. In the absence of kale or cabbage, a little oil-cake will aid the discharges and purify the body. New grass also operates medicinally upon the system.

\section{MANAGEMENT OF LAMBS.}

Thile the lamb is tumbling about and attempting to risethe ewe, meanwhile, licking it dry-it is well to be in no haste to interfere. A lamb that gets at the teat without help, and procures even a small quantity of milk, knows how to help itself afterward, and rarely perishes. If helped, it some- . times continues to expect it, and will do little for itself for two or three days. The same is true where lambs are fed from a spoon or bottle.

But if the lamb ceases to make efforts to rise-especially if the ewe has left off licking it while it is wet and chilly-it is time to render assistance. It is not advisable to throw the ewe down-as is frequently practised-in order to suckle the lamb; because instinct teaches the latter to point its nose upward in search of the teats. It is, therefore, doubly difficult to teach it to suck from the bag of the prostrate ewe; and when it is taught to do this, by being so suckled several times, it is awkward about finding the teat in the natural position, when it begins to stand and help itself. Carefully disengaging the ewe from her companions, with his crook-which useful article will be hereafter described-the assistant should place one hand before the neck and the other behind the 
buttocks of the ewe, and then, pressing her against his knees, he should hold her firmly and still, so that she will not be constantly crowding away from the shepherd, who should set the lamb on its feet, inducing it to stand, if possible; if not, supporting it on its feet by placing one hand under its body; put its mouth to the teat, and encourage it to suck by tickling it about the roots of the tail, flanks, etc., with a finger. The lamb, mistaking this last for the caresses of its dam, will redouble its efforts to suck. Sometimes it will manifest great dullness, and even apparent obstinacy, in refusing for a long time to attempt to assist itself, crowding backward, etc.; but the kind and gentle shepherd, who will not sink himself to the level of a brute, by resenting the stupidity of a brute, will - generally carry the point by perseverance. Sometimes milking a little into the lamb's mouth, holding the latter close to. the teat, will induce it to take hold.

If the ewe has no milk, the lamb should be fed, until the natural supply commences, with small quantities of the milk of a new-milch cow. This should be mixed, say half and half, with water, with enough molasses to give it the purgative effect of the first milk, gently warmed to the natural heat-not scalded and suffered to cool-and then fed through a bottle with a sponge in the opening of it, which the lamb should suck, if it can be induced so to do. If the milk is poured in its mouth from a spoon or bottle, it is frequently difficult, as before stated, to induce it to suck. Moreover, unless milk is poured into the mouth slowly and with care-no faster than the lamb can swallow-a speedy wheezing, the infallible precursor of death, will show that a portion of the fluid has 
been forced into the lungs. Lambs hare been frequently killed in this way.

If a lamb becomes chilled, it should be wrapped in a woollen blanket, placed in a warm room, and given a little milk as soon as it will swallow. A trifle of pepper is sometimes placed in the milk, and with good effect, for the purpose of rousing the cold and torpid stomach into action. In New England, under such circumstances, the lamb is sometimes "baked," as it is called-that is, put in a blanket in a moderately-heated oven, until warmth and animation are restored; others immerse it in tepid water, and subsequently rub it dry, which is said to be an excellent method where the lamb is nearly frozen. A good blanket however, a warm room, and sometimes, perhaps, a little gentle friction will generally suffice.

If a strong ewe, with a good bag of milk, chance to lose her lamb, she should be required to bring up one of some other ewe's twins, or the lamb of some feeble or young ewe, having an inadequate supply of milk. Her own lamb should be skinned as soon as possible after death, and the skin sewed over the lamb which she is to foster. She will sometimes be a little suspicious for a day or two; and if so, she should be kept in a small pen with the lamb, and occasionally looked to. After she has taken well to it, the false skin may be removed in three or four days. If no lamb is placed on a ewe which lost her lamb, and which has a full bag of milk, the milk should be drawn from the bag once or twice, or garget may ensue; even if this is not the result, permanent indurations, or other results of inflammatory action, will take place, injuring the subsequent nursing properties of the animal. 
When milked, it is well to wash the bag for some time in cold water, since it checks the subsequent secretions of milk, as well as allays inflammation.

Sometimes a young ewe, though exbibiting sufficient fondness for her lamb, will not stand for it to suck; and in this case, if the lamb is not very strong and persevering, and particularly if the weather is cold, it soon grows weak, and perishes. The conduct of the dam, in such instances, is occasioned by inflammatory action about the bag or teats, and perhaps somewhat by the novelty of her position. In this case, the sheep should be caught and held until the lamb has exhausted her bag, and there will not often be any trouble afterward; though it may be well enough to keep them in a pen together until the fact is determined.

Such pens-necessary in a variety of cases other than those mentioned-need not exceed eight or ten feet square, and should be built of light materials, and fastened together at the corners, so that they can be readily moved by one man, or, at the most, two, from place to place, where they are wanted. Their position should be daily shifted, when sheep are in them, for cleanliness and fresh feed. Light pine poles, laid up like a fence, and each nailed and pegged to the lower ones at the corners, or laid on, are quite serviceable. Two or three sides of a few of them should be wattled with twigs, and the tops partly covered, in order to shield feeble lambs from cold rains, piercing winds, and the like.

Young lambs are subject to what is commonly known as "pinning"-that is, their first excrements are so adhesive and tenacious that the orifice of the anus is closed, and subsequent evacuations prevented. The adhering matter, in such cases, 
should be entirely removed, and the part rubbed with a little Iry clay, to prevent subsequent adhesion. Lambs will frequently perish from this cause, if not looked to for the first few days.

The ewes and their joung ought to be divided into small flocks, and have a frequent change of pasture. Some careful shepherds adopt the plan of confining their lambs, allowing them to suck two or three times a day. By this method they suffer no fatigue, and thrive much faster. It is, however, troublesome as well as injurious, since the exercise is essential to the health and constitution of the lamb intended for rearing. It is admissible only when they are wanted for an early market; and with those who rear them for this purpose it is a common practice.

Where there are orphans or supernumeraries in the flock, the deserted lambs must be brought up by hand. Such animals, called pet lambs, are supported on cow's milk, which they reccive warm from the cows each time they are milked, and as much as they can drink. In the intervals of meals, in bad weather, they are kept under cover; in good weather they are put into a grass enclosure during the day, and sheltered at night until the nights become warm. They are fed by hand out of a small vessel, which should contain as much milk as it is known each can drink. They are first taught to drink out of the vessel with the fingers, like a calf, and as soon as they can hold a finger steady in the mouth, a small tin tube, about three inches in length, and of the thickness of a goose-quill, should be covered with several folds of linen, sewed tightly on, to use as a substitute for a teat, by means of which they will drink their allowance of milk with great ease and quick- 
ness. A goose-quill would answer the samie purpose, were it not easily squeezed together by the mouth. When the same person feeds the lambs-and this should be the dairy-maidthey soon become attached to her, and desire to follow her everywhere; but to prevent their bleating, and to make them contented, an apron or a piece of cloth, hung on a stake or bush in the inclosure, will keep them together.

It is much better for the lambs and for their dams that they be weaned from three and a half to four months old. When taken away, they should be put for several days in a ficld distant from the ewes, that they may not hear each other's bleatings, as the lambs, when in hearing of their dams, continue restless much longer, and make constant and, frequently, successful efforts to crawl through the fences which separate them. One or two tame old ewes are turned into the field with them, to teach them to come at the call, find salt when thrown to them, and eat out of troughs when winter approaches.

When weaned, the lambs should be put on the freshest and tenderest grass-rich, sweet food, but not too luxuriant. The grass and clover, sown the preceding spring, on grain-fields seeded down, is often reserved for them. The dams, on the contrary, should be put for a fortnight on short, dry feed, to stop the flow of milk. They should be looked to after a day or two, and if the bags of any are found much distended, the milk should be drawn away, and the bags washed for a little time in cold water. On short feed, they rarely give much trouble in this respect. When thoroughly dried off, they should have the best fare, to enable them to recover condition for subsequent breeding and wintering. The fall is a critical period in which to lose flesh, either for sheep or lambs; and 
if any are found deficient, they should at once be provided with extra feed and attention. If cold weather overtake them, poor or in ill health, they will scarcely outlive it; or if by chance they survive, their emaciated carcass, impaired constitution, and scant fleece will ill repay the food and attention they will have cost.

\section{CASTRATION AND DOCKING.}

Some breeders advocate castration in a day or two after birth, while others will not allow the operation to be performed until the lamb is a month old. The weight of authority, however, is in favor of any time between two and six weeks after birth, when the creature has attained some strength, and the parts have not become too rigid. In such circumstances, the best English breeders recommend from ten to fifteen days old as the proper time. A lamb of a day old cannot be confirmed in all the functions of its body, and, indeed, in many instances, the testicles can then scarcely be found. At a month old, on the other hand, the lamb may be so fat, and the weather so warm, that the operation may be attended with febrile action. Dry, pleasant weather should be selected for this: a cool day, if possible; if warm, it should be done early in the morning.

Castration is a simple and safe process. Let a man hold a lamb with its back pressed firmly against his breast and stomach, and all four legs gathered in front in his hands. Cut off the bottom of the pouch, free the testicle from the inclosing membrane, and then draw it steadily out, or clip the cord with a knife if it does not snap off at a proper distance from the testicle. Some shepherds draw both testicles at once with 
their teeth. It is usual to drop a little salt into the pouch. Where the weather is very warm, some touch the end of the pouch with an ointment, consisting of tar, lard, and turpentine. As a general thing, however, the animal will do as well without any application.

The object of docking is to keep the sheep behind clean from filth and vermin; since the tail, if left on, is apt to collect filth, and, if the animal purges, becomes an intolerable nuisance. The tail, however, should not be docked too short, since it is a protection against cold in winter. This operation is by many deferred till a late period, from apprehension of too much loss of blood; but, if the weather be favorable and the lamb in good condition, it may be performed at the same time as castration with the least trouble and without injury.

The tail should be laid upon a plank, the animal being beld in the same position as before. With one hand the skin is drawn toward the body, while another person, with a twoinch chisel and mallet, strikes it off at a blow, between the bone-joints, leaving it from one and a half to two inches long. The skin immediately slips back over the wound, which is soon healed. Should bleeding continue-as, however, rarely happens-so long as to sicken the lamb, a small cord should be tied firmly round the end of the tail; but this must not be allowed to remain on above twenty-four hours, as the points of the tail would slough off. Ewe lambs should be docked closer than rams. To prevent flies and maggots, and assist in healing, it is well to apply an ointment composed of lard and tar, in the proportion of four pounds of the former to one quart of the latter. The lambs should be carefully protected from cold and wet till they are perfectly well. 


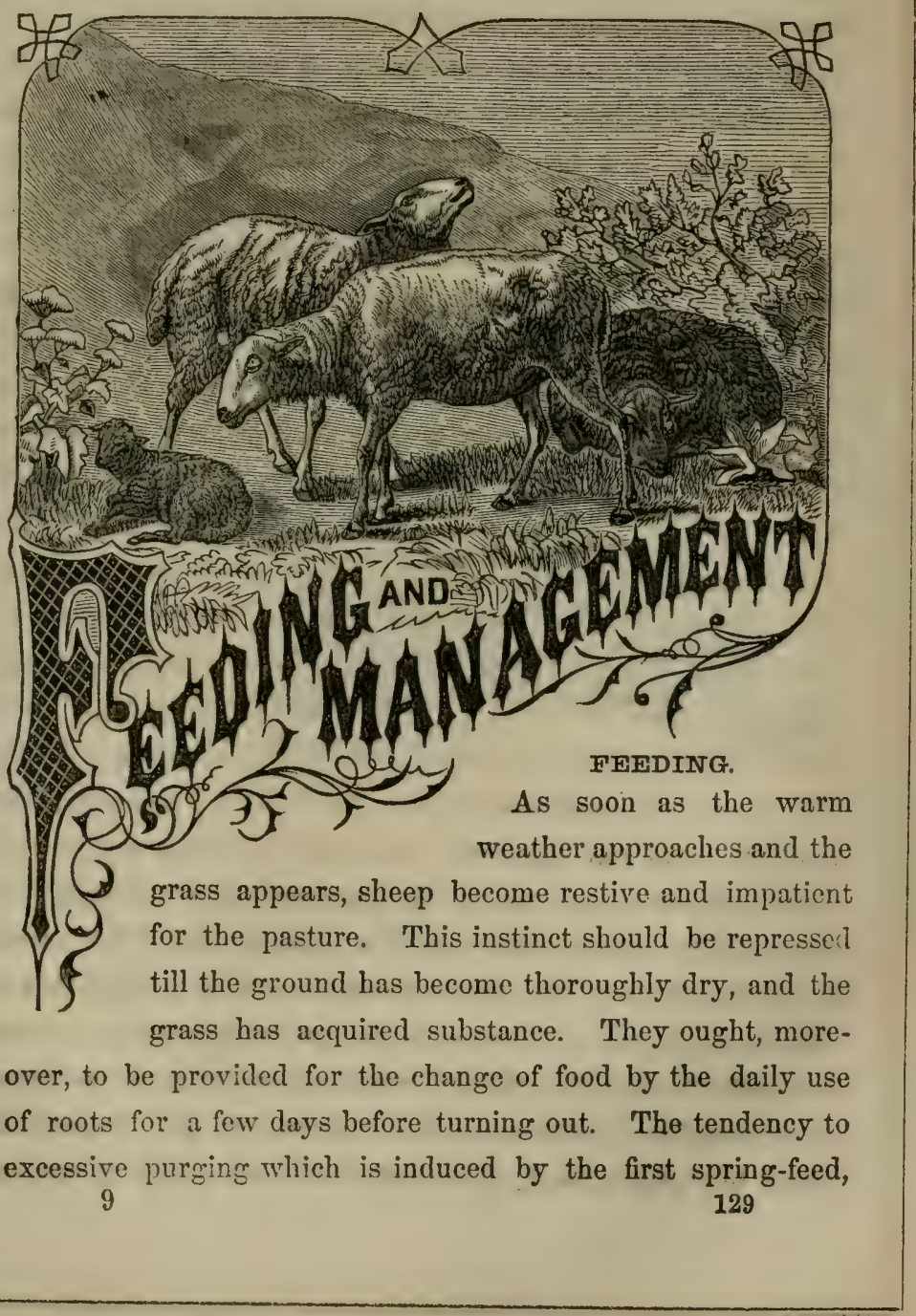


may be checked by housing them at night and feeding them for the first few days with a little sound, sweet hay. They must be provided with pure water and salt; for, though they may do tolerably well without either, yet thrift and freedom from disease are cheaply secured by this slight attention.

As to water, it may be said that it is not indispensable in the summer pastures, since the dews and the succulence of the feed answer as a substitute; but a wide experience having demonstrated that free access to it is advantageous, particularly to those having lambs, it should be considered a matter of importance on a sheep-farm so to arrange the pastures, if possible, as to bring water into each of them.

SALT is indispensable to the health, especially in the summer. It is common to give it once a week, while they

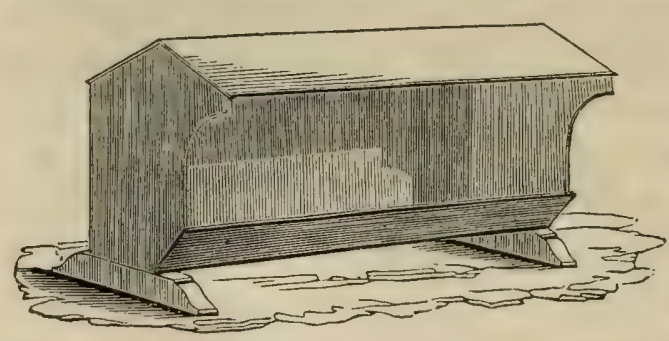

a COVERED SALting box. are at grass. It is still better to give them free access to it, at all times, by keeping it in a covered box, open on one side, as in the engraving annexed. A large hollow log, with holes cut along the side for the insertion of the heads of the animals, answers very well. A sheep having free access to salt at all times will never eat too much of it; and it will take its supply at such times and in such quantities as Nature demands, instead of eating of it voraciously at stated periods, as intermediate abstinence will stimulate it to do When salt is fed but once a week, it is better to have a stated day; so 
that it will not be forgotten; and it is well to lay the salt on flat stones-though if laid in little handfuls on the grass, very little of it will be lost.

TAR. This is supposed by many to form a very healthful condiment for sheep, and they smear the nose with it, which is licked and swallowed as the natural heat of the flesh, or that of the weather, causes it to trickle down over the nostrils and lips. Others, suffering the flock to get unusually salthungry, place tar upon flat stones, or in troughs, and then scatter salt upon it so that both may be consumed together. Applied to the nose, in the nature of a cataplasm, it may be advantageous in catarrhs; and in the same place, at the proper periods, its odor may, perhaps, repel the fly, the eggs of which produce the "gout in the head," as it is termed. However valuable it may be as a medicine, and even as a debergent in the case specified, there is but slight ground for confidence in it merely as a condiment.

Dry, sweet pastures, and such as abound in aromatic and bitter plants, are best suited for sheep-walks. No animal, with the exception of the goat, crops so great a variety of plants. They eat many which are rejected by the horse and. the $0 \mathrm{x}$, which are even essential to their own wants. In this respect they are valuable assistants to the husbandman, as they feed greedily on wild mustard, burdock, thistles, marshmallows, milk-weed, and various other offending plants; and the Merino exceeds the more recent breeds in the range of his selections.

In pastures, however, where the dry stalks of the burdock, or the hound's-tongue, or tory-weed have remained standing over the winter, the burs are caught in the now long wool, 
and, if they are numerous, the wool is rendered entirely unmarketable and almost valueless. Even the dry prickles of the common and Canada thistles, where they are very numerous, get into the neck-wool of sheep, as they thrust their heads under and among them to crop the first scarce feed of the northern spring; and, independently of injuring the wool, they make it difficult to wash and otherwise handle the sheep. Indeed, it is a matter of the soundest policy to keep sheep on the cleanest pastures, those free from these and similar plants; and in a region where they are pastured the year round, they should be kept from contact with them for some months prior to shearing:

-Many prepare artificial pastures for their flocks, which may be done with a number of plants. Winter rye, or wheat sown early in the season, may be fed off in the fall, without injury to the crop; and, in the following spring, the rye may be pastured till the stalks shoot up and begin to form a head. This affords an early and nutritious food. Corn may be sown broadcast, or thickly in drills, and either fed off in the fields or cut and carried to the sheep in their folds. White mustard is also a valuable crop for this purpose.

To give sheep sufficient variety, it is better to divide their range into several smaller ones, and change them as often, at least, as once a week. They seek a favorite resting-place, on a dry, elevated part of the field, which soon becomes soiled. By removing them from this for a few days, rain will cleanse or the sun dry it, so as to make it again suitable for them. More sheep may be kept, and in better condition, where this practice is adopted, than where they are confined to the same pasture. 
Shade. No one who has observed with what cagerness sheep seek shade in hot weather, and how they pant and apparently suffer when a hot sun is pouring down upon their nearly naked bodies, will doubt that, both as a matter of humanity and utility, they should be provided, during the hot summer-months, with a better shelter than that afforded by a common rail-fence. Forest trees are the most natural and the best shades, and it is as contrary to utility as it is to good taste to strip them entirely from the sheep-walks. A strip of stone-wall or close hoard fence on the south and west sides of the pasture, forms a tolerable substitute for trees. But in the absence of all these and of buildings of any kind, a shade can be cheaply constructed of poles and brush, in the same manner as the sheds of the same materials for winter shelter, which will be hereafter described.

Fences. Poor fences will teach ewes and wethers, as well as rams, to jump; and for a jumping flock there is no remedy but immoderately high fences, or extirpation. One jumper will soon teach the trick to a whole flock; and if one by chance is brought in, it should be immediately hoppled or killed. The last is by far the surest and safest remedy.

Hoppling is done by sewing the ends of a leather strap, broad at the extremities, so that it will not cut into the flesh, to a fore and hind leg, just above the pastern joints, leaving the legs at about the natural distance apart. Clogging is fastening a billet of wood to the fore leg by a leather strap. Yoking is fastening two rams two or three feet apart, by bows around their necks, inserted in a light piece of timber, some two or three inches in size. Poking is done by inserting a bow in a short bit of light timber, into which bit-worn on the 
under side of the neck-a rod is inserted, which projects a couple of feet in front of the sheep.

These and similar devices, to prevent rams from scaling fences, may be employed as a last resort by those improvident farmers who prefer, by such troublesome, injurious, and, at best, insecure means, to guard against that viciousness which they might so much more easily have prevented from being acquired.

Dangerous raMs. From being teased and annoyed by boys, or petted and played with when young, and sometimes without any other stimulant than a naturally vicious temper, rams occasionally become very troublesome by their propensity to attack men or cattle. Some will allow no man to enter the field where they are without making an immediate onset upon him; while others will knock down the ox or horse which presumes to dispute a lock of hay with them. A ram which is known to have acquired this propensity should at once be hooded, and, if not valuable, at the proper season converted into a wether. But the courage thus manifested is usually the concomitant of great strength and vigor of constitution, and of a powerfully developed frame. If good in other particulars, it is a pity to lose the services of so valuable an animal. In such cases, they may be hooded, by covering their faces with leather in such a manner that they can only see a little backward and forward. They must then, however, be kept apart from the flock of rams, or they will soon be killed or injured by blows, which they cannot see to escape.

It sometimes happens that a usually quiet-tempered ram will suddenly exhibit some pugnacity when one is salting or feeding the flock. If such a person turns to run, he is imme- 
diately knocked down, and the ram learns, from that single lesson, the secret of his mastery, and the propensity to exercise it. As the ram gives his blow from the summit of the parietal and the posterior portion of the frontal bones on the top of his head, and not from the forehead, he is obliged to crouch his head so low when he makes his onset that he does not see forward well enough to swerve suddenly from his right line, and $a$ few quick motions to the right and left enable one to escape him. Run in upon him, as he dashes by, with pitchfork, club, or boot-heel, and punish him severely by blows about the head, if the club is used, giving him no time to rally until he is thoroughly cowed. This may be deemed harsh treatment, and likely to increase the viciousness of the animal. Repeated instances have, however, proved the contrary; and if the animal once is forced to acknowledge that he is overcome, he never forgets the lesson.

Pratrie feeding. Sheep, when destined for the prairies, ought to commence their journey as early after the shearing as possible, since they are then disencumbered of their fleece, and do not catch and retain as much dust as when driven later; feed is also generally better, and the roads are dry and hard. Young and healthy sheep should be selected, with early lambs; or, if the latter are too young, and the distance great, they should be left, and the ewes dried off. A large wagon ought to accompany the flock, to carry such as occasionally give out; or they may be disposed of whenever they become enfeebled. With good care, a hardy flock may be driven at the rate of twelve or fourteen miles a day. Constant watchfulness is requisite, in order to keep them healthy and in good 
plight. One-half the expense of driving may be saved by the use of well-trained shepherd-dogs.

When arrived at their destination, they must be thoroughly washed, to free them from all dirt, and closely examined as to any diseases which they may have contracted, that these may be promptly removed. A variety of suitable food and good shelter must be provided for the autumn, winter, and spring ensuing, and every necessary attention given to them. This would be necessary if they were indigenous to the country; but it is much more so when they have just undergone a campaign to which neither they nor their race have been accustomed.

Sheep cannot be kept on the prairies without much care, artificial food, and proper attention; and losses have often occurred, by reason of a false system of economy attempted by many, from disease and mortality in the flocks, amply sufficient to have made a generous provision for the comfort and security of twice the number lost. More especially do they require proper food and attention after the first severe frosts set in, which wither and kill the natural grasses. By nibbling at the bog-the frostbitten, dead grass-they are inevitably subject to constipation, which a bountiful supply of roots, sulphur, etc., is alone sufficient to remove.

Roots, grain, good hay, straw, corn-stalks, and pea or beanvines are essential to the preservation of their health and thrift during the winter, everywhere north of thirty-nine degrees. In summer, the natural herbage is sufficient to sustain them in fine condition, till they shall have acquired a denser population of animals, when it will be found necessary 
to stock their meadows with the best varieties of artificial grasses.

The prairies seem adapted to the usual varieties of sheep introduced into the United States; and of such are the flocks made up, according to the taste or judgment of the owners. Shepherd dogs are invaluable to the owners of flocks, in these unfenced, illimitable ranges, both as a defence against the small prairie wolves, which prowl around the sheep, but have been rapidly thinned off by the settlers, and also as assistants to the shepherds in driving and herding their flocks on the open ground.

FALl FEEDiNG. In the North, the grass often gets very short by the tenth or fifteenth of November, and it has lost most of its nutritiousness from repeated freezing and thawing. At this time, although no snow may bave fallen, it is best to give the sheep a light, daily foddering of bright hay, and a few oats in the bundle. Given thus for the ten or twelve days which precede the covering of the ground by snow, fodder pays for itself as well as at any other time during the year. It is well to feed oats in the bundle, or threshed oats, about a gill to the head, in the feeding-troughs, carried to the field for that purpose.

Winter feeding. The time for taking sheep from the pastures must depend on the state of the weather and food. Severe frosts destroy much of the nutriment in the grasses, and they soon after cease to afford adequate nourishment. Long exposure to cold storms, with such food to sustain them, will rapidly reduce the condition of these animals. The only safe rule is to transfer them to their winter-quarters the first day they cease to thrive abroad. 
There is no better food for sheep than well-ripened, sound Timothy hay; though the clovers and nearly all the cultivated grasses may be advantageously fed. Hundreds and thousands of northern flocks receive, during the entire winter, nothing but ordinary bay, consisting mainly of Timothy, some red and white clover, and frequently a sprinkling of gum, or spear grass. Bean and pea straw are valuable, especially the former, which, if properly cured, they prefer to the best hay; and it is well adapted to the production of wool. Where hay is the principal feed, it may be well, where it is convenient, to give corn-stalks every fifth or sixth feed, or even once a day; or the daily feed, not of hay, might alternate between stalks, pea-straw, straws of the cereal grains, etc. It is mainly a question of convenience with the farmer, provided a proper supply of palatable nutriment within a proper compass is given. It would not, however, be entirely safe to confine any kind of sheep to the straw of the cereal grains, unless it were some of those little hardy varieties of animals which would be of no use in this country.

The expediency of feeding grain to store-sheep in winter depends much on circumstances. If in a climate where they can obtain a proper supply of grass or other green esculents, it would, of course, be unnecessary; nor is it a matter of necessity where the ground is frozen or covered with snow for weeks or months, provided the sheep be plentifully supplied with good dry fodder. Near markets where the coarser grains find a quick sale at fair prices, it is not usual, in the North, to feed grain. Remote from markets it is generally fed by the holders of large flocks. Oats are commonly preferred, and they are fed at the rate of a gill a head per day. Some feed 
balf the same amount of yellow corn. Fewer sheep, particularly lambs and yearlings, get thin and perish where they receive a daily feed of grain; they consume less hay, and their fleeces are increased in weight. On the whole, therefore, it is considered good economy. Where no grain is fed, three daily feeds of hay are given. The smaller sizes of the Saxon may be well sustained on two pounds of hay; but larger sheep will consume from three and a balf to four or even five pounds per day. Sheep, in common with all other animals, when exposed to cold, will consume much more than if well protected, or during a warmer season.

It is a common and very good practice to feed greenish cut oats in the bundle, at noon, and give but two feeds of hay, one at morning and one at night. Some feed greenish cut peas in the same way. In warm, thawing weather, when sheep get to the ground and refuse dry hay, a little grain assists materially in keeping up their strength and condition. When the feed is shortest in winter, in the South, there are many localities where sheep can get enough grass to take off their appetite for dry hay, but not quite enough to keep them in prime order. A moderate daily feed of oats or pease, placed in the depository racks, would keep them strong and in good plight for the lambing season, and increase their weight of . wool.

Few Northern farmers feed Indian corn to store-sheep, as it is considered too hot and stimulating; and sheep are thought to become more liable to become "cloyed" on it than on oats, pease, etc. Yellow corn is not generally judged a very safe feed for lambs and yearlings. Store-sheep should be kept in good, fair, plump condition. Lambs and yearlings may 
be as fat as thcy will become on proper feeding. It is stated that sheep will eat cotton-seed, and thrive on it.

It must be remembered that sheep are not to be allowed to get thin during the winter, with the idea that their condition can at any time be readily raised by better feed, as with the horse or ox. It is always difficult, and, unless properly managed, expensive and hazardous, to attempt to raise the condition of a poor flock in the winter, especially if they bave reached that point where they manifest weakness. If the feeding of a liberal allowance of grain be suddenly commenced, fatal diarrhœa will often supervene. All extra feeding, therefore, must be begun very gradually; and it does not appear, in any case, to produce proportionable results.

Roots, such as ruta-bagas, Irish potatoes, and the like, make a good substitute for grain, or as extra feed for grown sheep. The ruta-baga is preferable to the potatoe in its equiralents of nutriment. No root, however, is as good for lambs and yearlings as an equivalent of grain. Sheep may be taught to eat nearly all the cultivated roots. This is done by withholding salt from them, and then feeding the chopped roots a few times, rubbed with just sufficient salt to induce them to eat the root to obtain it; but not enough to satisfy their appetite for salt before they have acquired a taste for the roots.

It is customary with some farmers to cut down, from time to time in the winter, and draw into the sheep-yards, young trees of the hemlock, whose foliage is greedily eaten by the sheep, after being confined for some time to dry feea'. This browse is commonly used, like tar, for some supposed medicinal virtues. It is pronounced "healthy" for sheep. Much the 
same remarks might be made about this as have been already made concerning tar. No tonics and stimulants are needed for a healthy animal. If the foliage of the hemlock were constantly accessible to them, there would be no possible objection to their eating it, since their instincts, in that case, would teach them whether, and in what quantities, to devour it; but when entirely confined to dry feed for a protracted period, sheep will consume injurious and even poisonous succulents, and of the most wholesome ones, hurtful quantities. As a mere laxative, an occasional feed of hemlock may be beneficial; though, in this point of view, a day's run at grass, in a thaw; or a feed of roots, would produce the same result. In a climate where grass is procurable most of the time, browse for medicinal purposes is entirely unnecessary.

Sheep undoubtedly require salt in winter. Some salt their hay when it is stored in the barn or stack. This is objectionable, since the appetite of the sheep is much the safest guide in the premises. It may be left accessible to them in the saltbox, as in summer; or an occasional feed of grined hay or straw may be given them in warm, thawing weather, when their appetite is poor. This last is an excellent plan, and serves a double purpose. With a wisp of straw, sprinkle a thin layer of straw with brine, then another layer of straw, and another sprinkling, and so on. Let this lie until the next day, for the brine to be absorbed by the straw, and then feed it to all the grazing animals on the farm which need salting.

Water is indispensable, unless sheep have access to succulent food, or clean snow. Constant access to a brook or spring is best; but, in default of this, they should be watered at least once a day in some other way. 
Feeding with other stock. Sheep should not run, or lie fed, in yards, with any other stock. Cattle book them, often mortally; and colts tease and frequently injure them. It is often said that "colts will pick up what sheep leave." But well-managed sheep rarely leave any thing; and, if they chance so to do, it is better to rake it up and throw it into the colts' yard, than to feed them together. If sheep are not required to eat their food pretty clean, they will soon learn to waste large quantities. If, however, they are overfed with either hay or grain, it is not proper to compel them, by starvation, to come back and eat it. This they will not do, unless sorely pinched. Clean out the troughs, or rake up the hay, and the next time feed less.

Division of FLOCKs. If flocks are shut up in small inclosures during winter, according to the northern custom, it is necessary to divide them into flocks of about one hundred each, consisting of sheep of about the same size and strength; otherwise, the stronger rob the weaker, and the latter rapidly decline. This is not so important where the sheep roam at large; but, even in that case, some division and classification are best. It is best, indeed, even in summer. The poorer and feebler can by this means receive better pasture, or a little more grain and better shelter in winter.

By those who grow wool to any extent, breeding ewes, lambs, and wethers, are invariably kept in separate flocks in winter; and it is best to keep yearling sheep by themselves with a few of the smallest two-year-olds, and any old crones which are kept for their excellence as breeders, but which cannot maintain themselves in the flock of breeding ewes.

Old and feeble or wounded sheep, late-born lambs, etc., 
should be placed by themselves, even if the number be small, as they require better feed, warmer shelter, and more attention. Unless the sheep are of a peculiarly valuable variety, however, it is better to seil them off in the fall at any price, or to give them to some poor neighbor who has time to nurse them, and who may thus commence a flock.

Regularity in FEeding If any one principle in sheep husbandry deserves careful attention more than others, it is, that the utmost regularity must be preserved in feeding.

First, there should be regularity as to the times of feeding. However abundantly provided for, when a flock are foddered sometimes at one hour and sometimes at another-sometimes three times a day, and sometimes twice-some days grain, and some days none-they cannot be made to thrive. They will do far better on inferior keep, if fed with strict regularity. In a climate where they require hay three times a day, the best times for feeding are about sunrise in the morning, at noon, and an hour before dark at night. Unlike cattle and horses, sheep do not feed well in the dark; and, therefore, they should have time to consume their food before night sets in. Noon is the common time for feeding grain or roots, and is the best time, if but two fodderings of hay are given. If the sheep receive hay three times, it is not a matter of much consequence with which feeding grain is given, only that the practice be uniform.

Secondly, it is highly essential that there should be regularity in the amount fed. The consumption of hay will, it is true, depend much upon the weather; the keener the cold, the more the sheep will eat. In the South, much depends upon the amount of grass obtained. In many places, a light, daily 
foddering supplies; in others, a light foddering placed in the depository racks once in two days, answer's the purpose. In the steady cold weather of the North, the shepherd readily learns to determine about how much hay will be consumed before the next foddering time. And this amount should, as near as may be, be regularly fed. In feeding grain or roots, there is no difficulty in preserving entire regularity; and it is vastly more important than in feeding hay. Of the latter, a sheep will not over-eat and surfeit itself; of the former, it will. Even if it be not fed grain to the point of surfeiting, it will expect a like amount, however over-plenteous, at the next feeding; failing to receive which, it will pine for it, and manifest uneasiness. The effect of such irregularity on the stomach and system of any animal is bad; and the sheep suffers more from it than any other animal. It is much better that the flock receive no grain at all, than that they receive it without regard to regularity in the amount. The shepherd should measure out the grain to the shcep in all instances, instead of guessing it out, and measure it to each separate flock.

EFFECT OF FOOD. Well-fed sheep, as has been previously remarked, produce more wool than poorly fed ones. No doctrine is more clearly recognized in agricultural chemistry than that animal tissues derive their chemical components from the same components existing in their food. Tarious analyses show that the chemical composition of wool, hair, hoofs, nails, horns, feathers, lean meat, blood, cellular tissue, nerves, etc., are nearly identical.

The organic part of wool, according to standard authorities, consists of carbon, 50.65 ; hydrogen, 7.03 ; nitrogen, 17.71 ; oxygen and sulphur, 24.61. The inorganic constituents are small. When burned, it leares but a trifling per cent? of ash. 
The large quantity of nitrogen contained in wool shows that its production is increased by highly azotized food; and from various experiments made, a striking correspondence has been found to exist between the amount of wool and the amount of nitrogen in food. Pease rank first in increasing the wool, and very high in the average comparative increase which they produce in all the tissues.

The increase of fat and muscle, as of wool, depends upon the nature of the food. It is not very common, in the North, for wool-growers to fatten their wethers for market by extra winter feeding. Some give them a little more generous keep the winter before they are to be turned off, and then salt them when they have obtained their maximum fatness the succeding fall.

Stall-feeding is lost on an ill-shaped, unthrifty animal. The perfection of form and health, and the uniform good condition which characterizes the thrifty one, indicate, too plainly to be misunderstood, those which will best repay the care of their owner. The selection of any indifferent animal for stall-fattening will inevitably be attended with loss. Such ought to be got rid of, when first brought from the pasture, for the wool they will bring.

When winter fattening is attempted, sheep require warm, dry shelters, and should receive, in addition to all the bay they will eat, meal twice a day in troughs-or meal once and chopped roots once. The equiralent of from half a pint to a pint of yellow corn meal per head each day is about as much as ordinary stocks of Merino wethers will profitably consume; though in selected flocks, consisting of large animals, this amount is frequently exceeded.

- 10 


\section{YARDS.}

Experience has amply demonstrated that-in the climate of the Northern and Eastern States, where no grass grows from four to four and a half months in the winter, and where, therefore, all that can be obtained from the ground is the repeatedly frozen, unnutritious herbage left in the fall-it is better to keep sheep confined in yards, excepting where the ground is covered with snow. If suffered to roam over the fields at other times, they get enough grass to take away their appetite for dry hay, but not enough to sustain them; they fall away, and toward spring they become weak, and a large proportion of them frequently perish. Flocks of some size are here, of course, alluded to, and on properly stocked farms. A few sheep would do better with a boundless range.

Some let out their sheep occasionally for a single day, during a thaw; others keep them entirely from the ground until let out to grass in the spring. The former course is preferable where the sheep ordinarily get nothing but dry fodder. It affords a healthy laxative, and a single day's grazing will not take off their appetite from more than one succeeding dry feed. It is necessary, in the North, to keep sheep in the yards until the feed has got a good start in the spring, or they will get off from their feed-particularly the breeding ewes-and get weak at the most critical time for them in the year.

Yards should be firm-bottomed, dry, and, in the northern climate, kept well littered with straw. The yarding system is not practised to any great extent in the South; nor should it be, where sheep can get their living from the fields. 


\section{FEEDING-RACKS.}

When the ground is frozen, and especially when covered with snow, the sheep eats bay well on the ground; but when the land is soft, muddy, or foul with manure, they will scarcely touch hay placed on it-or, if they do, will tread much of it

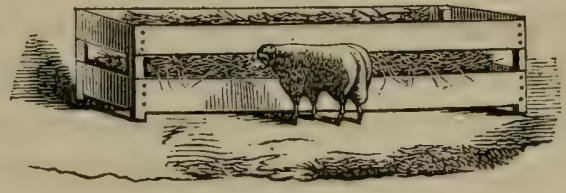

A CONVENIENT BOX-RACK.

into the mud, in their restlessness while feeding. It should then be fed in racks, which are more economical, even in the first-named case; since, when the hay is fed on the ground, the leaves and seeds, the most valuable part of the fodder, are almost wholly lost.

To make an economical box-rack-the one in most general use in the North-take six light pieces of scantling, say three inches square, one for each corner, and one for the centre of each side. Boards of pine or hemlock, twelve or fifteen feet long, and twelve or fourteen inches wide, may then be nailed on to the bottom of the posts for the sides, which are separated by similar boards at the ends, two and a half feet long. Boards twelve inches wide, raised above the lower ones by a space of from nine to twelve inches, are nailed on the sides and ends, which completes the rack. The edges of the opening should be made perfectly smooth, to prevent chafing or tearing out the wool. The largest dimensions given are suitable for the large breeds, and the smallest for the Saxon; and still smaller are proper for the lambs. These should be set on dry 
ground, or under the sheds; and they can be easily removed wherever necessary. Unless over-fed, sheep waste rery little bay in them.

Some prefer the racks made with slats, or smooth, upright sticks, in the form of the common horse-rack This kind should alrays be accompanied by a broad trough affixed to the bottom, to catch the fine hay which falls in feeding These racks may be attached to the side of a building, or used double. A small lamb requires fifteen inches of space, and a large sheep two feet, for quiet, comfortable feeding; and this amount of room, at least, should be provided around the racks for every sheep.

With what is termed a hole-rack, sheep do not crowd and take advantage of each other so much as with log-racks; but

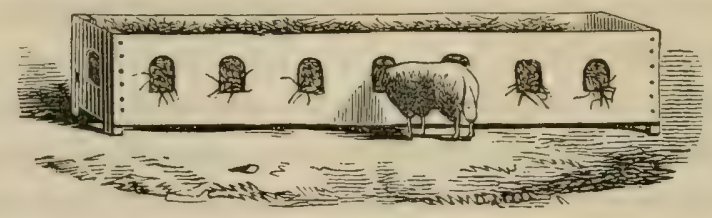

A HOLE-RACK.

they are too heary and unnecessarily expensive for a common out-door rack. This rack is box-shaped, with the front formed of a board nailed on horizontally, or, more commonly, by nailing the boards perpendicularly, the bottoms on the sill of a barn, and the tops to horizontal pieces of timber. The holes should be at least eight inches wide, nine inches high, and eighteen inches from centre to centre.

In the South, racks are not so necessary for that constant use to which they are put in colder sections, as they are for depositories of dry food, for the occasional visitation of the 
sheep. In soft, warm weather, when the ground is unfrozen, and any kind of green herbage is to be obtained, sheep will scarcely tonch dry fodder; though the little they will then eat will be highly serviceable to them. But in a sudden freeze, or on the occurrence of cold storms, they will resort to the racks, and fill themselves with dry food. They anticipate the coming storm by instinct, and eat an extra quantity of food to sustain the animal heat during the succeeding depression of temperature. They should always have racks of dry fodder for resort in such emergencies.

These racks should have corers or roofs to protect their contents from rain, as otherwise the feed would often be spoiled before but a small portion of it would be consumed. Hay or straw, saturated with water, or soaked and dried, is only eaten Wy the sheep as a matter of absolute necessity. The common box-rack would answer the purpose very well by placing on the top a triangular cover or roof, formed of a couple of boards, one hung at the upper edge with iron or leather hinges, so that it could be lifted up like a lid; making the ends tight; drawing in the lower edges of the sides, so that it should not be more than a foot wide on the bottom; inserting a flow; and then mounting it on, and making it fast to, two cross-sills, four or five inches square, to keep the floor off from the ground, and long enough to prevent it from being easily orerturned. The lower side-board should be narrow, on account of the increased height given its upper edge by the sills.

A rack of the same construction, with the sides like those described for the hole-rack, would be still better, though somewhat more expensire; or the sides might consist of rundles, 
the top being nailed down in either case, and the fodder inserted by little doors in the ends.

What is termed the hopper-rack, serving both for a rack and a feeding-trough, is a favorite with many sheep-owners.

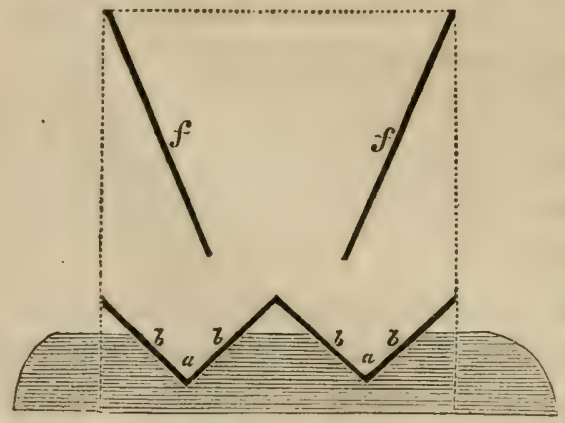

THE BOPPEK-RACK.

The accompanying cut represents a section of such a rack. A piece of durable wood, about four and a half feet long, six or eight inches deep, and four inches thick, having two notches, $a$ a, cut into it, and two troughs, made of inch boards, $b 6 . b$, placed in these notches, and nailed fast, constitute the formation. If the rack is to be fourteen feet long, three sills are required. The ends of the rack are made by nailing against the side of the sill-boards that reach up as high as it is desired to have the rack; and nails driven through these end-boards into the ends of the sideboards, $f f$, secure them. The sides may be further strengthened by pieces of board on the outside of them, fitted into the trough. A roof may be put over all, if desired, by means of which the fodder is kept entirely from the weather, and no seeds or chaff can get into the wool.

\section{TROUGES.}

Threshed grain, chopped roots, etc., when fed to sheep, should be placed in troughs. With either of the racks winich have been described, except the last, a separate trough would 
be required. The most economical are made of two boards of any convenient length, ten to twelve inches wide. Nail the lower side of one upon the edge of the other, fastening both into a two or three-inch plank, fifteen inches long, and a foot

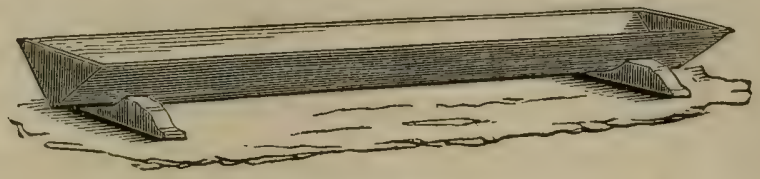

AN ECONOMICAL SHEEP-TROUGH,

wide, notched in its upper edge in the form required. In snowy sections they are turned over after feeding, and when falls of snow are anticipated one end is laid on the yard-fence.

Various contrivances have been brought to notice for keeping grain where sheep can feed on it at will, a description of which is omitted, since it is not thought best, by the most successful stock-raisers, in feeding or fattening any quadrupeds, to allow them grain at will, stated feeds being preferred by them; and the same is true of fodder. If this system is departed from in using depository racks, as recommended, it is because it is rendered necessary by the circumstances of the case. A Merino store-sheep, allowed as much grain as it chose to consume, would be likely to inflict injury on itself; and grain so fed would, generally speaking, be productive of more damage than benefit.

\section{BARNS AND SHEDS.}

Shelters, in northern climates, are indispensable to profitable sheep-raising; and in every latitude north of the Gulf of Mexico, they would probably be found advantageous. An animal eats much less when thus protected; he is more thrifty, 
less liable to disease, and his manure is richer and more abundant. The feeding may be done in the open yard in clear weather, and under cover in severe storms : for, even in the vigorous climate of the North, none but the breeders of Saxons make a regular practice of feeding under cover.

Humanity and economy alike dictate that, in the North, sheep should be provided with shelters under which to lie

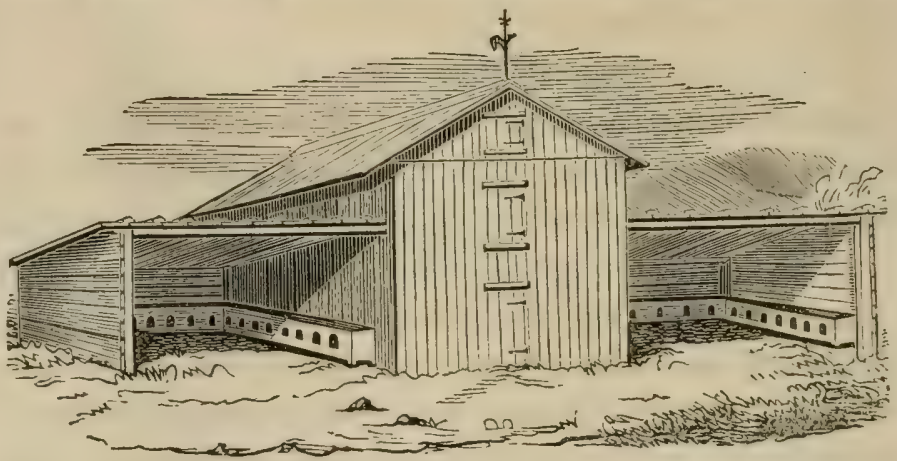

SHEEP-BARN WITH SHEDS.

nights, and to which they can resort at will. It is not an uncommon circumstance in New York and New England for snow to fall to the depth of from twenty to thirty inches within twenty-four or forty-eight hours, and then to be succeeded by a strong and intensely cold west or northwest wind of sereral days continuance, which lifts the snow, blocking up the roads, and piling huge drifts to the leeward of fences, barns, etc.

A flock without shelter will huddle closely together, turning their backs to the storm, constantly stepping, and thus treading down the snow as it rises about them. Strong, close-coated sheep do not seem to suffer as much from the cold, for a period, as would be expected. It is, however, almost impossible to 
feed them enough, or half enough, under such circumstances, without an immense waste of hay-entirely impossible, indeed, without racks. The hay is whirled away in an instant by the wind; and, even if racks are used, the sheep, leaving their huddle, where they were kept warm and even moist by the melting snow in their wool, soon get chilled, and are disposed to return to their huddle. Imperfectly filled with food, the supply of animal heat is lowered, and, at the end of the second or third day, the feeble ones sink down lropelessly, the yearlings, and those somewhat old, receive a shock from which nothing but the most careful nursing will enable them to rally, and even the strongest suffer an injurious loss in condition.

Few persons, therefore, who own as many as forty or fifty sheep, attempt to get along without some kind of shelters, which are variously constructed, to suit their tastes or circumstances. A sheep-barn, built upon a side-hill, will afford two floors: one underneath, surrounded by three sides of wall, should open to the south, with sliding or swinging doors to guard against storms; and another may be provided above, if the floors are perfectly tight, with proper gutters to carry off the urine; and sufficient storage for the fodder can be furnished by scaffolds overhead. They may also be constructed with twelve or fifteen-feet posts on level ground, allowing the sheep to occupy the lower part, with the fodder stored above.

In all cases, however, thorough ventilation should be pro. vided; for of the two evils, of exposure to cold or of too great privation of air, the former is to be preferred. Sheep cannot long endure close confinement without injury. In all ordinary weather, a shed, closely boarded on three sides, with a light 
roof, is sufficient protection; especially if the open side is shielded from bleak winds, or leads into a well-inclosed yard. If the floors above are used for storage, they should be made tight, that no hay, chaff, or dust can fall upon the fleece. The sheds attached to the barn are not usually framed or silled, but are supported by some posts of durable timber set in the ground. The roofs are formed of boards battened with slats. The barn has generally no partitions within, and is entirely flled with hay.

There are many situations in which open sheds are very liable to have snow drifted under them by certain winds, and they are subject in all severe gales to halve the snow carried over them to fall down in large drifts in front, which gradually encroach on the sheltered space, and are very inconvenient, particularly when they thaw. For these reasons, many prefer sheep-houses covered on all sides, with the exception of a wide doorway for ingress and egress, and one or two windows for the necessary ventilation. They are convenient for yarding sheep, and the various processes for which this is required; as for shearing, marking, sorting, etc., and especially so for lambing-places, or the confinement of newly-shorn sheep in cold storms. They should have so much space that, in addition to the outside racks, others can be placed temporarily through the middle when required.

The facts must not be orerlooked-as bearing upon the question of shelter, even in the warmer regions of the country - that cold rains, or rains of any temperature, when immediately succeeded by cold or freezing weather, or cold, piercing winds, are more hurtful to sheep than even snow-storms; and 
that, consequently, sheep must be adequately guarded against them.

Sheds. The simplest and cheapest kind of shed is formed by poles or rails, the upper end resting on a strong horizontal

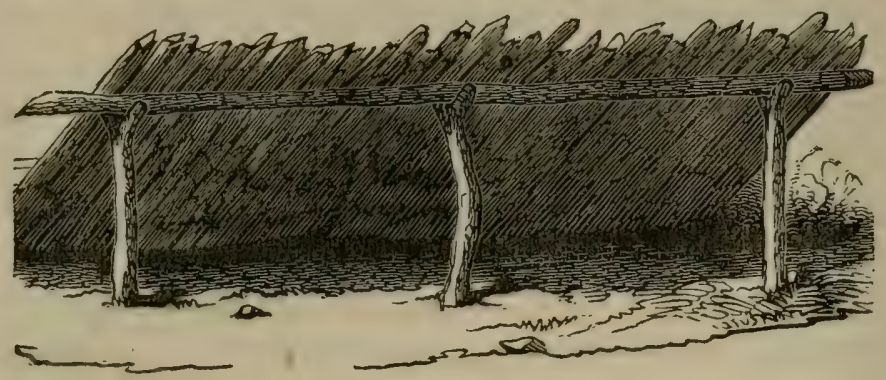

A SHED OF RAILg.

pole supported by crotched posts set in the ground. It may be rendered rain-proof by pea-vines, straw, or pine boughs. In a region where timber is very cheap, planks or boards, of a sufficient thickness not to spring downward, and thus open the roof, battened with slats, may take the place of the poles and boughs; and they would make a tighter and more durable roof. If the lower ends of the boards or poles. are raised a couple of feet from the ground, by placing a log under them, the shed will shelter more sheep.

These movable sheds may be connected with hay-barns"hay-barracks"-or they may surround an inclosed space with a stack in the middle. In the latter case, the yard should be square, on account of the divergence in the lower ends of the boards or poles, which a round form would render necessary.

Sheds of this description are frequently made between two stacks. The end of the horizontal supporting-pole is placed on the stack-pens when the stacks are built, and the middle is 
propped by crotched posts. The supporting-pole may rest, in the same way, on the upper girts of two hay-barracks; or two such sheds, at angles with each other, might form wings to this structure.

On all large sheep-farms, convenience requires that there be one barn of considerable size, to contain the shearing-floor, and the necessary conveniences about it for yarding the sheep, etc. This should also, for the sake of economy, be a bay-barn, where hay is used. It may be constructed in the corner of four fields, so that four hundred sheep can be fed from it, without racking flocks of improper size. At this barn it would be experlient to make the best shelters, and to bring together all the breeding-ewes on the farm, if their number does not exceed four hundred. The shepherd would thus be saved much travel at all times, and particularly at the lambing-time, and each flock would be under his almost constant supervision.

The size of this barn is a question to be determined entirely by the climate. For large flocks of sheep, the storage of some hay or other fodder for winter is an indispensable precautionary measure, at least in any part of the United States; and, other things being equal, the farther north, or the more elerated the land, the greater would be the amount necessary to be stored.

HAY-HOLDER. There hay or other fodder is thrown out of the upper door of a barn into the sheep-yard-as it always must necessarily be in any mere hay-barn-or where it is thrown from a barrack or stack, the sheep immediately rush on it, trampling it and soiling it, and the succeeding forkfuls fall on their backs, filling their wool with dust seed, and chaff. 
This is obviated by hay-holders-yards ten feet squareeither portable, by being made of posts and boards, or simply a pen of rails, placed under the doors of the barns, and by the sides of each stack or barrack. The hay is pitched into this holder in fair weather, enough for a day's foddering at a time, and is taken from it by the fork and placed in the racks.

The poles or rails for stack-pens or hay-holders should be so small as to entirely prevent the sheep from inserting their heads in them after hay. A sheep will often insert his head where the opening is wide enough for that purpose, shove it along, or get crowded, to where the opening is not wide enough to withdraw the head, and it will hang there until observed and extricated by the shepherd. If, as often happens, it is thus caught when its foreparts are elevated by climbing up the side of the pen, it will continue to lose its footing in its struggles, and will soon choke to death.

\section{TAGGING.}

Tagging, or clatting, is the remoral from the sheep of such wool as is liable to get foulec when the animal is turned on to, the fresh pastures. If sheep are kept on dry feed through the winter, they will usually purge, more or less, when let out to green feed in the spring. The wool around and below the anus becomes saturated with lung, which forms into hard pellets, if the purging ceases. Whether this take place or not, the adhering dung cannot be removed from the wool in the ordinary process of washing; and it forms a great impediment in shearing, dulling and straining the shears to cut through it, when in a dry state, and it is often impracticable so to do. Besides, it is diffeult to force the shears between it and the 
skin, without frequently and sererely wounding the latter. Occasionally, too, flies deposit their eggs under this mass of filth prior to shearing; and the ensuing swarm of maggots, unless speedily discovered and removed, will lead the sheep to a miserable death.

Before the animals are let out to grass, each one should have the wool sheared from the roots of the tail down the inside of the thighs; it should likewise be sheared from off the entire bag of the ewe, that the newly-dropped lamb may more readily find the teat, and from the scrotum, and so much space round the point of the sheath of the ram as is usually lept wet. If the latter place is neglected, soreness and ulceration sometimes ensue from the constant maceration of the urine.

An assistant should catch the sheep and hold them while they are tagged. The latter process requires a good shearer, as the wool must be cut off closely and smoothly, or the object is but half accomplished, and the sheep will have un unsightly and ridiculous appearance when the remainder of their fleeces is taken off ; while, on the other hand, it is not only improper to cut the skin of a sheep at any time, but it is peculiarly so to cut that or the bag of a ewe when near lambing. The wool saved by tagging will far more than pay the expenses of the operation. It answers well for stockings and other domestic purposes, or it will sell for nearly half the price of fleece-wool.

Care should be exercised at all times in handling sheep, especially ewes heavy with lamb. It is highly injurious and unsafe to chase them about and handle them roughly; for, even if abortion, the worst consequence of such treatment, is avoided, they become timid and shy of being touched, render. 
ing it difficult to catch them or render them assistance at the lambing period, and even a matter of difficulty to enter the cotes, in which it is sometimes necessary to confine them at that time, without having them driving about pell-mell, runing over their lambs, etc. If a sheep is suddenly caught by the wool on her running, or is lifted by the wool, the skin is to a certain extent loosened from the body at the points where it is thus seized; and, if killed a day or two afterward, blood will be found settled about those parts.

When sheep are to be bandled, they should be inclosed in a yard just large enough to hold them without their being crowded, so that they shall have no chance to run and dash about. The catcher should stop them by seizing them by the hind-leg just above the hock, or by clapping one hand before the neck and the other behind the buttocks. Then, not waiting for the sheep to make a violent struggle, he should throw its right arm over and about immediately back of the shoulders, place his hand on the brisket, and lift the animal on his hip. If the sheep is very heavy, he can throw both arms around it, clasp his fingers under the brisket, and lift it up against the front part of his body. He should then set it carefully on its rump upon the tagging-table, which should be eighteen or twenty inches high, support its back with his legs, and hold it gently and conveniently until the tagger has performed his duty. Two men should not be allowed to lift the same sheep together, as it will be pretty sure to receive some strain between them. A good shearer and assistant will tag two hundred sheep per day.

When sheep receive green feed all the year round-as they do in many parts of the South-and no purging ensues from 
eating the newly-starting grasses in the spring, tagging is unnecessary.

\section{WASHING.}

Many judicious farmers object to washing sheep, on account of its tendency to produce colds and catarrhal affections, to which this animal is particularly subject; but it cannot well be dispensed with, as the wool is always rendered more salable; and if the operation is carefully done, it need not be attended with injury.

Mr. Randall, the extensive sheep-breeder of Texas, states that he does not wash his sheep at all, for what he deems good reasons. About the middle of April, or at the time when one-half of the ewes hare young lambs at their sides, and the balance about to drop, would be the only time in that region when he could wash them. At this period he would not race or worry his ewes at all, on any account; as they should be troubled as little as possible, and no advantage to the fleece from rashing could compensate for the injury to the animal. In his high mountain-region, lambing-time could not prudently come before the latter part of March or Aprilthe very period when washing and shearing must be commenced-since in February, and even up to the fifteenth or twentieth of March, there is much bad weather, and a single cold, rainy or slecty norther would carry off one-half of the lambs dropped during its continuance.

In most of that portion of the United States lying north of forty degrees, the washing is performed from the middle of May till the first of June, according to the season and climate. When the streams are hard, which is frequently the case in 
limestone regions, it is better to attend to it immediately after an abundant rain, which proportionately lessens the lime derived from the springs. The climate of the Southern States would admit of an earlier time. The rule should be to wait until the water has acquired sufficient warmth for bathing, and until cold rains and storms and cold nights are no longer to be expected.

The practice of a large majority of farmers is to drive their shcep to the watering-ground early in the morning, on a warm day, leaving the lambs belind. The sheep are confined on the bank of the stream by a temporary enclosure, from which they are taken, and, if not too heavy, carried into water sufficiently deep to prevent their touching bottom. They are then washed, by gently squeczing the fleece with the hands, after which they are led ashore, and as much of the water pressed out as possible before letting them go, as the great weight retained in the wool frequently staggers and throws them down.

By the best flock-masters, sheep are usually washed in vats. A small stream is dammed up, and the water taken from it in an aqueduct, formed by nailing boards together, and carried till a sufficient fall is obtained to have it pour down a couple of feet or more into the vat. The body of water, to do the work fast and well, should be some twenty-four inches wide, and five or six deep; and the swifter the current the better. The rat should be some three and a half feet deep, and large enough for four sheep to swim in it. A yard is built near the vat, from the gate of which a platform extends to and incloses the vat on three sides. This keeps the washer from standing in the water, and makes it much easier to lift the sheep in and out. The yard is built opposite the corners of two fields11 
to take advantage of the angle of one of them to drive the sheep more readily into the yard, which should be large enough to contain the entire flock, if it does not exceed two hundred; and the bottom of it, as well as the smaller yard,

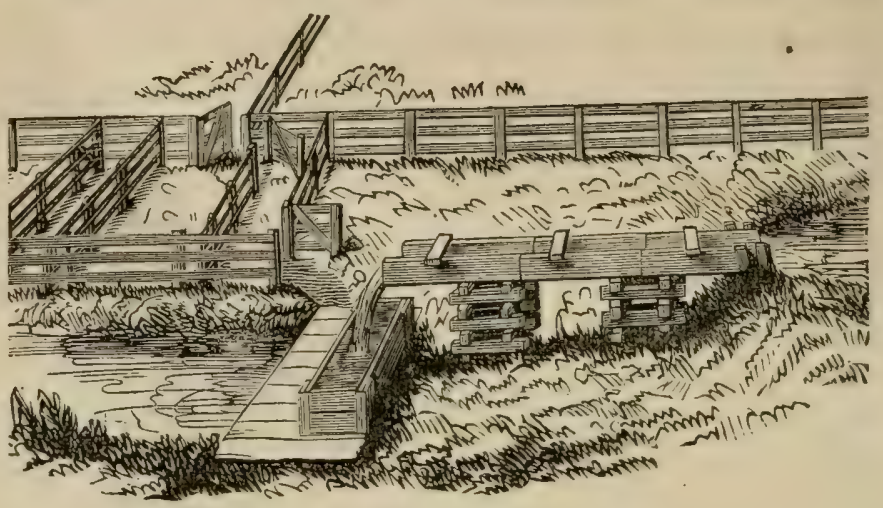

WASHING APPARATUS.

unless well sodded over, should be covered with coarse gravel, to aroid becoming muddy. If the same establishment is used by a number of flock-masters, gravelling will always be necessary.

As soon as the flocks are confined in the middle yard, the lambs are all immediately caught out from among them, and set over the fence into the yard to the left, to prevent their being trampled down, as often happens, by the old sheep, or straying off, if let loose. As many sheep are then driven out of the middle yard into the smaller yard to the right, as it will conveniently hold. A boy stands by the gate next to the rat, to open and shut it, or the gate is drawn together with a chain and weight, and two men, eatching the sheep as directed under the head of "tagging," commence placing them in the water 
for the preparatory process of "wetting." As soon as the water strikes through the wool, which occupies but an instant, the sheep is lifted out and let loose. Where there are conveniences for so doing, this process may be more readily performed by driving them through a stream deep enough to compel the sheep-to swim; but swimming the compact-fleeced, finewoolled sheep for any length of time-as is practised with the long-wools in England-will not properly cleanse the wool for steaming. The vat should, of course, be in an inclosed field, to prevent their escape. The whole flock should thus be passed over, and again driven round through the field into the middle yard, where they should stand for about an hour before washing commences.

There is a large per centage of potash in the wool oil, which acts upon the dirt independent of the favorable effect which would result from thys soaking it with water alone for some time. If washed soon after a good shower, previous wetting might be dispensed with; and it is not, perhaps, absolutely necessary in any case. If the water is warm enough to allow the sheep to remain in it for the requisite period, they may be got clean by washing without any previous wetting; though the snowy whiteness of fleece, which has such an influence on the purchaser, is not so often nor so perfectly attained in the latter way. But little time is saved by dispensing with "wetting," as it takes proportionably longer to wash, and it is not so well for the sheep to be kept so long in the water at once.

When the washing commences, two and sometimes four sheep are plunged in the vat. When four are put in, two soak while two are washed. This should not, however, be done, unless the water is very warm, and the washers are un- 
commonly quick and expert; and it is, upon the whole, rather an objectionable practice, since few animals suffer so much from the effects of a chill as the sheep; and, if they have been previously wetted, it is wholly unnecessary. When the sheep are in the water, the two washers commence kneading the wool with their hands about the dirtier parts-the breech, belly, etc. - and they continue to turn the sheep so that the descending current of water can strike into all parts of the fleece.

As soon as the sheep are clean, which may be known by the water running entirely clear, each washer seizes his own animal by the foreparts, plunges it deep in the vats, and, taking advantage of the rebound, lifts it out, setting it gently down on its breech upon the platform. He then-if the sheep is old and weak, and it is well in all cases-presses out some of the water from the wool, and after submitting the sheep to a process presently to be mentioned, lets it go.

There should be no mud about the vat, the earth not covered with sod, being gravelled. Sheep should be kept on clean pastures, from washing to shearing-not where they can come in contact with the ground, burnt logs, and the like-and they should not be driven over dusty roads. The washers should be strong and capable men, and, protected as they are from any thing but the water running orer the sides of the rat, they can labor several hours without inconvenience. Two hundred sheep will employ two experienced men not over half a day, and this rate is at times much exceeded.

It is a great object, not only as a matter of propriety and honesty, but even as an item of profit, to get the wool clean, and of a snowy whiteness, in which condition it will always 
sell for more than enough extra to offset the increased labor and the diminution in weight. The average loss in American Saxon wool in scouring, after being washed on the back, is estimated at thirty-sis per cent.; and in American Merino forty-two and a half per cent.

\section{CUTTING THE HOOFS.}

As the hoofs of fine-woolled sheep grow rapialy, turning up in front and under at the sides, they must be clipped as often as once a year, or they become unsightly, give an awkward, hobbling gait to the animal, and the part of the horn which turns under at the sides holds dirt or dung in constant contact with the soles, and even prevents it from being readily shaken or washed out of the cleft of the foot in the natural movement of the sheep about the pastures, as would take place were the hoof in its proper place. This greatly aggravates the hoofail, and renders the curing of it more difficult; and it is thought by many to be the exciting cause of the disease.

It is customary to elip the hoofs at tagging, or at or soon after the time of shearing. Some employ a chisel and mallet to shorten the hoofs; but the animal must afterward be turned upon its back, to pare off the crust which projects and turns under. If the weather be dry, or the sheep have stood for some time on dry straw, as at shearing, the hoofs are as tough as horn, and are cut with great difficulty; and this is increased by the grit and dirt adhering to the sole, which immediately takes the edge off from the knife. These periods are ill-chosen, and the method slow and bungling. It is particularly improper to submit heavily-pregnant ewes to all this unnecessary handling at the time of tagging. 
When the sheep is washed and lifted out of the vat, and placed on its rump upon the platform, the gate-keeper should advance with a pair of toe-nippers, and the washer present each foot separately, pressing the toes together so that they can

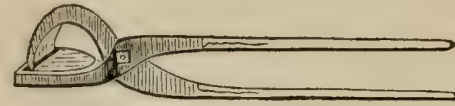

TOE-NIPPERS. be severed at a single clip. The nippers-which can be made by any blacksmith who can temper an axe or a chisel-must be made strong, with handles a little more than a foot long. the rivet being of balf-inch iron, and confined with a nut, so that they may be taken apart for sharpening. The cutting-edge should descend upon a strip of copper inserted in the iron, to prevent it from being dulled. With this powerful instrument, the largest hoofs are severed by a moderate compression of the hand. Two well-sharpened knives, which should be kept in a stand or box within reach, are then grasped by the washer and assistant, and with two dexterous strokes to each foot, the side-crust, being free from dirt, and soaked almost as soft as a cucumber, is reduced to the level of the sole. 'I'wo expert men will go through these processes in a very short space of time. The closer the paring and elipping the better, if blood be not drawn. An occasional sheep may require clipping again in the fall.

SHEARING.

The time which should elapse between washing and shearing depends altogether on circumstances. From four to six days of bright, warm weather is sufficient; if cold, or rainy, or cloudy, more time must intervene. Sometimes the wool remains in a condition unfit for shearing for a fortnight after 
washing. The rule to be observed is, that the water should be thoroughly dried out, and the natural oil of the wool should so far exude as to give the wool an unctious feeling, and a lively, glittering look. If it is sheared when dry, like cotton, and before the oil has exuded, it is very. difficult to thrust the shears through, the umer is checked, and the

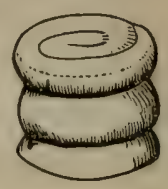

FLEECE. wool will not keep so well for long periods. If it is left until it gets too oily, either the manufacturer is cheated, or, what more frequently happens, the owner loses on the price.

Shearing, in this country, is always done on the threshingfloors of the barns-sometimes upon low platforms, some eighteen or twenty inches high, but more commonly on the floor itself. The place where the sheep remain should be well littered down with straw, and fresh straw thrown on occasionally, to keep the sheep clean while shearing. No chaff or other substance which will stick in the wool should be used for this purpose. The shearing should not commence until the dew, if any, has dried off from the sheep. All loose straws sticking to the wool should be picked off, and whatever dung may adhere to any of the feet brushed off. The floor or tables used should be planed or worn perfectly smooth, so that they will not hold dirt, or catch the wool. They should all be thoroughly cleaned, and, if necessary, washed, preparatory to the process. If there are any sheep in the pen dirty from purging, or other causes, they should first be caught out, to prevent them from contaminating others.

The manner of shearing varies with almost every district; and it is difficult, if not impossible, to give intelligible practical instructions, which would guide an entire novice in skilfully 
shearing a sheep. Practice is requisite. The following directions are as plain, perbaps, as can be made:

The shearer may place the sheep on that part of the floor assigned to him, resting on its rump, and himself in a posture with his right knee on a cushion, and the back of the animal resting against his left thigh. He grasps the shears about half-way from the point to the bow, resting his thumb along the blades, which gives him better command of the points. He may then commence cutting the wool at the brisket, and, proceeding downward, all upon the sides of the belly to the extremity of the ribs, the external sides of both sides to the edges of the flanks; then back to the brisket, and thence upward, shearing the wool from the breast, front, and both sides of the neck, but not yet the back of it, and also the poll, or forepart, and top of the bead. Then "the jacket is opened" of the sheep, and its position, as well as that of the shearer, is changed by the animal's being turned flat upon its side, one lnee of the shearer resting on the cushion, and the other genily pressing the fore-quarter of the animal, to prevent any struggling. He then resumes cutting upon the flank and rump, and thence onward to the head. Thus one side is complete. The sheep is then turned on the other side-in doing which great care is requisite to prevent the fleeces being tornand the shearer proceeds as upon the other, which finishes. He must then take the sheep near to the door through which it is to pass out, and neatly trim the legs, leaving not a solitary lock anywhere as a lodging-place for ticks. It is absolutely necessary for him to remove from his stand to trim, otherwise the useless stuff from the legs becomes intermingled with the. fleece-wool. In the use of the shears, the blades should be 
laid as flat to the skin as possible, the points not lowered too much, nor should more than from one to two inches be cut at a clip, and frequently not so much, depending on the part, and the compactness of the wool.

The wool should be cut off as close as conveniently practicable, and even. It may, indeed, be cut too close, so that the sheep can scarcely aroid sun-scald; but this is very unusual. If the wool is left in ridges, and uneven, it betrays a want of workmanship very distasteful to the really good farmer. Great care should be taken not to cut the wool twice in two, as inexperienced shearers are apt to do, since it is a great damage to the wool. This results from cutting too far from the points of the shears, and suffering them to get too elevated. In such cases, every time the shears are pushed forward, the wool before, cut off by the points, say a quarter or three-eighths of an inch from the hide, is again severed. To keep the fleece entire, which is of great importance to its good appearance when done up, and, therefore, to its salableness, it is very essential that the sheep be held easily for itself, so that it will not struggle violently. No man can hold it still by main strength, and shear it well. The posture of the shearer should be such that the sheep is actually confined to its position, so that it is unable to start up suddenly and tear its fleece; but it should not be confined there by severe pressure or force, or it will be continually kicking and struggling. Clumsy, careless men, therefore, always complain of getting the most troublesome sheep. The neek, for example, may be confined to the floor by placing it between the toe and knee of the leg on which the shearer kneels; but the lazy or brutal shearer who suffers his leg to rest directly on the neck, 
soon prorokes that struggle which the animal is obliged to make to free itself from severe pain, and even, perhaps, to draw its breath.

Good shearers will shear, on the average, twenty-five Merinos per day; but a new beginner should not attempt to exceed from one-third to one-half of that number. It is the last process in the world which should be hurried, as the shearer will, in that case, soon leave more than enough wool on his sheep to pay for his day's wages. Wool ought not to be sheared, and must not be done up with any water in it. If wounds. are made, as sometimes happens with unskilful operators, a mixture of tar and grease ought to be applied.

Shearing lambs is, in the Northern climate, at least, an unprofitable practice; since the lamb, at a year old, will give the same amount of wool, and it is thus stripped of its natural protection from cold when it is young and tender, for the mere pittance of the interest on a pound, or a pound and a half of wool for six months, not more than two or three cents, and this all consumed by the expense of shearing. Much the same may be said of the custom, which obtains in some places, of shearing from sheep twice a year. There may be a reason for it, where they receive so little care that a portion are expected to disappear every half year, and the wool to be torn from the backs of the remainder by bushes, thorns, etc., if left for a long period; but when sheep are inclosed, and treated as domestic animals, although there may be less barbarity in shearing them in the fall also, than in the case of the tender lambs, there is no ground for it on the score of utility; since any gain accruing from it cannot pay the additional expense which it occasions. 
COLD STORMs occurring soon after shearing sometimes destroy sheep, in the northern portions of the country, especially the delicate Saxons; forty or fifty of which have, at times, perished out of a single flock, from one night's exposure. Sheep, in such cases, should be housed; or, where this is impracticable, driven into dense forests.

Sun-SCALD. When they are sheared close in very hot weather, have no shade in their pastures, and especially where they are driven immediately considerable distances, or rapidly, over burning and dusty roads, their backs are sometimes so scorched by the sun that their wool comes off. If let alone, the matter is not a serious one; but the application of refuse lard to the back will hasten the cure, and the starting of the wool.

TICKs. These vermin, when very numerous, greatly annoy and enfeeble the sheep in winter, and should be kept entirely out of the flock. After shearing, the heat and cold, the rubbing and biting of the sheep, soon drive off the tick, and it takes refuge in the wool of the lamb. Let a fortnight elapse after shearing, to allow all to make this change of residence. Then boil refuse tobacco leaves until the decoction is strong enough to kill ticks beyond a peradrenture, which may be ascertained by experiment. Five or six pounds of cheap plug tobacco, or an equivalent in stems, and the like, may be made to answer for a hundred lambs.

This decoction is poured into a deep, narrow box, kept for the purpose, which has an inclined shelf on one side, covered with a wooden grate. One man holds the lamb by its hind legs, while another clasps the fore legs in one hand, and shuts the other about the nostrils, to prevent the liquid from enter. 
ing them, and then the animal is entirely immersed. It is then immediately lifted out, laid on one side upon the grate, and the water squeezed out of its wool, when it is turned over and squeezed on the other side. The grate conducts the fluid back into the box. If the lambs are regularly dipped every year, ticks will never trouble a flock.

\section{MARKING OR BRANDING.}

The sheep should be marked soon after shearing, or mistakes may occur. Every sheep-owner should be provided with a marking. instrument, which will stamp his initials, or some other distinctive mark, such as a small circle, an oval, a triangle, or a square, at a single stroke, and with uniformity, on the sheep. It is customary to have the mark cut out of a plate of thin iron, with an iron bandle terminating in wood; but one made by cutting a type, or raised letter, or character, on the end of a stick of light wood, such as pine or basswood, is found to be better. If the pigment used be thin, and the marker be thrust into it a little too deeply, as often happens, the surplus will not run off from the wood, as it does from a thin sheet of iron, to daub the sides of the sheep, and spoil the appearance of the mark; and, if the pigment be applied hot, the former will not get heated, like the latter, and increase the danger of burning the hide.

Various pigments are used for marking. Many boil tar until it assumes a glazed, hard consistency when cold, and give it a brilliant, black color by stirring in a little lamp-black during the boiling. This is applied when just cold enough not to burn the sheep's hide, and it forms a bright, conspicuous mark all the year round. The manufacturer, however, prefers 
the substitution of oil and turpentine for tar, as the latter is cleansed out of the wool with some difficulty. It should be boiled in an iron ressel, with high sides, to prevent it from taking fire, on a small furnace or chafing-dish near which it is to be used. When cool enough, forty or fifty sheep can be marked before it gets too stiff. It is then warmed from time to time, as necessary, on the chafing-dish. Paint, made of lampblack, to which a little spirits of turpentine is first added, and then diluted with linseed or lard oil, is also used. The rump is a better place to mark than the side, since it is there about as conspicuous under any circumstances, and more so when the sheep are huddled in a pen, or running away from one. Besides, should any wool be injured by the mark, that on the rump is less valuable than that on the side. Ewes are commonly distinguished from wethers by marking them on different sides of the rump.

Many mark each sheep as it is discharged from the barn by the shearer; but it consumes much less time to do it at a single job, after the shearing is completed; and it is necessary to take the latter course if a hot pigment is used.

MAGgots. Rams with horns growing closely to their heads are very liable to have maggots generated under them, particularly if the skin on the surrounding parts becomes broken by fighting; and these, unless removed, soon destroy the animal. Boiled tar, or the marking substance first described, is both remedy and preventive. If it is put under the horns at the time of marking, no trouble will ever arise from this cause.

Sometimes when a sheep scours in warm weather, and clotted dung adheres about the anus, maggots are generated 
under it, and the sheep perishes miserably. As a preventive, the dung should be removed; as a remedy, the dung and maggots should be removed-the latter by touching them with a little turpentine-and sulphur and grease afterward applied to the excoriated surface.

Maggot-flies sometimes deposit their eggs on the backs of the long, open-woolled English sheep, and the maggots, during the few days before they assume the pupa state, so tcase and irritate the animal, that fever and death ensue. Tar and turpentine, or butter and sulphur, smeared over the parts, are admirable preventives. The Merino and Saxon are exempt from these attacks.

Shortening tule Horns. A convolution of the horn of a ram sometimes so presses in upon the side of the head or neck that it is necessary to shave or rasp it away ou the under side, to prevent ultimately fatal effects. The point of the horn of both ram and ewe both frequently turn in so that they will grow into the flesh, and sometimes into the eye, unless shortened. The toe-nippers will often suffee on the thin extremity of a horn; if not, a fine saw must be used. The marking-time affords the best opportunity for attending to this operation.

\section{SELECTION AND DIVISION.}

The necessity of annually weeding the flock, by excluding all its members falling below a certain standard of quality, and the points which should be regarded in fixing that standard, have already been brought to notice in connection with the principles of breeding.

The time of shearing is by far the most farorable period for 
the flock-master to make his selection. Me should be present on the shearing-floor, and inspect the fleece of every sheep as it is gradually taken off; since, if there are faults about it, he will then discorer it better than at any other time. A glance will likewise reveal to him every defect in form, preriously concealed, wholly, or in part, by the wool, as soon as the newly-shorn sheep is permitted to stand up on its feet. A remarkably choice ewe is frequently retained until she dies of old age; a rather poor nurse or breeder is excluded for the slightest fault, and so on. Whatever animals are to be excluded, may be marked on the shoulder with Venetian red and hog's lard, conveniently applied with a brush or cob. Such of the wethers as have attained their prime, and those ewes that have passed it, should be provided with the best feed, and fitted for the butcher. If they have been properly pushed on grass, they will be in good flesh by the time they are taken from it; and, if not intended for stall-feeding, the sooner they are then disposed of the better.

Those divisions, also, in large flocks, which utility demands, are generally made at or soon after shearing. Not more than two hundred sheep should be allowed to run together in the pastures; although the number might, perhaps, be safely, increased to three hundred, if the range is extensive.

Wethers and dry ewes to be turned off should be kept separate from the nursing-ewes; and if the flock is large enough to require a third division, it is customary to put the yearling and two-year-old ewes and wethers, and the old, feeble sheep together. It is better, in all cases, to separate the rams from all the other sheep at the time of shearing, and to inclose them in a field which is particularly well-fenced. If 
they are put even with wethers, they are more quarrelsome; and when cool nights arrive, will worry themselves and waste their flesh in constant efforts to ride the wethers.

The Merino ram, although a quiet animal compared with the common-woolled one, will be tempted to jump, by poor fences, or fences half the time down; and if he is once taught this trick, he becomes very troublesome as the rutting period approaches, unless hoppling, roking, clogging, or poking is resorted to, either of which causes him to waste his strength, besides being the occasion of frequent accidents.

\section{THE CROOK.}

This convenient implement for catching sheep is of the form represcnted in the cut accompanying, of three-eighths inch

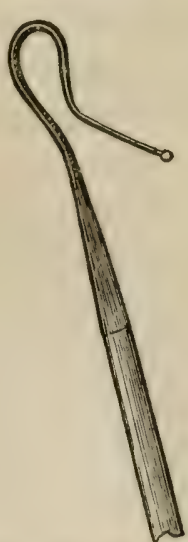

GHEPHERD'G CROOK. round iron, drawn smaller toward the point, which is made safe by a lnot. The other end is furnished with a socket, which receives a bandle six or eight feet long.

In using it, the hind leg is hooked in from behind the sheep, and it fills up the narrow part beyond that point, while passing along it until it reaches the loop, when the animal is caught by the hook, and when secured, its foot easily slips through the loop. Some caution is required in its use; for, should the animal give a sudden start forward to get awry, the moment it feels the crook, the leg will be drawn forcibly tbrough the narrow part, and strilic the bone with such violence against the bend of the loop as to cause the animal considerable pain, and even occasion 
iameness for some days. On first embracing the leg, the crook should be drawn quickly toward the shepherd, so as to bring the bend of the loop against the leg as high up as the hock, before the sheep has time even to break off; and being secure, its struggles will cease the moment the hand seizes the leg.

No shepherd should be without this implement, as it saves much yaiding and running, and leads to a prompt examination of every improper or suspicious appearance, and a seasonable application of remedy or preventive, which would often be deferred if the whole flock had to be driven to a distant yard to effect the catching of a single sheep.

Dexterity in its use is speedily acquired by any one; and if a flock are properly tame, any one of its number can be readily caught by it at salting-time, or, generally, at other times, by a person with whom the flock are familiar. It is, howerer, at the lambing-time, when sheep and lambs require to be so repeatedly caught, that the crook is more particularly serviceable. For this purpose, at that time alone, it will pay for itself ten times over in a single season, in saving time, to say nothing of the advantage of the sheep.

\section{DRIVING AND SLAUGHTERING.}

Driving. Mutton can be grown cheaper than any other kind of meat. It is fast becoming better appreciated; and, strange as it may seem, good mutton brings a higher price in our best markets than the same quality does in England. Its substitution in a large measure for pork would contribute materially to the health of the community.

Winter fattening of sheep may often be made very profitable 12 
and deserves greater attention, especially where manure is an object; and the instances are few, indeed, where it is not. In England, it is considered good policy to fatten sheep, if the increase of weight will pay for the oil-cake or grain consumed; the manure being deemed a fair equivalent for the other foodthat is, as much straw and turnips as they will eat. Lean sheep there usually command as high a price per pound in the fall as fatted ones in the spring; while, in this country, the latter usually bear a much higher price, which gives the feeder a great advantage.

The difference may be best illustrated by a simple calculation. Suppose a wether of a good mutton brecd, weighing eighty pounds in the fall, to cost six cents per pound, amounting to four dollars and eighty cents, and to require twenty pounds of hay per week, or its equivalent in other food, and to gain a pound and a half each week; the gain in weight in four months would be about twenty-five pounds, which, at six cents per pound, would be one dollar and fifty cents, or less than ten dollars per ton for the hay consumed; but if the same sheep could be bought in the fall for three cents per pound, and sold in the spring for six cents, the gain would amount to three dollars and ninety cents, or upwards of twenty dollars per ton for the hay-the manure being the same in either case.

For fattening, it is well to purchase animals as large and thrifty, and in as good condition as can be had at fair prices; and to feed liberally, so as to secure the most rapid increase that can be had without waste of food. The fattening of sheep by the aid of oil-cake, or grain purchased for the purpose, may often be made a cheaper mode of obtaining manure than by 
the purchase of artificial fertilizers, as guano, super-phosphate of lime, and the like; and it is altogether preferable. It is practised extensively and advantageously abroad, and deserves at least a fair trial among us.

Sheep which are to be driven to market should not begin their journey either when too full or too hungry; in the former state, they are a pt to purge while on the road, and in the latter, they will. los e strength at once. The sheep selected for market should be those in best condition at the time; and to ascertain this, it is necessary to examine the whole lot, and separate the fattest from the rest, which is best

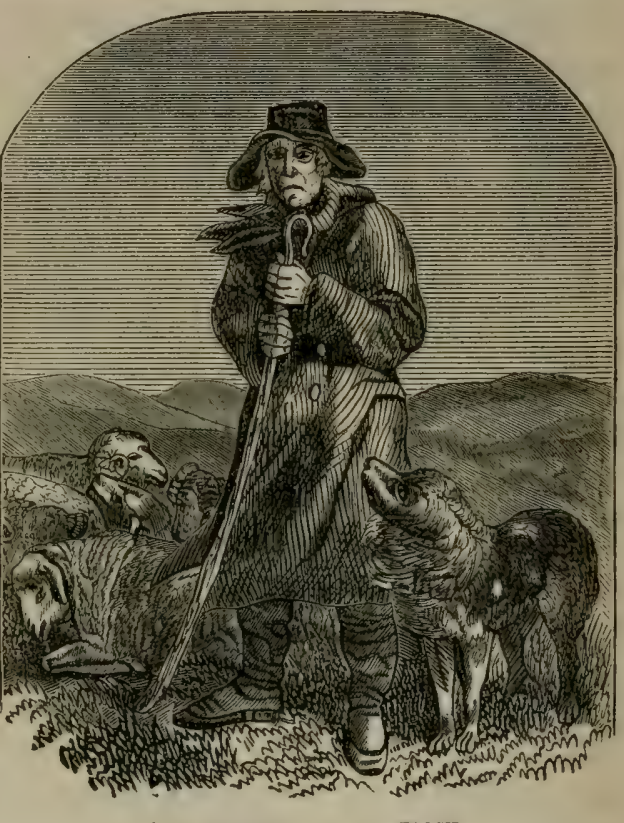

THE SHEPHERD AND FIS FLOCK.

done at about mid-day, before the sheep feed again in the afternoon. The selected ones are placed in a field by themselves, where they remain until the time for starting. If there be rough pasture to give them, they should be allowed to use it, in order to rid themselves of some of the food which might be productive of inconvenience on the journey. If there is no 
such pasture, a few cut turnips will answer. All their hoofs should be carefully examined, and every unuecessary appendage removed, though the firm portion of the horn should not be touched. Every clotted piece of wool shouid also be removed with the shears, and the animals properly marked.

Being thus prepared, they should have feed early in the morning, and be started, in the cold season, about mid-day. Let them walk quietly away; and as the road is new to them, they will go too fast at first, to prevent which, the drover should go before them, and let his dog bring up the rear. In a short time they will assume the proper speed-about one mile an hour. Should the road they travel be a green one, they will proceed nibbling their way onward at the grass along both sides; but if it is a narrow turnpike, the drover will require all his attention in meeting and being passed by various vehicles, to aroid injury to his charge. In this part of their business, drovers generally make too much ado; and the consequence is, that the sheep are driven more from side to side of the road than is requisite. Upon meeting a carriage, it would be much better for the sheep, were the drover to go forward, instead of sending his dog, and point off with his stick the leading sheep to the nearest side of the road; and the rest will follow, as a matter of course, while the dog walks behind the flock and brings up the stragglers. Open gates to fields are sources of great annoyance to drovers, the stock invariably making an endeavor to go through them. On observing an open gate alead, the drover should send his dog* behind him over the fence, to be ready to meet the sheep at the gate. When the sheep incline to rest, they should be allowed to lie down. 
When the animals are lodged for the night, a few turnips or a little hay should be furnished to them, if the road-sides are bare. If these are placed near the gate of the field which they occupy, they will be ready to take the road again in the morning. As a precaution against worrying dogs, the drover should go frequently through the flock with a light, retire to rest late, and rise up early in the morning. These precautions are necessary ; since, when sheep have once been disturbed by dogs, they will not settle again upon the road. The first day's journey should be a short one, not exceeding four or fire miles. The whole journey should be so marked out as that, allowance being made for unforeseen delays, the animals may have one day's rest near the market.

Points of Fat silerp. The formation of fat, in a sheep destined to be fattence, commences in the inside, the web of fat which envelopes the intestines being first formed, and a little deposited around the kidneys. After that, fat is seen on the outside; and first upon the end of the rump at the tailhead, continuing to move on along the back, on both sides of the spine, or back-bone, to the bend of the ribs to the neck. Then it is deposited between the muscles, parallel with the cellular tissue. Meanwhile, it is covering the lower round of the ribs descending to the flanks, until the two sides meet under the belly, whence it proceeds to the brisket, or breast, in front, and the sham or cod behind, filling up the inside of the arm-pits and thighs. While all these depositions are proceeding on the outside, the progress in the inside is not checked, but rather increased, by the fattening disposition encouraged by the acquired condition; and, hence, simultaneously, the kidneys become entirely covered, and the space 
between the intestines and the lumbar region, or loin, gradually filled up by the web and kidney fat.

By this time the cellular spaces around each fibre of muscle are receiving their share; and when fat is deposited there in quantity, it gives to the meat the term marbled. These interfibrous are the last to receive a deposition of fat; but after this has begun, every other part at the same time receives its due share, the back and kidneys securing the most, so much so that the former literally becomes nicked, as it is termedthat is, the fat is felt through the skin to be divided into two portions, from the tail-head along the back to the top of the shoulder; and the tail becoming thick and stiff, the top of the neck broad, the lower part of each side of the neck toward the breasts full, and the hollows between the breast-bone and the inside of the fore legs, and between the cod and the inside of the hind thighs, filled up. When all this has been accomplished, the sbeep is said to be fat, or ripe.

When the body of a fat sheep is entirely orerlaid with fat, it is in the most valuable state as mutton. Few sheep, however, lay on fat entirely over their body; one laying the largest proportion on the rump, another on the back; one on the parts adjoining the fore-quarter, another on those of the hindquarter; and one more on the inside, and another more on the outside. Taking so many parts, and combining any two or more of them together, a considerable variety of condition will be found in any lot of fat sheep, while any one is as ripe in its way as any other.

With these data for guides, the state of a sheep in its progress toward ripeness may be readily detected by handling. A fat sheep, however, is easily known by the eye, from the 
fullness exhibited by all the external parts of the particular animal. It may exhibit want in some parts when compared with others; but those parts, it may easily be seen, would never become so ripe as the others; and this arises from some constitutional defect in the animal itself; since, if this were so, there is no reason why all the parts should not be alike ripe. The state of a sheep that is obviously not ripe cannot altogether be ascertained by the eye. It must be handled, or subjected to the scrutiny of the hand. Even in so palpable an act as handling, discretion is requisite. A full-looking sheep needs hardly to be handled on the rump; for he would not seem so full, unless fat had first been deposited there. A thin-looking sheep, on the other hand, should be handled on the rump; and if there be no fat there, it is useless to handle the rest of the body, for certainly there will not be so much as to deserve the name of fat. Between these tro extremes of condition, every variety exists; and on that account examination by the hand is the rule, and by the eye alone the exception. The hand is, however, much assisted by the eye, whose acuteness detects deficiencies and redundancies at once.

In handling sheep, the points of the fingers are chiefly employed; and the accurate knowledge conveyed by them, through practice, of the exact state of the condition, is truly surprising, and establishes a convietion in the mind that some intimate relation exists between the external and internal state of an animal. Hence originates this practical maxim in judging stock of all kinds-that no animal will appear ripe to the eye, unless as much fat had previously been acquired in the inside as constitutional habit will allow.

The application of this rule is easy. When the rump is 
found nicked, on bandling, fat is to be found on the back; when the back is found nicked, fat is to be expected on the top of the shoulder and over the ribs; and when the top of the shoulder proves to be nicked, fat may be anticipated on the under side of the belly. To ascertain its existence below, the animal must be turned $u p$, as it is termed; that is, the sheep is set upon his rump, with his back down, and his hind feet pointing upward and outward. In this position, it can be seen whether the breast and thighs are filled up. Still, all these alone would not disclose the state of the inside of the sheep, which should, moreover, be looked for in the thickness of the flank; in the fullness of the breast, that is, the space in front from shoulder to shoulder toward the neck; in the stiffness and thickness of the root of the tail; and in the breadth of the back of the neck. All these latter parts, especially with the fullness of the inside of the thighs, indicate a fullness of fat in the inside; that is, largeness of the mass of fat on the kidneys, thickness of net, and thickness of layers between the abdominal muscles. Hence, the whole object of feeding sheep on turnips and the like seems to be to lay fat upon all the bundles of fleshy fibres, called muscles, that are capable of acquiring that substance; for, as to bone and muscle, these increase in weight and extent independently of fat, and fat only increases in their magnitude.

Slacartering. Sheep are easily slaughterei, and the operation is unattended with eruelty. They require some preparation before being deprired of life, which consists in food being withheld from them for not less than twenty-four hours, according to the season. The reason for fasting sheep before slaughtering is to give time for the paunch and intestines 
to empty themselvas entirely of food, as it is found that, when an animal is killed with a full stomach, the meat is more liable to putrefy, and is not so well flavored; and, as ruminating animals always retain a large quantity of food in their intestines, it is reasonable that they should fast somewhat longer to get rid of it, than animals with single - stomachs.

Sheep are placed on their side-sometimes upon a stool, called a killingstool-to be slaughtered, and, requiring no fastening with cords, are deprived of life by the use of a straight knife through the neck,

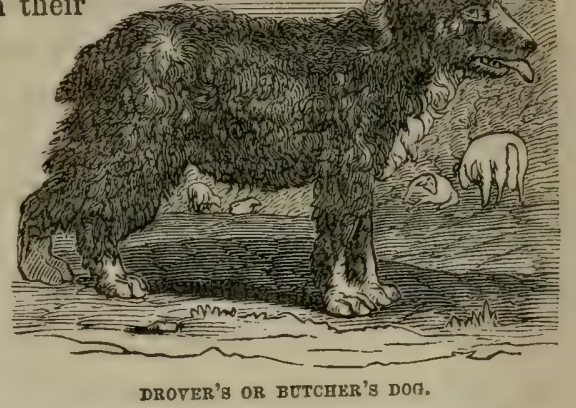
between its bone and the windpipe, severing the carotid artery and the jugular vein of both sides, from which the blood flows freely out, and the animal soon dies.

The skin, as far as it is corered with wool, is taken off, leaving that on the leg's and head, which are covered with hair, the legs being disjointed by the knee. The entrails are removed by an incision along the belly, after the carcass has been hung up by the tendons of the houghs. The net is carefully separated from the viscera, and rolled up by itself; but the kidney fat is not then extracted. The intestines are placed on the inner side of the skin until divided into the pluck, containing the heart, lungs, and liver; the bag, containing the stomach; and the puddings, consisting of the 
viscera, or guts. The latter are usually thrown away; though the Scotch, however, clean them and work them up into their favorite haggis. The skin is hung over a rope or pole under cover, with the skin-side uppermost, to dry in an airy place.

The carcass should hang twenty-four hours in a clean, cool, airy, dry apartment before it is cut down. It should be cool and dry; for, if warm, the meat will not become firm; and, if damp, a clamminess will cover it, and it will never feel dry, and present a fresh, clean appearance. The carcass is divided in two, by being sawed right down the back-bone. The kidney-fat is then taken out, being only attached to the peritoneum by the cellular membrane, and the kidney is extracted from the suet, the name given to sheep-tallow in an independent state.

Cutring up. Of the two modes of cutting up a carcass of mutton, the English and the Scotch-of the former, the practice in London being taken as the standard, and of the latter, that of Edinburgh, since more care is exercised in this respect in these two cities-the English is, perhaps, preferable; although the Scotch accomplish the task in a cleanly and workmanlike manner.

The jigot is the most handsome and valuable part of the carcass, bringing the highest price, and is either a roasting or a boiling piece. A jigot of Leicester, Cheviot, or South-Down mutton makes a beautiful boiled leg of mutton, which is prized the more the fatter it is-this part of the carcass being never overloaded with fat. The loin is almost always roasted, the flap of the flank being skewered up, and it is a juicy piece. Many consider this piece of Leicester mutton, roasted, as too rich; and when warm this is, probably, the case; but a cold 
roast loin is an excellent summer dish. The back-rib is divided into two, and used for very different purposes. The forepart-the neck-is boiled, and makes sweet barely-broth; and the meat, when boiled, or rather the whole simmered for a considerable time beside the fire, eats tenderly. The backribs make an excellent roast; indeed, there is not a sweeter or more varied one in the whole carcass, having both ribs and shoulder. The shoulder-blade eats best cold, and the ribs, warm. The ribs make excellent chops, the Leicester and South-Down affording the best. The breast is mostly a roasting-piece, consisting of rib and shoulder, and is particularly good when cold. When the piece is large, as of the SouthDown or Cheviot, the gristly parts of the ribs may be divided from the true ribs, and helped scparately. This piece also boils well; or, when corned for eight days, and served with onion sauce, with mashed turnips in it, there are few more savory dishes at a farmer's table. The shoulder is separated before being dressed, and makes an excellent roast for ramily use, being eaten warm or cold, or carved and dressed as the breast mentioned above. The shoulder is best from a large carcass of South-Down, Cheviot, or Leicester. The neck-piece is partly laid bare by the removal of the shoulder, the forepart being fitted for boiling and making into broth, and the best part for roasting or broiling into chops. On this account, it is a good family piece, and generally preferred to any part of the hind-quarter. Heary sheep, such as the Leicester, South-Down, and Cheviot, supply the most thrifty neck-piece.

Relative Qualities. The different sorts of mutton in common use differ as well in quality as in quantity. The flesh of the Leicester is large, though not coarse-grained, of a 
lively red color, and the cellular tissue between the fibres contains a considerable quantity of fat. When cooked, it is tender and juicy, yielding a red gravy, and having a sweet, rich taste; but the fat is rather too much and too rich for some people's tastes, and can be put aside. It must be allowed that the lean of fat meat is far better than lean meat that has never been fat. Cheviot mutton is smaller in the grain, not so bright of color, with less fat, less juice, not so tender and sweet; but the flavor is higher, and the fat not so luscious. The mutton of South-Downs is of medium fineness in grain, color pleasant red, fat well intermixed with the meat, juicy, and tenderer than Cheviot. The mutton of rams of any breed is always hard, of disagreeable flavor, and, in autumn, not eatable ; that of old ewes is dry, hard, and tasteless; of young ones, well enough flavored, but still rather dry; while wethermutton is the meat in perfection, according to its kind.

The want of relish, perhaps the distaste, for mutton has served as an obstacle to the extension of sheep husbandry in the United States. The common mistake in the management of mutton among us is, that it is eaten, as a general thing, at exactly the wrong time after it is killed. It should be eaten immediately after being killed, and, if possible, before the meat has time to get cold; or, if not, then it should be kept a week or more-in the ice-house, if the weather require-until the time is just at hand when the fibre passes the state of toughness which it takes on at first, and reaches that incipient or preliminary point in its process toward putrefaction when the fibres begin to gire way, and the meat becomes tender.

An opinion likewise generally prevails that mutton does not attain perfection in juiciness and flavor much under five years. 
If this be so, that breed of sheep must be very unprofitable which takes five years to attain its full state; and there is no breed of sheep in this country which requires five years to bring it to perfection. This being the case, it must be folly to restrain sheep from coming to perfection until they have reached that age. Lovers of five-year-old mutton do not pretend that this course bestows profit on the farmer, but only insist on its being best at that age. Were this the fact, one of two absurd conditions must exist in this department of agriculture : namely, the keeping a breed of sheep that cannot, or that should not be allowed to, attain to perfection before it is five years old; either of which conditions makes it obrious that mutton cannot be in its best state at five years.

The truth is, the idea of mutton of this age being especially excellent, is founded on a prejudice, arising, probably, from this circumstance: before winter food was discovered, which could maintain the condition of stock which had been acquired in summer, sheep lost much of their summer condition in winter, and, of course, an oscillation of condition occurred, year after year, until they attained the age of fire years; when their teeth beginning to fail, would cause them to lose their condition the more rapidly. Hence, it was expedient to slaughter them at not exceeding five years of age; and, no doubt, mutton would be high-flavored at that age, that had been exclusively fed on natural pasture and natural hay. Such treatment of sheep cannot, however, be justified on the principles of modern practice; because both reason and taste concur in mutton being at its best whenever sheep attain their perfect state of growth and condition, not their largest and heaviest; and as one breed attains its perfect state at an earlier 
age than another, its mutton attains its best before another breed attains what is its best state, although its sheep may be older; but taste alone prefers one kind of mutton to another, even when both are in their best state, from some peculiar property. The cry for five-year-old mutton is thus based on rery untenable grounds; the truth being that well-fed and fatted mutton is never better than when it gets its full growth in its second year; and the farmer cannot afford to keep it longer, unless the wool would pay for the keep, since we have not the epicures and men of wealth who would pay the butcher the extra price, which he must have, to enable him to pay a remunerating price to the grazier for keeping his sheep two or three years over.

All writers on diet agree in describing mutton as the most valuable of the articles of human food. Pork may be more stimulating, beef perhaps more nutritious, when the digestive powers are strong; but, while there is in mutton sufficient nutriment, there is also that degree of consistency and readiness of assimilation which renders it most congenial to the human stomach, most easy of digestion, and most promotive of human health. Of it, almost alone, can it be said that it is our food in sickness, as well as in health; its broth is the first thing, generally, that an invalid is permitted to taste, the first thing that he relishes, and is a natural preparation for his return to his natural aliment. In the same circumstances, it appears that fresh mutton, broiled or boiled, requires three hours for digestion; fresh mutton, roasted, three and onefourth Lours; and mutton-suet, boiled, four and one-half hours.

Good ham may be marle of any part of a carcass of mutton, though the leg is preferable; and for this purpose it is cut in 
the English fashion. It should be rubbed all over with good salt, and a little saltpetre, for ten minutes, and then laid in a dish and covered with a cloth for eight or ten days. After that, it should be slightly rubbed again, for about five minutes, and then hung up in a dry place, say the roof of the kitchen, until used. Wether mutton is used for hams, because it is fat, and it may be cured any time from November to MIay; but ram-mutton makes the largest and highest-flavored ham, provided it be cured in spring, because it is out of season in autumn.

There is an infallible rule for ascertaining the age of mutton by certain marks on the carcass. Observe the color of the breast-bone, when a sheep is dressed-that is, where the breast-bone is separated-which, in a lamb, or before it is one year old, will be quite red; from one to two years old, the upper and lower bone will be changing to white, and a small circle of white will appear round the edges of the other bones, and the middle part of the breast-bone will yet continue red; at three years old, a very small streak of red will be seen in the middle of the four middle bones, and the others will be white; and at four years, all the breast-bone will be of a white or gristly color.

Contributions to manUfactures. The products of sheep are not merely useful to man; they provide his luxuries as well. The skin of sheep is made into leather, and, when so manufactured with the fleece on, makes comfortable mats for the doors of rooms, and rugs for carriages. For this purpose, the best skins are selected, and such as are covered with the longest and most beautiful fleece. Tanned sheep-skin is used in coarse book-binding. White sheep-skin, which is not 
tanned, but so manufactured by a peculiar process, is used as aprons by many classes of workmen, and, in agriculture, as gloves in the harvest; and, when cut into strips, as twine for sewing together the leather coverings and stuffings of horsecollars. Morocco leather is made of sheep-skins, as well as of goat-skins, and the bright red color is given to it by cochineal. Russia leather is also made of sheep-skins, the peculiar odor of which repels insects from its vicinity, and resists the mould arising from damp, the odor being imparted to it in currying, by the empyreumatic oil of the bark of the birch-tree. Besides soft leather, sheep-skins are made into a fine, flexible, thin substance, known by the name of parchment; and, though the skins of all animals might be converted into writing materials, only those of the sheep and the she-goat are used for parchment. The finer quality of the substance, called vellum, is made of the skins of kids and dead-born lambs; and for its manufacture the town of Strasburgh has long been celebrated.

Mutton-suet is used in the manufacture of common candles, with a proportion of ox-tallow. Minced suet, subjected to the action of high-pressure steam in a digester, at two hundred and fifty or two hundred and sixty degrees of Fahrenheit, becomes so hard as to be sonorous when struck, whiter, and capable, when made into candles, of giving very superior light. Stearic candles, the invention of the celebrated Guy Lussac, are manufactured solely from mutton-suet.

Besides the fat, the intestines of sheep are manufactured into various articles of luxury and utility, which pass under the absurd name of catgut. All the intestines of sheep are composed of four layers, as in the horse and cattle. The outer, or peritoneal one, is formed of that membrane, by which 
erers portion of the belly and its contents is invested, and confined in its natural and proper situation. It is highly smouth and polished, and secretes a watery fluid which contributes to preserve that smoothness, and to prevent all friction and concussion during the different motions of the animal. The second is the muscular coat, by means of which the contents of the intestines are gradually propelled from the stomach to the rectum, thence to be expelled when all the useful nutriment is extracted. The muscles, as in all the other intestines, are disposed in two layers, the fibres of the outer coat taking a longitudinal direction, and the inner layer licing circular-an arrangement different from that of the inuscles of the œsophagus, and in both beautifully adapted to the respective functions of the tube. The submucous coat comes next. It is composed of numerous glands, surrounded by cellular tissue, and by which the inner coat is lubricated, so that there may be no obstruction to the passage of the food. The mucous coat is the soft villous one lining the intestinal cavity. In its healthy state, it is always covered with mucus; and when the glands beneath are stimulated, as under the action of physic, the quantity of mucus is increased; it becomes of a more watery character; the contents of the intestines are softened and dissolved by it; and by means of the increascd action of the muscular coat, which, as well as the mucous one, feels the stimulus of the physic, the foces are hurried on more rapidly and discharged.

In the manufacture of some sorts of cords from the intestines of sheep, the outer peritoneal coat is taken off and manufactured into a thread to sew intestines, and make the cords of rackets and battledores. Future washings cleanse the guts, which 13 
are then twisted into cifferent-sized corts for rarious purposes; some of the best known of which ale whip-curds, hatter's cords for bow-strings, clock-maker's cords, bauds for spinning-wheels, now almost obsolete, and fiddle and harp-strings. Of the last class, the cords manufactured in Italy are superior in gooduess and strength; and the reason assigned is, that the sheep of that country are both smaller and leaner than the breeds most in rogue in England and in this country. The difficulty in manufacturing from other breeds of sheep lies, it seems, in making the treble strings from the fine peritoneal coat, their chief fault being weakness; by reason of which the smaller ones are hardly able to bear the stretch required for the higher notes in concert-pitch, maintaining, at the same time, in their form and construction, that tenuity or smallness of diameter which is required in order to produce a brilliant and clear tone. 


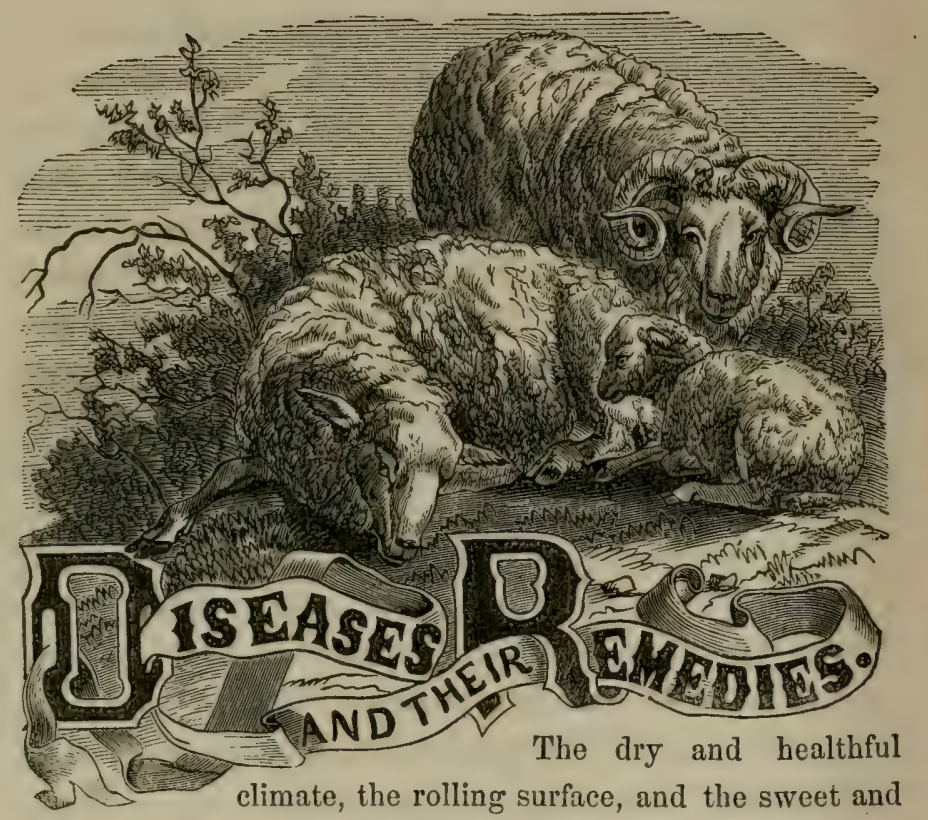
varied herbage, which generally prevail in the United States, insure perfect health to an originally sound and well-selected flock, unless they are peculiarly exposed to disease. No country is better suited to sheep than most of the Northern and some of the Southern portions of our own. In Europe, and especially in England, where the system of management is, necessarily, in the highest degree artificial, consisting, frequently, in an early and continued forcing of the system, folding on wet, ploughed ground, and the excessire use of that watery food, the Swedish turnip, there are numerous and 195 
fatal diseases, a long list of which invariably cumbers the pages of foreign writers on this animal.

The diseases incident to our flocks, on the contrary, may generally be considered as casualties, rather than as inbred, or necessarily arising from the quality of food, or from local causes. It may be safely asserted that, with a dry pasture, well stocked with varied and nutritious grasses; a clear, running stream; sufficient shade and protection against severe storms ; a constant supply of salt, tar, and sulphur in summer; good hay, and sometimes roots, with ample shelters in winter -young sheep, originally sound and healthy, will seldom or never become diseased on American soil.

The comparatively few diseases, which it may be necessary here to mention, are arranged in alphabetical order-as in the author"s "Cattle and their Diseases"-for convenience of reference, and treated in the simplest manner. Remedies of general application, to be administered often by the unskilful and ignorant, must neither be elaborate nor complicated; and, if expensive, the lives of most sheep would be dearly purchased by their application.

$\Lambda$ sheep, which has been reared or purchased at the ordinary price, is the only domestic animal which can die without material loss to its owner. The wool and felt will, in most instances, repay its cost, while the carcass of other animals will be worthless, except for manure. The loss of sheep, from occasional discase, will leave the farmer's pocket in a very different condition from the loss of an equal value in horses or cattle. Humanity, however, alike with interest, dictates the use of such simple remedies, for the removal of suffering and disease, as may be within reach. 


\section{ADMINISTERING MEDICINE.}

The stomach into which medicines are to be administered is the fourth, or digesting stomach. The comparatively insensible walls of the rumen, or paunch, are but slightly acted upon, except by doses of very improper magnitude. Medicine, to reach the fourth stomach, should be given in a state as nearly approaching fluidity as may be. Even then it may be given in such a manner as to defeat the object in view.

If the animal forcibly gulps fluids down, or if they, are given hastily and bodily, they will follow the caul at the base of the gullet with considerable momentum, force asunder the pillars, and enter the rumen; if they are drunk more slowly, or administered gently, they will trickle down the throat, glide over these pillars, and pass on through the maniplus to the true stomach.

\section{BLEEDING.}

Bleeding from the ears or tail, as is commonly practised, rarely extracts a quantity of blood sufficient to do any good where bleeding is indicated. To bleed from the eye-vein, the point of a knife is usually inserted near the lower extremity of the pouch below the eye, pressed down, and then a cut made inward toward the middle of the face.

Bleeding from the angular or cheek-vein is recommended, in the lower part of the cheek, at the spot where the root of the fourth tooth is placed, which is the thickest part of the cheek, and is marked on the external surface of the bone of the upper jaw by a tubercle, sufficiently prominent to be very sensible to the finger when the slin of the cheek is touched. This 
tubercle is a certain index to the angular vein, which is placed below. The shepherd takes the sheep between his legs; his left hand more advanced than his right, which be places under the head, and grasps the under jaw near to the hinder extremity, in order to press the angular vein, which passes in that place, for the purpose of making it swell ; he touches the right cheek at the spot nearly equidistant from the eye and mouth, and there finds the tubercle which is to guide him, and also feels the angular vein swelled below this tubercle; he then makgs the incision from below upward, half a finger's breadth below the middle of the tubercle. When the vein is no longer pressed upon, the bleeding will commonly cease; if not, a pin may be passed through the lips of the orifice, and a lock of wool tied round them.

For thorough bleeding, the jugular vein is generally to be preferred. The sheep should be firmly held by the head by an assistant, and the body confined between his knees, with its rump against a wall. Some of the wool is then cut away from the middle of the neck over the jugular vein, and a ligature, brought in contact with the neck by opening the wool, is tied around it below the shorn spot near the shoulder. The vein will soon rise. The orifice may be secured, after bleeding, as before described.

The good effects of bleeding depend almost as much on the rapidity with which the blood is abstracted, as the amount taken. This is especially true in acute diseases. Either bleed rapidly or do not bleed at all. The orifice in the vein, therefore, should be of some length, and made lengthwise with the vein. A lancet is by far the best implement; and even a short-pointed penknife is preferable to the bungling gleam. 
Bleeding, moreover, should always be resorted to, when it is indicated at all, as nearly as possible to the commencement of the malady.

The amount of blood drawn should never be determined by admeasurement, but by constitutional effect-the lowering of the pulse, and indications of weakness In urgent casesapoplexy, or cerebral inflammation, for example-it would be proper to bleed until the sheep staggers or falls. The quantity of blood in the sheep is less, in comparison, than that in the horse or ox. The blood of the horse constitutes about oneeighteenth part of his weight; and that of the ox at least onetwentieth; while that of the sheep, in ordinary condition, is one-twenty-second. For this reason, more caution should be exercised in bleeding the latter, especially in frequently resorting to it; otherwise, the vital powers will be rapidly and fatally prostrated. Many a sheep has been destroyed by bleeding freely in disorders not requiring it, and in disorders which did require it at the commencement, but of which the inflammatory stage had passed.

\section{FEEIING THE PULSE.}

The number of pulsations can be determined by feeling the heart beat on the left side. The femoral artery passes in an oblique direction across the inside of the thigh, and about the middle of the thigh its pulsations and the character of the pulse can be most readily noted. The pulsations per minute, in a healthy adult sheep, are sixty-five in number; though they have been stated at seventy, and even seventy-five. 


\section{APOPLEXY.}

Soon after the sheep are turned to grass in the spring, one of the best-conditioned sheep in the flock is sometimes suddenly found dead. The symptoms which precede the catastrophe are occasionally noted. The sheep leaps frantically into the air two or three times, dashes itself on the ground, and suddenly rises, and dies in a few minutes.

Where animals in somewhat poor condition are rather forced forward for the purpose of raising their condition, it sometimes happens that they become suddenly blind and motionless; they will not follow their companions; when approached, they run about, knocking their heads against fences, etc.; the head is drawn round toward one side; they fall, grind their teeth, and their mouths are covered with a frothy mucus. Such cases are, unquestionably, referable to a determination of blood to the brain.

Treatment. If the eyes are prominent and fixed, the membranes of the mouth and nose bighly florid, the nostrils highly dilated, and the respiration labored and stertorous, the veins of the head turgid, the pulse strong and rather slow, and these symptoms attended by a partial or entire loss of sight and hearing, it is one of those decided cases of apoplexy which require immediate and energetic treatment. Recourse should at once be had to the jugular vein, and the animal bled until an obvious constitutional effect is produced-the pulse lowered, and the rigidity of the muscles relaxed. An aperient should at once follow bleeding; and if the animal is strong and plathoric, a sheep of the size of the Merino would require at least two ounces of Epsom salts, and one of the large mutton 
sheep, more. If this should fail to open the bowels, half an ounce of the salts should be given, say twice a day.

\section{BRAXY.}

This is manifested by uneasiness; loathing of food ; frequent drinking; carrying the head down; drawing the back up; swollen belly; feverish symptoms; and avoidance of the flock. It appears mostly in late autumn and spring, and may be induced by exposure to severe storms, plunging in water when bot, and especially by constipation, brought on by feeding on frost-bitten, putrid, or indigestible herbage. Many sheep die on the prairies from this disease, induced by exposure and miserable forage. Entire prevention is secured by warm, dry shelters, and nutritious, dry food.

Treatment. Remedies, to be successful, must be promptly applied. Bleed freely; and to effect this, immersion in a tub of hot water may be necessary, in consequence of the staguant state of the blood. Then give two ounces of Epsom salts, dissolved in warm water, with a handful of common salt. If this is únsuccessful, give a clyster, made with a pipeful of tobacco, boiled for a few minutes in a pint of water. Administer half; and if this is not effectual, follow with the remainder. Then bed the animal in dry straw, and cover with blankets; assisting the purgatives with warm gruels, followed by laxative provender till well.

\section{BRONCHITIS.}

Where sheep are subject to pneumonia, they are liable to bronchitis as well, which is an inflammation of the mucous membrane, which lines the bronchial tubes, or the air-pas- 
sages of the lungs. The symptoms are those of an ordinary cold, but attended with more fever, and a tenderness of the throat and belly when pressed upon.

Treatment. Administer salt in doses of from one and a half to two ounces, with six or eight ounces of lime-water, given in some other part of the day.

\section{CATARRH.}

This is an inflammation of the mucous membrane, which lines the nasal passages, and it sometimes extends to the larynx and pharynx. In the first instance-where the lining of the nasal passages is alone and not very violently affectedit is merely accompanied by an increased discharge of mucus, and is rarely attended with much danger. In this form, it is usually termed snuffles; and high-bred English mutton-sheep, in this country, are apt to manifest more or less of it, after every sudden change of weather. When the inflammation extends to the mucous lining of the larynx and the pharynx, some degree of fever usually supervenes, accompanied by cough, and some loss of appetite. At this point, bleeding and purging are serviceable.

Catarrh rarely attacks the American fine-roolled sheep with sufficient violence in summer to require the application of remedies. Depletion, in catarrh, in our severe winter months, however, rapidly produces that fatal prostration, from which it is almost impossible to bring the sheep back, without bestowing an amount of time and care upon it, costing far more than the worth of an ordinary animal.

The best course is to prevent the disease by judicious precaution. With that amount of attention which every prudent 
farmer should bestow on his sheep, the American Merino is but little subject to it. Good, comfortable, and well-ventilated shelters, constantly accessible to the sheep in winter, with a sufficiency of food regularly administered, are usually a sufficient safeguard.

\section{MALIGNANT EPIZOÖTIC CATARRH.}

Essentially differing, in type and virulence, from the preceding, is an epidemic, or, more properly speaking, an epizoötic

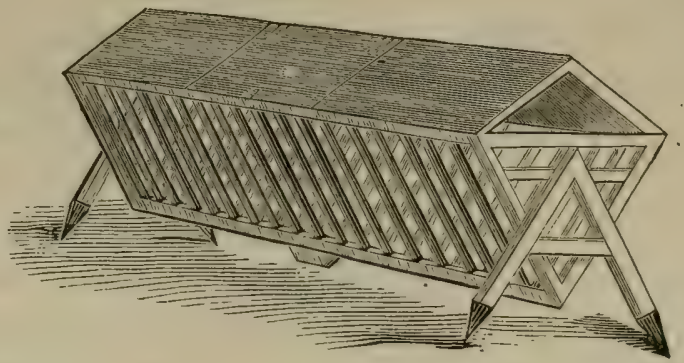

AX EXGLISH RACK FOR FEEDING SHEEP.

malady, which, as often as once in every eight or ten years, sweeps over extended sections of the Northern States, destroying more sheep than all other diseases combined. It commonly makes its appearance in winters characterized by rapid and violent changes of temperature, which are spoken of by the farmers as "bad winters" for sheep. The disease is sometimes termed the "distemper," and also, but erroneously, "grub in the head." The winter of 1846-7 proved peculiarly destructive to sheep in New York, and some of the adjoining States; scme owners losing one-half, others three-quarters, and a few seven-eighths, of their flocks. One person lost five 
hundred out of eight hundred; another, nine hundred out of a thousand. These severe losses, however, mainly fell on the holders of the delicate Saxons, and perhaps, generally, on those possessing not the best accommodations, or the greatest degree of energy and skill.

Symptoms. The primary and main disease, in such instances, is a species of catarrh; differing, however, from ordinary catarrh in its diagnosis, and in the extent of the lesions accompanying both the primary and the symptomatic diseases. The animals affected do not, necessarily, at first show any signs of violent colds, as coughing, sneezing, or labored respiration; the only indications of catarrh noticed, oftentimes, being a nasal discharge. Animals having this discharge appear dull and drooping; their eyes run a little, and are partially closed; the caruncle and lids look pale; their movements arc languid, and there is an indisposition to eat; the pulse is nearly natural, though at times somewhat too languid. In a few days these symptoms are evidently aggravated; there is rapid emaciation, accompanied with debility; the countenance is exceedingly dull and drooping; the eye is kept more than half closed; the caruncle, lids, etc., are almost bloodless; a gummy, yellow secretion about the eje; thick, glutinous mucus adhering in and about the nostrils; appetite feeble; pulse languid; and muscular energy greatly prostrated. They rapidly grow weaker, stumble, and fall as they walk, and soon become unable to rise; the appetite grows feebler; the mucus at the nose is, in some instances, tinged with dark, grumous blood; the respiration becomes oppressed; and the animals die within a day or two after they become unable to rise. Upon a post-mortem examination, the mucous membrane 
lining the whole nasal cavity is found highly congested and thickened throughout its entire extent, accompanied with the most intense inflammation; slight ulcers are found on the membranous lining, at the junction of the cellular ethmoid bones with the cribriform plate, in the ethmoidal cells; and the inflammation extends to the mucous membrane of the pharynx, and some inches, from two to four, of the upper portion of the csophagus.

No sheep, affected with this disease, recovers after emaciation and debility have proceeded to any great extent. In the generality of instances, the time, from the first observed symptoms until death, varies from ten to fifteen days; although death, in some cases, results more speedily.

Treatment. Nothing has been found so serviceable as mercury, which, from its action on the entire secretory system, powerfully tends to relieve the congested membranes of the head. Dissolve one grain of bi-chloride of mercury-corrosive sublimate-in two ounces of water; and give one-half ounce of the water, or one-eighth of a grain of corrosire sublimate, daily, in two doses. To stimulate and open the bowels, give, also, rhubarb in a decoction, the equivalent of ten or fifteen grains at a dose, accompanied with the ordinary carminative and stomachic adjuvants, ginger and gentian in infusion.

\section{COLIC.}

Sheep are occasionally seen, particularly in the winter, lying down and rising every moment or two, and constantly stretching their fore and hind legs so far apart that their bellies almost touch the ground. They appear to be in much pain, refuse all food, and not unfrequently die, unless relieved. 
This disease, popularly known as the "stretches," is erroneously attributed to an involution of one part of the intestine within another; it being, in reality, a species of flatulent colic, induced by costiveness.

Treatment. Half an ounce of Epsom salts, a drachm of Jamaica ginger, and sixty drops of essence of peppermint. The salts alone, however, will effect the cure; as will, also, an equivalent dose of linseed oil, or even hog's lard.

\section{COSTIVENESS.}

This difficulty is removed by giving two table-spoonfuls of castor oil every twelve hours, till the trouble ceases; or give one ounce of Epsom salts. This may be assisted by an injection of warm weak suds and molasses.

\section{DIARRHGA.}

Common diarrhœa-purging, or scours-manifests itself simply by the copiousness and fluidity of the alvine evacuations. It is generally owing to improper food, as bad hay, or noxious weeds; to a sudden change, as from dry food to fresh grass; to an excess, as from overloading the stomach; and sometimes to cold and wet. It is important to clearly distinguish this disease from dysentery. In diarrhœa, there is no apparent general fever; the appetite remains good; the stools are thin and watery, but unaccompanied with slime, or mucus, and blood; odor of the fæces is far less offensive than in dysentery; and the general condition of the animal is but little changed. When it is light, and not of long continuance, no remedy is called for, since it is a healthful provision of Nature 
for the more rapid expulsion of some offending matter in the system, which, if retained, might lead to disease.

Treatment. Confinement to dry food for a day or two, and a gradual return to it, often suffices, in the case of grown sheep. With lambs, especially if attacked in the fall, the disease is more scrious. If the purging is severe, and especially if any mucus is observed with the fæces, the feculent matter should be removed from the bowels by a gentle cathartic; balf a drachm of rhubarb, or an ounce of linseed oil, or half an ounce of Epsom salts to a lamb. This should be followed by an astringent; and, in nine cases out of ten, the latter will serve in the first instance. Give one quarter of an ounce of prepared chalk in half a pint of tepid milk, once a day for two or three days; at the end of which, and frequently after the first dose, the purging will have ordinarily abated, or entirely ceased.

"Sheep's cordial" is also a safe and excellent remedy-in severe cases, better than simple chalk and milk. Take of prepared chalk, one ounce; powdered catechu, half an ounce; powdered Jamaica ginger, two drachms; and powdered opium, half a drachm; mix with half a pint of peppermint water; give two or three table-spoonfuls morning and night to a grown sheep, and half that quantity to a lamb.

\section{DISEASE OF THE BIFLEX CANAL.}

From the introduction of foreign bodies into the biflex canal, or from other causes, it occasionally becomes the seat of inflammation. This canal is a small orifice, opening externally on the point of each pastern, immediately above the cleft between the tocs. It bifurcates within, a tube passing down 
on each side of the inner face of the pastern, winding round and ending in a cul de'sac. Inflammation of this canal causes an enlargement and redness of the pastern, particularly about the external orifice of the canal. The toes are thrown wide apart by the tumor. It rarely attacks more than one foot, and should not be allowed to proceed to the point of ulceration, which it will do, if neglected. There is none of that soreness and disorganization between the back part of the toes, and none of that peculiar fetor which distinguishes the hoof-ail, with which disease it is sometimes confounded.

Treatment. Scarify the coronet, making one or two deeper incisions in the principal swelling around the mouth of the canal; and cover the foot with tar.

\section{DYSENTERY.}

This is occasioned by an inflammation of the mucous or inner coat of the larger intestines, causing a preternatural increase in their secretions, and a morbid alteration in their character. It is frequently consequent on that form of diarrhoa, which is caused by an inflammation of the mucous coat of the smaller intestines. The inflammation extends throughout the whole alimentary canal, increases in virulence, and becomes dysentery, a disease frequently dangerous and obstinate in its character, but, fortunately, not common among sheep, generally, in the United States. Its diagnosis differs from that of diarrhœa, in several readily observed particulars. There is evident fever; the appetite is eapricious, commonly very feeble; the stools are as thin as in diarrhœa, or even thinner, but much more adhesive, in consequence of the presence of large quantities of mucus. As the erosion of the intestines 
advances, the fæces are tinged with blood; their odlor is intolerably offensive; and the animal rapidly wastes arvay, the course of the disease extending from a few days to several weeks.

Treatment. Moderate bleeding should be resorted to, in the first or inflammatory shape, or whenever decided febrile symptoms are found to be present. Two doses of physic having been administered, astringents are serviceable. The "sheep's cordial," already described, is as good as any; and to this, tonics may soon begin to be added; an additional quantity, of ginger may enter into the composition of the cordial, and gentian powder will be an useful auxiliary. With this, as an excellent stimulus to cause the sphincter of the anus to contract, and also the mouths of the innumerable secretory and exhalent ressels opening on the inner surface of the intestines, a half grain of strychnine may be combined. Smaller doses should be given for three or four days.

\section{FLIES.}

The proper treatment, upon the appearance of flies or maggots, has already been detailed under the head of "FEEDING ANd Management," to which the reader is referred.

\section{FOULS.}

Sheep are much less subject to this disease than cattle are; but encounter it, if kept in wet, filthy yards, or on moist, poachy ground. It is an irritation of the integument in the cleft of the foot, slightly resembling incipient hoof-ail, and producing lameness. It occasions, bowever, no serious structural disorganization, disappears without treatment, is not 14 
contagious, and appears in the wet weather of spring and fall, instead of in the dry, hot period of summer, when the hoof-ail rages most. A little solution of blue vitriol, or a little spirits of turpentine-either followed by a coating of warm tarpromptly cures it.

For foul noses, dip a small swab in tar, then roll it in salt; put some on the nose, and compel the sheep to swallow a small quantity.

\section{FRACTURES.}

If there be no wound of the soft parts, the bone simply being broken, the treatment is extremely easy. Apply a piece of wet leather, taking care to ease the limb when swelling supervenes. When the swelling is considerable, and fever present, the best course is to open a vein of the head or neck, allowing a quantity of blood to escape, proportioned to the size and condition of the animal, and the urgency of the symptoms. Purgatives in such cases should never be neglected. Epsom salts, in ounce doses, given either as a gruel or a drench, will be found to answer the purpose well. If the broken bones are kept steady, the cure will be complete in from three to four weeks, the process of reunion always proceeding faster in a young than in an old sheep. Should the soft parts be injured to any extent, or the ends of the bone protrude, recovery is very uncertain; and it will become a question whether it would not be better to convert the animal at once into mutton. 


\section{GARGET.}

This is an inflammation of the udder, sometimes known as "caked bag," with or without general inflammation. Where it is simply an inflammation of the udder, it is usually caused by too great an accumulation of milk in the latter prior to lambing, or in consequence of the death of the lamb.

Treatment. Drawing the milk partly from the bag, so that the hungry lamb will butt and work at it an unusual time in pursuit of its food, and bathing it a few times in cold water, usually suffices. If the lamb is dead, the milk should be drawn a few times, at increasing intervals, washing the udder for some time in cold water at each milking. In cases of obdurate induration, the udder should be anointed with iodine ointment. If there is general fever in the system, an ounce of Epsom salts may be given. If suppuration forms, the part affected should be opened with the lancet.

GOITRE.

The "swelled neck" in lambs is, like the goitre, or bronchocele, an enlargement of the thyroid glands, and is strikingly analogous to that disease, if not identical with it. It is congenital. The glands at birth are from the size of a pigeon's egg to that of a hen's egg, though more elongated and flattened than an egg in their form. The lamb is exceedingly feeble, and often perishes almost without an effort to suck. Many even make no effort to rise, and die as soon as they are dropped. It is rare, indeed, that one lives.

A considerable number of lambs annually perish from this disease, which does not appear to be an epizoötic, though 
it is more prevalent in some seasons than in others. It does not seem to depend upon the water, or any other natural circumstances of a region, as goitre is generally supposed to, since it may not prevail in the same flock, or on the same farm, once in ten years; nor can it be readily traced to any particular kind of food. Then it does appear, however, its attacks are rarely isolated; from which circumstance some have inferred that it is induced by some local or elimentary cause. Losses from this disease have ranged from ten per cent. to twenty, thirty, and even fifty per cent. of the whole number of lambs. Possibly, high condition in the ewes may be one of the inducing causes.

Treatment. None is known which will reach the case. Should one having the disease chance to live, it would scarcely be worth while to attempt reducing the entanglement of the glands Perhaps keeping the breeding-ewes uniformly in fair, plump, but not high condition, would be as effectual a preventive as any.

\section{GRUB IN THE HEAD.}

What is popularly known as the "grub" is the larva of the cestrus oris, or gad-fly of the sheep. It is composed of five rings; is tiger-colored on the back and belly, sprinkled with spots and patches of brown; its wings are striped.

The sheep gad-fly is led by instinct to deposit its eggs within the nostrils of the sheep. Its attempts to do thismost common in July, August, and September-are always indicated by the sheep, which collect in close clumps, with their heads inward, and their noses thrust close to the ground, and into it, if any loose dirt or sand is within reach. If the 
fly succeeds in depositing its egg, the latter is immediately hatched by the warmth and moisture of the part, and the young grubs, or larvæ, crawl up the nose, finding their devious way to the sinuses, where, by means of their tentaculæ, or feelers, they attach themselves to the mucous membrane lining: those cavities. During the ascent of the larvæ, the sheep stamps, tosses its head violently, and often dashes away. from its companions wildly over the field. The larvæ remain on the sinuses, feeding on the mucus secreted by the membrane, and apparently creating no further annoyance, until ready to assume their pupa form in the succeeding spring.

Having remained in the sinuses during the fall and winter, they abandon them as the warm weather approaches in the latter part of spring. They crawl down the nose, creating even greater irritation and excitement than when they originally ascended, drop on the ground, and rapidly burrow into it. In a few hours, the slin of the larvæ has contracted, become of a dark-brown color, and it has assumed the form of chrysalis. This fly never eats; the male, after impregnating two or three females, dies; and the latter, having deposited their ova in the nostrils of the sheep, also soon perish.

The larvæ in the heads of sheep may, and probably do, add to the irritation of those inflammatory diseases, such as catarrh, which attack the membranous lining of the nasal cavities; and they are a powerful source of momentary irritation in the first instance, when ascending to, and descending from, their lodging-place in the head. But in the interval between these events, extending over a period of several months, not a movement of the sheep indicates the least annoyance at their presence. They are, moreover, found in the heads of nearly 
all sheep, the healthy as well as the diseased, at the proper season.

Treaiment. Though the presence of the grub constitutes no disease, some think it well to diminish their number by all convenient means. One simple way of effecting this is, by turning up with a plough a furrow of earth in the sheeppasture, into which the sheep will thrust their noses on the approach of the cestrus, and thus many of them escape its attacks. Some farmers smear the noses of their sheep occasionally with tar, the odor of which is believed to repel the fly. Another plan, deemed efficacious in dislodging the larvæ from the sinuses, is as follows: Take half a pound of good Scotch snuff, and two quarts of boiling water; stir, and let it stand till cold. Inject about a table-spoonful of this liquid and sediment up each nostril, with a syringe ; repeat this three or four times, at intervals, from the middle of October till January. The efficacy of the snuff will be increased by adding half an ounce of asafœtida, pounded in a little water. The effects on the sheep are immediate prostration and apparent death; but they will soon recover. $\Lambda$ decoction of tobacco affords a substitute for snuff; and some recommend blowing tobacco smoke through the tail of a pipe into each nostril.

\section{HOOF-AIL.}

The first symptom of this troublesome malady, known, likewise, as foot-ail, which is ordinarily noticed, is a lameness of one or both of the forefeet. On daily examining, however, the feet of a flock which have the disease among them, it will readily be seen that the lesions manifest themselves for several days before they are followed with lameness. 
The horny covering of the sheep's foot extends up, gradually thinning out, some way between the toes and divisions of the hoof, and above these horny walls the cleft is lined with skin. When the points of the toes are spread apart, this skin is shown in front, covered with short, soft hair. The back part of the toes, or the heels, can be separated only to a little distance, and the skin in the cleft above them is naked. In a healthy foot, the skin throughout the whole cleft is as firm, dry, and uneroded as on any other part of the animal.

The first symptom of hoof-ail is a slight erosion, accompanied with inflammation and heat of the naked skin in the back parts of the clefts, immediately above the heels. The skin assumes a macerated appearance, and is kept moist by the presence of a sanious discharge from the ulcerated surface. As the inflammation extends, the friction of the parts causes pain, and the sheep limps. At this stage, the foot, externally, in a great majority of cases, exhibits not the least trace of disease, with the exception of a slight redness, and sometimes the appearance of a small sore at the upper edge of the cleft, when viewed from behind.

The ulceration of the surface rapidly extends. The thin upper edges of the inner walls of the hoof are disorganized, and an ulceration is established between the hoof and the fleshy sole. A purulent fetid matter is discharged from the cavity. The extent of the separation increases daily, and the ulcers also form sinuses deep into the fleshy sole. The bottom of the hoof disappears, eaten away by the acrid matter, and the outer walls, entirely separated from the flesh, hang only by their attachments at the coronet. The whole fleshy sole is now entirely disorganized, and the entire foot is a mass of 
black, putrid ulceration; or, as more commonly happens, the fly has struck it, and a dense mass of writhing maggots cover the surface, and burrow in every cavity.

The forefeet are generally first attacked; and, most usually but one of them. The animal at first manifests but little constitutional disturbance, and eats as usual. By the time that any considerable disorganization of the structures has taken place in the first foot, and sometimes sooner, the other forefoot is attacked. That becoming as lame as the first, the miserable animal seeks its food on its knees; and, if forced to rise, its strange, hobbling gait betrays the intense agony occasioned by bringing its feet in contact with the ground. There is a bare spot under the brisket, of the size of a man's hand, which looks red and inflamed. There is a degree of general fever, and the appetite is dull. The animal rapidly loses condition. The appearance of the maggot soon closes the scene. Where the rotten foot is brought in contact with the side, in lying down, the filthy, ulcerous matter adheres to, and saturates the short wool-it being but a month and a half, or two months, after shearing-and maggots are either carried there by the foot, or they are soon generated there. A black crust is speedily formed round the spot, which is the decomposition of the surrounding structures; and innumerable maggots are at work below, burrowing into the integuments and muscles, and eating up the wretched animal alive. The black, festering mass rapidly spreads, and the poor sufferer perishes, apparently in tortures the most excruciating.

Sometimes but one forefoot is attacked, and subsequently one or both hind ones. There is no uniformity in this particular; and it is a singular fact that, when two or even three 
of the feet are dreadfully diseased, the fourth may be entirely sound. So, also, one font may be cured, while every other one is laboring under the malady. The highly offensive odor of the ulcerated feet is so peculiar that it is strictly charac. teristic of the disease, and would reveal its character, to one familiar with it, in the darkest night.

Hoof-ail is probably propagated in this country exclusively by inoculation-the contact of the matter of a cliseased foot with the integuments lining the bifurcation of a bealthy foot. That it is propagated in some of the ways classed under the ordinary designation of contagion, is certain. That it may be propagated by inoculation, has been established by experiment. The matter of diseased feet has been placed on the skin lining the cleft of a healthy foot under a variety of circumstancessometimes when that skin is in its ordinary and natural state, sometimes after a very slight scorification, sometimes when macerated by moisture; and under each of these circumstances the disease has been communicated. The same inference may be drawn, also, from the manner in which the discase attacks flocks. The whole, or any considerable number, though sometimes rapidly, are never simultaneously attacked, as would be expected, among animals so gregarious, if the disease could be transmitted by simple contact, inhaling the breath, or other effluvium.

The matter of diseased feet is left on grass, straw, and other substances, and thus is brought in contact with the inner surfaces of healthy feet. Sheep, therefore, contract the disease from being driven over the pastures, yarded on the straw, etc., where diseased sheep have been, perhaps even days, before. The matter would probably continue to inoculate, until dried 
up by the air and heat, or washed away by the rains. The stiff, upright stems of closely mown grass, as on meadoris, are almost as well calculated to receive the matter of diseased feet, and deposit it in the clefts of healthy ones, as any means which could be artificially devised. It is not entirely safe to drive healthy sheep over roads, and especially into washing-yards, or sheep houses, where diseased sheep have been, until rain has fallen, or sufficient time has elapsed for the matter to dry up. On the moist bottom of a washing-yard, and particularly in houses or sheds, kept from sun and wind and rain, this matter might be preserved for some time in a condition to inoculate.

When the disease has been well kept under during the first season of its attack, but not entirely eradicated, it will almost or entirely disappear as cold weather approaches, and it does not manifest itself until the warm weather of the succeeding summer. It then assumes a mitigated form; the sheep are not rapidly and simultaneously attacked; there seems to be less inflammatory action constitutionally, and in the diseased parts; the course of the disease is less malignant and more tardy, and it more readily yields to treatment. If well kept under the second summer, it is still milder the third. A sheep will accasionally be seen to $\operatorname{limp}$; but its condition will scarcely be affected, and dangerous symptoms will rarely supervene. One or two applications made during the summer, in a manner presently to be described, will suffice to keep the discase under. At this point, a little vigor in the treatment will rapidly extinguish the disease.

Treatment. The preparation of the foot, where any separate individual treatment is resolved upon, is always necessary, at 
least in bad cases. Sheep should be jarded for the operation immediately after a rain, if practicable, as the hoofs can then be readily cut. In a dry time, and after a night which left no dew upon the grass, their hoofs are almost as tough as horn. They must be driren through no mud, or soft dung, on their way to the yard, which would double the labor of cleaning their feet. The yard should be small, so that they can be easily caught, and it must be kept well littered down, to prevent their filling their feet with their own excrement. If the straw is wetted, their hoofs will not, of course, dry and harden as rapidly as in dry straw. If the yard could be built over a shallow, gravelly-bottomed brook, it would be an admirable arrangement; for this purpose, a portion of any little brook might be prepared, by planking the bottom, and widening it, if desirable. By such means the hoofs would in kept so soft that the greatest and most unpleasant part of the labor, as ordinarily performed, would be in a great measure sared, and they would be kept free from that dung which, by any other arrangement; will, more or less, get into their clefts.

The principal operator seats himself on a chair, having within his reach a couple of good knives, a whetstone, the powerful toe-nippers already described, a bucket of water with a couple of linen rags in it, together with such medicines as may be deemed necessary. The assistant catches a sheep and lays it partly on its back and rump, between the legs of the foreman, the head coming up about to his middle. The assistant then kneels on some straw, or seats himself on a low stool at the hinder extremity of the sheep. If the hoofs are long, and especially if they are dry and tough, the assistant presents each foot to the operator who shortens the hoof with 
the toc-nippers. If there is any filth between the toes, each man takes his. rag from the bucket of water, and draws it between the toes, and rinses it, until the filth is remored Each then takes a knife, and the process of paring away the horn commences, upon the effectual performance of which all else depends. A glance at the foot will show whether it is the seat of the diseased action. The least experience cannot fail in properly settling this question. An cxperienced finger, even, placed upon the back of the pastern close above the heel, will at once detect the local inflammation, in the dark, by its heat.

If the disease is in the first stage-that is, if there are merely erosion and ulceration of the cuticle and flesh in the cleft above the walls of the hoof-no paring is neecssary. But if ulceration has established itself between the hoof and the fleshy sole, the ulcerated parts, however extensive, must be entively stripped of their horny covering, no matter what amount of time and care it may require. It is better not to wound the sole so as to cause it to bleed freely, as the ruming blood will wash off the subsequent application; but no fear of wounding the sole must prevent a full compliance with the rule laid down above. At the worst, the blood will stop flowing after a little while, during which time no application needs to be made to the foot.

If the foot is in the third stage-a mass of rottenness, and filled with maggots-pour, in the first place, a little spirits of turpentine-a bottle of which, with a quill through the cork, should be always ready - on the maggots, and most of them will immediately decamp, and the others can be remored with a probe or small stick. Then remove every particle of loose 
horn, though it should take the entire hoof, as it generally will in such cases. The foot should next be cleansed with a solution of chloride of lime, in the proportion of one pound of chloride to one gallon of water. If this is not at hand, plunging the foot repeatedly in hot water, just short of scalding hot, will answer every purpose. The great object is to clean the foot thoroughly. If there is any considerable "proud flesh," it should be removed with a pair of scissors, or by the actual cautery-hot iron.

The following are some of the most popular remedies: Take two ounces of blue vitriol and two ounces of verdigris, to a junk-bottle of wine; or spirits of turpentine, tar, and verdigris in equal parts; or three quarts of alcohol, one pint of spirits of turpentine, one pint of strong vinegar, one pound of blue vitriol, one pound of copperas, one and a half pounds of verdigris, one pound of alum, and one pound of saltpetre, pounded fine; mix in a close bottle, shake every day, and let it stand six or eight days before using; also mix two pounds of honey and two quarts of tar, which must be applied after the preceding compound. Or apply diluted aquafortis-nitric acid-with a feather to the ulcerated surface; or diluted oil of vitriol-sulphuric acid-in the same way; or the same of muriatic acid; or dip the foot in tar nearly at the boiling point.

In the first and second stages of the disease, before the ulcers have formed sinuses into the sole, and wholly or partly destroyed its structure, the best application is a saturated solution of blue vitriol-sulphate of copper. In the third stage, when the foot is a festering mass of corruption, after it has been cleansed as already directed, it requires some strong 
caustic to remove the unhealthy granulations-the dead muscular structures-and to restore healthy action. Lunar caustic, which is preferable to any other application, is too expensive; chloride of antimony is excellent, but frequently unattainable in the country drug-stores; and muriatic acid, or even nitric or sulphuric acids, may be userl instead. The diseased surface is touched with the caustic, applied with a swab, formed by fastening a little tow on the end of a stick, until the objects above pointed out are attained. The foot is then treated with the solution of blue vitriol, and subsequently coated over with tar which has been boiled, and is properly cooled, for the purpose of protecting the raw wound from dirt, flies, etc. Sheep in this stage of the disease should certainly be separated from the main flock, and looked to as often as once in three days. With this degree of attention, their cure will be rapid, and the obliterated structures of the foot will be restored with astonishing rapidity.

The common method of using the solution of blue vitriol is to pour it from a bottle with a quill in the cork, into the foot, when the animal lies on its back between the operators, as already described. In this way a few cents' worth of vitriol will answer for a large number of sheep. The method is, however, imperfect; since, without extraordinary care, there will almost always be some slight ulcerations not uncovered by the knife, which the solution will not reach, the passages to them being devious, and perhaps nearly or quite closed. The disease will thus be only temporarily suppressed, not cured.

$\Lambda$ flock of sheep which were in the second season of the disease, bad been but little looked to during the summer, and as cold weather set in, many of them became considerably 
lame, and some of them quite so. Their feet were thoroughly pared; and into a large washing-tub, in which two sheep could conveniently stand, a saturated solution of blue vitriol and water, as hot as could be endured by the hand even for a moment, was poured. The liquid was about four inches deep on the bottom of the tub, and was kept at that depth by frequent additions of hot solution. As soon as a sheep's fect were pared, it was placed in the tub, and held there by the neck. A second one was then prepared, and placed beside it; when the third was ready, the first was taken out; and so on. Two sheep were thus constantly in the tub, each remaining some five minutes. The cure was perfect; there was not a lame sheep in the flock during the winter or the next summer. The hot liquid penetrated to every cavity of the foot; and doubtless had a far more decisive effect, even on the uncovered ulcers, than would have been produced by merely wetting them. The expense attending the operation was about four cents per sheep. Three such applications, at intervals of a week, would effectually cure the disease, since every new case would thus be arrested and cured before it would have time to inoculate otbers. It would, undoubtedly, accomplish this at any time of year, and even during the first and most malignant prevalence of the contagion, provided the paring was sufficiently thorough. The second and third parings would be a mere trifle; and the liquid left at the first and second applications could again be used. Thus sheep could be cured at about twelve cents per head, which is much cheaper, in the long run, than any ordinary temporizing method, where the cost of a few pounds of blue vitriol is counted, but not the time consumed; and the disease is thus kept lingering in the flock for years. 
Some Northern farmers drive their sheep over dusty roads as a remedy for this disease; and in cases of ordinary virulence, especially where the disease is chronic, it seems to dry up the ulcers, and keep the malady under. Sheep are also sometimes cured by keeping them on a dry surface; and driving them over a barn-floor daily, which is well covered with quicklime. It may sometimes, and under peculiar circumstances, be cured by dryness, and repeated washing with soap-suds.

Many farmers select rainy weather as the time for doctoring their sheep. Their feet are then soft, and it is therefore on all accounts good economy, when the feet are to be pared, and each separately treated, provided they can be kept in sheephouses, or under shelters of any kind, until the rain is over, and the grass again dry. If immediately let out in wet grass of any length, the vitriol or other application is measurably washed away. This is avoided by many, by dipping the feet in more tar-an admirable plan under such circumstances.

A llock of sheep which have been cured of the hoof-ail, is considered more valuable than one which has never had it. They are far less liable to contract the disease from any casual exposure; and its ravages are far less violent and general among them.

This ailment should not be confounded with a temporary soreness, or inflammation of the hoof, occasioned by the irritation from the long, rough grasses which abound in low situations, which is remored with the cause; or, if it continues, white paint or tar may be applied, after a thorough washing. 


\section{HOOVE.}

This is not common, to any dangerous degree, among sheep; but, if turned upon clover when their stomachs are empty, it will sometimes ensue.

Hoove is a distension of the paunch by gas extricated from the fermentation of its regetable contents, and evolved more rapidly, or in larger quantities, than can be neutralized by the natural alkaline secretions of the stomach. When the distention is great, the blood is prevented from circulating in the ressels of the rumen, and is determined to the head. The diaphragm is mechanically obstructed from making its ordinary contractions, and respiration, therefore, becomes difficult and imperfect. Death, in such cases, soon supervenes.

Treatment. In ordinary cases, gentle but prolonged driving will effect a cure. When the animal appears swelled almost to bursting, and is disinclined to move, it is better to open the paunch at once. At the most protruberant point of the swelling, on the left side, a little below the hip bone, plunge a trocher or knife, sharp at the point and dull on the edge, into the stomach. The gas will rapidly escape, carrying with it some of the liquid and solid contents of the stomach. If no measures are taken to prevent it, the peristaltic motion, as well as the collapse of the stomach, will soon cause the orifices through the abdomen and paunch not to coincide, and thus portions of the contents of the former will escape into the cavity of the latter.

Howerer perfect the cure of hoove, these substances in the belly will ultimately produce fatal irritation. To prevent this, a canula, or little tube, should be inserted through both 15 
orifices as soon as the puncture is made. Where the case is not imminent, alkalies have sometimes been successfully administered, which combine with the carbonic acid gas, and thus at once reduce its volume. A flexible probang, or in default of it, a rattan, or grape-vine, with a knot on the end, may be gently forced down the gullet, and the gas thus permitted to escape.

\section{HYDATID ON THE BRAIN.}

The symptoms of this disease, known as turnsick, sturdy, staggers, water in the head, etc., are a dull, moping appearance, the sheep separating from the flock, a wandering and blue appearance of the eye, and sometimes partial or total blindness; the sheep appear's unsteady in its walk, will sometimes stop suddenly and fall down, at others gallop across the field, and, after the disease has existed for some time, will almost constantly more round in a circle-there seems, indeed, to be an aberration of the intellect of the animal. These symptoms, though rarely all present in the same subject, are ret sufficiently marked to prevent any mistake as to the nature of the disease.

On examining the brain of sheep thus affected, what appears to be a watery bladder, called a hydatid, is found, which may be either small or of the size of a hen's egg. This hydatid, one of the class of entozoöns, has been termed by naturalists the hydatis polycephalus cerebralis, or many-headed hydatid of the brain; these heads being irregularly distributed on the surface of the bladder, and on the front part of each head there is a mouth surrounded by minute sharp hooks within a ring of sucking disks. These dislis serve as the means of attachment, 
by forming a vacuum, and bring the mouth in contact with the surface, and thus, by the aid of the hooks, the parasite is nourished. The coats of the hydatid are disposed in several layers, one of which appears to possess a muscular power. These facts are developed by the microscope, which also dis. closes numerous little bodies adhering to the internal membrane. The fluid in the bladdes is usually clear but occasionally turbid, and then it has been found to contain a number of minute worms.

Treatment. This is deemed an almost incurable disorder. Where the hydatid is not imbedded in the brain, its constant pressure, singularly enough, causes a portion of the cranium to be absorbed, and finally the part immediately over the hydatid becomes thin and soft enough to yield under the pressure of the finger.

When such a spot is discovered, the English veterinarians usually dissect back the muscular integuments, remove a portion of the bone, carefully divide the investing membranes of the brain, and then, if possible, remove the hydatid whole; or, failing to do this, remove its fluid contents. The membranes and integuments are then restored to their position, and an adhesive plaster placed over the whole. The French veterinarians usually simply puncture the cranium and the cyst with a trochar, and laying the sheep on its back, allow the fluid to run out through the orifice thus made. A common awl would answer every purpose for such a puncture; and the puncture is the preferable method for the unskilled practitioner. An instance is, indeed, recorded of a cure having been effected, where the animal had been given up, by boring with a gimlet into the soft place on the head, when the water 
rushed out, and the sheep immediately followed the others to the pasture.

When, however, the hazard and cruelty attending the operation, under the most favorable circumstances, are considered, as well as the conceded liability of a return of the maladythe growth of new hydatids-it is evident that in this country, it would not be worth while, except in the case of uncommonly valuable sheep, to adopt any other remedy than depriving the miserable animal of life.

\section{OBSTRUCTION OF THE GULIET.}

After pouring a little oil in the throat, the obstructing substance which occasions the "choking," can frequently be

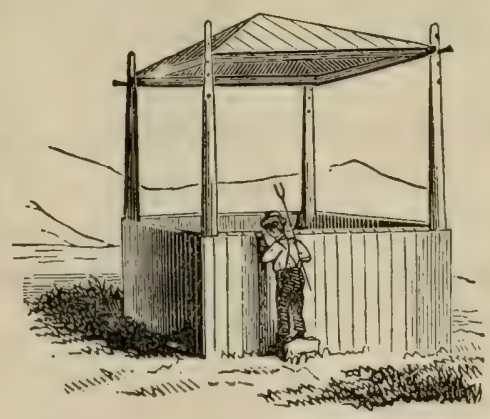

A BARRACK FOR STORING SHEEP-FODDER, removed up or down by external manipulation. If not, it may usually be forced down with the flexible probang, described in "Cattle and their Dis. eases," or a flexible rod, the head of which is guarded by a knot, or a little bag of flax-seed. The latter having been dipped in hot water for a minute or two, is partly converted into mucilage, which constantly exudes through the cloth, and protects the œsophagus, or gullet, from laceration. But little force must be used, and the whole operation conducted with the utmost care and gentleness; or the csophagus will be so far lacerated as to produce death, although the obstruction is removed. 


\section{OPHTHATMIA.}

Ophthalmia, or inflammation of the eyes, is not uncommon in this country; but it is little noticed, as, in most cases, it disappears in a few days, or, at worst, is only followed by cataract, which, being usually confined to one eye, does not appreciably effect the value of the animal, and therefore has no influence on its market price.

Treatment. Some recommend blowing pulverized red chalk in the inflamed eye; others squirt into it tobacco juice. As a matter of humanity, blood may be drawn from under the eye, and the eye bathed in tepid water, and occasionally with a weak solution of the sulphate of zinc combined with tincture of opium. These latter applications diminish the pain, and hasten the cure.

\section{PALSY.}

Paralysis, or palsy, is a diminution or entire loss of the powers of motion in some parts of the body. In the winter, poor lambs, or poor pregnant ewes, or poor feeble erwes immediately after yeaning in the spring, occasionally lose the power of walking or standing rather too suddenly to have it referable to increasing debility. The animal seems to have lost all strength in its loins, and the hind-quarters are powerless; it makes ineffectual attempts to rise, and cannot stand if placed upon its feet.

Treatment. Warmth, gentle stimulants, and good nursing may raise the patient; but, in the vast majority of cases, it is more economical and equally humane, to deprive it of life at once. 


\section{PELT-ROT.}

This is often mistaken for the scab, but it is, in fact, a different and less dangerous disease. The wool falls off, and leaves the sheep nearly naked; but it is attended with no soreness, though a redish crust will cover the skin, from the wool which has dropped. It generally arises from hard keening and much exposure to cold and wet; and, in fact, the animal often dies in severe weather from the cold it suffers on account of the loss of its coat.

The remedy is full feeding, a warm stall, and anointing the hard part of the skin with tar, oil, and butter. Some, however, do nothing for it, scarcely considering it a disease. Such say that if the condition of a poor sheep is raised as suddenly as practicable, by generous keep in the winter, the wool is very apt to drop off; and, if yet cold, the sheep will require warm shelter.

\section{PNEUMONIA.}

Pneumonia-or inflammation of the lungs-is not a common disease in the Northern States; but undoubted cases of it sometimes occur, after sheep have been exposed to sudden cold, particularly when recently shorn. The adhesions occasionally witnessed between the lungs and pleura of slaughtererl sheep, betray the former existence of this disease in the animal-though, in many instances, it was so slight as to he mistaken, at the time, for a hard cold.

Symptoms. The animal is dull, ceases to ruminate, neglects its food, drinks frequently and largely, and its breathing is rapid and laborious; the eye is clouded; the nose discharges 
a tenacious, fetid matter; the teeth are ground frequently, so that the sound is audible at some distance; the pulse is at first hard and rapid, sometimes intermits, but before death it becomes weak. During the height of the fever, the flanks heare violently; there is a hard, painful cough during the first stages, which becomes weaker, and seems to be accompanied with more pain as death approaches.

After death, the lungs are found more or less hepatizedthat is, permanently condensed and engorged with blood, so that their structure resembles that of the hepar, or liver-and they have so far lost their integrity that they are torn asunder by the slightest force. It may here be remarked that when sheep die from any cause, with their blood in them, the lungs have a dark, hepatized appearance. Whether they are actually hepatized or not, can readily be decided by compressing the wind-pipe, so that air cannot escape through it, and then between such compression and the body of the lungs, in a closely fitting orifice, inserting a goose-quill, or other tube, and continuing to blow until the lungs are inflated as far as they can be. As they inflate, they will become of a lighter color, and plainly manifest their cellular structure. If any portions of them cannot be inflated, and retain their dark, liver-like consistence, and color, they exhibit hepatization-the result of high inflammatory action_and a state utterly incompatible, in the living animal, with the discharge of the natural functions of the viscus.

Treatment. In the first, or inflammatory stages, bleeding and aperients are clearly called for. Some recommend early and copious bleeding, repeated, if necessary, in a few hours; this followed by aperient medicines, such as two ounces of 
Epsom salts, which may be repeated in smaller doses, if the bowels are not sufficiently relaxed. The following sedative may also be given with gruel, twice a day: nitrate of potash, one drachm; powdered digitalis, one scruple; and tartarized antimony, one scruple.

While depletion may be of inestimable value during the continuance-the short continuance-of the febrile state, yet excitation like this will soon be followed by corresponding exhaustion, when the bleeding and purging would be murderous expedients; and gentian, ginger, and the spirits of nitrous ether will afford the only hope of cure.

\section{POISON.}

Sheep will often, in the winter or spring, eat greedily of the low laurel. The animal appears afterward to be dull and stupid, swells a little, and is constantly gulping up a feverish fluid, which it swallows again; a part of it will trickle out of its mouth, and discolor its lips. The plant probably, brings on a fermentation in the stomach, and nature endeavors to throw off the poisonous herb by retching or vomiting.

Treatment. In the early stages, if the greenish fluid be allowed to escape from the stomach, the animal generally recovers. To effect this, gag the sheep, which may be done in this manner: Take a stick of the size of the wrist, six inches long-place it in the animal's mouth-tie a string to one end of it, pass it over the head and down to the other end, and there make it fast. The fluid will then run from the mouth as fast as thrown up from the stomach. In addition to this, give roasted onions and sweetened milk freely. A better plan, however, is to force a gill of melted lard down the throat; or, boil 
for an hour the twigs of the white ash, and give one-half to one gill of the strong liquor immediately; to be repeated, if not successful. Drenchers of milk and castor-oil are also recommended.

ROT.

This disease, which sometimes causes the death of a million of sheep, in England, in a single year, is comparatively unknown in this country. It prevails somewhat in the Western States, from allowing sheep to pasture on land that is overflowed with water. Even a crop of green oats, early in the fall, before a frost comes, has been known to rot young sheep.

Symptoms. The first are by no means strongly marked; there is no loss of condition, but rather the contrary, to all appearance. A paleness and want of liveliness of the membranes, generally, may be considered as the first symptoms, to which may be added a yellowness of the caruncle at the corner of the eye. When in warm, sultry, or rainy weather, sheep that are grazing on low and moist lands, feed rapidly, and some of them die suddenly, there is ground for fearing that they have contracted the rot. This suspicion will be farther increased if, a few days afterward, the sheep begin to shrink and grow flaccid about the loins. By pressure about the hips at this time, a crackling is perceptible now or soon afterward, the countenance looks pale, and upon parting the fleece, the skin is found to have changed its vermilion tint for a pale red, and the wool is easily separated from the felt; and as the disorder advances, the skin becomes dappled with yellow or black spots. To these symptoms succeed increased dullness, loss of condition, and greater paleness of the mucous mem- 
branes, the eyelids becoming almost white, and afterward yellow. This yellowness extends to other parts of the body, and a watery fluid appears under the skin, the latter becoming loose and flabby, and the wool coming of readily. The symptoms of dropsy often extend over the body, and sometimes the sheep becomes chockered, as it is termed; a large swelling forms under the jaw, which, from the appearance of the fluid which it contains, is sometimes called the watery polke. The duration of the disease is uncertain; the animal occasionally dies shortly after becoming affected, but more frequently it extends. to from three to six months, the sheep gradually losing flesh and pining away, particularly if, as is frequently the case, an obstinate purging supervenes.

Post-mortem. The whole cellular tissue is found to be infiltrated, and a jellow serous fluid everywhere follows the knife. The muscles are soft and flabby, having the appearance of being macerated. The kidneys are pale, flaccid, and infiltrated. The mesenteric glands are enlarged, and engorged with yellow serous fluid. The belly is frequently flled with water, or purulent matter; the peritoneum is everywhere thickened, and the bowels adhere together by means of an unnatural growth. The heart is enlarged and softened, and the lungs are filled with tubercles. The principal alterations of structure are in the liver, which is pale, livid, and broken down with the slightest pressure; and on being boiled, it will almost dissolve away. When the liver is not pale, it is often curiously spotted; in some cases it is speckled, like the back of a toad; some parts of it, however, are hard and schirrous; others are ulcerated, and the biliary ducts are filled with flukes. The malady is, unquestionably, inflammation of the liver. 
This fluke is from three-quarters of an inch to an inch and a quarter in length, and from one-third to one-half an inch in its greatest breadth. These fluke-worms undoubtedly âggravate the disease, and perpetuate a state of irritability and disorganization, which must necessarily undermine the strength of any animal.

Treatment. This must, to a considerable extent, be very unsatisfactory. After the use of dry food and dry bedding, one of the best preventives is the abundant use of pure salt. In violent attacks, take eight, ten, or twelve ounces of blood, according to the circumstances of the case ; to this, let a dose of physic succeed-two or three ounces of Epsom salts; and to these means add a change of diet, good hay in the field, and hay, straw, or chaff in the yard. After the operation of the physic-an additional dose having been administered, oftentimes, in order to quicken the action of the first-two or three grains of calomel may be given daily, mixed with half the quantity of opium, in order to secure its beneficial, and ward off its injurious effects on the ruminant. To this should be added common salt, which acts as a purgative and a tonic A mild tonic, as well as an aperient, is plainly indicated soon. after the commencement of rot. The doses should be from two to three drachms, repeated morning and night. When the inflammatory stage is clearly passed, stronger tonics may be added to the salt, and there are none superior to the gentian and ginger roots; from one to two drachms of each, finely pounded, may be added to each dose of the salt. The sheep having a little recovered from the disease, should still continue on the best and driest pasture on the farm, and 
should always have salt within their reach. The rot is not infectious.

\section{SCAB.}

This is a cutaneous disease, analogous to the mange in horses and the itch in man, and is caused and propagated by a minute insect, the acarus.

If one or more female acari are placed on the wool of a sound sheep, they quickly travel to the root of it, and bury

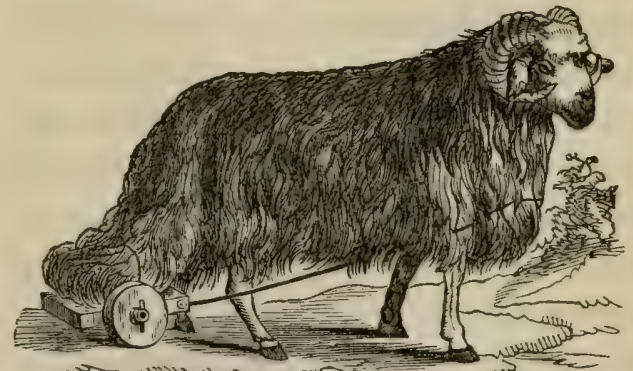

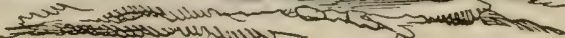

THE BROAD-TAILED SHEEP. themselves in the skin, the place at which they penetrate being scarcely visible, or only distinguishable by a minute red point. On the tenth or twelfth day, a little swelling may be detected with the finger, and the skin changes its color, and has a greenish blue tint. The pustule is now rapidly formed, and about the sixteenth day breaks, when the mothers again appear, with their little ones attached to their feet, and coverer by a portion of the shell of the egg from which they have just escaped. These little ones immediately set to work, penetrate the neighboring skin, bury themselves heneath it, find their proper nourishment, and grow and propagate, until the poor creature has myriads of them preying upon him. It is not wonderful that, under such circumstances, he should speedily sink. The male acari, when placed on the sound skin of a sheep, will likewise burrow their way and 
disappear for a while, the pustule rising in due time; but the itching and the scab soon disappear without the employment of any remedy. The female brings forth from eight to fifteen young at a time.

In the United States, this disease is comparatively little known, and nerer originates spontaneously. The fact, that short-woolled sheep-like the.Merino-are much less subject to its attacks, is probably one reason for this slight comparative prevalence. The disease spreads from individual to individual, and from flock to flock, not only by means of direct contact, but by the acari left on posts, stones, and other substances against which diseased sheep have rubbed themselves. Healthy sheep are, therefore, liable to contract the malady, if turned on pastures previously occupied by scabby sheep, although some considerable time may hare elapsed since the departure of the latter.

The sheep laboring under the scab is exceedingly restless. It rubs itself with violence against trees, stones, fences, etc.; scratches itself with its feet, bites its sores, and tears off its wool with its teeth; as the pustules are broken, their matter escapes, and forms scabs, causing red, inflamed sores, which constantly extend, increasing the misery of the tortured animal; if unrelieved, he pines away, and soon perishes.

The post-mortem appearances are very uncertain and inconclusive. There is generally chronic inflammation of the intestines, with the presence of a great number of worms. The liver is occasionally schirrous, and the spleen enlarged; and there are frequently serous effusions in the belly, and sometimes in the chest. There has been evident sympathy between the digestive and the cutaneous systems. 
Treatment. First, separate the sheep; then cut off the wool as far as the skin feels hard to the finger; the scab is then washed with soap-suds, and rubbed hard with a shoe-brush, so that it may be cleansed and broken. For this use take a decoction of tobacco, to which add one-third, by measure, of the lye of wood-ashes, as much hog's lard as will be dissolved by the lye, a small quantity of tar from a tar-bucket, which contains grease, and about one-eighth of the whole, by measure, of spirits of turpentine. This liquor is rubbed upon the part infected, and spread to a little distance around it, in three washings, with an interval of three days each. This will invariably effect a cure, when the disorder is only partial.

Or, the following: Dip the sheep in an infusion of arsenic, in the proportion of half a pound of arsenic to twelve gallons of water. The sheep should be previously washed in soap and water. The infusion must not be permitted to enter the mouth or nostrils.

Or, take common mercurial ointment; for bad cases, rub it down with three times its weight of lard-for ordinary cases, five times its weight. Rub a little of this ointment into the head of the sheep. Part the wool so as to expose the skin in a line from the head to the tail, and then apply a little of the ointment with the finger the whole way. Make a similar furrow and application on each side, four inches from the first; and so on, over the whole body. The quantity of ointment after composition with the lard, should not exceed two ounces; and, generally, less will suffice. A lamb requires but one-third as much as a grown sheep. This will generally cure; but, if the animal should continue to rub itself, a lighter application of the same should be made in ten days. 
Or, take two pounds of lard or palm oil; half a pound of oil of tar; and one pound of sulphur; gradually mix the last two, then rub down the compound with the first. Apply as before. Or, take of corrosive sublimate, one half a pound; white hellabore, powdered, three-fourths of a pound; whale or other oil, six gallons; rosin, two pounds; and tallow, two pounds. The first two to be mixed with a little of the oil, and the rest being melted together, the whole to be gradually mixed. This is a powerful preparation, and must not be applied too freely.

An erysipelatous scab, or erysipelas, attended with considerable itching, sometimes troubles sheep. This is a febrile disease, and is treated with a cooling purgative, bleeding, and oil or lard applied to the sores.

\section{SMALI-POX.}

The author.acknowledges himself indebted for what follows under this head to R. MIcClure, V.S., of Philadelphia, author of a Prize Essay on Diseases of Sheep, read before the U. S. Agricultural Society, in 1860, for which a medal and diploma were awarded.

Although the small-pox in domestic animals has, fortunately, been as yet confined to the European Continent-where it loas been chiefly limited to England-no good reason can ever be assigned why it should not at some future time make its appearance among us, especially when we remember how long a period elapsed, during which we escaped the cattle plague, although the Continent had long been suffering from it.

The small-pox in sheep-variola overia-is, at times, epizoötic in the flocks of France and Italy, but was unknown 
in England until 1847, when it was communicated to a flock at Datchett and another at Pinnier by some Merinos from Spain. It soon found its way into Hampshire and Norfolk, but was shortly afterward supposed to be eradicated. In 1862, however, it suddenly reappeared in a severe form among the flocks of Wiltshire; for which reappearance neither any traceable infection nor contagion could be assigned. With the present light upon the subject, it would seem to be an instance of the origination anew of a malignant type of varioloid discase. Such an origin is, in fact, assigned to this disease in Africa, it being well established that certain devitalizing atmospheric influences produce skin diseases, and facilitate the appearance of pustular eruptions.

The disease once rooted soon becomes epizoötic, and causes a greater mortality than any other malady affecting this animal. Out of a flock numbering 1720,920 were attacked in a natural way, of which 50 per cent. died. Of 800 inoculated cases, but 36 per cent. died.

Numerous experiments have proved beyond all doubt that this disease in sheep is both infectious and contagious; its period of incubation varies from seven to fourteen days. The mortality is never less than 25 per cent., and not unfrequently whole flocks have been swept away, death taking place in the early stages of the eruption, or in the stages of suppuration and ulceration.

The symptoms may be mapped out as follows: The animal is seized with a shivering fit, succeeded by a dull stupidity, which remains until death or recovery results; on the second or third day, pimples are seen on the thighs and arm-pits, accompanied with extreme redness of the eyes, complete 
loss of appetite, etc., etc. It is needless to enumerate other symptoms which exist in common with those of other disorders.

Prevention. At present, but two modes are resorted to, for the purpose of preventing the spread of the disease, which promise any degree of certainty of success. The first is by inoculation, which was recommended by Professor Simonds, of London. This distinguished pathologist appears to have orerlooked the fact that he was thereby only enlarging the sphere of mischief, by imparting the disease to animals that, in all probability, would otherwise have escaped it. By inoculation, moreover, a form of the disease is given, not of a modified character, but with all the virulence of the original affection which is to be arrested, and equally as potent for further destruction of others. By such teaching, inoculation and raccination would be made one and the same thing, notwithstanding their dissimilarity. Even raccination will not protect the animal, as has been already shown by the experiments of Hurbrel D'Arboval.

The second and best plan of prevention is isolation and destruction, as recommended by Professol Gamgee, of the Edinburgh Teterinary College. This proved a great protection to the sheep-farmers of Wiltshire, in 1862. In all epizoütic diseases, individual cases occur, which, when pointed out and recognized as soon as the fever sets in and the early eruptions appear, should be slaughtered at once and buried, and the rest of the flock isolated. By this means the disease has been confined to but two or three in a large flock.

Treatment. In treating this disease, resort has of late been had to a plant, known as Sarracenia purpura-Indian cup, 16 
or pitcher plant-used for this purpose by the Micmacs, a tribe of Indians in British North America. This plant is indigenous, perennial, and is found from the coast of Labrador to the shores of the Gulf of Mexico, growing in great abundance on wet, marshy ground. The use of this plant is becoming quite general, and good results have almost uniformly attended it.

Take from one to two ounces of the dried root, and slice in thin pieces; place in an earthen pot; add a quart of cold water, and allow the liquid to simmer gently over a steady fire for two or three hours, so as to lose one-fourth of the quantity. Give of this decoction three wine-glassfuls at once, and the same quantity from four to six hours afterwards, when a cure will generally be affected. Weaker and smaller doses are certain preventives of the disease. The public are inclebted to Dr. Morris, physician to the Halifax (Nova Scotia) Dispensary, for the manner of preparing this eminently useful article.

\section{SORE FACE.}

Sheep feeding on pastures infested with John's wort, frequently exhibit an irritation of skin about the nose and face, which causes the hair to drop off from the parts. The irritation sometimes extends over the entire body. If this plant is eaten in too large quantities, it produces violent inflammation of the bowels, and is frequently fatal to lambs, and sometimes to adults.

Treatment. Rub a little sulphur and lard on the irritated surface. If there are symptoms of inflammation of the bowels, 
SORE MOUTH-TICKS.

this should be put into the mouth of the sheep with a flattened stick. Abundance of salt is deemed a preventive.

\section{SORE MOUTH.}

The lips of sheep sometimes become suddenly sore in the winter, and swell to the thickness of a man's hand. The malady cccasionally attacks whole flocks, and becomes quite fatal. It is usually attributed to noxious weeds cut with the hay.

Treatment. Daub the lips and mouth plentifully with tar.

\section{TICKS.}

The treatment necessary as a preventive against these insects, and a remedy for them, has already been indicated under the head of "FeEding and Managenent," to which the reader is referred. 



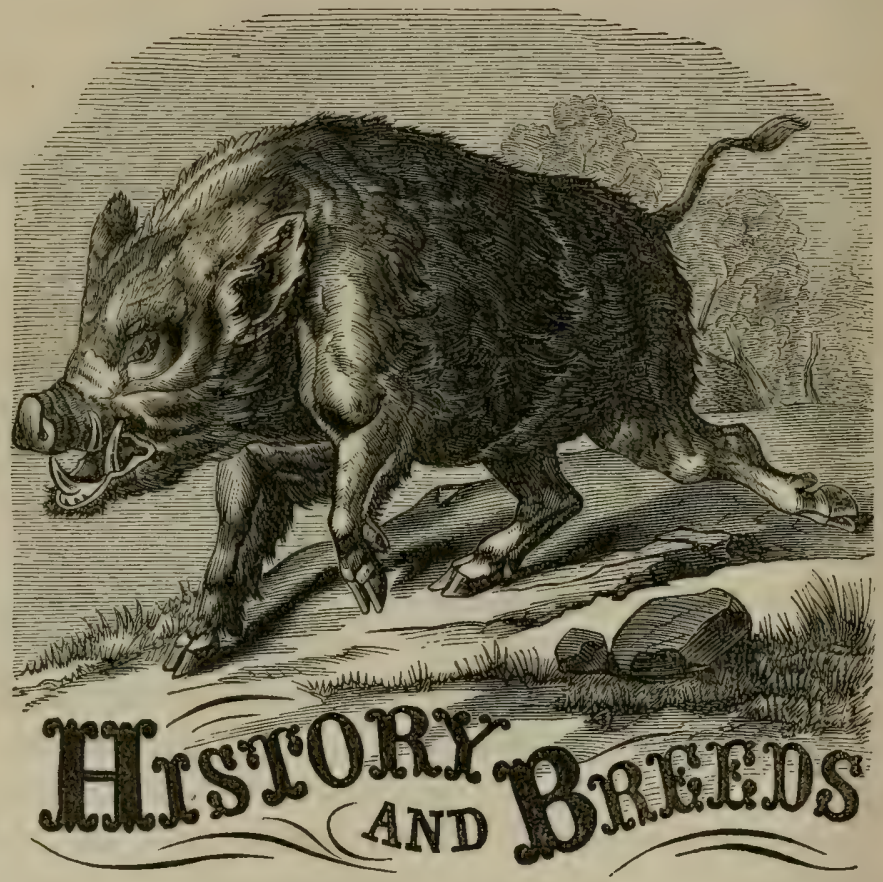

THE $\log$ is a cosmopolite, adapting itself to almost every climate; though its natural haunts-like those of the hippopotamus, the elephant, the rhinoceros, and most of the thickskinned animals-are in warm countries. They are most abundant in China, the East Indies, and the immense range of islands extending throughout the whole Southern and Pacific oceans; but they are also numerous throughout (7) 
Europe, from its Southern coast to the Russian dominions within the Arctic.

As far back as the records of history extend, this animal appears to have been known, and his flesh made use of as food. Nearly fifteen hundred years before Christ, Moses gave those laws to the Israelites which have given rise to so much discussion; and it is evident that, had not pork been the prevailing food of that nation at the time, such stringent commandments and prohibitions would not have been necessary. The various allusions to this kind of meat, which repeatedly occur in the writings of the old Greek authors, show the esteem in which it was held among that nation; and it appears that the Romans made the art of breeding, rearing, and fattening pigs a study. In fact, the hog was very highly prized among the early nations of Europe; and some of the ancients even paid it divine honors.

The Jews, the Egyptians, and the Mohammedans alone appear to have abstained from the flesh of swine. The former were expressly denied its use by the laws of Moses. "And the swine, though he divide the hoof, and be cloven-footed, yet he cheweth not the cud; he is unclean unto you." Lev. xi. 7. Upon this prohibition, Mohammed, probably, founded his own. For the Mosaic prohibition, various reasons have been assigned: the alleged extreme filthiness of the animal; it being afflicted with a leprosy; the great indigestibility of its flesh in hot climates; the intent to make the Jews " a peculiar people;" a preventive of gluttony; and an admonition of abstinence from sensual and disgusting liabits.

At what period the animal was reclaimed from his wild state, and by what nation, cannot be stated. From the 246 
carliest times, in England, the hog has been regarded as a very important animal, and vast herds were tended by swineherds, who watched over their safety in the woods, and collected them under shelter at night. Its flesh was the staple article of consumption in every household, and much of the wealth of the rich and free portion of the community consisted in these animals. Hence bequests of swine, with land for their support, were often made; rights and privileges connected with their feeding, and the extent of woodland to be occupied by a given number, were granted according to established rules. Long after the end of the Saxon dynasty, the practice of feeding swine upon the mast and acorns of the forest was continued till the forests were cut down, and the land laid open for the plough.

Nature designed the hog to fulfil many important functions in a forest country. By his burrowing after roots and the like, he turns up and destroys the larvæ of innumerable insects, which would otherwise injure the trees as well as their fruit. He destroys the slug-snail and adder, and thus not only rids the forests of these injurious and unpleasant inhahitants, but also makes them subservient to his own nourishment, and therefore to the benefit of mankind. The fruits which he eats are such as would otherwise rot on the ground and be wasted, or yield nutriment to vermin ; and his diggings for earth-nuts and the like, loosens the soil, and benefits the roots of the trees. Hogs in forest land may, therefore, be regarded as eminently beneficial; and it is only the abuse which is to be feared.

The hog is popularly regarded as a stupid, brutal, rapacious, and filtly animal, srovelling and disgusting in all his habits, 
intractable and obstinate in temper. The most offensire epithets anong men are borrowed from him, or his peculiarities. In their native state, however, swine seem by no means destitute of natural affections; they are gregarious, assemble together in defence of each other, herd together for warmth, and appear to have feelings in common; no mother is more tender to her joung than the sow, or more resolute in their lefence. Neglected as this animal has erer been by authors, recorded instances are not wanting of their sagacity, tractability, and susceptibility of affection. Among the European peasantry, where the $\log$ is, so to speak, one of the family, le may often be seen following his master from place to place, and grunting his recognition of his protectors.

The hog, in point of actual fact, is also a much more cleanly animal than he has the credit of being. IIe is fond of a good, cleanly bed; and when this is not provided for him, it is oftentimes interesting to note the degree of sagacity with which he will forage for himself. It is, however, so much the vogue to believe that he may be kept in any state of neglect, that the terms "pig," and "pig-sty" are usually regarded as synonymous with all that is dirty and disgusting. His rolling in the mud is cited as a proof of his filthy habits. This practice, which he shares in common with all the pachydermatous animals, is undoubtedly the teaching of instinct, and for the purpose of cooling himself and keeping off flies.

Pigs are exceedingly fond of comfort and warmth, and will nestle together in order to obtain the latter, and often strugggle vehemently to secure the warmest berth. They are likewise peculiarly sensitive of approaching changes in the weather, and may often be observed suddenly leaving the places in 248 
which they had been quietly feeding, and running off to their styes at full speed, making loud outcries. When storms are overhanging, they collect straw in their mouths, and run about as if inviting their companions to do the same; and if there is a shed or shelter near at hand, they will carry it there and deposit it, as if for the purpose of preparing a bed.

In their domesticated state, they are, undeniably, very greedy animals; eating is the business of their lires; nor do they appear to be very delicate as to the kind or quality of food which is placed before them. Although naturally herbivorous animals, they have been known to devour carrion with all the voracity of beasts of prey, to eat and mangle infants, and even gorge their appetites with their own joung. It is not, however, unreasonable to beliere that the last revolting act-rarely if ever happening in a state of nature-arises more from the pain and irritation produced by the state of confinement, and often filth, in which the animal is kept, and the disturbances to which it is subjected, than from any actual ferocity; for it is well known that a sow is always unusually irritable at this period, snapping at all animals that approach her. If she is gently treated, properly supplied with sustenance, and sequestered from all annoyance, there is little danger of this practice ever happening.

All the offences which swine commit are attributed to a disposition innately bad; whereas they too often arise from bad management, or total neglect. They are legitimate objects for the sport of idle boys, hunted with curs, pelted with stones, often neglected and obliged to find a meal for themselves, or wander about half-starved. Made thus the Ishmaelites of our domestic animals, is it a matter of wonder that 
they should, under such circumstances, incline to display Ishmaelitish traits.? In any well-regulated farm-yard, the swine are as tractable and as little disposed to wander or trespass as any of the animals that it contains.

The WILD BOAR is generally admitted to be the parent of the stock from which all our domesticated breeds and varieties have sprung. This animal is generally of a dusky brown or iron-gray color, inclining to black, and diversified with black spots or streaks. The body is covered with coarse hairs, intermixed with a downy wool ; these hairs become bristles as they approach the neck and shoulders, and are in those places so long as to form a mane, which the animal erects when irritated. The head is short, the forehead broad and flat, the ears short, rounded at the tips, and inclined toward the neck, the jaw armed with sharp, crooked tusks, which curre slightly upward, and are capable of inflicting fearful wounds, the eye full, neck thick and muscular, the shoulders high, the loins broad, the tail stiff, and finished off with a tuft of bristles at the tip, the haunch well turned, and the leg strong. A full-grown wild boar in India arerages from thirty to forty inches in height at the shoulder; the African wild boar is about twenty-eight or thirty inches high.

The wild boar is a very active and powerful animal, and becomes fiercer as he grows older. When existing in a state of nature, he is generally found in moist, shady, and wellwooded situations, not far remote from streams or water. In India, they are found in the thick jungles, in plantations of sugar-cane or rice, or in the thick patches of high, long grass. In England, France, Germany, Italy, and Spain, their resorts have been in the woods and forests. This animal is naturally 250 
herbivorous, and appears to feed by choice upon plants, fruits, and roots. He will, however, eat the worms and larvæ which he finds in the ground, also snakes and other such reptiles, and the eggs of birds. They seldom quit their corerts during the day, but prowl about in search of food during twilight and the night. Their acute sense of smell enables them to detect the presence of roots or fruits deeply imbedded in the soil, and they often do considerable mischief by ploughing up the ground in search of them, particularly as they do not, like the common hog, root up a little spot here and there, but plough long, continuous, furrows.

The wild boar, properly so called, is neither a solitary nor a gregarious animal. For the first two or three years, the whole herd follows the sow, and all unite in defence against any enemies, calling upon each other with loud cries in case of emergency, and forming in regular line of battle, the weakest occupying the rear. When arrived at maturity, the animals wander alone, as if in perfect consciousness of their strength, and appear as if they neitber sought nor avoided any living creature. They are reputed to live about thirty years; as they grow old, the hair becomes gray, and the tusks begin to show symptoms of decay. Old boars rarely associate with a herd, but seem to keep apart from the rest, and from each other.

The female produces but one litter in the year, much smaller in number than those of the domestic pig; she carries her young sixteen or twenty weeks, and generally is only seen 'with the male during the rutting season. She suckles her young for several months, and continues to protect them for some time afterward; if attacked at that time, she will defend 
herself and them with exceeding courage and ficreness. Many sows will often be found herding together, each followed by her litter of young; and in such parties they are exceedingly formidable to man and beast. Neither they nor the boar, however, seem desirous of attacking any thing; and only when roused by aggression, or disturbed in their retreat, do they turn upon their enemies and manifest the mighty strength with which Nature has endowed them. When attacked by dogs, the wild boar at first sullenly retreats, turning upon them from time to time and menacing them with his tusks; but gradually his anger rises, and at length he stands at bay, fights furiously for his life, and tears and rends

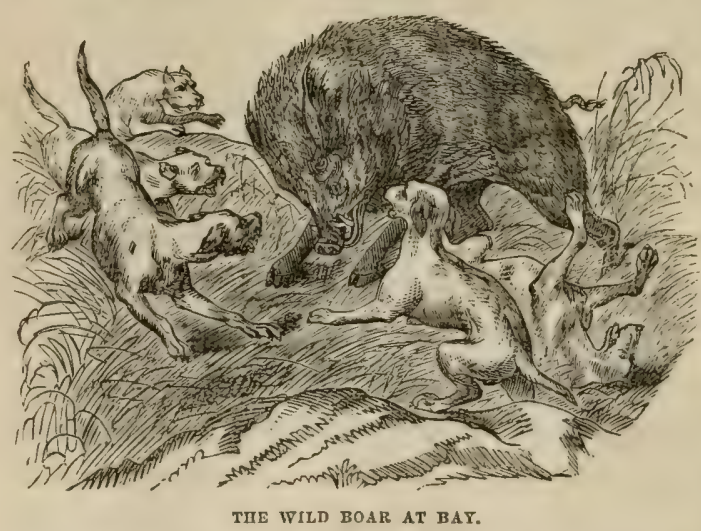

his persecutors. H e has even been observed to single out the most tormenting of them, and rush savagely upon him. Hunting this animal has been a favorite sport, in almost all countries in which it has been found, from the earliest ages.

Wild boars lingered in the forests of England and Scotland for several centuries after the Norman conquest, and many tracts of land in those countries derived their name from this circumstance; while instances of valor in their destruction are recorded in the heraldic devices of many of their noble 252 
families. The precise period at which the animal became cxterminated there cannot be precisely ascertained. They had, however, evidently been long extinct in the time of Charles I., since he endeavored to re-introduce them, and was at considerable expense to procure a wild boar and his mate from Germany. They still exist in Upper Austria, on the Syrian Alps, in many parts of Hungary, and in the forests of Poland, Spain, Russia, and Sweden; and the inhabitants of those countries hunt them with hounds, or attack them with fire-arms, or with the proper boar-spear.

All the varieties of the domestic hog will breed with the wild boar; the period of gestation is the same in the wild and the tame sow; their anatomical structure is identical; their general form bears the same characters; and their habits, so far as they are not changed by domestication, remain the same. Where individuals of the pure wild race have been caught young and subjected to the same treatment as a domestic pig, their ficceness has disappeared, they have become more social and less nocturnal in their habits, lost their activity, and lived more to eat. In the course of one or two generations, even the form undergoes certain modifications; the body becomes larger and heavier; the legs shorter, and less adanted for exercise ; the formidable tusks of the boar, being no longer needed as weapons of defence, disappear; the shape of the head and neck alters; and in character as well as in form, the animal adapts itself to its situation. Nor does it appear that a return to their native wilds restores to them their original appearance; for, in whatever country pigs have escaped from the control of man, and bred in the wilderness and woods, not a single instance is on record in which they 
have resumed the habits and form of the wild boar. They, indeed, become fierce, wild, gaunt, and grisly, and live upon roots and fruits; but they are, notwithstanding, merely degenerated swine, and they still associate together in herds, and do not walk solitary and alone, like their grim ancestors.

\section{AMERICAN SWINE.}

In the United States, swine have been an object of attention since its earliest settlement, and whenever a profitable market has been found for pork abroad, it has been exported to the full extent of the demand. Swine are not, however, indigenous to this country, but were doubtless originally brought hither by the early English settlers; and the breed thus introduced may still be distinguished by the traces they retain of their parent stock. France, also, as well as Spain, and, during the existence of the slave-trade, Africa, have also combined to furnish varieties of this animal, so much esteemed throughout the whole of the country, as furnishing a valuable article of food. For nearly twenty years following the commencement of the general European wars, soon after the organization of our national government, pork was a comparatively large article of commerce; but exports for a time diminished, and it was not until within a more recent period that this staple has been brought up to its former standard as an article of exportation to that country. The recent use which has been made of its carcass in converting it into lard oil, has tended to still further increase its consumption. By the census of 1860 , there were upward of thirty-two and a half millions of these animals in the United States.

They are reared in every part of the Union, and, when 254 
properly managed, always at a fair profit. At the extreme North, in the neighborhood of large markets, and on such of the Southern plantations as are particularly suited to sugar or rice, they should not be raised beyond the number required for the consumption of the coarse or refuse food produced. Swine are adrantageously kept in connection with a dairy or orchard; since, with little additional food besides what is thus afforded, they can be put in good condition for the butcher.

On the rich bottoms and other lands of the West, however, where Indian corn is raised in profusion and at small expense, they can be reared in the greatest numbers and yield the largest profit. The Scioto, Miami, Wabash, Illinois, and other valleys, and extensive tracts in Kentucky, Tennessee, Missouri, and some adjoining States, have for many years taken the lead in the production of Swine; and it is probable that the climate and soil, which are peculiarly suited to their rapid growth, as well as that of their appropriate food, will cuable them to hold their position as the leading pork-producers of the North American Continent.

The breeds cultivated in this country are numerous; and, like our native cattle, they embrace many of the best, and a few of the worst, to be found among the species. Great attention has been paid, for many years, to their improvement in the Eastern States; and nowhere are there better specimens than in many of their yards. This spirit has rapidly extended West and South; and among most of the intelligent farmers, who make them a leạding object of attention, on their rich corn-grounds, swine have attained a high degree of excellence. This does not consist in the introduction and perpetuity of any distinct races, so much as in the breeding up to a desir- 
able size and aptitude for fattening, from such meritorious individuals of any breed, or their crosses, as come within their reach.

\section{THE BYEFIFLD.}

This breed was formerly in high repute in the Eastern States, and did much good among the species generally. They are white, with fine curly hair, well made and compact, moderate in size and length, with broad backs, and at fifteen months attaining some three hundred to three hundred and fifty pounds net.

\section{THE BEDFORD.}

The Bedford or Woburn is a breed originating with the Duke of Bedford, on his estate at Woburn, and brought to their perfection, probably, by judicious crosses of the Chinese hog on some of the best English swine. A pair was sent by the duke to this country, as a present to General Washington; but they were dishonestly sold by the messenger, in Maryland, in which State, and in Pennsylvania, they were productive of much good at an early day, by their extensive distribution through different States. Several other importations of this breed have been made. at various times, and especially by the enterprising masters of the Liverpool packets, in the neighborhood of New York. They are a large, spotted animal, well made, and inclining to early maturity and fattening. This is an exceedingly valuable hog, but nearly extinct, both in England and in this country, as a breed. 
THE LEICESTER.

The old Leicestershire breed, in England, was a perfect type of the original hogs of the midland counties; large, ungainly, slab-sided animals, of a light color, and spotted with brown or black. The only good parts about them were their heads and ears, which showed greater traces of breeding than any other portions. These have been materially improved by various crosses, and the original breed has nearly lost all its peculiarities and defects. They may now be characterized as a large, white hog, generally coarse in the bone and hair, great eaters, and slow in maturing. Some varieties differ essentially in these particulars, and mature early on a moderate amount. of food. The crosses with small compact breeds are generally thrifty, desirable animals.

\section{THE YORKSHIRE.}

The old Yorkshire breed was one of the very large varieties, and one of the most unprofitable for a farmer, being greedy feeders, difficult to fatten; and unsound in constitution. They were of a dirty white or yellow color, spotted with black, had - long legs, flat sides, narrow backs, weak loins, and large bones. Their hair was short and wirey, and intermingled with numerous bristles about the head and neck, and their ears long. When full grown and fat, they seldom weighed more than from three hundred and fifty to four hundred pounds.

These have been crossed with pigs of the improved Leicester breed; and where the crossings have been judiciously managed, and not carried too far, a fine race of deep-sided. short-legged, 
thin-haired animals has been obtained, fattening kindly, and rising to a weight of from two hundred and fifty to four liundred pounds, when killed between one and two years old; and when kept over two years, reaching eren from five hundred to seven hundred pounds.

They have also been crossed with the Chinese, Neapolitan, and Berkshire breeds, and hardy, profitable, well-proportioned animals thereby obtained. The original breed, in its purity, size, and defectiveness, is now hardly to be met with, haring shared the fate of the other large old breeds, and giren phine. to smaller and more symmetrical animals. The Iorksine white is among the large breeds deserving commentation among us. To the same class belong also the large Miami white, and the Kenilworth; each frequently attaining, when dressed, a weight of from six hundred to eight hundred pounds.

\section{THE CHINESE.}

This hog is to be found in the southeastern countries of Asia, as Siam, Cochin China, the Burman Empire, Cambodia, Malacca, Sumatra, and in Batavia, and other Eastern islands; and is, without doubt, the parent stock of the best European and American swine.

There are two distinct varieties, the white and the black; both fatten readily, but from their diminutive size attain no great weight. They are small in $\operatorname{limb}$, round in body, short in the head, wide in the cheek, and high in the chime; covered with very fine bristles growing from an exceedingly thin skin; and not peculiarly symmetrical, since, when fat, the head is so buried in the neck that little more than the tip of 258 
the snout is risible. The pure Chinese is too delicate and su-ceptible to cold ever to become a really profitable animal in this country; it is difficult to rear, and the sows are not good nurses; but one or two judicious crosses have, in a manner, naturalized it. This

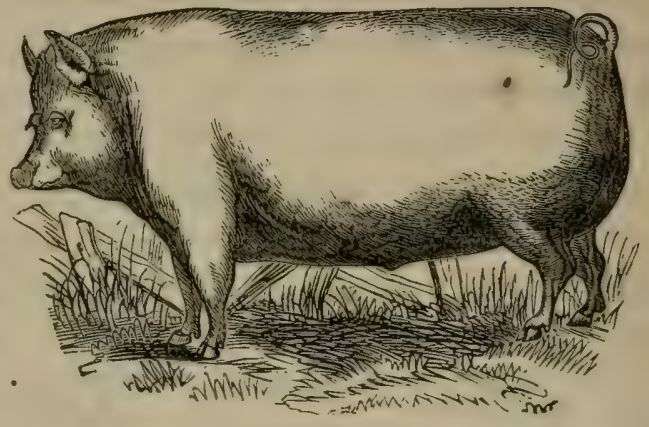
THE CHINESE HOG.

breed will fatten readily, and on a comparatively small quantity of food; the flesh is exceedingly delicate, but does not make good bacon, and is often too fat and oily to be generally esteemed as pork. They are chiefly kept by those who rear sucking-pigs for the market, as they make excellent roasters at three weeks or a month old. Five, and even seven, varieties of this breed are distinguished, but these are doubtless the results of different crosses with our native kinds; among these are black, white, black and white, spotted, blue and 'white, and'sandy.

Many valuable crosses have been made with these animals; for the prevalent fault of the old English breeds having been coarseness of flesh, unwieldiness of form, and want of aptitude to fatten, an admixture of the Chinese breed has materially corrected these defects. Most of our smaller breeds are more or less indebted to the Asiatic swine for their present compactness of form, the readiness with which they fatten on a small quantity of food, and their early maturity; but these 
advantages are not considered, in the judgment of some, as sufficiently great to compensate for the diminution in size, the increased delicacy of the animals, and the decrease of number in the litters. The best cross is between the Berkshire and Chinese.

\section{THE SUFFOLK.}

The old Suffolks are white in color, long-legged, longbodied, with narrow backs, broad foreheads, short hams, and

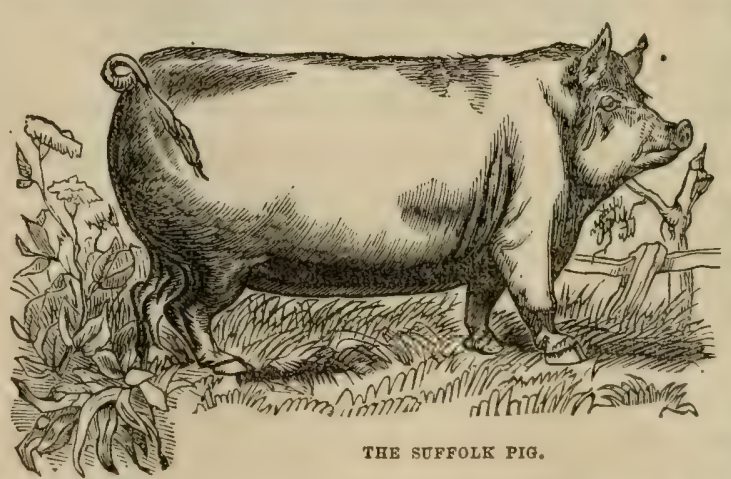

a $n$ abundance of brist 1 es. They are by no means profitable animals. $\cdot \mathbf{A}$ cross be tween the Suffolk and

Lincoln has produced a hardy animal, which fattens kindly, and attains the weight of from four hundred to five hundred and fifty, and even seven hundred pounds. Another cross, much approved by farmers, is that of the Suffolk and Berkshire.

There are few better breeds, perhaps, than the improved Suffolk-that is, the Suffolk crossed with the Chinese. The greater part of the pigs on the late Prince Albert's farm, near Windsor, were of this breed. They are well-formed, compact, of medium size, with round, bulky bodies, short legs, small heads, and fat cheeks. Many, at a year or fifteen months old, 260 
weigh from two hundred and fifty to three hundred pounds; at which age they make fine bacon hogs. The sucking-pigs are also very delicate and delicious.

Those arising from Berkshire and Suffolk are not so well shaped as the latter, being coarser, longer-legged, and more prominent about the hips. They are mostly white, with thin, fine hair; some few are spotted, and are easily kept in fine condition'; they have a decided aptitude to fatten early, and are likewise valuable as store-pigs.

\section{THE BERKSHIRE.}

The Berkshire pigs belong to the large class, and are distinguished by their color, which is a sandy or whitish brown, spotted regularly with dark brown or black spots, and by their having no bristles. The hair is long, th in, somewhat curly, and $100 \mathrm{ks}$ rough; the e ars are

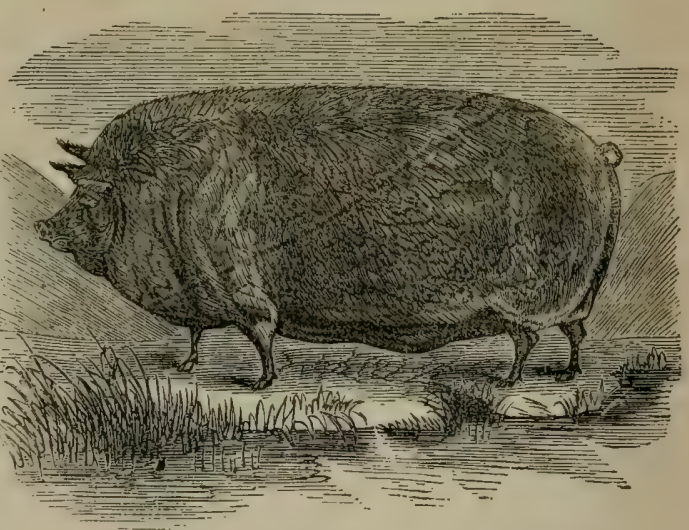

A BERKSHIRE BOAR.

fringed with long hair round the outer edge, which gives them a ragged or feathery appearance; the body is thick, compact, and well formed; the legs short, the sides broad, the head well set on, the snout short, the jowl thick, the ears erect, 
skin exceedingly thin in texture, the flesh firm and well flavored, and the bacon very superior. This breed has generally been considered one of the best in England, on account of its smallness of bone, early maturity, aptitude to fatten on little food, hardihood, and the females being good breeders. Hogs of the pure original breed have been known to weigh from eight hundred to nine hundred and fifty pounds.

Numerous crosses have been made from this breed; the principal foreign ones are those with the Chinese and Neapolitan swine, made with the view of decreasing the size of the animal, improving the flivor of the flesh, and rendering it more delicate; and the animals thus attained are superior to almost any others in their aptitude to fatten; but are very susceptible to cold, from being almost entirely without hair. A cross with the Suffolk and Norfolk also is much improved, which produces a hardy kind, yielding well when sent to the butcher; although, under most circumstances, the pure Berkshire is the best.

No other breerls have been so extensively diffused in the United States, within comparatively so brief a period, as the Berkshires, and they have produced a marked improvement in many of our former races. They weigh variously, from two hundred and fifty to four hundred pounds net, at sixteen months, according to their food and style of breeding; and some full-grown have dressed to more than eight hundred pounds. They particularly excel in their hams, which are round, full, and heary, and contain a large proportion of lean, tender, and juicy meat, of the best flavor.

None of our improved breeds afford long, coarse hair or bristles; and it is a gratifying evidence of our decided im262 
provement in this department of domestic animals, that our brush-makers are obliged to import most of what they use from Russia and northern Europe. This improvement is manifest not only in the hair, but in the skin, which is soft and mellow to the touch; in the finer bones, shorter head, upright ears, dishing face, delicate muzzle, and wild eye; and in the short legs, low flanks, deep and wide chest, broad back, and early maturity.

\section{THE NATURAL HISTORY OF THE HOG.}

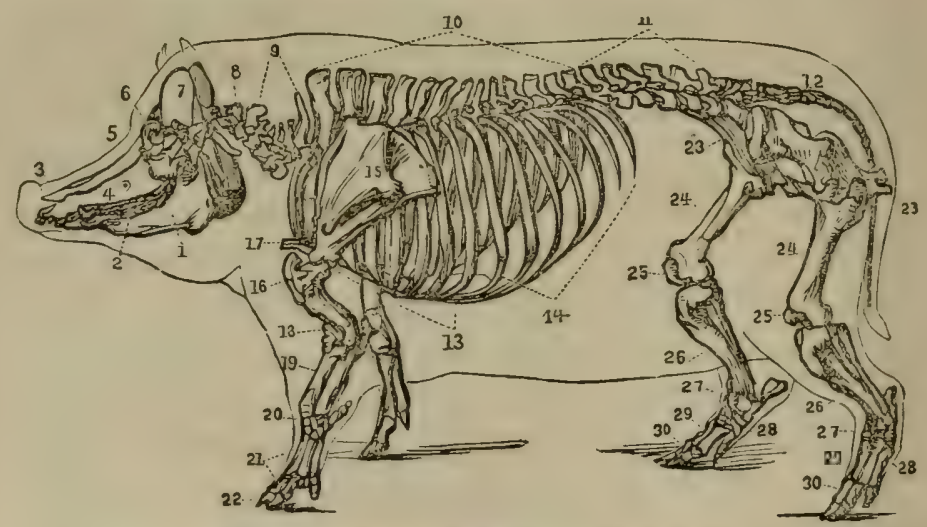

SEELETON OF THE HOG AS COVERED BY THE MUSCLES.

1. The lower jaw. 2. The teeth. 3. The nasal bones. 4. The upper jaw. 6. The Irontal bone. 6. The orbit or socket of the eye. 7. The occipital bone. 8. The first vertebræ of the neck. 9. The vertebræ of the neck. 10. The vertebræ of the back. 11. The vertebrx of the loins. 12. The bones of the tail. 13, 14 The true and false ribs. 15. The shoulder-blade. 16. The round shoulder-bone 17. The breast-bone. 18. The elbow. 19. The bone of the fore-arm, 20. The navicular bone. 21. The first and second bones of the foot. 22. The bones of the hoof. 23. The haunch bones. 24. The thigh bone. 25. The stifle bone, 26. The upper bone of the leg. 27. The hock bones. 23. The navicular bone. 29. The first digits of the foot. 30. The second digits of the foot.

Division. Vertebrata-possesșing a back-bone.

Cuass. Mammalia_such as give suck. 


\section{ORDER Pachydermata-thick-skinned.}

FAnILY. Suidoe-the swine kind.

Genus. Sus-the hog. Of this genus there are five varieties.

Sus Scropa, or Domestic Hog.

Sus Papuensis, or Bene.

Sus Guineensis, or Guinea Hog.

Sus Africanus, or Masked Boar.

Sus Babirussa, or Babirussa.

A very slight comparison of the face of this animal with that of any other will prove that strength is the object in view-strength toward the inferior part of the bone. In point of fact, the snout of the hog is his spade, with which, in his natural state, he digs and ruts in the ground for roots, earthnuts, worms, etc. To render this implement more nearly perfect, an extra bone is added to the nasal bone, being connected with it by strong ligaments, cartilages, and muscles, and termed the snout-bone, or spade-bone, or ploughshare. By it and its cartilaginous attachment, the snout is rendered strong as well as flexible, and far more efficient than it otherwise could be; and the hog often continues to give both farmers and gardeners very unpleasant proofs of its efficiency, by ploughing up deep furrows in newly-sown fields, and grubbing up the soil in all directions in quest of living and dead food.

As roots and fruits buried in the earth form the natural food of the hog, his face terminates in this strong, muscular snout, insensible at the extremity, and perfectly adapted for turning up the soil. There is a large plexus or fold of nerves proceeding down each side of the nose; and in these, doubtless, resides 264 
that peculiar power which enables the hog to select his food, though buried some inches below the surface of the ground. The olfactory nerve is likewise large, and occupies a middle rank between that of the herbivorous and carnivorous animals ; it is comparatively larger than that of the ox; indeed, few animals-with the exception of the dog, none-are gifted with a more acute sense of smell than the hog. To it epicures are indebted for the truffles which form such a delicious sauce, for they are the actual finders. A pig is turned into a field, allowed to pursue his own course, and watched. He stops, and begins to grub up the earth; the man hurries up, drives him away, and secures the truffe, which is invariably growing under that spot; and the poor pig goes off to sniff out another, and another, only nor and then being permitted, by way of encouragement, to reap the fruits of his research.

\section{FORMATION OF TEE TEETH.}

The hog has fourteen molar teeth in each jaw, six incisors, and two canines; these latter are curved upward, and commonly denominated tushes. The molar teeth are all slightly different in structure, and increase in size from first to last; they bear no slight resemblance to those of the human being. The incisors are so fantastic in form that they cannot well be described, and their destined functions are by no means clear. Those in the lower jaw are long, round, and nearly straight; of those in the upper jaw, four closely resemble the corresponding teeth in the horse; while the two corner incisors bear something of the shape of those of the dog. These latter are placed so near the tushes as often to obstruct their growth, and it is sometimes necessary to draw them, in order to relieve the animal and enable him to feed. 
The hog is born with two molars on each side of the jaw ; by the time he is three or four months old, he is provided with his incisive milk-teeth and the tushes; the supernumerary molars protrude between the fifth and seventh month, as does the first back molar; the second back molar is cut at about the age of ten montlis; and the third, generally, not until the animal is three years old. The upper corner teeth are shed at abqut the age of six or eight months; and the lower ones at about seren, nine, or ten months old, and replaced by the permanent ones. The milk tushes are also shed and replaced between six and ten months old. The age of twenty months, and from that to two years, is denoted by the shedding and replacement of the middle incisors, or pincers, in both jaws, and the formation of a black circle at the base of each of the tushes. At about two years and a half or three years of age, the adult middle teeth in both jaws protrude, and the pincers are becoming black and rounded at the ends.

After three years, the age may be computed by the growth of the tushes; at about four years, or rather before, the upper tushes begin to raise the lip; at five, they protrude through the lips; and at six years, the tushes of the lower jaw begin to show themselves out of the mouth, and assume a spiral form. These acquire a prodigious length in old animals, and particularly in uncastrated boars; and as they increase in size, they become curved backward and outward, and at length are so crooked as to interfere with the motion of the jaws to such a degree that it is necessary to cut off those projecting teeth, which is done with the file, or with nippers. 


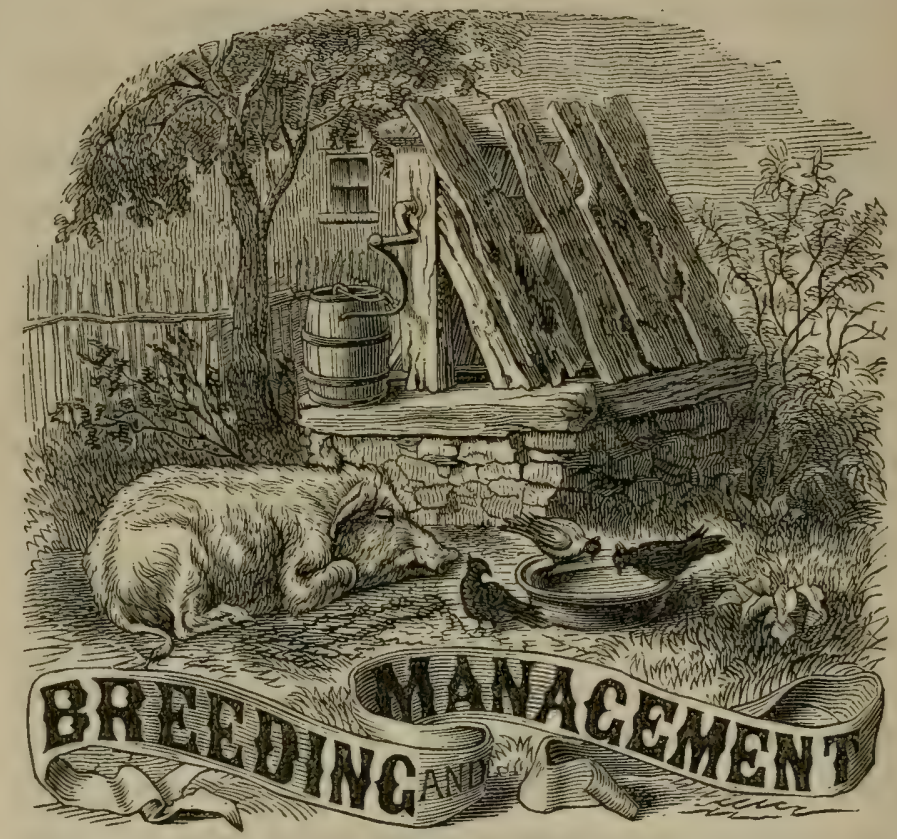

IN the selection of a boar and sow for breeding, much more attention and consideration are requisite than is generally imagined. It is as easy, with a very little judgment and management, to procure a good as an inferior breed; and the former is much more remunerative, in proportion to the outlay, than the latter can possibly ever be.

The object of the farmer or breeder is to produce and retain such an animal as will be best adapted to the purpose he has (29) 
in view, whether that is the consumption of certain things which could not otherwise be so well disposed of, the converting into hams, bacon, and pork, or the raising of sucking-pigs and porkers for the market. Almost all farmers keep one or more pigs to devour the offal and refuse, which would otherwise be wasted. This is, however, a matter totally distinct from breeding swine. In the former case, the animal or animals are purchased young for a small price, each person buying as many as he considers he shall have food enough for, and then sold to the butcher, or killed, when in proper condition; and thus a certain degree of profit is realized. In the latter, many contingencies must be taken into account: the available means of feeding them; whether or not the food may be more profitably disposed of; the facilities afforded by railroads, the vicinity of towns, or large markets, etc., for disposing of them.

In the breeding of swine, as much as that of any other livestock, it is important to pay great attention, not only to the breed, but also to the choice of individuals. The sow should produce a great number of young ones, and she must be well fed to enable her to support them. Some sows bring forth ten, twelve, or even fifteen pigs at a birth; but eight or nine is the usual number; and sows which produce fewer than this must be rejected. It is, however, probable that fecundity depends also on the boar; he should, therefore, be chosen from a race which multiplies quickly.

If a bacon and a late market be objects, the large and heary varieties should be selected, care being taken that the breed has the character of possessing those qualities most likely to insure a heavy return-growth, and facility of taking: 268 
fat. Good one-year bacon-hogs being in great demand, they may be known by their lang bodies, low bellies, and short legs. With these qualities are usually coupled long, pendulous ears, which attract purchasers. If, however, hogs are to be sold at all seasons to the butchers, the animals must attain their full growth and be ready for killing before they are a year old. This quality is particularly prominent in the Chinese breed; but among our ordinary varieties, hogs are often met with better aclapted for this purpose than for producing large quantities of bacon and lard. The Berkshire crossed with Chinese is an excellent porker.

The sow should be chosen from a breed of proper size and shape, sound and free from blemishes and defects. In every casc-whether the object be pork or bacon-the points to be looked for in the sow are a small, lively head; a broad and deep chest; round ribs; capacious barrel; a haunch falling almost to the hough; deep and broad loin; ample hips; and considerable length of body, in proportion to its height. One qualification should ever be kept in view, and, perhaps, should be the first point to which the attention should be directedthat is, smallness of bone. She should have at least twelve teats; for it is observed that each pig selects a teat for himself and keeps to it, so that a pig not having one belonging to him would be starved. A good sow should produce a great number of pigs, all of equal vigor. She must be very careful of them, and not crush them by her weight; above all, she must not be addicted to eating the after-birth, and; what may often follow, her own young. If a sow is tainted with those bad habits, or if she has difficult labors, or brings forth dead pigs, she must be spayed forthwith. It is, therefore, well to 
bring up several young sows at once, so as to keep those only which are free from defects. Breeding sows and boars should never be raisel from defective animals. Sows that have very low bellies, almost touching the ground, seldom produce large or fine litters. A good-sized sow is gencrally considered more likely to prove a good breeder aml nurse, and to farrow more easily and safely than a small, dulicate animal.

The ancients considered the distinguishing marks of a good boar to be a small head, short legs, a long body, large thighs and neck, and this latter part thickly covered with strong, erect bristles. The most experienced modern breeders prefer an animal with a long, cylindrical body; small bones; nelldeveloped muscles; a wide chest, which denotes strength of constitution: a broad, straight back; short head and fine snout; brilliant eyes; a short, thick neck; broad, well-developed shoulders; a loose, mellow skin; fine, bright, long hair, and few bristles; and small lcgs and hips. Some give the preference to long, flapping ears; but experience scems to demonstrate that those animals are best which have short, erect, fine ears The boar should always be vigorous and masculine in appearance.

Few domesticated animals suffer so much from in-and-in breeding as swine. Where this system is pursued, the number of young ones is decreased at every litter, until the sows become, in a manner, barren. This practice also undoubtedly contributes to their liability to hereditary diseases, such as scrofula, epilepsy, and rheumatism; and when those possessing any such diseases are coupled, the ruin of the flock is easily and speedily effected, since they are propagated by 270 
either parent, and always most certainly and in most aggravated form, when occurring in both. As soon as the slightest degeneracy is observed, the breed should be crossed from time to time, keeping sight, however, while so doing, of the end in view. The Chinese will generally be found the best which can be used for this purpose; since $\iota$ single cross, and eren two, with one of these animals, will seldom do harn, but often effect considerable improvements. The best formed of the progeny resulting from this cross must be selected as breeders, and with them the old original stock crossed back again. Selection, with judicious and cautious admixture, is the true secret of forming and improving the breed. Repeated and indiscriminate crosses are as injurious as an obstinate adherence to one particular breed, and as much to be avoided.

The following rules for the selection of the best stock of hogs will apply to all breeds:

Fertility. In a breeding suw, this quality is essential, and it is one which is inherited. Besides this, she should be a careful mother. A young, untried sow will generally display in her tendencies those which have predominated in the race from which she has descended. Both boar and sow should be sound, healthy, and in fair, but not over fat, condition.

Form Where a farmer has an excellent breed, but with certain defects, or too long in the limb, or too heavy in the bone, the sire to be chosen, whether of a pure or of a cross breed, should exhibit the opposite qualities, even to an extreme; and be, moreover, one of a strain noted for early and rapid fattening. If in perfect health, young stock selected 
for breeding will be lively, animated, hold up the head, and move freely and nimbly.

Bristles. These should be fine and scanty, so as to show the skin smooth and glossy; coarse, wirey, rough bristles usually accompany heary bones, large, spreading hoofs, and flapping ears, and thus become one of the indications of a thick-skinned and low breed.

Color. Different breeds of high excellence have their own colors; white, black, parti-colored, black and white, sandy, mottled with large marks of black, are the most prevalent. A black skin, with short, scanty bristles, and small stature, demonstrate the prevalence of the Neapolitan strain, or the black Chinese, or, perhaps, an admixture of both. Many prefer white; and in sucking-pigs, destined for the table, and for porkers, this color has its advantages, and the skin looks more attractive; it is, however, generally thought that the skin of black hogs is thimner than that of white, and less subject to eruptive diseases.

The influence of a first impregnation upon subsequent progeny by other males is at times curiously illustrated. This has been noticed in respect of the sow. A sow of the black and white breed, in one instance, became pregnant by a boar of the wild breed of a deep chestnut color. The pigs produced were duly mixed, the color of the boar being very predominant in some. The sow being afterwards put to a boar of the same breed as herself, some of the produce were still stained or marked with the chestnut color which prevailed in the first litter; and the same occurred after a third impregnation, the boar being then of the same kind as herself. What adds to the force of this case is, that in the course of many years' 272 
observation, the breed in question was never known to produce progeny having the slightest tinge of chestnut color.

A sow is capable of conceiving at the age of six or seven months; but it is always better not to let her commence breeding too early, as it tends to weaken her. From ten to twelve months-and the latter is preferable-is about the best age. The boar should be, at least, a twelvemonth old-some even recommend eighteen months, at least-before he is employed for the purpose of propagating his species. If, however, the sow has attained her second year, and the boar his third, a vigorous and numerous offspring is more likely to result. The boar and sow retain their ability to breed for almost five years; that is, until the former is upward of eight years old, and the latter seven. It is not advisable, however, to use a boar after he has passed his fifth year, nor a sow after her fourth, unless she has proved a peculiarly valuable breederin which case she might produce two or three more litters.

A boar left on the pasture, at liberty with the sows, might suffice for thirty or forty of them; but as he is commonily shut up, and allowed access at stated times only, so that the young ones may be born at nearly the same time, it is usual to allow him to serve from six to ten-on no account should he serve more. The best plan is, to shut up the boar and sow in a sty together; for, when turned in among several females, he is apt to ride them so often that he exhausts himself without effect. The breeding boar should be fed well and kept in high condition, but not fat. Full grown boars being often savage and difficult to tame, and prone to attack men and animals, should be deprived of their tusks.

Whenever it is practicable, it should always be so arranged 18 
that the animals shall farrow early in the spring, and at the latter end of summer, or quite the beginning of autumn. In the former case, the young pigs will have the run of the early pastures, which will be a benefit to them, and a saving to their owners; and there will also be more whey, milk, and other dairy produce which can be spared for them by the time they are ready to be weaned. In the second case, there will be sufficient time for the young to have grown and acquired strength before the cold weather comes on, which is always very injurious to sucking-pigs.

\section{POINTS OF A GOOD HOG.}

It may be not amiss to group together what is deemed desirable under this head. No one should be led away by mere name in his selection of a hog. It may be called a Berkshire, or a Suffolk, or any other breed most in estimation, and yet, in reality, may possess none of this valuable blood. The only sure way to aroid imposition is, to make name always secondary to points. If a hog is found possessing such points of form as are calculated to insure early maturity and faculty of taking on flesh, one needs to care but little by what name he is called; since no mere name can bestow value upon an animal deficient in the qualities already indicated.

The true Berkshire-that possessing a dash of the Chinese and Neapolitan varieties-comes, perhaps, nearer to the desired standard than any other.

The chief points which characterize such a hog are the following :- In the first place, sufficient depth of carcass, and such an elongation of body as will insure a sufficient lateral expan. sion. The loin and breast should be broad. The breadth of 274 
the former denotes good room for the play of the lungs, and, as a consequence, a free and healthy circulation, essential to the thriving or fattening of any animal. The bone should be small, and the joints fine-nothing is more indicative of high - breeding than this; and the legs should be no longer than, when fully fat, would just prevent the animal's belly from trailing upon the ground. The leg is the least profitable portion of the hog, and no more of it is required than is absolutely necessary for the support of the rest. The feet should be firm and sound; the toes should lie well together, and press straightly upon the ground ; the claws, also, should be even, upright and healthy.

The form of the head is sometimes deemed of little or no consequence, it being generally, perhaps, supposed that a good hog may have an ugly head; but the head of all animals is one of the very principal points in which pure or impure breeding will be most obviously indicated. A high-bred animal will invariably be found to arrive more speedily at maturity, to take flesh more easily, and at an earlier period, and, altogether, to turn out more profitably than one of questionable or impure stock. Such being the case, the head of the hog is a point by no means to be overlooked. The description of head most likely to promise-or, rather to be the accompaniment of-high breeding, is one not carrying heary bones, not too flat on the forehead, or possessing a snout too elongated; the snout should be short, and the forehead rather convex, curving upward; and the ear, while pendulous, should incline somewhat forward, and at the same time be light and thin. The carriage of the pig should also be noticed. If this be dull, heavy, and dejected, one may reason- 
ably suspect ill health, if not some concealed disorder actually existing, or just about to break forth; and there cannot be a more unfavorable symptom than a bung-down, slouching head. Of course, a fat hog for slaughter and a sow heavy with young, have not much sprightliness of deportment.

Color is, likewise, not to be disregarded. Those colors are preferable which are characteristic of the most esteemed breeds. If the hair is scant, black is desirable, as denoting connection with the Neapolitan; if too bare of hair, a too intimate alliance with that variety may be apprehended, and a consequent want of hardibood, which-however unimportant, if pork be the object-renders such animals a hazardous speculation for store purposes, on account of their extreme susceptibility of cold, and consequent liability to disease. If white, and not too small, they are valuable as exhibiting connection with the Chinese. If light, or sandy, or red with black marks, the favorite Berkshire is detected; and so on, with reference to every possible variety of hue.

\section{TREATMENT DURING PREGNANCY.}

Sows with pigs should be well and judiciously fed; that is to say, they should have a sufficiency of wholesome, nutritious food to maintain their strength and keep them in good condition, but should by no means be allowed to get fat; as when they are in high condition, the dangers of parturition are enhanced, the animal is more awkward and liable to smother and crush her young, and, moreover, never has as much or as good milk as a leaner sow. She should also have a separate sty; for swine are prone to lie so close together that, if she is even among others, her young would be in 276 
great danger; and this sty should be perfectly clean and comfortably littered, but not so thickly as to admit of the young being able to bury themselves in the straw.

As the time of her farrowing approaches, she should be well supplied with food, especially if she be a young sow, and this her first litter, and also carefully watched, in order to prevent her devouring the after-birth, and thus engendering a morbid appetite which will next induce her to fall upon her own young. A sow that has once done this can never afterward be depended upon. Hunger, thirst, or irritation of any kind, will often induce this unnatural conduct, which is another reason why a sow about to farrow should have a sty to herself, and be carefully attended to, and have all her wants supplied.

\section{ABORTION.}

This is by no means of so common occurrence in the case of the sow as in many other of the domesticated animals. Various causes tend to produce it: insufficiency of food, eating too much succulent vegetable food, or unwholesome, unsubstantial diet; blows and falls; and the animal's habit of rubbing itself against hard bodies, for the purpose of allaying the irritation produced by the vermin or cutaneous eruptions to which it is subject. Reiterated copulation does not appear to produce abortion in the sow; at least to the extent it does in other animals.

The symptoms indicative of approaching abortion are similar to those of parturition, but more intense. There are, generally, restlessness, irritation, and shivering; and the cries of the animal evince the presence of severe labor-pains. 
Sometimes the rectum, vagina, or uterus, becomes relaxed, and one or the other protrudes, and often becomes inverted at the moment of the expulsion of the fœtus, preceded by the placenta, which presents itself foremost.

Nothing can be done, at the last hour, to prevent abortion; but, from the first, every predisposing cause should be removed. 'The treatment will depend upon circumstances. Where the animal is young, vigorous, and in high condition, bleeding will be beneficial-not a copious blood-letting, but small quantities taken at different times; purgatives may also be administered. If, when abortion has taken place, the whole of the litter was not born, emollient injections may be resorted to with considerable benefit; otherwise, the after treatment should be made the same as in parturition, and the animal should be kept warm, quiet, and clean, and allowed a certain degree of liberty. Whenever one sow has aborted, the causes likely to have produced this accident should be sought, and an endeavor made, by removing them, to secure the rest of the inmates of the piggery from a similar mishap.

In cases of abortion, the fotus is seldom born alive, and often has been dead for some days; where this is the casewhich may be readily detected by a peculiarly unpleasant putrid exhalation, and the discharge of a fetid liquid from the vagina-the parts should be washed with a diluted solution of chloride of lime, in the proportion of one part of chloride to three parts of water, and a portion of this lotion gently injected into the uterus, if the animal will submit to it. Mild doses of Epsom salts, tincture of gentian, and Jamaica ginger, will also act beneficially in such cases, and, with attention to diet, soon restores the animal.

278 


\section{PARTURITION.}

The period of gestation varies according to age, constitution, food, and the peculiarities of the individual breed. The most usual period during which the sow carries her young is, according to some, t h r e e months, $\mathrm{t} h \mathrm{r}$ e e weeks, and three days,

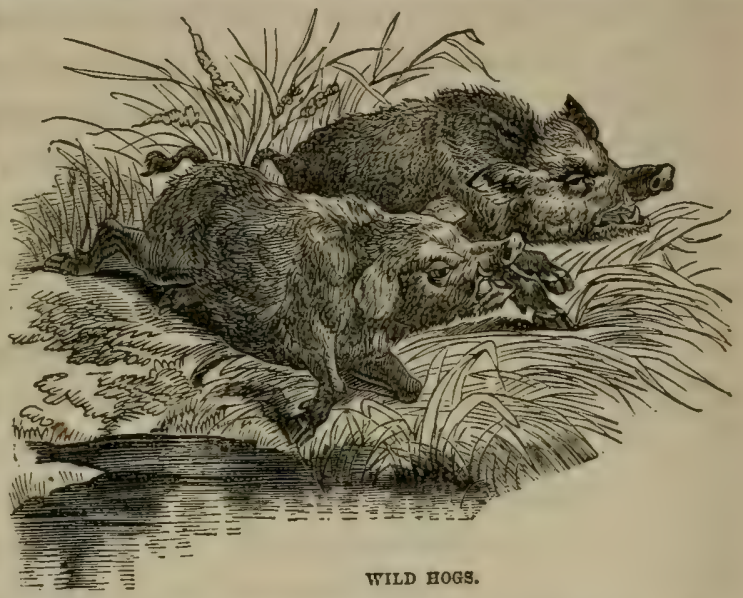
or one hundred and eight days; according to others, four lunar months, or sixteen weeks, or about one hundred and thirteen days. It may safely be said to range from one hundred and nine to one hundred and forty-three days.

The sow produces from eight to thirteen young at a litter, and sometimes even more. Young and weakly sows not only produce fewer pigs, but farrow earlier than those of maturer age and sounder condition; and besides, as might be expected, their offspring are deficient in vigor, oftentimes, indeed, puny and feeble. Extraordinary fecundity is not however, desirable, for nourishment cannot be afforded to more than twelve, the sow's number of teats. The supernumerary pigs must therefore suffer ; if but one, it is, of course, 
the smallest and weakest; a too numerous litter are all, indeed, generally undersized and weakly, and seldom or never prove profitable; a litter not excecding ten will usually be found to turn out most advantageously. On account of the discrepancy between the number farrowed by different sows, it is a good plan, if it can be managed, to have more than one breeding at the same time, in order that the number to be suckled by each may be equalized. The sow seldom recognizes the presence of a strange little one, if it has been introduced among the others during her absence, and has lain for half an hour or so among her own offspring in their sty.

The approach of the period of farrowing is marked by the immense size of the belly, by a depression of the back, and by the distention of the teats. The animal manifests symptoms of acute suffering, and wanders restlessly about, collecting straw, and carrying it to her sty, grunting piteously meanwhile. As soon as this is observed, she should be persuaded into a separate sty, and carefully watched. On no account should several sows be permitted to farrow in the same place at the same time, as they will inevitably irritate each other, or devour their own or one another's young.

The young ones should be taken away as soon as they are born, and deposited in a warm spot; for the sow being a clumsy animal, is not unlikely in her struggles to overlie them; nor should they be returned to her, until all is over, and the after-birth has been removed, which should always be done the moment it passes from her; for young sows, especially, will invariably devour it, if permitted, and then, as the young are wet with a similar fluid, and smell the same, they will eat them also, one after another. Some advise 250 
washing the backs of young pigs with a decoction of aloes, colocynth, or some other nauseous substance, as a remedy for this; but the simplest and easiest one is to remove the little ones until all is over, and the mother begins to recover herself and seek alout for them, when they should be put near her. Some also recommend strapping up the sow's mouth for the first three or four days, only releasing it to admit of her taking her meals.

Some sows are apt to lie upon and crush their young. This may best be avoided by not keeping her too fat or heavy, and by not leaving too many young upon her. The straw forming the bed should likewise be short, and not in too great quantity, lest the pigs get huddled up under it, and the sow unconsciously over-lie them in that condition.

It does not always happen that the parturition is effected with ease. Cases of false presentation, of enlarged fœtus, and of debility in the mother, often render it difficult and dangerous. The womb will occasionally become protruded and inverted, in consequence of the forcing pains of difficult parturition, and even the bladder has been known to come away. These parts must be returned as soon as may be; and if the womb has come in contact with the dung or litter, and acquired any dirt, it must first be washed in lukewarm water, and then returned, and confined in its place by means of a suture passed through the lips of the orifice. The easiest and perhaps the best way, however, is not to return the protruded parts at all, but merely tie a ligature round them and leave them to slough off, which they will do in the course of a few days, without effusion of blood, or farther injury to the animal. No sow 
that has once suffered from protrusion of the womb should be allowed to breed again.

\section{TREATMENT WHILE SUCKLING.}

Much depends upon this; as many a fine sow and promising litter have been ruined for want of proper and judicious care at this period. Immediately after farrowing, many sows incline to be feverish; where this is the case, a light and sparing diet only should be given them for the first day or two, as gruel, oatmeal porridge, whey, and the like. Others, again, are very much debilitated, and require strengthening; for them, strong soup, bread steeped in wine, or in a mixture of brandy and sweet spirits of nitre, administered in small quantities, will often prove highly beneficial.

The rations must gradually be increased and given more frequently; and they must be composed of wholesome, nutritious, and succulent substances. All kinds of roots-carrots, turnips, potatoes, and beet-roots-well steamed or boiled, but never raw, may be given; bran, barley, and oatmeal, branflour, Indian corn, whey, sour, skim, and butter-milk, are all well adapted for this period; and, should the animal appear to require it, grain well bruised and macerated may be added. Whenever it is possible, the sow should be turned out for an hour each day, to graze in a meadow or clover-field, as the fresh air, exercise, and herbage, will do her immense good. The young pigs must be shut up for the first ten days or fortnight, after which they will be able to follow her, and take their share of the benefit.

The food should be given regularly at certain hours; small and often-repeated meals are far preferable to large ones, since 282 
indigestion, or any disarrangement of the functions of the stomach vitiates the milk, and produces diarrhœa and other similar affections in the young. The mother should always be well fed, but not over-fed; the better and more carefully she is fed, the more abundant and nutritious will her milk be, the better will the sucking-pigs thrive, and the less will she be reduced by suckling them.

When a sow is weakly, and has not a sufficiency of milk, the young pigs must be taught to feed as early as possible. A kind of gruel, made of skim-milk and bran, or oatmeal, is a good thing for this purpose, or potatoes, boiled and then mashed in milk or whey, with or witbout the addition of a little bran or oatmeal. Toward the period when the pigs are to be weaned, the sow must be less plentifully fed, otherwise the secretion of milk will be as great as ever; it will, besides, accumulate, and there will be hardness, and perhaps inflammation of the teats. If necessary, a dose of physic may be given to assist in carrying off the milk; but, in general, a little judicious management in the feeding and weaning will be all that is required.

\section{TREATMENT OF YOUNG PIGS.}

For the first ten days, or a fortnight, the mother will generally be able to support her litter without assistance, unless, as has been already observed, she is weakly, or her young are too numerous; in either of which cases they must be fed from the first. When the young pigs are about a fortnight old, warm milk should be given to them. In another week, this may be thickened with some species of farina; and afterward, as they gain strength and increase in size, boiled 
roots and regetables may be added. As soon as they hey to eat, an open frame or railing should be placed in the sty, under which the little pigs can run, and on the otherofe d so this should be the small troughs containing their food; for it never answers to let them eat out of the same trough with their mother, because the food set before her is generally too strong and stimulating for them, even if they should secure any of it, which is, to say the least, extremely doubtful. Those intended to be killed for sucking-pigs should not be above four weeks old; most kill them for this purpose on the twenty-first or twenty-second day. The others, excepting those kept for breeding, should be castrated at the same time.

\section{CASTRATION AND SPAYING.}

Pigs are chiefly castrated with a view to fattening them; and, doubtless, this operation has the desired effect-for at the same time that it increases the quiescent qualities of the animal, it diminishes also his courage, spirits, and nobler attributes, and even affects his form. The tusks of a castrated boar never grow like those of the natural animal, but always have a dwarfed, stunted appearance. The operation, if possible, should be performed in the spring or autumn, as the temperature is the more uniform, and care should be taken that the animal is in perfect health. Those which are fat and plethoric should be prepared by bleeding, cooling diet and quiet. Pigs are castrated at all ages, from a fortnight to three, six and eight weeks, and even four months old.

There are various modes of performing this operation. If the pig is not more than six weeks old, an incision is made at 284 
the bottom of the scrotum, the testicle pushed out, and the cord cut, without any precautionary means whatever. When the animal is older, there is reason to fear that hemorrhage, to a greater or less extent, will supervene; consequently, it will be advisable to pass a ligature round the cord a little above the spot where the division is to take place.

By another mode-to be practised only on very young animals-a portion of the base of the scrotum is cut off, the testicles forced out, and, the cord sawn through with a somewhat serrated but blunt instrument. If there is any hemorrhage, it is arrested by putting ashes in the wound. The animal is then dismissed and nothing further done with him.

On animals two and three years old, the operation is some times performed in the following manner: An assistant holds the pig, pressing the back of the animal against his chest and belly, keeping the head elevated, and grasping all the four legs together; or, which is the preferable way, one assistant holds the animal against his chest, while another kneels down and secures the four legs. The operator then grasps the scrotum with his left hand, makes one horizontal incision across its base, opening both divisions of the oag at the same time. The testicles are then pressed out with his finger and thumb, and removed with a blunt knife, which lacerates the part without bruising it and rendering it painful. Laceration only is requisite in order to prevent the subsequent hemorrhage which would occur, if the cord were simply severed by a sharp instrument. The wound is then closed by pushing the edges gently together with the fingers, and it speedily heals. Some break the spermatic cord without tearing it; they twist it, and then pull it gently and finally until it gives way. 
In other cases, a waxed cord is passed as tightly as possible round the scrotum, above the epididymus, which completely stops the circulation, and in a few days the scrotum and testicles will drop off. This operation should never be performed on pigs of more than six weeks of age, and the spermatic should always, first of all, be measured. It, moreover requires great nicety and skill; otherwise, accidents will occur, and considerable pain and inflammation be caused. Too thick a cord, a knot not tied sufficiently tight, or a portion of the testicle included in the ligature, will prevent its success.

The most fatal consequence of castration is tetanus, or lockjaw, induced by the shock communicated to the nervous system by the torture of the operation.

\section{SPAYING.}

This operation consists in removing the ovaries, and sometimes a portion of the uterus, more or less considerable, of the female. The animal is laid upon its left side, and firmly held by one or two assistants; an incision is then made into the flank, the forefinger of the right hand introduced into it, and gently moved about until it encounters and hooks hold of the right ovary, which it draws through the opening; a ligature is then passed round this one, and the left ovary felt for in like manner. The operator then severs these two ovaries, either loy cutting or tearing, and returns the womb and its appurtenances to their proper position. This being done, he closes the wound with two or three stitches, sometimes rubs a little oil over it, and releases the animal. All goes on well, for the healing power of the pig is very great.

The after-treatment is very simple. The animals should be 286 
well littered with clean straw, in styes weather-tight and thoroughly ventilated; their diet should be cared for; some milk or whey, with barley-meal is an excellent article; it is well to confine them for a few days, as they should be pre. vented from getting into cold water or mud until the wound is perfectly healed, and also from creeping through fences.

The best age for spaying a sow is about six weeks; indeed, as a general rule, the younger the animal is when either operation is performed the quicker it recovers. Some persons, however, have two or three litters from their sows before they operate upen them; where this is the case, the result is more to be feared, as the parts have become more susceptible, and are, consequently, more liable to take on inflammation.

\section{WEANING.}

Some farmers wean the pigs a few hours after birth, and turn the sow at once to the boar. The best mode, however, is to turn the boar into the hog-yard about a week after parturition, at which time the sow should be removed a few hours daily from her young. It does not injure either the sow or her pigs if she takes the boar while suckling; but some sows will not do so until the drying of their milk.

The age at which pigs may be weaned to the greatest advantage is when they are about eight or ten weeks old; many, however, wean them as early as six weeks, but they seldom turn out as well. They should not be taken from the sow at once, but gradually weaned. At first they should be removed from her for a certain number of hours each day, and accustomed to be impelled by hunger to eat from the trough; then they may be turned out for an hour without her, and 
afterwards shut up while she also is turned out by herself. Subsequently, they must only be allowed to suck a certain number of times in twenty-four hours; perhaps six times at first, then four, then three, and, at last, only once; and meanwhile they must be proportionably better and more plentifully fed, and the mother's diet in a like manner diminished. Some advise that the whole litter should be weaned at once; this is not best, unless one or two of the pigs are much weaker and smaller than the others; in such case, if the sow remain in tolerable condition, they might be suffered to suck for a week longer; but this should be the exception, and not a general rule.

Pigs are more easily weaned than almost any other animals, because they learn to feed sooner; but attention must, nevertheless, be paid to them, if they are to grow up strong, healthy animals. Their styes must be warm, dry, clean, well-ventilated, and weather-tight. They should have the run of a grass meadow or enclosure for an hour or two every fine day, in spring and summer, or be turned into the farm-yard among the cattle in the winter, as frest air and exercise tend to prevent them from becoming rickety or crooked in the legs.

The most nutritious and succulent food that circumstances will permit should be furnished them. Newly-weaned pigs require five or six meals in the twenty-four hours. In about ten days, one may be omitted; in another week, a second; and then they should do with three regular meals each day. A little sulphur mingled with the food, or a small quantity of Epsom or Glauber salts dissolved in the water, will frequently prove beneficial. A plentiful supply of clear, cold water should always be within their reach; the food left in the 288 
trough after the animals have finished eating should be removed, and the trough thoroughly rinsed out before any more is put into it. Strict attention should also be paid to cleanliness. The boars and sows should be kept apart from the period of weaning.

The question, which is more profitable, to breed swine, or to buy young pigs and fatten them, can best be determined by those interested; since they know best what resources they can command, and what chance of profits each of these separate branches offers.

\section{RINGING.}

This operation is performed to counteract the propensity which swine lave of digging and furrowing up the earth. The ring is passed through what appears to be a prolongation of the septum, between the supplemental, or snout-bone, and the nasal. The animal is thus unable to obtain sufficient purchase to use his snout with any effect, without causing the ring to press so painfully upon the part that he is forced to desist. The ring, however, is apt to break, or it wears out in process of time, and has to be replaced.

The snout should be perforated at weaning-time, after the animal has recovered from castration or spaying; and it will be necessary to renew the operation as it becomes of large growth. It is too generally neglected at first; but no pigs, young or old, shoukd be suffered to run at large without this precaution. The sow's ring should be ascertained to be of sufficient strength previously to her taking the boar, on account of the risk of abortion, if the operation is renewed while she is with pig. Care must be taken by the operator 
not to go too close to the bone, and that the ring turn easily.

A far better mode of proceeding is, when the pig is young, to cut through the cartilaginous and ligamentous prolongations, by which the supplementary bone is united to the proper nasals. The divided edges of the cartilage will never re-unite, and the snout always remains powerless.

\section{FEEDING AND FATTENING.}

Roots and fruits are the natural food of the hog, in a wild as well as in a domesticated state; and it is evident that, however omnivorous it may occasionally appear, its palate is by no means insensible to the difference in eatables, since, whenever it finds variety, it will select the best with as much cleverness as other quadrupeds. Indeed, the hog is more nice in the selection of his vegetable diet than any of the other domesticated herbivorous animals. To a certain extent he is oiv-nm orous, and may be reared on the refuse of slaughter-houses; but such food is not wholesome, nor is it natural ; for, though he is omnivorous, he is not essentially carnivorous. The refuse of the dairy-farm is more congenial to his health, to say nothing of the quality of its flesh.

Swine are generally fattened for pork at from six to nine months old; and for bacon, at from a year to two years. Eighteen months is generally considered the proper age for a good bacon hog. The feeding will always, in a great measure, depend upon the circumstances of the owner-upon the kind of food which he has at his disposal, and can best spare-and the purpose for which the animal is intended. It will also, in some degree, be regulated by the season; it being possible to 290 
feed pigs very differently in the summer from what they'are fed in the winter.

The refuse wash and grains, and other residue of breweries and distilleries, may be given to swine with advantage, and seem to induce a tendency to lay on flesh. They should not, however, be given in too large quantities, nor unmixed with other and more substantial food; since, although they give flesh rapidly when fed on it, the meat is not firm, and never makes good bacon. Hogs eat acorns and beech-mast greedily, and so far thrive on this food that it is an easy matter to fatten them afterwards. Apples and pumpkins are likewise valuable for this purpose.

There is nothing so nutritious, so eminently and in every way adapted for the purpose of fattening, as are the various kinds of grain-nothing that tends more to create firmness as well as delicacy in the flesh. Indian corn is equal, if not superior, to any kind of grain for fattening purposes, and can be given in its natural state, as pigs are so fond of it that they will eat up every kernel. The pork and bacon of animals that have been thus fed are peculiarly firm and solid. Animal food tends to make swine savage and feverish, and often lays the foundation of serious inflammation of the intestines. Weekly washing with soap and a brush adds wonderfully tc the thriving condition of a hog.

In the rich corn regions of our States, upon that grain beginning to ripen, as it does in August, the fields are fenced off into suitable lots, and large herds are successively turned into them, to consume the grain at their leisure. They waste nothing except the stalks, which in that land of plenty are considered of little value, and they are still useful as manure 291 
for succeeding crops; and whatever grain is left by them, leaner droves which follow will readily glean. Peas, early buckwheat, and apples, may be fed on the ground in the same way.

There is an improvement in the character of the grain from a few months' keeping, which is fully equivalent to the interest of the money and the cost of storage. If fattened early in the season, hogs will consume less food to make an equal amount of flesh than in colder weather; they will require less attention; and, generally, early pork will conmmand the highest price in market.

It is most economical to provide swine with a fine clover pasture, to run in during the spring and summer; and they ought also to have access to the orchard, to pick up all the unripe and superfluous fruit that falls. They should also have the wash of the house and the dairy, to which add meal, and let it sour in large tubs or barrels. Not less than onethird, and perhaps more, of the whole grain fed to hogs, is saved by grinding and cooking, or souring. Care must, however, be taken that the souring be not carried so far as to injure the food by putrefaction. A mixture of meal and water, with the addition of yeast or such remains of a former fermentation as adhere to the sides or bottom of the vessel, and exposure to a temperature between sixty-eight and serenty-seven degrees Fahrenheit, will produce immediate. fermentation.

In this process there are five stages: the saccharine, by which the starch and gum of the vegetables, in their natural condition, are converted into sugar ; the vinous, which changes the sugar into alcohol; the mucilaginous, sometimes taking 292 
the place of the vinous, and occurring where the sugar solution, or fermenting principle, is weak, producing a slimy, glutinous product; the acetic, forming vinegar, from the vinous or alcoholic stage; and the putrefactive, which destroys all the nutritive principles and converts them into a poison. The precise points in fermentation, when the food becomes most profitable for feeding, has not as yet been satisfactorily determined; but that it should stop short of the putrefactive, and probably the full maturity of the acetic, is certain.

The roots for fattening ought to be washed, and steamed or boiled; and when not intended to be fermented, the meal may be scalded with the roots. A small quantity of salt should be added. Potatoes are the best roots for swine; then parsnips; orange or red carrots, white or Belgian; sugar-beets ; mangelwurtzels; ruta-bagas; and then white turnips, in the order mentioned. The nutritive properties of turnips are diffused through so large a bulk that it is doubtful if they can ever be fed to fattening swine with advantage; and they will barely sustain life when fed to them uncooked.

There is a great loss in feeding roots to fattening swine, without cooking. When unprepared grain is fed, it should be on a full stomach, to prevent imperfect mastication, and consequent loss of the food. It is better, indeed, to have it always before them. The animal machine is an expensive one to keep in motion; and it should be the object of the farmer to put his food in the most available condition for its immediate conversion into fat and muscle.

The following injunctions should be rigidly observed, if one would secure the greatest results :

1. Avoid foul feeding. 
2. Do not omit adding salt in moderate quantities to the mess given.

3. Feed at regular intervals.

4. Cleanse the troughs previous to feeding.

5. Do not over-feed; give only as much as will be consumed at the meal.

6. Vary the food. Tariety will create, or, at all events, increase appetite, and it is most conducive to health. Lei the variations be governed by the condition of the dung cast, which should be of a medium consistence, and of a grayishbrown color; if hard, increase the quantity of bran and succulent roots; if too liquid, diminish, or dispense with bran, and make the mess firmer; add a portion of corn.

7. Feed the stock separately, in classes, according to their relative conditions. Keep sows with young by themselves; store-hogs by themselves; and bacon-hogs and porkers by themselves. It is not advisable to keep the store-hogs too high in flesh, since high feeding is calculated to retard development of form and bulk. It is better to feed pigs intended to be put up for bacon loosely and not too abundantly, until they have attained their full stature; they can then be brought into the highest possible condition in a surprisingly short space of time.

8. Keep the swine clean, dry, and warm. Cleanliness, dryness, and warmth are essential, and as imperative as feeding; for an inferior description of food will, by their aid, succeed far better than the highest feeding will without them. 294 


\section{PIGGERIES.}

Few items conduce more to the thriving and well-being of swine than airy, spacious, well-constructed styes, and above all, cleanliness. They were formerly too often housed in damp, dirty, close, and imperfectly-built sheds, which was a fruitful source of disease and of unthrifty animals. Any place was once thought good enough to keep a pig in.

In large establishments, where numerous pigs are kept, there should be divisions appropriated to all the different kinds; the boars, the breeding sows, the newly weaned, and the fattening pigs should all be kept separate; and in the divisions assigned to the second and last of these classes, it is best to have a distinct apartment for each animal, all opening into a yard or inclosure of limited extent. As pigs require warmth, these buildings should face the south, and be kept weathertight and well drained. Good ventilation is also important; for it is idle to expect animals to make good flesh and retain their health, unless they have a sufficiency of pure air. The blood requires this to give it vitality and free it from impurities, as much as the stomach requires wholesome and strengthening food; and when it does not have it, it becomes vitiated, and impairs all the animal functions. Bad smells and exhalations, moreover, injure the flavor of the meat.

Damp and cold floors should be guarded against, as they tend to induce cramp and diarrhca; and the roof should be so contrived as to carry off the wet from the pigs. The walls of a well-constructed sty should be of solid masonry; the roof sloping, and furnished with spouts to carry off the rain; the floors either slightly inclined toward a gutter made to carry 
off the rain, or else raised from the ground on beams or joists, and perforated so that all urine and moisture shall drain off. Bricks and tiles, sometimes used for flooring, are objectionable, because, however well covered with straw, they still strike cold. Wood is far superior in this respect, as well as because it admits of those clefts or perforations being made, which serve not only to drain off all moisture, but also to admit fresh air.

The manure proceeding from the pig-sty has often been much undervalued, and for this reason, that the litter is supposed to form the principal portion of it; whereas it constitutes the least valuable part, and, indeed, it can scarcely be regarded as manure at all-at least by itself-where the requisite attention is paid to the cleanliness of the animals and of their dwellings. The urine and the dung are valuable, being, from the very nature of the food of the animals, exceedingly rich and oleaginous, and materially beneficial to cold soils and grass-lands. The manure from the sty should always be collected as carefully as that from the stable or cow-house, and husbanded in the same way.

The dool of each sty ought to be so hung that it will open inward or outward, so as to give the animals free ingress and egress. For this purpose, it should be hung across from side to side, and the animal can push it up to effect its entry or exit; for, if it were hung in the ordinary way, it would derange the litter every time it opened inward, and be very liable to hitch. If it is not intended that the pigs shall leave their sty, there should be an upper and lower door; the former. of which should always be left open when the weather is warm and dry, while the latter will serve to confine the animal. 296 
There should likewise be windows or slides, which can be opened or closed at will, to give admission to the fresh air, or exclude rain or cold.

Wherever it can be managed, the troughs-which should be of stone or cast metal, since wooden ones will soon be gnawed to pieces-should be so situated that they can be filled and cleaned from the outside, without interfering with or disturbing the animals at all; and for this purpose it is well to have a flap, or door, with swinging hinges, made to hang lorizontally on the trough, so that it can be moved to and fro, and alternately be fastened by a bolt to the inside or outside of the manger. When the hogs have fed sufficiently, the door is swung inward and fastened, and so remains until feeding-time, when the trough is cleansed and refilled without any trouble, and then the flap drawn back, and the animals admitted to their food. Some cover the trough with a lid having as many holes in it as there are pigs to eat from it, which gives each pig an opportunity of selecting his own hole, and eating away without interfering with or incommoding his neighbor.

A hog ought to have three apartments, one each for sleeping, eating, and evacuations; of which the last may occupy the lowest, and the first the highest level, so that nothing shall be drained, and as little carried into the first two as possible. The piggery should always be built as near as possible to that portion of the establishment from which the chief part of the provision is to come, since much labor will thus be saved. Washings, and combings, and brushings, as has been previously suggested, are valuable adjuncts in the treatment of swine; the energies of the skin are thus roused, the pores 
opened, the healthful functions aided, and that inertness, so likely to be engendered by the lazy life of a fattening pig, counteracted.

A supply of fresh water is essential to the well-being of swine, and should be freely furnished. If a stream can be brought through the piggery, it answers better than any thing else. Swine are dirty feeders and dirty drinkers, usually plunging their forefeet into the trough or pail, and thus polluting with mud or dirt whatever may be given to them. One of the advantages, therefore, to be derived from the stream of running water is, its being kept constantly clean and wholesome by its running. If this advantage cannot be procured, it is desirable to present water in vessels of a size to receive but one head at a time, and of such height as to render it impossible, or difficult, for the drinker to get his feet into it. The water should be renewed twice daily. If swine are closely confined in pens, they should have as much charcoal twice a week as they will eat, for the purpose of correcting any tendency to disorders of the stomach. Rotten wood is an imperfect substitute for charcoal.

\section{SIAUGHTERING.}

A pig that is to be killed should be kept without food for from twelve to sixteen hours previous to slaughtering; a little water must, however, be within his reach. He should, in the first place, be stunned by a blow on the head. Some advise that the knife should be thrust into the neck so as to sever the artery leading from the heart; while others prefer that the animal should be stuck through the brisket in the direction of the beart-care being exercised not to toucht he first rib. The 298 
blood should then be allowed to drain from the carcass into vessels placed for the purpose; and the more completely it does so, the better will be the meat.

A large tub, or other vessel, has been previously got ready, which is now filled with boiling water. The carcass of the lo o $\mathrm{g}$ is plunged into this, and the hair is then removed with the edge of a knife. The hair is more easily removed if the $\log$ is

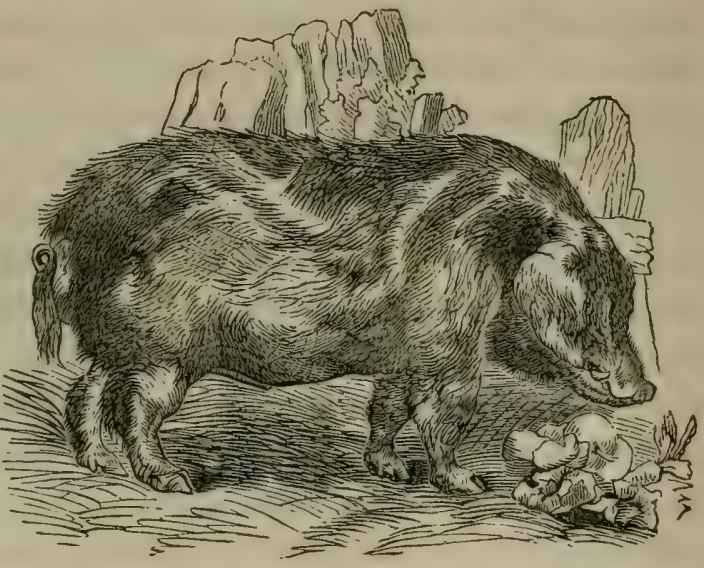
THE OLD ENGLISH HOG.

scalded before he stiffens, or becomes quite cold. It is not, however, necessary, but simply brutal and barbarous, to scald him while there is yet some life in him. Bacon-hogs may be singed, by enveloping the body in straw, and setting the straw on fire, and then scraping it all over. When this is done, care must be observed not to burn or parch the cuticle. The entrails should then be removed, and the interior of the body well washed with lukewarm water, so as to remove all blood and impurities, and afterward wiped dry with a clean cloth; the carcass should then be hung up in a cool place for eighteen or twenty hours, to become set and firm.

For cutting up, the carcass should be laid on the back, upon 
a strong table. The head should then be cut off close by the ears, and the hinder feet so far below the houghs as not to disfigure the hams, and leave room sufficient for hanging them up; after which the carcass is divided into equal halves, up the middle of the back bone, with a cleaving-knife, and, if necessary, a hand-mallet. Then cut the ham from the side by the second joint of the back-bone, which will appear on dividing the carcass, and dress the ham by paring a little off the flank, or skinny part, so as to shape it with a half round point, clearing off any top fat which may appear. Next cut off the sharp edge along the back bone with a knife and mallet, and slice off the first rib next the shoulder, where there is a bloody vein, which must be taken out, since, if it is left in, that part is apt to spoil. The corners should be squared off when the ham is cut. The ordinary practice is to cut out the spine, or back bone. Some take out the chine and upper parts of the ribs in the first place; indeed, almost every locality has its peculiar mode of proceeding.

\section{PICKLIING AND CURING.}

The usual method of curing is to pack the pork in clean salt, adding brine to the barrel when filled. But it may be dry-salted, by rubbing it in thoroughly on every side of each piece, with a strong leather rubber firmly secured to the palm of the right hand. The pieces are then thrown into heaps and sprinkled with salt, and occasionally turned till cured; or it may at once be packed in dry casks, which are rolled at times to bring the salt into contact with every part.

Hams and shoulders may be cured in the same manner either dry or in pickle, but with differently arranged materials. 300 
The following is a good pickle for two hundred pounds: Take fourteen pounds of Turk's Island salt; one-half pound of saltpetre ; two quarts of molasses, or four pounds of brown sugar; with water enough to dissolve them. Bring the liquor to the scalding-point, and skim off all the impurities which rise to the top. When cold, pour it upon the ham, which should be perfectly cool; but not frozen, and closely packed; if not sufficient to cover it, add pure water for this purpose. Some extcnsive packers of choice hams add pepper, allspice, cinnamon, nutmegs, or mace and cloves.

The hams may remain six or eight weeks in this pickle, then should be hung up in the smoke-house, with the small end down, and smoked from ten to twenty days, according to the quantity of smoke. The fire should not be near enough to heat the hams. In Holland and TVestphalia, the fire is made in the cellar, and the smoke carried by a flue into a cool, dry chamber. This is, undoubtedly, the best mode of smoking. 'The hams should at all times be dry and cool, or their flavor will suffer. Green sugar-maple chips are best for smoke; next to them are hickory, sweet birch, corn-cobs, white ash, or beech.

The smoke-house is the best place in which to keep hams until they are wanted. If removed, they should be kept cool, dry, and free from flies. A canvas cover for each, saturated with lime, which may be put on with a whitewash brush, is a perfect protection'against flies. When not to be kept long, they may be packed in dry salt, or even in sweet brine, without injury. A common method is to pack in dry oats, baked saw-dust, etc.

The following is the method in most general use in several 301 
of the Testern States. The chine is taken out, as also the spare-ribs from the shoulders, and the mouse-pieces and short-ribs, or griskins, from the middlings. No acute angles should be left to shoulders or hams. In salting up, all the meat, except the heads, joints, and chines, and smaller pieces, is put into powdering-tubs-water-tight half-hogsheads-or into large troughs, ten feet long and three or four feet wide at the top, made of the poplar tree. The latter are much more convenient for packing the meat in, and are easily caulked, if they should crack so as to leak. The saltingtray-or box in which the meat is to be salted, piece by piece, and from which each piece, as it is salted, is to be transferred to the powdering-tub, or trough-must be placed just so near the trough that the man standing between can transfer the pieces from one to the other easily, and without wasting the salt as they are lifted from the salting-box into the trough. The salter stands on the off-side of the salting-box. The hams should be salted first, the shoulders next, and the middlings last, which may be piled up two feet above the top of the trough or tub. The joints will thus in a short time be immersed in brine.

Measure into the salting-tray four measures of salt-a peck measure will be found most convenient-and one measure of rlean, dry, sifted ashes; mix, and incorporate them well. The salter takes a ham into the tray, rubs the skin and the raw end with his composition, turns it over, and packs the composition of salt and ashes on the fleshy side till it is at least three-quarters of an inch deep all over it; and on the interior lower part of the ham, which is covered with the skin, as much as will lie on it. The man standing ready to transfer 302 
the pieces, deposits it carefully, without disturbing the composition, with the skin-side down, in the bottom of the trough. Each succeeding bam is then deposited, side by side, so as to leave the least possible space unoccupied.

When the bottom is wholly covered, see that every visible part of this layer of meat is covered with the composition of salt and ashes. Then begin another layer, every piece being covered on the upper or fleshy side three-quarters of an inch thick with the composition. When the trough is filled, even full, in this way, with the joints, salt the middlings with salt only, without the ashes, and pile them up on the joints so that the liquified salt may pass from them into the trough. Heads, joints, back bones, etc., receive salt only, and should not be put in the trough with the large pieces.

Much slighter salting will preserve them, if they are salted upon loose boards, so that the bloody brine from them can pass off. The joints and middlings are to remain in and above the trough without being re-handled, re-salted, or disturbed in any way, till they are to be hung up to be smoked.

If the hogs do not weigh more than one hundred and fifty pounds, the joints need not remain longer than five weeks in the pickle; if they weigh two hundred, or upward, six or seven weeks are not too long. It is better that they should stay in too long, rather than too short a time.

In three weeks, the joints, etc., may be hung up. Taking out of pickle, and preparing for hanging up to smoke, are thus performed: Scrape off the undissolved salt; if the directions have been followed, there will be a considerable quantity on all the pieces not immersed in the brine; this salt and the brine are all saved; the brine is boiled down, and the dry 303 
composition given to stock, especially to hogs. Wash every piece in lukewarm water, and with a rough towel clean off the salt and ashes. Next, put the strings in to bang up. Set the pieces up edgewise, that they may drain and dry. Every piece is then to be dipped into the meat-paint, as it is termed, composed of warm-not hot-water and very fine ashes, stirred together until they are of the consistence of thick paint, and hang up to smoke. By being thus dipped, they receive a coating which protects them from the fly, prevents dripping, and tends to lessen all external injurious influences. Hang up the pieces while yet moist with the paint, and smoke them well.

\section{VALUE OF THE CARCASS.}

No part of the hog is valueless, excepting, perhaps, the bristles of the fine-bred races. The rery intestines are cleansed, and knotted into chittarlings, very much relished by some; the blood, mixed with fat and rice, is made into black puddings; and the tender muscle under the lumbar vertebræ is worked up into sausages, sweet, high-flavored, and delicious; the skin, roasted, is a rare and toothsome morsel; and a roast sucking-pig is a general delight; salt pork and bacon are in incessant demand, and form important articles of commerce.

One great value arises from the peculiarity of its fat, which, in contradistinction to that of the ox or of the sheep, is termed lard, and differs from either in the proportion of its constituent principles, which are essentially oleine and stearine. It is rendered, or fried out, in the same manner as mutton-suet. It melts completely at ninety-nine degrees Fahrenheit, and then has the appearance of a transparent and nearly colorless fixed 304 
oil. Eighty degrees is the melting-point. It consists of sixtytwo parts oleine, and thirty-eight of stearine, out of one hundred. When subjected to pressure between folds of blottingpaper, the oleine is absorbed, while the stearine remains. For domestic purposes, lard is much used; it is much better than butter for frying fish; and is much used in pastry, on the score of economy.

The stearine contains the stearic and margaric acids, which, when separated, are solid, and used as inferior substitutes for wax or spermaceti candles. The other, oleine, is fluid at a low temperature, and in American commerce is known as lard-oil, which is very pure, and extensively used for machinery, lamps, and most of the purposes for which olive or spermaceti oils are valued. It has given to pork a new and profitable use, by which the value of the carcass is greatly increased. A large amount of pork has thus been withdrawn from the market, and the depression, which must otherwise have occurred, has been thereby prevented.

Where the oil is required, the whole carcass, after taking out the hams and shoulders, is placed in a tub having two bottoms, the upper one perforated with holes. The pork is laid on the latter, and then tightly covered. Steam, at a high temperature, is then admitted into the tub, and in a short time all the fat is extracted, and falls upon the lower bottom. The remaining mass is bones and scraps. The last is fed to pigs, poultry, or dogs, or affords the best kind of manure. The bones are either used for manure, or are converted into animal charcoal, valuable for various purposes in the arts. When the object is to obtain lard of a fine quality, the animal 20 
is first skinned, and the adbering fat then carefully scraped off; thus avoiding the oily, viscid matter of the skin.

The bristles of the coarse breeds are long, strong, firm, and elastic. These are formed into brushes for painters and artists, as well as for numerous domestic uses. The skin, when tanned, is of a peculiar texture, and very tough. It is used for making pocket-books, and for some ornamental purposes; but chiefly for the seats of riding-saddles. The numerous little variegations on it, which constitute its beauty, are the orifices whence the bristles have been removed. 306 


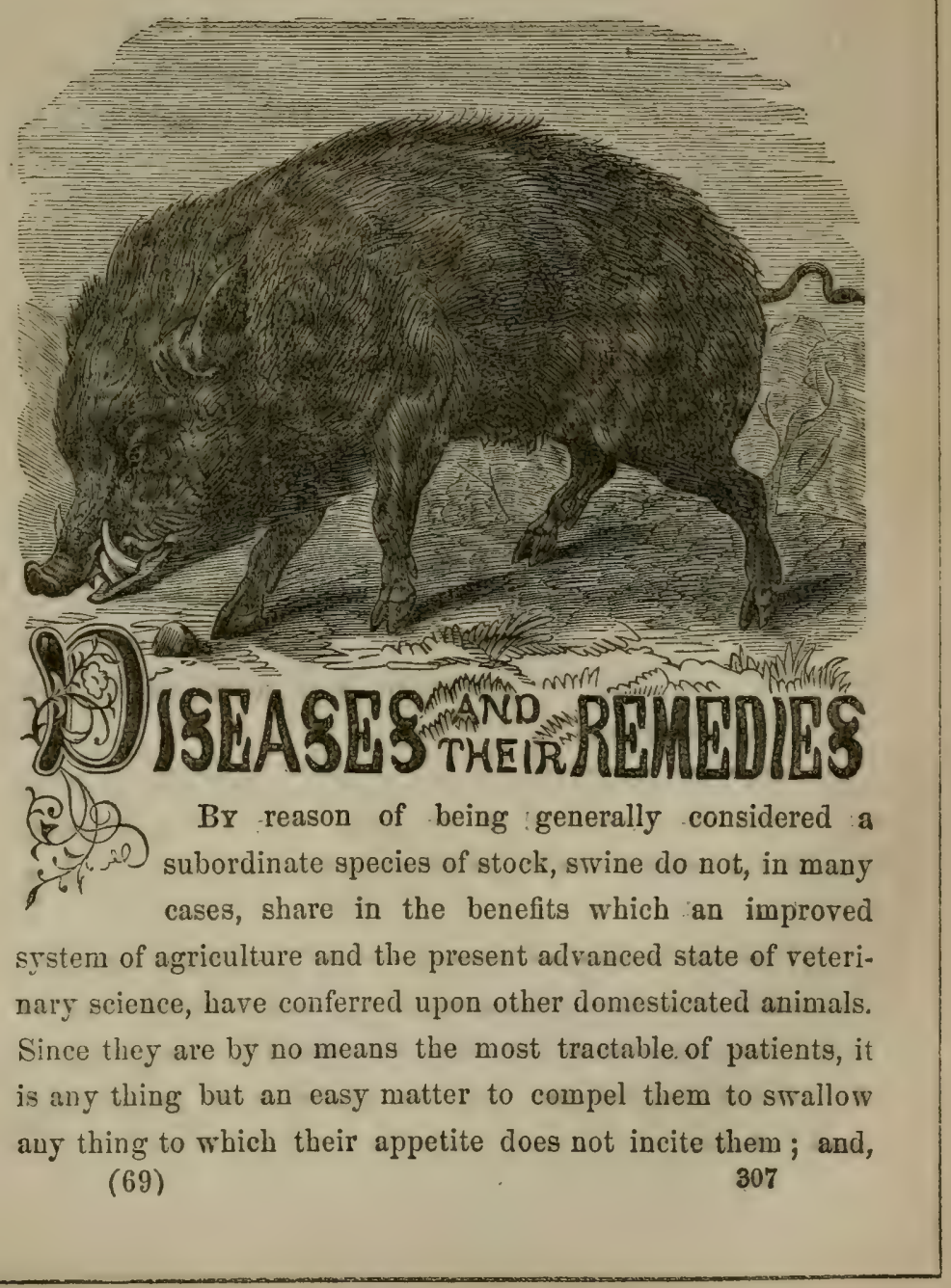


hence, prevention will be found better than cure. Cleanliness is the great point to be insisted upon in the management of these animals If this, and warmth, be only attended to, ailments among them are comparatively rare.

As, however, disappointment may occasionally occur, even under the best system of management, a brief view of the principal complaints with which they are liable to be attacked is presented, together with the best mode of treatment to be adopted in such cases.

\section{CATCHING THE PIG.}

Swine are very difficult animals to obtain any mastery over, or to operate on, or examine. Seldom tame, or easily handled, they are at such periods most unmanageable-kicking, screaming, and even biting fiercely. The following method of getting hold of them has been recommended: Fasten a double cord - to the end of a stick, and beneath the stick let there be a running noose in the cord; tie a piece of bread to the cord, and present it to the animal; and when he opens his mouth to seize the bait, catch the upper jaw in the noose, run it tight, and the animal is fast.

Another method is, to catch one foot in a running noose suspended from some place, so as to draw the imprisoned foot off the ground; or, to envelop the head of the animal in a cloth or sack.

All coercive measures, however, should, as far as possible, be avoided; for the pig is naturally so averse to being handled that in his struggles he will often do himself far more mischief than the disease which is to be investigated or remedied would effect. 


\section{BLEEDING.}

The common mode of drawing blood from the pig is by cutting off portions of the ears or tail; this should only be resorted to when local and instant blood-letting is requisite. The jugular veins of swine lie too deep, and are too much imbedded in fat to admit of their being raised by any ligature about the neck; it is, therefore, useless to attempt to puncture them, as it would only be striking at random.

Those veins, however, which run over the interior surface of the ear, and especially toward its outer edge, may be opened without much difficulty; if the ear is turned back on the poll, one or more of them may easily be made sufficiently prominent to admit of its being punctured by pressing the fingers on the base of the ear, near to the conch. When the necessary quantity of blood has been obtained, the finger may be raised, and it will cease to flow.

The palate veins, running on either side of the roof of the mouth, are also easily opened by making two incisions, one on each side of the palate, about half way between the centre of the roof of the mouth and the teeth. The flow of blood may be readily stopped by means of a pledget of tow and a string, as in bleeding the horse.

The brachial vein of the fore-leg-commonly called the plate-vein-running along the inner side under the skin affords a good opportunity. The best place for puncturing it is about an inch above the knee, and scarcely balf an inch backward from the radius, or the bone of the fore-arm. No danger need to be apprehended from cutting two or three times, if sufficient blood cannot be obtained at once. This vein will 
become easily discernible if a ligature is tied firmly around the leg, just below the shoulder.

This operation should always be performed with the lancet, if possible. In cases of urgent haste, where no lancet is at hand, a small penknife may be used; but the fleam is a dangerous and objectionable instrument.

\section{DRENCHING.}

Thenever it is possible, the medicine to be administered should be mingled with a portion of food, and the animal thus cheated or coaxed into taking it; since many instances are on record, in which the pig has ruptured some vessel in his struggles, and died on the spot, or so injured himself as to bring on inflammation and subsequent death.

Where this cannot be done, the following is the best method: Let a man get the head of the animal firmly between - his knees-without, however, pinching it-while another secures the hinder parts. Then let the first take hold of the head from below, raise it a little, and incline it slightly toward the right, at the same time separating the lips on the left side so as to form a hole into which the fluid may be gradually poured-no more being introduced into the mouth at a time than can be swallowed at once. Should the animal snort or choke, the head must be released for a few moments, or he will be in danger of being strangled.

\section{CATARRH.}

This ailment-an inflammation of the mucous membranes of the nose, etc. - is, if taken in time, easily cured by opening medicines, followed up by warm bran-wash-a warm, dry sty310 
and abstinence from rich grains, or stimulating, farinaceous diet. The cause, in most cases, is exposure to drafts of air, which should be guarded against.

\section{CHOLERA.}

For what is presented concerning this disease, the author is indebted to his friend, G. W. Bowler, V. S., of Cincinnati, Ohio, whose familiarity with the various diseases of our domestic animals and the best modes of treating them, entitles his opinions to great weight.

The term "cholera" is employed to designate a disease which has been very fatal among swine in different parts of the United States; and for the reason, that its symptoms, as well as the indications accompanying its termination, are very nearly allied to what is manifested in the disease of that name which visits man:

Epidemic cholera has, for several years past, committed fearful rarages among the swine of, particularly, Ohio, Indiana, and Kentucky. Indeed, many farmers who, until recently, have been accustomed to raise large numbers of these animals, are, in a great measure, disinclined to invest again in such stock, on account of the severe losses-in some instances to the extent of the entire drove upon particular places.

Various remedies have, of course, been prescribed; but the most have failed in nearly every case where the disease has secured a firm foothold. Preventives are, therefore, the most that can at present be expected; and in this direction something may be done. Although some peculiar change in the atmosphere is, probably, an impelling cause of cholera, its 
ravages may be somewhat stayed by removing other predisposing associate causes.

Granting that the hog is a filthy animal and fond of rooting among filth, it is by no means necessary to persist, for that reason, in surrounding him with all the nastiness possible; for even a hog, when penned up in a filthy place, in company with a large number of other hogs-particularly when that place is improperly rentilated-is not as healthy as when the animals are kept together in smaller numbers in a clean and well ventilated barn or pen. Look, for a moment, at a drove of hogs coming along the street, the animals all fat and ready for the knife. They have been driven several miles, and are scarcely able to crawl along, many of them having to be carried on drays, while others have died on the road. At last they are driven into a pen, perhaps, several inches deep with the manure and filth deposited there by hundreds of predecessors; every hole in the ground has become a puddle; and in such a place some one hundred or two hundred animals are piled together, exhausted from the drivo which they have had. They lie down in the mud; and in a short time one can see the steam beginning to rise from their bodies in volumes, increasing their already prostrate condition by the consequent inhalation of the noxious gas thus thrown off from the system; the blood becomes impregnated with poison; the various functions of the body are thereby impaired; and disease will inevitably be developed in one form or another. Should the disease, known as the hog cholera, prevail in the neighborhood, the chances are very greatly in favor of their being attacked by it, and consequently perishing.

The symptoms of cholera are as follows: The animal 312 
appears to be instantaneously deprived of energy; loss of appetite; lying down by himself; occasionally moving about slowly, as though experiencing some slight uneasiness internally; the eyes have a very dull and sunken appearance, which increases with the disease; the evacuations are almost continuous, of a dark color, having a fetid odor, and containing a large quantity of bile; the extremities are cold, and soreness is evinced when the abdumen is pressed; the pulse is quickened, and sometimes hardly perceptible, while the buccal membrane-that belonging to the cheek-presents a slight purple hue; the tongue has a furred appearance. The evacuations continue fluid until the animal expires, which may be in twelve hours from the first attack, or the disease may run on for several days.

In a very short time after death, the abdomen becomes of a dark purple color, and upon examination, the stomach is found to contain but a little fluid; the intestines are almost entirely empty, retaining a slight quantity of the dark colored matter before mentioned; the mucous membrane of the alimentary canal exhibits considerable inflammation, which sometimes appears only in patches, while the other parts are filled with dark venous blood-indicating a breaking up of the capillary vessels in such places.

Treatment. As a preventive, the following will be found valuable: Flour of sulphur, six pounds; animal charcoal, one pound; sulphate of iron, six ounces; cinchona pulverized, one pound. Mix well together in a large mortar; afterwards give a tablespoonful to each animal, mixed with a few potatopeelings and corn meal, three times a day. Continue this for 
one week, keeping the animal at the same time in a clean, dry place, and not allowing too many together.

\section{CRACKINGS.}

These will sometimes appear on the skin of a hog, especially about the root of the ears and of the tail, and at the flanks. They are not at all to be confounded with mange, as they never result from any thing but exposure to extremes of temperature, while the animal is unable to avail himself of such protection as, in a state of nature, instinct would bave induced him to adopt. They are peculiarly troublesome in the heat of summer, if he does not have access to water, in which to lave his parched limbs and half-scorched carcass.

Anoint the cracked parts twice or three times a day with tar and lard, well melted up together.

\section{DIARRECEA.}

Before attempting to stop the discharge in this diseasewhich, it permitted to continue unchecked, will rapidly pros. trate the animal, and probably terminate fatally-ascertain the quality of food which the animal has recently had.

In a majority of instances, this will be found to be the cause. If taken in its incipient stage, a mere change to a more binding diet, as corn, flour, etc., will suffice for a cure. If acidity is present-produced, probably, by the hog's having fed upon coarse, rank grasses in swampy places-give some chalk in the food, or powdered egg-shells, with about half a drachm of powdered rhubarb; the dose, of course, should vary with the size of the animal. In the acorn season, they alone will be 314 
EEVER.

found sufficiently curative, where facilities for obtaining them exist. Dry lodging is indispensable; and diligence is requisite to keep it dry and clean.

FEVER.

The symptoms of this disease are, redness of the eyes, dryness and heat of the nostrils, the lips, and the skin generally; appetite gone, or very defective; and, generally, a very violent thirst.

Bleed as soon as possible; after which house the animal well, taking care, at the same time, to have the sty well and

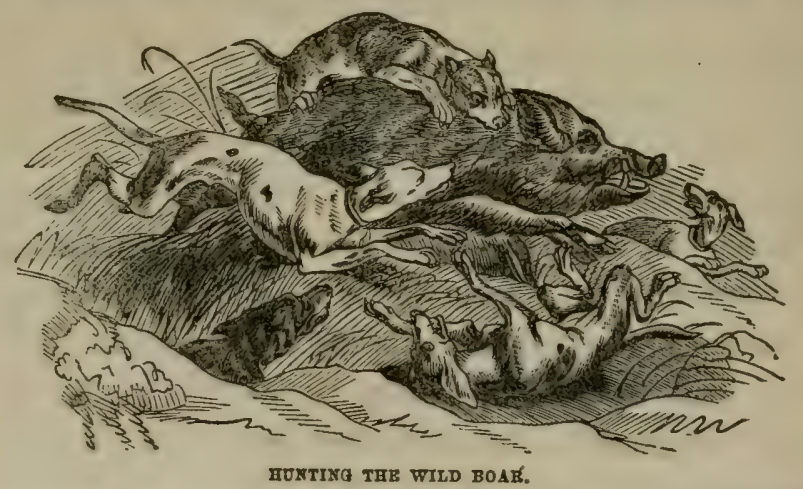

thoroughly rentilated. The bleeding will usually be followed, in an hour or two, by such a return of appetite as to induce the animal to eat a sufficient quantity of food to be made the vehicle for administering external remedies. The best is bread, steeped in broth. The hog, however, sinks so rapidly when his appetite is near gone, that no depletive medicines are, in general, necessary or proper; the fever will ordinarily yield to the bleeding, and the only object needs to be the sup- 
port of his strength, by small portions of nourishing food, administered frequently.

Do not let the animal eat as much as his inclination might prompt; when he appears to be no longer ravenous, remove the mess, and do not offer it again until after a lapse of three or four hours. If the bowels are confined, castor and linseed oil, in equal quantities, should be added to the bread and broth, in the proportion of two to six ounces.

A species of fever frequently occurs as an epizoötic, oftentimes attacking the male pigs, and generally the most vigorous and best looking, without any distinction of age, and with a force and rapidity absolutely astonishing. At other times, its progress is much slower; the symptoms are less intense and alarming; and the veterinary surgeon, employed at the outset, may meet with some succ

The causes are, in the majority of instances, the bad styes in which the pigs are lodged, and the noisome food which they often contain. In addition to these is the constant lying on the dung-heap, whence is exhaled a vast quantity of deleterious gas; also, the remaining far too long on the muddy or parched ground, or too protracted exposure to the rigor of the season.

When an animal is attacked with this disease, he should be separated from the others, placed in a warm situation; some stimulating ointment applied to the chest, and a decoction of sorrel administered. Frictions of vinegar should also be applied to the dorsal and lumbar region. The drinks should be emolient, slightly imbued with nitre and vinegar, and with aromatic fumigation about the belly.

If the fever then appears to be losing ground, which may be 316 
ascertained by the regularity of the pulse, by the absence of the plaintive cries before heard, by a less laborious respiration, by the absence of convulsions, and by the non-appearance of blotches on the skin, there is a fair chance of recovery. Then administer, every second hour, as before directed, and give a proper allowance of white water, with ground barley and rye.

When the symptoms redouble in intensity, it is best to destroy the animal; for it is rare that, after a certain period, much chance of recovery exists. Bleeding is seldom of much avail, but produces, occasionally, considerable loss of vital power, and augments the putrid diathesis.

\section{FOUL SKIN.}

A simple irritability or foulness of skin will usually yield to cleanliness, and a washing with a solution of chloride of lime; but, if it is neglected for any length of time, it assumes a malignant character-scabs and blotches, or red and fiery eruptions appear-and the disense rapidly passes into mange, which will be hereafter noticed.

\section{INFIAMMATION OF THE LUNGS.}

This disease, popularly known as heavings, is scarcely to be regarded as curable. Were it observed in its first stage, when indicated by loss of appetite and a short, hard cough, it might, possibly, be got under by copious bleeding, and friction with stimulating ointment on the region of the lungs; minute and frequent doses of tartar emetic should also be given in butter-all food of a stimulating nature carefully aroidedand the animal kept dry and warm. If once the heavings set in, it may be calculated with confidence that the formation of 
tubercles in the substance of the lungs has begun; and when these are formed, they are very rarely absorbed.

The causes of the disease are damp lodging, foul air, want of ventilation, and unwholesome food. Whien tubercular formation becomes established, the disease may be communicated through the medium of the atmosphere, the infectious influence depending upon the noxious particles respired from the lungs of the diseased animal.

The following may be tried, though the knife is probably the best resort, if for no other reason, at least to provide against the danger of infection: Shave the hair away from the chest, and beneath each fore-leg; wet the part with spirits of turpentine, and set fire to it, having previously had the animal well secured, with his head well raised, and a flannel cloth at hand with which to extinguish the flame after it has burned a sufficient time to produce slight blisters; if carried too far, a sore is formed, productive of no good effects, and causing unnecessary suffering. Calomel may also be used, with a view to promote the absorption of the tubercles; but the success is questionable.

\section{JAUNDICE.}

The symptoms of this disease are, yellowness of the white of the eye; a similar hue extending to the lips; and sometimes, but not invariably, swelling of the under part of the jaw.

Treatment. Bleed freely; diminish the quantity of food; and give an active aperient every second day. Aloes are, perhaps, the best, combined with colocynth; the dose will vary with the size of the animal.

318 


\section{IEPROSY.}

This complaint commonly commences with the formation of a small tumor in the eye, followed by a general prostration of spirits; the head is held down; the whole frame inclines toward the ground; universal languor succeeds; the animal - refuses food, languishes, and rapidly falls away in flesh; blisters soon make their appearance beneath the tongue, then upon the throat, the jarws, the head, and the entire body.

The Causes of this disease are want of cleanliness, absence of fresh air, want of due attention to ventilation. and foul feeding. The obvious treatment, therefore, is, first, bleed; clean out the sty daily; wash the affected animal thoroughly with soap and water, to which soda or potash has been adided; supply him with a clean bed; leep him dry and comiortable; let him have gentle exercise, and plenty of fresh air; limit the quantity of his food, and diminish its rankness; give bran with wash, in which add, for an average-sized hog-say one of one hundred and sixty pounds weight-a tablespoonful of the flour of sulphur, with as much nitre as will corer a dime, daily. A few grains of powdered antimony may also be given with effect.

\section{IETHARGY.}

Symptoms : torpor; desire to sleep; hanging of the head; and, frequently, redness of the eyes. The origin of this disease is, apparently, the same as that of indigestion, or surfeit, except that, in this instance, it acts upon a hog having a natural tendency to a redundancy of blood. 
Treatment. Bleed copiously; then administer an emetic. A decoction of camomile flowers will be safest; though a sufficient dose of tartar emetic will be far more certain. After this, reduce for a few days the amount of the animal's food, and administer a small portion of nitre and sulphur in each morning's meal.

\section{MANGE.}

This cutaneous affection owes its existence to the presence of a minute insect, called acarus scabiei, or mange-fly, which burrows beneath the cuticle, and occasions much irritation and annoyance in its progress through the skin.

Its symptoms are sufficiently well known, consisting of scabs, blotches, and sometimes multitudes of minute pustules on different parts of the body. If neglected, these symptoms become aggravated; the disease spreads rapidly over the entire surface of the skin, and if allowed to proceed on its course unchecked, will before long produce deep-seated ulcers and malignant sores, until the whole carcass of the affected animal becomes a mass of corruption.

The cause is to be looked for in dirt, accompanied by hotfeeding. Hogs, however well and properly kept, will occasionally become affected with this disease from contagion. Few diseases are more easily propagated by contact than mange. The introduction of a single affected pig into an establishment may, in one night, cause the seizure of scores of others. No foul-skinned pigs, therefore, should be introduced into the piggery; indeed, it would be an excellent precaution to wash every animal newly purchased with a strong solution of chloride of lime. 
Treatment. If the mange is but of moderate violence, and not of very long standing, the best mode is to wash the animal, from snout to tail, leaving no portion of the body uncleansed, with soft soap and water. Place him in a dry and clean sty, which is so situated as to command a constant supply of fresh air, without, at the same time, an exposure to cold or draught ; furnish a bed of clean, fresh straw. Reduce his food, both in quality and quantity; let boiled or steamed roots, with buttermilk, or dairy-wash take the place of any food of a heating or inflammatory character. Keep him without food for five or six hours, and then give to a hog of average size two ounces of Epsom salts in a warm bran mash-to be increased or diminished, of course, as the animal's size may require. This should be previously mixed with a pint of warm water, and added to about half a gallon of warm bran mash, and it will act as a gentle purgative. Give in every meal afterward one tablespoonful of flour of sulphur, and as much nitre as will cover a dime, for from three days to a week, according to the state of the disease. When the scabs begin to heal, the pustules to retreat, and the fiery sores to fade, a cure may be anticipated.

When the above treatment has been practised for fourteen days, without effecting a cure, prepare the following : train oil, one pint; oil of tar, two drachms; spirits of turpentine, two drachms; naphtha, one drachm; with as much flour of sulphur as will form the foregoing into a thick paste. Rub the animal previously washed with this mixture; let no portion of the hide escape. Keep the hog dry and warm after this application, and allow it to remain on his skin for three days. On the fourth day wash him again with soft soap, 21

321 
adding a small quantity of soda to the water. Dry hin well afterward, and let him remain as he is, having again changed his bedding, for a day or so; continue the sulphur and nitre as before. Almost all cases of mange, however obstinate, will, sooner or later, yield to this treatment. After he is convalescent, whitewash the sty, and fumigate it by placing a little chloride of lime in a cup, or other vessel, and pouring a little vitriol upon it. In the absence of vitriol, boiling water will answer nearly as well.

\section{MEASLES.}

This is one of the most common diseases to which hogs are liable. The symptoms are, redness of the eyes, foulness of the skin, and depression of spirits; decline, or total departure of the appetite; small pustules about the throat, and red and purple eruptions on the skin. The last are more plainly visible after deatl, when they impart a peculiar appearançe to the grain of the meat, with fading of its color, and distention of the fibre, giving an appearance similar to that which might be produced by puncturing the flesh.

Treatment. Allow the animal to fast, in the first instance, for twenty-four hours, and then arlminister a warm drink, containing a drachm of carbonate of soda, and an ounce of bole armenian; wash the animal, cleanse the sty, and change the bedding; give at every feeding, or thrice a day, thirty grains of flour of sulphur, and ten of nitre.

This malady is attributable to dirt, combined with the giving of steamed food or wash to hogs at too high a temperature. It is troublesome to eradicate, but usually yields to treatment, and is rarely fatal.

322 


\section{MURRAIN.}

This resembles leprosy in its symptoms, with the addition of staggering, shortness of breath, and discharge of viscid matter from the eyes and mouth.

The treatment sbould consist of cleanliness, coolness, bleeding, purging, and limitation of food. Cloves of garlic are recommended; and as in all febrile diseases there exists a greater or less disposition to putrefaction, it is probable that garlic, from its antiseptic properties, may be useful.

\section{QUINSY.}

This is an inflammatory affection of the glands of the throat.

Treatmert. Shave away the hair, and rub with tartar-emetic ointment. Fomenting with very warm water is also useful. When external suppuration takes place, it is to be regarded as a favorable symptom. In this case, wait until the swellings are thoroughly ripe; then with a sharp knife make an incision through the entire length, press out the matter, wash with warm water, and afterward dress the wound with any resinous ointment, or yellow soap with coarse brown sugar.

\section{STAGGERS.}

This disease is caused by an excessive determination of blood to the head.

Treatment. Bleed freely and purge.

\section{SWELIING OF THE SPIEEN.}

The symplom most positively indicative of this disease is the circumstance of the affected animal leaning toward one 323 
side, cringing, as it were, from internal pain, an bending toward the ground.

The cause of the obstruction on which the disease depends, is over-feeding-permitting the animal to indulge its appetite to the utmost extent that gluttony may prompt, and the capacity of its stomach admits. A very short perseverance in this mode of management-or, rather, mismanagementwill produce this, as well as other maladies, deriving their origin from a depraved condition of the secretions and the obstruction of the excretory ducts.

Treatment. Clean out the alimentary canal by means of a powerful aperient. Allow the animal to fast for four or five hours, when he will take a little sweet wash or broth, in which may be mingled a dose of Epsom salts proportioned to his size. This will generally effect the desired end-a copious evacuation-and the action of the medicine on the watery secretions will also relieve the existing diseased condition of the spleen.

If the affection has continued for any length, the animal should be bled. A decoction of the leaves and tops of wormwood and liverwort, produced by boiling them in soft water for six hours, may be given in doses of from balf a pint to a pint and a half, according to the size, age, etc., of the animal. Scammony and rhubarb, mixed in a bran wash, or with Indian meal, may be given with advantage on the following day; or, equal portions of blue-pill mass and compound colocynth pill, formed into a bolus with butter. The animal having been kept fasting the previous night, will probably swallow it; if not, let his fast continue a couple of hours longer. Lower his diet, and keep him on reduced fare, with exercise, and, if it 324 
can be managed, grazing, until the malady has passed away. If he is then to be fattened, it should be done gradually; be cautious of at once restoring him to full diet.

\section{SUREEIT.}

This is another name for indigestion. The symptoms are, panting; loss of appetite; swelling of the region about the stomach, etc. ; and frequently throwing up the contents of the stomach.

Treatment. In general, this affection will pass away, provided only it is allowed to cure itself, and all food carefully kept from the animal for a few hours; a small quantity of sweet grains, with a little bran mash, may then be given, but not nearly as much as the animal would wish to take. For a few days, the food should be limited in quantity, and of a washy, liquid nature. The ordinary food may then be resumed, only observing to feed regularly, and remove the fragments remaining after each meal.

\section{TUMORS.}

These are hard swellings, which make their appearance on different parts of the body. They are not formidable, and require only to be suffered to progress until they soften; then make a free incision, and press out the matter. Sulphur and nitre should be given in the food, as the appearance of these swellings, whatever be their cause. indicates the necessity of alterative medicines. 



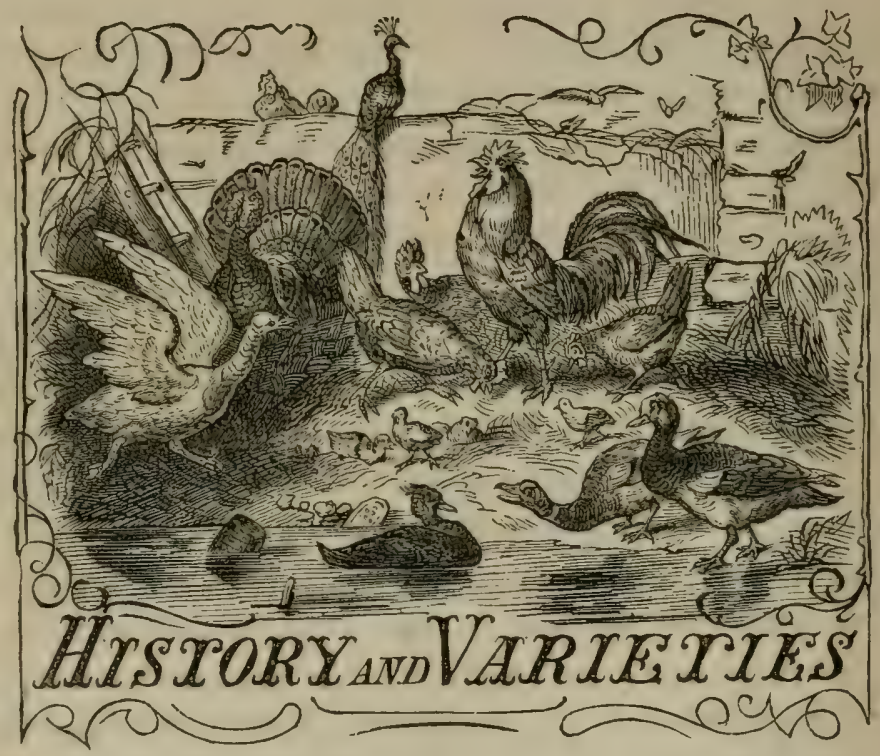

The Domestic Fowl. The cock tribe is used as a generic term, to include the whole family of domestic fowls; the name of the male, in this instance, furnishing an appellation suffciently comprehensive and well recognized.

The domestic cock appears to have been known to man from a very early period. Of his real origin there is little definitely known; and even the time and manner of his introduction into Greece, or Southern Europe, are enveloped in obscurity. In the palmiest days of Greece and Rome, however, he occupied a conspicuous place in those public shows (7) 
which amused the masses of the people. He was dedicated to the service of the pagan deities, and was connected with the worship of Apollo, Mercury, Mars, and particularly Esculapius. The flesh of this bird was highly esteemed as a delicacy, and occupied a prominent place at the Roman banquets. Great pains were taken in the rearing and fattening of poultry for this purpose.

The practice of cock-fighting, barbarous as it is, originated in classic times, and among the most polished and civilized people of antiquity. To its introduction into Britain by the Cæsars we owe our acquaintance with the domestic fowl.

It is impossible to state positively to what species of the wild cock, known at present, we are to look for the primitive type, so remote is the date of the original domestication of the fowl. Many writers have endeavored to show that all the varieties of the domestic fowl, of which we now have knowlcdge, are derived from a single primitive stock. It has, also, been confidently asserted that the domestic cock owes his origin to the jungle fowl of India. The most probable supposition, however, is, that the varieties known to us may be referred to a few of the more remarkable fowls, as the progenitors of the several species. The great fowl of St. Jago and Sumatra may, perhaps, safely be recognized as the type of some of the larger varieties, such as the Spanish and the Padua forls, and those resembling them; while to the Bankiva cock, probably, the smaller varieties belong, such as Bantans, the Turkish fowl, and the like.

The reasons assigned for supposing these kinds to be the true originals of our domestic poultry, are, first, the close resemblance subsisting between their females and our do328 
mestic hens; second, the size of our domestic cock being intermediate between the two, and alternating in degree, sometimes inclining toward the one, and sometimes toward the other; third, from the nature of their feathers and their general aspect-the form and distribution of their tails being the same as our domestic fowls; and, fourth, in these two birds alone are the females provided with a crest and small wattles, characteristics not to be met with in any other wild species.

The wild cock, or the St. Jago forl, is frequently so tall as to be able to peck crunibs without difficulty from an ordinary dinner-table. The weight is usually from ten to thirteen or fourteen pounds. The comb of both cock and hen is large, crown-shaped, often double, and sometimes, but not invariably, with a tufted crest of feathers, which occurs with the greatest frequency, and grows to the largest size, in the hen. The voice is strong and very harsh; and the young do not arrive to full plumage until more than half grown.

The Bankiva fowl is a native of Java, and is characterized by a red indented comb, red wattles, and ashy-gray legs and feet. The comb of the cock is scolloped, and the tail elevated a little above the rump, the feathers being disposed in the form of tiles or slates; the neck-feathers are of a gold color, long, dependent, and rounded at the tips; the head and neck are of a fawn color; the wing coverts a dusky brown and black; the tail and belly, black. The color of the hen is a dusky ash-gray and yellow; her comb and wattles much smaller than those of the cock, and-with the exception of the long hackles-she has no feathers on her neck. These forl are exceedingly wild, and inhabit the skirts of woods, forests, 
and other sarage and unfrequented places These Bankivas resemble our Bantams very much; and, like them, are also occasionally to be seen feathered to the feet and toes.

Independent of all considerations of profitableness, domestic fowls are gifted with two qualifications, which-whether in man, beast, or bird-are sure to be popular: a courageous temper and an affectionate disposition. When we add to these beauty of appearance and hardiness of constitution, it is no wonder that they are held in such universal esteem.

The courage of the cock is emblematic, his gallantry admirable, and his sense of discipline and subordination most exemplary. The hen is deservedly the acknowledged pattern of maternal love. When her passion of philoprogenitiveness is disappointed by the failure or subtraction of her own brood, she will either continue incubating till her natural powers fail, or will violently kidnap the young of other fowls, and insist upon adopting them.

It would be idle to attempt an enumeration here of the numerous breeds and varieties of the domestic fowl. Those only, therefore, will be described which are generally accepted as the best varieties; and these arranged, not in the order of their merits necessarily, but alphabetically, for convenience of reference.

\section{THE BANTAM.}

The original of the Bantam is, as has been already remarked, the Bankiva fowl. The small white, and also the colored Bantams, whose legs are heavily feathered, are sufficiently well-known to render a particular description unnecessary. Bantam-fanciers generally prefer those which have clean, 330 
bright legs, without any vestige of feathers. A thoroughbred cock, in their judgment, should have a rose comb; a wellfeathered tail, but without the sickle feathers; full hackles; a proud, lively carriage; and ought not to exceed a pound in weight. The niankeen-colored, and the black are the general favorites.

These little creatures $\mathrm{ex}$ hibit some peculiar habits and traits of disposition. Amongst others, the cocks

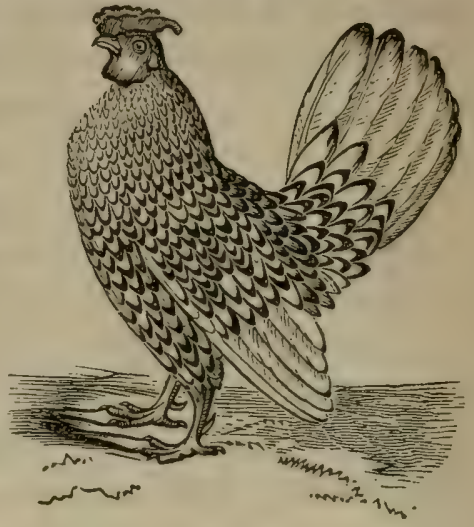

THE BANTAM. are so fond of sucking the eggs laid by the hen that they will often drive her from the nest in order to obtain them; they: have even been known to attack her, tear open the ovarium, and devour its shell-less contents. To prevent this, first a hard-boiled, and then a marble egg may be given them to fight with, taking care, at the same time, to prevent their access either to the hen or to any real eggs. Another strange propensity is a passion for sucking each other's blood, which is chiefly exhibited when they are moulting, when they have been known to peck each other naked, by pulling out the new feathers as they appear, and squeezing with their beaks the blood from the bulbs at the base. These fowls being sulject. to a great heat of the skin, its surface occasionally becomes hard and tightened; in which cases the hard roots of the feathers are drawn into a position more nearly at right angles with the body than at ordinary times, and the skin and super- 
ficial muscles are thus subjected to an unusual degree of painful irritation. The disagreeable habit is, therefore, simply a provision of Nature for their relief, which may be successfully accomplished by washing with warm water, and the

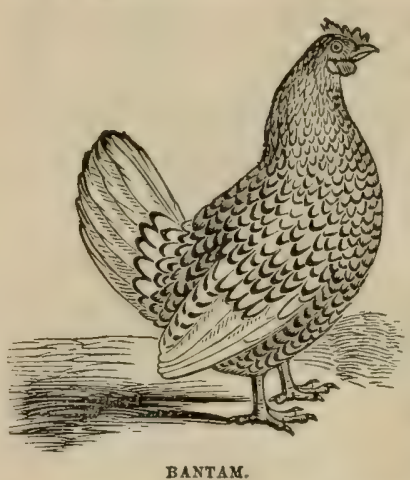
subsequent application of pomatum to the skin.

Bantams, in general, are greedy devourers of some of the most destructive of our insects; the grub of the cock-chafer and the crane-fly being especial favorites with them. Their chickens can hardly be raised so well, as by allowing them free access to minute insect dainties; hence, the suitableness of a worn-out lotbed for them during the first month or six weeks. They are thus positively serviceable creatures to the farmer, as far as their limited range extends; and still more so to the gardener and the nurseryman, as they will save various garden crops from injuries to which they would otherwise be exposerl.

The fowl commonly known as the Bantam is a small, elegantly-formed, and handsomely tinted variety, evidently but remotely allied to the game breed, and furnished with feathers to the toes.

The African Bantalr. The cock of this variety is red upon the neck, back, and hackles; tail, black and erect, studded with glossy green feathers upon the sides; breast, black ground spotted with yellow, like the Golden Pheasant; comb, single; cheeks, white or silvery; the pullet is entirely black, except the inside of the wing-tips, which is perfectly 332 
white. In size, they compare with the common pigeon, being very small; their wings are about two inches longer than their bodies; and their legs dark and destitute of feathers. They are rery quiet, and of decided benefit in gardens, in destroying bugs.

These symmetrically-formed birds are highly prized, both by the fancier and the practical man, and the pure-bloods are very rare. They weigh from eight to twelve ounces each for the hens; and the cocks, from sixteen to twenty ounces.

\section{THE BOLTON GRAY.}

These fowls_called, also, Dutch Every-day Layers, Pencilled Dutch Fowl, Chittaprats, and, in Pennsylvania, Creole

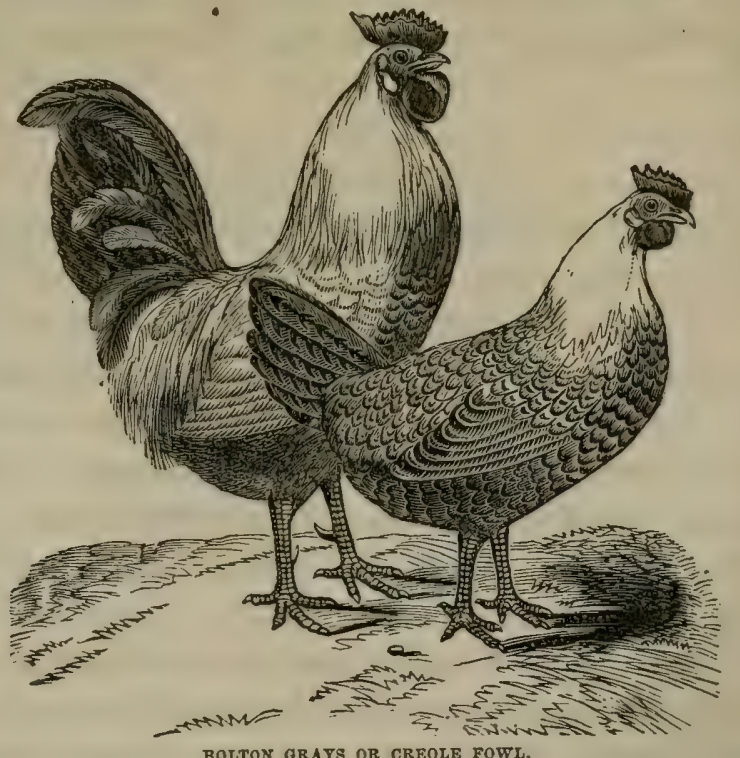

Fowl-were originally imported from Holland to Bolton, a town in Lancashire, England, whence they were named. 
They are small sized, short in the leg, and plump in the make; color of the genuine kind, invariably pure white in the whole cappel of the neck; the body white, thickly spotted with black, sometimes running into a grizzle, with one or more black bars at the extremity of the tail. A good cock of this breed may weigh from four to four and a half pounds; and a hen from three to three and a half pounds.

The superiority of a hen of this breed does not consist so much in rapid as in continued laying. She may not produce as many eggs in a month as some other kinds, but she will, it is claimed, lay more months in the year than probably any other variety. They are said to be very hardy; but their eggs, in the judgment of some, are rather watery and inhutritious.

\section{THE BLUE DUN.}

The variety known under this name originated in Dorsetshire, England. They are under the average size, rather slenderly made, of a soft and pleasing bluish-dun color, the neck being darker, with high, single combs, deeply serrated. The cock is of the same color as the hen, but has, in addition, some handsome dark stripes in the long feathers of the tail, and sometimes a few golden, or even scarlet marks, on the wings. They are exceedingly impudent, familiar, and pugnacious.

The hens are good layers, wanting to sit after laying a moderate number of eggs, and proving attentive and careful rearers of their own chickens, but rather savage to those of other hens. The eggs are small and short, tapering slightly at one end, and perfectly white. The chickens, on first 334 
coming from the egg, sometimes bear a resemblance to the gray and yellow catkin of the willow, being of a soft bluish gray, mixed with a little yellow here and there.

Some class these hirds among the game fowls, not recognizing them as a distinct race, upon the ground that, as there are Blue Dun families belonging to several breeds-the Spanish, the Polish, the Game, and the Hamburghs, for example -it is more correct to refer each Blue Dun to its own proper ancestry.

\section{THE CHITTAGONG.}

The Chittagong is a very superior bird, showy in plumage, exceedingly hardy, and of various colors. In some, the gray predominates, interspersed with lightish yellow and white feathers upon the pullets. The legs are of a reddish fleshcolor; the meat is delicately white, the comb large and single, wattles very full, wings good size. The legs are more or less feathered; the model is graceful, carriage proud and easy, and action prompt and determined.

This breed is the largest in the world; the pullets usually weighing from eight to nine pounds when they begin to lay, and the cocks from nine to ten pounds at the same age. They do not lay as many eggs in a year as smaller hens; but they lay as many pounds of eggs as the best breeds. This breed has been, by some, confounded with the great Malay; but the points of difference are very noticeable. There is less offal; the flesh is finer, although the size is greatly increased; their fecundity is greater; and the offspring arrive earlier at maturity than in the common Malay variety.

There is also a red variety of the Chittagong, which is 335 
rather smaller than the gray. These have legs sometimes yellow and sometimes blue; the latter color, perhaps, from some mixture with the dark variety; the wings and tail are short. Sometimes there is a rose-colored comb, and a topknot, through crossing. This variety may weigh sixteen or eighteen pounds a pair, as ordinarily bred. The eggs are large and rich, but not very abundant, and they do not batch remarkably well.

There is, besides, a dark-red variety; the hens yellow or brown, with single serrated comb, and no top-knot; legs heavily feathered, the feathers black and the legs yellow The cock is black on the breast and thighs.

The Chittagongs are generally quite leggy, standing some twenty-six inches high; and the hens twenty-two inches. A first cross with the Shanghae makes a very large and valuable bird for the table, but not for breeding purposes.

\section{THE COCHIN CHINA.}

The Cochin China fowl are said to have been presented to Queen Victoria from the East Indies. In order to promote their propagation, her majesty made presents of them occasionally to such persons as she supposed likely to appreciate them. They differ very little in their qualities, habits, and general appearance from the Shanghaes, to which they are undoubtedly nearly related. The egg is nearly the same size, shape, and color; both have an equal development of comb and wattles-the Cochins slightly differing from the Shanghaes, chiefly in being somewhat fuller and deeper in the breast, not quite so deep in the quarter, and being usually smooth-legged; while the Shanghaes, generally, are more or 336 
less heavily feathered. The plumage is much the same in both cases; and the crow in both is equally sonorous and prolonged, differing considerably from that of the Great Malay.

The cock has a large, upright, single, deeply-indented comb,

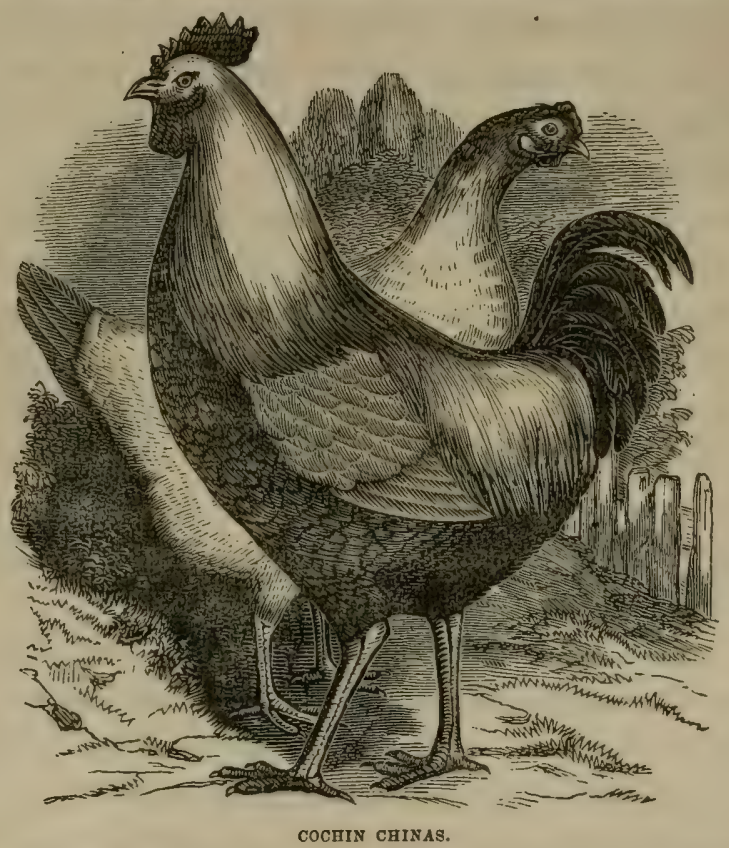

very much resembling that of the Black Spanish, and, when in high condition, of quite as brilliant a scarlet; like him, also, he has sometimes a rery large white ear-hole on each cheek, which, if not an indispensable or even a required qualification, is, however, to be preferred, for beauty at least. The wattles are large, wide, and pendent. The legs are of a pale fleshcolor; some specimens have them yellow, which is objectionable. The feathers on the breast and sides are of a bright 22 337 
chestnut-brown, large and well-defined, giving a scaly or im. bricated appearance to those parts. The hackle of the neck is of a light yellowish brown; the lower feathers being tipped with dark brown, so as to give a spotted appearance to the neck. The tail-feathers are black, and darkly iridescent; back, scarlet-orange; back-hackle, yellow-orange. It is, in short, altogether a flame-colored bird. Both sexes are lower in the leg than either the Black Spanish or the Malay.

The hen approaches in her build more nearly to the Dorking than to any other breed, except that the tail is very small and proportionately depressed; it is smaller and more horizontal than in any other fowl. Her comb is of moclerate size, almost small; she has, also, a small, white ear-hole. Her coloring is flat, being composed of various shades of very light brown, with light yellow on the neck. Her appearance is quiet, and only attracts attention by its extreme neatness, cleanliness, and compactness.

The eggs average about two ounces each They are smooth, of an oval shape, equally rounded at each end, and of a rich buff color, nearly resembling those of the Silver Pheasant. The newly-hatched chickens appear very large in proportion to the size of the egg. They have light, flesh-colored bills, feet, and legs, and are thickly covered with down, of the hue commonly called "carroty." They are not less thrifty than any other chickens, and feather somewhat more uniformly than either the Black Spanish or the Malay. It is, however, most desirable to hatch these-as well as other large-growing varieties-as early in the spring as possible; even so soon as the end of February. A peculiarity in the cockerels is, that they do not show eren the rudiments of their tail-feathers till 338 
they are nearly full-grown. They incrense so rapidly in other directions, that there is no material to spare for the production of these decorative appendages.

The merits of this breed are such that it may safely bo recommended to people residing in the country. For the inhabitants of towns it is less desirable, as the light tone of its plumage would show every mark of dirt and defilement; and the readiness with which they sit would be an inconvenience, rather than othorwise, in families with whom perpetual layers are most in requisition. Expense apart, they are equal or superior to any other forl for the table; their flesh is clolicate, white, tender, and well flavored.

\section{THE CUCKOO.}

The fowl so tormed in Norfolk, England, is, very probably, an old and distinct variety; although they are generally regarded as mere Barn-door fowls-that is, the merely aceidental result of promiscuous crossing.

The name probably originated from its barred plumage, which resembles that on the breast of the Cuckoo. The prevailing color is a slaty blue, undulated, and softly shaded with white all over the body, forming bands of various widths. The comb is very small; irides, bright orange; feet and legs, light flesh-color. The hens are of a good size; the cocks are large, approaching the heaviest breeds in weight. The chickens, at two or three months old, exhibits the barred plumage even more perfectly than the full-grown birds. The eggs average about two ounces each, are white, and of porcelain smoothness. The newly-hatched chickens are gray, 339 
much resembling those of the Silver Polands, except in the color of the feet and legs.

This breed supplies an unfailing troop of good layers, good sitters, good mothers and good feeders; and is well worth promotion in the poultry-yard.

\section{THE DOMINIQUE.}

This seems to be a tolerably distinct and permanent variety, about the size of the common Dunghill Fowl. Their combs are generally double-or rose, as it is sometimes called-and the wattles small. Their plumage presents, all over, a sort of greenish appearance, from a peculiar arrangement of blue and white feathers, which is the chief characteristic of the variety; although, in some specimens, the plumage is inevitably gray in both cock and hen. They are very hardy, healthy, excellent layers, and capital incubators. No fowl have better stood the tests of mixing without deteriorating than the pure Dominique.

Their name is taken from the island of Dominica, from which they are reported to have been imported. 'T'ake all in all, they are one of the very best breeds of fowl which we have; and although they do not come in to laying so young as the Spanish, they are far better sitters and nursers.

\section{THE DORKING.}

This has been termed the Capon Fowl of England. It forms the chief supply for the London market, and is distinguished by a white or flesh-colored smooth leg, armed with fire, instead of four toes, on each foot. Its flesh is extremely delicate, especially after caponization; and it has the adran340 
tage over some other fowls of feeding rapidly, and growing to a very respectable size when properly managed.

For those who wish to stock their poultry jards with fowls of the most desirable shape and size, clothed in rich and varigated plumage, and, not expecting perfection, are willing to overlook one or two other points, the Speckled Dorkings -so called from the town of Surrey, England, which brought them into modern repute-sh o u ld be selected. The lens, in addition to their gay colors, have a large, vertically flat comb, which, when they are in high health, adds very much to their brilliant ap-

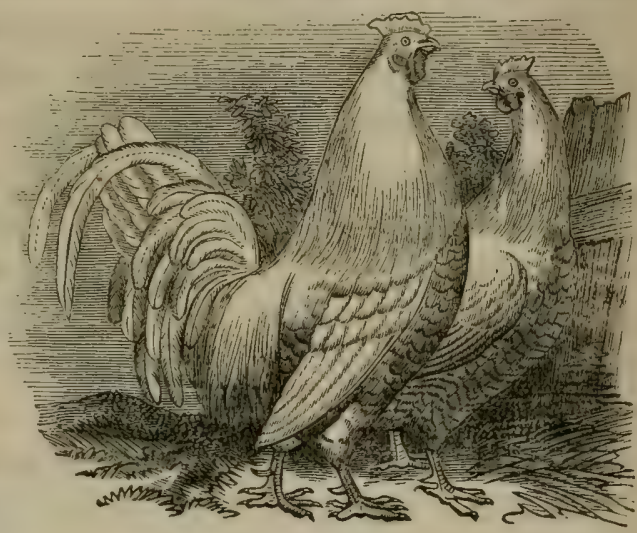

WHITE DORKINGS. pearance, particularly if seen in bright sunshine. The cocks are magnificent. The most gorgeous hues are lavished upon them, which their great size and peculiarly square-built form display to the greatest advantage. Their legs are short; thetr breast broad; there is but a small proportion of offal; and the good, profitable flesh is abundant. The cocks may be brought to considerable weight, and the flavor and appearance of their meat are inferior to none. The eggs are produced in reasonable abundance; and, though not equal in size to those of Spanish hens, may fairly be called large.

They are not everlasting layers, but at due or convenient 341 
intervals manifest the desire of sitting. In this resject, ti... are steady and good mothers when the little ones appear. They are better adapted than any other fowl, except the Malay, to hatch superabundant turkeys' eggs; as their size and bulk enable them to afford warmth and shelter to the young for a long period. For the same reason, spare goose eggs may be entrusted to them.

With all these merits, however, they are not found to be a profitable breed, if kept thorough-bred and unmixed. Their powers seem to fail at an early age. They are also apt to pine away and die just at the point of reaching maturity. They appear at a certain epoch to be seized with consumption -in the Speckled Dorkings, the lungs seeming to be the seat of the disease. The White Dorkings are, howerer, hardy and active birds, and are not subject to cousumption or any other disease.

As mothers, an objection to the Dorkings is, that they are too heary and clumsy to rear the chickens of any smaller and more delicate bird than themselves. Pheasants, partridges, bantans, and Guinea fowl are trampled under foot and crushed, if in the least weakly. The hen, in her affectionate industry in scratching for grub, kicks her smallest nurslings right and left, and leaves them sprawling on their backs; and before they are a month old, half of them will be muddled to death with this rough kindness.

In spite of these drawbacks, the Dorkings are still in high favor; but a cross is found to be more profitable than the true breed. A glossy, energetic game-cock, with Dorking hens, produces chickens in size and beauty little inferior to their maternal parentage, and much more robust. The supernu342 
merary toe on each foot almost always disappears with the first cross; but it is a point which can very well be spared without much disadvantage. In other respects, the appearance of the newly-hatched chickens is scarcely altered. The eggs of the Dorkings are large, pure white, very much rounded, and nearly equal in size at each end. The chickens are brownish-yellow, with a broad brown stripe down the middle of the back, and a narrower one on each side; feet and legs yellow.

The Fawn-colored Dorking. The fowl bearing this name is a cross between the white Dorking and the fawn-colored Turkish fowl. They are of lofty carriage, handsome, and healthy. The males of this breed weigh from eight to nine pounds, and the females from six to seven; and they come to maturity early for so large a forwl. Their tails are shorter and their eggs darker than those of other Dorkings; their flesh is fine and their eggs rich. It is one of the best varieties of fowl known, as the size is readily increased without diminishing the fineness of the flesh.

The Black Donking. The bodies of this variety are of a large size, witb the usual proportions of the race, and of a jetblack color. The neck-feathers of some of the cocks are tinged with a bright gold color, and those of some of the hens bear a silvery complexion. Their combs are usually double, and very short, though sometimes cupped, rose, or single, with wattles small; and they are usually very red about the head. Their tails are rather shorter and broader than most of the race, and they feather rather slowly. Their legs are short and black, with five toes on each foot, the bottom of which is sometimes yellow. The two back toes are very 
distinct, starting from the foot separately; and there is frequently a part of an extra toe between the two.

This breed commence laying when very young, and are very thrifty layers during winter. Their eggs are of a large size, and hatch well; they are perfectly hardy, as their color indicates, and for the product are considered among the most valuable of the Dorking breed.

\section{THE DUNGHILL FOWI.}

This is sometimes called the Barn-door fowl, and is characterized by a thin, serrated, upright comb, and wattles hanging from each side of the lower mandible; the tail rises in an arch, above the level of the rump; the feathers of the rump are long and line-like; and the color is finely variegated. The female's comb and wattles are smaller than those of the cock; she is less in size, and her: colors are more dull and sombre.

In the best specimens of this variety, the legs should be white and smooth, like those of the Dorking, and their bodies round and plump. Being mongrels, they breed all colors, and are usually from five to seven or eight pounds per pair.

\section{THE FRIZZLED FOWL.}

This fowl is erroneously supposed to be a native of Japan, and, by an equally common error, is frequently called the "Friesland," under the apprehension that it is derived from that place. Its name, however, originates from its peculiar appearance. It is difficult to say whether this is an aboriginal variety, or merely a peculiar instance of the morphology of feathers ; the circumstance that there are also frizzled Bantams, would seem to make in favor of the latter position. 
The feathers are ruffled or frizzled, and the reversion makes them peculiarly susceptible of cold and wet, since their plumage is of little use as clothing. They have thus the demerit of being tender as well as ugly. In good specimens, every feather looks as if it had been curled the wrong way with a pair of hot curling-irons. The plumage is variegated in its colors; and there are two varieties, called the Black and White Frizzled. The stock, which is rather curious than valuable, is retained in this country more by importation than by rearing.

Some writers say that this variety is a native of Asia, and that it exists in a domestic state throughout Java, Sumatra, and all the Philippine islands, where it succeeds well. It is, according to such, uncertain in what country it is still found wild.

\section{THE GAME FOWL.}

It is proballe that these fowl, like other choice varieties, are natives of India. It is certain that in that country an original race of some fowl exists, at the present day, bearing in full perfection all the peculiar characteristics of the specics. In India, as is well known, the natires are infected with a passion for cock-fighting. These fowls are carefully bred for this barbarous amusement, and the finest birds become articles of great value. In Sumatra, the inhabitants are so much addicted to the cruel sports to which these fowls are devoted, that instances are recorded of men staking not only their property upon the issue of a fight, but even their wives and children. The Chinese are likewise passionately fond of this pastime; as, indeed, are all the inbabitants of the Indian 
countries professing the Mussulman creed. The Romans introduced the practice into Britain, in which country the

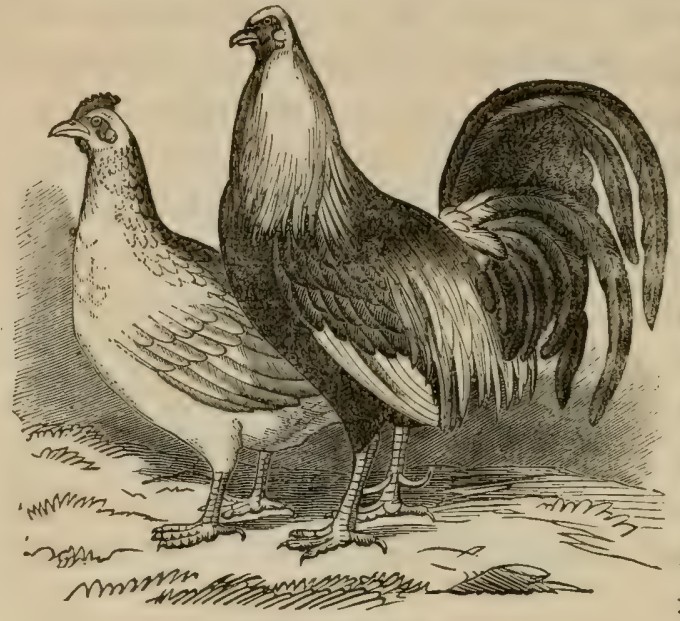

GRAT GAME FOWLS. earliest recorde d cock-fight dates back to about the year 1100. In Mexic o and the South American countries it is still a national amusement.

The game fowl is one of the most gracefully formed and beautifully colored of our domestic breeds of poultry; and in its form, aspect, and that extraordinary courage which characterizes its natural disposition, exhibits all that either the naturalist or the sportsman would at once recognize as the purest type of high blood, embodying, in short, all the most indubitable characteristics of gallinaceous aristocracy.

It is somewhat inferior in size to other breeds, and in its shape approximates more closely to the elegance and lightness of form usually characteristic of a pure and uncontaminated race. Amongst poultry, he is what the Arabian is amongst horses, the high-bred Short-horn amongst cattle, and the fleet greyhound amongst the canine race.

The flesh is beantifully white, as well as tender and delicate. The hens are excellent layers, and although the eggs are under 346 
the arerage size, they are not to be surpassed in excellence of flavor. Such being the character of this variety of fowl, it would doubtless be much more extensively cultirated than it is, were it not for the difficulty attending the rearing of the young; their pugnacity being such, that a brood is scarcely feathered before at least one-half are killed or blinded by fighting.

With proper care, however, most of the difficultics to be apprehended may be avoided. It is exceedingly desirable to perpetuate the race, for uses the most important and valuable. As a cross with other breeds, they are invaluable in improving the flavor of the flesh, which is an invariable consequence. The plumage of all fowl related to them is increased in brilliancy; and they are, moreover, very prolific, and the eggs are always enriched.

The Mexican Hen-cock. This unique breed is a favorite variety with the Mexicans, who term them IIen-cocks from the fact that the male birds have short, broad tails, and, in color and plumage, the appearance of the hens of the same variety, differing only in the comb, which is very large and erect in the cock, and small in the hen. They are generally pheasant-culored, with occasional changes in plumage from a light yellow to a dark gray; and, in some instances, there is a tendency to black tail-feathers and breast, as well as an inclination to gray and light yellow, and with a slight approximation to red hackles in some rare instances.

This variety has a strong frame, and very large and muscular thighs. The cocks are distinguished by large, upright combs, strong bills, and very large, lustrous eyes. The legs vary from a dirty to a dark-green color. The hen does not ma- 
teriaily differ in appearance from the cock. They are as good laycrs aud sitters as any other game breed, and are good nurses.

The Tild Indax Gane. This variety was originally imported into this country from Calcutta. The hen has a long neck, like a wild goose; neither comb nor wattles; of a dark, glossy green color ; very short fan tail; lofty in carriage, trim built, and wild in general appearance; legs very large and long, spotted with blue; ordinary weight from four and a half to six pounds. As a layer, she is equal to other fowls of the game variety.

The cock stands as high as a large turkey, and weighs nine pounds and upward; the plumage is of a reddish cast, interspersed with spots of glossy green; comb very small; no wattles; and bill unlike every other fowl, except the hen.

The Spanish Game. This variety is called the English fowl by some writers. It is more slender in the body, the neck, the bill, and the legs, than the other varieties, and the colors, particularly of the cock, are very bright and showy. The flesh is white, tender, and delicate, and on this account marketable; the eggs are small, and extremely delicate. The plumage is very beautiful-a clear, dark red, very bright, extencling from the back to the extremities, while the breast is beautifully black. The upper convex side of the wing is equally red and black, and the whole of the tail-feathers white. The beak and legs are black; the eyes resemble jet beads, very full and brilliant; and the whole contour of the head gires a most ferocious expression.

\section{8}




\section{THE GUELDERLAND.}

The Guelderland fowl were originally imported into this country from the north of Holland, where they are supposed to have originated. They are very symmetrical in form, and graceful in their motions. They have one noticeable peculiarity, which consists in the absence of a comb in either sex. This is re-

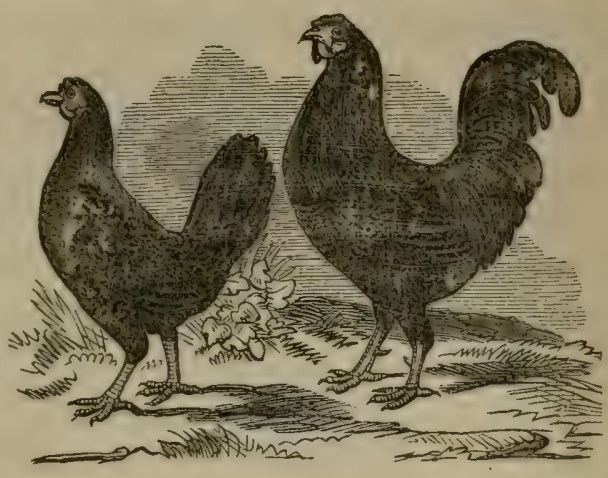

ATELDFRLANDS.

placed by an indentation on the top of the head; and from the extreme end of this, at the back, a small spike of feathers rises. This adds greatly to the beauty of the forl. The presence of the male is especially dignified, and the female is little inferior in carriage.

The plumage is of a beautiful black, tinged with blue, of very rich appearance, and bearing a brilliant gloss. The legs are black, and, in some few instances, slightly feathered. Crosses with the Shanghae have heavily feathered legs. The wattles are of good size in the cock, while those of the hen are slightly less. The flesh is fine, of white color, and of excellent Aavor. The eggs are large and delicate-the shell being thicker than in those of most other fowls-and are much prized for their good qualities. The hens are great layers, seldom inclining to sit. Their weight is from five pounds for the pullets, to seven pounds for the cocks. 
The Guelderlands, in short, possess all the characteristies of a perfect breed; and in breeding them, this is demonstrated by the uniform aspect which is observable in their descendants. They are light and active birds, and are not surpassed, in point of beauty and utility, by any breed known in this country. The only objection, indeed, which has been raised against them is the tenderness of the chickens. With a degree of care, however, equal to their value, this difficulty can be surmounted, and the breed must be highly appreciated by all who bave a taste for beauty, and who desire fine flesh and luscious eggs.

\section{THE SPANGLED HAMBURGH.}

The Spangled Hamburgh fowl are divided into two varieties,

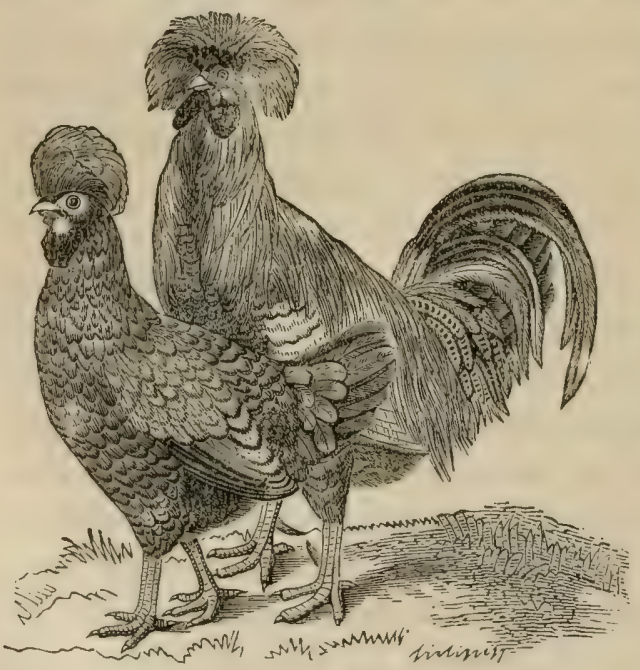

HAMBURGI FOWIS.

the distinctive char a cteristics being slight, and almost dependent upon color; these varieties a re termed the Golden and Silver-Spangled.

The Golden Spangled is one of no ordinary beauty; it is well and very neatly made, has a good body, and no very great offal. On the crest, immediately above the beak, are 350 
two small, fleshy horns, resembling, to some extent, an abortive comb. Above this crest, and occupying the place of a comb, is a very large brown or yellow tuft, the feathers composing it darkening toward their extremities. Under the insertion of the lower mandible-or that portion of the neck corresponding to the chin in man-is a full, dark-colored tuft, somewhat resembling a beard. The wattles are very small; the comb, as in other high-crested fowls, is very diminutive; and the skin and flesh white. The hackles on the neck are of a brilliant orange, or golden yellow; and the general groundcolor of the body is of the same hue, but somewhat darker. The thighs are of a dark-brown or blackish shade, and the legs and feet are of a bluish gray.

In the Silver-spangled variety, the only perceptible difference is, that the ground color is a silvery white. The extremity and a portion of the extreme margin of each feather are black, presenting, when in a state of rest, the appearance of regular semicircular marks, or spangles-and hence the name, "Spangled Hamburgh ;" the varieties being termed gold or silver, according to the prevailing color being bright yellow, or silvery white.

The eggs are of moderate size, but aiuundant; chickens easily reared. In mere excellence of flesh and as layers, they are inferior to the Dorking or the Spanish. They weigh from four and a half to five and a half pounds for the male, and tbree and a half for the female. The former stands some twenty inches in beight, and the latter about eighteen inches. 351 


\section{THE JAVA.}

The Great Java fowl is seldom seen in this country in its purity. They are of a black or dark auburn color, with very large, thick legs, single comb and wattles. They are good layers, and their eggs are very large and well-flavored; their gait is slow and majestic. They are, in fact, amongst the most valuable fowls in the country, and are frequently described as Spanish fowls, than which nothing is more erroneous.

They are as distinctly an original breed as the pure-blooded Great Malay, and possess about the same qualities as to excellence, but fall rather short of them in beauty. Some, however, consider the pure Java superior to all other large fowls, so far as beauty is concerned. Their plumage is decidedly rich.

\section{THE JERSEY-BLUE.}

The color of this variety is light-blue, sometimes approaching to dun; the tail and wings rather shorter than those of the common fowl; its legs are of various colors, generally black, sometimes lightly feathered. Of superior specimens, the cocks weigh from seven to nine pounds, and the hens from six to eight.

They are evidently mongrels; and though once much esteemed, they have been quite neglected, so far as breeding from them is concerned, since the introduction of the purer breeds, as the Shanghaes and the Cochin-Chinas.

\section{THE LARK-CRESTED FOWL.}

This breed is sometimes confounded with the Polish fowl; but the shape of the crest, as well as the proportions of the 352 
bird, is different. This variety, of whatever color it may be, is of a peculiar taper-form, inclining forward, with a moderately depressed, backward-directed crest, and deficient in the neats ness of the legs and feet so conspicuous in the Polands; the latter are of more upright carriage and of a more squarelybuilt frame. Perhaps a good distinction between the two varieties is, that the Lark-crested have an occipital crest, and the Poland more of a frontal one.

They are of various colors : pure snow white, brown with yellow hackles, and black. The white is, perhaps, more brilliant than is seen in any other domesticated gallinaceous bird, being much more dazzling than that of the White Guinea Fowl, or the White Pea Fowl. This white variety is in great esteem, having a remarkably neat and lively appearance when rambling about a homestead. They look very clean and attractive when dressed for market; an old bird, cleverly trussed, will be, apparently, as delicate and transparent in skin and flesh as an ordinary chicken. Their feathers are also more salable than those from darker colored fowls. They are but little, if, indeed, any, more tender than other kinds raised near the barn-door ; they are in every way preferable to the White Dorkings.

In the cocks, a single, upright comb sometimes almost entirely takes the place of the crest; the hens, too, vary in this respect, some having not more than half a dozen feathers in their head-dress.

If they were not of average merit, as to their laying and sitting qualifications, they would not retain the favor they do with the thrifty house-wives by whom they are chiefly cultivated. 


\section{THE MALAX.}

This majestic bird is found on the peninsula from which it derives its name, and, in the opinion of many, forms a connecting link between the wild and domesticated races of fowls.

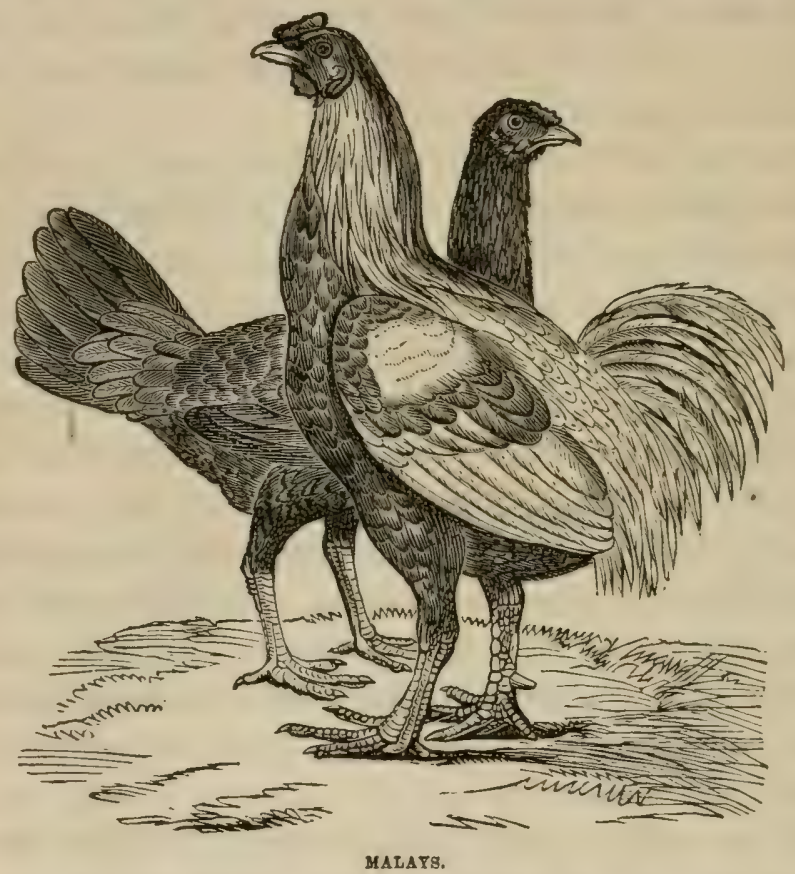

Something very like them is, indeed, still to be found in the East This native Indian bird-the Gigantic Cock, the Kulm Cock of Europeans-often stands considerably more than two feet from the crown of the head to the ground. The comb extends backward in a line with the eyes; it is thick, a little elevated, rounded upon the top, and has almost the appearance of having been cut off. The wattles of the under mandi354 
bles are comparatively small, and the throat is bare. Pale, golden-reddish hackles ornament the head, neck, and upper part of the back, and some of these spring before the bare part of the throat. The middle of the back and smaller wingcoverts are deep chestnut, the webs of the feathers disunited; pale reddish-yellow, long, drooping hackles cover the rump and base of the tail, which last is very ample, and entirely of a glossy green, of which color are the wing-coverts; the secondaries and quills are pale reddish-yellow on their outer webs. All the under parts are deep glossy blackish-green, with high reflections; the deep chestnut of the base of the feathers appears occasionally, and gives a mottled and interrupted appearance to those parts.

The weight of the Malay, in general, exceeds that of the Cochin-China; the male weighing, when full-grown, from eleven to twelve, and even thirteen pounds, and the female from eight to ten pounds; height, from twenty-six to twentyeight inches. They present no striking uniformity of plumage, being of all shades, from black to white; the more common color of the female is a light reddish-yellow, with sometimes a faint tinge of dunnish-blue, especially in the tail.

The cock is frequently of a yellowish-red color, with black intermingled in the breast, thighs, and tail. He has a small, but thick comb, generally inclined to one side; he should be snake-headed, and free from the slightest trace of top-knot; the wattles should be extremely small, even in an old bird; the legs are not feathered, as in the case of the Shanghaes, but, like them and the Cochin-Chinas, his tail is small, compared with his size. In the female, there is scarcely any show of comb or wattles. Their legs are long and stout; their flesh is 
very well flavored, when they have been properly fattened; and their eggs are so large and rich that two of them are equal to three of those of our ordinary fowls.

The Malay cock, in his perfection, is a remarkably courageous and strong bird. His beak is very thick, and he is a formidable antagonist when offended. His crow is loud, harsh, and prolonged, as in the case of the Cochin-China, but broken off abruptly at the termination; this is quite characteristic of the bird.

The chickens are at first very strong, with yellow legs; and are thickly covered with light brown down; but, by the time they are one-third grown, the increase of their bodies has so far outstripped that of their feathers, that they are half naked about the back and shoulders, and extremely susceptible of cold and wet. The great secret of rearing them is, to have them hatched very early indeed, so that they may have safely passed through this period of unclothed adolescence during the dry, sunny part of May and June, and reached nearly their full stature before the midsummer rains descend.

Malay hens are much used by some for hatching the eggs of turkeys-a task for which they are well adapted in every respect but one, which is, that they will follow their natural instinct in turning off their chickens at the usual time, instead of retaining charge of them as long as the mother turkey would have done. Goslings would suffer less from such untimely desertion.

The Pheasant Malay. This variety is highly valued by many, not on account of its intrinsic merits, which are considerable, but because it is believed to be a cross between the pheasant and the common fowl. This is, however, an errone356 
ous opinion. Hybrids between the pheasant and the fowl are, for the most part, absolutely sterile; when they do breed, it is not with each other, but with the stock of one of their progenitors; and the offspring of these either fail or assimilate to one or the other original type. No half-bred family is perpetuated, no new breed created, by human or volucrine agency.

'The Pheasant Malays are large, well-flavored, good sitters, good layers, good mothers, and, in many points, an ornamental and desirable stock. Some object to them as being a trifle too long in their make; but they have a healthy look of not being over-bred, which is a recommendation to those who rear for profit as well as pleasure. The eggs vary in size; some are very large in summer, smooth, but not polished, sometimes tinged with light buff, balloon-shaped, and without the zone of irregularity. The chickens, when first hatched, are all very much alike; yellow, with a black mark all down the back. The cock has a black tail, with black on the neck and wings.

\section{THE PLYMOUTH ROCK.}

This name has been given to a very good breed of fowls, produced by crossing a China cock with a hen, a cross between the Fawn-colored Dorking, the Great Malay, and the Wild Indian.

At a little over a year old, the cocks stand from thirty-two to thirty-five inches high, and weigh about ten pounds; and the pullets from six and a half to seven pounds each. The latter commence laying when five months old, and prove themselves very superior layers. Their eggs are of a medium size, rich, and reddish-yellow in color. Their plumage is rich 
and rariegated; the cocks usually red or speckled, and the pullets darkish brown. They have very fine flesh, and are fit for the table at an early age. The legs are very large, and usually blue or green, but occasionally yellow or white, generally having five toes upon each foot. Some bave their legs feathered, but this is not usual. They have large and single combs and wattles, large cheeks, rather short tails, and small wings in proportion to their bodies.

They are domestic, and not so destructive to gardens as smaller fowls. There is the same uniformity in size and general appearance, at the same age of the chickens, as in those of the pure bloods of primary races.

\section{THE POLAND.}

The Poland, or Polish fowl, is quite unknown in the country which would seem to have suggested the name, which originated from some fancied resemblance between its tufted crest and the square-spreading crown of the feathered caps worn by the Polish soldiers.

The breed of crested fowls is much esteemed by the curious, and is bred with great care. Those desirous of propagating any singular varieties, separate and confine the individuals, and do not suffer them to mingle with such as have the colors different. The varieties are more esteemed in proportion to the variety of the colors, or the contrast of the tuft with the rest of the plumage. Although the differences of plumage are thus preserved pretty constant, they seem to owe their origin to the same breed, and cannot be reproduced pure without careful superintendence. The cocks are much esteemed in Egypt, in consequence of the excellence of their flesh, and are 358 
so common that they are sold at a remarkably cheap rate. They are equally abundant at the Cape of Good Hope, where their legs are feathered.

The Polish are chiefly suited for keeping in a small way, and in a clean and grassy place. They are certainly not so fit for the farmyard, as they become blinded and miserable with dirt. Care should be exercised to procure them genuine, since there is no breed of fowls more $d$ isfig ured by mongrelism than this. They will, without

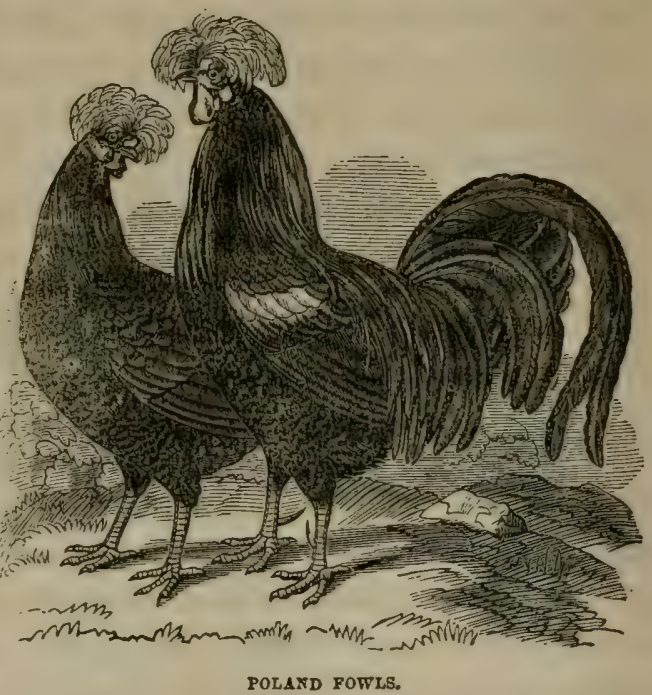
any cross-breeding, occasionally produce white stock that are very pretty, and equally good for laying. If, however, an attempt is made to establish a separate breed of them, they become puny and weak. It is, therefore, better for those who wish for them to depend upon chance; every brood almost of the black produces one white chicken, as strong and lively as the rest.

These fowls are excellent for the table, the flesh being white, tender, and juicy; but they are quite unsuitable for being reared in any numbers, or for general purposes, since they are 
so capricious in their growth, frequently remaining stationary in this respect for a whole month, getting no larger; and this, too, when they are about a quarter or half grown-the time of their life when they are most liable to disease. As aviary birds, they are unrivalled among fowls. Their plumage often requires a close inspection to appreciate its elaborate beauty; the confinement and fretting seem not uncongenial to their health; and their plumage improves in attractiveness with almost every month.

The great merit, however, of all the Polish fowls is, that for three or four years they continue to grow and gain in size, hardiness, and beauty - the male birds especially. This fact certainly points out a very wide deviation in constitution from those fowls which attain their full stature and perfect plumage in twelve or fifteen months. The similarity of coloring in the two sexes-almost a specific distinction of Polish and perhaps Spanish fowls-also separates them from those breeds, like the Game, in which the cocks and hens are remarkably dissimilar. 'Their edible qualities are as superior, compared with other fowls, as their outward apparel surpasses in elegance. They have also the reputation of being everlasting layers, which further fits them for keeping in small enclosures; but, in this respect, individual exceptions are often encountered-as in the case of the Hamburghs-however truly the habit may be ascribed to the race.

There are four known varieties of the Polish fowl, one of which appears to be lost to this country.

The Black Polish. This variety is of a uniform blackboth cock and hen-glossed with metallic green. The head is ornamented with a handsome crest of white feathers, 360 
springing from a fleshy protuberance, and fronted more or less deeply with black. The comb is merely two or three spikes, and the wattles are rather small. Both male and female are the same in color, except that the former has frequently narrow stripes of white in the waving feathers of the tail, a sign, it is said, of true breeding. The hens, also, have two or three feathers on each side of the tail, tinged in the tip with white. They do not lay quite so early in the spring as some varieties, especially after a hard winter; but they are exceedingly good layers, continuing a long time without wanting to sit, and laying rather large, very white, sub-ovate eggs. They will, however, sit at length, and prove of very diverse dispositions; some being excellent sitters and nurses, others heedless and spiteful.

The chickens, when first hatched, are dull black, with white breasts, and white down on the front of the head. They do not always grow and get out of harm's way so quickly as some other sorts, but are not particularly tender. In rearing a brood of these fowls, some of the hens may be observed with crests round and symmetrical as a ball, and others in which the feathers turn all ways, and fall loosely over the eyes; and in the cocks, also, some have the crest falling gracefully over the back of the head, and others have the feathers turning about and standing on end. These should be rejected, the chief beauty of the kind depending upon such little particulars. One hen of this variety laid just a hundred eggs, many of them on consecutive days, before wanting to incubate; and after rearing a brood successfully, she laid twenty-five eggs before moulting in autumn.

The Golden Polands. These are sometimes called Gold362 
spangled, as their plumage approaches to that of the Gold: Spangled Hamburghs; but many of the finest specimens have the feathers merely fringed with a darker color, and the cocks, more frequently than the hens, exhibit a spotted or spangled appearance. Many of them are disfigured by a muff or beard; as to which the question has been raised whether it is an original appendage to these birds or not. A distinct race, of which the muff is one permanent characteristic, is not at present known. This appendage, whenever introduced into the poultry-yard, is not easily got rid of; which has caused some to suspect either that the original Polish were beardless, or that there were two ancient races.

The Golden Polands, when well-bred, are exceedingly handsome; the cock has golden hackles, and gold and brown feathers on the back; breast and wings richly spotted with ochre and dark brown; tail darker; large golden and brown crest, falling back over the neck; but little comb and wattles. The hen is richly laced with dark-brown or black on an ochre ground; dark-spotted crest; legs light-blue, very cleanly made, and displaying a small web between the toes, almost as proportionately large as that in some of the waders.

They are good layers, and produce fair-sized eggs. Many of them make excellent mothers, although they cannot be induced to sit early in the season. The chickens are rather clumsy-looking little creatures, of a dingy-brown, with some dashes of ochre about the head, breast and wings. They are sometimes inclined to disease in the first week of their existence; but, if they pass this successfully, they become tolerably hardy, though liable to come to a pause when about halfgrown. It may be noted as a peculiarity in the temper of 362 
this breed, that, if one is caught, or attacked by any animal, the rest, whether cocks or hens, will iustantly make a furious attack upon the aggressor, and endearor to effect the rescue of their companion.

The Silver Polands. These are similar to the preceding in shape and markings, except that white, black, and gray are exchanged for ochre or yellow, and various shades of brown. They are even more delicate in their constitution, more liable to remain stationary at a certain point of their adolescence, and, still more than the other varieties, require and will repay extra care and accommodation. Their top-knots are, perhaps, not so large, as a general thing; but they retain the same neat bluish legs and slightly-webbed feet. The hens are much more ornamental than the cocks; though the latter are sure to attract notice. They may, unquestionably, be ranked among the choicest of forwls, whether their beauty or their rarity is considered. They lay, in tolerable abundance, eggs of moderate size, French-white, much pointed at one end; and when they sit, acquit themselves respectably.

The newly-hatched chickens are very pretty; gray, with black eyes, light lead-colored legs, and a swelling of down on the crown of the head, indicative of the future top-knot, which is exactly the color of a powdered wig, and, indeed, gives the chicken the appearance of wearing one. There is no difficulty in rearing them for the first six weeks or two months; the critical time being the interval between that age and their reaching the fifth or sixth month. They acquire their peculiar distinctive features at a very early age, and are then the most elegant little miniature fowls which can possibly be imagined. The distinction of sex is not very manifest till they are nearly 
full-grown; the first observable indication being in the tail. That of the pullet is carried uprightly, as it ought to be; but in the cockerel, it remains depressed, awaiting the growth of the sickle-feathers. The top-knot of the cockerel inclines to hang more backward than that of the pullets. It is remarkable that the Golden Polish cock produces as true Silver chickens, and those stronger, with the Silver Polish hen, as the Silver Polish cock would bring.

The Silver Polands have all the habits of their golden companions, the main difference being the silvery ground instead of the golden. This variety will sometimes make its appearance even if merely its Golden kind is bred, precisely as the Black Polish now and then produce some pure White chickens that make very elegant birds.

The Black-topped White. This variety does not at present exist among us; and some have even questioned whether it ever did. Buffon mentions them as if extant in France in his time. An attempt has been made to obtain them from the preceding, by acting on the imagination of the. parents. The experiment failed, though similar schemes are said to have succeeded with animals; it proved, however, that it will not do to breed from the White Polish as a separate breed. Being Albinos, the chickens come very weakly, and few survive.

This breed is now recoverable, probably, only by importation from Asia.

\section{THE SHANGHAE.}

For all the purposes of a really good fowl-for beauty of model, good size, and laying qualities-the thorough-bred 364 
Shanghae is among the best, and generally the most profitable of domestic birds. The cock, when full-grown, stands about twenty-eight inches high, if he is a good specimen; the female, about twenty-two or twenty-three inches. A large comb or heavy wattles are rarely seen on the hen at any age; but the comb of the male is high, deeply indented, and his wattles double and large. The comb and wattles are not, however, to be regarded as the chief characteristics of this variety, nor even its reddish-yellow feathered leg; but the abundant, soft, and downy covering of the thighs, hips, and region of the vent, together with the remarkably short tail, and large mound of feathers piled over the upper part of its root, giving rise to a considerable elevation on that part of the rump. It should be re-

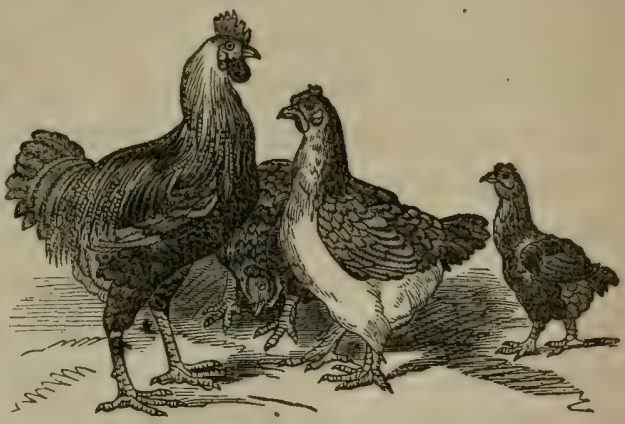

BHAXGHAES. marked, also, that the wings are quite short and small in proportion to the size of the fowl, and carried very high up the body, thus exposing the whole of the thighs, and a considerable portion of the side.

These characteristics are not found, in the same degree, in any other fowl. The peculiar arrangement of feathers gives the Shanghae in appearance, what it has in reality - a greater depth of quarter, in proportion to the brisket, than any other fowl. 
As to the legs, they are not very peculiar. The color is usually reddish-white, or flesh-color, or reddish-yellow, mostly corered down the outside, even to the end of the toes, with feathers. This last, however, is not always the case. The plumage of the thorough-bred is remarkably soft and silky, or rather downy; and is, in the opinion of many, equally as good for domestic purposes as that of the goose. The feathers are certainly quite as fine and soft, if not as abundant.

In laying qualities, the pure Shanghae equals, if it does not excel, any other fowl. The Black Poland, or the Boiton Gray, may, perhaps, lay a few more eggs in the course of a year, in consequence of not so frequently inclining to sit; but their eggs are not so rich and nutritious. A pullet of this breed laid one hundred and twenty eggs in one hundred and twentyfive days, then stopped six days, then laid sixteen eggs more, stopped four days, and again continued her laying. The eggs are generally of a pale yellow, or nankeen color, not remarkably large, compared with the size of the fowl, and generally blunt at the ends. The comb is commonly single, though, in some specimens, there is a slight tendency to rose.

The flesh of this fowl is tender, juicy, and unexceptionable in every respect. Taking into consideration the goodly size of the Shanghae-weighing, as the males do, at maturity, from ten to twelve pounds, and the females from seren and a half to eight and a half, and the males and females of six months, eight and six pounds respectively-the economical uses to which its soft, downy feathers may be applied, its productiveness, hardiness, and its quiet and docile temper, this variety must occupy, and deservedly so, a high rank among our 366 
domestic fowls; and the more it is known, the better will it be appreciated.

The Thite Sindugine. This rariety is entirely white, with the legs usually feathered, and differ in no material

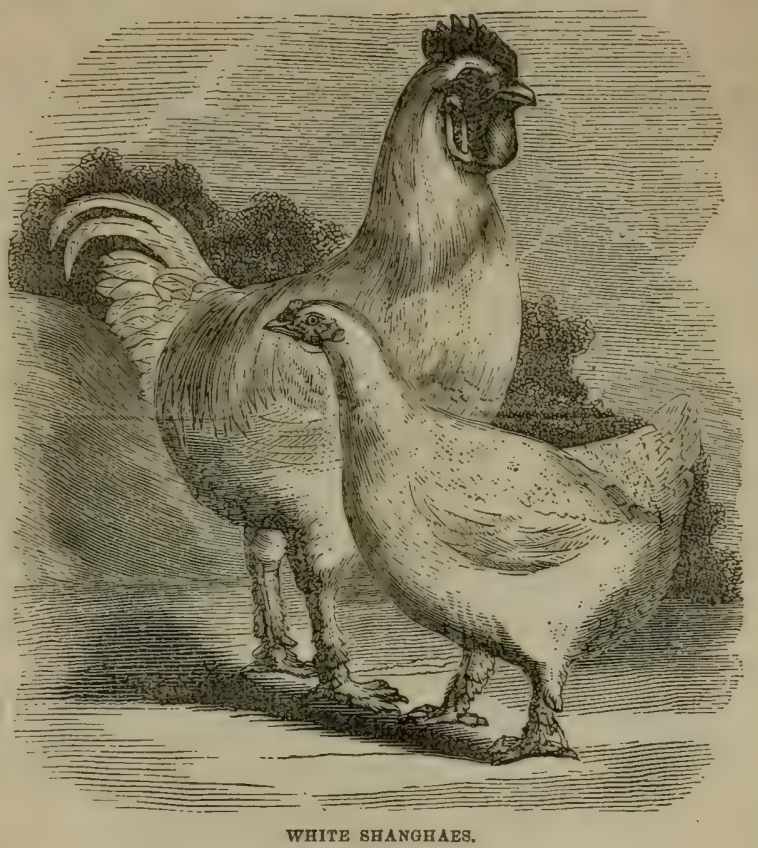

respect from the red, yellow, and Dominique, except in color. The legs are yellowish, or reddish-yellow, and sometimes of flesh-color. Many prefer them to all others. The eggs are of a nankeen, or dull yellow color, and blunt at both ends.

It is claimed by the friends of this variety that they are larger and more quiet than other rarieties, that their flesh is much superior, their eggs larger, and the hens more profitable. Being more quiet in their habits, and less inclined to ramble, 
the hens are invaluable as incubators and nurses; and the mildness of their disposition makes them excellent fostermother's, as ther never injure the chickens belonging to other hens:

These forvls will rank among the largest coming from China, and are very thrifty in our climate. A cock of this variety attained a weight of eight pounds, at about the age of eight months, and the pullets of the same brood were proportionably large. They are broad on the back and breast, with a body well rounded up; the plumage white, with a downy softness -in the latter respect much like the feathering of the Bremen goose; the tail-feathers short and full; the head small, surmounted by a small, single, serrated comb; wattles long and wide, overlaying the cheek-piece, which is also linge, and extends back on the neck; and the legs of a yellow hue, approaching a flesh-color, and feathered to the ends of the tocs.

\section{THE SILVER PHEASANT.}

This variety of fowls is remarkable for great brillianey of plumage and diversity of colors. On a white ground, which is usually termed silvery, there is an abundance of black spots. The feathers on the upper part of the head are much longer" than the rest, and unite together in a tuft. They have a small, double comb, and their wattles are also comparatively small. A remarkable peculiarity of the cock is, that there is a spot of a blue color on the cheeks, and a range of feathers under the throat; which has the appearance of a collar.

The hen is a smaller bird, with plumage similar to that of the cock, and at a little distance seems to be covered with 368 
scales. On the head is a top-knot of very large size, which droops over it on every side. The Silver Pheasants are beautiful and showy birds, and chiefly valuable as ornamental appendages to the poultry-yard.

\section{THE, SPANISH.}

This name is said to be a misnomer, as the breed in question. was originally brought by the Spaniards from the West

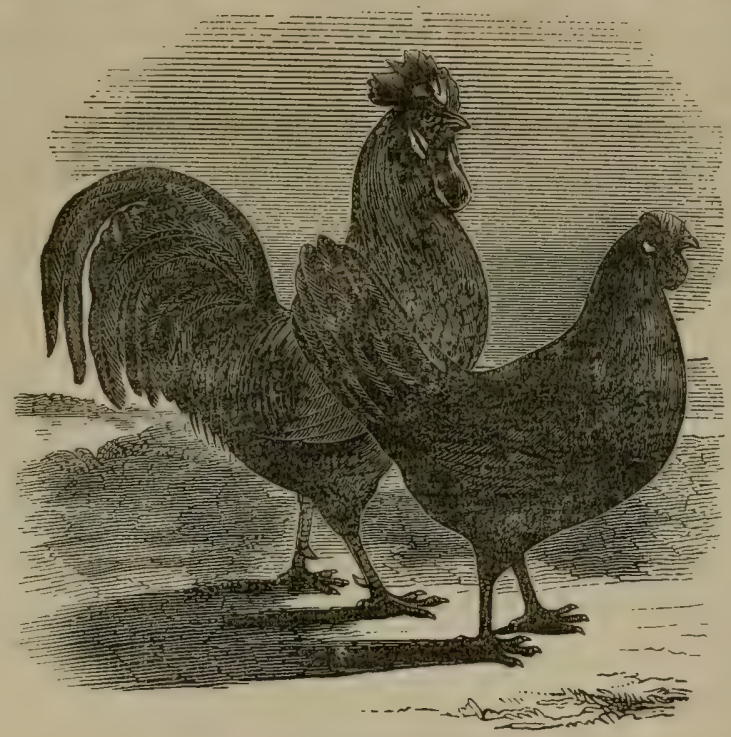

SPANISH FOWLS.

Indies; and, although subsequently propagated in Spain, it has for some time been very difficult to procure good specimens from that country. From Spain, they were taken in considerable numbers into Holland, where they have been carefully bred, for many years; and it is from that quarter that our best fowls of this variety come. 
The Spanish is a noble race of fowls, possessing many merits ; of spirited and animated appearance; of considerable size; excellent for the table, both in whiteness of flesb and skin, and also in flavor; and laying exceedingly large eggs in considerable numbers. Among birds of its own breed it is not deficient in courage; though it yields, without showing much fight, to those which have a dash of game blood in their veins. It is a general favorite in all large cities, for the additional advantage that no soil of smoke or dirt is apparent on its plumage.

The thorough-bred birds should be entirely black, as far as feathers are concerned; and when in high condition, display a greenish, metallic lustre. The combs of both cock and hen are exceedingly large, of a vivid and most brilliant scarlet; that of the hen droops over upon one side. Their most singular feature is a large, white patch, or ear-hole, on the cheek-in some specimens extending over a great part of the face-of a fleshy substance, similar to the wattle; it is smail in the female, but large and very conspicuous in the male. This marked contrast of black, bright red, and white, makes the breed of the Spanish cock as handsome as that of any variety which we have; in the genuine breed, the whole form is equally good.

Spanish hens are celebrated as good layers, and produce very large, quite white eggs, of a peculiar shape, being very thick at both ends, and yet tapering off a little at each. They are, by no means, good mothers of families, even when they do sit-which they will not often condescend to doproving very careless, and frequently trampling half their brood under foot. The inconveniences of this habit are, however, 370 
easily obviated by causing the eggs to be hatched by some more motherly hen.

This variety of fowl has frequently been known to lose nearly all the feathers in its body, besides the usual quantity on the neck, wings, and tail; and, if they moult late, and the weather is severe, they feel it much. This must often happen in the case of an "everlasting layer ;" for if the system of a bird is exhausted by the unremitting production of eggs, it cannot contain within itself the material for supplying the growth of feathers. They have not, even yet, become acclimated in this country, since continued frost at any time is productive of much injury to their combs ; frequently causing mortification in the end, which at times terminates in death. A warm poultry-house, high feeding, and care that they do not remain too long exposed to severe weather, are the best means of preventing this disfigurement. Some birds are occasionally produced, handsomely streaked with red on the hackle and back. This is no proof of bad breeding, if other points are right.

The chickens are large, as would be expected from such eggs, entirely shining black, except a pinafore of white on the breast-in which respect they are precisely like the Black Polish chickens-and a slight sprinkling under the chin, with sometimes also a little white round the back and eyes; their legs and feet are black. Many of them do not get perfectly feathered till they are three-fourths grown; and, therefore, to have this variety come to perfection in a country where the summers are much shorter than in their native climate, they must be hatched early in spring, so that they may be well covered with plumage before the cold rains of autumn. There is, how- 
ever, a great lack of uniformity in the time when they get their plumage; the pullets are always earlier and better feathered than the cockerels-the latter being generally half naked for a considerable time after being hatched, though some feather tolerably well at an early age.

The Black is not the only valuable race of Spanish fowl; there is, also, the Gruy, or Speckled, of a slaty gray color, with white legs. Their growth is so rapid, and their size, eventually, so large, that they are remarkably slow in obtaining their feathers. Although well covered with down when first hatehed, they look almost naked when half-grown, and should, therefore, be hatched as early in spring as possible. The cross between the Pheasant-Malay and the Spanish produces a particularly handsome fowl.

As early pullets, for laying purposes in the autumn and winter after they are hatched, no fowls can surpass the Spanish. They are believed, also, to be more precocious in their constitution; and consequently to lay at an earlier age than the pullets of other breeds.

THE NATURAI HISTORY OF DOMESTIC FOWLS.

Fowls are classed by modern naturalists as follows :

Division. Vertebrata_possessing a back bone.

Cuass. Aves-birds.

ORDER. Rasores-scrapers.

Famriy. Phasianido-Pheasants.

Genus. Gallus-the cock.

Birds, as well as quadrupeds, may be divided into two great clnsses, according to their food: the Camirorous and the Graminivorous. Fowls belong, strictly speaking, to the latter. 372 
In the structure of the digestive organs, birds exhibit a great uniformity. The œsophagus, which is often very muscular, is dilated into a large sac-called the crop-at its cntrance into the breast; this is abundantly supplied with glands, and serves as a species of first stomach, in which the food receives a certain amount of preparation before being submitted to the action of the proper digestive organs. A little below the crop, the narrow osophagus is again slightly dilated, forming what is called the ventriculus succenturiatus, the walls of which are very thick, and contain a great number of glands, which secrete the gastric juice. Below this, the intestinal canal is enlarged into a third stomach, the gizzard, in which the process of digestion is carried still farther. In the graminivorous birds, the walls of this cavity are very thick and muscular, and clothed internally with a strong, horny epithelium, serving for the trituration of the food. The intestine is rather short, but usually exhibits several convolutions; the large intestine is always furnished with two corea. It opens by a semicircular orifice into the cloaca, which also receives the orifices of the urinary and generative organs. The liver is of large size, and usually furnished with a gall-bladder. The pancreas is lodged in a kind of loop, formed by the small intestine immediately after quitting the gizzard. There are also large salivary glands in the neighborhood of the mouth, which pour their secretion into that cavity.

The organs of circulation and respiration in birds are adapted to their peculiar mode of life; but are not separated from the abdominal cavity by a diaphragm, as in the mammalia. The heart consists of four cavities distinctly separatedtwo auricles and two ventricles-so that the venous and 373 
arterial blood can never mix in that organ; and the whole of the blood returned from the different parts of the body passes through the lungs before being again driven into the systemic arteries. The blood is received from the veins of the body in the right auricle, from which it passes through a tabular opening into the right ventricle, and is thence driven into the lungs. From these organs it returns through the pulmonary veins into the left auricle, and passes thence into the ventricles of the same side, by the contraction of which it is driven into the aorta. This soon divides into two branches, which, by their subdivision, give rise to the arteries of the body.

The jaws, or mandibles, are sheathed in a horny case, usually of a conical form, on the sides of which are the nostrils. In most birds, the sides of this sheath or bill are smooth and sharp; but in some they are denticulated along the margins. The two anterior members of the body are extended into wings. The beak is used instead of hands; and such is the flexibility of the vertebral column, that the bird is able to touch with its beak every part of its body. This curious and important result is obtained chiefly by the lengthened vertebræ of the neck, which, in the swan, consists of twenty-three bones, and in the domestic cock, thirteen. The vertebræ of the back are seven to eleven; the ribs never exceed ten on each side.

The clothing of the skin consists of feathers, which in their nature and development resemble hair, butt are of a more complicated structure. A perfect feather consists of the shaft, a central stem, which is tubular at the base, where it is inserted into the skin, and the burbs, or fibres, which form the webs on each side of the shaft. The two principal modifica374 
tions of feathers are quills and plumes; the former confined to the wings and tail, the latter constituting the general clothing of the body. Besides the common feathers, the skin of many birds is covered with a thick coating of down, which consists of a multitude of small feathers of peculiar construction; each of these down feathers is composed of a very small, soft tube imbedded in the skin, from the interior of which there rises a small tuft of soft filaments, without any central shaft. These filaments are very slender, and bear on each side a series of still more delicate filaments, which may be regarded as analogous to the barbules of the ordinary feathers. This downy coat fulfils the same office as the soft, woolly fur of many quadrupeds; the ordinary feathers being analogous to the long, smooth hair by which the fur of these animals is concealed. The skin also bears many hair-like appendages, which are usually scattered sparingly over its surface ; they rise from a bulb which is imbedded in the skin, and usually indicate their relation to the ordinary feathers by the presence of a few minute barbs toward the apex.

Once or twice in the course of a year the whole plumage of the bird is renewed, the casting of the old feathers being called moulting. The base of the quills is cuvered by a series of large feathers, called the wing coverts; and the feathers of the tail are furnished with numerous muscles, by which they can be spread out and folded up like a fan. In the aquatic birdslike the goose, the duck, and the swan-the feathers are constantly lubricated by an oily secretion, which completely excludes the water.

In their reproduction, birds are strictly oviparous. The eggs are always enclosed in a hard shell, consisting of calcare- 
ous matter, and birds almost invariably devote their whole attention, during the breeding season, to the hatching of their eggs and the development of their offspring; sitting constantly upon the eggs to communicate to them the degree of warmth necessary for the evolution of the embryo, and attending to the wants of their newly-hatehed young, until the latter are in a condition to shift for themselves.

In the structure and development of the egg there is a great. uniformity; but there is a remarkable difference in the condition of the young bird at the moment of hatching. In the class under consideration, the young are able to run about from the moment of their breaking the egg-shell; and the only care of the parents is devoted to protecting their offspring from danger, and leading them into those places where they are likely to meet with food.

The longevily of birds is various, and, unlike the case of men and quadrupeds, seems to bear little proportion to the age at which they acquire maturity. A few months, or even a few weeks, suffice to bring them to their perfection of stature, instincts, and powers. Domestic fowls live to the age of twenty years; geese, fifty; while swans exceed a century.

The order Rasores includes the numerous species of gallinaceous birds, and the term is applied to them from their habit of scratching in the ground in search of food. They are generally marked by a small head, stout legs, plumage fine, the males usually adorned with magnificent colors, and the tails often developed in a manner to render the appearance extremely elegant. The wings are usually short and weak, and the flight of the birds is neither powerful nor pro376 
longed. The corla of this order are larger than in any other birds.

The species are found in almost all parts of the world, from the tropics to the frozen regions of the north; but the finest and most typical kinds are inhabitants of the temperate and warmer parts of Asia. They feed principally on seeds, fruit, and herbage, but also, to a considerable extent, on insects, worms, and other small animals. Their general habitation is on the ground, where they run with great celerity, but many of them roost on trees. They are mostly polygamous in their habits, the males being usually surrounded by a considerable troop of females; and to these, with a few exceptions, the whole business of incubation is generally left. The nest is always placed on the ground in some sheltered situation, and very little art is exhibited in its construction; indeed, an elaborate nest is the less necessary, as the young are able to run about and feed almost as soon as they have left the egg; and at night or on the approach of danger, they collect beneath the wings of their mother. Most of these species are esteemed for the table, and many of them are among the most celebrated of game birds.

The pheasant family, of this order, includes the most beautiful of the rasorial birds; indeed, some of them may, perhaps, be justly regarded as pre-eminent in this respect over all the rest of their class. In these, the bill is of moderate size and compressed, with the upper mandible arched to the tip, where it overhangs the lower one; the tarsi are of moderate length and thickness, usually armed with one or two spurs; the toes are moderate, and the hinder one short and elevated; the wings are rather short and rounded, and the tail more or less 
elongated and broad, but frequently wedge-shaped and pointed. The head is rarely feathered all over; the naked skin is sometimes confined to a space about the eye, but generally occupies a greater portion of the surface, occasionally covering the whole head, and even a part of the neck, and frequently forming combs and wattles of very remarkable forms. In some species, the crown is furnished with a crest of feathers.

The birds of this family are, for the most part, indigenous to the Asiatic continent and islands, from which, however, several species have been introduced into other parts of the globe. The Guinea Fowl of Africa, and the Turkeys of America, are almost the only instances of wild Phasianidous birds out of Asia. Some species, such as the Domestic Fowl, the Peacock, the Turkey, and the Guinea Fowl, have been recluced to a state of complete domestication, and are dis. tributed pretty generally over the world.

\section{THE GUINEA FOWL.}

This bird belongs to the same division, class, order, and family as the Domestic Fowl; but is assigned by naturalists to the genus Numida, or Numidian. It is indigenous to the tropical parts of Africa, and in a wild state, Guinea Fowls live in flocks, in woods, preferring marshy places, and feed on insects, worms, and seeds; they roost on trees; the nest is made on the ground, and usually contains as many as twenty eggs. They have been propagated in the Island of Jamaica to such an extent as to have become wild, and are shot like other game. They do much damage to the crops, and are therefore. destroyed by various means; one of which is, to get them tipsy by strewing corn steeped in rum, and mixed with the 378 
intoxicating juice of the cassava, upon the ground; the birds devour this, and are soon found in a helpless state of inebriety.

The Guinea Fowl, to a certain degree, unites the characteristics of the pheasant and the turkey; having the delicate

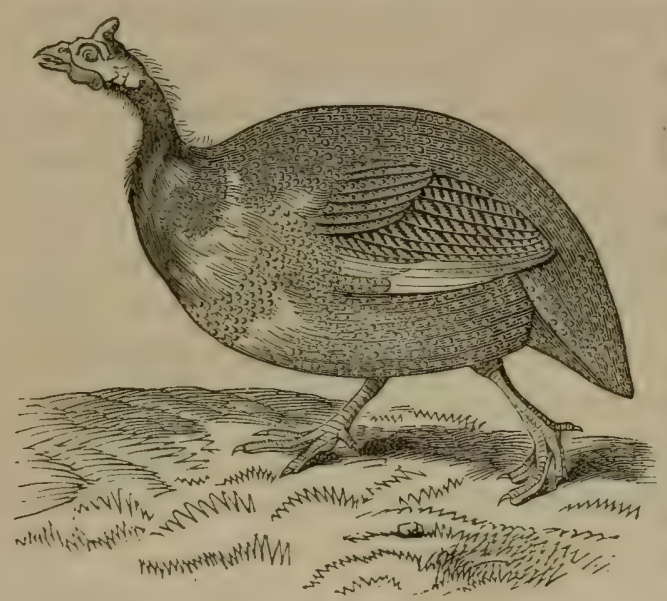

THE GUINEA FOWL. shape of the one, and the bare head of the other. There are several varieties: the White, the Spotted, the Madagascar, and the Crested: The latter is not so large as the common species; the head and neck are bare, of a dull blue, shaded with red, and, instead of the casque, it has an ample crest of hair-like, disunited feathers, of a bluish black, reaching as far forward as the nostrils, but, in general, turned backivard. The whole plumage, except the quills, is of a bluish black, covered with small grayish spots, sometimes four, sometimes six on each feather.

This fowl is not a great favorite among many keepers of poultry, being so unfortunate as to have gained a much worse reputation than it really deserves, from having been occasionally guilty of a few trifling faults. It is, however, useful, ornamental, and interesting during its life; and, when dead, a desirable addition to the table, at a time when all other poultry is scarce. 
The best way to commence keeping Guineas is to procure a sitting of eggs which can be depended upon for freshness, and, if possible, from a place where but a single pair is kept. A Bantam hen is the best mother; she is lighter, and less likely to injure them by treading on them than a full-sized fowl. She will cover nine eggs, and incubation will last a month. The young are excessively pretty. When first hatched, they are so strong and active as to appear not to require the attention which is really necessary to rear them. Almost as soon as they are dry from the moisture of the egg, they will peck each other's toes, as if supposing them to be worms, scramble with each other for a crumb of bread, and domineer over any little Bantam or chicken that may chance to have been hatched at the same time with themselves. No one, ignorant of the fact, would guess, from their appearance, to what species of bird they belonged; their orange-red bills and legs, and the dark, zebra-like stripes with which they are regularly marked from head to tail, bear no traces of the speckled plumage of their parents.

Of all known birds, the Guinea fowl is, perhaps, the most prolific of eggs. Week after week, and month after month, there are very few intermissions, if any, of the daily deposit. Even the process of moulting is sometimes insufficient to draw off the nutriment which it takes to make feathers instead of eggs; and the poor thing will sometimes go about half-naked in the chilly autumn months, unable to refrain from its diurnal visit to the nest, and consequently unable to furnish itself with a new outer garment. The body of the Guinea hen may be regarded, in fact, as a most admirable machine for producing 380 
eggs out of insects, grain, and regetables, garbage, or whatever material an omnivorous creature can appropriate.

Its normal plumage is singularly beautiful, being spangled over with an infinity of white spots on a black ground, shaded with gray and brown. The spots vary from the size of a pea to extreme minuteness. The black and white occasionally change places, causing the bird to appear covered with a net of lace.

The white variety is not uncommon, and is said to be equally hardy and profitable with the usual kind; but the peculiar beauty of the original plumage is, certainly, all exchanged for a dress of not the purest white. It is doubtful how long either this or the former variety would remain permanent; though, probably, but for a ferw generations. Pied birds blotched with patches of white, are frequent, but are not comparable, in point of beauty, with those of the original wild color.

THE: PEA. FOWI.

This bird is assigned to the genus paro, or peacock-the division, class, or sex, and family, being the same as the preceding. The male of this species is noted for its long, lustrous tail, which it occasionally spreads, glittering with hundreds of jowel-like eye-spots, producing an unrivalled effect of grace and beauty. The form of the bird is also exceedingly elegant, and the general plumage of the body exhibits rich metallic tints; that of the neck, particularly, being of a fine deep blue, tinged with golden green. The female, however, is of a mucb more sober hue, her whole plumage being usually of a brownish color. The voice of the peacock is by no means suitable to 381 . 
the beauty of its external appearance, consisting of a harsh, disagreeable cry, not unlike the word paon, which is the French name of the bird.

Although naturalized as a domestic bird in Europe and America, the pea fowl is a native of India, where it is still found abundantly in a wild. state; and the wild specimens are said to be more brilliant than those bred in captivity. The date of its introduction into England is not known; but the first peacocks appear to have been brought into Europe by

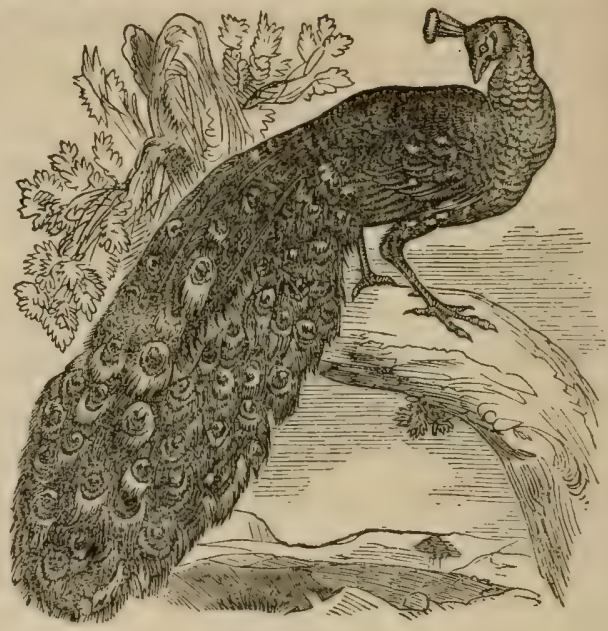

THE PEA FOWL.

Alexander the Great, although these birds were among the articles imported into Judea by the fleets of Solomon. They reached Rome toward the end of the republic, and their costliness soon caused them to be regarded as one of the greatest luxuries of the table, though the moderns find them dry and leathery. This, perhaps, as much as the desire of ostentation, may have induced the extravagance of Titellius and Heliogabulus, who introduced dishes composed only of the brains and tongues of peacocks at their feasts. In Europe, during the middle ages, the peacock was still a favorite article in the bill of fare of grand entertainments, at which it was served with 352 
the greatest pomp and magnificence. And during the period of chivalry, it was usual for knights to make rows of enterprize on these occasions, "before the peacock and the ladies." At present, however, the bird is kept entirely on account of the beauty of its appearance.

In a state of nature, pea forl frequent jungles and wooded localities, feeding upon grain, fruits, and insects. They are polygamous, and the females make their nests upon the ground among bushes; the nest is composed of grass, and the number of eggs laid is said to be five or six. They roost in high trees, and, even in captivity, their inclination to get into an elevated position frequently manifests itself; and they may often be seen perched upon high walls, or upon the ridges of buildings.

The latter characteristic is, indirectly, one reason why many are disinclined to keep pea forl in a domestic state. Their decided determination so to roost prevents such a control being exercised over them as would restrain them from mischief, until an eye could be kept on their movements; and, consequently, they commit many depredations upon gardens, stealing off to their work of plunder at the first dawn, or at the most unexpected moments. Their cunning indeed is such that, if 'frequently driven away from the garden at any particular hour of the day or evening, they will nerer be found there, after a certain time, at that special hour, but will invariably make their inroads at day-break. Many have tried, as a last resort, to eject them with every mark of scorn and insult, such as harsh words, the cracking of whips, and the throwing of harmless brooms; but they remain incorrigible 383 
marauders, indifferent to this disrespectful usage, and careless of severe rebuke.

A mansion, therefore, where the fruit and vegetable garden is at a distance, is almost the only place where they can be kept without daily vexation. The injury they do to flowers is comparatively trifling; though, like the Guinea-fowl, they are great eaters of buds, cutting them out cleanly from the axillac of leaves. They must likewise have a dusting-hole, which is large and unsightly; but this can be provided for them in some nook out of the way; and by feeding and encouragement, they will soon be taught to dispose themselves into a pleasing spectacle, at whatever point of view may be deemed desirable. No one with a very limited range should attempt to keep them at all, unless confined in an aviary. Where they can be kept at large, they should be collected in considerable numbers, that their dazzling effects may be as impressive as possible.

A wanton destructiveness toward the young of other poultry is also charged upon them. Relative to this, however, statements differ; some contending that such instances of cruelty constitute the exceptions, and not the rule.

The hen does not lay till her third summer; but she then seems to have an instinctive fear of her mate, manifested by the secrecy with which she selects the place for her nest; nor, if the eggs are disturbed, will she go there again. She lays from four or five to seven. If these are taken, she will frequently lay a second time during the summer; and the plan is recommended to those who are anxious to increase their stock. She sits from twenty-seven to twenty-nine days. A common hen will hatch and rear the young; but the same 384 
objection lies against her performing that office, except in very fine, long summers, for the pea fowl as for turkeys-that the young require to be brooded longer than the hen is conreniently able to do. A turkey will prove a much better foster-mother in every respect. The peahen should, of course, be pernitted to take charge of one set of eggs. Even without such assistance, she will be tolerably successful.

The same wise provision of Nature noticed in the case of the Guinea fowl is evinced in a still greater degree in the little pea chickens. Their native jungle-tall, dense, sometimes impervious, swarming with reptile, quadruped, and even insect, enemies-would be a most dangerous habitation for a little tender thing that could merely run and squall. . Accordingly, they escape from the egg with their quill-feathers very highly developed. In three days, they will fly up, and perch upon any thing three feet high; in a fortnight, they will roost on trees, or the tops of sheds; and in a month or six weeks, they will reach the ridge of a barn, if there are any intermediate low stables or other buildings to help them to mount from one to the other.

There are two varieties of the common pea fowl: the pied and the white. The first has irregular patches of white about it, like the pied Guinea fowl, and the remainder of the plumage resembling the original sorts; the white have the ocellated spots on the tail faintly visible in certain lights. These last are tender, and much prized by those who prefer variety to real beauty. They are occasionally produced by birds of the common kind, in cases where no intercourse with other white birds can have taken place. In one instance, in the same 25 
brood, whose parents were both of the usual colors, there were two of the common sort, and one white cock, and one white hen.

\section{THE TURKEY.}

The Wild Turkey. The turkey belongs to the genus meleagris, and, though now known as a domestic fowl in most civi-

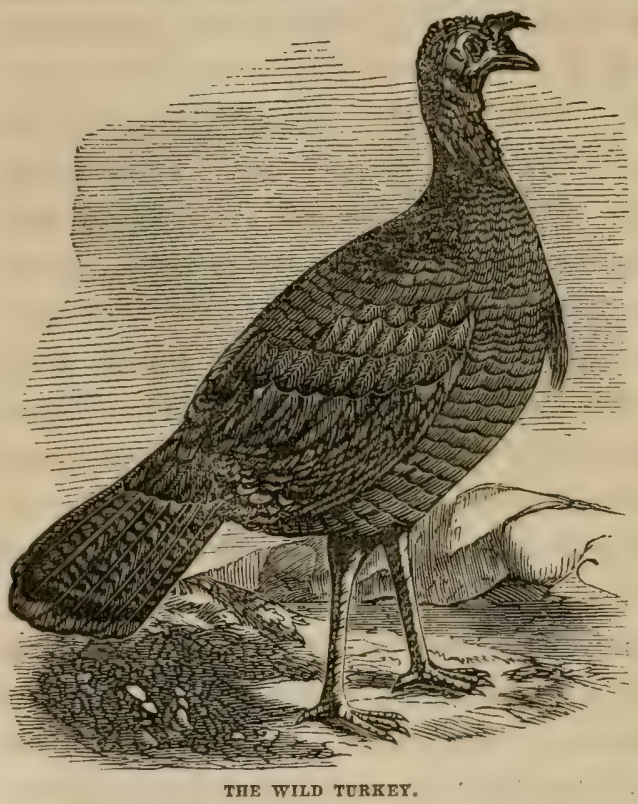

lized countries, was confined to America until after the discovery of that country by Columbus. It was probably introduced into Europe by the Spaniards about the year 1530. It was found in the forests of North America, when the country was first settled, from the Isthmus of Darien to Canada, being then abundant even in New England; at present, a few are found in the mountains of Massachusetts, New York, and New Jersey; in the Western and the Southwestern States they are still numerous, though constantly diminishing before the extending and increasing settlements.

The wild male bird measures about three feet and a half, or 386 
nearly four feet, in length, and almost six in expanse of the wings, and weighs from fifteen to forty pounds. The skin of the head is of a bluish color, as is also the upper part of the neck, and is marked with numerous reddish, warty elevations, with a few black hairs scattered here and there. On the under part of the neck, the skin hangs down loosely, and forms a sort of wattle; and from the point where the bill commences, and the forehead terminates, arises a fleshy protuberance, with a small tuft of hair at the extremity, which becomes greatly elongated when the bird is excited; and at the lower part of the neck is a tuft of black hair, eight or nine inches in length.

The feathers are, at the base, of a bright dusky tinge, succeeded by a brilliant metallic band, which changes, according to the point whence the light falls upon it, to bronze, copper, violet, or purple; and the tip is formed by a narrow, black, velvety band. This last marking is absent from the neck and breast. The color of the tail is brown, mottled with black, and crossed with numerous lines of the latter color; near the tip is a broad, black band, then a short mottled portion, and then a broad band of dingy yellow. The wings are white, banded closely with black, and shaded with brownish yellow, which deepens in tint toward the back. The head is very small, in proportion to the size of the body; the legs and feet are strongly made, and furnished with blunt spurs, about an inch long, and of a dusky reddish color; the bill is reddish, and brown-colored at the tip.

The female is less in size; her legs are destitute of spurs; her neck and head are less naked, being furnished with short, dirty, gray feathers; the feathers on the back of the neck have brownish tips, producing on that part a brown, longitudinal 
band. She also, frequently, but not invariably, wants the tuft of feathers on the breast. Her prevailing color is a dusky gray, each feather having a metallic band, less brilliant than that of the cock, then a blackish band, and a grayish fringe. Her whole color is, as usual among birds, duller than that of the cock; the wing-feathers display the white, and have no bands; the tail is similarly colored to that of the cock. When young, the sexes are so much alike that it is not easy to discern the difference between them; and the cock acquires his beauty only by degrees, his plumage not arriving at perfection until the fourth or fifth year.

The habits of these birds in their native wilds are exceedingly curious. The males, called Gobblers, associate in parties of from ten to a hundred, and seek their food apart from the females, which either go about singly with their young, at that time about two-thirds grown, or form troops with other females and their families, sometimes to the number of seventy or eighty. These all avoid the old males, who attack and destroy the young, whenever they can, by reiterated blows upon the skull. But all parties travel in the same direction, and on foot, unless the dog or the hunter or a river on their line of march compels them to take wing. When about to cross a river, they select the highest eminences, that their flight may be more sure, and in such positions they sometimes stay for a day or more, as if in consultation. The males upon such occasions gobble obstreperously, strutting with extraordinary importance, as if to animate their companions; and the females and the young assume much of the same pompous manner, and spread their tails as they move silently around. Having mounted, at length, to the tops of the highest trees, 388 
the assembled multitude, at the signal note of their leader, wing their way to the opposite shore. The old and fat birds, contrary to what might be expected, cross without difficulty, even when the river is a mile in width; but the wings of the young and the meagre, and, of course, those of the weak, frequently fail them before they have completed their passage, when they drop in, and are forced to swim for their lives, which they do cleverly enough, spreading their tails for a support, closing their wings, stretching out their necks, and striking out quickly and strongly with their feet. All, however, do not succeed in such attempts, and the weaker often perish.

The wild turkeys feed on maize, all sorts of berries, fruits, grasses, and beetles; tadpoles, young frogs, and lizards, are occasionally found in their crops. The pecan nut is a favorite food, and so is the acorn, on which last they fatten rapidly. About the beginning of October, while the mast still hangs on the trees, they gather together in flocks, directing their course to the rich bottom-lands, and are then seen in great numbers on the Ohio and Mississippi. This is the turkey-month of the Indians. When they have arrived at the land of abundance, they disperse in small, promiscuous flocks of both sexes and every age, devouring all the mast as they advance. "Thus they pass the autumn and winter, becoming comparatively familiar after their journeys, when they venture near plantations and farm-houses. They have even been known, on such occasions, to enter stables and corn-cribs in quest of food. Numbers are killed in the winter, and preserved in a frozen state for distant markets.

The beginning of March is the pairing season, for a short time previous to which the females separate from their mates, 389 
and shun them, though the latter pertinaciously follow them, gobbling loudly. The sexes roost apart, but at no great distance, so that when the female utters a call, every male within hearing responds, rolling note after note in the most rapid succession; not as when spreading the tail and strutting near the hen, but in a roice resembling that of the tame turkey when he hears any unusual or frequently-repeated noise.

Where the turkeys are numerous, the woods, from one end to the other, sometimes for hundreds of miles, resound with this remarkable voice of their wooing, uttered responsively from their roosting-places. This is continued for about an hour; and, on the rising of the sun, they silently descend from their perches, and the males begin to strut for the purpose of winning the admiration of their mates.

If the call of a female be given from the ground, the males in the vicinity fly toward the indivinn..., and, whether they perceive her or not, erect and spread their tails, throw the head backward, and distend the comb and wattles, shout pompously, and rustle their wings and body-feathers, at the same moment ejecting a puff of air from the lungs. While thus occupied, they occasionally halt to look out for the female, and then resume their strutting and puffing, moving with as much rapidity as the nature of their gait will admit. During this ceremonious approach, the males often encounter each other, and desperate battles ensue, when the conflict is only terminated by the flight or death of the ranquished. The usual fruits of such victories are reaped by the conqueror, who is followed by one or more females, that roost near him, if not upon the same tree, until they begin to lay, when their 390 
habits are altered, with the riew of saving their eggs, which the male breaks, if he can get at them. These are usually from nine to fifteen in number, sometimes twenty, whitish and spotted with brown, like those of the domestic bird. The nest consists of a few dried leaves placed on the ground, sometimes on a dry ridge, sometimes on the fallen top of a dead leafy tree, under a thicket of sumach or briers, or by the side of a $\log$. Whenever the female leaves the nest, she covers it with leares, so as to screen it from observation. She is a rery close sitter, and when she has chosen a spot will seldom leave it, on account of its being discovered by a human intruder. Should she find one of her eggs, however, sucked by a snake, or other enemy, she abandons the nest forever. When the eggs are near hatching, she will not forsake her nest while life remains.

The females are particularly attentive to their young, which are very sensitive to the effects of damp; and consequently wild turkeys are always scarce after a rainy season. The flesh of the wild turkey is much superior to that of the domestic bird; yet the flesh of such of the latter as have been suffered to roam at large in the woods and in the plains is, in no respect, improved by this partially wild mode of life.

\section{THE DOMESTIC TURKEY.}

The origin of the popular name, turkey, appears to be the confusion at first unaccountably subsisting relative to the ide 'y of the bird with the Guinea fowl, which was still scarce at the time of the introduction of the turkey. Some, however, say that the name arose from the proud and Turkish strut of the cock. There is a question whether the domestic 
turkey is actually a second and distinct species, or merely a variety of the wild bird, owing its diversity of aspect to circumstances dependent on locality, and consequent change of habit, combined with difference of climate and other

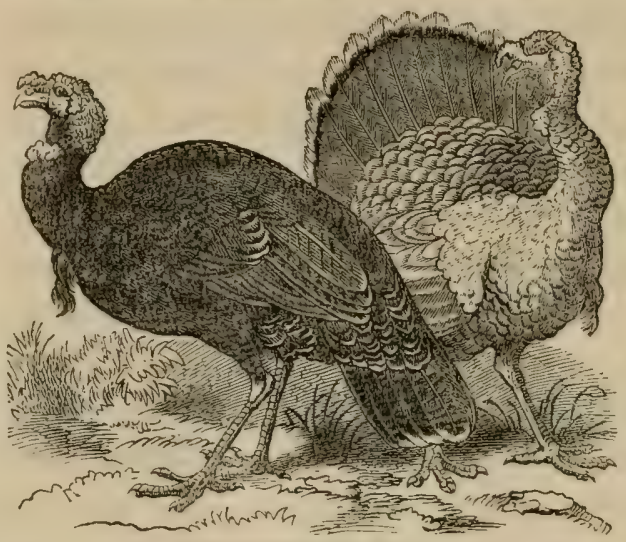

THE DOMESTIC TUREET. important causes, which are known in the case of other animals to produce such remarkable effects.

The varieties of the domesticated turkey are not very distinct; and as to their relative value, it is, perhaps, difficult to give any decisive opinion. Some suppose that the white turkey is the most robust, and most easily fattened. Experience has, however, shown to the contrary. The pure white are very elegant creatures; and though very tender to rear, are not so much so as the white pea fowl. Most birds, wild as well as tame, occasionally produce perfectly white individuals, of more delicate constitution than their parents. The selection and pairing of such have probably been the means of establishing and keeping up this breed. With all care, they will now and then produce speckled birds, and so show a tendency to return to the normal plumage. It is remarkable that in specimens which are, in other respects, snow-white, the tuft on the breast remains coal-black, appearing, in the hens, like a tail of ermine, and so showing us a 392 
great ornament. The head and caruncles on the neck of the male are, when excited, of the same blue and scarlet hues. The bird is truly beautiful, with its snowy and trembling flakes of plumage thus relieved with small portions of black, blue, and scarlet. They have one merit-they dress most temptingly white for market; but they are unsuited for mirey, smokey, or clayey situations, and show and thrive best where they have a range of clean, short pasture, on a light or chalky subsoil.

The bronze and copper-colored varieties are generally undersized, and are among the most difficult of all to rear ; but their flesh is, certainly, very delicate, and, perhaps, more so than that of other kinds-a circumstance, however, that may partly result from their far greater delicacy of constitution, and the consequent extra trouble devoted to their management.

The brown and ashy-gray are not particularly remarkable; but the black are decidedly superior, in every respect, not only as regards greater hardiness, and a consequent greater facility of rearing, but as acquiring flesh more readily, and that, too, of the very best and primest quality. Those of this color appear also to be far less removed than the others from the original wild stock. Fortunately, the black seems to be the favorite color of Nature; and black turkeys are produced far more abundantly than those of any other hue.

The turkey is a most profitable bird, since it can almost wholly provide for itself about the roads; snails, slugs, and worms are among the number of its dainties, and the nearest stream serves to slake its thirst. To the farmer, however, it is often a perfect nuisance, from its love of grain; and should, 393 
therefore, be kept in the yard until all corn is too strong in the root to present any temptation.

Notwithstanding the separation which, with the exception of certain seasons, subsists between the cock and hen turkey in a wild state, they have been taught to feed and live amiably together in a state of domesticity. The former, however, retains sufficient of his hereditary propensities to give an occasional sly blow to a froward chicken, but that very seldom of a serious or malicious character.

One reason why the turkeys seen in poultry-yards do not vie in splendor of plumage with their untamed brethren is, that they are not allowed to live long enough. For the same cause, the thorough development of their temper and disposition is seldom witnessed. It does not attain its full growth till its fifth or sixth year, yet it is killed at latest in the second, to the evident deterioration of the stock. If some of the best breeds were retained to their really adult state, and well fed meanwhile, they would quite recompense their keeper by their beauty in full plumage, their glancing hues of gilded green and purple, their lovely shades of bronze, brown, and black, and the pearly lustre that radiates from their polished feathers.

\section{THE DUCK.}

This bird is of the order of natatores, or swimmers ; family, anatidee, of the duck kind; genus, anas, or duck. The most striking character of the swimming bird is derived from the structure of the feet, which are always palmate-that is, furnished with webs between the toes. There are always three toes directed forward, and these are usually united by a membrane to their extremities; but, in some cases, the mem394 
brane is deeply cleft, and the toes are occasionally quite free, and furnished with a distinct web on each side. The fourth toe is generally but little developed, and often entirely wanting; when present, it is usually directed backward, and the membrane is sometimes continued to it along the side of the feet. These webbed feet are the principal agents by which the birds propel themselves through the 'water, upon the surface of which most. of them

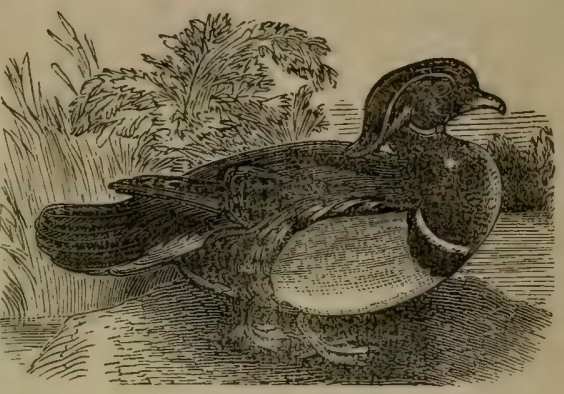

THE EIDER DUCK.

pass a great portion of their time. The feet are generally placed very far back, a position which is exceedingly favorable to their action in swimming, but which renders their progression on the land somewhat awkward.

The body is generally stout and heary, and covered with a rery thick, close, downy plumage, which the bird keeps constantly anointed with the greasy secretions of the caudal gland, so that it is completely water-proof. The wings exhibit a great variety in their development; in some species being merely rudimentary, destitute of quills, and covered with a scaly skin-in others, being of vast size and power, and the birds passing a great part of their lives in the air. The form of the bill is also very remarkable; in some, broad and flat; in $n$ thers, deep and compressed; and in others, long and slender.

Most of these birds live in societies, which are often ex395 
ceedingly numerous, inhabiting high northern and southern latitudes.

The distinguishing characteristic of the family of the anatida is the bill, which is usually of a flattened form, coverer with a soft skin, and furnished at the edges with a series of lamelloe, which serve to sift or strain the mud in which they generally seek their food. The feet are furnished with four toes, three of which are directed forward, and united by a web; the fourth is directed backward, usually of small size, and quite free. They are admirable swimmers, and live and move on the water with the utmost security, ease, and grace. Such is their adaptation to this element that the young, immediately after being hatched, will run to it, and fearlessly launch themselves upon its bosom, rowing themselves along with their webbed feet, without a single lesson, and yet as dexterously as the most experienced boatman. They are generally inhabitants of the fresh waters, and for the most part, prefer ponds and shallow lakes, in which they can investigate the bottom with their peculiar bills, without actually diving beneath the surface; yet at some seasons they are found along the borders of the sea. Their food generally consists of worms, mollusca, and aquatic insects, which they separate from the mud by the agency of the lamellæ at the margin of the bill; but most of them also feed upon seeds, fruits, and other vegetable substances.

\section{THE WILD DUCK.}

This bird, known also by the name of mallard, is the original of all the domestic varieties. It is twenty-four inches long, and marked with green, chestnut and white. Wild 396 
duchs are gregarious in their habits, and generally migrate in large flocks. The males are larger than the females, and the letter are also usually of a more uniform and sober tint.

It is an inhabitant of all the countries of Europe, especially toward the north, and is also abundant in North America,

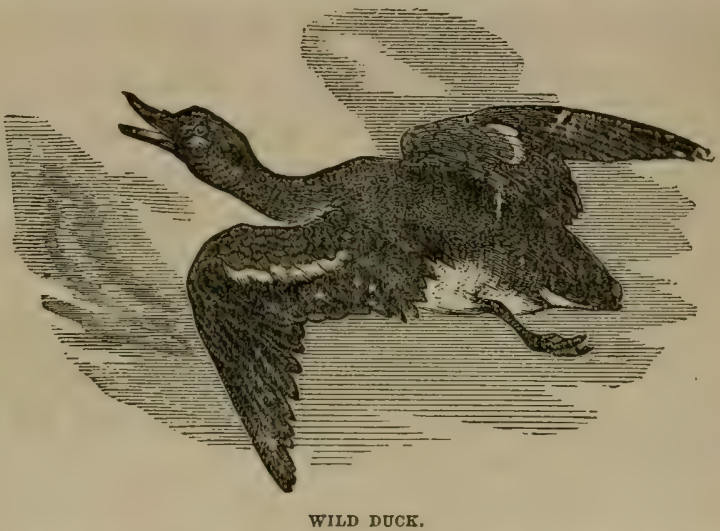

where it is migratory, passing to the North in Spring, and returning to the South in autumn. It frequents the lakes of the interior, as well as the sea-coasts. It is plentiful in Great Britain at all seasons, merely quitting the more exposed situations at the approach of winter, and taking shelter in the valleys; or, in case of a severe winter, visiting the estuaries.

They moult twice in the year, in June and Novenber; in June, the males acquire the female plumage to a certain extent, but regain their proper dress at the second moult, and retain it during the breeding season. In a wild state, the mallard always pairs, and, during the period of incubation, the male, although taking no part in the process, always keeps in the neighborhood of the female; and it is singular that halfbred birds between the wild and tame varieties always exhibit 
the same habits, although the ordinary domestic drakes aro polygamous, always endeavoring to get as many wives as they can. The nest is usually placed upon the ground among reeds and ledges near the water; sometimes in holes or hollow trees, but rarely among the branches. The eggs vary from about eight to fourteen in number, and the young are active from the moment of their exclusion, and soon take to the water, where they are as much at home as the old birds.

As the flesh of wild ducks is greatly valued, immense numbers are shot, or taken in other ways. In England, large numbers are captured by decoys, consisting of a piece of water situated in the midst of a quiet plantation, from which six semicircular canals are cut, which are roofed over with hoops, and covered in with netting. Into this rast trap the ducks are enticed by young ducks trained for the purpose.

\section{THE DOMESTIC DUCK.}

The duck should always find a place in the poultry-yard, provided that it can have access to water, even a small supply of which will suffice. They have been kept with success, and the ordinary duck fattened to the weight of eight pounds, with no further supply of water than that afforded by a large pool sunk in the ground. In a garden, ducks will do good service, voraciously consuming slops, frogs, and insectsnothing, indeed, coming amiss to them; not being scratchers, they do not, like other poultry, commit such a degree of mischief, in return, as to partially counterbalance their usefulness. A drake and two or three ducks cost little to maintain; and the only trouble they will give is, that if there is much extent of water or shrubbery about their home, they will lay 398 
and sit abroad, unless they are brought up every night, which should be done. They will otherwise drop their eggs care. lessly here and there, or incubate in places where their eggs will be sucked by crows, and half their progeny destroyed by rats.

The duck is very prolific, and its egg is very much relished by some, having a rich piquancy of flavor, which gives it a decided superiority over the egg of the domestic fowl; and these qualities render it much in request with the pastry-cook and confectioner-three duck's eggs

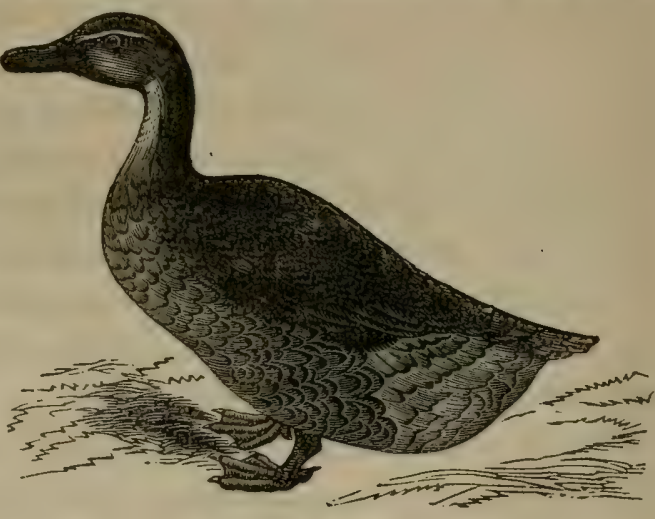

ROUEN DUCK. being equal in culinary value to six hen's eggs. The duck does not lay during the day, but generally in the night; exceptions, regulated by circumstances, will, of course, occasionally occur. While laying, it requires, as has been intimated, more attention than does the hen, until it is accustomed to resort to a regular nest for depositing its eggs; when, however, this is once effected, little care is needed beyond what has been indicated.

The duck is a bad hatcher, being too fond of the water, and, consequently, too apt to allow her eggs to get cold; she will also, no matter what kind of weather it may be, bring the 
ducklings to the water the moment they break the shell-a practice always injurious, and frequently fatal; hence the very common practice of setting duck's eggs under liens.

There are several varieties of tame ducks; but their merits are more diverse in an ornamental than in a profitable point of view. Of white ducks, the best is the Aylesbury, with its unspotted, snowy plumage, and yellow legs and feet. It is large and excellent for the table, but not larger or better than several others. They are assiduous mothers and nurses, especially after the experience of two or three seasons. A much smaller race of white ducks is imported from Holland, useful only to the proprietors of extensive or secluded waters, as enticers of passing wild birds to alight and join their society. This variety has a yellow-orange bill; that of the Aylesbury should be flesh-colored. There is, also, the white hook-billed duck, with a bill monstrously curved downward-a Tioman-nosed duck, in fact-with Jewish features, of a most grotesque and ludicrous appearance; the bill has some resemblance in its curvature to that of the Flamingo. White ducks, of course, make but a sorry figure in towns or dirty suburbs, or in any place where the means of washing themselves are scanty.

There are one or two pretty varieties, not very common; one of a slate-gray, or bluish dun, another of a sandy-yellow; there are also some with top-knots as compact and spherical as those of any Polish fowl, which rival the hook-billed in oddity. What are termed the white Poland and the black Poland are crested; they breed early, and are excellent layers; the former are deemed the most desirable though the black are the larger. 
Of mollled and pied sorts, there exists a great variety; black and white, bronze and white, lightly speckled, and many other mixtures. To this class belongs the Rouen-or Rhone, or Rohan, since each designation has been used-duck, which has been needlessly overpraised by interested dealers. This variety is bighly esteemed by epicures; it is a prolific bird, and lays large eggs; its size is the criterion of its value. There is - also a pied variety of the Poland ducks, a hybrid between the white and the black, the Beaver.

Another variety, known as the Labrador, the Buenos Ayres, or the black East Indian duck, is somewhat rare and highly esteemed by dealers. They are very beautiful birds. The feet, legs, and entire plumage should be black; a few white feathers will occasionally appear. The bill also is black, with a slight under-tinge of green. Not only the neck and back, but the larger feathers of the tail and wings are gilt with metallic green; the female also exhibits slight traces of the same decoration. On a sunshiny spring day, the effect of these glittering black ducks sporting in the blue water is very pleasing.

$\Lambda$ peculiarity of this variety is, that they occasionally-that is, at the commencement of the season-lay black eggs; the color of those subsequently laid gradually fades to that of the common kinds. This singular appearance is not caused by any internal strain penetrating the whole thickness of the shell, but by an oily pigment, whieh may be scraped off with the nail. They lay, perhaps, a little later than other ducks, but are not more difficult to rear. Their voice, likewise, is said to differ slightly from that of other varieties; but they are far superior in having a high, wild-duck flavor and, if well 26

401 
kept, are in deserved repute as being excellent food when killed immediately from the pond, without any fattening.

Still another breed, known as the DIuscovy duck, is a distinct species from the common duck; and the hybrid race will not, therefore, breed again between themselves, although they are capable of doing so with either of the species from the commixture of which they spring. This duck does not derive its name from having been brought from the country indicated, but from the flavor of its flesh, and should more properly be termed the musk duck, of which this name is but a corruption. It is easily distinguished by a red membrane surrounding the cyes, and covering the cheeks. Not being in esteem, on account of their peculiar odor, and the unpleasant flavor of their flesh, they are not worth breeding, unless to cross with the common rarieties; in which case, the musk drake must be put to the common duck. This will produce a very large cross, while the opposite course will beget a very inferior one.

\section{THE GOOSE.}

THE WILD Goose. The goose belongs to the same family as the duck, but is classed with the genus anser. The grayleg goose-a common wild goose of England-is by some regarded as the original of the domestic bird. It is thirtyfire inches long; upper parts ash-brown and ash-gray; under parts white. This variety is migratory, proceeding to the Northern parts of Europe and $\mathbf{A}$ sia in summer, and to the South in winter.

The Canada, or Cravat goose, the wild goose of this country, is a fine species, forty inches long, often seen in spring 402 
and autumn in large, triangular flocks, ligh in air, and led by an old, experienced gander, who frequently utters a loud honk, equivalent, doubtless, to "All's well!" This sound often comes upon the ear at night, when the flock are invisible; and

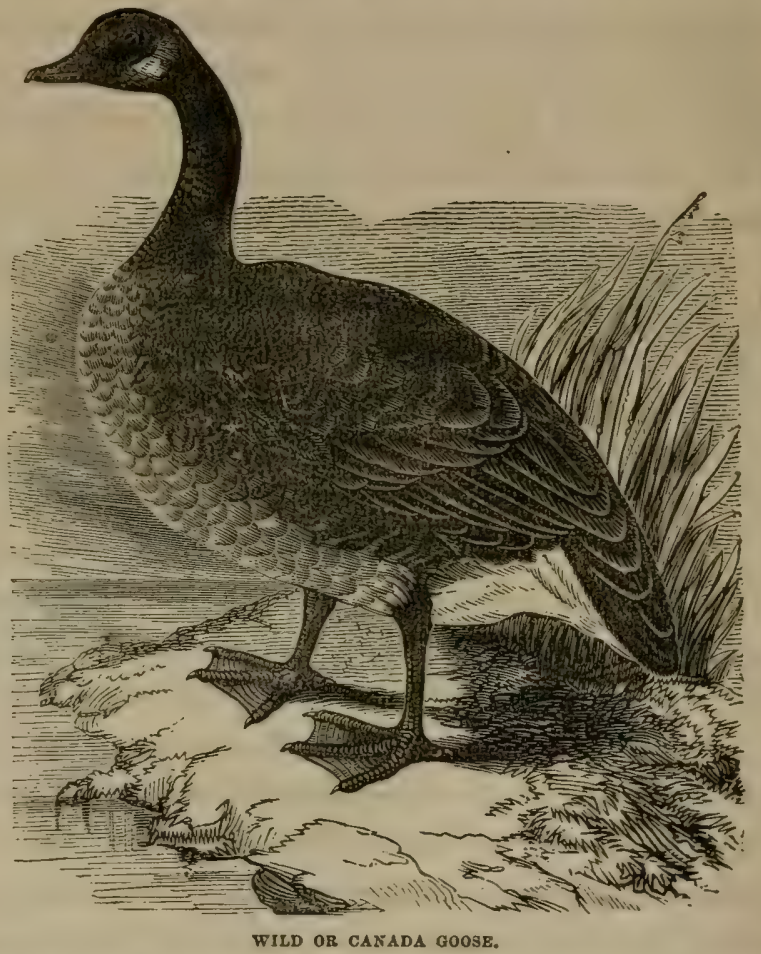

it is frequently heard even in the daytime, seeming to come from the sky, the birds being beyond the reach of vision. Immense numbers of these noble birds are killed in Canada, as well as along our coasts, where they assemble in the autumn in large flocks, and remain till driven to more Southern climates by the season. 
The Canada goose is capable of domestication, and, in spite of its original migratory habits - which it appears, in almost every instance, to forget in England-shows Inuch more disposition for a truly domestic life than the swan; and it may be maintained in perfect health with very limited opportunities for bathing. They eat worms and soft insects, as well as grass and aquatic plants; with us, they do not breed until they are at least two years old, and so far approach the swan; .like which bird, also, the male appears to be fit for reproduction at an eariier period than the female. Many writers speak highly of the balf-bred Canada. They are, certainly, very large, and may merit approbation on the table; but with whatever other species the cross is made, they are hideously disgusting:

\section{THE DOMESTIC GOOSE.}

The goose is not mentioned in the Bible, but it was known to the ancient Egyptians, and is represented in numerous instances on their monuments, showing that it was anciently used for food, as in our own times. It was held sacred by the Romans, because it was said to have alarmed, by its cackling at night, the sentinels of the capitol, at the invasion of the Gauls, and thus to have saved the city. This was attributed by one of the Roman writers to its fine sense of smell, which enables them to perceive at a great distance the odor of the human race. The liver of this bird seems to have been a favorite morsel with epicures in all ages; and invention appears to have been active in exercising the means of increasing the volume of that organ. It is generally esteemed a foolish bird; yet it displays courage in defending its young, and instances 404 
of attachment and gratitude have shown that it is not deficient in sentiment. The value and usefulness of geese are scarcely calculable. The only damage which they do lies in the quantity of food which they consume; the only care they require is to be saved from starvation. All the fears and anxieties requisite to educate the turkey and prepare it for making a proper appearance at the table are with them unnecessary; grass by day, a dry bed at night, and a tolerably attentive mother, are all that is required. Roast goose, fatted to the point of repletion, is almost the only luxury that is not decmed an extravagance in an economical farm-house; for there are the feathers, to swell the stock of beds; there is the dripping, to enrich the dumpling or pudding; there are the giblets, for market or a pie; and there is the wholesome, solid, savory flesh for all parties interested.

They are accused by some of rendering the spots where they feed offensive to other stock; but the explanation is simple. A horse bites closer than an ox; a sheep goes nearer to the ground than a horse; but, after the sharpest shearing by sheep, the goose will polish up the tuft, and grow fat upon the remnants of others. Consequently, where geese are kept in great numbers on a small area, little will be left to maintain any other grass-eating creature. If, however, the pastures are not short, it will not be found that other grazing animals object to feeding either together with, or immediately after, a flock of geese.

The goose has the merit of being the earliest of poultry. In three months, or, about four, from leaving the egg, the birds ought to be fit for the feather-bed, the spit, and the fire. It is not only very early in its laying, but also very late. It often 
anticipates the spring in Norember, and, afterward, when spring really comes in March, it cannot resist its general influence. The autumnal eggs afford useful employment to turkeys and hens that choose to sit at unseasonable times; and the period of incubation is less tedious than that required for the eggs of some other birds.

The flight of the domestic goose is quite powerful enough, especially in young birds, to allow them to escape in that way, where they are so inclined. In the autumn, whole broods may be seen by early risers taking their morning flight, and circling in the air for matutinal exercise, just like pigeons, when first let out of their locker. The bird lives to a very great age, sometimes seventy years or more.

As to the origin of our domestic species, opinions differ. By some, as already remarked, the gray-leg is regarded as the parent stock; others consider it a mongrel, like the dunghill fowl, made up of several varieties, to each of which it occasionally shows more or less affinity; and yet others contend that it is not to be referred to any existing species. The latter assert that there is really but one variety of the domestic goose, individuals of which are found from entirely white plumage, through different degrees of patchedness with gray, to entirely gray coloring, except on the abdomen.

The domestic gander is polygamous, but he is not an indiscriminate libertine; he will rarely couple with females of any other species. Hybrid common geese are almost always produced by the union of a wild gander with a domestic goose, and not by the opposite. The ganders are generally, though not invariably, white, and are sometimes called Embden geese, from a town of Hanover. High feeding, care, and moderate 406 
warmth will induce a prolific habit, which becomes, in some measure, hereditary. The season of the year at which the young are batched-and they may be reared at any seasoninfluences their future size and development. After allowing for these causes of diversity, it is claimed that the domestic goose constitutes only one species or permanent variety.

\section{THE BERNACLE GOOSE.}

This bird is sometimes called the Barnacle goose; its name originates from the fact that it was formerly supposed to be bred from the shells so termed, which cling to wood in the sea. It is about twenty-five inches long, and is found wild in Europe, abundantly in the Baltic; and, occasioually, as it is said, in Hudson's Bay, on this continent.

This bird is one of those species in which the impulse of reproduction has at length overcome the sullenness of captivity, and instances of their breeding when in confinement hare increased in frequency to such an extent that hopes are entertained of the continuance of that increase. The joung so reared should be pinioned at the wrist as a precaution. They would probably stay at home contentedly, if unpinioned, until the approach of inclement weather, when they would be tempted to leave their usual haunts in search of marshes, unfrozen springs, mud-banks left by the tide, and the open sea; or they might be induced to join a flock of wild birds, instead of returning to their former quarters.

Broods of five, six, and seven have been reared; but they are generally valued as embellishments to ponds merely, their small size rendering them suitable eren for a very limited pleasure-ground, and the variety being perhaps the prettiest 407. 
geese that are thus employed. The lively combination of black, white, gray, and lavender, gives them the appearance of being in agreeable half-mourning. The female differs little from the male, being distinguished by voice and deportment more than by plumage. Their short bill, the moderate-sized webs of their feet, and their rounded proportions, indicate an affinity with the curious Cereopsis goose, which is found in considerable numbers on the seashore of Sucky Bay and Goose Island, at the soutbeastern point of Australia.

The number of eggs laid is six or seven, and the time of incubation is about a month; it being difficult to name the exact period, from the uncertainty respecting the precise hour when the process commences. They are steady sitters. The young are lively and active little creatures, running hither and thither, and tugging at the blades of grass. Their ground color is of a dirty white; their legs, feet, eyes, and short stump of a bill, are black; they have a gray spot on the crown of the head, gray patches on the back and wings, and a yellowish tinge about the forepart of the head. The old birds are very gentle in their disposition and habits, and are less noisy than most geese.

The service they may render as weed-eaters is important, though their size alone precludes any comparison of them, in this respect, with the swan. Their favorite feeding-grounds are extensive flats, partially inundated by the higher tides; and their breeding may perhaps best be promoted by their being furnished with a little sea-weed during winter and early spring; a few shrimps, or small muscles, would probably not be unacceptable. $A$ single pair is more likely to breed than it they are congregated in larger numbers:

408 
THE BREMEN. GOOSE.

The Bremen geese-so called from the place whence they were originally imported, though some term them Embden

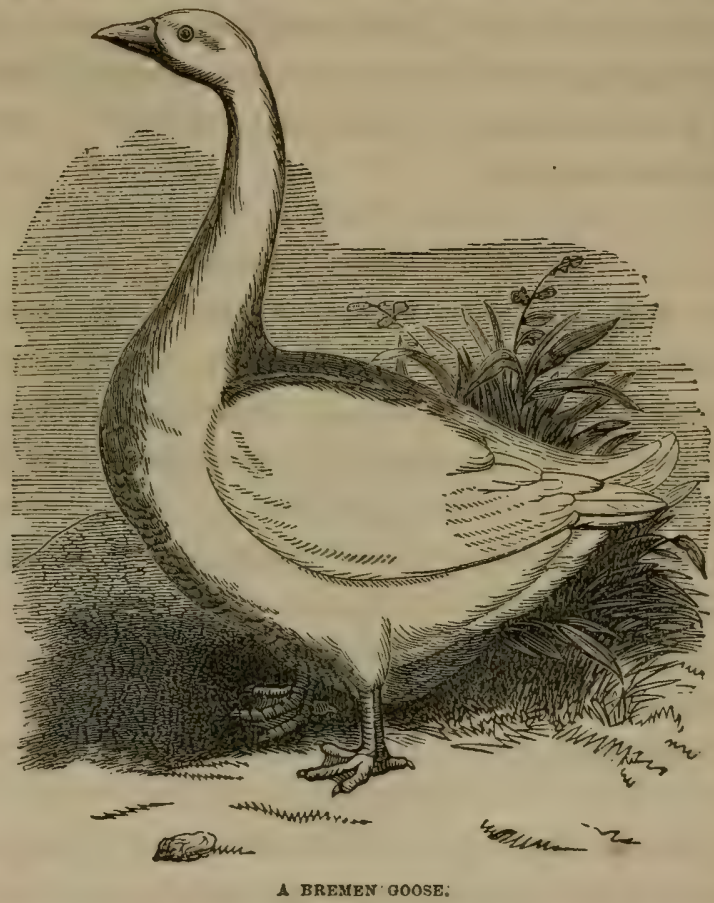

geese-hare been bred in this country, pure, and to a feather, since 1821 ; no single instance having occurred in which the slightest deterioration of character could be observed. Thie produce has invariably been of the purest white; the bill, legs, and feet being of a beautiful yellow.

The flesh of this goose does not partake of that dry character which belongs to other and more common kinds, but is as 
tender and juicy as the flesh of a wild fowl; it shrinks less in couking than that of any other fowl. Some pronounce its flesh equal if not superior to that of the canvas-back duck.

They likewise sit and hatch with more certainty than common barn-yard geese; will weigh nearly, and in some instances quite, twice the weight-the full-blood weighing twenty pounds and upward; they have double the quantity of feathers; and never fly.

\section{THE BRENT GOOSE.}

This is a small species, twenty-one inches long, common in a wild state, in both Europe and America. On our coast, it is a favorite game-bird, and known by the name of Brant. It is easily tamed, and is said to have produced young in captivity, though no details have been furnished.

This and the Sandwich Island goose are the smallest of their tribe yet introduced to our aquatic ariaries. Their almost uniform color of leaden black, and their compactness of form, make them a striking feature in the scene, though they cannot be compared in beauty with many other waterfowl. There is so little difference in the sexes that it is not easy to distinguish them. Their chief merit rests in their fondness for water-weeds, in which respect they appear to be second only to the swan. They are quiet, gentle, and harmless in captivity. Some praise their flesh, while others pronounce it fishy, strong, and oily; they may, however, be converted into tolerable meat by being skinned and baked in a pie. 
THE CHINA GOOSE.

This bird figures under a variety of aliases: Knob goose, Hong Kong goose, Asiatic goose, Swan goose, Chinese Swan,

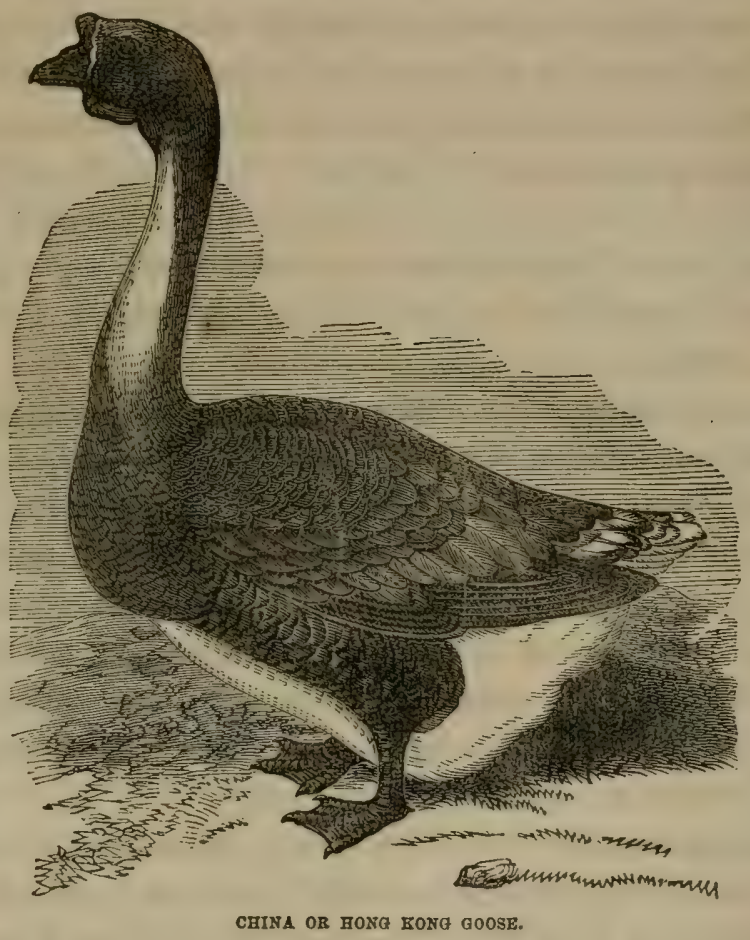

Guinea goose, Polish goose, Muscory goose, and, probably, others.

There is something in the aspect of this creature-in the dark-brown stripe down its neck, its small, bright eye, its harsh voice, its ceremonious strut, and its affectation of seldom being in a burry-which seems to say that it came from 411 
China. If so, it has no doubt been domesticated for many hundred years, perhaps as long as the pea fowl or the common fowl. They may be made to lay a large number of eggs by an increased supply of nourishing food. If liberally furnished with oats, boiled rice, etc., the China goose will, in the spring, lay from twenty to thirty eggs before she begins to sit, and again in the autumn, after her moult, from ten to fifteen more. Another peculiarity is their deficient power of flight, compared with other geese, owing to the larger proportionate size of their bodies. Indeed, of all geese, this is the worst flyer; there is no occasion to pinion them; the common domestic goose flies much more strongly.

The prevailing color of their plumage is brown, comparable to the color of wheat. The different shades are very harmoniously blended, and are well relieved by the black tuberculated bill, and the pure white of the abdomen. Their movements on the water are graceful and swan-like. Slight variations occur in the color of the feet and legs, some having them of a dull orange, others black; a delicate fringe of minute white feathers is occasionally seen at the base of the bill. These peculiarities are hereditarily transmitted.

The male is almost as much disproportionately larger than the female as the Musk drake is in comparison with his mate. He is much inclined to libertine wanderings, without, however, neglecting proper attention at home. If there is any other gander on the premises, a disagreement is sure to result. Both male and female are, perhaps, the noisiest of all geese; at night, the least footfall or motion in their neighborhood is sufficient to call forth their clangor and resonant trumpetings.

The eggs are somewhat less than those of the domestic kind, 412 
of a short oval, with a smooth, thick shell, white, but slightly tinged with yellow at the smaller end. The goslings, when first hatched, are usually very strong. They are of a dirty green, like the color produced by mixing India-ink and yellow ochre, with darker patches here and there. The legs and feet are lead-color, but afterward change to a dull red. With good pasturage, they require no farther attention than that bestowed by their parents. After a time, a little grain will strengthen and forward them. If well fed, they come to maturity very rapidly; in between three and four months from the time of leaving the shell, they will be full-grown and ready for food. They do not bear being shut up to fatten so well as common geese, and, therefore, those destined for the table are the better for profuse hand-feeding. Their flesh is well-flavored, short, and tender; their eggs, excellent for cooking purposes

They are said to be a short-lived species; the ganders, at least, not lasting more than ten or a dozen years. Hybrids between them and the common goose are prolific with the latter; the second and third cross is much prized by some farmers, particularly for their ganders; and in many flocks the blood of the China goose may be traced oftentimes by the more erect gait of the birds, accompanied by a faint stripe down the back of the neck. With the White-grented goose they also breed freely.

The White-China. These are larger than the preceding, and apparently more terrestrial in their habits; the knob on the head is not only of greater proportion, but of a different shape. It is of a spotless, pure white-though a very few gray feathers occasionally appear-more swan-like than the brown, with a bright orange-colored bill, and a large knot of the same color 413 
at its base. It is particularly beautiful, either in or out of the water, its neck being long, slender, and gracefully arched when swimming. It breeds three or four times in the season; the egr is quite small for the size of the bird, being not more l'ian half the size of that of the common goose.

In many instances, efforts to obtain young from their eggs have been unsuccessful; but if the female is supplied with the eggs of the common goose, she invariably liatches and rears the goslings. They sit remarkably well, never showing themselves out of the nest by day; lut, possibly, they may leave the nest too long in the cold of the night. Some think that a quiet lake is more to their taste than a rapid running stream, and more conducive to the fecundity of their eggs. It is also believed by many that, under farorable circumstances, they would be very prolific.

\section{THE EGYPTIAN GOOSE.}

This species is bred to a certain extent in this country. It is a most stately and rich bird, reminding one of the solemn antiquity of the Nile, with its gorgeous mantle of golden hues and its long history.

It is dark red round the eyes; red ring round the neck; white bill; neck and breast light fawn-gray; a maroon star on the breast; belly red and gray; half of the wing-feathers rich black, the other part of them pure white; black bar running across the centre, back light-red, growing dark-red toward the tail; the tail a deep black.

They are very prolific, bringing off three broods a year, from eight to twelve each time; their weight is about eight pounds each. 


\section{THE JAVA GOOSE.}

The gander of this species is white, with head and half the neck light-fawn; red tubercle at the root of the bill; larger than the common goose, and longer in the body; walks erect, standing as high as the China goose, the female appearing to carry two pouches, or egg-bags, under the belly.

It is very prolific; and the meat is of fine flavor.

\section{THE TOULOUBE GOOSE.}

This bird is said to have been originally imported from the Mediterranean; and is known also by the names Mediterranean goose, and Pyrenean goose. It is chiefly remarkable for its vast size, in which respect it surpasses all others.

Its prevailing color is a slaty blue, marked with brown bars, and occasionally relieved with black; the head, neck, as far as the beginning of the breast, and the back of the neck, as far as the shoulders, of a dark-brown; the breast slaty-blue; the belly is white, in common with the under surface of the tail; the bill is orange-red, and the feet flesh-color.

In habit, the Toulouse goose resembles his congeners, but seems to possess a milder and more tractable disposition, which greatly conduces to the chance of his early fattening, and that, too, at a little cost. The curl of the plumage on the neck comes closer to the head than that on common geese, and the abdominal pouch, which, in other varieties, is an accompaniment of age, exists from the shell. The flesh is said to be tender and well-flavored.

Some pronounce this bird the unmixed and immediate descendant of the Gray-leg; while others assert that it is only 
the common domestic, enlarged by early hatching, very liberal feeding during youth, fine climate, and, perhaps, by age, and style them grenadier individuals of the domestic goosenothing more.

\section{THE WHITE-FRONTED GOOSE.}

In its wild state, the White-fronted or Laughing goose is twenty-seren inches long, and found in great numbers in Europe and in the North American Fur countries, but rare along our coasts.

When domesticated, it belongs to the class of birds which are restrained from resuming their original wild habits more by the influence of local and personal attachment than from any love which they seem to have for the comforts of domestication; which may be trusted with their entire liberty, or nearly so, but require an eye to be kept on them from time to time, lest they stray away and assume an independent condition. The white-fronted goose well deserves the patronage of those who have even a small piece of grass.

The first impression of every one, upon seeing this species in confinement, would be that it could not be trusted with liberty; and the sight of it exercising its wings at its first escape would make its owner despair of recovering it. This is not, however, the case. By no great amount of care and attention, they will manifest such a degree of confidence and attachment as to remove all hesitation as to the future; and they may be regarded as patterns of all that is valuable in anserine nature-gentle, affectionate, cheerful, hardy, useful, and self-dependent. The gander is an attentive parent, but not a faithful spouse.

The eggs are smaller than those of the common goose, pure 416 
THE EGG.

white, and of a very long oval; the shell is also thinner than in, most others; the flesh is excellent.

Having completed the enumeration and description of the varieties of poultry, it will, perhaps, be appropriate to gire some account, before proceeding to the next general division of the subject, of the structure, or anatomy, so to speak, of

THE EGG.

In a laying hen may be found, upon opening the body, what is called the ovarium-a cluster of rudimental eggs, of different sizes, from very minute points up to shapes of easilydistinguished forms. These rudimental eggs have as yet no shell or white, these being exhibited in a different stage of development; but consist wholly of yolk, on the surface of which the germ of the future chicken lies. The yolk and the germ are enveloped by a very thin membrane.

When the rudimental egg, still attached to the ovarium, becomes longer and larger, and arrives at a certain size, either its own weight, or some other efficient cause, detaches it from the cluster, and makes it fall into a sort of funnel, leading to a pipe, which is termed the oviduct.

Here the yolk of the rudimental egg, hitherto imperfectly formed, puts on its mature appearance of a thick yellow fluid; while the rudimental chick or embryo, lying on the surface opposite to that by which it had been attached to the ovarium, is white, and somewhat like paste.

The white, or albumen, of the egg now becomes diffused around the yolk, being secreted from the blood vessels of the egg-pipe, or oviduct, in the form of a thin, glassy fluid; and it is prevented from mixing with the yolk and the embryo chicken by the thin membrane which surrounded them before 
they were detached from the egg-cluster, while it is strengthened by a second and stronger membrane, formed around the first, immediately after falling into the oviduct. This second membrane, enveloping the yolk of the germ of the chicken, is thickest at the two ends, having what may be termed bulgings, termed chalazes by anatomists; these bulgings of the second membrane pass quite through the white at the ends, and being thus, as it were, embedded in the white, they keep the inclosed yolk and germ somewhat in a fixed position, preventing them from rolling about within the egg when it is moved.

The white of the egg being thus formed, a third membrane, or', rather, a double membrane, much stronger than either of the first two, is formed around it, becoming attached to the chalazes of the second membrane, and tending still more to keep all the parts in their relative positions.

During the progress of these several formations, the egg gradually advances about half way along the oviduct. It is still, however, destitute of the shell, which begins to be formed by a process similar to the formation of the shell of a snail, as soon as the outer layer of the third membrane has been completed. When the shell is fully formed, the egg continues to advance along the oviduct, till the hen goes to her nest and lays it.

From ill health, or accidents, eggs are sometimes excluderl from the oviducts before the shell has begun to be formed, and in this state they are popularly called wind-eggs.

Reckoning, then, from the shell inward, there are six different envelopes, of which one only could be detected before the descent of the egg into the oviduct : the shell; the external layer of the membrane lining the shell; the internal layel of same lining; the white, composed of a thinner liquid on the 418 
outside, and a thicker and more yellowish liquid on the inside; the bulgings, or chalaziferus membrane; and the proper membrane.

One important part of the egg is the air.bag, placed at the larger end, between the shell and its lining membrane. This is about the size of the eye of a small bird in new-laid eggs, but is increased as much as ten times in the process of hatching. The air bag is of such great importance to the development of the chicken-probably by supplying it with a limited atmosphere of oxygen-that, if the blunt end of an egg be pierced with the point of the smallest needle, the egg cannot be hatched.

Instead of one rudimental egg falling from the ovarium, two may be detected, and will, of course, be inclosed in the same shell, when the egg will be double-yolked. The eggs of a goose have, in some instances, contained even three yolks. If the double-yolked eggs be hatched, they will rarely produce two separate chickens, but, more commonly, monstrositieschickens with two heads, and the like.

The shell of an egg, chemically speaking, consists chiefly of carbonate of lime, similar to chalk, with a small quantity of phosphate of line, and animal mucus. When burnt, the animal matter and the carbonic acid gas of the carbonate of lime are separated; the first being reduced to ashes, or animal charcoal, while the second is dissipated, leaving the decarbonized lime mixed with a little phosphate of lime.

The white of the egg is without taste or smell, of a viscid, glairy consistence, readily dissolving in water, coagullable by acids, by spirits of wine, and by a temperature of one hundred and sixty-five degrees, Fahrenheit. If it has once been coagulated. it is no longer soluble in either cold or hot water, 
and acquires a slight insipid taste. It is composed of eighty parts of water, fifteen and a half parts of albumen, and four and a half parts of mucus; besides giving traces of soda, benzoic acid, and sulphuretted hydrogen gas. The latter, on an egro being eaten on a silver spoon, stains the spoon of a blackish purple, by combining with the silver, and forming sulphuret of silver.

The white of the egg is a very feeble conductor of heat, retarding its escape; and preventing its entrance to the yolk; a providential contrivance, not merely to prevent speedy fermentation and corruption, but to arrest the fatal chills, which might occur in hatching, when the mother hen leaves her eggs, from time to time, in search of food. Eels and other fish which can live long out of water, secrete a similar viscid substance on the surface of their bodies, furnished to them, doubtless, for a similar purpose.

The yolk has an insipid, bland, oily taste; and, when agitated with water, forms a milky emulsion. If it is long boiled it becomes a granular, friable solid, yielding upon expression, a yellow, insipid, fixed oil. It consists, chemically, of water, oil, albumen, and gelatine. In proportion to the quantity of albumen, the egg boils hard.

The weight of the eggs of the domestic fowl varies materially; in some breeds, averaging thirty-three ounces per dozen, in others, but fourteen and a half ounces. A fair average weight for a dozen is twenty-two and a half ounces. Yellow, mahogany, and salmon-colored eggs are generally richer than white ones, containing, as they do, a larger quantity of yolk. These are generally preferred for culinary purposes; while the latter, containing an excess of albumen, are preferred for boiling, etc., for the table. 


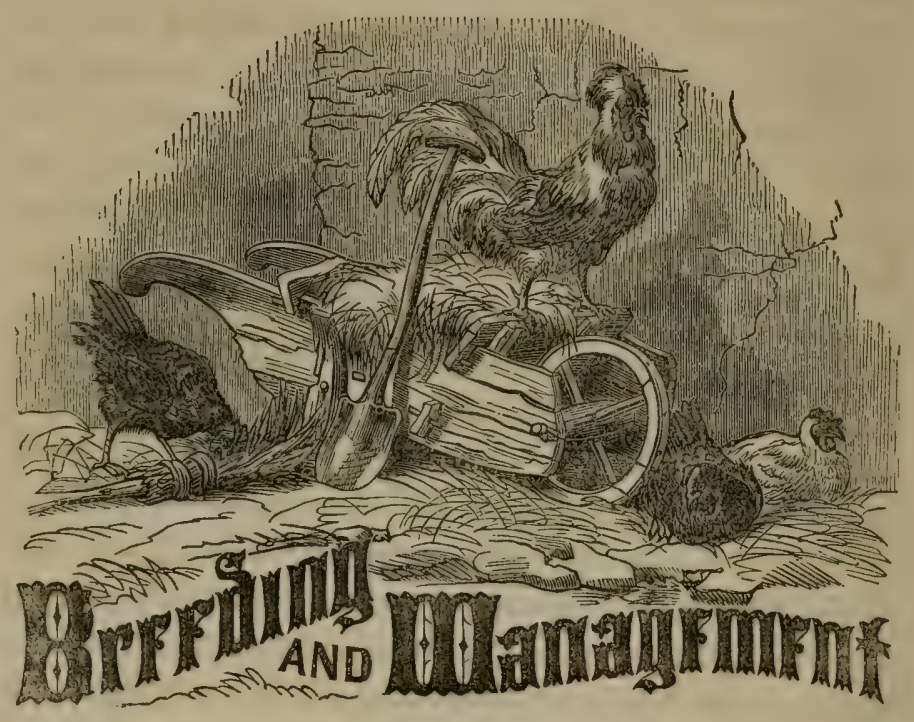

Breeding. Good fowls are very profitable in the keeping of intelligent breeders. It is stated, by those most competent to express the opinion, that four acres of land, devoted to the rearing of the best varieties of poultry, will, at ordinary prices, he quite as productive as a farm of one hundred and fifty acres cultivated in the usual way. The eggs of the common and cheaper kinds which might be used for incubators and nurses, would pay-or could be made to pay, if properly preserved, and sold at the right time-all expenses of feed, etc.; while good capons of the larger breeds will bring, in any of our larger (101) 421 
markets, from three to five dollars per pair, and early spring chickens from twenty to twenty-five cents per pound.

To make poultry profitable, then, it is only necessary that the better kinds be bred from, that suitable places be provided for them, that they be properly fed, and carefully and intelligently managed. These requirements are too rarely complied with, in every respect, to enable a correct opinion to be formed as to what may be made out of poultry under the most farorable circumstances.

A few general principles, well-understood and faithfully applied, will prove of great value. By "in-and-in breeding" is meant commerce between individuals of the same brood, or brother and sister, so to speak; by "close breeding," commerce between the parent and his offspring, in whatever degree.

Crossing the breed. To insure successful and beneficial crossing of distinct breeds, in order to produce a new and valuable variety, the breeder must have an accurate knowledge of the laws of procreation, and the varied influences of parents upon their offspring. All the breeds in this country are crosses, produced either by accident or design. Crossing does not necessarily produce a breed; but it always produces a rariety, and that variety becomes a breed only where there is a sufficiency of stamina to make a distinctive race, and continue a progeny with the uniform or leading characteristics of its progenitors.

Highbreeding. Then uniformity of plumage can be effected in mixed breeds or varieties without a resort to in-and-in, or close breeding, and without sacrificing the health and vigor of the race, it is desirable; and, in many instances, it can be accomplished in a satisfactory manner. What are called 422 
highly-bred fowls are, however, too often the deteriorated offspring of progenitors far below the original stock. Genuine high breeding consists in the selection of parent stock of the same race, perfect in all the general characteristics, and of remote consanguinity. This should be resorted to periodically, in order to secure the best results.

If a race is pure-that is, if the species or variety is absolutely distinct and unsophisticated-the progeny resembles the progenitors in almost every respect. The mixture of races, where the consanguinity is remote, is productive of decided benefits.

To illustrate, in the case of fowls: when the blood is unmixed-as with the Guelderlands, and some others-the offspring, in all respects, resemble their parents; in plumage, general habits, form, outline, etc. In this case, they look almost identically the same. But when the blood is mixedas with the Cochin Chinas, and many others-the plumage will rary widely, or slightly, according to circumstances, though many or most of the general characteristics may remain the same. The close breeding, to which many resort for the purpose of procuring uniformity, generally results in an absolute deterioration of the race in important respects.

In some cases, close breeding-and, occasionally, in-and-in - seems to be in accordance with the laws of Nature; as with the wild turkey, which, in its natural state, resorts to these modes of breeding; and yet the race does not change in appearance or degenerate. The reason is that the breed is pure. In comparing any number of these birds, not the least dissimilarity is discoverable; they all look alike, as they 
always have, and always will. They are changed, or deteriorated, only by crossing or confinement.

Most breeds of the hen kind degenerate rapidly from close, or in-and-in breeding, because they are not perfect of their kind; that is, the breed is not pure, but of mixed blood; and in such objectionable breeding, the race degenerates just in proportion as the breed is imperfect, or impure. The perfect Guelderland will admit of these modes of breeding, for a great length of time, without deterioration; but the impure or mixed will rapidly degenerate. This is also true of all breeds, wherein the characteristic marks are uniform and confirmed, showing perfection in the race.

As a general rule, however, close and in-and-in breecling should be carefully avoided where the race is not absolutely perfect, if it is desired to improve the breed; and as all the breeds of this kind of fowls are of mixed blood, the danger of such breeding is greater or less, in exact proportion as the distinctive characteristics are variant or fixed; and the danger still increases if the breed is composed of strains of blood greatly dissinilar, or of races widely differing in the conformation or general habits.

Preserving the distinctive breeds. As to the time when the different breeds of hens should be separated in the spring, in order to preserve the breed pure, the most ample experience indicates that if the eggs be preserved and set after a separation of two days, the breed will be perfect, the offspring having all the characteristics or distinctive marks.

When a valuable breed is produced, either by accident or design, it should be preserved, and the subsequent breeding should continue from that stock; otherwise, there is no 424 
certainty of the purity of the blood of the new breed, for it does not follow that a different parentage, though of the same name or original breed precisely, will produce the same new breed, or any thing resembling it. The Dorking fowl, for instance, was originally produced by crossing the Great Malay with the English Game, as an accident; but it by no means follows that Dorkings are the uniform, or even the common result of such a cross, for hundreds of similar experiments have proved unsuccessful. The breeding, therefore, to be pure-blooded, must continue from the stock originally produced by accident; and as such breeding produces the leading characteristics of the race with great uniformity, the genuineness of the breed cannot be doubted.

In order to produce a good cross, the parentage should be healthy, and from healthy races, not materially dissimilar in their general habits. The size of the leg should always be looked to, in order to judge accurately as to purity of blood. If the leg is large for the breed-that is, if larger than the generality of the same breed-the purity of the blood, the fineness of the flesh, and most of the other valuable qualities, can be relied on; but, if the legs are smaller than most others of the same breed, the fowl is spurious, and of deteriorated blood. The fifth toe and feathered legs of some breeds were originally the result of accident; but by long and careful breeding, they have become incorporated into the nature of . certain races of general, though not universal or essential, requisites. When a fowl exhibits any special marks indicative of all the races or breeds from which the cross originated, it is a sure evidence of extraordinary purity of blood, and of the superior excellence of the race. The best fowls of the 425. 
race should always be selected for crossing or general breed: ing; otherwise the breeds will degenerate.

The qualily_that is, the fineness, juiciness, and richness of flaror-of the flesh of domestic fowls is of much more importance than their size. All coarse-meated forls should, therefore, be rejected, no matter how large they may be. There is no difficulty in discriminating between coarse and fine fowls at any time. In the case of chickens, if the down is straight and stands out, and the body and limbs are loosely joined, the meat is coarse; but if the down is glossy, and lies close to the body, and the body and limbs are compactly. formed, the meat is fine; and when grown, if the forvl is light in weight, in proportion to its size, the flesh is coarse; but if heary, the flesh is fine.

There is also a finess in the quality of the flesh; for, if the meat is fine, the bones are fine, and the feathers are fine; and the converse holds true. If the flesh is fine, it, is juicy and richly flavored; if coarse, it is dry, fibrous, and insipid.

The color of the legs, too, is quite material in judging of the quality of fowls. All other things being equal, dark-leggred fowls have the finest flesh, and are most hardy. Turkeys, which have the finest flesh of any fowl of their size, have black legs; the game-cock, likewise, which is universally acknowledged to be the finest-fleshed of any of the domestic fowls, except the Wild Indian fowl of Calcutta, has dark legs. It does not, however, of necessity follow that all dark-legged fowls are fine, or that all yellow or white-legged ones are coarse, since much depends upon the breed; but it is true that the darkest leg which pertains to the breed indicates the finest fowl. 
The color of the feathers, also, has more or less to do with the quality of the fowl. Some breeds have a much more lorilliant plumage than others; but when brilliancy of plumage is here spoken of, it is to be understood in comparison with others of the same breed. If, therefore, a fowl is selected of rich and glossy plumage, when compared with others of the same breed, the legs will be dark of the kind, and the quality of the bird will excel.

The best breeding is to cross or mix the races; this process improves the breeds, in all respects. When the object in view is to perpetuate distinct varieties of uncontaminated blood, the first requisite is to procure fowls known to be of pure blood, and possessing all the necessary characteristics of their kind. Labor is lost, unless the fowl selected is a perfect specimen of the variety; for whatever imperfection exists is likely to be perpetuated in the progeny. Regard should be had to plumage, size, and form, in making a selection either of a cock or a pullet; and those are preferable which are hatched earliest in the year. The age of the fowls is a matter of considerable importance; and, though it is true that a pullet will lay the greatest number of eggs in her first year, yet it is believed that the chickens which are hatched from the second year's eggs are more vigorous and hardy. Old hens are. generally preferred to pullets as sitters, on account of their more sedate and matronly character. A young cock, though more active in his earliest days, and likely to bestow his attention on the hens with less reserve, is not, however, best for use in keeping up a breed. The eggs impregnated by him after his first season are likely to produce the strongest chickens. It is an error to suppose-as is often represented- 
that his procreative power is decayed or vitiated after three or four years. On the contrary, a healthy, vigorous cock, if not allowed to walk with too many hens, may be valuable and useful in the poultry-yard for a longer time.

An error is often committed by assigning too many hens to one cock; and the result is a weakly and otherwise deteriorated progeny. Not more than five hens should be allowed to associate with a single cock, when the quality of the breed is a matter of interest. Three, indeed, would be the better number for restriction; but five is the fartbest limit which can be safely assigned.

Most persons, in obtaining a single vigorous cock and hen of a desirable variety, find their anticipations more than realized in the production of a fine progeny. The plumage is brilliant, and the chickens are of increased size, and remarkably strong and healthy. This desirable state of things continues so long as the cock is restricted to a small number of hens; but as soon as his harem is enlarged, different effects are manifested, and a deterioration in the stock is clearly observable-attributable, not to close-breeding, but to the increased disproportion of the females to the male, and the consequent overtasking of his powers.

In breeding-time, great cleanliness should be preserved in. the lodgings of the fowls, and the quantity and quality of food should be attended to. They should not be suffered to feed to repletion, and such kinds of food as are most nutritious should be carefully provided. Variety of food is essential; and a proper proportion of animal and green food should be given with their usual fare. Suitable arrangements should, of course, be made to prevent any intermixture of breeds. A constant 428 
vigilance in this respect is the price of success; and when all proper precautions are taken, the breeder may be perfectly secure that his anticipations will be realized.

\section{SELECTION OF STOCK.}

The habits of the domestic fowl, in a wild state, are too little known to ascortain whether the cocks always associate with the hens, or only occasionally. Though hens will lay some eggs without pairing, as this is not natural, the number will, for the most part, be less, and the laying uncertain; it is, therefore, indispensable to attend to the laws of Nature in this respect.

The number of hens to be allowed to one cock should vary with the olject in view. The limit for valuable breeding purposes has already been indicated. If profit is sought for, in the production of eggs alone, one cock-if a stout, young,

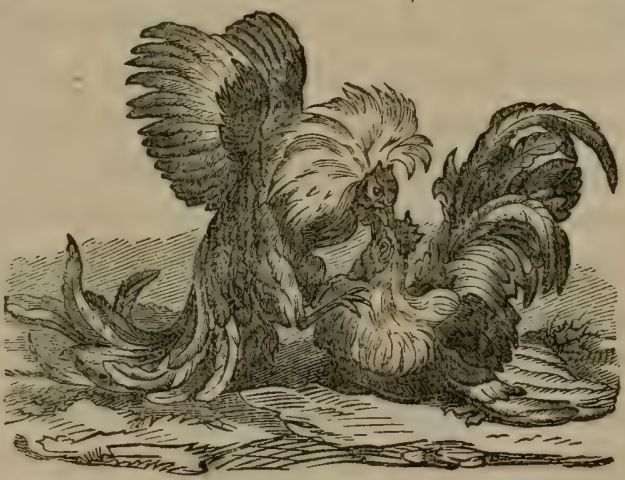

FIGHTING COCES. and lively birdmay have as many as twenty-four hens.

The choice of a cock is a very important thing. $\mathrm{He}$ is considered to have every requisite quality when he is of a good middling size; carries his head high; has a quick, animated look; a strong and shrill voice; a fine red comb, shining as if varnished; wattles of a large size, and of the same color as the 
comb ; the breast broad; the wings strong; the plumage black or of an obscure red; the thighs very muscular; the legs thick, and furnished with strong spurs; and the claws rather bent and sharply pointed. He ought, also, to be free in his ..otions, to crow frequently, and to scratch the ground often in search of worms, not so much for himself as to treat his hens. He ought, withal, to be brisk, spirited, ardent, and ready in caressing the hens; quick in defending them, attentive in soliciting them to eat, in keeping them together, and in assembling them at night.

In breeding game cocks, the qualities required are every mark of perfect health, such as a ruddy complexion; the feathers close, short, and not feeling cold or dry; the flesh firm and compact; and a full breast, betokening good lungs; a tapering and thinness behind. He should be full in the girth, well coupled, lofty and aspiring, with a good thigh, the beam of his leg very strong, the eye large and vivid, and the beak strong, crooked, and thick at the base.

A cock is in his prime at two years old; though cocks are sometimes so precocious as to show every mark of full vigor at four months, while others of the same brood do not appear in that state for several months afterward. When marks of declining vigor are perceived, the cock must be displaced, to make way for a successor, which should be chosen from among the finest and bravest of the supernumerary young cocks, that ought to be reared for this special purpose.

The change of cocks is of much importance, and is frequently very troublesome to manage; for peace does not long subsist between them when they hold a divided dominion in the poultry-yard, since they are all actuated by a restless, jealous, 430 
hasty, fiery, ardent disposition; and hence their quarrels become no less frequent than sanguinary. A battle soon succeeds to provocation or affront. The two opponents face each other, their feathers bristling up, their necks stretched out, their heads low, and their beaks ready for the onslaught. They observe each other in silence, with fixed and sparkling eyes. On the least motion of either, they stand stiffly up, and rush furiously forward, dashing at each other with beak and spur in repeated sallies, till the more powerful or the more adroit has grievously torn the comb and wattles of his adversary, has thrown him down by the beary stroke of his wings, or has stabbed him with his spurs.

In the choice of a hen for sitting, a large bird should be selected, with large, wide-spreading wings. Though large, she must not, however, be heavy nor leggy. No one of judgment would sit a Malay; as, in such case, not only would many eggs remain uncovered, but many, also, would be trampled upon and broken. Elderly hens will be more willing to sit than young and giddy pullets.

After the common hen, which, on account of her fecundity, is deservedly esteemed, the tufted hens may be justly ranked; particularly from being more delicate eating, because she fattens more readily, on account of laying less. The large breed, though less prolific, is preferable in rearing chickens for the market, or for making capons. With regard to these three kinds, the general opinion of breeders is, that the first is more prolific in the number of eggs, while the others produce larger chickens, which bring good prices.

The Spanish fowl are not generally good sitters, but are excellent layers; the Dorkings reverse the order, being better 
sitters than layers. These qualities will be found to extend pretty generally to hens partaking of the prevailing colors of these two varieties; the black being usually the best layers, and but careless or indifferent sitters, while gray or checkered hens are the best that can be produced.

\section{FEEDING.}

Experiments have demonstrated that what may be called the gastric juice in fowls has not sufficient power to dissolve their food, without the aid of the grinding action of the gizzard. Before the food is prepared for digestion, therefore, the grains must be subjected to a triturating process; and such as are not sufficiently bruised in this manner, before passing into the gizzard, are there reluced to the proper state, by its natural action. The action of the gizzard is, in this respect, mechanical; this organ serving as a mill to grind the food to pieces, and then, by means of its powerful muscles, pressing it gradually into the intestines, in the form of pulp. The power of this organ is said to be sufficient to pulverize hollow globules of glass in a very short time, and solid masses of the same substance in a few weeks. The rapidity of this process seems to be proportionate, generally, to the size of the bird. A chicken, for example, breaks up such substances as are received into its stomach less readily than the capon; while a goose performs the same operation sooner than either. Needles, and even lancets, given to turkeys, have been broken in pieces and voided, without any apparent injury to the stomach. The reason, undoubtedly, is, that the larger species of birds have thicker and more powerful organs of digestion.

It has long been the general opinion that, from some defi432 
ciency in the digestive apparatus, fowls are obliged to resort to the use of stones and gravel, in order to enable them to dispose of the food which they consume. Some have supposed that the use of these stones is to sheath the gizzard, in order to fit it to break into smaller fragments the hard, angular substances which might be swallowed; they have also been considered to have a medicinal effect; others have imagined that they acted as absorbents for undue quantities of acids in the stomach, or as stimulants to digestion; while it has even been gravely asserted that they contribute directly to nutrition.

Repeated experiments, however, have established that pebbles are not at all necessary to the trituration of the hardest kinds of substances which can be introduced into their stomachs; and, of course, the usual food of fowls can be bruised without their aid. They do, however, serve a useful auxiliary purpose. When put in motion by the muscles, they are capable of producing some effects upon the contents of the siomach; thus assisting to grind down the grain, and separating its parts, the digestive fluid, or gastric juice, comes more readily in contact with it.

VArieties of FOOD. Fowls about a poultry-yard can usually pick up a portion of their subsistence, and, under favorable circumstances, the largest portion. When so situated, the keeping of poultry pays decidedly the best. The support even of poultry not designed for fattening should not, however, be made to depend entirely upon such precarious resources. Fowls should be fed with punctuality, faithfulness, and discretion.

They are fond of all sorts of grain-such as Indian corn, wheat, oats, rye, buckwheat, barley, millet, etc.; but their 28 
particular preferences are not so likely to guide in the selection of their food, as the consideration of what is most economical, and easiest to be procured on the part of their owner. They will readily eat most kinds of vegetables in their green state, both cooked and raw. They likewise manifest an inclination for animal food-such as blood, fish, and flesh-whether raw or otherwise; and scem by no means averse to feeding on 'their own species. Insects, worms, and snails they will tale with avidity.

It is usual to give to domestic forvls a quantity of grain once, at least, daily; but, commonly, in less quantity than they would consume, if unrestricted. They feed with great voracity; but their apparent greediness is not the criterion by which the possibility of satisfying them is to be judged. Moderate quantities of food will suffice; and the amount consumed will usually be proportioned to the size of the individuals. Whatever is cheapest, at any given time, may be given, without regard to any other considerations. Different circumstances and different seasons may occasion a variation. in their appetite; but a gill of grain is, generally speaking, about the usual daily portion. Some very voracious fowls, of the largest size, will need the allowance of a third of a pint each day:

Wheat is the most nutritive of cereal grains-with, perhaps, the exception of rice-as an article of human food. It is, therefore, natural to suppose that it is the best for fowls; and the avidity with which they eat it would induce the conclusion that they would eat more of this than of any other grain. Yet it appears that when fowls have as much wheat as they can, consume, they will eat about a fourth part less than of 434 
oats, barley, or buckwheat; the largest quantity of wheat eaten by a fowl in one day being, according to several experiments, about three-sixteenths of a pint. The difference in bulk is, however, compensated by the difference in weight, these three-sixteenths of wheat weighing more than one-fourth of a pint of oats. The difference in weight is not, in every instance, the reason why a fowl is satisfied with a larger or smaller measure of one sort than another. Rye weighs less than wheat; but still a fowl will be satisfied with half the quantity of this grain. Indian corn ranks intermediately between wheat and rye; five-fourths of a pint of Indian corn with fowls being found, by experiment, equal to six-fourths of wheat, and three-fourths of rye.

In estimating the quantity of grain daily consumed by the common fowl, it is wise to use data a little above than below the average. It may, therefore, safely be said that a fowl of the common size, having free access to as much as can be eaten through the day, will consume, day by day, of oats, buckwheat, or barley, one-fourth of a pint; of wheat, threesixteenths; of Indian corn, five thirty-seconds; and of rye, three thirty-seconds.

It has been conclusively settled, by experiments instituted to that end, that there is the best economy in feeding poultry with boiled grain rather than with dry, in every case where Indian corn, barley, and wheat can be procured. The expense of fuel, and the additional trouble incident to the process of cooking, are inconsiderable in comparison with the advantages derived. Where oats, buckwheat, or rye are used, boiling is useless, when profit is concerned.

Bran. It is an erroneous notion that money can be saved 435 
by feeding bran to fowls; since, then, so little of the farina of the grain remains in it, that the nourishment derived from its use is hardly worth mentioning. When boiled, as it always must be, its bulk is but slightly increased. Two measures of dry bran, mixed with water, are equal to but three-fifths of a measure of dry barley.

Mrluet. This is recommended as excellent food for young chickens. Fowls always prefer it raw; though, as its bulk is increased one-half by boiling, it is doubtless more economical to feed it cooked.

Rice. Fowls are especially fond of this food, although they soon lose their relish for it when allowed to have it at their discretion. It should always be boiled; but its expense puts it out of the question as a daily diet. When used continuously, it should always be mixed with some substance containing less nutritive matter, in order that the appetite may not be cloyed by it.

Potatoes. These are very nutritious, and are usually acceptable to fowls, when properly prepared. When raw, or in a cold state, they appear to dislike them; they should, therefore, be boiled and given when moderately hot; when very hot, it is said that fowls will injure themselves by eating them, and burning their mouths. They should also be broken into pieces of convenient size; otherwise, they will be avoided. Occasionally raw pieces of potato will be devoured; but fowls cannot be said to be fond of the root in this state. The same remark applies to most other roots, especially to carrots and parsnips; these should always be prepared, in order to be wholesome and palatable. Fowls should never be confined to 436 
a root diet, in any case; but such food should be mingled or alternated with a sufficient quantity of grain.

GreEN FOOD. Indulgence in this kind of diet is absolutely necessary to the health of fowls, and is also advantageous in an economical point of view. The more delicate kinds of green vegetables are eaten with the utmost avidity; all succulent weeds, grass, and the leaves of trees and shrubs will also be consumed. If hens have green plots to graze in during the day, the expense of their keeping will be reduced one-half. All the refuse of the kitchen, of a vegetable nature, should be freely thrown into the poultry-yard.

Green food, however, will not answer for an exclusive diet. Experiment has shown that fowls fed with this food alone for a few days together exhibit severe symptoms of relaxation of the bowels; and, after the lapse of eight or nine days, their combs become pale and livid, which is the same indication of disease in them that paleness of the lips is in the luman species.

EARth-Tronms. These are regarded as delicacies by the inhabitants of the poultry-yard: and the individual who is fortunate enough to capture one is often forced to undergo a severe ordeal in order to retain his captive. Earth-worms are more plentiful in moist land, such as pastures, etc., than in that which is cultivated; in gardens, also, they exist in vast numbers. When it is desirable to take worms in quantities, it is only necessary to thrust a stake or three-pronged fork into the ground, to the depth of about a foot, and to move it suddenly backward and forward, in order to shake the soil all around; the worms are instinctively terrified by any motion in the ground, and, when disturbed, hasten to the surface. 
It is adrisable to store worms, on account of the trouble and difficulty of making frequent collections. They may be placed in casks, filled one-third full with earth, in quantities at least equal in bulk to the earth. The earth should be sprinkled occasionally, to prevent it from becoming too dry. Care should, however, be exercised that the earth does not become too moist; since, in such an event, the worms will perish. In rainy weather, the casks should be protected with a covering.

ANimal FOoD. Fowls readily eat both fish and flesh meat, and have no reluctance to feeding even on their own kind, picking much more faithfully than quadrupeds. Blood of any kind is esteemed by them a delicacy; and fish, even when salted, is devoured with a relish. They seem to be indifferent whether animal food is given to them in a cooked or raw state; though, if any preference can be detected, it is for the latter. They are sometimes so greedy that they will attack each other in order to taste the blood which flows from the wounds so inflicted; and it is quite common for them, in the moulting season, to gratify themselves by picking at the sprouting feathers on their own bodies and those of their companions. They appear to be partial to suct and fat; but they should not be allowed to devour these substances in large quantities, on account of their tendency to render them inconveniently fat.

It is highly advantageous to fowls to allow them a reasonable quantity of animal food for their diet, which should be fed to them in small pices, both for safety and convenience. Bones and meat may be boiled; and the liquor, when mixed with bran or meal, is healthy, and not expensive.

438 
LAYING.

InsECTS. Fowls have a decided liking to flies, beetles, grasshoppers, and crickets; and grubs, caterpillars, and maggots are held by them in equal esteem. It is difficult, however, to supply the poultry-yard with this species of food in sufficient quantity; but enough may be provided, probably, to serve as luxuries. Some recommend that pailfuls of blood should be thrown on dunghills, where fowls are allowed to run, for the purpose of enticing flies to deposit their eggs; which, when hatched, produce swarms of maggots for the fowls. With the same view, any sort of garbage or offal may be thrown out, if the dunghill is so situated-as it always should be-that its exhalations will not prove an annoyance.

\section{IAYING.}

The ordinary productiveness of a single individual of the family of domestic fowls is astonishing. - While few hens are capable of hatching more than fifteen eggs, and are incapable usually of sitting more than twice in the year, frequent instances have occurred of hens laying three hundred eggs annually, while two hundred is the average number. Some hens are accustomed to lay at longer intervals than others. The habit of one variety is to lay once in three days only; others will lay every other day; and some produce an egg daily. The productiveness of hens depends, undoubtedly, upon circumstances, to a great degree. Climate has a great influence in this respect; and their lodging and food, as well as the care bestowed upon them, have more or less effect in promoting or obstructing their fecundity.

There seems to be, naturally, two periods of the year in which fowls lay-early in the spring, and in the summer; and this 439 
fact would snem to indicate that, if they were left to themselves, like wild birds, they would bring forth two broods in a year. The laying continues, with few interruptions, till the close of summer, when the natural process of moulting causes

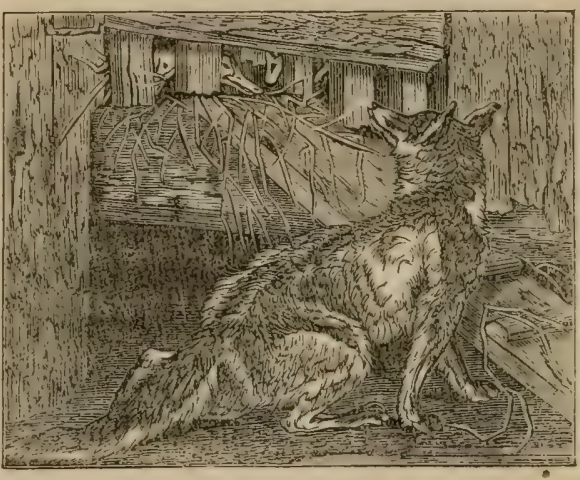

ON THE WATCH

them to cease. This annual process commences about $\mathrm{Au}$ gust, and continues through the three following months. The constitutional effect attending the beginning, continuance, and consequences of this period - a very critical one in the case of all feathered animalsprevents them from laying, until its very close, when the entire coat of new feathers replaces the old, the washing of the nutritive juices, yielded by the blood for the express purpose of promoting this growth, is a great drain upon the system; and the constitutional forees, which would otherwise assist in forming the egg, are rendered inoperative. The approach of cold weather, also, at the close of the moulting period, contributes to the same result. As the season of moulting is erery year later, the older the hen is, the later in the spring she will begin to lay. As pullets, on the contrary, do not moult the first year, they commence laying sooner than the elder hens; and it is possible, by judicious and careful management, so to arrange, in a collection of poultry tolerably numerous, as to hare eggs throughout the year. It is a 440 
singular fact that pullets hatched very late in autumn, and therefore of stunted growth, will lay nearly as early as those Latched in spring. The checking of their growth seems to have a tendency to produce egrgs; of course, very tiny ones at first.

When a hen is near to the time of laying, her comb and wattles change from their previous dull hue to a bright red, while the eje becomes more bright, the gait more spirited, and she occasionally cackles for three or four days. These signs rarely prove false; and when the time comes that she desires to lay, she appears very restless, going backward and forward, risiting every nook and corner, cackling meanwhile, as if displeased because she cannot suit herself with a convenient nest. Not having looked out for one previously, she rarely succeeds in pleasing herself till the moment comes when she can no longer tarry, when she is compelled to choose one of the boxes or baskets provided for this purpose in the poultry-house, where she settles herself in silence and lays.

In some instances, a hen will make choice of a particular nest in which to lay, and when she finds, upon desiring to lay, that this is pre-occupied by another hen, she will wait till it is vacated; but, in other cases, hens will go into any nest which they find, preferring, for the most part, those having the greatest number of egrs. The process of laying is, most probably, rather painful, though the hen does not indicate this by her cries; but the instant she has done she leaves the nest, and utters her joy by peculiarly loud notes, which are re-echoed by the cock, as well as by some of the other hens. Some hens, however, leave the nest in silence, after laying.

It scems ever to hare been an object of great importance, in 441 
an economical point of view, to secure the laying of hens during those parts of the year when, if left to themselves, they are indisposed to deposit their eggs. For this purpose many methods have been devised, the most of which embrace an increase of rich and stimulating food. Some recommend shutting hens up in a warm place during winter, and giving them boiled potatoes, turnips, carrots, and parsnips. Others assign as the reason for their not laying in winter, in some climates, that the earth is covered with snow, so that they can find no ground, or other calcarsous matter, to form the shells; and advise, therefore, that bones of meat or poultry should be pounded and given to them, either mixed with their food, or by itself, which they will greedily eat. Upon the whole, it would seem that the most feasible means of obtaining fresh eggs during the winter is to have young hens-pullets hatched only the previous spring being the best-to use extreme liberality in feeding, and to cautiously abstain from over-stocking the poultry-yard.

As serviceable fond to increase laying, scraps of animal food, given two or three times a week, answer admirably; the best modo of doing so is throwing down a bullock's liver, leaving it with them, and permitting them to pick at it will; this is better raw than boiled. Lights, or guts, or any other animal refuse, will be found to answer the same purpose; but these substances require, or, at all events, are better for, boiling. Cayenne pepper-in fact all deseriptions of pepper, but especially cayenne pepper in pods-is a favorite food with fowls; and, being a powerful stimulant, it promotes laying.

An abundant supply of lime, in some form, should not be omitted; either chopped bones, old mortar, or a lump of 442 
chalky marl. The shell of every egg used in the house should be roughly crushed and thrown down to the hens, which will greedily eat them. A green, living turf will be of service, both for its grass and the insects it may contain. A dusting-place, wherein to get rid of vermin, is indispensable. A daily hot meal of potatoes, boiled as carefully as for the family table, then chopped, and sprinkled or mixed with bran, will be comfortable and stimulating. After cvery meal of the household, the bones and other scraps should be collected and thrown out.

As to the number of eggs, the varieties which possess the greatest fecundity are the Shanghaes, Guelderlands, Dorkings, Polish, and Spanish. The Poland and Spanish lay the largest eggs; the Dorkings, eggs of good size; while the Game and the smaller kinds produce only small eggs. Those eggs which have the brightest yolks are the finest flavored; and this is usually the case with the smaller kinds. The large eggs of the larger varieties often have yolks of a pale color, and are inferior in flavor.

\section{PRESERVATION OF EGGS.}

Eggs, after being laid, lose daily, by transpiration, a portion of the matter which they contain, notwithstanding the compact texture of their shell, and of the close tissue of the flexible membranes lining the shell, and enveloping the white. Then an egg is fresh, it is full, without any vacancy; and this is a matter of common observation, whether it be broken raw, or when it is either soft or bard-boiled. In all stale eggs, on the contrary, there is uniformly more or less vacancy, proportioned to the loss they have sustained by transpiration; hence, in 
order to judge of the freshness of an egg, it is usual to hold it up to the light, when the transparency of the shell makes it appear whether or not there is any vacancy in the upper portion, as well as whether the yolk and white are mingled and muddy, by the rotting and bursting of their enveloping membranes.

The transpiration of eggs, besides, is proportional to the temperature in which they are placed, cold retarding and heat promoting the process; hence, by keeping fresh-lain eggs in a cool cellar, or, better still, in an ice-house, they will transpire less, and be preserved for a longer period sound, than if they are kept in a warm place, or exposed to the sun's light, which has also a good effect in promoting the exhalation of moisture. As, therefore, fermentation and putridity can only take place by communication with the air at a moderate temperature, such connection must be excluded by closing the pores of the shell.

It is an indispensable condition of the material used for this purpose, that it shall be incapable of being dissolved by the moisture transpired from the interior. Spirits of wine varnish, made with lac, answers the requirement; this is not very expensive, but is rather an uncommon article in country places, where eggs are most abundantly produced.

A better material is a mixture of mutton and beef suet, which should be melted together over a slow fire, and strained through a linen cloth into an earthen pan. The chief advantage in the use of this is, that the eggs rubbed over with it will boil as quickly as if notbing had been done to them, the fat melting off as soon as they touch the water. The transpiration is as effectually stopped by the thinnest layer of fat as 444 
by a thick coating, provided that no sensible restige be left on the surface of the shell. All sorts of fat, grease, or oil are well adapted to this purpose ; by means of butter, hog's lard, olive oil, and similar substances, eggs may be preserved for nive months as fresh as the day upon which they were laid.

Another method is, to dip each egg into melted pork-larel, rubbing it into the shell with the finger, and pack them in oill fig-drums, or butter firkins, setting every egg upright, with the small end downward. Or, the eggs may be packed in the same way in an upright earthen pan; then cut some rough sheep's tallow, procured the same day that the animal is killed, into small pieces, and melt it down; strain it from the scraps, and pour it while warm, not hot, orer the eggs in the jar till they are completely covered. When all is cold and firm, set the ressel in a cool, dry place till the contents are wanted.

Eggra will also keep well when preserved in salt, by arranging them in a barrel, first a layer of salt, then a layer of eggs, alternately. This can, however, also act mechanically, like bran or saw-dust, so long as the salt continues dry; for, in that case, the chlorine, which is the antiseptic principle of the salt, is not evolved. When the salt, howerer, becomes damp, its preservative principle will be brought into action, and may penetrate through the pores of the shell.

Immersing eggs in vitriol, or sulphuric acid, is likewise a very effectual means of preserving them; the sulphuric acid acts chemically upon the carbonate of lime in the shell, by setting free the carbonic acid gas, while it unites with the lime, and forms sulphate of lime, or plaster of Paris. Another metbod is, to mix together a bushel of quick-lime, two pounds of salt, and eight ounces of cream of tartar, adding a sufficient 
quantity of water, so that eggs may be plunged into the pairt. When a paste is made of this consistence, the eggs are put into it, and may be kept fresh, it is said, for two years.

Another method of preserving eggs a long while fresh, depends upon a very different principle. Eggs that have not been rendered reproductive by the cock have been found to continue very uncorrupted. In order, therefore, to bave egrgs liecp fresh from spring to the middle or even to the end of winter, it is only necessary to deprive the hens of all communication with the cocks, for at least a month before the eggs are put away.

It ought not to be overlooked, in this connection, that eggs not only spoil by the transpiration of their moisture and the putrid fermentation of their contents; in consequence of air penetrating through the pores of the shell, but also by being moved about and jostled, when carried to a distance by sea or land. Any kind of rough motion, indeed, ruptures the membranes which keep the white, the yolk, and the germ of the chicken in their appropriate places; and, upon these being mixed, putrefaction is promoted.

\section{CHOICE OF EGGS FOR SETTING.}

Eggs for hatching should be as fresh as possible; if laid the very same day, so much the better. This is not alwars possible when a particular stock is required; but, if a numerous and healthy brood is all that is wanted, the most recent eggs should be selected. Eggs may be kept for this purpose in either of the ways first mentioned; or they may be placed on their points in a box, in a cool, dry place; the temperature about sixty or sixty-five, Fahrenheit; the bottom of the box 446 
'should be covered with a layer of wheat bran, then a layer of eggs put in, and covered with bran; and so on, alternating. In this mode, evaporation is prevented, and the eggs are almost as certain to hatch out, at the end of six weeks, or even two months, as when they were laid.

It is difficult to fix the exact term during which the vitality of an egg remains unextinguished; as it, unquestionably, varies from the very first, according to the vigor of the parents of the inclosed germ, and fades away gradually till the final moment of non-existence. The chickens in stale eggs have not sufficient strength to extricate themselves from the shell; if assisted, the yolk is found to be partially absorbed into the abdomen, or not at all; they are too faint to stand; the muscles of the neck are unable to lift their heads, much less to peck; and although they may sometimes be saved by extreme care, their usual fate is to be trampled to death by the mother, if they do not expire almost as soon as they begin to draw their breath. Thick-shelled eggs, like those of geese, Guinea fowls, etc., will retain life longer than thin-shelled ones, as those of hens and ducks. When choice eggs are expected to be laid, it is more prudent to have the hen which is to sit upon them wait for them, than to keep other eggs waiting for her. A good sitter may be amused for two or three weeks with a few addle-eggs, and so be ready to take charge of those of value immediately upon their arrival.

As to the choice of eggs for hatching, such should be taken, of course, as are believed to have been rendered productive. Those of medium size-the average size that the hen laysare most apt to fiulfil this requirement. A very fair judgment may be formed of eggs from their specific gravity; such 
as do not sink to the bottom in a bowl of tepid water should be rejected.

The old-time notion, that small, round eggs produce females, and long, pointed ones males-originally applied, by the ancients, to eating rather than hatching purposes-may be considered exploded. The hen that lays one round egg, continues to lay all her egrss round; and the hen that lays one oblong, lays all oblong. According to this theory, then, one hen would be the perpetual mother of cocks, and another the perpetual producer of pullets; which is absurd, as daily experience proves.

The same fate has been meted out to that other venerable test of sex, the position of the air-bag at the blunt end of the shell. "If the vacancy is a little on one side, it will produce a hen; if it is exactly in the centre, a cock." Upon this assumption, the cock should be a very rare bird; since there are very few eggs indeed in which the air bottle is exactly concentric with the axis of the egg. In many breeds, on the contrary, the cockerels bear a proportion of at least one-third, and sometimes two-thirds, especially in those hatched during winter, or in unfavorable seasons; the immediate cause, doubtless, being that the eggs producing a more robust sex possess a stronger vitality.

Nor are these two alleged tests-the shape of the egg, and the position of the air-tube-consistent with each other; for, if the round egg produces a pullet, and an egg with the air-bag a little on one side does the same, then all round eggs should have the air bag in that position, or one test contradicts the other; and the same argument applies to the long or oval egg. The examination of a few eggs by the light of a candle will 448 
satisfy any one that the position of the air-bag differs as much in a long egg as it does in a round.

There are, indeed, no known means of determining beforehand the sex of fowl; except, perhaps, that cocks may be more likely to issue from large eggs, and hens from small ones. As, however, the egg of each hen may be recognized, the means are accessible of propagating from those parents whose race it is judged most desirable to continue.

\section{INCUBATION.}

The hen manifests the desire of incubation in a manner different from that of any other known bird. Nature having been sufficiently tasked in one direction, she becomes feverish, and loses flesh; her comb is livid; her eyes are dull; she bristles her feathers to intimidate an imaginary enemy; and, as if her chickens were already around her, utters the maternal "cluck."

When the determination to sit becomes fixed-it is not necessary to immediately gratify the first faint inclinationsthe nest which she has selected should be well cleaned, and filled with fresh straw. The number of eggs to be allowed will depend upon the season, and upon the size of egg and hen. The wisest plan is not to be too greedy; the number of chickens hatched is often in inverse proportion to the number of eggs set-five have only been obtained from sixteen. An odd number is, however, to be preferred, as being better adapted to covering in the nest. Hens will, in general, well cover from eleven to thirteen eggs laid by themselves. A bantam may be trusted with about half a dozen eggs of a large breed, such as the Spanish. A hen of the largest size 29 
as a Dorking, will successfully hatch, at the most, five gooseeggs.

When hens are determined to sit at seasons of the jear at which there is little chance of bringing up chickens, the eggs of ducks or geese may be furnished her; the young may be reared, with a little painstaking, at any time of the year. The autumnal laying of the China and of the common goose is very valuable for this purpose. Turkey-hens frequently hare this fit of unseasonable incubation.

Where, however, it is inconvenient to gratify the desire, one or two doses of jalap will often entirely remove it; and. fowls often lay in three weeks afterward. Some place the would-be - sitter in an aviary, for four or five days at most, and feed her but sparingly; from the commencement of her confinement, she will gradually leave off clucking, and when this has ceased, she may be again set free, without manifesting the least desire to take to the nest again, and in a short time the hen will commence laying with renewed vigor. The barbarous measures sometimes resorted to should be frowned upon by every person with humane feelings.

Three weeks is the period of incubation; though chickens are sometimes excluded on the eighteenth day. When the hen does not sit close for the first day or two, or in early spring, it will occasionally be some hours longer; when the hen is assiduous, and the weather hot, the time will be a trifle shorter. Chickens have been known to come out as late as the twenty-seventh day.

It may not be uninteresting to note the changes which the egg passes through in hatching. In twelve hours, traces of the head and body of the chicken may be discerned; at the 450 
end of the second day, it assumes the form of a horse-shoe, but no red blood as yet is seen; at the fiflieth hour, two vesicles of blood, the rudiments of the heart, may be distinguished, one resembling a noose folded down on itself, and pulsating distinctly; at the end of seventy hours, the wings may be scen, and, in the head, the brain and the bill, in the form of bubbles; toward the end of the fourth day, the heart is more completely formed; and on the fifth day, the liver is discernible; at the end of one hundred and thirty hours, the first voluntary motions may be observed; in seven hours more, the lungs and stomach appear ; and, in four hours after this, the intestines, the loins, and the upper jaw. At the end of the one hundred and forty-fourth hour, two drops of blood are observable in the heart, which is also further developed; and, on the seventh day, the brain exhibits some consistence. At the one hundred and ninetieth hour, the bill opens, and the muscular flesh appears on the breast; in four hours more, the breast bone is seen ; and, in six hours afterward, the ribs may be observed forming from the back. At the expiration of two hundred and thirty-six hours, the bill assumes a green color, and, if the chicken be taken out of the egg, it will visibly move. At two hundred and sixly-four hours, the eyes appear; at two hundred and eighty eight hours, the ribs are perfect; and at three hundred and thirty-one hours, the spleen approaches near to the stomach, and the lungs to the chest; at the end of ihree hundred and fifty-five hours, the bill frequently opens and shuts. At the end of the eighteenth day, the first cry of the chicken is heard; and it gradually acquires more strength, till it is enabled to release itself from confinemient. 
After the hen has set a week, the fertility of the eggs may be satisfactorily ascertained by taking a thin board with a small orifice in it, placing a candle at the back, and holding up each egg to the points of light. The barren eggs may then be removed, and used, hard-boiled, for young chickens. Some reserve this for the eleventh or twelfth day.

About the twenty-first day, the chicken is excluded from the egg; for the purpose of breaking the shell of which it is furnished with a horny-pointed scale, greatly harder than the bill itself, at the upper tip of the bill-a scale which falls off, or becomes absorbed, after the chicken is two or three days old. The chicken is rolled up in the egg in the form of a ball, with its forepart toward the highest end, and its beak uppermost, the hard scale nearly touching the shell.

The first few strokes of the chicken's beak produce a small crack, rather nearer the larger than the smaller end of the egg, and the egg is said to be chipped. From the first crack, the chicken turns gradually round, from left to right, chipping the shell as it turns, in a circular manner, never obliquely. All do not succeed in producing the result in the same time; some being able to complete the work within an hour, and others taking two or three hours, while half a day is most usually employed, and some require twenty-four hours, or more, but rarely two days. Some have greater obstacles to overcome than others, all shells not being alike in thickness and hardness.

When chickens do not effect their escape easily, some little assistance is needed; but the difficulty is to know when to give it, as a rash attempt to help them, by breaking the shell, particularly in a downward direction toward the smaller end, 452 
is often followed by a loss of blood, which can ill be spared. It is better not to interfere, until it is apparent that a part of the brood have been batched for some time, say twelve hours, and that the rest cannot succeed in making their appearance. It will then generally be found that the whole fluid contents of the egg, yolk and all, are taken up into the body of the chicken, and that weakness alone has prevented its forcing itself out. The causes of such weakness are rarious; sometimes, insufficient warmth, from the hen having set on too many eggs; sometimes the original feebleness of the vital spark; but, most frequently, the staleness of the eggs employed for incubation.

The chances of rearing such chickens are small; but, if they surrive the first twenty-four hours, they may be considered as safe. The only thing to be done is to take them from the ben till she is settled at night, keeping them in the meanwhile as snug and warm as possible. If a gentle hand can persuade a crust of bread down their throats, it will do no harm; but all rough and clumsy manipulation will utterly defeat the end in view. Animal heat will be their greatest restorative. At night, they should be quietly slipped under their mother; the next morning will disclose the sequel.

The period of incubation in the Guinea fowl is twenty-eight days, or one month; in the pea fowl, from twenty-seven to twenty-nine days; in turkeys, a month; in ducks, thirty or thirty-one days; and in geese, from twenty-seven to thirty days.

INCUBATION OF TURKeYs. When the turkey hen has once selected a spot for her nest, she will continue to lay there till the time for incubation; so that the egg may be brought home 
from day to day, there being no need of a nest-egg, as with the domestic fowl. She will lay from fifteen to twenty eggs, more or less. If there are any dead leaves or dry grass at hand, she will cover her eggs with these; but if not, she will take no trouble to collect them from a distance.

Her determination to sit will be known by her constantly remaining on the nest, though it is empty; and, as it is seldom in a position sufficiently secure against the weather or, pilferers, a nest should be prepared for her, by placing some straw, with her eggs, on the floor of a convenient out-building. She should then be brought home, and gently and kindly placed upon it. With the smallest varieties, thirteen eggs will suffice ; a large hen might cover more. At the end of a week, it is usual to add some fowls' eggs; the activity of the chickens excites some emulation in the larger brethren, and the eggs take up but little room in the nest.

Some believe it necessary to turn the eggs once a day; but the hen herself does that many times daily. If the eggs are marked, and their position noticed when she leaves the nest, they will never be found in the same order. In about four weeks, the young will be hatched.

INCUBATION OF GEESE. Geese breed in general only once a year; but, if well kept, they sometimes hatch twice a season. During the sitting, in sections where the most attention is paid to breeding them, each bird has a space allotted to it, in rows of wicker-pens, placed one above another, and the person in charge of them drives the whole flock to water three times a day, and, bringing them back to their habitations, places each bird in its own nest.

The most successful breeders of Bremen geese adopt the 454 
following method: The birds are, in the first place, carefully and properly fed; the eggs are removed every day in the gentlest manner from the nest, and placed in a basket of cotton kept in a moderate temperature, and free from damp. When all the geese begin to sit steadily, each is furnished with a nest composed of chopped straw; and care is taken that it is sufficiently capacious.

Not more than one of the geese is allowed to leave the eggs at a time. As soon as one leaves, she makes a cackling noise, which is the signal for the attendant to shut up the boxes in which the others are sitting. These are made somewhat like a dog-kennel, with a roof pitched both ways; and are thrty inches long, by twenty-four wide, and twenty-four high; the door is in the end, and is covered by a sliding panel, which moves upward, when egress or ingress is sought, and may be shut down at pleasure. The goose, upon returning, finds only her own box open. When she re-enters her box, the whole of the doors are again opened, and the same rule observed throughout the period of hatching. In this way, each goose is kept to its own nest.

\section{REARING OF THE YOUNG.}

For about twenty-four hours after birth, the chickens can not only do well enough without any extraneous nourishment, but will be far more likely to thrive subsequently, if let alone, than if crammed or incited to eat prematurely. More chickens are destroyed by over-feeding than are lost by the want of it. It is, however, well to turn them in among other chickens that already feed themselves; they will, in such cases, generally 
follow the example of the rest, and pick away at whatever is around.

A roomy, boarded coop, in a dry, sunny spot, is the best position for them during the first month; after which it may be left open during the day, for the hen to retire to when she

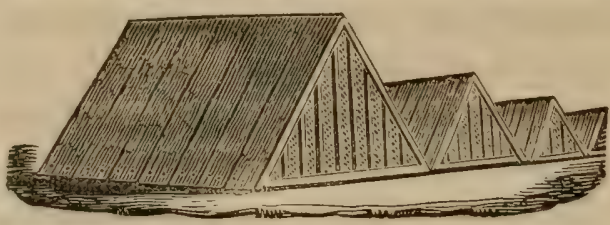

MARQUEE, OR TENT-SHADED COOPS. pleases. In quiet, grassy places, it is scarcely necessary to coop the ben at all. As to food, they may have everry thing which is not absolutely poisonous; though if wet food is given, the chicken is thus obliged to take water, whether it requires it or not, in order to get a sufficient supply of solid food, and diseased bowels will be likely to follow; whereas, if the food is dry, they can supply themselves with food and water according to their pleasure. If Indian meal is well boiled, and fed not too moist, it will answer a very good purpose, particularly after they are eight or ten days old. Pure water must be placed near them in such a manner as to enable them to drink without getting into the water, which, by wetting their feathers, benumbs and injures them. Meat and insect diet are almost necessary; but, whatever the food, the meals must be given at short intervals; as much as they can swallow, and as often as they can eat. With all their industry, they are only half-clad till flesh and bone stop growing for a while, and allow down and feathers to overtake them.

Chickens should not be let out of their coops too early in the morning, or whilst the dew is on the ground; still less should they be suffered to range orer the wet grass, which is 456 
a common cause of disease and death. They should also be guarded against sudden unfavorable changes of the weather, more particularly if attended with rain. Nearly all the diseases of gallinaceous fowls arise from cold moisture.

The period at which they are left to shift for themselves depends upon the disposition of the hen. Some will continue their attentions to their chickens till they are nearly fullgrown, while others will cast them off much earlier. In the latter case, an eye should be kept upon them for a few days; for chickens in this half-grown state are much more liable to disease than when they were apparently tender little weaklings, crowded under their mother's wings. They should be kept in a dry, warm, place; dryness is especially necessary.

If the chickens feather rapidly when very young-as is the case with the Golden Pheasant, Black Poland, Guelderland, and some others-they are always weakly, however healthy in other respects, from the fact that their food goes to sustain their feathers rather than their bodies; and they frequently languish and die, from this circumstance alone. If, on the other hand, they feather slowly, as do the Cochin Chinas, Shanghaes, and others, the food in early life goes to nourish and sustain their bodies until they become more vigorous, and old enough to sustain the shock of feathering without detriment. Pure tan-colored Dorkings are more easily raised than others of the race, because they feather more slowly.

Chickens which feather rapidly must be kept perfectly dry and warm, or they will die; while naked chickens, as they are termed, or those which feather at a more advanced age, and very slowly, seldom suffer from the cold, from the fact that their down is very warm, and their blood is hotter, and 
crrculates more rapidly; since their food principally goes to blood, and flesh, and bones, and not to feathers.

Rearing of Guinea fowls. For the young of these, ants' egres, so called, hard-boiled eggs chopped fine, small worms, maggots, bread-crumbs, chopped meat, or suet-whatever, in short, is most nutritious, is the most appropriate food. This need not be offered to them in large quantities, as it would only be devoured by the mother Bantam as soon as she saw that they had for the time satisfied their appetites, or it would be stolen by other birds; but it should frequently be administered to them in small supplies. Feeding them three, four, or five times a day, is not often enough; every half hour during daylight they should be tempted to fill their crass, which are soon emptied again by an extraordinary power and quickness of digestion.

The newly-hatched Guinea fowl is a tiny creature, and its growth is, consequently, rery rapid, requiring incessant supplics. A check once received can never be recovered. They do not, in such cases, mope and pine for a day or two, like young turkeys under similar circumstances, and then die; but, in half an hour after being in apparent health, they fall on their backs, give a convulsive kick or two, and fall victims, in fact, to starvation. The demands of Nature for the growth of bone, muscle, and particularly of feathers, are so great, that no subsequent abundant supply of food can compensate for a fast of a couple of hours. The feathers still go on growing in geometrical progression, and drawing the sources of vitality still faster than they can be supplied, till the bird faints and expires from inanition.

A dry, sunny corner in the garden will be the best place to 458 
coop them with their bantam hen. As lhey increase in strength, they will do no harm, but much good, by devouring worms, grubs, caterpillars, margots, and all sorts of insects. By the time their bodies are little longer than those of sparrows, they will be able to fly with some degree of strength; other additions to their complete stature are successively and less immediately developed, the spurs, comb, and ornamental plumage not appearing till a subsequent period.

When they are about the size of thrushes, or a little larger, unless the summer be very fine, the bantam may be allowed to range loose in the orchard and shrubbery, and no longer permitted to enter the garden. The young must, however, still receive a bountiful and frequent supply of food; they are not to be considered safe till the horn on their head is fairly grown. Oatmeal is a great treat; cookul potatocs, boiled rice, or any thing, in short, that is eatable, may be thrown to them; they will pick the bones left after dinner with evident satisfaction. The tamer they can be made, the less troublesome will they be when grown; the more kindly they are treated, the fatter will they be for food, and the better price will they bring in market.

For rearing the young of the pea fowl, the same directions will be found useful, and should be carried out in practice.

REARING of turkeys. Much quackery has been recommended in the treatment of young turkeys. Nothing, however, should be given to them, nothing done for them; they should remain in the nest, under the shelter of their mother's wings, for at least eight or ten lsours; if hatched in the afternoon, till the following morning. The hen should then be placed on the grass, in the sun, under a roomy coop. If the 
weather is fine, she may be stationed at any point desired, by a long piece of flannel-list tied round one leg, and fastened to a stump or stone.

At first, a few crumbs of bread should be offered; for some hours, the little ones will be in no hurry to eat; but, when they do commence, they should be supplied constantly and abundantly with chopped egg, shreds of meat and fat, curd, boiled rice mixed with cress, lettuce, and the green of onions; melted mutton-suet poured over barley-meal, and cut up when cold, as also bullock's liver boiled and minced, are excellent things. Young turkeys do not like to have their food minced much smaller than they can swallow it, preferring to make a meal at three or four mouthfuls, rather than to trouble themselves with the incessunt pecking and scratching in which chickens so much delight. Pepper will be found particularly useful in feeding them; as, indeed, all stimulating vegetables, such as horse-radish, and the like.

Young turkeys are sometimes attacked by fasciola, or worms in the trachea; but not so often as chickens. Cramp is the most fatal to them, particularly in bad weather. A few pieces of board laid under and about the coop are useful; sometimes rubbing the leg with spirit will bring back the circulation.

The time when the hen may be allowed full liberty with her brood depends most upon the season, the situation, etc. Some think that if the young are thriving, the sooner the old ones are out with them the better, after the first ten days or so. A safer rule may be fixed at the season, called "shooting the red," when young turkeys approach the size of a partridge, or before the granular, fleshy excrescences on the bead and 460 
neck begin to appcar; soon after, the whole plumage, particularly the tail-feathers, shoot into rapid growth, and liberal nourishment is imperatively required If let loose at this time, they will obtain much foraging, and still be thankful for all that is given to them. Caraway-seeds, as a tonic, are beneficial, if added to plenty of barley, boiled potatoes, chopped regetables, and refuse meat. At this time the turkeys, naturally enough, begin to be troublesome and voracious; they have to grow from the size of a lark to twelve or fourteen pounds, in eight or nine months. One great merit in old birds is, that in situations where nuts, acorns, and mast are to be had, they will lead off their brood to these, and all of them will abstain, comparatively, from ravaging other crops.

Rearing of Ducklings. The best mode of rearing the young of ducks depends very much upon the situation in

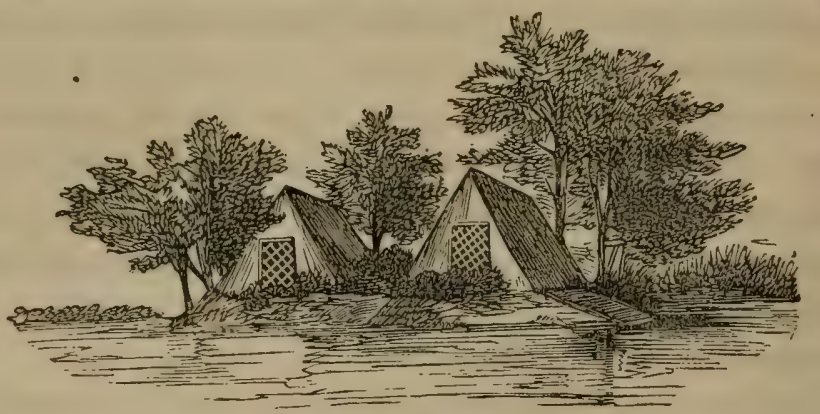

NUCK-POND AND HOUEES.

which they are hatched. It is customary to dip their feet in water as soon as they are hatched, and then to clip the down on their tails close with a pair of scissors, to prevent their lecoming drabbled and water-logged; and before their introfiuction to the pond, which should not be until a day or two afier liatching, it is thought advisable by many to let them have 461 
a prirate swim or two in a small pan of water, that they may try their strength and practice their webbed feet before venturing upon a larger space.

For the first month, the confinement of the mother under a coop is better than too much liberty. Their first food may be boiled eggs, nettles, and a little barley; all kinds of sapped food, cornmeal and water mixed thin, worms, etc., suit them; they will also greedily eat cabbages or other greens, mixed with boiled bran; and this mess, with the addition of pepper, forms a valuable dietetic. In a few days, they require no care, being perfectly able to shift for themsclves; but at any age they are the most helpless of the inhabitants of the poultryyard, having no weapons with which to defend themselves from vermin, or animals of prey, and their awkward, waddling gait precluding their sceking safety in flight. The old duck is not so brave in defence of her brood as the hen; but she will, nevertheless, display at times much spirit. The young seldom die of any disease, and with proper precaution there will be no trouble in raising almost as many ducklings as are hatched. They come early to maturity, being nearly fullgrown and in fine eating order at three months old; far excelling, in this respect, all other poultry, except geese.

None are more successful in rearing ducklings than those who keep them, for the first period of their existence, in pens two or three yards square, and cram them night and morning with long, dried pellets of flour and water, or egg and flour, until they are judged old enough to be turned out with their mother to forage for themselves. They are cheerful, harmless, govil-natured, cleanly creatures, carefully washing themselves, an l armnging their dress, before commencing their meals; and 4. 2 
the healthy heartiness of their appetite is amusing, rather than disgusting.

Rearing of gostings. For the first three or four days, goslings must be kept warm and dry, and fed on barley-meal, or oatmeal, mixed with milk, if easily procurable; if not, with water. They will begin to grow in about a week. For a week or two, they should not be turned out until late in the morning, and should always be taken in early in the evening. Their great enemy is the cramp, which can be kept off by making them sleep on dry straw. A little boiled rice, daily, assists their growth; with corn, of course, as soon as they can eat it. When goslings are first allowed to go at large with their mother, every plant of hemlock which grows within their range should be pulled up, as they are very apt to eat it, and it generally proves fatal. . Nightshade is equally pernicious to them; and they have been known to be poisoned by eating sprigs of yew-tree:

The young of Bremen geese, when first hatched, are of a very delicate and tender constitution. It is best to let them remain in the breeding-box in which they are hatched for twenty-four hours after they leave the shell. This should, however, be regulated by the weather: since, if it is fair and warm, they may be let out an hour or two in the middle of the day, when they will wet their little bills and nibble at the grass. They ought not to be out in the rain at any time during the first month; and both geese and goslings should be shut up in the boxes at night, during the same period, as a protection against rats and rermin. A very shallow pool, dug in the yard, with a bucket or two of water thrown into it, to suit the temporary purpose of bathing, is sufficient during that 
period. If well fed on grain from the time they are hatched, twenty-five pounds weight can be secured, at seven or eight months old. By feeding them till four days old, and then literally turning them out to grass, an average weight of from serenteen to eighteen pounds each has been attained, at that age after the feathers are cleanly picked off.

\section{CAPONIZING.}

Capons have ever been esteemed among the greatest delicacies of the table; and are made by the extirpation of the reproductive organs in male fowls. If a cock, when young, is emasculated, a remarkable change takes place in him. IHis natural fierceness is calmed; he bccomes placid and peaceful ; his pugnacity has deserted him; he no longer sceks the company of the hens; he loses his previous strong, shrill voice; he grows to a far larger size than he would otherwise have done, haring nothing to interfere with the main business of his life-to eat, drink, sleep, and get fat as speedily as possible; his flesh is peculiarly white, firm and succulent; and even the fat is perfectly destitute of rankness. The capon may, also, by a little management be converted into an admirable nurse. Some assert that caponized cocks are never afterward subject to the natural process of moulting; but this is denied by others.

The art has been practised from the earliest antiquity, in Greece, India, and China, for the purpose of improving the flesh of birds for the table, in tenderness, juiciness, and flavor. It is extensively performed in the great poultry-breeding districts of England; but in this country it is by no means so generally practised as would naturally be expected. 
The instruments most approred by skilful operators consist of two five or seven-pound weights for confining the fowl; a scalpel, for cutting open the thin skin enveloping the testicles; a silver retractor, for stretching open the wound sufficiently wide for operating within; a pair of spring forceps-with a sharp, cutting edge, resembling that of a chisel, having a level half an inch in its greatest width-for making the incision, and securing the thin membrane; a spoon-shaped instrument, with a sharp hook at one end, for pushing and removing the testicles, adjusting the loop, and assisting in tearing open the tender covering; and a double silver canula, for containing the two ends of horse-hair, or fibre, constituting the loop. The expense of these instruments is in the neighborhood of six dollars. A cheap penknife may be used instead of the scalpel; and the other instruments may be obtained of a cheaper construction-the whole not costing more than half the abovenamed amount.

The cockerel intended for capons should be of the largest breeds, as the Dorking, Cochin China, or the Great Malay. They may be operated upon at any time after they are a month old; the age of from two to three months is considered preferable. If possible, it should be done before July; as capons made later never prove so fine.

The fowl should be confined to a table or board, by laying him with the left side downward, the wings drawn behind the rump, the legs extended backward, with the upper one farthest drawn out, and the head and neck left perfectly free. The feathers are next to be plucked from the right side, near the hip-joint, on a line with, and between the joint of the shoulder. The space uncovered may be from an inch to an inch and a 30 465 
half in diameter, according to the size of the bird. After drawing off the skin from the part, backward-so that, when left to itself after the operation is completed, it will cover the wound in the flesh-make an incision with the bevel-edged knife, at the end of the forceps, between the list two ribs, commencing about an inch from the back-bone, and extending it obliquely duwnward, from an inch to an inch and a half, cutting just deep enough to separate the ribs, taking due care not to wound the intestines.

Next, adjust and apply the retractor by means of the small thumb-screw, and stretch the wound sufficiently wide apart to afford room for an examination of the organs to be removed. Then, with the scalpel, or a sharp penknife, carefully cut open the skin, or membrane, covering the intestines, which, if not sufficiently drawn up, in consequence of the previous confinement, may be pushed forward toward the breast-ione, by means of the bowl of the spoon-shaped instrument, or-what would answer equally well-with the handle of a tea-spoon. .

As the testicles are exposed to view, they will be found connected with the back and sides by a thin membrane, or skin, passing over them. This covering must then be seized with the forceps, and torn open with the sharp-pointed hook at the small end of the spoon-shaped instrument; after which the bowl of the spoon must be introduced, with the left hand, under the lower or left testicle, which is, generally, a little nearer to the rump than the right one. Then take the double canula, adjust the hair-loop, and, with the right hand, pass the loop over the small hooked end of the spoon, running it down under the bowl of the spoon containing the testicle, so as to bring the loop to act upon the parts which connect the testicle to the back. By drawing the ends of the hair-loop backward and 466 
forward, and at the same time pushing the lower end of the tube, or canula, toward the rump of the fowl, the cord or fastening of the testicle is severed.

A similar process is then to be repeated with the uppermost or right testicle ; after which, any remains of the testicles, together with the blood at or around the bottom of the wound, must be scooped out with the bowl of the spoon. The left testicle is first cut out, in order to prevent the blood which may issue from covering the one remaining, and so rendering it more difficult to be seen. The operation, if skilfully done, occupies but a fer moments; when the skin of the fowl should be drawn over the wound with the retractor, and the wound covered with the feathers that were plucked off at the commencement.

In some fowls, the fore part of the thigh covers the two hindmost ribs; in which case, care must be taken to draw the fleshy part of the thigh well back, to prevent it from being cut; since, otherwise, the operation might lame the fowl, or even cause its death.

For loops, nothing answers better than the fibre of a cocoanut husk, which is rough, and readily separates the testicles by sawing. The next best substance is the hair of a horse's mane or tail.

After the operation, the bird may be placed in a warm house, where there are no perches; since if such appliances are present, the newly-made capon will very probably injure himself in his attempts to perch. For about a week, the food should be soft, meal porridge, and that in small quantities, alternated with bread steeped in milk; he may be given as much pure water as he will drink, it being best to use it in a 
tepid state, or at least with the chill taken off. At the end of a week, or ten days, at most, the fowl, if previously of a sound, vigorous constitution, will be all right, and may be turned out with the others.

The usual method, in France, of making poulardes, or hencapons, as they are sometimes improperly designated, is to extirpate the egg-cluster, or ovarium, in the same manner as the testicles are extracted from the cockerel; but it is quite sufficient merely to cut across the oviduct, or egg-tube, with a sharp knife. Otherwise, they may be treated in the same manner as the capons. Capons are fattened in precisely the same manner as other fowls.

\section{FATTENING AND SLAUGHTERING.}

Fat is not a necessary part of any animal body, being the form which superabundant nourishment assumes, which would,

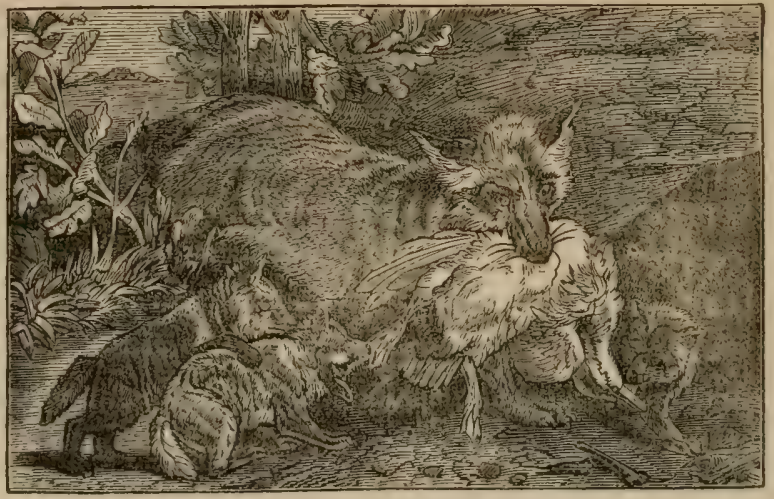

A BAD BTtLe OF SLAdGHTERING.

if needed, be converted into museles and other solids. It is contained in certain membranous receptacles provided for it, distributed over the body, and it is turned to use whenever 408 
the supply of nourishment is defective, which should be pro , vided by the stomach, and other great organs. In such emergencies it is taken up, in the animal economy, by the absorbents; if the latter, from any cause, act feebly, the health suffers. When, however, nourishment is talien into the system in greater quantities than is necessary for ordinary purposes, the absorbent vessels take it up; and the fat thus made is generally healthy, provided there is a good digestion.

A common method of fattening fowl is to give them the run of a farm-yard, where they thrive upon the offal of the stable and other refuse, with perhaps some small regular daily feeds; but at threshing-time, they become fat, and are styled barndoor fowls, probably the most delicate and high-flinvored of all, both from their full allowance of the finest grain, and the constant health in which they are kept, by living in the natural state, and having the full enjoyment of air and exercise; or, they are confined in coops during a certain number of weeks, those fowls which are soonest ready being taken as wanted.

Fowls may also be fattened to the highest pitch, and yet preserved in a healthy state-their flesh being equal in quality to that of the barn-door fowl-when confined in feedinghouses. These should be at once warm and airy, with earth floors, well-raised, and sufficiently capacious to accommodate well the number desired. The floor may be slightly littered down, the litter being often changed; and the greatest cleanliness should be observed. Sandy gravel should be placed in several different layers, and often changed. A sufficient number of troughs, for both water and food, should be placed around, that the fowls may feed with as little interruption as possible from each other; and perches in the same proportion 469 
should be furnished for those which are inclined to arail themselves of them; though the number will be few, after they have begun to fatten. This arrangement, however, assists in keeping them quiet and contented until that period. Insects and animal food forming a part of the natural diet of poultry, they are medicinal to them in a weakly state, and the want of such food may sometimes impede their thriving.

The least nutritious articles of food, so far as it can be done conveniently, should be fed out first; afterward, those that are more nutritive. Fattening fowls should be kept quiet, and suffered to take no more exercise than is necessary for their health; since more exercise than this calls for an expenditure of food which does not avail any thing in the process of fattening. They should be fed regularly with suitable food, and that properly prepared; and as much should be given them as they are able to convert into flesh and fat, without waste. The larger the quantity of food which a fattening animal can be made to consume daily, with a good appetite, or which it can digest thoroughly, the greater will be the amount of flesh and fat gained, in proportion to the whole quantity of food consumed.

Substances in which the nutriment is much concentrated should be fed with care. There is danger, especially when the bird is first put to feed, that more may be eaten at once than the digestive organs can manage. Meal of Indian corn is highly nutritive; and, when properly fed, causes fowls to fatten faster than almost any other food. They will not, however, bear to be kept exclusively on this article for a great length of time. Meal made from the heaviest varieties of corn, especially that made from the hard, flinty kinds grown in the 470 
Torthern and Eastern States, is quite too strong for fow's 10 be full-fed upon. Attention should also be paid to the bulk of the food given; since sufficient bulk is necessary to effect a proper distending of the stomach, as a necessary condition of healthy digestion.

One simple mode of fattening, which is adopted by many, is the following: Shut the fowls up where they can get no gravel; keep corn by them all the tine, and also give then dough enough once a day; for drink, gire them skimner milk; with this feed, they will fatten in ten days; if kept longer, they should hare some gravel, or they will fall away.

Qats ground into meal, and mixed with a little molasses and water, barley-menl with sweet milk, and boiled oats, mixed with meat, are all excellent for fattening poultry-reference. being had to time, expense, and quality of flesh.

In fattening ducks, it must be remembered that their flesh will be found to partake, to a great extent, of the flavor of the food on which they have been fattened; and as they are naturally quite indiscriminate feeders, care should be taken, for at least a week or so before killing, to confine them to select food. Boiled potatoes are very good feeding, and are still better if a little grain is mixed with them; Indian meal is both economical and nutritive, but should be used sparingly at first. Some recommend butcher's offal; but, although ducks may be fattened on such food to an unusual weight, and thus be profitable for the market, their flesh will be rendered rank and gross, and not at all fit for the table.

To fatten geese, it is necessary to give them a little corn daily, with the addition of some raw Swedish turnips, carrots, mangel-wurtzel leaves, lucerne, tares, cabbage leaves, and 
lettuces. Barley-meal and water is recommended by some; but full-grown geese that have never been habituated to the mixture when young, will occasionally refuse to eat it. Cooked potatoes, in small quantities, do no harm; and, apart from the consideration of expense, steeped wheat would produce a firstrate delicacy.

Those who can only afford to bring up one or two, should confine them in a crib or some such place, about the beginning of July, and feed them as directed, giving them a daily supply of clean water for drink. If from a dozen to twenty are kept, a large pen of from fifteen to twenty feet square should be made, well covered with straw on the bottom, and a covered house in a corner for protection against the sun and rain, when required; since exposure to either of these is not good. It will be observed that, about noon, if geese are at liberty, they will seek some shady spot, to aroid the influence of the sun; and when confined in small places, they have not sufficient space for flapping their wings, and drying themselves after being wet, nor have they room for moving about so as to keep themselves warm. There should be three troughs in the crib: one for dry oats; another for vegetables, which ought always to be cut down; and a third for clean water, of which they must always have a plentiful supply. The riper the cabbages and lettuces are with which they are supplied the better.

Slaughtering axd Dressing. Both ducks and geese should be led out to the pond a few hours before being slaughtered, where they will neatly purify and arrange their feathers. The common mode of slaughtering the latter-bleeding them from the internal parts of the throat-is needlessly slow and cruel. 
Fowls for cooking, that are to be sent to a distance, or to be kept any time before being served, should be plucked, drawn, and dressed immediately after being killed. The feathers strip off much more easily and cleanly while the bird is yet warm. When large numbers are to be slaughtered and prepared in a short time, the process is expedited by scalding the bird in boiling water, when the feathers drop off almost at once. Fowls thus treated are, however, generally thought inferior in flavor, and are more likely to acquire a taint in close, warm weather, than such as are plucked and dressed dry.

In dressing, all bruises or rupturing of the skin should be avoided. A coarse, half-worn cloth, that is pervious to the air, like a wire sieve, and perfectly dry and clean, forms the best wrapper. The color of yellow-skinned turkeys-equally well-flavored, by the way-is improved for appearance at market by wrapping them for twelve or twenty-four hours in cloths soaked in cold salt and water, frequently changed. For the same purpose, the loose fat is first laid in warm salt and mater, and afterward in milk and water for two or three hours. Some dust with flour, inside and out, any fowls that are to be carred far, or to hang many days before being cooked.

The oldest and toughest fowls, which are often pronounced unfit for eating, thrown away, and wasted, may be made into a savory and nutritious dish by jointing, after the bird is plucked and drawn, as for a pie; it should not be skinned. Stew it five hours in a close saucepan, with salt, mace, onions, or any other flavoring ingredients desired. When tender, turn it cut into a deep dish, so that the meat may be entirely covered with the liquor. Let it stand thus in its own jelly for 473 
a day or two; it may then be served in the shape of a curry, a hash, or a pic, and will be found to furaish an agreeable repast.

Old geese, killed in the axisum, after they have recovered from moulting, and before they have begun to think about the breeding time, make excellent meat, if cut into small portions, stewed slowly five or six hours with savory condiments, and made into pie the next day. By roasting and broiling, the large quantity of nutriment contained in the bones and cartilages is lost, and what might easily be made tender has to be swallowed tough. Young geese, as well as the old, are, also, often salted and boiled.

\section{POJLTRY-HOUSES.}

The three grand requisites in a poultry hou=e are cleanliness, dryness, and warmth. A simple arrangement for this purpose is a shed built against the gable of the house, opposite to the part warmed by the kitchen fire, in which are placed cross-bars for roosting, with boxes for laying in, or quantities of fresh straw. This should always have an opening, to allow the poultry-house to be cleansed out, at least once a weo?. Fowls will never thrive long amidst uncleanliness; and even with the utmost care a place where they have been long kept becomes tainted, as it is called; the surface of the ground becomes saturated with their exurice, and is therefore no longer conducive to health.

To avoid this effect, some persons in the country frequently change the sites of their poultry-houses, to obtain fresh ground; while others, who cannot thus change, purify the bouses by fumigations of blazing pitch, by washing with hot 474 
lime water, and by strewing large quantities of pure sand both within and without. Washing the floor every week is a necessity; for which purpose it is advantageous to have the house paved either with stones, bricks, or tiles. A good flooring, however, and cheaper than either of these, may be formed by using a composition of lime and swithy ashes, together with the riddlings of common kitchen ashes; these, having been all finely broken, must be mixed together with water, put on the floor with a mason's trowel, and nicely smoothed on the

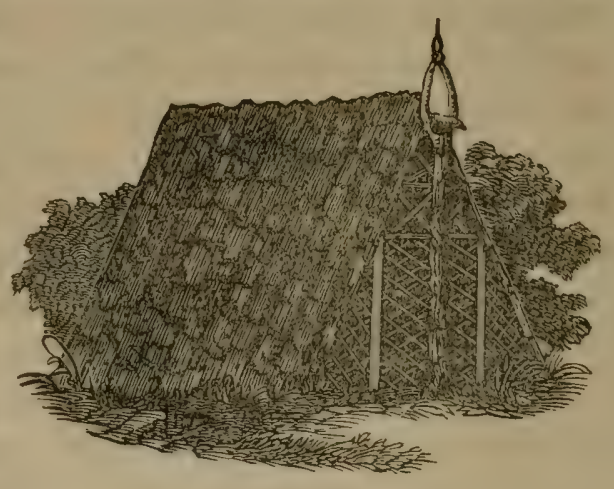

RUSTIC POULTRY-HOUSE.

surface. If this is put on a floor which is in a tolerably dry situation, and allowed to harden before being used, it will become nearly as solid and compact as stone, and is almost as durable.

The inside of the laying-boxes should be frequently washed with hot lime water, to free them from vermin, which greatly torment the sitting hens. For the same purpose, poultry should always have a heap of dry sand, or fine ashes, laid under some corered place or thick tree near their yard, in which they may dust themselres; this being their means of ridding themselves of the vermin with which they are annoyed.

In every establishment for poultry-rearing, there ought to 475 
be some separate crib or cribs, into which to remove forl when laboring under disease; for, not nuly are many of the diseases to which poultry are liable highly contagious, but the sick birds are also regarded with dislike by such as are in health; and the latter will, generally, attack and maltreat them, aggravating, at least, their sufferings, if not actually depriving them of life. The moment, therefore, that a bird is perceived to droop, or appears pining, it should be removed to one of these infirmaries.

Separate pens are also necessary, to avoid quarrelling among some of the highly-blooded birds, more particularly the game fowl. They are also necessary when different varieties are

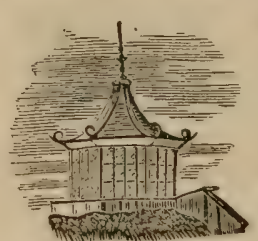
kept, in order to avoid improper or undesirable commixture from accidental crossing. These lodgings may be most readily constructed in rows, parallel to each other; the partitions may be formed of lattice-work, $\triangle$ FANCY COOP IN CrINESE being thus rather ornamental, and the cost or сотнас вттLв. of erection but trifling. Each of these lodgings should be divided into two compartnents, one somewhat larger than the other; one to be close and warm, for the sleeping-room; and the other, a large one, airy and open, that the birds may enjoy themselves in the daytime. Both must be kept particularly dry and clean, and be well protected from the weather.

A hen-ladder is an indispensable piece of furniture, though frequently absent. This is a sort of ascending scale of perches, one a little higher than the other; not exactly above its predecessor, but somewhat in advance. By neglecting the use of this very simple contrivance, many valuable fowls may be $476^{\circ}$ 
lost or severely injured, by attempting to fly down from their roost-an attempt from succeeding in which the birds are incapacitated, in consequence of the bulk of their body preponderating over the power of their wings.

Some people allow their fowl to roost abroad all night, in all weathers, in trees, or upon fences near the poultry-house. This is a slovenly mode of keeping even the humblest live stock; it offers a temptation to thieres, and the health of the fowls cannot be improved by their being soaked all night long in drenching rain, or having their feet frozen to the branches or rails. There is no difficulty in accustoming any sort of poultry, except the pea fowl, to regular housing at night.

It is better that turkeys should not roost in the same house with the domestic fowl, as they are apt to be cross to sitting and laying hens.

No poultry-house is what it ought to be, it may be suggested, in conclusion, unless it is in such a state as to afford a lady, without offending her sense of decent propriety, a respectable shelter on a showery day. 


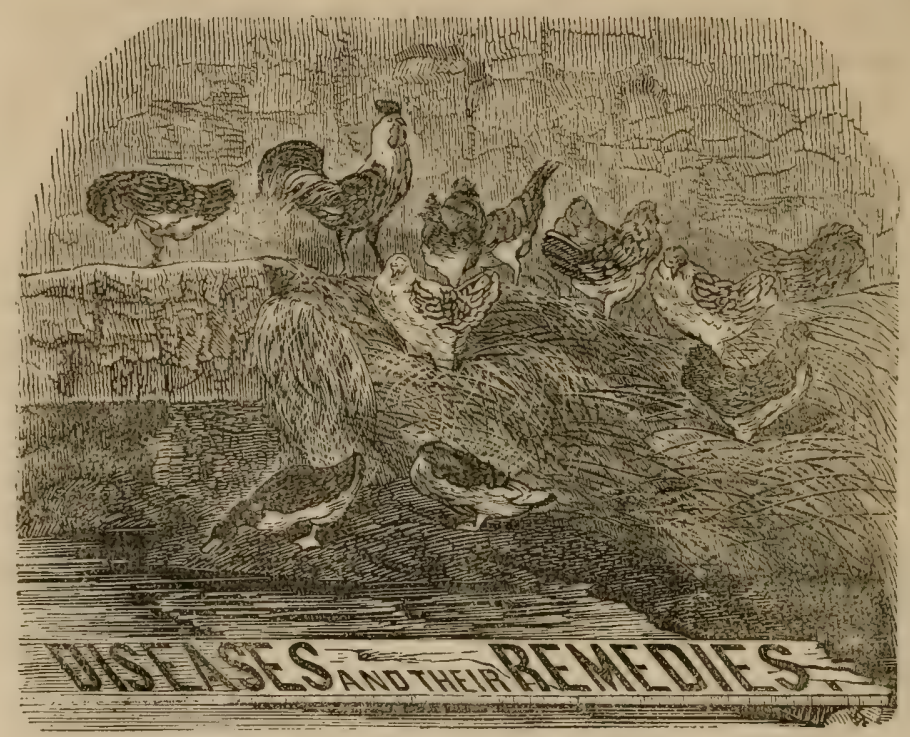

In our climate, the disorders to which poultry are liable are, comparatively, few in number, and they usually yield to judicious treatment. The little attention that has too generally been bestowed upon this subject may be accounted for from the circumstance that, in an economical point of view, the value of an individual fowl is relatively insignificant; and while the ailments of other domesticated animals generally claim a prompt and efficient care, the unhappy inhabitants of the poultry-yard are too often relieved of their sufferings in the most summary manner. 'There are reasons, however, 473 
which will justify a more careful regard in this matter, besides the humanity of adding to the comfort of these useful creatures; and the attempt to cure, in cases of disease, will often be rewarded by their flesh being rendered more palatable, and their eggs more wholesome.

Most of the diseases to which forwls are subject are the result of errors in diet or management, and should have been prevented, or may be removed by a change, and the adoption of a suitable regimen. When an individual is attaiked, it should be forthwith removed, to prevent the contamination of the rest of the flock. Nature, who proves a guardian to fowls in health, will nurse them in their weakness, and act as a most efficient physician to the sick; and the aim of all medical treatment should be to follow the indications which Nature holds ont, and assist in the effort which she constantly makes for the restoration of health.

The more common diseases which afflict poultry will ice so described that they need not be misapprehended, and such remedies suggested as experience has proved to be salutary; and, taken alphabetically, the first on the list is

\section{ASTHMA.}

This common disease seems to differ sufficiently in its characteristics to warrant a distinction into two species. In one it appears to be caused by an obstruction of the air-ciells, by an accumulation of phlegm, which interferes with the exercise of their functions. The fowl labors for breath, in consequence of not being able to take in the usual quant ity of air at an inspiration. The capacity of the lungs is therelby diminished, the lining membrane of the windpipe becomfes 
thickenci, and its minute branches are more or less affected. These effects may, perhaps, be attributed to the fact that, as our poultry are originally natives of tropical climates, they require a more equal temperature than is afforded, except by artificial, means, however well they may appear acclimated.

Anotlier variety of asthma is induced by fright, or undue excitement. It is sometimes produced by chasing fowls to catch them, by seizing them suddenly, or by their fighting with elach other. In these cases, a blood-vessel is often rupturad, and sometimes one or more of the air-cells. The sympto,pss are, short breathing; opening of the beak often, and for quite a time; heaving and panting of the chest; and, in case of a rupture of a blood-vessel, a drop of blood appearing on the beak.

Treatment. Confirmed asthma is difficult to cure. For the disease in its incipient state, the fowl should be kept warm, and treated with repeated doses of hippo-powder and sulphir, mixed with butter, with the addition of a small quantity of Cayenne pepper.

\section{COSTIVENESS.}

The existence of this disorder will become apparent by observing the unsuccessful attempts of the fowl to relieve itself. It frequently results from continued feeding on dry diet, without access to green vegetables. Indeed, without the use of these, or some substitute-such as mashed potatoescostiveness is certain to ensue. The want of a sufficient suplply of good water will also occasion the disease, on account of that peculiar structure of the fowl, which renders 480 
them unable to void their urine, except in connection with the foeces of solid food, and through the same channel.

Treatment. Soaked bread, with warm skimmed-milk, is a mild remedial agent, and will usually suffice. Boiled carrots or cabbage are more efficient. A meal of earth-worms is sometimes advisable; and hot potatoes, mixed with bacon-fat, are said to be excellent. Castor-oil and burned butter will remove the most obstinate cases; though a clyster of oil, in addition, may sometimes be required, in order to effect a cure.

\section{DIARRHCEA.}

There are times when fowls dung more loosely than at others, especially when they have been fed on green or soft food; but this may occur without the presence of disease. Should this state, howerer, deteriorate into a confirmed and continued laxity, immediate attention is required to guard against fatal effects. The causes of diarrhœa are dampness, undue acidity in the bowels, or the presence of irritating matter there:

The symptoms are lassitude and emaciation; and, in very severe cases, the voiding of calcareous matter, white, streaked with yellow. This resembles the yolk of a stale egg, and clings to the feathers near the vent. It becomes acrid, from the presence of ammonia, and causes inflammation, which speedily extends throughout the intestines.

Treatment. This, of course, depends upon the cause. If the disease is brought on by a diet of green or soft food, the food must be changed, and water sparingly given; if it arises from undue acidity, chalk mixed with meal is advantageous, but rice-flour boluses are most reliable. Alum-water, of 31 481 
moderate strength, is also beneficial. In cases of bloody fux, boiled rice and milk, given warm, with a little magnesia, or chalk, may be successfully used.

\section{FEVER.}

The most decided species of fever to which fowls are subject occurs at the period of hatching, when the animal heat is often so increased as to be perceptible to the touch. A state of fever may also be observed when they are about to lay. This is, generally, of small consequence, when the birds are otherwise healthy; but it is of moment, if any other disorder is present, since, in such case, the original malady will be aggravated. Fighting also frequently occasions fever, which sometimes proves fatal.

The symptoms are an increased circulation of the blood; excessive heat; and restlessness.

Treatment. Light food and change of air; and, if necessary, aperient medicine, such as castor oil, with a little burned butter.

\section{INDIGESTION.}

Cases of indigestion among fowls are common, and deserve attention according to the causes from which they proceed. A change of food will often produce crop-sickness, as it is called, when the fowl takes but little food, and suddenly loses flesh. Such disease is of little consequence, and shortly disappears. When it requires attention at all, all the symptoms will be removed by giving their diet in a warm state.

Sometimes, however, a fit of indigestion threatens severe consequences, especially if long continued. Every effort 482 
should be made to ascertain the cause, and the remedy must be governed by the circumstances of the case.

The symptoms are heaviness, moping, keeping away from the nest, and want of appetite.

Treatment. Lessen the quantity of food, and oblige the fowl to exercise in an open walk. Give some powdered cayenne and gentian, mixed with the usual food. Iron-rust, mixed with soft food, or diffused in water, is an excellent tonic, and is indicated when there is atrophy, or diminution of the flesh. It may be combined "with oats or grain. Milk-

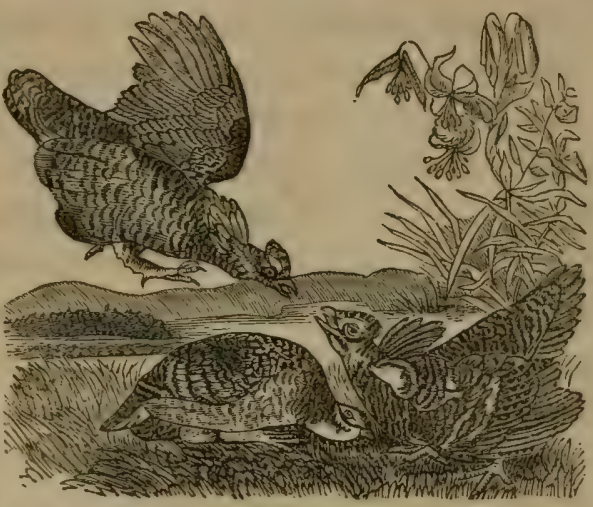

PRAIRIE HENS. warm ale has also a good effect, when added to the diet of diseased fowls.

\section{工ICE.}

The whole feathered tribe seem to be peculiarly liable to be infested with lice; and there have been instances when fowls have been so covered in this loathsome manner that the natural color of the feathers has been undistinguishable. The presence of vermin is not only annoying to poultry, but materially interferes with their growth, and prevents their fattening. They are, indeed, the greatest drawback to the success and pleasure of the poultry fanciers; and nothing but unre- 
mitting vigilance will exterminate them, and keep them exterminated.

Treatment. To attain this, whitewash frequently all the parts adjacent to the roosting-pole, take the poles down and run them slowly through a fire made of wood shavings, dry weeds, or other light waste combustibles. Flour of sulphur, placed in a vessel, and set on fire in a close poultry-house, will penetrate every crevice, and effectually exterminate the vermin. When a hen comes off with her brood, the old nest should be cleaned out, and a new one placed; and dry tobacco-leaves, rubbed to a powder between the hands, and mixed with the hay of the nest, will add much to the health of the poultry.

Flour of sulphur may also be mixed with Indian-meal and water, and fed in the proportion of one pound of sulphur to two dozen fowls, in two parcels, two days apart. Almost any kind of grease, or unctuous matter, is also certain death to the vermin of domestic poultry. In the case of very young chickens, it should only be used in a warm, sunny day, when they should be put into a coop with their mother, the coop darkened for an hour or two, and every thing made quiet, that they may secure a good rest and nap after the fatigue occasioned by greasing them. They should be handled with great care, and greased thoroughly; the hen, also. After resting, they may be permitted to come out and bask in the sun; and in a few days they will look sprightly enough.

To guard against vermin, however, it should not be forgotten that cleanliness is of vital importance; and there must always be plenty of slacked lime, dry ashes, and sand, easy of access to the fowls, in which they can roll and dust themselves. 484 


\section{LOSS OF FEATHERS.}

This disease, common to confined fowls, should not be confounded with the natural process of moulting. In this diseased state, no new feathers come to replace the old, but the fowl is left bald and naked; a sort of roughness also appears on the skin; there is a falling off in appetite, as well as moping and inactivity.

Treatment. As this affection is, in all probability, constitutional rather than local, external remedies may not alnays prove sufficient. Stimulants, however, applied externally, will serve to assist the operation of whatever medicine may be given. Sulphur may be thus applied, mixed with lard. Sulphur and cayenne, in the proportion of one quarter each, mixed with fresh butter, is good to be given internally, and will act as a powerful alterative. The diet should be changed; and cleanliness and fresh air are indispensable.

In diseased moulting, where the feathers stare and fall off, till the naked skin appears, sugar should be added to the water which the fowls drink, and corn and hemp-seed be given. They should be kept warm, and occasionally be treated to doses of cayenne pepper.

\section{PIP.}

This disorder, known also as the gapes, is the most common ailment of poultry and all domestic birds. It is especially the disease of young fowls, and is most prevalent in the hottest months, being not only troublesome but frequently fatal.

As to its cause and nature, there has been some diversity 
of opinion. Some consider it a catarthal inflammation, which produces a thickening of the membrane lining the nostrils and mouth, and particularly the tongue; others assert that it is caused by want of water, or by bad water; while others describe it as commencing in the form of a vesicle on the tip of the tongue, which occasions a thickened state of the skin, by the absorption of its contents. The better opinion, however, is, that the disease is occasioned by the presence of worms, or fasciolce, in the windpipe. On the dissection of chickens dying with this disorder, the windpipe will be found to contain numerous small, red worms, about the size of a cambric needle, which, at the first glance, might be mistaken for blood-vessels. It is supposed by some that these worms continue to grow, until, by their enlargement, the windpipe is so filled up that the chicken is suffocated.

The common symptoms of this malady are the thickened state of the membrane of the tongue, particularly toward the tip; the breathing is impeded, and the beak is frequently held open, as if the creature were gasping for breath; the beak becomes yellow at its base; and the feathers on the head appear ruffled and disordered; the tongue is very dry; the appetite is not always impaired; but yet the fowl cannot eat, probably on account of the difficulty which the act involves, and sits in a corner, pining in solitude.

Treatment. Most recommend the immediate removal of the thickened membrane, which can be effected by anointing the part with butter or fresh cream. If necessary, the scab may be pricked with a needle. It will also be found beneficial to use a pill, composed of equal parts of scraped garlic and horse-radish, with as much cayenne pepper as will outweigh 486 
a grain of wheat; to be mixed with fresh butter, and given every morning; the fowl to be kept warm.

If the disease is in an advanced state, shown by the chicken's holding up its head and gaping for want of breath, the fowl should be thrown on its back, and while the neck is held straight, the bill should be opened, and a quill inserted into the windpipe, with a little turpentine. This being round, will loosen and destroy a number of small, red worms, some of which will be drawn up by the feather, and others will be coughed up by the chicken. The operation should be repeated the following day, if the gaping continues. If it ceases, the cure is effected.

It is stated, also, that the disease has been entirely prevented by mixing a small quantity of spirits of turpentine with the food of fowls; from five to ten drops, to a pint of meal, to be made into a dough. Another specific remmended is to keep iron standing in vinegar, and put a little of the liquid in the food every few days.

Some assert that it is promoted by simply scanting fowls in their food; and this upon the ground that chickens which are not confined with the hen, but both suffered to run at large and collect their own food, are not troubled with this disease. There can be little doubt that it is caused by inattention to cleanliness in the habits and lodgings of fowls; and some, therefore, think that if the chicken-houses and coops are kept clean, and frequently washed with thin whitewash, having plenty of salt and brine mixed with it, that it would be eradicated. 


\section{ROUP.}

This disease is caused mainly by cold and moisture; but it is often ascribed to improper feeding and want of cleanliness and exercise. It affects fowls of all ages, and is either acute or chronic; sometimes commencing suddenly, on exposure; at others gradually, as the consequence of neglected colds, or

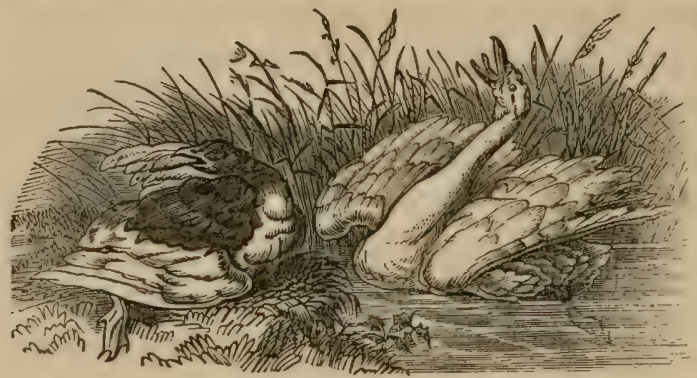

ISWANS.

damp weather or lodging. Chronic roup h a s be en known to extend through two years.

The most prominent symploms are difficult and noisy breathing and gaping, terminating in a rattling in the throat; the head swells, and is feverish; the eyes are swollen, and the eye-lids appear livid; the sight decays, and sometimes total blindness ensues; there are discharges from the nostrils and mouth, at first thin and limpid, afterward thick, purulent, and fetid. In this stage, which resembles the glanders in horses, the disease becomes infectious.

As secondary' synuptoms, it may be noticed that the appetite fails, except for drink; the crop feels hard; the feathers are staring, ruffled, and without the gloss that appears in health; the fowl mopes by itself and seems to suffer much pain.

Treatment. The fowls should be kept warm, and have plenty of water and scalded bran, or other light food. When 488 
chronic, change of food and air is advisable. The ordinary remedies-such as salt dissolved in water-are inefficacious. A solution of sulphate of zinc, as an eye-water, is a valuable cleausing application. Rue-pills, and a decoction of rue, as a tonic, have been administered with apparent benefit.

The following is recommended: of powdered gentian and Jamaica ginger, each one part; Epsom salts, one and a half parts; and flour of sulphur, one part; to be made up with butter, and given every morning

The following method of treatment is practised by some of the most successful poulterers in the country: As soon as discovered, if in warm weather, remove the infected fowls to some well-ventilated apartment, or yard; if in winter, to some warm place; then give a dessert-spoonful of castor-oil; wash their heads with warm Castile-soap suds, and let them remain till next morning fasting. Scald for them Indian-meal, adding two and a half ounces of Epsom salts for ten hens, or in proportion for a less or larger number; give it warm, and repeat the dose in a day or two, if they do not recover.

Perhaps, however, the best mode of dealing with roup and all putrid affections is as follows: Take of finely pulverized, fresh-burnt charcoal, and of new yeast, each three parts; of pulverized sulphur, two parts; of flour, one part; of water, a sufficient quantity; mix well, and make into two doses, of the size of a hazel-nut, and give one three times a day. Cleanliness is no less necessary than warmth; and it will sometimes be desirable to bathe the eyes and nostrils with warm milk and water, or suds, as convenient. 


\section{WOUNDS AND SORES.}

Fowls are exposed to wounds from many sources. In their frequent encounters with each other, they often result; the poultry-house is besieged by enemies at night, and, in spite of all precaution, rats, weasels, and other animals will assault the occupants of the roost, or nest, to their damage. These wounds, if neglected, often degenerate into painful and dangerous ulcers.

When such injuries occur, cleanliness is the first step toward a cure. The wound should be cleared from all foreign matter, washed with tepid milk and water, and excluded as far as possible from the air. The fowl should be removed from its companions, which, in such cases; seldom or never show any sympathy, but, on the contrary, are always ready to assault the invalid, and aggravate the injury. Should the wound not readily heal, but ulcerate, it may be bathed with alum-water. The ointment of creosote is said to be effectual, even when the ulcer exhibits a fungous character, or proud flesh is present. Ulcers may also be kept clean, if dressed with a little lard, or washed with a weak solution of sugar of lead; if they are indolent, they may be touched with blue-stone.

When severe fractures occur to the limbs of fowls, the best course, undoubtedly, to pursue-unless they are very valuable -is to kill them at once, as an act of humanity. When, however, it is decmed worth while to preserve them, splints may be used, when practicable. Great cleanliness must be observed; the diet should be reduced; and every precaution taken against the inflammation, which is sure to supervene. When it is established, cooling lotions-such as warm milk and water-may be applied.

490 







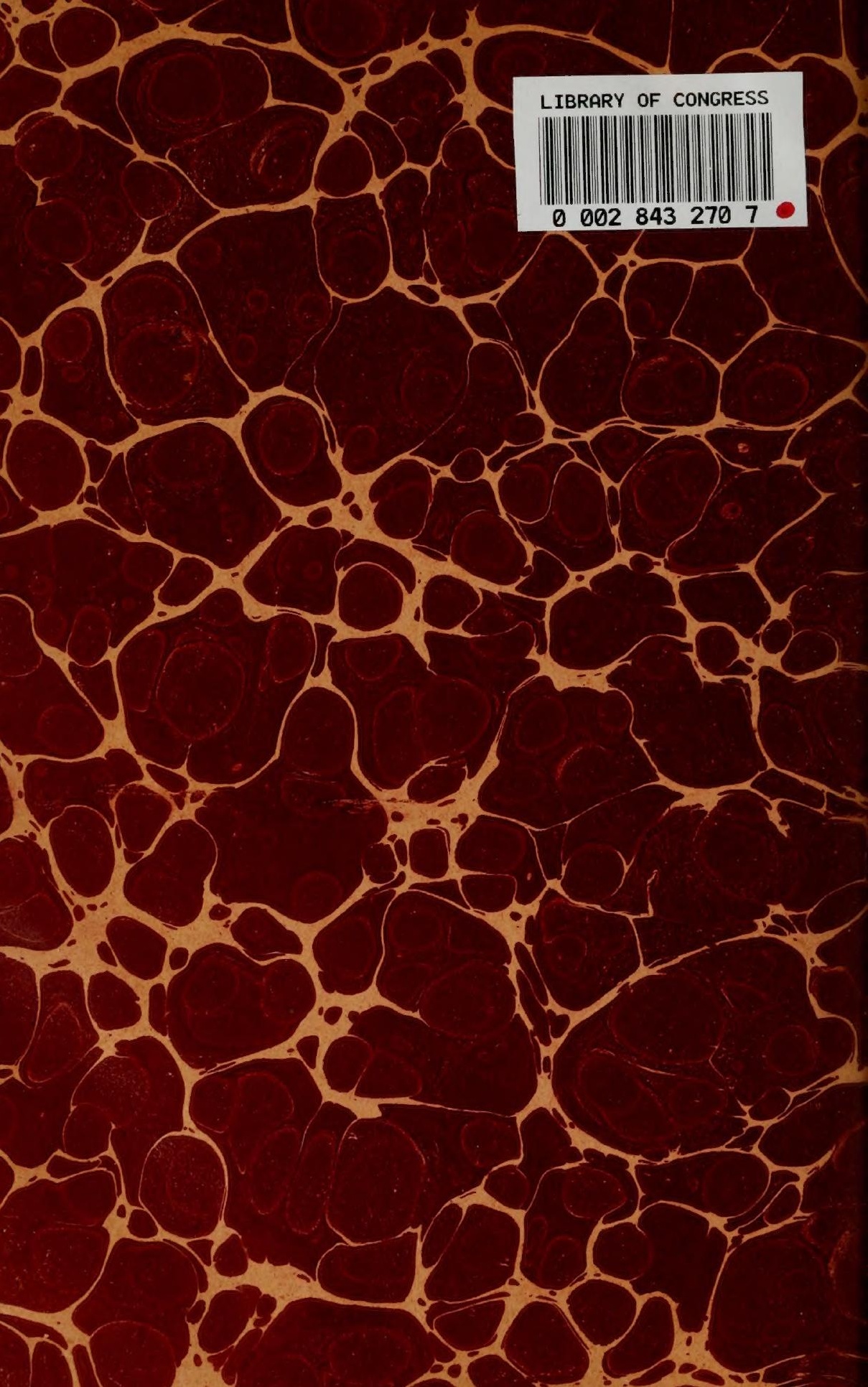


